Comparative Effectiveness Review Number 205

\title{
Physiologic Predictors of Severe Injury: Systematic Review
}




\section{Comparative Effectiveness Review}

Number 205

\section{Physiologic Predictors of Severe Injury: Systematic Review}

Prepared for:

Agency for Healthcare Research and Quality

U.S. Department of Health and Human Services

5600 Fishers Lane

Rockville, MD 20857

www.ahrq.gov

Contract No. 290-2015-00009-I

Prepared by:

Pacific Northwest Evidence-based Practice Center

Portland, OR

Investigators:

Annette M. Totten, Ph.D.

Tamara P. Cheney, M.D.

Maya E. O'Neil, Ph.D.

Craig D. Newgard, M.D., M.P.H.

Mohamud Daya, M.D., M.S.

Rongwei Fu, Ph.D.

Ngoc Wasson, M.P.H.

Erica L. Hart, M.S.T.

Roger Chou, M.D.

AHRQ Publication No. 18-EHC008-EF

April 2018 


\section{Key Messages}

\section{Purpose of Review}

To summarize evaluations of physiologic measures that can be used by emergency medical services personnel to identify patients at high risk of serious injury and inform decisions about the level of trauma care needed.

\section{Key Messages}

- Studies examined individual measures and combinations for trauma triage, including systolic blood pressure, heart rate, shock index, lactate, base deficit, respiratory rate, oxygen saturation, and need for airway support.

- Included measures have:

o Low sensitivities, so normal values on the physiologic measure (a negative test) cannot be used with confidence to determine that patients are not seriously injured.

o High specificities, meaning abnormal values on the physiologic measure (positive test) are unlikely in patients not seriously injured.

- Combinations of physiologic measures with measures of consciousness may perform better than physiologic measures alone, but feasibility and reliability of performance in the field are significant challenges.

- Measures perform less well in children and older people. Changes in cut-points for these age groups may improve performance but have not yet been rigorously evaluated.

- Research is needed on the feasibility of combination measures and how precisely physiologic parameters are measured, including use of technology.

- Researchers should use standard definitions of serious injury to permit comparisons across studies and measures. 
This report is based on research conducted by the Pacific Northwest Evidence-based Practice Center (EPC) under contract to the Agency for Healthcare Research and Quality (AHRQ), Rockville, MD (Contract No. 290-2015-00009-I). The findings and conclusions in this document are those of the authors, who are responsible for its contents; the findings and conclusions do not necessarily represent the views of AHRQ. Therefore, no statement in this report should be construed as an official position of AHRQ or of the U.S. Department of Health and Human Services.

\section{None of the investigators have any affiliations or financial involvement that conflicts with the material presented in this report.}

The information in this report is intended to help health care decisionmakers - patients and clinicians, health system leaders, and policymakers, among others - make well-informed decisions and thereby improve the quality of health care services. This report is not intended to be a substitute for the application of clinical judgment. Anyone who makes decisions concerning the provision of clinical care should consider this report in the same way as any medical reference and in conjunction with all other pertinent information, i.e., in the context of available resources and circumstances presented by individual patients.

This report is made available to the public under the terms of a licensing agreement between the author and the Agency for Healthcare Research and Quality. This report may be used and reprinted without permission except those copyrighted materials that are clearly noted in the report. Further reproduction of those copyrighted materials is prohibited without the express permission of copyright holders.

AHRQ or U.S. Department of Health and Human Services endorsement of any derivative products that may be developed from this report, such as clinical practice guidelines, other quality enhancement tools, or reimbursement or coverage policies, may not be stated or implied.

This report may periodically be assessed for the currency of conclusions. If an assessment is done, the resulting surveillance report describing the methodology and findings will be found on the Effective Health Care Program Web site at www.effectivehealthcare.ahrq.gov. Search on the title of the report.

Persons using assistive technology may not be able to fully access information in this report. For assistance contact epc@ahrq.hhs.gov.

Suggested citation: Totten AM, Cheney TP, O'Neil ME, Newgard CD, Daya M, Fu R, Wasson N, Hart EL, Chou R. Physiologic Predictors of Severe Injury: Systematic Review. Comparative Effectiveness Review No. 205. (Prepared by the Pacific Northwest Evidence-based Practice Center under Contract No. 290-2015-00009-I.) AHRQ Publication No. 18-EHC008-EF. Rockville, MD: Agency for Healthcare Research and Quality; April 2018. Posted final reports are located on the Effective Health Care Program search page.

DOI: https://doi.org/10.23970/AHRQEPCCER205 


\section{Preface}

The Agency for Healthcare Research and Quality (AHRQ), through its Evidence-based Practice Centers (EPCs), sponsors the development of evidence reports and technology assessments to assist public- and private-sector organizations in their efforts to improve the quality of health care in the United States. The National Highway Traffic Safety Administration requested this report from the EPC Program at AHRQ to support revision of the Field Triage Guidelines. AHRQ assigned this report to the Pacific Northwest Evidence-based Practice Center (Contract No. 290-2015-00009-I).

The reports and assessments provide organizations with comprehensive, evidence-based information on common medical conditions and new health care technologies and strategies. They also identify research gaps in the selected scientific area, identify methodological and scientific weaknesses, suggest research needs, and move the field forward through an unbiased, evidence-based assessment of the available literature. The EPCs systematically review the relevant scientific literature on topics assigned to them by AHRQ and conduct additional analyses when appropriate prior to developing their reports and assessments.

To bring the broadest range of experts into the development of evidence reports and health technology assessments, AHRQ encourages the EPCs to form partnerships and enter into collaborations with other medical and research organizations. The EPCs work with these partner organizations to ensure that the evidence reports and technology assessments they produce will become building blocks for health care quality improvement projects throughout the Nation. The reports undergo peer review and public comment prior to their release as a final report.

AHRQ expects that the EPC evidence reports and technology assessments, when appropriate, will inform individual health plans, providers, and purchasers as well as the health care system as a whole by providing important information to help improve health care quality.

If you have comments on this evidence report, they may be sent by mail to the Task Order Officer named below at: Agency for Healthcare Research and Quality, 5600 Fishers Lane, Rockville, MD 20857, or by email to epc@ahrq.hhs.gov.

Gopal Khanna, M.B.A.

Director

Agency for Healthcare Research and Quality

Stephanie Chang, M.D., M.P.H.

Director

Evidence-based Practice Center Program

Center for Evidence and Practice Improvement Agency for Healthcare Research and Quality
Arlene S. Bierman, M.D., M.S.

Director

Center for Evidence and Practice Improvement

Agency for Healthcare Research and Quality

David W. Niebuhr, M.D., M.P.H., M.Sc.

Task Order Officer

Center for Evidence and Practice

Improvement

Agency for Healthcare Research and Quality 


\section{Acknowledgments}

The authors gratefully acknowledge the following individuals for their contributions to this project: Tracy Dana, M.L.S., Leah Williams, B.S., Liev Miller, B.A., Shaun Ramirez, B.S., and Elaine Graham, M.L.S.

\section{Technical Expert Panel}

In designing the study questions and methodology at the outset of this report, the EPC consulted several technical and content experts. Broad expertise and perspectives were sought. Divergent and conflicted opinions are common and perceived as healthy scientific discourse that results in a thoughtful, relevant systematic review. Therefore, in the end, study questions, design, methodologic approaches, and/or conclusions do not necessarily represent the views of individual technical and content experts.

Technical Experts must disclose any financial conflicts of interest greater than $\$ 5,000$ and any other relevant business or professional conflicts of interest. Because of their unique clinical or content expertise, individuals with potential conflicts may be retained. The TOO and the EPC work to balance, manage, or mitigate any potential conflicts of interest identified.

The list of Technical Experts who provided input to this report follows:

Joe Acker, EMT-P, M.P.H.*

Executive Director

Birmingham Regional Emergency Medical Services System

Birmingham, AL

Eileen Metzger Bulger, M.D., FACS*

American College of Surgeons Representative

Chief of Trauma, Harborview Medical Center

Professor of Surgery, University of Washington

Seattle, WA

Francis X. Guyette, M.D., M.S., M.P.H., FACEP*

Associate Professor of Emergency Medicine

Medical Director, STAT MedEvac

University of Pittsburgh

Pittsburgh, PA

John Holcomb, M.D., FACS

Professor, Department of Surgery

UTHealth

Houston, TX

Jonathan Jui, M.D., M.S., M.P.H.

Professor, Department of Emergency Medicine, Oregon Health \& Science University

EMS Medical Director, Multnomah County

Portland, OR 
E. Brooke Lerner, Ph.D.*

Professor of Emergency Medicine and Pediatrics

Research Director for the Department of Emergency Medicine

Medical College of Wisconsin

Milwaukee, WI

N. Clay Mann, Ph.D., M.S., M.B.A.*

Professor of Pediatrics, University of Utah School of Medicine

Salt Lake City, UT

*Provided input on Draft Report.

\section{Peer Reviewers}

Prior to publication of the final evidence report, the EPC sought input from independent Peer Reviewers without financial conflicts of interest. However, the conclusions and synthesis of the scientific literature presented in this report do not necessarily represent the views of individual reviewers.

Peer Reviewers must disclose any financial conflicts of interest greater than $\$ 5,000$ and any other relevant business or professional conflicts of interest. Because of their unique clinical or content expertise, individuals with potential nonfinancial conflicts may be retained. The TOO and the EPC work to balance, manage, or mitigate any potential nonfinancial conflicts of interest identified.

The list of Peer Reviewers follows:

Kathleen Brown, M.D.

Professor of Pediatrics and Emergency Medicine

The George Washington University School of Medicine

Associate Division Chief, Medical Director of Quality Division of Emergency Medicine Children's National Medical Center

Washington, DC

Mary Fallat, M.D., FACS, FAAP

Hirikati S. Nagaraj Professor and Chief, Pediatric Surgery

University of Louisville School of Medicine

Louisville, KY

Richard C. Hunt, M.D., FACEP

Senior Medical Advisor, National Healthcare Preparedness Programs

Office of the Assistant Secretary for Preparedness and Response

U.S. Department of Health and Human Services

Washington, DC 


\section{Physiologic Predictors of Severe Injury: Systematic Review}

\section{Structured Abstract}

Objectives. To systematically identify and summarize evaluations of measures of circulatory and respiratory compromise, focusing on measures that can be used in field assessment by emergency medical services to inform decisions about the level of trauma care needed. We identified research on the ability of different measures to predict whether a patient was seriously injured and thus required transport to the highest level of trauma care available.

Data sources. We searched Ovid MEDLINE ${ }^{\circledR}$, CINAHL ${ }^{\circledR}$, and the Cochrane databases from 1996 through August 2017. Reference lists of included articles were reviewed for additional relevant citations.

Review methods. We included studies of individual measures and measures that combined circulatory, respiratory, and level of consciousness assessment. Evaluations included diagnostic accuracy (sensitivity and specificity) and area under the receiver operating characteristic curve (AUROC). We used data provided to calculate values that were not reported and pooled estimates across studies when feasible.

Results. We identified and included 138 articles reporting results of 134 studies. Circulatory compromise measures evaluated in these studies included systolic blood pressure, heart rate, shock index, lactate, base deficit, and heart rate variability or complexity. The respiratory measures evaluated included respiration rate, oxygen saturation, partial pressure of carbon dioxide, and need for airway support. Many different combination measures were identified, but most were evaluated in only one or two studies. Pooled AUROCs from out-of-hospital data were 0.67 for systolic blood pressure (moderate strength of evidence); 0.67 for heart rate, 0.72 for shock index, 0.77 for lactate, 0.70 for respiratory rate, and 0.89 for Revised Trauma Score combination measure (all low strength of evidence); and were considered poor to fair. The only AUROC that reached a level considered excellent was for the Glasgow Coma Scale, age, and arterial pressure (GAP) combination measure (AUROC, 0.96; estimate based on emergency department data). All of the measures had low sensitivities and comparatively high specificities (e.g., sensitivities ranging from $13 \%$ to $74 \%$ and specificities ranging from $62 \%$ to $96 \%$ for outof-hospital pooled estimates).

Conclusions. Physiologic measures usable in triaging trauma patients have been evaluated in multiple studies; however, their predictive utilities are moderate and far from ideal. Overall, the measures have low sensitivities, high specificities, and AUROCs in the poor-to-fair range. Combination measures that include assessments of consciousness seem to perform better, but whether they are feasible and valuable for out-of-hospital use needs to be determined. Modification of triage measures for children or older adults is needed, given that the measures perform worse in these age groups; however, research has not yet conclusively identified modifications that result in better performance. 


\section{Contents}

Evidence Summary ......................................................................................................................... ES-1

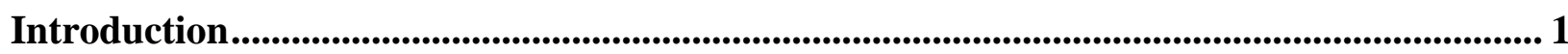

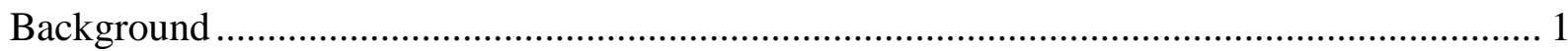

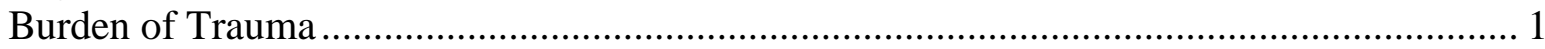

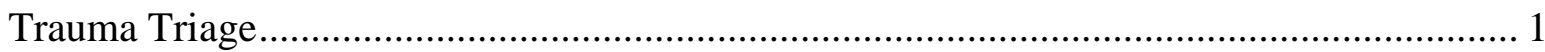

Physiologic Measures in Field Triage.................................................................................. 2

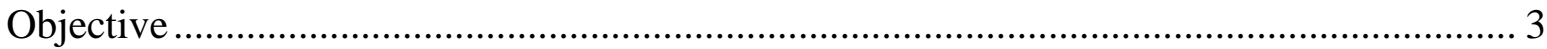

Key Questions and Scope ......................................................................................... 3

Analytic Framework ……………………………..................................................... 5

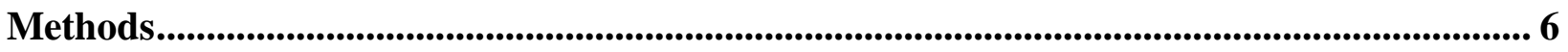

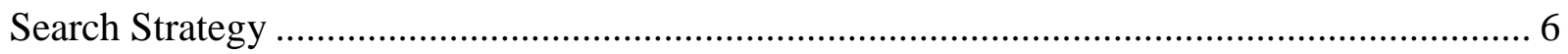

Criteria for Inclusion/Exclusion of Studies in the Review ......................................................... 6

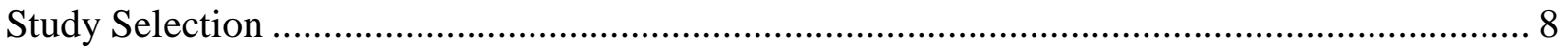

Data Abstraction and Data Management ………………….................................................... 8

Assessment of Methodological Risk of Bias of Individual Studies.......................................... 8

Data Analysis and Synthesis................................................................................................... 9

Grading the Strength of Evidence for Major Comparisons and Outcomes ............................... 11

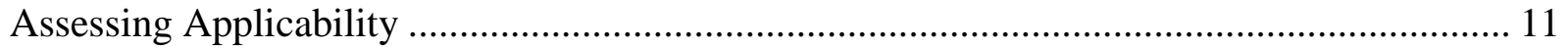

Managing Bias and the Appearance of Bias .......................................................................... 12

Peer Review and Public Commentary …………………...................................................... 12

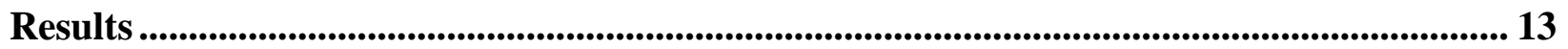

Literature Search Yield ........................................................................................................ 13

Description of Included Studies...................................................................................... 14

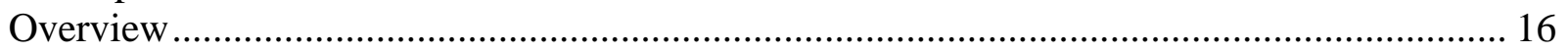

Key Question 1: Measures of Circulatory Compromise.......................................................... 20

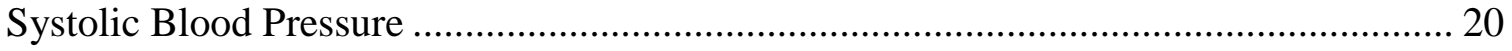

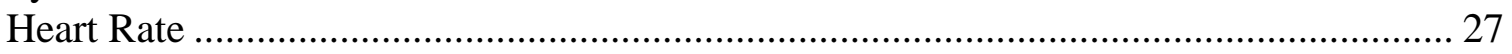

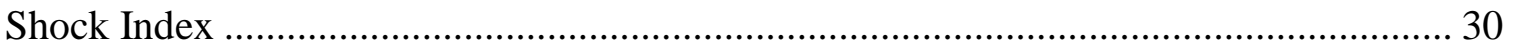

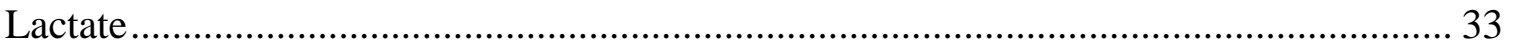

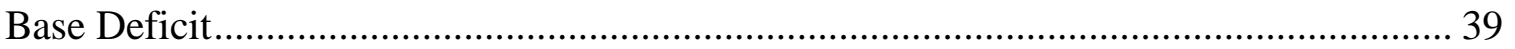

Heart Rate Variability or Heart Rate Complexity............................................................... 41

Other Measures of Circulatory Compromise..................................................................... 45

Key Question 2: Measures of Respiratory Compromise …………............................................ 49

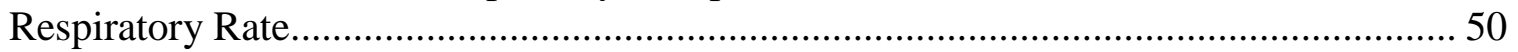

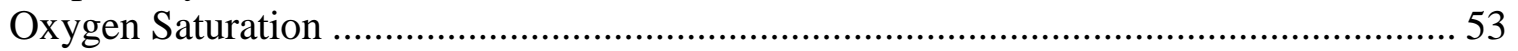

Airway/Ventilatory Support.......................................................................................... 56

Other Respiratory Measures ………………………………………………………..... 57

Key Question 3: Combination Measures .................................................................................. 59

Combinations of Physiologic Measures and Glasgow Coma Scale .................................. 64

Combinations of Physiologic Measures Without Glasgow Coma Scale ........................... 77

Key Questions 1a, 2a, and 3a: Differences Across Age Groups ............................................... 80

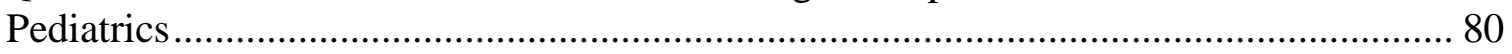

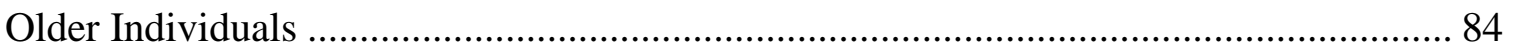

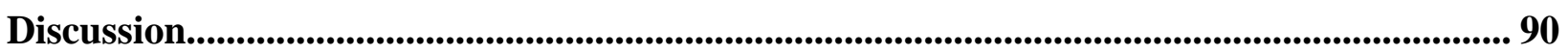




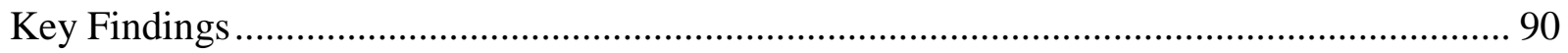

Findings in Relationship to What Is Already Known...................................................... 92

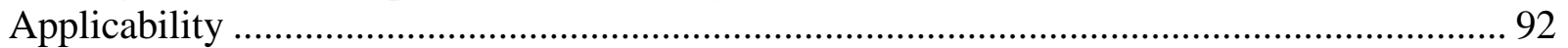

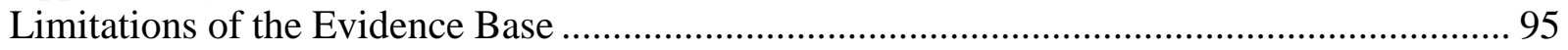

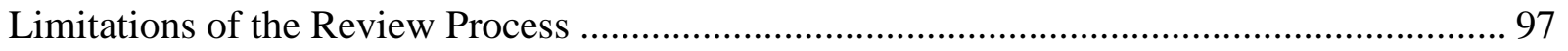

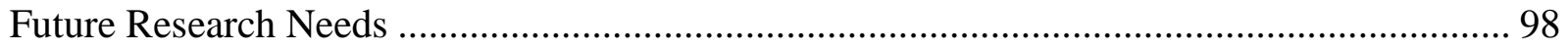

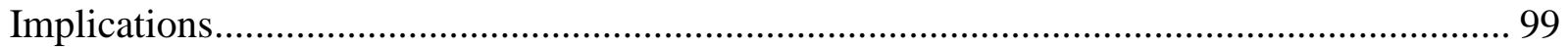

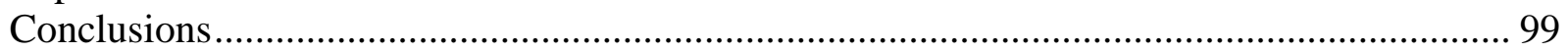

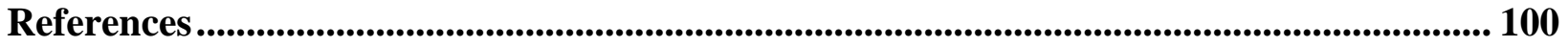

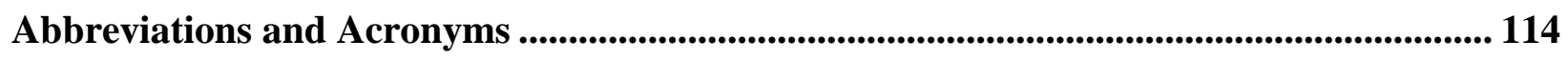

Tables

Table A. Key Question 1 results: overview of predictive utility of circulatory measures for serious injury by setting.

Table B. Key Question 2 results: overview of predictive utility of respiratory measures for serious injury by setting

Table C. Key Question 3 results: overview of predictive utility of combination of circulatory, respiratory, and level of consciousness measures for serious injury by setting...................... ES-7

Table D. Post-test odds and probability of serious injury given pre-test assumptions ............. ES-9

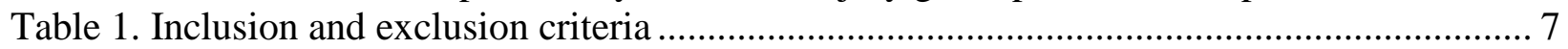

Table 2. Overall key characteristics of included studies........................................................ 15

Table 3. Key Question 1 results: overview of predictive utility of circulatory measures for serious injury by setting .................................................................................................... 17

Table 4. Key Question 2 results: overview of predictive utility of respiratory measures for serious injury by setting ................................................................................................... 18

Table 5. Key Question 3 results: overview of predictive utility of combination of circulatory, respiratory, and level of consciousness measures for serious injury by setting.......................... 19 Table 6. Measures of circulatory compromise (Key Question 1) evaluated by included studies. 20 Table 7. Pooled sensitivity and specificity of systolic blood pressure for identifying high-risk patients across all serious injury indicators .......................................................................... 21

Table 8. Pooled sensitivity and specificity for predictive utility of heart rate across all serious

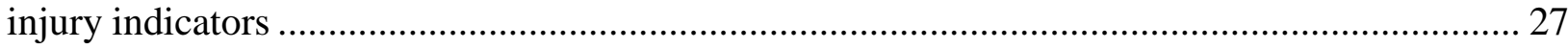

Table 9. Pooled sensitivity and specificity for predictive utility of shock index across all serious

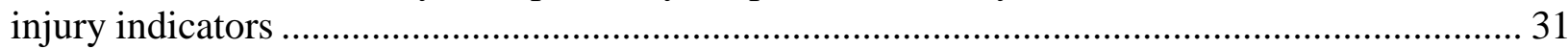

Table 10. Pooled sensitivity and specificity for predictive utility of lactate across all serious

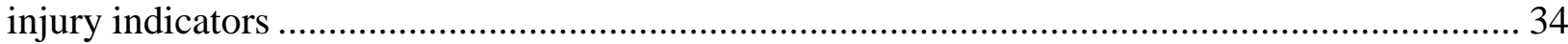

Table 11. Predictive utility of base deficit measured in emergency department ........................ 40

Table 12. Predictive utility of heart rate variability/complexity: out-of-hospital ...................... 42 Table 13. Predictive utility of heart rate variability/complexity: out-of-hospital heart rate measure

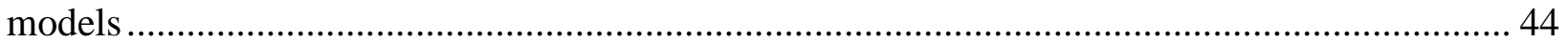

Table 14. Predictive utility of heart rate variability/complexity: emergency department ........... 45

Table 15. Predictive utility of other circulatory measures: out-of-hospital ............................... 45

Table 16. Predictive utility of other circulatory measures: emergency department .................... 47 Table 17. Measures of respiratory compromise (Key Question 2) evaluated by included studies50 Table 18. Pooled sensitivity and specificity for predictive utility of respiratory rate across all

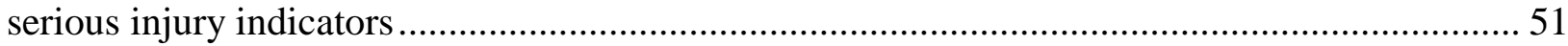


Table 19. Predictive utility of oxygen saturation: out-of-hospital................................................ 54

Table 20. Predictive utility of oxygen saturation: emergency department ...................................... 55

Table 21. Predictive utility of airway support: out-of-hospital and upon ED arrival .................... 56

Table 22. Predictive utility of other respiratory measures: emergency department ....................... 58

Table 23. Information on combination measures identified in the review ..................................6 60

Table 24. Studies that evaluate the predictive utility of combination measures (Key Question 3)

Table 25. Predictive utility of Revised Trauma Score and Triage Revised Trauma Score: out-of-

hospital 67

Table 26. Predictive utility of Revised Trauma Score and Triage Revised Trauma Score:

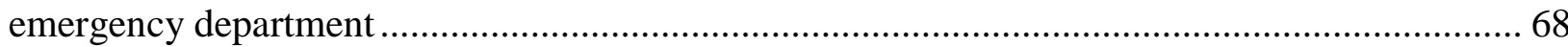

Table 27. Predictive utility of other combinations of circulatory and/or respiratory measures with

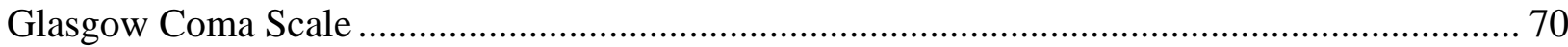

Table 28. Predictive utility of variations and combinations of triage protocols ........................... 74

Table 29. Combination circulatory and respiratory measures (Key Question 3) without

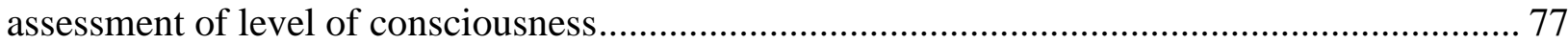

Table 30. Predictive utility of combinations of physiologic measures ........................................... 77

Table 31. Predictive utility of circulatory measures (Key Question 1) in pediatric patients......... 81

Table 32. Predictive utility of respiratory predictors (Key Question 2) in studies of pediatric

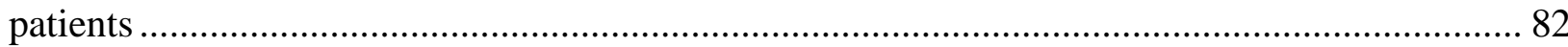

Table 33. Predictive utility of combination predictors (Key Question 3) in pediatric patients .... 83

Table 34. Predictive utility of single physiologic measures in older patients ................................ 86

Table 35. Predictive utility of shock index in older patients ......................................................... 87

Table 36. Predictive utility of combination triage criteria in older patients .................................. 88

Table 37. Post-test odds and probability of serious injury given pre-test assumptions ................. 93

Table 38. Out-of-hospital head-to-head studies comparing physiologic measures ....................... 95

\section{Figures}

Figure 1. Emergency medical services field triage ..................................................................... 1

Figure 2. Analytic framework .......................................................................................... 5

Figure 3. Literature flow diagram......................................................................................... 13

Figure 4. Pooled sensitivity of out-of-hospital blood pressure $<90 \mathrm{mmHg}$.................................. 22

Figure 5. Pooled specificity of out-of-hospital blood pressure $<90 \mathrm{mmHg}$.................................. 23

Figure 6. Pooled sensitivity of out-of-hospital blood pressure $<100 \mathrm{mmHg}$................................. 24

Figure 7. Pooled specificity of out-of-hospital systolic blood pressure $<100 \mathrm{mmHg}$................... 25

Figure 8. Pooled AUROC of out-of-hospital systolic blood pressure ………………………........ 26

Figure 9. Pooled sensitivity of out-of-hospital heart rate $\geq 110$ beats per minute........................... 28

Figure 10. Pooled specificity of out-of-hospital heart rate $\geq 110$ beats per minute......................... 29

Figure 11. Pooled AUROC of out-of-hospital heart rate ............................................................ 30

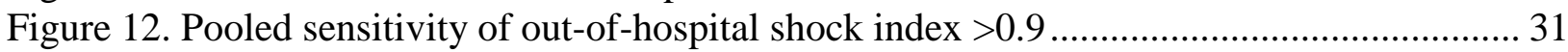

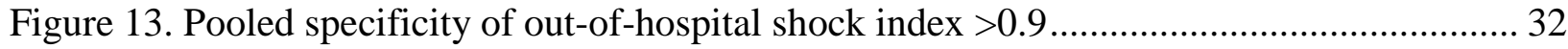

Figure 14. Pooled AUROC of out-of-hospital shock index........................................................... 33

Figure 15. Pooled sensitivity of out-of-hospital lactate $>2 \mathrm{mmol} / \mathrm{L}$............................................ 35

Figure 16. Pooled specificity of out-of-hospital lactate $>2 \mathrm{mmol} / \mathrm{L}$............................................... 36

Figure 17. Sensitivity of out-of-hospital lactate $>4 \mathrm{mmol} / \mathrm{L}$....................................................... 37

Figure 18. Specificity of out-of-hospital lactate $>4 \mathrm{mmol} / \mathrm{L}$...................................................... 38

Figure 19. Pooled AUROC of out-of-hospital lactate ................................................................... 39 
Figure 20. Pooled sensitivity of out-of-hospital respiratory rate $<10$ or $>29$ breaths per minute 51 Figure 21. Pooled specificity of out-of-hospital respiratory rate $<10$ or $>29$ breaths per minute 52 Figure 22. Pooled AUROC of out-of-hospital respiratory rate.

\section{Appendixes}

Appendix A. Search Strategies

Appendix B. List of Included Studies

Appendix C. List of Excluded Studies

Appendix D. Evidence Tables

Appendix E. Risk of Bias Criteria

Appendix F. Risk of Bias Assessment

Appendix G. Multivariate Results Summaries

Appendix H. Strength of Evidence

Appendix I. Meta-Analysis Results for Studies of Predictive Utility in the Emergency Room Setting 


\section{Evidence Summary}

\section{Background}

Unintentional injury is the fourth leading cause of death in the United States, the leading cause for people 1 to 44 years of age, ${ }^{1}$ and the reason for millions of emergency department (ED) visits. ${ }^{2}$ Trauma is the primary reason emergency medical services (EMS) transport people to the hospital. ${ }^{3}$ Out-of-hospital care includes the early interventions and life support needed to prevent immediate deterioration and to secure vital functions after injury.

In the United States, out-of-hospital trauma care is delivered predominately by EMS personnel. EMS personnel can include individuals with different levels of training and certification, including emergency medical responder, emergency medical technician (EMT), advanced EMT, and paramedic. ${ }^{4}$ EMS personnel assess patients in environments that are often chaotic and sometimes dangerous. Some out-of-hospital care decisions can be made based on observable characteristics of the injury (e.g., a crush injury or amputation), but other injuries require additional assessment. Triage guidelines and protocols include the assessment of circulatory and respiratory compromise as essential components of the triage process to identify high-risk trauma patients and inform transport destination decisions.

In the current guidelines, ${ }^{5}$ field triage of injured patients consists of four steps designed to identify different levels of risk and match patient risk to hospital transport decisions. The first step is to assess variables such as level of consciousness, circulation, and respiration. This assessment is combined with the results of the second step, an assessment of the anatomy of the injury. The combined results of steps 1 and 2 are used to identify the most seriously injured patients who "should be transported preferentially to the highest level of care within the defined trauma system." The initial triage criteria in the current guidelines are physiologic status and level of consciousness. Measures, monitors, and tools are needed to facilitate assessment of physiologic status because, unlike the anatomy of the injury, physiologic status cannot be directly observed. Thresholds indicating need for major level trauma care have been operationalized in the triage guidelines as Glasgow Coma Scale (GCS) $\leq 13$, systolic blood pressure (SBP) $<90 \mathrm{mmHg}$, and respiratory rate $<10$ or $>29$ breaths per minute ( $>20$ in infants aged less than 1 year) or need for ventilatory support. ${ }^{5}$ If steps 1 and 2 do not specify the patient as requiring transport to a major trauma center, steps 3 and 4 consider the mechanism of injury and additional factors such as age and comorbidities.

The purpose of this systematic review is to identify and summarize the research evidence evaluating measures of circulatory and respiratory compromise, focusing on measures that can be used in the field to triage trauma patients.

This review is designed to help inform decisions about what measures should be recommended in field triage guidelines and promoted for use in EMS practice. This is one of a series of reviews conducted for this purpose. A similar review compared the total GCS to the single item of the motor component for use in out-of-hospital assessment. ${ }^{6}$ The ultimate goal is to promote the efficient and effective use of trauma care resources in order to achieve good outcomes for patients. 


\section{Methods}

Detailed methods are available in the full report and the posted protocol (http://effectivehealthcare.ahrq.gov/index.cfm).

This review focuses on measures that assess the physiologic status (i.e., circulatory or respiratory compromise) of a trauma patient and that can be used in the field by EMS personnel. The purpose of the measures is to identify patients at high risk of serious injury so this information can be used to inform decisions about whether an injured patient needs immediate transport to the highest-level trauma center available.

The scope is limited to considering how well the physiologic measures predict serious injury in trauma patients evaluated by EMS personnel. The assumption is that being able to identify seriously injured patients will inform triage and transport decisions, and these decisions will impact care for the injury, which will affect outcomes. These assumed relationships and the ultimate patient outcomes are important, but not part of the review.

We included measures in the review that can be obtained by standard medical equipment or devices specially designed for field assessment or monitoring. We included ED studies and their data because conducting studies in the field is difficult and the body of evidence based on out-ofhospital data is limited for some measures. However, the data were analyzed and the results are presented separately for out-of-hospital and ED data.

The Key Questions for the review were:

Key Question 1: For patients with known or suspected trauma who are treated out-of-hospital by EMS personnel, what is the predictive utility of measures of circulatory compromise or derivative measures (e.g., the shock index) for predicting serious injury requiring transport to the highest level trauma center available?

1a. How does the predictive utility of the studied measures of circulatory compromise vary across age groups (e.g., children or the elderly)? Specifically, what values for the different age ranges are supported by the evidence?

Key Question 2: For patients with known or suspected trauma who are treated out-of-hospital by EMS personnel, what is the predictive utility of measures of respiratory compromise for predicting serious injury requiring transport to the highest level trauma center available?

2a. How does the predictive utility of the studied measures of respiratory compromise vary across age groups (e.g., children or the elderly)? Specifically, what values for the different age ranges are supported by the evidence? 
Key Question 3: For patients with known or suspected trauma who are treated out-of-hospital by EMS personnel, what is the evidence that scales combining (a) measures of respiratory and circulatory compromise or (b) measures of respiratory and/or circulatory compromise together with measurement of altered levels of consciousness (as defined by Glasgow Coma Scale or its components) can predict the need for transport to a trauma center?

\section{3a. How does the predictive utility of combinations of measures vary across age groups (e.g., children or the elderly)? Specifically, what values for the different age ranges are supported by the evidence?}

The scope and Key Questions for this topic were initially developed by the Agency for Healthcare Research and Quality in conjunction with the sponsoring partner agency, the National Highway Transportation Safety Administration.

To identify studies we searched Ovid MEDLINE ${ }^{\circledR}$, CINAHL ${ }^{\circledR}$, and the Cochrane Databases from 1996 through August 2017. We included studies of individual measures and measures that combined circulatory, respiratory, and level of consciousness assessment. For studies that met inclusion criteria, the key characteristics and results were abstracted into evidence tables that provide the basis for the description and synthesis of this body of literature. Studies were evaluated for risk of bias using the Quality in Prognosis Studies (QUIPS) tool. ${ }^{7}$ The complete evidence tables and the risk of bias ratings for each included study are available in Appendixes D and $\mathrm{F}$ of the full report.

The end points or outcomes of interest were the predictive utility of the measures. We included different approaches to assessing predictive utility: (1) measures of diagnostic accuracy (e.g., sensitivity and specificity,) and (2) discrimination (e.g., area under the receiver operating characteristic curve [AUROC]). Studies that provided only descriptive information, unadjusted risk estimates, or assessments of continuous variables (e.g., correlations or tests of differences in means) were excluded unless data were provided that could be used to calculate included outcomes. For this review our focus was on the predictive utility for identifying patients at high risk of being seriously injured. We defined seriously injured broadly and used a range of indicators of serious injury, including resource use (e.g., blood transfusion, intensive care unit [ICU] admission, and life-saving interventions), measures of anatomic injury severity measures (e.g., the Injury Severity Score [ISS]), and mortality, or combinations of any of these).

We conducted quantitative synthesis (i.e., meta-analysis) of diagnostic measures when there were adequate data from included studies. In cases with few studies, lack of data, or when data were only available as adjusted risk estimates from multivariate analyses, the range of the results and qualitative summaries were provided.

For meta-analyses we used a bivariate logistic mixed effects model ${ }^{8}$ to analyze sensitivity and specificity, incorporating the correlation between sensitivity and specificity. We assumed random effects across studies for sensitivity and specificity, and heterogeneity among the studies was measured based on the random effect variance. We also assessed statistical heterogeneity using the standard $\chi^{2}$ test and $I^{2}$ statistic. We calculated positive likelihood ratio (LR+) and negative likelihood ratio (LR-) using the summarized sensitivity and specificity. ${ }^{9,10}$ Analyses were stratified by different cutoff points when necessary to generate clinically meaningful combined estimates. Similarly, we performed random effects meta-analysis to calculate the 
combined AUROC using the profile likelihood method, which incorporates the uncertainty related to estimating between-study heterogeneity into account.

All analyses were conducted using Stata/IC 13.1 (StataCorp LP, College Station, TX), except for the bivariate logistic mixed effects model, for which SAS 9.4 (SAS Institute Inc., Cary, NC) was used.

The review team and Technical Expert Panel included experts who have conducted and published research in this field. In order to avoid bias, or the appearance of bias, we took the following steps: (1) authors were not involved in any decisions about including or excluding their own work, (2) to the extent it was feasible, reviewers were blinded to authors during title and abstract review so that the other team members/reviewers were not biased in favor of colleagues, (3) for full-text review, no one was assigned to review research they contributed to, and (4) team members and experts did not rate the risk of bias or abstract data from studies to which they contributed.

\section{Results}

We identified and included 138 articles reporting results of 134 studies: 90 evaluated measures of circulatory compromise, 39 respiratory compromise, and 64 included combination measures. Over two-thirds (96) of the studies were retrospective and the remainder (42) were prospective. A total of 25 studies used data from multi-site registries, 65 studies used administrative or registry data from a single site, and 48 studies engaged in primary data collection for the study. Three-quarters (103) of the studies were assessed as moderate risk of bias and the others were rated low risk of bias (10) or high risk of bias (25 studies). The concerns about bias were primarily related to three domains: study participation (e.g., concerns about sampling or recruitment), attrition (e.g., lost to followup), and lack of control for confounding factors that were not adequately addressed in the study design.

Studies used different indicators for serious injury, and often assessed more than one indicator. We grouped the indicators into three categories: (1) resource utilization, which includes lists of life-saving interventions, surgery, transfusion, ICU admission, or the published consensus-base criterion standard; ${ }^{11}$ (2) ratings of anatomic injury severity such as the ISS or types of injury or diagnosis such as traumatic brain injury; and (3) mortality. Resource utilization was the most common indicator (110 studies). A similar number of studies reported on the relationship between the measures and mortality (95 studies), while injury severity or type was less common (19 studies).

Tables A, B, and C consolidate the key estimates of the predictive utility of each identified measure. Sensitivity, specificity, and AUROC values for out-of-hospital and ED measurements are provided. When we were able to pool data, the pooled estimates are given in bold; when data were not pooled, the range of values from the included studies are given in italics. Additional information, such as the number of patients in the included studies and 95\% confidence intervals for the estimates, are available in the figures and tables in the full report. 
Table A. Key Question 1 results: overview of predictive utility of circulatory measures for serious injury* by setting

\begin{tabular}{|c|c|c|c|c|}
\hline Measure & $\begin{array}{l}\text { Out-of-Hospital: } \\
\text { Sensitivity (SOE) } \\
\text { Specificity (SOE) } \\
\text { Number of Studies }\end{array}$ & $\begin{array}{c}\text { Emergency } \\
\text { Department: } \\
\text { Sensitivity (SOE) } \\
\text { Specificity (SOE) } \\
\text { Number of Studies }\end{array}$ & $\begin{array}{l}\text { Out-of-Hospital: } \\
\text { AUROC (SOE) } \\
\text { Number of } \\
\text { Studies }\end{array}$ & $\begin{array}{c}\text { Emergency } \\
\text { Department: } \\
\text { AUROC (SOE) } \\
\text { Number of Studies }\end{array}$ \\
\hline $\begin{array}{l}\text { Systolic Blood } \\
\text { Pressure }\end{array}$ & $\begin{array}{l}\text { SBP <90 mmHg } \\
\text { Sen: } 19 \% \text { (SOE: Low) } \\
\text { Sp: } 95 \% \text { (SOE: } \\
\text { Moderate) } \\
17 \text { studies }^{12-28} \\
\text { SBP higher } \\
\text { thresholds (<100, } \\
\text { 110, or } 120 \text { mmHg) } \\
\text { Sen: } \mathbf{3 5 \%} \text { (SOE: Low) } \\
\text { Sp: } 88 \% \text { (SOE: Low) } \\
6 \text { studies }{ }^{12,13,19,29-31}\end{array}$ & $\begin{array}{l}\text { SBP }<90 \text { mmHg } \\
\text { Sen: } \mathbf{1 8 \%} \text { (SOE: Low) } \\
\text { Sp: } \mathbf{9 7 \%} \text { (SOE: } \\
\text { Moderate) } \\
9 \text { studies (in } 10 \\
\text { articles) }{ }^{12,21,29,30,32-37} \\
\text { SBP higher } \\
\text { thresholds (<100, } \\
\text { 110, or } 120 \text { mmHg) } \\
\text { Sen: } \mathbf{3 5 \%} \text { (SOE: Low) } \\
\text { Sp: } \mathbf{8 9 \%}(\mathrm{SOE}: \\
\text { Moderate) } \\
\\
4 \text { studies }\end{array}$ & $\begin{array}{l}0.67 \text { (SOE: } \\
\text { Moderate) } \\
9 \text { studies }^{16,28,41-47}\end{array}$ & $\begin{array}{l}\mathbf{0 . 6 4} \text { (SOE: } \\
\text { Moderate) } \\
12 \text { studies (in } 13 \\
\text { articles) } \\
55\end{array}$ \\
\hline Heart Rate & $\begin{array}{l}\text { HR >110 bpm } \\
\text { Sen: } \mathbf{2 8 \%} \text { (SOE: Low) } \\
\text { Sp: } \mathbf{8 5 \%} \text { (SOE: Low) } \\
\\
4 \text { studies }^{19,28,30,31}\end{array}$ & $\begin{array}{l}\text { HR >110 bpm } \\
\text { Sen: } 29 \% \text { (SOE: } \\
\text { Moderate) } \\
\text { Sp: } 93 \% \text { (SOE: } \\
\text { Moderate) } \\
\\
5 \text { studies }^{33,37,40,51,56}\end{array}$ & $\begin{array}{l}0.67 \text { (SOE: Low) } \\
5 \text { studies }^{28,42,44-46}\end{array}$ & $\begin{array}{l}\mathbf{0 . 6 6} \text { (SOE: } \\
\text { Moderate) } \\
9 \text { studies (in } 10 \\
\text { articles) } \\
53,55,57,36,38,49,51-\end{array}$ \\
\hline Shock Index & $\begin{array}{l}\text { SI >0.9 or }>1 \\
\text { Sen: } \mathbf{3 7 \%} \text { (SOE: Low) } \\
\text { Sp: } \mathbf{8 5 \%} \text { (SOE: Low) } \\
\\
5 \text { studies } 47,54,58-60\end{array}$ & $\begin{array}{l}\text { SI }>0.9 \text { or }>1 \\
\text { Sen: } 40 \% \text { (SOE: Low) } \\
\text { Sp: } 93 \% \text { (SOE: } \\
\text { Moderate) } \\
11 \text { studies (in } 12 \\
\text { articles) } \\
35,36,38,59-67\end{array}$ & $\begin{array}{l}\mathbf{0 . 7 2} \text { (SOE: Low) } \\
7 \\
\text { studies }^{16,28,41,45,47,58} \\
, 68\end{array}$ & $\begin{array}{l}\mathbf{0 . 7 1} \text { (SOE: } \\
\text { Moderate) } \\
11 \text { studies (in } 12 \\
\text { articles) } 35,36,38,40,49,53,5 \\
5,62,63,65,69,70\end{array}$ \\
\hline Lactate & $\begin{array}{l}\text { Lactate }>2 \text { or } 2.5 \\
\text { mmol/L } \\
\text { Sen: } 74 \% \text { (SOE: Low) } \\
\text { Sp: } \mathbf{6 2 \%} \text { (SOE: } \\
\text { Moderate) } \\
3 \text { studies } 16,71,72 \\
\text { Lactate }>4 \text { mmol/L } \\
\text { Sen: } \mathbf{2 3} \% \text { (SOE: } \\
\text { Insufficient) } \\
\text { Sp: } \mathbf{9 3 \%} \text { (SOE: } \\
\text { Insufficient) } \\
1 \text { study }{ }^{71}\end{array}$ & $\begin{array}{l}\text { Lactate }>2 \text { or } 2.5 \\
\text { mmol/L } \\
\text { Sen: } \mathbf{7 4 \%} \text { (SOE: Low) } \\
\text { Sp: } \mathbf{5 2 \%} \text { (SOE: Low) } \\
9 \text { studies (in } 10 \\
\text { articles) }{ }^{35,36,43,73-79} \\
\text { Lactate }>4 \text { mmol/L } \\
\text { Sen: } \mathbf{5 0 \%} \text { (SOE: Low) } \\
\text { Sp: } \mathbf{8 6} \% \text { (SOE: } \\
\text { Moderate) } \\
9 \\
\text { studies } \\
, 81\end{array}$ & $\begin{array}{l}0.77 \text { (SOE: Low) } \\
2 \text { studies }^{16,72}\end{array}$ & $\begin{array}{l}\mathbf{0 . 6 8} \text { (SOE: } \\
\text { Moderate) } \\
14 \text { studies (in } 15 \\
\text { articles) } 35,36,43,58,73,74,7 \\
6,78-80,82-86\end{array}$ \\
\hline
\end{tabular}




\begin{tabular}{|c|c|c|c|c|}
\hline Measure & $\begin{array}{l}\text { Out-of-Hospital: } \\
\text { Sensitivity (SOE) } \\
\text { Specificity (SOE) } \\
\text { Number of Studies }\end{array}$ & $\begin{array}{c}\text { Emergency } \\
\text { Department: } \\
\text { Sensitivity (SOE) } \\
\text { Specificity (SOE) } \\
\text { Number of Studies }\end{array}$ & $\begin{array}{l}\text { Out-of-Hospital: } \\
\text { AUROC (SOE) } \\
\text { Number of } \\
\text { Studies }\end{array}$ & $\begin{array}{c}\text { Emergency } \\
\text { Department: } \\
\text { AUROC (SOE) } \\
\text { Number of Studies }\end{array}$ \\
\hline Base Deficit & None & $\begin{array}{l}\text { Sen: } 19 \text { to } 59 \% \\
\text { (SOE: Low) } \\
\text { Sp: } 59 \text { to } 98 \% \text { (SOE: } \\
\text { Moderate) } \\
9 \text { studies (in } 10 \\
\text { articles) } \\
37,31,35- \\
\text { 37,65,80,83,87 }\end{array}$ & None & $\begin{array}{l}0.67 \text { to } 0.90 \text { (SOE: } \\
\text { Moderate) } \\
12 \text { studies (in } 13 \\
\text { articles) } 32,35,36,49,52,65,7 \\
\text { 3,77,80,82,83,85,86 }\end{array}$ \\
\hline $\begin{array}{l}\text { Heart Rate } \\
\text { Variability/Heart } \\
\text { Rate Complexity }\end{array}$ & $\begin{array}{l}\text { Sen: } 80 \text { to } 90 \% \text { (SOE: } \\
\text { Low) } \\
\text { Sp: } 67 \text { to } 100 \% \text { (SOE: } \\
\text { Low) } \\
2 \text { studies }^{44,88}\end{array}$ & None & $\begin{array}{l}0.60 \text { to } 0.95 \\
\text { (SOE: Low) } \\
7 \text { studies }^{44,46,88-92}\end{array}$ & $\begin{array}{l}0.67 \text { to } 0.68 \text { (SOE: } \\
\text { Insufficient) } \\
1 \text { study }^{93}\end{array}$ \\
\hline
\end{tabular}

AUROC = area under the receiver operating characteristic curve; bpm = beats per minute; HR = heart rate; SBP = systolic blood pressure; Sen = sensitivity; SI = shock index; SOE = strength of evidence; $\mathrm{Sp}$ = specificity

Note: Bold font $=$ data from pooled estimates; italic font $=$ range from unpooled studies

*Serious injury includes resource use (e.g., blood transfusion, intensive care unit [ICU] admission, and life-saving interventions) and injury severity measures (e.g., the Injury Severity Score [ISS], mortality, or combinations of any of these)

Table B. Key Question 2 results: overview of predictive utility of respiratory measures for serious injury* by setting

\begin{tabular}{|c|c|c|c|c|}
\hline Measure & $\begin{array}{l}\text { Out-of-Hospital: } \\
\text { Sensitivity } \\
\text { (SOE) } \\
\text { Specificity } \\
\text { (SOE) } \\
\text { Number of } \\
\text { Studies }\end{array}$ & $\begin{array}{c}\text { Emergency } \\
\text { Department: } \\
\text { Sensitivity (SOE) } \\
\text { Specificity (SOE) } \\
\text { Number of Studies }\end{array}$ & $\begin{array}{l}\text { Out-of-Hospital: } \\
\text { AUROC (SOE) } \\
\text { Number of } \\
\text { Studies }\end{array}$ & $\begin{array}{c}\text { Emergency } \\
\text { Department: } \\
\text { AUROC (SOE) } \\
\text { Number of Studies }\end{array}$ \\
\hline $\begin{array}{l}\text { Respiratory } \\
\text { Rate }\end{array}$ & $\begin{array}{l}\text { RR }<10 \text { or }>29 \\
\text { Sen: } 13 \% \text { (SOE: } \\
\text { Low) } \\
\text { Sp: } 96 \% \text { (SOE: } \\
\text { Low ) } \\
6 \text { studies }^{14,20,23-} \\
25,94\end{array}$ & $\begin{array}{l}\text { RR }<10 \text { or }>29 \\
\text { Sen: } 27 \% \text { (SOE: } \\
\text { Moderate) } \\
\text { Sp: } 95 \% \text { (SOE: } \\
\text { Moderate) } \\
4 \text { studies }\end{array}$ & $\begin{array}{l}0.70 \text { (SOE: Low) } \\
3 \text { studies }^{46,95,96}\end{array}$ & $\begin{array}{l}\mathbf{0 . 6 1} \text { (SOE: Moderate) } \\
3 \text { studies }^{38,48,51}\end{array}$ \\
\hline $\begin{array}{l}\mathrm{O}_{2} \\
\text { Saturation }\end{array}$ & 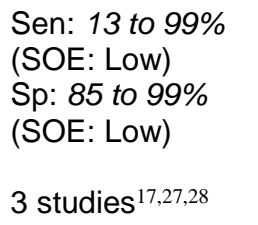 & $\begin{array}{l}\text { Sen: } 25 \text { to } 100 \% \text { (SOE: } \\
\text { Low) } \\
\text { Sp: } 39 \text { to } 94 \% \text { (SOE: } \\
\text { Low) } \\
2 \text { studies }^{32,97}\end{array}$ & $\begin{array}{l}0.53 \text { to } 0.76 \text { (SOE: } \\
\text { Low) } \\
3 \text { studies }^{27,28,96}\end{array}$ & $\begin{array}{l}0.61 \text { to } 0.76 \text { (SOE: Low) } \\
2 \text { studies }^{32,53}\end{array}$ \\
\hline
\end{tabular}




\begin{tabular}{|c|c|c|c|c|}
\hline Measure & $\begin{array}{l}\text { Out-of-Hospital: } \\
\text { Sensitivity } \\
\text { (SOE) } \\
\text { Specificity } \\
\text { (SOE) } \\
\text { Number of } \\
\text { Studies }\end{array}$ & $\begin{array}{c}\text { Emergency } \\
\text { Department: } \\
\text { Sensitivity (SOE) } \\
\text { Specificity (SOE) } \\
\text { Number of Studies }\end{array}$ & $\begin{array}{l}\text { Out-of-Hospital: } \\
\text { AUROC (SOE) } \\
\text { Number of } \\
\text { Studies }\end{array}$ & $\begin{array}{c}\text { Emergency } \\
\text { Department: } \\
\text { AUROC (SOE) } \\
\text { Number of Studies }\end{array}$ \\
\hline $\begin{array}{l}\text { Airway } \\
\text { Support }\end{array}$ & $\begin{array}{l}\text { Sen: } 8 \text { to } 53 \% \\
\text { (SOE: Low) } \\
\text { Sp: } 61 \text { to } 100 \% \\
\text { (SOE: Low) } \\
4 \text { studies (in } 5 \\
\text { articles) } \\
17,24,92,98,99\end{array}$ & $\begin{array}{l}\text { Sen: } 32 \text { to } 57 \% \text { (SOE: } \\
\text { Low) } \\
\text { Sp: } 85 \text { to } 96 \% \text { (SOE: } \\
\text { Low) } \\
3 \text { studies } 34,93,100\end{array}$ & None & None \\
\hline
\end{tabular}

AUROC = area under the receiver operating characteristic curve; O2 = oxygen; RR = respiratory rate; Sen = sensitivity; SOE = strength of evidence; $\mathrm{Sp}=$ specificity

Note: Bold font = data from pooled estimates; italic font = range from unpooled studies

*Serious injury includes resource use (e.g., blood transfusion, intensive care unit [ICU] admission, and life-saving interventions) and injury severity measures (e.g., the Injury Severity Score [ISS], mortality, or combinations of any of these)

Table C. Key Question 3 results: overview of predictive utility of combination of circulatory, respiratory, and level of consciousness measures for serious injury* by setting

\begin{tabular}{|c|c|c|c|c|}
\hline Measure & $\begin{array}{l}\text { Out-of-Hospital: } \\
\text { Sensitivity } \\
\text { (SOE) } \\
\text { Specificity } \\
\text { (SOE) } \\
\text { Number of } \\
\text { Studies }\end{array}$ & $\begin{array}{l}\text { Emergency Department: } \\
\text { Sensitivity (SOE) } \\
\text { Specificity (SOE) } \\
\text { Number of Studies }\end{array}$ & $\begin{array}{l}\text { Out-of-Hospital: } \\
\text { AUROC (SOE) } \\
\text { Number of } \\
\text { Studies }\end{array}$ & $\begin{array}{c}\text { Emergency } \\
\text { Department: } \\
\text { AUROC (SOE) } \\
\text { Number of Studies }\end{array}$ \\
\hline $\begin{array}{l}\text { Revised } \\
\text { Trauma } \\
\text { Score and } \\
\text { Revised } \\
\text { Trauma } \\
\text { Score for } \\
\text { Triage }\end{array}$ & $\begin{array}{l}\text { RTS }<7.5 \text {, T-RTS } \\
<12 \\
\text { Sen: } 95 \text { to } 96 \% \\
\text { (SOE: } \\
\text { Insufficient) } \\
\text { Sp: } 38 \text { to } 42 \% \\
\text { (SOE: } \\
\text { Insufficient) } \\
1 \text { study (in } 2 \\
\text { articles) } \\
\text { 98,99 }\end{array}$ & $\begin{array}{l}\text { RTS }<5.68 \text { or }<5.97, \text { T- } \\
\text { RTS <8 or <12 } \\
\text { Sen: } 19 \text { to } 84 \% \text { (SOE: } \\
\text { Low) } \\
\text { Sp: } 64 \text { to } 100 \% \text { (SOE: } \\
\text { Low) } \\
6 \text { studies }\end{array}$ & $\begin{array}{l}\mathbf{0 . 5 7} \text { for Resource } \\
\text { use (SOE: Low) } \\
\mathbf{0 . 8 9} \text { for Mortality } \\
\text { (SOE: Low) } \\
\text { 3 studies (in } 4 \\
\text { articles) } \\
28,45,98,99\end{array}$ & $\begin{array}{l}\text { 0.88 for Mortality } \\
\text { (SOE: Low) } \\
7 \\
\text { studies }^{48,69,70,83,101,103,104}\end{array}$ \\
\hline $\begin{array}{l}\text { Glasgow } \\
\text { Coma } \\
\text { Scale, Age, } \\
\text { and Arterial } \\
\text { Pressure } \\
\text { (GAP) }\end{array}$ & None & $\begin{array}{l}\text { Sen: } 75 \text { to } 98 \% \text { (SOE: } \\
\text { Low) } \\
\text { Sp: } 57 \text { to } 91 \% \text { (SOE: Low) } \\
2 \text { studies }^{101,105}\end{array}$ & None & $\begin{array}{l}\mathbf{0 . 9 6} \text { for both Mortality } \\
\text { and Early Mortality } \\
\text { (SOE: Moderate) } \\
3 \text { studies }^{101,103,105}\end{array}$ \\
\hline
\end{tabular}

AUROC = area under the receiver operating characteristic curve; RTS = Revised Trauma Score; Sen = sensitivity; SOE = strength of evidence; $\mathrm{Sp}$ = specificity; T-RTS = Revised Trauma Score for Triage

Note: Bold font $=$ data from pooled estimates; italic font $=$ range from unpooled studies

*Serious injury includes resource use (e.g., blood transfusion, intensive care unit [ICU] admission, and life-saving interventions) and injury severity measures (e.g., the Injury Severity Score [ISS], mortality, or combinations of any of these) 
Our analysis of individual measures of circulatory and respiratory compromise (Key Question 1 and Key Question 2) included pooled analyses of SBP, shock index (SI), heart rate (HR), lactate, and respiratory rate (RR), and qualitative summaries of studies of heart rate variability/heart rate complexity, base deficit, and oxygen saturation. Other measures that were the subject of one or two studies were included but not synthesized.

Most of the strength of evidence assessments were "low" due to inconsistency in results across studies and imprecise estimates, though in some cases study limitations also contributed to the low rating. There were a few "moderate" ratings for measures where there were more studies and subjects and the results were consistent and the estimates more precise. There were no "high" strength of evidence ratings as we are not confident that the results will not change based on future studies of physiologic measures that are larger, better, and purposefully designed to study trauma triage.

Across all the measures, the pooled AUROC values we calculated generally fell into the ranges considered poor (0.60 to 0.69 ) or fair (0.70 to 0.79$)$. Focusing on data collected out-ofhospital, the lowest pooled AUROCs were for SBP (0.67) and HR (0.67). The AUROCs were in the fair range for SI (0.72), lactate (0.77), and RR (0.70). We also pooled data to estimate sensitivity and specificity results for blood pressure and lactate at different thresholds ( $<90$ and $<100 \mathrm{mmHg}$ for blood pressure and $>2.0$ or $>4.0 \mathrm{mmol} / \mathrm{L}$ for lactate). Using the higher threshold of $<100 \mathrm{mmHg}$ for SBP did increase sensitivity compared the lower threshold of $<90 \mathrm{mmHg}$ (from 19\% at the lower threshold to 35\% at the higher threshold for out-of-hospital studies, and from 18\% to 35\% for ED studies) with a moderate decrease in specificity (from 95\% at the lower threshold to $88 \%$ at the higher threshold for out-of-hospital, and from $97 \%$ to $89 \%$ in ED). For lactate, defining abnormal with a more extreme value of $>4.0 \mathrm{mmol} / \mathrm{L}$ decreased sensitivity and increased specificity. The changes were more extreme in the out-of-hospital data (sensitivity was $74 \%$ for lactate $>2.0 \mathrm{mmol} / \mathrm{L}$ and $23 \%$ for $>4.0 \mathrm{mmol} / \mathrm{L}$; specificity increased from $62 \%$ to $93 \%$ ) than in the ED data (sensitivity was $74 \%$ for lactate $>2.0 \mathrm{mmol} / \mathrm{L}$ and $50 \%$ at $>4.0 \mathrm{mmol} / \mathrm{L}$; specificity increased from 52\% to $86 \%$ ). However, the out-of-hospital estimates are from fewer studies and patients and the estimates are less stable and less precise.

We identified numerous combination measures (Key Question 3); however, most were analyzed in only one or two articles. The exception was the Revised Trauma Score (RTS) and variations on this score. Given that the formula for RTS cannot be calculated quickly without a calculator or app, some studies suggested and evaluated revisions that simplified the calculation. The produced minor decreases in AUROCs (from 0.90 for the RTS to $0.88^{99}$ for the simpler version, or from 0.75 to $0.74^{98}$ ). Another combination of potential interest is Glasgow Coma Scale, age, and arterial pressure (GAP), which combines the Glasgow Coma Scale (GCS) score, adds points if the patient is over 60 years of age (age is the A in GAP), and scores SBP as above or below $120 \mathrm{mmHg}$. Adding age means this is not purely a physiologic measure, but it is included as it is simple and there is small but growing evidence of its performance. While the data we reviewed is from a smaller number of studies than are available for other measures, and the measures were all collected in the ED, these initial indications are that the GAP performs well. Reported AUROCs were over 0.9 and sensitivities ranged from 75 to 98 percent and specificities from 57 to 91 percent across different indicators of serious injury.

We examined the utility of the measures or specific thresholds for pediatric and older trauma patients. The included studies that assessed measures in pediatric patients reported that the standard thresholds used for adults for SBP and base deficit resulted in low sensitivities in children. Lactate $>2.0$ resulted in higher sensitivities compared to the other measures, but the 
values were still low. Performance of this measure varied across indicators of serious injury and in age subgroups in the one study with subgroup comparisons; however, larger studies are needed to confirm these variations. The results of evaluations of respiratory rate are inconsistent, with reported sensitivities ranging from 2 to 76 percent. Combination measures performed better, with better results for a trauma score developed specifically for pediatrics.

In older adults, studies reported consistently low sensitivities and AUROCs for SBP, lactate, base deficit, respiratory rate, and assisted ventilation. Shock index also performed less well in older patients. ${ }^{106}$ Some variations of triage criteria modified for older adults by either changing thresholds or adding additional criteria (e.g., mechanism of injury) have demonstrated substantial increases in sensitivity (e.g., $76 \%$ to $92 \%{ }^{107}$ ), but this magnitude of improvement is not consistent across indicators of serious injury and came with similar substantial decreases in specificity (e.g., $78 \%$ to $42 \%{ }^{107}$ ).

\section{Discussion}

\section{Implications and Applicability}

For out-of-hospital clinical practice, our findings demonstrated that current circulatory and respiratory measures have low sensitivities but higher specificities. The evidence does not point to necessarily "better" cut-points for measures such as SBP, SI, and RR. In general, more liberal cut-points (e.g., SBP $<110 \mathrm{mmHg}$ vs. $<90 \mathrm{mmHg}$ ) will raise sensitivity and lower specificityan inevitable trade-off, but the magnitude of this trade-off may differ across tests.

However, based on the evidence we identified, no physiologic measures have high enough sensitivity that a negative result (e.g., normal physiologic value) could be confidently used to conclude that a patient is not at risk of being seriously injured, even with more liberal cut-points.

Our findings were based on a relatively large number of diverse studies. Having data from studies across a wide range of possible situations mirrored the reality of field triage and out-ofhospital assessment. While the diversity across the studies meant heterogeneity was high in the pooled estimates and the consistency across results was lower, the range was likely to reflect the variation that will be seen in trauma assessment and triage.

An approach to summarizing the data across studies and considering their impact is presented in Table D. This is a standard approach often used to present the implications of how well a screening test or triage tool performs. The pooled data are modeled to generate positive and negative likelihood ratios (LR+ and LR-). The positive likelihood ratio is Sensitivity/(1Specificity) and the negative likelihood ratio is (1-Sensitivity)/Specificity. The likelihood ratios are then applied to different hypothetical pre-test probabilities and odds to produce post-test odds of the outcome (in this case serious injury) given a negative or positive test. The post-test probability if the test is negative (1-Negative Predictive Value) is also referred to as under-triage. 
Table D. Post-test odds and probability of serious injury given pre-test assumptions

\begin{tabular}{|c|c|c|c|c|c|c|c|c|c|}
\hline $\begin{array}{l}\text { Physiological } \\
\text { Predictor } \\
\text { (Test) }\end{array}$ & $\begin{array}{c}\text { Serious } \\
\text { Injury } \\
\text { Indicator } \\
\text { (Outcome) }\end{array}$ & $\begin{array}{c}\text { Pre-Test } \\
\text { Probability } \\
\text { (Hypo- } \\
\text { thetical) } \\
\end{array}$ & $\begin{array}{l}\text { Pre- } \\
\text { Test } \\
\text { Odds } \\
\end{array}$ & LR+ & LR- & $\begin{array}{l}\text { Post- } \\
\text { Test } \\
\text { Odds } \\
\text { (if a } \\
\text { patient } \\
\text { has } \\
\text { positive } \\
\text { test) }\end{array}$ & $\begin{array}{c}\text { Post-Test } \\
\text { Probability } \\
\text { (PPV) } \\
\text { (if a patient } \\
\text { has positive } \\
\text { test) }\end{array}$ & $\begin{array}{c}\text { Post- } \\
\text { Test } \\
\text { Odds } \\
\text { (if a } \\
\text { patient } \\
\text { has } \\
\text { negative } \\
\text { test) } \\
\end{array}$ & $\begin{array}{c}\text { Post-Test } \\
\text { Probability } \\
\text { (1-NPV) } \\
\text { (if a patient } \\
\text { has negative } \\
\text { test) }\end{array}$ \\
\hline SBP $<90$ & Resource Use & $10 \%$ & 0.11 & 4.32 & 0.83 & 0.48 & $32 \%$ & 0.09 & $8 \%$ \\
\hline SBP $<90$ & Resource Use & $20 \%$ & 0.25 & 4.32 & 0.83 & 1.08 & $52 \%$ & 0.21 & $17 \%$ \\
\hline SBP $<100$ & Resource Use & $10 \%$ & 0.11 & 3.30 & 0.80 & 0.36 & $27 \%$ & 0.09 & $8 \%$ \\
\hline SBP $<100$ & Resource Use & $20 \%$ & 0.25 & 3.30 & 0.80 & 0.83 & $45 \%$ & 0.20 & $17 \%$ \\
\hline$H R \geq 110$ & Resource Use & $10 \%$ & 0.11 & 1.37 & 0.91 & 0.15 & $13 \%$ & 0.10 & $9 \%$ \\
\hline$H R \geq 110$ & Resource Use & $20 \%$ & 0.25 & 1.37 & 0.91 & 0.34 & $25 \%$ & 0.23 & $19 \%$ \\
\hline SI $>1$ & Resource Use & $10 \%$ & 0.11 & 3.13 & 0.71 & 0.34 & $26 \%$ & 0.08 & $7 \%$ \\
\hline SI $>1$ & Resource Use & $20 \%$ & 0.25 & 3.13 & 0.71 & 0.78 & $44 \%$ & 0.18 & $15 \%$ \\
\hline Lactate $>2^{*}$ & Resource Use & $10 \%$ & 0.11 & 1.94 & 0.29 & 0.21 & $18 \%$ & 0.03 & $3 \%$ \\
\hline Lactate $>2^{*}$ & Resource Use & $20 \%$ & 0.25 & 1.94 & 0.29 & 0.48 & $33 \%$ & 0.07 & $7 \%$ \\
\hline Lactate $>4^{*}$ & Resource Use & $10 \%$ & 0.11 & 2.34 & 0.59 & 0.26 & $21 \%$ & 0.07 & $6 \%$ \\
\hline Lactate $>4^{*}$ & Resource Use & $20 \%$ & 0.25 & 2.34 & 0.59 & 0.59 & $37 \%$ & 0.15 & $13 \%$ \\
\hline $\mathrm{RR}<10$ or $>29$ & Resource Use & $10 \%$ & 0.11 & 5.61 & 0.90 & 0.62 & $38 \%$ & 0.10 & $9 \%$ \\
\hline$R R<10$ or $>29$ & Resource Use & $20 \%$ & 0.25 & 5.61 & 0.90 & 1.40 & $58 \%$ & 0.23 & $18 \%$ \\
\hline
\end{tabular}

$\mathrm{HR}$ = heart rate; $\mathrm{LR}+$ = positive likelihood ratio; LR- = negative likelihood ratio; NPV = negative predictive value; PPV = positive predictive value; $\mathrm{RR}=$ respiratory rate; $\mathrm{SBP}=$ systolic blood pressure; $\mathrm{SI}=$ shock index

*Lactate $>4$ is based on emergency department data; lactate $>2$ is out-of-hospital

Overall, our analysis demonstrated that physiologic measures have low sensitivity for identifying high-risk trauma patients (i.e., many patients will have normal physiology and prove to have serious injuries - there are higher numbers of false negatives), but have high specificity (i.e., patients with abnormal physiologic measures are likely to have resource needs, serious injuries, and are at higher mortality risk - there are few false positives). There was little evidence to suggest that one physiologic measure is significantly better than another (e.g., SBP versus SI versus lactate) because fewer studies compared these measures directly in head-to-head studies, the head-to-head studies were not amenable to pooling as they use different thresholds and outcomes, and the differences across our pooled estimate were small to moderate. However, combining different categories of physiologic measures (e.g., circulatory and level of consciousness) may increase predictive yield. Less extreme cut-points (e.g., lactate $>2$, SBP 
$<110$ ) raised sensitivity and lowered specificity, demonstrating that sensitivity and specificity have an inverse relationship when selecting dichotomous cut-points in continuous measures.

\section{Limitations}

The major limitations of the evidence base are the limited number of head-to-head comparisons and generally low strength of evidence available. As this review illustrates, there are a number of potential physiologic measures that could be used in triage and a range of indicators of serious injury used in this body of research. Our approach to this diversity was to focus on combining information for the same measure across studies and then looking across the measures. If we had limited our examination to comparable head-to-head comparisons we would have had small numbers of studies in each of a larger number of pairwise comparisons.

However, there is a risk in comparing measure across studies rather than relying on comparisons within studies. Measures in different studies may produce similar results but for different populations. For example, if estimates of the AUROC for SBP and HR are similar, based on different studies with different populations, we could erroneously conclude that they will perform similarly across all patients when in truth SBP has this discriminant level for one subtype of patients while HR is similar but in a different subtype of patients. In order to assess this risk, we examined the results of the available head-to-head studies from the smaller number of studies that included direct comparisons and this did not change our conclusions. An overview of selected comparisons and all the results from these studies are included in the text and Appendix of the full report.

The literature available for analysis was dominated by studies that effectively limited their population to trauma patients who are transported by EMS. Most of the studies were based on data from trauma registries. While the specifics for inclusion vary across registries and also across studies that use administrative records in a similar way, standard practice seems to be inclusion of data collected on transported and/or admitted patients. The implication is that patients assessed by EMS but not transported are either not included at all or included inconsistently.

Another characteristic of the data in these registries is that it is usually collected prospectively but analyzed retrospectively, thus blurring the distinction between retrospective and prospective study types. In many cases the data sources are difficult to determine based on the published reports. Analysis is also complicated by the fact that the registry studies usually have large samples, while more clearly prospective studies we identified were often exploratory with small samples. The distinction matters because in other situations we might be able to make assumptions about the potential for differences in bias in prospective and retrospective studies, but in this literature the direction of the potential bias was not clear.

A substantial limitation in the evidence base was the lack of population-based samples where physiologic measures were collected in the out-of-hospital setting and patients were tracked across all hospitals (i.e., not limited to patients transported to major trauma centers), across phases of care (e.g., ED, hospital \#1, transfer, hospital \#2), and using population-based sampling to reduce selection bias.

There was also limited detail about how the physiologic measure data were collected. Studies rarely reported details that could be important, such as what equipment was used, how and when the measurement was taken, and who was involved. Another important limitation of the research on this topic is the lack information on subpopulations, particularly children and older adults. 
The evidence base also was inconsistent in how high-risk, seriously injured, trauma patients were defined, especially related to resource use. Studies tended to use a single indicator, such as need for a massive transfusion, rather than include multiple indicators, and even the definitions of given indicator varied across studies (e.g., what volume is considered massive and over what time period?). While the trauma research community has made efforts to come up with a comprehensive resource-based definition (i.e., the consensus-based criteria ${ }^{11}$ and lists of lifesaving interventions), such a uniform definition is not yet common in the trauma research. The result is that many studies may underestimate the utility of measures by requiring that they predict single or narrowly-defined indicators of severe injury.

There were also limitations to this review resulting from our decisions and processes. We included measurements in the ED as well as out-of-hospital measurements, but presented the ED and out-of-hospital results separately. We identified and included prognostic studies as they are similar but not identical to studies of predictive utility.

\section{Future Research Needs}

This review summarizes a sizable body of literature and it highlights several areas in which future research is needed.

One priority is for studies that compare, or at least document, differences in measurement (e.g., instrumentation, timing). This would allow the impact of these differences on the predictive utility of the measure to be considered.

Another priority is to encourage more research using the consensus-based criteria of the need for care in a major trauma center or a standardized list of life-saving interventions. If the indicators of high-risk patients were consistent, cleaner comparisons could be made both across studies and across measures. This would also permit an assessment of the utility of individual measures in a broader context.

Also, sampling patients in the out-of-hospital setting and tracking them through their hospital course and beyond, regardless of which hospital they were transported to, would help to reduce a large source of potential bias.

A key topic for additional research is the assessment of the utility of measures across age groups. While we did identify some studies that considered the use of physiologic measures for children and older adults, this is still a small subset of the literature and many questions remain. Age is often available or collected and if more researchers stratified analyses by age, even if age is not the focus of the study, a substantial amount of information would become available to inform decisions and improve care for children and older individuals.

\section{Conclusions}

While specifics vary across measures, settings, and populations, overall the predictive utilities of physiologic measures that are either currently used for trauma assessment and triage, or have been suggested, are moderate and not ideal. Measures of circulatory compromise (SBP, $\mathrm{HR}$, SI, and lactate) and respiratory compromise (RR) have been evaluated in multiple studies, some with large numbers of patients. In general, these measures have low sensitivities, high specificities, and AUROCs in the fair-to-good range. Use of these measures should be guided by the understanding that when they are abnormal, that they are highly predictive of high-risk of serious injury in trauma patients, but that many patients with serious injuries will have normal physiologic measures. Combinations of these measures with assessments of consciousness seem to perform better, but how they would be implemented out-of-hospital needs to be determined, 
and then they need to be tested under field conditions to confirm their effectiveness and utility. Modification of triage measures for children or older adults is needed, given that these measures perform worse in these age groups than in adults; yet, the research has not yet identified better performing variations or replacements. 


\section{References}

1. Centers for Disease Control and Prevention. 10 Leading Causes of Death by Age Group, United States - 2015. https://www.cdc.gov/injury/images/lccharts/leading_causes_of_death_age_group_ 2015_1050w740h.gif. Accessed July 7, 2017.

2. Centers for Disease Control and Prevention. National Hospital Ambulatory Medical Care Survey: 2014 Emergency Department Summary Tables. https://www.cdc.gov/nchs/data/nhamcs/web _tables/2014_ed_web_tables.pdf. Accessed November 282017.

3. Wang HE, Mann NC, Jacobson KE, et al. National characteristics of emergency medical services responses in the United States. Prehosp Emerg Care. 2013 JanMar;17(1):8-14. doi: 10.3109/10903127.2012.722178. PMID: 23072355.

4. National Emergency Medical Services Workforce Data Definitions. (Prepared by the American Institutes for Research through contract DTNH22-080F-00122.) Washington, DC: National Highway Traffic Safety Administration; February 2013. www.nhtsa.gov/staticfiles/nti/pdf/811720.pd f.

5. Sasser SM, Hunt RC, Faul M, et al. Guidelines for field triage of injured patients: recommendations of the National Expert Panel on Field Triage, 2011. MMWR Recomm Rep. 2012;61(RR-1):1-20. PMID: 22237112.

6. Chou R, Totten AM, Carney N, et al. Predictive utility of the total Glasgow Coma Scale versus the motor component of the Glasgow Coma Scale for identification of patients with serious traumatic injuries. Ann Emerg Med. 2017 2017/08/01/;70(2):14357.e6. doi:

10.1016/j.annemergmed.2016.11.032.

7. Hayden JA, van der Windt DA, Cartwright $\mathrm{JL}$, et al. Assessing bias in studies of prognostic factors. Ann Intern Med. 2013;158(4):280-6. doi: 10.7326/00034819-158-4-201302190-00009. PMID: 23420236.
8. Chu H, Cole SR. Bivariate meta-analysis of sensitivity and specificity with sparse data: a generalized linear mixed model approach. $\mathrm{J}$ Clin Epidemiol. 2006;59(12):1331-2; author reply 2-3. doi: 10.1016/j.jclinepi.2006.06.011. PMID: 17098577.

9. Trikalinos TA, Balion CM, Coleman CI, et al. Chapter 8: meta-analysis of test performance when there is a "gold standard". J Gen Intern Med. 2012;27 Suppl 1:S56-66. doi: 10.1007/s11606-012-2029-1. PMID: 22648676.

10. Zwinderman AH, Bossuyt PM. We should not pool diagnostic likelihood ratios in systematic reviews. Stat Med. 2008;27(5):687-97. doi: 10.1002/sim.2992. PMID: 17611957.

11. Lerner EB, Willenbring BD, Pirrallo RG, et al. A consensus-based criterion standard for trauma center need. J Trauma Acute Care Surg. 2014;76(4):1157-63. doi: 10.1097/TA.0000000000000189. PMID: 24662885.

12. Arbabi S, Jurkovich GJ, Wahl WL, et al. A comparison of prehospital and hospital data in trauma patients. $\mathrm{J}$ Trauma. 2004;56(5):1029-32. doi: 10.1097/01.TA.0000123036.20919.4B. PMID: 15179242.

13. Brown JB, Gestring ML, Forsythe RM, et al. Systolic blood pressure criteria in the National Trauma Triage Protocol for geriatric trauma: 110 is the new 90 . J Trauma Acute Care Surg. 2015;78(2):352-9. doi: 10.1097/TA.0000000000000523. PMID: 25757122.

14. Engum SA, Mitchell MK, Scherer LR, et al. Prehospital triage in the injured pediatric patient. J Pediatr Surg. 2000;35(1):82-7. doi: 10.1016/S0022-3468(00)80019-6. PMID: 10646780 .

15. Franklin GA, Boaz PW, Spain DA, et al. Prehospital hypotension as a valid indicator of trauma team activation. J Trauma. 2000;48(6):1034-9. PMID: 10866247. 
16. Guyette FX, Meier EN, Newgard C, et al. A comparison of prehospital lactate and systolic blood pressure for predicting the need for resuscitative care in trauma transported by ground. J Trauma Acute Care Surg. 2015;78(3):600-6. doi: 10.1097/TA.0000000000000549. PMID: 25710433.

17. Hamada SR, Gauss T, Duchateau FX, et al. Evaluation of the performance of French physician-staffed emergency medical service in the triage of major trauma patients. J Trauma Acute Care Surg. 2014;76(6):1476-83. doi: 10.1097/ta.0000000000000239. PMID: 24854319.

18. Henry MC, Hollander JE, Alicandro JM, et al. Incremental benefit of individual American College of Surgeons trauma triage criteria. Acad Emerg Med. 1996;3(11):9921000. doi: 10.1111/j.1553-

2712.1996.tb03340.x. PMID: 8922003.

19. Holcomb JB, Niles SE, Miller CC, et al. Prehospital physiologic data and lifesaving interventions in trauma patients. Mil Med. 2005;170(1):7-13. doi:

10.7205/MILMED.170.1.7. PMID: 15724847.

20. Lerner EB, Drendel AL, Cushman JT, et al. Ability of the physiologic criteria of the field triage guidelines to identify children who need the resources of a trauma center. Prehosp Emerg Care. 2017;21(2):180-4. doi: 10.1080/10903127.2016.1233311. PMID: 27710155.

21. Lin G, Becker A, Lynn M. Changes in vital signs of trauma victims from prehospital to hospital settings. Journal of Paramedic Practice. 2011;3(10):558-62.

22. Lipsky AM, Gausche-Hill M, Henneman PL, et al. Prehospital hypotension is a predictor of the need for an emergent, therapeutic operation in trauma patients with normal systolic blood pressure in the emergency department. J Trauma. 2006;61(5):1228-33. doi: 10.1097/01.ta.0000196694.52615.84. PMID: 17099534.
23. Newgard CD, Rudser K, Atkins DL, et al. The availability and use of out-of-hospital physiologic information to identify high-risk injured children in a multisite, populationbased cohort. Prehosp Emerg Care. 2009;13(4):420-31. doi: 10.1080/10903120903144882. PMID: 19731152.

24. Newgard CD, Richardson D, Holmes JF, et al. Physiologic field triage criteria for identifying seriously injured older adults. Prehosp Emerg Care. 2014;18(4):461-70. doi: 10.3109/10903127.2014.912707. PMID: 24933614.

25. Ocak G, Sturms LM, Hoogeveen JM, et al. Prehospital identification of major trauma patients. Langenbecks Arch Surg. 2009;394(2):285-92. doi: 10.1007/s00423008-0340-4. PMID: 18581133.

26. Schenarts PJ, Phade SV, Agle SC, et al. Field hypotension in patients who arrive at the hospital normotensive: a marker of severe injury or crying wolf? N C Med J. 2008;69(4):265-9. PMID: 18828314.

27. Van Haren RM, Thorson CM, Valle EJ, et al. Novel prehospital monitor with injury acuity alarm to identify trauma patients who require lifesaving intervention. J Trauma Acute Care Surg. 2014;76(3):743-9. doi: 10.1097/TA.0000000000000099. PMID: 24553543.

28. Woodford MR, Mackenzie CF, DuBose J, et al. Continuously recorded oxygen saturation and heart rate during prehospital transport outperform initial measurement in prediction of mortality after trauma. J Trauma Acute Care Surg. 2012;72(4):1006-11. doi: 10.1097/TA.0b013e318241c059. PMID: 22491618.

29. Lalezarzadeh F, Wisniewski P, Huynh K, et al. Evaluation of prehospital and emergency department systolic blood pressure as a predictor of in-hospital mortality. Am Surg. 2009;75(10):1009-14. PMID: 19886155.

30. Lehmann RK, Arthurs ZM, Cuadrado DG, et al. Trauma team activation: simplified criteria safely reduces overtriage. Am J Surg. 2007;193(5):630-4; discussion 4-5. doi: 10.1016/j.amjsurg.2007.01.017. PMID: 17434371. 
31. Liu NT, Holcomb JB, Wade CE, et al. Evaluation of standard versus nonstandard vital signs monitors in the prehospital and emergency departments: results and lessons learned from a trauma patient care protocol. J Trauma Acute Care Surg. 2014;77(3 Suppl 2):S121-6. doi: 10.1097/TA.0000000000000192. PMID: 24770560.

32. Beekley AC, Martin MJ, Nelson T, et al. Continuous noninvasive tissue oximetry in the early evaluation of the combat casualty: a prospective study. J Trauma. 2010;69(1 Suppl):S14-S25. doi: 10.1097/TA.0b013e3181e42326. PMID: 20622608.

33. Dinh MM, Bein KJ, Oliver M, et al. Refining the trauma triage algorithm at an Australian major trauma centre: derivation and internal validation of a triage risk score. Eur J Trauma Emerg Surg. 2014;40(1):6774. doi: 10.1007/s00068-013-0315-1. PMID: 26815779.

34. Jones JM, Skaga NO, Sovik S, et al. Norwegian survival prediction model in trauma: modelling effects of anatomic injury, acute physiology, age, and comorbidity. Acta Anaesthesiol Scand. 2014;58(3):303-15. doi: 10.1111/aas.12256. PMID: 24438461.

35. Paladino L, Sinert R, Wallace D, et al. The utility of base deficit and arterial lactate in differentiating major from minor injury in trauma patients with normal vital signs. Resuscitation. 2008;77(3):363-8. doi: 10.1016/j.resuscitation.2008.01.022. PMID: 18367305.

36. Paladino L, Subramanian RA, Nabors S, et al. The utility of shock index in differentiating major from minor injury. Eur J Emerg Med. 2011;18(2):94-8. doi: 10.1097/MEJ.0b013e32833f212b. PMID: 20842040.

37. Rainer TH, Ho AM, Yeung JH, et al. Early risk stratification of patients with major trauma requiring massive blood transfusion. Resuscitation. 2011;82(6):724-9. doi: 10.1016/j.resuscitation.2011.02.016. PMID: 21458905.
38. Bruijns SR, Guly HR, Bouamra O, et al. The value of traditional vital signs, shock index, and age-based markers in predicting trauma mortality. J Trauma Acute Care Surg. 2013;74(6):1432-7. doi: 10.1097/TA.0b013e31829246c7. PMID: 23694869.

39. Caputo ND, Fraser RM, Paliga A, et al. Nasal cannula end-tidal CO2 correlates with serum lactate levels and odds of operative intervention in penetrating trauma patients: a prospective cohort study. J Trauma Acute Care Surg. 2012;73(5):1202-7. doi: 10.1097/TA.0b013e318270198c. PMID: 23117381.

40. King RW, Plewa MC, Buderer NM, et al. Shock index as a marker for significant injury in trauma patients. Acad Emerg Med. 1996;3(11):1041-5. doi: 10.1111/j.15532712.1996.tb03351.x. PMID: 8922013.

41. Chen L, Reisner AT, McKenna TM, et al. Diagnosis of hemorrhage in a prehospital trauma population using linear and nonlinear multiparameter analysis of vital signs. Conf Proc IEEE Eng Med Biol Soc. 2007 29th Annual International Conference of the IEEE Engineering in Medicine and Biology Society; 2007 August 22-26; Lyon, France. IEEE; 2007:3748-51.

42. Chen L, Reisner AT, Gribok A, et al. Is respiration-induced variation in the photoplethysmogram associated with major hypovolemia in patients with acute traumatic injuries? Shock. 2010;34(5):45560. doi: 10.1097/SHK.0b013e3181dc07da. PMID: 20220568.

43. Vandromme MJ, Griffin RL, Weinberg JA, et al. Lactate is a better predictor than systolic blood pressure for determining blood requirement and mortality: could prehospital measures improve trauma triage? J Am Coll Surg. 2010;210(5):861-7; discussion 7-9. doi: 10.1016/j.jamcollsurg.2010.01.012. PMID: 20421067.

44. Vettorello M, Santambrogio SM, Calini AR, et al. Predicting haemorrhage in pre-hospital traumatic patients: evaluation of the novel heart-to-arm time index. Acta Anaesthesiol Scand. 2013;57(7):929-35. doi: 10.1111/aas.12135. PMID: 23701337. 
45. Grimme K, Pape HC, Probst C, et al. Calculation of different triage scores based on the German Trauma Registry: value of the shock index. Eur J Traum. 2005;31(5):480-7. doi: 10.1007/s00068-0052026-8.

46. Edla S, Reisner AT, Liu J, et al. Is heart rate variability better than routine vital signs for prehospital identification of major hemorrhage? Am J Emerg Med. 2015;33(2):254-61. doi: 10.1016/j.ajem.2014.11.046. PMID: 25534122.

47. Pottecher J, Ageron FX, Fauche C, et al. Prehospital shock index and pulse pressure/heart rate ratio to predict massive transfusion after severe trauma:

Retrospective analysis of a large regional trauma database. J Trauma Acute Care Surg. 2016;81(4):713-22. doi: 10.1097/TA.0000000000001191. PMID: 27648770 .

48. Al-Salamah MA, McDowell I, Stiell IG, et al. Initial emergency department trauma scores from the OPALS Study: the case for the motor score in blunt trauma. Acad Emerg Med. 2004;11(8):834-42. doi: 10.1197/j.aem.2004.03.008. PMID: 15289188.

49. Dunham MP, Sartorius B, Laing GL, et al. A comparison of base deficit and vital signs in the early assessment of patients with penetrating trauma in a high burden setting. Injury. 2017;48(9):1972-7. doi: 10.1016/j.injury.2017.06.011. PMID: 28684079.

50. Eastridge BJ, Salinas J, McManus JG, et al. Hypotension begins at $110 \mathrm{~mm} \mathrm{Hg}$ : redefining "hypotension" with data. J Trauma. 2007;63(2):291-7; discussion 7-9. doi: 10.1097/TA.0b013e31809ed924. PMID: 17693826.

51. Garner A, Lee A, Harrison K, et al. Comparative analysis of multiple-casualty incident triage algorithms. Ann Emerg Med. 2001;38(5):541-8. doi: 10.1067/mem.2001.119053. PMID: 11679866.

52. Paladino L, Subramanian RA, Bonilla E, et al. Leukocytosis as prognostic indicator of major injury. West J Emerg Med. 2010;11(5):450-5. PMID: 21293764.
53. Reisner AT, Edla S, Liu J, et al. Muscle oxygen saturation improves diagnostic association between initial vital signs and major hemorrhage: a prospective observational study. Acad Emerg Med. 2016;23(3):353-7. doi: 10.1111/acem.12899. PMID: 26743804.

54. Vandromme MJ, Griffin RL, McGwin G, Jr., et al. Prospective identification of patients at risk for massive transfusion: an imprecise endeavor. Am Surg. 2011;77(2):155-61. PMID: 21337871.

55. Zarzaur BL, Croce MA, Fischer PE, et al. New vitals after injury: shock index for the young and age $\mathrm{x}$ shock index for the old. $\mathrm{J}$ Surg Res. 2008;147(2):229-36. doi: 10.1016/j.jss.2008.03.025. PMID: 18498875.

56. Bruijns SR, Guly HR, Bouamra O, et al. The value of the difference between ED and prehospital vital signs in predicting outcome in trauma. Emerg Med J. 2014;31(7):579-82. doi: 10.1136/emermed-2012-202271. PMID: 23616498.

57. Shoemaker WC, Bayard DS, Botnen A, et al. Mathematical program for outcome prediction and therapeutic support for trauma beginning within $1 \mathrm{hr}$ of admission: a preliminary report. Crit Care Med. 2005;33(7):1499-506. doi: 10.1097/01.CCM.0000162641.92400.AA. PMID: 16003054.

58. Bouzat P, Schilte C, Vinclair M, et al. Capillary lactate concentration on admission of normotensive trauma patients: a prospective study. Scand J Trauma Resusc Emerg Med. 2016;24:82. doi: 10.1186/s13049-016-0272-x. PMID: 27267942.

59. Cannon CM, Braxton CC, Kling-Smith M, et al. Utility of the shock index in predicting mortality in traumatically injured patients. J Trauma. 2009;67(6):1426-30. doi: 10.1097/TA.0b013e3181bbf728. PMID: 20009697.

60. Lai WH, Rau CS, Hsu SY, et al. Using the reverse shock index at the injury scene and in the emergency department to identify high-risk patients: a cross-sectional retrospective study. Int J Environ Res Public Health. 2016;13(4):357. doi: 10.3390/ijerph13040357. PMID: 27023577. 
61. Aslar AK, Kuzu MA, Elhan AH, et al. Admission lactate level and the APACHE II score are the most useful predictors of prognosis following torso trauma. Injury. 2004;35(8):746-52. doi: 10.1016/j.injury.2003.09.030. PMID: 15246796.

62. DeMuro JP, Simmons S, Jax J, et al. Application of the shock index to the prediction of need for hemostasis intervention. Am J Emerg Med.

2013;31(8):1260-3. doi: 10.1016/j.ajem.2013.05.027. PMID: 23806728 .

63. Kim SY, Hong KJ, Shin SD, et al. Validation of the shock index, modified shock index, and age shock index for predicting mortality of geriatric trauma patients in emergency departments. J Korean Med Sci. 2016;31(12):2026-32. doi: 10.3346/jkms.2016.31.12.2026. PMID: 27822945.

64. Montoya KF, Charry JD, Calle-Toro JS, et al. Shock index as a mortality predictor in patients with acute polytrauma. Journal of Acute Disease. 2015;4(3):202-4. doi: 10.1016/j.joad.2015.04.006.

65. Mutschler M, Nienaber U, Munzberg M, et al. The shock index revisited - a fast guide to transfusion requirement? A retrospective analysis on 21,853 patients derived from the TraumaRegister DGU. Crit Care. 2013;17(4):R172. doi: 10.1186/cc12851. PMID: 23938104.

66. Pandit V, Rhee P, Hashmi A, et al. Shock index predicts mortality in geriatric trauma patients: an analysis of the National Trauma Data Bank. J Trauma Acute Care Surg. 2014;76(4):1111-5. doi: 10.1097/TA.0000000000000160. PMID: 24662879.

67. Vassallo J, Horne S, Ball S, et al. Usefulness of the shock index as a secondary triage tool. J R Army Med Corps. 2015;161(1):537. doi: 10.1136/jramc-2013-000178. PMID: 24794704.

68. Chen L, McKenna TM, Reisner AT, et al. Decision tool for the early diagnosis of trauma patient hypovolemia. J Biomed Inform. 2008;41(3):469-78. doi: 10.1016/j.jbi.2007.12.002. PMID: 18255342.
69. Imhoff BF, Thompson NJ, Hastings MA, et al. Rapid Emergency Medicine Score (REMS) in the trauma population: a retrospective study. BMJ Open. 2014;4(5):e004738. doi: 10.1136/bmjopen2013-004738. PMID: 24793256.

70. Miller RT, Nazir N, McDonald T, et al. The modified rapid emergency medicine score: a novel trauma triage tool to predict inhospital mortality. Injury. 2017;48(9):1870 7. doi: 10.1016/j.injury.2017.04.048. PMID: 28465003.

71. Brown JB, Lerner EB, Sperry JL, et al. Prehospital lactate improves accuracy of prehospital criteria for designating trauma activation level. J Trauma Acute Care Surg. 2016;81(3):445-52. doi: 10.1097/ta.0000000000001085. PMID: 27116410.

72. Shah A, Guyette F, Suffoletto B, et al. Diagnostic accuracy of a single point-ofcare prehospital serum lactate for predicting outcomes in pediatric trauma patients. Pediatr Emerg Care. 2013;29(6):715-9. doi: 10.1097/PEC.0b013e318294ddb1. PMID: 23714761.

73. Callaway DW, Shapiro NI, Donnino MW, et al. Serum lactate and base deficit as predictors of mortality in normotensive elderly blunt trauma patients. J Trauma. 2009;66(4):1040-4. doi: 10.1097/TA.0b013e3181895e9e. PMID: 19359912.

74. Folkert IW, Sims CA, Pascual JL, et al. Initial venous lactate levels in patients with isolated penetrating extremity trauma: a retrospective cohort study. Eur J Trauma Emerg Surg. 2015;41(2):203-9. doi: 10.1007/s00068-014-0442-3. PMID: 26038266.

75. Mizushima Y, Ueno M, Watanabe H, et al. Discrepancy between heart rate and makers of hypoperfusion is a predictor of mortality in trauma patients. $\mathrm{J}$ Trauma. 2011;71(4):789-92. doi: 10.1097/TA.0b013e31822f7bbd. PMID: 21986732. 
76. Pal JD, Victorino GP, Twomey P, et al. Admission serum lactate levels do not predict mortality in the acutely injured patient. J Trauma. 2006;60(3):583-7;

discussion 7-9. doi:

10.1097/01.ta.0000205858.82575.55. PMID: 16531858.

77. Ramanathan R, Parrish DW, Hartwich JE, et al. Utility of admission serum lactate in pediatric trauma. J Pediatr Surg. 2015;50(4):598-603. doi: 10.1016/j.jpedsurg.2014.08.013. PMID: 25840070.

78. Regnier MA, Raux M, Le Manach Y, et al. Prognostic significance of blood lactate and lactate clearance in trauma patients. Anesthesiology. 2012;117(6):1276-88. doi: 10.1097/ALN.0b013e318273349d. PMID: 23168430.

79. Sammour T, Kahokehr A, Caldwell S, et al. Venous glucose and arterial lactate as biochemical predictors of mortality in clinically severely injured trauma patientsa comparison with ISS and TRISS. Injury. 2009;40(1):104-8. doi:

10.1016/j.injury.2008.07.032. PMID: 19117566.

80. Caputo ND, Kanter M, Fraser R, et al. Comparing biomarkers of traumatic shock: the utility of anion gap, base excess, and serum lactate in the ED. Am J Emerg Med. 2015;33(9):1134-9. doi: 10.1016/j.ajem.2015.04.085. PMID: 26027886.

81. Dunne JR, Tracy JK, Scalea TM, et al. Lactate and base deficit in trauma: does alcohol or drug use impair their predictive accuracy? J Trauma. 2005;58(5):959-66. doi: 10.1097/01.TA.0000158508.84009.49. PMID: 15920409.

82. Baron BJ, Sinert R, Zehtabchi S, et al. Diagnostic utility of sublingual PCO2 for detecting hemorrhage in penetrating trauma patients. J Trauma. 2004;57(1):69-74. doi: 10.1097/01.TA.0000090754.94232.2C. PMID: 15284551.
83. Raux M, Le Manach Y, Gauss T, et al. Comparison of the prognostic significance of initial blood lactate and base deficit in trauma patients. Anesthesiology. 2017;126(3):522-33. doi: 10.1097/ALN.0000000000001490. PMID: 28059838.

84. Parsikia A, Bones K, Kaplan M, et al. The predictive value of initial serum lactate in trauma patients. Shock. 2014;42(3):199-204. doi: 10.1097/shk.0000000000000208. PMID: 24978889.

85. Paladino L, Subramanian RA, Nabors S, et al. Triage hyperglycemia as a prognostic indicator of major trauma. J Trauma. 2010;69(1):41-5. doi: 10.1097/TA.0b013e3181c9f0cb. PMID: 20665990.

86. Baron BJ, Dutton RP, Zehtabchi S, et al. Sublingual capnometry for rapid determination of the severity of hemorrhagic shock. J Trauma. 2007;62(1):120-4. doi: 10.1097/TA.0b013e31802d96ec. PMID: 17215742.

87. Davis JW, Parks SN, Kaups KL, et al. Admission base deficit predicts transfusion requirements and risk of complications. J Trauma. 1996;41(5):769-74. PMID: 8913202.

88. King DR, Ogilvie MP, Pereira BM, et al. Heart rate variability as a triage tool in patients with trauma during prehospital helicopter transport. J Trauma. 2009;67(3):436-40. doi: 10.1097/TA.0b013e3181ad67de. PMID: 19741382.

89. Batchinsky AI, Cancio LC, Salinas J, et al. Prehospital loss of R-to-R interval complexity is associated with mortality in trauma patients. J Trauma. 2007;63(3):5128. doi: 10.1097/TA.0b013e318142d2f0. PMID: 18073594.

90. Batchinsky AI, Salinas J, Kuusela T, et al. Rapid prediction of trauma patient survival by analysis of heart rate complexity: impact of reducing data set size. Shock. 2009;32(6):565-71. doi: 10.1097/SHK.0b013e3181a993dc. PMID: 19487984. 
91. Cancio LC, Batchinsky AI, Salinas J, et al. Heart-rate complexity for prediction of prehospital lifesaving interventions in trauma patients. J Trauma. 2008;65(4):8139. doi: 10.1097/TA.0b013e3181848241. PMID: 18849796.

92. Cooke WH, Salinas J, Convertino VA, et al. Heart rate variability and its association with mortality in prehospital trauma patients. $\mathrm{J}$ Trauma. 2006;60(2):363-70; discussion 70. doi: 10.1097/01.ta.0000196623.48952.0e. PMID: 16508497.

93. Ryan ML, Ogilvie MP, Pereira BM, et al. Heart rate variability is an independent predictor of morbidity and mortality in hemodynamically stable trauma patients. J Trauma. 2011;70(6):1371-80. doi: 10.1097/TA.0b013e31821858e6. PMID: 21817974.

94. Liu NT, Holcomb JB, Wade CE, et al. Development and validation of a machine learning algorithm and hybrid system to predict the need for life-saving interventions in trauma patients. Med Biol Eng Comput. 2014;52(2):193-203. doi: 10.1007/s11517013-1130-x. PMID: 24263362.

95. Chen L, Reisner AT, Gribok A, et al. Can we improve the clinical utility of respiratory rate as a monitored vital sign? Shock. 2009;31(6):574-80. doi: 10.1097/SHK.0b013e318193e885. PMID: 19008777.

96. Raux M, Thicoipe M, Wiel E, et al. Comparison of respiratory rate and peripheral oxygen saturation to assess severity in trauma patients. Intensive Care Med. 2006;32(3):405-12. doi: 10.1007/s00134-005-0063-8. PMID: 16485093.

97. Khasawneh MA, Zielinski MD, Jenkins DH, et al. Low tissue oxygen saturation is associated with requirements for transfusion in the rural trauma population. World J

Surg. 2014;38(8):1892-7. doi: 10.1007/s00268-014-2505-3. PMID: 24969044.

98. Raux M, Sartorius D, Le Manach Y, et al. What do prehospital trauma scores predict besides mortality? J Trauma.

2011;71(3):754-9. doi: 10.1097/TA.0b013e3181fd0dae. PMID: 21336194.
99. Sartorius D, Le Manach Y, David JS, et al. Mechanism, Glasgow Coma Scale, Age, and Arterial Pressure (MGAP): a new simple prehospital triage score to predict mortality in trauma patients. Crit Care Med. 2010;38(3):831-7. doi: 10.1097/CCM.0b013e3181cc4a67. PMID: 20068467.

100. Courville XF, Koval KJ, Carney BT, et al. Early prediction of posttraumatic in-hospital mortality in pediatric patients. J Pediatr Orthop. 2009;29(5):439-44. doi: 10.1097/BPO.0b013e3181aad60f. PMID: 19568013.

101. Ahun E, Koksal O, Sigirli D, et al. Value of the Glasgow Coma Scale, Age, and Arterial Blood Pressure score for predicting the mortality of major trauma patients presenting to the emergency department. Ulus Travma Acil Cerrahi Derg. 2014;20(4):241-7. doi: 10.5505/tjtes.2014.76399. PMID: 25135017.

102. Gray A, Goyder EC, Goodacre SW, et al. Trauma triage: a comparison of CRAMS and TRTS in a UK population. Injury. 1997;28(2):97-101. PMID: 9205573.

103. Kondo Y, Abe T, Kohshi K, et al. Revised trauma scoring system to predict in-hospital mortality in the emergency department: Glasgow Coma Scale, Age, and Systolic Blood Pressure score. Crit Care. 2011;15(4):R191. doi: 10.1186/cc10348. PMID: 21831280.

104. Yuen MSY, Mann SKF, Chow DHK. A simplified emergency trauma score for predicting mortality in emergency setting. Nurs Crit Care. 2016;21(4):9-15. doi: 10.1111/nicc.12137. PMID: 25382107.

105. Rahmani F, Bakhtavar HE, Vahdati SS, et al. Evaluation of MGAP and GAP trauma scores to predict prognosis of multipletrauma patients. Trauma Mon. 2017;22(3):e33249. doi: 10.5812/traumamon.33249.

106. McNab A, Burns B, Bhullar I, et al. An analysis of shock index as a correlate for outcomes in trauma by age group. Surgery. 2013;154(2):384-7. doi: 10.1016/j.surg.2013.05.007. PMID: 23889965. 
107. Newgard CD, Holmes JF, Haukoos JS, et al. Improving early identification of the highrisk elderly trauma patient by emergency medical services. Injury. 2016;47(1):19-25. doi: 10.1016/j.injury.2015.09.010. PMID: 26477345. 


\section{Introduction}

\section{Background}

\section{Burden of Trauma}

In 2015, unintentional injury was the fourth leading cause of death in the United States, the leading cause for individuals 1 to 44 years of age, and in the top five for all age groups except people 65 years of age and older (seventh for this group). ${ }^{1}$ In 2014, there were approximately 40 million emergency department (ED) visits for injuries (28.3\% of all ED visits); of these, 3 million were due to trauma complications and unspecified injuries. ${ }^{2}$ Trauma is also the most frequent reason for emergency medical services (EMS) emergency responses, accounting for over 25 percent of all encounters in the United States in $2010 .^{3}$

\section{Trauma Triage}

Pathways of care for injured patients, which include people with intentional as well as unintentional injuries, are based on systems of care that address the various stages along the trauma chain of survival. ${ }^{4}$ Out-of-hospital care includes the early interventions and life support needed to prevent immediate deterioration and secure vital functions as well as triaging (sorting) patients to appropriate sites for additional care.

In the United States, out-of-hospital trauma care is delivered predominately by EMS personnel. EMS personnel can include individuals with different levels of training and certification, including an emergency medical responder, emergency medical technician (EMT), advanced EMT, and a paramedic. ${ }^{5}$ EMS personnel must assess patients in environments that are often chaotic and sometimes dangerous. While it is often clear that a patient is injured, a more nuanced assessment is frequently required to identify high-risk patients and inform the best course of action and transport decisions. EMS providers must quickly identify if there are immediate life-threatening conditions or serious injuries that require emergent interventions. The treatment of injured patients includes assessment of injuries and stabilization as well as deciding where to transport the patient. Triage (from French, "to sort”) is the process of deciding where the patient will be transported. While the assessment, treatment, and stabilization are direct care activities, when combined with the transport destination decision they are often referred to as field triage (Figure 1).

Figure 1. Emergency medical services field triage
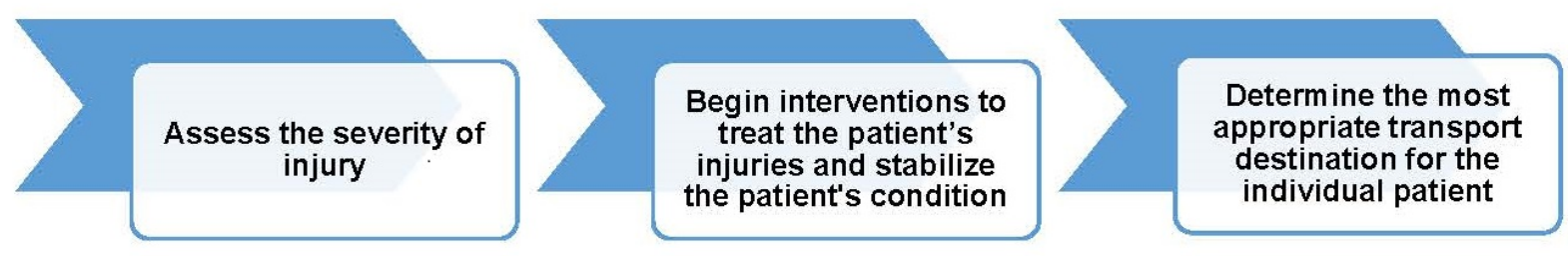

An important aspect of this initial care for informing triage and transport decisions is accurately identifying those trauma patients who are likely to have a serious injury, require early 
critical resources, or are at risk for death. Selecting the appropriate destination hospital, specifically whether or not a patient should be transported to a designated major trauma center, is a key decision affecting patient outcomes. ${ }^{6,7}$ Under-triage, meaning transporting someone to a lower level of care than needed after trauma, is associated with a substantial increase in mortality. ${ }^{8}$ Survival among patients with serious injuries is 25 percent higher when treated at a major trauma center compared with a nontrauma center. ${ }^{9}$ However, major trauma centers are a costly and limited resource. Patients without serious injuries can be treated effectively outside of major trauma centers and at hospitals that may be closer, and studies suggest that accurate triage could reduce over-use and produce substantial cost savings. ${ }^{10,11}$ Therefore, one of the goals of trauma systems is to efficiently concentrate patients with serious injuries in major trauma centers. Field trauma triage plays a critical role in this process.

Field triage criteria have been developed to help EMS personnel match patient needs with the appropriate level of care. The utility of these criteria is based on their ability to help identify high-risk trauma patients with serious injuries who have a high likelihood of mortality and other adverse clinical outcomes and who, therefore, needs higher levels of care.

In the current guidelines, field triage of injured patients consists of four steps designed to identify different levels of risk and match patient risk to hospital transport decisions. The first step is to assess variables such as level of consciousness, circulation, and respiration. This assessment is combined with the second step, an assessment of the anatomy of the injury, and the combined results of steps 1 and 2 are used to identify the most seriously injured patients who "should be transported preferentially to the highest level of care available within the defined trauma system." If steps 1 and 2 do not identify the patient as requiring transport to a major trauma center, step 3 considers the detailed mechanism of injury (i.e., falls, high-risk auto crash, or motorcycle crash) and the recommendation is that patients with these injuries should be transported to the "closest trauma center, which need not be the highest level." Step 4 adds consideration of several additional factors such as age, comorbidities (e.g., anticoagulation and bleeding disorders, end-stage renal disease, pregnancy $>20$ weeks), burns with or without trauma, and EMS judgment, and recommends that medical control be contacted with transport to a trauma center or specific resource hospital considered. ${ }^{12}$

The initial (step 1) triage criteria in the current guidelines are physiologic (blood pressure, respiratory rate $[\mathrm{RR}]$ ) measures and level of consciousness. Measures, monitors, and tools are often needed to facilitate assessment of physiologic status because, unlike the anatomy of the injury, physiologic status cannot be directly observed. Thresholds indicating need for major level trauma care have been operationalized in the most recent trauma triage guideline as Glasgow Coma Scale (GCS) $\leq 13$, systolic blood pressure (SBP) $<90 \mathrm{mmHg}$, and respiratory rate (RR) $<10$ or $>29$ breaths per minute ( $>20$ in infants aged less than 1 year), or a need for ventilatory support. $^{12}$

\section{Physiologic Measures in Field Triage}

Blood pressure, RR, and GCS have been part of the field triage guidelines since their initial publication in 1987. Ventilatory support was added in 2011, and the threshold for GCS was changed from $\leq 14$ to $\leq 13$ since the initial publication. ${ }^{13}$

In 2007, the Institute of Medicine issued a report on the future of EMS, Emergency Medical Services: At the Crossroads, which pointed out evidence gaps in prehospital trauma care. ${ }^{14}$ Over the past decade, the research base has grown: the number of studies used to support the trauma triage guidelines has increased 24-fold from approximately two per year in the 2006 guidelines 
to about 48 per year in the 2011 guidelines. ${ }^{12}$ Other developments, including point-of-care testing and advanced monitoring technology such as sensors, may impact the entire triage process. Despite these changes, the criteria have remained relatively stable since the initial version. ${ }^{13}$ Recent prospective research suggests that the current Field Triage Decision Scheme fails to identify a substantial number of patients with serious injuries ${ }^{15}$ and that there is opportunity to optimize the field triage criteria, particularly the physiologic measures. New continuous monitoring and communications technologies have been developed and present opportunities to collect, use, and transmit additional information in trauma care. ${ }^{16-19}$ Additionally, testing and evaluation of these physiologic indicators of trauma have revealed that they may perform differently in different populations. For example, some measures may underestimate risk and therefore lead to undertriage of elderly trauma victims, ${ }^{20,21}$ and some measures may require different cutoffs when assessing children. ${ }^{22}$ These factors have led to proposals to consider new potential indicators such as complexity/variability of heart rate (HR), tissue $\mathrm{O}_{2}$ saturation, mean arterial pressure, lactate, end-tidal $\mathrm{CO}_{2}$, descriptors for respiratory effort, or derivatives such as the shock index (HR divided by SBP), as well as new age-specific thresholds. ${ }^{23,24}$ Individual measures may also be combined into risk assessment instruments. For trauma care in the field, ideal measures and instruments need to be easy to use, accurate, and easy to interpret under a variety of field conditions by personnel with varying levels of training.

Determining the need for trauma center care among injured patients is important in evaluating and comparing different measures of physiologic compromise that can be used to inform triage decisions, but operationalizing the identification of high-risk trauma patients requiring care in major trauma centers is challenging. Indicators of the need for trauma care that have been used or proposed include in-hospital mortality, measures of resource use (e.g., a published consensus-based criterion, ${ }^{15,25}$ lists of life-saving interventions, ${ }^{16,17}$ or a need for a single intervention such as major nonorthopedic surgery), and anatomic injury severity (e.g., the Injury Severity Score [ISS]). However, none of these indicators is perfect and their advantages and disadvantages need to be considered when evaluating the evidence base for the predictive utility of the various physiologic measures.

\section{Objective}

The purpose of this systematic review is to identify and summarize the research evidence evaluating measures of circulatory and respiratory compromise, focusing on measures that can be easily used in the field to triage trauma patients. This review is designed to help inform decisions about what measures should be recommended in the next version of the field trauma triage guidelines and promoted for use in EMS practice. This is one of a series of reviews conducted for this purpose. A similar review compared the total GCS to the single item of the motor component for use in out of hospital assessment. ${ }^{26}$ The ultimate goal is to promote the efficient and effective use of EMS and trauma care resources in order to achieve optimal outcomes for injured patients.

\section{Key Questions and Scope}

The scope of this review is limited to measures of circulatory or respiratory compromise in a trauma patient that can be used in the field by out-of-hospital providers to identify high-risk trauma patients requiring care in a major trauma center. The purpose of the measures is to identify patients likely to have serious injuries, require early critical resources, or at risk of death, and to use this information to inform decisions about whether an injured patient needs immediate 
transport to the highest level trauma center available. We included measures in the review that can be readily obtained by standard medical equipment or devices designed specifically for field assessment or monitoring.

The Key Questions for this review are listed below. Key Questions 1, 2, and 3 differ only in that they address the utility of different categories of physiologic measures (i.e., circulatory, respiratory, or combinations) for predicting the likelihood that a patient has a serious injury. There are multiple ways to define serious injury and several indicators have been included in the review. These are listed in the PICOTS (populations, interventions, comparators, outcomes, timing, setting) section.

Key Question 1: For patients with known or suspected trauma who are treated out-of-hospital by EMS personnel, what is the predictive utility of measures of circulatory compromise or derivative measures (e.g., the shock index) for predicting serious injury requiring transport to the highest level trauma center available?

1a: How does the predictive utility of the studied measures of circulatory compromise vary across age groups (e.g., children or the elderly)? Specifically, what values for the different age ranges are supported by the evidence?

Key Question 2: For patients with known or suspected trauma who are treated out-of-hospital by EMS personnel, what is the predictive utility of measures of respiratory compromise for predicting serious injury requiring transport to the highest level trauma center available?

2a: How does the predictive utility of the studied measures of respiratory compromise vary across age groups (e.g., children or the elderly)? Specifically, what values for the different age ranges are supported by the evidence?

Key Question 3: For patients with known or suspected trauma who are treated out-of-hospital by EMS personnel, what is the evidence that scales combining (a) measures of respiratory and circulatory compromise or (b) measures of respiratory and/or circulatory compromise together with measurement of altered levels of consciousness (as defined by Glasgow Coma Scale or its components) can predict the need for transport to a trauma center?

3a. How does the predictive utility of combinations of measures vary across age groups (e.g., children or the elderly)? Specifically, what values for the different age ranges are supported by the evidence? 
The scope and Key Questions for this topic were initially developed by the Agency for Healthcare Research and Quality in conjunction with the sponsoring partner agency, the National Highway Transportation Safety Administration. The questions were reorganized by the project team and revised after input from the Technical Expert Panel. There was no formal topic refinement process for this review.

We adapted the graphical analytic framework and PICOTS framework, tools designed for intervention studies, to this review. Combined, the analytic framework (Figure 2) and the PICOTS further delineated the scope and established our inclusion and exclusion criteria.

\section{Analytic Framework}

The analytic framework depicts the relationship among the major elements of the Key Questions as well as their expected relationships to intermediate and clinical outcomes, even though these relationships are not always included in the review. This review is limited to considering how well the physiologic measures predict serious injury in trauma patients evaluated by EMS personnel. These are the components connected with solid lines. The assumption is that being able to identify seriously injured patients will inform triage and transport decisions, and these decisions will impact care for the injury, which will affect outcomes. These relationships are represented with dashed lines as they are important assumptions, but not part of the review.

\section{Figure 2. Analytic framework}

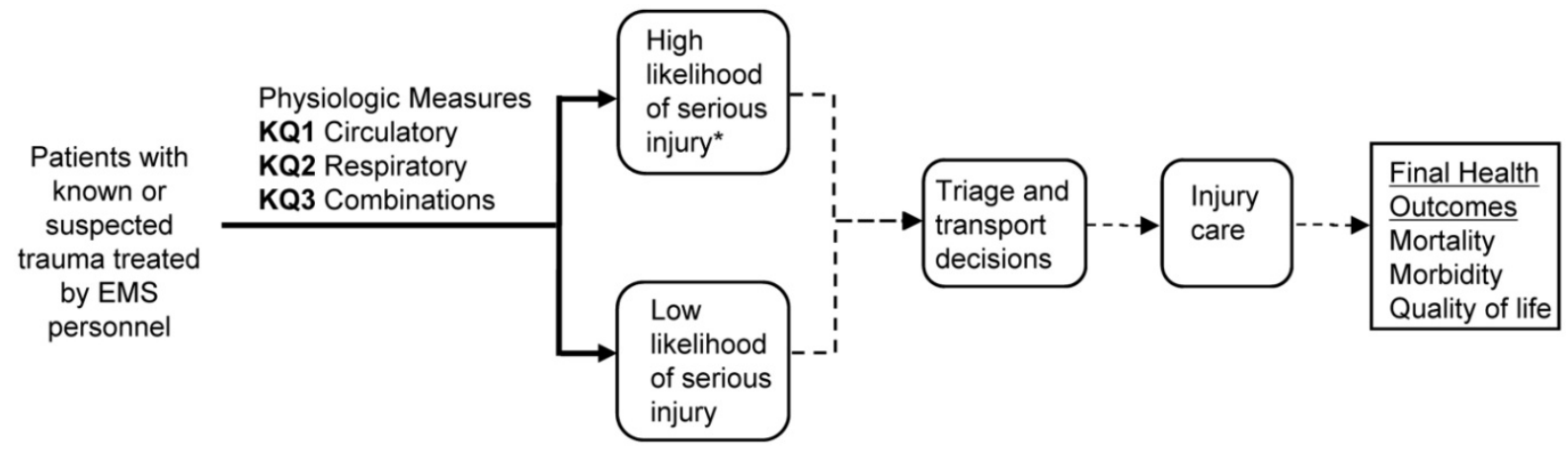

EMS = emergency medical services; KQ = Key Question

Note: Solid lines = relationships within the scope; dashed lines = assumed relationships outside the scope of the review

*Defined by inpatient mortality, resource use (e.g., the published consensus-based criterion standard, need for life-saving interventions, major surgery), or injury severity score (ISS) $>15$ 


\section{Methods}

The procedures for conducting this review are based on the Agency for Healthcare Research and Quality (AHRQ) Methods Guide for Systematic Reviews of Diagnostic Tests in addition to the Methods Guide for Effectiveness and Comparative Effectiveness Reviews. ${ }^{27,28}$ These methods have been adapted to this review of studies that evaluate physiologic measures of circulatory and respiratory compromise in term of predictive utility. In this section we summarize key elements of the methods that are necessary to understand the results. The protocol for this review, posted on the AHRQ Web site (http://effectivehealthcare.ahrq.gov/index.cfm), includes a detailed description of methods.

\section{Search Strategy}

We included studies with publication dates from 1996 to August 2017. This search start date was selected because trauma care has changed over time; only rudimentary measures and monitors existed prior to 1996 and only five States had fully implemented trauma systems in the early 1990s. ${ }^{29}$ We searched MEDLINE ${ }^{\circledR}$, CINAHL $^{\circledR}$, Embase ${ }^{\circledR}$, and the Cochrane databases. The search strategies are provided in Appendix A. Notice was posted in the Federal Register requesting published and unpublished evidence relevant to the review; no submissions were received. Reference lists of included articles were reviewed for additional relevant citations.

\section{Criteria for Inclusion/Exclusion of Studies in the Review}

The criteria for inclusion and exclusion of studies were based on the Key Questions and the analytic framework. The PICOTS (Populations, Interventions, Comparators, Outcomes, Timing, Setting/Study Design) framework was used to delineate what we included and excluded, as described in Table 1.

- Population refers to the patients who are the subjects in the studies to be included.

- The Intervention is usually the treatment or health service of interest that is being evaluated in terms of its impact on the population. In this review, physiologic measures are being evaluated.

- The Comparator in this review is what was used to evaluate the physiologic measure's ability to identify patients who are at high risk of having a severe injury. Defining and operationalizing what "high risk" means is challenging for several reasons. The extent of injury at the time of field triage cannot be determined conclusively and we expect that clinical outcomes (e.g., death or disability) are affected by out-of-hospital and in-hospital treatment (i.e., a person can have a serious injury and recover). For this reason, we included several indicators that a patient was seriously injured.

- The end points or Outcomes of interest are the predictive utility of the measures. We included two different approaches to assessing predictive utility: (1) measures of diagnostic accuracy (e.g., sensitivity and specificity); and (2) discrimination (e.g., area under the receiver operating characteristic curve [AUROC]). Studies that provide only descriptive information, unadjusted risk estimates, or assessments of continuous variables (e.g., correlations or tests of differences in means) were excluded unless data were provided that could be used to calculate included outcomes.

- The Timing of the measurement is important for this review. We were primarily interested in data collected upon the arrival of emergency medical services personnel to the scene of injury, during treatment in the field, and during transport (collectively 
referred to as out-of-hospital or in the field). Studies with measures taken upon arrival at an emergency department (ED) were considered in instances where there was insufficient out-of-hospital data.

- Relevant Settings are the locations of care, and in this review settings are closely related to timing, as we focused on out-of-hospital or early ED care.

- Study Designs are not formally part of PICOTS, but are important as the design determines a study's ability to address a question of interest. We included any study that evaluated a measure that met our inclusion criteria and produced an outcome of interest or provided data that allowed the outcome to be calculated.

Table 1. Inclusion and exclusion criteria

\begin{tabular}{|c|c|c|}
\hline \begin{tabular}{|l|} 
Adapted \\
PICOTS
\end{tabular} & Included & Excluded \\
\hline $\begin{array}{l}\text { Populations } \\
\text { (P) }\end{array}$ & $\begin{array}{l}\text { Patients of any age with known or suspected } \\
\text { trauma } \\
\text { - Require assessment of physiologic } \\
\text { compromise by EMS out-of-hospital personnel }\end{array}$ & $\begin{array}{l}\text { - Nontrauma conditions (e.g., burns, chemical } \\
\text { exposure) or illnesses } \\
\text { - Healthy people } \\
\text { - Animal studies } \\
\text { - Study population restricted to patients with: } \\
\text { o Serious injuries only (sample limited major } \\
\text { trauma patients automatically transported to } \\
\text { a trauma center (ISS }>15, \mathrm{GCS} 8 \text { or less) } \\
\text { o Injuries that can be assessed or defined as } \\
\text { serious based on direct observation (e.g., an } \\
\text { amputation) }\end{array}$ \\
\hline $\begin{array}{l}\text { Interventions } \\
\text { (I) } \\
\text { (Measures) }\end{array}$ & $\begin{array}{l}\text { KQ 1: Physiologic measures of circulatory } \\
\text { compromise } \\
\text { KQ 2: Physiologic measures of respiratory } \\
\text { compromise or effort } \\
\text { KQ 3: Measures of respiratory and/or circulatory } \\
\text { compromise together with measurement of altered } \\
\text { levels of consciousness compromise with or } \\
\text { without measures of altered levels of } \\
\text { consciousness (as defined by Glasgow Coma } \\
\text { Scale or its components) } \\
\text { Measures applicable to screening or triage out-of- } \\
\text { hospital }\end{array}$ & $\begin{array}{l}\text { - Measures not assessing a circulatory or } \\
\text { respiratory compromise (e.g., temperature, } \\
\text { coagulation musculoskeletal soundness, blood } \\
\text { glucose) } \\
\text { - Measures that would be included but are used } \\
\text { to evaluate a treatment or monitor a patient } \\
\text { after a treatment } \\
\text { - Measures that could not be used out-of- } \\
\text { hospital (e.g., a CT scan) }\end{array}$ \\
\hline $\begin{array}{l}\text { Comparators } \\
\text { (C) } \\
\text { (Indicators of } \\
\text { serious injury) }\end{array}$ & $\begin{array}{l}\text { - Resource use or interventions } \\
\text { o The published consensus-based criterion } \\
\text { standard } \\
\text { o Lists of life-saving interventions } \\
\text { o Surgery } \\
\text { o Transfusion } \\
\text { o ICU admission or length of stay } \\
\text { - Ratings of injury severity such as ISS } \\
\text { - Mortality }\end{array}$ & $\begin{array}{l}\text { - No indicator of serious injury } \\
\text { - Orthopedic surgery } \\
\text { - Elective procedures }\end{array}$ \\
\hline $\begin{array}{l}\text { Outcomes } \\
\text { (0) }\end{array}$ & $\begin{array}{l}\text { - Measures of Predictive Utility } \\
\text { o Standard measures of diagnostic accuracy } \\
\text { (e.g., sensitivity, specificity, and predictive } \\
\text { values) } \\
\text { o AUROC }\end{array}$ & $\begin{array}{l}\text { - Does not include a measure of predictive utility } \\
\text { o Descriptive measures or continuous } \\
\text { measure (e.g., correlations, differences in } \\
\text { means) } \\
\text { o Unadjusted risk estimates }\end{array}$ \\
\hline $\begin{array}{l}\text { Timing } \\
(\mathrm{T})\end{array}$ & $\begin{array}{l}\text { - Assessment at or near the time of injury during } \\
\text { resuscitation and acute care }\end{array}$ & $\begin{array}{l}\text { - Assessment to evaluate ongoing treatment or } \\
\text { status several hours after injury } \\
\text { - Transport from initial hospital to another }\end{array}$ \\
\hline
\end{tabular}




\begin{tabular}{|c|c|c|}
\hline $\begin{array}{l}\text { Adapted } \\
\text { PICOTS }\end{array}$ & Included & Excluded \\
\hline $\begin{array}{l}\text { Setting } \\
\text { (S) }\end{array}$ & $\begin{array}{l}\text { - Out-of-hospital: upon the arrival of EMS } \\
\text { personnel to the scene of injury, during } \\
\text { treatment in the field, and during transport } \\
\text { - ED: on arrival or during early treatment and } \\
\text { resuscitation in ED } \\
\text { - Civilian or military settings }\end{array}$ & $\begin{array}{l}\text { - Inpatient hospital } \\
\text { - Outpatient care } \\
\text { - Countries with out-of-hospital care systems } \\
\text { that differ from those in the United States }\end{array}$ \\
\hline $\begin{array}{l}\text { Study } \\
\text { Design }\end{array}$ & $\begin{array}{l}\text { - Randomized controlled trials } \\
\text { - Observational studies: prospective or } \\
\text { retrospective } \\
\text { - Evaluations of a single measure } \\
\text { - Head-to-head comparisons of two or more } \\
\text { measures }\end{array}$ & 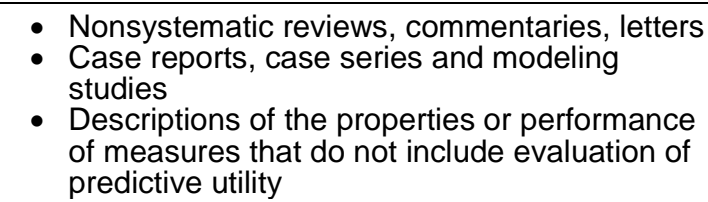 \\
\hline
\end{tabular}

AUROC = area under the receiver operating characteristic curve; CT = computerized tomography; ED = emergency department; EMS = emergency medical services; GCS = Glasgow Coma Scale; ICU = intensive care unit; ISS = Injury Severity Score; KQ = Key Question; PICOTS = Populations, Intervention, Outcomes, Comparators, Timing, Setting/Study Design

\section{Study Selection}

To ensure accuracy, all excluded abstracts were independently reviewed by at least two reviewers. To avoid bias or the appearance of bias, team members who conduct research and have published studies on this topic did not triage studies. All citations deemed appropriate for inclusion by at least one of the reviewers were retrieved for full-text review. Each full-text article was independently reviewed for eligibility by at least two investigators, including any articles suggested by peer reviewers. Any disagreements were resolved by discussion and consensus across the investigators to arrive at the final list of included studies (Appendix B). A record of studies excluded at the full-text level with reasons for exclusion was maintained and is provided as an appendix to this report (Appendix C).

\section{Data Abstraction and Data Management}

For studies that met inclusion criteria, the key characteristics and results were abstracted into evidence tables that provide the basis for the description and synthesis of this body of literature. The complete evidence tables are provided in Appendix D and selected data are included in the in-text tables in the Results sections of this report.

All abstracted study data were verified for accuracy and completeness by a second team member.

\section{Assessment of Methodological Risk of Bias of Individual Studies}

Predefined criteria were used to assess the risk of bias for individual studies by using clearly defined templates and criteria (Appendix E). Studies were evaluated using appropriate study design-specific criteria, ${ }^{28}$ in this case the Quality in Prognosis Studies (QUIPS) tool. ${ }^{30}$ Each study evaluated was independently reviewed for risk of bias by two team members. Any disagreements were resolved by consensus. Team members who were involved in the conduct of a study were not involved in risk of bias assessment for that study. The QUIPS tool includes domains on: study participation, study attrition, prognostic factor measurement, outcomes measurement, study funding, and statistical analysis and reporting. Studies were rated as "low risk of bias," "medium risk of bias,” or "high risk of bias" (Appendix F). 
Studies rated as low risk of bias are considered to have minimal risk of bias, and their results are generally considered valid. Low risk of bias studies included clear descriptions of the population, setting, and measures; sufficient description of how the measure was executed and instrumentation used; how the measure was interpreted; if specific threshold values were used; and how the risk of serious injury was evaluated.

Studies rated medium risk of bias are susceptible to some bias, though not enough to invalidate the results. These studies may not meet all of the criteria for a rating of low risk of bias, but no flaw is likely to cause major bias. The study may be missing information, making it difficult to assess limitations and potential problems. The medium risk of bias category is broad, and studies with this rating will vary in their strengths and weaknesses. The results of some medium risk of bias studies are likely to be valid, while others may be only possibly valid.

Studies rated high risk of bias have significant flaws that imply biases of various types that may invalidate the results. They have one or more serious or "fatal" flaw in design, analysis, or reporting; large amounts of missing information; or discrepancies in reporting.

We did not exclude studies rated high risk of bias a priori, but high risk of bias studies were considered to be less reliable than low or medium risk of bias studies when synthesizing the evidence, particularly when discrepancies between studies were present.

\section{Data Analysis and Synthesis}

We analyzed and reported results from studies using out-of-hospital and ED data separately when studies in both settings were available, as our interest is primarily in the out-of-hospital performance of measures. Also, rapid changes are possible as patients are resuscitated, transported, and treated on scene or en route. We included ED studies and their data because conducting studies in the field is difficult and the body of evidence based on out-of-hospital data is limited for some measures. When data by age group were available we presented this to address the sub Key Questions on the performance of the tests and different thresholds in various age groups.

Results were synthesized, either quantitatively or qualitatively, across studies of each identified physiologic measure, and qualitatively compared across measures. We consulted with the clinical experts on our review team, local experts, and TEP members to determine which serious injury indicators were clinically similar enough to allow grouping. As there are many different indicators of serious injury used in trauma research, we grouped them into four categories: resource use, injury severity, mortality, and composite indicators that included two or three of the above categories. Resource use included the provision of services such as life-saving interventions, emergent surgery, blood transfusion, or intensive care unit (ICU) admission. To avoid survival bias and fully account for resource use, early death, when reported together with other resource use, was also counted as a resource use indicator (i.e., the patient would have required interventions had they survived). Injury severity included assessment by tools such as the Injury Severity Score (ISS) or a diagnosis such as potentially severe head injury. Mortality included any death reported in the studies regardless of the timing of death (the timing of death was recorded in the evidence tables if it was reported in the article). If a study reported death within 24 hours alone as a serious injury indicator, it was counted as mortality, not resource use. We reported the results grouped by these categories in the same forest plot to allow assessment of consistency across categories, and also generated an overall estimate across the categories. When studies reported data for more than one indicator of serious injury, all data were included in the indicator-specific analysis, but only data from one indicator were included in the overall 
estimate based on the following order: resource use, injury, mortality and composite. Therefore, each study were only included once when generating the overall estimate for a physiologic measure.

Results were also synthesized separately according to the predictive utility outcomes: (1) diagnostic accuracy (e.g., sensitivity and specificity), or (2) AUROC. We extracted all data that could be used to calculate diagnostic accuracy measures whether or not these diagnostic measures were reported in the included studies, and calculated sensitivity and specificity when necessary (noted as calculated in the in-text tables and the complete evidence tables in Appendix D). When positive and negative predictive values were reported in the studies, they were included in the evidence tables (Appendix D). We did not include these in the in-text tables as they are dependent on the prevalence, making comparisons across studies and populations problematic. AUROC values were reported as well as confidence intervals (CIs) when they were provided. We used AUROC both as an indicator of the level of performance of a measure and to compare performance across measures. We followed conventions that specify AUROCs of less than 0.70 as poor, $0.70-0.79$ as fair, $0.80-0.89$ as good, and $0.90-1$ as excellent. ${ }^{31}$ As in other work, ${ }^{26}$ we defined a small difference in the AUROC as a difference of less than 0.05 , moderate as a difference of 0.05 to 0.10 , and large as a difference of greater than 0.10 .

We conducted quantitative synthesis (i.e., meta-analysis) of diagnostic measures when there were adequate data from included studies. In cases with few studies, lack of data, or when data were only available as adjusted risk estimates from multivariate analyses (Appendix $G$ ), the range of the results and qualitative summaries were provided.

First the random effects DerSimonian-Laird model ${ }^{32}$ was used to pool data and statistical heterogeneity was assessed using the standard $\chi^{2}$ test and $I^{2}$ statistic. The $I^{2}$ statistic from these analyses are included in the plots. Given the high statistical heterogeneity and that the DerSimonain-Laird Model can result in confidence intervals that are too narrow when heterogeneity is high, we used alternative random effects models and reported the pooled estimates and confidence intervals from these alternative analyses in the forest plots and tables.

We used a bivariate logistic mixed effects model ${ }^{33}$ to analyze sensitivity and specificity, taking the correlation between sensitivity and specificity into account. We assumed random effects across studies for sensitivity and specificity, and heterogeneity among the studies was measured based on the random effect variance. We calculated positive likelihood ratio (LR+) and negative likelihood ratio (LR-) using the summarized sensitivity and specificity. ${ }^{34,35}$ Analyses were stratified by different cutoff points when necessary to generate clinically meaningful combined estimates. For example, we combined studies of lactate using a cutoff point of 2.0 $\mathrm{mmol} / \mathrm{L}$ and separately using a cutoff point greater than $4.0 \mathrm{mmol} / \mathrm{L}$. We also conducted sensitivity analyses by comparing results when outlying studies were included or excluded.

Similarly, we performed random effects meta-analysis to calculate the combined AUROC using the profile likelihood method, which incorporates the uncertainty related to estimating between-study heterogeneity. When a study only reported the point estimate of AUROC without providing a 95\% CI or a standard error, we calculated the standard error if the study reported the number of patients with and without the serious injury indicator of interest; ${ }^{36}$ otherwise the standard error was imputed using the average standard error from other studies with similar sample size.

All analyses were conducted using Stata/IC 13.1 (StataCorp LP, College Station, TX), except for the bivariate logistic mixed effects model, for which SAS 9.4 (SAS Institute Inc., Cary, NC) was used. 


\section{Grading the Strength of Evidence for Major Comparisons and Outcomes}

The strength of evidence for each Key Question (Appendix H) was initially assessed by one researcher for the predictive utility of each identified measure paired with each indicator of the need for trauma care in accordance with the approaches described in the Methods Guide for Effectiveness and Comparative Effectiveness Reviews ${ }^{28}$ and the guidance for diagnostic tests. ${ }^{37}$ To ensure consistency and validity of the evaluation, the grades were reviewed by the entire team of investigators for:

- Study limitations: low, medium, or high level of risk of bias

- Consistency of results: consistent, inconsistent, or unknown/not applicable

- Directness of the evidence: direct or indirect

- Precision of the outcome estimates: precise or imprecise

- Reporting bias: suspected or undetected

The strength of evidence assessment criteria was adapted for this review. For example, while measures of predictive utility can be considered indirect measures because they are not clinical outcomes, we did not downgrade the evidence on this basis as these are appropriate outcomes given the objectives and Key Questions of this review.

The strength of evidence was assigned an overall grade of high, moderate, low, or insufficient, according to a four-level scale by evaluating and weighing the combined results of the above domains:

- High-We are very confident that the estimate of effect lies close to the true effect for this outcome and that the findings are stable (i.e., another study would not change the conclusions).

- Moderate-We are moderately confident that the estimate of effect lies close to the true effect for this outcome and that the findings are likely to be stable, but some doubt remains.

- Low-We have limited confidence that the estimate of effect lies close to the true effect for this outcome and additional evidence is needed before concluding either that the findings are stable or that the estimate of effect is close to the true effect.

- Insufficient - No evidence is available or the body of evidence has unacceptable deficiencies, precluding reaching a conclusion.

\section{Assessing Applicability}

Applicability is the extent to which the findings in published studies are likely to reflect the results when the measures are used to evaluate trauma patients in similar situations. Applicability was considered according to the approach described in the Methods Guide for Effectiveness and Comparative Effectiveness Reviews ${ }^{28}$ and the guidance for systematic reviews of diagnostic tests. ${ }^{38}$ We used the PICOTS framework to consider the applicability of the evidence base for each Key Question; for example, examining the characteristics of the patient populations (e.g., patient age and type of trauma) and triage situation, as well as how the measures of physiologic compromise are obtained and used (e.g., use of different monitors or threshold values). Variability or limitations of the body of evidence may restrict the ability of the users of this review to apply the results to other populations and settings. 


\section{Managing Bias and the Appearance of Bias}

The review team and Technical Expert Panel include experts who have conducted and published research in this field. In order to avoid bias, or the appearance of bias, we took the following steps: (1) authors were not involved in any decisions about including or excluding their own work, (2) to the extent it was feasible, reviewers were blinded to authors during title and abstract review so that the other team members/reviewers were not biased in favor of colleagues, (3) for full-text review, no one was assigned to review research they contributed to, (4) team members and experts did not rate the risk of bias or abstract data from studies to which they contributed.

\section{Peer Review and Public Commentary}

Experts were invited to provide external peer review of this systematic review; AHRQ and an associate editor also provided comments. We addressed relevant reviewer comments and revised the text as appropriate. In addition, the draft report was posted on the AHRQ Web site for 4 weeks to elicit public comment; no comments were received. 


\section{Results}

\section{Literature Search Yield}

The search and selection of articles are summarized in Figure 3. Database searches yielded 4,188 potentially relevant citations. Dual review of titles and abstracts identified 789 articles that appeared to meet the inclusion criteria. The full text of these articles was reviewed, and we included 138 articles (Appendix B).

\section{Figure 3. Literature flow diagram}

Abstracts of potentially relevant articles identified through MEDLINE, CINAHL, Embase, Cochrane, ${ }^{*}$ and other sources ${ }^{\dagger}(\mathrm{N}=4,188)$

Excluded abstracts and

background articles $(n=3,399)$

Full-text articles reviewed for relevance to Key Questions $(n=789)$

Full-text articles excluded $=651$

Background $=37$

Not trauma patients $=84$

No included measure $=159$

No indicator of serious injury $=47$

No assessment of predictive

utility $=54$

Ineligible setting $=50$

Ineligible study design $=17$

Ineligible publication type $=64$

Review not meeting our

requirements $=4$

Studies outside of search dates $=5$

Indirect studies $=0$

Not English language $=2$

Population restricted to seriously

injured $=112$

Insufficient data $=16$

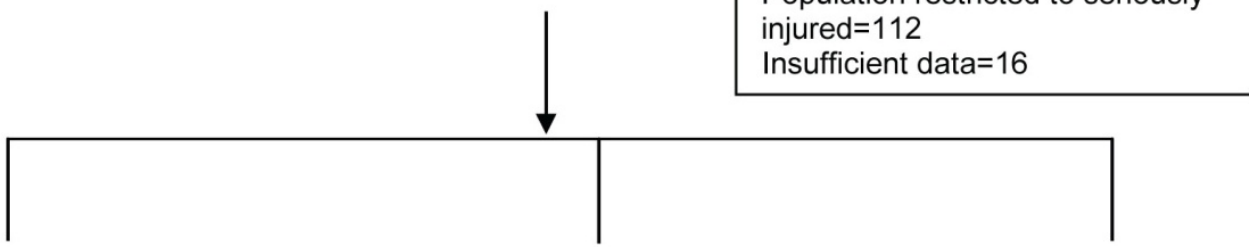

Key Question 1

Key Question 2

Key Question 3
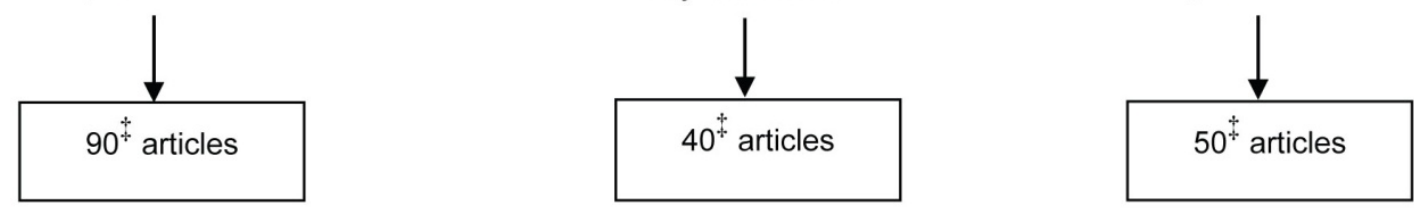

*Cochrane databases include the Cochrane Central Register of Controlled Trials and the Cochrane Database of Systematic Reviews

${ }^{\dagger}$ Other sources include reference list, experts, etc

‡Studies of multiple measures were used in more than one Key Question 


\section{Description of Included Studies}

Table 2 summarizes selected characteristics of the 138 included articles. For some characteristics a publication may be included in multiple categories. For example, some studies included measurements collected both out-of-hospital as well as after the patient arrived at an emergency department (ED).

Despite the challenges of conducting studies in the field, half (71 out of 138) of the included articles assessed out-of-hospital data for the evaluated measures. Two-thirds (96) of the articles were retrospective and one-third (41) were prospective. Twenty-five studies used data from multi-site registries, 65 studies used administrative or registry data from one site, and 47 studies engaged in primary data collection for the study.

The majority of the studies (102) were evaluated as having a moderate risk of bias, with 10 studies rated low risk of bias and 25 rated high risk of bias. The concerns about bias were primarily related to three domains: study participation (e.g., concerns about sampling or recruitment), attrition (e.g., lost to followup), and lack of adequate control for confounding factors that were not adequately addressed in the design. Common limitations and potential sources of bias included: retrospective study design; trauma registry data (limited to patients presenting to trauma centers and meeting criteria for inclusion in a registry); loss to followup; selection exclusion of certain types of patients; and data were not always available for important variables believed to affect outcomes. The ratings for each domain as well as the overall ratings are provided in Appendix F.

Studies used different indicators for "serious injury" and often assessed more than one indicator. We grouped the indicators into three categories for clarity: (1) resource utilization, which included lists of life-saving interventions, surgery, transfusion, intensive care unit admission or a version of a published consensus-base criterion standard; ${ }^{25}$ (2) ratings of injury severity such as the Injury Severity Score (ISS) or types of anatomic injury or diagnosis such as traumatic brain injury; and (3) mortality (most commonly in-hospital mortality). Resource utilization was the most common indicator (113 studies), though many studies reported on the relationship between the measures and mortality (98 studies), while injury severity or type was less common (19 studies). A detailed list of the measures studied is included in tables at the beginning of the results for each Key Question below.

The most common population for these studies consisted of adult patients treated in the United States. The majority of the studies (93 of 138) were conducted in the United States, with 18 studies conducted in Europe, 8 in Asia, 9 in the Middle East, 3 in Australia and New Zealand, 5 in Canada, 2 in South Africa, 1 in Colombia, and 2 in multiple countries (international). Most studies were of adult patients or patients of all age groups, with only 13 studies providing data separately on older patients and 10 providing data on children. Most of the studies were of civilian populations. We did not exclude military studies if they met our other inclusion criteria. Three of the included studies were conducted at military support hospitals: two U.S. hospitals in Iraq and one U.K. hospital in Afghanistan. These hospitals treated predominately military casualties but also cared for injured civilians. Not all studies explicitly stated how patients were transported, but the studies included some that were limited to patients transported by air (25 studies) or ground (10 studies) while others were mixed (17 studies). One-third of the studies (50) were funded by public entities, another third did not report funding (55), 20 reported no external support, and 5 reported partial or full private funding support. 
Table 2. Overall key characteristics of included studies

\begin{tabular}{|c|c|c|c|}
\hline $\begin{array}{c}\text { Key } \\
\text { Characteristics }\end{array}$ & $\begin{array}{l}\text { Study } \\
\text { Information }\end{array}$ & $\begin{array}{l}\text { Number of } \\
\text { Publication } \\
\mathrm{s}(\mathrm{N}=138)\end{array}$ & References \\
\hline \multirow[t]{3}{*}{ Setting* } & Out-of-hospital & $\mathrm{n}=71$ & $17,39-108$ \\
\hline & $\begin{array}{l}\text { Emergency } \\
\text { department }\end{array}$ & $\mathrm{n}=86$ & $\begin{array}{l}39,42,44,48,50,51,57,60,74-79,81,82,87,92,94,99,103-105,108- \\
170\end{array}$ \\
\hline & $\begin{array}{l}\text { Not reported or } \\
\text { unclear }\end{array}$ & $n=5$ & $171-175$ \\
\hline \multirow[t]{3}{*}{ Study Design } & $\begin{array}{l}\text { Prospective } \\
\text { cohort }\end{array}$ & $\mathrm{n}=42$ & $\begin{array}{l}44,58,63-65,68,70,77-82,84,95,96,100,101,103,106,108-110,112- \\
115,119,120,126,138,141,146,155,157-160,162,166,168,171\end{array}$ \\
\hline & $\begin{array}{l}\text { Retrospective } \\
\text { cohort }\end{array}$ & $n=96$ & $\begin{array}{l}17,39-43,45-57,59-62,66,67,69,71-76,83,85-94,97- \\
99,102,104,105,107,111,116-118,121-125,127-137,139,140,142- \\
145,147-154,156,161,163-165,167,169,170,172-175\end{array}$ \\
\hline & Trials & $\mathrm{n}=0$ & None \\
\hline \multirow[t]{6}{*}{$\begin{array}{l}\text { Study } \\
\text { Populations* }\end{array}$} & Adult & $\mathrm{n}=90$ & $\begin{array}{l}17,39,43-49,51,58,59,61-67,72,76,78,80-84,86,87,89-93,97- \\
100,102,103,106,108-110,113-118,120,123- \\
125,128,129,131,132,134-138,141-156,158-161,163,164,166- \\
168,170,172\end{array}$ \\
\hline & Pediatric & $\mathrm{n}=10$ & $57,77,88,101,111,140,157,171,173,175$ \\
\hline & Elderly & $\mathrm{n}=13$ & $46,72,87,89,90,116,117,123,136,146,151,163,170$ \\
\hline & Military & $\mathrm{n}=3$ & $\begin{array}{l}\text { U.S. military in Iraq: } 115,118 \\
\text { U.K. military in Afghanistan: } 166\end{array}$ \\
\hline & Civilian & $\mathrm{n}=129$ & $\begin{array}{l}17,39-41,43-48,50-70,72-75,77-114,116,117,119- \\
165,168,169,171-175\end{array}$ \\
\hline & $\begin{array}{l}\text { Not reported, } \\
\text { unclear, or } \\
\text { mixed } \\
\text { population }\end{array}$ & $\mathrm{n}=34$ & $\begin{array}{l}40-42,50,52-56,60,68-71,73-75,79,87,94- \\
96,104,105,107,119,121,126,127,130,133,162,165,169\end{array}$ \\
\hline \multirow[t]{3}{*}{$\begin{array}{l}\text { Type of Data } \\
\text { Source }\end{array}$} & $\begin{array}{l}\text { Multi-site } \\
\text { registry }\end{array}$ & $n=26$ & $\begin{array}{l}39,45,46,48,57,61,62,65,66,71,72,88,93,102,116,125,127,134,13 \\
6,138,142,145,151,164,169,172\end{array}$ \\
\hline & $\begin{array}{l}\text { Administrative } \\
\text { data/single site } \\
\text { registry }\end{array}$ & $\mathrm{n}=65$ & $\begin{array}{l}17,40-42,47,49-56,59,60,67,69,74-76,83- \\
87,89,90,92,98,99,104,105,107,111,117,118,120- \\
124,126,128,129,131-133,137,139,140,143,144,149,152- \\
154,156,163,165,167,170,171,173-175\end{array}$ \\
\hline & $\begin{array}{l}\text { Primary data } \\
\text { collection }\end{array}$ & $\mathrm{n}=47$ & $\begin{array}{l}43,44,58,63,64,68,70,73,77-82,91,94-97,100,101,103,106,108- \\
110,112-115,119,130,135,141,146-148,150,155,157-162,166,168\end{array}$ \\
\hline \multirow{3}{*}{$\begin{array}{l}\text { Type of } \\
\text { Indicator of } \\
\text { Serious Injury* }\end{array}$} & $\begin{array}{l}\text { Resource } \\
\text { utilization }\end{array}$ & $n=113$ & $\begin{array}{l}17,42,44-47,49-55,59-61,63-66,68-83,85-108,110,111,113- \\
115,118-120,122-124,128,130,135,137-175\end{array}$ \\
\hline & $\begin{array}{l}\text { Injury severity } \\
\text { or type }\end{array}$ & $\mathrm{n}=19$ & $43,45,46,57,58,66-68,72-74,78,124,127,130,137-140$ \\
\hline & Mortality & $\mathrm{n}=98$ & $\begin{array}{l}17,39-41,48,51,56,60,62,63,65,66,68,72,74,75,77,84- \\
110,112,114,116-118,121,122,125,126,129,131-139,141-175\end{array}$ \\
\hline \multirow{4}{*}{$\begin{array}{l}\text { Mode of } \\
\text { Transport }\end{array}$} & Ground & $\mathrm{n}=10$ & $65,94-97,109,110,115,136,158$ \\
\hline & Air & $\mathrm{n}=25$ & $17,40,41,47,49,52-56,58,59,63,64,69,70,73,80-83,86,101,106,107$ \\
\hline & Ground and air & $\mathrm{n}=17$ & $50,51,61,62,68,72,77,91,92,98,103,124,133,137,138,173,174$ \\
\hline & Not reported & $n=86$ & $\begin{array}{l}39,42-46,48,57,60,66,67,71,74-76,78,79,84,85,87- \\
90,93,99,100,102,104,105,108,111-114,116-123,125- \\
132,134,135,139-157,159-172,175\end{array}$ \\
\hline \multirow[t]{2}{*}{$\begin{array}{l}\text { Geographic } \\
\text { Location* }\end{array}$} & United States & $\mathrm{n}=93$ & $\begin{array}{l}17,39-42,45-47,49-60,63-66,68-70,72,73,75-90,92,98-101,103- \\
105,107,108,111,113,114,117,119-123,126- \\
129,131,135,137,141,142,146-152,157,159,160,162- \\
165,168,170,171,173-175\end{array}$ \\
\hline & $\begin{array}{l}\text { Europe } \\
\text { (Germany, } \\
\text { France, } \\
\text { Norway, } \\
\text { Sweden, The } \\
\text { Netherlands, } \\
\text { United } \\
\text { Kingdom) }\end{array}$ & $\mathrm{n}=18$ & $44,62,67,91,93-97,106,116,130,133,134,140,145,158,164$ \\
\hline
\end{tabular}




\begin{tabular}{|c|c|c|c|}
\hline $\begin{array}{c}\text { Key } \\
\text { Characteristics }\end{array}$ & $\begin{array}{l}\text { Study } \\
\text { Information }\end{array}$ & $\begin{array}{c}\text { Number of } \\
\text { Publication } \\
\mathrm{s}(\mathrm{N}=138)\end{array}$ & References \\
\hline & 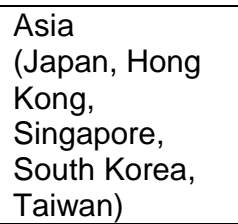 & $n=8$ & $74,132,136,138,139,143,156,169$ \\
\hline & $\begin{array}{l}\text { Middle East } \\
\text { (Afghanistan, } \\
\text { Iraq, Turkey) }\end{array}$ & $n=9$ & $42,71,109,112,115,118,155,166,167$ \\
\hline & $\begin{array}{l}\text { Australia and } \\
\text { New Zealand }\end{array}$ & $n=3$ & $61,124,161$ \\
\hline & Canada & $n=5$ & $43,65,102,110,172$ \\
\hline & $\begin{array}{l}\text { Africa (South } \\
\text { Africa) }\end{array}$ & $n=2$ & 48,125 \\
\hline & $\begin{array}{l}\text { South America } \\
\text { (Colombia) }\end{array}$ & $n=1$ & 144 \\
\hline & $\begin{array}{l}\text { International } \\
\text { (multiple } \\
\text { countries) }\end{array}$ & $n=2$ & 153,154 \\
\hline \multirow[t]{6}{*}{ Funding* } & Public entity & $n=50$ & $\begin{array}{l}17,40,41,48,49,52,53,55,56,58,63-65,68-70,72-74,77,79-84,88- \\
90,97,98,100,102,103,107,108,111,118,128,133,139,141,153,154 \\
, 159,160,162,168,172,175\end{array}$ \\
\hline & Foundation & $\mathrm{n}=2$ & 89,90 \\
\hline & $\begin{array}{l}\text { No external } \\
\text { support }\end{array}$ & $n=20$ & $\begin{array}{l}46,47,57,85,93,106,116,120,131,135,142,145,147,148,155,156,1 \\
58,161,164,166\end{array}$ \\
\hline & Private & $n=5$ & $86,108,113-115$ \\
\hline & $\begin{array}{l}\text { Not reported, } \\
\text { but declared no } \\
\text { conflicts of } \\
\text { interest }\end{array}$ & $n=9$ & $66,67,71,95,96,124,132,134,144$ \\
\hline & Not reported & $n=55$ & $\begin{array}{l}39,42-45,50,51,54,59- \\
62,75,76,78,87,91,92,94,99,101,104,105,109,110,112,117,119,12 \\
1-123,125-127,129,130,136-138,140,143,146,149- \\
152,157,163,165,167,169-171,173,174\end{array}$ \\
\hline
\end{tabular}

*The total number of publications is more than 138 for this characteristic as a publication may be in more than one category.

Detailed information from each study is included in the evidence tables in Appendix D, and the risk of bias assessments are in Appendix F. The following results sections summarize the available evidence for each Key Question and highlight additional characteristics when they add to the understanding of the results. Relevant study characteristics are also included in the discussion of the limitations and applicability of the findings of this review.

\section{Overview}

The 134 studies reported in 138 articles evaluated three major categories of physiologic measures: (1) the current physiologic measures included in many trauma triage guidelines (e.g., systolic blood pressure [SBP] and respiratory rate [RR]); (2) other physiologic measures and scores in current use for triage as well as prognosis; and (3) newly developed or improved proposed measurement strategies including specific thresholds. The diversity of measures as well as the variety of study designs makes synthesis challenging. The results are presented and summarized for each measure separately within sections organized by Key Question (i.e., circulatory, respiratory, and combinations). 
Tables 3-5 consolidate the key estimates of the predictive utility of each measure. Sensitivity, specificity, and area under the receiver operating characteristic curve (AUROC) values for outof-hospital and ED measurements are provided. The overall combined estimates are reported unless otherwise specified. When we were able to pool data, the pooled estimates are given in bold; when data were not pooled, the range of values from the included studies are provided in italics. Additional information, such as the number of patients in the included studies and 95\% confidence intervals (CIs) for the estimates are included in the figures and tables that follow in the results sections, while the detailed extracted study information is included in the evidence tables in Appendix D.

Table 3. Key Question 1 results: overview of predictive utility of circulatory measures for serious injury* by setting

\begin{tabular}{|c|c|c|c|c|}
\hline Measure & $\begin{array}{l}\text { Out-of-Hospital: } \\
\text { Sensitivity (SOE) } \\
\text { Specificity (SOE) } \\
\text { Number of Studies }\end{array}$ & $\begin{array}{c}\text { Emergency Department: } \\
\text { Sensitivity (SOE) } \\
\text { Specificity (SOE) } \\
\\
\text { Number of Studies }\end{array}$ & $\begin{array}{l}\text { Out-of-Hospital: } \\
\text { AUROC (SOE) } \\
\text { Number of } \\
\text { Studies }\end{array}$ & $\begin{array}{l}\text { Emergency } \\
\text { Department: } \\
\text { AUROC (SOE) } \\
\text { Number of } \\
\text { Studies }\end{array}$ \\
\hline $\begin{array}{l}\text { Systolic } \\
\text { Blood } \\
\text { Pressure }\end{array}$ & $\begin{array}{l}\text { SBP <90 mmHg } \\
\text { Sen: } 19 \% \text { (SOE: Low) } \\
\text { Sp: } 95 \% \text { (SOE: } \\
\text { Moderate) } \\
17 \\
\text { studies } 39,46,60,65,67,68,70,77- \\
79,88,89,91,99,103,107,171 \\
\text { SBP higher thresholds } \\
\text { (<100, 110, or } 120 \\
\text { mmHg) } \\
\text { Sen: } \mathbf{3 5 \%} \text { (SOE: Low) } \\
\text { Sp: } \mathbf{8 8 \%} \text { (SOE: Low) } \\
\text { 6 studies } \\
\text { 39,46,70,75,76,80 }\end{array}$ & $\begin{array}{l}\text { SBP <90 mmHg } \\
\text { Sen: } \mathbf{1 8 \%} \text { (SOE: Low) } \\
\text { Sp: } \mathbf{9 7 \%} \text { (SOE: Moderate) } \\
9 \text { studies (in } 10 \\
\text { articles) } \\
48,156 \\
\text { SBP hig,76,78,115,124,133,147,1 } \\
\text { (<100, 110, or } 120 \text { mmHg) } \\
\text { Sen: } \mathbf{3 5 \%} \text { (SOE: Low) } \\
\text { Sp: } \mathbf{8 9 \%} \text { (SOE: Moderate) } \\
4 \text { studies } \\
\text { 39,116,119,137 }\end{array}$ & $\begin{array}{l}\mathbf{0 . 6 7} \text { (SOE: } \\
\text { Moderate) } \\
9 \\
\text { studies }^{52,55,59,62,65,93,} \\
104,106,107\end{array}$ & $\begin{array}{l}\text { 0.64 (SOE: } \\
\text { Moderate) } \\
12 \text { studies (in } 13 \\
\text { articles) } 61,104,110,115,1 \\
16,125,127,147- \\
149,159,165,170\end{array}$ \\
\hline Heart Rate & $\begin{array}{l}\text { HR >110 bpm } \\
\text { Sen: } \mathbf{2 8 \%} \text { (SOE: Low) } \\
\text { Sp: } \mathbf{8 5 \%} \text { (SOE: Low) } \\
4 \text { studies }^{70,76,80,107}\end{array}$ & $\begin{array}{l}\text { HR >110 bpm } \\
\text { Sen: } 29 \% \text { (SOE: } \\
\text { Moderate) } \\
\text { Sp: } \mathbf{9 3 \%} \text { (SOE: Moderate) } \\
5 \text { studies }^{48,61,124,137,156}\end{array}$ & $\begin{array}{l}\mathbf{0 . 6 7} \text { (SOE: Low) } \\
5 \\
\text { studies }^{55,59,62,106,107}\end{array}$ & $\begin{array}{l}\mathbf{0 . 6 6} \text { (SOE: } \\
\text { Moderate) } \\
9 \text { studies (in } 10 \\
\text { articles) } 61,115,116,125,1 \\
47-149,159,162,170\end{array}$ \\
\hline $\begin{array}{l}\text { Shock } \\
\text { Index }\end{array}$ & $\begin{array}{l}\text { SI }>0.9 \text { or }>1 \\
\text { Sen: } \mathbf{3 7 \%} \text { (SOE: Low) } \\
\text { Sp: } \mathbf{8 5 \%} \text { (SOE: Low) } \\
5 \text { studies }^{44,50,74,93,165}\end{array}$ & $\begin{array}{l}\text { SI >0.9 or >1 } \\
\text { Sen: } \mathbf{4 0 \%} \text { (SOE: Low) } \\
\text { Sp: } \mathbf{9 3 \%} \text { (SOE: Moderate) } \\
11 \text { studies (in } 12 \\
\text { articles) } \\
, 140,74,1148,151,166\end{array}$ & $\begin{array}{l}\mathbf{0 . 7 2} \text { (SOE: Low) } \\
7 \\
\text { studies } 44,52,53,62,65,93, \\
107\end{array}$ & $\begin{array}{l}\mathbf{0 . 7 1} \text { (SOE: } \\
\text { Moderate) } \\
11 \text { studies (in 12 } \\
\text { articles) } 116,123,125,131, \\
136,137,142,145,147,148,159, \\
170\end{array}$ \\
\hline
\end{tabular}




\begin{tabular}{|c|c|c|c|c|}
\hline Measure & $\begin{array}{l}\text { Out-of-Hospital: } \\
\text { Sensitivity (SOE) } \\
\text { Specificity (SOE) } \\
\text { Number of Studies }\end{array}$ & $\begin{array}{l}\text { Emergency Department: } \\
\text { Sensitivity (SOE) } \\
\text { Specificity (SOE) } \\
\text { Number of Studies }\end{array}$ & $\begin{array}{l}\text { Out-of-Hospital: } \\
\text { AUROC (SOE) } \\
\text { Number of } \\
\text { Studies }\end{array}$ & $\begin{array}{l}\text { Emergency } \\
\text { Department: } \\
\text { AUROC (SOE) } \\
\text { Number of } \\
\text { Studies }\end{array}$ \\
\hline Lactate & $\begin{array}{l}\text { Lactate }>2 \text { or } 2.5 \mathrm{mmol} / \mathrm{L} \\
\text { Sen: } \mathbf{7 4 \%} \text { (SOE: Low) } \\
\text { Sp: } \mathbf{6 2 \%} \text { (SOE: } \\
\text { Moderate) } \\
3 \text { studies }{ }^{47,65,101} \\
\text { Lactate }>4 \mathrm{mmol} / \mathrm{L} \\
\text { Sen: } \mathbf{2 3} \% \text { (SOE: } \\
\text { Insufficient) } \\
\text { Sp: } \mathbf{9 3 \%} \text { (SOE: } \\
\text { Insufficient) } \\
1 \text { study } 47\end{array}$ & $\begin{array}{l}\text { Lactate >2 or } 2.5 \text { mmol/L } \\
\text { Sen: } \mathbf{7 4 \%} \text { (SOE: Low) } \\
\text { Sp: } \mathbf{5 2 \%} \text { (SOE: Low) } \\
9 \text { studies (in } 10 \\
\text { articles) }{ }^{104,117,128,143,146-} \\
\text { 148,157,158,161 } \\
\text { Lactate >4 mmol/L } \\
\text { Sen: } \mathbf{5 0 \%} \text { (SOE: Low) } \\
\text { Sp: } \mathbf{8 6 \%} \text { (SOE: Moderate) } \\
9 \\
\text { studies }{ }^{44,104,112,117,119,120,126,143} \\
, 157\end{array}$ & $\begin{array}{l}0.77 \text { (SOE: Low) } \\
2 \text { studies }^{65,101}\end{array}$ & $\begin{array}{l}\mathbf{0 . 6 8} \text { (SOE: } \\
\text { Moderate) } \\
14 \text { studies (in } 15 \\
\text { articles) }{ }^{44,97,104,113,11} \\
4,117,120,128,146- \\
148,150,152,158,161\end{array}$ \\
\hline $\begin{array}{l}\text { Base } \\
\text { Deficit }\end{array}$ & None & $\begin{array}{l}\text { Sen: } 19 \text { to } 59 \% \text { (SOE: } \\
\text { Low) } \\
\text { Sp: } 59 \text { to } 98 \% \text { (SOE: } \\
\text { Moderate) } \\
9 \text { studies (in } 10 \\
\text { articles) } \\
8,156\end{array}$ & None & $\begin{array}{l}0.67 \text { to } 0.90 \text { (SOE: } \\
\text { Moderate) } \\
12 \text { studies (in } 13 \\
\text { articles) }{ }^{97,113-} \\
115,117,120,125,145,147- \\
150,157\end{array}$ \\
\hline $\begin{array}{l}\text { Heart Rate } \\
\text { Variabilityl } \\
\text { Heart Rate } \\
\text { Complexity }\end{array}$ & $\begin{array}{l}\text { Sen: } 80 \text { to } 90 \% \text { (SOE: } \\
\text { Low) } \\
\text { Sp: } 67 \text { to } 100 \% \text { (SOE: } \\
\text { Low) } \\
2 \text { studies }^{73,106}\end{array}$ & None & $\begin{array}{l}0.60 \text { to } 0.95 \text { (SOE: } \\
\text { Low) } \\
7 \text { studies }^{40,41,49,56,59,} \\
73,106\end{array}$ & $\begin{array}{l}0.67 \text { to } 0.68 \text { (SOE: } \\
\text { Insufficient) } \\
1 \text { study }^{160}\end{array}$ \\
\hline
\end{tabular}

AUROC = area under the receiver operating characteristic curve; bpm = beats per minute; HR = heart rate; SBP = systolic blood pressure; Sen = sensitivity; SI = shock index; SOE = strength of evidence; $\mathrm{Sp}=$ specificity

Bold font = data from pooled estimates (see corresponding figures); italic font = range from unpooled studies, details in corresponding results tables

*Serious injury includes resource use (e.g., blood transfusion, intensive care unit admission, and life-saving interventions) and injury severity measures (e.g., the Injury Severity Score , mortality, or combinations of any of these) 
Table 4. Key Question 2 results: overview of predictive utility of respiratory measures for serious injury* by setting

\begin{tabular}{|c|c|c|c|c|}
\hline Measure & $\begin{array}{l}\text { Out-of-Hospital: } \\
\text { Sensitivity (SOE) } \\
\text { Specificity (SOE) } \\
\text { Number of Studies }\end{array}$ & $\begin{array}{l}\text { Emergency Department: } \\
\text { Sensitivity (SOE) } \\
\text { Specificity (SOE) } \\
\text { Number of Studies }\end{array}$ & $\begin{array}{l}\text { Out-of-Hospital: } \\
\text { AUROC (SOE) } \\
\text { Number of } \\
\text { Studies }\end{array}$ & $\begin{array}{l}\text { Emergency } \\
\text { Department: } \\
\text { AUROC (SOE) } \\
\text { Number of } \\
\text { Studies }\end{array}$ \\
\hline $\begin{array}{l}\text { Respiratory } \\
\text { Rate }\end{array}$ & $\begin{array}{l}\text { RR }<10 \text { or }>29 \\
\text { Sen: } 13 \% \text { (SOE: Low) } \\
\text { Sp: } 96 \% \text { (SOE: Low) } \\
6 \text { studies }^{77,83,88,89,91,171}\end{array}$ & $\begin{array}{l}\text { RR }<10 \text { or }>29 \\
\text { Sen: } \mathbf{2 7 \%} \text { (SOE: Moderate) } \\
\text { Sp: } \mathbf{9 5 \%} \text { (SOE: Moderate) } \\
\text { 4 } \text { studies }^{61,116,124,133}\end{array}$ & $\begin{array}{l}\mathbf{0 . 7 0} \text { (SOE: Low) } \\
3 \text { studies }^{54,59,94}\end{array}$ & $\begin{array}{l}\mathbf{0 . 6 1} \text { (SOE: } \\
\text { Moderate) } \\
3 \text { studies }^{61,110,116}\end{array}$ \\
\hline $\begin{array}{l}\mathrm{O}_{2} \\
\text { Saturation }\end{array}$ & $\begin{array}{l}\text { Sen: } 13 \text { to } 99 \% \text { (SOE: } \\
\text { Low) } \\
\text { Sp: } 85 \text { to } 99 \% \text { (SOE: } \\
\text { Low) } \\
\text { 3 studies } \text { s7,103,107 }^{60}\end{array}$ & $\begin{array}{l}\text { Sen: } 25 \text { to 100\% (SOE: } \\
\text { Low) } \\
\text { Sp: } 39 \text { to } 94 \% \text { (SOE: Low) } \\
2 \text { studies }^{115,135}\end{array}$ & $\begin{array}{l}0.53 \text { to } 0.76 \\
\text { (SOE: Low) } \\
4 \\
\text { studies }^{64,94,103,107}\end{array}$ & $\begin{array}{l}0.61 \text { to } 0.76 \\
\text { (SOE: Low) } \\
2 \text { studies }^{115,159}\end{array}$ \\
\hline $\begin{array}{l}\text { Airway } \\
\text { Support }\end{array}$ & $\begin{array}{l}\text { Sen: } 8 \text { to 53\% (SOE: } \\
\text { Low) } \\
\text { Sp: } 61 \text { to } 100 \% \text { (SOE: } \\
\text { Low) } \\
4 \text { studies (in } 5 \\
\text { articles) } \\
56,67,89,95,96\end{array}$ & $\begin{array}{l}\text { Sen: } 32 \text { to } 57 \% \text { (SOE: Low) } \\
\text { Sp: } 85 \text { to } 96 \% \text { (SOE: Low) } \\
3 \text { studies }^{57,133,160}\end{array}$ & None & None \\
\hline
\end{tabular}

AUROC = area under the receiver operating characteristic curve; bpm = beats per minute; HR = heart rate; HRC = heart rate complexity; HRV = heart rate variability; O2 = oxygen; RR = respiratory rate; $\mathrm{SBP}=$ systolic blood pressure; Sen = sensitivity; $\mathrm{SI}=$ shock index; SOE = strength of evidence; $\mathrm{Sp}=$ specificity

Note: Bold font = data from pooled estimates (see corresponding figures); italic font = range from unpooled studies, details in corresponding results tables

*Serious injury includes resource use (e.g., blood transfusion, intensive care unit admission, and life-saving interventions) and injury severity measures (e.g., the Injury Severity Score, mortality, or combinations of any of these) 
Table 5. Key Question 3 results: overview of predictive utility of combination of circulatory, respiratory, and level of consciousness measures for serious injury* by setting

\begin{tabular}{|c|c|c|c|c|}
\hline Measure & $\begin{array}{l}\text { Out-of-Hospital: } \\
\text { Sensitivity } \\
\text { (SOE) } \\
\text { Specificity } \\
\text { (SOE) } \\
\text { Number of } \\
\text { Studies }\end{array}$ & $\begin{array}{c}\text { Emergency Department: } \\
\text { Sensitivity (SOE) } \\
\text { Specificity (SOE) } \\
\\
\text { Number of Studies }\end{array}$ & $\begin{array}{l}\text { Out-of-Hospital: } \\
\text { AUROC (SOE) } \\
\text { Number of } \\
\text { Studies }\end{array}$ & $\begin{array}{c}\text { Emergency } \\
\text { Department: } \\
\text { AUROC (SOE) } \\
\text { Number of Studies }\end{array}$ \\
\hline $\begin{array}{l}\text { Revised } \\
\text { Trauma } \\
\text { Score and } \\
\text { Revised } \\
\text { Trauma } \\
\text { Score for } \\
\text { Triage }\end{array}$ & $\begin{array}{l}\text { RTS <7.5, T- } \\
\text { RTS <12 } \\
\text { Sen: } 95 \text { to } 96 \% \\
\text { (SOE: } \\
\text { Insufficient) } \\
\text { Sp: } 38 \text { to } 42 \% \\
\text { (SOE: } \\
\text { Insufficient) } \\
1 \text { study (in } 2 \\
\text { articles) } \\
\text { (55,96 }\end{array}$ & $\begin{array}{l}\text { RTS }<5.68 \text { or }<5.97 \text {, T- } \\
\text { RTS }<8 \text { or }<12 \\
\text { Sen: } 19 \text { to } 84 \% \text { (SOE: } \\
\text { Low) } \\
\text { Sp: } 64 \text { to } 100 \% \text { (SOE: } \\
\text { Low) } \\
6 \text { studies }^{107,109,110,112,130,133}\end{array}$ & $\begin{array}{l}\mathbf{0 . 5 7} \text { for Resource } \\
\text { use (SOE: Low) } \\
\mathbf{0 . 8 9} \text { for Mortality } \\
\text { (SOE: Low) } \\
\text { 3 studies (in } 4 \\
\text { articles) }^{62,95,96,107}\end{array}$ & $\begin{array}{l}\mathbf{0 . 8 8} \text { for Mortality (SOE: } \\
\text { Low) } \\
7 \\
\text { studies }^{97,109,110,131,138,142,169}\end{array}$ \\
\hline $\begin{array}{l}\text { Glasgow } \\
\text { Coma Scale }\end{array}$ & None & $\begin{array}{l}\text { Sen: } 75 \text { to } 98 \% \text { (SOE: } \\
\text { Low) } \\
\text { Sp: } 57 \text { to } 91 \% \text { (SOE: Low) } \\
2 \text { studies }^{109,155}\end{array}$ & None & $\begin{array}{l}\text { 0.96 for both Mortality } \\
\text { and Early Mortality } \\
\text { (SOE: Moderate) } \\
3 \text { studies }^{109,138,155}\end{array}$ \\
\hline
\end{tabular}

AUROC = area under the receiver operating characteristic curve; RTS = Revised Trauma Score; T-RTS = Revised Trauma Score for Triage; Sen = sensitivity; SOE = strength of evidence; $\mathrm{Sp}=$ specificity

Note: Bold font = pooled, see corresponding figures; italic font = range from unpooled studies, details in corresponding results tables

*Serious injury includes resource use (e.g., blood transfusion, intensive care unit admission, and life-saving interventions) and injury severity measures (e.g., the Injury Severity Score, mortality, or combinations of any of these)

\section{Key Question 1: Measures of Circulatory Compromise}

For Key Question 1, we included the results from 90 articles (from 89 studies). Six measures of circulatory compromise were evaluated in eight or more studies: SBP, heart rate (HR), shock index (SI), lactate, base deficit, and heart rate variability (HRV)/heart rate complexity (HRC). Few studies evaluated the remaining measures identified, which we grouped into three other categories. The measures, number of included articles with data on each measure, and corresponding references are provided in Table 6. 
Table 6. Measures of circulatory compromise (Key Question 1) evaluated by included studies

\begin{tabular}{|c|c|c|}
\hline Measure Evaluated & $\begin{array}{l}\text { Number of } \\
\text { Studies } \\
\text { (articles) }\end{array}$ & References \\
\hline Systolic blood pressure & 49 & $\begin{array}{l}39,46,48,51,52,54,55,59-62,65-68,70,75- \\
80,83,88,89,91,93,99,103,104,106,107,110,1 \\
15,116,119,124,125,127,133,137,147- \\
149,156,159,165,170,171\end{array}$ \\
\hline Heart rate & 16 & $\begin{array}{l}54,55,59,61,62,70,76,80,83,103,106,107,116 \\
, 124,137,156\end{array}$ \\
\hline Shock index & $\begin{array}{l}26 \text { studies (28 } \\
\text { articles) }\end{array}$ & $\begin{array}{l}44,50,52- \\
54,62,65,66,74,87,93,105,107,108,112,116,1 \\
23,125,136,137,142,144,145,147,148,151,15 \\
9,166,170\end{array}$ \\
\hline Lactate & $\begin{array}{l}22 \text { studies (23 } \\
\text { articles) }\end{array}$ & $\begin{array}{l}47,63,65,101,104,112- \\
114,117,119,120,128,143,146- \\
150,152,157,158,161,165\end{array}$ \\
\hline Base deficit & $\begin{array}{l}15 \text { studies (16 } \\
\text { articles) }\end{array}$ & $\begin{array}{l}97,112-115,117,120,122,125,143,145,147- \\
150,156\end{array}$ \\
\hline Heart rate variability and complexity & 8 & $40,41,49,56,59,73,106,160$ \\
\hline $\begin{array}{l}\text { Other: Blood pressure related (diastolic blood } \\
\text { pressure, mean arterial pressure, pulse } \\
\text { pressure) }\end{array}$ & 7 & $52-54,59,115,149,162$ \\
\hline Other: Variations on shock index & 3 & $53,93,136$ \\
\hline $\begin{array}{l}\text { Other: Miscellaneous (radial pulse character } \\
\text { min pulse, Max pulse index, capillary refill, } \\
\text { cardiac index, photoplethysmogram) }\end{array}$ & 8 & $55,61,70,84,86,115,116,162$ \\
\hline
\end{tabular}

\section{Systolic Blood Pressure}

The most frequently evaluated measure of circulatory compromise in the identified literature is SBP. We identified 49 studies that evaluated the predictive utility of SBP. Current triage guidelines recommend that trauma patients with SBP $<90 \mathrm{mmHg}$ be considered at risk of serious injury. Many of the included studies evaluated the predictive utility of this threshold. Five studies were not included in the pooled estimates reported below. ${ }^{48,51,54,66,83}$ These studies were not included in the pooled estimates because they did not provide data that could be used to calculate sensitivity and specificity; ${ }^{48,66}$ their populations overlapped with larger studies; ${ }^{54,83}$ or they reported change in pressure. ${ }^{48}$

We combined 17 studies of out-of-hospital SBP (cited in Table 7) and calculated a pooled sensitivity of 19 percent (95\% confidence interval [CI] 12 to 29, $\mathrm{I}^{2}=98.8 \%$ ) and a pooled specificity of 95 percent (95\% CI 91 to $97, \mathrm{I}^{2}=99.2 \%$ ) across all serious injury indicators for SBP $<90 \mathrm{mmHg}$. In this analysis, all studies were included only once. Figures 4 and 5 provide the estimates stratified by type of serious injury indicator (resource use, injury type or severity, mortality, or composite indicators) and demonstrate that the estimates are similar for the different categories of indicators of serious injury. The pooled sensitivity and pooled specificity of out-ofhospital SBP $<100 \mathrm{mmHg}$ are indicated in Figures 6 and 7 . Table 7 reports these values, as well as estimates from studies using SBP $<90 \mathrm{mmHg}$ measured in the ED, and studies that evaluated higher thresholds including 100, 110, and $120 \mathrm{mmHg}$, measured both in the field and in the ED. Plots for the ED analyses are included in Appendix I. 
The pooled AUROC for out-of-hospital SBP was 0.67 (95\% CI 0.58 to 0.75 , $\mathrm{I}^{2}=90.1 \%$; Figure 8) based on 9 studies $^{52,55,59,62,65,93,104,106,107}$ and 0.64 (95\% CI 0.60 to $\left.0.68, \mathrm{I}^{2}=95.7 \%\right)$ for ED SBP based on 12 studies. $^{61,104,110,115,116,125,127,147-149,159,165,170}$ The low sensitivities and high specificities resulted in poor to fair discriminative ability; these results reflect the fact that low SBP is highly specific in identifying high-risk trauma patients (few false positives) but that patients with SBP above the thresholds can still be seriously injured (many false negatives-low sensitivity). Higher SBP thresholds yielded higher sensitivity and lower specificity.

Table 7. Pooled sensitivity and specificity of systolic blood pressure for identifying high-risk patients across all serious injury indicators

\begin{tabular}{|c|c|c|c|}
\hline Measure, Setting & Number of Studies & Sensitivity $\left(95 \% \mathrm{Cl}, \mathrm{I}^{2}\right)$ & Specificity $\left(95 \% \mathrm{Cl}, \mathrm{I}^{2}\right)$ \\
\hline $\mathrm{SBP}<90 \mathrm{mmHg}, \mathrm{OH}$ & $17^{39,46,60,65,67,68,70,77-79,88,89,91,99,103,107,171}$ & $19 \%(12$ to $29,98.8 \%)$ & $95 \%(91$ to $97,99.2 \%)$ \\
\hline $\mathrm{SBP}<90 \mathrm{mmHg}$, ED & $9^{39,75,76,78,115,124,133,147,148,156}$ & $18 \%$ (11 to $28,99.1 \%)$ & $97 \%(97$ to $98,93.5 \%)$ \\
\hline $\begin{array}{l}\mathrm{SBP}<100-120 \\
\mathrm{mmHg}, \mathrm{OH}\end{array}$ & $6^{39,46,69,75,76,80}$ & $35 \%$ (19 to $54,99.7 \%)$ & $88 \%(73$ to $95,99.8 \%)$ \\
\hline $\begin{array}{l}\text { SBP }<100-120 \\
m m H g, E D\end{array}$ & $4^{39,116,119,137}$ & $35 \%(14$ to $63,98.7 \%)$ & $89 \%(75$ to $95,99.5 \%)$ \\
\hline
\end{tabular}

CI = confidence interval; ED = emergency department; $\mathrm{OH}$ = out-of-hospital; SBP = systolic blood pressure 
Figure 4. Pooled sensitivity of out-of-hospital blood pressure $<90 \mathrm{mmHg}$

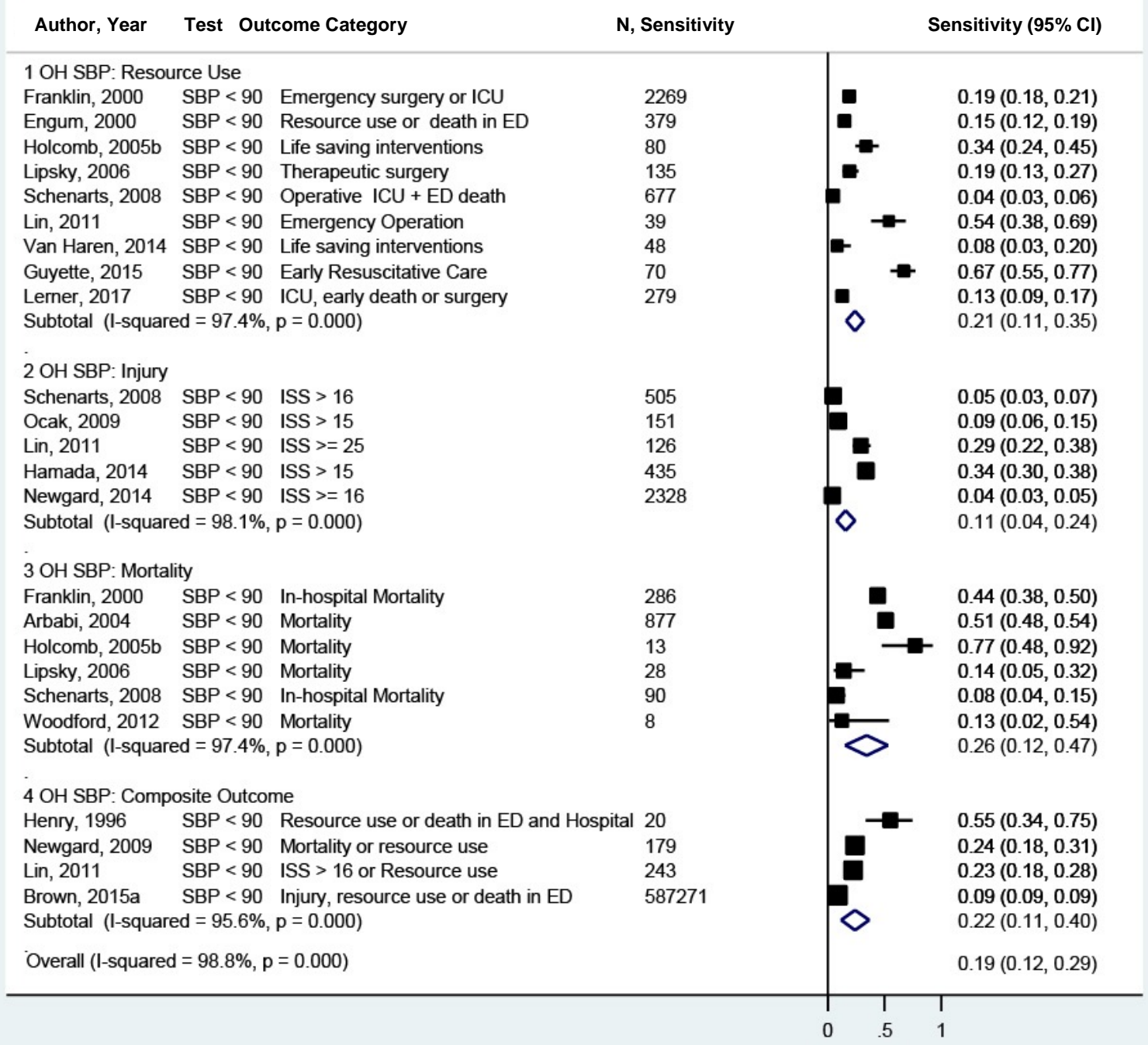

$\mathrm{CI}$ = confidence interval; ED = emergency department; ICU = intensive care unit; ISS = injury severity score; $\mathrm{N}=$ number; $\mathrm{OH}=$ out-of-hospital; SBP = systolic blood pressure.

Note: Holcomb, 2005b = Reference no. 70 in this report.

Note: Overall results are from the bivariate logistic mixed effects model analysis. 
Figure 5. Pooled specificity of out-of-hospital blood pressure $<90 \mathrm{mmHg}$

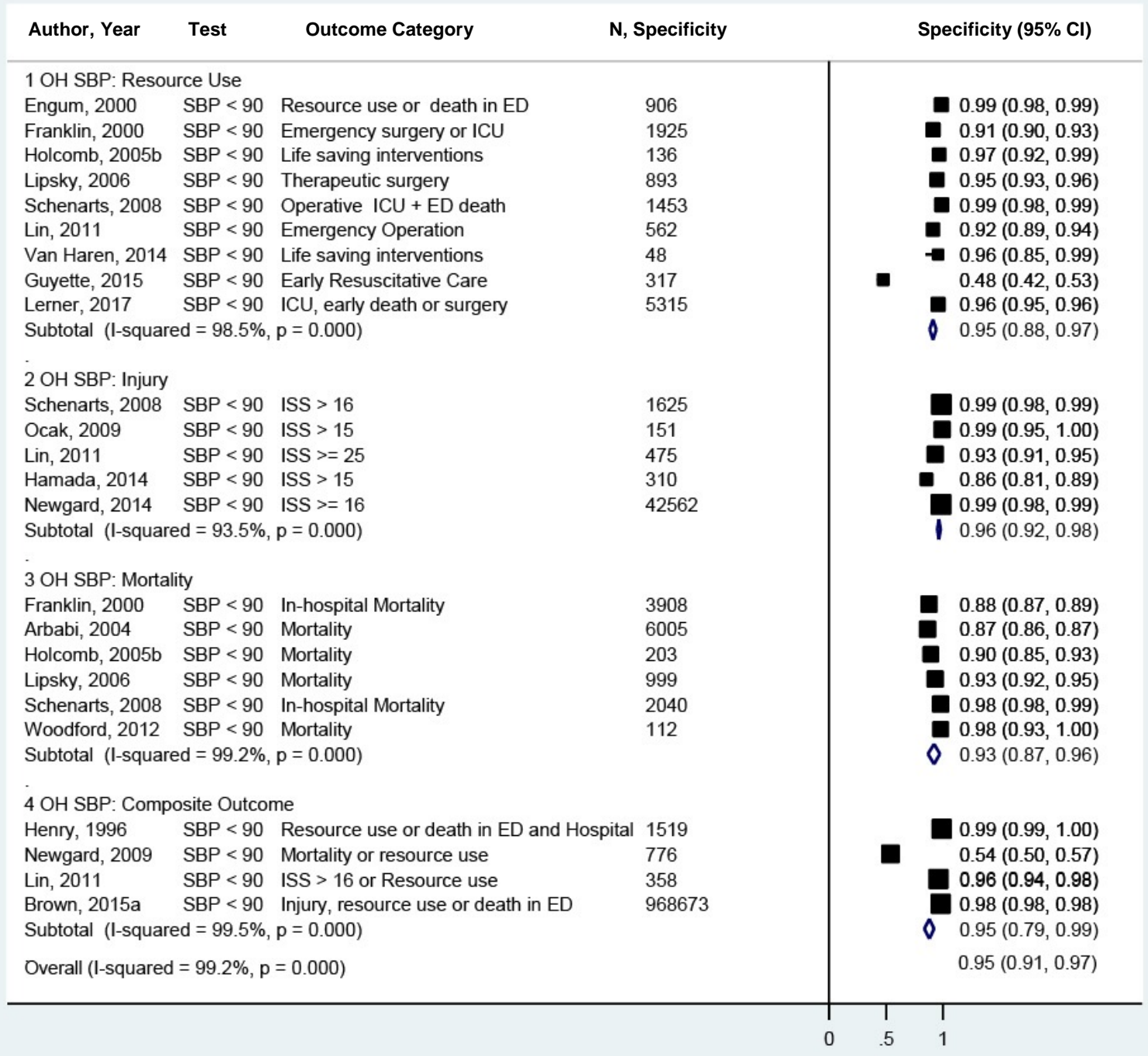

$\mathrm{CI}$ = confidence interval; ED = emergency department; ICU = intensive care unit; ISS = injury severity score; $\mathrm{N}=$ number; $\mathrm{OH}=$ out-of-hospital; SBP = systolic blood pressure.

Note: Holcomb, 2005b = Reference no. 70 in this report.

Note: Overall results are from the bivariate logistic mixed effects model analysis. 
Figure 6. Pooled sensitivity of out-of-hospital blood pressure $<100 \mathrm{mmHg}$

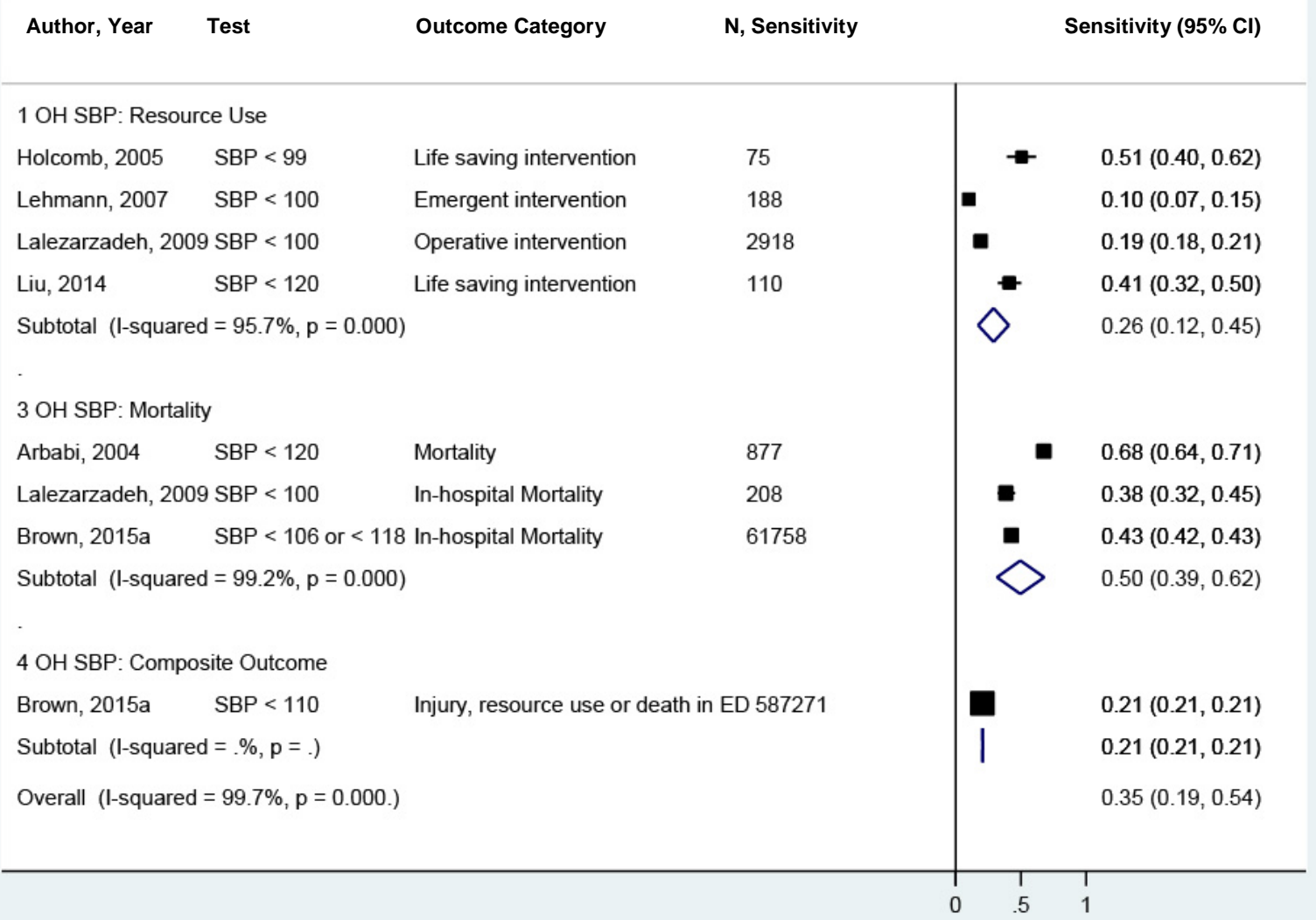

$\mathrm{CI}=$ confidence interval; ED = emergency department; $\mathrm{N}$ = number; $\mathrm{OH}$ = out-of-hospital; $\mathrm{SBP}$ = systolic blood pressure. Note: Holcomb, 2005 = Reference no. 69 in this report; Liu, 2014 = Reference no. 80 in this report.

Note: Overall results are from the bivariate logistic mixed effects model analysis. 


\section{Figure 7. Pooled specificity of out-of-hospital systolic blood pressure $<100 \mathrm{mmHg}$}

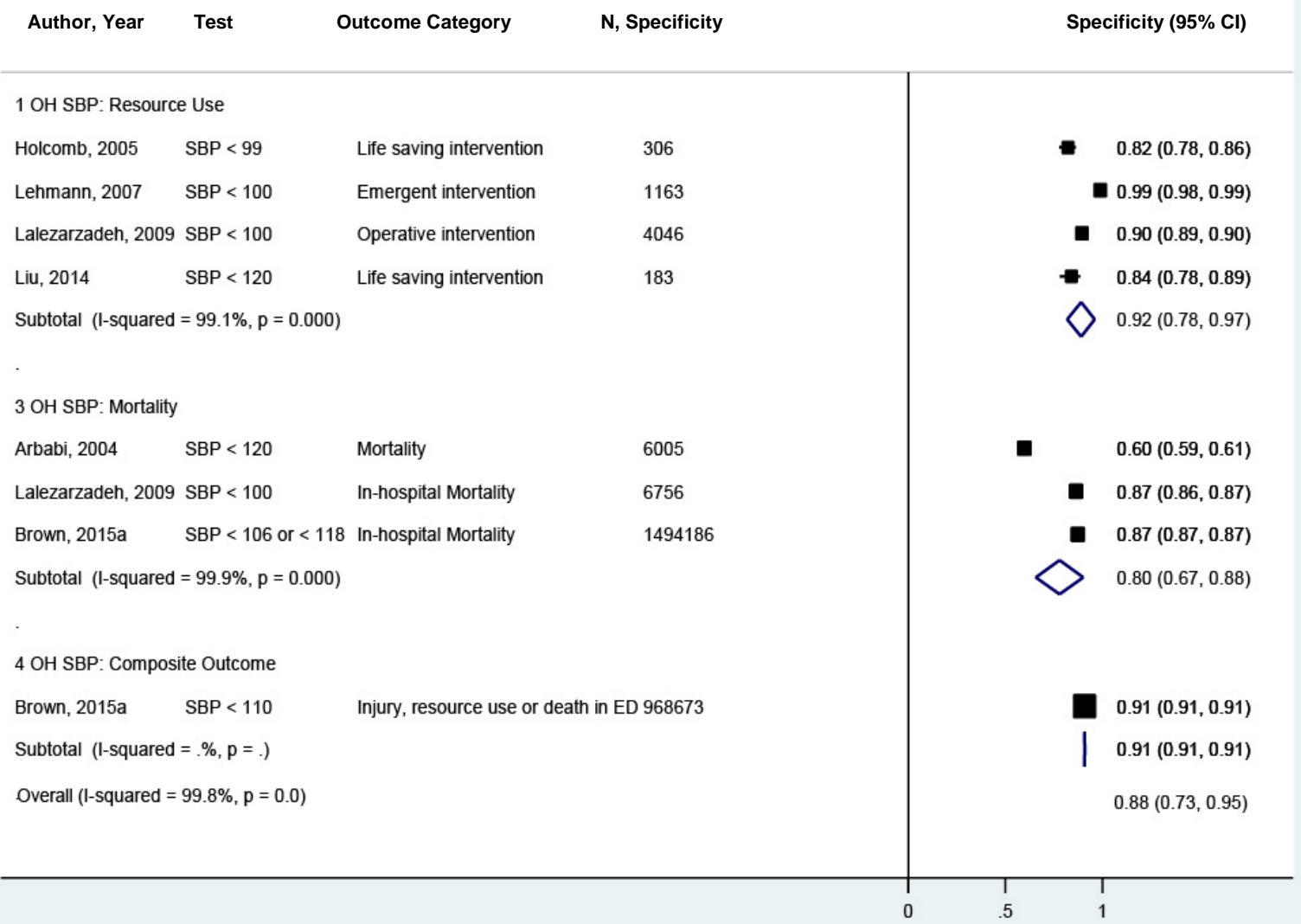

$\mathrm{CI}$ = confidence interval; $\mathrm{ED}=$ emergency department; $\mathrm{N}=$ number; $\mathrm{OH}$ = out-of-hospital; $\mathrm{SBP}=$ systolic blood pressure . Note: Holcomb, 2005 = Reference no. 69 in this report; Liu, 2014 = Reference no. 80 in this report.

Note: Overall results are from the bivariate logistic mixed effects model analysis. 
Figure 8. Pooled AUROC of out-of-hospital systolic blood pressure

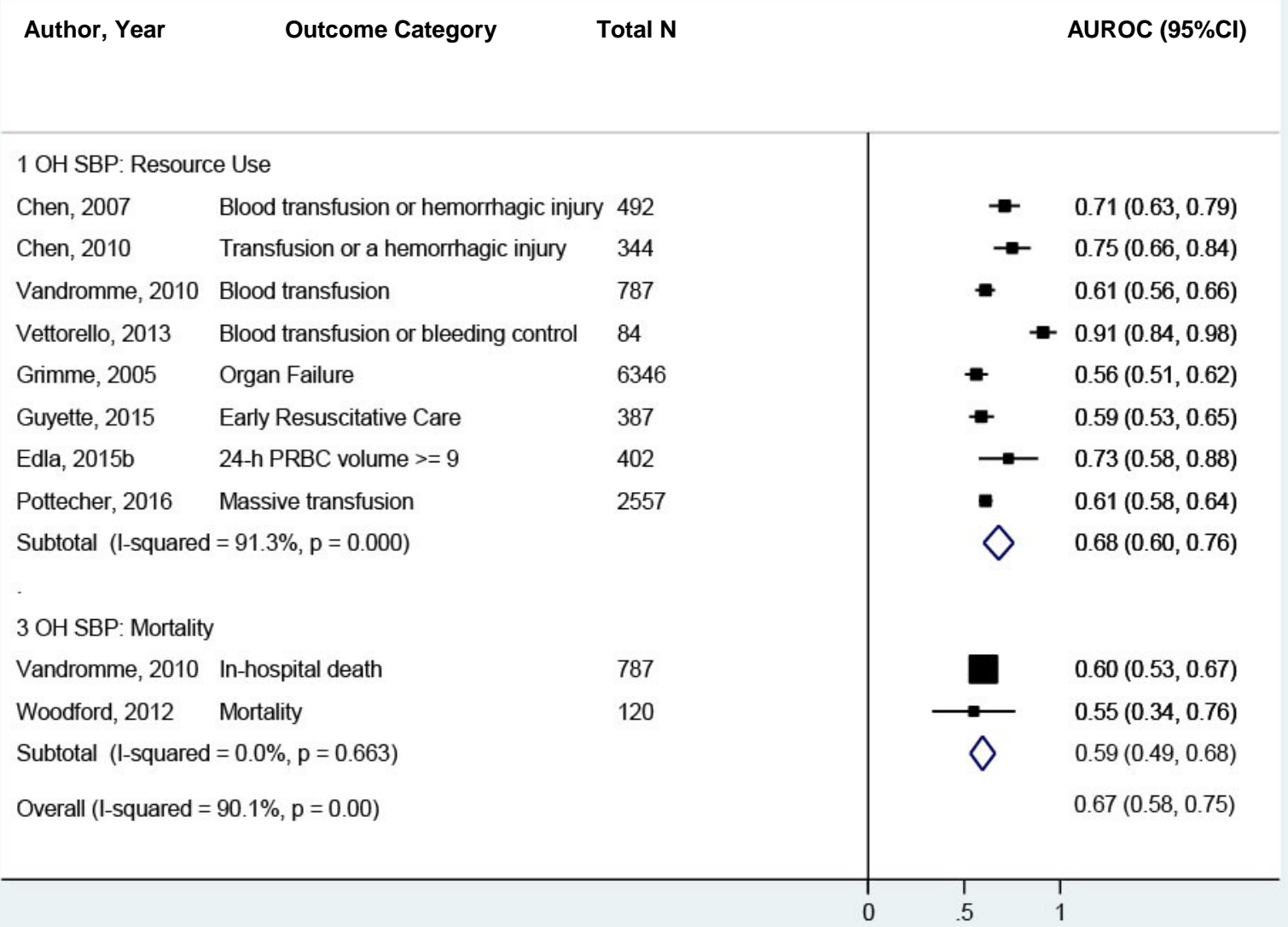

AUROC = area under the receiver operating characteristic curve; $\mathrm{CI}=$ confidence interval; $\mathrm{N}=$ number; $\mathrm{OH}=$ out-of-hospital; pRBC = packed red blood cells; SBP = systolic blood pressure.

Note: Overall results are from the bivariate logistic mixed effects model analysis. 


\section{Heart Rate}

Heart rate is a commonly measured vital sign and is also a component of other combination measures such as SI. It can be measured manually or automatically with monitoring devices ranging from simple to complex. HR is rarely measured alone and some studies provided data collected on HR in the course of studying other measures (e.g., HRV ${ }^{59}$ or hemoglobin oximetry ${ }^{108}$ ) or comparing continuous vital sign monitoring with point-in-time measures. ${ }^{107}$

We included 24 studies that evaluated HR measured either out-of-hospital or in the ED. Five studies were not included in the pooled estimates. ${ }^{54,80,83,103,165}$ Four of these used lower cut-offs (HR $>100$ or 105 beats per minute [bpm] $)^{80,83,103,165}$ and one was not included because the population overlapped with a larger study. ${ }^{54}$ The remainder are cited in the tables and figures below. We combined four studies of out-of-hospital HR $\geq 110 \mathrm{bpm}$ and calculated a pooled sensitivity of 28 percent ( $95 \%$ CI 20 to 37, $\mathrm{I}^{2}=41.3 \%$ ) and a pooled specificity of 85 percent (95\% CI 74 to $91, I^{2}=95.8 .0 \%$ ) across all serious injury indicators. Figures 9 and 10 provide the estimates stratified by type of serious injury indicator (resource use, mortality, and composite indicators). Table 8 reports these values as well as the estimates from five studies using HR $>110$ bpm measured in the ED. ${ }^{61,116,124,137,156}$ Plots for the ED analyses are included in Appendix I.

The pooled AUROC for out-of-hospital HR $\geq 110 \mathrm{bpm}$ was 0.67 (95\% CI 0.56 to 0.79 , $\mathrm{I}^{2}=84.5 \%$ ) based on five studies ${ }^{55,59,62,106,107}$ (Figure 11) and 0.66 (95\% CI 0.62 to 0.70 , $\mathrm{I}^{2}=83.9 \%$ ) for ED HR based on nine studies (Appendix I) ${ }^{61,115,116,125,147-149,159,162,170}$

Table 8. Pooled sensitivity and specificity for predictive utility of heart rate across all serious injury indicators

\begin{tabular}{|l|l|l|l|}
\hline Measure, Setting & $\begin{array}{l}\text { Number of } \\
\text { Studies }\end{array}$ & Sensitivity (95\% Cl, I $\left.^{2}\right)$ & Specificity (95\% Cl, $\left.{ }^{2}\right)$ \\
\hline $\mathrm{HR} \geq 110 \mathrm{bpm},{ }^{*} \mathrm{OH}$ & $4^{70,76,80,107}$ & $28 \%(20$ to $37,41.3 \%)$ & $85 \%(74$ to $91,88.0 \%)$ \\
\hline $\mathrm{HR} \geq 110 \mathrm{bpm}, \mathrm{ED}$ & $5^{48,61,124,137,156}$ & $29 \%(26$ to $32,26.7 \%)$ & $93 \%(90$ to $95,94.5 \%)$ \\
\hline
\end{tabular}

bpm = beats per minute; $\mathrm{CI}$ = confidence interval; $\mathrm{ED}$ = emergency department; $\mathrm{HR}$ = heart rate; $\mathrm{OH}$ = out-of-hospital

*The exact threshold varied across studies (i.e., $>110, \geq 110$, or $\geq 116$ beats per minute) 
Figure 9. Pooled sensitivity of out-of-hospital heart rate $\geq 110$ beats per minute*

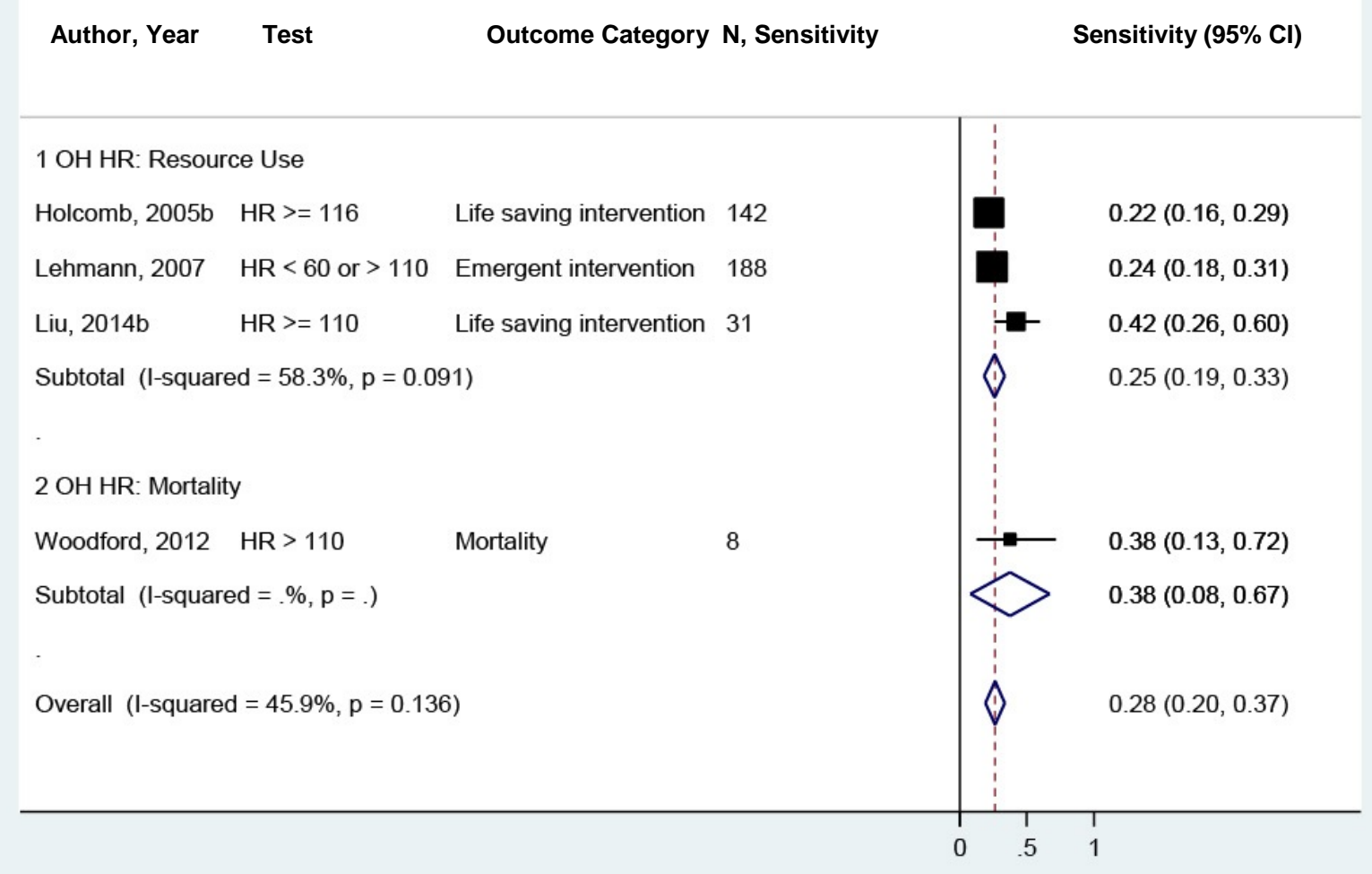

$\mathrm{CI}=$ confidence interval; $\mathrm{HR}=$ heart rate; $\mathrm{N}$ = number; $\mathrm{OH}=$ out-of-hospital.

Note: Holcomb, 2005b = Reference no. 70 in this report; Liu, 2014b = Reference no. 81 in this report.

Note: Overall results are from the bivariate logistic mixed effects model analysis.

*The exact threshold varied across studies (i.e., $>110, \geq 110$, or $\geq 116$ beats per minute) 
Figure 10. Pooled specificity of out-of-hospital heart rate $\geq 110$ beats per minute*

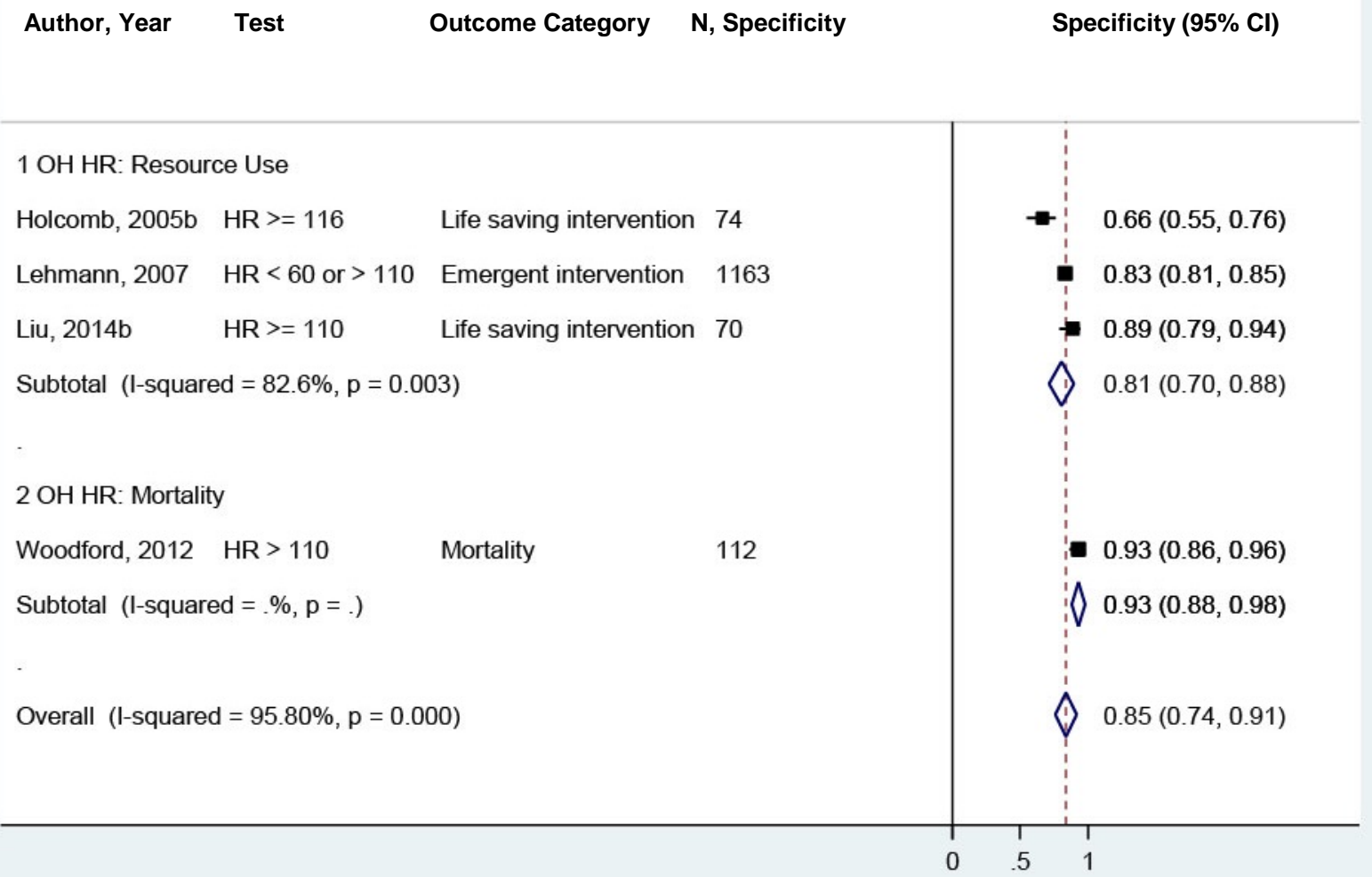

$\mathrm{CI}=$ confidence interval; $\mathrm{HR}=$ heart rate; $\mathrm{N}$ = number; $\mathrm{OH}=$ out-of-hospital.

Holcomb, 2005b = Reference no. 70 in this report; Liu, 2014b = Reference no. 81 in this report.

Overall results are from the bivariate logistic mixed effects model analysis.

*The exact threshold varied across studies (i.e., $>110, \geq 110$, or $\geq 116$ beats per minute) 
Figure 11. Pooled AUROC of out-of-hospital heart rate

\begin{tabular}{|c|c|c|c|}
\hline Author, Year & Outcome Category & Total $\mathbf{N}$ & AUROC $(95 \% \mathrm{Cl})$ \\
\hline \multicolumn{4}{|c|}{$1 \mathrm{OH}$ HR: Resource Use } \\
\hline Grimme, 2005 & Organ Failure & 6346 & $0.58(0.53,0.63)$ \\
\hline Chen, 2010 & Transfusion or a hemorrhagic injury & 344 & $0.62(0.51,0.73)$ \\
\hline Vettorello, 2013 & Blood transfusion or bleeding control & 84 & $0.83(0.75,0.92)$ \\
\hline Edla, 2015b & Transfusion & 402 & $0.72(0.56,0.88)$ \\
\hline $\begin{array}{l}\text { Subtotal (I-squar } \\
2 \text { OH HR: Mortali }\end{array}$ & $\begin{array}{l}\text { red }=88.4 \%, p=0.000) \\
\text { lity }\end{array}$ & & $0.68(0.55,0.82)$ \\
\hline Woodford, 2012 & Mortality & 120 & $0.65(0.44,0.86)$ \\
\hline Subtotal (I-squar & red $=. \%, p=$. ) & & $0.65(0.44,0.86)$ \\
\hline Overall (I-square & $\mathrm{ed}=84.5 \%, \mathrm{p}=0.000)$ & & $0.67(0.56,0.79)$ \\
\hline
\end{tabular}

AUROC = area under the receiver characteristic curve; $\mathrm{CI}=$ confidence interval; $\mathrm{HR}=$ heart rate; $\mathrm{N}=$ number; $\mathrm{OH}=$ out-ofhospital.

Note: Overall results are from the bivariate logistic mixed effects model analysis.

\section{Shock Index}

SI combines two measures of circulatory function: SBP and HR, by dividing HR by SBP. SI has been shown to predict hemorrhage and indicate the severity of shock and the need for transfusion. Values of 0.5 to 0.7 are considered normal in healthy adults, while values greater than 0.9 or 1.0 are considered abnormal and indicators of underlying shock. In trauma triage, a threshold of 1.0 is often used, as it is simpler to determine; the person doing the assessment must only realize that the patient's HR is higher than their SBP.

We identified 26 studies reported in 28 articles (see Table 9 for citations). All but two ${ }^{66,108}$ were included in the pooled measures for either out-of-hospital or ED. We combined five studies of out-of-hospital SI and calculated a pooled sensitivity of 37 percent (95\% CI 22 to 56, $\mathrm{I}^{2}=94.5 \%$ ) and a pooled specificity of 85 percent ( $95 \%$ CI 72 to $92, \mathrm{I}^{2}=99.6 \%$ ) across all serious injury indicators. Figures 12 and 13 provide the estimates stratified by type of serious injury indicator (resource use, injury type or severity, mortality, or composite indicators). Table 9 reports these values as well as the estimates from 11 studies using SI measured in the ED. Plots for the ED analyses are included in Appendix I. 
The pooled AUROC for out-of-hospital SI was 0.72 (95\% CI 0.66 to $0.77, \mathrm{I}^{2}=54.6 \%$ ) based on seven studies ${ }^{44,52,53,62,65,93,107}$ (Figure 14) and 0.71 (95\% CI 0.66 to $0.76, \mathrm{I}^{2}=94.7 \%$ ) for ED SI based on 11 studies (reported in 12 articles) (Appendix I). ${ }^{116,123,125,131,136,137,142,145,147,148,159,170}$

Table 9. Pooled sensitivity and specificity for predictive utility of shock index across all serious injury indicators

\begin{tabular}{|l|l|l|l|}
\hline Measure, Setting & Number of Studies & Sensitivity $\left.\mathbf{( 9 5 \% ~ C l , ~} \mathbf{I}^{\mathbf{2}}\right)$ & Specificity $\left.\mathbf{( 9 5 \%} \mathbf{~ C l ,} \mathbf{I}^{\mathbf{2}}\right)$ \\
\hline $\mathrm{SI}>0.9$ or $1, \mathrm{OH}$ & $5^{44,50,74,93,165}$ & $37 \%(22$ to $56,94.5 \%)$ & $85 \%(72$ to $92,99.6 \%)$ \\
\hline $\mathrm{SI}>0.9$ or $1, \mathrm{ED}$ & $11^{50,74,116,123,136,144,145,147,148,151,166}$ & $40 \%(24$ to $57,99.7 \%)$ & $93 \%(85$ to $96,99.6 \%)$ \\
\hline
\end{tabular}

$\mathrm{CI}$ = confidence interval; $\mathrm{ED}$ = emergency department; $\mathrm{OH}$ = out-of-hospital; $\mathrm{SI}$ = shock index

Figure 12. Pooled sensitivity of out-of-hospital shock index $>0.9$

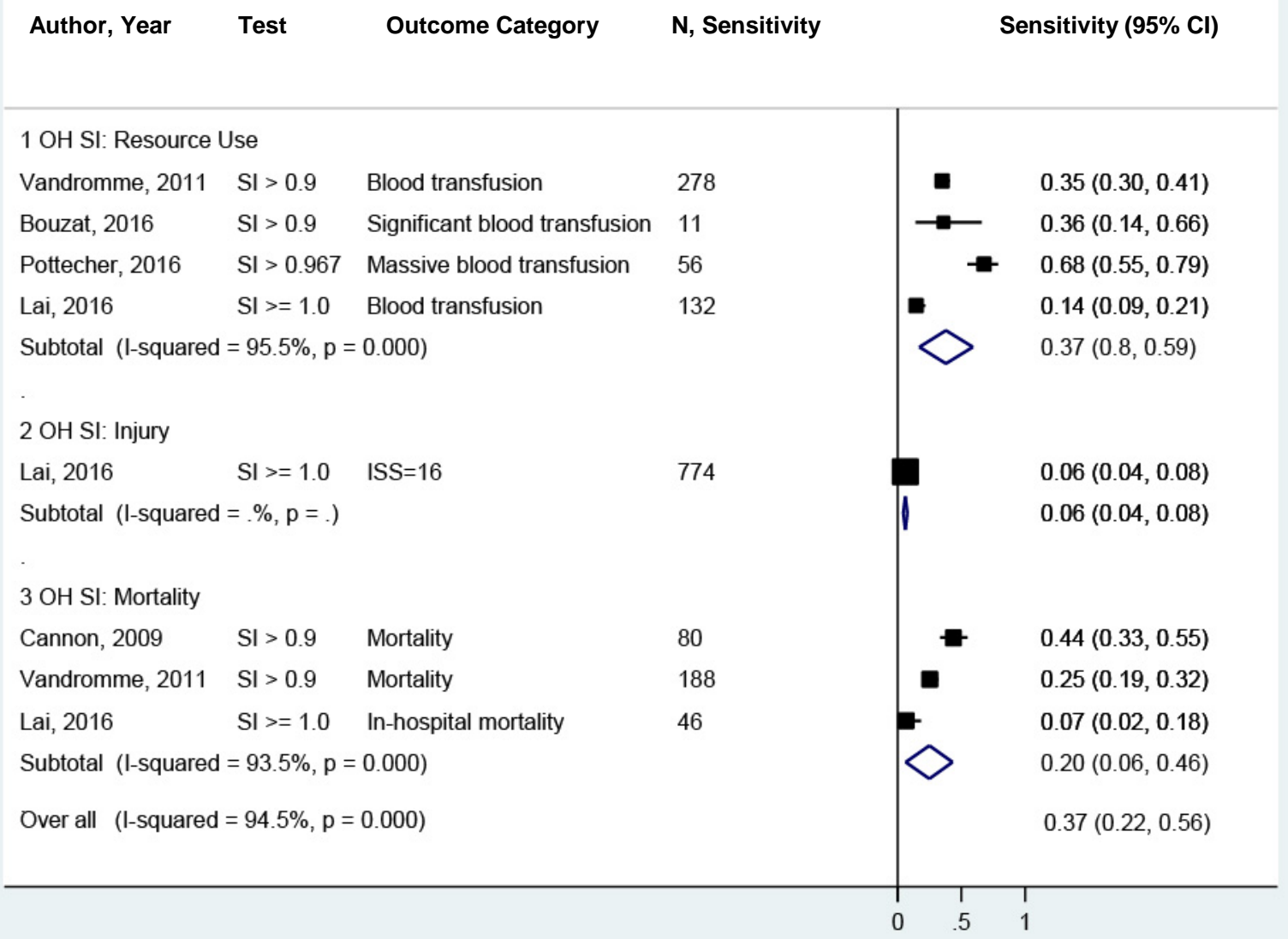

$\mathrm{CI}$ = confidence interval; ISS = injury severity score; $\mathrm{N}=$ number; $\mathrm{OH}$ = out-of-hospital; $\mathrm{SI}=$ shock index.

Note: Vandromme, 2011 = Reference no. 105 in this report.

Note: Overall results are from the bivariate logistic mixed effects model analysis. 
Figure 13. Pooled specificity of out-of-hospital shock index $>0.9$

\begin{tabular}{|c|c|c|c|c|}
\hline Author, Year & Test & Outcome Category & N, Specificity & Specificity (95\% Cl) \\
\hline \multicolumn{5}{|c|}{$1 \mathrm{OH}$ SI: Resource Use } \\
\hline Vandromme, 2011 & $\mathrm{SI}>0.9$ & Blood transfusion & 7833 & - $\quad 0.82(0.81,0.83)$ \\
\hline Bouzat, 2016 & $\mathrm{SI}>0.9$ & Significant blood transfusion & 96 & $\Rightarrow \quad 0.78(0.69,0.85)$ \\
\hline Pottecher, 2016 & $\mathrm{SI}>0.967$ & Massive blood transfusion & 2501 & - $0.86(0.85,0.87)$ \\
\hline Lai, 2016 & $\mathrm{SI}>=1.0$ & Blood transfusion & 3583 & $0.96(0.96,0.97)$ \\
\hline $\begin{array}{l}\text { Subtotal (I-squared } \\
2 \mathrm{OH} \mathrm{SI} \text { : Injury }\end{array}$ & $=99.6 \%, \mathrm{p}=$ & $0.000)$ & & $0.88(0.77,0.94)$ \\
\hline Lai, 2016 & $\mathrm{SI}>=1.0$ & ISS=16 & 2941 & $0.97(0.96,0.97)$ \\
\hline $\begin{array}{l}\text { Subtotal (I-squared } \\
3 \mathrm{OH} \text { SI: Mortality }\end{array}$ & $=. \%, p=)$. & & & $0.97(0.96,0.97)$ \\
\hline Cannon, 2009 & $\mathrm{SI}>0.9$ & Mortality & 1086 & $0.67(0.64,0.70)$ \\
\hline Vandromme, 2011 & $\mathrm{SI}>0.9$ & Mortality & 7923 & - $0.82(0.81,0.83)$ \\
\hline Lai, 2016 & $\mathrm{SI}>=1.0$ & In-hospital mortality & 3669 & $0.96(0.95,0.97)$ \\
\hline \multicolumn{4}{|c|}{ Subtotal $($ I-squared $=99.8 \%, p=0.000)$} & $0.85(0.65,0.95)$ \\
\hline \multicolumn{4}{|c|}{ Overall (I-squared $=99.6 \%, p=0.000)$} & $0.85(0.72,0.92)$ \\
\hline & & & & $\begin{array}{l}T \\
1\end{array}$ \\
\hline
\end{tabular}

$\mathrm{CI}$ = confidence interval; ISS = injury severity score; $\mathrm{N}$ = number; $\mathrm{OH}$ = out-of-hospital; $\mathrm{SI}$ = shock index.

Note: Vandromme, 2011 = Reference no. 105 in this report.

Note: Overall results are from the bivariate logistic mixed effects model analysis. 
Figure 14. Pooled AUROC of out-of-hospital shock index

\begin{tabular}{|c|c|c|c|}
\hline Author, Year & Outcome Category & Total N & AUROC $(95 \% \mathrm{Cl})$ \\
\hline \multicolumn{3}{|c|}{$1 \mathrm{OH}$ SI: Resource Use } & \\
\hline Chen, 2007 & Blood transfusion or hemorrhagic injury & 492 & $0.77(0.69,0.85)$ \\
\hline Chen, 2008 & Blood transfusion & 246 & $0.76(0.64,0.88)$ \\
\hline Grimme, 2005 & Organ Failure & 6346 & $0.68(0.62,0.74)$ \\
\hline Guyette, 2015 & Early Resuscitative Care & 387 & $0.66(0.59,0.73)$ \\
\hline Bouzat, 2016 & Significant blood transfusion & 120 & $0.68(0.51,0.85)$ \\
\hline Pottecher, 2016 & Massive blood transfusion & 2557 & $0.80(0.74,0.87)$ \\
\hline $\begin{array}{l}\text { Subtotal (I-squa } \\
3 \mathrm{OH} \mathrm{SI} \text { : Mortalit }\end{array}$ & $\mathrm{d}=59.8 \%, \mathrm{p}=0.029)$ & & $0.72(0.67,0.78)$ \\
\hline Woodford, 2012 & Mortality & 120 & $0.63(0.42,0.84)$ \\
\hline $\begin{array}{l}\text { Subtotal (I-squa } \\
\text { Overall (I-square }\end{array}$ & $\begin{array}{l}d=. \%, p=.) \\
=54.6 \%, p=0.040)\end{array}$ & & $0.63(0.42,0.84)$ \\
\hline
\end{tabular}

AUROC $=$ area under the receiver characteristic curve; $\mathrm{CI}=$ confidence interval; $\mathrm{N}=$ number; $\mathrm{OH}=$ out-of-hospital; $\mathrm{SI}=$ shock index.

Note: Overall results are from the bivariate logistic mixed effects model analysis.

\section{Lactate}

Lactate is produced predominately from anaerobic metabolism and cleared from the blood primarily through utilization by the liver. ${ }^{176,177}$ Elevated lactate is present in states of inadequate perfusion, such as shock, in which decreased oxygen delivery leads to tissue hypoxia resulting in increased anaerobic metabolism and consequent lactate production. ${ }^{177,178}$ Hyperlactatemia is not restricted to shock states, may be caused by other mechanisms, and is often multifactorial in etiology. Trauma patients in particular may have elevated lactate due to local tissue ischemia from burn or crush injuries, ethanol or illicit drug intoxication, or increased epinephrine seen in the stress response. Comorbidities such as liver disease or malignancy, and use of certain medications are also known causes of hyperlactatemia. ${ }^{179,180}$

Plasma lactate concentration can be obtained from arterial, venous, or capillary blood samples. A normal lactate concentration is considered to be less than $2 \mathrm{mmol} / \mathrm{L}$, and levels greater than $4 \mathrm{mmol} / \mathrm{L}$ are considered markers of perfusion failure ${ }^{177}$ Lactate levels between 2 and $4 \mathrm{mmol} / \mathrm{L}$ are challenging to interpret since they can be caused by many factors, including 
the stress response, which may be normal following traumatic injury. The use of lactate testing to inform field triage of trauma patients is of particular interest-availability of point-of-care testing devices in recent years and their use both out-of-hospital and in EDs make lactate testing potentially feasible to incorporate into out-of-hospital triage.

The predictive utility of lactate concentration in trauma was examined in multiple studies. As point-of-care measurement is relatively recent, fewer studies using out-of-hospital data were identified. We identified 23 studies in 24 articles, and all but one ${ }^{165}$ included data that could be pooled. The figures below report the pooled sensitivity and specificity for lactate measured outof-hospital using different cutoff values. Similar figures for lactate measured in the ED are in Appendix I. Figures 15 and 16 contain the results for three studies that used a cutoff value of 2 or $2.5 \mathrm{mmol} / \mathrm{L}$ or higher. Figures 17 and 18 are for the one study that used a higher threshold of 4 $\mathrm{mmol} / \mathrm{L}$ or higher as the definition of abnormal. Table 10 summarizes the pooled sensitivity and specificity at the lower cutoff value and the higher value for both out-of-hospital and ED.

Comparing the lower threshold to the higher demonstrates the trade-offs between sensitivity and specificity: for the out-of-hospital measures sensitivity decreases from 72 percent at the lower threshold to 23 percent at the higher threshold, while specificity increases from 62 to 93 percent, though there was only one study that evaluated the higher threshold. ${ }^{47}$ We pooled the two studies that reported an AUROC for out-of-hospital measurements ${ }^{65,101}$ (Figure 19) to obtain a combined estimate of 0.77 (95\% CI 0.67 to 0.82 , $\left.\mathrm{I}^{2}=10.2 \%\right)$, and the 14 studies that reported an AUROC for ED lactate to obtain an estimate of 0.68 (95\% CI 0.65 to 0.71 , $\left.\mathrm{I}^{2}=66.6 \%\right)_{.}^{44,97,104,113,114,117,120,128,146-148,150,152,158,161}$ It is also possible that the change in lactate or lactate clearance could be an important predictor once volume is restored or stable, but this change is usually reported over 2 hours, making it less useful for field triage. This was explored in one included study that reported a higher AUROC for initial lactate values than lactate clearance $(0.78$ vs. 0.70$) .{ }^{158}$

As most of the studies to date have been done in the ED, more out-of-hospital research is needed to directly evaluate how lactate would perform as a field triage measure. This is important because early interventions, particularly use of intravenous fluids, influence lactate levels, making it plausible that out-of-hospital lactate levels will differ from those obtained in the ED and the predictive utility of this measure for out-of-hospital may be significantly different compared to performance when used in the ED.

Table 10. Pooled sensitivity and specificity for predictive utility of lactate across all serious injury indicators

\begin{tabular}{|c|c|c|c|}
\hline Measure, Setting & Number of Studies & Sensitivity $\left(95 \% \mathrm{Cl}, \mathrm{I}^{2}\right)$ & Specificity (95\% Cl, $\left.\mathrm{I}^{2}\right)$ \\
\hline $\begin{array}{l}\text { Lactate }>2 \text { or } 2.5 \\
\mathrm{mmol} / \mathrm{L} \\
\text { Out-of-hospital }\end{array}$ & $3^{47,65,101}$ & $74 \%$ (48 to $90,98.5 \%)$ & $62 \%$ (51 to $72,98.6 \%)$ \\
\hline $\begin{array}{l}\text { Lactate }>4 \mathrm{mmol} / \mathrm{L} \\
\text { Out-of-hospital }\end{array}$ & $1^{47}$ & $23 \%(21$ to $25, N A)$ & $93 \%(92$ to $94, N A)$ \\
\hline $\begin{array}{l}\text { Lactate }>2 \text { or } 2.5 \\
\mathrm{mmol} / \mathrm{L} \\
\text { Emergency department }\end{array}$ & $9^{104,117,128,143,146-148,157,158,161}$ & $74 \%$ (66 to $81,89.6 \%)$ & $52 \%$ (43 to $60,98.7 \%)$ \\
\hline $\begin{array}{l}\text { Lactate }>4 \text { or } 5 \mathrm{mmol} / \mathrm{L} \\
\text { Emergency department }\end{array}$ & $9^{44,104,112,117,119,120,126,143,157}$ & $50 \%$ (37 to $63,93.5 \%)$ & $86 \%$ (78 to $91,92.1 \%)$ \\
\hline
\end{tabular}

$\mathrm{CI}=$ confidence interval; NA = not applicable 
Figure 15. Pooled sensitivity of out-of-hospital lactate $>2 \mathrm{mmol} / \mathrm{L}$

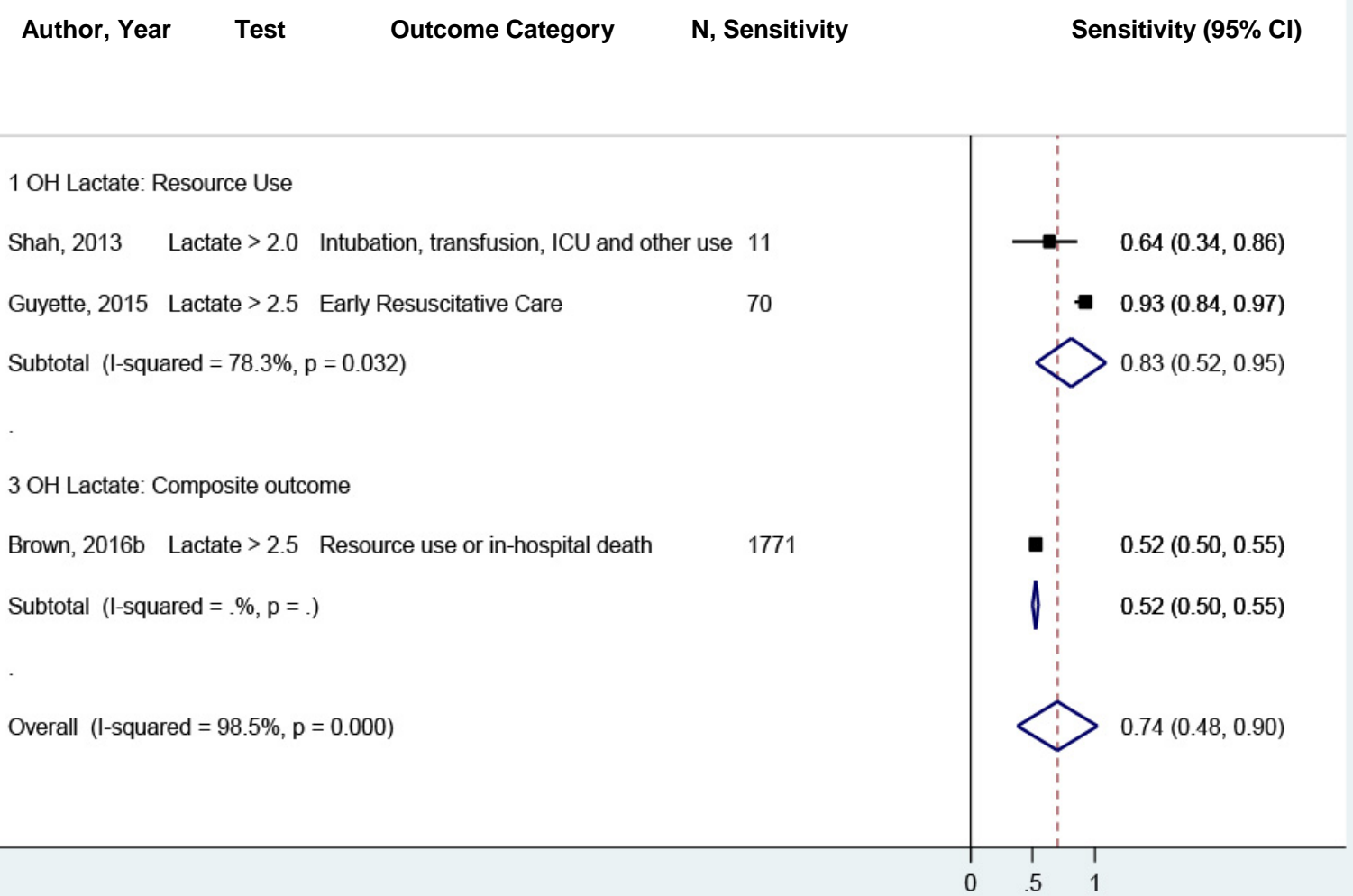

$\mathrm{CI}$ = confidence interval; ICU = intensive care unit; $\mathrm{N}$ = number; $\mathrm{OH}$ = out-of-hospital.

Note: Overall results are from the bivariate logistic mixed effects model analysis. 
Figure 16. Pooled specificity of out-of-hospital lactate $>2 \mathrm{mmol} / \mathrm{L}$

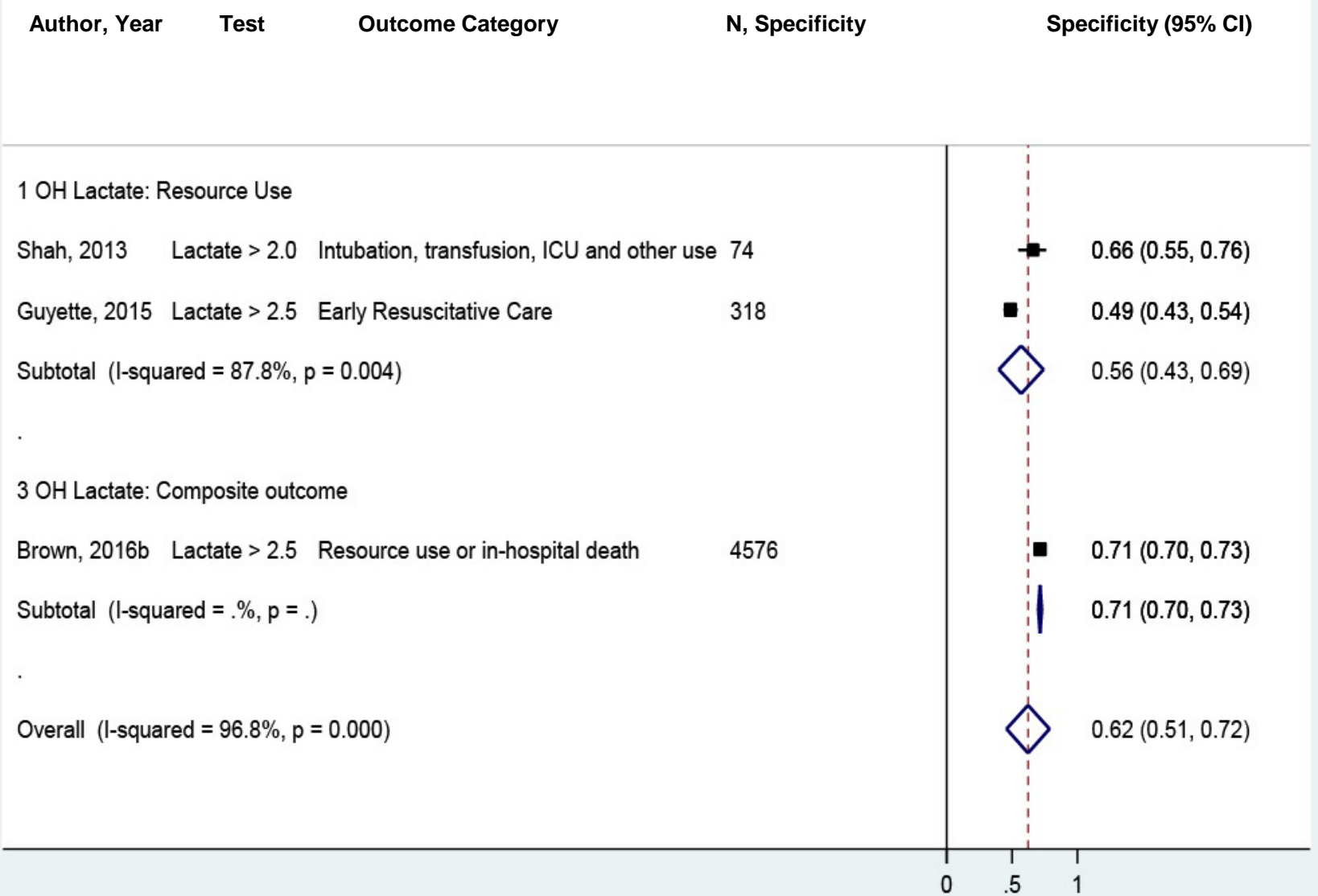

$\mathrm{CI}$ = confidence interval; ICU = intensive care unit; $\mathrm{N}$ = number; $\mathrm{OH}$ = out-of-hospital.

Note: Overall results are from the bivariate logistic mixed effects model analysis. 
Figure 17. Sensitivity of out-of-hospital lactate $>4 \mathrm{mmol} / \mathrm{L}$

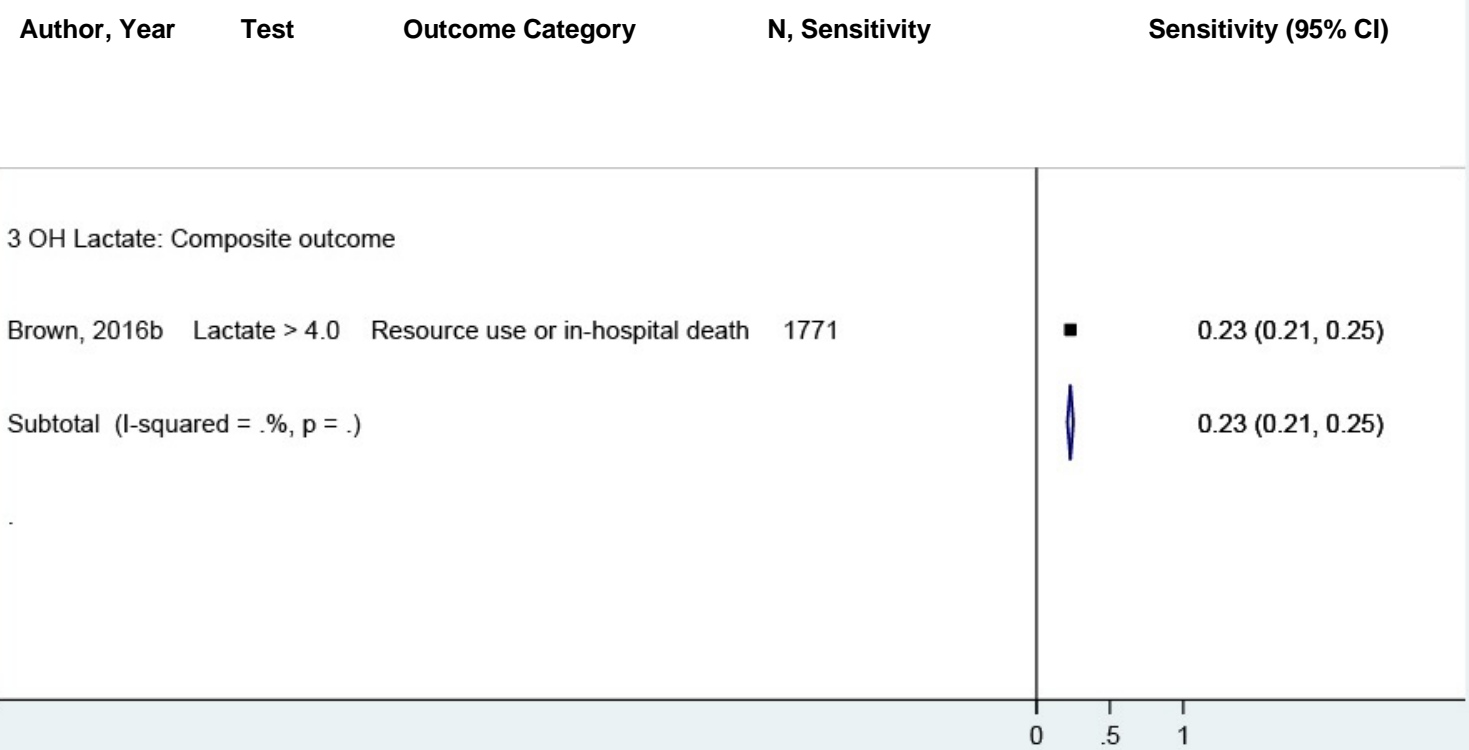

$\mathrm{CI}=$ confidence interval; $\mathrm{N}$ = number; $\mathrm{OH}$ = out-of-hospital.

Note: Overall results are from the bivariate logistic mixed effects model analysis. 
Figure 18. Specificity of out-of-hospital lactate $>4 \mathrm{mmol} / \mathrm{L}$

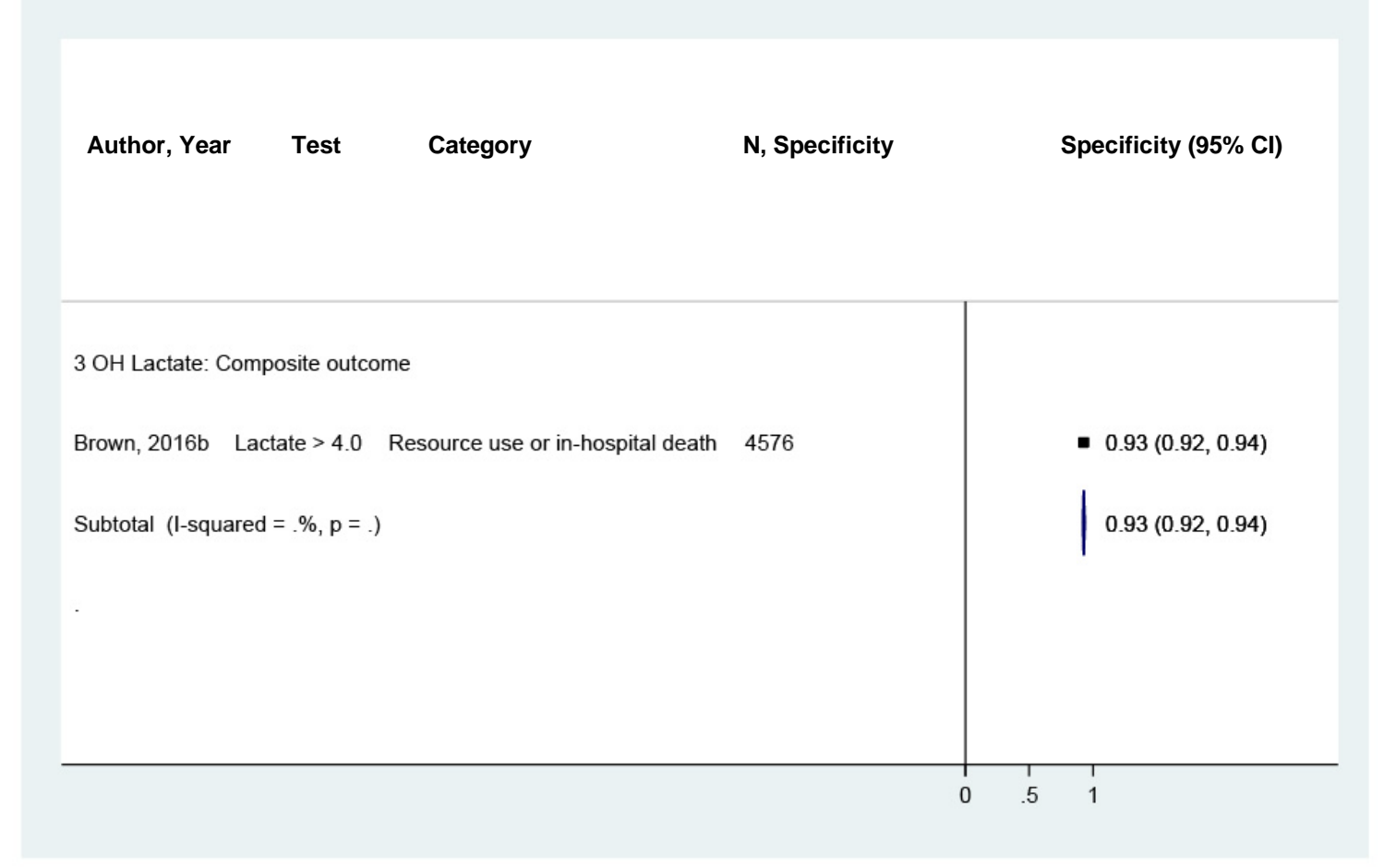

$\mathrm{CI}=$ confidence interval; $\mathrm{N}=$ number OH = out-of-hospital.

Note: Overall results are from the bivariate logistic mixed effects model analysis. 
Figure 19. Pooled AUROC of out-of-hospital lactate

Author, Year

Outcome Category

AUROC (95\%Cl)

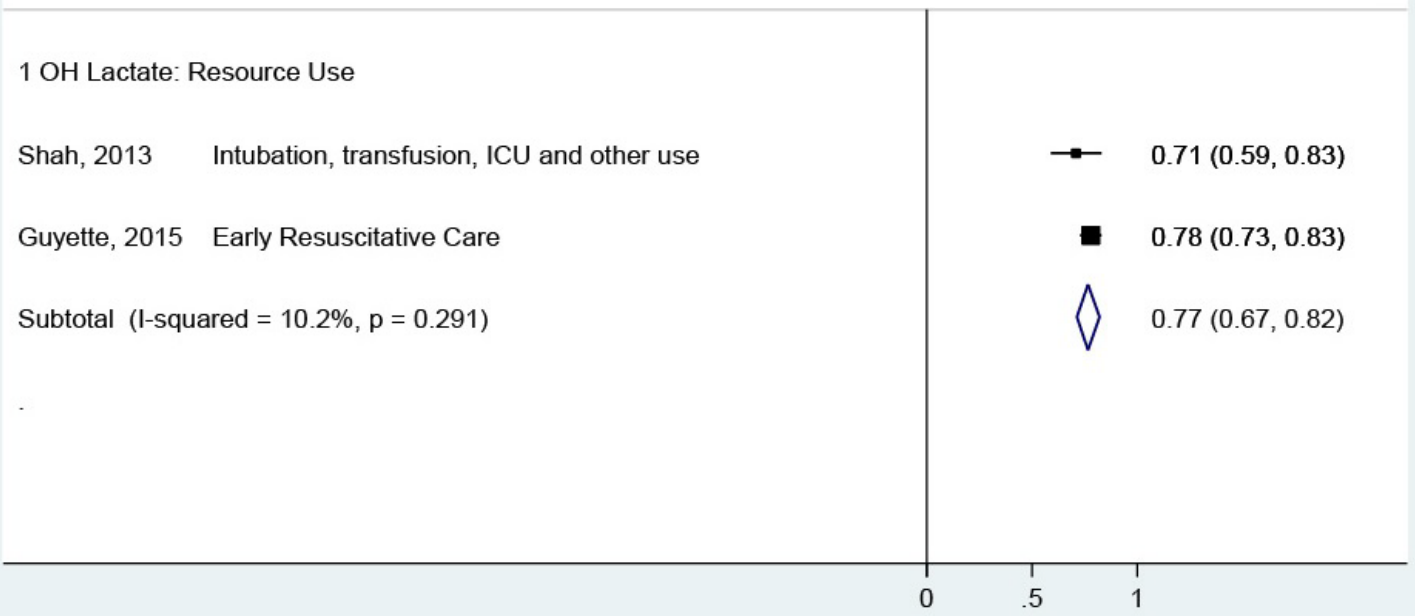

AUROC = area under the receiver operating characteristic curve; $\mathrm{CI}=$ confidence interval; $\mathrm{ICU}=$ intensive care unit; $\mathrm{N}=$ number; $\mathrm{OH}$ = out-of-hospital.

Note: Overall results are from the bivariate logistic mixed effects model analysis.

\section{Base Deficit}

Base deficit is a negative base excess and is equivalent to an acid excess or insufficient level of bicarbonate. Base excess is the amount of acid $\left(\mathrm{H}^{+}\right.$ions) that would be needed to return the blood $\mathrm{pH}$ to normal (7.4), assuming a normal partial pressure of carbon dioxide $\left(\mathrm{pCO}_{2}\right){ }^{181}$ Base deficit is clinically similar to lactate concentration, in that base deficit is a nonspecific indicator of metabolic acidosis and correlates with anaerobic metabolism. ${ }^{182}$ Normal base excess is -2 to $+2 \mathrm{mEq} / \mathrm{L} .{ }^{181}$ Large base deficit can be due to shock and respiratory failure, resulting in tissue hypoperfusion and hypoxemia.

Table 11 provides the results from 15 studies reported in 16 articles that included data evaluating base deficit. Many of these studies tested different thresholds and repeated the analysis using different indicators of serious injury. We included the highest and lowest threshold tested in each study in Table 11 below (results for every threshold reported are available in the evidence tables in Appendix D). The results are grouped by type of serious injury indicator within the table. All of the identified studies analyzed base deficit measured in the ED; we did not identify any studies of base deficit in the out-of-hospital setting. As more advanced technologies are developed for out-of-hospital monitoring, resuscitation, and treatment, base deficit may become more useful or feasible in emergency medical services (EMS) trauma assessment. 
Table 11. Predictive utility of base deficit measured in emergency department

\begin{tabular}{|c|c|c|c|c|c|}
\hline $\begin{array}{l}\text { Measure } \\
\text { Threshold(s) }\end{array}$ & $\begin{array}{l}\text { Author, Year } \\
\text { Risk of Bias }\end{array}$ & $\begin{array}{l}\text { Serious } \\
\text { Injury } \\
\text { Indicator } \\
\text { Type: } \\
\text { Indicator }\end{array}$ & $\begin{array}{l}\text { Number } \\
\text { Analyzed } \\
\text { Age } \\
\text { Mean (SD) }\end{array}$ & $\begin{array}{l}\text { Sensitivity } \\
\text { Specificity } \\
(95 \% \mathrm{Cl})\end{array}$ & AUROC (95\% Cl) \\
\hline $\begin{array}{l}\text { Base Deficit } \\
<-2\end{array}$ & $\begin{array}{l}\text { Caputo, } \\
2015^{120} \\
\text { Low }\end{array}$ & $\begin{array}{l}\text { R: operative } \\
\text { intervention }\end{array}$ & $\begin{array}{l}100 \\
34(\mathrm{NR})\end{array}$ & $\begin{array}{l}\text { Sen: } 57 \%(42 \text { to } 76) \\
\text { Sp: } 61 \%(52 \text { to } 77)\end{array}$ & 0.67 (0.58 to 0.76$)$ \\
\hline $\begin{array}{l}\begin{array}{l}\text { Base Deficit } \\
<-4\end{array} \\
<-7\end{array}$ & $\begin{array}{l}\text { Beekley, } \\
2010^{115} \\
\text { Moderate }\end{array}$ & R: LSI & $\begin{array}{l}147 \\
27(11)\end{array}$ & $\begin{array}{l}\text { Base Deficit <-4 } \\
\text { Sen: } 28 \%(17 \text { to } 40) \\
\text { Sp: } 91 \% \text { ( } 81 \text { to } 96 \\
\text { Base Deficit <-7Sen: } \\
\text { 15\% (8 to } 26) \\
\text { Sp: } \quad 97 \%(89 \text { to } 100)\end{array}$ & $0.71(0.64$ to 0.78$)$ \\
\hline Base Deficit & $\begin{array}{l}\text { Raux, 201797 } \\
\text { Moderate }\end{array}$ & $\begin{array}{l}\text { R: emergency } \\
\text { procedure }\end{array}$ & $\begin{array}{l}1,075 \\
39(18)\end{array}$ & NR & 0.74 (0.68 to 0.80$)$ \\
\hline $\begin{array}{l}\begin{array}{l}\text { Base Deficit } \\
<-4 \\
<-7\end{array} \\
<-10\end{array}$ & $\begin{array}{l}\text { Beekley, } \\
2010^{115} \\
\text { Moderate }\end{array}$ & $\begin{array}{l}\mathrm{R}: \text { massive } \\
\text { transfusion }\end{array}$ & $\begin{array}{l}147 \\
27(11)\end{array}$ & $\begin{array}{l}\text { Base Deficit <-4 } \\
\text { Sen: } 38 \%(9 \text { to } 76) \\
\text { Sp: } 83 \%(75 \text { to } 89) \\
\text { Base Deficit <-7 } \\
\text { Sen: } 25 \%(3 \text { to } 65) \\
\text { Sp: } 92 \%(85 \text { to } 96)\end{array}$ & 0.69 (0.51 to 0.87$)$ \\
\hline $\begin{array}{l}\text { Base Deficit } \\
<-2\end{array}$ & $\begin{array}{l}\text { Caputo, } \\
2015^{120} \\
\text { Low }\end{array}$ & $\begin{array}{l}\text { R: massive } \\
\text { transfusion }\end{array}$ & $\begin{array}{l}100 \\
34(N R)\end{array}$ & $\begin{array}{l}\text { Sen: } 59 \% \text { (45 to } 72) \\
\text { Sp: } 59 \%(45 \text { to } 71)\end{array}$ & $0.82(0.75$ to 0.89$)$ \\
\hline $\begin{array}{l}\text { Base Deficit } \\
<-5\end{array}$ & $\begin{array}{l}\text { Rainer, 2011 } \\
\text { Moderate }\end{array}$ & $\begin{array}{l}\text { R: massive } \\
\text { transfusion }\end{array}$ & $\begin{array}{l}1,891 \\
44(19)\end{array}$ & $\begin{array}{l}\text { *Sen: } 41 \% \text { (31 to } 52) \\
\text { *Sp: } 94 \% \text { (93 to } 95)\end{array}$ & NR \\
\hline Base Deficit & $\begin{array}{l}\text { Raux, } 2017^{97} \\
\text { Moderate }\end{array}$ & $\begin{array}{l}\text { R: massive } \\
\text { hemorrhage }\end{array}$ & $\begin{array}{l}1,075 \\
39(18)\end{array}$ & NR & 0.85 (0.81 to 0.89$)$ \\
\hline $\begin{array}{l}\text { Base Deficit } \\
<-4 \\
<-7\end{array}$ & $\begin{array}{l}\text { Beekley, } \\
2010^{115} \\
\text { Moderate }\end{array}$ & $\begin{array}{l}\mathrm{R}: \text { blood } \\
\text { transfusion }\end{array}$ & $\begin{array}{l}147 \\
27(11)\end{array}$ & $\begin{array}{l}\text { Base Deficit <-4 } \\
\text { Sen: } 40 \%(24 \text { to } 57) \\
\text { Sp: } 90 \%(82 \text { to } 95) \\
\text { Base Deficit <-7 } \\
\text { Sen: } 21 \%(10 \text { to } 37) \\
\text { Sp: } 96 \%(89 \text { to } 99)\end{array}$ & 0.70 (0.61 to 0.79$)$ \\
\hline $\begin{array}{l}\text { Base Deficit } \\
-3 \text { to }-5 \\
\leq-10\end{array}$ & $\begin{array}{l}\text { Davis, } 1996^{122} \\
\text { Moderate }\end{array}$ & $\begin{array}{l}\text { R: blood } \\
\text { transfusion }\end{array}$ & $\begin{array}{l}2,954 \\
32(0.3)\end{array}$ & $\begin{array}{l}\text { Base Deficit }-3 \text { to }-5 \\
\text { *Sen: } 23 \%(21 \text { to } 26) \\
\text { *Sp: } 73 \%(71 \text { to } 75) \\
\text { Base Deficit } \leq-10 \\
\text { *Sen: } 27 \%(24 \text { to } 30) \\
\text { *Sp: } 98 \%(97 \text { to } 98)\end{array}$ & NR \\
\hline Base Deficit & $\begin{array}{l}\text { Mutschler, } \\
2013^{145} \\
\text { Moderate }\end{array}$ & $\begin{array}{l}\text { R: blood } \\
\text { transfusion }\end{array}$ & $\begin{array}{l}21,853 \\
45(20)\end{array}$ & NR & $0.71(0.70$ to 0.72$)$ \\
\hline Base Deficit & $\begin{array}{l}\text { Baron, } 2004^{113} \\
\text { Moderate }\end{array}$ & R: Blood loss & $\begin{array}{l}N=108 \\
28(11)\end{array}$ & NR & 0.76 (0.68 to 0.85$)$ \\
\hline Base Deficit & $\begin{array}{l}\text { Baron, } 2007^{114} \\
\text { Moderate }\end{array}$ & M: mortality & $\begin{array}{l}86 \\
35(17) \\
\end{array}$ & NR & $0.87(0.77$ to 0.98$)$ \\
\hline
\end{tabular}




\begin{tabular}{|c|c|c|c|c|c|}
\hline $\begin{array}{l}\text { Measure } \\
\text { Threshold(s) }\end{array}$ & $\begin{array}{l}\text { Author, Year } \\
\text { Risk of Bias }\end{array}$ & $\begin{array}{l}\text { Serious } \\
\text { Injury } \\
\text { Indicator } \\
\text { Type: } \\
\text { Indicator }\end{array}$ & $\begin{array}{l}\text { Number } \\
\text { Analyzed } \\
\text { Age } \\
\text { Mean (SD) }\end{array}$ & $\begin{array}{l}\text { Sensitivity } \\
\text { Specificity } \\
(95 \% \mathrm{Cl})\end{array}$ & AUROC $(95 \% \mathrm{Cl})$ \\
\hline Base Deficit & $\begin{array}{l}\text { Callaway, } \\
2009^{117} \\
\text { Moderate }\end{array}$ & M: mortality & $\begin{array}{l}1,776 \\
38(14)\end{array}$ & NR & 0.65 (NR) \\
\hline $\begin{array}{l}\text { Base Deficit } \\
-3 \text { to }-5 \\
\leq-10\end{array}$ & $\begin{array}{l}\text { Davis, } 1996^{122} \\
\text { Moderate }\end{array}$ & M: mortality & $\begin{array}{l}2,954 \\
32(0.3)\end{array}$ & $\begin{array}{l}\text { Base Deficit -3 to }-5 \\
\text { *Sen: } 19 \%(16 \text { to } 24) \\
\text { *Sp: } 73 \% \text { ( } 71 \text { to } 74) \\
\text { Base Deficit } \leq- \\
10 * \text { Sen: } 33 \% \text { ( } 29 \text { to } \\
38 \text { ) } \\
\text { *Sp: } 94 \%(93 \text { to } 95)\end{array}$ & NR \\
\hline Base Deficit & $\begin{array}{l}\text { Dunham, } \\
2017^{125} \\
\text { High }\end{array}$ & M: mortality & $\begin{array}{l}1,863 \\
29(11)\end{array}$ & NR & 0.90 (0.85 to 0.94$)$ \\
\hline $\begin{array}{l}\text { Base Deficit } \\
<-5 \\
<-10\end{array}$ & $\begin{array}{l}\text { Mizushima, } \\
2011^{143} \\
\text { Moderate }\end{array}$ & M: mortality & $\begin{array}{l}1,742 \\
44(20)\end{array}$ & $\begin{array}{l}\text { Base Deficit <-5 } \\
\text { *Sen: } 56 \%(47 \text { to } 64) \\
\text { *Sp: } 87 \%(86 \text { to } 89) \\
\text { Base Deficit <-10 } \\
\text { *Sen: } 32 \%(25 \text { to } 40) \\
\text { *Sp: } 96 \%(95 \text { to } 97)\end{array}$ & NR \\
\hline $\begin{array}{l}\text { Base Deficit } \\
\leq-6\end{array}$ & $\begin{array}{l}\text { Aslar, } 2004^{112} \\
\text { Moderate }\end{array}$ & $\begin{array}{l}\text { M: 30-day in- } \\
\text { hospital } \\
\text { mortality }\end{array}$ & $\begin{array}{l}64 \\
36(19)\end{array}$ & $\begin{array}{l}\text { *Sen: } 76 \%(54 \text { to } 90) \\
{ }^{*} \text { Sp: } \quad 62 \%(44 \text { to } 77)\end{array}$ & NR \\
\hline Base Deficit & $\begin{array}{l}\text { Raux, } 2017^{97} \\
\text { Moderate }\end{array}$ & $\begin{array}{l}\text { M: 30-day in- } \\
\text { hospital } \\
\text { 48-hour }\end{array}$ & $\begin{array}{l}1,075 \\
39(18)\end{array}$ & NR & $\begin{array}{l}0.75(0.70 \text { to } 0.80) \\
0.82(0.75 \text { to } 0.87)\end{array}$ \\
\hline Base Deficit & $\begin{array}{l}\text { Raux, } 2017^{97} \\
\text { Moderate }\end{array}$ & I: ISS >15 & $\begin{array}{l}1,075 \\
39(18)\end{array}$ & NR & 0.67 (0.63 to 0.70$)$ \\
\hline $\begin{array}{l}\text { Base Deficit } \\
<-1.3 \text { : } \\
\text { subgroup with } \\
\text { normal vital } \\
\text { signs }\end{array}$ & $\begin{array}{l}\text { Paladino, } \\
2008, \\
2011^{147,148} \\
\\
\text { Moderate }\end{array}$ & $\begin{array}{l}\text { C: major } \\
\text { injury (blood } \\
\text { transfusion, } \\
\text { hemorrhage } \\
\text { or ISS } \geq 16 \text { ) }\end{array}$ & $\begin{array}{l}\begin{array}{l}1,034 \text { (total } \\
\mathrm{n}=1,435) \\
\text { Overall: } 35 \\
(17)\end{array} \\
\end{array}$ & $\begin{array}{l}\text { Sen: } 56 \% \text { (NR) } \\
\text { Sp: } 71 \% \text { (NR) }\end{array}$ & $\begin{array}{l}0.68(0.63 \text { to } 0.73) \\
\text { For total } n \\
0.72(0.69 \text { to } 0.76)\end{array}$ \\
\hline Base Deficit & $\begin{array}{l}\text { Paladino, } \\
\text { 2010a, } \mathrm{b}^{149,150} \dagger \\
\text { Moderate }\end{array}$ & $\begin{array}{l}\text { C: major } \\
\text { injury (blood } \\
\text { transfusion, } \\
\text { hemorrhage } \\
\text { or ISS } \geq 16 \text { ) }\end{array}$ & $\begin{array}{l}1,649 \\
36 \text { (range } \\
13 \text { to } 95)\end{array}$ & NR & 0.72 (0.68 to 0.76$)$ \\
\hline Base Deficit & $\begin{array}{l}\text { Raux, } 2017^{97} \\
\text { Moderate }\end{array}$ & $\begin{array}{l}\text { C: ICU LOS } \\
>2 \text { days or in- } \\
\text { hospital } \\
\text { mortality }\end{array}$ & $\begin{array}{l}1,075 \\
39(18)\end{array}$ & NR & 0.70 (0.67 to 0.73 ) \\
\hline
\end{tabular}

AUROC = area under the receiver operating characteristic curve; $\mathrm{C}=$ composite; $\mathrm{CI}$ = confidence interval; $\mathrm{I}=$ injury; $\mathrm{ICU}=$ intensive care unit; ISS = injury severity score; LOS = length of stay; LSI = life-saving intervention; $\mathrm{M}=$ mortality; $\mathrm{NR}=$ not reported; $\mathrm{R}$ = resource use; $\mathrm{SD}$ = standard deviation; $\mathrm{Sen}=$ sensitivity; $\mathrm{Sp}$ = specificity

*Results calculated by reviewers

${ }^{\dagger}$ Samples in the two articles appear to overlap; results reported for larger sample 


\section{Heart Rate Variability or Heart Rate Complexity}

Routine electrocardiography (ECG) can be used to measure characteristics of heart beats that reflect the state of a patient's autonomic nervous system. Several metrics exist, including standard deviation of the normal-to-normal intervals, rate of sinus arrhythmia, sample entropy (SampEn), and detrended fluctuations analysis. Lack of variability or complexity can be an indicator of reduced physiologic capacity or increased stress. These changes may be detectible before the impact of trauma is seen in the commonly measured vital signs such as blood pressure, HR, and RR. That is, they may help identify critically injured patients who would otherwise not be recognized as seriously injured using traditional vital signs. The availability of ECG and software that analyzes ECG output in real time makes it possible to use these measures in field triage.

Eight studies analyzed HRV or HRC (Tables 12, 13, and 14). Seven ${ }^{40,41,49,56,59,73,106}$ studies collected prehospital data during helicopter transport, while one study evaluated patients in the ED waiting for CT

scans to evaluate head trauma. ${ }^{160}$ Two studies were different analyses of the same patient population. ${ }^{40,41}$ The out-of-hospital studies were divided into two tables: Table 12 reports the results based on a single metrics from the ECG, which is most similar to the analysis of other individual measures in this report, while Table 13 reports results that combine metrics from the ECG. Five studies were conducted in the state of Texas, with common researchers among the authors, ${ }^{40,41,49,56,59}$ while the others were conducted in Florida ${ }^{73}$ and Italy ${ }^{106}$ by different researchers.

Overall, the studies reported AUROCs ranging from 0.60 to 0.95 . However, the highest value was produced by an analysis that excluded outliers. ${ }^{40}$ The risk of bias in some studies was rated as high if in addition to one or more other methodologic concerns, a significant proportion of cases were dropped if the data were incomplete due to interference and instrumentation issues, which could plausibly be confounded with severity of injury. Additionally, as the patients were transported by helicopter, these patients may be inherently different than patients transported by ground ambulance, and this may make these results less generalizable to all trauma patients.

As this is a developing technology, the earlier studies had smaller sample sizes (e.g., $n=75$, $n=84)$. The most recent study was larger $(n=402)$ and combined data from two air ambulance services - one in Texas and the other in Massachusetts. ${ }^{59}$ This study reported AUROC estimates which were similar for HRV metrics and routine vital signs, but also found that adding HRV to vital signs did not improve diagnostic performance (in this case, the ability to predict need for transfusion). The authors conducted sensitivity analyses that involved repeating their analyses on all cases, including those without complete reliable data, and using different transfusion volumes $(\geq 1,5$, or 9 units of packed red blood cells in 24 hours) as the serious injury indicator. The results of these repeated analyses did not change the conclusions. 
Table 12. Predictive utility of heart rate variability/complexity: out-of-hospital

\begin{tabular}{|c|c|c|c|c|c|}
\hline $\begin{array}{l}\text { Measure } \\
\text { Threshold }\end{array}$ & $\begin{array}{l}\text { Author, Year } \\
\text { Risk of Bias }\end{array}$ & $\begin{array}{l}\text { Serious } \\
\text { Injury } \\
\text { Indicator } \\
\text { Type: } \\
\text { Indicator }\end{array}$ & $\begin{array}{l}\text { Number } \\
\text { Analyzed } \\
\text { Age } \\
\text { Mean (SD) }\end{array}$ & $\begin{array}{l}\text { Sensitivity } \\
\text { Specificity } \\
(95 \% \mathrm{CI})\end{array}$ & AUROC (95\% Cl) \\
\hline $\begin{array}{l}\text { HRV } \\
\text { Heart-to-arm } \\
\text { time index } \\
\text { (iHAT) } \\
>58.78 \%\end{array}$ & $\begin{array}{l}\text { Vettorello, } \\
2013^{106} \\
\text { High }\end{array}$ & $\begin{array}{l}\text { R: blood } \\
\text { transfusion or } \\
\text { bleeding } \\
\text { control }\end{array}$ & $\begin{array}{l}84 \\
\text { Median (range) } \\
41(18-83) \text { for } \\
\text { no hemorrhage } \\
\text { group } \\
29(18-74) \text { for } \\
\text { hemorrhage } \\
\text { group }\end{array}$ & $\begin{array}{l}\text { Sen: } 90.9 \% \text { (58.7 to } \\
\text { 99.8) } \\
\text { Sp: } 100 \% \text { (94.9 to } \\
\text { 100) }\end{array}$ & $0.952(0.880$ to 0.987$)$ \\
\hline $\begin{array}{l}\text { HRV } \\
\text { Rate of sinus } \\
\text { arrhythmia } \\
\text { (RSA) }\end{array}$ & $\begin{array}{l}\text { Edla, } 2015 b^{59} \\
\text { Moderate }\end{array}$ & $\begin{array}{l}\text { R: blood } \\
\text { transfusion } \\
\geq 1 \text { pRBC } \\
\text { units in } 24 \\
\text { hours }\end{array}$ & $\begin{array}{l}402 \\
39(16)\end{array}$ & NR & 0.72 (0.64 to 0.79$)$ \\
\hline $\begin{array}{l}\text { HRV } \\
\text { Rate of sinus } \\
\text { arrhythmia } \\
\text { (RSA) }\end{array}$ & $\begin{array}{l}\text { Edla, } 2015 b^{59} \\
\text { Moderate }\end{array}$ & $\begin{array}{l}\text { R: blood } \\
\text { transfusion } \\
\geq 5 \text { pRBC } \\
\text { units in } 24 \\
\text { hours }\end{array}$ & $\begin{array}{l}402 \\
39(16)\end{array}$ & NR & 0.76 (0.62 to 0.85$)$ \\
\hline $\begin{array}{l}\text { HRV } \\
\text { Rate of sinus } \\
\text { arrhythmia } \\
\text { (RSA) }\end{array}$ & $\begin{array}{l}\text { Edla, } 2015 b^{59} \\
\text { Moderate }\end{array}$ & $\begin{array}{l}\text { R: blood } \\
\text { transfusion } \\
\geq 9 \text { pRBC } \\
\text { units in } 24 \\
\text { hours }\end{array}$ & $\begin{array}{l}402 \\
39(16)\end{array}$ & NR & 0.79 (0.64 to 0.89$)$ \\
\hline $\begin{array}{l}\text { HRV } \\
\text { Sample } \\
\text { entropy } \\
\text { (SampEn) }\end{array}$ & $\begin{array}{l}\text { Edla, 2015b } b^{59} \\
\text { Moderate }\end{array}$ & $\begin{array}{l}\mathrm{R}: \text { blood } \\
\text { transfusion } \\
\geq 1 \text { pRBC } \\
\text { units in } 24 \\
\text { hours }\end{array}$ & $\begin{array}{l}402 \\
39(16)\end{array}$ & NR & $0.60(0.53$ to 0.68$)$ \\
\hline $\begin{array}{l}\text { HRV } \\
\text { Sample } \\
\text { entropy } \\
\text { (SampEn) }\end{array}$ & $\begin{array}{l}\text { Edla, 2015b } b^{59} \\
\text { Moderate }\end{array}$ & $\begin{array}{l}\text { R: blood } \\
\text { transfusion } \\
\geq 5 \text { pRBC } \\
\text { units in } 24 \\
\text { hours }\end{array}$ & $\begin{array}{l}402 \\
39(16)\end{array}$ & NR & 0.63 (0.52 to 0.73$)$ \\
\hline $\begin{array}{l}\text { HRV } \\
\text { Sample } \\
\text { entropy } \\
\text { (SampEn) }\end{array}$ & $\begin{array}{l}\text { Edla, 2015b } b^{59} \\
\text { Moderate }\end{array}$ & $\begin{array}{l}\text { R: blood } \\
\text { transfusion } \\
\geq 9 \text { pRBC } \\
\text { units in } 24 \\
\text { hours }\end{array}$ & $\begin{array}{l}402 \\
39(16)\end{array}$ & NR & $0.62(0.46$ to 0.75$)$ \\
\hline $\begin{array}{l}\text { HRV } \\
\text { Standard } \\
\text { deviation of } \\
\text { the R-to-R } \\
\text { intervals } \\
\text { (SDNN) }\end{array}$ & $\begin{array}{l}\text { Edla, 2015b } b^{59} \\
\text { Moderate }\end{array}$ & $\begin{array}{l}\text { R: blood } \\
\text { transfusion } \\
\geq 1 \text { pRBC } \\
\text { units in } 24 \\
\text { hours }\end{array}$ & $\begin{array}{l}402 \\
39(16)\end{array}$ & NR & 0.67 (0.59 to 0.75$)$ \\
\hline $\begin{array}{l}\text { HRV } \\
\text { Standard } \\
\text { deviation of } \\
\text { the R-to-R } \\
\text { intervals } \\
\text { (SDNN) }\end{array}$ & $\begin{array}{l}\text { Edla, } 2015 b^{59} \\
\text { Moderate }\end{array}$ & $\begin{array}{l}\text { R: blood } \\
\text { transfusion } \\
\geq 5 \text { pRBC } \\
\text { units in } 24 \\
\text { hours }\end{array}$ & $\begin{array}{l}402 \\
39(16)\end{array}$ & NR & 0.72 (0.61 to 0.82$)$ \\
\hline
\end{tabular}




\begin{tabular}{|c|c|c|c|c|c|}
\hline $\begin{array}{l}\text { Measure } \\
\text { Threshold }\end{array}$ & $\begin{array}{l}\text { Author, Year } \\
\text { Risk of Bias }\end{array}$ & $\begin{array}{l}\text { Serious } \\
\text { Injury } \\
\text { Indicator } \\
\text { Type: } \\
\text { Indicator }\end{array}$ & $\begin{array}{l}\text { Number } \\
\text { Analyzed } \\
\text { Age } \\
\text { Mean (SD) }\end{array}$ & $\begin{array}{l}\text { Sensitivity } \\
\text { Specificity } \\
(95 \% \mathrm{Cl})\end{array}$ & AUROC $(95 \% \mathrm{Cl})$ \\
\hline $\begin{array}{l}\text { HRV } \\
\text { Standard } \\
\text { deviation of } \\
\text { the R-to-R } \\
\text { intervals } \\
\text { (SDNN) }\end{array}$ & $\begin{array}{l}\text { Edla, } 2015 b^{59} \\
\text { Moderate }\end{array}$ & $\begin{array}{l}\text { R: blood } \\
\text { transfusion } \\
\geq 9 \text { pRBC } \\
\text { units in } 24 \\
\text { hours }\end{array}$ & $\begin{array}{l}402 \\
39(16)\end{array}$ & NR & $0.71(0.57$ to 0.82$)$ \\
\hline $\begin{array}{l}\text { HRV } \\
\text { Standard } \\
\text { deviation of } \\
\text { the R-to-R } \\
\text { intervals } \\
\text { (SDNN) } \\
<24 \text { msec }\end{array}$ & $\begin{array}{l}\text { King, } 2009^{73} \\
\text { Moderate }\end{array}$ & R: LSI & $\begin{array}{l}75 \\
47(20)\end{array}$ & $\begin{array}{l}\text { Sen: } 80 \%(N R) \\
\text { Sp: } 75 \% \text { (NR) }\end{array}$ & 0.74 (NR) \\
\hline $\begin{array}{l}\text { HRV } \\
\text { Standard } \\
\text { deviation of } \\
\text { the R-to-R } \\
\text { intervals } \\
\text { (SDNN) } \\
<39 \text { msec } \\
<55 \text { msec }\end{array}$ & $\begin{array}{l}\text { King, } 2009^{73} \\
\text { Moderate }\end{array}$ & $\begin{array}{l}\text { C: serious } \\
\text { injury } \\
\text { including } \\
\text { death }\end{array}$ & $\begin{array}{l}75 \\
47(20)\end{array}$ & $\begin{array}{l}\text { Sen: 80\% (NR) } \\
\text { Sp: NR } \\
\text { Sen: 94\% (NR) } \\
\text { Sp: NR }\end{array}$ & 0.80 (NR) \\
\hline
\end{tabular}

AUROC = area under the receiver operating characteristic curve; $\mathrm{C}=$ composite; $\mathrm{CI}=$ confidence interval; $\mathrm{HRV}=\mathrm{heart}$ rate variability; iHAT = heart-to-arm time index; LSI = life-saving intervention; NR = not reported; pRBC = packed red blood cells; $\mathrm{R}=$ resource use; $\mathrm{R}-\mathrm{R}$ interval = time between heart beats; $\mathrm{RSA}=$ rate of sinus arrhythmia; SampEn = sample entropy; $\mathrm{SD}=$ standard deviation; SDNN = standard deviation of normal-to-normal R-to-R intervals; Sen = sensitivity; Sp = specificity

Table 13. Predictive utility of heart rate variability/complexity: out-of-hospital heart rate measure models

\begin{tabular}{|c|c|c|c|c|c|}
\hline Measure & $\begin{array}{l}\text { Author, Year } \\
\text { Risk of Bias }\end{array}$ & $\begin{array}{l}\text { Serious Injury } \\
\text { Indicator } \\
\text { Type: } \\
\text { Indicator }\end{array}$ & $\begin{array}{l}\text { Number } \\
\text { Analyzed } \\
\text { Age } \\
\text { Mean (SD) }\end{array}$ & Measures in Model & AUROC (95\% Cl) \\
\hline $\begin{array}{l}\text { Heart Rate } \\
\text { Complexity }\end{array}$ & $\begin{array}{l}\text { Cancio, } 2008^{49} \\
\text { High }\end{array}$ & R: LSI & $\begin{array}{l}192 \\
37(\mathrm{NR})\end{array}$ & SampEn and DFA & 0.76 (0.68 to 0.83$)$ \\
\hline $\begin{array}{l}\text { Heart Rate } \\
\text { Variability }\end{array}$ & $\begin{array}{l}\text { Batchinsky, } \\
2007^{40} \\
\text { Moderate }\end{array}$ & M: mortality & $\begin{array}{l}31 \\
38 \text { (3) for } \\
\text { survivors } \\
43 \text { (6) for } \\
\text { deceased }\end{array}$ & $\begin{array}{l}\text { R-to-R interval derived } \\
\text { data, approximate } \\
\text { entropy, and distribution } \\
\text { of symbol } 2\end{array}$ & $\begin{array}{l}0.956 \text { (0.86 to } 1.0) \\
0.86(0.71 \text { to } 1.0) \\
\text { including outliers }\end{array}$ \\
\hline
\end{tabular}




\begin{tabular}{|c|c|c|c|c|c|}
\hline Measure & $\begin{array}{l}\text { Author, Year } \\
\text { Risk of Bias }\end{array}$ & $\begin{array}{l}\text { Serious Injury } \\
\text { Indicator } \\
\text { Type: } \\
\text { Indicator }\end{array}$ & $\begin{array}{l}\text { Number } \\
\text { Analyzed } \\
\text { Age } \\
\text { Mean (SD) }\end{array}$ & Measures in Model & AUROC (95\% Cl) \\
\hline $\begin{array}{l}\text { Heart Rate } \\
\text { Variability }\end{array}$ & $\begin{array}{l}\text { Batchinsky, } \\
2009^{41} \\
\text { Moderate }\end{array}$ & M: mortality & $\begin{array}{l}31^{*} \text { same } \\
\text { patients as } \\
\text { Batchinsky } \\
\text { 2007, different } \\
\text { analysis }\end{array}$ & $\begin{array}{l}\text { SampEn combined with } \\
\text { data set derived weights } \\
\text { and intercepts }\end{array}$ & $\begin{array}{l}\text { Data set length }=800 \\
\text { beats (longest reported) } \\
0.895(0.780 \text { to } 1.010) \\
\text { Data set length }=200 \\
\text { beats: } 0.895 \text { ( } 0.781 \text { to } \\
1.000) \\
\text { Data set length }=100 \\
\text { beats: } 0.821 \text { ( } 0.662 \text { to } \\
0.980)\end{array}$ \\
\hline $\begin{array}{l}\text { Heart Rate } \\
\text { Variability }\end{array}$ & $\begin{array}{l}\text { Cooke, } \\
\text { 2006a }^{56} \\
\text { High }\end{array}$ & M: mortality & $\begin{array}{l}30 \\
43 \text { (2) for } \\
\text { deceased } \\
35 \text { (3) for } \\
\text { survivors }\end{array}$ & $\begin{array}{l}\text { R-to-R interval } \\
\text { oscillations: HF/LF ratio } \\
\text { as a global index of } \\
\text { changes in autonomic } \\
\text { balance } \\
\text { *HF = R-to-R interval } \\
\text { spectral power at the } \\
\text { high frequency (0.15- } \\
0.4 \mathrm{~Hz} \text { ) } \\
\text { *LF = R-to-R interval } \\
\text { spectral power at the } \\
\text { low frequency }(0.05- \\
0.15 \mathrm{~Hz} \text { ) }\end{array}$ & $\begin{array}{l}\text { Likelihood ratio } \\
\text { (AUROC not reported) } \\
\text { HF/LF: } 9.96 \\
\text { With adjustments: } \\
\text { HF/LF, covariate age: } \\
5.19 \\
\text { HF/LF, covariate R-to-R } \\
\text { interval: } 7.06 \\
\text { HF/LF, covariate GCS: } \\
1.96 \\
\text { HF/LF, covariates age, } \\
\text { R-to-R interval, and } \\
\text { GCS: } 0.43\end{array}$ \\
\hline
\end{tabular}

AUROC = area under the receiver operating characteristic curve; $\mathrm{CI}=$ confidence interval; DFA = detrended fluctuations analysis; GCS = Glasgow Coma Scale; HF = high frequency; HR = heart rate; IQR = interquartile range; $L F=$ low frequency; LSI = life-saving intervention; $\mathrm{M}$ = mortality; $\mathrm{NR}$ = not reported; $\mathrm{pRBC}$ = packed red blood cells; $\mathrm{R}$ = resource use; R-to-R interval = time between heart beats; SampEn = sample entropy; Sen = sensitivity; Sp = specificity 
Table 14. Predictive utility of heart rate variability/complexity: emergency department

\begin{tabular}{|c|c|c|c|c|c|}
\hline Measure & $\begin{array}{l}\text { Author, Year } \\
\text { Risk of Bias }\end{array}$ & $\begin{array}{l}\text { Serious Injury } \\
\text { Indicator } \\
\text { Type: } \\
\text { Indicator }\end{array}$ & $\begin{array}{l}\text { Number } \\
\text { Analyzed } \\
\text { Age } \\
\text { Mean (SD) }\end{array}$ & $\begin{array}{l}\text { Sensitivity } \\
\text { Specificity } \\
\text { (95\% Cl) }\end{array}$ & AUROC $(95 \% \mathrm{Cl})$ \\
\hline $\begin{array}{l}\text { HRV } \\
\text { low to high } \\
\text { frequency } \\
\text { index ratio } \\
\text { (LF/HF) }\end{array}$ & $\begin{array}{l}\text { Ryan, 2011b } b^{160} \\
\text { Moderate }\end{array}$ & M: mortality & $\begin{array}{l}216 \\
50(1)\end{array}$ & NR & $0.68(\mathrm{NR})$ \\
\hline $\begin{array}{l}\text { HRV } \\
\text { spectral } \\
\text { power at } \\
\text { very low } \\
\text { frequency } \\
\text { (VLF) }\end{array}$ & $\begin{array}{l}\text { Ryan, 2011b }{ }^{160} \\
\text { Moderate }\end{array}$ & M: mortality & $\begin{array}{l}216 \\
50(1)\end{array}$ & NR & 0.67 (NR) \\
\hline
\end{tabular}

AUROC = area under the receiver operating characteristic curve; CI = confidence interval; HF = high frequency; HRV = heart rate variability; $\mathrm{LF}=$ low frequency; $\mathrm{M}$ = mortality; $\mathrm{NR}=$ not reported; $\mathrm{SD}$ = standard deviation; Sen = sensitivity; $\mathrm{Sp}=$ specificity; VLF = very low frequency

\section{Other Measures of Circulatory Compromise}

In addition to SBP, lactate, base deficit, HR, SI, and HRV and HRC, the literature on measures of circulatory compromise contains additional measures. These are categorized into those using out-of-hospital measures and those using ED measures in Tables 15 and 16 below. Within the tables similar measures are grouped between bold dividing lines. First, measures similar or related to SBP, which is addressed by a large volume of studies and reported in the first detailed results section, are listed. These are diastolic blood pressure (DBP), mean arterial pressure (MAP), and pulse pressure (PP). The second group contains variations on SI including HR/PP, PP/HR, and modified SI (HR/MAP). The last section of the tables includes miscellaneous measures such as radial pulse character, min pulse, pulse max index, capillary refill, cardiac index, and data collected through photoplethysmography (PPG).

One unique aspect of this group of measures is that two, radial pulse character ${ }^{86}$ and capillary refill, ${ }^{70}$ do not require instruments of any kind, but depend on the technique and judgment of the person doing the assessment.

Table 15. Predictive utility of other circulatory measures: out-of-hospital

\begin{tabular}{|c|c|c|c|c|c|}
\hline $\begin{array}{l}\text { Measure } \\
\text { Threshold }\end{array}$ & $\begin{array}{l}\text { Author, Year } \\
\text { Risk of Bias }\end{array}$ & $\begin{array}{l}\text { Serious } \\
\text { Injury } \\
\text { Indicator } \\
\text { Type: } \\
\text { Indicator }\end{array}$ & $\begin{array}{l}\text { Number } \\
\text { analyzed } \\
\text { Age } \\
\text { Mean } \\
\text { (SD) }\end{array}$ & $\begin{array}{l}\text { Sensitivity } \\
\text { Specificity } \\
(95 \% \mathrm{Cl})\end{array}$ & AUROC $(95 \% \mathrm{Cl})$ \\
\hline $\begin{array}{l}\text { Diastolic } \\
\text { Blood } \\
\text { Pressure }\end{array}$ & $\begin{array}{l}\text { Chen, } 2009^{54} \\
\text { Moderate }\end{array}$ & $\begin{array}{l}\text { R: blood } \\
\text { transfusion } \\
\text { with } \\
\text { hemorrhagic } \\
\text { injury }\end{array}$ & $\begin{array}{l}326 \\
38(16)\end{array}$ & NR & 0.55 (0.43 to 0.67$)$ \\
\hline $\begin{array}{l}\text { Mean } \\
\text { Arterial } \\
\text { Pressure }\end{array}$ & $\begin{array}{l}\text { Chen, } 2009^{54} \\
\text { Moderate }\end{array}$ & $\begin{array}{l}\text { R: blood } \\
\text { transfusion } \\
\text { with } \\
\text { hemorrhagic } \\
\text { injury }\end{array}$ & $\begin{array}{l}326 \\
38(16)\end{array}$ & NR & 0.60 (0.49 to 0.71$)$ \\
\hline
\end{tabular}




\begin{tabular}{|c|c|c|c|c|c|}
\hline $\begin{array}{l}\text { Measure } \\
\text { Threshold }\end{array}$ & $\begin{array}{l}\text { Author, Year } \\
\text { Risk of Bias }\end{array}$ & $\begin{array}{l}\text { Serious } \\
\text { Injury } \\
\text { Indicator } \\
\text { Type: } \\
\text { Indicator }\end{array}$ & 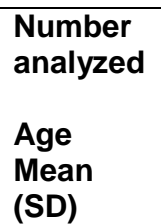 & $\begin{array}{l}\text { Sensitivity } \\
\text { Specificity } \\
(95 \% \mathrm{Cl})\end{array}$ & AUROC $(95 \% \mathrm{Cl})$ \\
\hline $\begin{array}{l}\text { Pulse } \\
\text { Pressure } \\
\text { linear } \\
\text { classifier }\end{array}$ & $\begin{array}{l}\text { Chen, } 2007^{52} \\
\text { High }\end{array}$ & $\begin{array}{l}\text { R: blood } \\
\text { transfusion } \\
\text { with } \\
\text { hemorrhagic } \\
\text { injury }\end{array}$ & $\begin{array}{l}492 \\
N R\end{array}$ & NR & 0.73 (NR) \\
\hline $\begin{array}{l}\text { Pulse } \\
\text { Pressure }\end{array}$ & $\begin{array}{l}\text { Chen, } 2008^{53} \\
\text { Moderate }\end{array}$ & $\begin{array}{l}\text { R: blood } \\
\text { transfusion } \\
\text { with } \\
\text { hemorrhagic } \\
\text { injury }\end{array}$ & $\begin{array}{l}627 \\
39(N R)\end{array}$ & NR & 0.73 (SD 0.06) \\
\hline $\begin{array}{l}\text { Pulse } \\
\text { Pressure } \\
\text { reliable data }\end{array}$ & $\begin{array}{l}\text { Chen, } 2009^{54} \\
\text { Moderate }\end{array}$ & $\begin{array}{l}\text { R: blood } \\
\text { transfusion } \\
\text { with } \\
\text { hemorrhagic } \\
\text { injury }\end{array}$ & $\begin{array}{l}326 \\
38(16)\end{array}$ & NR & 0.78 (0.69 to 0.86$)$ \\
\hline $\begin{array}{l}\text { Pulse } \\
\text { Pressure }\end{array}$ & $\begin{array}{l}\text { Edla, 2015b }{ }^{59} \\
\text { Moderate }\end{array}$ & $\begin{array}{l}\text { R: blood } \\
\text { transfusion } \\
\geq 1 \text { pRBC } \\
\text { unit in } 24 \\
\text { hours }\end{array}$ & $\begin{array}{l}402 \\
39(16)\end{array}$ & NR & 0.74 (0.65 to 0.81$)$ \\
\hline $\begin{array}{l}\text { Pulse } \\
\text { Pressure }\end{array}$ & $\begin{array}{l}\text { Edla, } 2015 b^{59} \\
\text { Moderate }\end{array}$ & $\begin{array}{l}\text { R: blood } \\
\text { transfusion } \\
\geq 9 \text { pRBC } \\
\text { unit in } 24 \\
\text { hours }\end{array}$ & $\begin{array}{l}402 \\
39(16)\end{array}$ & NR & 0.79 (0.61 to 0.90$)$ \\
\hline $\begin{array}{l}\text { HR/PP } \\
\text { Ratio }\end{array}$ & $\begin{array}{l}\text { Chen, } 2008^{53} \\
\text { Moderate }\end{array}$ & $\begin{array}{l}\text { R: } \\
\text { hemorrhage }\end{array}$ & $\begin{array}{l}627 \\
39(N R)\end{array}$ & NR & 0.75 (SD 0.10) \\
\hline $\begin{array}{l}\text { PP/HR } \\
\text { Ratio } \\
<0.443\end{array}$ & $\begin{array}{l}\text { Pottecher, } 2016^{93} \\
\text { Moderate }\end{array}$ & $\begin{array}{l}\text { R: massive } \\
\text { transfusion } \\
(\geq 10 \mathrm{pRBC} \\
\text { units in } 24 \\
\text { hours) }\end{array}$ & $\begin{array}{l}2,557 \\
37(19)\end{array}$ & $\begin{array}{l}\text { Sen: } 75 \%(N R) \\
\text { Sp: } 74 \%(N R)\end{array}$ & 0.767 (0.70 to 0.84$)$ \\
\hline $\begin{array}{l}\text { PP/HR ratio } \\
<0.443\end{array}$ & $\begin{array}{l}\text { Pottecher, } 2016^{93} \\
\text { Moderate }\end{array}$ & $\begin{array}{l}\text { R: massive } \\
\text { transfusion } \\
(\geq 3 \mathrm{pRBC} \\
\text { units in } 1 \\
\text { hour) }\end{array}$ & $\begin{array}{l}2,557 \\
37(19)\end{array}$ & $\begin{array}{l}\text { Sen: } 75 \%(N R) \\
\text { Sp: } 62 \%(N R)\end{array}$ & 0.713 (0.67 to 0.76$)$ \\
\hline $\begin{array}{l}\text { Radial } \\
\text { Pulse } \\
\text { Character } \\
\text { Weak }\end{array}$ & $\begin{array}{l}\text { McManus, } 2005^{86} \\
\text { High }\end{array}$ & $\begin{array}{l}\mathrm{R}: \mathrm{ICU} \\
\text { admission }\end{array}$ & $\begin{array}{l}314+ \\
32(N R)\end{array}$ & $\begin{array}{l}\text { *Sen: } 14.0 \%(8.2 \text { to } 21.8) \\
\text { *Sp: } 97.0 \%(93.6 \text { to } 98.9)\end{array}$ & NR \\
\hline $\begin{array}{l}\text { Radial } \\
\text { Pulse } \\
\text { Character } \\
\text { Weak }\end{array}$ & $\begin{array}{l}\text { McManus, } 2005^{86} \\
\text { High }\end{array}$ & R: intubation & $\begin{array}{l}341+ \\
32(N R)\end{array}$ & $\begin{array}{l}\text { *Sen: } 26.7 \%(16.1 \text { to } 39.7) \\
\text { *Sp: } 95.4 \%(92.2 \text { to } 97.5)\end{array}$ & NR \\
\hline $\begin{array}{l}\text { Radial } \\
\text { Pulse } \\
\text { Character } \\
\text { Weak }\end{array}$ & $\begin{array}{l}\text { McManus, } 2005^{86} \\
\text { High }\end{array}$ & M: mortality & $\begin{array}{l}340+ \\
32(N R)\end{array}$ & $\begin{array}{l}\text { *Sen: } 50.0 \%(24.7 \text { to } 75.4) \\
* \text { Sp: } 93.8 \%(90.6 \text { to } 96.2)\end{array}$ & NR \\
\hline $\begin{array}{l}\text { Capillary } \\
\text { Refill } \\
\text { Delayed }\end{array}$ & $\begin{array}{l}\text { Holcomb, } \\
2005 b^{70} \\
\text { Moderate }\end{array}$ & R: LSI & $\begin{array}{l}216 \\
33(17)\end{array}$ & $\begin{array}{l}\text { *Sen: } 22.1 \%(13.4 \text { to } 33.0) \\
\text { *Sp: } 98.4 \%(94.3 \text { to } 99.8)\end{array}$ & NR \\
\hline
\end{tabular}




\begin{tabular}{|c|c|c|c|c|c|}
\hline $\begin{array}{l}\text { Measure } \\
\text { Threshold }\end{array}$ & $\begin{array}{l}\text { Author, Year } \\
\text { Risk of Bias }\end{array}$ & $\begin{array}{l}\text { Serious } \\
\text { Injury } \\
\text { Indicator } \\
\text { Type: } \\
\text { Indicator }\end{array}$ & 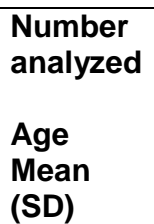 & $\begin{array}{l}\text { Sensitivity } \\
\text { Specificity } \\
(95 \% \mathrm{Cl})\end{array}$ & AUROC (95\% Cl) \\
\hline $\begin{array}{l}\text { PPG metric } \\
\text { amplitude } \\
\text { IQR }\end{array}$ & $\begin{array}{l}\text { Chen, } 2010^{55} \\
\text { Moderate }\end{array}$ & $\begin{array}{l}\text { R: blood } \\
\text { transfusion } \\
\text { with } \\
\text { hemorrhagic } \\
\text { injury }\end{array}$ & $\begin{array}{l}344 \\
37(15)\end{array}$ & NR & 0.64 (0.51 to 0.75$)$ \\
\hline $\begin{array}{l}\text { PPG metric } \\
\text { amplitude } \\
\text { maximum- } \\
\text { minimum }\end{array}$ & $\begin{array}{l}\text { Chen, } 2010^{55} \\
\text { Moderate }\end{array}$ & $\begin{array}{l}\text { R: blood } \\
\text { transfusion } \\
\text { with } \\
\text { hemorrhagic } \\
\text { injury }\end{array}$ & $\begin{array}{l}344 \\
37(15)\end{array}$ & NR & 0.57 (0.45 to 0.68$)$ \\
\hline $\begin{array}{l}\text { PPG metric } \\
\text { peak height } \\
\text { maximum- } \\
\text { minimum }\end{array}$ & $\begin{array}{l}\text { Chen, } 2010^{55} \\
\text { Moderate }\end{array}$ & $\begin{array}{l}\text { R: blood } \\
\text { transfusion } \\
\text { with } \\
\text { hemorrhagic } \\
\text { injury }\end{array}$ & $\begin{array}{l}344 \\
37(15)\end{array}$ & NR & 0.60 (0.48 to 0.71$)$ \\
\hline $\begin{array}{l}\text { PPG metric } \\
\text { peak height } \\
\text { IQR }\end{array}$ & $\begin{array}{l}\text { Chen, } 2010^{55} \\
\text { Moderate }\end{array}$ & $\begin{array}{l}\text { R: blood } \\
\text { transfusion } \\
\text { with } \\
\text { hemorrhagic } \\
\text { injury }\end{array}$ & $\begin{array}{l}344 \\
37(15)\end{array}$ & $\begin{array}{l}\text { Sen: } 54 \% \text { (NR) } \\
\text { Sp: 73\% (NR) }\end{array}$ & 0.65 (0.54 to 0.76$)$ \\
\hline
\end{tabular}

AUROC = area under the receiver operating characteristic curve; $\mathrm{C}=$ composite; $\mathrm{CI}=$ confidence interval; $\mathrm{DBP}=$ diastolic blood pressure; HR = heart rate; ICU = intensive care unit; IQR = interquartile range; ISS = injury severity score; LSI = life-saving intervention; $\mathrm{M}=$ mortality; $\mathrm{MAP}=$ mean arterial pressure; $\mathrm{NR}=$ not reported; $\mathrm{PP}=$ pulse pressure $(\mathrm{SBP}-\mathrm{DBP})$; $\mathrm{PPG}=$ photoplethysmogram; pRBC = packed red blood cell; $\mathrm{R}=$ resource use; $\mathrm{SD}=$ standard deviation; Sen = sensitivity; $\mathrm{Sp}=$ specificity

Note: Similar measures are grouped between bold dividing lines.

*Results calculated by reviewers. + n varies by serious injury indicator in this study

Table 16. Predictive utility of other circulatory measures: emergency department

\begin{tabular}{|c|c|c|c|c|c|}
\hline Measure & $\begin{array}{l}\text { Author, Year } \\
\text { Risk of Bias }\end{array}$ & $\begin{array}{l}\text { Serious Injury } \\
\text { Indicator } \\
\text { Type: Indicator }\end{array}$ & $\begin{array}{l}\text { Number } \\
\text { Analyzed } \\
\text { Age } \\
\text { Mean } \\
\text { (SD) }\end{array}$ & $\begin{array}{l}\text { Sensitivity } \\
\text { Specificity } \\
(95 \% \mathrm{Cl})\end{array}$ & AUROC (95\% Cl) \\
\hline $\begin{array}{l}\text { Diastolic Blood } \\
\text { Pressure }\end{array}$ & $\begin{array}{l}\text { Beekley, } 2010^{115} \\
\text { Moderate }\end{array}$ & R: LSI & $\begin{array}{l}147 \\
27(11) \\
\end{array}$ & NR & $0.59(0.51$ to 0.67$)$ \\
\hline $\begin{array}{l}\text { Diastolic Blood } \\
\text { Pressure }\end{array}$ & $\begin{array}{l}\text { Beekley, } 2010^{115} \\
\text { Moderate }\end{array}$ & $\begin{array}{l}\text { R: massive } \\
\text { transfusion }\end{array}$ & $\begin{array}{l}147 \\
27(11)\end{array}$ & NR & $0.70(0.54$ to 0.86$)$ \\
\hline $\begin{array}{l}\text { Diastolic Blood } \\
\text { Pressure }\end{array}$ & $\begin{array}{l}\text { Paladino, 2010a } 149 \\
\text { Moderate }\end{array}$ & $\begin{array}{l}\text { C: major injury } \\
\text { (blood } \\
\text { transfusion, } \\
\text { hemorrhage or } \\
\text { ISS } \geq 16 \text { ) }\end{array}$ & $\begin{array}{l}805 \\
39 \text { (range } \\
13 \text { to } 95 \text { ) }\end{array}$ & NR & 0.49 (NR) \\
\hline
\end{tabular}




\begin{tabular}{|c|c|c|c|c|c|}
\hline Measure & $\begin{array}{l}\text { Author, Year } \\
\text { Risk of Bias }\end{array}$ & $\begin{array}{l}\text { Serious Injury } \\
\text { Indicator } \\
\text { Type: Indicator }\end{array}$ & $\begin{array}{l}\text { Number } \\
\text { Analyzed } \\
\text { Age } \\
\text { Mean } \\
\text { (SD) }\end{array}$ & $\begin{array}{l}\text { Sensitivity } \\
\text { Specificity } \\
(95 \% \mathrm{Cl})\end{array}$ & AUROC $(95 \% \mathrm{Cl})$ \\
\hline $\begin{array}{l}\text { Mean Arterial } \\
\text { Pressure (MAP) }\end{array}$ & $\begin{array}{l}\text { Shoemaker, } 2005^{162} \\
\text { Low }\end{array}$ & M: mortality & $\begin{array}{l}185 \\
32(15) \\
\text { for } \\
\text { survivors } \\
39(21) \\
\text { for non- } \\
\text { survivors }\end{array}$ & NR & $0.73(\mathrm{NR})$ \\
\hline $\begin{array}{l}\text { Pulse Pressure } \\
\text { (PP) }\end{array}$ & $\begin{array}{l}\text { Reisner, 2016 } \\
\text { Moderate }\end{array}$ & $\begin{array}{l}\text { R: hemorrhagic } \\
\text { injury requiring } \\
\text { blood } \\
\text { transfusion of } \geq 3 \\
\text { units pRBCs } \\
\end{array}$ & $\begin{array}{l}487 \\
\text { Median } \\
47 \text { (IQR } \\
31-64) \\
\end{array}$ & NR & 0.68 (0.54 to 0.80$)$ \\
\hline $\begin{array}{l}\text { Modified Shock } \\
\text { Index } \\
\geq 0.9 \\
\geq 1.1 \\
\geq 1.3\end{array}$ & $\begin{array}{l}\text { Kim, 2016 } \\
\text { High }\end{array}$ & $\begin{array}{l}\text { M: in-hospital } \\
\text { mortality }\end{array}$ & $\begin{array}{l}45,880 \\
\text { Median } \\
72 \text { (IQR } \\
68-78)\end{array}$ & $\begin{array}{l}\text { Sen: } 75.8 \% \\
\text { (NR) } \\
\text { Sp: } 65.4 \% \\
\text { (NR) } \\
\text { Sen: } 55.9 \% \\
\text { (NR) } \\
\text { Sp: } 90.9 \% \\
\text { (NR) } \\
\text { *Sen: } 38.7 \% \\
\text { (34.5 to } 42.9) \\
\text { *Sp: } 97.8 \% \\
\text { (97.6 to } 97.9)\end{array}$ & $\begin{array}{l}0.788 \text { ( } 0.765 \text { to } 0.812) \\
\text { continuous model } \\
0.682(0.661 \text { to } 0.703) \\
\text { binary model at } \geq 1.3\end{array}$ \\
\hline $\begin{array}{l}\text { Modified Shock } \\
\text { Index } \\
\text { continuous } \\
\text { model } \\
\geq 1.3 \text { binary } \\
\text { model }\end{array}$ & $\begin{array}{l}\text { Kim, 2016 } \\
\text { High }\end{array}$ & R: ED mortality & $\begin{array}{l}45,880 \\
\text { Median } \\
72 \text { (IQR } \\
68-78)\end{array}$ & NR & $\begin{array}{l}0.884(0.853 \text { to } 0.915) \\
\text { continuous model } \\
0.779(0.744 \text { to } 0.814) \\
\text { binary model }\end{array}$ \\
\hline $\begin{array}{l}\text { Radial Pulse } \\
\text { Character }\end{array}$ & $\begin{array}{l}\text { Beekley, } 2010^{115} \\
\text { Moderate }\end{array}$ & R: LSI & $\begin{array}{l}147 \\
27(11)\end{array}$ & NR & 0.58 (0.50 to 0.66$)$ \\
\hline $\begin{array}{l}\text { Radial Pulse } \\
\text { Character }\end{array}$ & $\begin{array}{l}\text { Beekley, } 2010^{115} \\
\text { Moderate }\end{array}$ & $\begin{array}{l}\text { R: massive } \\
\text { transfusion }\end{array}$ & $\begin{array}{l}147 \\
27(11) \\
\end{array}$ & NR & 0.72 (0.57 to 0.87$)$ \\
\hline $\begin{array}{l}\text { Minpulse } \\
\leq 44 \\
\leq 54\end{array}$ & $\begin{array}{l}\text { Bruijns, } 2013^{116} \\
\text { Moderate }\end{array}$ & $\begin{array}{l}\text { M: 48-hour } \\
\text { mortality }\end{array}$ & $\begin{array}{l}69,367 \\
\text { Median } \\
49(\text { IQR } \\
32-67)\end{array}$ & $\begin{array}{l}\text { Sen: } 30.9 \% \\
(25.5 \text { to } 36.9) \\
\text { Sp: } 94.9 \% \\
(94.8 \text { to } 95.1) \\
\text { Sen: } 43.0 \% \\
(37.0 \text { to } 49.2) \\
\text { Sp: } 90.0 \% \\
(89.8 \text { to } 90.2)\end{array}$ & 0.77 (0.74 to 0.80$)$ \\
\hline
\end{tabular}




\begin{tabular}{|c|c|c|c|c|c|}
\hline Measure & $\begin{array}{l}\text { Author, Year } \\
\text { Risk of Bias }\end{array}$ & $\begin{array}{l}\text { Serious Injury } \\
\text { Indicator } \\
\text { Type: Indicator }\end{array}$ & $\begin{array}{l}\text { Number } \\
\text { Analyzed } \\
\text { Age } \\
\text { Mean } \\
\text { (SD) }\end{array}$ & $\begin{array}{l}\text { Sensitivity } \\
\text { Specificity } \\
(95 \% \mathrm{Cl})\end{array}$ & AUROC $(95 \% \mathrm{Cl})$ \\
\hline $\begin{array}{l}\text { Pulse Max } \\
\text { Index } \\
\geq 60 \\
\geq 70\end{array}$ & $\begin{array}{l}\text { Bruijns, } 2013^{116} \\
\text { Moderate }\end{array}$ & $\begin{array}{l}\text { M: 48-hour } \\
\text { mortality }\end{array}$ & $\begin{array}{l}69,367 \\
\text { Median } \\
49(\mathrm{IQR} \\
32-67)\end{array}$ & $\begin{array}{l}\text { Sen: } 46.0 \% \\
(40.0 \text { to } 52.2) \\
\text { Sp: } 90.0 \% \\
(89.7 \text { to } 90.2) \\
\\
\text { Sen: } 34.0 \% \\
(28.3-40.1) \\
\text { Sp: } 95.0 \% \\
(94.8-95.1)\end{array}$ & $0.77(0.73$ to 0.80$)$ \\
\hline $\begin{array}{l}\text { Capillary Refill } \\
>2 \text { seconds }\end{array}$ & $\begin{array}{l}\text { Garner, 200161 } \\
\text { Moderate }\end{array}$ & R: LSI & $\begin{array}{l}1,144 \\
\text { Median } \\
33 \text { (IQR } \\
21-53)\end{array}$ & $\begin{array}{l}\text { Sen: } 36.3 \% \\
\text { (NR) } \\
\text { Sp: } 93.2 \% \\
\text { (NR) }\end{array}$ & NR \\
\hline $\begin{array}{l}\text { Cardiac Index } \\
\text { initial value } \\
\text { data over first } 4 \\
\text { hours }\end{array}$ & $\begin{array}{l}\text { Shoemaker, } 2005^{162} \\
\text { Low }\end{array}$ & M: mortality & $\begin{array}{l}185 \\
32(15) \\
\text { for } \\
\text { survivors } \\
39(21) \\
\text { for non- } \\
\text { survivors }\end{array}$ & NR & $\begin{array}{l}0.61(\mathrm{NR}) \\
0.68(\mathrm{NR})\end{array}$ \\
\hline $\begin{array}{l}\text { PPG Algorithm } \\
\text { used } 30 \text { PPG } \\
\text { features }\end{array}$ & $\begin{array}{l}\text { Mackenzie, } 2015^{84} \\
\text { Moderate }\end{array}$ & $\begin{array}{l}\text { R: blood } \\
\text { transfusion } \\
\text { within } 6 \text { hours }\end{array}$ & $\begin{array}{l}135 \\
39(17)\end{array}$ & $\begin{array}{l}\text { Sen: } 100 \% \\
\text { (NR) } \\
\text { Sp: } 70 \% \\
\text { (NR) }\end{array}$ & $0.92(\mathrm{NR})$ \\
\hline $\begin{array}{l}\text { PPG Algorithm } \\
\text { used } 30 \text { PPG } \\
\text { features }\end{array}$ & $\begin{array}{l}\text { Mackenzie, } 2015^{84} \\
\text { Moderate }\end{array}$ & $\begin{array}{l}\text { R: endotracheal } \\
\text { intubation within } \\
1 \text { hour }\end{array}$ & $\begin{array}{l}135 \\
39(17)\end{array}$ & NR & $0.92(\mathrm{NR})$ \\
\hline $\begin{array}{l}\text { PPG Algorithm } \\
\text { used } 30 \text { PPG } \\
\text { features }\end{array}$ & $\begin{array}{l}\text { Mackenzie, } 2015^{84} \\
\text { Moderate }\end{array}$ & $\begin{array}{l}\text { R: surgical } \\
\text { intervention }\end{array}$ & $\begin{array}{l}135 \\
39(17)\end{array}$ & NR & 0.74 (NR) \\
\hline
\end{tabular}

AUROC = area under the receiver operating characteristic curve; $\mathrm{CI}=$ confidence interval; $\mathrm{DBP}=$ diastolic blood pressure; $\mathrm{HR}=$ heart rate; ICU = intensive care unit; IQR = interquartile range; LSI = life-saving intervention; $\mathrm{M}=$ mortality; $\mathrm{MAP}=$ mean arterial pressure; NR = not reported; PP = pulse pressure (SBP-DBP); PPG = photoplethysmogram; pRBC = packed red blood cell; R = resource use; SD = standard deviation; Sen = sensitivity; $\mathrm{SI}$ = shock index; $\mathrm{Sp}$ = specificity

Note: Similar measures are grouped between bold dividing lines.

*Results calculated by reviewers

\section{Key Question 2: Measures of Respiratory Compromise}

To summarize evidence to address Key Question 2, we included the results from 38 studies reported in 40 articles (Table 17). These studies evaluated six different measures of respiratory compromise. These measures are listed in Table 17 along with the corresponding citations and the detailed results are provided for each measure.

The focus of this section is RR. We identified enough studies with similar data that we were able to produce pooled estimates. The forest plots for the out-of-hospital RR data are provided in the next section in Figures 20, 21, and 22. Forest plots based on ED data are included in Appendix I. Tables are provided for oxygen saturation, which is measured in different ways; the 
need for ventilatory support, which includes intubation, as well as studies that considered any form of airway support. We report studies of arterial blood $\mathrm{pH}$, end tidal carbon dioxide, sublingual carbon dioxide, and respiratory effort in the last section.

Table 17. Measures of respiratory compromise (Key Question 2) evaluated by included studies

\begin{tabular}{|l|c|l|}
\hline Measure Evaluated & $\begin{array}{l}\text { Number of } \\
\text { Studies } \\
\text { (articles) }^{\dagger}\end{array}$ & References \\
\hline Respiratory rate & 20 (21 articles) & $\begin{array}{l}48,54,59,61,62,70,77,80- \\
83,88,89,91,94,110,116,124,133,140,171\end{array}$ \\
\hline Oxygen saturation* & 8 & $64,67,94,103,107,115,135,159$ \\
\hline Airway support & 7 (8 articles) & $56,57,67,89,95,96,133,160$ \\
\hline Arterial blood pH & 4 & $112,115,156,157$ \\
\hline End-tidal $\mathrm{CO}_{2}$ & 2 & 119,168 \\
\hline Sublingual $\mathrm{CO}_{2}$ & 2 & 113,114 \\
\hline
\end{tabular}

CO2 = carbon dioxide

*Studies noted oxygen saturation with various abbreviations: SmO2, SpO2, StO2

†Five publications evaluated multiple measures67,89,94,115,133

\section{Respiratory Rate}

RR, like SBP, is part of the National Trauma Triage Protocol Step 1 criteria. In the current Field Triage Decision Scheme, ${ }^{183} \mathrm{RR}<10$ or $>29$ breaths per minute is used as an indicator of the potential for serious injury and the need for higher-level trauma care. Breathing that is too slow or too fast may in and of itself be a change in function caused by serious trauma or an indication that the body is trying to compensate for underlying injuries.

We identified 20 studies that reported RR data (see Table 17). Six studies ${ }^{48,62,70,80-82,140}$ were not included in the pooled analyses presented below, but the data were abstracted and are included in the evidence tables in Appendix D. These studies were not included in the pooled estimates because they used lower thresholds of $R R \geq 24^{70}$ or $R R \geq 20,{ }^{80-82}$ used age-specific rates defined as abnormal, ${ }^{140}$ reported change in rate ${ }^{48}$ and did not provide raw data, or used a different indicator of serious injury, in this case, organ failure. ${ }^{62}$ We repeated the meta-analyses including the studies with lower thresholds and organ failure and confirmed that the estimates were not affected enough to change our conclusions. We combined data on out-of-hospital RR from six studies and calculated a pooled sensitivity of 13 percent (95\% CI 5 to $29, \mathrm{I}^{2}=97.8 \%$ ) and a pooled specificity of 96 percent (95\% CI 83 to $99, \mathrm{I}^{2}=99.6 \%$ ) across all serious injury indicators. ${ }^{77,83,88,89,91,171}$ Figures 20 and 21 provide the estimates stratified by type of serious injury indicator (resource use, injury type or severity, and composite indicators). Table 18 reports these values as well as the estimates from four studies using ED data. Plots for the ED analyses are included in Appendix I.

The pooled AUROC for out-of-hospital RR was 0.70 (95\% CI 0.66 to $0.79, \mathrm{I}^{2}=16.6 \%$ ) based on three studies ${ }^{54,59,94}$ (Figure 22) and 0.61 (95\% CI 0.48 to $0.74, \mathrm{I}^{2}=90.5 \%$ ) for ED RR based on three different studies ${ }^{61,110,116}$ (Appendix I). 
Table 18. Pooled sensitivity and specificity for predictive utility of respiratory rate across all serious injury indicators

\begin{tabular}{|c|c|c|c|}
\hline Measure, Setting & $\begin{array}{l}\text { Number of } \\
\text { Studies }\end{array}$ & Sensitivity $\left(95 \% \mathrm{Cl}, \mathrm{I}^{2}\right)$ & Specificity $\left(95 \% \mathrm{Cl}, \mathrm{I}^{2}\right)$ \\
\hline $\begin{array}{l}\mathrm{RR}<10 \text { or }>29 \text { breaths } \\
\text { per minute } \\
\mathrm{OH}\end{array}$ & $6^{77,83,88,89,91,171}$ & $13 \%$ (5 to $29,97.8 \%$ ) & $96 \%$ (83 to $99,99.6 \%$ ) \\
\hline $\begin{array}{l}\mathrm{RR}<10 \text { or }>29 \text { breaths } \\
\text { per minute } \\
\text { ED }\end{array}$ & $4^{61,116,124,133}$ & $27 \%$ (21 to $35,95.2 \%$ ) & $95 \%$ (94 to $96,93.5 \%$ ) \\
\hline
\end{tabular}

$\mathrm{CI}$ = confidence interval; ED = emergency department; $\mathrm{OH}$ = out-of-hospital; RR = respiratory rate

Figure 20. Pooled sensitivity of out-of-hospital respiratory rate $<10$ or $>29$ breaths per

Author, Year Test $\quad$ Outcome Category $\quad$ N, Sensitivity Sensitivity $(95 \% \mathrm{Cl})$

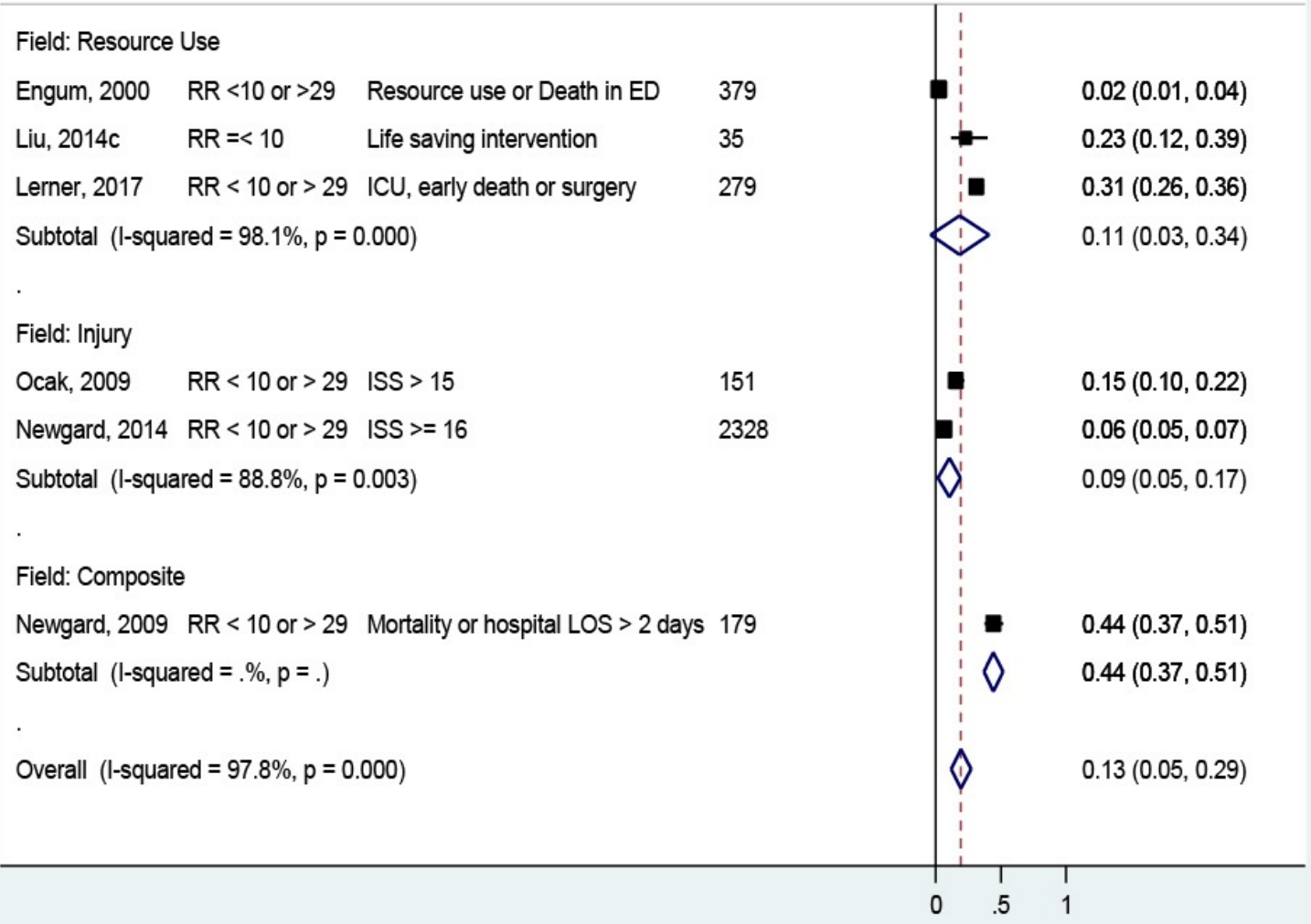

$\mathrm{CI}$ = confidence interval; ED = emergency department; ICU = intensive care unit; ISS = injury severity score; LOS = length of stay; $\mathrm{N}$ = number; $\mathrm{OH}$ = out-of-hospital; $\mathrm{RR}$ = respiratory rate.

Note: Liu, 2014c = Reference no. 83 in this report.

Note: Overall results are from the bivariate logistic mixed effects model analysis. 
Figure 21. Pooled specificity of out-of-hospital respiratory rate $<10$ or $>29$ breaths per minute

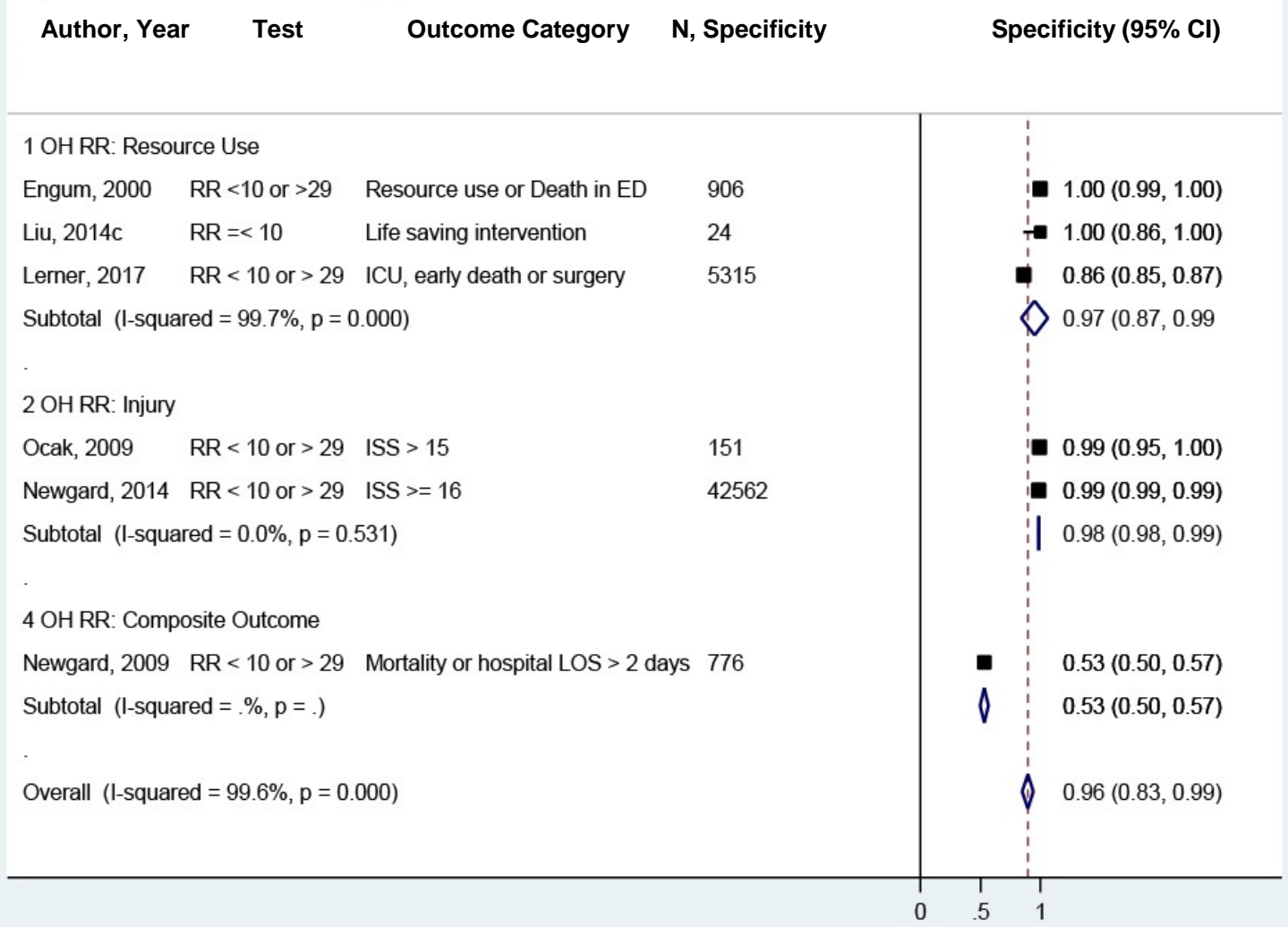

$\mathrm{CI}=$ confidence interval; ED = emergency department; ICU = intensive care unit; ISS = injury severity score; LOS = length of stay; $\mathrm{N}$ = number; $\mathrm{OH}$ = out-of-hospital; $\mathrm{RR}$ = respiratory rate.

Note: Liu, 2014c = Reference no. 83 in this report.

Note: Overall results are from the bivariate logistic mixed effects model analysis. 
Figure 22. Pooled AUROC of out-of-hospital respiratory rate

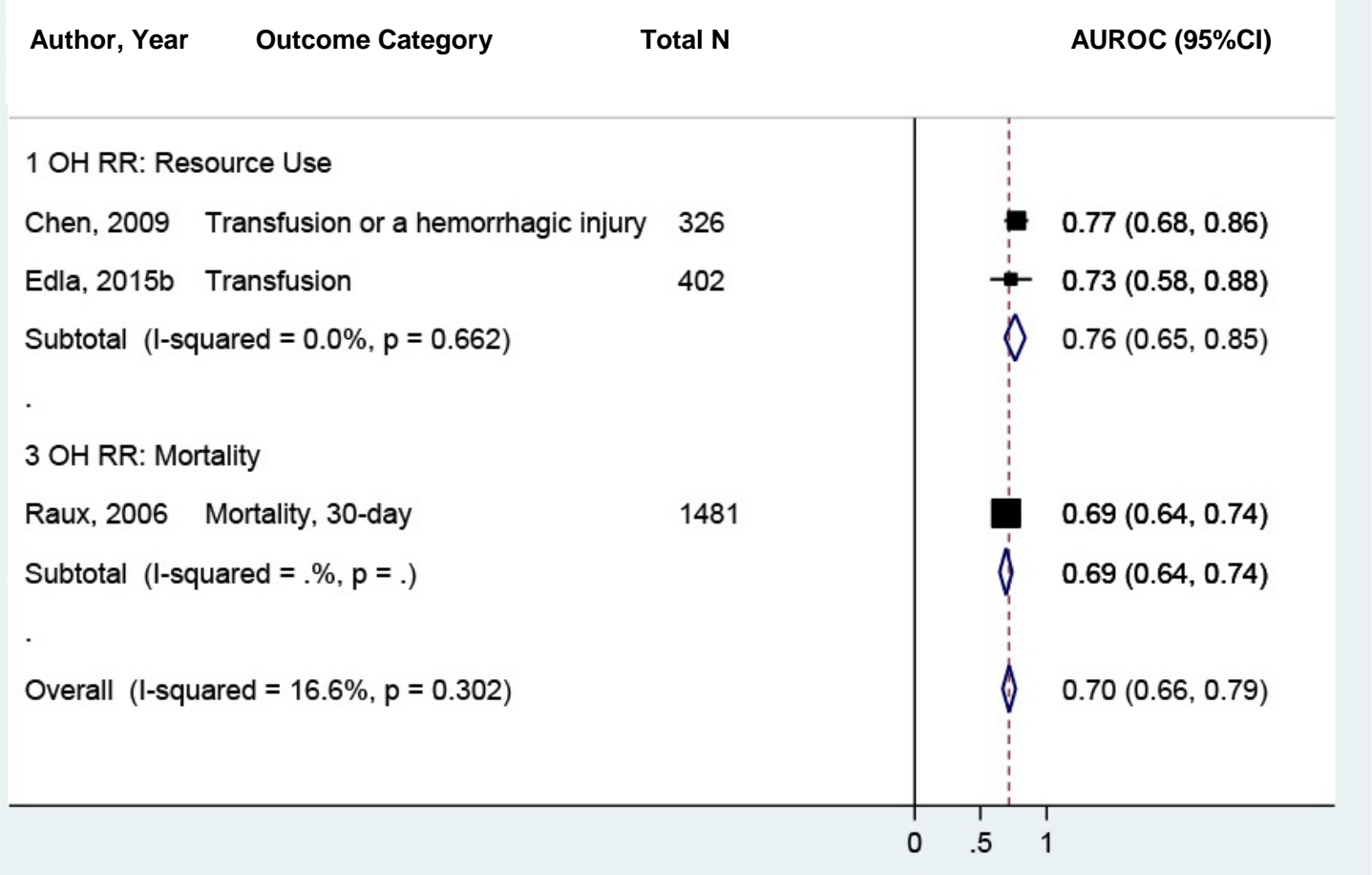

AUROC = area under the receiver operating characteristic curve; $\mathrm{CI}=$ confidence interval; $\mathrm{N}=$ number; $\mathrm{OH}=$ out-of-hospital; $\mathrm{RR}=$ respiratory rate.

Note: Overall results are from the bivariate logistic mixed effects model analysis.

\section{Oxygen Saturation}

Various types of monitoring devices are now available to assess measures of arterial oxygen $\left(\mathrm{SaO}_{2}\right.$ and $\left.\mathrm{SpO}_{2}\right)$ and measures of tissue oxygenation $\left(\mathrm{StO}_{2}\right.$ and $\left.\mathrm{SmO}_{2}\right)$. These present an opportunity to add a direct measure to field triage and replace or supplement RR, which can be unreliable as it requires counting and calculation by the field provider and there is no standardized method, hence the result is prone to error. Measures of arterial oxygen have been standardized and estimates are often consistent. ${ }^{94}$ As measuring oxygen saturation requires technology, most of the studies assessed the measure, the technology, and the utility of continuous versus point-in-time measurement.

Table 19 reports the results of five studies of $\mathrm{SaO}_{2}, \mathrm{SpO}_{2}$, or $\mathrm{StO}_{2}$ collected in the field. ${ }^{64,67,94,103,107}$ In all of these studies patients were either transported via helicopter or specialty ground transport and the monitors used were more complex than current standard EMS equipment.

Three of the studies were smaller, reflecting the fact that they employed technologies or monitors that are not widely used. ${ }^{64,103,107}$ Another study consisted of two cohorts of patients treated using physician-staffed mobile intensive care units in the suburbs of Paris, France. ${ }^{67}$ Finally, the largest study in this group was a subanalysis of a larger epidemiologic study of prehospital variables. $^{94}$ 
The three studies conducted in EDs (Table 20) used measures of tissue oxygenation $\left(\mathrm{StO}_{2}\right.$ and $\mathrm{SmO}_{2}$ ), which are intended to reflect tissue perfusion (how well tissues are getting oxygen versus how much is in the blood). One study used these measures in a U.S. military field hospital ${ }^{115}$ and examined the utility of different threshold values as well as mean and minimum values. All three studies focused on the ability to predict hemorrhage and the need for transfusions.

Table 19. Predictive utility of oxygen saturation: out-of-hospital

\begin{tabular}{|c|c|c|c|c|c|}
\hline $\begin{array}{l}\text { Measure } \\
\text { Threshold }\end{array}$ & $\begin{array}{l}\text { Author, Year } \\
\text { Risk of Bias }\end{array}$ & $\begin{array}{l}\text { Serious } \\
\text { Injury } \\
\text { Indicator } \\
\text { Type: } \\
\text { Specific } \\
\text { Indicator }\end{array}$ & $\begin{array}{l}\text { Number } \\
\text { Analyzed } \\
\text { Age } \\
\text { Mean (SD) }\end{array}$ & $\begin{array}{l}\text { Sensitivity } \\
\text { Specificity } \\
(95 \% \mathrm{Cl})\end{array}$ & AUROC (95\% Cl) \\
\hline $\begin{array}{l}\text { Oxygen } \\
\text { Saturation } \\
\mathrm{SpO}_{2}<95 \%\end{array}$ & $\begin{array}{l}\text { Van Haren, } \\
2014^{103} \\
\text { Moderate }\end{array}$ & R: LSI & $\begin{array}{l}96 \\
48(19)\end{array}$ & $\begin{array}{l}\text { Sen: } 13 \%(N R) \\
\text { Sp: } 94 \%(N R)\end{array}$ & 0.530 (NR) \\
\hline $\begin{array}{l}\text { Oxygen } \\
\text { Saturation } \\
\mathrm{StO}_{2} \\
\text { deoxygenation } \\
\text { slope }\end{array}$ & $\begin{array}{l}\text { Guyette, } 2012^{64} \\
\text { Moderate }\end{array}$ & R: LSI & $\begin{array}{l}150 \\
47(20)\end{array}$ & NR & 0.712 (NR) \\
\hline $\begin{array}{l}\text { Oxygen } \\
\text { Saturation } \\
\mathrm{SpO}_{2}<90 \%\end{array}$ & $\begin{array}{l}\text { Hamada, } 2014^{67} \\
\text { Moderate }\end{array}$ & $\begin{array}{l}\text { I: major } \\
\text { trauma }\end{array}$ & $\begin{array}{l}825 \\
37(17)\end{array}$ & $\begin{array}{l}\text { Sen: } 16 \% \text { (NR) } \\
\text { Sp: } 94 \% \text { (NR) }\end{array}$ & NR \\
\hline $\begin{array}{l}\text { Oxygen } \\
\text { Saturation } \\
\mathrm{SpO}_{2}\end{array}$ & $\begin{array}{l}\text { Raux, 2006 } \\
\text { Moderate }\end{array}$ & $\begin{array}{l}\text { M: mortality } \\
\text { 30-day }\end{array}$ & $\begin{array}{l}1481 \\
37(18)\end{array}$ & NR & 0.747 (SE 0.022) \\
\hline $\begin{array}{l}\text { Oxygen } \\
\text { Saturation } \\
\text { Mean } \mathrm{SpO}_{2}, \\
\text { continuous }\end{array}$ & $\begin{array}{l}\text { Woodford, } \\
2012^{107} \\
\text { Moderate }\end{array}$ & M: mortality & $\begin{array}{l}120 \\
42(\mathrm{NR})\end{array}$ & $\begin{array}{l}\text { Sen: 63\% (NR) } \\
\text { Sp: } 85 \%(N R)\end{array}$ & 0.76 (0.56 to 0.96$)$ \\
\hline $\begin{array}{l}\text { Oxygen } \\
\text { Saturation } \\
\mathrm{SpO}_{2}<90 \%, \\
\text { manual }\end{array}$ & $\begin{array}{l}\text { Woodford, } \\
2012^{107} \\
\text { Moderate }\end{array}$ & M: mortality & $\begin{array}{l}120 \\
42(N R)\end{array}$ & $\begin{array}{l}\text { Sen: 38\% (NR) } \\
\text { Sp: } \quad 99 \%(N R)\end{array}$ & 0.68 (0.47 to 0.89$)$ \\
\hline $\begin{array}{l}\text { Oxygen } \\
\text { Saturation } \\
\text { Mean } \mathrm{SpO}_{2} \\
<90 \%, \\
\text { continuous }\end{array}$ & $\begin{array}{l}\text { Woodford, } \\
2012^{107} \\
\text { Moderate }\end{array}$ & M: mortality & $\begin{array}{l}120 \\
42 \text { (NR) }\end{array}$ & $\begin{array}{l}\text { Sen: } 50 \%(\mathrm{NR}) \\
\text { Sp: } 96 \%(\mathrm{NR})\end{array}$ & $0.73(0.53$ to 0.94$)$ \\
\hline $\begin{array}{l}\text { Oxygen } \\
\text { Saturation } \\
\mathrm{SpO}_{2} \text { readings } \\
<90 \% \text { only, } \\
\text { manual }\end{array}$ & $\begin{array}{l}\text { Woodford, } \\
2012^{107} \\
\text { Moderate }\end{array}$ & M: mortality & $\begin{array}{l}120 \\
42 \text { (NR) }\end{array}$ & $\begin{array}{l}\text { Sen: 38\% (NR) } \\
\text { Sp: } 99 \%(N R)\end{array}$ & $0.59(0.38$ to 0.81$)$ \\
\hline
\end{tabular}

AUROC = area under the receiver operating characteristic curve; CI = confidence interval; I = injury; LSI = life-saving intervention; $\mathrm{M}$ = mortality; $\mathrm{NR}=$ not reported; $\mathrm{R}$ = resource use; $\mathrm{SD}=$ standard deviation; $\mathrm{SE}$ = standard error; Sen = sensitivity; $\mathrm{Sp}=$ specificity; $\mathrm{SpO}_{2}=$ peripheral oxygen saturation; $\mathrm{StO}_{2}=$ tissue oxygen saturation 
Table 20. Predictive utility of oxygen saturation: emergency department

\begin{tabular}{|c|c|c|c|c|c|}
\hline $\begin{array}{l}\text { Measure } \\
\text { Threshold }\end{array}$ & $\begin{array}{l}\text { Author, Year } \\
\text { Risk of Bias }\end{array}$ & $\begin{array}{l}\text { Serious Injury } \\
\text { Indicator } \\
\text { Type: Specific } \\
\text { Indicator }\end{array}$ & $\begin{array}{l}\text { Number } \\
\text { Analyzed } \\
\text { Age } \\
\text { Mean (SD) }\end{array}$ & $\begin{array}{l}\text { Sensitivity } \\
\text { Specificity } \\
(95 \% \mathrm{Cl})\end{array}$ & AUROC (95\% Cl) \\
\hline $\begin{array}{l}\text { Oxygen } \\
\text { Saturation } \\
\text { Minimum } \mathrm{StO}_{2} \\
\leq 75 \%\end{array}$ & $\begin{array}{l}\text { Beekley, } \\
2010^{115} \\
\text { Moderate }\end{array}$ & R: LSI & $\begin{array}{l}147 \\
27(11)\end{array}$ & $\begin{array}{l}\text { Sen: } 61 \% \text { (49 } \\
\text { to } 72) \\
\text { Sp: } 65 \%(53 \\
\text { to } 76)\end{array}$ & NR \\
\hline $\begin{array}{l}\text { Oxygen } \\
\text { Saturation } \\
\text { Minimum } \mathrm{StO}_{2} \\
\leq 75 \%\end{array}$ & $\begin{array}{l}\text { Beekley, } \\
2010^{115} \\
\text { Moderate }\end{array}$ & $\begin{array}{l}\text { R: blood } \\
\text { transfusion }\end{array}$ & $\begin{array}{l}147 \\
27(11)\end{array}$ & $\begin{array}{l}\text { Sen: } 64 \% \text { (48 } \\
\text { to } 78) \\
\text { Sp: } 59 \%(49 \\
\text { to } 69)\end{array}$ & NR \\
\hline $\begin{array}{l}\text { Oxygen } \\
\text { Saturation } \\
\text { Minimum } \mathrm{StO}_{2} \\
\leq 75 \%\end{array}$ & $\begin{array}{l}\text { Beekley, } \\
2010^{115} \\
\text { Moderate }\end{array}$ & $\begin{array}{l}\mathrm{R}: \text { massive } \\
\text { transfusion }\end{array}$ & $\begin{array}{l}147 \\
27(11)\end{array}$ & $\begin{array}{l}\text { Sen: } 90 \%(56 \\
\text { to } 100) \\
\text { Sp: } 55 \%(47 \\
\text { to } 64)\end{array}$ & NR \\
\hline $\begin{array}{l}\text { Oxygen } \\
\text { Saturation } \\
\text { Minimum } \mathrm{StO}_{2} \\
\leq 78 \%\end{array}$ & $\begin{array}{l}\text { Beekley, } \\
2010^{115} \\
\text { Moderate }\end{array}$ & $\begin{array}{l}\text { R: LSI or blood } \\
\text { transfusion }\end{array}$ & $\begin{array}{l}147 \\
27(11)\end{array}$ & $\begin{array}{l}\text { Sen: } 71 \% \\
\text { (NR) } \\
\text { Sp: NR }\end{array}$ & NR \\
\hline $\begin{array}{l}\text { Oxygen } \\
\text { Saturation } \\
\text { Minimum } \mathrm{StO}_{2} \\
\leq 78 \%\end{array}$ & $\begin{array}{l}\text { Beekley, } \\
2010^{115} \\
\text { Moderate }\end{array}$ & $\begin{array}{l}\mathrm{R}: \text { massive } \\
\text { transfusion }\end{array}$ & $\begin{array}{l}147 \\
27(11)\end{array}$ & $\begin{array}{l}\text { Sen: } 100 \% \\
\text { (NR) } \\
\text { Sp: NR }\end{array}$ & NR \\
\hline $\begin{array}{l}\text { Oxygen } \\
\text { Saturation } \\
\text { Minimum } \mathrm{StO}_{2} \\
\leq 80 \%\end{array}$ & $\begin{array}{l}\text { Beekley, } \\
2010^{115} \\
\text { Moderate }\end{array}$ & R: LSI & $\begin{array}{l}147 \\
27(11)\end{array}$ & $\begin{array}{l}\text { Sen: } 75 \% \text { (63 } \\
\text { to } 84) \\
\text { Sp: } 47 \% \text { (35 } \\
\text { to } 59)\end{array}$ & NR \\
\hline $\begin{array}{l}\text { Oxygen } \\
\text { Saturation } \\
\text { Minimum } \mathrm{StO}_{2} \\
\leq 80 \%\end{array}$ & $\begin{array}{l}\text { Beekley, } \\
2010^{115} \\
\text { Moderate }\end{array}$ & $\begin{array}{l}\text { R: blood } \\
\text { transfusion }\end{array}$ & $\begin{array}{l}147 \\
27(11)\end{array}$ & $\begin{array}{l}\text { Sen: } 76 \% \text { (61 } \\
\text { to } 88) \\
\text { Sp: } 41 \% \text { (31 } \\
\text { to } 51)\end{array}$ & NR \\
\hline $\begin{array}{l}\text { Oxygen } \\
\text { Saturation } \\
\text { Minimum } \mathrm{StO}_{2} \\
\leq 80 \%\end{array}$ & $\begin{array}{l}\text { Beekley, } \\
2010^{115} \\
\text { Moderate }\end{array}$ & $\begin{array}{l}\text { R: massive } \\
\text { transfusion }\end{array}$ & $\begin{array}{l}147 \\
27(11)\end{array}$ & $\begin{array}{l}\text { Sen: } 100 \% \\
(69 \text { to } 100) \\
\text { Sp: } 39 \% \\
\text { (30 to } 47)\end{array}$ & NR \\
\hline $\begin{array}{l}\text { Oxygen } \\
\text { Saturation } \\
\text { Average } \mathrm{StO}_{2} \text { over } \\
2 \text { minutes following } \\
\text { arrival }\end{array}$ & $\begin{array}{l}\text { Beekley, } \\
2010^{115} \\
\text { Moderate }\end{array}$ & R: LSI & $\begin{array}{l}147 \\
27(11)\end{array}$ & NR & 0.61 (0.53 to 0.69$)$ \\
\hline $\begin{array}{l}\text { Oxygen } \\
\text { Saturation } \\
\text { Average } \mathrm{StO}_{2} \text { over } \\
2 \text { minutes following } \\
\text { arrival }\end{array}$ & $\begin{array}{l}\text { Beekley, } \\
2010^{115} \\
\text { Moderate }\end{array}$ & $\begin{array}{l}\text { R: blood } \\
\text { transfusion }\end{array}$ & $\begin{array}{l}147 \\
27(11)\end{array}$ & NR & $0.64(0.55$ to 0.73$)$ \\
\hline $\begin{array}{l}\text { Oxygen } \\
\text { Saturation } \\
\text { Minimum } \mathrm{StO}_{2} \\
\text { during ED course }\end{array}$ & $\begin{array}{l}\text { Beekley, } \\
2010^{115} \\
\text { Moderate }\end{array}$ & R: LSI & $\begin{array}{l}147 \\
27(11)\end{array}$ & NR & $0.67(0.60$ to 0.74$)$ \\
\hline $\begin{array}{l}\text { Oxygen } \\
\text { Saturation } \\
\text { Minimum } \mathrm{StO}_{2} \\
\text { during ED course }\end{array}$ & $\begin{array}{l}\text { Beekley, } \\
2010^{115} \\
\text { Moderate }\end{array}$ & $\begin{array}{l}\text { R: blood } \\
\text { transfusion }\end{array}$ & $\begin{array}{l}147 \\
27(11)\end{array}$ & NR & $0.69(0.61$ to 0.77$)$ \\
\hline $\begin{array}{l}\text { Oxygen } \\
\text { Saturation } \mathrm{StO}_{2} \\
<65 \%\end{array}$ & $\begin{array}{l}\text { Khasawneh, } \\
2014^{135} \\
\text { Moderate }\end{array}$ & $\begin{array}{l}\text { R: massive } \\
\text { transfusion }\end{array}$ & $\begin{array}{l}325 \\
46(N R)\end{array}$ & $\begin{array}{l}\text { Sen: } 25 \%(9 \\
\text { to } 49) \\
\text { Sp: } 94 \%(90 \\
\text { to } 96)\end{array}$ & NR \\
\hline
\end{tabular}




\begin{tabular}{|l|l|l|l|l|l|}
\hline $\begin{array}{l}\text { Measure } \\
\text { Threshold }\end{array}$ & Author, Year & $\begin{array}{l}\text { Serious Injury } \\
\text { Indicator } \\
\text { Type: Specific } \\
\text { Indicator }\end{array}$ & $\begin{array}{l}\text { Number } \\
\text { Analyzed } \\
\text { Age } \\
\text { Mean (SD) }\end{array}$ & $\begin{array}{l}\text { Sensitivity } \\
\text { Specificity } \\
\text { (95\% Cl) }\end{array}$ & AUROC (95\% Cl) \\
\hline $\begin{array}{l}\text { Saturation } \mathrm{SmO}_{2} \\
\text { Refias }\end{array}$ & $\begin{array}{l}\text { Reisner, } \\
2016159\end{array}$ & $\begin{array}{l}\text { R: hemorrhagic } \\
\text { injury requiring } \\
\text { blood transfusion } \\
\text { of } \geq 3 \text { units } \\
\text { pRBCs }\end{array}$ & $\begin{array}{l}\text { Median 47 } \\
\text { (IQR 31 to } \\
\text { 64) }\end{array}$ & NR & $0.76(0.65$ to 0.84) \\
\hline
\end{tabular}

AUROC = area under the receiver operating characteristic curve; CI = confidence interval; ED = emergency department; IQR = interquartile range; $\mathrm{LSI}=$ life-saving intervention; $\mathrm{NR}=$ not reported; $\mathrm{pRBC}$ = packed red blood cell; $\mathrm{R}=$ resource use; $\mathrm{SD}=$ standard deviation; $\mathrm{Sen}=$ sensitivity; $\mathrm{SmO}_{2}=$ muscle oxygen saturation; $\mathrm{Sp}=$ specificity; $\mathrm{StO}_{2}=$ tissue oxygen saturation

\section{Airway/Ventilatory Support}

A functional approach used in triage to assess respiration status is to categorize the patient as either needing or not needing airway or ventilatory support. This is part of the current trauma triage guideline, ${ }^{183}$ which includes abnormal RR ( $>10$ or $<29$ breaths per minute) or the need for this type of support as indicators of the need for higher-level trauma care. Support can include moving the head or jaw, bag-mask assisted ventilation, using devices that are introduced into the pharynx but not into the trachea (i.e., supraglottic airways), or intubation, which involves passing a tube through the glottis into the trachea. In extreme situations an incision may be made in the neck to bypass the upper respiratory tract and ensure air reaches the lungs.

We identified seven studies reported in eight articles with data on whether any type of airway support predicted serious injury. ${ }^{56,57,67,89,95,96,133,160}$ In all of these studies, multiple measures were evaluated. Four studies (reported in 5 articles) used data collected in the field ${ }^{56,67,89,95,96}$ (listed first in Table 21), and three were based on the status of the patient on arrival at the ED. ${ }^{57,133,160}$ One study ${ }^{89}$ was of adults over 55 years of age and one was of pediatric trauma patients. ${ }^{57}$ Three studies compared patients who were intubated with those who were not, ${ }^{56,57,133}$ while the others included any type of support ${ }^{89}$ or did not provide specifics. ${ }^{67,95,96,160}$

Table 21. Predictive utility of airway support: out-of-hospital and upon ED arrival

\begin{tabular}{|c|c|c|c|c|c|}
\hline $\begin{array}{l}\text { Measure } \\
\text { Setting }\end{array}$ & $\begin{array}{l}\text { Author, Year } \\
\text { Risk of Bias }\end{array}$ & $\begin{array}{l}\text { Serious } \\
\text { Injury } \\
\text { Indicator } \\
\text { Type: } \\
\text { Indicator }\end{array}$ & $\begin{array}{l}\text { Number } \\
\text { Analyzed } \\
\text { Age } \\
\text { Mean (SD) }\end{array}$ & $\begin{array}{l}\text { Sensitivity } \\
\text { Specificity } \\
(95 \% \mathrm{Cl})\end{array}$ & $\begin{array}{l}\text { AUROC } \\
\text { (95\% CI) }\end{array}$ \\
\hline $\begin{array}{l}\text { Mechanical } \\
\text { ventilation } \\
\text { OH }\end{array}$ & $\begin{array}{l}\text { Raux, } 2011^{95+} \\
\text { Moderate }\end{array}$ & $\begin{array}{l}\text { R: } \\
\text { emergency } \\
\text { procedure }\end{array}$ & $\begin{array}{l}1,360 \\
38(17)\end{array}$ & $\begin{array}{l}\text { *Sen: } 44.7 \%(41.0 \text { to } 48.6) \\
\text { *Sp: } 61.1 \%(57.3 \text { to } 64.8)\end{array}$ & NR \\
\hline $\begin{array}{l}\text { Airway } \\
\text { support } \\
\text { OH }\end{array}$ & $\begin{array}{l}\text { Hamada, 2014 }{ }^{67} \\
\text { Moderate }\end{array}$ & I: ISS >15 & $\begin{array}{l}825 \\
37(17)\end{array}$ & $\begin{array}{l}\text { Sen: } 52 \%(N R) \\
\text { Sp: } 88 \%(N R)\end{array}$ & NR \\
\hline $\begin{array}{l}\text { Assisted } \\
\text { ventilation } \\
\text { OH }\end{array}$ & $\begin{array}{l}\text { Newgard, } 2014^{89} \\
\text { Moderate }\end{array}$ & I: ISS $\geq 16$ & $\begin{array}{l}44,890 \\
\text { Median } 77 \\
\text { (IQR } 64 \text { to } \\
85)\end{array}$ & $\begin{array}{l}\text { *Sen: } 7.9 \%(6.8 \text { to } 9.1) \\
\text { *Sp: } 99.6 \%(99.5 \text { to } 99.7)\end{array}$ & NR \\
\hline $\begin{array}{l}\text { Intubation } \\
\text { status } \\
\text { OH }\end{array}$ & $\begin{array}{l}\text { Cooke, } 2006 a^{56} \\
\text { High }\end{array}$ & $\begin{array}{l}\text { M: } \\
\text { mortality }\end{array}$ & $\begin{array}{l}30 \\
39(3)\end{array}$ & $\begin{array}{l}\text { *Sen: } 53.3 \%(26.6 \text { to } 87.8) \\
\text { *Sp: } \quad 100.0 \%(78.2 \text { to } 100.0)\end{array}$ & NR \\
\hline $\begin{array}{l}\text { Mechanical } \\
\text { ventilation } \\
\text { OH }\end{array}$ & $\begin{array}{l}\text { Sartorius, } 2010^{96+} \\
\text { Moderate }\end{array}$ & $\begin{array}{l}\text { M: 30-day } \\
\text { all-cause } \\
\text { mortality }\end{array}$ & $\begin{array}{l}1,360 \\
38(17)\end{array}$ & $\begin{array}{l}\text { *Sen: } 39.0 \% \text { (35.0 to } 43.2) \\
\text { *Sp: } 96.5 \% \text { (94.9 to } 97.6)\end{array}$ & NR \\
\hline
\end{tabular}




\begin{tabular}{|c|c|c|c|c|c|}
\hline $\begin{array}{l}\text { Measure } \\
\text { Setting }\end{array}$ & $\begin{array}{l}\text { Author, Year } \\
\text { Risk of Bias }\end{array}$ & $\begin{array}{l}\text { Serious } \\
\text { Injury } \\
\text { Indicator } \\
\text { Type: } \\
\text { Indicator }\end{array}$ & $\begin{array}{l}\text { Number } \\
\text { Analyzed } \\
\text { Age } \\
\text { Mean (SD) }\end{array}$ & $\begin{array}{l}\text { Sensitivity } \\
\text { Specificity } \\
(95 \% \mathrm{Cl})\end{array}$ & $\begin{array}{l}\text { AUROC } \\
(95 \% \mathrm{Cl})\end{array}$ \\
\hline $\begin{array}{l}\text { Airway } \\
\text { status } \\
\text { ED } \\
\text { Intubated, } \\
\text { with or } \\
\text { without } \\
\text { chemical } \\
\text { sedation }\end{array}$ & $\begin{array}{l}\text { Courville, } 2009^{57} \\
\text { Low }\end{array}$ & $\begin{array}{l}\text { M: in- } \\
\text { hospital } \\
\text { mortality }\end{array}$ & $\begin{array}{l}224,682 \\
N R\end{array}$ & $\begin{array}{l}\text { *Sen: } 55.3 \%(53.5 \text { to } 57.0) \\
\text { *Sp: } 96.7 \%(96.6 \text { to } 96.8)\end{array}$ & NR \\
\hline $\begin{array}{l}\text { Intubation } \\
\text { status } \\
\text { ED }\end{array}$ & $\begin{array}{l}\text { Jones, } 2014^{133} \\
\text { Moderate }\end{array}$ & $\begin{array}{l}\text { M: 30-day } \\
\text { mortality }\end{array}$ & $\begin{array}{l}5,363 \\
\text { Median } 33 \\
\text { (IQR } 22 \text { to } \\
51 \text { ) }\end{array}$ & $\begin{array}{l}\text { *Sen: } 56.6 \%(51.7 \text { to } 61.4) \\
{ }^{*} \text { Sp: } 84.9 \%(83.9 \text { to } 85.9)\end{array}$ & NR \\
\hline $\begin{array}{l}\text { Mechanical } \\
\text { ventilation } \\
\text { ED }\end{array}$ & $\begin{array}{l}\text { Ryan, 2011b }{ }^{160} \\
\text { Moderate }\end{array}$ & $\begin{array}{l}\text { M: } \\
\text { mortality }\end{array}$ & $\begin{array}{l}216 \\
50(1)\end{array}$ & $\begin{array}{l}\text { *Sen: } 32.1 \%(15.9 \text { to } 52.4) \\
\text { *Sp: } 95.2 \%(91.1 \text { to } 97.8)\end{array}$ & NR \\
\hline
\end{tabular}

AUROC = area under the receiver operating characteristic curve; $\mathrm{CI}=$ confidence interval; ED = emergency department; $\mathrm{I}=$ injury type or severity; IQR = interquartile range; ISS = injury severity score; $\mathrm{M}$ = mortality; NR = not reported; OH = out-ofhospital; $\mathrm{R}$ = resource use; $\mathrm{SD}$ = standard deviation; Sen = sensitivity; $\mathrm{Sp}$ = specificity

*Results calculated by reviewers.

+Same study, different results reported in different articles

\section{Other Respiratory Measures}

Three other respiratory measures, arterial blood $\mathrm{pH}$, end-tidal $\mathrm{CO}_{2}\left(\mathrm{ETCO}_{2}\right)$, and sublingual $\mathrm{PCO}_{2}\left(\mathrm{SLCO}_{2}\right)$ were also reported in the included studies. The primary findings from these studies are included in Table 22. All of these studies relied on data collected in EDs; we did not identify any studies that reported data collected out-of-hospital.

These measures are different ways of assessing levels of $\mathrm{CO}_{2} \cdot \mathrm{CO}_{2}$ is a waste product of metabolism at the tissue level and is eliminated through the lungs. $\mathrm{ETCO}_{2}$ measures the partial pressure of carbon dioxide in the exhaled breath of patients and correlates with the arterial $\mathrm{CO}_{2}$ pressure. A low $\mathrm{ETCO}_{2}$ can reflect decreased tissue perfusion and reduced removal of waste (i.e., $\mathrm{CO}_{2}$ ). ETCO 2 however is also affected by respiratory rate and a low pressure can be due to an increased RR. $\mathrm{ETCO}_{2}$ monitoring is routinely used in confirming intubation, ventilation, and efficacy of chest compressions during cardiopulmonary resuscitation. In these studies, $\mathrm{ETCO}_{2}$ was measured in nonintubated patients, using nasal cannulas to explore the predictive utility of $\mathrm{ETCO}_{2}$ for identifying high-risk patients.

Tissue $\mathrm{CO}_{2}$ levels rise in the setting of perfusion failure and impaired oxygen delivery, mirroring the increase in arterial lactate, and where bicarbonate buffering of acids produced through anaerobic metabolism results in higher $\mathrm{CO}_{2}$ concentration within the tissues. ${ }^{184}$ Tissue $\mathrm{CO}_{2}$ can be measured using sublingual capnometry as $\mathrm{SLCO}_{2}$, with a capnometry sensor placed under the patient's tongue to measure the pressure of regional tissue $\mathrm{CO}_{2}$.

Abnormal values for $\mathrm{ETCO}_{2}$ are low (lower than $30 \mathrm{mmHg}$ in the included studies) while abnormal $\mathrm{SLCO}_{2}$ values are high (over 45 and $62 \mathrm{mmHg}$ in the included studies).

Arterial blood $\mathrm{pH}$ is measured from a blood sample drawn from an artery. Abnormal arterial blood $\mathrm{pH}$ can be either high or low, though in trauma it is usually low. In trauma, some causes of low $\mathrm{pH}$ include metabolic acidosis in states of hypoperfusion and/or respiratory acidosis from 
hypoventilation which may be due to obstruction, impaired respiratory drive, or chest or lung injury. Studies of arterial blood $\mathrm{pH}$ focused on $\mathrm{pH}$ below 7.3.

The four studies that included data on arterial blood $\mathrm{pH}$ reported this in the course of conducting studies on lactate, ${ }^{112,157}$ comparing blood analysis to noninvasive near-infrared spectroscopy, ${ }^{115}$ or creating a risk stratification score for massive blood transfusion. ${ }^{156}$ One of these studies was limited to pediatric trauma patients. ${ }^{157}$

Both studies of $\mathrm{ETCO}_{2}$ had moderate samples sizes ( $\mathrm{n}=105$ and $\left.\mathrm{n}=170\right)$, but the authors highlighted statistical power issues and the need for additional research. ${ }^{119,168}$ These two studies concluded that abnormal ETCO 2 can help predict which patients have a major injury or need procedures, but normal levels cannot be used to rule out serious injury.

The two identified studies of $\mathrm{SLCO}_{2}$ were conducted by the same researchers and the studies evaluated whether this measure could predict blood loss, ICU stays, and mortality. ${ }^{113,114}$ While $\mathrm{SLCO}_{2}$ was limited in its ability to predict resource use, it was equivalent to base deficit and lactate in predicting mortality, and it has the advantage of being noninvasive. ${ }^{113,114}$

Table 22. Predictive utility of other respiratory measures: emergency department

\begin{tabular}{|c|c|c|c|c|c|}
\hline $\begin{array}{l}\text { Measure } \\
\text { Threshold }\end{array}$ & $\begin{array}{l}\text { Author, Year } \\
\text { Risk of Bias }\end{array}$ & $\begin{array}{l}\text { Serious } \\
\text { Injury } \\
\text { Indicator } \\
\text { Type: } \\
\text { Indicator }\end{array}$ & $\begin{array}{l}\text { Number } \\
\text { Analyzed } \\
\text { Age } \\
\text { Mean } \\
\text { (SD) }\end{array}$ & $\begin{array}{l}\text { Sensitivity } \\
\text { Specificity } \\
(95 \% \mathrm{Cl})\end{array}$ & AUROC (95\% Cl) \\
\hline $\begin{array}{l}\text { Arterial } \\
\text { blood pH }\end{array}$ & $\begin{array}{l}\text { Beekley, } 2010^{115} \\
\text { Moderate }\end{array}$ & R: LSI & $\begin{array}{l}147 \\
27(11)\end{array}$ & NR & $0.68(0.60$ to 0.76$)$ \\
\hline $\begin{array}{l}\text { Arterial } \\
\text { blood pH }\end{array}$ & $\begin{array}{l}\text { Beekley, } 2010^{115} \\
\text { Moderate }\end{array}$ & $\begin{array}{l}\text { R: blood } \\
\text { transfusion }\end{array}$ & $\begin{array}{l}147 \\
27(11)\end{array}$ & NR & $0.70(0.61$ to 0.79$)$ \\
\hline $\begin{array}{l}\text { Arterial } \\
\text { blood pH }\end{array}$ & $\begin{array}{l}\text { Beekley, } 2010^{115} \\
\text { Moderate }\end{array}$ & $\begin{array}{l}\mathrm{R}: \text { massive } \\
\text { transfusion }\end{array}$ & 147 & NR & $0.75(0.59$ to 0.91$)$ \\
\hline $\begin{array}{l}\text { Arterial } \\
\text { blood } \mathrm{pH} \\
<7.33\end{array}$ & $\begin{array}{l}\text { Rainer, } 2011^{156} \\
\text { Moderate }\end{array}$ & $\begin{array}{l}\mathrm{R}: \text { massive } \\
\text { transfusion }\end{array}$ & $\begin{array}{l}1,891 \\
44(19)\end{array}$ & $\begin{array}{l}\text { *Sen: } 35.9 \%(26.1 \text { to } 46.5) \\
\text { *Sp: } 95.2 \%(94.1 \text { to } 96.1)\end{array}$ & NR \\
\hline $\begin{array}{l}\text { Arterial } \\
\text { blood pH } \\
<7.30\end{array}$ & $\begin{array}{l}\text { Ramanathan, } \\
2015^{157} \\
\text { Low }\end{array}$ & I: ISS >15 & $\begin{array}{l}236 \\
9(5)\end{array}$ & $\begin{array}{l}\text { Sen: } 56.8 \% \text { (41.0 to } 71.6) \\
\text { Sp: } 94.3 \% \text { (89.9 to } 97.2)\end{array}$ & NR \\
\hline $\begin{array}{l}\text { Arterial } \\
\text { blood pH } \\
\leq 7.3\end{array}$ & $\begin{array}{l}\text { Aslar, } 2004^{112} \\
\text { Moderate }\end{array}$ & $\begin{array}{l}\text { M: 30-day in- } \\
\text { hospital } \\
\text { mortality }\end{array}$ & $\begin{array}{l}64 \\
36(19)\end{array}$ & $\begin{array}{l}\text { *Sen: } 72.0 \%(50.6 \text { to } 87.9) \\
\text { *Sp: } 84.6 \%(69.5 \text { to } 94.4)\end{array}$ & NR \\
\hline $\begin{array}{l}\mathrm{ETCO}_{2} \\
\leq 30 \\
\mathrm{mmHg}\end{array}$ & $\begin{array}{l}\text { Williams, } 2016^{168} \\
\text { Moderate }\end{array}$ & $\begin{array}{l}\mathrm{R} \text { : invasive } \\
\text { procedure }\end{array}$ & $\begin{array}{l}170 \\
43(N R)\end{array}$ & $\begin{array}{l}\text { *Sen: } 47.2 \% \text { (30.4 to } 64.5) \\
\text { *Sp: } \quad 69.4 \% \text { (60.9 to } 77.1)\end{array}$ & NR \\
\hline $\begin{array}{l}\text { ETCO } 2 \\
\leq 30 \\
\mathrm{mmHg}\end{array}$ & $\begin{array}{l}\text { Williams, } 2016^{168} \\
\text { Moderate }\end{array}$ & $\begin{array}{l}\mathrm{R}: \text { blood } \\
\text { transfusion }\end{array}$ & $\begin{array}{l}170 \\
43 \text { (NR) }\end{array}$ & $\begin{array}{l}\text { *Sen: } 62.5 \%(24.5 \text { to } 91.5) \\
\text { *Sp: } 67.3 \%(59.5 \text { to } 74.4)\end{array}$ & NR \\
\hline $\begin{array}{l}\mathrm{ETCO}_{2} \\
\leq 30 \\
\mathrm{mmHg}\end{array}$ & $\begin{array}{l}\text { Williams, } 2016^{168} \\
\text { Moderate }\end{array}$ & $\begin{array}{l}\text { R: ICU or } \\
\text { admission }\end{array}$ & $\begin{array}{l}170 \\
43 \text { (NR) }\end{array}$ & $\begin{array}{l}\text { *Sen: } 63.6 \%(40.7 \text { to } 82.8) \\
\text { *Sp: } 70.3 \%(62.2 \text { to } 77.5)\end{array}$ & NR \\
\hline $\begin{array}{l}\mathrm{ETCO}_{2} \\
\leq 30 \\
\mathrm{mmHg}\end{array}$ & $\begin{array}{l}\text { Williams, } 2016^{168} \\
\text { Moderate }\end{array}$ & $\begin{array}{l}\text { R: severe } \\
\text { injury } \\
\text { composite }\end{array}$ & $\begin{array}{l}170 \\
43 \text { (NR) }\end{array}$ & $\begin{array}{l}\text { *Sen: } 52.7 \% \text { (38.8 to } 66.4) \\
\text { *Sp: } 74.8 \% \text { (65.8 to } 82.4)\end{array}$ & NR \\
\hline $\begin{array}{l}\mathrm{ETCO}_{2} \\
<35 \\
\mathrm{mmHg}\end{array}$ & $\begin{array}{l}\text { Caputo, } 2012^{119} \\
\text { Moderate }\end{array}$ & $\begin{array}{l}\text { R: operative } \\
\text { intervention }\end{array}$ & $\begin{array}{l}105 \\
26(N R)\end{array}$ & $\begin{array}{l}\text { *Sen: } 82.0 \%(70.0 \text { to } 90.6) \\
\text { *Sp: } \quad 81.8 \%(67.3 \text { to } 91.8)\end{array}$ & NR \\
\hline
\end{tabular}




\begin{tabular}{|c|c|c|c|c|c|}
\hline $\begin{array}{l}\text { Measure } \\
\text { Threshold }\end{array}$ & $\begin{array}{l}\text { Author, Year } \\
\text { Risk of Bias }\end{array}$ & $\begin{array}{l}\text { Serious } \\
\text { Injury } \\
\text { Indicator } \\
\text { Type: } \\
\text { Indicator }\end{array}$ & $\begin{array}{l}\text { Number } \\
\text { Analyzed } \\
\text { Age } \\
\text { Mean } \\
\text { (SD) }\end{array}$ & $\begin{array}{l}\text { Sensitivity } \\
\text { Specificity } \\
(95 \% \mathrm{Cl})\end{array}$ & AUROC $(95 \% \mathrm{Cl})$ \\
\hline $\begin{array}{l}\mathrm{ETCO}_{2} \\
<35 \\
\mathrm{mmHg}\end{array}$ & $\begin{array}{l}\text { Caputo, } 2012^{119} \\
\text { Moderate }\end{array}$ & $\begin{array}{l}\text { R: massive } \\
\text { transfusion }\end{array}$ & $\begin{array}{l}105 \\
26(N R)\end{array}$ & $\begin{array}{l}\text { *Sen: } 97.2 \%(85.5 \text { to } 99.9) \\
{ }^{*} \text { Sp: } \quad 66.7 \%(54.3 \text { to } 77.6)\end{array}$ & NR \\
\hline $\begin{array}{l}\mathrm{SLCO}_{2} \\
>45 \\
\mathrm{mmHg}\end{array}$ & $\begin{array}{l}\text { Baron, 2004113 } \\
\text { Moderate }\end{array}$ & R: blood loss & $\begin{array}{l}108 \\
28(11)\end{array}$ & $\begin{array}{l}\text { Sen: } 90 \% \text { (79 to } 96) \\
\text { Sp: } 45 \% \text { (31 to } 60)\end{array}$ & 0.74 (0.65 to 0.84$)$ \\
\hline $\mathrm{SLCO}_{2}$ & $\begin{array}{l}\text { Baron, } 2007^{114} \\
\text { Moderate }\end{array}$ & $\begin{array}{l}\text { R: blood } \\
\text { transfusion }\end{array}$ & $\begin{array}{l}86 \\
35(17) \\
\end{array}$ & NR & 0.64 (0.49 to 0.79$)$ \\
\hline $\mathrm{SLCO}_{2}$ & $\begin{array}{l}\text { Baron, } 2007^{114} \\
\text { Moderate }\end{array}$ & R: ICU stay & $\begin{array}{l}86 \\
35(17) \\
\end{array}$ & NR & 0.71 (0.58 to 0.84$)$ \\
\hline $\begin{array}{l}\mathrm{SLCO}_{2} \\
>62 \\
\mathrm{mmHg}\end{array}$ & $\begin{array}{l}\text { Baron, } 2007^{114} \\
\text { Moderate }\end{array}$ & M: mortality & $\begin{array}{l}86 \\
35(17) \\
\end{array}$ & $\begin{array}{l}\text { Sen: } 75 \% \\
\text { Sp: } 86 \%\end{array}$ & 0.82 (0.70 to 0.96$)$ \\
\hline
\end{tabular}

AUROC = area under the receiver operating characteristic curve; $\mathrm{CI}$ = confidence interval; ETCO2 = end-tidal carbon dioxide; I = injury type or severity; ICU = intensive care unit; ISS = injury severity score; LSI = life-saving intervention; $\mathrm{M}$ = mortality; $\mathrm{NR}$ = not reported; $\mathrm{OR}$ = operating room; $\mathrm{R}$ = resource use; $\mathrm{SD}$ = standard deviation; Sen = sensitivity; $\mathrm{SLCO2}$ = sublingual partial pressure of carbon dioxide; $\mathrm{Sp}=$ specificity

*Results calculated by reviewers

\section{Key Question 3: Combination Measures}

The third Key Question for this review concerns the predictive utility of measures created by combining several variables. Measures in this section include formal scores, triage protocols for routine use, combat settings or mass casualty incidents, and various combinations of variables chosen with different methods such as clinical significance or predictive ability. Utilizing measures in combination may provide more information than a single measure, resulting in better assessment and triage performance. The core question, however, is whether the resources (i.e., time, expertise, or equipment) needed to obtain and use combination measures produces a corresponding benefit. In this case, the desired benefit is an improvement in the ability to identify patients at risk of serious injury.

We included studies of any combination measure that combined two or more relevant variables as long at least one was a measure of circulatory or respiratory compromise (Table 23). We prioritized combinations that combined a measure of the patient's level of consciousness, determined by the Glasgow Coma Scale (GCS), with physiologic measures. These combinations are listed and discussed first, after which, in the second part of this section, we present the combinations that do not include GCS or a measure of consciousness. We provided more limited information in the text on combinations that add additional factors such as mechanism of injury, and instead included more information and results from these studies in the evidence tables in Appendix D.

Many of the formal scores and triage protocols are commonly referred to by their acronyms, and their constituent measures and scoring are not always specified in the research. We aggregated this information in Table 23, in alphabetic order for reference. 
Table 23. Information on combination measures identified in the review

\begin{tabular}{|c|c|c|}
\hline $\begin{array}{l}\text { Name } \\
\text { (Full Name) } \\
\text { Primary Use }\end{array}$ & Components & Scoring \\
\hline $\begin{array}{l}\text { APACHE II } \\
\text { (Acute Physiology } \\
\text { and Chronic Health } \\
\text { Evaluation (revised)) } \\
\text { Severity assessment } \\
\text { and risk adjustment } \\
\text { in intensive care }\end{array}$ & $\begin{array}{l}\text { Temperature } \\
\text { MAP } \\
\text { HR } \\
\text { RR } \\
\text { Oxygenation } \\
\text { Arterial pH } \\
\text { Lab tests (commonly } \\
\text { obtained) } \\
\text { GCS } \\
\text { Severe chronic health } \\
\text { problems } \\
\text { Age }\end{array}$ & $\begin{array}{l}\text { Range: } 0-71 \\
\text { Direction: higher score=greater risk } \\
\text { Common threshold: not specified } \\
\text { Scoring: } \\
12 \text { components scored } 0-4 \text { points } \\
\text { Age } \geq 45 \text { years scored } 2-6 \text { points; increases in points at every } 10 \text { - } \\
\text { year increment } \\
\text { Severe chronic health problems scored } 2 \text { or } 5 \text { points }\end{array}$ \\
\hline $\begin{array}{l}\text { CareFlight Triage }^{61} \\
\text { Mass Casualty } \\
\text { Incident triage }\end{array}$ & $\begin{array}{l}\text { Mental status } \\
\text { Radial pulse } \\
\text { As evaluated: } \\
\text { GCS } \\
\text { SBP }\end{array}$ & $\begin{array}{l}\text { Stratification: Immediate, Urgent, Delayed, Unsalvageable } \\
\text { Algorithm } \\
\text { Walks } \\
\text { Obeys commands } \\
\text { Breathes with open airway } \\
\text { Palpable radial pulse } \\
\text { As evaluated } \\
\text { Garner } 2001^{61} \text { : SBP <80 = no palpable radial pulse; GCS motor } \\
\text { component < } 6 \text { unable to follow commands } \\
\text { Vassallo } 2017^{167}: \text { SBP < } 90=\text { no palpable radial pulse; GCS }<13= \\
\text { unable to follow commands }\end{array}$ \\
\hline $\begin{array}{l}\text { CRAMS }^{186} \\
\text { (Circulation, } \\
\text { Respiration, } \\
\text { Abdomen, Motor, } \\
\text { Speech) } \\
\text { Trauma triage }\end{array}$ & $\begin{array}{l}\text { Capillary refill and SBP } \\
\text { Respirations } \\
\text { Abdomen and thorax } \\
\text { Motor response } \\
\text { Speech response } \\
\text { (Capillary refill and SBP } \\
\text { are scored as a single } \\
\text { component) }\end{array}$ & $\begin{array}{l}\text { Range: } 0-10 \\
\text { Direction: lower score=more severe trauma } \\
\text { Common threshold: major trauma }=\leq 8 \\
\text { Scoring: } \\
5 \text { components, each scored as } 0 \text { (severely abnormal), } 1 \text { (mildly } \\
\text { abnormal), or } 2 \text { (normal) }\end{array}$ \\
\hline $\begin{array}{l}\text { EMTRAS }^{187} \\
\text { (Emergency Trauma } \\
\text { Score) } \\
\text { Mortality risk } \\
\text { prediction }\end{array}$ & $\begin{array}{l}\text { Age } \\
\text { GCS } \\
\text { Base deficit } \\
\text { Prothrombin time }\end{array}$ & $\begin{array}{l}\text { Range: } 0-12 \\
\text { Direction: higher score=higher risk of death } \\
\text { Common threshold: high risk }=\geq 5 \\
\text { Scoring: } \\
4 \text { components each scored } 0-3 \\
\text { Age (years): }<40=0,40-60=1,61-75=2,>75=3 \\
\text { GCS score: } 13-15=0,10-12=1,6-9=2,3-5=3 \\
\text { Base deficit (mmol/L): }>-1=0,-1 \text { to }-5=1,-5.1 \text { to }-10=2,<-10=3 \\
\text { Prothrombin time }(\% \text { normal): }>80=0,80-50=1,49-20=2,<20=3\end{array}$ \\
\hline $\begin{array}{l}\text { FTS }_{07}^{118} \\
\text { (Field Triage Score, } \\
\text { revised) } \\
\text { Battlefield triage }\end{array}$ & $\begin{array}{l}\text { SBP } \\
\text { GCS }\end{array}$ & $\begin{array}{l}\text { Range: } 0-2 \\
\text { Direction: higher score=higher risk of death } \\
\text { Common threshold: not specified } \\
\text { Scoring: } \\
2 \text { components scored } 0 \text { points for abnormal and } 1 \text { point for normal } \\
\text { SBP: abnormal }<100 \mathrm{mmHg} \\
\text { GCS: abnormal }<8\end{array}$ \\
\hline
\end{tabular}




\begin{tabular}{|c|c|c|}
\hline $\begin{array}{l}\text { Name } \\
\text { (Full Name) } \\
\text { Primary Use }\end{array}$ & Components & Scoring \\
\hline $\begin{array}{l}\text { GAP } 138 \\
\text { (GCS, age, pressure) } \\
\text { Assess trauma } \\
\text { patients/predict } \\
\text { mortality }\end{array}$ & $\begin{array}{l}\text { GCS } \\
\text { Age } \\
\text { SBP }\end{array}$ & $\begin{array}{l}\text { Range: } 3-24 \\
\text { Direction: higher score=lower risk of death } \\
\text { Common thresholds: high risk }=3-10 \text { points; moderate risk = 11-18 } \\
\text { points; low risk }=19-24 \text { points } \\
\text { Scoring: } \\
\text { GCS: actual value }=3-15 \text { points } \\
\text { Age: }<60 \text { years }=3 \text { points } \\
\text { SBP }(\mathrm{mmHg}):>120=6 \text { points; } 60-120=4 \text { points }\end{array}$ \\
\hline $\begin{array}{l}\text { MGAP } 96 \\
\text { (Mechanism, GCS, } \\
\text { age, pressure) } \\
\text { Assess trauma } \\
\text { patients/predict } \\
\text { mortality }\end{array}$ & $\begin{array}{l}\text { GCS } \\
\text { Age } \\
\text { SBP } \\
\text { Mechanism of injury }\end{array}$ & $\begin{array}{l}\text { Range: } 3-29 \\
\text { Direction: higher score=lower risk of death } \\
\text { Common thresholds: high risk }=3-17 \text { points; intermediate risk = } \\
\text { 18-22 points; low risk = } 23-29 \text { points } \\
\text { Scoring: } \\
\text { Mechanism: blunt }=4 \text { points; penetrating }=0 \text { points } \\
\text { GCS score: actual value }=3-15 \text { points } \\
\text { Age: }<60 \text { years }=5 \text { points; } \geq 60 \text { years }=0 \text { points } \\
\text { SBP }(\mathrm{mmHg}):>120=5 \text { points; } 60-120=3 \text { points; }<60=0\end{array}$ \\
\hline $\begin{array}{l}\text { Military Triage } \\
\text { Sieve }^{71}\end{array}$ & $\begin{array}{l}\text { Respiration } \\
\text { RR } \\
\text { HR } \\
\text { Level of consciousness } \\
\text { As evaluated: } \\
\text { GCS }\end{array}$ & $\begin{array}{l}\text { Stratification: Priority } 1,2 \text { or } 3 \text {; Dead } \\
\text { Algorithm: } \\
\text { Walking } \\
\text { Breathing } \\
\text { RR (breaths/min): }<10 \text { or }>29 \text { vs. } 10-29 \\
\text { HR (bpm): }>120 \text { vs. } \leq 120 \\
\text { Unconscious } \\
\text { As evaluated: } \\
\text { Horne, } 2013^{71} \text {, Vassallo, } 2017^{167} \text { : GCS }<13=\text { unconscious }\end{array}$ \\
\hline $\begin{array}{l}\text { MPTT }^{167} \\
\text { (Modified } \\
\text { Physiological Triage } \\
\text { Tool) } \\
\text { Mass Casualty } \\
\text { Incident triage }\end{array}$ & $\begin{array}{l}\text { RR } \\
\text { HR } \\
\text { GCS }\end{array}$ & $\begin{array}{l}\text { Stratification: Priority } 1,2 \text { or } 3 \text {; Dead } \\
\text { Algorithm: } \\
\text { Walking } \\
\text { Breathing } \\
\text { RR (breaths/min): }<12 \text { or }>22 \\
\text { HR } \geq 100 \text { bpm } \\
\text { GCS }<14\end{array}$ \\
\hline $\begin{array}{l}\text { PHI }^{188} \\
\text { (Prehospital Index) } \\
\text { Trauma } \\
\text { triage/severity score }\end{array}$ & $\begin{array}{l}\text { SBP } \\
\text { HR } \\
\text { Respirations } \\
\text { Level of consciousness } \\
\text { Mechanism (penetrating) }\end{array}$ & $\begin{array}{l}\text { Range: } 0-24 \\
\text { Direction: higher score=more severe trauma } \\
\text { Common threshold: major trauma }=4-24 \\
\text { Scoring: } \\
\text { SBP }(\mathrm{mmHg}):>100=0 ; 86-100=1 ; 75-85=2 ; 0-74=5 \\
\text { HR }(\mathrm{bpm}): \geq 120=3 ; 51-119=0 ;<50=5 \\
\text { Respirations: normal =0; labored/shallow }=3 ; \mathrm{RR}<10 \text { or needs } \\
\text { intubation }=5 \\
\text { Consciousness: normal = } 0 \text {; confused/combative }=3 ; \text { no intelligible } \\
\text { words }=5 \\
\text { Penetrating abdominal or chest injuries }=4\end{array}$ \\
\hline
\end{tabular}




\begin{tabular}{|c|c|c|}
\hline $\begin{array}{l}\text { Name } \\
\text { (Full Name) }\end{array}$ & Components & Scoring \\
\hline $\begin{array}{l}\text { PTS }^{189} \\
\text { (Pediatric Trauma } \\
\text { Score) } \\
\text { Pediatric trauma } \\
\text { triage }\end{array}$ & $\begin{array}{l}\text { Weight } \\
\text { Airway } \\
\text { SBP } \\
\text { Level of consciousness } \\
\text { Open wound } \\
\text { Skeletal (fractures) }\end{array}$ & $\begin{array}{l}\text { Range: }-6 \text { to } 12 \\
\text { Direction: lower score=higher mortality risk } \\
\text { Common threshold: high risk of death }=\leq 8 \\
\text { Scoring: } \\
6 \text { components scored }-1,+1 \text { or }+2 \text { points } \\
\text { Weight }(\mathrm{kg}): \geq 20=+2 ; 10-20=+1 ;<10=-1 \\
\text { Airway: } \text { normal }=+2 ; \text { maintainable }=+1 ; \text { unmaintainable }=-1 \\
\text { SBP }(\mathrm{mmHg}): \leq 90=+2 ; 50-90=+1 ;<50=-1 \\
\text { Level of consciousness: awake }=+2 ; \text { obtunded/loss of } \\
\text { consciousness }=+1 ; \text { coma/decerebrate }=-1 \\
\text { Open wound: none }=+2 ; \text { minor }=+1 ; \text { major/penetrating }=-1 \\
\text { Skeletal: none }=+2 ; \text { closed fracture }=+1 ; \text { open/multiple fractures }=- \\
1\end{array}$ \\
\hline $\begin{array}{l}\text { REMS }^{190} \\
\text { mREMS } \\
\\
\text { (Rapid Emergency } \\
\text { Medicine Score) } \\
\text { (modified Rapid } \\
\text { Emergency Medicine } \\
\text { Score) } \\
\text { Severity assessment } \\
\text { REMS non-surgical } \\
\text { mREMS trauma }\end{array}$ & $\begin{array}{l}\text { Age } \\
\text { MAP or SBP } \\
\text { HR } \\
\text { RR } \\
\text { Oxygen saturation } \\
\text { GCS } \\
\text { (REMS uses MAP, } \\
\text { mREMS uses SBP) }\end{array}$ & $\begin{array}{l}\text { Range: } 0-26 \\
\text { Direction: higher score=more severe trauma } \\
\text { Common threshold: not specified } \\
\text { Scoring: } \\
\text { GCS scored 0-6 points and other } 5 \text { components scored } 0-4 \text { points } \\
\text { Age (years): } \leq 44=0 ; 45-64=1 ; 65-74=3 ;>74=4 \\
\text { *MAP (mmHg): } 70-109=0 ; 50-69 \text { or } 110-129=2 ; 130-159=3 ;<49 \\
\text { or }>159=4 \\
\text { HR (bpm): } 70-109=0 ; 55-69 \text { or } 110-139=2 ; 40-54 \text { or } 140-179=3 \text {; } \\
\leq 39 \text { or }>179=4 \\
\text { RR (breaths/min): } 12-24=0 ; 10-11 \text { or } 25-34=1 ; 6-9=2 ; 35-49=3 \text {; } \\
\leq 5 \text { or }>49=4 \\
\text { Oxygen saturation }(\%):>89=0 ; 86-89=1 ; 75-85=3 ;<75=4 \\
\text { GCS: } 14-15=0 ; 8-13=2 ; 5-7=5 ; 3-4=6 \\
\text { *Modified REMS uses SBP instead of MAP } \\
\text { SBP (mmHg): } 110-159=0 ; 90-109 \text { or } 160-199=1 ; 80-89 \text { or } \geq 200= \\
2 ; \leq 79=4\end{array}$ \\
\hline $\begin{array}{l}\text { RTS }^{191} \\
\text { T-RTS } \\
\\
\text { (Revised Trauma } \\
\text { Score) } \\
\text { (Revised Trauma } \\
\text { Score for Triage) } \\
\text { Trauma triage }\end{array}$ & $\begin{array}{l}\text { GCS } \\
\text { SBP } \\
\text { RR }\end{array}$ & $\begin{array}{l}\frac{R T S}{R a n g e: ~} 0-7.84 \\
\text { Direction: lower score=more severely injured } \\
\text { Common thresholds: severe injury }=<6 \text { or }<7.5 \\
\text { Scoring: } \\
3 \text { components assigned coded value } \\
\text { GCS: } 13-15=4,9-12=3,6-8=2,4-5=1,3=0 \\
\text { SBP }(\mathrm{mmHg}):>89=4,76-89=3,50-75=2,1-49=1,0=0 \\
\text { RR (breaths/min): } 10-29=4,>29=3,6-9=2,1-5=1,0=0 \\
\text { Score calculated using coded values: RTS }=0.9368 \mathrm{GCS}_{\mathrm{c}}+0.7326 \\
\text { SBPc }+0.2908 \text { RRc } \\
\text { T-RTS } \\
\text { Range: } 0-12 \\
\text { Direction: lower score=more severely injured } \\
\text { Common thresholds: severe injury }=<12 \text { or }<8 \\
\text { Scoring: } \\
\text { Same components and coded values as in RTS } \\
\text { T-RTS = sum of coded values (not weighted) }\end{array}$ \\
\hline
\end{tabular}




\begin{tabular}{|c|c|c|}
\hline $\begin{array}{l}\text { Name } \\
\text { (Full Name) } \\
\text { Primary Use }\end{array}$ & Components & Scoring \\
\hline $\begin{array}{l}\text { SETS } 169 \\
\text { (Simplified } \\
\text { Emergency Trauma } \\
\text { Score) } \\
\text { Trauma triage and } \\
\text { injury severity rating }\end{array}$ & $\begin{array}{l}\text { Age } \\
\text { GCS } \\
\text { RR } \\
\text { Mechanism of injury }\end{array}$ & $\begin{array}{l}\text { Range: } 0-100 \\
\text { Direction: higher score=more severe injury } \\
\text { Common thresholds: injury rated as low = 0-60; moderate = 61-80; } \\
\text { or severe = >80 } \\
\text { Scoring: } \\
\text { Score = [age }-7(\mathrm{GCS})-\mathrm{RR}+31(\mathrm{ACS} \text { Injury) }+180] / 3 \\
\text { Uses actual values for RR and GCS, with mechanism of injury } \\
\text { scored } 0 \text { (absent) or } 1 \text { (present) } \\
\text { Mechanism of injury based on American College of Surgeons (ACS) } \\
\text { list }\end{array}$ \\
\hline $\begin{array}{l}\text { START }^{129} \\
\text { Modified START }^{61,192} \\
\text { (Simple Triage and } \\
\text { Rapid Treatment) } \\
\text { (Modified Simple } \\
\text { Triage and Rapid } \\
\text { Treatment) } \\
\text { Mass Casualty } \\
\text { Incident triage }\end{array}$ & $\begin{array}{l}\text { Respirations } \\
\text { RR } \\
\text { Capillary refill or radial } \\
\text { pulse* } \\
\text { Mental status } \\
\text { START uses capillary } \\
\text { refill, modified START } \\
\text { uses radial pulse }\end{array}$ & $\begin{array}{l}\text { Stratification: Immediate, Delayed, Unsalvageable } \\
\text { Algorithm: } \\
\text { Walking } \\
\text { Respirations present } \\
\text { RR (breaths/min) } \geq 30 \text { or }<30 \\
\text { *Capillary refill }>2 \text { seconds } \\
\text { Follows simple commands } \\
\text { *Modified START uses presence of radial pulse instead of capillary } \\
\text { refill } \\
\text { As evaluated: } \\
\text { Garner, } 2001^{61}: \text { SBP }<80 \text { mmHg = no palpable radial pulse; GCS } \\
\text { motor component } \leq 5=\text { unable to follow commands } \\
\text { Gebhart, } 2007^{193}: \text { GCS } \leq 14=\text { unable to follow commands }\end{array}$ \\
\hline $\begin{array}{l}\text { T-ASPTS } \\
\text { (Triage Age-Specific } \\
\text { Pediatric Trauma } \\
\text { Score) } \\
\text { Pediatric trauma } \\
\text { triage }\end{array}$ & $\begin{array}{l}\text { GCS } \\
\text { SBP } \\
\text { HR } \\
\text { RR }\end{array}$ & $\begin{array}{l}\text { Range: } 0-12 \\
\text { Direction: lower score = more severe injury } \\
\text { Common threshold: severe injury }=<10 \\
\text { Scoring: } \\
\text { SBP, HR and RR scored using age-specific ranges (not specified) } \\
\text { GCS: } 3=0 ; 4-9=1 ; 10-13=2 ; 14-15=3 \\
\text { SBP: severe hypotension = } 1 ; \text { mild to moderate hypotension = } 2 \text {; } \\
\text { normal = } 3 \\
\text { HR: } 0=0 ; \text { bradycardia = } 1 \text {; tachycardia }=2 ; \text { normal }=3 \\
\text { RR: intubated = } 0 \text {; hypoventilation }=1 ; \text { tachypnea }=2 ; \text { normal }=3\end{array}$ \\
\hline $\begin{array}{l}\text { Triage Sieve }^{61} \\
\text { Mass Casualty } \\
\text { Incident Triage }\end{array}$ & $\begin{array}{l}\text { RR } \\
\text { Capillary refill or HR }\end{array}$ & $\begin{array}{l}\text { Stratification: Priority } 1,2 \text { or } 3 \text {; Dead } \\
\text { Algorithm: } \\
\text { Walking } \\
\text { Breathing } \\
\text { RR (breaths/min): }<10 \text { or }>29 \text { vs. } 10-29 \\
\text { Capillary refill: }>2 \text { vs. }<2 \text { seconds (in cold conditions or poor lighting } \\
\text { use HR }>120 \text { vs. } \leq 120 \text { bpm instead of capillary refill) }\end{array}$ \\
\hline
\end{tabular}




\begin{tabular}{|c|c|c|}
\hline $\begin{array}{l}\text { Name } \\
\text { (Full Name) } \\
\text { Primary Use }\end{array}$ & Components & Scoring \\
\hline $\begin{array}{l}\text { ViEWS } 194 \\
\text { ViEWS-L }{ }^{195} \\
\text { (VitalPAC Early } \\
\text { Warning Score) } \\
\text { (modified VitalPAC } \\
\text { Early Warning Score } \\
\text { with rapid lactate } \\
\text { level) } \\
\text { Trauma triage/patient } \\
\text { deterioration } \\
\text { detection }\end{array}$ & $\begin{array}{l}\text { HR } \\
\text { RR } \\
\text { SBP } \\
\text { Oxygen saturation } \\
\text { Temperature } \\
\text { Supplemental oxygen } \\
\text { Level of consciousness } \\
\text { Lactate- } \\
\text {-Lactate in ViEWS-L } \\
\text { score only }\end{array}$ & $\begin{array}{l}\frac{\text { ViEWS }}{\text { Range: } 0-21} \\
\text { Direction: higher score=higher risk of death } \\
\text { Scoring: } \\
7 \text { components each scored } 0-3 \text { points } \\
\text { HR (bpm): } 51-90=0 ; 41-50 \text { or } 91-110=1 ; \leq 40 \text { or } 111-130=2 \text {; } \\
\geq 131=3 \\
\text { RR (breaths/min): } 12-20=0 ; 9-11=1 ; 21-24=2 ; \leq 8 \text { or } \geq 25=3 \\
\text { Temperature }(\text { Celsius): } 36.1-38.0=0 ; 35.1-36.0 \text { or } 38.1-39.0=1 ; \\
\geq 39.1=2 ; \leq 35.0=3 \\
\text { SBP (mmHg): } \leq 111-249-0 ; 101-110 \text { or }>250=1 ; 91-100=2 ; \leq 90 \\
=3 \\
\text { Oxygen saturation }(\%): \geq 96=0 ; 94-95=1 ; 92-93=2 ; \leq 91=3 \\
\text { Supplemental oxygen = } 3 \\
\text { Level of consciousness: alert = } 0 ; \text { responds only to voice or pain, or } \\
\text { unresponsive = } 3 \\
\text { ViEWS-L } \\
\text { Adds lactate level to ViEWS score } \\
\text { Score = ViEWS score plus lactate level (mmol/L) }\end{array}$ \\
\hline
\end{tabular}

APACHE II = Acute Physiology and Chronic Health Evaluation (revised); CRAMS = Circulation, Respiration, Abdomen, Motor, Speech; EMTRAS = Emergency Trauma Score; FTS07 = Field Triage Score (revised); GAP = Glasgow Coma Scale, age, pressure; GCS = Glasgow Coma Scale; HR = heart rate; MAP = mean arterial pressure; MGAP = Mechanism, Glasgow Coma Scale, age, pressure; MPTT = Modified Physiological Triage Tool; mREMS = modified Rapid Emergency Medicine Score; PHI = Prehospital Index; PTS = Pediatric Trauma Score; REMS = Rapid Emergency Medicine Score; RR = respiratory rate; RTS = Revised Trauma Score; SBP = systolic blood pressure; SETS = Simplified Emergency Trauma Score; START = Simple Triage and Rapid Treatment; T-ASPTS = Triage Age-Specific Pediatric Trauma Score; T-RTS = Revised Trauma Score for Triage; ViEWS = VitalPAC Early Warning Score; ViEWS-L = modified VitalPAC Early Warning Score with rapid lactate level

\section{Combinations of Physiologic Measures and Glasgow Coma Scale}

Table 24 lists the combination measures identified that include GCS. This table is split into four sections by bold lines. The first section includes the Revised Trauma Score (RTS) and variations designed to be easier to calculate or for use with pediatric patients. The next section below the bold line lists studies of different combinations that are similar to the RTS in that they combine GCS with physiologic measures; which physiology measures are used and how they are combined differ. The third section of the table lists studies that add mechanism or type of injury to the physiologic measures and GCS. The fourth and final sections list studies that evaluate triage protocols, which are the consideration of several measures following a prescribed order or algorithm. 
Table 24. Studies that evaluate the predictive utility of combination measures (Key Question 3)

\begin{tabular}{|c|c|c|}
\hline Measure Evaluated & $\begin{array}{l}\text { Number } \\
\text { of } \\
\text { Studies } \\
\text { (articles) }\end{array}$ & References \\
\hline Revised Trauma Score (RTS) & $\begin{array}{l}9 \text { studies } \\
(10 \\
\text { articles })\end{array}$ & $62,95,96,107,109,118,138,142,150,169$ \\
\hline Triage RTS & $\begin{array}{l}8 \text { studies } \\
(9 \\
\text { articles })\end{array}$ & $95,96,110,112,130,131,133,138,175$ \\
\hline $\begin{array}{l}\text { Triage Age-Specific Pediatric Trauma Score (ASPTS) } \\
\text { Includes SBP, RR, HR, and GCS }\end{array}$ & 1 & 175 \\
\hline $\begin{array}{l}\text { Pediatric Trauma Score (PTS) } \\
\text { Includes patient size, airway status, SBP, level of } \\
\text { consciousness, open wound, or fracture }\end{array}$ & 1 & 140 \\
\hline GAP & 3 & $109,138,155$ \\
\hline $\begin{array}{l}\text { Rapid Emergency Medicine Score (REMS) } \\
\text { Consists of GCS, RR, oxygen saturation, MAP, and age } \\
\text { Modified REMS (SBP replaces MAP, and different weights } \\
\text { placed on GCS and age) }\end{array}$ & 2 & 131,142 \\
\hline $\begin{array}{l}\text { Gglasgow Coma Scale (GCS) and Heart Rate } \\
\text { Complexity (HRC) }\end{array}$ & $\begin{array}{l}3(4 \\
\text { articles) }\end{array}$ & $40,49,81,82$ \\
\hline GCS, HRC and HR/vital signs & $\begin{array}{c}1(2 \\
\text { articles })\end{array}$ & 17,81 \\
\hline GCS and vital signs & $\begin{array}{c}2 \text { (3 } \\
\text { articles) }\end{array}$ & $17,81,82$ \\
\hline GCS and HR & $\begin{array}{c}2(3 \\
\text { articles) }\end{array}$ & $81,82,173$ \\
\hline Model (author-derived) using lactate, GCS, HR and SBP & 1 & 63 \\
\hline $\begin{array}{l}\text { GCS and manual, semi-automated and automated vital } \\
\text { signs } \\
\text { GCS and SBP }\end{array}$ & 1 & 70 \\
\hline MGAP & $\begin{array}{l}5(6 \\
\text { articles) }\end{array}$ & $95,96,109,138,142,155$ \\
\hline $\begin{array}{l}\text { Other measures including mechanism: } \\
\text { - } \quad \text { SETS (uses GCS, RR, mechanism of injury, and age } \\
\text { - } \quad \text { Model (author-derived) using GCS, RR, SBP, and } \\
\text { anatomic and mechanism criteria } \\
\text { - } \quad \text { Model (author-derived) using age, chest injury, GCS, } \\
\text { and SBP) }\end{array}$ & 3 & 58,169 \\
\hline APACHE II & 1 & 112 \\
\hline CareFlight triage & 2 & 61,167 \\
\hline EMTRAS & 1 & 134 \\
\hline $\begin{array}{l}\text { START triage } \\
\text { Modified START triage (palpable radial pulse replaces } \\
\text { capillary refill) }\end{array}$ & 3 & $61,129,167$ \\
\hline $\begin{array}{l}\text { ViEWS (includes SBP, HR, RR, temperature, } \mathrm{SpO}_{2} \text {, } \\
\text { supplemental } \mathrm{O}_{2} \text {, level of consciousness) } \\
\text { ViEWS-L (ViEWS with lactate) }\end{array}$ & 1 & 132 \\
\hline
\end{tabular}




\begin{tabular}{|l|c|l|}
\hline Measure Evaluated & $\begin{array}{c}\text { Number } \\
\text { of } \\
\text { Studies } \\
\text { (articles) }\end{array}$ & References \\
\hline Military Sieve, Modified Military Sieve, Triage Sort & 3 & $71,166,167$ \\
\hline Modified Physiological Triage Tool (MPTT) & 1 & 167 \\
\hline Prehospital Index (PHI) & 2 & 43,102 \\
\hline NTTP & 3 & $46,66,91$ \\
\hline $\begin{array}{l}\text { Current triage criteria: initial out-of-hospital physiologic } \\
\text { measures (GCS, SBP, RR, HR, SI) with different } \\
\text { combinations of values }\end{array}$ & 2 & 89,90 \\
\hline $\begin{array}{l}\text { Alternative triage guidelines (GCS } \leq 14 ; \text { SBP } \leq 110 \text { or } \\
\geq 200 ; \text { RR }<10 \text { or }>29 ; \text { HR } \leq 60 \text { or } \geq 110)\end{array}$ & 1 & 90 \\
\hline
\end{tabular}

APACHE II = Acute Physiology and Chronic Health Evaluation (revised); ASPTS = Age-Specific Pediatric Trauma Score; EMTRAS = Emergency Trauma Score; GAP = Glasgow Coma Scale, age, pressure; GCS = Glasgow Coma Scale; HR = heart rate; $\mathrm{HRC}$ = heart rate complexity; MAP = mean arterial pressure; MGAP = Mechanism, Glasgow Coma Scale, age, pressure; MPTT = Modified Physiological Triage Tool; NTTP = national trauma triage protocol; O2 = oxygen; PHI = Prehospital Index; PTS = Pediatric Trauma Score; REMS = Rapid Emergency Medicine Score; RR = respiratory rate; RTS = Revised Trauma Score; SBP = systolic blood pressure; SETS = Simplified Emergency Trauma Score; SI = shock index; SpO2 = peripheral oxygen saturation; START = Simple Triage and Rapid Treatment; ViEWS = VitalPAC Early Warning Score; ViEWS-L = modified VitalPAC Early Warning Score with rapid lactate level

Note: Similar measures are grouped between bold dividing lines.

\section{Revised Trauma Score and Variations}

Tables 25 and 26 report the results of the studies that evaluate the RTS as well as the triage RTS (T-RTS) listed in Table 24 for out-of-hospital and ED data. The two studies of variations developed to assess pediatric patients are reported in the section on subquestions about age groups. ${ }^{140,175}$

The RTS is a combination of SBP, RR, and GCS using coded values 0 to 4 assigned to ranges for each measure. The score is calculated as the weighted sum of these values: RTS = $0.9368 \mathrm{GCS}_{\mathrm{c}}+0.7326 \mathrm{SBP}_{\mathrm{c}}+0.2908 \mathrm{RR}_{\mathrm{c}}$, where subscript c indicates the coded value. This formula combines the three measures in a way that increases its prognostic accuracy but makes it difficult to calculate, requiring the use of a computer, smart phone, or monitor/medical device. The T-RTS is a simple sum of the coded values designed for use in triage.

The included studies often use RTS as reference or comparison for other measures and report AUROC values more frequently than sensitivity or specificity for specific threshold values. In the studies that compared the two versions, the differences were small (e.g., AUROC decreasing from 0.90 for the RTS to 0.88 for the T-RTS ${ }^{96}$ or from 0.75 to 0.74$) .{ }^{95}$ The plot for the ED analysis is in Appendix I. ${ }^{95,109,110,131,138,142,169}$ 
Table 25. Predictive utility of Revised Trauma Score and Triage Revised Trauma Score: out-ofhospital

\begin{tabular}{|c|c|c|c|c|c|}
\hline $\begin{array}{l}\text { Author, Year } \\
\text { Risk of Bias }\end{array}$ & $\begin{array}{l}\text { Measure } \\
\text { Threshold }\end{array}$ & $\begin{array}{l}\text { Serious Injury } \\
\text { Indicator } \\
\text { Type: Specific } \\
\text { Indicator }\end{array}$ & $\begin{array}{l}\text { Number } \\
\text { Analyzed } \\
\text { Age } \\
\text { Mean (SD) }\end{array}$ & $\begin{array}{l}\text { Sensitivity } \\
\text { Specificity } \\
(95 \% \mathrm{Cl})\end{array}$ & AUROC $(95 \% \mathrm{Cl})$ \\
\hline $\begin{array}{l}\text { Raux, } 2011^{95} \\
\text { Moderate }\end{array}$ & $\begin{array}{l}\text { RTS } \\
\text { Lyon cohort }\end{array}$ & $\begin{array}{l}\text { R: ICU LOS >2 } \\
\text { days }\end{array}$ & $\begin{array}{l}1,003 \\
39(18)\end{array}$ & NR & 0.83 (0.81 to 0.86$)$ \\
\hline $\begin{array}{l}\text { Raux, } 2011^{95} \\
\text { Moderate }\end{array}$ & $\begin{array}{l}\text { RTS } \\
\text { National cohort }\end{array}$ & $\begin{array}{l}\text { R: emergency } \\
\text { procedure }\end{array}$ & $\begin{array}{l}1,360 \\
38(17)\end{array}$ & NR & 0.51 (0.48 to 0.54$)$ \\
\hline $\begin{array}{l}\text { Raux, 201195 } \\
\text { Moderate }\end{array}$ & $\begin{array}{l}\text { RTS } \\
\text { National cohort }\end{array}$ & $\begin{array}{l}\text { R: massive } \\
\text { hemorrhage }\end{array}$ & $\begin{array}{l}1,360 \\
38(17)\end{array}$ & NR & 0.72 (0.69 to 0.73$)$ \\
\hline $\begin{array}{l}\text { Grimme, } \\
2005^{62} \\
\text { Moderate }\end{array}$ & RTS & I: organ failure & $\begin{array}{l}6,346 \\
33 \text { (range } 16 \\
\text { to } 81 \text { ) }\end{array}$ & NR & 0.633 (NR) \\
\hline $\begin{array}{l}\text { Raux, } 2011^{95} \\
\text { Moderate }\end{array}$ & $\begin{array}{l}\text { RTS } \\
\text { National cohort }\end{array}$ & $\begin{array}{l}\text { I: severe trauma } \\
(\text { ISS }>15)\end{array}$ & $\begin{array}{l}1,360 \\
38(17)\end{array}$ & NR & 0.75 (0.73 to 0.78$)$ \\
\hline $\begin{array}{l}\text { Miller, } 2017 \\
142 \\
\text { Moderate } \\
\end{array}$ & RTS & $\begin{array}{l}\text { M: in-hospital } \\
\text { mortality }\end{array}$ & $\begin{array}{l}429,711 \\
50(23)\end{array}$ & NR & $\begin{array}{l}0.959(0.955 \text { to } \\
0.964)\end{array}$ \\
\hline $\begin{array}{l}\text { Raux, 201195 } \\
\text { Sartorius, } \\
2010^{96} \\
\text { Moderate }\end{array}$ & $\begin{array}{l}\text { RTS } \\
<7.5 \\
\text { National cohort }\end{array}$ & M: mortality & $\begin{array}{l}1,360 \\
38(17)\end{array}$ & $\begin{array}{l}\text { Sen: } 95 \%(92 \text { to } 97) \\
\text { Sp: } 38 \% \text { (35 to } 41)\end{array}$ & 0.90 (0.88 to 0.92$)$ \\
\hline $\begin{array}{l}\text { Raux, } 2017^{95} \\
\text { Moderate }\end{array}$ & RTS & $\begin{array}{l}\text { M: } 30-\text { day all- } \\
\text { cause mortality }\end{array}$ & $\begin{array}{l}1,075 \\
39(18)\end{array}$ & NR & 0.89 (0.85 to 0.92$)$ \\
\hline $\begin{array}{l}\text { Raux, } 2011^{95} \\
\text { Moderate }\end{array}$ & $\begin{array}{l}\text { T-RTS } \\
\text { Lyon cohort }\end{array}$ & $\begin{array}{l}\text { R: ICU LOS >2 } \\
\text { days }\end{array}$ & $\begin{array}{l}1,003 \\
39(18)\end{array}$ & NR & 0.83 (0.81 to 0.86$)$ \\
\hline $\begin{array}{l}\text { Raux, } 2011^{95} \\
\text { Moderate }\end{array}$ & $\begin{array}{l}\text { T-RTS } \\
\text { National cohort }\end{array}$ & $\begin{array}{l}\text { R: massive } \\
\text { hemorrhage }\end{array}$ & $\begin{array}{l}1,360 \\
38(17)\end{array}$ & NR & $0.73(0.70$ to 0.77$)$ \\
\hline $\begin{array}{l}\text { Raux, } 2011^{95} \\
\text { Moderate }\end{array}$ & $\begin{array}{l}\text { T-RTS } \\
\text { National cohort }\end{array}$ & $\begin{array}{l}\text { R: emergency } \\
\text { procedure }\end{array}$ & $\begin{array}{l}1,360 \\
38(17) \\
\end{array}$ & NR & 0.52 (0.49 to 0.54$)$ \\
\hline $\begin{array}{l}\text { Raux, 201195 } \\
\text { Moderate }\end{array}$ & $\begin{array}{l}\text { T-RTS } \\
\text { National cohort }\end{array}$ & $\begin{array}{l}\text { I: severe trauma } \\
(\text { ISS }>15)\end{array}$ & $\begin{array}{l}1,360 \\
38(17)\end{array}$ & NR & 0.74 (0.71 to 0.76$)$ \\
\hline $\begin{array}{l}\text { Raux, 201195 } \\
\text { Sartorius, } \\
2010^{96} \\
\text { Moderate }\end{array}$ & $\begin{array}{l}\text { T-RTS } \\
<12 \\
\text { National cohort }\end{array}$ & M: mortality & $\begin{array}{l}1,360 \\
38(17)\end{array}$ & $\begin{array}{l}\text { Sen: } 96 \% \text { (93 to } 98) \\
\text { Sp: } 42 \% \text { (39 to } 45 \text { ) }\end{array}$ & 0.88 (0.86 to 0.92$)$ \\
\hline
\end{tabular}

AUROC = area under the receiver operating characteristic curve; CI = confidence interval; I = injury; ICU = intensive care unit; ISS = injury severity score; LOS = length of stay; LSI = life-saving intervention; $\mathrm{M}$ = mortality; $\mathrm{NR}=$ not reported; $\mathrm{R}=$ resource use; RTS = Revised Trauma Score; SD = standard deviation; Sen = sensitivity; Sp = specificity; T-RTS = Revised Trauma Score for Triage 
Table 26. Predictive utility of Revised Trauma Score and Triage Revised Trauma Score: emergency department

\begin{tabular}{|c|c|c|c|c|c|}
\hline $\begin{array}{l}\text { Author, } \\
\text { Year } \\
\text { Risk of Bias }\end{array}$ & $\begin{array}{l}\text { Measure } \\
\text { Threshold }\end{array}$ & $\begin{array}{l}\text { Serious Injury } \\
\text { Indicator } \\
\text { Type: Indicator }\end{array}$ & $\begin{array}{l}\text { Number } \\
\text { Analyzed } \\
\text { Age } \\
\text { Mean (SD) }\end{array}$ & $\begin{array}{l}\text { Sensitivity } \\
\text { Specificity } \\
(95 \% \mathrm{Cl})\end{array}$ & $\begin{array}{l}\text { AUROC } \\
(95 \% \mathrm{Cl})\end{array}$ \\
\hline $\begin{array}{l}\text { Woodford, } \\
2012^{107} \\
\text { Moderate }\end{array}$ & RTS & M: mortality & $\begin{array}{l}120 \\
42 \text { (range } 18 \text { to } \\
82 \text { ) } \\
\end{array}$ & $\begin{array}{l}\text { Sen: } 63 \%(N R) \\
\text { Sp: } 83 \%(N R)\end{array}$ & $\begin{array}{l}0.73(0.53 \\
\text { to } 0.94)\end{array}$ \\
\hline $\begin{array}{l}\text { Yuen, } \\
2016^{169} \\
\text { Moderate }\end{array}$ & RTS & M: mortality & $\begin{array}{l}850 \\
48(25)\end{array}$ & NR & 0.85 (NR) \\
\hline $\begin{array}{l}\text { Paladino, } \\
\text { 2010b 150 } \\
\text { Moderate }\end{array}$ & RTS & $\begin{array}{l}\text { C: major injury } \\
\text { (blood transfusion, } \\
\text { hemorrhage, or ISS } \\
\geq 16 \text { ) }\end{array}$ & $\begin{array}{l}1,649 \\
35 \text { (range } 13 \text { to } \\
95 \text { ) }\end{array}$ & NR & $\begin{array}{l}0.63(0.60 \\
\text { to } 0.67)\end{array}$ \\
\hline $\begin{array}{l}\text { Ahun, } \\
2014^{109} \\
\text { Moderate }\end{array}$ & $\begin{array}{l}\text { RTS } \\
<5.68\end{array}$ & M: 24-hour mortality & $\begin{array}{l}100 \\
40(16)\end{array}$ & $\begin{array}{l}\text { Sen: } 50.0 \%(12.4 \text { to } 87.6) \\
\text { Sp: } 100.0 \%(95.9 \text { to } 100.0)\end{array}$ & $0.727(\mathrm{NR})$ \\
\hline $\begin{array}{l}\text { Ahun, } \\
2014^{109} \\
\text { Moderate }\end{array}$ & $\begin{array}{l}\text { RTS } \\
<5.97\end{array}$ & M: 4-week mortality & $\begin{array}{l}100 \\
40(16)\end{array}$ & $\begin{array}{l}\text { Sen: } 41.7 \%(15.2 \text { to } 72.3) \\
\text { Sp: } 95.5 \%(88.8 \text { to } 98.7)\end{array}$ & 0.680 (NR) \\
\hline $\begin{array}{l}\text { Kondo, } \\
2011^{138} \\
\text { Moderate }\end{array}$ & RTS & $\begin{array}{l}\text { M: in-hospital } \\
\text { mortality }\end{array}$ & $\begin{array}{l}13,691 \\
51(22)\end{array}$ & NR & 0.919 (NR) \\
\hline $\begin{array}{l}\text { Kondo, } \\
2011^{138} \\
\text { Moderate }\end{array}$ & RTS & $\begin{array}{l}\text { M: mortality in ED or } \\
\text { OR }\end{array}$ & $\begin{array}{l}13,691 \\
51(22)\end{array}$ & NR & 0.966 (NR) \\
\hline $\begin{array}{l}\text { Al-Salamah, } \\
2004^{110} \\
\text { Moderate }\end{array}$ & $\begin{array}{l}\text { T-RTS } \\
<12\end{array}$ & $\begin{array}{l}\text { M: in-hospital } \\
\text { mortality }\end{array}$ & $\begin{array}{l}795 \\
44(21)\end{array}$ & $\begin{array}{l}\text { Sen: } 84 \%(N R) \\
\text { Sp: } 64 \%(N R)\end{array}$ & $0.83(\mathrm{NR})$ \\
\hline $\begin{array}{l}\text { Aslar, } \\
2004^{112} \\
\text { Moderate }\end{array}$ & $\begin{array}{l}\text { T-RTS } \\
\leq 8\end{array}$ & $\begin{array}{l}\text { M: 30-day in-hospital } \\
\text { mortality }\end{array}$ & $\begin{array}{l}64 \\
36(19)\end{array}$ & $\begin{array}{l}\text { *Sen: } 68.0 \%(46.5 \text { to } 85.1) \\
\text { *Sp: } 94.9 \%(82.7 \text { to } 99.4)\end{array}$ & NR \\
\hline $\begin{array}{l}\text { Imhoff, } \\
2014^{131} \\
\text { Moderate }\end{array}$ & T-RTS & $\begin{array}{l}\text { M: in-hospital } \\
\text { mortality }\end{array}$ & $\begin{array}{l}3,680 \\
37(17)\end{array}$ & NR & $\begin{array}{l}0.89(0.889 \\
\text { to } 0.891)\end{array}$ \\
\hline $\begin{array}{l}\text { Jones, } \\
2014^{133} \\
\text { Moderate }\end{array}$ & $\begin{array}{l}\text { T-RTS } \\
\leq 8 \\
<12\end{array}$ & M: 30-day mortality & $\begin{array}{l}5,363 \\
\text { Median (IQR) } \\
\text { Derivation } \\
\text { dataset } 33 \text { (22 } \\
\text { to } 51 \text { ) } \\
\text { Validation } \\
\text { dataset } 34 \text { (21 } \\
\text { to 51) }\end{array}$ & $\begin{array}{l}\text { *Sen: } 54.0 \%(49.1 \text { to } 58.8) \\
\text { *Sp: } 96.1 \% \text { (95.5 to } 96.6) \\
\text { *Sen: } 84.2 \%(80.4 \text { to } 87.5) \\
\text { *Sp: } 77.2 \%(76.0 \text { to } 78.4)\end{array}$ & NR \\
\hline $\begin{array}{l}\text { Kondo, } \\
2011^{138} \\
\text { Moderate }\end{array}$ & T-RTS & $\begin{array}{l}\text { M: in-hospital } \\
\text { mortality }\end{array}$ & $\begin{array}{l}13,691 \\
51(22)\end{array}$ & NR & 0.917 (NR) \\
\hline
\end{tabular}




\begin{tabular}{|c|c|c|c|c|c|}
\hline $\begin{array}{l}\text { Author, } \\
\text { Year } \\
\text { Risk of Bias }\end{array}$ & $\begin{array}{l}\text { Measure } \\
\text { Threshold }\end{array}$ & $\begin{array}{l}\text { Serious Injury } \\
\text { Indicator } \\
\text { Type: Indicator }\end{array}$ & $\begin{array}{l}\text { Number } \\
\text { Analyzed } \\
\text { Age } \\
\text { Mean (SD) }\end{array}$ & $\begin{array}{l}\text { Sensitivity } \\
\text { Specificity } \\
(95 \% \mathrm{Cl})\end{array}$ & $\begin{array}{l}\text { AUROC } \\
(95 \% \mathrm{Cl})\end{array}$ \\
\hline $\begin{array}{l}\text { Kondo, } \\
2011^{138} \\
\text { Moderate }\end{array}$ & T-RTS & $\begin{array}{l}\text { M: mortality in ED or } \\
\text { OR }\end{array}$ & $\begin{array}{l}13,691 \\
51(22)\end{array}$ & NR & 0.968 (NR) \\
\hline $\begin{array}{l}\text { Gray, } \\
1997^{130} \\
\text { Moderate }\end{array}$ & 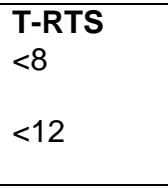 & $\begin{array}{l}\text { C: major injury } \\
\text { composite (ISS } \geq 15 \text {, } \\
\text { ICU admission or } \\
\text { mortality) }\end{array}$ & $\begin{array}{l}213 \\
\text { Median } 33 \\
\text { (range } 2 \text { to 95) }\end{array}$ & $\begin{array}{l}\text { Sen: } 19 \%(11.4 \text { to } 27.7) \\
\text { Sp: } 100 \%(96.9 \text { to } 100) \\
\text { Sen: } 60 \%(49.3 \text { to } 69.6) \\
\text { Sp: } 90 \%(84.1 \text { to } 95.2)\end{array}$ & NR \\
\hline
\end{tabular}

AUROC = area under the receiver operating characteristic curve; $\mathrm{C}=$ composite; $\mathrm{CI}$ = confidence interval; ED = emergency department; I = injury; ICU = intensive care unit; IQR = interquartile range; ISS = injury severity score; LSI = life-saving intervention; $\mathrm{M}$ = mortality; $\mathrm{NR}$ = not reported; OR = operating room; $\mathrm{R}$ = resource use; RTS = Revised Trauma Score; SD = standard deviation; Sen = sensitivity; $\mathrm{Sp}$ = specificity; T-RTS = Revised Trauma Score for Triage

*Results calculated by reviewers

\section{Other Combinations of Physiologic Measures With Glasgow Coma Scale}

In addition to the RTS, other combinations of physiologic measures and GCS have been studied, though less frequently (Table 27). These studies sought either to simplify an existing approach or to validate the addition of specific measures.

GAP (Glasgow Coma Scale, age, and arterial pressure) has been proposed as a simpler version of MGAP (mechanism, Glasgow Coma Scale, age, and arterial pressure). MGAP includes the mechanism of injury (see next section), and has been evaluated as a tool to predict mortality in the ED. ${ }^{109,138}$ GAP is calculated by starting with the GCS score (3-15) and adding points for SBP ( 6 if $>120$, 4 if $60-120$, and 0 if $<60$ ) and age ( 3 if $<60$ years old; 0 if $\geq 60$ ). Another simplification of an existing measure for use in triage is the Rapid Emergency Medicine Score (REMS), a simplified version of APACHE II, which is a severity assessment tool for use in intensive care. REMS does not require laboratory results but does require monitors/equipment to measure oxygen saturation and MAP. ${ }^{131}$

Some included studies explored the value of adding measures that required equipment for assessment. One study ${ }^{69}$ compared an assessment that could be done with no equipment (described as manual) with one that required a light to assess pupils and a pulse oximetry meter (semi-automated) to automate monitoring of blood pressure, $\mathrm{ETCO}_{2}$, and RR. The study concluded that the manual assessment performed as well as those requiring equipment. Point-ofcare lactate analyzers have become available, and another study focused on adding lactate measured in the field to a base combination of vital signs and GCS. ${ }^{63}$ 
Table 27. Predictive utility of other combinations of circulatory and/or respiratory measures with Glasgow Coma Scale

\begin{tabular}{|c|c|c|c|c|c|}
\hline $\begin{array}{l}\text { Measure } \\
\text { Threshold } \\
\text { Setting } \\
\end{array}$ & $\begin{array}{l}\text { Author, Year } \\
\text { Risk of Bias }\end{array}$ & $\begin{array}{l}\text { Serious Injury } \\
\text { Indicator } \\
\text { Type: Indicator }\end{array}$ & $\begin{array}{l}\begin{array}{l}\text { Number } \\
\text { Analyzed }\end{array} \\
\text { Age } \\
\text { Mean (SD) }\end{array}$ & $\begin{array}{l}\text { Sensitivity } \\
\text { Specificity } \\
(95 \% \mathrm{Cl})\end{array}$ & $\begin{array}{l}\text { AUROC } \\
\text { (95\% Cl) }\end{array}$ \\
\hline $\begin{array}{l}\text { GAP } \\
<19 \\
\text { ED }\end{array}$ & $\begin{array}{l}\text { Ahun, 2014 } \\
\text { Moderate }\end{array}$ & M: 24-hour mortality & $\begin{array}{l}\mathrm{N}=100 \\
40(16)\end{array}$ & $\begin{array}{l}\text { Sen: } 83 \% \text { ( } 36 \text { to } \\
97 \text { ) } \\
\text { Sp: } 88 \% \text { ( } 79 \text { to } \\
94 \text { ) }\end{array}$ & 0.910 (NR) \\
\hline $\begin{array}{l}\text { GAP } \\
<21 \\
\text { ED } \\
\end{array}$ & $\begin{array}{l}\text { Ahun, } 2014^{109} \\
\text { Moderate }\end{array}$ & M: 4-week mortality & $\begin{array}{l}N=100 \\
40(16)\end{array}$ & $\begin{array}{l}\text { Sen: } 92 \% \text { (62 to } \\
99 \%) \\
\text { Sp: } 78 \% \text { (68 to } \\
87 \text { ) }\end{array}$ & $0.904(\mathrm{NR})$ \\
\hline $\begin{array}{l}\text { GAP } \\
\text { ED }\end{array}$ & $\begin{array}{l}\text { Kondo, 2011 } \\
\text { Low }\end{array}$ & $\begin{array}{l}\text { M: short-term } \\
\text { mortality }\end{array}$ & $\begin{array}{l}N=13,691 \\
47(20)\end{array}$ & NR & $0.965(\mathrm{NR})$ \\
\hline $\begin{array}{l}\text { GAP } \\
\text { ED }\end{array}$ & $\begin{array}{l}\text { Kondo, } 2011^{138} \\
\text { Low }\end{array}$ & $\begin{array}{l}\text { M: long-term } \\
\text { mortality }\end{array}$ & $\begin{array}{l}\mathrm{N}=13,691 \\
47(20)\end{array}$ & NR & $0.933(\mathrm{NR})$ \\
\hline $\begin{array}{l}\text { GAP } \\
\text { ISS }>16 \text { subgroup } \\
\text { ED }\end{array}$ & $\begin{array}{l}\text { Kondo, } 2011^{138} \\
\text { Low }\end{array}$ & $\begin{array}{l}\text { M: long-term } \\
\text { mortality }\end{array}$ & $\begin{array}{l}\mathrm{N}=6,552 \\
47(20)\end{array}$ & NR & 0.905 (NR) \\
\hline $\begin{array}{l}\text { GAP } \\
\text { ISS }>16 \text { subgroup } \\
\text { ED }\end{array}$ & $\begin{array}{l}\text { Kondo, } 2011^{138} \\
\text { Low }\end{array}$ & $\begin{array}{l}\text { M: short-term } \\
\text { mortality }\end{array}$ & $\begin{array}{l}\mathrm{N}=6,552 \\
47(20)\end{array}$ & NR & $0.943(\mathrm{NR})$ \\
\hline $\begin{array}{l}\text { GAP } \\
\leq 21 \\
\text { ED }\end{array}$ & $\begin{array}{l}\text { Rahmani, } \\
2017^{155} \\
\text { Moderate }\end{array}$ & R: no surgery & $\begin{array}{l}\mathrm{N}=374 \\
42(18)\end{array}$ & $\begin{array}{l}\text { Sen: } 75 \%(N R) \\
\text { Sp: } 57 \%(N R)\end{array}$ & $0.74(\mathrm{NR})$ \\
\hline $\begin{array}{l}\text { GAP } \\
\leq 18 \\
\text { ED }\end{array}$ & $\begin{array}{l}\text { Rahmani, } \\
2017^{155} \\
\text { Moderate }\end{array}$ & M: ED survival & $\begin{array}{l}\mathrm{N}=374 \\
42(18)\end{array}$ & $\begin{array}{l}\text { Sen: } 88 \%(N R) \\
\text { Sp: } 85 \%(N R)\end{array}$ & $0.93(\mathrm{NR})$ \\
\hline $\begin{array}{l}\text { GAP } \\
\leq 14 \\
\text { ED }\end{array}$ & $\begin{array}{l}\text { Rahmani, } \\
2017^{155} \\
\text { Moderate }\end{array}$ & $\begin{array}{l}\text { M: In-hospital } \\
\text { survival }\end{array}$ & $\begin{array}{l}\mathrm{N}=374 \\
42(18)\end{array}$ & $\begin{array}{l}\text { Sen: } 98 \%(N R) \\
\text { Sp: } 91 \%(N R)\end{array}$ & 0.99 (NR) \\
\hline $\begin{array}{l}\text { REMS } \\
\text { ED }\end{array}$ & $\begin{array}{l}\text { Imhoff, } 2014^{131} \\
\text { Moderate }\end{array}$ & $\begin{array}{l}\text { M: mortality in- } \\
\text { hospital }\end{array}$ & $\begin{array}{l}N=3,680 \\
37(17)\end{array}$ & NR & $\begin{array}{l}0.91 \text { (SD } \\
0.02)\end{array}$ \\
\hline $\begin{array}{l}\text { Modified REMS } \\
\text { ED }\end{array}$ & $\begin{array}{l}\text { Miller, } 2017^{142} \\
\text { Moderate }\end{array}$ & $\begin{array}{l}\text { M: in-hospital } \\
\text { mortality }\end{array}$ & $\begin{array}{l}\mathrm{N}=429,711 \\
50(23)\end{array}$ & NR & $\begin{array}{l}0.967(0.963 \\
\text { to } 0.971)\end{array}$ \\
\hline
\end{tabular}




\begin{tabular}{|c|c|c|c|c|c|}
\hline $\begin{array}{l}\text { Measure } \\
\text { Threshold } \\
\text { Setting }\end{array}$ & $\begin{array}{l}\text { Author, Year } \\
\text { Risk of Bias }\end{array}$ & $\begin{array}{l}\text { Serious Injury } \\
\text { Indicator } \\
\text { Type: Indicator }\end{array}$ & $\begin{array}{l}\text { Number } \\
\text { Analyzed } \\
\text { Age } \\
\text { Mean (SD) }\end{array}$ & $\begin{array}{l}\text { Sensitivity } \\
\text { Specificity } \\
(95 \% \mathrm{Cl})\end{array}$ & $\begin{array}{l}\text { AUROC } \\
(95 \% \mathrm{CI})\end{array}$ \\
\hline $\begin{array}{l}\text { Author-created } \\
\text { model } \\
\text { Base (SI, HR, } \\
\text { SBP, RR, and } \\
\text { GCS) } \\
\text { with and without } \\
\text { lactate } \\
\text { Thresholds } \\
\text { SI }>0.8, \mathrm{HR}>110 \text {, } \\
\mathrm{SBP}<100, \mathrm{RR} \\
\geq 30 \text {, and GCS } \\
<15 \text {; Lactate }>2 \\
\mathrm{OH}\end{array}$ & $\begin{array}{l}\text { Guyette, } \\
2011^{63} \\
\text { Moderate }\end{array}$ & $\begin{array}{l}\text { R: emergent } \\
\text { operation }\end{array}$ & $\begin{array}{l}\mathrm{N}=1168 \\
\text { Median 44 } \\
\text { (IQR 27-58) }\end{array}$ & $\begin{array}{l}\text { Base with } \\
\text { lactate } \\
\text { Sen: } 86 \% \text { ( } 77 \text { to } \\
93 \% \text { ) } \\
\text { Sp: } 25 \% \text { (22 to } \\
\text { 18\%) } \\
\text { Base without } \\
\text { lactate } \\
\text { Sen: } 64 \% \text { (53 to } \\
74 \% \text { ) } \\
\text { Sp: } 51 \% \text { (48 to } \\
\text { 54\%) }\end{array}$ & $\begin{array}{l}\text { Base with } \\
\text { Lactate } \\
0.71 \text { (CI NR) } \\
\\
\text { Base without } \\
\text { lactate } \\
0.68 \text { (NR) }\end{array}$ \\
\hline $\begin{array}{l}\text { Author-created } \\
\text { model } \\
\text { Base (SI, HR, } \\
\text { SBP, RR, and } \\
\text { GCS) } \\
\text { with and without } \\
\text { lactate } \\
\text { Thresholds } \\
\mathrm{SI}>0.8, \mathrm{HR}>110 \text {, } \\
\mathrm{SBP}<100, \mathrm{RR} \\
\geq 30 \text {, and GCS } \\
<15 \text {; Lactate }>2 \\
\mathrm{OH}\end{array}$ & $\begin{array}{l}\text { Guyette, } \\
2011^{63} \\
\text { Moderate }\end{array}$ & $\begin{array}{l}\text { R: multiple organ } \\
\text { dysfunction }\end{array}$ & $\begin{array}{l}\mathrm{N}=1168 \\
\text { Median 44 } \\
\text { (IQR 27-58) }\end{array}$ & $\begin{array}{l}\text { Base with } \\
\text { Lactate } \\
\text { Sen: } 99 \% \text { (92 to } \\
100 \% \text { ) } \\
\text { Sp: } 25 \% \text { (23 to } \\
28 \% \text { ) } \\
\text { Base without } \\
\text { Lactate } \\
\text { Sen: } 94 \% \text { (85 to } \\
98 \% \text { ) } \\
\text { Sp: } 53 \% \text { (50 to } \\
\text { 56\%) }\end{array}$ & $\begin{array}{l}\text { Base with } \\
\text { Lactate } \\
0.81(N R) \\
\\
\text { Base without } \\
\text { lactate } \\
0.78 \text { (NR) }\end{array}$ \\
\hline $\begin{array}{l}\begin{array}{l}\text { Author-created } \\
\text { model }\end{array} \\
\text { Base (SI, HR, } \\
\text { SBP, RR, and } \\
\text { GCS) } \\
\text { with and without } \\
\text { lactate } \\
\text { Thresholds } \\
\text { SI }>0.8, \mathrm{HR}>110 \text {, } \\
\mathrm{SBP}<100, \mathrm{RR} \\
\geq 30 \text {, and GCS } \\
<15 \text {; Lactate }>2 \\
\mathrm{OH}\end{array}$ & $\begin{array}{l}\text { Guyette, } \\
2011^{63} \\
\text { Moderate }\end{array}$ & M: mortality & $\begin{array}{l}\mathrm{N}=1168 \\
\text { Median 44 } \\
\text { (IQR 27-58) }\end{array}$ & $\begin{array}{l}\text { Base with } \\
\text { lactate } \\
\text { Sen: } 97 \% \text { (89 to } \\
100 \% \text { ) } \\
\text { Sp: } 25 \% \text { (23 to } \\
28 \% \text { ) } \\
\text { Base without } \\
\text { lactate } \\
\text { Sen: } 88 \% \text { (77 to } \\
\text { 95\%) } \\
\text { Sp: } 52 \% \text { (49 to } \\
\text { 55\%) }\end{array}$ & $\begin{array}{l}\text { Base with } \\
\text { lactate } \\
0.89(N R) \\
\\
\text { Base without } \\
\text { lactate } \\
0.85 \text { (NR) }\end{array}$ \\
\hline $\begin{array}{l}\text { Manual/Group 1: } \\
\text { Radial pulse } \\
\text { character, verbal } \\
\text { and motor GCS }\end{array}$ & $\begin{array}{l}\text { Holcomb, } \\
2005^{69} \\
\text { High }\end{array}$ & $\begin{array}{l}\text { R: prehospital life- } \\
\text { saving intervention }\end{array}$ & $\begin{array}{l}\mathrm{N}=381 \\
35(16) \\
\text { Patients with } \\
\text { LSI } \\
37 \text { (17) } \\
\text { Patients } \\
\text { without LSI }\end{array}$ & NR & \begin{tabular}{|l|}
$0.969(\mathrm{NR})$ \\
(multivariate)
\end{tabular} \\
\hline
\end{tabular}




\begin{tabular}{|c|c|c|c|c|c|}
\hline $\begin{array}{l}\text { Measure } \\
\text { Threshold } \\
\text { Setting }\end{array}$ & $\begin{array}{l}\text { Author, Year } \\
\text { Risk of Bias }\end{array}$ & $\begin{array}{l}\text { Serious Injury } \\
\text { Indicator } \\
\text { Type: Indicator }\end{array}$ & $\begin{array}{l}\text { Number } \\
\text { Analyzed } \\
\text { Age } \\
\text { Mean (SD) }\end{array}$ & $\begin{array}{l}\text { Sensitivity } \\
\text { Specificity } \\
(95 \% \mathrm{Cl})\end{array}$ & $\begin{array}{l}\text { AUROC } \\
(95 \% \mathrm{Cl})\end{array}$ \\
\hline $\begin{array}{l}\text { Manual/Group 1: } \\
\text { Radial pulse } \\
\text { character, verbal } \\
\text { and motor GCS }\end{array}$ & $\begin{array}{l}\text { Holcomb, } \\
2005^{69} \\
\text { High }\end{array}$ & $\begin{array}{l}\text { R: hospital life-saving } \\
\text { intervention }\end{array}$ & $\begin{array}{l}\mathrm{N}=381 \\
35(16) \\
\text { Patients with } \\
\text { LSI } \\
37 \text { (17) } \\
\text { Patients } \\
\text { without LSI }\end{array}$ & NR & $\begin{array}{l}0.619(\mathrm{NR}) \\
\text { (multivariate) }\end{array}$ \\
\hline $\begin{array}{l}\text { Manual/Group 1: } \\
\text { Radial pulse } \\
\text { character, verbal } \\
\text { and motor GCS }\end{array}$ & $\begin{array}{l}\text { Holcomb, } \\
2005^{69} \\
\text { High }\end{array}$ & R: overall LSI & $\begin{array}{l}\mathrm{N}=381 \\
35(16) \\
\text { Patients with } \\
\text { LSI } \\
37(17) \\
\text { Patients } \\
\text { without LSI }\end{array}$ & NR & $\begin{array}{l}0.804 \text { (NR) } \\
\text { (multivariate) }\end{array}$ \\
\hline $\begin{array}{l}\text { Semi- } \\
\text { automated/Group } \\
\text { 2: Radial pulse } \\
\text { character, eye and } \\
\text { motor GCS }\end{array}$ & $\begin{array}{l}\text { Holcomb, } \\
2005^{69} \\
\text { High }\end{array}$ & R: prehospital LSI & $\begin{array}{l}\mathrm{N}=381 \\
35(16) \\
\text { Patients with } \\
\text { LSI } \\
37 \text { (17) } \\
\text { Patients } \\
\text { without LSI }\end{array}$ & NR & $\begin{array}{l}0.970(\mathrm{NR}) \\
\text { (multivariate) }\end{array}$ \\
\hline $\begin{array}{l}\text { Semi- } \\
\text { automated/Group } \\
\text { 2: Radial pulse } \\
\text { character, eye and } \\
\text { motor GCS }\end{array}$ & $\begin{array}{l}\text { Holcomb, } \\
2005^{69} \\
\text { High }\end{array}$ & R: hospital LSI & $\begin{array}{l}\mathrm{N}=381 \\
35(16) \\
\text { Patients with } \\
\text { LSI } \\
37 \text { (17) } \\
\text { Patients } \\
\text { without LSI }\end{array}$ & NR & $\begin{array}{l}0.616(\mathrm{NR}), \\
\mathrm{p}<0.05 \\
\text { (multivariate) }\end{array}$ \\
\hline $\begin{array}{l}\text { Semi- } \\
\text { automated/Group } \\
\text { 2: Radial pulse } \\
\text { character, eye and } \\
\text { motor GCS }\end{array}$ & $\begin{array}{l}\text { Holcomb, } \\
2005^{69} \\
\text { High }\end{array}$ & R: overall LSI & $\begin{array}{l}\mathrm{N}=381 \\
35(16) \\
\text { Patients with } \\
\text { LSI } \\
37 \text { (17) } \\
\text { Patients } \\
\text { without LSI }\end{array}$ & NR & $\begin{array}{l}0.807 \text { (NR) } \\
\text { (multivariate) }\end{array}$ \\
\hline $\begin{array}{l}\text { Automated/Group } \\
\text { 3: radial pulse } \\
\text { character, eye and } \\
\text { motor GCS, and } \\
\text { SBP }\end{array}$ & $\begin{array}{l}\text { Holcomb, } \\
2005^{69} \\
\text { High }\end{array}$ & R: prehospital LSI & $\begin{array}{l}\mathrm{N}=381 \\
35(16) \\
\text { Patients with } \\
\text { LSI } \\
37 \text { (17) } \\
\text { Patients } \\
\text { without LSI }\end{array}$ & NR & $\begin{array}{l}0.975 \text { (NR) } \\
\text { (multivariate) }\end{array}$ \\
\hline $\begin{array}{l}\text { Automated/Group } \\
\text { 3: radial pulse } \\
\text { character, eye and } \\
\text { motor GCS, and } \\
\text { SBP }\end{array}$ & $\begin{array}{l}\text { Holcomb, } \\
2005^{69} \\
\text { High }\end{array}$ & R: hospital LSI & $\begin{array}{l}\mathrm{N}=381 \\
35 \text { (16) } \\
\text { Patients with } \\
\text { LSI } \\
37 \text { (17) } \\
\text { Patients } \\
\text { without LSI }\end{array}$ & NR & $\begin{array}{l}0.717(\mathrm{NR}), \\
\mathrm{p}<0.05 \\
\text { (multivariate) }\end{array}$ \\
\hline
\end{tabular}




\begin{tabular}{|c|c|c|c|c|c|}
\hline $\begin{array}{l}\text { Measure } \\
\text { Threshold } \\
\text { Setting } \\
\end{array}$ & $\begin{array}{l}\text { Author, Year } \\
\text { Risk of Bias }\end{array}$ & $\begin{array}{l}\text { Serious Injury } \\
\text { Indicator } \\
\text { Type: Indicator }\end{array}$ & $\begin{array}{l}\begin{array}{l}\text { Number } \\
\text { Analyzed }\end{array} \\
\text { Age } \\
\text { Mean (SD) }\end{array}$ & $\begin{array}{l}\text { Sensitivity } \\
\text { Specificity } \\
(95 \% \mathrm{Cl})\end{array}$ & $\begin{array}{l}\text { AUROC } \\
\text { (95\% CI) }\end{array}$ \\
\hline $\begin{array}{l}\text { Automated/Group } \\
\text { 3: radial pulse } \\
\text { character, eye and } \\
\text { motor GCS, and } \\
\text { SBP }\end{array}$ & $\begin{array}{l}\text { Holcomb, } \\
2005^{69} \\
\text { High }\end{array}$ & R: overall LSI & $\begin{array}{l}\mathrm{N}=381 \\
35(16) \\
\text { Patients with } \\
\text { LSI } \\
37 \text { (17) } \\
\text { Patients } \\
\text { without LSI } \\
\end{array}$ & NR & $\begin{array}{l}0.846 \text { (NR) } \\
\text { (multivariate) }\end{array}$ \\
\hline
\end{tabular}

AUROC = area under the receiver operating characteristic curve; CI = confidence interval; ED = emergency department; GAP = Glasgow Coma Scale, age, blood pressure; GCS = Glasgow Coma Scale; HR = heart rate; IQR = interquartile range; ISS = injury severity score; LSI = life-saving intervention; $\mathrm{M}$ = mortality; $\mathrm{NR}=$ not reported; $\mathrm{OH}$ = out-of-hospital; $\mathrm{R}=$ resource use; REMS = Rapid Emergency Medicine Score; RR = respiratory rate; SBP = systolic blood pressure; Sen = sensitivity; SI = shock index; $\mathrm{Sp}=$ specificity

\section{Addition of Mechanism of Injury}

Adding information on how trauma patients were injured has been included in field assessment, based on the idea that the mechanism of injury was relevant information that could be easily collected. Early studies verified that mechanism criteria was associated with severity of injury when considered independently but that this information did not add predictive value when vital signs and GCS were available. ${ }^{68}$ The MGAP was developed including a general indicator of type of injury produced, and studies recommended and evaluated MGAP 95,96,109,138 as a predictor of mortality; however, the addition of mechanism added little or no predictive value over the GAP measure. Studies of other combinations of mechanism of injury with physiologic measures and GCS also reported good predictive utility ${ }^{95,96,109,138,142,155}$ but not better than that achieved without including mechanism. Details about these studies and their results are available in the evidence tables in Appendix D.

\section{Triage Protocols}

Another approach to assessing physiologic indicators is to consider the predictive utility of the overall triage algorithm or protocol in which they are included (Table 28). In order to compare the utility of measures, they need to be varied within the protocol. The studies identified varied the measures for different age groups or tested combinations across age groups. Studies examined the impact of changing the threshold for SBP from 90 to $110 \mathrm{mmHg}$ for trauma patients 16-65 years old and those over $65^{46}$ and assessed the utility of current criteria for people over $55 .^{89}$ Another study derived criteria that could increase sensitivity and reduce undertriage, but at the cost of substantial increases in overtriage. ${ }^{90}$ 
Table 28. Predictive utility of variations and combinations of triage protocols

\begin{tabular}{|c|c|c|c|c|c|}
\hline $\begin{array}{l}\text { Author, Year } \\
\text { Risk of Bias }\end{array}$ & $\begin{array}{l}\text { Measure and } \\
\text { Threshold } \\
\text { Setting }\end{array}$ & $\begin{array}{l}\text { Serious Injury } \\
\text { Indicator } \\
\text { Type: Indicator }\end{array}$ & $\begin{array}{l}\text { Number } \\
\text { Analyzed } \\
\text { Age } \\
\text { Mean (SD) }\end{array}$ & $\begin{array}{l}\text { Sensitivity } \\
\text { Specificity } \\
(95 \% \mathrm{Cl})\end{array}$ & $\begin{array}{l}\text { AUROC } \\
(95 \% \text { C) }\end{array}$ \\
\hline $\begin{array}{l}\text { Brown, 2015a }{ }^{46} \\
\text { Moderate }\end{array}$ & $\begin{array}{l}\text { NTTP Step } 1+2 ; \\
\text { SBP <110 } \\
\text { OH }\end{array}$ & $\begin{array}{l}\mathrm{R}, \mathrm{I} \text { : trauma center } \\
\text { need }\end{array}$ & $\begin{array}{l}\text { 1,555,944 } \\
\text { Median } 49\end{array}$ & $\begin{array}{l}\text { Age } 16-65 \\
\text { Sen: } 67 \%(\mathrm{Cl} N R) \\
\text { Sp: } 62 \%(\mathrm{Cl} N R)\end{array}$ & $\begin{array}{l}0.641(0.64 \\
\text { to } 0.642)\end{array}$ \\
\hline $\begin{array}{l}\text { Aslar, } 2004^{112} \\
\text { Moderate }\end{array}$ & $\begin{array}{l}\text { APACHE II score } \\
\geq 15 \\
\text { ED }\end{array}$ & M: mortality & $\begin{array}{l}64 \\
36(18.6)\end{array}$ & $\begin{array}{l}\text { Sen: } 80 \% \text { (59 to } \\
\text { 93\%) } \\
\text { Sp: } 95 \% \text { (83 to } \\
99 \% \text { ) } \\
\text { (values } \\
\text { calculated) }\end{array}$ & NR \\
\hline $\begin{array}{l}\text { Vassallo, } 2017^{167} \\
\text { High }\end{array}$ & CareFlight Triage & $\begin{array}{l}\text { R: Live saving } \\
\text { intervention }\end{array}$ & $\begin{array}{l}3654 \\
\text { Age (median) } \\
\text { No } \\
\text { hemorrhage : } \\
41 \text { (range: 18- } \\
83 \text { ) } \\
\text { Hemorrhage } \\
\text { group: } 29 \\
\text { (range: } 18- \\
74) \\
\end{array}$ & $\begin{array}{l}\text { Sen: } 33.5 \%(31.3 \\
\text { to } 35.8) \\
\text { Sp: } 98.4 \%(97.7 \text { to } \\
98.9)\end{array}$ & NR \\
\hline $\begin{array}{l}\text { Garner, } 2001^{61} \\
\text { Low }\end{array}$ & $\begin{array}{l}\text { CareFlight Triage } \\
\text { algorithm } \\
\text { OH }\end{array}$ & R: critical injury & $\begin{array}{l}1144 \\
\text { Median 33 } \\
\text { (IQR 21-53) }\end{array}$ & $\begin{array}{l}\text { Sen: } 82 \% \text { ( } 75 \text { to } \\
88 \%) \\
\text { Sp: } 96 \% \text { (94 to } \\
97 \%)\end{array}$ & NR \\
\hline $\begin{array}{l}\text { Joosse, } 2014^{134} \\
\text { Low }\end{array}$ & $\begin{array}{l}\text { EMTRAS (age, } \\
\text { GCS, base } \\
\text { excess, } \\
\text { prothrombin time) } \\
\text { ED }\end{array}$ & $\begin{array}{l}\text { M: Mortality, in- } \\
\text { hospital }\end{array}$ & 4418 & $\begin{array}{l}\text { NR } \\
\text { NR }\end{array}$ & $\begin{array}{l}0.94(0.93 \text { to } \\
0.96)\end{array}$ \\
\hline $\begin{array}{l}\text { Vassallo, } 2017^{167} \\
\text { High }\end{array}$ & Military Sieve & $\begin{array}{l}\text { R: Live saving } \\
\text { intervention }\end{array}$ & $\begin{array}{l}3654 \\
\text { Age (median) } \\
\text { No } \\
\text { hemorrhage : } \\
41 \text { (range: 18- } \\
83 \text { ) } \\
\text { Hemorrhage } \\
\text { group: } 29 \\
\text { (range: } 18- \\
74) \\
\end{array}$ & $\begin{array}{l}\text { Sen: } 43.8 \%(41.5 \\
\text { to } 46.2) \\
\text { Sp: } 93.6 \%(92.4 \text { to } \\
94.6)\end{array}$ & NR \\
\hline $\begin{array}{l}\text { Vassallo, } 2017^{167} \\
\text { High }\end{array}$ & $\begin{array}{l}\text { Modified Military } \\
\text { Sieve }\end{array}$ & $\begin{array}{l}\text { R: Live saving } \\
\text { intervention }\end{array}$ & $\begin{array}{l}3654 \\
\text { Age (median) } \\
\text { No } \\
\text { hemorrhage : } \\
41 \text { (range: 18- } \\
83 \text { ) } \\
\text { Hemorrhage } \\
\text { group: } 29 \\
\text { (range: 18- } \\
74 \text { ) }\end{array}$ & $\begin{array}{l}\text { Sen: } 50.9 \% \text { (48.6 } \\
\text { to } 53.3) \\
\text { Sp: } 87.5 \% \text { (85.9 to } \\
88.9)\end{array}$ & NR \\
\hline
\end{tabular}




\begin{tabular}{|c|c|c|c|c|c|}
\hline $\begin{array}{l}\text { Author, Year } \\
\text { Risk of Bias }\end{array}$ & $\begin{array}{l}\text { Measure and } \\
\text { Threshold } \\
\text { Setting }\end{array}$ & $\begin{array}{l}\text { Serious Injury } \\
\text { Indicator } \\
\text { Type: Indicator }\end{array}$ & $\begin{array}{l}\text { Number } \\
\text { Analyzed } \\
\text { Age } \\
\text { Mean (SD) }\end{array}$ & $\begin{array}{l}\text { Sensitivity } \\
\text { Specificity } \\
(95 \% \mathrm{Cl})\end{array}$ & $\begin{array}{l}\text { AUROC } \\
(95 \% \text { C) }\end{array}$ \\
\hline $\begin{array}{l}\text { Horne, } 2013^{71} \\
\text { High }\end{array}$ & $\begin{array}{l}\text { Triage Sieve } \\
\text { military UK Triage } \\
\text { Sieve RR }<12 \text { or } \\
>24 \text { and } \mathrm{HR}>60 \\
\text { and }<120 \\
\mathrm{OH}\end{array}$ & $\begin{array}{l}\text { R: Live saving } \\
\text { intervention }\end{array}$ & $\begin{array}{l}1213 \\
N R(N R)\end{array}$ & $\begin{array}{l}\text { Sen: } 72.3 \%(N R) \\
\text { Sp: } 77.1 \%(N R)\end{array}$ & NR \\
\hline $\begin{array}{l}\text { Vassallo, } 2015^{166} \\
\text { Moderate }\end{array}$ & $\begin{array}{l}\text { Triage Sort } \\
\text { ED }\end{array}$ & $\begin{array}{l}\text { R: Live saving } \\
\text { intervention }\end{array}$ & $\begin{array}{l}345 \\
\text { Age (median) } \\
\text { No } \\
\text { hemorrhage : } \\
41 \text { (range: } 18- \\
83 \text { ) } \\
\text { Hemorrhage } \\
\text { group: } 29 \\
\text { (range: } 18- \\
74)\end{array}$ & $\begin{array}{l}\text { Sen: } 58.6 \%(51.8 \\
\text { to } 65.4) \\
\text { Sp: } 88.7 \% \text { (83.5 to } \\
93.9)\end{array}$ & NR \\
\hline $\begin{array}{l}\text { Vassallo, } 2017^{167} \\
\text { High }\end{array}$ & $\begin{array}{l}\text { Modified } \\
\text { Physiological } \\
\text { Triage Tool } \\
\text { ED }\end{array}$ & $\begin{array}{l}\text { R: Live saving } \\
\text { intervention }\end{array}$ & $\begin{array}{l}3654 \\
\text { Age (median) } \\
\text { No } \\
\text { hemorrhage : } \\
41 \text { (range: } 18- \\
83 \text { ) } \\
\text { Hemorrhage } \\
\text { group: } 29 \\
\text { (range: } 18- \\
74)\end{array}$ & $\begin{array}{l}\text { Sen: } 69.9 \% \text { (67.7 } \\
\text { to } 72.0) \\
\text { Sp: } 65.3 \% \text { (63.2 to } \\
67.5)\end{array}$ & NR \\
\hline $\begin{array}{l}\text { Ocak, } 2009^{91} \\
\text { Moderate }\end{array}$ & $\begin{array}{l}\text { NTTP - } \\
\text { physiologic } \\
\text { component } \\
\text { - any of: GCS } \\
<14 \text {, SBP }<90, \text { RR } \\
<10 \text { or }>29 \\
\text { OH }\end{array}$ & I: Major trauma & $\begin{array}{l}302 \\
54(24)\end{array}$ & $\begin{array}{l}\text { *Sen: 63\% (55 to } \\
\text { 70) } \\
\text { `Sp: } 93 \% \text { (88 to } \\
97 \text { ) }\end{array}$ & NR \\
\hline $\begin{array}{l}\text { Haider, } 2016^{66} \\
\text { Moderate }\end{array}$ & $\begin{array}{l}\begin{array}{l}\text { NTTP with SBP } \\
<90 \\
\mathrm{OH}\end{array} \\
\end{array}$ & $\begin{array}{l}\mathrm{R}, \mathrm{I}, \mathrm{M} \text { : ISS or } \\
\text { surgery or ICU or } \\
\text { death }\end{array}$ & $\begin{array}{l}505,296 \\
47(19.7)\end{array}$ & $\begin{array}{l}\text { Sen: } 42 \% \text { (NR) } \\
\text { Sp: 82\% (NR) }\end{array}$ & NR \\
\hline $\begin{array}{l}\text { Haider, } 2016^{66} \\
\text { Moderate }\end{array}$ & $\begin{array}{l}\text { NTTP with SI>1 } \\
\mathrm{OH}\end{array}$ & $\begin{array}{l}\mathrm{R}, \mathrm{I}, \mathrm{M}: \text { ISS or } \\
\text { surgery or ICU or } \\
\text { death }\end{array}$ & $\begin{array}{l}505,296 \\
47(19.7) \\
\end{array}$ & $\begin{array}{l}\text { Sen: } 4 \%(N R) \\
\text { Sp: } 80 \%(N R)\end{array}$ & NR \\
\hline $\begin{array}{l}\text { Brown, } 2015 \mathrm{a}^{46} \\
\text { Moderate }\end{array}$ & $\begin{array}{l}\text { NTTP Step 1+2; } \\
\text { SPB <90 } \\
\text { OH }\end{array}$ & $\begin{array}{l}\mathrm{R}, \mathrm{I} \text { : trauma center } \\
\text { need }\end{array}$ & $\begin{array}{l}1,555,944 \\
\text { Median } 49\end{array}$ & $\begin{array}{l}\text { Ages } 16-65 \\
62 \% \text { (CI NR) / } \\
67 \% \text { (CI NR) } \\
59 \% \text { (CI NR) / } \\
69 \% \text { (CI NR) } \\
\end{array}$ & $\begin{array}{l}0.646(0.645 \\
\text { to } 0.647)\end{array}$ \\
\hline
\end{tabular}




\begin{tabular}{|c|c|c|c|c|c|}
\hline $\begin{array}{l}\text { Author, Year } \\
\text { Risk of Bias }\end{array}$ & $\begin{array}{l}\text { Measure and } \\
\text { Threshold } \\
\text { Setting }\end{array}$ & $\begin{array}{l}\text { Serious Injury } \\
\text { Indicator } \\
\text { Type: Indicator }\end{array}$ & $\begin{array}{l}\text { Number } \\
\text { Analyzed } \\
\text { Age } \\
\text { Mean (SD) }\end{array}$ & $\begin{array}{l}\text { Sensitivity } \\
\text { Specificity } \\
(95 \% \mathrm{Cl})\end{array}$ & $\begin{array}{l}\text { AUROC } \\
(95 \% \text { C) }\end{array}$ \\
\hline $\begin{array}{l}\text { Tamim, } 2002^{102} \\
\text { Moderate }\end{array}$ & $\begin{array}{l}\mathrm{PHI} \\
\mathrm{OH}\end{array}$ & $\begin{array}{l}\text { Composite: Surgical } \\
\text { intervention, ICU } \\
\text { care, mortality }\end{array}$ & $\begin{array}{l}1291 \\
48(19)\end{array}$ & $\begin{array}{l}\geq 1 \\
\text { Sen: } 55 \% \text { (52 to } \\
57 \text { ) } \\
\text { Sp: } 71 \% \text { ( } 69 \text { to } \\
74 \text { ) } \\
\geq 4 \\
\text { Sen: } 35 \% \text { (32 to } \\
\text { 38) } \\
\text { Sp: } 91 \% \text { (90 to } \\
\text { 93) }\end{array}$ & $\begin{array}{l}0.66 \text { (SE } \\
0.02)\end{array}$ \\
\hline $\begin{array}{l}\text { Bond, } 1997^{43} \\
\text { Moderate }\end{array}$ & $\begin{array}{l}\mathrm{PHI} \\
\mathrm{OH}\end{array}$ & I: ISS $\geq 16$ & $\begin{array}{l}3147 \\
N R\end{array}$ & $\begin{array}{l}\geq 4 \\
\text { Sen: } 41 \%(N R) \\
\text { Sp: } 98 \%(N R)\end{array}$ & NR \\
\hline $\begin{array}{l}\text { Vassallo, } 2017^{167} \\
\text { High }\end{array}$ & $\begin{array}{l}\text { START } \\
\text { ED }\end{array}$ & $\begin{array}{l}\text { R: Live saving } \\
\text { intervention }\end{array}$ & $\begin{array}{l}3654 \\
\text { Age (median) } \\
\text { No } \\
\text { hemorrhage: } \\
41 \text { (range: 18- } \\
\text { 83) } \\
\text { Hemorrhage } \\
\text { group: } 29 \\
\text { (range: 18- } \\
74)\end{array}$ & $\begin{array}{l}\text { Sen: } 38.7 \% \text { (36.5 } \\
\text { to } 41.1) \\
\text { Sp: } 96.9 \% \text { (96.0 to } \\
97.6)\end{array}$ & NR \\
\hline $\begin{array}{l}\text { Garner, } 2001^{61} \\
\text { Low }\end{array}$ & $\begin{array}{l}\text { START } \\
\mathrm{OH}\end{array}$ & R: critical injury & $\begin{array}{l}1144 \\
\text { Median 33 } \\
\text { (IQR 21-53) }\end{array}$ & $\begin{array}{l}\text { Sen: } 85 \% \text { ( } 78 \text { to } \\
90 \%) \\
\text { Sp: } 86 \% \text { (84 to } \\
88 \%)\end{array}$ & NR \\
\hline $\begin{array}{l}\text { Garner, } 2001^{61} \\
\text { Low }\end{array}$ & $\begin{array}{l}\text { Modified START } \\
\mathrm{OH}\end{array}$ & R: critical injury & $\begin{array}{l}1144 \\
\text { Median 33 } \\
\text { (IQR 21-53) } \\
\end{array}$ & $\begin{array}{l}\text { Sen: } 84 \% \text { ( } 76 \text { to } \\
89 \%) \\
\text { Sp: } 91 \% \text { (89 to } \\
93 \%)\end{array}$ & NR \\
\hline $\begin{array}{l}\text { Gebhart, } 2007^{129} \\
\text { Moderate }\end{array}$ & $\begin{array}{l}\text { START protocol } \\
\text { model using } \\
\text { tabulated score, } \\
\geq 2 \text { of: GCS }<15 \text {, } \\
\mathrm{RR}<30, \mathrm{HR}<100 \\
\mathrm{OH}\end{array}$ & M: mortality & $\begin{array}{l}355 \\
41(21.1)\end{array}$ & $\begin{array}{l}\text { Sen: 85\% (NR) } \\
\text { Sp: 63\% (NR) }\end{array}$ & $0.86(\mathrm{NR})$ \\
\hline $\begin{array}{l}\text { Jo, } 2014^{132} \\
\text { Moderate }\end{array}$ & $\begin{array}{l}\text { ViEWS-Li32 } \\
\text { ED }\end{array}$ & M: mortality & $\begin{array}{l}299 \\
62 \text { Median } \\
\text { (IQR 45-73) } \\
\end{array}$ & $\begin{array}{l}\text { Sen: NR } \\
\text { Sp: NR }\end{array}$ & $\begin{array}{l}0.84(95 \% \\
\text { Cl } 0.77 \text { to } \\
0.91)\end{array}$ \\
\hline
\end{tabular}

AUROC = area under the receiver operating characteristic curve; $\mathrm{CI}=$ confidence interval; GCS = Glasgow Coma Scale; HR = heart rate; I = injury type or severity; ICU = intensive care unit; IQR = interquartile range; ISS = Injury Severity Score; M = mortality; MPTT = Modified Physiological Triage Tool; NR = not reported; NTTP = National Trauma Triage Protocol; OH = out-of-hospital; $\mathrm{PHI}=$ Prehospital Index; $\mathrm{R}=$ resource use; $\mathrm{RR}=$ respiratory rate; $\mathrm{SBP}=$ systolic blood pressure; Sen = sensitivity; Sp = specificity; START = Simple Triage and Rapid Treatment; ViEWS-L = modified VitalPAC Early Warning Score with rapid lactate level 


\section{Combinations of Physiologic Measures Without Glasgow Coma Scale}

Table 29 lists combinations of circulatory and respiratory measures that do not include GCS or a measure of consciousness. Most of these combinations were only evaluated in one or two identified studies.

This table is split into three sections by bold lines. The first section lists studies that evaluated comparatively straight forward combinations of circulatory and respiratory measures. The second section lists more complex combinations and models. The third and last section lists studies that evaluated triage protocols or prediction models, which involved considering several measures following a prescribed order or algorithm.

Table 29. Combination circulatory and respiratory measures (Key Question 3) without assessment of level of consciousness

\begin{tabular}{|c|c|c|}
\hline Measure Evaluated & $\begin{array}{l}\text { Number of } \\
\text { Studies (articles) }\end{array}$ & References \\
\hline Breath index (RR/PP) & 2 & 53,54 \\
\hline Hemorrhage index $(\mathrm{HR} \times \mathrm{RR}) /(\mathrm{MAP} \times \mathrm{PP})$ & 1 & 53 \\
\hline HR and SBP with lactate or BD & 1 (2 articles) & 147,148 \\
\hline $\mathrm{HR}, \mathrm{SBP}$ and $\mathrm{SaO}_{2}$ & 1 & 103 \\
\hline Multiple vital signs & 1 & 80 \\
\hline HRC with vital signs & 1 (2 articles) & 81,82 \\
\hline New Field Triage Score (FTS 07$)$ & 1 & 118 \\
\hline Ensemble classifier (model using HR, RR, DBP, SBP, and $\mathrm{SaO}_{2}$ ) & 1 & 53 \\
\hline CHAID analysis of multiple variables & 1 & 57 \\
\hline Murphy Factor (injury acuity algorithm) & 1 & 103 \\
\hline Triage Sieve & 3 & $61,71,167$ \\
\hline
\end{tabular}

Note: Similar measures are grouped between bold dividing lines.

While there were some similarities across these measures, the diversity as well as the lack of multiple studies on these combinations made it difficult to assess their utility. The results are presented in Table 30 below, grouped in the same arrangement as in the table above. 
Table 30. Predictive utility of combinations of physiologic measures

\begin{tabular}{|c|c|c|c|c|c|}
\hline $\begin{array}{l}\text { Author, Year } \\
\text { Risk of Bias }\end{array}$ & $\begin{array}{l}\text { Measure and } \\
\text { Threshold } \\
\text { Setting }\end{array}$ & $\begin{array}{l}\text { Serious Injury } \\
\text { Indicator } \\
\text { Type: Indicator }\end{array}$ & $\begin{array}{l}\text { Number } \\
\text { Analyzed } \\
\text { Age } \\
\text { Mean (SD) }\end{array}$ & $\begin{array}{l}\text { Sensitivity } \\
\text { Specificity } \\
(95 \% \mathrm{Cl})\end{array}$ & $\begin{array}{l}\text { AUROC }(95 \% \\
\text { CI) }\end{array}$ \\
\hline $\begin{array}{l}\text { Chen, } 2008^{53} \\
\text { Moderate }\end{array}$ & $\begin{array}{l}\text { Breath index (RR/PP) } \\
\mathrm{OH}\end{array}$ & R: hemorrhage & $\begin{array}{l}627 \\
39(\mathrm{NR})\end{array}$ & $\begin{array}{l}\text { Sen: NR } \\
\text { Sp: NR }\end{array}$ & $0.67(0.08)$ \\
\hline $\begin{array}{l}\text { Chen, } 2009^{54} \\
\text { Moderate }\end{array}$ & $\begin{array}{l}\text { Breath index } \\
\text { (RR/PP), reliable } \\
\mathrm{OH}\end{array}$ & $\begin{array}{l}\mathrm{R}: \text { major } \\
\text { hemorrhage }\end{array}$ & $\begin{array}{l}326 \\
38(16)\end{array}$ & $\begin{array}{l}\text { Sen: NR } \\
\text { Sp: NR }\end{array}$ & $\begin{array}{l}0.85(0.77 \text { to } \\
0.91)\end{array}$ \\
\hline $\begin{array}{l}\text { Chen, } 2008^{53} \\
\text { Moderate }\end{array}$ & $\begin{array}{l}\text { Hemorrhage index } \\
(\mathrm{HR} \times \mathrm{RR}) /(\mathrm{MAP} \times \\
\mathrm{PP}) \\
\mathrm{OH}\end{array}$ & R: hemorrhage & $\begin{array}{l}627 \\
39(\mathrm{NR})\end{array}$ & $\begin{array}{l}\text { Sen: NR } \\
\text { Sp: NR }\end{array}$ & $0.73(0.06)$ \\
\hline $\begin{array}{l}\text { Paladino, } \\
2008^{147,148} \\
\text { Moderate }\end{array}$ & $\begin{array}{l}\text { Lactate }>2.5 \text { : } \\
\text { subgroup with normal } \\
\text { vital signs } \\
\text { ED }\end{array}$ & R: major injury & $\begin{array}{l}1435 \\
35(16.9) \\
\text { (range } 13 \text { to } \\
95 \text { ) }\end{array}$ & $\begin{array}{l}\text { Sen: } 76 \%(\mathrm{Cl} \\
\text { NR) } \\
\text { Sp: } 49 \%(\mathrm{Cl} N R)\end{array}$ & NR \\
\hline $\begin{array}{l}\text { Paladino, } \\
2008^{147,148} \\
\text { Moderate }\end{array}$ & $\begin{array}{l}\text { Lactate: subgroup } \\
\text { with normal vital signs } \\
\text { ED }\end{array}$ & R: major injury & $\begin{array}{l}1435 \\
35(16.9) \\
\text { (range } 13 \text { to } \\
95 \text { ) }\end{array}$ & $\begin{array}{l}\text { Sen: NR } \\
\text { Sp: NR }\end{array}$ & $\begin{array}{l}0.64(0.58 \text { to } \\
0.69) \\
p<0.0001\end{array}$ \\
\hline $\begin{array}{l}\text { Paladino, } \\
2008^{147,148} \\
\text { Moderate }\end{array}$ & $\begin{array}{l}\text { Author-created model } \\
\text { with measures: } \\
\text { abnormal lactate or } \\
\text { BD; subgroup with } \\
\text { normal vital signs } \\
\text { ED }\end{array}$ & R: major injury & $\begin{array}{l}1435 \\
35(16.9) \\
\text { (range } 13 \text { to } \\
95)\end{array}$ & $\begin{array}{l}\text { Sen: } 76 \% \text { (71 to } \\
82 \%) \\
\text { Sp: } 48 \% \text { (45 to } \\
51 \%)\end{array}$ & NR \\
\hline $\begin{array}{l}\text { Paladino, } \\
2008^{147,148} \\
\text { Moderate }\end{array}$ & $\begin{array}{l}\text { BD <-1.3: subgroup } \\
\text { with normal vital signs } \\
\text { ED }\end{array}$ & R: major injury & $\begin{array}{l}1435 \\
35(16.9) \\
\text { (range } 13 \text { to } \\
95 \text { ) }\end{array}$ & $\begin{array}{l}\text { Sen: } 56 \%(N R) \\
\text { Sp: } 71 \%(N R)\end{array}$ & NR \\
\hline $\begin{array}{l}\text { Paladino, } \\
2008^{147,148} \\
\text { Moderate }\end{array}$ & $\begin{array}{l}\text { BD: subgroup with } \\
\text { normal vital signs } \\
\text { ED }\end{array}$ & R: major injury & $\begin{array}{l}1435 \\
35(16.9) \\
\text { (range } 13 \text { to } \\
95)\end{array}$ & $\begin{array}{l}\text { Sen: NR } \\
\text { Sp: NR }\end{array}$ & $\begin{array}{l}0.68(0.63 \text { to } \\
0.73) \\
p<0.0001\end{array}$ \\
\hline $\begin{array}{l}\text { Van Haren, } \\
2014^{103} \\
\text { Moderate }\end{array}$ & $\begin{array}{l}\mathrm{HR}>100, \mathrm{SBP}<90, \\
\mathrm{SaO}_{2}<95 \% \\
\mathrm{OH}\end{array}$ & R: LSI & $\begin{array}{l}96 \\
48(19)\end{array}$ & $\begin{array}{l}\text { Sen: } 44 \% \text { (NR) } \\
\text { Sp: } 75 \%(N R)\end{array}$ & $\begin{array}{l}0.607 \\
p=0.119\end{array}$ \\
\hline $\begin{array}{l}\text { Liu, } 2015 a^{17} \\
\text { Moderate }\end{array}$ & $\begin{array}{l}\text { Vital signs with heart } \\
\text { rate complexity } \\
\text { ED }\end{array}$ & M: mortality & $\begin{array}{l}108 \\
37 \pm 14\end{array}$ & $\begin{array}{l}\text { Sen: NR } \\
\text { Sp: NR }\end{array}$ & $\begin{array}{l}0.86 \text { (NR) } \\
\text { (multivariate) }\end{array}$ \\
\hline $\begin{array}{l}\text { Liu, } 2015 a^{17} \\
\text { Moderate }\end{array}$ & $\begin{array}{l}\text { Vital signs with heart } \\
\text { rate complexity } \\
\text { ED }\end{array}$ & R: LSI & $\begin{array}{l}108 \\
37 \pm 14\end{array}$ & $\begin{array}{l}\text { Sen: NR } \\
\text { Sp: NR }\end{array}$ & $\begin{array}{l}0.86 \text { (NR) } \\
\text { (multivariate) }\end{array}$ \\
\hline $\begin{array}{l}\text { Liu, 2014b } b^{81,82} \\
\text { High }\end{array}$ & $\begin{array}{l}\text { Vital signs and HRC } \\
\mathrm{OH}\end{array}$ & R: LSI & $\begin{array}{l}104 \\
40(16)\end{array}$ & $\begin{array}{l}\text { Sen: NR } \\
\text { Sp: NR }\end{array}$ & $\begin{array}{l}0.81 \text { (NR) } \\
\text { (multivariate) }\end{array}$ \\
\hline
\end{tabular}




\begin{tabular}{|c|c|c|c|c|c|}
\hline $\begin{array}{l}\text { Author, Year } \\
\text { Risk of Bias }\end{array}$ & $\begin{array}{l}\text { Measure and } \\
\text { Threshold } \\
\text { Setting }\end{array}$ & $\begin{array}{l}\text { Serious Injury } \\
\text { Indicator } \\
\text { Type: Indicator }\end{array}$ & $\begin{array}{l}\text { Number } \\
\text { Analyzed } \\
\text { Age } \\
\text { Mean (SD) }\end{array}$ & $\begin{array}{l}\text { Sensitivity } \\
\text { Specificity } \\
(95 \% \mathrm{Cl})\end{array}$ & $\begin{array}{l}\text { AUROC }(95 \% \\
\text { Cl) }\end{array}$ \\
\hline $\begin{array}{l}\text { Liu, 2014a } \\
\text { Moderate }\end{array}$ & $\begin{array}{l}\text { Wireless vital sign } \\
\text { monitor using HR, } \\
\text { RR, and SBP } \\
\mathrm{OH}\end{array}$ & $\begin{array}{l}\text { R: LSI } \\
\text { ED }\end{array}$ & $\begin{array}{l}305 \\
39(16)\end{array}$ & $\begin{array}{l}\text { Sen: NR } \\
\text { Sp: NR }\end{array}$ & $\begin{array}{l}0.86 \text { (NR) } \\
\text { (multivariate) }\end{array}$ \\
\hline $\begin{array}{l}\text { Liu, 2014a }{ }^{80} \\
\text { Moderate }\end{array}$ & $\begin{array}{l}\text { Wireless vital sign } \\
\text { monitor using HR, } \\
\text { RR, and SBP } \\
\mathrm{OH}\end{array}$ & $\begin{array}{l}\text { R: LSI } \\
\text { EMS or ED }\end{array}$ & $\begin{array}{l}305 \\
39(16)\end{array}$ & $\begin{array}{l}\text { Sen: NR } \\
\text { Sp: NR }\end{array}$ & $\begin{array}{l}0.94 \text { (NR) } \\
\text { (multivariate) }\end{array}$ \\
\hline $\begin{array}{l}\text { Cancio, } \\
2008 a^{118} \\
\text { High }\end{array}$ & $\begin{array}{l}\text { New FTS } \\
\text { ED }\end{array}$ & M: mortality & $\begin{array}{l}536 \\
N R(N R)\end{array}$ & $\begin{array}{l}\text { Sen: NR } \\
\text { Sp: NR }\end{array}$ & $\begin{array}{l}0.687(0.620 \\
\text { to } 0.754) \\
\text { (multivariate) }\end{array}$ \\
\hline $\begin{array}{l}\text { Cancio, } \\
2008 a^{118} \\
\text { High }\end{array}$ & $\begin{array}{l}\text { New FTS }{ }^{118} \\
\text { ED }\end{array}$ & $\begin{array}{l}\text { R: massive } \\
\text { transfusion }\end{array}$ & $\begin{array}{l}536 \\
N R(N R)\end{array}$ & $\begin{array}{l}\text { Sen: NR } \\
\text { Sp: NR }\end{array}$ & $\begin{array}{l}0.618(0.569 \\
\text { to } 0.666) \\
\text { (multivariate) }\end{array}$ \\
\hline $\begin{array}{l}\text { Chen, } 2008^{53} \\
\text { Moderate }\end{array}$ & $\begin{array}{l}\text { Ensemble classifier } \\
\text { (nonlinear model of } \\
\text { vital signs that allows } \\
\text { missing data) } \\
\mathrm{OH}\end{array}$ & R: hemorrhage & $\begin{array}{l}627 \\
39(N R)\end{array}$ & $\begin{array}{l}\text { Sen: 69\% (SD } \\
0.08) \\
\text { Sp: 68\% (SD } \\
0.09)\end{array}$ & $\begin{array}{l}0.76 \text { (SD } \\
0.05)\end{array}$ \\
\hline $\begin{array}{l}\text { Chen, } 2008^{53} \\
\text { Moderate }\end{array}$ & $\begin{array}{l}\text { Ensemble classifier } \\
\text { (nonlinear model of } \\
\text { vital signs that allows } \\
\text { missing data; uses } \\
\mathrm{HR}, \mathrm{RR}, \mathrm{DBP}, \mathrm{SBP}, \\
\text { and } \mathrm{SaO}_{2} \text { ) } \\
\mathrm{OH}\end{array}$ & R: hemorrhage & $\begin{array}{l}627 \\
39(N R)\end{array}$ & $\begin{array}{l}\text { Sen: } 90 \% \text { (NR) } \\
\text { Sp: } 40 \% \text { (SD } \\
0.10)\end{array}$ & NR \\
\hline $\begin{array}{l}\text { Courville, } \\
2009^{57} \\
\text { Low }\end{array}$ & $\begin{array}{l}\text { CHAID testing } \\
\text { analysis } \\
\mathrm{OH}\end{array}$ & M: mortality & $\begin{array}{l}224,682 \\
\text { NR (NR) }\end{array}$ & $\begin{array}{l}\text { Sen: 60\% (Cl } \\
\text { NR) } \\
\text { Sp: } 99 \%(\mathrm{Cl} N R)\end{array}$ & NR \\
\hline $\begin{array}{l}\text { Van Haren, } \\
2014^{103} \\
\text { Moderate }\end{array}$ & $\begin{array}{l}\text { Murphy Factor }>3 \\
\mathrm{OH}\end{array}$ & R: LSI & 96 & $\begin{array}{l}\text { Sen: 39\% (NR) } \\
\text { Sp: } 81 \% \text { (NR) }\end{array}$ & $\begin{array}{l}0.620 \\
p=0.081\end{array}$ \\
\hline $\begin{array}{l}\text { Garner, 200161 } \\
\text { Low }\end{array}$ & $\begin{array}{l}\text { Triage sieve } \\
\text { algorithm using } \\
\text { capillary refill } \\
\mathrm{OH}\end{array}$ & R: critical injury & $\begin{array}{l}1144 \\
\text { Median 33 } \\
\text { (IQR 21-53) }\end{array}$ & $\begin{array}{l}\text { Sen: } 45 \% \text { ( } 37 \text { to } \\
54 \%) \\
\text { Sp: } 89 \% \text { ( } 87 \text { to } \\
91 \%)\end{array}$ & NR \\
\hline $\begin{array}{l}\text { Garner, 200161 } \\
\text { Low }\end{array}$ & $\begin{array}{l}\text { Triage sieve } \\
\text { algorithm using HR } \\
\mathrm{OH}\end{array}$ & R: critical injury & $\begin{array}{l}1144 \\
\text { Median 33 } \\
\text { (IQR 21-53) }\end{array}$ & $\begin{array}{l}\text { Sen: } 45 \% \text { ( } 37 \text { to } \\
54 \%) \\
\text { Sp: } 88 \% \text { ( } 86 \text { to } \\
90 \%)\end{array}$ & NR \\
\hline $\begin{array}{l}\text { Horne, } 2013^{71} \\
\text { High }\end{array}$ & $\begin{array}{l}\text { UK Triage Sieve } \\
\mathrm{OH}\end{array}$ & $\begin{array}{l}\text { R: Resource-based } \\
\text { definition of Priority } \\
1 \text { casualty }\end{array}$ & $\begin{array}{l}1213 \\
N R(N R)\end{array}$ & $\begin{array}{l}\text { Sen: } 53 \% \text { (49 to } \\
57 \%) \\
\text { Sp: } 88 \% \text { (85 to } \\
90 \%)\end{array}$ & NR \\
\hline
\end{tabular}




\begin{tabular}{|c|c|c|c|c|c|}
\hline $\begin{array}{l}\text { Author, Year } \\
\text { Risk of Bias }\end{array}$ & $\begin{array}{l}\text { Measure and } \\
\text { Threshold } \\
\text { Setting }\end{array}$ & $\begin{array}{l}\text { Serious Injury } \\
\text { Indicator } \\
\text { Type: Indicator }\end{array}$ & $\begin{array}{l}\text { Number } \\
\text { Analyzed } \\
\text { Age } \\
\text { Mean (SD) }\end{array}$ & $\begin{array}{l}\text { Sensitivity } \\
\text { Specificity } \\
(95 \% \mathrm{Cl})\end{array}$ & $\begin{array}{l}\text { AUROC (95\% } \\
\text { Cl) }\end{array}$ \\
\hline $\begin{array}{l}\text { Horne, } 2013^{71} \\
\text { High }\end{array}$ & $\begin{array}{l}\text { Military Version UK } \\
\text { Triage Sieve } \\
\mathrm{OH}\end{array}$ & $\begin{array}{l}\text { R: Resource-based } \\
\text { definition of Priority } \\
1 \text { casualty }\end{array}$ & $\begin{array}{l}1213 \\
N R(N R)\end{array}$ & $\begin{array}{l}\text { Sen: } 59 \% \text { (58 to } \\
62 \% \text { ) } \\
\text { Sp: } 89 \% \text { (85 to } \\
90 \% \text { ) }\end{array}$ & NR \\
\hline $\begin{array}{l}\text { Horne, } 2013^{71} \\
\text { High }\end{array}$ & $\begin{array}{l}\text { Military Version UK } \\
\text { Triage Sieve } \mathrm{RR}<12 \\
\text { or }>24 \text { and } \mathrm{HR}>60 \\
\text { and }<120 \\
\mathrm{OH}\end{array}$ & $\begin{array}{l}\text { R: Resource-based } \\
\text { definition of Priority } \\
1 \text { casualty }\end{array}$ & $\begin{array}{l}1213 \\
N R(N R)\end{array}$ & $\begin{array}{l}\text { Sen: 71\% (NR) } \\
\text { Sp: 79\% (NR) }\end{array}$ & NR \\
\hline
\end{tabular}

AUROC = area under the receiver operating characteristic curve; BD = base deficit; CHAID = Chi-square-assisted interaction detection; $\mathrm{CI}$ = confidence interval; DBP = diastolic blood pressure; $\mathrm{ED}$ = emergency department; EMS = emergency medical services; FTS07 = new Field Triage Score; HR = heart rate; HRC = heart rate complexity; IQR = interquartile range; LSI = lifesaving intervention; $\mathrm{M}=$ mortality; $\mathrm{MAP}$ = mean arterial pressure; $\mathrm{NR}$ = not reported; $\mathrm{OH}$ = out-of-hospital; $\mathrm{PP}=$ pulse pressure; $\mathrm{R}$ = resource use; $\mathrm{RR}$ = respiratory rate; $\mathrm{SaO} 2$ = oxygen saturation; $\mathrm{SBP}=$ systolic blood pressure; $\mathrm{SD}=$ standard deviation; $\mathrm{SI}=$ shock index; START = simple triage and rapid treatment; UK = United Kingdom; ViEWS-L = VitalPAC Early Warning Score with rapid lactate level

Note: Similar measures are grouped between bold dividing lines.

\section{Key Questions 1a, 2a, and 3a: Differences Across Age Groups}

Each Key Question for this review has a subquestion that asks if the predictive utility of the identified measures varies across age groups (i.e., is it different for children or older adults) and if the evidence supports different measures or different thresholds for specific age ranges. There are ample anecdotal reports, as well as epidemiologic research, documenting that people at the extremes of the age range (the young and the old) experience trauma less frequently than the adult nonelderly population, but that their outcomes are worse. This raises questions about the appropriateness of treatment and about how children and older trauma patients are assessed and triaged.

We identified 10 studies with relevant data specific to pediatric trauma patients $^{57,77,88,101,111,140,157,171,173,175}$ and 13 studies with data specific to older trauma patients (ages included vary). ${ }^{46,72,87,89,90,116,117,123,136,146,151,163,170}$

\section{Pediatrics}

The 10 pediatric studies included 6 evaluations of circulatory measures (Table 31); ${ }^{77,88,101,111,157,171} 4$ assessments of respiratory measures (Table 32); ${ }^{77,88,140,171}$ and 6 reports on combination measures (Table 33). ${ }^{57,77,88,140,173,175}$

The assessments of circulatory measures demonstrated that using the standard thresholds for $\mathrm{SBP}^{77,88,171}$ and base deficit ${ }^{111,157}$ resulted in low sensitivities, indicating they do not identify most children with serious injury. Lactate $>2.0$ resulted in higher sensitivities compared with the other measures, but the values were still low and they varied across indicators of serious injury and in age subgroups in the one study with subgroup comparisons; ${ }^{157}$ however, larger studies are need to confirm these variations. 
In the four studies that assessed the predictive utility of RR in children, the results were inconsistent. For example sensitivities range from $2.11^{171}$ to 76.2 percent. ${ }^{140}$ This may be because the studies used different indicators of injury or the study populations differed (e.g., the distribution of ages may differ). Additionally, RR in children has even a larger range than in adults and it is also affected by stress as well as pain, both of which are common in trauma.

Overall, the combination measures performed better than individual measures. Reported sensitivities and specificities were higher, with most over 60 percent. The highest were reported in an early study (1996) of HR and GCS combined ${ }^{173}$ and a trauma score developed specifically for pediatrics. ${ }^{175}$ Using the physiologic measures from the current adult triage guidelines resulted in lower sensitivity (49\%) than the customized measures but was still better than individual measures. ${ }^{77}$

Table 31. Predictive utility of circulatory measures (Key Question 1) in pediatric patients

\begin{tabular}{|c|c|c|c|c|c|}
\hline $\begin{array}{l}\text { Author, Year } \\
\text { Risk of Bias }\end{array}$ & $\begin{array}{l}\text { Measure } \\
\text { and } \\
\text { Threshold } \\
\text { Setting }\end{array}$ & $\begin{array}{l}\text { Type: } \\
\text { Serious } \\
\text { Injury } \\
\text { Specific } \\
\text { Indicator }\end{array}$ & $\begin{array}{l}\text { Number } \\
\text { Analyzed } \\
\text { Age Group } \\
\text { Mean Age } \\
\text { (SD) }\end{array}$ & $\begin{array}{l}\text { Sensitivity } \\
\text { Specificity } \\
(95 \% \mathrm{Cl})\end{array}$ & $\begin{array}{l}\text { AUROC } \\
\text { (95\% Cl) }\end{array}$ \\
\hline $\begin{array}{l}\text { Engum, } 2000^{171} \\
\text { Low }\end{array}$ & $\begin{array}{l}\mathrm{SBP} \leq 90 \\
\mathrm{OH}\end{array}$ & $\begin{array}{l}\text { R: Major } \\
\text { trauma } \\
\text { (death in } \\
\text { ED, ICU } \\
\text { admission, } \\
\text { major } \\
\text { surgery) }\end{array}$ & $\begin{array}{l}\mathrm{N}=1,285 \\
\text { Age: } 1-15 \\
\text { years } \\
7.2 \text { (range 1- } \\
15 \text { ) }\end{array}$ & $\begin{array}{l}\text { *Sen: } 14.78 \%(11.36 \text { to } 18.75) \\
* \text { *Sp: } 99.01 \%(98.12 \text { to } 99.54)\end{array}$ & \begin{tabular}{|l|}
$N R$ \\
\end{tabular} \\
\hline $\begin{array}{l}\text { Newgard, } 2009^{88} \\
\text { Low }\end{array}$ & $\begin{array}{l}\text { SBP } \leq 90 \\
\mathrm{OH}\end{array}$ & $\begin{array}{l}\text { Composite: } \\
\text { LOS >2 } \\
\text { days or } \\
\text { death }\end{array}$ & $\begin{array}{l}\mathrm{N}=955 \\
\\
\leq 14 \\
5.23(4.57)\end{array}$ & $\begin{array}{l}\text { *Sen: } 24.02 \%(17.96 \text { to } \\
\text { 30.96\%) } \\
\text { *Sp: } 53.99 \% \text { (50.41 to } 57.55 \mathrm{~T})\end{array}$ & NR \\
\hline $\begin{array}{l}\text { Lerner, } 2017^{77} \\
\text { Low }\end{array}$ & $\begin{array}{l}\mathrm{SBP} \leq 90 \\
\mathrm{OH}\end{array}$ & $\begin{array}{l}\text { Composite: } \\
\text { Trauma } \\
\text { center need } \\
\text { (non- } \\
\text { orthopedic } \\
\text { surgery in } 24 \\
\text { hours, ICU } \\
\text { admission or } \\
\text { mortality }\end{array}$ & $\begin{array}{l}N=5,594 \\
\leq 15 \\
8(5)\end{array}$ & $\begin{array}{l}\text { 1-NPV: 87\% (under-triage) } \\
\text { 1-PPV: } 4 \% \text { (over-triage) }\end{array}$ & NR \\
\hline $\begin{array}{l}\text { Shah, } 2013^{101} \\
\text { Moderate }\end{array}$ & $\begin{array}{l}\text { Lactate } \\
\geq 2.0 \\
\mathrm{OH}\end{array}$ & $\begin{array}{l}\text { R: need for } \\
\text { critical care }\end{array}$ & $\begin{array}{l}\mathrm{N}=217 \\
<18 \\
11 \text { (median) } \\
\text { IQR 6-14 }\end{array}$ & $\begin{array}{l}\text { Sen: } 64 \%(N R) \\
\text { Sp: } 66 \%(N R)\end{array}$ & NR \\
\hline $\begin{array}{l}\text { Ramanathan, } \\
2015^{157} \\
\text { Low }\end{array}$ & $\begin{array}{l}\text { Lactate } \\
>4.7 \\
\text { ED }\end{array}$ & I: ISS >15 & $\begin{array}{l}\mathrm{N}=236 \\
<15 \text { years } \\
9.2(4.7)\end{array}$ & $\begin{array}{l}\text { Sen: } 26.7 \%(14.6 \text { to } 41.9 \%) \\
\text { Sp: } \quad 95.8 \%(91.9 \text { to } 98.2 \%)\end{array}$ & $0.706(\mathrm{NR})$ \\
\hline $\begin{array}{l}\text { Ramanathan, } \\
2015^{157} \\
\text { Low } \\
\end{array}$ & $\begin{array}{l}\text { Lactate } \\
\geq 2.0 \\
\text { ED }\end{array}$ & I: ISS >15 & $\begin{array}{l}\mathrm{N}=236 \\
\\
<15 \text { years } \\
9.2(4.7)\end{array}$ & $\begin{array}{l}\text { Sen: } 86.7 \%(73.2 \text { to } 95.0 \%) \\
\text { Sp: } \quad 54.5 \%(47.1 \text { to } 61.6 \%)\end{array}$ & $0.652(\mathrm{NR})$ \\
\hline $\begin{array}{l}\text { Ramanathan, } \\
2015^{157} \\
\text { Low }\end{array}$ & $\begin{array}{l}\text { Lactate } \\
\geq 2.0 \\
\text { ED }\end{array}$ & I: ISS >15 & $\begin{array}{l}\mathrm{N}=78 \\
\text { Adolescents } \\
\text { 13-14 years }\end{array}$ & $\begin{array}{l}\text { Sen: } 35.6 \%(21.9 \text { to } 51.2 \%) \\
\text { Sp: } \quad 67.5 \%(60.4 \text { to } 74.1)\end{array}$ & NR \\
\hline
\end{tabular}




\begin{tabular}{|c|c|c|c|c|c|}
\hline $\begin{array}{l}\text { Author, Year } \\
\text { Risk of Bias }\end{array}$ & $\begin{array}{l}\text { Measure } \\
\text { and } \\
\text { Threshold } \\
\text { Setting }\end{array}$ & $\begin{array}{l}\text { Type: } \\
\text { Serious } \\
\text { Injury } \\
\text { Specific } \\
\text { Indicator }\end{array}$ & $\begin{array}{l}\text { Number } \\
\text { Analyzed } \\
\text { Age Group } \\
\text { Mean Age } \\
\text { (SD) }\end{array}$ & $\begin{array}{l}\text { Sensitivity } \\
\text { Specificity } \\
(95 \% \mathrm{Cl})\end{array}$ & $\begin{array}{l}\text { AUROC } \\
\text { (95\% Cl) }\end{array}$ \\
\hline $\begin{array}{l}\text { Ramanathan, } \\
2015^{157} \\
\text { Low }\end{array}$ & $\begin{array}{l}\text { Lactate } \\
\geq 2.0 \\
\text { ED }\end{array}$ & I: ISS >15 & $\begin{array}{l}\mathrm{N}=98 \\
\text { School age } \\
6-12 \text { years }\end{array}$ & $\begin{array}{l}\text { Sen: } 40.0 \%(25.7 \text { to } 55.7 \%) \\
\text { Sp: } 58.1 \%(50.8 \text { to } 65.2 \%)\end{array}$ & NR \\
\hline $\begin{array}{l}\text { Ramanathan, } \\
2015^{157} \\
\text { Low }\end{array}$ & $\begin{array}{l}\text { Lactate } \\
\geq 2.0 \\
\text { ED }\end{array}$ & I: ISS >15 & $\begin{array}{l}\mathrm{N}=42 \\
\text { Toddlers } \\
19 \text { months-5 } \\
\text { years } \\
\text { NR } \\
\end{array}$ & $\begin{array}{l}\text { Sen: } 17.8 \%(8.0 \text { to } 32.1 \%) \\
\text { Sp: } \quad 82.2 \%(76.0 \text { to } 87.3 \%)\end{array}$ & NR \\
\hline $\begin{array}{l}\text { Ramanathan, } \\
2015^{157} \\
\text { Low }\end{array}$ & $\begin{array}{l}\text { Lactate } \\
\geq 2.0 \\
\text { ED }\end{array}$ & I: ISS >15 & $\begin{array}{l}\mathrm{N}=18 \\
\text { Infants } \\
0-18 \text { months } \\
\mathrm{NR}\end{array}$ & $\begin{array}{l}\text { Sen: } 6.7 \%(1.5 \text { to } 18.3 \%) \\
\text { Sp: } 92.1 \%(87.4 \text { to } 95.5 \%)\end{array}$ & NR \\
\hline $\begin{array}{l}\text { Ramanathan, } \\
2015^{157} \\
\text { Low }\end{array}$ & $\begin{array}{l}\text { Lactate } \\
\geq 2.0 \\
\text { ED }\end{array}$ & $\begin{array}{l}\mathrm{R}: \mathrm{ICU} \\
\text { admission }\end{array}$ & $\begin{array}{l}\mathrm{N}=126 \\
\\
<15 \text { years } \\
9.2(4.7)\end{array}$ & $\begin{array}{l}\text { Sen: } 77.9 \%(67.0 \text { to } 86.6 \%) \\
\text { Sp: } 58.5 \% \text { (50.4 to } 66.2 \%)\end{array}$ & NR \\
\hline $\begin{array}{l}\text { Ramanathan, } \\
2015^{157} \\
\text { Low }\end{array}$ & $\begin{array}{l}\text { Lactate } \\
\geq 2.0 \\
\text { ED }\end{array}$ & R: Intubation & $\begin{array}{l}\mathrm{N}=126 \\
<15 \text { years } \\
9.2(4.7)\end{array}$ & $\begin{array}{l}\text { Sen: } 88.2 \% \text { (72.5 to } 96.6 \%) \\
\text { Sp: } 52.5 \%(45.3 \text { to } 59.5 \%)\end{array}$ & NR \\
\hline $\begin{array}{l}\text { Ramanathan, } \\
2015^{157} \\
\text { Low }\end{array}$ & $\begin{array}{l}\text { Lactate } \\
\geq 2.0 \\
\text { ED }\end{array}$ & $\begin{array}{l}\text { R: Major } \\
\text { procedure }\end{array}$ & $\begin{array}{l}\mathrm{N}=126 \\
<15 \text { years } \\
9.2(4.7)\end{array}$ & $\begin{array}{l}\text { Sen: } 70.6 \%(56.2 \text { to } 82.5 \%) \\
\text { Sp: } \quad 51.3 \%(43.9 \text { to } 58.7 \%)\end{array}$ & NR \\
\hline $\begin{array}{l}\text { Allen, } 2014^{111} \\
\text { Moderate }\end{array}$ & $\begin{array}{l}\mathrm{BD}<-7 \\
\mathrm{BD}<-5 \\
\mathrm{BD}<0 \\
\mathrm{ED}\end{array}$ & $\begin{array}{l}\text { R: Blood } \\
\text { transfusion }\end{array}$ & $\begin{array}{l}\mathrm{N}=1928 \\
<18 \text { years } \\
11(6)\end{array}$ & $\begin{array}{l}\text { Sen: } 29 \%(N R) \\
\text { Sp: } \quad 95 \%(N R) \\
\text { Sen: } 54 \%(N R) \\
\text { Sp: } 88 \%(N R) \\
\text { Sen: } 94 \%(N R) \\
\text { Sp: } \quad 30 \%(N R)\end{array}$ & NR \\
\hline $\begin{array}{l}\text { Ramanathan, } \\
2015^{157} \\
\text { Low }\end{array}$ & $\begin{array}{l}\mathrm{BD}<-5.0 \\
\mathrm{ED}\end{array}$ & I: ISS >15 & $\begin{array}{l}\mathrm{N}=126 \\
<15 \text { years } \\
9.2(4.7)\end{array}$ & $\begin{array}{l}\text { Sen: } 25.0 \%(13.2 \text { to } 40.3 \%) \\
\text { Sp: } 98.3 \%(95.1 \text { to } 99.6 \%)\end{array}$ & NR \\
\hline $\begin{array}{l}\text { Ramanathan, } \\
2015^{157} \\
\text { Low }\end{array}$ & $\begin{array}{l}\mathrm{pH}<7.30 \\
\mathrm{ED}\end{array}$ & I: ISS >15 & $\begin{array}{l}\mathrm{N}=126 \\
<15 \text { years } \\
9.2(4.7)\end{array}$ & $\begin{array}{l}\text { Sen: } 56.8 \% \text { (41.0 to } 71.6 \%) \\
\text { Sp: } 94.3 \%(89.9 \text { to } 97.2 \%)\end{array}$ & NR \\
\hline
\end{tabular}

AUROC = area under the operating characteristic curve; $\mathrm{BD}=$ base deficit; $\mathrm{CI}=$ confidence interval; ED = emergency department; ICU = intensive care unit; GCS = Glasgow Coma Scale; ICU = intensive care unit; ISS = injury severity score; LOS = length of stay; NR = not reported; $\mathrm{OH}$ : out-of-hospital; $\mathrm{SBP}$ = systolic blood pressure; $\mathrm{SD}$ = standard deviation; Sen = sensitivity; $\mathrm{Sp}=$ specificity

*Results calculated by reviewers 
Table 32. Predictive utility of respiratory predictors (Key Question 2) in studies of pediatric patients

\begin{tabular}{|c|c|c|c|c|c|}
\hline $\begin{array}{l}\text { Author, Year } \\
\text { Risk of Bias }\end{array}$ & $\begin{array}{l}\text { Measure } \\
\text { and } \\
\text { Threshold } \\
\text { Setting }\end{array}$ & $\begin{array}{l}\text { Type: } \\
\text { Serious } \\
\text { Injury } \\
\text { Specific } \\
\text { Indicator }\end{array}$ & $\begin{array}{l}\text { Number } \\
\text { Analyzed } \\
\text { Age Group } \\
\text { Mean Age } \\
\text { (SD) }\end{array}$ & $\begin{array}{l}\text { Sensitivity } \\
\text { Specificity } \\
(95 \% \mathrm{Cl})\end{array}$ & $\begin{array}{l}\text { AUROC } \\
(95 \% \mathrm{Cl})\end{array}$ \\
\hline $\begin{array}{l}\text { Engum, } \\
2000^{171} \\
\text { Low }\end{array}$ & $\begin{array}{l}\text { RR } \\
<10 \text { or }>29 \\
\mathrm{OH}\end{array}$ & $\begin{array}{l}\text { R: Major } \\
\text { trauma } \\
\text { (death in ED, } \\
\text { ICU } \\
\text { admission, } \\
\text { major } \\
\text { surgery) }\end{array}$ & $\begin{array}{l}\mathrm{N}=1,285 \\
1-15 \text { years } \\
7.2 \text { (range 1- } \\
15 \text { ) }\end{array}$ & $\begin{array}{l}\text { *Sen: } 2.11 \%(0.92 \text { to } 4.12 \%) \\
\star \text { `Sp: } \quad 99.67 \%(99.04 \text { to } 99.93 \%)\end{array}$ & NR \\
\hline $\begin{array}{l}\text { Lerner, } 2017^{77} \\
\text { Low }\end{array}$ & $\begin{array}{l}\mathrm{RR} \\
<10 \text { or }>29 \\
\mathrm{OH}\end{array}$ & $\begin{array}{l}\text { Composite:: } \\
\text { Trauma } \\
\text { center need } \\
\text { (non- } \\
\text { orthopedic } \\
\text { surgery in } 24 \\
\text { hours, ICU } \\
\text { admission or } \\
\text { mortality }\end{array}$ & $\begin{array}{l}N=5,594 \\
\leq 15 \\
8(5)\end{array}$ & $\begin{array}{l}\text { 1-NPV: } 69 \% \text { (under-triage) } \\
\text { 1-PPV: } 14 \% \text { (over-triage) }\end{array}$ & NR \\
\hline $\begin{array}{l}\text { Newgard, } \\
2009^{88} \\
\text { Low }\end{array}$ & $\begin{array}{l}\mathrm{RR} \\
<10 \text { or }>29 \\
\mathrm{OH}\end{array}$ & $\begin{array}{l}\text { Composite: } \\
\text { LOS > } 2 \text { days } \\
\text { or death }\end{array}$ & $\begin{array}{l}\mathrm{N}=955 \\
\leq 14 \\
5.23(4.57)\end{array}$ & $\begin{array}{l}\text { *Sen: } 44.13 \%(36.73 \text { to } 51.73 \%) \\
\text { *Sp: } \quad 53.09 \%(49.51 \text { to } 56.65 \%)\end{array}$ & NR \\
\hline $\begin{array}{l}\text { Lee, } 2014^{140} \\
\text { Low }\end{array}$ & $\begin{array}{l}\text { RR } \\
\text { Abnormal: } \\
\text { not defined } \\
\text { ED }\end{array}$ & $\begin{array}{l}\text { R: Receipt of } \\
\text { resuscitation } \\
\text { in the ED }\end{array}$ & $\begin{array}{l}\mathrm{N}=92 \\
\leq 16 \\
\text { Median: } 4.75 \\
\text { (range } 2 \\
\text { months to } 15 \\
\text { years) }\end{array}$ & $\begin{array}{l}\text { Sen: } 76.2 \%(N R) \\
\text { Sp: } \quad 66.2 \%(N R)\end{array}$ & NR \\
\hline $\begin{array}{l}\text { Lee, } 2014^{140} \\
\text { Low }\end{array}$ & $\begin{array}{l}\text { RR } \\
\text { Abnormal: } \\
\text { not defined } \\
\text { ED }\end{array}$ & $\begin{array}{l}\text { Composite: } \\
\text { Major trauma }\end{array}$ & $\begin{array}{l}\mathrm{N}=92 \\
\leq 16 \\
\text { Median: } 4.75 \\
\text { (range } 2 \\
\text { months to } 15 \\
\text { years) }\end{array}$ & $\begin{array}{l}\text { Sen: } 53.8 \%(N R) \\
\text { Sp: } \quad 60.6 \%(N R)\end{array}$ & NR \\
\hline
\end{tabular}

AUROC = area under the operating characteristic curve; CI = confidence interval; ED = emergency department; I = injury type or severity; ICU = intensive care unit; LOS = length of stay; NPV = negative predictive value; NR = not reported; OH: Out-ofhospital; PPV = positive predictive value; $\mathrm{R}$ = resource use; $\mathrm{RR}$ = respiratory rate; $\mathrm{SD}=$ standard deviation; $\mathrm{Sen}=$ sensitivity; $\mathrm{Sp}$ = specificity

*Results calculated by reviewers 
Table 33. Predictive utility of combination predictors (Key Question 3) in pediatric patients

\begin{tabular}{|c|c|c|c|c|c|}
\hline $\begin{array}{l}\text { Author, Year } \\
\text { Risk of Bias }\end{array}$ & $\begin{array}{l}\text { Measure } \\
\text { and } \\
\text { Threshold } \\
\text { Setting }\end{array}$ & $\begin{array}{l}\text { Type: Serious } \\
\text { Injury Specific } \\
\text { Indicator }\end{array}$ & $\begin{array}{l}\text { Number } \\
\text { Analyzed } \\
\text { Age Group } \\
\text { Mean Age (SD) }\end{array}$ & $\begin{array}{l}\text { Sensitivity } \\
\text { Specificity } \\
(95 \% \mathrm{Cl})\end{array}$ & $\begin{array}{l}\text { AUROC } \\
(95 \% \mathrm{Cl})\end{array}$ \\
\hline $\begin{array}{l}\text { Courville, } \\
2009^{57} \\
\text { Low }\end{array}$ & $\begin{array}{l}\text { Vitals, GCS, } \\
\text { demo- } \\
\text { graphics, } \\
\text { injury } \\
\text { mechanism } \\
\text { and days to } \\
\text { admission } \\
\mathrm{OH}\end{array}$ & $\begin{array}{l}\text { M: Mortality-in } \\
\text { hospital }\end{array}$ & $\begin{array}{l}\mathrm{N}=224,628 \\
<18 \\
9.7(\mathrm{NR})\end{array}$ & $\begin{array}{l}\text { For overall model } \\
\text { Sen: } 59.9 \%(N R) \\
\text { Sp: } \quad 99.0 \%(N R)\end{array}$ & NR \\
\hline $\begin{array}{l}\text { Lee, } 2014^{140} \\
\text { Low }\end{array}$ & $\begin{array}{l}\text { Combined } \\
\text { criteria (PTS } \\
\leq 8, \text { GCS } \\
\leq 10, \\
\text { Abnormal } \\
\text { RR) } \\
\text { ED }\end{array}$ & $\begin{array}{l}\text { Composite: } \\
\text { Major trauma } \\
\text { R: Receipt of } \\
\text { resuscitation in } \\
\text { the ED }\end{array}$ & $\begin{array}{l}\mathrm{N}=92 \\
\leq 16 \\
\text { Median: } 4.75 \\
\text { (range } 2 \text { months } \\
\text { to } 15 \text { years) }\end{array}$ & $\begin{array}{l}\text { Sen: } 69.2 \%(N R) \\
\text { Sp: } 53 \%(N R) \\
\text { Sen: } 90.5 \%(N R) \\
\text { Sp: } 83.1 \%(N R)\end{array}$ & NR \\
\hline $\begin{array}{l}\text { Moront, } \\
1996^{173} \\
\text { Moderate }\end{array}$ & $\begin{array}{l}\text { HR and } \\
\text { GCS } \\
\mathrm{OH} \text { and ED }\end{array}$ & $\begin{array}{l}\text { R: Correctness } \\
\text { of triage }\end{array}$ & $\begin{array}{l}N=3,861 \\
<15 \\
7(4)\end{array}$ & $\begin{array}{l}\text { Sen: } 97.8 \% \\
\text { Sp: } 95.8 \%\end{array}$ & $\begin{array}{l}\text { AUROC } \\
\text { analysis } \\
\text { mentioned; } \\
\text { results not } \\
\text { reported }\end{array}$ \\
\hline $\begin{array}{l}\text { Potoka, } \\
2001^{175} \\
\text { Moderate }\end{array}$ & $\begin{array}{l}\text { Pediatric } \\
\text { Trauma } \\
\text { Score } \\
\text { NR }\end{array}$ & $\begin{array}{l}\text { M: mortality } \\
\mathrm{I}: \text { ISS > } 20\end{array}$ & $\begin{array}{l}\mathrm{N}=2,248 \\
0-16 \\
9.5(5.1)\end{array}$ & $\begin{array}{l}\text { For mortality } \\
\text { Sen: } 96.7 \% \\
\text { Sp: } 88.83 \% \\
\text { For ISS } \\
\text { Sen: } 49.43 \% \\
\text { Sp: } 91.83 \%\end{array}$ & NR \\
\hline $\begin{array}{l}\text { Lerner, } 2017^{77} \\
\text { Low }\end{array}$ & $\begin{array}{l}\text { Physiologic } \\
\text { Measures of } \\
\text { Field Triage } \\
\text { measures } \\
\mathrm{OH}\end{array}$ & $\begin{array}{l}\text { Composite:: } \\
\text { Trauma center } \\
\text { need (non- } \\
\text { orthopedic } \\
\text { surgery in } 24 \\
\text { hours, ICU } \\
\text { admission or } \\
\text { mortality }\end{array}$ & $\begin{array}{l}N=5,594 \\
\leq 15 \\
8(5)\end{array}$ & $\begin{array}{l}\text { *Sen: } 49 \% \text { (43 to } 55) \\
* \text { Sp: } 82 \% \text { (81 to } 83 \text { ) } \\
\text { 1-NPV: } 51 \% \text { (under-triage) } \\
\text { 1-PPV: } 18 \% \text { (over-triage) }\end{array}$ & NR \\
\hline $\begin{array}{l}\text { Newgard, } \\
2009^{88} \\
\text { Low }\end{array}$ & $\begin{array}{l}\text { Pediatric } \\
\text { Clinical } \\
\text { Decision } \\
\text { Tree, } \\
\text { (ventilatory } \\
\text { assistance, } \\
\mathrm{GCS}<11 \text {, } \\
\mathrm{SaO}_{2}<95 \% \text {, } \\
\mathrm{SBP}>96 \text { ): } \\
\text { validation } \\
\text { group } \\
\mathrm{OH}\end{array}$ & $\begin{array}{l}\text { Composite: } \\
\text { LOS > } 2 \text { days or } \\
\text { death }\end{array}$ & $\begin{array}{l}\mathrm{N}=955 \\
\leq 14 \\
5.23(4.57)\end{array}$ & $\begin{array}{l}\text { Sen: } 76.5 \%(66.4 \text { to } 86.6) \\
\text { Sp: } 71.7 \%(66.7 \text { to } 76.6)\end{array}$ & NR \\
\hline
\end{tabular}

AUROC = area under the operating characteristic curve; CI = confidence interval; ED = emergency department; GCS = Glasgow Coma Scale; HR = heart rate; I = injury type or severity; ICU = intensive care unit; ISS = injury severity score; LOS = length of stay; $\mathrm{M}=$ mortality; NPV = negative predictive value; $\mathrm{NR}=$ not reported; $\mathrm{OH}$ = out-of- hospital; $\mathrm{PPV}=$ positive predictive value; PTS = Pediatric Trauma Score; $\mathrm{R}$ = resource use; $\mathrm{RR}=$ respiratory rate; $\mathrm{SaO} 2$ = oxygen saturation; $\mathrm{SBP}=$ systolic blood pressure; $\mathrm{SD}$ = standard deviation; Sen = sensitivity; $\mathrm{Sp}$ = specificity

*Results calculated by reviewers 


\section{Older Individuals}

We identified 13 studies that addressed the performance of physiologic measures in older people. ${ }^{46,72,87,89,90,116,117,123,136,146,151,163,170}$ Key results of the studies that explicitly analyzed the predictive utility of measures in older people are presented in Tables 34, 35, and 36 and are described briefly in the text by type of measure.

\section{Individual Measures of Circulatory and Respiratory Compromise}

Four studies evaluated individual measures. ${ }^{46,89,117,146}$ For the measures evaluated (SBP, lactate, base deficit, RR, and assisted ventilation), the sensitivities and AUROCs were consistently low. The standard definition of low SBP of under $<90 \mathrm{mmHg}$ fails to identify older patients at risk of serious injury or death, ${ }^{46,89}$ while higher threshold performs better. ${ }^{46}$ One study reported that SBP divided by age in a sample of adults of all ages performed better than SBP alone (results in Appendix D). ${ }^{116}$ Similarly, studies documented that lactate and base deficit did not predict mortality in older patients in general ${ }^{146}$ or in older patients with normal SBP of $>90$ mmHg. ${ }^{117}$ An additional study also evaluated RR and assisted ventilation and reported similar findings. ${ }^{89}$

\section{Shock Index}

Table 35 reports the results of four studies that evaluated SI in older people either on its own or by comparing a modified version in which SI is multiplied by age. ${ }^{123,136,151,170}$ Like SBP, SI was less able to identify serious injury in older people. In addition to the studies in Table 35, one study that evaluated SI in a sample of adults of all ages demonstrated that the correlation between SI and several different outcomes decreased when patients were stratified into age groups by decade to the point that in patients over 80 , SI was not significantly correlated with any outcomes. ${ }^{87}$ Multiplying SI by age increased AUROC values in two studies limited to older people but the increases were small ${ }^{136,170}$ and one study reported similar increases when SI age was used in a sample of adults of all ages (results in the evidence tables in Appendix D). ${ }^{116}$

\section{Combination Triage Criteria}

Another approach to age differences is to modify triage criteria that combine measures by either changing thresholds, adding criteria, or both. Table 36 reports the results of two studies ${ }^{72,90}$ that compared standard to modified criteria for older patients. Both reported that the modified criteria increased sensitivity and AUROC for serious injury. Ichawan et al. created geriatric triage criteria that increased the SBP threshold from 90 to $100 \mathrm{mmHg}$ and GCS from 13 or less to 14 or less and also added more anatomic and cause of injury criteria. ${ }^{72}$ This increased sensitivity by over 30 percentage points for ISS $>15$ with less extreme improvements for other indicators of serious injury. Newgard et al. also increased the GCS threshold to 14, adjusted the vital signs (SBP to $<110$ or $>200 \mathrm{mmHg}$, respirations to $<10$ or $>24$ per minute, and $\mathrm{HR}<60$ or $>110$ beats per minute), and added high-risk mechanism. ${ }^{90}$ This increased sensitivity from 75.9 to 92.1 percent but decreased specificity from 77.8 to 41.5 percent. The authors estimated that the impact would be a reduction in under-triage from 146 to 48 patients, but over-triage would increase from 2,840 to 7,485 in a validation sample of 13,401 patients. A third study examined a related issue and found that when using the same criteria for all adults, trauma teams were less likely to be activated for older patients with severe multi-system injury (adjusted odds ratio 1.37 [95\% CI 1.12 to 1.69 , $\mathrm{p}=0.0003$ ] for missed trauma team activation for patients $\geq 65$ years of age vs. $<65$ years of age). ${ }^{163}$ 
Table 34. Predictive utility of single physiologic measures in older patients

\begin{tabular}{|c|c|c|c|c|c|}
\hline $\begin{array}{l}\text { Author, Year } \\
\text { Risk of Bias }\end{array}$ & $\begin{array}{l}\text { Measure and } \\
\text { Threshold } \\
\text { Settting }\end{array}$ & $\begin{array}{l}\text { Type: } \\
\text { Serious } \\
\text { Injury } \\
\text { Specific } \\
\text { Indicator }\end{array}$ & $\begin{array}{l}\text { N Analyzed } \\
\text { Age Group } \\
\text { Mean Age } \\
\text { (SD) }\end{array}$ & $\begin{array}{l}\text { Sensitivity } \\
\text { Specificity } \\
(95 \% \mathrm{Cl})\end{array}$ & $\begin{array}{l}\text { AUROC } \\
(95 \% \mathrm{Cl}) \\
\end{array}$ \\
\hline $\begin{array}{l}\text { Brown, 2015a }{ }^{46} \\
\text { Moderate }\end{array}$ & $\begin{array}{l}\text { SBP } \\
\text { alone } \\
\text { In NTTP step } 1 \\
\& 2 \\
<110 \\
\mathrm{OH}\end{array}$ & $\begin{array}{l}\mathrm{R}, \mathrm{I} \text { : trauma } \\
\text { care need }\end{array}$ & $\begin{array}{l}\mathrm{N}=438,828 \\
\geq 65 \\
\text { Median: } 80 \\
\text { (IQR 73-86) }\end{array}$ & $\begin{array}{l}\text { Sen: } 13 \%(N R) \\
\text { Sp: } 93 \%(N R) \\
\text { Sen: } 44 \%(N R) \\
\text { Sp: } 71 \%(N R)\end{array}$ & $\begin{array}{l}0.532(0.53 \text { to } \\
0.534) \\
0.575(0.572 \text { to } \\
0.577)\end{array}$ \\
\hline $\begin{array}{l}\text { Brown, 2015a }{ }^{46} \\
\text { Moderate }\end{array}$ & $\begin{array}{l}\text { SBP } \\
\text { alone } \\
\text { In NTTP step } 1 \\
\& 2 \\
<90 \\
\mathrm{OH}\end{array}$ & $\begin{array}{l}\mathrm{R}, \mathrm{I} \text { : trauma } \\
\text { care need }\end{array}$ & $\begin{array}{l}\mathrm{N}=438,828 \\
\geq 65 \\
\text { Median: } 80 \\
\text { (IQR 73-86) }\end{array}$ & $\begin{array}{l}\text { Sen: } 5 \%(N R) \\
\text { Sp: } 99 \%(N R) \\
\text { Sen: } 40 \%(N R) \\
\text { Sp: } 75 \%(N R)\end{array}$ & $\begin{array}{l}0.519(0.517 \text { to } \\
0.52) \\
0.574(0.571 \text { to } \\
0.576)\end{array}$ \\
\hline $\begin{array}{l}\text { Brown, } 2015 \mathrm{a}^{46} \\
\text { Moderate }\end{array}$ & $\begin{array}{l}\text { SBP } \\
\text { Derived optimal } \\
\text { cutoff } \\
<122 \\
\mathrm{OH}\end{array}$ & $\begin{array}{l}\mathrm{R}, \mathrm{I} \text { : trauma } \\
\text { care need }\end{array}$ & $\begin{array}{l}\mathrm{N}=438,828 \\
\geq 65 \\
\text { Median: } 80 \\
\text { (IQR 73-86) }\end{array}$ & $\begin{array}{l}\text { Sen: 22\% (NR) } \\
\text { Sp: } 83 \%(N R)\end{array}$ & NR \\
\hline $\begin{array}{l}\text { Brown, 2015a }{ }^{46} \\
\text { Moderate }\end{array}$ & $\begin{array}{l}\text { SBP } \\
\text { Derived optimal } \\
\text { cutoff } \\
<118 \\
\mathrm{OH}\end{array}$ & M: mortality & $\begin{array}{l}\mathrm{N}=438,828 \\
\geq 65 \\
\text { Median: } 80 \\
\text { (IQR 73-86) }\end{array}$ & $\begin{array}{l}\text { Sen: 29\% (NR) } \\
\text { Sp: } 86 \% \text { (NR) }\end{array}$ & NR \\
\hline $\begin{array}{l}\text { Newgard, } \\
2014^{89} \\
\text { Moderate }\end{array}$ & $\begin{array}{l}\text { SBP } \\
<90 \mathrm{mmHg} \\
\mathrm{OH}\end{array}$ & I: ISS $\geq 16$ & $\begin{array}{l}\mathrm{N}=44,890 \\
\geq 55 \\
\text { Age } \\
\text { (median): } 77 \\
\text { (IQR 64-85) }\end{array}$ & $\begin{array}{l}\text { *Sen: } 4.08 \% \text { (3.31 to } \\
4.97) \\
\text { *Sp: } 98.52 \%(98.40 \\
\text { to } 98.63)\end{array}$ & NR \\
\hline $\begin{array}{l}\text { Pal, 2006 } \\
\text { Low }\end{array}$ & $\begin{array}{l}\text { Lactate } \\
>2.0 \\
\text { ED }\end{array}$ & M: mortality & $\begin{array}{l}\text { Total sample } \\
N=5,995 \\
\text { NR for older } \\
\text { groups } \\
38.8 \text { (range } \\
16-100)\end{array}$ & NR & $\begin{array}{l}0.65(\mathrm{NR}) \text { age } \\
>50 \\
0.63(\mathrm{NR}) \text { age } \\
>60 \\
0.62(\mathrm{NR}) \text { age } \\
>70 \\
\\
0.72(\mathrm{NR}) \text { all } \\
\text { ages }\end{array}$ \\
\hline $\begin{array}{l}\text { Callaway, } \\
2009^{117} \\
\text { Moderate }\end{array}$ & $\begin{array}{l}\text { Lactate } \\
2.5 \text { to } 4.0 \\
\text { ED }\end{array}$ & M: mortality & $\begin{array}{l}\mathrm{N}=588 \\
\text { Normotensive } \\
(\mathrm{SBP}>90 \\
\mathrm{mmHg}) \\
\geq 65 \text { years old } \\
80(8)\end{array}$ & $\begin{array}{l}\text { *Sen: } 22.32 \%(15.00 \\
\text { to } 31.16 \%) \\
\text { *Sp: } 82.77 \%(79.07 \\
\text { to } 86.06 \%)\end{array}$ & NR \\
\hline
\end{tabular}




\begin{tabular}{|c|c|c|c|c|c|}
\hline $\begin{array}{l}\text { Author, Year } \\
\text { Risk of Bias }\end{array}$ & $\begin{array}{l}\text { Measure and } \\
\text { Threshold } \\
\text { Settting }\end{array}$ & $\begin{array}{l}\text { Type: } \\
\text { Serious } \\
\text { Injury } \\
\text { Specific } \\
\text { Indicator }\end{array}$ & $\begin{array}{l}\text { N Analyzed } \\
\text { Age Group } \\
\text { Mean Age } \\
\text { (SD) } \\
\end{array}$ & $\begin{array}{l}\text { Sensitivity } \\
\text { Specificity } \\
(95 \% \mathrm{Cl})\end{array}$ & $\begin{array}{l}\text { AUROC } \\
(95 \% \mathrm{Cl})\end{array}$ \\
\hline $\begin{array}{l}\text { Callaway, } \\
2009^{117} \\
\text { Moderate }\end{array}$ & $\begin{array}{l}\text { Lactate } \\
>4.0 \\
\text { ED }\end{array}$ & M: mortality & $\begin{array}{l}\mathrm{N}=588 \\
\text { Normotensive } \\
(\mathrm{SBP}>90 \\
\mathrm{mmHg}) \\
\geq 65 \text { years old } \\
80 \text { (8) }\end{array}$ & $\begin{array}{l}\text { *Sen: } 18.75 \%(12.00 \\
\text { to } 27.22 \%) \\
\text { *Sp: } 93.28 \%(90.64 \\
\text { to } 95.36 \%)\end{array}$ & NR \\
\hline $\begin{array}{l}\text { Callaway, } \\
2009^{117} \\
\text { Moderate }\end{array}$ & $\begin{array}{l}\text { BD } \\
0 \text { to }-6 \\
\text { ED }\end{array}$ & M: mortality & $\begin{array}{l}\mathrm{N}=588 \\
\text { Normotensive } \\
(\mathrm{SBP}>90 \\
\mathrm{mmHg}) \\
\geq 65 \text { years old } \\
80(8)\end{array}$ & $\begin{array}{l}\text { *Sen: } 36.94 \%(27.97 \\
\text { to } 46.62 \%) \\
\text { *Sp: } 76.60 \%(72.50 \\
\text { to } 80.35)\end{array}$ & NR \\
\hline $\begin{array}{l}\text { Callaway, } \\
2009^{117} \\
\text { Moderate }\end{array}$ & $\begin{array}{l}\text { BD } \\
<-6 \\
\text { ED }\end{array}$ & M: mortality & $\begin{array}{l}\mathrm{N}=588 \\
\text { Normotensive } \\
(\mathrm{SBP}>90 \\
\mathrm{mmHg}) \\
\geq 65 \text { years old } \\
80 \text { (8) }\end{array}$ & $\begin{array}{l}\text { *Sen: } 15.32 \%(9.18 \\
\text { to } 23.39 \%) \\
\text { *Sp: } 94.47 \%(92.00 \\
\text { to } 96.35 \%)\end{array}$ & NR \\
\hline $\begin{array}{l}\text { Newgard, } \\
2014^{89} \\
\text { Moderate }\end{array}$ & $\begin{array}{l}\text { RR } \\
<10 \text { or }>29 \\
\text { OH }\end{array}$ & I: ISS $\geq 16$ & $\begin{array}{l}\mathrm{N}=44,890 \\
\geq 55 \\
\text { Age } \\
\text { (median): } 77 \\
\text { (IQR 64-85) }\end{array}$ & $\begin{array}{l}\text { *Sen: } 6.31 \% \text { (5.36 to } \\
7.38) \\
\text { *Sp: } 98.63 \%(98.51 \\
\text { to } 98.73)\end{array}$ & NR \\
\hline $\begin{array}{l}\text { Newgard, } \\
2014^{89} \\
\text { Moderate }\end{array}$ & $\begin{array}{l}\text { Assisted } \\
\text { Ventilation } \\
\mathrm{OH}\end{array}$ & I: ISS $\geq 16$ & $\begin{array}{l}\mathrm{N}=44,890 \\
\geq 55 \\
\text { Age } \\
\text { (median): } 77 \\
\text { (IQR 64-85) }\end{array}$ & $\begin{array}{l}\text { *Sen: } 7.90 \% \text { (6.84 to } \\
9.08) \\
\text { *Sp: } 99.60 \%(99.53 \\
\text { to } 99.66)\end{array}$ & NR \\
\hline
\end{tabular}

AUROC = area under the operating characteristic curve; BD = base deficit; CI = confidence interval; ED = emergency department; I = injury type or severity; ICU = intensive care unit; IQR = interquartile range; ISS = injury severity score; LOS = length of stay; $\mathrm{M}$ = mortality; $\mathrm{N}$ = number; NR = not reported; NTTP = National Trauma Triage Protocol; OH = out-of- hospital; $\mathrm{R}=$ resource use; $\mathrm{RR}=$ respiratory rate; $\mathrm{SBP}=$ systolic blood pressure; $\mathrm{SD}=$ standard deviation; $\mathrm{Sen}=$ sensitivity; $\mathrm{Sp}=$ specificity

*Results calculated by reviewers 
Table 35. Predictive utility of shock index in older patients

\begin{tabular}{|c|c|c|c|c|c|}
\hline $\begin{array}{l}\text { Author, Year } \\
\text { Risk of Bias }\end{array}$ & $\begin{array}{l}\text { Measure and } \\
\text { Threshold } \\
\text { Setting }\end{array}$ & $\begin{array}{l}\text { Type: } \\
\text { Serious } \\
\text { Injury } \\
\text { Specific } \\
\text { Indicator }\end{array}$ & $\begin{array}{l}\text { N Analyzed } \\
\text { Age Group } \\
\text { Mean Age } \\
\text { (SD) }\end{array}$ & $\begin{array}{l}\text { Sensitivity } \\
\text { Specificity } \\
(95 \% \mathrm{Cl})\end{array}$ & $\begin{array}{l}\text { AUROC } \\
(95 \% \mathrm{Cl})\end{array}$ \\
\hline $\begin{array}{l}\text { DeMuro, } 2013^{123} \\
\text { Moderate }\end{array}$ & $\begin{array}{l}\text { SI } \\
\geq 0.8 \\
\geq 0.9 \\
\geq 1 \\
\text { ED }\end{array}$ & R: bleeding & $\begin{array}{l}\mathrm{N}=2,093 \\
\geq 65 \\
N R\end{array}$ & $\begin{array}{l}\text { Sen: } 58.8 \%(N R) \\
\text { Sp: } 91.9 \%(N R) \\
\text { Sen: } 41.2 \%(N R) \\
\text { Sp: } 95.7 \%(N R) \\
\text { Sen: } 29.4 \%(N R) \\
\text { Sp: } 98.1 \%(N R)\end{array}$ & NR \\
\hline $\begin{array}{l}\text { Pandit, } 2014^{151} \\
\text { Moderate }\end{array}$ & $\begin{array}{l}\text { SI } \\
\geq 1 \\
\text { ED }\end{array}$ & $\begin{array}{l}\text { R: blood } \\
\text { transfusion }\end{array}$ & $\begin{array}{l}\mathrm{N}=217,190 \\
\geq 65 \\
77.7(7.1)\end{array}$ & $\begin{array}{l}\text { *Sen: } 5.80 \% \text { (5.44 to } \\
6.17 \%) \\
\text { *Sp: } 97.19 \%(97.11 \\
\text { to } 97.26 \%)\end{array}$ & NR \\
\hline $\begin{array}{l}\text { Pandit, } 2014^{151} \\
\text { Moderate }\end{array}$ & $\begin{array}{l}\text { SI } \\
\geq 1 \\
\text { ED }\end{array}$ & $\begin{array}{l}\text { R: exploratory } \\
\text { laparotomy }\end{array}$ & $\begin{array}{l}\mathrm{N}=217,190 \\
\geq 65 \\
77.7(7.1)\end{array}$ & $\begin{array}{l}\text { *Sen: } 7.54 \% \text { (6.84 to } \\
8.29 \%) \\
\text { *Sp: } 97.08 \%(97.01 \\
\text { to } 97.15 \%)\end{array}$ & NR \\
\hline $\begin{array}{l}\text { Pandit, } 2014^{151} \\
\text { Moderate }\end{array}$ & $\begin{array}{l}\text { SI } \\
\geq 1 \\
\text { ED }\end{array}$ & $\begin{array}{l}\text { M: mortality } \\
\text { in-hospital }\end{array}$ & $\begin{array}{l}\mathrm{N}=217,190 \\
\geq 65 \\
77.7(7.1)\end{array}$ & $\begin{array}{l}\text { Sen: } 45 \% \text { (NR) } \\
\text { Sp: } 97 \% \text { (NR) }\end{array}$ & NR \\
\hline $\begin{array}{l}\text { Kim, } 2016{ }^{136} \\
\text { High }\end{array}$ & $\begin{array}{l}\text { SI } \\
\text { SI*Age } \\
\text { ED }\end{array}$ & $\begin{array}{l}\text { M: ED } \\
\text { mortality }\end{array}$ & $\begin{array}{l}\mathrm{N}=45,880 \\
\geq 65 \\
\text { Age } \\
\text { (median): } 72 \\
\text { (IQR: } 68-78 \text { ) }\end{array}$ & NR & $\begin{array}{l}0.807(0.780 \text { to } \\
0.834) \text { SI*age } \\
\text { vs. } \\
0.771(0.735 \text { to } \\
0.806) \text { for } \mathrm{SI}\end{array}$ \\
\hline $\begin{array}{l}\text { Zarzaur, 2008 } \\
\text { Moderate }\end{array}$ & $\begin{array}{l}\text { SI } \\
\text { SI*Age } \\
\text { ED }\end{array}$ & $\begin{array}{l}\text { R: Blood } \\
\text { Transfusion } \geq \\
4 \text { units in } 48 \\
\text { hours }\end{array}$ & $\begin{array}{l}\mathrm{N}=2420 \\
\geq 55 \\
67(8.1)\end{array}$ & NR & $\begin{array}{l}0.805(0.776 \text { to } \\
0.834) \\
\text { vs. } \\
0.789(0.758 \text { to } \\
0.819)\end{array}$ \\
\hline $\begin{array}{l}\text { Zarzaur, 2008 } \\
\text { Moderate }\end{array}$ & $\begin{array}{l}\text { SI } \\
\text { SI*Age } \\
\geq 52.1 \\
\text { ED }\end{array}$ & $\begin{array}{l}\text { M: Mortality } \\
\text { 48-hour }\end{array}$ & $\begin{array}{l}N=2420 \\
\geq 55 \\
67(8.1)\end{array}$ & $\begin{array}{l}\text { Sen: } 72 \%(N R) \\
\text { Sp: } 81 \%(N R)\end{array}$ & $\begin{array}{l}0.830(0.780 \text { to } \\
0.880) \\
\text { vs. } \\
0.789(0.730 \text { to } \\
0.848)\end{array}$ \\
\hline
\end{tabular}

AUROC = area under the operating characteristic curve; $\mathrm{CI}=$ confidence interval; $\mathrm{ED}=$ emergency department; $\mathrm{M}=$ mortality; $\mathrm{N}$ = number; $\mathrm{NR}$ = not reported; $\mathrm{R}$ = resource use; $\mathrm{SD}$ = standard deviation; $\mathrm{Sen}=$ sensitivity; $\mathrm{SI}=$ shock index; $\mathrm{Sp}=$ specificity

*Results calculated by reviewers 
Table 36. Predictive utility of combination triage criteria in older patients

\begin{tabular}{|c|c|c|c|c|c|}
\hline $\begin{array}{l}\text { Author, Year } \\
\text { Risk of Bias }\end{array}$ & $\begin{array}{l}\text { Measure } \\
\text { Comparator } \\
\text { Setting }\end{array}$ & $\begin{array}{l}\text { Type: } \\
\text { Serious } \\
\text { Injury } \\
\text { Specific } \\
\text { Indicator }\end{array}$ & $\begin{array}{l}\text { N Analyzed } \\
\text { Age Group } \\
\text { Mean Age } \\
\text { (SD) }\end{array}$ & $\begin{array}{l}\text { Sensitivity } \\
\text { Specificity } \\
(95 \% \mathrm{Cl})\end{array}$ & $\begin{array}{l}\text { AUROC } \\
(95 \% \mathrm{CI})\end{array}$ \\
\hline $\begin{array}{l}\text { Ichwan, } 2015^{72} \\
\text { Moderate }\end{array}$ & $\begin{array}{l}\text { Geriatric Triage } \\
\text { Criteria } \\
\text { vs. Adult Criteria } \\
\mathrm{OH}\end{array}$ & $\begin{array}{l}\text { R: OR within } \\
48 \text { hours }\end{array}$ & $\begin{array}{l}\mathrm{N}=33,379 \\
\geq 70 \text { years old } \\
N R\end{array}$ & $\begin{array}{l}\text { Sen: } 47 \% \text { (46 to } 49) \\
\text { Sp: } 42 \% \text { (41 to } 42 \text { ) } \\
\text { vs. } \\
\text { Sen: } 35 \% \text { (34 to } 37 \text { ) } \\
\text { Sp: } 57 \% \text { (56 to } 58)\end{array}$ & $\begin{array}{l}0.44(\mathrm{NR}) \\
\text { vs. } \\
0.46(\mathrm{NR})\end{array}$ \\
\hline $\begin{array}{l}\text { Ichwan, } 2015^{72} \\
\text { Moderate }\end{array}$ & $\begin{array}{l}\text { Geriatric Triage } \\
\text { Criteria } \\
\text { vs. Adult Criteria } \\
\mathrm{OH}\end{array}$ & R: ICU stay & $\begin{array}{l}\mathrm{N}=33,379 \\
\geq 70 \text { years old } \\
\mathrm{NR}\end{array}$ & $\begin{array}{l}\text { Sen: } 81 \% \text { (80 to } 82) \\
\text { Sp: } \quad 48 \% \text { (47 to } 48) \\
\text { vs. } \\
\text { Sen: } 56 \%(55 \text { to } 57) \\
\text { Sp: } \quad 61 \%(60 \text { to } 62)\end{array}$ & $\begin{array}{l}0.64(\mathrm{NR}) \\
\text { vs. } \\
0.58(\mathrm{NR})\end{array}$ \\
\hline $\begin{array}{l}\text { Ichwan, } 2015^{72} \\
\text { Moderate }\end{array}$ & $\begin{array}{l}\text { Geriatric Triage } \\
\text { Criteria } \\
\text { vs. Adult Criteria } \\
\mathrm{OH}\end{array}$ & I: ISS >15 & $\begin{array}{l}\mathrm{N}=33,379 \\
\geq 70 \text { years old } \\
N R\end{array}$ & $\begin{array}{l}\text { Sen: } 93 \% \text { (92 to } 93) \\
\text { Sp: } 49 \% \text { (48 to } 49) \\
\text { vs. } \\
\text { Sen: } 61 \%(60 \text { to } 62) \\
\text { Sp: } 61 \%(61 \text { to } 62)\end{array}$ & $\begin{array}{l}0.71(\mathrm{NR}) \\
\text { vs. } \\
0.61(\mathrm{NR})\end{array}$ \\
\hline $\begin{array}{l}\text { Ichwan, } 2015^{72} \\
\text { Moderate }\end{array}$ & $\begin{array}{l}\text { Geriatric Triage } \\
\text { Criteria } \\
\text { vs. Adult Criteria } \\
\mathrm{OH}\end{array}$ & M: Mortality & $\begin{array}{l}\mathrm{N}=33,379 \\
\geq 70 \text { years old } \\
N R\end{array}$ & $\begin{array}{l}\text { Sen: } 90 \% \text { (89 to } 91) \\
\text { Sp: } 45 \% \text { (45 to } 46) \\
\text { vs. } \\
\text { Sen: } 74 \%(72 \text { to } 76) \\
\text { Sp: } \quad 60 \%(60 \text { to } 61)\end{array}$ & $\begin{array}{l}0.68(\mathrm{NR}) \\
\text { vs. } \\
0.67(\mathrm{NR})\end{array}$ \\
\hline $\begin{array}{l}\text { Newgard, } 2016^{90} \\
\text { Moderate }\end{array}$ & $\begin{array}{l}\text { Alternative } \\
\text { Guidelines } \\
\text { vs. Current } \\
\mathrm{OH}\end{array}$ & I: ISS $\geq 16$ & $\begin{array}{l}N=33,298^{*} \\
\geq 65 \\
N R\end{array}$ & $\begin{array}{l}\text { Sen: } 92.1 \% \text { ( } 89.8 \text { to } \\
94.5) \\
\text { Sp: } 41.5 \% \text { ( } 40.6 \text { to } \\
42.4) \\
\text { vs. } \\
\text { Sen: } 75.9 \% \text { ( } 72.5 \text { to } \\
79.3) \\
\text { Sp: } 77.8 \% \text { ( } 77.1 \text { to } \\
78.5)\end{array}$ & $\begin{array}{l}0.67(0.66 \text { to } 0.68) \\
\text { vs. } \\
0.77(0.75 \text { to } 0.79)\end{array}$ \\
\hline
\end{tabular}

AUROC = area under the operating characteristic curve; $\mathrm{CI}=$ confidence interval; $\mathrm{I}=$ injury type or severity; ICU = intensive care unit; ISS = injury severity score; $\mathrm{M}=$ mortality; $\mathrm{N}=$ number; $\mathrm{NR}=$ not reported; $\mathrm{OH}$ = out-of-hospital; OR = operating room; $\mathrm{R}$ = resource use; Sen: sensitivity; $\mathrm{SI}$ = shock index; $\mathrm{Sp}=$ specificity; vs. = versus

*Patients in Newgard, 2016, a subset of patients in Newgard, 2014 


\section{Discussion}

\section{Key Findings}

The key findings are based on our quantitative and qualitative syntheses of findings and data across 138 identified articles. In this report we provided an assessment of the strength of evidence for the sensitivity, specificity, and the area under the receiver operating characteristic curve (AUROC), for measures of circulatory and respiratory measures as well as measures that combine these with measures of consciousness. We generated pooled estimates and completed strength of evidence ratings separately for out-of-hospital and emergency department (ED) data to make any differences by setting apparent. We reported pooled estimates both by category (i.e., resource use, injury severity, and mortality) and then totaled across all indicators of risk of serious injury. The key estimates and strength of evidence ratings are provided in Appendix $\mathrm{H}$ and summarized in Tables 3, 4, and 5.

Most of the strength of evidence assessments were "low" due to inconsistency in results across studies and imprecision of the estimates, although in some cases study limitations also contributed to the low rating. There were a few "moderate" ratings for measures for which there were more studies or subjects, the results were consistent, and the estimates were more precise. There were no "high" strength of evidence ratings as we are not confident that the results will not change based on the results of larger, better, and more purposefully designed studies of physiologic measures for trauma triage.

Across all the measures, the AUROC values we calculated through meta-analysis generally fell into the ranges considered poor ( 0.60 to 0.69 ) or fair ( 0.70 to 0.79$)$, with only the combination measures assessed with ED data reaching good to excellent (0.8 to 1.0). AUROCs are measures of discrimination that summarize the performance of the measure in terms of both sensitivity (the probability the patient who is seriously injured will be assessed as positive by the measure) and specificity (the probability a patient is not seriously injured will be assessed as negative). The lower AUROC values reflect the fact that in general the measures we identified have high specificities and low sensitivities when used to predict the risk of serious injury and the need for trauma care.

Our analysis of individual measures of circulatory and respiratory compromise (Key Question 1 and Key Question 2) included pooled analyses of systolic blood pressure (SBP), shock index (SI), heart rate (HR), lactate, and respiratory rate (RR), and qualitative summaries of studies of heart rate variability (HRV)/heart rate complexity (HRC), base deficit, and oxygen saturation. Other measures that were the subject of one or two studies were included for completeness but not synthesized.

Focusing on data collected out-of-hospital, the lowest pooled AUROCs were for SBP (0.67) and HR (0.67). The AUROCs were in the fair range for SI (0.72), lactate (0.77), and RR (0.70). The only AUROC that reached the excellent range was for the combination measure known as Glasgow Coma Scale, age, and arterial pressure (GAP), for which the pooled AUROC estimate based on ED data was 0.96 .

We also pooled data to estimate sensitivity and specificity results for blood pressure and lactate at different thresholds ( $>90$ or $>100 \mathrm{mmHg}$ for blood pressure and $>2$ or $>4 \mathrm{mmol} / \mathrm{L}$ for lactate). Using the higher threshold for SBP did increase sensitivity (from 19\% to 35\% for outof-hospital and 18\% to 35\% for ED) with a moderate decrease in specificity (from 95\% to $88 \%$ for out-of-hospital and from $97 \%$ to $89 \%$ in ED). The changes were more extreme in the out-ofhospital data (sensitivity was $74 \%$ at $<90$ and $23 \%$ at $<100$; specificity increased from $62 \%$ to 
93\%) than in the ED data (sensitivity was $74 \%$ at $<90$ and $50 \%$ at $<100$; specificity increased from $52 \%$ to $86 \%$ ). However, the out-of-hospital estimates were from fewer studies and patients and the estimates were less stable and less precise. For lactate, defining abnormal with a more extreme value ( $>4 \mathrm{mmol} / \mathrm{L} \mathrm{vs}$. $>2 \mathrm{mmol} / \mathrm{L}$ ) decreased sensitivity from 74 to 23 percent and increased specificity form 62 to 93 percent.

We identified numerous combination measures (Key Question 3); however, most were analyzed in only one or two articles. The exception was the Revised Trauma Score (RTS) and variations on this score. The RTS has been examined primarily in studies that compare several measures; it was used as a tool for evaluation of these measures more than as a triage or assessment tool with specific cuts offs in the field. Given that the formula for RTS cannot be calculated quickly without a calculator or app, some studies suggested and evaluated revisions that simplified the calculation. These produced minor decreases in AUROCs (from 0.90 for the RTS to $0.88^{96}$ for the simpler version, or from 0.75 to $0.74^{95}$ ).

Another combination of potential interest is GAP, which combines the Glasgow Coma Scale, adds points if the patient is under 60 years of age (age is the A in GAP), and scores SBP as above or below $120 \mathrm{mmHg}$. While the data we reviewed are from a smaller number of studies and the measures were all collected in the ED, the initial indications are that the GAP performs well. Reported AUROCs were over 0.9 and sensitivities ranged from 75 to 98 percent and specificities from 57 to 91 percent across different indicators of serious injury.

We examined the utility of the measures or specific thresholds for pediatric or older trauma patients. The research identified in this review underscores the importance of age. Children, adults, and older people differ physiologically and their responses to trauma differ. While some measures may work across age groups, others may be less useful and new measures or approaches are needed. The available body of research in this area is exploratory and growing. Few studies took steps to separate results by age, although it would seem to be possible. For studies of children, the focus was often on considering whether adult triage thresholds were appropriate or should be changed. The message across studies was that adult triage approaches are generally useful for pediatrics but refinements could increase their predictive utility. For older people, the studies attempted to identify new thresholds with better predictive utility or they incorporated age into the calculation, essentially adjusting the measure.

The included studies that assessed measures in pediatric patients reported that the standard thresholds used for adults for SBP and base deficit resulted in low sensitivities in children. Lactate $>2.0 \mathrm{mmol} / \mathrm{L}$ resulted in higher sensitivities compared with the other measures, but the values are still low. Performance of this measure varied across indicators of serious injury and in age groups in the one study with subgroup comparisons; however, larger studies are needed to confirm these variations. The results of evaluations of RR were inconsistent, with reported sensitivities ranging from 2 to 76 percent. As in studies of adults or mixed age populations, the studies of combination measures performed better with better results with a trauma score developed specifically for pediatrics. Using the physiologic measures from the current adult triage guidelines resulted in lower sensitivity (49\%) than the customized measures but was still better than individual measures, according to one study. ${ }^{77}$

In older adults, studies reported consistently low sensitivities and AUROCs for SBP, lactate, base deficit, RR, and assisted ventilation. SI performed less well in older patients. One study reported that when patients were stratified into age groups by decade, the correlation between SI and outcomes decreased with older age to the point that in patients over age 80, SI was not significantly correlated with any outcomes. ${ }^{87}$ Variations of triage criteria modified for older 
adults by either changing thresholds or adding additional criteria (e.g., mechanism of injury) may be promising in that they have demonstrated substantial increases in sensitivity (e.g., $76 \%$ to $92 \%{ }^{90}$ ), but this magnitude of improvement is not consistent across indicators of serious injury and may come with similar substantial decreases in specificity (e.g., $78 \%$ to $42 \%{ }^{90}$ ).

Overall, our analysis demonstrates that physiologic measures have low sensitivity for identifying high-risk trauma patients (i.e., many patients will have normal physiology and prove to have serious injuries - there are higher numbers of false negatives), but have high specificity (i.e., patients with abnormal physiologic measures are likely to have resource needs, serious injuries, and are at higher mortality risk - there are few false positives). There was little evidence to suggest that one physiologic measure is significantly better than another (e.g., SBP versus SI versus lactate) because fewer studies compared these measures directly in head-to-head studies, the head-to-head studies were not amenable to pooling as they use different thresholds and outcomes, and the differences across our pooled estimate were small to moderate. However, combining different categories of physiologic measures (e.g., circulatory and level of consciousness) may increase predictive yield. Overall, less extreme cut-points (e.g., lactate $>2$ $\mathrm{mmol} / \mathrm{L}, \mathrm{SBP}<110 \mathrm{mmHg}$ ) raised sensitivity and lowered specificity, demonstrating that sensitivity and specificity have an inverse relationship when selecting dichotomous cut-points in continuous measures.

\section{Findings in Relationship to What Is Already Known}

We did not identify any prior systematic reviews that attempted to summarize evaluations of multiple measures of circulatory and respiratory compromise and make comparisons across studies and across measures. We did identify two reviews that focused exclusively on lactate, we reviewed the studies identified in this review, and we included those that met our inclusion criteria. Our analysis differs in that we were able to report the pooled results rather than qualitatively synthesizing the results, and in that we were able to report pooled sensitivities and specificities in addition to AUROCS for lactate thresholds of $>2$ and $>4 \mathrm{mmol} / \mathrm{L}$. This provides a way to explore the impact of changing the threshold and to consider the tradeoffs between sensitivity and specificity.

One of the prior reviews identified five studies that evaluated lactate as a marker for mortality in the ED and concluded that initial lactate does not identify patients at high risk of death. ${ }^{196} \mathrm{~A}$ more recent and comprehensive review assessed ED lactate as predictor of mortality and other outcomes such as intensive care unit (ICU) admission and blood loss. Updated in March 2016, this review identified, assessed, and summarized 28 studies. ${ }^{197}$ The review did not attempt to pool the study results, and it did not compare the utility of lactate to other measures. The authors concluded that initial lactate measured in the ED was predictive of mortality, although only three of eight studies reported an AUROC of 0.8 or higher.

\section{Applicability}

Our findings were based on a relatively large number of diverse studies, with the majority conducted in the United States and several multi-site studies. Some of the studies were large retrospective analyses of trauma databases, while others were smaller prospective studies designed to evaluate a less common measure or a specific monitoring technology. A small number (3 studies) were conducted in Iraq and Afghanistan in military hospitals that treated mostly military casualties. Table 2 provides an overview of this diversity and details on the studies are included in the evidence tables in Appendix D. 
Given the objectives of this review, this diversity is an advantage as well as a challenge. Differences across studies can make synthesis problematic-increasing heterogeneity in pooled estimates and making it difficult to construct a framework for qualitative synthesis. These differences are critical when synthesizing comparative studies because if the studies differ in important ways, the comparisons may not be similar enough to combine. However, the objective of this review was different. Our goal was to identify physiologic measures that can be used to assess whether patients are high risk for serious injury and evaluate their predictive utility. Having data from studies across a wide range of possible situations mirrors the reality of field triage and out-of-hospital assessment. While the diversity across the studies means heterogeneity is high in the pooled estimates, the range is likely to reflect the variation that will be seen in trauma assessment and triage across different locales as well as within the patients served by a trauma system.

An important consideration for applicability is the location of assessment and measurement. We included studies in which the data were collected in the ED if studies clearly identified data as being collected immediately upon presentation to the ED. These data were less applicable to field triage decisions as the patients had already been transported and had undergone initial treatment. However, not including ED data would have prevented us from including certain measures at all (e.g., base deficit would not be included as we did not identify any out-ofhospital studies) or only limited data on others (e.g., information on lactate testing out-ofhospital is available from few studies). Additionally, for some measures the settings were limited to a certain type (e.g., all the studies of HRC were conducted in air ambulances, and some measures were designed specifically for mass casualty situations even though they were tested on data from single trauma incidents), and it was unclear if the results would be similar if the measures were used in different situations or more broadly.

An approach to summarizing the data across studies and then comparing and considering their impact is presented in Table 37. This is a standard approach often used to present the implications of how well a screening test or triage tool performs. The pooled data are modeled to generate positive and negative likelihood ratios (LR+ and LR-). The positive likelihood ratio is Sensitivity/(1-Specificity) and the negative likelihood ratio is (1-Sensitivity)/Specificity. The likelihood ratios are then applied to different hypothetical pretest probabilities and odds to produce post-test odds of the outcome (in this case serious injury) given a negative or positive test. Table 37 shows values derived for SBP at thresholds of $<90$ and $<100 \mathrm{mmHg}$, and for HR $\geq 100$, SI $>1$, lactate $>2$ and $>4 \mathrm{mmol} / \mathrm{L}$, and $\mathrm{RR}<10$ or $>29$.

Table 37. Post-test odds and probability of serious injury given pre-test assumptions

\begin{tabular}{|c|c|c|c|c|c|c|c|c|c|}
\hline $\begin{array}{c}\text { Physiologic } \\
\text { Predictor } \\
\text { (Test) }\end{array}$ & $\begin{array}{c}\text { Serious } \\
\text { Injury } \\
\text { Indicator } \\
\text { (Outcome) }\end{array}$ & $\begin{array}{c}\text { Pre-test } \\
\text { Probability } \\
\text { (Hypo- } \\
\text { thetical) } \\
\end{array}$ & \begin{tabular}{|l} 
Pre- \\
Test \\
Odds \\
\end{tabular} & LR+ & LR- & $\begin{array}{c}\text { Post- } \\
\text { Test } \\
\text { Odds } \\
\text { (if a } \\
\text { patient } \\
\text { has } \\
\text { positive } \\
\text { test) }\end{array}$ & $\begin{array}{c}\text { Post-Test } \\
\text { Probability } \\
\text { (PPV) } \\
\text { (if a patient } \\
\text { has positive } \\
\text { test) }\end{array}$ & \begin{tabular}{|c} 
Post- \\
Test \\
Odds \\
(if a \\
patient \\
has \\
negative \\
test) \\
\end{tabular} & $\begin{array}{c}\text { Post-Test } \\
\text { Probability } \\
\text { (1-NPV) } \\
\text { (if a patient } \\
\text { has } \\
\text { negative } \\
\text { test) } \\
\end{array}$ \\
\hline SBP $<90$ & Resource Use & $10 \%$ & 0.11 & 4.32 & 0.83 & 0.48 & $32 \%$ & 0.09 & $8 \%$ \\
\hline SBP $<90$ & Resource Use & $20 \%$ & 0.25 & 4.32 & 0.83 & 1.08 & $52 \%$ & 0.21 & $17 \%$ \\
\hline SBP $<100$ & Resource Use & $10 \%$ & 0.11 & 3.30 & 0.80 & 0.36 & $27 \%$ & 0.09 & $8 \%$ \\
\hline
\end{tabular}




\begin{tabular}{|c|c|c|c|c|c|c|c|c|c|}
\hline $\begin{array}{c}\text { Physiologic } \\
\text { Predictor } \\
\text { (Test) }\end{array}$ & $\begin{array}{c}\text { Serious } \\
\text { Injury } \\
\text { Indicator } \\
\text { (Outcome) }\end{array}$ & $\begin{array}{c}\text { Pre-test } \\
\text { Probability } \\
\text { (Hypo- } \\
\text { thetical) } \\
\end{array}$ & $\begin{array}{l}\text { Pre- } \\
\text { Test } \\
\text { Odds }\end{array}$ & LR+ & LR- & $\begin{array}{c}\text { Post- } \\
\text { Test } \\
\text { Odds } \\
\text { (if a } \\
\text { patient } \\
\text { has } \\
\text { positive } \\
\text { test) } \\
\end{array}$ & \begin{tabular}{|c} 
Post-Test \\
Probability \\
(PPV) \\
(if a patient \\
has positive \\
test)
\end{tabular} & 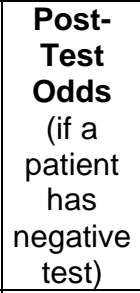 & $\begin{array}{c}\text { Post-Test } \\
\text { Probability } \\
\text { (1-NPV) } \\
\text { (if a patient } \\
\text { has } \\
\text { negative } \\
\text { test) }\end{array}$ \\
\hline SBP $<100$ & Resource Use & $20 \%$ & 0.25 & 3.30 & 0.80 & 0.83 & $45 \%$ & 0.20 & $17 \%$ \\
\hline$H R \geq 110$ & Resource Use & $10 \%$ & 0.11 & 1.37 & 0.91 & 0.15 & $13 \%$ & 0.10 & $9 \%$ \\
\hline$H R \geq 110$ & Resource Use & $20 \%$ & 0.25 & 1.37 & 0.91 & 0.34 & $25 \%$ & 0.23 & $19 \%$ \\
\hline $\mathrm{SI}>1$ & Resource Use & $10 \%$ & 0.11 & 3.13 & 0.71 & 0.34 & $26 \%$ & 0.08 & $7 \%$ \\
\hline $\mathrm{SI}>1$ & Resource Use & $20 \%$ & 0.25 & 3.13 & 0.71 & 0.78 & $44 \%$ & 0.18 & $15 \%$ \\
\hline Lactate $>2^{*}$ & Resource Use & $10 \%$ & 0.11 & 1.94 & 0.29 & 0.21 & $18 \%$ & 0.03 & $3 \%$ \\
\hline Lactate $>2^{*}$ & Resource Use & $20 \%$ & 0.25 & 1.94 & 0.29 & 0.48 & $33 \%$ & 0.07 & $7 \%$ \\
\hline Lactate $>4^{*}$ & Resource Use & $10 \%$ & 0.11 & 2.34 & 0.59 & 0.26 & $21 \%$ & 0.07 & $6 \%$ \\
\hline Lactate $>\mathbf{4}^{*}$ & Resource Use & $20 \%$ & 0.25 & 2.34 & 0.59 & 0.59 & $37 \%$ & 0.15 & $13 \%$ \\
\hline$R R<10$ or $>29$ & Resource Use & $10 \%$ & 0.11 & 5.61 & 0.90 & 0.62 & $38 \%$ & 0.10 & $9 \%$ \\
\hline$R R<10$ or $>29$ & Resource Use & $20 \%$ & 0.25 & 5.61 & 0.90 & 1.40 & $58 \%$ & 0.23 & $18 \%$ \\
\hline
\end{tabular}

$\mathrm{HR}=$ heart rate; $\mathrm{LR}+=$ positive likelihood ratio; LR- = negative likelihood ratio; NPV = negative predictive value; $\mathrm{PPV}=$ positive predictive value; $\mathrm{RR}=$ respiratory rate; $\mathrm{SBP}=$ systolic blood pressure; $\mathrm{SI}=$ shock index

*Lactate $>4$ is based on Emergency department data; Lactate $>2$ is out-of-hospital

While the ideal would be for a measure to have both high sensitivity and high specificity, this combination of favorable predictive properties is often difficult or impossible to achieve. Either low sensitivity or low specificity can be problematic in trauma triage, but for different reasons.

For most of the measures we evaluated sensitivities were low. As sensitivity is defined as "true positives" divided by the sum of "true positives” plus "false negatives", measures with low sensitivity produce a relatively high number of "false negatives"- that is, a high proportion of people who have normal values (a negative test) are actually at high risk of being seriously injured (i.e., the "disease or condition we are using the physiologic measure to detect). With low sensitivity an emergency medical services (EMS) provider cannot be confident that a person is truly negative (NOT seriously injured) based on a normal value for that measure (SBP >100 $\mathrm{mmHg}$ or lactate $<2 \mathrm{mmol} / \mathrm{L}$ ).

Specificity is defined as "true negatives" divided by the sum of "true negatives" plus "false positives", so as the specificity gets higher (closer to 100\%) the number of false positives approaches zero. When specificity is high, a positive test, in this case an abnormal value on a measure, is less likely to be a false positive (the patient is not seriously injured) and more likely 
to represent a true positive (the patient is seriously injured). Therefore, abnormal values on measures with high specificity should alert an EMS provider that the patient is likely at high risk.

It is important to note that the measures summarized in this report are almost always part of a larger assessment. For example, clinical judgment and experience affect appraisals of the clearly visible injuries, and trauma site characteristics can play a major role in determining appropriateness of trauma center triage. The national triage guidelines include over 20 different criteria representing physiologic, anatomic, mechanism, and special considerations. ${ }^{12}$ Additionally, although not all measures were compared individually or in combination in the studies included in this report, trauma triage in practice requires consideration of many measures simultaneously or in combination. Essentially, no single measure or variable is likely to ever be sufficient as the sole criterion for determining the need for trauma center care. Identifying those measures that are best able to quickly and accurately identify patients who do need such care is clinically useful and motivates the search for measures with better discrimination.

\section{Limitations of the Evidence Base}

The major limitations of the evidence base are the limited number of head-to-head comparisons and generally low strength of evidence available. As this review illustrates, there are a number of potential physiologic measures that could be used in triage and a range of indicators of serious injury used in this body of research. Our approach to this diversity was to focus on combining information for the same measure across studies and then looking across the measures. If we had limited our examination to head-to-head comparisons we would have had small numbers of studies in each of a larger number of pairwise comparisons. However, there is a risk in comparing measures across studies rather than relying on comparisons within studies. Measures in different studies may produce similar results but for different populations. For example, if estimates of the AUROC for SBP and HR are similar, but based on different studies with different populations, we could erroneously conclude that they will perform similarly across all patients when in truth SBP has this discriminant level for one subtype of patients while HR is similar but in a different subtype of patients.

In order to assess this risk, we examined the results of head-to-head studies as well. We reviewed all the combinations studied, but in many cases there were few head-to-head studies that used similar evaluation approaches (e.g., for respiratory measures there were two studies that compared $\mathrm{RR}$ and $\mathrm{SpO}_{2}$; only one reported AUROCs ${ }^{94}$ while the other calculated adjusted odds ratios $^{131}$ ). Table 38 below provides an example of this by providing information from the out-ofhospital studies that compared the AUROCs for two physiologic measures directly. The results of all head-to-head comparisons are included in the evidence tables in Appendix D. 
Table 38. Out-of-hospital head-to-head studies comparing physiologic measures

\begin{tabular}{|c|c|c|c|c|c|}
\hline $\begin{array}{l}\text { Comparison } \\
\text { Measure } 1 \text { Vs. } \\
\text { Measure } 2\end{array}$ & $\begin{array}{l}\text { Author, } \\
\text { Year }\end{array}$ & $\begin{array}{l}\text { Indicator of } \\
\text { Serious Injury }\end{array}$ & $\begin{array}{l}\text { AUROC }(95 \% \mathrm{Cl}) \\
\text { Measure } 1\end{array}$ & $\begin{array}{l}\text { AUROC }(95 \% \mathrm{Cl}) \\
\text { Measure } 2\end{array}$ & $\begin{array}{l}\text { Measure Favored; } \\
\text { Magnitude of } \\
\text { Difference* }\end{array}$ \\
\hline SBP vs. HR & $\begin{array}{l}\text { Chen, } \\
2010^{55}\end{array}$ & $\begin{array}{l}\text { Major } \\
\text { hemorrhage }\end{array}$ & $\begin{array}{l}0.75 \text { (0.65 to } \\
0.84)\end{array}$ & $\begin{array}{l}0.62(0.50 \text { to } \\
0.73)\end{array}$ & SBP; large \\
\hline SBP vs. HR & $\begin{array}{l}\text { Edla, } \\
2015^{59}\end{array}$ & $\begin{array}{l}\text { Blood } \\
\text { transfusion } \geq 9 \\
\text { pRBC units in } 24 \\
\text { hours }\end{array}$ & $\begin{array}{l}0.73(0.55 \text { to } \\
0.86)\end{array}$ & $\begin{array}{l}0.72(0.53 \text { to } \\
0.85)\end{array}$ & SBP; small \\
\hline SBP vs. HR & $\begin{array}{l}\text { Grimme, } \\
2005^{62}\end{array}$ & Organ failure & 0.564 (NR) & 0.579 (NR) & HR; small \\
\hline SBP vs. HR & $\begin{array}{l}\text { Van Haren, } \\
2014^{103}\end{array}$ & $\begin{array}{l}\text { Life saving } \\
\text { intervention }\end{array}$ & $0.544(\mathrm{NR})$ & 0.535 (NR) & SBP; small \\
\hline SBP vs. HR & $\begin{array}{l}\text { Vettorello, } \\
2013^{106}\end{array}$ & $\begin{array}{l}\text { Blood } \\
\text { transfusion or } \\
\text { bleeding control }\end{array}$ & $\begin{array}{l}0.911(0.824 \text { to } \\
0.963)\end{array}$ & $\begin{array}{l}0.835(0.734 \text { to } \\
0.909)\end{array}$ & SBP; moderate \\
\hline SBP vs. HR & $\begin{array}{l}\text { Woodford, } \\
2012^{107}\end{array}$ & Mortality & $\begin{array}{l}0.55 \text { (0.34 to } \\
0.77)\end{array}$ & $\begin{array}{l}0.65(0.44 \text { to } \\
0.86)\end{array}$ & HR; moderate \\
\hline SBP vs. SI & $\begin{array}{l}\text { Chen, } \\
2007^{52}\end{array}$ & $\begin{array}{l}\text { Major } \\
\text { hemorrhage }\end{array}$ & $\begin{array}{l}0.71(0.706 \text { to } \\
0.714)\end{array}$ & 0.77 (NR) & Sl; moderate \\
\hline SBP vs. SI & $\begin{array}{l}\text { Grimme, } \\
2005^{62}\end{array}$ & Organ failure & 0.564 (NR) & $0.684(\mathrm{NR})$ & Sl; large \\
\hline SBP vs. SI & $\begin{array}{l}\text { Guyette, } \\
2015^{65}\end{array}$ & $\begin{array}{l}\text { Need for } \\
\text { resuscitative } \\
\text { care }\end{array}$ & $\begin{array}{l}0.59(0.53 \text { to } \\
0.66)\end{array}$ & $\begin{array}{l}0.66(0.60 \text { to } \\
0.74)\end{array}$ & Sl; moderate \\
\hline SBP vs. SI & $\begin{array}{l}\text { Haider, } \\
2016^{66}\end{array}$ & $\begin{array}{l}\text { Trauma center } \\
\text { need }\end{array}$ & $\begin{array}{l}0.526(0.524 \text { to } \\
0.527)\end{array}$ & $\begin{array}{l}0.534 \text { (0.532 to } \\
0.535)\end{array}$ & SI; small \\
\hline SBP vs. SI & $\begin{array}{l}\text { Pottecher, } \\
2016^{93}\end{array}$ & $\begin{array}{l}\text { Massive } \\
\text { transfusion }(\geq 10 \\
\text { units in } 24 \\
\text { hours) }\end{array}$ & $\begin{array}{l}0.61(0.57 \text { to } \\
0.64)\end{array}$ & $\begin{array}{l}0.802(0.74 \text { to } \\
0.87)\end{array}$ & Sl; large \\
\hline $\begin{array}{l}\text { SBP vs. } \\
\text { Lactate }\end{array}$ & $\begin{array}{l}\text { Guyette, } \\
2015^{65}\end{array}$ & $\begin{array}{l}\text { Need for } \\
\text { resuscitative } \\
\text { care }\end{array}$ & $\begin{array}{l}0.59 \text { (0.53 to } \\
0.66)\end{array}$ & $\begin{array}{l}0.78 \text { (0.73 to } \\
0.83)\end{array}$ & Lactate; large \\
\hline SI vs. Lactate & $\begin{array}{l}\text { Guyette, } \\
2015^{65}\end{array}$ & $\begin{array}{l}\text { Need for } \\
\text { resuscitative } \\
\text { care }\end{array}$ & $\begin{array}{l}0.66 \text { (0.60 to } \\
0.74)\end{array}$ & $\begin{array}{l}0.78 \text { (0.73 to } \\
0.83)\end{array}$ & Lactate; large \\
\hline RR vs. $\mathrm{SpO}_{2}$ & $\begin{array}{l}\text { Raux, } \\
2006^{94}\end{array}$ & Mortality & $\begin{array}{l}0.691 \text { (0.644 to } \\
0.738)\end{array}$ & $\begin{array}{l}0.747(0.704 \text { to } \\
0.790)\end{array}$ & $\mathrm{SpO}_{2}$ \\
\hline
\end{tabular}

$\mathrm{CI}$ = confidence interval; $\mathrm{HR}$ = heart rate; $\mathrm{NR}$ = not reported; $\mathrm{pRBC}$ = packed red blood cell; $\mathrm{RR}$ = respiratory rate; $\mathrm{SBP}=$ systolic blood pressure; SI = shock index

*Definitions for magnitude of differences in AUROCs: small <0.05, moderate 0.05 to 0.10 , large >0.10

The literature available for analysis was dominated by studies that effectively limited their population to trauma patients who are transported by EMS. Most of the studies were based on data from trauma registries. While the specifics for inclusion vary across registries and also across studies that use administrative records in a similar way, standard practice seems to be to include data on patients transported and/or admitted. The implication is that patients assessed by EMS and not transported are either not included at all or included inconsistently.

Another characteristic of the data in these registries is that it is usually collected prospectively but analyzed retrospectively, thus blurring the distinction between prospective and retrospective study designs. In many cases data sources are difficult to determine based on the published reports. Analysis is also complicated by the fact that the registry studies usually have large samples, while the more clearly prospective studies we identified were often exploratory 
with small samples. This distinction matters because in other situations we might be able to make assumptions about the potential for differences in bias in prospective and retrospective studies, but in this literature the direction of the potential bias is not clear.

Another deficiency in the evidence is the lack of detail about how the physiologic measure data were collected. Studies rarely reported details that could be important, such as what equipment was used, how and when the measurement was taken, and who was involved. Many of the measures of physiologic compromise can be taken in different ways. For example, blood pressure can be recorded using automated cuffs or recorded by emergency personnel manually. These measurements may be taken at specific times or monitored continuously during assessment and transport. Similarly, lactate may be measured from venous, arterial, or capillary blood. In addition to instrumentation, timing matters. Identifying that measurements were taken either out-of-hospital or in the ED is a start, but with trauma the situation is dynamic and changes occur rapidly. Knowing whether a measurement was first taken on arrival at the scene or if it was after resuscitation or during transport would allow us to examine the impact of timing on the pattern of values and identify whether their ability to predict serious injury varies with the timing of measurement. Finally, information on the training or role of the person doing the assessment was almost never reported. EMS personnel include people with different levels of training, and some studies involved nurses or physicians who traveled with special trauma units or air ambulances. Even in EDs it is not necessarily a given how the data are collected. The impacts of instrumentation, timing, or training on measurement may be small or they may be significant. The concern is that when detail in not provided in the research reports, neither sensitivity analysis nor an analysis of trends is possible, making it harder to determine if the variability seen both across and within studies could be related to measurement differences.

An important limitation of the evidence base is the lack information on subpopulations, particularly children and older adults. Most studies either included all patients or limited their population only to adults, which was defined differently, ranging from over 14 years old to over 18 years old, and to those under 60, or to all ages. Fewer studies specifically focused on children or older adults and those that did were split between studies that only studied one group and those that made comparisons across age groups.

Gaps in the evidence base included the limited number of studies available for some measures or the lack of studies in the field. In some cases, measures have only been evaluated in a small number of studies (e.g., ETCO ${ }_{2}$ ). Other measures have only been tested in a particular setting: all the studies of base deficit were based on ED measurement; most studies of HRC were studies in which the patients were transported via helicopter; and most of the lactate studies did not use point-of-care measurement, likely due to the limited availability of the devices, although an assessment of the devices was beyond the scope of this review.

Studies also varied and were inconsistent in defining and using indicators of serious injury. We included a broad range of indictors divided into four categories, created to group the studies: resource use, injury severity or type, mortality, or composites that mixed indicators from two or all three of these groups. The studies tended to select a specific indicator, such as need for a massive transfusion, rather than include multiple indicators, and the definitions varied across studies (e.g., what volume is considered massive and over what time period). While the trauma research community has made efforts to come up with a comprehensive definition (i.e., the consensus-based criteria ${ }^{25}$ and lists of life-saving interventions), these are not yet widely used. The result is that many studies may underestimate the utility of measures by requiring that they predict a single or narrowly defined set of indicators for risk of severe injury. 


\section{Limitations of the Review Process}

There were also limitations to this review resulting from our decisions and processes. These included both conceptual and technical issues.

Evaluating physiologic measures in terms of their ability to estimate need for trauma center care asks a predictive utility question. While we identified and included studies of predictive utility, we also included prognostic studies. These are similar but not identical. The structure of the studies differed in that predictive utility studies usually started with one or more measure and quantified the measure's relationship with an indicator of serious injury such as admission to the ICU or need for blood transfusion. The prognostic studies were often more exploratory and iterative, in that they identified several variables and looked for which variables differed across an outcome. Most of the prognostic studies sought to determine what characteristics are shared by patients who died and what differed from those who survived or what patients needed or didn't need a specific resource such as blood transfusion. There may be underlying differences in these two approaches that affected our results. An important related consideration is that mortality is not the most relevant indicator of severity of injury and need for trauma care, as mortality is usually impacted by the care received. Resource use and injury type or severity occur closer to the time of injury and are not as likely as mortality to be affected by as many intervening factors.

The fact that we included measurements in the ED as well as out-of-hospital was another limitation. However, we attempted to mitigate this by presenting the ED and out-of-hospital results separately to underscore the likelihood that the results for each subgroup were influenced by the setting in which the measures were obtained.

Similarly, we included a wide range of indicators of serious injury, but we grouped them into categories (resource use, injury severity or type, mortality, and composites). We reported results separately by these categories in the plots in the text and reported the specific indicator used in each study in the evidence tables in Appendix D. We computed pooled estimates for studies in each group and a total that combined all groups. These subtotals and overall totals may not be viewed as appropriate, depending on one's assessment of whether the equivalence within each group and across all indicators is considered reasonable.

Our approach to meta-analysis involved first using the random effects DerSimonian-Laird model to pool data and evaluate heterogeneity. As statistical heterogeneity was high, this estimator can result in confidence intervals (CIs) that are too narrow. ${ }^{198}$ To address this, we also used bivariate and profile likelihood methods, alternative random effects model, and though the results were similar we reported these more accurate estimates. While this may partially address the statistical heterogeneity, it does not negate the fact that the pooled estimates required combining studies that differ in important ways.

\section{Future Research Needs}

This review summarized a sizable body of literature, but also highlighted several areas in which future research is needed. One priority is studies that compare, or at least document, factors that directly affect measurement (instrumentation, timing, etc.). This would allow the impact of these differences on the predictive utility of the measure to be considered.

Increasingly, the amount of technology available to field providers is changing practice. Ideally, some of these technologies could incorporate smart software (e.g., in out-of-hospital monitors) that integrates different measures to better identify seriously injured patients. Since 
these measures are dynamic and can be obtained continuously, the monitor could be placed and then followed or trended to see if there is something of concern. Other technological advances may facilitate measurement in the field. This is the case with the development of point-of-care testing for lactate and may be the case with other measures in the future.

Our findings demonstrated the high specificity and low sensitivity of physiologic measures used in trauma. There are different possible reasons for this that could be explored or delineated in future research. It is possible that responses to trauma vary across individuals given their physiologic reserve. Perhaps the changes in physiology observable in the field are not of a magnitude that the measures can ever be effectively sensitive. It may be that our current measurement methods are relatively crude and not able to detect important changes or differences. Technological advances in monitoring may be able to produce measurement that is automated (removing some human error), and more sensitive to smaller changes or to changes that occur more immediately after injury.

An additional priority would be to encourage more research using the consensus-based criteria of the need for trauma care or a standardized list of life-saving interventions. If the indicators of serious injury were consistent, cleaner comparisons could be made both across studies and across measures. This would also permit an assessment of the utility of individual measures in a broader context. For example, this approach to research would make it possible to say whether lactate is limited to predicting need for transfusion or if it predicts other indicators of injury as well.

Our findings suggest, but are not sufficient to conclude, that combination measures have a yet unrealized potential to improve field triage and assessment. Modeling or other simulation studies may be able to add to our understanding as to whether and how individual measures could be combined to improve predictive utility. However, parallel research or device development would also be needed to learn about how these combination measures could be collected and reported so that they would be feasible for EMS personnel to use out-of-hospital.

Another key topic for additional research is the assessment of the utility of measures across age groups. While we did identify some studies that considered the use of physiologic measures for children and older adults, this is still a small subset of the literature and many questions remain. Given the likelihood that many existing studies collected (but did not analyze) data on age, future research could combine age-related data across these studies and obtain large enough samples to meaningfully stratify results and examine age-related subgroup differences.

\section{Implications}

For out-of-hospital clinical practice, our findings demonstrated that current circulatory and respiratory measures have low sensitivity but higher specificity. Our findings also suggested equivalence in predictive value across multiple circulatory and respiratory measures. The evidence does not point to necessarily "better" cut-points for measures such as SBP, SI, and RR. In general, more liberal cut-points (e.g., SBP $<110 \mathrm{mmHg}$ vs. $<90 \mathrm{mmHg}$ ) will raise sensitivity and lower specificity —an inevitable trade-off_-but the magnitude of this trade-off may differ across tests. However, based on the evidence we identified, no physiologic measures have high enough sensitivity that a negative result (that is normal physiologic values) could be confidently used to conclude that a patient is not at risk of being seriously injured, even with more liberal cut-points. 


\section{Conclusions}

While specifics vary across measures, settings, and populations, overall the predictive utilities of physiologic measures that are either currently used for trauma assessment and triage, or have been suggested, are moderate and not ideal. Measures of circulatory compromise (SBP, HR, SI, lactate) and respiratory compromise - have been evaluated in multiple studies, some with large numbers of patients. In general, these measures have low sensitivities, high specificities, and AUROCs in the fair-to-good range. Use of these measures should be guided by the understanding that when they are abnormal, they are highly predictive of high risk of serious injury in trauma patients, but that many patients with serious injuries will have normal physiologic measures. Combinations of these measures with assessments of consciousness seem to perform better, but how they would be implemented out-of-hospital needs to be determined, and then they need to be tested under field conditions to confirm their effectiveness and utility. Modification of triage measures for children or older adults is needed, given that these measures perform worse in these age groups than in adults; however, the research has not yet identified better performing variations or replacements. 


\section{References}

1. Centers for Disease Control and Prevention. 10 Leading Causes of Death by Age Group, United States - 2015. https://www.cdc.gov/injury/images/lccharts/leading_causes_of death_age_group 2015_1050w740h.gif. Accessed July 7, 2017.

2. Centers for Disease Control and Prevention. National Hospital Ambulatory Medical Care Survey: 2014 Emergency Department Summary Tables. https://www.cdc.gov/nchs/data/nhamcs/web tables/2014_ed_web_tables.pdf. Accessed November 282017.

3. Wang HE, Mann NC, Jacobson KE, et al. National characteristics of emergency medical services responses in the United States. Prehosp Emerg Care. 2013 JanMar;17(1):8-14. doi: 10.3109/10903127.2012.722178. PMID: 23072355.

4. Soreide K. Strengthening the trauma chain of survival. Br J Surg. 2012;99 Suppl 1:1-3. doi: 10.1002/bjs.7795. PMID: 22441846.

5. National Emergency Medical Services Workforce Data Definitions. (Prepared by the American Institutes for Research through contract DTNH22-080F-00122.) Washington, DC: National Highway Traffic Safety Administration; February 2013. www.nhtsa.gov/staticfiles/nti/pdf/811720.pd f.

6. Demetriades D, Martin M, Salim A, et al. Relationship between American College of Surgeons trauma center designation and mortality in patients with severe trauma (injury severity score $>15$ ). J Am Coll Surg. 2006;202(2):212-5; quiz A45. doi: 10.1016/j.jamcollsurg.2005.09.027. PMID: 16427544.

7. Sampalis JS, Denis R, Frechette P, et al. Direct transport to tertiary trauma centers versus transfer from lower level facilities: impact on mortality and morbidity among patients with major trauma. J Trauma. 1997;43(2):288-95; discussion 95-6. PMID: 9291375.
8. Haas B, Gomez D, Zagorski B, et al. Survival of the fittest: the hidden cost of undertriage of major trauma. J Am Coll Surg. 2010;211(6):804-11. doi: 10.1016/j.jamcollsurg.2010.08.014. PMID: 21036070.

9. MacKenzie EJ, Rivara FP, Jurkovich GJ, et al. A national evaluation of the effect of trauma-center care on mortality. N Engl J Med. 2006;354(4):366-78. doi: 10.1056/NEJMsa052049. PMID: 16436768.

10. Faul M, Wald MM, Sullivent EE, et al. Large cost savings realized from the 2006 Field Triage Guideline: reduction in overtriage in U.S. trauma centers. Prehosp Emerg Care. 2012;16(2):222-9. doi: 10.3109/10903127.2011.615013. PMID: 22008012.

11. Lerner EB, Shah MN, Swor RA, et al. Comparison of the 1999 and 2006 trauma triage guidelines: where do patients go? Prehosp Emerg Care. 2011;15(1):12-7. doi: 10.3109/10903127.2010.519819. PMID: 21054176.

12. Sasser SM, Hunt RC, Faul M, et al. Guidelines for field triage of injured patients: recommendations of the National Expert Panel on Field Triage, 2011. MMWR Recomm Rep. 2012;61(RR-1):1-20. PMID: 22237112.

13. Mackersie RC. History of trauma field triage development and the American College of Surgeons criteria. Prehosp Emerg Care. 2006;10(3):287-94. doi: 10.1080/10903120600721636. PMID: 16801263.

14. Institute of Medicine. Emergency Medical Services: At the Crossroads. Washington, DC: The National Academies Press; 2007.

15. Newgard CD, Fu R, Zive D, et al. Prospective Validation of the National Field Triage Guidelines for Identifying Seriously Injured Persons. J Am Coll Surg. 2016;222(2):146-58 e2. doi: 10.1016/j.jamcollsurg.2015.10.016. PMID: 26712244. 
16. Convertino VA, Ryan KL, Rickards CA, et al. Physiological and medical monitoring for en route care of combat casualties. J Trauma. 2008;64(4 Suppl):S342-53. doi: 10.1097/TA.0b013e31816c82f4. PMID: 18385586.

17. Liu NT, Holcomb JB, Wade CE, et al. Improving the prediction of mortality and the need for life-saving interventions in trauma patients using standard vital signs with heart-rate variability and complexity. Shock. 2015;43(6):549-55. doi: 10.1097/SHK.0000000000000356. PMID: 25692260.

18. Woodford MR, Mackenzie CF, DuBose J, et al. Continuously recorded oxygen saturation and heart rate during prehospital transport outperform initial measurement in prediction of mortality after trauma. J Trauma Acute Care Surg. 2012;72(4):1006-11. doi: 10.1097/TA.0b013e318241c059. PMID: 22491618.

19. Traverso G, Ciccarelli G, Schwartz S, et al. Physiologic Status Monitoring via the Gastrointestinal Tract. PLoS One. 2015;10(11):e0141666. doi: 10.1371/journal.pone.0141666. PMID: 26580216.

20. Kehoe A, Rennie S, Smith JE. Glasgow Coma Scale is unreliable for the prediction of severe head injury in elderly trauma patients. Emerg Med J. 2015;32(8):613-5. doi: 10.1136/emermed-2013-203488. PMID: 25280479.

21. Zarzaur BL, Croce MA, Magnotti LJ, et al. Identifying life-threatening shock in the older injured patient: an analysis of the National Trauma Data Bank. J Trauma. 2010;68(5):1134-8. doi: 10.1097/TA.0b013e3181d87488. PMID: 20453769.

22. Price CL, Brace-McDonnell SJ, Stallard N, et al. Performance characteristics of five triage tools for major incidents involving traumatic injuries to children. Injury. 2016;47(5):988-92. doi: 10.1016/j.injury.2015.10.076. PMID: 26653268.
23. Bruijns SR, Guly HR, Bouamra O, et al. The value of traditional vital signs, shock index, and age-based markers in predicting trauma mortality. J Trauma Acute Care Surg. 2013;74(6):1432-7. doi: 10.1097/TA.0b013e31829246c7. PMID: 23694869.

24. Chuang JF, Rau CS, Wu SC, et al. Use of the reverse shock index for identifying highrisk patients in a five-level triage system. Scand J Trauma Resusc Emerg Med. 2016;24:12. doi: 10.1186/s13049-016-02085. PMID: 26861172.

25. Lerner EB, Willenbring BD, Pirrallo RG, et al. A consensus-based criterion standard for trauma center need. J Trauma Acute Care Surg. 2014;76(4):1157-63. doi: 10.1097/TA.0000000000000189. PMID: 24662885

26. Chou R, Totten AM, Carney N, et al. Predictive Utility of the Total Glasgow Coma Scale Versus the Motor Component of the Glasgow Coma Scale for Identification of Patients With Serious Traumatic Injuries. Ann Emerg Med. 2017 2017/08/01/;70(2):143-57.e6. doi: https://doi.org/10.1016/j.annemergmed.2016 .11 .032 .

27. Samson D, Schoelles KM. Chapter 2: medical tests guidance (2) developing the topic and structuring systematic reviews of medical tests: utility of PICOTS, analytic frameworks, decision trees, and other frameworks. J Gen Intern Med. 2012;27 Suppl 1:S11-9. doi: 10.1007/s11606-0122007-7. PMID: 22648670.

28. Methods Guide for Effectiveness and Comparative Effectiveness Reviews. AHRQ Publication No. 10(14)-EHC063-EF. Rockville, MD: Agency for Healthcare Research and Quality; January 2014. Chapters available at: www.effectivehealthcare.ahrq.gov.

29. Bazzoli GJ, Madura KJ, Cooper GF, et al. Progress in the development of trauma systems in the United States. Results of a national survey. JAMA. 1995;273(5):395401. PMID: 7823385. 
30. Hayden JA, van der Windt DA, Cartwright $\mathrm{JL}$, et al. Assessing bias in studies of prognostic factors. Ann Intern Med. 2013;158(4):280-6. doi: 10.7326/00034819-158-4-201302190-00009. PMID: 23420236.

31. Hosmer DW, Jr., Lemeshow S, Sturdivant RX. Chapter 5: Assessing the fit of the model. In: Applied Logistic Regression. 3rd ed., Hoboken: John Wiley \& Sons, Inc.; 2013.

32. DerSimonian R, Laird N. Meta-analysis in clinical trials. Control Clin Trials. 1986 Sep;7(3):177-88. PMID: 3802833.

33. Chu H, Cole SR. Bivariate meta-analysis of sensitivity and specificity with sparse data: a generalized linear mixed model approach. J Clin Epidemiol. 2006;59(12):1331-2; author reply 2-3. doi:

10.1016/j.jclinepi.2006.06.011. PMID: 17098577.

34. Trikalinos TA, Balion CM, Coleman CI, et al. Chapter 8: meta-analysis of test performance when there is a "gold standard". J Gen Intern Med. 2012;27 Suppl 1:S56-66. doi: 10.1007/s11606-012-2029-1. PMID: 22648676.

35. Zwinderman AH, Bossuyt PM. We should not pool diagnostic likelihood ratios in systematic reviews. Stat Med. 2008;27(5):687-97. doi: 10.1002/sim.2992. PMID: 17611957.

36. Hanley JA, McNeil BJ. The meaning and use of the area under a receiver operating characteristic (ROC) curve. Radiology. 1982;143(1):29-36. doi: 10.1148/radiology.143.1.7063747. PMID: 7063747.

37. Singh S, Chang SM, Matchar DB, et al. Chapter 7: grading a body of evidence on diagnostic tests. J Gen Intern Med. 2012;27 Suppl 1:S47-55. doi: 10.1007/s11606-0122021-9. PMID: 22648675.

38. Hartmann KE, Matchar DB, Chang S. Chapter 6: assessing applicability of medical test studies in systematic reviews. J Gen Intern Med. 2012;27 Suppl 1:S39-46. doi: 10.1007/s11606-011-1961-9. PMID: 22648674.
39. Arbabi S, Jurkovich GJ, Wahl WL, et al. A comparison of prehospital and hospital data in trauma patients. J Trauma.

2004;56(5):1029-32. doi: 10.1097/01.TA.0000123036.20919.4B. PMID: 15179242.

40. Batchinsky AI, Cancio LC, Salinas J, et al. Prehospital loss of R-to-R interval complexity is associated with mortality in trauma patients. J Trauma. 2007;63(3):5128. doi: 10.1097/TA.0b013e318142d2f0. PMID: 18073594.

41. Batchinsky AI, Salinas J, Kuusela T, et al. Rapid prediction of trauma patient survival by analysis of heart rate complexity: impact of reducing data set size. Shock. 2009;32(6):565-71. doi: 10.1097/SHK.0b013e3181a993dc. PMID: 19487984.

42. Batchinsky AI, Salinas J, Jones JA, et al. Predicting the need to perform life-saving interventions in trauma patients by using new vital signs and artificial neural networks. In: Combi C, Shahar Y, A. A-H, eds. AIME 2009; 2009 July 18-22; Verona, Italy. Berlin, Heidelberg: Springer; 5651. pp. 390-4.

43. Bond RJ, Kortbeek JB, Preshaw RM. Field trauma triage: combining mechanism of injury with the prehospital index for an improved trauma triage tool. J Trauma. 1997;43(2):283-7. PMID: 9291374.

44. Bouzat P, Schilte C, Vinclair M, et al. Capillary lactate concentration on admission of normotensive trauma patients: a prospective study. Scand J Trauma Resusc Emerg Med. 2016;24:82. doi: 10.1186/s13049-016-0272-x. PMID: 27267942.

45. Brown JB, Stassen NA, Bankey PE, et al. Mechanism of injury and special consideration criteria still matter: an evaluation of the National Trauma Triage Protocol. J Trauma. 2011;70(1):38-44; discussion -5. doi: 10.1097/TA.0b013e3182077ea8. PMID: 21217479. 
46. Brown JB, Gestring ML, Forsythe RM, et al. Systolic blood pressure criteria in the National Trauma Triage Protocol for geriatric trauma: 110 is the new 90 . $\mathrm{J}$ Trauma Acute Care Surg. 2015;78(2):352-9. doi: 10.1097/TA.0000000000000523. PMID: 25757122.

47. Brown JB, Lerner EB, Sperry JL, et al. Prehospital lactate improves accuracy of prehospital criteria for designating trauma activation level. J Trauma Acute Care Surg. 2016;81(3):445-52. doi: 10.1097/ta.0000000000001085. PMID: 27116410.

48. Bruijns SR, Guly HR, Bouamra O, et al. The value of the difference between ED and prehospital vital signs in predicting outcome in trauma. Emerg Med J. 2014;31(7):579-82. doi: 10.1136/emermed-2012-202271. PMID: 23616498.

49. Cancio LC, Batchinsky AI, Salinas J, et al. Heart-rate complexity for prediction of prehospital lifesaving interventions in trauma patients. J Trauma. 2008;65(4):8139. doi: 10.1097/TA.0b013e3181848241. PMID: 18849796.

50. Cannon CM, Braxton CC, Kling-Smith M, et al. Utility of the shock index in predicting mortality in traumatically injured patients. J Trauma. 2009;67(6):1426-30. doi: 10.1097/TA.0b013e3181bbf728. PMID: 20009697.

51. Chan L, Bartfield JM, Reilly KM. The significance of out-of-hospital hypotension in blunt trauma patients. Acad Emerg Med. 1997;4(8):785-8. doi: 10.1111/j.15532712.1997.tb03785.x. PMID: 9262696.

52. Chen L, Reisner AT, McKenna TM, et al. Diagnosis of hemorrhage in a prehospital trauma population using linear and nonlinear multiparameter analysis of vital signs. 2007 29th Annual International Conference of the IEEE Engineering in Medicine and Biology Society; 2007 August 22-26; Lyon, France. IEEE; 2007. pp. 3748-51.

53. Chen L, McKenna TM, Reisner AT, et al. Decision tool for the early diagnosis of trauma patient hypovolemia. J Biomed Inform. 2008;41(3):469-78. doi: 10.1016/j.jbi.2007.12.002. PMID: 18255342.
54. Chen L, Reisner AT, Gribok A, et al. Can we improve the clinical utility of respiratory rate as a monitored vital sign? Shock. 2009;31(6):574-80. doi: 10.1097/SHK.0b013e318193e885. PMID: 19008777.

55. Chen L, Reisner AT, Gribok A, et al. Is respiration-induced variation in the photoplethysmogram associated with major hypovolemia in patients with acute traumatic injuries? Shock. 2010;34(5):45560. doi: 10.1097/SHK.0b013e3181dc07da. PMID: 20220568.

56. Cooke WH, Salinas J, Convertino VA, et al. Heart rate variability and its association with mortality in prehospital trauma patients. J Trauma. 2006;60(2):363-70; discussion 70. doi: 10.1097/01.ta.0000196623.48952.0e. PMID: 16508497.

57. Courville XF, Koval KJ, Carney BT, et al. Early prediction of posttraumatic in-hospital mortality in pediatric patients. J Pediatr Orthop. 2009;29(5):439-44. doi: 10.1097/BPO.0b013e3181aad60f. PMID: 19568013.

58. Cudnik MT, Werman HA, White LJ, et al. Prehospital factors associated with mortality in injured air medical patients. Prehosp Emerg Care. 2012;16(1):121-7. doi: 10.3109/10903127.2011.615011. PMID: 21958032.

59. Edla S, Reisner AT, Liu J, et al. Is heart rate variability better than routine vital signs for prehospital identification of major hemorrhage? Am J Emerg Med. 2015;33(2):254-61. doi: 10.1016/j.ajem.2014.11.046. PMID: 25534122.

60. Franklin GA, Boaz PW, Spain DA, et al. Prehospital hypotension as a valid indicator of trauma team activation. J Trauma. 2000;48(6):1034-9. PMID: 10866247.

61. Garner A, Lee A, Harrison K, et al. Comparative analysis of multiple-casualty incident triage algorithms. Annals of Emergency Medicine. 2001;38(5):541-8. doi: 10.1067/mem.2001.119053. PMID: 11679866. 
62. Grimme K, Pape HC, Probst C, et al. Calculation of different triage scores based on the German Trauma Registry: value of the shock index. European Journal of Trauma. 2005;31(5):480-7. doi: 10.1007/s00068-005-2026-8.

63. Guyette F, Suffoletto B, Castillo JL, et al. Prehospital serum lactate as a predictor of outcomes in trauma patients: a retrospective observational study. J Trauma.

2011;70(4):782-6. doi: 10.1097/TA.0b013e318210f5c9. PMID: 21610386.

64. Guyette FX, Gomez H, Suffoletto B, et al. Prehospital dynamic tissue oxygen saturation response predicts in-hospital lifesaving interventions in trauma patients. J Trauma Acute Care Surg. 2012;72(4):930-5. doi: 10.1097/TA.0b013e31823d0677. PMID: 22491607.

65. Guyette FX, Meier EN, Newgard C, et al. A comparison of prehospital lactate and systolic blood pressure for predicting the need for resuscitative care in trauma transported by ground. J Trauma Acute Care Surg. 2015;78(3):600-6. doi: 10.1097/TA.0000000000000549. PMID: 25710433.

66. Haider AA, Azim A, Rhee P, et al. Substituting systolic blood pressure with shock index in the National Trauma Triage Protocol. J Trauma Acute Care Surg. 2016;81(6):1136-41. doi: 10.1097/TA.0000000000001205. PMID: 27893619.

67. Hamada SR, Gauss T, Duchateau FX, et al. Evaluation of the performance of French physician-staffed emergency medical service in the triage of major trauma patients. J Trauma Acute Care Surg. 2014;76(6):1476-83. doi: 10.1097/ta.0000000000000239. PMID: 24854319.

68. Henry MC, Hollander JE, Alicandro JM, et al. Incremental benefit of individual American College of Surgeons trauma triage criteria. Acad Emerg Med. 1996;3(11):9921000. doi: $10.1111 / \mathrm{j} .1553-$ 2712.1996.tb03340.x. PMID: 8922003.
69. Holcomb JB, Salinas J, McManus JM, et al. Manual vital signs reliably predict need for life-saving interventions in trauma patients. J Trauma. 2005;59(4):821-8; discussion 8-9. doi: 10.1097/01.ta.0000188125.44129.7c. PMID: 16374268.

70. Holcomb JB, Niles SE, Miller CC, et al. Prehospital physiologic data and lifesaving interventions in trauma patients. Mil Med. 2005;170(1):7-13. doi: 10.7205/MILMED.170.1.7. PMID: 15724847.

71. Horne S, Vassallo J, Read J, et al. UK triage-an improved tool for an evolving threat. Injury. 2013;44(1):23-8. doi: 10.1016/j.injury.2011.10.005. PMID: 22077989.

72. Ichwan B, Darbha S, Shah MN, et al. Geriatric-specific triage criteria are more sensitive than standard adult criteria in identifying need for trauma center care in injured older adults. Ann Emerg Med. 2015;65(1):92-100.e3. doi: 10.1016/j.annemergmed.2014.04.019. PMID: 24908590.

73. King DR, Ogilvie MP, Pereira BM, et al. Heart rate variability as a triage tool in patients with trauma during prehospital helicopter transport. J Trauma. 2009;67(3):436-40. doi: 10.1097/TA.0b013e3181ad67de. PMID: 19741382.

74. Lai WH, Rau CS, Hsu SY, et al. Using the reverse shock index at the injury scene and in the emergency department to identify high-risk patients: a cross-sectional retrospective study.Int J Environ Res Public Health. 2016;13(4):357. doi: 10.3390/ijerph13040357. PMID: 27023577.

75. Lalezarzadeh F, Wisniewski P, Huynh K, et al. Evaluation of prehospital and emergency department systolic blood pressure as a predictor of in-hospital mortality. Am Surg. 2009;75(10):1009-14. PMID: 19886155.

76. Lehmann RK, Arthurs ZM, Cuadrado DG, et al. Trauma team activation: simplified criteria safely reduces overtriage. Am J Surg. 2007;193(5):630-4; discussion 4-5. doi: 10.1016/j.amjsurg.2007.01.017. PMID: 17434371. 
77. Lerner EB, Drendel AL, Cushman JT, et al. Ability of the physiologic criteria of the field triage guidelines to identify children who need the resources of a trauma center. Prehosp Emerg Care. 2017;21(2):180-4. doi: 10.1080/10903127.2016.1233311. PMID: 27710155.

78. Lin G, Becker A, Lynn M. Changes in vital signs of trauma victims from prehospital to hospital settings. Journal of Paramedic Practice. 2011;3(10):558-62.

79. Lipsky AM, Gausche-Hill M, Henneman PL, et al. Prehospital hypotension is a predictor of the need for an emergent, therapeutic operation in trauma patients with normal systolic blood pressure in the emergency department. J Trauma. 2006;61(5):1228-33. doi: 10.1097/01.ta.0000196694.52615.84. PMID: 17099534.

80. Liu NT, Holcomb JB, Wade CE, et al. Evaluation of standard versus nonstandard vital signs monitors in the prehospital and emergency departments: results and lessons learned from a trauma patient care protocol. J Trauma Acute Care Surg. 2014;77(3 Suppl 2):S121-6. doi: 10.1097/TA.0000000000000192. PMID: 24770560 .

81. Liu NT, Holcomb JB, Wade CE, et al. Utility of vital signs, heart rate variability and complexity, and machine learning for identifying the need for lifesaving interventions in trauma patients. Shock. 2014;42(2):108-14. doi: 10.1097/SHK.0000000000000186. PMID: 24727872.

82. Liu NT, Holcomb JB, Wade CE, et al. Data quality of a wearable vital signs monitor in the pre-hospital and emergency departments for enhancing prediction of needs for lifesaving interventions in trauma patients. $\mathrm{J}$ Med Eng Technol. 2015;39(6):316-21. doi: 10.3109/03091902.2015.1054524. PMID: 26088543.

83. Liu NT, Holcomb JB, Wade CE, et al. Development and validation of a machine learning algorithm and hybrid system to predict the need for life-saving interventions in trauma patients. Med Biol Eng Comput. 2014;52(2):193-203. doi: 10.1007/s11517013-1130-x. PMID: 24263362.
84. Mackenzie CF, Wang Y, Hu PF, et al. Automated prediction of early blood transfusion and mortality in trauma patients. J Trauma Acute Care Surg. 2014;76(6):1379-85. doi: 10.1097/TA.0000000000000235. PMID: 24854304.

85. Matsushima K, Chouliaras K, Koenig W, et al. Should we still use motor vehicle intrusion as a sole triage criterion for the use of trauma center resources? Injury. 2016;47(1):235-8. doi: 10.1016/j.injury.2015.10.033. PMID: 26542464.

86. McManus J, Yershov AL, Ludwig D, et al. Radial pulse character relationships to systolic blood pressure and trauma outcomes. Prehosp Emerg Care. 2005;9(4):423-8. doi: 10.1080/10903120500255891. PMID: 16263676.

87. McNab A, Burns B, Bhullar I, et al. An analysis of shock index as a correlate for outcomes in trauma by age group. Surgery. 2013;154(2):384-7. doi: 10.1016/j.surg.2013.05.007. PMID: 23889965.

88. Newgard CD, Rudser K, Atkins DL, et al. The availability and use of out-of-hospital physiologic information to identify high-risk injured children in a multisite, populationbased cohort. Prehosp Emerg Care. 2009;13(4):420-31. doi: 10.1080/10903120903144882. PMID: 19731152.

89. Newgard CD, Richardson D, Holmes JF, et al. Physiologic field triage criteria for identifying seriously injured older adults. Prehosp Emerg Care. 2014;18(4):461-70. doi: 10.3109/10903127.2014.912707. PMID: 24933614.

90. Newgard CD, Holmes JF, Haukoos JS, et al. Improving early identification of the highrisk elderly trauma patient by emergency medical services. Injury. 2016;47(1):19-25. doi: 10.1016/j.injury.2015.09.010. PMID: 26477345.

91. Ocak G, Sturms LM, Hoogeveen JM, et al. Prehospital identification of major trauma patients. Langenbecks Arch Surg. 2009;394(2):285-92. doi: 10.1007/s00423008-0340-4. PMID: 18581133. 
92. Parimi N, Hu PF, MacKenzie CF, et al. Automated continuous vital signs predict use of uncrossed matched blood and massive transfusion following trauma. J Trauma Acute Care Surg. 2016;80(6):897-906. doi: 10.1097/TA.0000000000001047. PMID: 27027555.

93. Pottecher J, Ageron FX, Fauche C, et al. Prehospital shock index and pulse pressure/heart rate ratio to predict massive transfusion after severe trauma:

Retrospective analysis of a large regional trauma database. J Trauma Acute Care Surg. 2016;81(4):713-22. doi: 10.1097/TA.0000000000001191. PMID: 27648770 .

94. Raux M, Thicoipe M, Wiel E, et al. Comparison of respiratory rate and peripheral oxygen saturation to assess severity in trauma patients. Intensive Care Med. 2006;32(3):405-12. doi: 10.1007/s00134-005-0063-8. PMID: 16485093.

95. Raux M, Sartorius D, Le Manach Y, et al. What do prehospital trauma scores predict besides mortality? J Trauma.

2011;71(3):754-9. doi:

10.1097/TA.0b013e3181fd0dae. PMID: 21336194.

96. Sartorius D, Le Manach Y, David JS, et al. Mechanism, Glasgow Coma Scale, Age, and Arterial Pressure (MGAP): a new simple prehospital triage score to predict mortality in trauma patients. Crit Care Med.

2010;38(3):831-7. doi:

10.1097/CCM.0b013e3181cc4a67. PMID: 20068467.

97. Raux M, Le Manach Y, Gauss T, et al. Comparison of the prognostic significance of initial blood lactate and base deficit in trauma patients. Anesthesiology.

2017;126(3):522-33. doi: 10.1097/ALN.0000000000001490. PMID: 28059838.

98. Rickards CA, Ryan KL, Ludwig DA, et al. Is heart period variability associated with the administration of lifesaving interventions in individual prehospital trauma patients with normal standard vital signs? Crit Care Med. 2010;38(8):1666-73. doi: 10.1097/CCM.0b013e3181e74cab. PMID: 20562705.
99. Schenarts PJ, Phade SV, Agle SC, et al. Field hypotension in patients who arrive at the hospital normotensive: a marker of severe injury or crying wolf? N C Med J. 2008;69(4):265-9. PMID: 18828314.

100. Shackelford S, Yang S, Hu P, et al. Predicting blood transfusion using automated analysis of pulse oximetry signals and laboratory values. J Trauma Acute Care Surg. 2015;79(4 Suppl 2):S175-80. doi: 10.1097/TA.0000000000000738. PMID: 26406427.

101. Shah A, Guyette F, Suffoletto B, et al. Diagnostic accuracy of a single point-ofcare prehospital serum lactate for predicting outcomes in pediatric trauma patients. Pediatr Emerg Care. 2013;29(6):715-9. doi: 10.1097/PEC.0b013e318294ddb1. PMID: 23714761.

102. Tamim H, Joseph L, Mulder D, et al. Field triage of trauma patients: improving on the Prehospital Index. Am J Emerg Med. 2002;20(3):170-6. PMID: 11992335.

103. Van Haren RM, Thorson CM, Valle EJ, et al. Novel prehospital monitor with injury acuity alarm to identify trauma patients who require lifesaving intervention. J Trauma Acute Care Surg. 2014;76(3):743-9. doi: 10.1097/TA.0000000000000099. PMID: 24553543.

104. Vandromme MJ, Griffin RL, Weinberg JA, et al. Lactate is a better predictor than systolic blood pressure for determining blood requirement and mortality: could prehospital measures improve trauma triage? J Am Coll Surg. 2010;210(5):861-7; discussion 7-9. doi: 10.1016/j.jamcollsurg.2010.01.012. PMID: 20421067.

105. Vandromme MJ, Griffin RL, Kerby JD, et al. Identifying risk for massive transfusion in the relatively normotensive patient: utility of the prehospital shock index. J Trauma. 2011;70(2):384-8; discussion 8-90. doi: 10.1097/TA.0b013e3182095a0a. PMID: 21307738.

106. Vettorello M, Santambrogio SM, Calini AR, et al. Predicting haemorrhage in pre-hospital traumatic patients: evaluation of the novel heart-to-arm time index. Acta Anaesthesiol Scand. 2013;57(7):929-35. doi: 10.1111/aas.12135. PMID: 23701337. 
107. Woodford MR, Mackenzie CF, DuBose J, et al. Continuously recorded oxygen saturation and heart rate during prehospital transport outperform initial measurement in prediction of mortality after trauma. J Trauma Acute Care Surg. 2012;72(4):1006-11. doi: 10.1097/TA.0b013e318241c059. PMID: 22491618.

108. Yang S, Hu PF, Anazodo A, et al. Trends of hemoglobin oximetry: do they help predict blood transfusion during trauma patient resuscitation? Anesth Analg. 2016;122(1):115-25. doi: 10.1213/ANE.0000000000000927. PMID: 26683104.

109. Ahun E, Koksal O, Sigirli D, et al. Value of the Glasgow Coma Scale, Age, and Arterial Blood Pressure score for predicting the mortality of major trauma patients presenting to the emergency department. Ulus Travma Acil Cerrahi Derg [Turkish Journal of Trauma and Emergency Surgery] 2014;20(4):241-7. doi: 10.5505/tjtes.2014.76399. PMID: 25135017.

110. Al-Salamah MA, McDowell I, Stiell IG, et al. Initial emergency department trauma scores from the OPALS Study: the case for the motor score in blunt trauma. Acad Emerg Med. 2004;11(8):834-42. doi: 10.1197/j.aem.2004.03.008. PMID: 15289188.

111. Allen CJ, Tashiro J, Valle EJ, et al. Initial hematocrit predicts the use of blood transfusion in the pediatric trauma patient. J Pediatr Surg. 2014;49(11):1678-82. doi: 10.1016/j.jpedsurg.2014.10.044. PMID: 25475817.

112. Aslar AK, Kuzu MA, Elhan AH, et al. Admission lactate level and the APACHE II score are the most useful predictors of prognosis following torso trauma. Injury. 2004;35(8):746-52. doi: 10.1016/j.injury.2003.09.030. PMID: 15246796.

113. Baron BJ, Sinert R, Zehtabchi S, et al. Diagnostic utility of sublingual PCO2 for detecting hemorrhage in penetrating trauma patients. J Trauma. 2004;57(1):69-74. doi: 10.1097/01.TA.0000090754.94232.2C. PMID: 15284551.
114. Baron BJ, Dutton RP, Zehtabchi S, et al. Sublingual capnometry for rapid determination of the severity of hemorrhagic shock. J Trauma. 2007;62(1):120-4. doi: 10.1097/TA.0b013e31802d96ec. PMID: 17215742.

115. Beekley AC, Martin MJ, Nelson T, et al. Continuous noninvasive tissue oximetry in the early evaluation of the combat casualty: a prospective study. J Trauma. 2010;69(1 Suppl):S14-S25. doi: 10.1097/TA.0b013e3181e42326. PMID: 20622608.

116. Bruijns SR, Guly HR, Bouamra O, et al. The value of traditional vital signs, shock index, and age-based markers in predicting trauma mortality. J Trauma Acute Care Surg. 2013;74(6):1432-7. doi: 10.1097/TA.0b013e31829246c7. PMID: 23694869.

117. Callaway DW, Shapiro NI, Donnino MW, et al. Serum lactate and base deficit as predictors of mortality in normotensive elderly blunt trauma patients. J Trauma. 2009;66(4):1040-4. doi: 10.1097/TA.0b013e3181895e9e. PMID: 19359912.

118. Cancio LC, Wade CE, West SA, et al. Prediction of mortality and of the need for massive transfusion in casualties arriving at combat support hospitals in Iraq. J Trauma. 2008;64(2 Suppl):S51-5; discussion S5-6. doi: 10.1097/TA.0b013e3181608c21. PMID: 18376172.

119. Caputo ND, Fraser RM, Paliga A, et al. Nasal cannula end-tidal CO2 correlates with serum lactate levels and odds of operative intervention in penetrating trauma patients: a prospective cohort study. J Trauma Acute Care Surg. 2012;73(5):1202-7. doi: 10.1097/TA.0b013e318270198c. PMID: 23117381.

120. Caputo ND, Kanter M, Fraser R, et al. Comparing biomarkers of traumatic shock: the utility of anion gap, base excess, and serum lactate in the ED. Am J Emerg Med. 2015;33(9):1134-9. doi: 10.1016/j.ajem.2015.04.085. PMID: 26027886. 
121. Cherry RA, King TS, Carney DE, et al. Trauma team activation and the impact on mortality. J Trauma. 2007;63(2):326-30. doi: 10.1097/TA.0b013e31811eaad1. PMID: 17693831.

122. Davis JW, Parks SN, Kaups KL, et al. Admission base deficit predicts transfusion requirements and risk of complications. $\mathrm{J}$ Trauma. 1996;41(5):769-74. PMID: 8913202.

123. DeMuro JP, Simmons S, Jax J, et al. Application of the shock index to the prediction of need for hemostasis intervention. Am J Emerg Med. 2013;31(8):1260-3. doi: 10.1016/j.ajem.2013.05.027. PMID: 23806728.

124. Dinh MM, Bein KJ, Oliver M, et al. Refining the trauma triage algorithm at an Australian major trauma centre: derivation and internal validation of a triage risk score. Eur J Trauma Emerg Surg. 2014;40(1):6774. doi: 10.1007/s00068-013-0315-1. PMID: 26815779.

125. Dunham MP, Sartorius B, Laing GL, et al. A comparison of base deficit and vital signs in the early assessment of patients with penetrating trauma in a high burden setting. Injury. 2017;48(9):1972-7. doi: 10.1016/j.injury.2017.06.011. PMID: 28684079.

126. Dunne JR, Tracy JK, Scalea TM, et al. Lactate and base deficit in trauma: does alcohol or drug use impair their predictive accuracy? J Trauma. 2005;58(5):959-66. doi: 10.1097/01.TA.0000158508.84009.49. PMID: 15920409.

127. Eastridge BJ, Salinas J, McManus JG, et al. Hypotension begins at $110 \mathrm{~mm} \mathrm{Hg:}$ redefining "hypotension" with data. J Trauma. 2007;63(2):291-7; discussion 7-9. doi: 10.1097/TA.0b013e31809ed924. PMID: 17693826.

128. Folkert IW, Sims CA, Pascual JL, et al. Initial venous lactate levels in patients with isolated penetrating extremity trauma: a retrospective cohort study. Eur J Trauma Emerg Surg. 2015;41(2):203-9. doi: 10.1007/s00068-014-0442-3. PMID: 26038266.
129. Gebhart ME, Pence R. START triage: does it work? Disaster Management \& Response: DMR. 2007;5(3):68-73. doi: 10.1016/j.dmr.2007.05.002. PMID: 17719507.

130. Gray A, Goyder EC, Goodacre SW, et al. Trauma triage: a comparison of CRAMS and TRTS in a UK population. Injury. 1997;28(2):97-101. PMID: 9205573.

131. Imhoff BF, Thompson NJ, Hastings MA, et al. Rapid Emergency Medicine Score (REMS) in the trauma population: a retrospective study. BMJ Open. 2014;4(5):e004738. doi: 10.1136/bmjopen2013-004738. PMID: 24793256.

132. Jo S, Lee JB, Jin YH, et al. Comparison of the trauma and injury severity score and modified early warning score with rapid lactate level (the ViEWS-L score) in blunt trauma patients. Eur J Emerg Med. 2014;21(3):199-205. doi: 10.1097/MEJ.0b013e32836192d6. PMID: 23628928.

133. Jones JM, Skaga NO, Sovik S, et al. Norwegian survival prediction model in trauma: modelling effects of anatomic injury, acute physiology, age, and comorbidity. Acta Anaesthesiol Scand. 2014;58(3):303-15. doi: 10.1111/aas.12256. PMID: 24438461.

134. Joosse P, de Jong WJ, Reitsma JB, et al. External validation of the Emergency Trauma Score for early prediction of mortality in trauma patients. Crit Care Med. 2014;42(1):83-9. doi: 10.1097/CCM.0b013e31829e53f5. PMID: 23982027.

135. Khasawneh MA, Zielinski MD, Jenkins DH, et al. Low tissue oxygen saturation is associated with requirements for transfusion in the rural trauma population. World $\mathrm{J}$ Surg. 2014;38(8):1892-7. doi: 10.1007/s00268-014-2505-3. PMID: 24969044.

136. Kim SY, Hong KJ, Shin SD, et al. Validation of the shock index, modified shock index, and age shock index for predicting mortality of geriatric trauma patients in emergency departments. J Korean Med Sci. 2016;31(12):2026-32. doi: 10.3346/jkms.2016.31.12.2026. PMID: 27822945. 
137. King RW, Plewa MC, Buderer NM, et al. Shock index as a marker for significant injury in trauma patients. Acad Emerg Med. 1996;3(11):1041-5. doi: 10.1111/j.15532712.1996.tb03351.x. PMID: 8922013.

138. Kondo Y, Abe T, Kohshi K, et al. Revised trauma scoring system to predict in-hospital mortality in the emergency department: Glasgow Coma Scale, Age, and Systolic Blood Pressure score. Crit Care. 2011;15(4):R191. doi: 10.1186/cc10348. PMID: 21831280.

139. Kuo SCH, Kuo PJ, Hsu SY, et al. The use of the reverse shock index to identify high-risk trauma patients in addition to the criteria for trauma team activation: a cross-sectional study based on a trauma registry system. BMJ Open. 2016;6(6):e011072. doi: 10.1136/bmjopen-2016-011072. PMID: 27329440.

140. Lee YT, Feng XY, Lin YC, et al. Pediatric trauma team activation: are we making the right call? European J Pediatr Surg. 2014;24(1):46-50. doi: 10.1055/s-00331349717. PMID: 23852723.

141. Mackenzie CF, Gao C, Hu PF, et al. Comparison of decision-assist and clinical judgment of experts for prediction of lifesaving interventions. Shock. 2015;43(3):238-43. doi: 10.1097/shk.0000000000000288. PMID: 25394243.

142. Miller RT, Nazir N, McDonald T, et al. The modified rapid emergency medicine score: $\mathrm{a}$ novel trauma triage tool to predict inhospital mortality. Injury. 2017;48(9):18707. doi: 10.1016/j.injury.2017.04.048. PMID: 28465003.

143. Mizushima Y, Ueno M, Watanabe H, et al. Discrepancy between heart rate and makers of hypoperfusion is a predictor of mortality in trauma patients. J Trauma.

2011;71(4):789-92. doi: 10.1097/TA.0b013e31822f7bbd. PMID: 21986732.

144. Montoya KF, Charry JD, Calle-Toro JS, et al. Shock index as a mortality predictor in patients with acute polytrauma. Journal of Acute Disease. 2015;4(3):202-4. doi: 10.1016/j.joad.2015.04.006.
145. Mutschler M, Nienaber U, Munzberg M, et al. The shock index revisited - a fast guide to transfusion requirement? A retrospective analysis on 21,853 patients derived from the TraumaRegister DGU. Crit Care. 2013;17(4):R172. doi: 10.1186/cc12851. PMID: 23938104.

146. Pal JD, Victorino GP, Twomey P, et al. Admission serum lactate levels do not predict mortality in the acutely injured patient. J Trauma. 2006;60(3):583-7; discussion 7-9. doi: 10.1097/01.ta.0000205858.82575.55. PMID: 16531858.

147. Paladino L, Sinert R, Wallace D, et al. The utility of base deficit and arterial lactate in differentiating major from minor injury in trauma patients with normal vital signs. Resuscitation. 2008;77(3):363-8. doi: 10.1016/j.resuscitation.2008.01.022. PMID: 18367305.

148. Paladino L, Subramanian RA, Nabors S, et al. The utility of shock index in differentiating major from minor injury. Eur J Emerg Med. 2011;18(2):94-8. doi: 10.1097/MEJ.0b013e32833f212b. PMID: 20842040.

149. Paladino L, Subramanian RA, Bonilla E, et al. Leukocytosis as prognostic indicator of major injury. West J Emerg Med. 2010;11(5):450-5. PMID: 21293764.

150. Paladino L, Subramanian RA, Nabors S, et al. Triage hyperglycemia as a prognostic indicator of major trauma. J Trauma. 2010;69(1):41-5. doi: 10.1097/TA.0b013e3181c9f0cb. PMID: 20665990.

151. Pandit V, Rhee P, Hashmi A, et al. Shock index predicts mortality in geriatric trauma patients: an analysis of the National Trauma Data Bank. J Trauma Acute Care Surg. 2014;76(4):1111-5. doi: 10.1097/TA.0000000000000160. PMID: 24662879.

152. Parsikia A, Bones K, Kaplan M, et al. The predictive value of initial serum lactate in trauma patients. Shock. 2014;42(3):199-204. doi: 10.1097/shk.0000000000000208. PMID: 24978889. 
153. Perel P, Prieto-Merino D, Shakur H, et al. Predicting early death in patients with traumatic bleeding: development and validation of prognostic model. BMJ. 2012;345:e5166. doi: 10.1136/bmj.e5166. PMID: 22896030.

154. Perel P, Prieto-Merino D, Shakur H, et al. Development and validation of a prognostic model to predict death in patients with traumatic bleeding, and evaluation of the effect of tranexamic acid on mortality according to baseline risk: a secondary analysis of a randomised controlled trial. Health Technol Assess (Winchester, England). 2013;17(24)doi: 10.3310/hta17240. PMID: 23782457.

155. Rahmani F, Bakhtavar HE, Vahdati SS, et al. Evaluation of MGAP and GAP trauma scores to predict prognosis of multipletrauma patients. Trauma Mon.

2017;22(3):e33249. doi:

10.5812/traumamon.33249.

156. Rainer TH, Ho AM, Yeung JH, et al. Early risk stratification of patients with major trauma requiring massive blood transfusion. Resuscitation. 2011;82(6):724-9. doi: 10.1016/j.resuscitation.2011.02.016. PMID: 21458905.

157. Ramanathan R, Parrish DW, Hartwich JE, et al. Utility of admission serum lactate in pediatric trauma. J Pediatr Surg. 2015;50(4):598-603. doi: 10.1016/j.jpedsurg.2014.08.013. PMID: 25840070.

158. Regnier MA, Raux M, Le Manach Y, et al. Prognostic significance of blood lactate and lactate clearance in trauma patients. Anesthesiology. 2012;117(6):1276-88. doi: 10.1097/ALN.0b013e318273349d. PMID: 23168430.

159. Reisner AT, Edla S, Liu J, et al. Muscle oxygen saturation improves diagnostic association between initial vital signs and major hemorrhage: a prospective observational study. Acad Emerg Med. 2016;23(3):353-7. doi: 10.1111/acem.12899. PMID: 26743804.
160. Ryan ML, Ogilvie MP, Pereira BM, et al. Heart rate variability is an independent predictor of morbidity and mortality in hemodynamically stable trauma patients. J Trauma. 2011;70(6):1371-80. doi: 10.1097/TA.0b013e31821858e6. PMID: 21817974.

161. Sammour T, Kahokehr A, Caldwell S, et al. Venous glucose and arterial lactate as biochemical predictors of mortality in clinically severely injured trauma patientsa comparison with ISS and TRISS. Injury. 2009;40(1):104-8. doi: 10.1016/j.injury.2008.07.032. PMID: 19117566.

162. Shoemaker WC, Bayard DS, Botnen A, et al. Mathematical program for outcome prediction and therapeutic support for trauma beginning within $1 \mathrm{hr}$ of admission: a preliminary report. Crit Care Med. 2005;33(7):1499-506. doi: 10.1097/01.CCM.0000162641.92400.AA. PMID: 16003054.

163. St. John AE, Rowhani-Rahbar A, Arbabi S, et al. Role of trauma team activation in poor outcomes of elderly patients. J Surg Res. 2016;203(1):95-102. doi: 10.1016/j.jss.2016.01.036. PMID: 27338540.

164. Stanworth SJ, Morris TP, Gaarder C, et al. Reappraising the concept of massive transfusion in trauma. Crit Care. 2010;14(6):R239. doi: 10.1186/cc9394. PMID: 21192812.

165. Vandromme MJ, Griffin RL, McGwin G, Jr., et al. Prospective identification of patients at risk for massive transfusion: an imprecise endeavor. Am Surg. 2011;77(2):155-61. PMID: 21337871.

166. Vassallo J, Horne S, Ball S, et al. Usefulness of the shock index as a secondary triage tool. J R Army Med Corps. 2015;161(1):537. doi: 10.1136/jramc-2013-000178. PMID: 24794704.

167. Vassallo J, Beavis J, Smith JE, et al. Major incident triage: derivation and comparative analysis of the Modified Physiological Triage Tool (MPTT). Injury. 2017;48(5):992-9. doi: 10.1016/j.injury.2017.01.038. PMID: 28131484. 
168. Williams DJ, Guirgis FW, Morrissey TK, et al. End-tidal carbon dioxide and occult injury in trauma patients: ETCO(2) does not rule out severe injury. Am J Emerg Med. 2016;34(11):2146-9. doi: 10.1016/j.ajem.2016.08.007. PMID: 27567419.

169. Yuen MSY, Mann SKF, Chow DHK. A simplified emergency trauma score for predicting mortality in emergency setting. Nursing in Crit Care. 2016;21(4):9-15. doi: 10.1111/nicc.12137. PMID: 25382107.

170. Zarzaur BL, Croce MA, Fischer PE, et al. New vitals after injury: shock index for the young and age $\mathrm{x}$ shock index for the old. $\mathrm{J}$ Surg Res. 2008;147(2):229-36. doi: 10.1016/j.jss.2008.03.025. PMID: 18498875.

171. Engum SA, Mitchell MK, Scherer LR, et al. Prehospital triage in the injured pediatric patient. J Pediatr Surg. 2000;35(1):82-7. doi: 10.1016/S0022-3468(00)80019-6. PMID: 10646780 .

172. Moore L, Lavoie A, LeSage N, et al. Statistical validation of the Revised Trauma Score. J Trauma. 2006;60(2):305-11. doi: 10.1097/01.ta.0000200840.89685.b0. PMID: 16508487.

173. Moront ML, Gotschall CS, Eichelberger MR. Helicopter transport of injured children: system effectiveness and triage criteria. J Pediatr Surg. 1996;31(8):1183-6; discussion 7-8. doi: 10.1016/S00223468(96)90114-1. PMID: 8863261.

174. Nabaweesi R, Morlock L, Lule C, et al. Do prehospital criteria optimally assign injured children to the appropriate level of trauma team activation and emergency department disposition at a level I pediatric trauma center? Pediatr Surg Int. 2014;30(11):1097102. doi: 10.1007/s00383-014-3587-6. PMID: 25142797.

175. Potoka DA, Schall LC, Ford HR. Development of a novel age-specific pediatric trauma score. J Pediatr Surg. 2001;36(1):106-12. doi: 10.1053/jpsu.2001.20023. PMID: 11150447.
176. Adeva-Andany M, Lopez-Ojen M, Funcasta-Calderon R, et al. Comprehensive review on lactate metabolism in human health. Mitochondrion. 2014;17:76-100. doi: 10.1016/j.mito.2014.05.007. PMID: 24929216.

177. Emmett M, Szerlip H. Causes of Lactic Acidosis. UpToDate. Updated September 19, 2017.

https://www.uptodate.com/contents/causesof-lactic-acidosis

178. Reddi A. Chapter 28: High anion gap metabolic acidosis (pages 319-346). In: Fluid, Electrolyte and Acid-Base Disorders: Clinical Evaluation and Management. New York: Springer; 2014.

179. Andersen LW, Mackenhauer J, Roberts JC, et al. Etiology and therapeutic approach to elevated lactate levels. Mayo Clin Proc. 2013 Oct;88(10):1127-40. doi: 10.1016/j.mayocp.2013.06.012. PMID: 24079682.

180. Kraut JA, Madias NE. Lactic acidosis. N Engl J Med. 2014;371(24):2309-19. doi: 10.1056/NEJMra1309483. PMID: 25494270 .

181. Kibble J. Renal physiology and acid-base balance. In: Kibble J, Halsey C, eds. Medical Physiology: The Big Picture. New York: McGraw-Hill; 2014.

182. Parrillo J, Dellinger R. Crit Care Med EBook. Chapter 27: traumatic shock and tissue hypoperfusion: nonsurgical management. Elsevier Health Sciences, proQuest Ebook Central; 2013. http://ebookcentral.proquest.com/lib/ohsu/de tail.action?docID $=1746317$. Accessed July 11, 2017.

183. Sasser SM, Hunt RC, Sullivent EE, et al. Guidelines for field triage of injured patients. Recommendations of the National Expert Panel on Field Triage. MMWR Recomm Rep. 2009;58(RR-1):1-35. PMID: 19165138.

184. Sato Y, Weil MH, Tang W. Tissue hypercarbic acidosis as a marker of acute circulatory failure (shock). Chest. 1998 Jul;114(1):263-74. PMID: 9674478. 
185. Knaus WA, Draper EA, Wagner DP, et al. APACHE II: a severity of disease classification system. Crit Care Med. 1985;13(10):818-29. PMID: 3928249.

186. Gormican SP. CRAMS scale: field triage of trauma victims. Ann Emerg Med. 1982;11(3):132-5. PMID: 7065486.

187. Raum MR, Nijsten MW, Vogelzang M, et al. Emergency trauma score: an instrument for early estimation of trauma severity. Crit Care Med. 2009;37(6):1972-7. doi: 10.1097/CCM.0b013e31819fe96a. PMID: 19384227.

188. Koehler JJ, Baer LJ, Malafa SA, et al. Prehospital Index: a scoring system for field triage of trauma victims. Ann Emerg Med. 1986;15(2):178-82. PMID: 3946860.

189. Tepas JJ, 3rd, Mollitt DL, Talbert JL, et al. The pediatric trauma score as a predictor of injury severity in the injured child. J Pediatr Surg. 1987;22(1):14-8. PMID: 3102714.

190. Olsson T, Terent A, Lind L. Rapid Emergency Medicine score: a new prognostic tool for in-hospital mortality in nonsurgical emergency department patients. J Intern Med. 2004;255(5):579-87. doi: 10.1111/j.1365-2796.2004.01321.x. PMID: 15078500 .

191. Champion HR, Sacco WJ, Copes WS, et al. A revision of the Trauma Score. J Trauma. 1989;29(5):623-9. PMID: 2657085.

192. Schultz CH, Koenig KL, Noji EK. A medical disaster response to reduce immediate mortality after an earthquake. $\mathrm{N}$ Engl J Med. 1996;334(7):438-44. doi: 10.1056/nejm199602153340706. PMID: 8552147.
193. Gebhart ME, Pence R. START triage: does it work? Disaster Manag Response. 2007;5(3):68-73. doi: 10.1016/j.dmr.2007.05.002. PMID: 17719507.

194. Prytherch DR, Smith GB, Schmidt PE, et al. ViEWS--Towards a national early warning score for detecting adult inpatient deterioration. Resuscitation.

2010;81(8):932-7. doi: 10.1016/j.resuscitation.2010.04.014. PMID: 20637974.

195. Jo S, Lee JB, Jin YH, et al. Modified early warning score with rapid lactate level in critically ill medical patients: the ViEWS-L score. Emerg Med J. 2013;30(2):123-9. doi: 10.1136/emermed-2011-200760. PMID: 22427404.

196. Hung KK. Best Evidence Topic report. BET 2. Serum lactate as a marker for mortality in patients presenting to the emergency department with trauma. Emerg Med J. 2009;26(2):118-9. doi: 10.1136/emj.2008.070797. PMID: 19164625.

197. Baxter J, Cranfield KR, Clark G, et al. Do lactate levels in the emergency department predict outcome in adult trauma patients? A systematic review. J Trauma Acute Care Surg. 2016;81(3):555-66. doi: 10.1097/TA.0000000000001156. PMID: 27280943.

198. Cornell JE, Mulrow CD, Localio R, et al. Random-effects meta-analysis of inconsistent effects: a time for change. Ann Intern Med. 2014;160(4):267-70. doi: 10.7326/M13-2886. PMID: 24727843. 


\section{Abbreviations and Acronyms}

\begin{tabular}{|c|c|}
\hline Abbreviation/Acronym & Term \\
\hline AHRQ & Agency for Healthcare Research and Quality \\
\hline APACHE II score & Acute Physiology and Chronic Health Evaluation II Score \\
\hline ASPTS & Age-Specific Pediatric Trauma Score \\
\hline AUROC & area under the receiver operating characteristic curve \\
\hline $\mathrm{BD}$ & base deficit \\
\hline bpm & beats per minute \\
\hline C & Composite \\
\hline CHAID & chi-square automatic interaction detection \\
\hline $\mathrm{Cl}$ & confidence interval \\
\hline $\mathrm{CO}_{2}$ & carbon dioxide \\
\hline CRAMS & Circulation, Respiration, Abdomen, Motor, Speech \\
\hline CT & computed tomography \\
\hline DBP & diastolic blood pressure \\
\hline DFA & detrended fluctuations analysis \\
\hline ECG & Electrocardiogram \\
\hline ED & emergency department \\
\hline EMS & emergency medical services \\
\hline EMT & emergency medical technician \\
\hline EMTRAS & Emergency Trauma Score \\
\hline $\mathrm{ETCO}_{2}$ & end-tidal carbon dioxide \\
\hline FTS & Field Triage Score \\
\hline GAP & Glasgow Coma Scale, age, and arterial pressure \\
\hline GCS & Glasgow Coma Scale \\
\hline $\mathrm{HF}$ & high frequency \\
\hline HR & heart rate \\
\hline HRC & heart rate complexity \\
\hline HRV & heart rate variability \\
\hline $\mathrm{I}$ & injury type or severity \\
\hline ICU & intensive care unit \\
\hline iHat & heart-to-arm time index \\
\hline IQR & interquartile range \\
\hline ISS & Injury Severity Score \\
\hline KQ & Key Question \\
\hline LF & low frequency \\
\hline LOS & length of stay \\
\hline LSI & life-saving intervention \\
\hline $\mathrm{M}$ & Mortality \\
\hline MAP & mean arterial pressure \\
\hline MGAP & mechanism, Glasgow Coma Scale, age, and arterial pressure \\
\hline MPTT & Modified Physiological Triage Tool \\
\hline mREMS & modified Rapid Emergency Medicine Score \\
\hline NA & not applicable \\
\hline NHTSA & National Highway Transportation Safety Administration \\
\hline NR & not reported \\
\hline NTTP & National Trauma Triage Protocol \\
\hline $\mathrm{O}_{2}$ & Oxygen \\
\hline $\mathrm{OH}$ & out-of-hospital \\
\hline $\mathrm{pCO}_{2}$ & partial pressure of carbon dioxide \\
\hline PICOTS & population, intervention, comparator, outcome, timing, setting \\
\hline $\mathrm{PHI}$ & Prehospital Index \\
\hline
\end{tabular}




\begin{tabular}{|l|l|}
\hline Abbreviation/Acronym & Term \\
\hline PP & pulse pressure \\
\hline PPG & photoplethysmography, photoplethysmogram \\
\hline PPV & positive predictive value \\
\hline pRBC & packed red blood cell \\
\hline PTS & Pediatric Trauma Score \\
\hline QUIPS & Quality in Prognosis Studies \\
\hline R & resource use \\
\hline R-to-R interval & time between heart beats \\
\hline REMS & Rapid Emergency Medicine Score \\
\hline RR & respiratory rate \\
\hline RSA & rate of sinus arrhythmia \\
\hline RTS & Revised Trauma Score \\
\hline SampEn & sample entropy \\
\hline SaO & oxygen saturation \\
\hline SBP & systolic blood pressure \\
\hline SD & standard deviation \\
\hline SDNN & standard deviation of the normal-to-normal intervals \\
\hline SE & standard error \\
\hline Sen & sensitivity \\
\hline SETS & Simplified Emergency Trauma Score \\
\hline SI & shock index \\
\hline SLCO & sublingual partial pressure of carbon dioxide \\
\hline SmO & \\
\hline SOE & muscle oxygen saturation \\
\hline Sp & strength of evidence \\
\hline SpO & specificity \\
\hline START & peripheral oxygen saturation \\
\hline StO & Simple Triage and Rapid Treatment \\
\hline T-ASPTS & tissue oxygen saturation \\
\hline T-RTS & Triage Age-Specific Pediatric Trauma Score \\
\hline TC & Revised Trauma Score for Triage \\
\hline TEP & trauma center \\
\hline ViEWS & Technical Expert Panel \\
\hline ViEWS-L & VitalPAC Early Warning Score \\
\hline VLF & modified VitalPAC Early Warning Score with rapid lactate level \\
\hline & very low frequency \\
\hline \\
\hline
\end{tabular}




\section{Appendix A. Search Strategies}

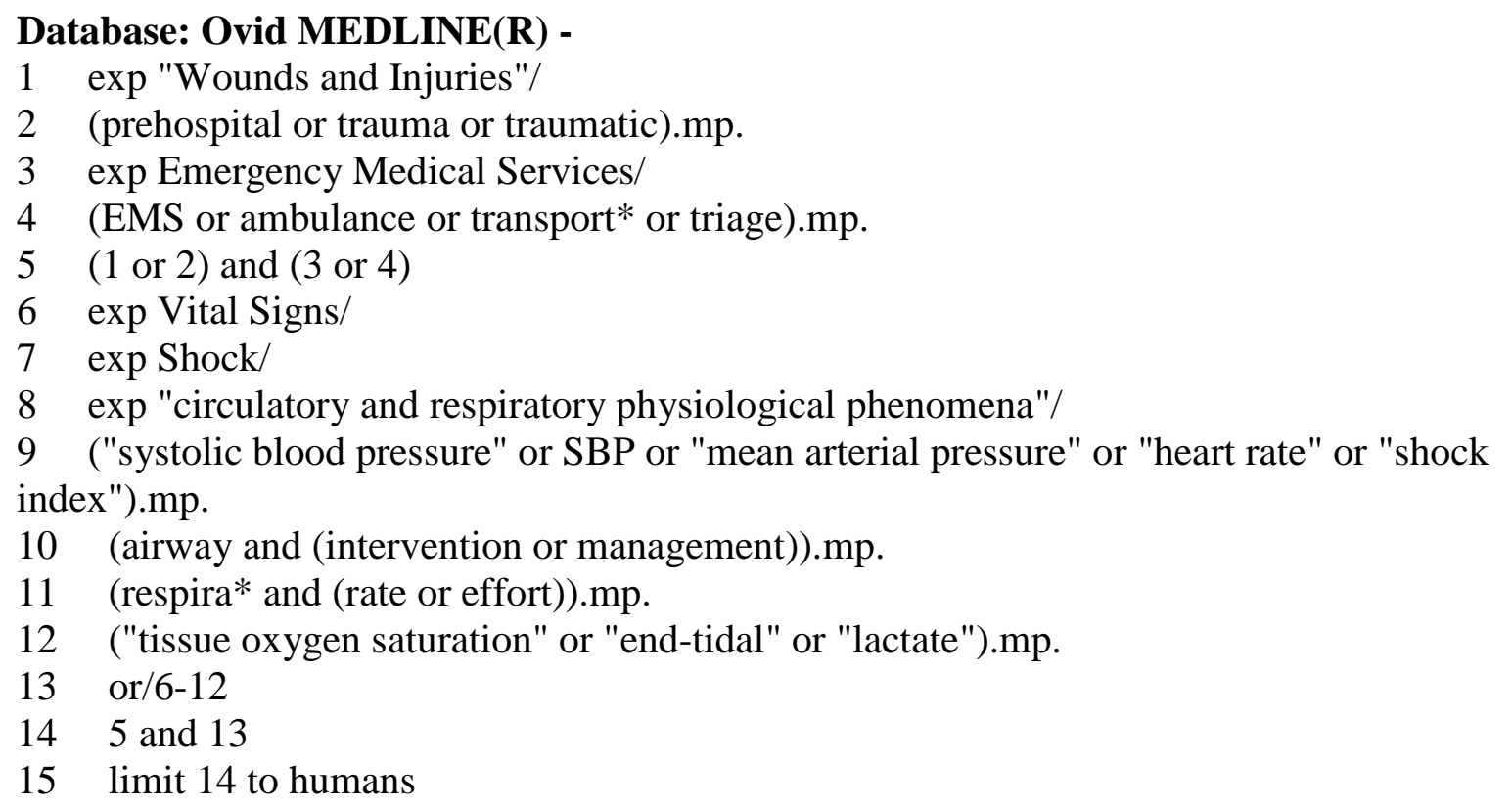

Database: EBM Reviews - Cochrane Central Register of Controlled Trials 1 exp "Wounds and Injuries"/

2 (prehospital or trauma or traumatic).mp.

3 exp Emergency Medical Services/

4 (EMS or ambulance or transport* or triage).mp.

5 (1 or 2 ) and (3 or 4)

6 exp Vital Signs/

7 exp Shock/

8 exp "circulatory and respiratory physiological phenomena"/

9 ("systolic blood pressure" or SBP or "mean arterial pressure" or "heart rate" or "shock index").mp.

10 (airway and (intervention or management)).mp.

11 (respira* and (rate or effort)).mp.

12 ("tissue oxygen saturation" or "end-tidal" or "lactate").mp.

13 or/6-12

145 and 13

\section{Database: EBM Reviews - Cochrane Database of Systematic Reviews}

1 ("systolic blood pressure" or SBP or "mean arterial pressure" or "heart rate" or "shock index").mp. [mp=title, abstract, full text, keywords, caption text] (1001)

2 (airway and (intervention or management)).mp. [mp=title, abstract, full text, keywords, caption text] (787)

3 (respira* and (rate or effort)).mp. [mp=title, abstract, full text, keywords, caption text] (2033)

4 ("tissue oxygen saturation" or "end-tidal" or "lactate").mp. [mp=title, abstract, full text, keywords, caption text] (203) 
5 or/1-4 (2845)

6 (prehospital or pre-hospital or trauma or traumatic or EMS or ambulance or transport* or triage).ti. (119)

75 and $6(23)$

Database: CINAHL Plus with Full Text

S1 (MH "Wounds and Injuries+")

S2 (MH "Trauma+")

S3 (MH "Prehospital Care")

S4 (MH "Emergency Medical Services+")

S5 (MH "Transportation of Patients+")

S6 S1 OR S2

S7 $\quad$ S3 OR S4 OR S5

S8 S6 AND S7

S9 (MH "Cardiopulmonary Physiology+")

S10 (MH "Respiratory Tract Physiology+")

S11 S9 OR S10

S12 S8 AND S11

S13 S12 Limiters - Published Date: 19960101-20161231

\section{Database: Elsevier Embase}

((('injury'/exp or prehospital:ab,ti or trauma:ab,ti or traumatic:ab,ti) and ('emergency health service'/exp or ems:ab,ti or ambulance:ab,ti or transport*:ab,ti)) and ('vital sign'/exp or 'shock'/exp or 'cardiovascular function'/exp)) and [embase]/lim not [medline]/lim and ('article'/it or 'article in press'/it or 'review'/it) and (1996:py or 1997:py or 1998:py or 1999:py or 2000:py or 2001:py or 2002:py or 2003:py or 2004:py or 2005:py or 2006:py or 2007:py or 2008:py or 2009:py or 2010:py or 2011:py or 2012:py or 2013:py or 2014:py or 2015:py or 2016:py or 2017:py) and 'human'/de 


\section{Appendix B. List of Included Studies}

1. Ahun E, Koksal O, Sigirli D, et al. Value of the Glasgow Coma Scale, Age, and Arterial Blood Pressure score for predicting the mortality of major trauma patients presenting to the emergency department. Ulus Travma Acil Cerrahi Derg. 2014;20(4):241-7. doi: 10.5505/tjtes.2014.76399. PMID: 25135017.

2. Allen CJ, Tashiro J, Valle EJ, et al. Initial hematocrit predicts the use of blood transfusion in the pediatric trauma patient. J Pediatr Surg. 2014;49(11):1678-82. doi: 10.1016/j.jpedsurg.2014.10.044. PMID: 25475817.

3. Al-Salamah MA, McDowell I, Stiell IG, et al. Initial emergency department trauma scores from the OPALS Study: the case for the motor score in blunt trauma. Acad Emerg Med. 2004;11(8):834-42. doi: 10.1197/j.aem.2004.03.008. PMID: 15289188.

4. Arbabi S, Jurkovich GJ, Wahl WL, et al. A comparison of prehospital and hospital data in trauma patients. J Trauma.

2004;56(5):1029-32. doi:

10.1097/01.TA.0000123036.20919.4B. PMID: 15179242.

5. Aslar AK, Kuzu MA, Elhan AH, et al. Admission lactate level and the APACHE II score are the most useful predictors of prognosis following torso trauma. Injury. 2004;35(8):746-52. doi: 10.1016/j.injury.2003.09.030. PMID: 15246796.

6. Baron BJ, Dutton RP, Zehtabchi S, et al. Sublingual capnometry for rapid determination of the severity of hemorrhagic shock. J Trauma. 2007;62(1):120-4. doi: 10.1097/TA.0b013e31802d96ec. PMID: 17215742.

7. Baron BJ, Sinert R, Zehtabchi S, et al. Diagnostic utility of sublingual PCO2 for detecting hemorrhage in penetrating trauma patients. J Trauma. 2004;57(1):69-74. doi: 10.1097/01.TA.0000090754.94232.2C. PMID: 15284551.
8. Batchinsky AI, Cancio LC, Salinas J, et al. Prehospital loss of R-to-R interval complexity is associated with mortality in trauma patients. J Trauma. 2007;63(3):5128. doi: 10.1097/TA.0b013e318142d2f0. PMID: 18073594.

9. Batchinsky AI, Salinas J, Jones JA, et al. Predicting the need to perform life-saving interventions in trauma patients by using new vital signs and artificial neural networks. In: Combi C, Shahar Y, A. A-H, editors. Artificial Intelligence in Medicine. AIME 2009; 2009 July 18-22; Verona, Italy. Berlin, Heidelberg: Springer; 2009:390-4.

10. Batchinsky AI, Salinas J, Kuusela T, et al. Rapid prediction of trauma patient survival by analysis of heart rate complexity: impact of reducing data set size. Shock. 2009;32(6):565-71. doi: 10.1097/SHK.0b013e3181a993dc. PMID: 19487984.

11. Beekley AC, Martin MJ, Nelson T, et al. Continuous noninvasive tissue oximetry in the early evaluation of the combat casualty: a prospective study. J Trauma. 2010;69(1 Suppl):S14-S25. doi: 10.1097/TA.0b013e3181e42326. PMID: 20622608.

12. Bond RJ, Kortbeek JB, Preshaw RM. Field trauma triage: combining mechanism of injury with the prehospital index for an improved trauma triage tool. J Trauma. 1997;43(2):283-7. PMID: 9291374.

13. Bouzat P, Schilte C, Vinclair M, et al. Capillary lactate concentration on admission of normotensive trauma patients: a prospective study. Scand J Trauma Resusc Emerg Med. 2016;24:82. doi: 10.1186/s13049-016-0272-x. PMID: 27267942.

14. Brown JB, Gestring ML, Forsythe RM, et al. Systolic blood pressure criteria in the National Trauma Triage Protocol for geriatric trauma: 110 is the new 90 . J Trauma Acute Care Surg. 2015;78(2):352-9. doi: 10.1097/TA.0000000000000523. PMID: 25757122. 
15. Brown JB, Lerner EB, Sperry JL, et al. Prehospital lactate improves accuracy of prehospital criteria for designating trauma activation level. J Trauma Acute Care Surg. 2016;81(3):445-52. doi: 10.1097/ta.0000000000001085. PMID: 27116410.

16. Brown JB, Stassen NA, Bankey PE, et al. Mechanism of injury and special consideration criteria still matter: an evaluation of the National Trauma Triage Protocol. J Trauma. 2011;70(1):38-44; discussion -5. doi: 10.1097/TA.0b013e3182077ea8. PMID: 21217479.

17. Bruijns SR, Guly HR, Bouamra O, et al. The value of traditional vital signs, shock index, and age-based markers in predicting trauma mortality. J Trauma Acute Care Surg. 2013;74(6):1432-7. doi: 10.1097/TA.0b013e31829246c7. PMID: 23694869.

18. Bruijns SR, Guly HR, Bouamra O, et al. The value of the difference between ED and prehospital vital signs in predicting outcome in trauma. Emerg Med J. 2014;31(7):579-82. doi: 10.1136/emermed-2012-202271. PMID: 23616498.

19. Callaway DW, Shapiro NI, Donnino MW, et al. Serum lactate and base deficit as predictors of mortality in normotensive elderly blunt trauma patients. J Trauma. 2009;66(4):1040-4. doi: 10.1097/TA.0b013e3181895e9e. PMID 19359912.

20. Cancio LC, Batchinsky AI, Salinas J, et al. Heart-rate complexity for prediction of prehospital lifesaving interventions in trauma patients. J Trauma. 2008;65(4):8139. doi: 10.1097/TA.0b013e3181848241. PMID: 18849796.

21. Cancio LC, Wade CE, West SA, et al. Prediction of mortality and of the need for massive transfusion in casualties arriving at combat support hospitals in Iraq. J Trauma. 2008;64(2 Suppl):S51-5; discussion S5-6. doi: 10.1097/TA.0b013e3181608c21. PMID: 18376172.
22. Cannon CM, Braxton CC, Kling-Smith M, et al. Utility of the shock index in predicting mortality in traumatically injured patients. J Trauma. 2009;67(6):1426-30. doi: 10.1097/TA.0b013e3181bbf728. PMID: 20009697.

23. Caputo ND, Fraser RM, Paliga A, et al. Nasal cannula end-tidal CO2 correlates with serum lactate levels and odds of operative intervention in penetrating trauma patients: a prospective cohort study. J Trauma Acute Care Surg. 2012;73(5):1202-7. doi: 10.1097/TA.0b013e318270198c. PMID: 23117381.

24. Caputo ND, Kanter M, Fraser R, et al. Comparing biomarkers of traumatic shock: the utility of anion gap, base excess, and serum lactate in the ED. Am J Emerg Med. 2015;33(9):1134-9. doi: 10.1016/j.ajem.2015.04.085. PMID: 26027886.

25. Chan L, Bartfield JM, Reilly KM. The significance of out-of-hospital hypotension in blunt trauma patients. Acad Emerg Med. 1997;4(8):785-8. doi: 10.1111/j.15532712.1997.tb03785.x. PMID: 9262696.

26. Chen L, McKenna TM, Reisner AT, et al. Decision tool for the early diagnosis of trauma patient hypovolemia. J Biomed Inform. 2008;41(3):469-78. doi: 10.1016/j.jbi.2007.12.002. PMID: 18255342.

27. Chen L, Reisner AT, Gribok A, et al. Can we improve the clinical utility of respiratory rate as a monitored vital sign? Shock. 2009;31(6):574-80. doi: 10.1097/SHK.0b013e318193e885. PMID: 19008777.

28. Chen L, Reisner AT, Gribok A, et al. Is respiration-induced variation in the photoplethysmogram associated with major hypovolemia in patients with acute traumatic injuries? Shock. 2010;34(5):45560. doi: 10.1097/SHK.0b013e3181dc07da. PMID: 20220568. 
29. Chen L, Reisner AT, McKenna TM, et al. Diagnosis of hemorrhage in a prehospital trauma population using linear and nonlinear multiparameter analysis of vital signs. Conf Proc IEEE Eng Med Biol Soc. 2007 29th Annual International Conference of the IEEE Engineering in Medicine and Biology Society; 2007 August 22-26; Lyon, France. IEEE; 2007:3748-51.

30. Cherry RA, King TS, Carney DE, et al. Trauma team activation and the impact on mortality. J Trauma. 2007;63(2):326-30. doi: 10.1097/TA.0b013e31811eaad1. PMID: 17693831.

31. Cooke WH, Salinas J, Convertino VA, et al. Heart rate variability and its association with mortality in prehospital trauma patients. $\mathrm{J}$ Trauma. 2006;60(2):363-70; discussion 70. doi: 10.1097/01.ta.0000196623.48952.0e. PMID: 16508497.

32. Courville XF, Koval KJ, Carney BT, et al. Early prediction of posttraumatic in-hospital mortality in pediatric patients. J Pediatr Orthop. 2009;29(5):439-44. doi: 10.1097/BPO.0b013e3181aad60f. PMID: 19568013.

33. Cudnik MT, Werman HA, White LJ, et al. Prehospital factors associated with mortality in injured air medical patients. Prehosp Emerg Care. 2012;16(1):121-7. doi: 10.3109/10903127.2011.615011. PMID: 21958032.

34. Davis JW, Parks SN, Kaups KL, et al. Admission base deficit predicts transfusion requirements and risk of complications. J Trauma. 1996;41(5):769-74. PMID: 8913202.

35. DeMuro JP, Simmons S, Jax J, et al. Application of the shock index to the prediction of need for hemostasis intervention. Am J Emerg Med. 2013;31(8):1260-3. doi: 10.1016/j.ajem.2013.05.027. PMID: 23806728.

36. Dinh MM, Bein KJ, Oliver M, et al. Refining the trauma triage algorithm at an Australian major trauma centre: derivation and internal validation of a triage risk score. Eur J Trauma Emerg Surg. 2014;40(1):6774. doi: 10.1007/s00068-013-0315-1. PMID: 26815779.
37. Dunham MP, Sartorius B, Laing GL, et al. A comparison of base deficit and vital signs in the early assessment of patients with penetrating trauma in a high burden setting. Injury. 2017;48(9):1972-7. doi: 10.1016/j.injury.2017.06.011. PMID: 28684079.

38. Dunne JR, Tracy JK, Scalea TM, et al. Lactate and base deficit in trauma: does alcohol or drug use impair their predictive accuracy? J Trauma. 2005;58(5):959-66. doi: 10.1097/01.TA.0000158508.84009.49. PMID: 15920409.

39. Eastridge BJ, Salinas J, McManus JG, et al. Hypotension begins at $110 \mathrm{~mm} \mathrm{Hg:}$ redefining "hypotension" with data. J Trauma. 2007;63(2):291-7; discussion 7-9. doi: 10.1097/TA.0b013e31809ed924. PMID: 17693826.

40. Edla S, Reisner AT, Liu J, et al. Is heart rate variability better than routine vital signs for prehospital identification of major hemorrhage? Am J Emerg Med. 2015;33(2):254-61. doi: 10.1016/j.ajem.2014.11.046. PMID: 25534122.

41. Engum SA, Mitchell MK, Scherer LR, et al. Prehospital triage in the injured pediatric patient. J Pediatr Surg. 2000;35(1):82-7. doi: 10.1016/S0022-3468(00)80019-6. PMID: 10646780.

42. Folkert IW, Sims CA, Pascual JL, et al. Initial venous lactate levels in patients with isolated penetrating extremity trauma: a retrospective cohort study. Eur J Trauma Emerg Surg. 2015;41(2):203-9. doi: 10.1007/s00068-014-0442-3. PMID: 26038266.

43. Franklin GA, Boaz PW, Spain DA, et al. Prehospital hypotension as a valid indicator of trauma team activation. J Trauma. 2000;48(6):1034-9. PMID: 10866247.

44. Garner A, Lee A, Harrison K, et al. Comparative analysis of multiple-casualty incident triage algorithms. Ann Emerg Med. 2001;38(5):541-8. doi: 10.1067/mem.2001.119053. PMID: 11679866. 
45. Gebhart ME, Pence R. START triage: does it work? Disaster Manag Response. 2007;5(3):68-73. doi:

10.1016/j.dmr.2007.05.002. PMID: 17719507.

46. Gray A, Goyder EC, Goodacre SW, et al. Trauma triage: a comparison of CRAMS and TRTS in a UK population. Injury. 1997;28(2):97-101. PMID: 9205573.

47. Grimme K, Pape HC, Probst C, et al. Calculation of different triage scores based on the German Trauma Registry: value of the shock index. Eur J Traum. 2005;31(5):480-7. doi: 10.1007/s00068-0052026-8.

48. Guyette F, Suffoletto B, Castillo JL, et al. Prehospital serum lactate as a predictor of outcomes in trauma patients: a retrospective observational study. J Trauma.

2011;70(4):782-6. doi:

10.1097/TA.0b013e318210f5c9. PMID: 21610386.

49. Guyette FX, Gomez H, Suffoletto B, et al. Prehospital dynamic tissue oxygen saturation response predicts in-hospital lifesaving interventions in trauma patients. J Trauma Acute Care Surg. 2012;72(4):930-5. doi: 10.1097/TA.0b013e31823d0677. PMID: 22491607.

50. Guyette FX, Meier EN, Newgard C, et al. A comparison of prehospital lactate and systolic blood pressure for predicting the need for resuscitative care in trauma transported by ground. J Trauma Acute Care Surg. 2015;78(3):600-6. doi: 10.1097/TA.0000000000000549. PMID: 25710433.

51. Haider AA, Azim A, Rhee P, et al. Substituting systolic blood pressure with shock index in the National Trauma Triage Protocol. J Trauma Acute Care Surg. 2016;81(6):1136-41. doi: 10.1097/TA.0000000000001205. PMID: 27893619.

52. Hamada SR, Gauss T, Duchateau FX, et al. Evaluation of the performance of French physician-staffed emergency medical service in the triage of major trauma patients. J Trauma Acute Care Surg. 2014;76(6):1476-83. doi: 10.1097/ta.0000000000000239. PMID: 24854319.
53. Henry MC, Hollander JE, Alicandro JM, et al. Incremental benefit of individual American College of Surgeons trauma triage criteria. Acad Emerg Med. 1996;3(11):9921000. doi: 10.1111/j.15532712.1996.tb03340.x. PMID: 8922003.

54. Holcomb JB, Niles SE, Miller CC, et al. Prehospital physiologic data and lifesaving interventions in trauma patients. Mil Med. 2005;170(1):7-13. doi: 10.7205/MILMED.170.1.7. PMID: 15724847.

55. Holcomb JB, Salinas J, McManus JM, et al. Manual vital signs reliably predict need for life-saving interventions in trauma patients. J Trauma. 2005;59(4):821-8; discussion 8-9. doi: 10.1097/01.ta.0000188125.44129.7c. PMID: 16374268.

56. Horne S, Vassallo J, Read J, et al. UK triage-an improved tool for an evolving threat. Injury. 2013;44(1):23-8. doi: 10.1016/j.injury.2011.10.005. PMID: 22077989.

57. Ichwan B, Darbha S, Shah MN, et al. Geriatric-specific triage criteria are more sensitive than standard adult criteria in identifying need for trauma center care in injured older adults. Ann Emerg Med. 2015;65(1):92-100.e3. doi: 10.1016/j.annemergmed.2014.04.019. PMID: 24908590.

58. Imhoff BF, Thompson NJ, Hastings MA, et al. Rapid Emergency Medicine Score (REMS) in the trauma population: a retrospective study. BMJ Open. 2014;4(5):e004738. doi: 10.1136/bmjopen2013-004738. PMID: 24793256.

59. Jo S, Lee JB, Jin YH, et al. Comparison of the trauma and injury severity score and modified early warning score with rapid lactate level (the ViEWS-L score) in blunt trauma patients. Eur J Emerg Med. 2014;21(3):199-205. doi: 10.1097/MEJ.0b013e32836192d6. PMID: 23628928.

60. Jones JM, Skaga NO, Sovik S, et al. Norwegian survival prediction model in trauma: modelling effects of anatomic injury, acute physiology, age, and comorbidity. Acta Anaesthesiol Scand. 2014;58(3):303-15. doi: 10.1111/aas.12256. PMID: 24438461. 
61. Joosse P, de Jong WJ, Reitsma JB, et al. External validation of the Emergency Trauma Score for early prediction of mortality in trauma patients. Crit Care Med. 2014;42(1):83-9. doi: 10.1097/CCM.0b013e31829e53f5. PMID: 23982027.

62. Khasawneh MA, Zielinski MD, Jenkins DH, et al. Low tissue oxygen saturation is associated with requirements for transfusion in the rural trauma population. World $\mathrm{J}$

Surg. 2014;38(8):1892-7. doi: 10.1007/s00268-014-2505-3. PMID: 24969044.

63. Kim SY, Hong KJ, Shin SD, et al. Validation of the shock index, modified shock index, and age shock index for predicting mortality of geriatric trauma patients in emergency departments. J Korean Med Sci. 2016;31(12):2026-32. doi: 10.3346/jkms.2016.31.12.2026. PMID: 27822945.

64. King DR, Ogilvie MP, Pereira BM, et al. Heart rate variability as a triage tool in patients with trauma during prehospital helicopter transport. J Trauma. 2009;67(3):436-40. doi: 10.1097/TA.0b013e3181ad67de. PMID: 19741382.

65. King RW, Plewa MC, Buderer NM, et al. Shock index as a marker for significant injury in trauma patients. Acad Emerg Med. 1996;3(11):1041-5. doi: 10.1111/j.15532712.1996.tb03351.x. PMID: 8922013.

66. Kondo Y, Abe T, Kohshi K, et al. Revised trauma scoring system to predict in-hospital mortality in the emergency department: Glasgow Coma Scale, Age, and Systolic Blood Pressure score. Crit Care. 2011;15(4):R191. doi: 10.1186/cc10348. PMID: 21831280.

67. Kuo SCH, Kuo PJ, Hsu SY, et al. The use of the reverse shock index to identify high-risk trauma patients in addition to the criteria for trauma team activation: a cross-sectional study based on a trauma registry system. BMJ Open. 2016;6(6):e011072. doi: 10.1136/bmjopen-2016-011072. PMID: 27329440 .
68. Lai WH, Rau CS, Hsu SY, et al. Using the reverse shock index at the injury scene and in the emergency department to identify high-risk patients: a cross-sectional retrospective study. Int J Environ Res Public Health. 2016;13(4):357. doi: 10.3390/ijerph13040357. PMID: 27023577.

69. Lalezarzadeh F, Wisniewski P, Huynh K, et al. Evaluation of prehospital and emergency department systolic blood pressure as a predictor of in-hospital mortality. Am Surg. 2009;75(10):1009-14. PMID: 19886155.

70. Lee YT, Feng XY, Lin YC, et al. Pediatric trauma team activation: are we making the right call? Eur J Pediatr Surg. 2014;24(1):46-50. doi: 10.1055/s-00331349717. PMID: 23852723.

71. Lehmann RK, Arthurs ZM, Cuadrado DG, et al. Trauma team activation: simplified criteria safely reduces overtriage. Am J Surg. 2007;193(5):630-4; discussion 4-5. doi: 10.1016/j.amjsurg.2007.01.017. PMID: 17434371.

72. Lerner EB, Drendel AL, Cushman JT, et al. Ability of the physiologic criteria of the field triage guidelines to identify children who need the resources of a trauma center. Prehosp Emerg Care. 2017;21(2):180-4. doi: 10.1080/10903127.2016.1233311. PMID: 27710155.

73. Lin G, Becker A, Lynn M. Changes in vital signs of trauma victims from prehospital to hospital settings. Journal of Paramedic Practice. 2011;3(10):558-62.

74. Lipsky AM, Gausche-Hill M, Henneman PL, et al. Prehospital hypotension is a predictor of the need for an emergent, therapeutic operation in trauma patients with normal systolic blood pressure in the emergency department. J Trauma. 2006;61(5):1228-33. doi: 10.1097/01.ta.0000196694.52615.84. PMID: 17099534.

75. Liu NT, Holcomb JB, Wade CE, et al. Development and validation of a machine learning algorithm and hybrid system to predict the need for life-saving interventions in trauma patients. Med Biol Eng Comput. 2014;52(2):193-203. doi: 10.1007/s11517013-1130-x. PMID: 24263362. 
76. Liu NT, Holcomb JB, Wade CE, et al. Evaluation of standard versus nonstandard vital signs monitors in the prehospital and emergency departments: results and lessons learned from a trauma patient care protocol. J Trauma Acute Care Surg. 2014;77(3 Suppl 2):S121-6. doi: 10.1097/TA.0000000000000192. PMID: 24770560.

77. Liu NT, Holcomb JB, Wade CE, et al. Utility of vital signs, heart rate variability and complexity, and machine learning for identifying the need for lifesaving interventions in trauma patients. Shock. 2014;42(2):108-14. doi: 10.1097/SHK.0000000000000186. PMID: 24727872.

78. Liu NT, Holcomb JB, Wade CE, et al. Data quality of a wearable vital signs monitor in the pre-hospital and emergency departments for enhancing prediction of needs for lifesaving interventions in trauma patients. $\mathrm{J}$ Med Eng Technol. 2015;39(6):316-21. doi: 10.3109/03091902.2015.1054524. PMID: 26088543.

79. Liu NT, Holcomb JB, Wade CE, et al. Improving the prediction of mortality and the need for life-saving interventions in trauma patients using standard vital signs with heart-rate variability and complexity. Shock. 2015;43(6):549-55. doi: 10.1097/SHK.0000000000000356. PMID: 25692260.

80. Mackenzie CF, Gao C, Hu PF, et al. Comparison of decision-assist and clinical judgment of experts for prediction of lifesaving interventions. Shock. 2015;43(3):238-43. doi: 10.1097/shk.0000000000000288. PMID: 25394243.

81. Mackenzie CF, Wang Y, Hu PF, et al. Automated prediction of early blood transfusion and mortality in trauma patients. J Trauma Acute Care Surg. 2014;76(6):1379-85. doi: 10.1097/TA.0000000000000235. PMID: 24854304.
82. Matsushima K, Chouliaras K, Koenig W, et al. Should we still use motor vehicle intrusion as a sole triage criterion for the use of trauma center resources? Injury. 2016;47(1):235-8. doi: 10.1016/j.injury.2015.10.033. PMID: 26542464.

83. McManus J, Yershov AL, Ludwig D, et al. Radial pulse character relationships to systolic blood pressure and trauma outcomes. Prehosp Emerg Care. 2005;9(4):423-8. doi: 10.1080/10903120500255891. PMID: 16263676.

84. McNab A, Burns B, Bhullar I, et al. An analysis of shock index as a correlate for outcomes in trauma by age group. Surgery. 2013;154(2):384-7. doi: 10.1016/j.surg.2013.05.007. PMID: 23889965.

85. Miller RT, Nazir N, McDonald T, et al. The modified rapid emergency medicine score: a novel trauma triage tool to predict inhospital mortality. Injury. 2017;48(9):18707. doi: 10.1016/j.injury.2017.04.048. PMID: 28465003.

86. Mizushima Y, Ueno M, Watanabe H, et al. Discrepancy between heart rate and makers of hypoperfusion is a predictor of mortality in trauma patients. $\mathrm{J}$ Trauma. 2011;71(4):789-92. doi: 10.1097/TA.0b013e31822f7bbd. PMID: 21986732.

87. Montoya KF, Charry JD, Calle-Toro JS, et al. Shock index as a mortality predictor in patients with acute polytrauma. Journal of Acute Disease. 2015;4(3):202-4. doi: 10.1016/j.joad.2015.04.006.

88. Moore L, Lavoie A, LeSage N, et al. Statistical validation of the Revised Trauma Score. J Trauma. 2006;60(2):305-11. doi: 10.1097/01.ta.0000200840.89685.b0. PMID: 16508487.

89. Moront ML, Gotschall CS, Eichelberger MR. Helicopter transport of injured children: system effectiveness and triage criteria. J Pediatr Surg. 1996;31(8):1183-6; discussion 7-8. doi: 10.1016/S00223468(96)90114-1. PMID: 8863261. 
90. Mutschler M, Nienaber U, Munzberg M, et al. The shock index revisited - a fast guide to transfusion requirement? A retrospective analysis on 21,853 patients derived from the TraumaRegister DGU. Crit Care. 2013;17(4):R172. doi: 10.1186/cc12851. PMID: 23938104.

91. Nabaweesi R, Morlock L, Lule C, et al. Do prehospital criteria optimally assign injured children to the appropriate level of trauma team activation and emergency department disposition at a level I pediatric trauma center? Pediatr Surg Int. 2014;30(11):1097102. doi: 10.1007/s00383-014-3587-6. PMID: 25142797.

92. Newgard CD, Holmes JF, Haukoos JS, et al. Improving early identification of the highrisk elderly trauma patient by emergency medical services. Injury. 2016;47(1):19-25. doi: 10.1016/j.injury.2015.09.010. PMID: 26477345.

93. Newgard CD, Richardson D, Holmes JF, et al. Physiologic field triage criteria for identifying seriously injured older adults. Prehosp Emerg Care. 2014;18(4):461-70. doi: 10.3109/10903127.2014.912707. PMID: 24933614.

94. Newgard CD, Rudser K, Atkins DL, et al. The availability and use of out-of-hospital physiologic information to identify high-risk injured children in a multisite, populationbased cohort. Prehosp Emerg Care. 2009;13(4):420-31. doi: 10.1080/10903120903144882. PMID: 19731152.

95. Ocak G, Sturms LM, Hoogeveen JM, et al. Prehospital identification of major trauma patients. Langenbecks Arch Surg. 2009;394(2):285-92. doi: 10.1007/s00423008-0340-4. PMID: 18581133.

96. Pal JD, Victorino GP, Twomey P, et al. Admission serum lactate levels do not predict mortality in the acutely injured patient. J Trauma. 2006;60(3):583-7; discussion 7-9. doi: 10.1097/01.ta.0000205858.82575.55. PMID: 16531858.
97. Paladino L, Sinert R, Wallace D, et al. The utility of base deficit and arterial lactate in differentiating major from minor injury in trauma patients with normal vital signs. Resuscitation. 2008;77(3):363-8. doi: 10.1016/j.resuscitation.2008.01.022. PMID: 18367305.

98. Paladino L, Subramanian RA, Bonilla E, et al. Leukocytosis as prognostic indicator of major injury. West J Emerg Med. 2010;11(5):450-5. PMID: 21293764.

99. Paladino L, Subramanian RA, Nabors S, et al. Triage hyperglycemia as a prognostic indicator of major trauma. J Trauma. 2010;69(1):41-5. doi: 10.1097/TA.0b013e3181c9f0cb. PMID: 20665990.

100. Paladino L, Subramanian RA, Nabors S, et al. The utility of shock index in differentiating major from minor injury. Eur J Emerg Med. 2011;18(2):94-8. doi: 10.1097/MEJ.0b013e32833f212b. PMID: 20842040.

101. Pandit V, Rhee P, Hashmi A, et al. Shock index predicts mortality in geriatric trauma patients: an analysis of the National Trauma Data Bank. J Trauma Acute Care Surg. 2014;76(4):1111-5. doi: 10.1097/TA.0000000000000160. PMID: 24662879.

102. Parimi N, Hu PF, MacKenzie CF, et al. Automated continuous vital signs predict use of uncrossed matched blood and massive transfusion following trauma. J Trauma Acute Care Surg. 2016;80(6):897-906. doi: 10.1097/TA.0000000000001047. PMID: 27027555.

103. Parsikia A, Bones K, Kaplan M, et al. The predictive value of initial serum lactate in trauma patients. Shock. 2014;42(3):199-204. doi: 10.1097/shk.0000000000000208. PMID: 24978889.

104. Perel P, Prieto-Merino D, Shakur H, et al. Predicting early death in patients with traumatic bleeding: development and validation of prognostic model. BMJ. 2012;345:e5166. doi: 10.1136/bmj.e5166. PMID: 22896030. 
105. Perel P, Prieto-Merino D, Shakur H, et al. Development and validation of a prognostic model to predict death in patients with traumatic bleeding, and evaluation of the effect of tranexamic acid on mortality according to baseline risk: a secondary analysis of a randomised controlled trial. Health Technol Assess. 2013;17(24) doi: 10.3310/hta17240. PMID: 23782457.

106. Potoka DA, Schall LC, Ford HR. Development of a novel age-specific pediatric trauma score. J Pediatr Surg. 2001;36(1):106-12. doi: 10.1053/jpsu.2001.20023. PMID: 11150447.

107. Pottecher J, Ageron FX, Fauche C, et al. Prehospital shock index and pulse pressure/heart rate ratio to predict massive transfusion after severe trauma:

Retrospective analysis of a large regional trauma database. J Trauma Acute Care Surg. 2016;81(4):713-22. doi:

10.1097/TA.0000000000001191. PMID: 27648770 .

108. Rahmani F, Bakhtavar HE, Vahdati SS, et al. Evaluation of MGAP and GAP trauma scores to predict prognosis of multipletrauma patients. Trauma Mon.

2017;22(3):e33249. doi:

10.5812/traumamon.33249.

109. Rainer TH, Ho AM, Yeung JH, et al. Early risk stratification of patients with major trauma requiring massive blood transfusion. Resuscitation. 2011;82(6):724-9. doi: 10.1016/j.resuscitation.2011.02.016. PMID: 21458905.

110. Ramanathan R, Parrish DW, Hartwich JE, et al. Utility of admission serum lactate in pediatric trauma. J Pediatr Surg. 2015;50(4):598-603. doi: 10.1016/j.jpedsurg.2014.08.013. PMID: 25840070 .

111. Raux M, Le Manach Y, Gauss T, et al. Comparison of the prognostic significance of initial blood lactate and base deficit in trauma patients. Anesthesiology.

2017;126(3):522-33. doi: 10.1097/ALN.0000000000001490. PMID: 28059838.
112. Raux M, Sartorius D, Le Manach Y, et al. What do prehospital trauma scores predict besides mortality? J Trauma.

2011;71(3):754-9. doi: 10.1097/TA.0b013e3181fd0dae. PMID: 21336194.

113. Raux M, Thicoipe M, Wiel E, et al. Comparison of respiratory rate and peripheral oxygen saturation to assess severity in trauma patients. Intensive Care Med. 2006;32(3):405-12. doi: 10.1007/s00134-005-0063-8. PMID: 16485093.

114. Regnier MA, Raux M, Le Manach Y, et al. Prognostic significance of blood lactate and lactate clearance in trauma patients. Anesthesiology. 2012;117(6):1276-88. doi: 10.1097/ALN.0b013e318273349d. PMID: 23168430.

115. Reisner AT, Edla S, Liu J, et al. Muscle oxygen saturation improves diagnostic association between initial vital signs and major hemorrhage: a prospective observational study. Acad Emerg Med. 2016;23(3):353-7. doi: 10.1111/acem.12899. PMID: 26743804.

116. Rickards CA, Ryan KL, Ludwig DA, et al. Is heart period variability associated with the administration of lifesaving interventions in individual prehospital trauma patients with normal standard vital signs? Crit Care Med. 2010;38(8):1666-73. doi: 10.1097/CCM.0b013e3181e74cab. PMID: 20562705.

117. Ryan ML, Ogilvie MP, Pereira BM, et al. Heart rate variability is an independent predictor of morbidity and mortality in hemodynamically stable trauma patients. J Trauma. 2011;70(6):1371-80. doi: 10.1097/TA.0b013e31821858e6. PMID: 21817974.

118. Sammour T, Kahokehr A, Caldwell S, et al. Venous glucose and arterial lactate as biochemical predictors of mortality in clinically severely injured trauma patientsa comparison with ISS and TRISS. Injury. 2009;40(1):104-8. doi: 10.1016/j.injury.2008.07.032. PMID: 19117566. 
119. Sartorius D, Le Manach Y, David JS, et al. Mechanism, Glasgow Coma Scale, Age, and Arterial Pressure (MGAP): a new simple prehospital triage score to predict mortality in trauma patients. Crit Care Med. 2010;38(3):831-7. doi: 10.1097/CCM.0b013e3181cc4a67. PMID: 20068467.

120. Schenarts PJ, Phade SV, Agle SC, et al. Field hypotension in patients who arrive at the hospital normotensive: a marker of severe injury or crying wolf? N C Med J. 2008;69(4):265-9. PMID: 18828314.

121. Shackelford S, Yang S, Hu P, et al. Predicting blood transfusion using automated analysis of pulse oximetry signals and laboratory values. J Trauma Acute Care Surg. 2015;79(4 Suppl 2):S175-80. doi: 10.1097/TA.0000000000000738. PMID: 26406427.

122. Shah A, Guyette F, Suffoletto B, et al. Diagnostic accuracy of a single point-ofcare prehospital serum lactate for predicting outcomes in pediatric trauma patients. Pediatr Emerg Care. 2013;29(6):715-9. doi: 10.1097/PEC.0b013e318294ddb1. PMID: 23714761.

123. Shoemaker WC, Bayard DS, Botnen A, et al. Mathematical program for outcome prediction and therapeutic support for trauma beginning within $1 \mathrm{hr}$ of admission: a preliminary report. Crit Care Med. 2005;33(7):1499-506. doi: 10.1097/01.CCM.0000162641.92400.AA. PMID: 16003054.

124. St. John AE, Rowhani-Rahbar A, Arbabi S, et al. Role of trauma team activation in poor outcomes of elderly patients. J Surg Res. 2016;203(1):95-102. doi: 10.1016/j.jss.2016.01.036. PMID: 27338540.

125. Stanworth SJ, Morris TP, Gaarder C, et al. Reappraising the concept of massive transfusion in trauma. Crit Care. 2010;14(6):R239. doi: 10.1186/cc9394. PMID: 21192812.

126. Tamim H, Joseph L, Mulder D, et al. Field triage of trauma patients: improving on the Prehospital Index. Am J Emerg Med. 2002;20(3):170-6. PMID: 11992335.
127. Van Haren RM, Thorson CM, Valle EJ, et al. Novel prehospital monitor with injury acuity alarm to identify trauma patients who require lifesaving intervention. J Trauma Acute Care Surg. 2014;76(3):743-9. doi: 10.1097/TA.0000000000000099. PMID: 24553543.

128. Vandromme MJ, Griffin RL, Kerby JD, et al. Identifying risk for massive transfusion in the relatively normotensive patient: utility of the prehospital shock index. J Trauma. 2011;70(2):384-8; discussion 8-90. doi: 10.1097/TA.0b013e3182095a0a. PMID: 21307738.

129. Vandromme MJ, Griffin RL, McGwin G, Jr., et al. Prospective identification of patients at risk for massive transfusion: an imprecise endeavor. Am Surg. 2011;77(2):155-61. PMID: 21337871.

130. Vandromme MJ, Griffin RL, Weinberg JA, et al. Lactate is a better predictor than systolic blood pressure for determining blood requirement and mortality: could prehospital measures improve trauma triage? J Am Coll Surg. 2010;210(5):861-7; discussion 7-9. doi: 10.1016/j.jamcollsurg.2010.01.012. PMID: 20421067.

131. Vassallo J, Beavis J, Smith JE, et al. Major incident triage: derivation and comparative analysis of the Modified Physiological Triage Tool (MPTT). Injury. 2017;48(5):992-9. doi: 10.1016/j.injury.2017.01.038. PMID: 28131484.

132. Vassallo J, Horne S, Ball S, et al. Usefulness of the shock index as a secondary triage tool. J R Army Med Corps. 2015;161(1):537. doi: 10.1136/jramc-2013-000178. PMID: 24794704.

133. Vettorello M, Santambrogio SM, Calini AR, et al. Predicting haemorrhage in pre-hospital traumatic patients: evaluation of the novel heart-to-arm time index. Acta Anaesthesiol Scand. 2013;57(7):929-35. doi: 10.1111/aas.12135. PMID: 23701337. 
134. Williams DJ, Guirgis FW, Morrissey TK, et al. End-tidal carbon dioxide and occult injury in trauma patients: ETCO(2) does not rule out severe injury. Am J Emerg Med. 2016;34(11):2146-9. doi:

10.1016/j.ajem.2016.08.007. PMID: 27567419.

135. Woodford MR, Mackenzie CF, DuBose J, et al. Continuously recorded oxygen saturation and heart rate during prehospital transport outperform initial measurement in prediction of mortality after trauma. J Trauma Acute Care Surg. 2012;72(4):1006-11. doi: 10.1097/TA.0b013e318241c059. PMID: 22491618.
136. Yang S, Hu PF, Anazodo A, et al. Trends of hemoglobin oximetry: do they help predict blood transfusion during trauma patient resuscitation? Anesth Analg. 2016;122(1):115-25. doi: 10.1213/ANE.0000000000000927. PMID: 26683104.

137. Yuen MSY, Mann SKF, Chow DHK. A simplified emergency trauma score for predicting mortality in emergency setting. Nurs Crit Care. 2016;21(4):9-15. doi: 10.1111/nicc.12137. PMID: 25382107.

138. Zarzaur BL, Croce MA, Fischer PE, et al. New vitals after injury: shock index for the young and age $\mathrm{x}$ shock index for the old. $\mathrm{J}$ Surg Res. 2008;147(2):229-36. doi: 10.1016/j.jss.2008.03.025. PMID: 18498875. 


\section{Appendix C. List of Excluded Studies}

Table C1. Exclusion code key

\begin{tabular}{|c|c|}
\hline Codes & Reason \\
\hline 2 & Background or discussion paper only, no data for evidence \\
\hline 3 & $\begin{array}{l}\text { Not trauma patients (non-human population, patients without known or suspected trauma, transferred } \\
\text { patients, chemical exposure, burns) }\end{array}$ \\
\hline 4 & $\begin{array}{l}\text { No included measure (the study does not evaluate a measure of respiration, circulation, or combination, } \\
\text { measures temperature or coagulation, or evaluates a treatment) }\end{array}$ \\
\hline 5 & $\begin{array}{l}\text { No indicator of serious injury (study does not evaluate a measure in terms of predicting any of our } \\
\text { indicators of serious injury) }\end{array}$ \\
\hline 6 & $\begin{array}{l}\text { No assessment of predictive utility (study does not include a predictive utility measure such as diagnostic } \\
\text { accuracy, risk ratios, AUROC) }\end{array}$ \\
\hline 7 & $\begin{array}{l}\text { Ineligible setting (in hospital not ED, not immediately upon arrival in ED, studies conducted in the } \\
\text { developing world) }\end{array}$ \\
\hline 8 & Ineligible study design (case reports, case series, cross-sectional studies, modeling studies) \\
\hline 9 & Ineligible publication type (opinion, editorial, letter, guideline document) \\
\hline 10 & $\begin{array}{l}\text { Review not meeting our requirements (ineligible study designs, no quality rating, only one database } \\
\text { searched, non-systematic review, more updated review available, not in English) }\end{array}$ \\
\hline 11 & Studies outside of search dates (published before January 1996) \\
\hline 12 & Indirect studies that do not address one of the subgroups of interest \\
\hline 13 & Not English language but may be relevant \\
\hline 14 & $\begin{array}{l}\text { Population restricted to seriously injured (study sample limited major trauma patients automatically } \\
\text { transported to trauma center [ISS }>15, \mathrm{BP}<90 \mathrm{mmHg}, \mathrm{GCS} 8 \text { or less]) }\end{array}$ \\
\hline 15 & Insufficient data \\
\hline
\end{tabular}

\section{Excluded Studies With Exclusion Code}

Abe T, Takahashi O, Saitoh D, et al. Association between helicopter with physician versus ground emergency medical services and survival of adults with major trauma in Japan. Crit Care. 2014;18(4):R146. doi: 10.1186/cc13981. PMID: 25008159. Exclusion: 14.

Acker SN, Ross JT, Partrick DA, et al. Pediatric specific shock index accurately identifies severely injured children. J Pediatr Surg. 2015;50(2):331-4. doi: 10.1016/j.jpedsurg.2014.08.009. PMID: 25638631. Exclusion: 14.

Afifi RY. Blunt abdominal trauma: back to clinical judgement in the era of modern technology. Int $\mathrm{J}$ Surg. 2008;6(2):91-5. doi: 10.1016/j.ijsu.2006.09.005. PMID: 18442804. Exclusion: 9.
Afshar M, Smith GS, Terrin ML, et al. Blood alcohol content, injury severity, and adult respiratory distress syndrome. J Trauma Acute Care Surg.

2014;76(6):1447-55. doi:

10.1097/TA.0000000000000238. PMID: 24854314.

Exclusion: 4.

Akkose S, Ozgurer A, Bulut M, et al. Relationships between markers of inflammation, severity of injury, and clinical outcomes in hemorrhagic shock. Adv Ther. 2007;24(5):955-62. PMID: 18029320.

Exclusion: 7.

Alter SM, Infinger A, Swanson D, et al. Evaluating clinical care in the prehospital setting: is Rapid Emergency Medicine Score the missing metric of EMS? Am J Emerg Med. 2017;35(2):218-21. doi: 10.1016/j.ajem.2016.10.047. PMID: 27890300. Exclusion: 3. 
Andruszkow H, Schweigkofler U, Lefering R, et al. Impact of helicopter emergency medical service in traumatized patients: which patient benefits most? PLoS ONE. 2016;11(1):e0146897. doi:

10.1371/journal.pone.0146897. PMID: 26771462. Exclusion: 14.

Aoki N, Demsar J, Zupan B, et al. Predictive model for estimating risk of crush syndrome: a data mining approach. J Trauma. 2007;62(4):940-5. PMID: 17426552. Exclusion: 14.

Ardagh MW, Hodgson T, Shaw L, et al. Pulse rate over pressure evaluation (ROPE) is useful in the assessment of compensated haemorrhagic shock. Emerg Med (Fremantle). 2001;13(1):43-6. PMID: 11476410. Exclusion: 5.

Arnold TD, Miller M, van Wessem KP, et al. Base deficit from the first peripheral venous sample: a surrogate for arterial base deficit in the trauma bay. J Trauma. 2011;71(4):793-7; discussion 7. doi: 10.1097/TA.0b013e31822ad694. PMID: 21841507. Exclusion: 5.

Arslan A, Flax L, Fraser R, et al. Twenty-four-hour packed red blood cell requirement is the strongest independent prognostic marker of mortality in ED trauma patients. Am J Emerg Med. 2016;34(6):11214. doi: 10.1016/j.ajem.2016.03.036. PMID: 27066932. Exclusion: 7.

Asensio JA, Demetriades D, Berne TV, et al. Invasive and noninvasive monitoring for early recognition and treatment of shock in high-risk trauma and surgical patients. Surg Clin North Am. 1996;76(4):985-97. PMID: 8782484. Exclusion: 9.

Asensio JA, McDuffie L, Petrone P, et al. Reliable variables in the exsanguinated patient which indicate damage control and predict outcome. Am J Surg. 2001;182(6):743-51. PMID: 11839351. Exclusion: 14.

Asimos AW, Gibbs MA, Marx JA, et al. Value of point-of-care blood testing in emergent trauma management. J Trauma. 2000;48(6):1101-8. PMID: 10866258. Exclusion: 6.

Augustine JJ. The new vital sign parameter: COoximetry should be in the BLS toolkit. JEMS. 2010;35(10):24-8. PMID: 104946035. Language: English. Entry Date: 20110107. Revision Date: 20150820. Publication Type: Journal Article. Exclusion: 9.
Ausserer J, Moritz E, Stroehle M, et al. Physician staffed helicopter emergency medical systems can provide advanced trauma life support in mountainous and remote areas. Injury. 2017;48(1):20-5. doi: 10.1016/j.injury.2016.09.005. PMID: 27650943. Exclusion: 6.

Balta S, Demirkol S, Akgul EO. Red blood cell distribution width is predictive of mortality in trauma patients. J Trauma Acute Care Surg. 2013;75(2):3456. doi: 10.1097/TA.0b013e31829957c0. PMID: 23887573. Exclusion: 9.

Baltazar GA, Pate AJ, Panigrahi B, et al. Higher haemoglobin levels and dedicated trauma admission are associated with survival after severe traumatic brain injury. Brain Inj. 2015;29(5):607-11. doi: 10.3109/02699052.2015.1004558. PMID: 25789550. Exclusion: 14.

Barmparas G, Liou DZ, Lamb AW, et al. Prehospital hypertension is predictive of traumatic brain injury and is associated with higher mortality. J Trauma Acute Care Surg. 2014;77(4):592-8. doi: 10.1097/TA.0000000000000382. PMID: 25250599. Exclusion: 14.

Baron BJ, Scalea TM. Acute blood loss. Emerg Med Clin North Am. 1996;14(1):35-55. PMID: 8591784. Exclusion: 9.

Bar-Or D, Salottolo KM, Orlando A, et al. Association between a geriatric trauma resuscitation protocol using venous lactate measurements and early trauma surgeon involvement and mortality risk. J Am Geriatr Soc. 2013;61(8):1358-64. doi: 10.1111/jgs.12365. PMID: 23889501. Exclusion: 5.

Barsi C, Harris P, Menaik R, et al. Risk factors and mortality associated with undertriage at a level I safety-net trauma center: a retrospective study. Open Access Emerg Med. 2016;8:103-10. doi: 10.2147/OAEM.S117397. PMID: 27877069.

Exclusion: 14.

Batchinsky AI, Cooke WH, Kuusela TA, et al. Sympathetic nerve activity and heart rate variability during severe hemorrhagic shock in sheep.

Autonomic neuroscience : basic \& clinical.

2007;136(1-2):43-51. doi:

10.1016/j.autneu.2007.03.004. PMID: 17482525.

Exclusion: 3.

Batchinsky AI, Skinner JE, Necsoiu C, et al. New measures of heart-rate complexity: effect of chest trauma and hemorrhage. J Trauma. 2010;68(5):117885. doi: 10.1097/TA.0b013e3181bb98a6. PMID: 20173662. Exclusion: 3. 
Batchinsky AI, Wolf SE, Molter N, et al. Assessment of cardiovascular regulation after burns by nonlinear analysis of the electrocardiogram. J Burn Care Res. 2008;29(1):56-63. doi:

10.1097/BCR.0b013e31815f5a8b. PMID: 18182898. Exclusion: 3.

Baxter J, Cranfield KR, Clark G, et al. Do lactate levels in the emergency department predict outcome in adult trauma patients? A systematic review. J Trauma Acute Care Surg. 2016;81(3):555-66. doi: 10.1097/TA.0000000000001156. PMID: 27280943. Exclusion: 2.

Beilman GJ, Blondet JJ, Nelson TR, et al. Early hypothermia in severely injured trauma patients is a significant risk factor for multiple organ dysfunction syndrome but not mortality. [Erratum appears in Ann Surg. 2009 Oct;250(4):661]. Ann Surg. 2009;249(5):845-50. doi:

10.1097/SLA.0b013e3181a41f6f. PMID: 19387315. Exclusion: 14.

Bilello JF, Davis JW, Lemaster D, et al. Prehospital hypotension in blunt trauma: identifying the 'crump factor'. J Trauma. 2011;70(5):1038-42. doi: 10.1097/TA.0b013e31819638d0. PMID: 19996792. Exclusion: 14.

Birkhahn RH, Gaeta TJ, Terry D, et al. Shock index in diagnosing early acute hypovolemia. Am J Emerg Med. 2005;23(3):323-6. PMID: 15915406.

Exclusion: 3.

Bishop MH, Shoemaker WC, Shuleshko J, et al. Noninvasive cardiac index monitoring in gunshot wound victims. Acad Emerg Med. 1996;3(7):682-8. PMID: 8816184. Exclusion: 14.

Biswas AK, Scott WA, Sommerauer JF, et al. Heart rate variability after acute traumatic brain injury in children. Crit Care Med. 2000;28(12):3907-12. PMID: 11153634. Exclusion: 8.

Bledsoe BE, McEvoy M. Where there's CO, there's not always fire: how pulse CO-oximetry serves as an important assessment \& triage tool. JEMS.

2009;34(3):5-8. Exclusion: 9.

Blow O, Magliore L, Claridge JA, et al. The golden hour and the silver day: detection and correction of occult hypoperfusion within 24 hours improves outcome from major trauma. J Trauma. 1999;47(5):964-9. PMID: 10568731. Exclusion: 14.
Bohnen JD, Chang DC, Ramly EP, et al. Low baseline (pre-injury) blood pressure predicts inpatient mortality in elderly trauma patients: a bi-institutional study. J Trauma Acute Care Surg. 2016;81(6):11429. doi: 10.1097/TA.0000000000001144. PMID: 27244581. Exclusion: 15.

Boland LL, Hokanson JS, Fernstrom KM, et al. Prehospital lactate measurement by emergency medical services in patients meeting sepsis criteria. West J Emerg Med. 2016;17(5):648-55. doi: 10.5811/westjem.2016.6.30233. PMID: 27625735. Exclusion: 3.

Bradburn E, Rogers FB, Krasne M, et al. High-risk geriatric protocol: improving mortality in the elderly. [Erratum appears in J Trauma Acute Care Surg. 2012 Oct;73(4):1035 Note: Belan, Matthew J [corrected to Beelen, Matthew J]]. J Trauma Acute Care Surg. 2012;73(2):435-40. doi: 10.1097/TA.0b013e31825c7cf4. PMID: 22846952. Exclusion: 7.

Brorsson C, Rodling-Wahlstrom M, Olivecrona M, et al. Severe traumatic brain injury: consequences of early adverse events. Acta Anaesthesiol Scand. 2011;55(8):944-51. doi: 10.1111/j.13996576.2011.02451.x. PMID: 21574969. Exclusion: 14.

Brown JB, Cohen MJ, Minei JP, et al. Goal-directed resuscitation in the prehospital setting: a propensityadjusted analysis. J Trauma Acute Care Surg. 2013;74(5):1207-12; discussion 12-4. doi: 10.1097/TA.0b013e31828c44fd. PMID: 23609269. Exclusion: 14.

Brown JB, Cohen MJ, Minei JP, et al. Pretrauma center red blood cell transfusion is associated with reduced mortality and coagulopathy in severely injured patients with blunt trauma. Ann Surg. 2015;261(5):997-1005. doi: 10.1097/SLA.0000000000000674. PMID: 24670858. Exclusion: 14.

Brown JB, Gestring ML, Guyette FX, et al. External validation of the Air Medical Prehospital Triage Score for identifying trauma patients likely to benefit from scene helicopter transport. J Trauma Acute Care Surg. 2016;82(2):270-9. doi: 10.1097/TA.0000000000001326. PMID: 27906867. Exclusion: 6.

Brown JB, Gestring ML, Guyette FX, et al. Development and validation of the air medical prehospital triage score for helicopter transport of trauma patients. Ann Surg. 2016;264(2):378-85. doi: 10.1097/SLA.0000000000001496. PMID: 26501703. Exclusion: 6. 
Brown LH, Prasad NH, Whitley TW, et al. Does basic life support in a rural EMS system influence the outcome of patients with respiratory distress? Prehospital Disaster Med. 1996;11(4):285-90; discussion 90-1. PMID: 10163610. Exclusion: 3.

Bruns B, Gentilello L, Elliott A, et al. Prehospital hypotension redefined. J Trauma. 2008;65(6):121721. doi: 10.1097/TA.0b013e318184ee63. PMID: 19077604. Exclusion: 15.

Callcut RA, Cotton BA, Muskat P, et al. Defining when to initiate massive transfusion: a validation study of individual massive transfusion triggers in PROMMTT patients. J Trauma Acute Care Surg. 2013;74(1):59-65, 7-8; discussion 6-7. doi: 10.1097/TA.0b013e3182788b34. PMID: 23271078. Exclusion: 3.

Callcut RA, Cripps MW, Nelson MF, et al. The Massive Transfusion Score as a decision aid for resuscitation: learning when to turn the massive transfusion protocol on and off. J Trauma Acute Care Surg. 2016;80(3):450-6. doi:

10.1097/TA.0000000000000914. PMID: 26517786. Exclusion: 3.

4Callcut RA, Johannigman JA, Kadon KS, et al. All massive transfusion criteria are not created equal: defining the predictive value of individual transfusion triggers to better determine who benefits from blood. J Trauma. 2011;70(4):794-801. doi: 10.1097/TA.0b013e3182127e40. PMID: 21610387. Exclusion: 3.

Caputo N, Fraser R, Paliga A, et al. Triage vital signs do not correlate with serum lactate or base deficit, and are less predictive of operative intervention in penetrating trauma patients: a prospective cohort study. Emerg Med J. 2013;30(7):546-50. doi: 10.1136/emermed-2012-201343. PMID: 22802455. Exclusion: 6.

Cerovic O, Golubovic V, Spec-Marn A, et al. Relationship between injury severity and lactate levels in severely injured patients. Intensive Care Med. 2003 Aug;29(8):1300-5. doi: 10.1007/s00134003-1753-8. PMID: 12904861. Exclusion: 7.

Chalari E, Intas G, Stergiannis P, et al. The importance of vital signs in the triage of injured patients. Crit Care Nurs Q. 2012;35(3):292-8. PMID: 22669003. Exclusion: 7.
Chalari E, Intas G, Stergiannis P, et al. The importance of vital signs in the triage of injured patients. [Erratum appears in Crit Care Nurs Q. 2013 Jan-Mar;36(1):147 Note: Paraskevas, Veziridis [corrected to Vezyridis, Paraskevas]]. Crit Care Nurs Q. 2012;35(3):292-8. doi:

10.1097/CNQ.0b013e318255d6b3. PMID: 22669003. Exclusion: 9.

Chang MC, Mondy JS, Meredith JW, et al. Redefining cardiovascular performance during resuscitation: ventricular stroke work, power, and the pressure-volume diagram. J Trauma. 1998;45(3):4708. PMID: 9751535. Exclusion: 4.

Cherry RA, Bradburn E, Carney DE, et al. Do early ionized calcium levels really matter in trauma patients? J Trauma. 2006;61(4):774-9. PMID: 17033540. Exclusion: 14.

Choi YC, Hwang SY. The value of initial ionized calcium as a predictor of mortality and triage tool in adult trauma patients. J Korean Med Sci.

2008;23(4):700-5. doi: 10.3346/jkms.2008.23.4.700. PMID: 18756060. Exclusion: 4.

Chou D, Harada MY, Barmparas G, et al. Field intubation in civilian patients with hemorrhagic shock is associated with higher mortality. J Trauma Acute Care Surg. 2016;80(2):278-82. doi: 10.1097/TA.0000000000000901. PMID: 26491803. Exclusion: 4.

Chuang JF, Rau CS, Wu SC, et al. Use of the reverse shock index for identifying high-risk patients in a five-level triage system. Scand J Trauma Resusc Emerg Med. 2016;24:12. doi: 10.1186/s13049-0160208-5. PMID: 26861172. Exclusion: 7.

Chunguang Z, Rigao C, Fuguo H, et al. Characteristics of crush syndrome caused by prolonged limb compression longer than $24 \mathrm{~h}$ in the Sichuan earthquake. Emerg Med J. 2010;27(8):62730. doi: 10.1136/emj.2008.070961. PMID: 20558493. Exclusion: 7.

Ciesla DJ, Moore EE, Moore JB, et al. Intubation alone does not mandate trauma surgeon presence on patient arrival to the emergency department. J Trauma. 2004;56(5):937-41; discussion 41-2. PMID: 15179230. Exclusion: 14.

Ciesla DJ, Pracht EE, Tepas JJ, 3rd, et al. Measuring trauma system performance: right patient, right place-mission accomplished? J Trauma Acute Care Surg. 2015;79(2):263-8. doi: 10.1097/ta.0000000000000660. PMID: 26218695. Exclusion: 4. 
Cipolle M, Rhodes M, Tinkoff G. Deadly dozen: dealing with the 12 types of thoracic injures. JEMS. 2012;37(9):60-5. PMID: 23342703. Exclusion: 9.

Claessens YE, Taupin P, Kierzek G, et al. How emergency departments might alert for prehospital heat-related excess mortality? Crit Care. 2006;10(6):R156. PMID: 17096836. Exclusion: 3.

Clark J. A new tool in the box. JEMS. 2013:15-7. Exclusion: 9.

Clarke JR, Trooskin SZ, Doshi PJ, et al. Time to laparotomy for intra-abdominal bleeding from trauma does affect survival for delays up to 90 minutes. J Trauma. 2002;52(3):420-5. PMID: 11901314. Exclusion: 4.

Clawson J, Olola C, Heward A, et al. Profile of emergency medical dispatch calls for breathing problems within the medical priority dispatch system protocol. Prehospital Disaster Med. 2008;23(5):4129. PMID: 19189610. Exclusion: 3.

Cleland HJ, Proud D, Spinks A, et al. Multidisciplinary team response to a mass burn casualty event: outcomes and implications. Med J Aust. 2011;194(11):589-93. PMID: 21644872. Exclusion: 2.

Coats TJ, Smith JE, Lockey D, et al. Early increases in blood lactate following injury. J R Army Med Corps. 2002;148(2):140-3. PMID: 12174556.

Exclusion: 15.

Cobas MA, De la Pena MA, Manning R, et al. Prehospital intubations and mortality: a level 1 trauma center perspective. Anesth Analg. 2009;109(2):489-93. doi: 10.1213/ane.0b013e3181aa3063. PMID: 19608824. Exclusion: 4.

Codner P, Obaid A, Porral D, et al. Is field hypotension a reliable indicator of significant injury in trauma patients who are normotensive on arrival to the emergency department? Am Surg.

2005;71(9):768-71. PMID: 16468515. Exclusion: 14.

Cohen MJ, Brohi K, Calfee CS, et al. Early release of high mobility group box nuclear protein 1 after severe trauma in humans: role of injury severity and tissue hypoperfusion. Crit Care. 2009;13(6):R174. doi: 10.1186/cc8152. PMID: 19887013. Exclusion: 14.

Cohen MJ, Brohi K, Ganter MT, et al. Early coagulopathy after traumatic brain injury: the role of hypoperfusion and the protein C pathway. J Trauma. 2007;63(6):1254-62. PMID: 18212647. Exclusion: 4.
Cohen MJ, Kutcher M, Redick B, et al. Clinical and mechanistic drivers of acute traumatic coagulopathy. J Trauma Acute Care Surg. 2013;75(1 Suppl 1):S407. doi: 10.1097/TA.0b013e31828fa43d. PMID: 23778510. Exclusion: 4.

Cole EM, West A, Davenport R, et al. Can residents be effective trauma team leaders in a major trauma centre? Injury. 2013;44(1):18-22. doi: 10.1016/j.injury.2011.09.020. PMID: 21999937. Exclusion: 4.

Collopy KT, Friese G. Abdominal trauma. EMS Mag. 2010;39(3):62-9. PMID: 20336973. Exclusion: 8.

73. Collopy KT, Kivlehan SM, Snyder SR. Managing Unstable Musculoskeletal Injuries. EMS World. 2012;41(2):36-43. PMID: 22413699.

Exclusion: 9.

Collopy KT, Kivlehan SM, Snyder SR. Busting Top Trauma Myths. EMS World. 2015;44(3):38-45. PMID: 25821875. Exclusion: 9.

Combes X, Jabre P, Jbeili C, et al. Prehospital standardization of medical airway management: incidence and risk factors of difficult airway. Acad Emerg Med. 2006;13(8):828-34. PMID: 16807397. Exclusion: 6.

Combes X, Jabre P, Margenet A, et al. Unanticipated difficult airway management in the prehospital emergency setting: prospective validation of an algorithm. Anesthesiology. 2011;114(1):105-10. doi: 10.1097/ALN.0b013e318201c42e. PMID: 21169803. Exclusion: 6.

Conroy MJ, Weingart GS, Carlson JN. Impact of checklists on peri-intubation care in ED trauma patients. Am J Emerg Med. 2014;32(6):541-4. doi: 10.1016/j.ajem.2014.02.006. PMID: 24637135. Exclusion: 6.

Convertino VA, Parquette B, Zeihr J, et al. Use of respiratory impedance in prehospital care of hypotensive patients associated with hemorrhage and trauma: a case series. J Trauma Acute Care Surg. 2012;73(2 Suppl 1):S54-9. PMID: 22847095.

Exclusion: 9.

Convertino VA, Ryan KL, Rickards CA, et al. Physiological and medical monitoring for en route care of combat casualties. J Trauma. 2008;64(4 Suppl):S342-53. doi: 10.1097/TA.0b013e31816c82f4. PMID: 18385586. Exclusion: 6. 
Cooke WH, Rickards CA, Ryan KL, et al. Autonomic compensation to simulated hemorrhage monitored with heart period variability. Crit Care Med. 2008;36(6):1892-9. doi: 10.1097/CCM.0b013e3181760d0c. PMID: 18496361. Exclusion: 3.

Cooke WH, Salinas J, McManus JG, et al. Heart period variability in trauma patients may predict mortality and allow remote triage. Aviat Space Environ Med. 2006;77(11):1107-12. PMID: 17086761. Exclusion: 15.

Cooper CJ, Kraatz JJ, Kubiak DS, et al. Utility of Prehospital Quantitative End Tidal CO2? Prehospital Disaster Med. 2013;28(2):87-93. doi: 10.1017/S1049023X12001768. PMID: 23343590. Exclusion: 4.

Cooper DJ, Myles PS, McDermott FT, et al. Prehospital hypertonic saline resuscitation of patients with hypotension and severe traumatic brain injury: a randomized controlled trial. Jama. 2004;291(11):1350-7. PMID: 15026402. Exclusion: 4.

Coppler PJ, Padmanabhan R, Martin-Gill C, et al. Accuracy of Prehospital Intravenous Fluid Volume Measurement by Emergency Medical Services. Prehosp Emerg Care. 2016;20(1):125-31. doi: 10.3109/10903127.2015.1051681. PMID: 26270558. Exclusion: 3.

Corcostegui SP, Beaume S, Prunet B, et al. Impact de la mise en place d'une filière régionale de traumatologie sur l'activité d'un centre référent [Impact of a regional trauma network creation on trauma centre activity]. Annales Francaises de Medecine d'Urgence. 2015;5(6):290-300. doi: 10.1007/s13341-015-0580-1. Exclusion: 4.

Corfield AR, Thomas L, Inglis A, et al. A rural emergency medical retrieval service: the first year. Emerg Med J. 2006;23(9):679-83. PMID: 16921078. Exclusion: 4.

Coslovsky M, Takala J, Exadaktylos AK, et al. A clinical prediction model to identify patients at high risk of death in the emergency department. Intensive Care Med. 2015;41(6):1029-36. doi: 10.1007/s00134015-3737-x. PMID: 25792208. Exclusion: 3.

Costantini TW, Coimbra R, Holcomb JB, et al. Current management of hemorrhage from severe pelvic fractures: results of an American Association for the Surgery of Trauma multi-institutional trial. J Trauma Acute Care Surg. 2016;80(5):717-23; discussion 23-5. doi: 10.1097/TA.0000000000001034. PMID: 26958799. Exclusion: 2.
Cotton BA. Alternative fluids for prehospital resuscitation: "pharmacological" resuscitation fluids. J Trauma. 2011;70(5 Suppl):S30-1. doi: 10.1097/TA.0b013e31821a55a. PMID: 21841566. Exclusion: 9.

Cotton BA, Beckert BW, Smith MK, et al. The utility of clinical and laboratory data for predicting intraabdominal injury among children. J Trauma. 2004;56(5):1068-74; discussion 74-5. PMID: 15179248. Exclusion: 4.

Cotton BA, Dossett LA, Au BK, et al. Room for (performance) improvement: provider-related factors associated with poor outcomes in massive transfusion. J Trauma. 2009;67(5):1004-12. doi: 10.1097/TA.0b013e3181bcb2a8. PMID: 19901661. Exclusion: 4.

Cotton BA, Harvin JA, Kostousouv V, et al. Hyperfibrinolysis at admission is an uncommon but highly lethal event associated with shock and prehospital fluid administration. J Trauma Acute Care Surg. 2012;73(2):365-70; discussion 70. doi: 10.1097/TA.0b013e31825c1234. PMID: 22846941. Exclusion: 4.

Cox S, Smith K, Currell A, et al. Differentiation of confirmed major trauma patients and potential major trauma patients using pre-hospital trauma triage criteria. Injury. 2011;42(9):889-95. doi: 10.1016/j.injury.2010.03.035. PMID: 20430387. Exclusion: 6.

Crawford I, Ghosh A. Towards evidence based emergency medicine: best BETs from the Manchester Royal Infirmary. The prehospital use of pneumatic anti-shock garments. Emerg Med J. 2001;18(4):2745. PMID: 11435366. Exclusion: 4.

Croce MA, Swanson JM, Magnotti LJ, et al. The futility of the clinical pulmonary infection score in trauma patients. J Trauma. 2006;60(3):523-7; discussion 7-8. PMID: 16531849. Exclusion: 4.

Cross KP, Petry MJ, Cicero MX. A better START for low-acuity victims: data-driven refinement of mass casualty triage. Prehosp Emerg Care.

2015;19(2):272-8. doi: 10.3109/10903127.2014.942481. PMID: 25153986. Exclusion: 8.

Crump C, Silvers CT, Wilson B, et al. Using principal component analysis to aid bayesian network development for prediction of critical care patient outcomes. J Trauma. 2011;71(6):1841-9. doi: 10.1097/TA.0b013e3182250184. PMID: 22182894. Exclusion: 7. 
Cruz J, Minoja G, Okuchi K. Major clinical and physiological benefits of early high doses of mannitol for intraparenchymal temporal lobe hemorrhages with abnormal pupillary widening: a randomized trial. Neurosurgery. 2002;51(3):628-37; discussion 37-8. PMID: 12188940. Exclusion: 4.

Cudnik MT, Newgard CD, Daya M, et al. The impact of rapid sequence intubation on trauma patient mortality in attempted prehospital intubation. $\mathrm{J}$ Emerg Med. 2010;38(2):175-81. doi: 10.1016/j.jemermed.2008.01.022. PMID: 18790586. Exclusion: 4.

Cudnik MT, Newgard CD, Sayre MR, et al. Level I versus Level II trauma centers: an outcomes-based assessment. J Trauma. 2009;66(5):1321-6. doi: 10.1097/TA.0b013e3181929e2b. PMID: 19430234. Exclusion: 2.

Cudnik MT, Newgard CD, Wang H, et al. Endotracheal intubation increases out-of-hospital time in trauma patients. Prehosp Emerg Care. 2007;11(2):224-9. PMID: 17454813. Exclusion: 4.

Culley JM, Svendsen E, Craig J, et al. A validation study of 5 triage systems using data from the 2005 Graniteville, South Carolina, chlorine spill. J Emerg Nurs. 2014;40(5):453-60. doi: 10.1016/j.jen.2014.04.020. PMID: 25063047. Exclusion: 4.

Cullison K, Milne WK, Crocco AG. Hot off the press: comparison of clinical suspicion versus a clinical prediction rule when evaluating children following blunt torso trauma. Acad Emerg Med. 2016;23(1):110-2. doi: 10.1111/acem.12851. PMID: 26720745. Exclusion: 4.

Cupera J, Mannova J, Rihova H, et al. Quality of prehospital management of patients with burn injuries--a retrospective study. Acta Chir Plast. 2002;44(2):59-62. PMID: 12197163. Exclusion: 3.

Cureton EL, Yeung LY, Kwan RO, et al. The heart of the matter: utility of ultrasound of cardiac activity during traumatic arrest. J Trauma Acute Care Surg. 2012;73(1):102-10. doi:

10.1097/TA.0b013e3182569ebc. PMID: 22743379. Exclusion: 5.

Dami F, Golay C, Pasquier M, et al. Prehospital triage accuracy in a criteria based dispatch centre. BMC Emerg Med. 2015;15(32) doi: 10.1186/s12873015-0058-x. PMID: 26507648. Exclusion: 4.

Danks RR. Triangle of death: how hypothermia, acidosis \& coagulopathy can adversely impact trauma patients. JEMS. 2002;27(5):61-70. PMID: 12004557. Exclusion: 9.
Davey AL, Macnab AJ, Green G. Changes in pCO2 during air medical transport of children with closed head injuries. Air Med J. 2001;20(4):27-30. PMID: 11438810. Exclusion: 6.

David JS, Voiglio EJ, Cesareo E, et al. Prehospital parameters can help to predict coagulopathy and massive transfusion in trauma patients. Vox Sang. 2017 doi: 10.1111/vox.12545. PMID: 28612932. Exclusion: 14.

Davis DP. Should invasive airway management be done in the field? Cmaj. 2008;178(9):1171-3. doi: 10.1503/cmaj.080234. PMID: 18427092. Exclusion: 9.

Davis DP, Aguilar SA, Smith K, et al. Preliminary report of a mathematical model of ventilation and intrathoracic pressure applied to prehospital patients with severe traumatic brain injury. Prehosp Emerg Care. 2015;19(2):328-35. doi: 10.3109/10903127.2014.959228. PMID: 25291381. Exclusion: 4.

Davis DP, Douglas DJ, Koenig W, et al. Hyperventilation following aero-medical rapid sequence intubation may be a deliberate response to hypoxemia. Resuscitation. 2007;73(3):354-61. PMID: 17291673. Exclusion: 6.

Davis DP, Dunford JV, Ochs M, et al. The use of quantitative end-tidal capnometry to avoid inadvertent severe hyperventilation in patients with head injury after paramedic rapid sequence intubation. J Trauma. 2004;56(4):808-14. PMID: 15187747. Exclusion: 5.

Davis DP, Dunford JV, Poste JC, et al. The impact of hypoxia and hyperventilation on outcome after paramedic rapid sequence intubation of severely head-injured patients. J Trauma. 2004;57(1):1-8; discussion -10. PMID: 15284540. Exclusion: 14.

Davis DP, Heister R, Poste JC, et al. Ventilation patterns in patients with severe traumatic brain injury following paramedic rapid sequence intubation. Neurocrit Care. 2005;2(2):165-71. PMID: 16159059. Exclusion: 5.

Davis DP, Kimbro TA, Vilke GM. The use of midazolam for prehospital rapid-sequence intubation may be associated with a dose-related increase in hypotension. Prehosp Emerg Care. 2001;5(2):163-8. PMID: 11339727. Exclusion: 4. 
Davis DP, Koprowicz KM, Newgard CD, et al. The relationship between out-of-hospital airway management and outcome among trauma patients with Glasgow Coma Scale Scores of 8 or less. Prehosp Emerg Care. 2011;15(2):184-92. doi: 10.3109/10903127.2010.545473. PMID: 21309705. Exclusion: 14.

Davis DP, Lemieux J, Serra J, et al. Preoxygenation reduces desaturation events and improves intubation success. Air Med J. 2015;34(2):82-5. doi: 10.1016/j.amj.2014.12.007. PMID: 25733113. Exclusion: 4.

Davis DP, Peay J, Sise MJ, et al. Prehospital airway and ventilation management: a trauma score and injury severity score-based analysis. J Trauma. 2010;69(2):294-301. doi: 10.1097/TA.0b013e3181dc6c7f. PMID: 20699737. Exclusion: 14.

Davis DP, Pettit K, Rom CD, et al. The safety and efficacy of prehospital needle and tube thoracostomy by aeromedical personnel. Prehosp Emerg Care. 2005;9(2):191-7. PMID: 16036846. Exclusion: 5.

Davis DP, Wiesner C, Chan TC, et al. The efficacy of nebulized albuterol/ipratropium bromide versus albuterol alone in the prehospital treatment of suspected reactive airways disease. Prehosp Emerg Care. 2005;9(4):386-90. PMID: 16263670.

Exclusion: 4.

Davis JW, Davis IC, Bennink LD, et al. Are automated blood pressure measurements accurate in trauma patients? J Trauma. 2003;55(5):860-3. PMID: 14608157. Exclusion: 6.

Davis JW, Dirks RC, Sue LP, et al. Attempting to validate the over/under triage matrix at a level I trauma center. J Trauma Acute Care Surg. 2017 doi: 10.1097/TA.0000000000001623. PMID: 28715359. Exclusion: 4.

Dawes RJ. Prehospital intubation: delving deeper into the evidence. Emerg Med J. 2006;23(9):740. doi: 10.1136/emj.2006.034264. PMID: 16921103. Exclusion: 9.

Day DL, Anzelon KM, Conde FA. Association of prehospital shock index and trauma bay uncrossmatched red blood cell transfusion with multiple transfusion. J Trauma Nurs. 2016;23(2):8995. doi: 10.1097/JTN.0000000000000192. PMID: 26953537. Exclusion: 14. de Crescenzo C, Gorouhi F, Salcedo ES, et al. Prehospital hypertonic fluid resuscitation for trauma patients: a systematic review and meta-analysis. J Trauma Acute Care Surg. 2017;82(5):956-62. doi: 10.1097/TA.0000000000001409. PMID: 28257392. Exclusion: 4.

de Moya MA, Manolakaki D, Chang Y, et al. Blunt pulmonary contusion: admission computed tomography scan predicts mechanical ventilation. J Trauma. 2011;71(6):1543-7. doi: 10.1097/TA.0b013e31822c4a8b. PMID: 21857256. Exclusion: 4.

de Vries HM, Dekker SE, Boer C. Lactate clearance as a predictor of mortality. J Trauma Acute Care Surg. 2014;77(1):183. doi: 10.1097/TA.0000000000000252. PMID: 24977779. Exclusion: 9.

Deakin CD, King P, Thompson F. Prehospital advanced airway management by ambulance technicians and paramedics: is clinical practice sufficient to maintain skills? Emerg Med J. 2009;26(12):888-91. doi: 10.1136/emj.2008.064642. PMID: 19934141. Exclusion: 4.

Deakin CD, Sado DM, Coats TJ, et al. Prehospital end-tidal carbon dioxide concentration and outcome in major trauma. J Trauma. 2004;57(1):65-8. PMID: 15284550. Exclusion: 14.

Dean D, Wetzel B, White N, et al. From 9-1-1 call to death: evaluating traumatic deaths in seven regions for early recognition of high-risk patients. J Trauma Acute Care Surg. 2014;76(3):846-53. doi: 10.1097/TA.0b013e3182aafd9a. PMID: 24553559. Exclusion: 2.

DeBoer S, Seaver M, McNeil M, et al. Prehospital airway management. It's time to reconsider how we maintain pediatric airways. EMS Mag. 2009;38(1):42-4, 6, 8 passim. PMID: 19198536. Exclusion: 4.

Deitch S, Davis DP, Schatteman J, et al. The use of etomidate for prehospital rapid-sequence intubation. Prehosp Emerg Care. 2003;7(3):380-3. PMID: 12879390. Exclusion: 4.

Delano MJ, Rizoli SB, Rhind SG, et al. Prehospital resuscitation of traumatic hemorrhagic shock with hypertonic solutions worsens hypocoagulation and hyperfibrinolysis. Shock. 2015;44(1):25-31. doi: 10.1097/SHK.0000000000000368. PMID: 25784523. Exclusion: 4. 
Demirkiran O, Dikmen Y, Utku T, et al. Crush syndrome patients after the Marmara earthquake. Emerg Med J. 2003;20(3):247-50. PMID: 12748140. Exclusion: 4.

Dente CJ, Shaz BH, Nicholas JM, et al. Early predictors of massive transfusion in patients sustaining torso gunshot wounds in a civilian level I trauma center. J Trauma. 2010;68(2):298-304. doi: 10.1097/TA.0b013e3181cf7f2a. PMID: 20154541. Exclusion: 14.

Deras P, Villiet M, Manzanera J, et al. Early coagulopathy at hospital admission predicts initial or delayed fibrinogen deficit in severe trauma patients. $\mathrm{J}$ Trauma Acute Care Surg. 2014;77(3):433-40. doi: 10.1097/TA.0000000000000314. PMID: 25159247. Exclusion: 4.

Deree J, Shenvi E, Fortlage D, et al. Patient factors and operating room resuscitation predict mortality in traumatic abdominal aortic injury: a 20-year analysis. J Vasc Surg. 2007;45(3):493-7. PMID: 17254736. Exclusion: 7.

Dewar DC, Mackay P, Balogh Z. Epidemiology of post-injury multiple organ failure in an Australian trauma system. ANZ J Surg. 2009;79(6):431-6. doi: 10.1111/j.1445-2197.2009.04968.x. PMID: 19566865. Exclusion: 4.

Dewar DC, Tarrant SM, King KL, et al. Changes in the epidemiology and prediction of multiple-organ failure after injury. J Trauma Acute Care Surg. 2013;74(3):774-9. doi:

10.1097/TA.0b013e31827a6e69. PMID: 23425734. Exclusion: 4.

Dezman ZD, Comer AC, Smith GS, et al. Failure to clear elevated lactate predicts 24-hour mortality in trauma patients. J Trauma Acute Care Surg. 2015;79(4):580-5. doi: 10.1097/ta.0000000000000810. PMID: 26402531. Exclusion: 7.

Dezman ZD, Gao C, Yang S, et al. Anomaly Detection Outperforms Logistic Regression in Predicting Outcomes in Trauma Patients. Prehosp Emerg Care. 2017;21(2):174-9. doi: https://dx.doi.org/10.1080/10903127.2016.1241327. PMID: 27918852. Exclusion: 5.

Dezman ZDW, Comer AC, Narayan M, et al. Alcohol consumption decreases lactate clearance in acutely injured patients. Injury. 2016;47(9):1908-12. PMID: 27025567. Exclusion: 7.
Di Bartolomeo S, Sanson G, Nardi G, et al. Inadequate ventilation of patients with severe brain injury: a possible drawback to prehospital advanced trauma care? Eur J Emerg Med. 2003;10(4):268-71. PMID: 14676502. Exclusion: 14.

Di Bartolomeo S, Sanson G, Nardi G, et al. Effects of 2 patterns of prehospital care on the outcome of patients with severe head injury. Arch Surg. 2001;136(11):1293-300. PMID: 11695976. Exclusion: 4.

Di Saverio S, Gambale G, Coccolini F, et al. Changes in the outcomes of severe trauma patients from 15year experience in a Western European trauma ICU of Emilia Romagna region (1996-2010). A population cross-sectional survey study. Langenbecks Arch Surg. 2014;399(1):109-26. doi: 10.1007/s00423-013-1143-9. PMID: 24292078. Exclusion: 4.

Dinh MM, Oliver M, Bein K, et al. Level of agreement between prehospital and emergency department vital signs in trauma patients. Emerg Med Australas. 2013;25(5):457-63. doi: 10.1111/17426723.12126. PMID: 24099376. Exclusion: 2.

Dirks J, Jorgensen H, Jensen CH, et al. Blood product ratio in acute traumatic coagulopathy--effect on mortality in a Scandinavian level 1 trauma centre. Scand J Trauma Resusc Emerg Med. 2010;18:65. doi: 10.1186/1757-7241-18-65. PMID: 21138569. Exclusion: 4.

DiRusso SM, Sullivan T, Holly C, et al. An artificial neural network as a model for prediction of survival in trauma patients: validation for a regional trauma area. J Trauma. 2000;49(2):212-20; discussion 20-3. PMID: 10963531. Exclusion: 4.

Domico M, Checchia PA. Biomonitors of cardiac injury and performance: B-type natriuretic peptide and troponin as monitors of hemodynamics and oxygen transport balance. Pediatr Crit Care Med. 2011;12(4 Suppl):S33-42. doi: 10.1097/PCC.0b013e318221178d. PMID: 22129548. Exclusion: 7.

Dongel I, Coskun A, Ozbay S, et al. Management of thoracic trauma in emergency service: analysis of 1139 cases. Pak J Med Sci. 2013;29(1):58-63. doi: 10.12669/pjms.291.2704. PMID: 24353508.

Exclusion: 8.

Doran CM, Woolley T, Midwinter MJ. Feasibility of using rotational thromboelastometry to assess coagulation status of combat casualties in a deployed setting. J Trauma. 2010;69 Suppl 1:S40-8. doi: 10.1097/TA.0b013e3181e4257b. PMID: 20622618. Exclusion: 7. 
Drayna PC, Browne LR, Guse CE, et al. Prehospital pediatric care: opportunities for training, treatment, and research. Prehosp Emerg Care. 2015;19(3):4417. doi: 10.3109/10903127.2014.995850. PMID: 25658967. Exclusion: 8.

Dretzke J, Sandercock J, Bayliss S, et al. Clinical effectiveness and cost-effectiveness of prehospital intravenous fluids in trauma patients. Health Technol Assess. 2004;8(23):iii-x, 1-118. PMID: 15193210. Exclusion: 4.

Dries DJ, Morton CT. Coagulation: part 2. Air Med J. 2014;33(6):246-9. doi: 10.1016/j.amj.2014.08.008. PMID: 25441515. Exclusion: 4.

Duane TM, Ivatury RR, Dechert T, et al. Blood glucose levels at 24 hours after trauma fails to predict outcomes. J Trauma. 2008;64(5):1184-7. doi: 10.1097/TA.0b013e31816c5c95. PMID: 18469639. Exclusion: 7.

Dubick MA, Shek P, Wade CE. ROC trials update on prehospital hypertonic saline resuscitation in the aftermath of the US-Canadian trials. Clinics. 2013;68(6):883-6. doi: 10.6061/clinics/2013(06)25. PMID: 23778489. Exclusion: 4.

DuBose JJ, Browder T, Inaba K, et al. Effect of trauma center designation on outcome in patients with severe traumatic brain injury. Arch Surg. 2008;143(12):1213-7; discussion 7. doi: 10.1001/archsurg.143.12.1213. PMID: 19075174. Exclusion: 6.

DuBose JJ, Savage SA, Fabian TC, et al. The American Association for the Surgery of Trauma PROspective Observational Vascular Injury Treatment (PROOVIT) registry: multicenter data on modern vascular injury diagnosis, management, and outcomes. [Erratum appears in J Trauma Acute Care Surg. 2015 Mar;78(3):657]. J Trauma Acute Care Surg. 2015;78(2):215-22; discussion 22-3. doi: 10.1097/TA.0000000000000520. PMID: 25757104. Exclusion: 8.

DuBose JJ, Scalea TM, Brenner M, et al. The AAST prospective Aortic Occlusion for Resuscitation in Trauma and Acute Care Surgery (AORTA) registry: data on contemporary utilization and outcomes of aortic occlusion and resuscitative balloon occlusion of the aorta (REBOA). J Trauma Acute Care Surg. 2016;81(3):409-19. doi:

10.1097/TA.0000000000001079. PMID: 27050883. Exclusion: 6.

Ducharme-Crevier L, Wainwright M. Acute management of children with traumatic brain injury. Clin Pediatr Emerg Med. 2015;16(1):48-54.

Exclusion: 2.
Duchateau FX, Pariente D, Ducarme G, et al. Fetal monitoring in the prehospital setting. J Emerg Med. 2010;39(5):623-8. doi:

10.1016/j.jemermed.2008.05.020. PMID: 19062222. Exclusion: 3.

Ducrocq SC, Meyer PG, Orliaguet GA, et al. Epidemiology and early predictive factors of mortality and outcome in children with traumatic severe brain injury: experience of a French pediatric trauma center. Pediatr Crit Care Med. 2006;7(5):4617. PMID: 16885795. Exclusion: 4.

Dudkiewicz M, Harpaul TA, Proctor KG. Hemoglobin-based oxygen carrying compound-201 as salvage therapy for severe neuro- and polytrauma (Injury Severity Score $=27-41$ ) . Crit Care Med. 2008;36(10):2838-48. PMID: 18766094. Exclusion: 3.

Duke MD, Guidry C, Guice J, et al. Restrictive fluid resuscitation in combination with damage control resuscitation: time for adaptation. J Trauma Acute Care Surg. 2012;73(3):674-8. doi:

10.1097/TA.0b013e318265ce1f. PMID: 22929496.

Exclusion: 4.

Dula DJ, Wood GC, Rejmer AR, et al. Use of prehospital fluids in hypotensive blunt trauma patients. Prehosp Emerg Care. 2002;6(4):417-20. PMID: 12385609. Exclusion: 4.

Dunford JV, Davis DP, Ochs M, et al. Incidence of transient hypoxia and pulse rate reactivity during paramedic rapid sequence intubation. Ann Emerg Med. 2003;42(6):721-8. PMID: 14634593. Exclusion: 14.

Dunham CM, Chirichella TJ, Gruber BS, et al. Emergency department noninvasive (NICOM) cardiac outputs are associated with trauma activation, patient injury severity and host conditions and mortality. J Trauma Acute Care Surg. 2012;73(2):479-85. PMID: 23019674. Exclusion: 15.

Dunham CM, Sosnowski C, Porter JM, et al. Correlation of noninvasive cerebral oximetry with cerebral perfusion in the severe head injured patient: a pilot study. J Trauma. 2002;52(1):40-6. PMID: 11791050. Exclusion: 14.

170. Dutton RP, McCunn M, Hyder M, et al. Factor VIIa for correction of traumatic coagulopathy. J Trauma. 2004;57(4):709-18; discussion 18-9. PMID: 15514523. Exclusion: 4.

Eachempati SR, Robb T, Ivatury RR, et al. Factors associated with mortality in patients with penetrating abdominal vascular trauma. J Surg Res. 2002;108(2):222-6. PMID: 12505045. Exclusion: 14. 
Eastman AL, Arnoldo BA, Hunt JL, et al. Pre-burn center management of the burned airway: do we know enough? J Burn Care Res. 2010;31(5):701-5. doi: 10.1097/BCR.0b013e3181eebe4f. PMID: 20634705. Exclusion: 3.

Easton R, Bendinelli C, Sisak K, et al. Prehospital nausea and vomiting after trauma: prevalence, risk factors, and development of a predictive scoring system. J Trauma Acute Care Surg. 2012;72(5):124953; discussion 53-4. doi: 10.1097/TA.0b013e318249668e. PMID: 22673251. Exclusion: 6.

Eastridge BJ, Butler F, Wade CE, et al. Field triage score (FTS) in battlefield casualties: validation of a novel triage technique in a combat environment. Am J Surg. 2010;200(6):724-7; discussion 7. doi: 10.1016/j.amjsurg.2010.08.006. PMID: 21146011. Exclusion: 15.

Eastridge BJ, Owsley J, Sebesta J, et al. Admission physiology criteria after injury on the battlefield predict medical resource utilization and patient mortality. J Trauma. 2006;61(4):820-3. PMID: 17033546. Exclusion: 15.

Eastridge BJ, Starr A, Minei JP, et al. The importance of fracture pattern in guiding therapeutic decisionmaking in patients with hemorrhagic shock and pelvic ring disruptions. J Trauma. 2002;53(3):446-50; discussion 50-1. PMID: 12352479. Exclusion: 4.

Echeverria AB, Branco BC, Goshima KR, et al. Outcomes of endovascular management of acute thoracic aortic emergencies in an academic level 1 trauma center. Am J Surg. 2014;208(6):974-80; discussion 9-80. doi: 10.1016/j.amjsurg.2014.08.008. PMID: 25440483. Exclusion: 14.

Edelman DA, White MT, Tyburski JG, et al. Posttraumatic hypotension: should systolic blood pressure of 90-109 mmHg be included? Shock. 2007;27(2):134-8. PMID: 17224786. Exclusion: 4.

Edla S, Reisner AT, Liu J, et al. In reply to "Utility of shock index calculation in hemorrhagic trauma". Am J Emerg Med. 2015;33(7):978-9. doi: 10.1016/j.ajem.2015.04.002. PMID: 25913084. Exclusion: 9.

Ehrlich PF, Seidman PS, Atallah O, et al. Endotracheal intubations in rural pediatric trauma patients. J Pediatr Surg. 2004;39(9):1376-80. PMID: 15359393. Exclusion: 14.
Eich C, Roessler M, Nemeth M, et al. Characteristics and outcome of prehospital paediatric tracheal intubation attended by anaesthesia-trained emergency physicians. Resuscitation. 2009;80(12):1371-7. doi: 10.1016/j.resuscitation.2009.09.004. PMID: 19804939. Exclusion: 3.

Elofson KA, Rhoads SF, Tang A, et al. Long-acting neuromuscular blocker use during prehospital transport of trauma patients. Air Med J. 2013;32(4):203-7. doi: 10.1016/j.amj.2012.10.021. PMID: 23816214. Exclusion: 14.

Elterman J, Brasel K, Brown S, et al. Transfusion of red blood cells in patients with a prehospital Glasgow Coma Scale score of 8 or less and no evidence of shock is associated with worse outcomes. J Trauma Acute Care Surg. 2013;75(1):8-14; discussion doi: 10.1097/TA.0b013e318298492e. PMID: 23778432. Exclusion: 14.

Engbrecht BW, Hollenbeak CS, Lubin JS, et al. Interfacility transfer of pediatric trauma patients by helicopter does not predict the need for urgent intervention. Pediatr Emerg Care. 2013;29(6):729-36. doi: 10.1097/PEC.0b013e318294ddcc. PMID: 23714762. Exclusion: 6.

Engels PT, Passos E, Beckett AN, et al. IV access in bleeding trauma patients: a performance review. Injury. 2014;45(1):77-82. doi: 10.1016/j.injury.2012.12.026. PMID: 23352673. Exclusion: 14.

Ernest E, Burnett A, Frascone RJ. High index of suspicion. Recognizing \& managing traumatic neck injuries. JEMS. 2014;39(4):50-4. PMID: 24779100. Exclusion: 9.

Evans CC, Brison RJ, Howes D, et al. Prehospital non-drug assisted intubation for adult trauma patients with a Glasgow Coma Score less than 9. Emerg Med J. 2013;30(11):935-41. doi: 10.1136/emermed-2012201578. PMID: 23144080. Exclusion: 14.

Evans HL, Zonies DH, Warner KJ, et al. Timing of intubation and ventilator-associated pneumonia following injury. Arch Surg. 2010;145(11):1041-6. doi: 10.1001/archsurg.2010.239. PMID: 21079091. Exclusion: 14.

Faizi M, Farrier AJ, Venkatesan M, et al. Is body temperature an independent predictor of mortality in hip fracture patients? Injury. 2014;45(12):1942-5. PMID: 25458058. Exclusion: 3. 
Fakhry SM, Scanlon JM, Robinson L, et al. Prehospital rapid sequence intubation for head trauma: conditions for a successful program. J Trauma. 2006;60(5):997-1001. PMID: 16688061. Exclusion: 14.

Fan JS, Chen YC, Huang HH, et al. The association between on-scene blood pressure and early neurological deterioration in patients with spontaneous intracerebral haemorrhage. Emerg Med J. 2015;32(3):239-43. doi: 10.1136/emermed-2013203114. PMID: 24123169. Exclusion: 3.

Farkash U, Lynn M, Scope A, et al. Does prehospital fluid administration impact core body temperature and coagulation functions in combat casualties? Injury. 2002;33(2):103-10. PMID: 11890910. Exclusion: 14.

Fathizadeh P, Shoemaker WC, Wo CC, et al. Autonomic activity in trauma patients based on variability of heart rate and respiratory rate. Crit Care Med. 2004;32(6):1300-5. PMID: 15187510. Exclusion: 8.

Fedakar A, Findik O, Kalender M, et al. Unusual emergent presentations of abdominal aortic aneurysm: can simple blood tests predict the state of emergency? Ulus Travma Acil Cerrahi Derg. 2011;17(6):525-32. doi: 10.5505/tjtes.2011.65983. PMID: 22290006. Exclusion: 3.

Fehlings MG, Cadotte DW, Fehlings LN. A series of systematic reviews on the treatment of acute spinal cord injury: a foundation for best medical practice. J Neurotrauma. 2011;28(8):1329-33. doi: 10.1089/neu.2011.1955. PMID: 21651382. Exclusion: 10.

Fein M, Quinn J, Watt K, et al. Prehospital paediatric burn care: new priorities in paramedic reporting. Emerg Med Australas. 2014;26(6):609-15. doi: 10.1111/1742-6723.12313. PMID: 25348749.

Exclusion: 3.

Femling J, Weiss S, Hauswald E, et al. EMS patients and walk-in patients presenting with severe sepsis: differences in management and outcome. South Med J. 2014;107(12):751-6. doi: 10.14423/SMJ.0000000000000206. PMID: 25502152. Exclusion: 3.

Floccard B, Rugeri L, Faure A, et al. Early coagulopathy in trauma patients: an on-scene and hospital admission study. Injury. 2012;43(1):26-32. doi: 10.1016/j.injury.2010.11.003. PMID: 21112053. Exclusion: 4.
Forsberg S, Hojer J, Ludwigs U, et al. Metabolic vs structural coma in the ED--an observational study. Am J Emerg Med. 2012;30(9):1986-90. doi: 10.1016/j.ajem.2012.04.032. PMID: 22795990. Exclusion: 3.

Fox AD. Shock sense: detecting \& correcting hemorrhagic shock in trauma patients. JEMS. 2011;36(4):58-62; quiz 5. doi: 10.1016/S01972510(11)70090-0. PMID: 21481684. Exclusion: 9.

Fox AD. Spinal shock. Assessment \& treatment of spinal cord injuries \& neurogenic shock. JEMS. 2014;39(11):64-7. PMID: 25630163. Exclusion: 9.

Frakes MA, Lord WR. Sedative use in patients receiving neuromuscular blocking agents from a helicopter flight team. Air Med J. 2006;25(4):173-5. PMID: 16818168. Exclusion: 3.

Franchin M, Jost D, Lefort $\mathrm{H}$, et al. Utility of shock index calculation in hemorrhagic trauma. Am J Emerg Med. 2015;33(7):978. doi: 10.1016/j.ajem.2015.04.001. PMID: 25899768. Exclusion: 9.

Frank M, Schmucker U, Stengel D, et al. Proper estimation of blood loss on scene of trauma: tool or tale? J Trauma. 2010;69(5):1191-5. doi: 10.1097/TA.0b013e3181c452e7. PMID: 20130487. Exclusion: 3.

Franschman G, Peerdeman SM, Andriessen TM, et al. Effect of secondary prehospital risk factors on outcome in severe traumatic brain injury in the context of fast access to trauma care. J Trauma. 2011;71(4):826-32. doi: 10.1097/TA.0b013e31820cebf0. PMID: 21427618. Exclusion: 14.

Franschman G, Peerdeman SM, Greuters S, et al. Prehospital endotracheal intubation in patients with severe traumatic brain injury: guidelines versus reality. Resuscitation. 2009;80(10):1147-51. doi: 10.1016/j.resuscitation.2009.06.029. PMID: 19632024. Exclusion: 6.

Frascone RJ, Russi C, Lick C, et al. Comparison of prehospital insertion success rates and time to insertion between standard endotracheal intubation and a supraglottic airway. Resuscitation.

2011;82(12):1529-36. doi:

10.1016/j.resuscitation.2011.07.009. PMID:

21763247. Exclusion: 5.

Freeman JF, Ciarallo C, Rappaport L, et al. Use of capnographs to assess quality of pediatric ventilation with 3 different airway modalities. Am J Emerg Med. 2016;34(1):69-74. doi: 10.1016/j.ajem.2015.09.012. PMID: 26508582. Exclusion: 4. 
Fremgen HE, Bratton SL, Metzger RR, et al. Pediatric liver lacerations and intensive care: evaluation of ICU triage strategies. Pediatr Crit Care Med. 2014;15(4):e183-91. doi: 10.1097/PCC.0000000000000102. PMID: 24632581. Exclusion: 6.

Freund Y, Duchateau FX, Devaud ML, et al. Factors associated with difficult intubation in prehospital emergency medicine. Eur J Emerg Med.

2012;19(5):304-8. doi:

10.1097/MEJ.0b013e32834d3e4f. PMID: 22008586. Exclusion: 5.

Friese G, Wojciehoski RF. Fetal trauma from motor vehicle collisions. Emerg Med Serv. 2005;34(7):6973. PMID: 16116864. Exclusion: 4.

Frisch A, Cammarata S, Mosesso VN, Jr., et al. Multivariate analysis of successful intravenous line placement in the prehospital setting. Prehosp Emerg Care. 2013;17(1):46-50. doi:

10.3109/10903127.2012.710717. PMID: 22913329.

Exclusion: 5.

Frohlich M, Lefering R, Probst C, et al. Epidemiology and risk factors of multiple-organ failure after multiple trauma: an analysis of 31,154 patients from the TraumaRegister DGU. J Trauma Acute Care Surg. 2014;76(4):921-7; discussion 7-8. doi: 10.1097/TA.0000000000000199. PMID: 24662853. Exclusion: 14.

Fryman L, Murray L. Managing acute head trauma in a crowded emergency department. J Emerg Nurs. 2007;33(3):208-13. PMID: 17517265. Exclusion: 9.

Fuglistaler-Montali I, Attenberger C, Fuglistaler P, et al. In search of benchmarking for mortality following multiple trauma: a Swiss trauma center experience. World J Surg. 2009;33(11):2477-89. doi: 10.1007/s00268-009-0193-1. PMID: 19693630. Exclusion: 14.

Fuller G, Bouamra O, Woodford M, et al. Recent massive blood transfusion practice in England and Wales: view from a trauma registry. Emerg Med J. 2012;29(2):118-23. doi: 10.1136/emj.2010.104349. PMID: 21398249. Exclusion: 7.

Fuller G, Hasler RM, Mealing N, et al. The association between admission systolic blood pressure and mortality in significant traumatic brain injury: a multi-centre cohort study. Injury. 2014;45(3):612-7. doi: 10.1016/j.injury.2013.09.008. PMID: 24206920. Exclusion: 14.
Fuller G, Woodford M, Lawrence T, et al. Do prolonged primary transport times for traumatic brain injury patients result in deteriorating physiology? A cohort study. Prehosp Emerg Care. 2014;18(1):60-7. doi: 10.3109/10903127.2013.831507. PMID: 24112033. Exclusion: 2.

Gabbe BJ, de Steiger R, Esser M, et al. Predictors of mortality following severe pelvic ring fracture: results of a population-based study. Injury.

2011;42(10):985-91. doi: 10.1016/j.injury.2011.06.003. PMID: 21733513. Exclusion: 5.

Gaither JB, Spaite DW, Stolz U, et al. Prevalence of difficult airway predictors in cases of failed prehospital endotracheal intubation. J Emerg Med. 2014;47(3):294-300. doi:

10.1016/j.jemermed.2014.04.021. PMID: 24906900. Exclusion: 4.

Galvagno Jr SM, Sikorski R, Hirshon JM, et al. Helicopter emergency medical services for adults with major trauma. Cochrane Database Syst Rev. 2015(12) PMID: 26671262. Exclusion: 2.

Galvagno SM, Jr., Floccare DJ, Scalea TM. Impact of prehospital mode of transport after severe injuries: reevaluation of results. J Trauma Acute Care Surg. 2012;73(3):778. doi: 10.1097/TA.0b013e318265d1d9. PMID: 22929507. Exclusion: 9.

Gandy WE, Grayson SK. More oxygen can't hurt...can it? EMS World. 2013;42(5):24-7. PMID: 23763059. Exclusion: 9.

Gangloff A, Nadeau L, Perry JJ, et al. Ruptured aneurysmal subarachnoid hemorrhage in the emergency department: clinical outcome of patients having a lumbar puncture for red blood cell count, visual and spectrophotometric xanthochromia after a negative computed tomography. Clin Biochem. 2015;48(10-11):634-9. doi: 10.1016/j.clinbiochem.2015.03.011. PMID: 25819839. Exclusion: 4.

Gao L, Smielewski P, Czosnyka M, et al. Cerebrovascular signal complexity six hours after intensive care unit admission correlates with outcome after severe traumatic brain injury. J Neurotrauma. 2016;33(22):2011-8. doi: 10.1089/neu.2015.4228. PMID: 26916703. Exclusion: 4. 
Garner AA, Barker CL, Weatherall AD.

Retrospective evaluation of prehospital triage, presentation, interventions and outcome in paediatric drowning managed by a physician staffed helicopter emergency medical service. Scand J Trauma Resusc Emerg Med. 2015;23:92. doi: 10.1186/s13049-0150177-0. PMID: 26545870. Exclusion: 3.

Garrett PD, Boyd SY, Bauch TD, et al. Feasibility of real-time echocardiographic evaluation during patient transport. J Am Soc Echocardiogr. 2003;16(3):197201. PMID: 12618725. Exclusion: 5.

Garwe T, Cowan LD, Neas BR, et al. A propensity score analysis of prehospital factors and directness of transport of major trauma patients to a level I trauma center. J Trauma. 2011;70(1):120-9. doi:

10.1097/TA.0b013e3181d89439. PMID: 20526210. Exclusion: 5.

Garwe T, Roberts ZV, Albrecht RM, et al. Direct transport of geriatric trauma patients with pelvic fractures to a Level I trauma center within an organized trauma system: impact on two-week incidence of in-hospital complications. Am J Surg. 2012;204(6):921-5; discussion 5-6. doi: 10.1016/j.amjsurg.2012.05.020. PMID: 23063096. Exclusion: 5.

Gaughan M, McIntosh D, Brown A, et al. Emergency abdominal aortic aneurysm presenting without haemodynamic shock is associated with misdiagnosis and delay in appropriate clinical management. Emerg Med J. 2009;26(5):334-9. doi:

10.1136/emj.2007.056424. PMID: 19386866.

Exclusion: 3.

Gaunt C, Woolley T. Management of haemorrhage in major trauma. Continuing Education in Anaesthesia, Critical Care \& Pain. 2014;14(6):251-5. Exclusion: 5.

Gausche M, Lewis RJ, Stratton SJ, et al. Effect of out-of-hospital pediatric endotracheal intubation on survival and neurological outcome: a controlled clinical trial. Jama. 2000;283(6):783-90. PMID: 10683058. Exclusion: 4.

Geeraedts LM, Jr., Pothof LA, Caldwell E, et al. Prehospital fluid resuscitation in hypotensive trauma patients: do we need a tailored approach? Injury. 2015;46(1):4-9. doi: 10.1016/j.injury.2014.08.001. PMID: 25173671. Exclusion: 4.

Geisser W, Maybauer DM, Wolff H, et al. Radiological validation of tracheal tube insertion depth in out-of-hospital and in-hospital emergency patients. Anaesthesia. 2009;64(9):973-7. doi: 10.1111/j.1365-2044.2009.06007.x. PMID: 19686482. Exclusion: 4.
Gellerfors M, Larsson A, Svensen CH, et al. Use of the Airtraq device for airway management in the prehospital setting--a retrospective study. Scand J Trauma Resusc Emerg Med. 2014;22:10. doi: 10.1186/1757-7241-22-10. PMID: 24484856. Exclusion: 8.

George S, Macnab AJ. Evaluation of a semiquantitative $\mathrm{CO} 2$ monitor with pulse oximetry for prehospital endotracheal tube placement and management. Prehospital Disaster Med. 2002;17(1):38-41. PMID: 12357564. Exclusion: 4.

Gerdtz MF, Waite R, Vassiliou T, et al. Evaluation of a multifaceted intervention on documentation of vital signs at triage: a before-and-after study. Emerg Med Australas. 2013;25(6):580-7. doi: 10.1111/17426723.12153. PMID: 24308615. Exclusion: 8.

Gerecht R. the Lethal Triad. JEMS. 2014;39(4):5660. PMID: 24779101. Exclusion: 9.

Gerecht R, Larrimore A, Steuerwald M. Critical management of deadly pelvic injuries. JEMS : a journal of emergency medical services. 2014;39(12):28-35. PMID: 25630178. Exclusion: 10.

Glapa M, Zorio M, Snyckers FD, et al. Gunshot wounds to the head in civilian practice. Am Surg. 2009;75(3):223-6. PMID: 19350857. Exclusion: 7.

Goldstein B, Toweill D, Lai S, et al. Uncoupling of the autonomic and cardiovascular systems in acute brain injury. The American journal of physiology. 1998;275(4 Pt 2):R1287-92. PMID: 9756562.

Exclusion: 7.

Gomez R, O'Keeffe T, Chang LY, et al. Association of mitochondrial allele 4216C with increased risk for complicated sepsis and death after traumatic injury. J Trauma. 2009;66(3):850-7; discussion 7-8. doi: 10.1097/TA.0b013e3181991ac8. PMID: 19276764. Exclusion: 7.

Gonzalez-Robledo J, Martin-Gonzalez F, MorenoGarcia M, et al. Prognostic factors associated with mortality in patients with severe trauma: from prehospital care to the Intensive Care Unit. Med Intensiva. 2015;39(7):412-21. doi: 10.1016/j.medin.2014.06.004. PMID: 25189470. Exclusion: 14.

Goodacre S, Stevens JW, Pandor A, et al. Prehospital noninvasive ventilation for acute respiratory failure: systematic review, network meta-analysis, and individual patient data meta-analysis. Acad Emerg Med. 2014;21(9):960-70. doi: 10.1111/acem.12466. PMID: 25269576. Exclusion: 10. 
245. Goodloe JM, Howerton DS, McAnallen D, et al. How can tranexamic acid help in EMS? TXA offers new hope for an old challenge in traumatic hemorrhagic shock. EMS World. 2013;42(5):I5-6. PMID: 23763065. Exclusion: 9.

Goodwin ML, Rothberg DL. Lactate metabolism in trauma. J Trauma Acute Care Surg. 2014;77(1):1823. doi: 10.1097/TA.0000000000000162. PMID: 24977778. Exclusion: 9.

Gottschalk SB, Warner C, Burch VC, et al. Les scores d'alerte dans le triage: est-ce vraiment utile? [Warning scores in triage-is there any point?]. Afr J Emerg Med. 2012;2(3):103-7. doi: 10.1016/j.afjem.2012.04.004. Exclusion: 2.

Graham CA, Wares GM, Munro PT. Mortality after trauma intubation without drugs in Scottish emergency departments. Resuscitation. 2006;69(3):395-7. PMID: 16584828. Exclusion: 4.

Gray A, Ward K, Lees F, et al. The epidemiology of adults with severe sepsis and septic shock in Scottish emergency departments. Emerg Med J.

2013;30(5):397-401. doi: 10.1136/emermed-2012201361. PMID: 22753641. Exclusion: 7.

Green RS, MacIntyre JK. Critical care in the emergency department: an assessment of the length of stay and invasive procedures performed on critically ill ED patients. Scand J Trauma Resusc Emerg Med. 2009;17:47. doi: 10.1186/1757-724117-47. PMID: 19778429. Exclusion: 7.

Griffin D. Traumatic brain injuries: continuing dilemmas in the pre-hospital care arena. Journal of Paramedic Practice. 2013;5(2):83-93. Exclusion: 4.

Grissom CK, Brown SM, Kuttler KG, et al. A modified sequential organ failure assessment score for critical care triage. Disaster med. 2010;4(4):27784. doi: 10.1001/dmp.2010.40. PMID: 21149228. Exclusion: 4.

Grmec S. Comparison of three different methods to confirm tracheal tube placement in emergency intubation. Intensive Care Med. 2002;28(6):701-4. PMID: 12107674. Exclusion: 4.

Grmec S, Mally S. Prehospital determination of tracheal tube placement in severe head injury. Emerg Med J. 2004;21(4):518-20. PMID: 15208251. Exclusion: 4.

Grogan EL, Morris JA, Jr., Norris PR, et al. Reduced heart rate volatility: an early predictor of death in trauma patients. Ann Surg. 2004;240(3):547-54; discussion 54-6. PMID: 15319726. Exclusion: 7.
Grogan EL, Norris PR, Speroff T, et al. Volatility: a new vital sign identified using a novel bedside monitoring strategy. J Trauma. 2005;58(1):7-12; discussion -4. PMID: 15674143. Exclusion: 7.

Gross BW, Edavettal MM, Cook AD, et al. Big children or little adults? A statewide analysis of adolescent isolated severe traumatic brain injury outcomes at pediatric versus adult trauma centers. J Trauma Acute Care Surg. 2016;82(2):368-73. doi: 10.1097/TA.0000000000001291. PMID: 27805998. Exclusion: 4.

Guerra WF, Mayfield TR, Meyers MS, et al. Early detection and treatment of patients with severe sepsis by prehospital personnel. J Emerg Med.

2013;44(6):1116-25. doi:

10.1016/j.jemermed.2012.11.003. PMID: 23321295. Exclusion: 3.

259. Guly HR, Bouamra O, Lecky FE, et al. The incidence of neurogenic shock in patients with isolated spinal cord injury in the emergency department. Resuscitation. 2008;76(1):57-62. PMID: 17688997. Exclusion: 4.

Gunning M, O'Loughlin E, Fletcher M, et al. Emergency intubation: a prospective multicentre descriptive audit in an Australian helicopter emergency medical service. Emerg Med J. 2009;26(1):65-9. doi: 10.1136/emj.2008.059345. PMID: 19104110. Exclusion: 4.

Gustafson ML, Hollosi S, Chumbe JT, et al. The effect of ethanol on lactate and base deficit as predictors of morbidity and mortality in trauma. Am J Emerg Med. 2015;33(5):607-13. doi: 10.1016/j.ajem.2015.01.030. PMID: 25770595. Exclusion: 5.

Guyette FX, Wang H, Cole JS. King airway use by air medical providers. Prehosp Emerg Care. 2007;11(4):473-6. PMID: 17907036. Exclusion: 4.

Gwely NN, Mowafy A, Khalaf S, et al. Management of stab wounds of the heart: analysis of 73 cases in 10 years. Thorac Cardiovasc Surg. 2010;58(4):210-4. doi: 10.1055/s-0029-1240921. PMID: 20514575.

Exclusion: 9.

Hagemo JS. Prehospital detection of traumatic coagulopathy. Transfusion. 2013;53 Suppl 1:48S51S. doi: 10.1111/trf.12035. PMID: 23301972. Exclusion: 5. 
Hagemo JS, Christiaans SC, Stanworth SJ, et al. Detection of acute traumatic coagulopathy and massive transfusion requirements by means of rotational thromboelastometry: an international prospective validation study. Crit Care. 2015;19:97. doi: 10.1186/s13054-015-0823-y. PMID: 25888032. Exclusion: 4.

Hagemo JS, Naess PA, Johansson P, et al. Evaluation of TEG() and RoTEM() inter-changeability in trauma patients. Injury. 2013;44(5):600-5. doi:

10.1016/j.injury.2012.11.016. PMID: 23260867. Exclusion: 5.

Hagiwara A, Kimura A, Kato H, et al. Hemodynamic reactions in patients with hemorrhagic shock from blunt trauma after initial fluid therapy. J Trauma. 2010;69(5):1161-8. doi: 10.1097/TA.0b013e3181d27c94. PMID: 20489665. Exclusion: 14.

Halliwell D. Challenge your thinking: mechanical direct pressure device. Journal of Paramedic Practice. 2014;6(9):448-50. Exclusion: 4.

Hammell CL, Henning JD. Prehospital management of severe traumatic brain injury. BMJ. 2009;338:b1683. doi: 10.1136/bmj.b1683. PMID: 19454738. Exclusion: 9.

Hampson NB, Weaver LK. Noninvasive CO measurement by first responders: a suggested management algorithm. Wildland Firefighter. 2006;10(6):10-2. PMID: 16739272. Exclusion: 9.

Hampton DA, Fabricant LJ, Differding J, et al. Prehospital intravenous fluid is associated with increased survival in trauma patients. J Trauma Acute Care Surg. 2013;75(1 Suppl 1):S9-15. doi: 10.1097/TA.0b013e318290cd52. PMID: 23778518. Exclusion: 4.

272. Handly N, Bass RR, New JP, et al. Effect of patient age on airway response by paramedics: frailty or futility? Prehosp Emerg Care. 2011;15(3):351-8. doi: 10.3109/10903127.2011.561402. PMID: 21612387. Exclusion: 6.

Hankins D. High-risk, low-volume procedures. Air Med J. 2010;29(6):279-81. doi: 10.1016/j.amj.2010.08.003. Exclusion: 9.

Hankins D. Etomidate versus ketamine, disaster triage. Air Med J. 2010;29(1):14-5. doi: 10.1016/j.amj.2009.10.004. Exclusion: 9.

Hankins D. Acute heart conditions. Air Med J. 2012;31(4):157-8. doi: 10.1016/j.amj.2012.04.004. Exclusion: 9.
Hankins D. Time to abandon the GCS in prehospital care? Air Med J. 2012;31(2):70-1. doi: 10.1016/j.amj.2011.12.004. Exclusion: 9.

Hankins D. Overtriage. Air Med J. 2013;32(6):307-9. doi: 10.1016/j.amj.2013.08.003. PMID: 24182876.

Exclusion: 9.

Hankins D. Volume resuscitation of blunt trauma. Air Med J. 2013;32(5):236-7. doi: 10.1016/j.amj.2013.06.001. PMID: 24001909. Exclusion: 9.

Hankins D. Volume resuscitation issues. Air Med J. 2013;32(4):188-9. doi: 10.1016/j.amj.2013.04.005. PMID: 23816212. Exclusion: 9.

Hankins D. National Trauma Triage Protocol. Air Med J. 2013;32(1):17-8. doi: 10.1016/j.amj.2012.10.008. Exclusion: 9.

Hansen M, Lambert W, Guise JM, et al. Out-ofhospital pediatric airway management in the United States. Resuscitation. 2015;90:104-10. doi: 10.1016/j.resuscitation.2015.02.018. PMID: 25725298. Exclusion: 6.

Harbrecht BG, Franklin GA, Smith JW, et al. Intubated Trauma Patients Do Not Require Full Trauma Team Activation when Effectively Triaged. J Am Coll Surg. 2016;222(4):603-11. doi: 10.1016/j.jamcollsurg.2015.12.039. PMID: 26847589. Exclusion: 4.

Harbrecht BG, Zenati MS, Doyle HR, et al. Hepatic dysfunction increases length of stay and risk of death after injury. J Trauma. 2002;53(3):517-23. PMID: 12352490. Exclusion: 4.

Hardcastle TC, Goff T. Trauma unit emergency doctor airway management. Samj, S. 2007;97(9):8647. PMID: 17985058. Exclusion: 4.

Harjola P, Boyd J, Tarvasmaki T, et al. The impact of emergency medical services in acute heart failure. Int J Cardiol. 2017;232:222-6. PMID: 28096039. Exclusion: 3.

Harrington DT, Connolly M, Biffl WL, et al. Transfer times to definitive care facilities are too long: a consequence of an immature trauma system. Ann Surg. 2005;241(6):961-6; discussion 6-8. PMID: 15912045. Exclusion: 4.

Hartl R, Gerber LM, Iacono L, et al. Direct transport within an organized state trauma system reduces mortality in patients with severe traumatic brain injury. J Trauma. 2006;60(6):1250-6; discussion 6. PMID: 16766968. Exclusion: 14. 
Harvin JA, Peirce CA, Mims MM, et al. The impact of tranexamic acid on mortality in injured patients with hyperfibrinolysis. J Trauma Acute Care Surg. 2015;78(5):905-9; discussion 9-11. doi: 10.1097/TA.0000000000000612. PMID: 25909408. Exclusion: 6.

Harwood PJ, Giannoudis PV, van Griensven M, et al. Alterations in the systemic inflammatory response after early total care and damage control procedures for femoral shaft fracture in severely injured patients. J Trauma. 2005;58(3):446-52; discussion 52-4. PMID: 15761335. Exclusion: 14.

Hasegawa K, Shigemitsu K, Hagiwara Y, et al. Association between repeated intubation attempts and adverse events in emergency departments: an analysis of a multicenter prospective observational study. Ann Emerg Med. 2012;60(6):749-54.e2. doi: 10.1016/j.annemergmed.2012.04.005. PMID: 22542734. Exclusion: 4.

Hashemzadeh S, Mameghani K, Fouladi RF, et al. Diagnostic peritoneal lavage in hemodynamically stable patients with lower chest or anterior abdominal stab wounds. Ulus Travma Acil Cerrahi Derg. 2012;18(1):37-42. doi: 10.5505/tjtes.2011.89137. PMID: 22290048. Exclusion: 4.

Hashimoto A, Ueda T, Kuboyama K, et al. Application of a first impression triage in the Japan railway west disaster. Acta Med Okayama. 2013;67(3):171-6. PMID: 23804140. Exclusion: 4.

Hasler RM, Nuesch E, Juni P, et al. Systolic blood pressure below $110 \mathrm{mmHg}$ is associated with increased mortality in blunt major trauma patients: multicentre cohort study. Resuscitation.

2011;82(9):1202-7. doi:

10.1016/j.resuscitation.2011.04.021. PMID:

21632168. Exclusion: 14.

Hasler RM, Nuesch E, Juni P, et al. Systolic blood pressure below $110 \mathrm{mmHg}$ is associated with increased mortality in penetrating major trauma patients: multicentre cohort study. Resuscitation. 2012;83(4):476-81. doi:

10.1016/j.resuscitation.2011.10.018. PMID:

22056618. Exclusion: 14.

Hattori N, Huang SC, Wu HM, et al. Acute changes in regional cerebral (18)F-FDG kinetics in patients with traumatic brain injury. J Nucl Med. 2004;45(5):775-83. PMID: 15136626. Exclusion: 6.
Haukoos JS, Byyny RL, Erickson C, et al. Validation and refinement of a rule to predict emergency intervention in adult trauma patients. Ann Emerg Med. 2011;58(2):164-71. doi:

10.1016/j.annemergmed.2011.02.027. PMID: 21658802. Exclusion: 14.

Havens JM, Carter C, Gu X, et al. Preinjury beta blocker usage does not affect the heart rate response to initial trauma resuscitation. Int J Surg. 2012;10(9):518-21. doi: 10.1016/j.ijsu.2012.08.004. PMID: 22906692. Exclusion: 6.

Heaney JB, Guidry C, Simms E, et al. To TQIP or not to TQIP? That is the question. Am Surg. 2014;80(4):386-90. PMID: 24887671. Exclusion: 6.

Hedges JR, Adams AL, Gunnels MD. ATLS practices and survival at rural level III trauma hospitals, 1995-1999. Prehosp Emerg Care. 2002;6(3):299-305. PMID: 12109572. Exclusion: 4.

Heegaard WG, Black C, Pasquerella C, et al. Use of the endotracheal tube introducer as an adjunct for oral tracheal intubation in the prehospital setting. Air Med J. 2003;22(1):28-31. PMID: 12522361.

Exclusion: 6.

Heffernan DS, Adams CA, Jr. Advancing boundaries in the care of the trauma patient. Med Health R I. 2009;92(5):166-9. PMID: 19530480. Exclusion: 4.

Heightman AJ. The new ITD-7 inspiratory impedance aids trauma patients. JEMS. 2009;34(8):14. doi: 10.1016/S0197-2510(09)702013. PMID: 19665649. Exclusion: 9.

Hein C, Owen H, Plummer J. A 12-month audit of laryngeal mask airway (LMA) use in a South Australian ambulance service. Resuscitation. 2008;79(2):219-24. doi: 10.1016/j.resuscitation.2008.06.014. PMID: 18684549. Exclusion: 6.

Helm M, Faul M, Unger T, et al. Notärztliche Diagnosequalität bei eingeklemmten Verkehrsunfallopfern-eine retrospektive Erhebung [Quality of prehospital injury assessment in entrapped road traffic accident victims-a retrospective study]. Notarzt. 2015;31(1):25-31. doi: 10.1055/s-0035-1544215. Exclusion: 14. 
Helm M, Hauke J, Helmschrott E, et al. Schnittstellenübergreifende Verlaufsdokumentation am Beispiel von Hypotension und Hypoxie bei schwerem SHT: Eine Pilotstudie [Comprehensive interface course documentation exemplified by hypotension and hypoxemia in patients with severe traumatic brain injury: a pilot study]. Notfall und Rettungsmedizin. 2012;15(8):675-82. doi: 10.1007/s10049-012-1589-2. Exclusion: 14.

Helm M, Hossfeld B, Schafer S, et al. Factors influencing emergency intubation in the pre-hospital setting--a multicentre study in the German Helicopter Emergency Medical Service. Br J Anaesth. 2006;96(1):67-71. PMID: 16311285. Exclusion: 6.

Helm M, Kremers G, Lampl L, et al. Incidence of transient hypoxia during pre-hospital rapid sequence intubation by anaesthesiologists. Acta Anaesthesiol Scand. 2013;57(2):199-205. doi: 10.1111/aas.12032. PMID: 23210510. Exclusion: 6.

Helm M, Schuster R, Hauke J, et al. Tight control of prehospital ventilation by capnography in major trauma victims. Br J Anaesth. 2003;90(3):327-32. PMID: 12594146. Exclusion: 6.

Hemmila MR, Cain-Nielsen AH, Wahl WL, et al. Regional collaborative quality improvement for trauma reduces complications and costs. J Trauma Acute Care Surg. 2015;78(1):78-85; discussion -7. doi: 10.1097/TA.0000000000000494. PMID: 25539206. Exclusion: 6.

Henry SM, Pollak AN, Jones AL, et al. Pelvic fracture in geriatric patients: a distinct clinical entity. J Trauma. 2002;53(1):15-20. PMID: 12131383. Exclusion: 14.

Herbert HK, Dechert TA, Wolfe L, et al. Lactate in trauma: a poor predictor of mortality in the setting of alcohol ingestion. Am Surg. 2011;77(12):1576-9. PMID: 22273211. Exclusion: 15.

Hess JR, Dutton RP. Who needs blood? Crit Care Med. 2005;33(5):1171-2. PMID: 15891370.

Exclusion: 9.

Hess JR, Lindell AL, Stansbury LG, et al. The prevalence of abnormal results of conventional coagulation tests on admission to a trauma center. Transfusion. 2009;49(1):34-9. doi: 10.1111/j.15372995.2008.01944.x. PMID: 18954393. Exclusion: 4.

Hewes H, Hunsaker S, Christensen M, et al. Documentation of pediatric vital signs by EMS providers over time. J Pediatr Surg. 2016;51(2):32932. doi: 10.1016/j.jpedsurg.2015.10.001. PMID: 26563528. Exclusion: 6.
Hilbert-Carius P, Hofmann GO, Lefering R, et al. Clinical presentation and blood gas analysis of multiple trauma patients for prediction of standard coagulation parameters at emergency department arrival. Anaesthesist. 2016;65(4):274-80. doi: 10.1007/s00101-016-0150-y. PMID: 27059795. Exclusion: 6.

Hildebrand F, Giannoudis PV, Griensven M, et al. Management of polytraumatized patients with associated blunt chest trauma: a comparison of two European countries. Injury. 2005;36(2):293-302. PMID: 15664594. Exclusion: 14.

Hill DA, Delaney LM, Roncal S. A chi-square automatic interaction detection (CHAID) analysis of factors determining trauma outcomes. J Trauma. 1997;42(1):62-6. PMID: 9003259. Exclusion: 14.

Hinojosa-Laborde C, Aden JK, Goei KA, et al. Evidence for a higher risk of hypovolemia-induced hemodynamic instability in females: implications for decision support during prehospital triage. Mil Med. 2015;180(3 Suppl):19-23. doi: 10.7205/MILMED-D14-00394. PMID: 25747625. Exclusion: 3.

Hirsch F, Brokmann JC, Beckers SK, et al. Verfügbarkeit, Performanz und Funktionalität telemetrisch übertragener Daten im Rettungsdienst: Prospektive, monozentrische Analyse telemetrisch übertragener 12-Kanal-EKG und Echtzeit-Vitaldaten mittels Mobilfunk in einem städtischen Gebiet [Availability, performance, and functionality of telemedical data transfer by ambulance services: prospective, single center analysis of telemedical 12channel ECG and real-time vitality data using mobile services in an urban setting]. Notfall und Rettungsmedizin. 2016;19(5):373-9. doi: 10.1007/s10049-016-0152-y. Exclusion: 9.

Ho KK, Moody GB, Peng CK, et al. Predicting survival in heart failure case and control subjects by use of fully automated methods for deriving nonlinear and conventional indices of heart rate dynamics. Circulation. 1997;96(3):842-8. PMID: 9264491. Exclusion: 7.

Hodell EM, Sporer KA, Brown JF. Which emergency medical dispatch codes predict high prehospital nontransport rates in an urban community? Prehosp Emerg Care. 2014;18(1):28-34. doi: 10.3109/10903127.2013.825349. PMID: 24028558. Exclusion: 4.

Hoey BA, Schwab CW. Damage control surgery. Scand J Surg. 2002;91(1):92-103. PMID: 12075844. Exclusion: 4. 
Holcomb JB, del Junco DJ, Fox EE, et al. The prospective, observational, multicenter, major trauma transfusion (PROMMTT) study: comparative effectiveness of a time-varying treatment with competing risks. JAMA Surg. 2013;148(2):127-36. PMID: 23560283. Exclusion: 4.

Holcomb JB, Fox EE, Zhang X, et al. Cryoprecipitate use in the PROMMTT study. J Trauma Acute Care Surg. 2013;75(1 Suppl 1):S31-9. doi: 10.1097/TA.0b013e31828fa3ed. PMID: 23778509. Exclusion: 4.

Holcomb JB, Swartz MD, DeSantis SM, et al. Multicenter observational prehospital resuscitation on helicopter study (PROHS). J Trauma Acute Care Surg. 2017 doi: 10.1097/TA.0000000000001484. PMID: 28383476. Exclusion: 6.

Holcomb JB, Zarzabal LA, Michalek JE, et al. Increased platelet:RBC ratios are associated with improved survival after massive transfusion. J Trauma. 2011;71(2 Suppl 3):S318-28. doi: 10.1097/TA.0b013e318227edbb. PMID: 21814099. Exclusion: 4.

Holcroft JW, Vassar MJ, Turner JE, et al. 3\% NaCl and $7.5 \% \mathrm{NaCl} /$ dextran 70 in the resuscitation of severely injured patients. Ann Surg. 1987;206(3):279. PMID: 2443087. Exclusion: 11.

Holler JG, Henriksen DP, Mikkelsen S, et al. Increasing incidence of hypotension in the emergency department; a 12 year population-based cohort study. Scand J Trauma Resusc Emerg Med. 2016;24:20. doi: 10.1186/s13049-016-0209-4. PMID: 26936190. Exclusion: 6.

Holliman D, Russell W, Lecky F. The head injury transportation straight to neurosurgery (HITS-NS) trial. J Neurosurg. 2014;122(6):A1543. Exclusion: 9.

Holm C, Melcer B, Horbrand F, et al. The relationship between oxygen delivery and oxygen consumption during fluid resuscitation of burnrelated shock. J Burn Care Rehabil. 2000;21(2):14754. PMID: 10752748. Exclusion: 3.

Holm C, Melcer B, Horbrand F, et al. Intrathoracic blood volume as an end point in resuscitation of the severely burned: an observational study of 24 patients. J Trauma. 2000;48(4):728-34. PMID: 10780609. Exclusion: 3.

Holm C, Melcer B, Horbrand F, et al. Haemodynamic and oxygen transport responses in survivors and non-survivors following thermal injury. Burns. 2000;26(1):25-33. PMID: 10630316.

Exclusion: 3.
Holmberg TJ, Bowman SM, Warner KJ, et al. The association between obesity and difficult prehospital tracheal intubation. Anesth Analg. 2011;112(5):11328. doi: 10.1213/ANE.0b013e31820effcc. PMID: 21346165. Exclusion: 4.

Holmes J, Peng J, Bair A. Abnormal end-tidal carbon dioxide levels on emergency department arrival in adult and pediatric intubated patients. Prehosp Emerg Care. 2012;16(2):210-6. doi: 10.3109/10903127.2011.640416. PMID: 22217189. Exclusion: 4.

Holmes JF, Caltagirone R, Murphy M, et al. Does young age merit increased emergency department trauma team response? West J Emerg Med.

2013;14(6):569-75. doi:

10.5811/westjem.2013.5.12654. PMID: 24381673.

Exclusion: 2.

Holmes JF, Goodwin HC, Land C, et al. Coagulation testing in pediatric blunt trauma patients. Pediatr Emerg Care. 2001;17(5):324-8. PMID: 11673707. Exclusion: 4.

Holmes JF, Harris D, Battistella FD. Performance of abdominal ultrasonography in blunt trauma patients with out-of-hospital or emergency department hypotension. Ann Emerg Med. 2004;43(3):354-61. PMID: 14985663. Exclusion: 14.

Holmes JF, Mao A, Awasthi S, et al. Validation of a prediction rule for the identification of children with intra-abdominal injuries after blunt torso trauma. Ann Emerg Med. 2009;54(4):528-33. doi:

10.1016/j.annemergmed.2009.01.019. PMID: 19250706. Exclusion: 14.

Holmes JF, Sokolove PE, Brant WE, et al. A clinical decision rule for identifying children with thoracic injuries after blunt torso trauma. Ann Emerg Med. 2002;39(5):492-9. PMID: 11973556. Exclusion: 4.

Holmes JF, Wisner DH, McGahan JP, et al. Clinical prediction rules for identifying adults at very low risk for intra-abdominal injuries after blunt trauma. Ann Emerg Med. 2009;54(4):575-84. doi: 10.1016/j.annemergmed.2009.04.007. PMID: 19457583. Exclusion: 14.

Hornero R, Aboy M, Abasolo D, et al. Interpretation of approximate entropy: analysis of intracranial pressure approximate entropy during acute intracranial hypertension. IEEE Trans Biomed Eng. 2005;52(10):1671-80. doi: 10.1109/tbme.2005.855722. PMID: 16235653. Exclusion: 8. 
Hornero R, Aboy M, Abasolo D, et al. Complex analysis of intracranial hypertension using approximate entropy. Crit Care Med. 2006;34(1):8795. PMID: 16374161. Exclusion: 8.

Howard BM, Kornblith LZ, Hendrickson CM, et al. Differences in degree, differences in kind: characterizing lung injury in trauma. J Trauma Acute Care Surg. 2015;78(4):735-41. doi: 10.1097/TA.0000000000000583. PMID: 25742257. Exclusion: 14.

Hranjec T, Sawyer RG, Young JS, et al. Mortality factors in geriatric blunt trauma patients: creation of a highly predictive statistical model for mortality using 50,765 consecutive elderly trauma admissions from the National Sample Project. Am Surg. 2012;78(12):1369-75. PMID: 23265126. Exclusion: 7.

Hsiao KY, Lin LC, Li WC, et al. The association between hypertension and traumatic intracranial haemorrhage. Injury. 2015;46(5):859-62. doi: 10.1016/j.injury.2014.11.025. PMID: 25541416. Exclusion: 14.

Hsu JM, Hitos K, Fletcher JP. Identifying the bleeding trauma patient: predictive factors for massive transfusion in an Australasian trauma population. J Trauma Acute Care Surg. 2013;75(3):359-64. doi: 10.1097/TA.0b013e31829e2248. PMID: 24089108. Exclusion: 14.

Hu P, Galvagno SM, Jr., Sen A, et al. Identification of dynamic prehospital changes with continuous vital signs acquisition. Air Med J. 2014;33(1):27-33. doi: 10.1016/j.amj.2013.09.003. PMID: 24373474. Exclusion: 6.

Huang C-C, Chen W-L, Hsu C-C, et al. Elderly and nonelderly use of a dedicated ambulance corps' emergency medical services in Taiwan. Biomed Res Int. 2016;2016:1-7. doi: 10.1155/2016/1506436. PMID: 27478825. Exclusion: 4.

Huang CY, Rau CS, Chuang JF, et al. Characteristics and outcomes of patients injured in road traffic crashes and transported by emergency medical services. Int J Environ Res Public Health. 2016;13(2):236. doi: 10.3390/ijerph13020236. PMID: 26907318. Exclusion: 4.

Hubble MW, Richards ME, Jarvis R, et al. Effectiveness of prehospital continuous positive airway pressure in the management of acute pulmonary edema. Prehosp Emerg Care. 2006;10(4):430-9. PMID: 16997770. Exclusion: 4.
Huber S, Biberthaler P, Delhey P, et al. Predictors of poor outcomes after significant chest trauma in multiply injured patients: a retrospective analysis from the German Trauma Registry (Trauma Register DGU). Scand J Trauma Resusc Emerg Med. 2014;22:52. doi: 10.1186/s13049-014-0052-4. PMID: 25204466. Exclusion: 14

Huber-Wagner S, Biberthaler P, Haberle S, et al. Whole-body CT in haemodynamically unstable severely injured patients--a retrospective, multicentre study. PLoS ONE. 2013;8(7):e68880. doi: 10.1371/journal.pone.0068880. PMID: 23894365. Exclusion: 4.

Huber-Wagner S, Qvick M, Mussack T, et al. Massive blood transfusion and outcome in 1062 polytrauma patients: a prospective study based on the Trauma Registry of the German Trauma Society. Vox Sang. 2007;92(1):69-78. PMID: 17181593. Exclusion: 14.

Huebinger RM, Gomez R, McGee D, et al. Association of mitochondrial allele 4216C with increased risk for sepsis-related organ dysfunction and shock after burn injury. Shock. 2010;33(1):1923. doi: 10.1097/SHK.0b013e3181a99508. PMID: 19487983. Exclusion: 3.

Hung KK. Best Evidence Topic report. BET 2. Serum lactate as a marker for mortality in patients presenting to the emergency department with trauma. Emerg Med J. 2009;26(2):118-9. doi: 10.1136/emj.2008.070797. PMID: 19164625. Exclusion: 9.

Hunt H, Stanworth S, Curry N, et al. Thromboelastography (TEG) and rotational thromboelastometry (ROTEM) for trauma-induced coagulopathy in adult trauma patients with bleeding. Cochrane Database Syst Rev. 2015(2) PMID: 25686465. Exclusion: 4.

Hunter CL, Silvestri S, Ralls G, et al. The sixth vital sign: prehospital end-tidal carbon dioxide predicts inhospital mortality and metabolic disturbances. Am J Emerg Med. 2014;32(2):160-5. doi: 10.1016/j.ajem.2013.10.049. PMID: 24332900. Exclusion: 3.

Hunter CL, Silvestri S, Ralls G, et al. Prehospital end-tidal carbon dioxide differentiates between cardiac and obstructive causes of dyspnoea. Emerg Med J. 2015;32(6):453-6. doi: 10.1136/emermed2013-203405. PMID: 24986960. Exclusion: 3. 
Hunter CL, Silvestri S, Ralls G, et al. A prehospital screening tool utilizing end-tidal carbon dioxide predicts sepsis and severe sepsis. Am J Emerg Med. 2016;34(5):813-9. doi: 10.1016/j.ajem.2016.01.017. PMID: 26879597. Exclusion: 3.

Husain FA, Martin MJ, Mullenix PS, et al. Serum lactate and base deficit as predictors of mortality and morbidity. Am J Surg. 2003 May;185(5):485-91. PMID: 12727572. Exclusion: 7.

Husari AW, Belzberg H, Kassak K, et al. Relationship between intensive care complications and costs and initial $24 \mathrm{~h}$ events of trauma patients with severe haemorrhage. Emerg Med J. 2009;26(5):340-3. doi: 10.1136/emj.2008.058214. PMID: 19386867. Exclusion: 14.

Hussmann B, Lefering R, Kauther MD, et al. Influence of prehospital volume replacement on outcome in polytraumatized children. Crit Care. 2012;16(5):R201. doi: 10.1186/cc11809. PMID: 23078792. Exclusion: 4.

Hussmann B, Lefering R, Waydhas C, et al. Prehospital intubation of the moderately injured patient: a cause of morbidity? A matched-pairs analysis of 1,200 patients from the DGU Trauma Registry. Crit Care. 2011;15(5):R207. doi: 10.1186/cc10442. PMID: 21914175. Exclusion: 6.

Hussmann B, Lefering R, Waydhas C, et al. Does increased prehospital replacement volume lead to a poor clinical course and an increased mortality? A matched-pair analysis of 1896 patients of the Trauma Registry of the German Society for Trauma Surgery who were managed by an emergency doctor at the accident site. Injury. 2013;44(5):611-7. doi: 10.1016/j.injury.2012.02.004. PMID: 22377276. Exclusion: 4.

Husum H, Gilbert M, Wisborg T, et al. Respiratory rate as a prehospital triage tool in rural trauma. $\mathrm{J}$ Trauma. 2003;55(3):466-70. PMID: 14501888. Exclusion: 7.

Hutchings S, Naumann DN, Harris T, et al. Observational study of the effects of traumatic injury, haemorrhagic shock and resuscitation on the microcirculation: a protocol for the MICROSHOCK study. BMJ Open. 2016;6(3):e010893. doi: 10.1136/bmjopen-2015-010893. PMID: 26944694. Exclusion: 2.

Huynh T, Messer M, Sing RF, et al. Positive endexpiratory pressure alters intracranial and cerebral perfusion pressure in severe traumatic brain injury. $\mathrm{J}$ Trauma. 2002;53(3):488-92; discussion 92-3. PMID: 12352486. Exclusion: 14.
Ikeda M, Matsunaga T, Irabu N, et al. Using vital signs to diagnose impaired consciousness: cross sectional observational study. BMJ.

2002;325(7368):800-2. doi:

10.1136/bmj.325.7368.800. PMID: 12376438.

Exclusion: 3.

Inaba K, Byerly S, Bush LD, et al. Cervical spinal clearance: a prospective Western Trauma Association multi-institutional trial. J Trauma Acute Care Surg. 2016;81(6):1122-9. doi: 10.1097/TA.0000000000001194. PMID: 27438681. Exclusion: 4.

İpekci A, Ãzkan S, İkizceli İ, et al. Correlation between blood copeptin level and blood lactate level, trauma severity scores, and clinical parameters. International Medical Journal. 2013;20(5):626-9. PMID: 107939906. Language: English. Entry Date: 20131203. Revision Date: 20150712. Publication Type: Journal Article. Exclusion: 14.

Iqbal MB, Al-Hussaini A, Rosser G, et al. Predictors of survival and favorable functional outcomes after an out-of-hospital cardiac arrest in patients systematically brought to a dedicated heart attack center (from the Harefield Cardiac Arrest Study). Am J Cardiol. 2015;115(6):730-7. doi: 10.1016/j.amjcard.2014.12.033. PMID: 25644852. Exclusion: 3.

Irisawa T, Iwami T, Kitamura T, et al. An association between systolic blood pressure and stroke among patients with impaired consciousness in out-ofhospital emergency settings. BMC Emerg Med. 2013;13:24. doi: 10.1186/1471-227X-13-24. PMID: 24341562. Exclusion: 3.

Ishikawa K, Omori K, Jitsuiki K, et al. Clinical significance of fibrinogen degradation product among traumatized patients. Air Med J. 2017;36(2):59-61. doi: 10.1016/j.amj.2016.12.009. PMID: 28336014. Exclusion: 6.

Ivatury RR, Simon RJ, Islam S, et al. A prospective randomized study of end points of resuscitation after major trauma: global oxygen transport indices versus organ-specific gastric mucosal pH. J Am Coll Surg. 1996;183(2):145-54. PMID: 8696546. Exclusion: 7.

$\mathrm{J}$ W, Blow O, Krall SP, et al. Predictive value of point-of-care lactate measurement in patients meeting level II and II trauma team activation criteria who present to the emergency department: a prospective study. Ann Emerg Med. Conference: American college of emergency physicians, ACEP. 2016;68(4 Supplement 1). Exclusion: 9. 
Jang JY, Shim H, Jung PY, et al. Preperitoneal pelvic packing in patients with hemodynamic instability due to severe pelvic fracture: early experience in a Korean trauma center. Scand J Trauma Resusc Emerg Med. 2016;24:3. doi: 10.1186/s13049-0160196-5. PMID: 26762284. Exclusion: 14.

Jansen TC, van Bommel J, Mulder PG, et al. The prognostic value of blood lactate levels relative to that of vital signs in the pre-hospital setting: a pilot study. Crit Care. 2008;12(6):R160. doi: 10.1186/cc7159. PMID: 19091118. Exclusion: 3.

Jeger V, Zimmermann H, Exadaktylos AK. Can RapidTEG accelerate the search for coagulopathies in the patient with multiple injuries? J Trauma. 2009;66(4):1253-7. doi: 10.1097/TA.0b013e31819d3caf. PMID: 19359945. Exclusion: 4.

Jin HQ, Wang JC, Sun YA, et al. Prehospital identification of stroke subtypes in Chinese rural areas. Chin Med J (Engl). 2016;129(9):1041-6. doi: 10.4103/0366-6999.180521. PMID: 27098788. Exclusion: 3.

380. Johansson PI, Stensballe J, Rasmussen LS, et al. High circulating adrenaline levels at admission predict increased mortality after trauma. J Trauma Acute Care Surg. 2012;72(2):428-36. PMID: 22439205. Exclusion: 14.

Jung J, Eo E, Ahn K, et al. Initial base deficit as predictors for mortality and transfusion requirement in the severe pediatric trauma except brain injury. Pediatr Emerg Care. 2009;25(9):579-81. doi: 10.1097/PEC.0b013e3181b9b38a. PMID: 19755892. Exclusion: 4.

Kahraman S, Dutton RP, Hu P, et al. Heart rate and pulse pressure variability are associated with intractable intracranial hypertension after severe traumatic brain injury. J Neurosurg Anesthesiol. 2010;22(4):296-302. doi:

10.1097/ANA.0b013e3181e25fc3. PMID: 20622688.

Exclusion: 14.

Kaiser M, Ahearn P, Nguyen XM, et al. Early predictors of the need for emergent surgery to control hemorrhage in hypotensive trauma patients. Am Surg. 2009;75(10):986-90. PMID: 19886150. Exclusion: 4.

Kallinen O, Koljonen V, Tukiainen E, et al. Prehospital Care of Burn Patients and Trajectories on Survival. Prehosp Emerg Care. 2016;20(1):97-105. doi: 10.3109/10903127.2015.1056895. PMID: 26270935. Exclusion: 3.
Kannan N, Wang J, Mink RB, et al. Timely hemodynamic resuscitation and outcomes in severe pediatric traumatic brain injury: preliminary findings. Pediatr Emerg Care. 2016. doi: 10.1097/PEC.0000000000000803. PMID: 27387972. Exclusion: 14.

Kaplan LJ, Kellum JA. Initial pH, base deficit, lactate, anion gap, strong ion difference, and strong ion gap predict outcome from major vascular injury. Crit Care Med. 2004;32(5):1120-4. PMID: 15190960. Exclusion: 14.

Karabacak M, Varol E, Türkdogan KA, et al. Mean platelet volume in patients with carbon monoxide poisoning. Angiology. 2014;65(3):252-6. doi: 10.1177/0003319713497422. PMID: 23901146. Exclusion: 3.

Kassar OM, Eklund EA, Barnhardt WF, et al. Trauma survival margin analysis: a dissection of trauma center performance through initial lactate. Am Surg. 2016;82(7):649-53. PMID: 27457866. Exclusion: 4.

Kearney D, Cahill RA, O'Brien E, et al. Influence of delays on perforation risk in adults with acute appendicitis. Dis Colon Rectum. 2008;51(12):1823-7. doi: 10.1007/s10350-008-9373-6. PMID: 18584252.

Exclusion: 3.

Khunti K, Fisher H, Paul S, et al. Severe hypoglycaemia requiring emergency medical assistance by ambulance services in the East Midlands: a retrospective study. Prim Care Diabetes. 2013;7(2):159-65. doi: 10.1016/j.pcd.2013.01.001. PMID: 23375384. Exclusion: 3.

Kimura Y, Kimura S, Sumita S, et al. Predictors of hypofibrinogenemia in blunt trauma patients on admission. J. 2015;29(2):242-8. doi: 10.1007/s00540014-1895-6. PMID: 25112812. Exclusion: 4.

Kincaid EH, Miller PR, Meredith JW, et al. Elevated arterial base deficit in trauma patients: a marker of impaired oxygen utilization. J Am Coll Surg. 1998;187(4):384-92. PMID: 9783784. Exclusion: 7.

Kisat M, Morrison JJ, Hashmi ZG, et al. Epidemiology and outcomes of non-compressible torso hemorrhage. J Surg Res. 2013;184(1):414-21. doi: 10.1016/j.jss.2013.05.099. PMID: 23831230. Exclusion: 14.

Kober A, Scheck T, Lieba F, et al. The influence of active warming on signal quality of pulse oximetry in prehospital trauma care. Anesth Analg. 2002;95(4):961-6, table of contents. PMID: 12351277. Exclusion: 6. 
Kocuvan S, Brilej D, Stropnik D, et al. Evaluation of major trauma in elderly patients - a single trauma center analysis. Wien Klin Wochenschr. 2016;128(Suppl 7):535-42. doi: 10.1007/s00508-0161140-4. PMID: 27896468. Exclusion: 6.

Kolb JJ, Smith EL. SUSPENSION SHOCK: Redefining the diagnosis and treatment of suspension trauma. JEMS. 2015;40(6):48-51. PMID: 26263737. Exclusion: 4.

Komatsu T, Kinoshita K, Sakurai A, et al. Shorter time until return of spontaneous circulation is the only independent factor for a good neurological outcome in patients with postcardiac arrest syndrome. Emerg Med J. 2014;31(7):549-55. doi: 10.1136/emermed-2013-202457. PMID: 23639589. Exclusion: 3.

Krauss B. Capnography in EMS: a powerful way to objectively monitor ventilatory status. JEMS. 2003;28(1):28-38. PMID: 12556762. Exclusion: 9.

Kristensen AK, Holler JG, Mikkelsen S, et al. Systolic blood pressure and short-term mortality in the emergency department and prehospital setting: a hospital-based cohort study. Crit Care. 2015;19:158. doi: 10.1186/s13054-015-0884-y. PMID: 25888035. Exclusion: 3.

Kuluz J. Improving prehospital airway management and care of children with severe traumatic brain injury. Pediatr Crit Care Med. 2011;12(1):112-3. doi: 10.1097/PCC.0b013e3181e28a0b. PMID: 21209576. Exclusion: 9.

Kurz MC, Prince DK, Christenson J, et al. Association of advanced airway device with chest compression fraction during out-of-hospital cardiopulmonary arrest. Resuscitation. 2016;98:3540. doi: 10.1016/j.resuscitation.2015.10.011. PMID: 26520783. Exclusion: 3.

Kuster M, Exadaktylos A, Schnüriger B. Noninvasive hemodynamic monitoring in trauma patients. World J Emerg Surg. 2015;10:11. doi: 10.1186/s13017-015-0002-0. PMID: 25774210. Exclusion: 6.

Kutcher ME, Xu J, Vilardi RF, et al. Extracellular histone release in response to traumatic injury: implications for a compensatory role of activated protein C. J Trauma Acute Care Surg.

2012;73(6):1389-94. doi:

10.1097/TA.0b013e318270d595. PMID: 23188230. Exclusion: 4.
Kuzma K, Sporer KA, Michael GE, et al. When are prehospital intravenous catheters used for treatment? J Emerg Med. 2009;36(4):357-62. doi:

10.1016/j.jemermed.2007.11.054. PMID: 18571888. Exclusion: 4.

LaMantia MA, Platts-Mills TF, Biese K, et al. Predicting hospital admission and returns to the emergency department for elderly patients. Acad Emerg Med. 2010;17(3):252-9. doi: 10.1111/j.15532712.2009.00675.x. PMID: 20370757. Exclusion: 3.

LaMantia MA, Stewart PW, Platts-Mills TF, et al. Predictive value of initial triage vital signs for critically ill older adults. West J Emerg Med. 2013;14(5):453-60. doi: 10.5811/westjem.2013.5.13411. PMID: 24106542. Exclusion: 3.

Langhelle A, Sunde K, Wik L, et al. Arterial bloodgases with 500 - versus 1000 -ml tidal volumes during out-of-hospital CPR. Resuscitation. 2000;45(1):2733. PMID: 10838236. Exclusion: 3.

Larson CR, White CE, Spinella PC, et al. Association of shock, coagulopathy, and initial vital signs with massive transfusion in combat casualties. J Trauma. 2010;69 Suppl 1:S26-32. doi: 10.1097/TA.0b013e3181e423f4. PMID: 20622616. Exclusion: 4.

Lavery RF, Livingston DH, Tortella BJ, et al. The utility of venous lactate to triage injured patients in the trauma center. J Am Coll Surg. 2000;190(6):65664. PMID: 10873000. Exclusion: 2.

Layon AJ, Gabrielli A, Goldfeder BW, et al. Utstein style analysis of rural out-of-hospital cardiac arrest [OOHCA]: total cardiopulmonary resuscitation (CPR) time inversely correlates with hospital discharge rate. Resuscitation. 2003;56(1):59-66. PMID: 12505740. Exclusion: 3.

Laytin AD, Kumar V, Juillard CJ, et al. Choice of injury scoring system in low- and middle-income countries: lessons from Mumbai. Injury.

2015;46(12):2491-7. doi:

10.1016/j.injury.2015.06.029. PMID: 26233630. Exclusion: 14.

Lederer W, Lichtenberger C, Pechlaner C, et al. Recombinant tissue plasminogen activator during cardiopulmonary resuscitation in 108 patients with out-of-hospital cardiac arrest. Resuscitation. 2001;50(1):71-6. PMID: 11719132. Exclusion: 3. 
Lehmann R, Beekley A, Casey L, et al. The impact of advanced age on trauma triage decisions and outcomes: a statewide analysis. Am J Surg. 2009;197(5):571-4; discussion 4-5. doi: 10.1016/j.amjsurg.2008.12.037. PMID: 19393350. Exclusion: 6.

Lenartova L, Janciak I, Wilbacher I, et al. Severe traumatic brain injury in Austria III: prehospital status and treatment. Wien Klin Wochenschr. 2007;119(1-2):35-45. PMID: 17318749. Exclusion: 14.

Lerner EB, Shah MN, Swor RA, et al. Comparison of the 1999 and 2006 trauma triage guidelines: where do patients go? Prehosp Emerg Care. 2011;15(1):12-7. doi: 10.3109/10903127.2010.519819. PMID: 21054176. Exclusion: 4.

Levitt MA, Dresden GM. The efficacy of esmolol versus lidocaine to attenuate the hemodynamic response to intubation in isolated head trauma patients. Acad Emerg Med. 2001;8(1):19-24. PMID: 11136142. Exclusion: 3.

Lewis CT, Naumann DN, Crombie N, et al. Prehospital point-of-care lactate following trauma: a systematic review. J Trauma Acute Care Surg. 2016;81(4):748-55. doi: 10.1097/TA.0000000000001192. PMID: 27648771. Exclusion: 2.

Liao CH, Lin KJ, Fu CY, et al. Adrenal gland trauma: is extravasation an absolute indication for intervention? World J Surg. 2015;39(5):1312-9. doi: 10.1007/s00268-015-2953-4. PMID: 25613549. Exclusion: 4.

Lichte P, Weber C, Sellei RM, et al. Are bilateral tibial shaft fractures associated with an increased risk for adverse outcome? Injury. 2014;45(12):1985-9. PMID: 25458064. Exclusion: 4.

Lienhart HG, Wenzel V, Braun J, et al. Vasopressin zur Therapie eines therapierefraktären traumatischhämorrhagischen Schocks [Vasopressin for therapy of persistent traumatic hemorrhagic shock: the VITRIS.at study]. Der Anaesthesist. 2007;56(2):14550. PMID: 17265038. Exclusion: 9.

Lin CC, Yu JH, Lin CC, et al. Postintubation hemodynamic effects of intravenous lidocaine in severe traumatic brain injury. Am J Emerg Med. 2012;30(9):1782-7. doi: 10.1016/j.ajem.2012.02.013. PMID: 22633717. Exclusion: 14.
Lin G, Becker A, Lynn M. Do pre-hospital trauma alert criteria predict the severity of injury and a need for an emergent surgical intervention? Injury. 2012;43(9):1381-5. doi: 10.1016/j.injury.2010.11.014. PMID: 21145057. Exclusion: 6.

Lin YR, Wu HP, Chen WL, et al. Predictors of survival and neurologic outcomes in children with traumatic out-of-hospital cardiac arrest during the early postresuscitative period. J Trauma Acute Care Surg. 2013;75(3):439-47. doi:

10.1097/TA.0b013e31829e2543. PMID: 24089114. Exclusion: 14.

Liu N, Koh ZX, Goh J, et al. Prediction of adverse cardiac events in emergency department patients with chest pain using machine learning for variable selection. BMC Med Inf Decis Mak. 2014;14:75. doi: 10.1186/1472-6947-14-75. PMID: 25150702. Exclusion: 4.

Liu NT, Batchinsky AI, Cancio LC, et al. Development and validation of a novel fusion algorithm for continuous, accurate, and automated Rwave detection and calculation of signal-derived metrics. J Crit Care. 2013;28(5):885.e9-18. doi: 10.1016/j.jcrc.2013.02.015. PMID: 23618780. Exclusion: 4.

Liu NT, Salinas J. Machine learning and new vital signs monitoring in civilian en route care: a systematic review of the literature and future implications for the military. J Trauma Acute Care Surg. 2016;81(5 Suppl 2 Proceedings of the 2015 Military Health System Research Symposium):S111S5. doi: 10.1097/TA.0000000000000937. PMID: 26670115. Exclusion: 2.

Lockey DJ, Healey B, Crewdson K, et al. Advanced airway management is necessary in prehospital trauma patients. Br J Anaesth. 2015;114(4):657-62. doi: 10.1093/bja/aeu412. PMID: 25540067. Exclusion: 4.

Loomba RS, Nijhawan K, Aggarwal S, et al. Increased return of spontaneous circulation at the expense of neurologic outcomes: is prehospital epinephrine for out-of-hospital cardiac arrest really worth it? J Crit Care. 2015;30(6):1376-81. doi: 10.1016/j.jcrc.2015.08.016. PMID: 26428074. Exclusion: 4.

Lord B, Woollard M. The reliability of vital signs in estimating pain severity among adult patients treated by paramedics. Emerg Med J. 2011;28(2):147-50. doi: 10.1136/emj.2009.079384. PMID: 20926627. Exclusion: 3. 
Losvik OK, Murad MK, Skjerve E, et al. Ketamine for prehospital trauma analgesia in a low-resource rural trauma system: a retrospective comparative study of ketamine and opioid analgesia in a ten-year cohort in Iraq. Scand J Trauma Resusc Emerg Med. 2015;23:94. doi: 10.1186/s13049-015-0176-1. PMID: 26552691. Exclusion: 4.

Luk SS, Jacobs L, Ciraulo DL, et al. Outcome assessment of physiologic and clinical predictors of survival in patients after traumatic injury with a trauma score less than 5. J Trauma. 1999;46(1):1228. PMID: 9932694. Exclusion: 3.

Lund H, Kofoed SC, Hillingso JG, et al. High mortality after emergency room laparotomy in haemodynamically unstable trauma patients. Dan Med Bull. 2011;58(5):A4275. PMID: 21535986. Exclusion: 14.

Lusczek ER, Muratore SL, Dubick MA, et al. Assessment of key plasma metabolites in combat casualties. J Trauma Acute Care Surg. 2017;82(2):309-16. doi: 10.1097/TA.0000000000001277. PMID: 27787435. Exclusion: 7.

Lynch KT, Essig RM, Long DM, et al. Nationwide secondary overtriage in level 3 and level 4 trauma centers: are these transfers necessary? J Surg Res. 2016;204(2):460-6. doi: 10.1016/j.jss.2016.05.035. PMID: 27565083. Exclusion: 5.

Ma OJ, Kefer MP, Stevison KF, et al. Operative versus nonoperative management of blunt abdominal trauma: role of ultrasound-measured intraperitoneal fluid levels. Am J Emerg Med. 2001;19(4):284-6. PMID: 11447513. Exclusion: 4.

Mackenzie CF, Hu P, Sen A, et al. Automatic prehospital vital signs waveform and trend data capture fills quality management, triage and outcome prediction gaps. AMIA Annu Symp Proc. 2008;Annual Symposium Proceedings/AMIA Symposium.:318-22. PMID: 18999022. Exclusion: 6.

MacLeod JB, Lynn M, McKenney MG, et al. Early coagulopathy predicts mortality in trauma. J Trauma. 2003;55(1):39-44. PMID: 12855879. Exclusion: 5.

Magnotti LJ, Zarzaur BL, Fischer PE, et al. Improved survival after hemostatic resuscitation: does the emperor have no clothes? J Trauma. 2011;70(1):97102. doi: 10.1097/TA.0b013e3182051691. PMID: 21217487. Exclusion: 4.
Majercik S. Re: red cell distribution width is predictive of mortality in trauma patients. J Trauma Acute Care Surg. 2013;75(2):346. doi: 10.1097/TA.0b013e31829957d4. PMID: 23887574. Exclusion: 9.

Malone DL, Kuhls D, Napolitano LM, et al. Back to basics: validation of the admission systemic inflammatory response syndrome score in predicting outcome in trauma. J Trauma. 2001;51(3):458-63. PMID: 11535891. Exclusion: 7.

Malvestio MA, de Sousa RM. [Advanced life support: care provided to motor vehicle crash victims]. Rev Saude Publica. 2002;36(5):584-9. PMID: 12471383. Exclusion: 13.

Martin SK, Shatney CH, Sherck JP, et al. Blunt trauma patients with prehospital pulseless electrical activity (PEA): poor ending assured. J Trauma. 2002;53(5):876-80; discussion 80-1. PMID: 12435937. Exclusion: 14.

Mattox KL, Maningas PA, Moore EE, et al. Prehospital hypertonic saline/dextran infusion for post-traumatic hypotension. The USA Multicenter Trial. Ann Surg. 1991;213(5):482. PMID: 1708984. Exclusion: 11.

Mauritz W, Schimetta W, Oberreither S, et al. Are hypertonic hyperoncotic solutions safe for prehospital small-volume resuscitation? Results of a prospective observational study. Eur J Emerg Med. 2002;9(4):315-9. PMID: 12501029. Exclusion: 4.

McCoy CE, Chakravarthy B, Lotfipour S. Guidelines for field triage of injured patients: in conjunction with the morbidity and mortality weekly report published by the Center for Disease Control and Prevention. West J Emerg Med. 2013;14(1):69-76. doi: 10.5811/westjem.2013.1.15981. PMID: PMC3582524. Exclusion: 2.

McDermott FT, Rosenfeld JV, Laidlaw JD, et al. Evaluation of management of road trauma survivors with brain injury and neurologic disability in Victoria. J Trauma. 2004;56(1):137-49. PMID: 14749581. Exclusion: 4.

McKee A, Baskett PJF. Management of major trauma: immediate care in the field. Current Anaesthesia and Critical Care. 1996;7(3):115-9. doi: 10.1016/S0953-7112(96)80080-9. Exclusion: 8.

McLaughlin DF, Niles SE, Salinas J, et al. A predictive model for massive transfusion in combat casualty patients. J Trauma. 2008;64(2 Suppl):S5763; discussion S. doi:

10.1097/TA.0b013e318160a566. PMID: 18376173. Exclusion: 14. 
McNab A, Burns B, Bhullar I, et al. A prehospital shock index for trauma correlates with measures of hospital resource use and mortality. Surgery. 2012;152(3):473-6. doi: 10.1016/j.surg.2012.07.010. PMID: 22938906. Exclusion: 15.

Mellick LB. Open airway, neutral cervical spine. Pediatr Emerg Care. 2016;32(3):e7-8. doi: 10.1097/PEC.0000000000000738. PMID: 26928108. Exclusion: 2.

Mica L, Albrecht K, Keel M, et al. Independent predictors of early death of polytrauma patients: an analysis of 696 patients. Journal of Trauma Treatment. 2012;1(3) doi: 10.4172/21671222.1000118. Exclusion: 14.

Michailidou M, Velmahos GC, van der Wilden GM, et al. "Blush" on trauma computed tomography: not as bad as we think! [Erratum appears in J Trauma Acute Care Surg. 2013 Jan;74(1):347 Note: van der Wilden, Gwen [corrected to van der Wilden, Gwendolyn M]]. J Trauma Acute Care Surg. 2012;73(3):580-4; discussion 4-6. doi: 10.1097/TA.0b013e318265cbd4. PMID: 22929487. Exclusion: 7.

Mifflin KA, Richenberger E, Horning J, et al. Seeing the difference. JEMS. 2013;38(12):26-7. PMID: 24592563. Exclusion: 4.

Mitra B, Cameron PA, Mori A, et al. Early prediction of acute traumatic coagulopathy. Resuscitation. 2011;82(9):1208-13. doi: 10.1016/j.resuscitation.2011.04.007. PMID: 21600687. Exclusion: 14.

Mitra B, Fitzgerald M, Chan J. The utility of a shock index $>1$ as an indication for pre-hospital oxygen carrier administration in major trauma. Injury. 2014;45(1):61-5. doi: 10.1016/j.injury.2013.01.010. PMID: 23391451. Exclusion: 14.

Mock K, Keeley J, Moazzez A, et al. Predictors of mortality in trauma patients aged 80 years or older. Am Surg. 2016;82(10):926-9. PMID: 27779975. Exclusion: 7.

Moore HB, Moore EE, Liras IN, et al. Acute fibrinolysis shutdown after injury occurs frequently and increases mortality: a multicenter evaluation of 2,540 severely injured patients. J Am Coll Surg. 2016;222(4):347-55. doi: 10.1016/j.jamcollsurg.2016.01.006. PMID: 26920989. Exclusion: 14.
Mora AG, Ervin AT, Ganem VJ, et al. Aeromedical evacuation of combat patients by military critical care air transport teams with a lower hemoglobin threshold approach is safe. J Trauma Acute Care Surg. 2014;77(5):724-8. doi: 10.1097/TA.0000000000000446. PMID: 25494424. Exclusion: 7.

Morley AP. Prehospital monitoring of trauma patients: experience of a helicopter emergency medical service. Br J Anaesth. 1996;76(5):726-30. PMID: 8688277. Exclusion: 8.

Morris JA, Jr., Norris PR. Role of reduced heart rate volatility in predicting death in trauma patients. Advances in surgery. 2005;39:77-96. PMID: 16250547. Exclusion: 7.

Morris JA, Jr., Norris PR, Ozdas A, et al. Reduced heart rate variability: an indicator of cardiac uncoupling and diminished physiologic reserve in 1,425 trauma patients. J Trauma. 2006;60(6):116573; discussion 73-4. doi:

10.1097/01.ta.0000220384.04978.3b. PMID: 16766957. Exclusion: 7.

Morris JA, Jr., Norris PR, Waitman LR, et al. Adrenal insufficiency, heart rate variability, and complex biologic systems: a study of 1,871 critically ill trauma patients. J Am Coll Surg. 2007;204(5):88592; discussion 92-3. doi:

10.1016/j.jamcollsurg.2007.01.019. PMID: 17481504. Exclusion: 7.

Morrison JJ, Dickson EJ, Jansen JO, et al. Utility of admission physiology in the surgical triage of isolated ballistic battlefield torso trauma. J Emerg Trauma Shock. 2012;5(3):233-7. doi: 10.4103/09742700.99690. PMID: 22988401. Exclusion: 7.

Morrison LJ, Baker AJ, Rhind SG, et al. The Toronto prehospital hypertonic resuscitation--head injury and multiorgan dysfunction trial: feasibility study of a randomized controlled trial. J Crit Care.

2011;26(4):363-72. PMID: 21106341. Exclusion: 4.

Moustafa F, Loze C, Pereira B, et al. Assessment of urinary dipstick in patients admitted to an ED for blunt abdominal trauma. Am J Emerg Med. 2017;35(4):628-31. doi: 10.1016/j.ajem.2016.12.047. PMID: 28040382. Exclusion: 4.

Mowat J. Shock horror! How accurate is the PHTLS classification of hypovolaemic shock on scene? Journal of Paramedic Practice. 2014;6(4):200-1. Exclusion: 4. 
Mowery NT, Norris PR, Riordan W, et al. Cardiac uncoupling and heart rate variability are associated with intracranial hypertension and mortality: a study of 145 trauma patients with continuous monitoring. J Trauma. 2008;65(3):621-7. doi: 10.1097/TA.0b013e3181837980. PMID: 18784576. Exclusion: 7.

Moy HP, Cosgrove A. Permissive hypotension in trauma. EMS World. 2016;45(3):44-7. PMID: 27048075. Exclusion: 9.

Mukherjee K, Rimer M, McConnell MD, et al. Physiologically focused triage criteria improve utilization of pediatric surgeon-directed trauma teams and reduce costs. J Pediatr Surg. 2010;45(6):1315-23. doi: 10.1016/j.jpedsurg.2010.02.108. PMID: 20620338. Exclusion: 2.

Mullen M, Cerri G, Murray R, et al. Use of point-ofcare lactate in the prehospital aeromedical environment. Prehospital Disaster Med. 2014;29(2):200-3. doi: 10.1017/S1049023X13009254. PMID: 24642116. Exclusion: 3.

Murphy MF, Keller M, Luten R, et al. The young airway: prehospital assessment \& management of pediatric respiratory distress. JEMS. 2008;33(6):5871. doi: 10.1016/S0197-2510(08)70226-2. PMID: 18513595. Exclusion: 9.

Mutschler M, Nienaber U, Brockamp T, et al. A critical reappraisal of the ATLS classification of hypovolaemic shock: does it really reflect clinical reality? Resuscitation. 2013;84(3):309-13. doi: 10.1016/j.resuscitation.2012.07.012. PMID: 22835498. Exclusion: 5.

Mutschler M, Nienaber U, Munzberg M, et al. Assessment of hypovolaemic shock at scene: is the PHTLS classification of hypovolaemic shock really valid? Emerg Med J. 2014;31(1):35-40. doi: 10.1136/emermed-2012-202130. PMID: 23302502. Exclusion: 5.

Mutschler M, Paffrath T, Wolfl C, et al. The ATLS() classification of hypovolaemic shock: a well established teaching tool on the edge? Injury. 2014;45 Suppl 3:S35-8. doi: 10.1016/j.injury.2014.08.015. PMID: 25284231. Exclusion: 5.

Nable JV, Lawner BJ, Brady WJ. 2016: emergency medical services annotated literature in review. Am J Emerg Med. 2016;34(11):2193-9. doi: 10.1016/j.ajem.2016.07.024. PMID: 27592723. Exclusion: 3.
Nakahara S, Matsuoka T, Ueno M, et al. Triage protocol modifications to reduce undertriage. $\mathrm{J}$ Trauma. 2011;71(1):267-8. doi: 10.1097/TA.0b013e318220fe7a. PMID: 21818045. Exclusion: 9.

Nakatani K, Yukioka H, Fujimori M, et al. Utility of colorimetric end-tidal carbon dioxide detector for monitoring during prehospital cardiopulmonary resuscitation. Am J Emerg Med. 1999;17(2):203-6. PMID: 10102328. Exclusion: 3.

Naraghi L, Mejaddam AY, Birkhan OA, et al. Sample entropy predicts lifesaving interventions in trauma patients with normal vital signs. J Crit Care. 2015;30(4):705-10. doi: 10.1016/j.jcrc.2015.03.018. PMID: 25858820. Exclusion: 14.

Nast-Kolb D, Waydhas C, Gippner-Steppert C, et al. Indicators of the posttraumatic inflammatory response correlate with organ failure in patients with multiple injuries. J Trauma. 1997;42(3):446-54; discussion 54-5. PMID: 9095112. Exclusion: 14.

Navin DM, Sacco WJ, McGill G. Application of a new resource-constrained triage method to militaryage victims. Mil Med. 2009;174(12):1247-55. PMID: 20055064. Exclusion: 6.

Neuhaus V, Simmen HP. Vom SchockraumManagement bis zur definitiven Versorgung in der Unfallchirurgie

Praxis (Bern 1994). 2017;106(5):249-53. doi: 10.1024/1661-8157/a002611. PMID: 28253806. Exclusion: 13.

Neville AL, Nemtsev D, Manasrah R, et al. Mortality risk stratification in elderly trauma patients based on initial arterial lactate and base deficit levels. Am Surg. 2011;77(10):1337-41. PMID: 22127083. Exclusion: 15.

Nevin DG, Green SJ, Weaver AE, et al. An observational study of paediatric pre-hospital intubation and anaesthesia in 1933 children attended by a physician-led, pre-hospital trauma service. Resuscitation. 2014;85(2):189-95. doi: 10.1016/j.resuscitation.2013.10.006. PMID: 24145041. Exclusion: 8.

Newgard CD, Cudnik M, Warden CR, et al. The predictive value and appropriate ranges of prehospital physiological parameters for high-risk injured children. Pediatr Emerg Care. 2007;23(7):450-6. PMID: 17666925. Exclusion: 15. 
Newgard CD, Fu R, Zive D, et al. Prospective validation of the National Field Triage Guidelines for identifying seriously injured persons. J Am Coll Surg. 2016;222(2):146-58e2. doi: 10.1016/j.jamcollsurg.2015.10.016. PMID: 26712244. Exclusion: 2.

Newgard CD, Hedges JR, Adams A, et al. Secondary triage: early identification of high-risk trauma patients presenting to non-tertiary hospitals. Prehosp Emerg Care. 2007;11(2):154-63. PMID: 17454801. Exclusion: 7.

Newgard CD, Koprowicz K, Wang H, et al. Variation in the type, rate, and selection of patients for out-ofhospital airway procedures among injured children and adults. Acad Emerg Med. 2009;16(12):1269-76. doi: 10.1111/j.1553-2712.2009.00604.x. PMID: 20053248. Exclusion: 4.

Newgard CD, Meier EN, McKnight B, et al. Understanding traumatic shock: out-of-hospital hypotension with and without other physiologic compromise. J Trauma Acute Care Surg.

2015;78(2):342-51. doi: 10.1097/TA.0000000000000478. PMID: 25757121. Exclusion: 15.

Newgard CD, Rudser K, Hedges JR, et al. A critical assessment of the out-of-hospital trauma triage guidelines for physiologic abnormality. J Trauma. 2010;68(2):452-62. doi: 10.1097/TA.0b013e3181ae20c9. PMID: 20154558. Exclusion: 14.

Nieman CT, Merlino JI, Kovach B, et al. Intubated pediatric patients requiring transport: a review of patients, indications, and standards. Air Med J. 2002;21(1):22-5. PMID: 11805763. Exclusion: 3.

Nirula R, Maier R, Moore E, et al. Scoop and run to the trauma center or stay and play at the local hospital: hospital transfer's effect on mortality. J Trauma. 2010;69(3):595-9; discussion 9-601. doi: 10.1097/TA.0b013e3181ee6e32. PMID: 20838131. Exclusion: 3.

Norris PR, Anderson SM, Jenkins JM, et al. Heart rate multiscale entropy at three hours predicts hospital mortality in 3,154 trauma patients. Shock. 2008;30(1):17-22. doi: 10.1097/SHK.0b013e318164e4d0. PMID: 18323736. Exclusion: 7.

Norris PR, Canter JA, Jenkins JM, et al. Personalized medicine: genetic variation and loss of physiologic complexity are associated with mortality in 644 trauma patients. Ann Surg. 2009;250(4):524-30. doi: 10.1097/SLA.0b013e3181b8fb1f. PMID: 19730237. Exclusion: 7.
Norris PR, Stein PK, Morris JA, Jr. Reduced heart rate multiscale entropy predicts death in critical illness: a study of physiologic complexity in 285 trauma patients. J Crit Care. 2008;23(3):399-405. doi: 10.1016/j.jcrc.2007.08.001. PMID: 18725047. Exclusion: 7.

Nunez TC, Voskresensky IV, Dossett LA, et al. Early prediction of massive transfusion in trauma: simple as ABC (assessment of blood consumption)? J

Trauma. 2009;66(2):346-52. doi: 10.1097/TA.0b013e3181961c35. PMID: 19204506. Exclusion: 14.

Odom SR. Re: lactate clearance as a predictor of mortality. J Trauma Acute Care Surg. 2014;77(1):183-4. doi: 10.1097/TA.0000000000000285. PMID: 24977780. Exclusion: 9.

Odom SR, Howell MD, Silva GS, et al. Lactate clearance as a predictor of mortality in trauma patients. [Erratum appears in J Trauma Acute Care Surg. 2014 Mar;76(3):902]. J Trauma Acute Care Surg. 2013;74(4):999-1004. doi: 10.1097/TA.0b013e3182858a3e. PMID: 23511137. Exclusion: 9.

Olaussen A, Peterson EL, Mitra B, et al. Massive transfusion prediction with inclusion of the prehospital Shock Index. Injury. 2015;46(5):822-6. doi: 10.1016/j.injury.2014.12.009. PMID: 25555919. Exclusion: 14.

Ouellet JF, Roberts DJ, Tiruta C, et al. Admission base deficit and lactate levels in Canadian patients with blunt trauma: are they useful markers of mortality? J Trauma Acute Care Surg.

2012;72(6):1532-5. doi: 10.1097/TA.0b013e318256dd5a. PMID: 22695417. Exclusion: 15.

Oyetunji TA, Chang DC, Crompton JG, et al. Redefining hypotension in the elderly: normotension is not reassuring. Arch Surg. 2011;146(7):865-9. doi: 10.1001/archsurg.2011.154. PMID: 21768435.

Exclusion: 15.

Papaioannou V, Giannakou M, Maglaveras N, et al. Investigation of heart rate and blood pressure variability, baroreflex sensitivity, and approximate entropy in acute brain injury patients. J Crit Care. 2008;23(3):380-6. doi: 10.1016/j.jcrc.2007.04.006. PMID: 18725044. Exclusion: 7. 
Papaioannou VE, Maglaveras N, Houvarda I, et al. Investigation of altered heart rate variability, nonlinear properties of heart rate signals, and organ dysfunction longitudinally over time in intensive care unit patients. J Crit Care. 2006;21(1):95-103; discussion -4. doi: 10.1016/j.jcrc.2005.12.007. PMID: 16616632. Exclusion: 7.

Parks JK, Elliott AC, Gentilello LM, et al. Systemic hypotension is a late marker of shock after trauma: a validation study of Advanced Trauma Life Support principles in a large national sample. Am J Surg. 2006;192(6):727-31. PMID: 17161083. Exclusion: 6.

Pasquier P, Boutonnet M, Giraud N, et al. Hypotension redefined, shock index and massive transfusion. J Trauma. 2011;71(3):784-5. doi: 10.1097/TA.0b013e318228b83d. PMID: 21909011. Exclusion: 9.

Pasquier P, Dubost C, Malgras B, et al. The shock index for pre-hospital identification of trauma patients with early acute coagulopathy and massive bleeding. Crit Care. 2015;19:152. doi:

10.1186/s13054-015-0839-3. PMID: 25887371. Exclusion: 9.

Pasquier P, Tourtier JP, Boutonnet M, et al. The shock index: a further simple tool of triage in combat casualties. Injury. 2012;43(7):1230. doi: 10.1016/j.injury.2011.12.019. PMID: 22244997. Exclusion: 9.

Pasquier P, Tourtier JP, Boutonnet M, et al. Utility of shock index calculation in combat casualty triage protocol? Am J Surg. 2012;204(5):812. doi: 10.1016/j.amjsurg.2011.10.022. PMID: 22579231. Exclusion: 9.

Pearl A, Bar-Or R, Bar-Or D. An artificial neural network derived trauma outcome prediction score as an aid to triage for non-clinicians. Stud Health Technol Inform. 2008;136:253-8. PMID: 18487740. Exclusion: 4.

Pearse RM. Extending the role of lactate measurement into the prehospital environment. Crit Care. 2009;13(1):115. doi: 10.1186/cc7687. PMID: 19232076. Exclusion: 9.

Pedersen M, Brandt VS, Holler JG, et al. Lactate level, aetiology and mortality of adult patients in an emergency department: a cohort study. Emerg Med J. 2015;32(9):678-84. doi: 10.1136/emermed-2014204305. PMID: 25755268. Exclusion: 3.

Pérez LR, Chan GK. Clinical decision making and management of blunt traumatic thoracic aortic injuries. Air Med J. 2008;27(3):139-43. PMID: 18456176. Exclusion: 9.
512. impact of discharging minimally injured trauma patient: does age play a role in trauma admission? J Trauma. 2011;70(6):1331-6. doi: 10.1097/TA.0b013e31821693e2. PMID: 21817969. Exclusion: 5.

Peterson DL, Schinco MA, Kerwin AJ, et al. Evaluation of initial base deficit as a prognosticator of outcome in the pediatric trauma population. Am Surg. 2004;70(4):326-8. PMID: 15098786.

Exclusion: 14.

Plackett TP, Nielsen JS, Hahn CD, et al. Accuracy and reliability of triage at the point of injury during operation enduring freedom. J Spec Oper Med. 2016;16(1):51-6. PMID: 27045494. Exclusion: 2.

Porter JM, Ivatury RR. In search of the optimal end points of resuscitation in trauma patients: a review. J Trauma. 1998;44(5):908-14. PMID: 9603098.

Exclusion: 2.

Price CL, Brace-Mcdonnell SJ, Stallard N, et al. Performance characteristics of five triage tools for major incidents involving traumatic injuries to children. Injury. 2016;47(5):988-92. doi: 10.1016/j.injury.2015.10.076. PMID: 26653268. Exclusion: 4.

Proctor KG, Atapattu SA, Duncan RC. Heart rate variability index in trauma patients. J Trauma. 2007;63(1):33-43. doi: 10.1097/01.ta.0000251593.32396.df. PMID: 17622866. Exclusion: 7.

Raatiniemi L, Mikkelsen K, Fredriksen K, et al. Do pre-hospital anaesthesiologists reliably predict mortality using the NACA severity score? A retrospective cohort study. Acta Anaesthesiol Scand. 2013;57(10):1253-9. doi: 10.1111/aas.12208. PMID: 24134443. Exclusion: 4.

Rady MY. The role of central venous oximetry, lactic acid concentration and shock index in the evaluation of clinical shock: a review. Resuscitation. 1992;24(1):55-60. PMID: 1332162. Exclusion: 11.

Rady MY, Smithline HA, Blake H, et al. A comparison of the shock index and conventional vital signs to identify acute, critical illness in the emergency department. Ann Emerg Med. 1994;24(4):685-90. PMID: 8092595. Exclusion: 11.

Rahbar MH, del Junco DJ, Huang H, et al. A latent class model for defining severe hemorrhage: experience from the PROMMTT study. J Trauma Acute Care Surg. 2013;75(1 Suppl 1):S82-8. doi: 10.1097/TA.0b013e31828fa3d3. PMID: 23778516. Exclusion: 4. 
Rainer TH, Cheung NK, Yeung JH, et al. Do trauma teams make a difference? A single centre registry study. Resuscitation. 2007;73(3):374-81. PMID: 17289243. Exclusion: 2.

Rapenne T, Moreau D, Lenfant F, et al. Could heart rate variability analysis become an early predictor of imminent brain death? A pilot study. Anesth Analg. 2000;91(2):329-36. PMID: 10910843. Exclusion: 14.

Rapenne T, Moreau D, Lenfant F, et al. Could heart rate variability predict outcome in patients with severe head injury? A pilot study. J Neurosurg Anesthesiol. 2001;13(3):260-8. PMID: 11426105. Exclusion: 14.

Rappold JF, Coimbra R, Hoyt DB, et al. Female gender does not protect blunt trauma patients from complications and mortality. J Trauma.

2002;53(3):436-41; discussion 41. PMID: 12352477. Exclusion: 2.

Rau CS, Wu SC, Kuo SCH, et al. Prediction of massive transfusion in trauma patients with shock index, modified shock index, and age shock index. Int J Environ Res Public Health. 2016;13(7):683. doi: 10.3390/ijerph13070683. PMID: 27399737.

Exclusion: 14.

Rehn M, Perel P, Blackhall K, et al. Prognostic models for the early care of trauma patients: a systematic review. Scand J Trauma Resusc Emerg Med. 2011;19:17. doi: 10.1186/1757-7241-19-17. PMID: 21418599. Exclusion: 2.

Remick KN, Schwab CW, Smith BP, et al. Defining the optimal time to the operating room may salvage early trauma deaths. J Trauma Acute Care Surg. 2014;76(5):1251-8. doi:

10.1097/TA.0000000000000218. PMID: 24747456. Exclusion: 14.

Rendy L, Sapan HB, Kalesaran LTB. Multiple organ dysfunction syndrome (MODS) prediction score in multi-trauma patients. International Journal of Surgery Open. 2017;8:1-6. doi: 10.1016/j.ijso.2017.05.003. Exclusion: 14.

Richards JE, Matuszewski PE, Griffin SM, et al. The eole of elevated lactate as a risk factor for pulmonary morbidity after early fixation of femoral shaft fractures. J Orthop Trauma. 2016;30(6):312-8. doi: 10.1097/BOT.0000000000000528. PMID: 27206261. Exclusion: 14.

Richards JR, Ferrall SJ. Triage ability of emergency medical services providers and patient disposition: a prospective study. Prehospital Disaster Med. 1999;14(3):174-9. PMID: 10724742. Exclusion: 4.
Riordan WP, Jr., Norris PR, Jenkins JM, et al. Early loss of heart rate complexity predicts mortality regardless of mechanism, anatomic location, or severity of injury in 2178 trauma patients. J Surg Res. 2009;156(2):283-9. doi: 10.1016/j.jss.2009.03.086.

PMID: 19592027. Exclusion: 7.

Roberts TCN, Berry RD. Pre-hospital trauma care and aero-medical transfer: a military perspective. Continuing Education in Anaesthesia, Critical Care \& Pain. 2012;12(4):186-9. Exclusion: 2.

Rognas L, Hansen TM, Kirkegaard H, et al. Standard operating procedure changed pre-hospital critical care anaesthesiologists' behaviour: a quality control study. Scand J Trauma Resusc Emerg Med. 2013;21:84. doi: 10.1186/1757-7241-21-84. PMID: 24308781. Exclusion: 4.

Rojas-Marcial C, Pedraza-Zarate MA, BautistaBarranco $\mathrm{H}$, et al. [Lactate levels with regards to the pulse pressure in patients with shock]. Rev Med Inst Mex Seguro Soc. 2016;54(1):16-9. PMID: 26820193. Exclusion: 3.

Ross DW, Caputo LM, Salottolo KM, et al. Lights and siren transport and the need for hospital intervention in trauma patients. Prehosp Emerg Care. 2016;20(2):260-5. doi: 10.3109/10903127.2015.1076094. PMID: 26382707. Exclusion: 4.

Ryan ML, Thorson CM, Otero CA, et al. Clinical applications of heart rate variability in the triage and assessment of traumatically injured patients. Anesthesiol Res Pract. 2011;2011:416590. doi: 10.1155/2011/416590. PMID: 21350685. Exclusion: 2.

Saad S, Mohamed N, Moghazy A, et al. Venous glucose, serum lactate and base deficit as biochemical predictors of mortality in patients with polytrauma. Ulus Travma Acil Cerrahi Derg. 2016;22(1):29-33. doi: 10.5505/tjtes.2015.96832. PMID: 27135075. Exclusion: 14.

Sagraves SG, Newell MA, Bard MR, et al. Tissue oxygenation monitoring in the field: a new EMS vital sign. J Trauma. 2009;67(3):441-4. doi: 10.1097/TA.0b013e3181b88de7. PMID: 19741383. Exclusion: 15.

Salcedo MC, Tart K, Hall K. A systematic review of human and veterinary applications of noninvasive tissue oxygen monitoring. J Vet Emerg Crit Care (San Antonio). 2016;26(3):323-32. doi: 10.1111/vec.12465. PMID: 27062438. Exclusion: 2. 
Salvucci A, Jr. Medical abstract reviews.

Desaturation, pulse reactivity in...RSI. Emerg Med Serv. 2004;33(3):42-. Exclusion: 4.

Sampalis JS, Tamim H, Nikolis A, et al. Predictive validity and internal consistency of the pre-hospital index measured on-site by physicians. Accid Anal Prev. 1996;28(6):675-84. PMID: 9006636. Exclusion: 4.

Santaguida PL, Riley CM, Matchar DB. Chapter 5: assessing risk of bias as a domain of quality in medical test studies. J Gen Intern Med. 2012;27 Suppl 1:S33-8. doi: 10.1007/s11606-012-2030-8. PMID: 22648673. Exclusion: 2.

Santos D, Carron PN, Yersin B, et al. EZ-IO() intraosseous device implementation in a pre-hospital emergency service: a prospective study and review of the literature. Resuscitation. 2013;84(4):440-5. doi: 10.1016/j.resuscitation.2012.11.006. PMID: 23160104. Exclusion: 4.

Sasser SM, Hunt RC, Faul M, et al. Guidelines for field triage of injured patients recommendations of the National Expert Panel on Field Triage, 2011. MMWR Recommendations \& Reports. 2012;61(RR1):1-21. PMID: 22237112. Exclusion: 2.

Sasser SM, Hunt RC, Sullivent EE, et al. Guidelines for field triage of injured patients. Recommendations of the National Expert Panel on Field Triage. MMWR Recommendations \& Reports. 2009;58(RR1):1-35. PMID: 19165138. Exclusion: 2.

Scerbo M, Radhakrishnan H, Cotton B, et al. Prehospital triage of trauma patients using the Random Forest computer algorithm. J Surg Res. 2014;187(2):371-6. doi: 10.1016/j.jss.2013.06.037. PMID: 24484906. Exclusion: 6.

Schalk R, Meininger D, Ruesseler M, et al. Emergency airway management in trauma patients using laryngeal tube suction. Prehosp Emerg Care. 2011;15(3):347-50. doi: 10.3109/10903127.2011.561405. PMID: 21521037. Exclusion: 14.

Scheetz LJ. Prehospital factors associated with severe injury in older adults. Injury. 2010;41(9):886-93. doi: 10.1016/j.injury.2010.05.018. PMID: 20542270. Exclusion: 2.

Schmelzer TM, Perron AD, Thomason MH, et al. A comparison of central venous and arterial base deficit as a predictor of survival in acute trauma. Am J Emerg Med. 2008;26(2):119-23. doi: 10.1016/j.ajem.2007.01.024. PMID: 18272088. Exclusion: 15.
Schnoor J, Herfurtner-Pröpper C, Kunitz O, et al. AEDs im rettungsdienst: Ein 4-jahres-rückblick [AED's and ambulance service: a 4 years retrospect]. Notarzt. 2003;19(2):64-7. doi: 10.1055/s-200338595. Exclusion: 3.

Schreiber MA, Meier EN, Tisherman SA, et al. A controlled resuscitation strategy is feasible and safe in hypotensive trauma patients: results of a prospective randomized pilot trial. J Trauma Acute Care Surg. 2015;78(4):687-95; discussion 95-7. doi: 10.1097/TA.0000000000000600. PMID: 25807399. Exclusion: 14.

Schreiber MA, Perkins J, Kiraly L, et al. Early predictors of massive transfusion in combat casualties. J Am Coll Surg. 2007;205(4):541-5. doi: 10.1016/j.jamcollsurg.2007.05.007. PMID: 17903727. Exclusion: 4.

Seymour CW, Cooke CR, Heckbert SR, et al. Prehospital systolic blood pressure thresholds: a community-based outcomes study. Acad Emerg Med. 2013;20(6):597-604. doi: 10.1111/acem.12142. PMID: 23758307. Exclusion: 3.

Shackelford SA, Colton K, Stansbury LG, et al. Early identification of uncontrolled hemorrhage after trauma: current status and future direction. J Trauma Acute Care Surg. 2014;77(3 Suppl 2):S222-7. doi: 10.1097/TA.0000000000000198. PMID: 24770559. Exclusion: 2.

Sheffy N, Chemsian RV, Grabinsky A. Anaesthesia considerations in penetrating trauma. Br J Anaesth. 2014;113(2):276-85. doi: 10.1093/bja/aeu234. PMID: 24980427. Exclusion: 2.

Shin SD, Ahn KO, Song KJ, et al. Out-of-hospital airway management and cardiac arrest outcomes: a propensity score matched analysis. Resuscitation. 2012;83(3):313-9. doi:

10.1016/j.resuscitation.2011.10.028. PMID:

22101202. Exclusion: 14.

Shirley PJ. Prehospital airway management by paramedics. Anaesthesia. 2005;60(2):204. PMID: 15644027. Exclusion: 9.

Siegel JH, Rivkind AI, Dalal S, et al. Early physiologic predictors of injury severity and death in blunt multiple trauma. Arch Surg. 1990;125(4):498508. PMID: 2322117. Exclusion: 11. 
Silvestri S, Ralls GA, Krauss B, et al. The effectiveness of out-of-hospital use of continuous end-tidal carbon dioxide monitoring on the rate of unrecognized misplaced intubation within a regional emergency medical services system. Ann Emerg Med. 2005;45(5):497-503. PMID: 15855946. Exclusion: 5.

Singh JM, MacDonald RD, Bronskill SE, et al. Incidence and predictors of critical events during urgent air-medical transport. Cmaj. 2009;181(9):57984. doi: 10.1503/cmaj.080886. PMID: 19752105. Exclusion: 6.

Singh S, Allen WD, Jr., Venkataraman ST, et al. Utility of a novel quantitative handheld microstream capnometer during transport of critically ill children. Am J Emerg Med. 2006;24(3):302-7. PMID: 16635702. Exclusion: 5.

Sivagangabalan G, Ong AT, Narayan A, et al. Effect of prehospital triage on revascularization times, left ventricular function, and survival in patients with STelevation myocardial infarction. Am J Cardiol. 2009;103(7):907-12. doi:

10.1016/j.amjcard.2008.12.007. PMID: 19327414.

Exclusion: 5.

Smith CE, Kovach B, Polk JD, et al. Prehospital tracheal intubating conditions during rapid sequence intubation: rocuronium versus vecuronium. Air Med J. 2002;21(1):26-32. PMID: 11805764. Exclusion: 5.

Smith G, Morgans A, Boyle M. Use of the Valsalva manoeuvre in the prehospital setting: a review of the literature. Emerg Med J. 2009;26(1):8-10. doi: 10.1136/emj.2008.061572. PMID: 19104086. Exclusion: 7.

Smith IM, James RH, Dretzke J, et al. Prehospital blood product resuscitation for trauma: a systematic review. Shock. 2016;46(1):3-16. doi: 10.1097/SHK.0000000000000569. PMID: 26825635. Exclusion: 4.

Sokol KK, Black GE, Azarow KS, et al. Prehospital interventions in severely injured pediatric patients: rethinking the ABCs. J Trauma Acute Care Surg. 2015;79(6):983-9; discussion 9-90. doi: 10.1097/TA.0000000000000706. PMID: 26680137. Exclusion: 4.

Soreide E, Deakin CD. Pre-hospital fluid therapy in the critically injured patient--a clinical update. Injury. 2005;36(9):1001-10. PMID: 16098325. Exclusion: 5.
Soti A, Temesvari P, Hetzman L, et al. Implementing new advanced airway management standards in the Hungarian physician staffed Helicopter Emergency Medical Service. Scand J Trauma Resusc Emerg Med. 2015;23:3. doi: 10.1186/s13049-014-0081-z. PMID: 25571961. Exclusion: 5.

Spaite DW, Hu C, Bobrow BJ, et al. Mortality and prehospital blood pressure in patients with major traumatic brain injury: implications for the hypotension threshold. JAMA Surg. 2017;152(4):360-8. doi: 10.1001/jamasurg.2016.4686. PMID: 27926759. Exclusion: 14.

Sporer KA, Tabas JA, Tam RK, et al. Do medications affect vital signs in the prehospital treatment of acute decompensated heart failure? Prehosp Emerg Care. 2006;10(1):41-5. PMID: 16418090. Exclusion: 14.

SR K, Seymour R, Manoli A, et al. Development of a middle-age and geriatric trauma mortality risk score: a tool to guide palliative care consultations. Bull Hosp Jt Dis (2013). 2016;74(4):298-305. PMID: 27815954. Exclusion: 4.

Steg PG, Bonnefoy E, Chabaud S, et al. Impact of time to treatment on mortality after prehospital fibrinolysis or primary angioplasty: data from the CAPTIM randomized clinical trial. Circulation. 2003;108(23):2851-6. PMID: 14623806. Exclusion: 5 .

Steuerwald MT, Robinson BR, Hanseman DJ, et al. Prehospital airway technique does not influence incidence of ventilator-associated pneumonia in trauma patients. J Trauma Acute Care Surg. 2016;80(2):283-8. doi: 10.1097/TA.0000000000000886. PMID: 26491793. Exclusion: 5.

Stiell IG, Spaite DW, Field B, et al. Advanced life support for out-of-hospital respiratory distress. N Engl J Med. 2007;356(21):2156-64. PMID: 17522399. Exclusion: 5.

576. Stockinger ZT, McSwain NE, Jr. Additional evidence in support of withholding or terminating cardiopulmonary resuscitation for trauma patients in the field. J Am Coll Surg. 2004;198(2):227-31. PMID: 14759779. Exclusion: 14.

Stockinger ZT, McSwain NE, Jr. Prehospital endotracheal intubation for trauma does not improve survival over bag-valve-mask ventilation. J Trauma. 2004;56(3):531-6. PMID: 15128123. Exclusion: 5. 
Storm C, Wutzler A, Trenkmann L, et al. Good neurological outcome despite very low regional cerebral oxygen saturation during resuscitation--a prospective preclinical trial in 29 patients. Scand J Trauma Resusc Emerg Med. 2016;24(43):1-7. doi: 10.1186/s13049-016-0234-3. PMID: 27048406. Exclusion: 3.

Stratton SJ. Epinephrine for prehospital cardiac arrest with non-shockable rhythm. Crit Care. 2013;17(5):1006. doi: 10.1186/cc13044. PMID: 24089709. Exclusion: 10.

Strnad M, Lesjak VB, Vujanovic V, et al. Predictors of mortality and prehospital monitoring limitations in blunt trauma patients. Biomed Res Int. 2015;2015:983409. doi: 10.1155/2015/983409. PMID: 25710039. Exclusion: 7.

Strnad M, Prosen G, Borovnik Lesjak V. Bedside lung ultrasound for monitoring the effectiveness of prehospital treatment with continuous positive airway pressure in acute decompensated heart failure. Eur J Emerg Med. 2016;23(1):50-5. doi: 10.1097/MEJ.0000000000000205. PMID: 25222428. Exclusion: 5.

Studer NM, Horn GT, Studer LL, et al. Feasibility of supraglottic airway use by combat lifesavers on the modern battlefield. Mil Med. 2013;178(11):1202-7. doi: 10.7205/MILMED-D-13-00250. PMID: 24183766. Exclusion: 5.

Sturms LM, Hoogeveen JM, Le Cessie S, et al. Prehospital triage and survival of major trauma patients in a Dutch regional trauma system: relevance of trauma registry. Langenbecks Arch Surg. 2006;391(4):343-9. doi: 10.1007/s00423-006-0057-1. PMID: 16699803. Exclusion: 14.

Su CF, Kuo TB, Kuo JS, et al. Sympathetic and parasympathetic activities evaluated by heart-rate variability in head injury of various severities. Clinical neurophysiology : official journal of the International Federation of Clinical Neurophysiology. 2005;116(6):1273-9. doi: 10.1016/j.clinph.2005.01.010. PMID: 15978489. Exclusion: 3.

Sunde GA, Brattebo G, Odegarden T, et al. Laryngeal tube use in out-of-hospital cardiac arrest by paramedics in Norway. Scand J Trauma Resusc Emerg Med. 2012;20:84. doi: 10.1186/1757-724120-84. PMID: 23249522. Exclusion: 5.
Sunde GA, Heltne JK, Lockey D, et al. Airway management by physician-staffed Helicopter Emergency Medical Services - a prospective, multicentre, observational study of 2,327 patients. Scand J Trauma Resusc Emerg Med. 2015;23:57. doi: 10.1186/s13049-015-0136-9. PMID: 26250700. Exclusion: 5.

Swanson ER, Fosnocht DE, Jensen SC. Comparison of etomidate and midazolam for prehospital rapidsequence intubation. Prehosp Emerg Care. 2004;8(3):273-9. PMID: 15295727. Exclusion: 14.

Swaroop M, Straus DC, Agubuzu O, et al. Prehospital transport times and survival for hypotensive patients with penetrating thoracic trauma. J Emerg Trauma Shock. 2013;6(1):16-20. doi: 10.4103/09742700.106320. PMID: 23494152. Exclusion: 3.

Tanabe S, Ogawa T, Akahane M, et al. Comparison of neurological outcome between tracheal intubation and supraglottic airway device insertion of out-ofhospital cardiac arrest patients: a nationwide, population-based, observational study. J Emerg Med. 2013;44(2):389-97. doi:

10.1016/j.jemermed.2012.02.026. PMID: 22541878. Exclusion: 5.

Taylor DM, Bernard SA, Masci K, et al. Prehospital noninvasive ventilation: a viable treatment option in the urban setting. [Erratum appears in Prehosp Emerg Care. 2009 Jan-Mar;13(1):151 Note: Zalstein, Salomon [added]]. Prehosp Emerg Care. 2008;12(1):42-5. doi: 10.1080/10903120701710389. PMID: 18189176. Exclusion: 4.

Thierbach AR. Advanced prehospital airway management techniques. Eur J Emerg Med. 2002;9(3):298-302. PMID: 12394633. Exclusion: 9.

Thoeni N, Piegeler T, Brueesch M, et al. Incidence of difficult airway situations during prehospital airway management by emergency physicians--a retrospective analysis of 692 consecutive patients. Resuscitation. 2015;90:42-5. doi: 10.1016/j.resuscitation.2015.02.010. PMID: 25708959. Exclusion: 5.

Thompson M, Wise S, Rodenberg H. A preliminary comparison of levalbuterol and albuterol in prehospital care. J Emerg Med. 2004;26(3):271-7. PMID: 15028323. Exclusion: 5.

Tiamfook-Morgan TO, Harrison TH, Thomas SH. What happens to SpO2 during air medical crew intubations? Prehosp Emerg Care. 2006;10(3):363-8. PMID: 16801281. Exclusion: 6. 
Timmermann A, Russo SG, Rosenblatt WH, et al. Intubating laryngeal mask airway for difficult out-ofhospital airway management: a prospective evaluation. Br J Anaesth. 2007;99(2):286-91. PMID: 17584849. Exclusion: 6.

Tobias AZ, Guyette FX, Seymour CW, et al. Preresuscitation lactate and hospital mortality in prehospital patients. Prehosp Emerg Care. 2014;18(3):321-7. doi: 10.3109/10903127.2013.869645. PMID: 24548128. Exclusion: 3.

Tollefsen WW, Brown CA, 3rd, Cox KL, et al. Two hundred sixty pediatric emergency airway encounters by air transport personnel: a report of the air transport emergency airway management (NEAR VI: "ATEAM") project. Pediatr Emerg Care. 2013;29(9):963-8. doi: 10.1097/PEC.0b013e3182a219ea. PMID: 23974713. Exclusion: 6.

Torabi M, Mirafzal A, Rastegari A, et al. Association of triage time Shock Index, Modified Shock Index, and Age Shock Index with mortality in Emergency Severity Index level 2 patients. Am J Emerg Med. 2016;34(1):63-8. doi: 10.1016/j.ajem.2015.09.014. PMID: 26602240. Exclusion: 14.

Tourtier JP, Le Moullec D, Jault P, et al. Shock index and undertriage. J Trauma. 2010;69(3):733. doi: 10.1097/TA.0b013e3181e8f696. PMID: 20838153. Exclusion: 5.

Tourtier JP, Libert N, Schaal JV, et al. Advocacy for modern triage tools. J Trauma. 2010;68(6):1514. doi: 10.1097/TA.0b013e3181d3cc8a. PMID: 20539198. Exclusion: 8.

Toyoda Y, Mastuo Y, Tanaka H, et al. Prehospital score for acute disease: a community-based observational study in Japan. BMC Emerg Med. 2007;7 Article Number: 17. doi: 10.1186/1471-227X7-17. PMID: 17937796. Exclusion: 3.

Trimmel H, Kreutziger J, Fertsak G, et al. Use of the Airtraq laryngoscope for emergency intubation in the prehospital setting: a randomized control trial. Crit Care Med. 2011;39(3):489-93. doi: 10.1097/CCM.0b013e318206b69b. PMID: 21169822. Exclusion: 6.

Vadeboncoeur TF, Davis DP, Ochs M, et al. The ability of paramedics to predict aspiration in patients undergoing prehospital rapid sequence intubation. J Emerg Med. 2006;30(2):131-6. PMID: 16567245. Exclusion: 14. van Olden GD, van Vugt AB, Biert J, et al. Trauma resuscitation time. Injury. 2003;34(3):191-5. PMID: 12623249. Exclusion: 6.

van Rein EAJ, Houwert RM, Gunning AC, et al. Accuracy of prehospital triage protocols in selecting severely injured patients: a systematic review. J Trauma Acute Care Surg. 2017;83(2):328-39. doi: 10.1097/ta.0000000000001516. PMID: 28452898. Exclusion: 2.

Veale WN, Jr., Morgan JH, Beatty JS, et al. Hemodynamic and pulmonary fluid status in the trauma patient: are we slipping? Am Surg. 2005;71(8):621-5; discussion 5-6. PMID: 16217942. Exclusion: 7.

Velmahos GC, Wo CC, Demetriades D, et al. Invasive and non-invasive physiological monitoring of blunt trauma patients in the early period after emergency admission. Int Surg. 1999;84(4):354-60. PMID: 10667817. Exclusion: 4.

Vohra T, Paxton J. Abnormal arterial blood gas and serum lactate levels do not alter disposition in adult blunt trauma patients after early computed tomography. West J Emerg Med. 2013;14(3):212-7. doi: 10.5811/westjem.2012.3.6905. PMID: 23687538. Exclusion: 14.

von Elm E, Schoettker P, Henzi I, et al. Pre-hospital tracheal intubation in patients with traumatic brain injury: systematic review of current evidence. Br J Anaesth. 2009;103(3):371-86. doi: 10.1093/bja/aep202. PMID: 19648153. Exclusion: 4.

Voskresensky IV, Rivera-Tyler T, Dossett LA, et al. Use of scene vital signs improves TRISS predicted survival in intubated trauma patients. J Surg Res. 2009;154(1):105-11. doi: 10.1016/j.jss.2008.04.010. PMID: 18805552. Exclusion: 14.

Vu EN, Schlamp RS, Wand RT, et al. Prehospital use of tranexamic acid for hemorrhagic shock in primary and secondary air medical evacuation. Air Med J. 2013;32(5):289-92. doi: 10.1016/j.amj.2013.05.001. PMID: 24001917. Exclusion: 4.

Wallgren UM, Castren M, Svensson AE, et al. Identification of adult septic patients in the prehospital setting: a comparison of two screening tools and clinical judgment. Eur J Emerg Med. 2014;21(4):260-5. doi: 10.1097/MEJ.0000000000000084. PMID: 24080997. Exclusion: 3. 
Wang HE, Balasubramani GK, Cook LJ, et al. Outof-hospital endotracheal intubation experience and patient outcomes. Ann Emerg Med. 2010;55(6):52737.e6. doi: 10.1016/j.annemergmed.2009.12.020. PMID: 20138400. Exclusion: 4.

Wang HE, Balasubramani GK, Cook LJ, et al. Medical conditions associated with out-of-hospital endotracheal intubation. Prehosp Emerg Care. 2011;15(3):338-46. doi: 10.3109/10903127.2011.569850. PMID: 21612386. Exclusion: 4.

Wang HE, Brown SP, MacDonald RD, et al. Association of out-of-hospital advanced airway management with outcomes after traumatic brain injury and hemorrhagic shock in the ROC hypertonic saline trial. Emerg Med J. 2014;31(3):186-91. doi: 10.1136/emermed-2012-202101. PMID: 23353663. Exclusion: 14.

Wang HE, Kupas DF, Greenwood MJ, et al. An algorithmic approach to prehospital airway management. Prehosp Emerg Care. 2005;9(2):14555. PMID: 16036838. Exclusion: 8.

Wang HE, Kupas DF, Paris PM, et al. Multivariate predictors of failed prehospital endotracheal intubation. Acad Emerg Med. 2003;10(7):717-24. PMID: 12837645. Exclusion: 4.

Wang HE, Kupas DF, Paris PM, et al. Preliminary experience with a prospective, multi-centered evaluation of out-of-hospital endotracheal intubation. Resuscitation. 2003;58(1):49-58. PMID: 12867309. Exclusion: 3.

Wang HE, Peitzman AB, Cassidy LD, et al. Out-ofhospital endotracheal intubation and outcome after traumatic brain injury. Ann Emerg Med. 2004;44(5):439-50. PMID: 15520702. Exclusion: 4.

Wang HE, Shapiro NI, Yealy DM. Characteristics of out-of-hospital shock care. Crit Care Med. 2011;39(11):2431-9. doi: 10.1097/CCM.0b013e3182257310. PMID: 21705898. Exclusion: 3.

Wang HE, Sweeney TA, O'Connor RE, et al. Failed prehospital intubations: an analysis of emergency department courses and outcomes. Prehosp Emerg Care. 2001;5(2):134-41. PMID: 11339722.

Exclusion: 4.

Wang HE, Szydlo D, Stouffer JA, et al. Endotracheal intubation versus supraglottic airway insertion in outof-hospital cardiac arrest. Resuscitation. 2012;83(9):1061-6. PMID: 22664746. Exclusion: 3.
Warner GS. Evaluation of the effect of prehospital application of continuous positive airway pressure therapy in acute respiratory distress. Prehospital Disaster Med. 2010;25(1):87-91. PMID: 20405469. Exclusion: 4.

Warner KJ, Cuschieri J, Copass MK, et al. The impact of prehospital ventilation on outcome after severe traumatic brain injury. J Trauma. 2007;62(6):1330-6; discussion 6-8. PMID: 17563643. Exclusion: 4.

Warner KJ, Sharar SR, Copass MK, et al. Prehospital management of the difficult airway: a prospective cohort study. J Emerg Med. 2009;36(3):257-65. doi: 10.1016/j.jemermed.2007.10.058. PMID: 18439793. Exclusion: 5.

Weaver AE, Hunter-Dunn C, Lyon RM, et al. The effectiveness of a 'Code Red' transfusion request policy initiated by pre-hospital physicians. Injury. 2016;47(1):3-6. doi: 10.1016/j.injury.2015.06.023. PMID: 26239421. Exclusion: 14.

Webman RB, Carter EA, Mittal S, et al. Association between trauma center type and mortality among injured adolescent patients. JAMA Pediatrics. 2016;170(8):780-6. doi:

10.1001/jamapediatrics.2016.0805. PMID: 27368110. Exclusion: 2.

Weeks SR, Stevens KA, Haider AH, et al. A modified Kampala trauma score (KTS) effectively predicts mortality in trauma patients. Injury. 2016;47(1):125-9. doi: 10.1016/j.injury.2015.07.004. PMID: 26256783. Exclusion: 14.

Weiss SJ, Ernst AA, Phillips J, et al. Gender differences in state-wide EMS transports. Am J Emerg Med. 2000;18(6):666-70. PMID: 11043618. Exclusion: 4.

Weitz G, Struck J, Zonak A, et al. Prehospital noninvasive pressure support ventilation for acute cardiogenic pulmonary edema. Eur J Emerg Med. 2007;14(5):276-9. PMID: 17823565. Exclusion: 3.

Weng TI, Huang $\mathrm{CH}$, Ma $\mathrm{MH}$, et al. Improving the rate of return of spontaneous circulation for out-ofhospital cardiac arrests with a formal, structured emergency resuscitation team. Resuscitation. 2004;60(2):137-42. PMID: 15036730. Exclusion: 3.

Werman HA, Erskine T, Caterino J, et al. Development of statewide geriatric patients trauma triage criteria. Prehospital Disaster Med.

2011;26(3):170-9. doi: 10.1017/S1049023X11006315. PMID: 22107767. Exclusion: 2. 
Wesley K, Wesley K. TRIAGING GERIATRICS. 110 is the new 90 for systolic blood pressure in elderly patients. JEMS. 2015;40(10):29. PMID: 26669063. Exclusion: 9.

Wibring K, Herlitz J, Christensson L, et al. Prehospital factors associated with an acute lifethreatening condition in non-traumatic chest pain patients - a systematic review. Int J Cardiol. 2016;219:373-9. doi: 10.1016/j.ijcard.2016.06.066. PMID: 27352210. Exclusion: 4.

Wijaya R, Ng JH, Ong L, et al. Can venous base excess replace arterial base excess as a marker of early shock and a predictor of survival in trauma? Singapore Med J. 2016;57(2):73-6. doi: 10.11622/smedj.2016031. PMID: 26892937. Exclusion: 6.

Wilde ET, Robbins LS, Pressley JC. Racial differences in out-of-hospital cardiac arrest survival and treatment. Emerg Med J. 2012;29(5):415-9. doi: 10.1136/emj.2010.109736. PMID: 21546508. Exclusion: 2.

Winchell RJ, Hoyt DB. Analysis of heart-rate variability: a noninvasive predictor of death and poor outcome in patients with severe head injury. $\mathrm{J}$ Trauma. 1997;43(6):927-33. PMID: 9420107. Exclusion: 7.

Wirtz DD, Ortiz C, Newman DH, et al. Unrecognized misplacement of endotracheal tubes by ground prehospital providers. Prehosp Emerg Care. 2007;11(2):213-8. PMID: 17454811. Exclusion: 4.

Wong DT, Tam AD, Van Zundert TC. The usage of the Boussignac continuous positive airway pressure system in acute respiratory failure. Minerva Anestesiol. 2013;79(5):564-70. PMID: 23419338. Exclusion: 4.

World MJ. Methods of estimating cardiac output in the field. Qjm. 1996;89(6):457-62. PMID: 8758049. Exclusion: 4.

Wu C-Y, Yang S-J, Fu C-Y, et al. The risk factors of concomitant intraperitoneal and retroperitoneal hemorrhage in the patients with blunt abdominal trauma. World J Emerg Surg. 2015;10:4. doi: 10.1186/1749-7922-10-4. PMID: 25972915. Exclusion: 4.

Xue FS, Liao X, Yuan YJ, et al. Management of unanticipated difficult airway in the prehospital emergency setting. Anesthesiology. 2011;115(2):4412; author reply 2. doi: 10.1097/ALN.0b013e318223bb93. PMID: 21792001. Exclusion: 9.
Yannopoulos D, Bartos JA, Martin C, et al. Minnesota Resuscitation Consortium's advanced perfusion and reperfusion cardiac life support strategy for out-of-hospital refractory ventricular fibrillation. J Am Heart Assoc. 2016;5(6):e003732. doi: 10.1161/JAHA.116.003732. PMID: 27412906. Exclusion: 3.

Young B. The intubating laryngeal-mask airway may be an ideal device for airway control in the rural trauma patient. Am J Emerg Med. 2003;21(1):80-5. PMID: 12563589. Exclusion: 5.

Youngquist S, Gausche-Hill M, Burbulys D. Alternative airway devices for use in children requiring prehospital airway management: update and case discussion. Pediatr Emerg Care. 2007;23(4):2508; quiz 9-61. PMID: 17438442. Exclusion: 8.

Yperzeele L, van Hooff RJ, De Smedt A, et al. Feasibility, reliability and predictive value Of inambulance heart rate variability registration. PLoS ONE. 2016;11(5):e0154834. doi:

10.1371/journal.pone.0154834. PMID: 27144492.

Exclusion: 3.

Yumoto T, Mitsuhashi T, Yamakawa Y, et al. Impact of Cushing's sign in the prehospital setting on predicting the need for immediate neurosurgical intervention in trauma patients: a nationwide retrospective observational study. Scand J Trauma Resusc Emerg Med. 2016;24(1):147. doi: 10.1186/s13049-016-0341-1. PMID: 27938387. Exclusion: 14.

Zadel S, Strnad M, Prosen G, et al. Point of care ultrasound for orotracheal tube placement assessment in out-of hospital setting. Resuscitation. 2015;87:1-6. doi: 10.1016/j.resuscitation.2014.11.006. PMID: 25450569. Exclusion: 5.

Zafonte RD, Hammond FM, Mann NR, et al. Revised trauma score: an additive predictor of disability following traumatic brain injury? Am J Phys Med Rehabil. 1996;75(6):456-61. PMID: 8985110. Exclusion: 5.

Zewude RT, Gioia LC, Kate M, et al. Lower prehospital blood pressure is not associated with larger infarct volumes in non-lacunar ischemic stroke patients. Stroke. Conference: American Heart Association/American Stroke Association. 2016;47. Exclusion: 3. 
Zeymer U, Arntz HR, Dirks B, et al. Aktueller stand der prähospitalen therapie des akuten [Current status of prehospital therapy of patients with acute ST elevation myocardial infarction in Germany. Design and baseline data of PREMIR (prehospital

myocardial infarction registry)]. Intensiv- und Notfallbehandlung. 2007;32(4):159-66. Exclusion: 3. 


\section{Appendix D. Evidence Tables}

Table D1. Study characteristics

\begin{tabular}{|c|c|c|c|c|}
\hline $\begin{array}{l}\text { Author, Year } \\
\text { (See Appendix B for } \\
\text { complete reference) }\end{array}$ & Study Design & Setting and Dates Performed & Number of Study Subjects & Data Source \\
\hline Ahun, 2014 & Prospective & $\begin{array}{l}\text { Turkey, Bursa } \\
\text { Urban } \\
\text { Trauma system level: NR } \\
\text { Study time period: NR }\end{array}$ & 100 analyzed & $\begin{array}{l}\text { Initial data collected during } \\
\text { hospitalization. Followup during } \\
\text { 4-week period to calculate short } \\
\text { term and long-term mortality } \\
\text { prediction rates. }\end{array}$ \\
\hline Al-Salamah, 2004 & Prospective & $\begin{array}{l}\text { Canada, Ontario } \\
\text { Urban and suburban } \\
\text { Trauma system level: NR (trauma hospitals) } \\
1 / 1 / 1993 \text { to } 2 / 21 / 1998 \\
5 \text { years, } 3 \text { months }\end{array}$ & $\begin{array}{l}795 \text { analyzed } \\
992 \text { identified } \\
127 \text { excluded } \\
-64 \text { excluded for penetrating trauma } \\
-43 \text { excluded for burns } \\
-20 \text { excluded for missing data }\end{array}$ & $\begin{array}{l}\text { Out of hospital data: OPALS } \\
\text { Study database } \\
\text { Hospital data: Ontario Trauma } \\
\text { Registry Comprehensive Data } \\
\text { Set }\end{array}$ \\
\hline Allen, 2014 & Retrospective & $\begin{array}{l}\text { USA, Florida } \\
\text { Urban } \\
\text { Level I trauma center } \\
1 / 2000 \text { to } 12 / 2012 \\
13 \text { years }\end{array}$ & 1,928 analyzed & $\begin{array}{l}\text { Trauma registry for a single } \\
\text { trauma center. }\end{array}$ \\
\hline Arbabi, 2004 & Retrospective & $\begin{array}{l}\text { USA, Washington and Michigan } \\
\text { Urban } \\
\text { Level I trauma centers } \\
\begin{array}{l}1 / 1994 \text { to } 12 / 2001 \\
8 \text { years }\end{array}\end{array}$ & 19,409 analyzed & $\begin{array}{l}\text { Trauma registry data at two } \\
\text { academic Level I trauma } \\
\text { centers. }\end{array}$ \\
\hline
\end{tabular}




\begin{tabular}{|c|c|c|c|}
\hline $\begin{array}{l}\text { Author, Year } \\
\text { (See Appendix B for } \\
\text { complete reference) }\end{array}$ & Eligibility Criteria & $\begin{array}{l}\text { Age Groups Included (Age Range Used): \% } \\
\text { of Study Population }\end{array}$ & Type of Population \\
\hline Ahun, 2014 & $\begin{array}{l}\text { Included: Major trauma patients } \geq 18 \text { years old. } \\
\text { Excluded: Pregnant patients and those with psychiatric illnesses. }\end{array}$ & Adults ( $\geq 18): 100 \%$ & Civilian \\
\hline Al-Salamah, 2004 & $\begin{array}{l}\text { Included: Patients with blunt trauma, with records in the OPALS } \\
\text { study database, and were entered into the Ontario Trauma Registry } \\
\text { Comprehensive Data Set. The OPALS database includes patients } \\
\text { who had an injury caused by any mechanism, ISS }>12 \text {, and were } \\
\text { transported by land ambulance within the study communities. } \\
\text { Excluded: Patients with penetrating trauma or burns, or with missing } \\
\text { data from the trauma registry. }\end{array}$ & Adults ( $\geq 16): 100 \%$ & Civilian \\
\hline Allen, 2014 & $\begin{array}{l}\text { Included: Patients }<18 \text { years old. } \\
\text { Excluded: Patients who were pregnant, incarcerated, or who were } \\
\text { not admitted to the trauma or pediatric surgery service. }\end{array}$ & Pediatrics (<18): 100\% & Civilian \\
\hline Arbabi, 2004 & $\begin{array}{l}\text { Included: Adult trauma patients ( } \geq 18 \text { years old) during study period. } \\
\text { Excluded: Patients transferred from an outside hospital, and all burn } \\
\text { patients. }\end{array}$ & Adults ( $\geq 18): 100 \%$ & Civilian \\
\hline
\end{tabular}




\begin{tabular}{|c|c|c|c|c|}
\hline \begin{tabular}{|l|} 
Author, Year \\
(See Appendix B for \\
complete reference)
\end{tabular} & Mechanism or Type Injury & Mode of Transport & $\begin{array}{l}\text { Other Population Characteristics } \\
\text { (Sex, Race) }\end{array}$ & $\begin{array}{l}\text { Name of Measure Being } \\
\text { Evaluated }\end{array}$ \\
\hline Ahun, 2014 & $\begin{array}{l}\text { Type of injury } \\
\text { Blunt: } 98 \%(98 / 100) \\
\text { Penetrating: } 2 \%(2 / 100) \\
\\
\text { Mechanism of injury } \\
\text { In-vehicle traffic accident: } 68 \%(68 / 100) \\
\text { Extravehicular traffic accident: } 6 \%(6 / 100) \\
\text { Falling from a height: } 13 \%(13 / 100) \\
\text { Motorbike accident: } 11 \%(11 / 100) \\
\text { Injury by firearms: } 1 \%(1 / 100) \\
\text { Sharp object injuries: } 1 \%(1 / 100)\end{array}$ & $\begin{array}{l}\text { Ambulance: } 99 \% \\
\text { (99/100) } \\
\text { Private vehicle: } 1 \% \\
(1 / 100) \\
\\
\text { Direct from scene: } \\
80 \%(80 / 100) \\
\text { Transferred: } 20 \% \\
(20 / 100)\end{array}$ & $\begin{array}{l}\text { Male: } 77 \%(77 / 100) \\
\text { Race: NR } \\
\text { Age (mean): } 40 \text { (SD 16) }\end{array}$ & $\begin{array}{l}\text { GAP score } \\
\text { MGAP score } \\
\text { RTS }\end{array}$ \\
\hline Al-Salamah, 2004 & Blunt: $100 \%$ & Land & $\begin{array}{l}\text { Male: } 70 \% \\
\text { Race: NR } \\
\text { Age (mean): } 44 \text { (SD 21) }\end{array}$ & \begin{tabular}{|l} 
RR \\
RTS \\
SBP
\end{tabular} \\
\hline Allen, 2014 & \begin{tabular}{|l} 
Blunt: $76 \%$ \\
Penetrating: $24 \%$
\end{tabular} & NR & $\begin{array}{l}\text { Male: } 70 \% \\
\text { Race: NR } \\
\text { Age (mean): } 11 \text { (SD 6) }\end{array}$ & $\mathrm{BD}$ \\
\hline Arbabi, 2004 & \begin{tabular}{|l|} 
Blunt: $84 \%(16,277 / 19,409)$ \\
Penetrating: $16 \%(3,132 / 19,409)$
\end{tabular} & NR & \begin{tabular}{|l} 
Overall \\
Male: $74 \%$ \\
Race: NR \\
Age (mean): 41 (SD 17)
\end{tabular} & SBP \\
\hline
\end{tabular}




\begin{tabular}{|c|c|c|c|c|}
\hline $\begin{array}{l}\text { Author, Year } \\
\text { (See Appendix B for } \\
\text { complete reference) }\end{array}$ & $\begin{array}{l}\text { Location and Timing of } \\
\text { Measurement }\end{array}$ & Method of Measurement & $\begin{array}{l}\text { Personnel Administering Test or } \\
\text { Using Measure }\end{array}$ & Equipment Used/Needed \\
\hline Ahun, 2014 & ED: not specified & NR & NR & $\begin{array}{l}\text { RTS calculated using score } \\
\text { calculator available at } \\
\text { www.trauma.org }\end{array}$ \\
\hline Al-Salamah, 2004 & ED: on arrival & NR & ED: trauma team & $\mathrm{NR}$ \\
\hline Allen, 2014 & ED: on arrival & NR & $\overline{N R}$ & $\overline{N R}$ \\
\hline Arbabi, 2004 & $\begin{array}{l}\text { Out of Hospital: NR } \\
\text { ED: NR }\end{array}$ & NR & NR & NR \\
\hline
\end{tabular}




\begin{tabular}{|c|c|c|c|c|}
\hline $\begin{array}{l}\text { Author, Year } \\
\text { (See Appendix B for } \\
\text { complete reference) }\end{array}$ & $\begin{array}{l}\text { Threshold Value(s) for Physiologic } \\
\text { Measures }\end{array}$ & $\begin{array}{l}\text { Indicator of Serious Injury Used } \\
\text { (including definition and time period) }\end{array}$ & Funding Source & Risk of Bias \\
\hline Ahun, 2014 & $\begin{array}{l}\text { Scoring system cut-offs used } \\
\text { 24-hour mortality } \\
\text { GAP: } 19 \\
\text { MGAP: } 23 \\
\text { RTS: } 5.68 \\
\\
\text { 4-week mortality } \\
\text { GAP: } 21 \\
\text { MGAP: } 25 \\
\text { RTS: } 5.97\end{array}$ & $\begin{array}{l}\text { Mortality: 24-hour } \\
\text { Mortality: 4-week }\end{array}$ & NR & Moderate \\
\hline Al-Salamah, 2004 & $\begin{array}{l}\text { Score cutpoints chosen as values at which there } \\
\text { were similar sensitivities and specificities. } \\
\text { RTS: }<12\end{array}$ & $\begin{array}{l}\text { Mortality: In-hospital } \\
\text { ICU Admission } \\
\text { Required intubation in ED }\end{array}$ & NR & Moderate \\
\hline Allen, 2014 & $\begin{array}{l}\text { BD: abnormal } \\
<0 \\
<-5 \\
<-7\end{array}$ & Blood transfusion: NR & $\begin{array}{l}\text { Partial support by grant } \\
\text { N140610670 from the Office of } \\
\text { Naval Research and grant } \\
09078015 \text { from the U.S. Army } \\
\text { Medical Research and Materiel } \\
\text { Command. }\end{array}$ & Moderate \\
\hline Arbabi, 2004 & $\mathrm{SBP}<90,<120$ & Mortality: NR & NR & Moderate \\
\hline
\end{tabular}




\begin{tabular}{|c|c|c|c|c|}
\hline $\begin{array}{l}\text { Author, Year } \\
\text { (See Appendix B for } \\
\text { complete reference) } \\
\end{array}$ & Study Design & Setting and Dates Performed & Number of Study Subjects & Data Source \\
\hline Aslar, 2004 & Prospective & $\begin{array}{l}\text { Turkey, Ankara } \\
\text { Urban } \\
\text { Trauma system level: NR } \\
\\
3 / 1 / 1996 \text { to } 1 / 30 / 1998 \\
1 \text { year, } 11 \text { months }\end{array}$ & $\begin{array}{l}64 \text { analyzed } \\
149 \text { identified } \\
85 \text { excluded } \\
-21 \text { excluded for major head injury } \\
-2 \text { excluded for known acid-base } \\
\text { disturbances } \\
-5 \text { excluded for receipt of exogenous sodium } \\
\text { bicarbonate prior to arterial blood gas and } \\
\text { lactate analysis } \\
-9 \text { excluded for admission for observation } \\
\text { only } \\
-1 \text { excluded for age }<5 \text { years } \\
-22 \text { excluded for thermal or penetrating } \\
\text { injuries } \\
-1 \text { excluded for seizure } \\
-7 \text { excluded as dead on arrival }\end{array}$ & $\begin{array}{l}\text { Prospective collection of ED } \\
\text { admission data for a single } \\
\text { hospital. }\end{array}$ \\
\hline Baron, 2004 & Prospective & $\begin{array}{l}\text { USA, New York } \\
\text { Urban } \\
\text { Level I trauma center } \\
\text { 7/2001 to } 3 / 2002 \\
9 \text { months }\end{array}$ & 108 analyzed & Primary data collection \\
\hline
\end{tabular}




\begin{tabular}{|c|c|c|c|}
\hline \begin{tabular}{|l|} 
Author, Year \\
(See Appendix B for \\
complete reference)
\end{tabular} & Eligibility Criteria & $\begin{array}{l}\text { Age Groups Included (Age Range Used*): \% } \\
\text { of Study Population }\end{array}$ & Type of Population \\
\hline Aslar, 2004 & $\begin{array}{l}\text { Included: Patients with torso trauma admitted to the ED during the } \\
\text { study period } \\
\text { Excluded: Patients with major head injury, known acid-base } \\
\text { disturbances, those who received exogenous sodium bicarbonate } \\
\text { before arterial blood gas and lactate analysis, were admitted for } \\
\text { observation only, were under age } 5 \text {, had trauma caused by thermal } \\
\text { and penetrating injuries, seizure, or were pronounced dead on } \\
\text { arrival. }\end{array}$ & Pediatrics ( $\geq 5): 100 \%$ & Civilian \\
\hline Baron, 2004 & $\begin{array}{l}\text { Included: Patients } \geq 13 \text { years old with penetrating torso trauma. } \\
\text { Excluded: Patients transferred from other hospitals and those who } \\
\text { died in the ED. }\end{array}$ & Adults and adolescents ( $\geq 13): 100 \%$ & Civilian \\
\hline
\end{tabular}




\begin{tabular}{|c|c|c|c|c|}
\hline $\begin{array}{l}\text { Author, Year } \\
\text { (See Appendix B for } \\
\text { complete reference) }\end{array}$ & Mechanism or Type Injury & Mode of Transport & $\begin{array}{l}\text { Other Population Characteristics } \\
\text { (Sex, Race) }\end{array}$ & $\begin{array}{l}\text { Name of Measure Being } \\
\text { Evaluated }\end{array}$ \\
\hline Aslar, 2004 & $\begin{array}{l}\text { Mechanism of injury: } \\
\text {-Traffic accident: } 73 \%(47 / 64) \\
\text {-Fall: } 11 \%(7 / 64) \\
\text {-Gunshot: } 16 \%(10 / 64) \\
\\
\text { Major injury site* } \\
\text { Abdomen: } 72 \%(46 / 64) \\
\text { Chest: } 11 \%(7 / 64) \\
\text { Vascular: } 8 \%(5 / 64) \\
\text { Orthopedics: } 6 \%(4 / 64) \\
\text { NR: } 3 \%(2 / 64) \\
\text { *Study limited to patients with torso trauma, } \\
\text { and excludes those with penetrating trauma } \\
\text { or burn injury. }\end{array}$ & NR & $\begin{array}{l}\text { Male: } 75 \%(48 / 64) \\
\text { Race: NR } \\
\text { Age (mean): } 36 \text { (SD 19) }\end{array}$ & \begin{tabular}{|l} 
APACHE II score \\
BD \\
Lactate \\
pH \\
RTS \\
SI \\
Model: multivariate model with \\
APACHE II score and lactate
\end{tabular} \\
\hline Baron, 2004 & \begin{tabular}{|l} 
Type of injury \\
Penetrating: $100 \%$ \\
Mechanism of injury \\
Gunshot: $31 \%(33 / 108)$ \\
Stab wound: $69 \%(74 / 108)$ \\
Fall: $<1 \%(1 / 108)$
\end{tabular} & NR & \begin{tabular}{|l|} 
Male: $90 \%$ \\
Race: NR \\
Age (mean): 28 (SD 1)
\end{tabular} & $\begin{array}{l}\text { Base deficit } \\
\text { Lactate } \\
\text { SLCO2 }\end{array}$ \\
\hline
\end{tabular}




\begin{tabular}{|c|c|c|c|c|}
\hline \begin{tabular}{|l|} 
Author, Year \\
(See Appendix B for \\
complete reference) \\
\end{tabular} & $\begin{array}{l}\text { Location and Timing of } \\
\text { Measurement }\end{array}$ & Method of Measurement & $\begin{array}{l}\text { Personnel Administering Test or } \\
\text { Using Measure }\end{array}$ & Equipment Used/Needed \\
\hline Aslar, 2004 & ED: on arrival & Lactate: arterial & NR & NR \\
\hline
\end{tabular}




\begin{tabular}{|c|c|c|c|c|}
\hline \begin{tabular}{|l|} 
Author, Year \\
(See Appendix B for \\
complete reference)
\end{tabular} & $\begin{array}{l}\text { Threshold Value(s) for Physiologic } \\
\text { Measures }\end{array}$ & $\begin{array}{l}\text { Indicator of Serious Injury Used } \\
\text { (including definition and time period) }\end{array}$ & Funding Source & Risk of Bias \\
\hline Aslar, 2004 & $\begin{array}{l}\text { Cutpoints in univariate analysis: } \\
\text { APACHE II score: } \geq 15 \\
\text { BD: } \leq-6 \\
\text { Lactate: } \geq 4 \\
\text { pH: } \leq 7.30 \\
\text { RTS: } \leq 8 \\
\text { SI: }>0.9 \\
\text { Predetermined: NR }\end{array}$ & $\begin{array}{l}\text { Mortality: Inpatient within } 30 \text { days of } \\
\text { admission. }\end{array}$ & NR & Moderate \\
\hline Baron, 2004 & $\begin{array}{l}\mathrm{SLCO} 2>45 \mathrm{~mm} \mathrm{Hg} \\
\text { value corresponding to a sensitivity of } 90 \%\end{array}$ & \begin{tabular}{|l|} 
Blood loss: best estimate of intracavitary blood \\
loss determined by chest tube drainage, \\
intraoperative blood loss, radiographic \\
evidence of bleeding, change in hematocrit \\
and number of packed RBC transfusions in \\
the first 24 hours of admission. \\
- none \\
- minimal-moderate: $<1500 \mathrm{~mL}$ \\
- severe: $\geq 1500 \mathrm{~mL}$
\end{tabular} & $\begin{array}{l}\text { The CapnoProbe sublingual CO2 } \\
\text { measurement devices and } \\
\text { disposable sensors were supplied } \\
\text { by Optical Sensors, Inc., } \\
\text { Minneapolis, MN. }\end{array}$ & Moderate \\
\hline
\end{tabular}




\begin{tabular}{|c|c|c|c|c|}
\hline $\begin{array}{l}\text { Author, Year } \\
\text { (See Appendix B for } \\
\text { complete reference) }\end{array}$ & Study Design & Setting and Dates Performed & Number of Study Subjects & Data Source \\
\hline Baron, 2007 & Prospective & $\begin{array}{l}\text { USA, New York and Maryland } \\
\text { Urban } \\
\text { Level I trauma centers } \\
3 / 2003 \text { to } 1 / 2004 \\
11 \text { months }\end{array}$ & 86 analyzed & Primary data collection \\
\hline $\begin{array}{l}\text { Batchinsky, } 2007 \\
\text { *Batchinsky, } 2007 \text { and } \\
\text { Batchinsky, } 2009 \\
\text { analyze the same } 31 \\
\text { patient ECGs but differ } \\
\text { in measures evaluated. }\end{array}$ & Retrospective & $\begin{array}{l}\text { USA, Texas } \\
\text { Urban } \\
\text { Level I trauma center } \\
\text { Study time period: NR }\end{array}$ & $\begin{array}{l}31 \text { analyzed } \\
117 \text { identified } \\
86 \text { excluded } \\
-47 \text { with multiple ectopic beats in the time } \\
\text { series } \\
-32 \text { for electromechanical noise } \\
-7 \text { for inadequate data length }\end{array}$ & $\begin{array}{l}\text { Trauma Vitals database (from } \\
\text { the US Army Institute of Surgical } \\
\text { Research) } \\
\text { Data collection by monitor and } \\
\text { standard run sheet. }\end{array}$ \\
\hline $\begin{array}{l}\text { Batchinsky, } 2009 \\
\text { *Batchinsky, } 2007 \text { and } \\
\text { Batchinsky, 2009 } \\
\text { analyze the same } 31 \\
\text { patient ECGs but differ } \\
\text { in measures evaluated. }\end{array}$ & Retrospective & $\begin{array}{l}\text { USA, Texas } \\
\text { Urban } \\
\text { Level I trauma center } \\
\text { Study time period: NR }\end{array}$ & 31 analyzed & $\begin{array}{l}\text { Trauma Vitals database, housed } \\
\text { at the US Army Institute of } \\
\text { Surgical Research. } \\
\\
\text { Data collection by monitor and } \\
\text { standard run sheet. }\end{array}$ \\
\hline
\end{tabular}




\begin{tabular}{|c|c|c|c|}
\hline $\begin{array}{l}\text { Author, Year } \\
\text { (See Appendix B for } \\
\text { complete reference) }\end{array}$ & Eligibility Criteria & $\begin{array}{l}\text { Age Groups Included (Age Range Used*): \% } \\
\text { of Study Population }\end{array}$ & Type of Population \\
\hline Baron, 2007 & $\begin{array}{l}\text { Included: Patients } \geq 16 \text { years old with blunt or penetrating trauma } \\
\text { who presented to the ED with hypotension (SBP } \leq 90 \mathrm{~mm} \mathrm{Hg} \text { ). } \\
\text { Excluded: Patients with focal neurologic deficits and those } \\
\text { transferred from other hospitals. }\end{array}$ & Adults ( $\geq 16): 100 \%$ & Civilian \\
\hline $\begin{array}{l}\text { Batchinsky, } 2007 \\
\\
\text { *Batchinsky, } 2007 \text { and } \\
\text { Batchinsky, } 2009 \\
\text { analyze the same } 31 \\
\text { patient ECGs but differ } \\
\text { in measures evaluated. }\end{array}$ & $\begin{array}{l}\text { Included: Patients with ECG recordings free of electromechanical } \\
\text { noise severe enough to prevent R-wave identification, free of } \\
\text { ectopic beats, and at least } 800 \text { heart beats in length. } \\
\text { Excluded: No exclusion criteria specified. }\end{array}$ & NR & Civilian \\
\hline $\begin{array}{l}\text { Batchinsky, } 2009 \\
\text { *Batchinsky, } 2007 \text { and } \\
\text { Batchinsky, } 2009 \\
\text { analyze the same } 31 \\
\text { patient ECGs but differ } \\
\text { in measures evaluated. }\end{array}$ & $\begin{array}{l}\text { Included: ECG recordings free of electromechanical noise severe } \\
\text { enough to prevent R-wave identification, free of ectopic beats, and } \\
\text { at least } 800 \text { heartbeats in length. } \\
\text { Excluded: No exclusion criteria specified. }\end{array}$ & NR & Civilian \\
\hline
\end{tabular}




\begin{tabular}{|c|c|c|c|c|}
\hline $\begin{array}{l}\text { Author, Year } \\
\text { (See Appendix B for } \\
\text { complete reference) }\end{array}$ & Mechanism or Type Injury & Mode of Transport & $\begin{array}{l}\text { Other Population Characteristics } \\
\text { (Sex, Race) }\end{array}$ & $\begin{array}{l}\text { Name of Measure Being } \\
\text { Evaluated }\end{array}$ \\
\hline Baron, 2007 & $\begin{array}{l}\text { Type of injury } \\
\text { Blunt: } 51 \%(44 / 86) \\
\text { Penetrating: 49\% (42/86) } \\
\text { Mechanism of injury } \\
\text { Motor vehicle crash: } 23 \%(20 / 86) \\
\text { Pedestrian struck by automobile: 13\% (11/86) } \\
\text { Motorcycle crash: 5\% (4/86) } \\
\text { Fall: 5\% (4/86) } \\
\text { Assault: } 2 \%(2 / 86) \\
\text { Bicyclist struck by automobile: } 1 \%(1 / 86) \\
\text { Gunshot wound: } 27 \%(23 / 86) \\
\text { Stab wound: } 22 \% \text { (19/86) } \\
\text { Other: } 2 \%(2 / 86)\end{array}$ & NR & $\begin{array}{l}\text { Male: } 80 \% \text { (69/86) } \\
\text { Race: NR } \\
\text { Age (mean): } 35 \text { (SD 17) }\end{array}$ & $\begin{array}{l}\text { Base deficit } \\
\text { Lactate } \\
\text { SLCO2 }\end{array}$ \\
\hline $\begin{array}{l}\text { Batchinsky, } 2007 \\
\text { ^Batchinsky, } 2007 \text { and } \\
\text { Batchinsky, } 2009 \\
\text { analyze the same } 31 \\
\text { patient ECGs but differ } \\
\text { in measures evaluated. }\end{array}$ & $\begin{array}{l}\text { Blunt: 61.3\% (19/31) } \\
\text { Penetrating: } 38.7 \%(12 / 31)\end{array}$ & Helicopter & $\begin{array}{l}\text { Male: } 71 \% \text { (22/31) } \\
\text { Race: NR } \\
\text { Age (mean): } 40 \text { (SD 4) }\end{array}$ & $\begin{array}{l}\text { Heart rate complexity: sample } \\
\text { entropy (SampEn) }\end{array}$ \\
\hline $\begin{array}{l}\text { Batchinsky, } 2009 \\
\text { ^Batchinsky, } 2007 \text { and } \\
\text { Batchinsky, } 2009 \\
\text { analyze the same } 31 \\
\text { patient ECGs but differ } \\
\text { in measures evaluated. }\end{array}$ & \begin{tabular}{|l} 
Blunt: $61.3 \%(19 / 31)$ \\
Penetrating: $38.7 \%(12 / 31)$
\end{tabular} & Helicopter & $\begin{array}{l}\text { Male: } 71 \%(22 / 31) \\
\text { Race: NR } \\
\text { Age (mean): } 40 \text { (SD 4) }\end{array}$ & $\begin{array}{l}\text { Heart rate complexity metrics } \\
\text { - Approximate entropy } \\
\text { - Distribution of symbol } 2 \\
\text { Heart rate complexity models: } \\
\text { combined metrics with and } \\
\text { without GCS motor score }\end{array}$ \\
\hline
\end{tabular}




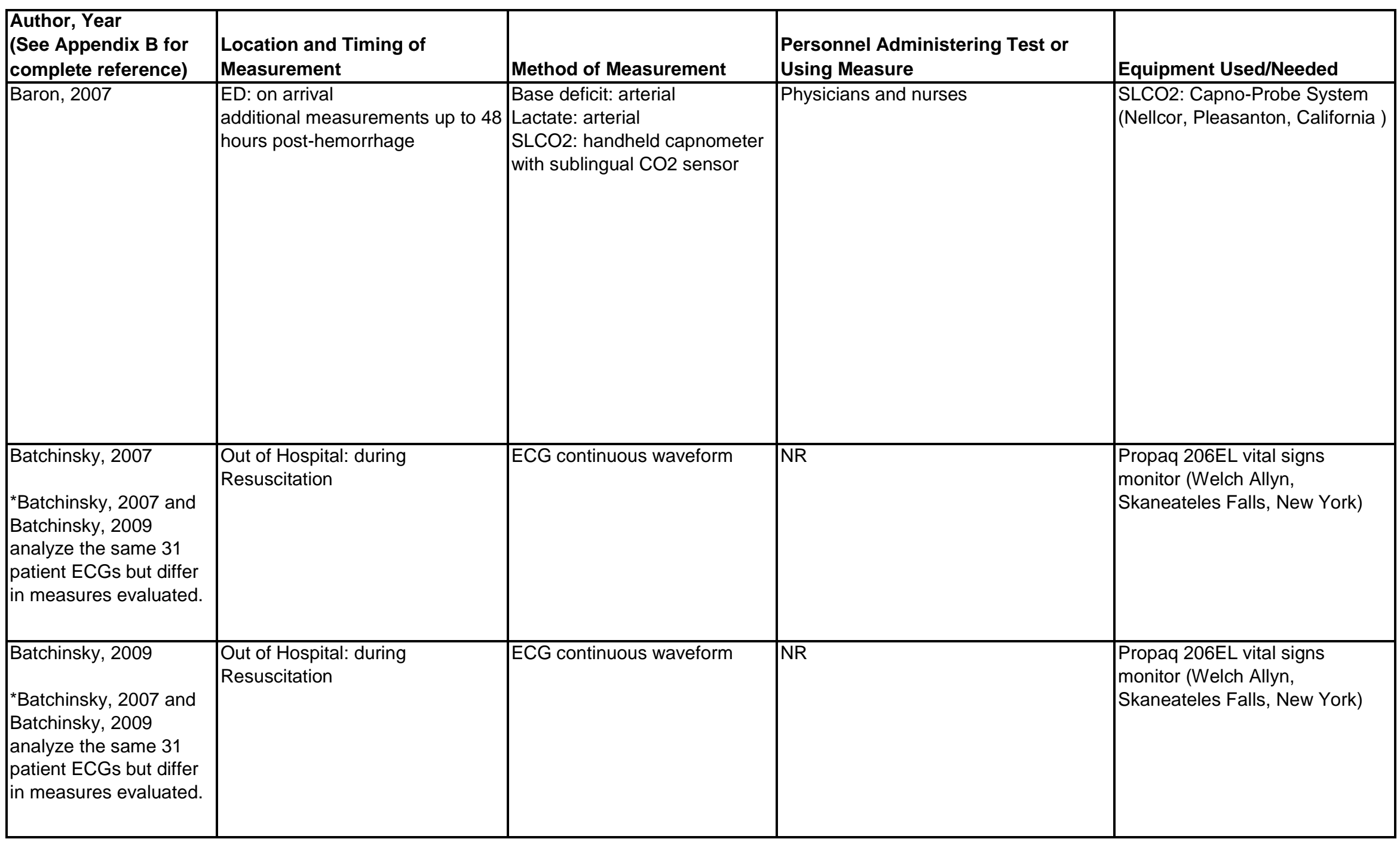




\begin{tabular}{|c|c|c|c|c|}
\hline $\begin{array}{l}\text { Author, Year } \\
\text { (See Appendix B for } \\
\text { complete reference) }\end{array}$ & $\begin{array}{l}\text { Threshold Value(s) for Physiologic } \\
\text { Measures }\end{array}$ & $\begin{array}{l}\text { Indicator of Serious Injury Used } \\
\text { (including definition and time period) }\end{array}$ & Funding Source & Risk of Bias \\
\hline Baron, 2007 & $\begin{array}{l}\text { SLCO2 } \geq 62 \mathrm{~mm} \mathrm{Hg} \\
\text { threshold with optimal combination of sensitivity } \\
\text { and specificity }\end{array}$ & $\begin{array}{l}\text { Mortality: not specified } \\
\text { ICU stay } \\
\text { Blood transfusion }\end{array}$ & $\begin{array}{l}\text { Supported by Nellcor, Pleasanton, } \\
\text { CA. }\end{array}$ & Moderate \\
\hline $\begin{array}{l}\text { Batchinsky, } 2007 \\
\text { *Batchinsky, } 2007 \text { and } \\
\text { Batchinsky, } 2009 \\
\text { analyze the same } 31 \\
\text { patient ECGs but differ } \\
\text { in measures evaluated. }\end{array}$ & NR & Mortality: Inpatient & $\begin{array}{l}\text { Supported by the Combat Critical } \\
\text { Care Engineering Program, US } \\
\text { Army Medical Research and } \\
\text { Materiel Command, Fort Detrick, } \\
\text { Maryland. }\end{array}$ & Moderate \\
\hline $\begin{array}{l}\text { Batchinsky, } 2009 \\
\text { *Batchinsky, } 2007 \text { and } \\
\text { Batchinsky, } 2009 \\
\text { analyze the same } 31 \\
\text { patient ECGs but differ } \\
\text { in measures evaluated. }\end{array}$ & NR & Mortality & $\begin{array}{l}\text { Supported by the Combat Casualty } \\
\text { Care Research Program and the } \\
\text { Telemedicine and Advanced } \\
\text { Technology Research Center, US } \\
\text { Army Medical Research and } \\
\text { Materiel Command. }\end{array}$ & Moderate \\
\hline
\end{tabular}




\begin{tabular}{|c|c|c|c|c|}
\hline $\begin{array}{l}\text { Author, Year } \\
\text { (See Appendix B for } \\
\text { complete reference) }\end{array}$ & Study Design & Setting and Dates Performed & Number of Study Subjects & Data Source \\
\hline Batchinsky, 2009b & Retrospective & $\begin{array}{l}\text { USA, Texas; Iraq, Baghdad } \\
\text { Urban vs. rural: NR } \\
\text { Trauma system level: NR } \\
\\
\text { Study time period: NR }\end{array}$ & $\begin{array}{l}262 \text { analyzed } \\
464 \text { identified }\end{array}$ & Trauma Vitals database \\
\hline Beekley, 2010 & Prospective & $\begin{array}{l}\text { Iraq, Baghdad (U.S. military) } \\
\text { Setting: Combat } \\
\text { U.S. Army Combat Support Hospital } \\
8 / 2007 \text { to } 12 / 2007 \\
5 \text { months }\end{array}$ & 147 analyzed & $\begin{array}{l}\text { Primary Data Collection and data } \\
\text { in the Joint Theater Trauma } \\
\text { Registry }\end{array}$ \\
\hline Bond, 1997 & Retrospective & $\begin{array}{l}\text { Canada, Calgary } \\
\text { Urban and rural } \\
2 \text { major trauma centers and } 2 \text { community } \\
\text { acute care centers } \\
5 / 1 / 1995 \text { to } 10 / 31 / 1995 \\
6 \text { months }\end{array}$ & $\begin{array}{l}3,147 \text { analyzed } \\
3,272 \text { identified } \\
125 \text { excluded for incomplete documentation }\end{array}$ & $\begin{array}{l}\text { Primary data collected from } \\
\text { medical charts, including EMS } \\
\text { patient care record. }\end{array}$ \\
\hline
\end{tabular}




\begin{tabular}{|c|c|c|c|}
\hline \begin{tabular}{|l|} 
Author, Year \\
(See Appendix B for \\
complete reference)
\end{tabular} & Eligibility Criteria & $\begin{array}{l}\text { Age Groups Included (Age Range Used*): \% } \\
\text { of Study Population }\end{array}$ & Type of Population \\
\hline Batchinsky, 2009b & $\begin{array}{l}\text { Included: Patients with blunt or penetrating injuries admitted to study } \\
\text { EDs. } \\
\text { Excluded: Patients whose ECG sections had }<800 \text { R-to-R intervals, } \\
\text { there were ectopic beats within the analyzed data segments, or the } \\
\text { ECG contained electromechanical noise. }\end{array}$ & $\mathrm{NR}$ & NR \\
\hline Beekley, 2010 & $\begin{array}{l}\text { Included: US soldiers, US civilians, and foreign nationals with a } \\
\text { battle or nonbattle injury brought via litter between } 7 \text { AM and } 7 \text { PM. } \\
\text { Excluded: Patients with detainee status, who were "walking } \\
\text { wounded" or with clearly minimal injuries. }\end{array}$ & Adults (NR): $100 \%$ & Military \\
\hline Bond, 1997 & $\begin{array}{l}\text { Included: Trauma patients age } \geq 14 \text { years old who were transported } \\
\text { by one EMS provider to any of the } 4 \text { study centers. } \\
\text { Excluded: Patients }<14 \text { years old, those transported by an EMS unit } \\
\text { other than that specified, those pronounced dead in the field, and } \\
\text { those with incomplete documentation. }\end{array}$ & Adults $(\geq 14): 100 \%$ & Civilian \\
\hline
\end{tabular}




\begin{tabular}{|c|c|c|c|c|}
\hline $\begin{array}{l}\text { Author, Year } \\
\text { (See Appendix B for } \\
\text { complete reference) }\end{array}$ & Mechanism or Type Injury & Mode of Transport & $\begin{array}{l}\text { Other Population Characteristics } \\
\text { (Sex, Race) }\end{array}$ & $\begin{array}{l}\text { Name of Measure Being } \\
\text { Evaluated }\end{array}$ \\
\hline Batchinsky, 2009b & $\begin{array}{l}\text { Blunt and penetrating injuries } \\
\text { Patients with and without life-saving } \\
\text { interventions were clinically indistinguishable } \\
\text { with respect to mechanism of injury. Patients } \\
\text { who received LSIs were more severely injured } \\
\text { based on ISS. }\end{array}$ & NR & $\begin{array}{l}\text { NR } \\
\text { Patients with and without life-saving } \\
\text { interventions were clinically } \\
\text { indistinguishable with respect to age and } \\
\text { sex. }\end{array}$ & $\begin{array}{l}\text { HRC artificial neural network } \\
\text { (ANN) model using } 16 \text { ECG- } \\
\text { derived New Vital Signs } \\
\text { - Linear time- and frequency- } \\
\text { domain metrics } \\
\text { - HRC metrics }\end{array}$ \\
\hline Beekley, 2010 & $\begin{array}{l}\text { Primary mechanism } \\
\text { Gunshot: } 39 \% \\
\text { Explosion } 46 \% \\
\text { Motor vehicle crash: } 7 \% \\
\text { All others: } 8 \%\end{array}$ & $\begin{array}{l}\text { Litter (combat } \\
\text { casualty) }\end{array}$ & $\begin{array}{l}\text { Male: } 93 \% \\
\text { Race: NR } \\
\text { Age (mean): } 27 \text { (SD 11) }\end{array}$ & $\begin{array}{l}\text { Base deficit } \\
\text { DBP } \\
\text { HR } \\
\text { Radial pulse character } \\
\text { SBP } \\
\text { Tissue Oxygenation Saturation } \\
\left(\mathrm{StO}_{2}\right)\end{array}$ \\
\hline Bond, 1997 & $\begin{array}{l}\text { Type of injury } \\
\text { Penetrating: } 2 \%(59 / 3,147) \\
\text { Blunt: } 98 \%(3,088 / 3,147) \\
\text { Mechanism of injury } \\
\text { Motor vehicle crash: } 32 \%(997 / 3,147) \\
\text { Falls: } 38 \%(1,190 / 3,147) \\
\text { Pedestrian vs. auto crashes: } 4 \%(125 / 3,147) \\
\text { Assault: } 13 \%(422 / 3,147) \\
\text { Sports injuries: } 5 \%(171 / 3,147) \\
\text { Burns: } 2 \%(50 / 3,147) \\
\text { Industrial accidents: } 2 \%(68 / 3,147) \\
\text { Not classified: } 4 \%(124 / 3,147)\end{array}$ & NR & NR & Prehospital Index (PHI) score \\
\hline
\end{tabular}




\begin{tabular}{|c|c|c|c|c|}
\hline $\begin{array}{l}\text { Author, Year } \\
\text { (See Appendix B for } \\
\text { complete reference) }\end{array}$ & $\begin{array}{l}\text { Location and Timing of } \\
\text { Measurement }\end{array}$ & Method of Measurement & $\begin{array}{l}\text { Personnel Administering Test or } \\
\text { Using Measure }\end{array}$ & Equipment Used/Needed \\
\hline Batchinsky, 2009b & $\begin{array}{l}\text { Out of hospital: timing NR } \\
-27 \% \text { of patients (70/262) } \\
\text { ED: timing NR } \\
-73 \%(192 / 262)\end{array}$ & $\begin{array}{l}\text { ECG: earliest available } 800- \\
\text { beat data set from continuous } \\
20-30 \text { minute sections of } \\
\text { waveform }\end{array}$ & $\mathrm{NR}$ & $\begin{array}{l}\text { ECG waveform analysis: } \\
\text { WinCPRS software (Absolute } \\
\text { Aliens Oy; Turku, Finland) } \\
\text { Artificial neural network (ANN): } \\
\text { commercially available feed- } \\
\text { forward back-propagation ANN } \\
\text { (NeuralWare; Carnegie, } \\
\text { Pennsylvania) }\end{array}$ \\
\hline Beekley, 2010 & ED: on arrival & $\begin{array}{l}\mathrm{StO}_{2} \text { : Near-infrared } \\
\text { spectroscopy sensor, applied } \\
\text { to uninjured extremity. }\end{array}$ & Research nurses & $\begin{array}{l}\text { StO.33 } \\
\text { monitor: In-Spectra } 650 \\
\text { (Hutchinson Technology, Inc.) }\end{array}$ \\
\hline Bond, 1997 & Out of hospital: not specified & NR & EMS personnel & NR \\
\hline
\end{tabular}




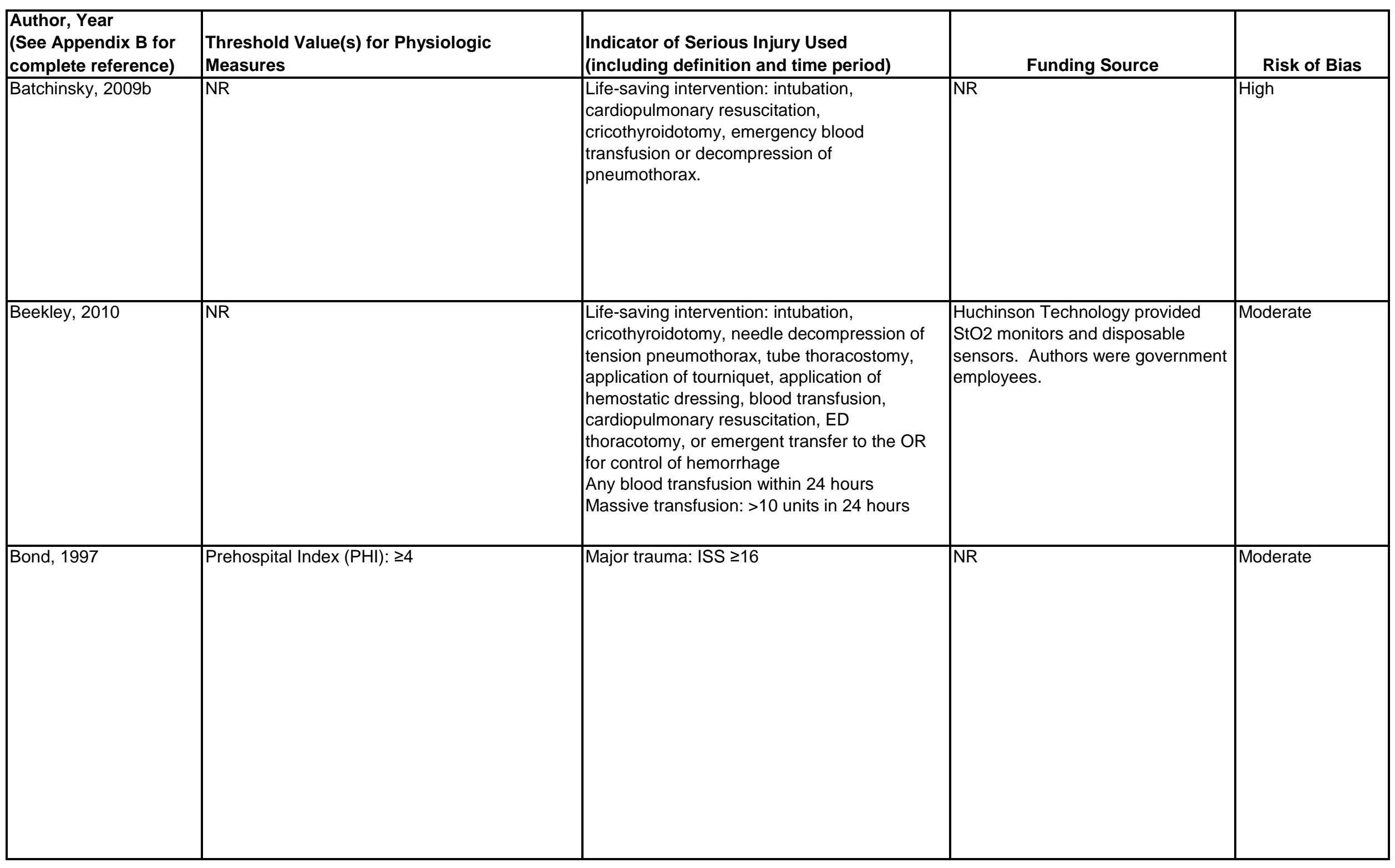




\begin{tabular}{|c|c|c|c|c|}
\hline $\begin{array}{l}\text { Author, Year } \\
\text { (See Appendix B for } \\
\text { complete reference) } \\
\end{array}$ & Study Design & Setting and Dates Performed & Number of Study Subjects & Data Source \\
\hline Bouzat, 2016 & Prospective & $\begin{array}{l}\text { France, Grenoble } \\
\text { Urban } \\
\text { Level I trauma center } \\
\\
8 / 2011 \text { to } 2 / 2013 \\
1 \text { year, } 7 \text { months }\end{array}$ & 120 analyzed & $\begin{array}{l}\text { Primary collection of data from } \\
\text { consecutive patients }\end{array}$ \\
\hline Brown, 2011 & Retrospective & $\begin{array}{l}\text { USA } \\
\text { Urban vs. rural: NR (national database) } \\
\text { Levels I-IV trauma centers and } \\
\text { undesignated hospitals } \\
2002 \text { to } 2006 \\
5 \text { years }\end{array}$ & $\begin{array}{l}1,086,764 \text { analyzed } \\
1,477,099 \text { identified } \\
390,355 \text { excluded for incomplete data }\end{array}$ & NTDB version 7 \\
\hline Brown, 2015 & Retrospective & $\begin{array}{l}\text { USA } \\
\text { Urban vs. rural: NR (national database) } \\
\text { Trauma system level: NR } \\
2010 \text { to } 2012 \\
3 \text { years }\end{array}$ & $1,555,944$ analyzed & NTDB \\
\hline
\end{tabular}




\begin{tabular}{|c|c|c|c|}
\hline $\begin{array}{l}\text { Author, Year } \\
\text { (See Appendix B for } \\
\text { complete reference) }\end{array}$ & Eligibility Criteria & $\begin{array}{l}\text { Age Groups Included (Age Range Used*): \% } \\
\text { of Study Population }\end{array}$ & Type of Population \\
\hline Bouzat, 2016 & $\begin{array}{l}\text { Included: Patients age } \geq 18 \text { years with SBP }<90 \text { who were admitted } \\
\text { to the trauma bay for suspected severe trauma based on French } \\
\text { Vittel triage criteria. } \\
\text { Excluded: Patients with chronic liver disease, pregnant patients, } \\
\text { those who received pre-hospital transfusion, pre-hospital infusion of } \\
\text { norepinephrine }<0.1 \mathrm{mcg} / \mathrm{kg} / \mathrm{min} \text {, or had a body core temperature } \\
<35 \text { C. }\end{array}$ & Adults ( $\geq 18): 100 \%$ & Civilian \\
\hline Brown, 2011 & $\begin{array}{l}\text { Included: Trauma patients age } \geq 18 \text { years. } \\
\text { Excluded: Patients with missing ISS, GCS, SBP or RR data. }\end{array}$ & Adults ( $(\geq 18): 100 \%$ & Civilian \\
\hline Brown, 2015 & $\begin{array}{l}\text { Included: Patients age } \geq 15 \text { transported from the scene of injury. } \\
\text { Excluded: Patients undergoing interfacility transfer or who died on } \\
\text { arrival. }\end{array}$ & $\begin{array}{l}\text { Adults (16-65): 72\% } \\
\text { Elderly (>65): } 28 \%\end{array}$ & Civilian \\
\hline
\end{tabular}




\begin{tabular}{|c|c|c|c|c|}
\hline $\begin{array}{l}\text { Author, Year } \\
\text { (See Appendix B for } \\
\text { complete reference) } \\
\end{array}$ & Mechanism or Type Injury & Mode of Transport & $\begin{array}{l}\text { Other Population Characteristics } \\
\text { (Sex, Race) }\end{array}$ & $\begin{array}{l}\text { Name of Measure Being } \\
\text { Evaluated }\end{array}$ \\
\hline Bouzat, 2016 & Blunt: 94\% (113/120) & NR & $\begin{array}{l}\text { Male: } 85 \%(102 / 120) \\
\text { Race: NR } \\
\text { Age (median): } 37 \text { (IQR: 27-56) }\end{array}$ & $\begin{array}{l}\text { Lactate } \\
\text { SI }\end{array}$ \\
\hline Brown, 2011 & \begin{tabular}{|l|} 
Blunt: NR \\
Penetrating: \% NR
\end{tabular} & NR & $\begin{array}{l}\text { Male: } 66 \% \\
\text { Race: NR } \\
\text { Age (mean): } 45 \text { (SD 20) }\end{array}$ & \begin{tabular}{|l|} 
RR \\
SBP \\
Physiologic criteria of the \\
National Trauma Triage Protocol \\
(NTTP), uses GCS, SBP, RR
\end{tabular} \\
\hline Brown, 2015 & $\begin{array}{l}\text { Blunt injury } \\
\text { - overall: } 89 \% \\
\text { - adults: } 85 \% \\
\text { - elderly: } 99 \%\end{array}$ & NR & $\begin{array}{l}\text { Overall } \\
\text { Male: } 62 \% \\
\text { Race: NR } \\
\text { Age: NR } \\
\\
\text { Adults } \\
\text { Male: } 71 \% \\
\text { Race: NR } \\
\text { Age (median): } 37 \text { (IQR 25-50) } \\
\\
\text { Elderly } \\
\text { Male: 39\% } \\
\text { Race: NR } \\
\text { Age (median): } 80 \text { (IQR 73-86) }\end{array}$ & SBP \\
\hline
\end{tabular}




\begin{tabular}{|c|c|c|c|c|}
\hline $\begin{array}{l}\text { Author, Year } \\
\text { (See Appendix B for } \\
\text { complete reference) }\end{array}$ & $\begin{array}{l}\text { Location and Timing of } \\
\text { Measurement }\end{array}$ & Method of Measurement & $\begin{array}{l}\text { Personnel Administering Test or } \\
\text { Using Measure }\end{array}$ & Equipment Used/Needed \\
\hline Bouzat, 2016 & $\begin{array}{l}\text { Out of hospital: not specified } \\
\text { - SI } \\
\text { ED: on arrival } \\
\text { - Lactate: capillary; serum } \\
\text { (venous or arterial) }\end{array}$ & \begin{tabular}{|l|} 
Lactate: capillary (handheld \\
POC) \\
average value of 2 consecutive \\
samples at same collection site \\
(fingertip or ear lobe)
\end{tabular} & Nurse & $\begin{array}{l}\text { Lactate, capillary: lactate scou } \\
\text { (Senslab, Leipzig, Germany) }\end{array}$ \\
\hline Brown, 2011 & $\begin{array}{l}\text { Out of hospital: on arrival } \\
\text { - GCS (available for } 56 \% \text { of } \\
\text { patients) } \\
\text { ED: on arrival } \\
\text { - SBP, RR } \\
\text { - GCS (for } 44 \% \text { with no out of } \\
\text { hospital scores) } \\
\\
\text { GCS: out of hospital available in } \\
56 \% \text {; remainder used ED score }\end{array}$ & NR & NR & NR \\
\hline Brown, 2015 & Out of Hospital: not specified & $\mathrm{NR}$ & NR & NR \\
\hline
\end{tabular}




\begin{tabular}{|c|c|c|c|c|}
\hline $\begin{array}{l}\text { Author, Year } \\
\text { (See Appendix B for } \\
\text { complete reference) }\end{array}$ & $\begin{array}{l}\text { Threshold Value(s) for Physiologic } \\
\text { Measures }\end{array}$ & $\begin{array}{l}\text { Indicator of Serious Injury Used } \\
\text { (including definition and time period) }\end{array}$ & Funding Source & Risk of Bias \\
\hline Bouzat, 2016 & $\begin{array}{l}\text { Lactate: } \\
\text { normal: }<3.5 \\
\text { abnormal: } \geq 3.5\end{array}$ & $\begin{array}{l}\text { Significant blood transfusion: } \geq 4 \text { RBC units } \\
\text { transfused within the first } 48 \text { hours after } \\
\text { trauma } \\
\text { Any blood transfusion: any transfusion within } \\
\text { the first } 48 \text { hours } \\
\text { Emergency treatment for hemostasis: } \\
\text { embolization and/or damage control surgery } \\
\text { (laparotomy, thoracotomy and orthopedic } \\
\text { surgery for hemostasis) }\end{array}$ & $\mathrm{NR}$ & High \\
\hline Brown, 2011 & $\begin{array}{l}\mathrm{SBP}<90 \\
\mathrm{RR}<10 \text { or }>29\end{array}$ & \begin{tabular}{|l|} 
ICU admission $\geq 24$ hours \\
ISS $>15$ \\
Urgent surgery: ED disposition to the OR \\
Trauma center need: ISS $>15$, ICU admission \\
$\geq 24$ hours, or urgent surgery (defined as ED \\
disposition to the OR).
\end{tabular} & NR & Moderate \\
\hline Brown, 2015 & $\begin{array}{l}\text { SBP from triage criteria: }<90 \mathrm{~mm} \mathrm{Hg} \text { vs. }<110 \\
\mathrm{~mm} \mathrm{Hg} \\
\text { SBP optimal cutoffs to maximize sensitivity and } \\
\text { specificity } \\
\text { - Trauma center need: adults }<118 \text {, elderly }<122 \\
\text { - Mortality: adults }<106 \text {, elderly }<118\end{array}$ & $\begin{array}{l}\text { Trauma center need: any of ISS }>15, \text { ICU } \\
\text { admission } \geq 24 \text { hours, need for urgent surgery, } \\
\text { death in the ED } \\
\text { Mortality: in hospital }\end{array}$ & $\begin{array}{l}\text { No funding or support was directly } \\
\text { received to perform the current } \\
\text { study. } \\
\text { Dr. Brown receives support from an } \\
\text { institutional T32 Ruth L. Kirschstein } \\
\text { National Research Service Award } \\
\text { training grant (5-T32-GM-008516- } \\
\text { 20) from the National Institutes of } \\
\text { Health. Dr. Sperry receives support } \\
\text { from a career development award } \\
\text { (K23GM093032) from the National } \\
\text { Institute of General Medical } \\
\text { Sciences. }\end{array}$ & Moderate \\
\hline
\end{tabular}




\begin{tabular}{|c|c|c|c|c|}
\hline $\begin{array}{l}\text { Author, Year } \\
\text { (See Appendix B for } \\
\text { complete reference) } \\
\end{array}$ & Study Design & Setting and Dates Performed & Number of Study Subjects & Data Source \\
\hline Brown, 2016 & Retrospective & $\begin{array}{l}\text { USA, Pennsylvania } \\
\text { Urban } \\
\text { Level I trauma center } \\
1 / 2009 \text { to } 9 / 2014 \\
5 \text { years, } 9 \text { months }\end{array}$ & $\begin{array}{l}\text { 6,347 analyzed } \\
\text { 8,729 identified } \\
1,354 \text { excluded for no prehospital lactate } \\
\text { level } \\
\text { 1,028 excluded for not meeting remaining } \\
\text { inclusion criteria }\end{array}$ & $\begin{array}{l}\text { Prehospital database and } \\
\text { electronic health records from a } \\
\text { single trauma center. }\end{array}$ \\
\hline Bruijns, 2013 & Retrospective & $\begin{array}{l}\text { UK, England and Wales } \\
\text { Urban vs. Rural: NR } \\
\text { Trauma system level: NR } \\
1996 \text { to } 2006 \\
11 \text { years }\end{array}$ & $\begin{array}{l}69,367 \text { analyzed } \\
71,882 \text { identified } \\
2,515 \text { excluded as outliers ( } z \text { score }>3 \text { for } \\
\text { age, SBP, HR, or RR) }\end{array}$ & TARN \\
\hline
\end{tabular}




\begin{tabular}{|c|c|c|c|}
\hline $\begin{array}{l}\text { Author, Year } \\
\text { (See Appendix B for } \\
\text { complete reference) }\end{array}$ & Eligibility Criteria & $\begin{array}{l}\text { Age Groups Included (Age Range Used*): \% } \\
\text { of Study Population }\end{array}$ & Type of Population \\
\hline Brown, 2016 & $\begin{array}{l}\text { Included: Patients }>15 \text { years old transported by air medical transport } \\
\text { by a single transport provider who had a prehospital lactate } \\
\text { measurement. } \\
\text { Excluded: NR* } \\
\text { * Trauma center has a separate burn center and obstetric support; } \\
\text { outcome and activation criteria related to burns or pregnancy were } \\
\text { not considered. }\end{array}$ & Adults (>15): $100 \%$ & Civilian \\
\hline Bruijns, 2013 & $\begin{array}{l}\text { Included: Patients }>16 \text { years old. } \\
\text { Excluded: Patients with head or spinal injuries other than minor } \\
\text { (injury with AIS } \leq 1) \text {; unknown injuries, or who required prehospital } \\
\text { intubation or cardiopulmonary resuscitation. }\end{array}$ & Adults (>16): 100\% & Civilian \\
\hline
\end{tabular}




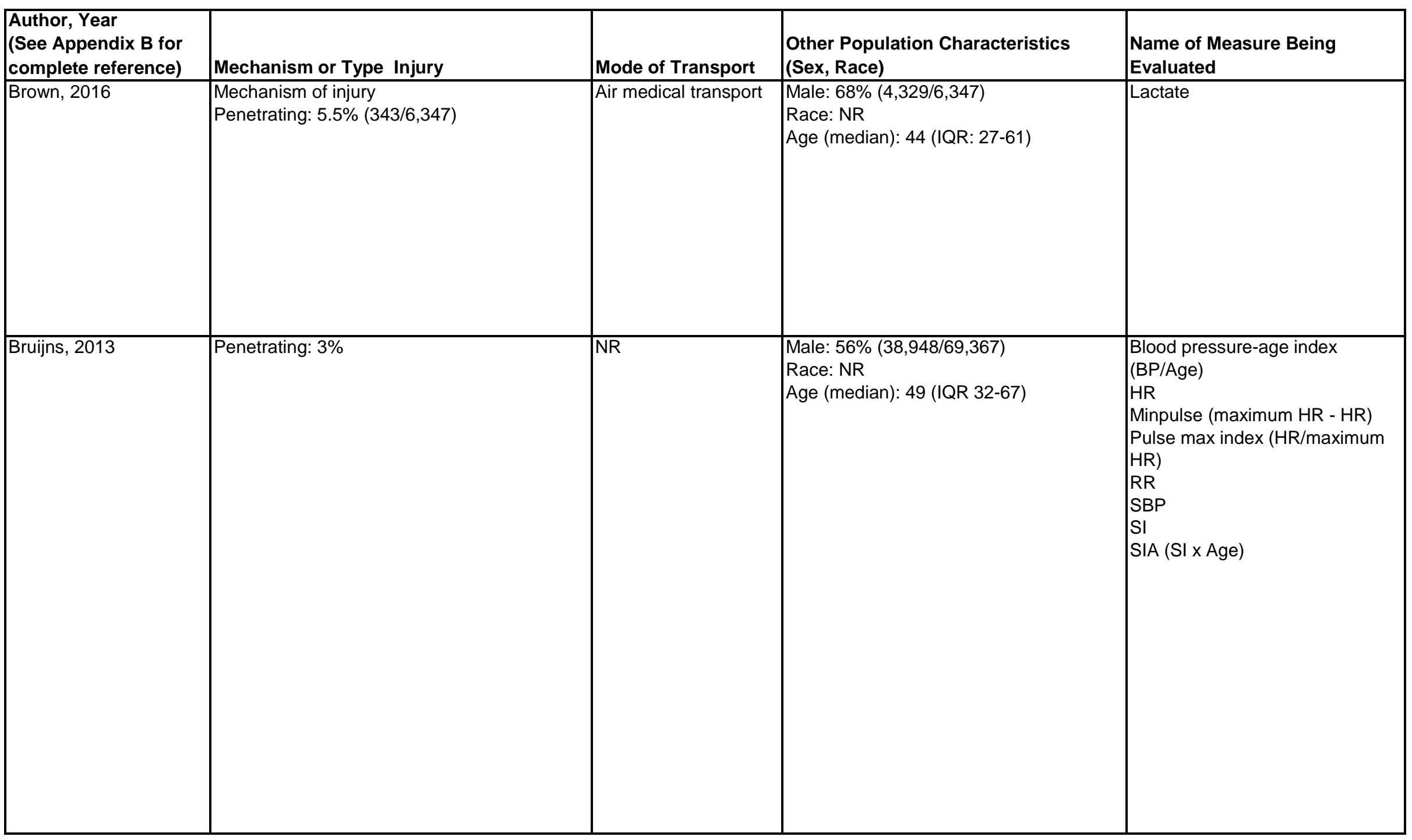




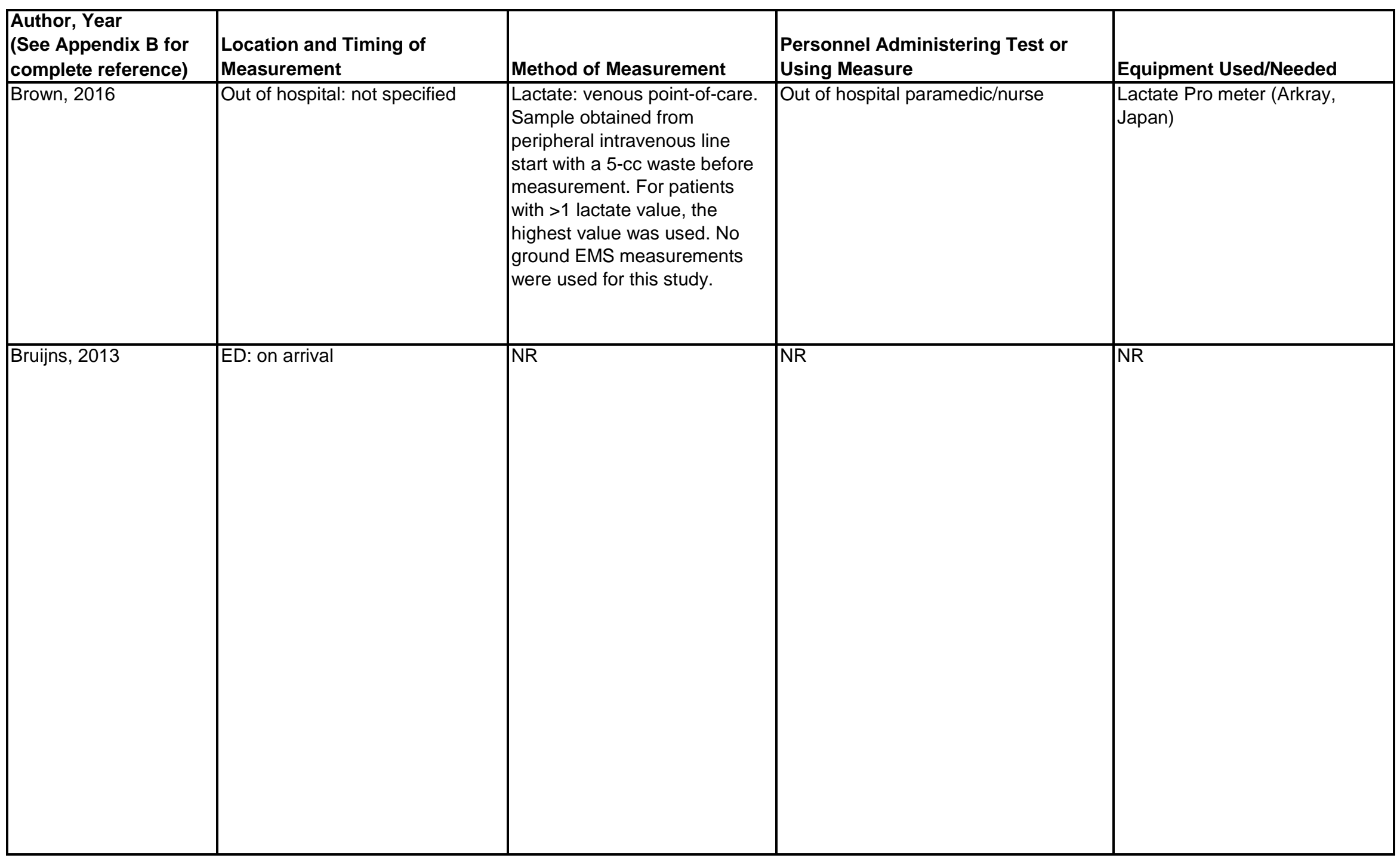




\begin{tabular}{|c|c|c|c|c|}
\hline $\begin{array}{l}\text { Author, Year } \\
\text { (See Appendix B for } \\
\text { complete reference) }\end{array}$ & $\begin{array}{l}\text { Threshold Value(s) for Physiologic } \\
\text { Measures }\end{array}$ & $\begin{array}{l}\text { Indicator of Serious Injury Used } \\
\text { (including definition and time period) }\end{array}$ & Funding Source & Risk of Bias \\
\hline Brown, 2016 & $\overline{N R}$ & $\begin{array}{l}\text { Trauma center need: any of the following: } \\
\text { blood transfusion }>1 \text { unit in the ED; spinal } \\
\text { cord injury; advanced airway placed } \\
\text { prehospital or in the ED; thoracotomy within } \\
48 \text { hours of admission; pericardiocentesis } \\
\text { within } 24 \text { hours of admission; intracranial } \\
\text { pressure monitoring; interventional radiology } \\
\text { procedure within } 4 \text { hours of admission; } \\
\text { abdominal/thoracic/vascular/neurologic } \\
\text { surgical procedure within } 24 \text { hours; death. }\end{array}$ & $\begin{array}{l}\text { No direct funding or support for this } \\
\text { study. }\end{array}$ & Moderate \\
\hline Bruijns, 2013 & $\begin{array}{l}\text { Thresholds chosen as values corresponding to } \\
90 \% \text { specificity in analysis } \\
\text { Blood pressure-age index: } \leq 1.7 \\
\text { HR: } \geq 104 \\
\text { Minpulse: } \leq 54 \\
\text { Pulse max index: } \geq 60 \% \\
\text { RR: } \geq 24 \\
\text { SBP: } \leq 110 \\
\text { SI: } \geq 0.8 \\
\text { SIA (SI x Age): } \geq 48 \\
\\
\text { Thresholds chosen as values corresponding to } \\
95 \% \text { specificity in analysis } \\
\text { Blood pressure-age index: } \leq 1.5 \\
\text { HR: } \geq 112 \\
\text { Minpulse: } \leq 44 \\
\text { Pulse max index: } \geq 70 \% \\
\text { RR: } \geq 27 \\
\text { SBP: } \leq 101 \\
\text { SI: } \geq 0.9 \\
\text { SIA (SI } x \text { Age): } \geq 55\end{array}$ & Mortality: 48-hour & No external funding & Moderate \\
\hline
\end{tabular}




\begin{tabular}{|c|c|c|c|c|}
\hline $\begin{array}{l}\text { Author, Year } \\
\text { (See Appendix B for } \\
\text { complete reference) }\end{array}$ & Study Design & Setting and Dates Performed & Number of Study Subjects & Data Source \\
\hline Bruijns, 2014 & Retrospective & $\begin{array}{l}\text { South Africa, Cape Town* } \\
\text { *data from UK registry } \\
\text { Urban vs. rural: NR } \\
\text { Trauma system level: NR } \\
1996 \text { to } 2006 \\
11 \text { years }\end{array}$ & $\begin{array}{l}28,273 \text { analyzed } \\
29,935 \text { cases extracted } \\
1,662 \text { excluded for outlying values (z-score } \\
>3 \text { ) } \\
-594 \text { cases with outlying value for change in } \\
\text { RR } \\
-531 \text { cases with outlying value for change in } \\
\text { HR } \\
-447 \text { cases with outlying value for change in } \\
\text { SI } \\
-1 \text { case with outlying value for age }\end{array}$ & $\begin{array}{l}\text { TARN, a trauma database with } \\
\text { data from collaborative hospitals } \\
\text { in England and Wales }\end{array}$ \\
\hline Callaway, 2009 & Retrospective & $\begin{array}{l}\text { USA } \\
\text { Urban } \\
\text { Level I trauma center } \\
1 / 1 / 2000 \text { to } 12 / 31 / 2006 \\
7 \text { years }\end{array}$ & $\begin{array}{l}1,776 \text { analyzed } \\
\geq 65 \text { years with both lactate and BD: } \\
588 / 1,776 \\
<65 \text { years with lactate: } 1,188 / 1,776 \\
<65 \text { years with lactate and BD: } 1,156 / 1,188\end{array}$ & $\begin{array}{l}\text { Trauma registry from a Level I } \\
\text { trauma center. }\end{array}$ \\
\hline Cancio, 2008 & Retrospective & $\begin{array}{l}\text { USA, Texas } \\
\text { Urban } \\
\text { Level I trauma centers } \\
\text { Study time period: NR }\end{array}$ & $\begin{array}{l}192 \text { analyzed } \\
182 \text { excluded due to waveform issues } \\
\text { (multiple ectopic beats, electromechanical } \\
\text { noise, inadequate data set length) }\end{array}$ & $\begin{array}{l}\text { Trauma Vitals (US Army Institute } \\
\text { of Surgical Research, Ft. Sam } \\
\text { Houston, TX) }\end{array}$ \\
\hline
\end{tabular}




\begin{tabular}{|c|c|c|c|}
\hline $\begin{array}{l}\text { Author, Year } \\
\text { (See Appendix B for } \\
\text { complete reference) }\end{array}$ & Eligibility Criteria & $\begin{array}{l}\text { Age Groups Included (Age Range Used*): \% } \\
\text { of Study Population }\end{array}$ & Type of Population \\
\hline Bruijns, 2014 & $\begin{array}{l}\text { Included: Patients }>16 \text { years old and with recorded values for HR, } \\
\text { RR and SBP both prehospital and in the ED. } \\
\text { Excluded: Patients with head or spinal injuries other than minor } \\
\text { (minor defined as injury with AIS } \leq 1 \text { ), had unknown injuries, or who } \\
\text { required prehospital intubation or CPR. }\end{array}$ & Adults (>16): $100 \%$ & Civilian \\
\hline Callaway, 2009 & $\begin{array}{l}\text { Included: Patients with SBP } \geq 90 \mathrm{~mm} \mathrm{Hg} \text { upon arrival to the ED, BD } \\
\text { or lactate measured at ED admission, and blunt mechanisms of } \\
\text { trauma. }\end{array}$ & $\begin{array}{l}\text { Adults: } 100 \% \\
\text { Elderly ( } \geq 65 \text { yrs): } 33 \%(588 / 1,776)\end{array}$ & Civilian \\
\hline Cancio, 2008 & $\begin{array}{l}\text { Included: Trauma patients transported by one of } 2 \text { life flight services } \\
\text { to any of the } 3 \text { study centers. } \\
\text { Excluded: Patients without available ECG of } 800 \text { R-to-R intervals } \\
\text { (RRIs) in length, who had ectopic beats within the analyzed data } \\
\text { segments, or whose ECG quality was inadequate (due to } \\
\text { electromechanical noise or disruption of the signal or both). }\end{array}$ & NR (presumably 100\% adult) & Unclear \\
\hline
\end{tabular}




\begin{tabular}{|c|c|c|c|c|}
\hline $\begin{array}{l}\text { Author, Year } \\
\text { (See Appendix B for } \\
\text { complete reference) }\end{array}$ & Mechanism or Type Injury & Mode of Transport & $\begin{array}{l}\text { Other Population Characteristics } \\
\text { (Sex, Race) }\end{array}$ & $\begin{array}{l}\text { Name of Measure Being } \\
\text { Evaluated }\end{array}$ \\
\hline Bruijns, 2014 & $\begin{array}{l}\text { Type of injury: } \\
\text { Penetrating: } 3 \%(896 / 28,273)\end{array}$ & NR & $\begin{array}{l}\text { Overall } \\
\text { Male: } 57 \%(16,214 / 28,273) \\
\text { Race: NR } \\
\text { Age (median): } 49 \text { (IQR: 31-67) }\end{array}$ & \begin{tabular}{|l} 
HR difference \\
RR difference \\
SBP difference \\
SI difference \\
*Difference is calculated as ED \\
value minus Out of hospital value
\end{tabular} \\
\hline Callaway, 2009 & Blunt: $100 \%$ & NR & $\begin{array}{l}\text { Elderly } \\
\text { Male: 46\% } \\
\text { Race: NR } \\
\text { Age (mean): } 80 \text { (SD 8) } \\
\\
\text { Nonelderly Adults } \\
\text { Survivors } \\
\text { Male: 73\% } \\
\text { Race: NR } \\
\text { Age (mean): } 38 \text { (SD 14) } \\
\text { Nonsurvivors } \\
\text { Male: 78\% } \\
\text { Race: NR } \\
\text { Age (mean): } 42 \text { (SD 14) }\end{array}$ & \begin{tabular}{|l} 
BD \\
Lactate
\end{tabular} \\
\hline Cancio, 2008 & \begin{tabular}{|l|} 
Blunt: $85 \%$ \\
Not recorded: $3 \%$
\end{tabular} & Helicopter & \begin{tabular}{|l|} 
Male: $71 \%$ \\
Race: NR \\
Age (mean): 37 (SD 5)
\end{tabular} & $\begin{array}{l}\text { HRC metrics: } \\
\text { - Sample Entropy (SampEn) } \\
\text { - Detrended Fluctuations } \\
\text { Analysis (DFA) } \\
\text { - SampEn plus DFA } \\
\text { HRC plus GCS motor component } \\
\text { (HRC metrics SampEn and DFA) }\end{array}$ \\
\hline
\end{tabular}




\begin{tabular}{|c|c|c|c|c|}
\hline $\begin{array}{l}\text { Author, Year } \\
\text { (See Appendix B for } \\
\text { complete reference) }\end{array}$ & $\begin{array}{l}\text { Location and Timing of } \\
\text { Measurement }\end{array}$ & Method of Measurement & $\begin{array}{l}\text { Personnel Administering Test or } \\
\text { Using Measure }\end{array}$ & Equipment Used/Needed \\
\hline Bruijns, 2014 & $\begin{array}{l}\text { Out of hospital: NR } \\
\text { ED: NR }\end{array}$ & NR & NR & NR \\
\hline Callaway, 2009 & ED: on arrival & Lactate: venous & NR & NR \\
\hline Cancio, 2008 & $\begin{array}{l}\text { Out of Hospital: during } \\
\text { Resuscitation }\end{array}$ & ECG: continuous waveform & NR & $\begin{array}{l}\text { ECG: Pic } 50 \text { vital sign monitor } \\
\text { (Welch Allyn, Skaneateles Falls } \\
\text { NY) } \\
\text { ECG R-wave identification: } \\
\text { WinCPRS software (Absolute } \\
\text { Aliens Oy, Turku, Finland) }\end{array}$ \\
\hline
\end{tabular}




\begin{tabular}{|c|c|c|c|c|}
\hline $\begin{array}{l}\text { Author, Year } \\
\text { (See Appendix B for } \\
\text { complete reference) }\end{array}$ & $\begin{array}{l}\text { Threshold Value(s) for Physiologic } \\
\text { Measures }\end{array}$ & $\begin{array}{l}\text { Indicator of Serious Injury Used } \\
\text { (including definition and time period) }\end{array}$ & Funding Source & Risk of Bias \\
\hline Bruijns, 2014 & $\begin{array}{l}\text { Cutpoints determined as values corresponding } \\
\text { to } 90 \% \text { specificity and } 95 \% \text { specificity. }\end{array}$ & Mortality: 48-hour & $\begin{array}{l}\text { Sponsored by the Plymouth } \\
\text { Hospitals Research and } \\
\text { Development service; no funding } \\
\text { involvement. }\end{array}$ & Moderate \\
\hline Callaway, 2009 & $\begin{array}{l}\text { Previously established thresholds. } \\
\text { Hypotension: SBP <90 } \\
\text { Lactate }(\mathrm{mmol} / \mathrm{L}) \text { : } \\
\text { Normal 0-2.4 } \\
\text { Moderately elevated } 2.5-4.0 \\
\text { Severely elevated }>4.0 \\
\\
\text { BD }(\mathrm{mEq} / \mathrm{L}): \\
\text { Normal }<0 \\
\text { Moderate } 0-6 \\
\text { Severe }>6\end{array}$ & Mortality: Inpatient & NR & Moderate \\
\hline Cancio, 2008 & NR & $\begin{array}{l}\text { LSI: any of the following, performed in the } \\
\text { field: cardiopulmonary resuscitation, } \\
\text { cricothyroidotomy, endotracheal intubation, } \\
\text { needle decompression of the chest, } \\
\text { pericardiocentesis, or cardioversion. }\end{array}$ & $\begin{array}{l}\text { Telemedicine and Advanced } \\
\text { Technology Research Center } \\
\text { (W81XWH-06-2-0065) and the } \\
\text { Advanced Capabilities for Combat } \\
\text { Medics Task Area of the Combat } \\
\text { Critical Care Engineering program } \\
\text { (E52-021-2005-USAISR), U.S. } \\
\text { Army Medical Research and } \\
\text { Materiel Command, Fort Detrick, } \\
\text { MD. }\end{array}$ & High \\
\hline
\end{tabular}




\begin{tabular}{|c|c|c|c|c|}
\hline $\begin{array}{l}\text { Author, Year } \\
\text { (See Appendix B for } \\
\text { complete reference) }\end{array}$ & Study Design & Setting and Dates Performed & Number of Study Subjects & Data Source \\
\hline Cancio, 2008a & Retrospective & $\begin{array}{l}\text { Iraq (U.S. military) } \\
\text { Setting: Combat } \\
\text { U.S. military Level } 3 \text { (combat support } \\
\text { hospital) } \\
\text { Time study period: NR }\end{array}$ & $\begin{array}{l}536 \text { analyzed } \\
692 \text { identified } \\
156 \text { excluded for missing data }\end{array}$ & $\begin{array}{l}\text { Existing internal performance- } \\
\text { improvement database including } \\
\text { cases from multiple US Level } 3 \\
\text { hospitals in Iraq. Ultimate } \\
\text { hospital mortality verified by } \\
\text { review of the Joint Theater } \\
\text { Trauma Registry. }\end{array}$ \\
\hline Cannon, 2009 & Retrospective & $\begin{array}{l}\text { USA } \\
\text { Urban } \\
\text { Level I Trauma Center } \\
1996 \text { to } 2005 \\
10 \text { years }\end{array}$ & $\begin{array}{l}2,445 \text { analyzed } \\
1,166 / 2,445 \text { with Out of Hospital data }\end{array}$ & Collector Trauma Registry \\
\hline Caputo, 2012 & Prospective & $\begin{array}{l}\text { USA, New York } \\
\text { Urban } \\
\text { Level I trauma center } \\
7 / 11 / 2011 \text { to } 12 / 16 / 2011 \\
5 \text { months }\end{array}$ & $\begin{array}{l}105 \text { analyzed } \\
126 \text { trauma team activations } \\
21 \text { excluded } \\
-2 \text { excluded for airway support } \\
-7 \text { excluded for intubated on arrival } \\
-7 \text { excluded for lost vital signs } \\
-5 \text { excluded as missed cases }\end{array}$ & $\begin{array}{l}\text { Primary data collection and data } \\
\text { from the electronic medical } \\
\text { record }\end{array}$ \\
\hline Caputo, 2015 & Prospective & $\begin{array}{l}\text { USA, New York } \\
\text { Urban } \\
\text { Level I trauma center } \\
7 / 2012 \text { to } 12 / 2012 \\
6 \text { months }\end{array}$ & $\begin{array}{l}100 \text { analyzed } \\
113 \text { identified } \\
13 \text { excluded } \\
-9 \text { excluded due inappropriate trauma team } \\
\text { activation } \\
-4 \text { excluded due to death before ED arrival }\end{array}$ & $\begin{array}{l}\text { Prospective collection of ED } \\
\text { admission data }\end{array}$ \\
\hline
\end{tabular}




\begin{tabular}{|c|c|c|c|}
\hline $\begin{array}{l}\text { Author, Year } \\
\text { (See Appendix B for } \\
\text { complete reference) }\end{array}$ & Eligibility Criteria & $\begin{array}{l}\text { Age Groups Included (Age Range Used*): \% } \\
\text { of Study Population }\end{array}$ & Type of Population \\
\hline Cancio, 2008a & $\begin{array}{l}\text { Included: US combat casualties with complete data for SBP, DBP, } \\
\text { HR, RR, total GCS, RTS, artificial ventilation, number of PRBC and } \\
\text { whole blood units transfused in } 24 \text { hours, and in-hospital mortality. } \\
\text { Excluded: Patients with incomplete data. }\end{array}$ & NR (presumably $100 \%$ adult) & Military \\
\hline Cannon, 2009 & $\begin{array}{l}\text { Included: Patients with a mechanism of injury and an ICD-9 code } \\
800-959, \text { who met trauma system activation criteria, were brought to } \\
\text { ED as a type } 2 \text { (moderate trauma, mechanism) or type } 1 \text { (severe } \\
\text { trauma with or without hemodynamic stability) trauma patient, were } \\
\text { direct arrivals to the ED from the field, and either died in the ED or } \\
\text { were admitted to the hospital. } \\
\text { Excluded: Patients transferred to the hospital from an outside } \\
\text { institution, those with incomplete records, or who were admitted } \\
\text { through the ED but did not require trauma system activation. }\end{array}$ & NR & Civilian \\
\hline Caputo, 2012 & $\begin{array}{l}\text { Included: Patients with penetrating trauma for whom the trauma } \\
\text { team was activated. } \\
\text { Excluded: Patients with lost vital signs before reaching the trauma } \\
\text { bay, those already intubated on arrival, and those with activations } \\
\text { for surgical airway support. }\end{array}$ & $\begin{array}{l}\text { NR } \\
\text { IQR for age: } 19-30\end{array}$ & Civilian \\
\hline Caputo, 2015 & $\begin{array}{l}\text { Included: Patients age }>18 \text { years with penetrating or blunt trauma in } \\
\text { which trauma team was activated. } \\
\text { Excluded: Patients age }<18 \text { years and those with no trauma team } \\
\text { activation. }\end{array}$ & Adults (>18): $100 \%$ & Civilian \\
\hline
\end{tabular}




\begin{tabular}{|c|c|c|c|c|}
\hline $\begin{array}{l}\text { Author, Year } \\
\text { (See Appendix B for } \\
\text { complete reference) }\end{array}$ & Mechanism or Type Injury & Mode of Transport & $\begin{array}{l}\text { Other Population Characteristics } \\
\text { (Sex, Race) }\end{array}$ & $\begin{array}{l}\text { Name of Measure Being } \\
\text { Evaluated }\end{array}$ \\
\hline Cancio, 2008a & NR & NR & NR & $\begin{array}{l}\text { DBP } \\
\text { FTS07 (new Field Triage Score) } \\
\text { SI } \\
\text { RTS }\end{array}$ \\
\hline Cannon, 2009 & Penetrating: $26 \%$ & $\begin{array}{l}\text { Ambulance, } \\
\text { helicopter, or private } \\
\text { vehicle }\end{array}$ & $\begin{array}{l}\text { Male: } 73.7 \% \\
\text { Race: NR } \\
\text { Age (median), patients with ED SI >0.9: } \\
32 \\
\text { Age (median), patients with ED SI } \leq 0.9 \text { : } \\
28\end{array}$ & $\begin{array}{l}\mathrm{SBP} \\
\mathrm{SI}\end{array}$ \\
\hline Caputo, 2012 & $\begin{array}{l}\text { Mechanism of injury } \\
\text { Stab wound: } 53 \% \\
\text { Gunshot wound: } 47 \%\end{array}$ & NR & $\begin{array}{l}\text { Male: } 91 \% \\
\text { Race: NR } \\
\text { Age (mean): } 26\end{array}$ & $\begin{array}{l}\text { ET CO2 } \\
\text { Lactate } \\
\text { SBP }\end{array}$ \\
\hline Caputo, 2015 & $\begin{array}{l}\text { Blunt: } 53 \% \\
\text { Penetrating: } 47 \%\end{array}$ & NR & $\begin{array}{l}\text { Male: } 89 \% \\
\text { Race: NR } \\
\text { Age (mean): } 34 \text { (SD NR) }\end{array}$ & $\begin{array}{l}\text { Anion gap } \\
\text { BD } \\
\text { Lactate }\end{array}$ \\
\hline
\end{tabular}




\begin{tabular}{|c|c|c|c|c|}
\hline \begin{tabular}{|l|} 
Author, Year \\
(See Appendix B for \\
complete reference) \\
\end{tabular} & $\begin{array}{l}\text { Location and Timing of } \\
\text { Measurement }\end{array}$ & Method of Measurement & $\begin{array}{l}\text { Personnel Administering Test or } \\
\text { Using Measure } \\
\end{array}$ & Equipment Used/Needed \\
\hline Cancio, 2008a & ED: on arrival & NR & NR & NR \\
\hline Caputo, 2015 & ED: on arrival & $\begin{array}{l}\text { Anion gap: arterial blood gas } \\
\text { Lactate: arterial }\end{array}$ & ED clinician & $\begin{array}{l}\text { iStat point-of-care blood } \\
\text { sampling analyzer (Abbott, } \\
\text { Dallas, Texas) using arterial } \\
\text { sample. } \\
\text { - Lactate (direct) } \\
\text { - Anion gap (calculated) } \\
\text { - BE (calculated) }\end{array}$ \\
\hline
\end{tabular}




\begin{tabular}{|c|c|c|c|c|}
\hline $\begin{array}{l}\text { Author, Year } \\
\text { (See Appendix B for } \\
\text { complete reference) }\end{array}$ & $\begin{array}{l}\text { Threshold Value(s) for Physiologic } \\
\text { Measures }\end{array}$ & $\begin{array}{l}\text { Indicator of Serious Injury Used } \\
\text { (including definition and time period) }\end{array}$ & Funding Source & Risk of Bias \\
\hline Cancio, 2008a & Thresholds specified in each scoring systems. & $\begin{array}{l}\text { Massive transfusion: }>10 \text { units of packed RBC } \\
\text { or whole blood units in } 24 \text { hours. } \\
\text { Mortality: in-hospital }\end{array}$ & $\begin{array}{l}\text { Partially funded by the Combat } \\
\text { Critical Care Engineering Program, } \\
\text { US Army Medical Research and } \\
\text { Materiel Command, Ft. Detrick, MD. }\end{array}$ & High \\
\hline Cannon, 2009 & $\begin{array}{l}\text { SI }>0.9 \text {, predetermined } \\
\text { Change in } \mathrm{SI} \geq 0.3 \text {, selected during analysis } \\
-0.291 \text { value able to predict increased mortality; } \\
\text { Rounded }\end{array}$ & Mortality: NR & NR & Moderate \\
\hline Caputo, 2012 & $\begin{array}{l}\text { Lactate }>4 \mathrm{mmol} / \mathrm{L}: \text { abnormal high } \\
\text { ET CO2 }<35 \mathrm{mmHg} \text { : abnormal low }\end{array}$ & $\begin{array}{l}\text { Operative intervention } \\
\text { Massive transfusion }\end{array}$ & NR & Moderate \\
\hline Caputo, 2015 & $\begin{array}{l}\text { Anion gap: }>16 \mathrm{mEq} / \mathrm{L} \\
\text { BD: }<-2 \mathrm{mEq} / \mathrm{L} \\
\text { Lactate: }>4 \mathrm{mmol} / \mathrm{L}\end{array}$ & $\begin{array}{l}\text { Massive transfusion } \\
\text { Operative intervention }\end{array}$ & No external funding & Low \\
\hline
\end{tabular}




\begin{tabular}{|c|c|c|c|c|}
\hline $\begin{array}{l}\text { Author, Year } \\
\text { (See Appendix B for } \\
\text { complete reference) }\end{array}$ & Study Design & Setting and Dates Performed & Number of Study Subjects & Data Source \\
\hline Chan, 1997 & Retrospective case-control & $\begin{array}{l}\text { USA, New York } \\
\text { Urban } \\
\text { Level I trauma center } \\
1 / 1 / 1993 \text { to } 5 / 31 / 1994 \\
1 \text { year, } 5 \text { months }\end{array}$ & $\begin{array}{l}104 \text { analyzed } \\
\text { Group } 1 \text { (case): } n=52 \\
\text { Group } 2 \text { (control): } n=52\end{array}$ & Internal hospital trauma registry \\
\hline $\begin{array}{l}\text { Chen, } 2007 \\
\text { *Chen 2007, 2008, } \\
2009, \text { and } 2010 \text { draw } \\
\text { from the same } 898 \\
\text { patients, but differ in } \\
\text { eligibility criteria, } \\
\text { number analyzed, and } \\
\text { some measures } \\
\text { evaluated. }\end{array}$ & Retrospective & $\begin{array}{l}\text { USA, Texas } \\
\text { Urban } \\
\text { Level I trauma center } \\
\text { Study time period: NR }\end{array}$ & $\begin{array}{l}492 \text { analyzed } \\
898 \text { identified }\end{array}$ & $\begin{array}{l}\text { Dataset of trauma patients } \\
\text { transported by helicopter from } \\
\text { the scene of injury to a single } \\
\text { trauma center. }\end{array}$ \\
\hline $\begin{array}{l}\text { Chen, } 2008 \\
\text { ^Chen 2007, 2008, } \\
2009, \text { and } 2010 \text { draw } \\
\text { from the same } 898 \\
\text { patients, but differ in } \\
\text { eligibility criteria, } \\
\text { number analyzed, and } \\
\text { some measures } \\
\text { evaluated. }\end{array}$ & Retrospective & $\begin{array}{l}\text { USA, Texas } \\
\text { Urban } \\
\text { Level I trauma center } \\
\text { Study time period: NR }\end{array}$ & $\begin{array}{l}627 \text { analyzed } \\
898 \text { identified* } \\
271 \text { excluded } \\
\text { - } 196 \text { excluded for not meeting minimal-data } \\
\text { criterion } \\
-75 \text { excluded for receiving blood in the ED } \\
\text { but not meeting documented injury criteria }\end{array}$ & $\begin{array}{l}\text { Database of physiologic data } \\
\text { collected during transport with } \\
\text { additional data collected } \\
\text { retrospectively via chart review. }\end{array}$ \\
\hline
\end{tabular}




\begin{tabular}{|c|c|c|c|}
\hline $\begin{array}{l}\text { Author, Year } \\
\text { (See Appendix B for } \\
\text { complete reference) }\end{array}$ & Eligibility Criteria & $\begin{array}{l}\text { Age Groups Included (Age Range Used*): \% } \\
\text { of Study Population }\end{array}$ & Type of Population \\
\hline Chan, 1997 & $\begin{array}{l}\text { Included: Patients with blunt trauma who were admitted to the } \\
\text { hospital who were normotensive on initial ED evaluation. } \\
\text { - Group } 1 \text { (case): Patients with } \geq 1 \text { out-of-hospital SBP } \leq 90 \text {. } \\
\text { - Group } 2 \text { (control): Patients with all out-of-hospital SBP readings } \\
>90 \text {. Selection by best age and initial ED SBP matches. } \\
\text { Excluded: Patients transferred from another institution, those who } \\
\text { did not arrive by ambulance, and patients who were discharged from } \\
\text { the ED. }\end{array}$ & NR (presumably $100 \%$ adult) & Civilian \\
\hline $\begin{array}{l}\text { Chen, } 2007 \\
\text { *Chen } 2007,2008, \\
2009, \text { and } 2010 \text { draw } \\
\text { from the same } 898 \\
\text { patients, but differ in } \\
\text { eligibility criteria, } \\
\text { number analyzed, and } \\
\text { some measures } \\
\text { evaluated. }\end{array}$ & $\begin{array}{l}\text { Included: Trauma patients transported by helicopter from the scene } \\
\text { of injury to the study trauma center. } \\
\text { Excluded: Patients whose records had missing variables for SBP, } \\
\text { DBP, HR, RR, or oxygen saturation (SaO2), during the } 5 \text {-to-7- } \\
\text { minute interval of transport; patients who received } \geq 1 \text { unit of red } \\
\text { blood cells without an explicit hemorrhagic injury (laceration of solid } \\
\text { organs, abdominal hematoma, hemothorax, explicit vascular injury } \\
\text { and operative repair or limb amputation). }\end{array}$ & NR & Civilian \\
\hline $\begin{array}{l}\text { Chen, } 2008 \\
\text { *Chen } 2007,2008, \\
2009 \text {, and } 2010 \text { draw } \\
\text { from the same } 898 \\
\text { patients, but differ in } \\
\text { eligibility criteria, } \\
\text { number analyzed, and } \\
\text { some measures } \\
\text { evaluated. }\end{array}$ & $\begin{array}{l}\text { Included: Patients with at least one non-zero vital sign (HR, RR, } \\
\text { DBP, SBP, or SaO2) available in every 2-minute window during the } \\
\text { initial } 16 \text { minutes of transport. } \\
\text { Excluded: Patients who received blood but did not have } \\
\text { documented injuries consistent with hemorrhage. }\end{array}$ & NR & Civilian \\
\hline
\end{tabular}




\begin{tabular}{|c|c|c|c|c|}
\hline $\begin{array}{l}\text { Author, Year } \\
\text { (See Appendix B for } \\
\text { complete reference) }\end{array}$ & Mechanism or Type Injury & Mode of Transport & $\begin{array}{l}\text { Other Population Characteristics } \\
\text { (Sex, Race) }\end{array}$ & $\begin{array}{l}\text { Name of Measure Being } \\
\text { Evaluated }\end{array}$ \\
\hline Chan, 1997 & Blunt: $100 \%$ & $\begin{array}{l}\text { Ambulance (land vs. } \\
\text { air not specified) }\end{array}$ & $\begin{array}{l}\text { Male: } 78 \%(81 / 104) \\
\text { Race: NR } \\
\text { Age (mean): } 32 \text { (SD 19) }\end{array}$ & SBP \\
\hline $\begin{array}{l}\text { Chen, } 2007 \\
\text { ^Chen 2007, 2008, } \\
2009, \text { and } 2010 \text { draw } \\
\text { from the same } 898 \\
\text { patients, but differ in } \\
\text { eligibility criteria, } \\
\text { number analyzed, and } \\
\text { some measures } \\
\text { evaluated. }\end{array}$ & $\begin{array}{l}\text { Mechanism of injury } \\
\text { Blunt: } 90 \% \\
\text { Penetrating: } 10 \%\end{array}$ & Helicopter & NR & $\begin{array}{l}\text { Linear classifier system using } \\
\text { combinations of } 5 \text { vital signs: } \\
\text { SBP, DBP, HR RR, oxygen } \\
\text { saturation (SaO2) }\end{array}$ \\
\hline $\begin{array}{l}\text { Chen, } 2008 \\
\text { *Chen 2007, 2008, } \\
2009, \text { and } 2010 \text { draw } \\
\text { from the same } 898 \\
\text { patients, but differ in } \\
\text { eligibility criteria, } \\
\text { number analyzed, and } \\
\text { some measures } \\
\text { evaluated. }\end{array}$ & $\begin{array}{l}\text { Blunt: 89\% (555/627) } \\
\text { Penetrating: 10\% (65/627) } \\
\text { NR: } 1 \%(7 / 627)\end{array}$ & Helicopter & $\begin{array}{l}\text { Male: } 75 \%(473 / 627) \\
\text { Race: NR } \\
\text { Age (mean): } 39 \text { (SD NR) }\end{array}$ & $\begin{array}{l}\text { Classifier to identify major } \\
\text { hemorrhage in trauma casualties } \\
\text { Composite-variable features } \\
\text { Hemorrhage index (HR x } \\
\text { RR)/(MAP x PP) } \\
\text { HR/PP } \\
\text { PP } \\
\text { RR/PP } \\
\text { SI }\end{array}$ \\
\hline
\end{tabular}




\begin{tabular}{|c|c|c|c|c|}
\hline $\begin{array}{l}\text { Author, Year } \\
\text { (See Appendix B for } \\
\text { complete reference) }\end{array}$ & $\begin{array}{l}\text { Location and Timing of } \\
\text { Measurement }\end{array}$ & Method of Measurement & $\begin{array}{l}\text { Personnel Administering Test or } \\
\text { Using Measure }\end{array}$ & Equipment Used/Needed \\
\hline Chan, 1997 & $\begin{array}{l}\text { Out of Hospital: not specified } \\
\text { ED: on arrival }\end{array}$ & NR & NR & $\overline{N R}$ \\
\hline $\begin{array}{l}\text { Chen, } 2007 \\
\text { *Chen 2007, 2008, } \\
2009 \text {, and } 2010 \text { draw } \\
\text { from the same } 898 \\
\text { patients, but differ in } \\
\text { eligibility criteria, } \\
\text { number analyzed, and } \\
\text { some measures } \\
\text { evaluated. }\end{array}$ & $\begin{array}{l}\text { Out of hospital: during } \\
\text { Resuscitation }\end{array}$ & $\begin{array}{l}\text { Vital signs measured } \\
\text { automatically by monitor or } \\
\text { monitor-calculated using } \\
\text { electrocardiogram, } \\
\text { photoplethysmogram, and } \\
\text { respiratory waveform signals. } \\
\text { Average value of } 5 \text { seconds of } \\
\text { reliable vital-signs data within a } \\
\text { 2-minute time window. }\end{array}$ & NR & $\begin{array}{l}\text { Vital signs: Propaq 206EL vital- } \\
\text { signs monitor }\end{array}$ \\
\hline $\begin{array}{l}\text { Chen, } 2008 \\
\\
{ }^{\star} \text { Chen 2007, 2008, } \\
2009 \text {, and } 2010 \text { draw } \\
\text { from the same } 898 \\
\text { patients, but differ in } \\
\text { eligibility criteria, } \\
\text { number analyzed, and } \\
\text { some measures } \\
\text { evaluated. }\end{array}$ & $\begin{array}{l}\text { Out of Hospital: during } \\
\text { Resuscitation }\end{array}$ & $\begin{array}{l}\text { Automated measurement by } \\
\text { monitor: ECG, } \\
\text { photoplethysmogram } \\
\text { respiratory, waveform, SBP, } \\
\text { MAP, DBP } \\
\text { Monitor-calculated: HR, SaO2, } \\
\text { RR }\end{array}$ & NR & Propaq 206EL vital-sign monitor \\
\hline
\end{tabular}




\begin{tabular}{|c|c|c|c|c|}
\hline $\begin{array}{l}\text { Author, Year } \\
\text { (See Appendix B for } \\
\text { complete reference) }\end{array}$ & $\begin{array}{l}\text { Threshold Value(s) for Physiologic } \\
\text { Measures }\end{array}$ & $\begin{array}{l}\text { Indicator of Serious Injury Used } \\
\text { (including definition and time period) }\end{array}$ & Funding Source & Risk of Bias \\
\hline Chan, 1997 & $\begin{array}{l}\text { Hypotension: SBP } \leq 90 \mathrm{mmHg} \\
\text { Normotension: SBP }>90 \mathrm{mmHg}\end{array}$ & $\begin{array}{l}\text { Mortality: not specified } \\
\text { ICU admission } \\
\text { Blood transfusion: received transfusion in the } \\
\text { first } 12 \text { hours }\end{array}$ & NR & High \\
\hline $\begin{array}{l}\text { Chen, } 2007 \\
\text { *Chen 2007, 2008, } \\
2009, \text { and } 2010 \text { draw } \\
\text { from the same } 898 \\
\text { patients, but differ in } \\
\text { eligibility criteria, } \\
\text { number analyzed, and } \\
\text { some measures } \\
\text { evaluated. }\end{array}$ & NR & $\begin{array}{l}\text { Major hemorrhage: Transfusion of } \geq 1 \text { unit of } \\
\text { red blood cells and an explicit hemorrhagic } \\
\text { injury (laceration of solid organs, hematoma in } \\
\text { the abdomen, explicit vascular injury and } \\
\text { operative repair, or limb amputation). }\end{array}$ & $\begin{array}{l}\text { Supported by the Combat Casualty } \\
\text { Care and the Military Operational } \\
\text { Medicine research programs of the } \\
\text { U.S. Army Medical Research and } \\
\text { Materiel Command (USAMRMC), } \\
\text { Fort Detrick, Maryland. }\end{array}$ & High \\
\hline $\begin{array}{l}\text { Chen, } 2008 \\
{ }^{\star} \text { Chen } 2007,2008, \\
2009 \text {, and } 2010 \text { draw } \\
\text { from the same } 898 \\
\text { patients, but differ in } \\
\text { eligibility criteria, } \\
\text { number analyzed, and } \\
\text { some measures } \\
\text { evaluated. }\end{array}$ & $\begin{array}{l}\text { Vital-sign variables calculated by } 3 \text { methods, } \\
\text { based on 2-minute time windows: } \\
\text { - best-quality 5-second data } \\
\text { - first } 5 \text {-second data } \\
\text { - all data combined } \\
\text { Predetermined: NR }\end{array}$ & $\begin{array}{l}\text { Hemorrhage: Received blood in the ED and } \\
\text { had documented injuries consistent with } \\
\text { hemorrhage. Injuries consistent with } \\
\text { hemorrhage defined as at least one of: } \\
\text { laceration of solid organs; internal bleeding as } \\
\text { indicated by abdomino-pelvic hematoma or } \\
\text { hemothorax; or explicit vascular injury and } \\
\text { operative repair or limb amputation. }\end{array}$ & $\begin{array}{l}\text { Partially supported by the Combat } \\
\text { Casualty Care Directorate of the US } \\
\text { Army Medical Research and } \\
\text { Materiel Command, Fort Detrick, } \\
\text { Maryland. }\end{array}$ & Moderate \\
\hline
\end{tabular}




\begin{tabular}{|c|c|c|c|c|}
\hline $\begin{array}{l}\text { Author, Year } \\
\text { (See Appendix B for } \\
\text { complete reference) }\end{array}$ & Study Design & Setting and Dates Performed & Number of Study Subjects & Data Source \\
\hline $\begin{array}{l}\text { Chen, } 2009 \\
\text { ^Chen 2007, 2008, } \\
2009, \text { and } 2010 \text { draw } \\
\text { from the same } 898 \\
\text { patients, but differ in } \\
\text { eligibility criteria, } \\
\text { number analyzed, and } \\
\text { some measures } \\
\text { evaluated. }\end{array}$ & Retrospective & $\begin{array}{l}\text { USA, Texas } \\
\text { Urban } \\
\text { Level I trauma center } \\
\text { Study time period: NR }\end{array}$ & $\begin{array}{l}326 \text { analyzed } \\
898 \text { identified* }^{\star} \\
473 \text { excluded for not having reliable vital } \\
\text { signs } \\
99 \text { excluded for out of hospital intubation }\end{array}$ & $\begin{array}{l}\text { Database of physiologic data } \\
\text { collected during transport with } \\
\text { additional data collected } \\
\text { retrospectively via chart review. }\end{array}$ \\
\hline $\begin{array}{l}\text { Chen, } 2010 \\
\text { *Chen } 2007,2008, \\
2009, \text { and } 2010 \text { draw } \\
\text { from the same } 898 \\
\text { patients, but differ in } \\
\text { eligibility criteria, } \\
\text { number analyzed, and } \\
\text { some measures } \\
\text { evaluated. }\end{array}$ & Retrospective & $\begin{array}{l}\text { USA, Texas } \\
\text { Urban } \\
\text { Level I trauma center } \\
8 / 2001 \text { to } 4 / 2004 \\
2 \text { years, } 9 \text { months }\end{array}$ & $\begin{array}{l}344 \text { analyzed } \\
898 \text { identified* } \\
554 \text { excluded } \\
\text { - } 399 \text { excluded for no suitable PPG } \\
\text { waveform data available } \\
\text { - } 121 \text { excluded for blood transfusion without } \\
\text { an explicitly hemorrhagic injury } \\
\text { - } 34 \text { excluded for } \geq 1 \text { other basic vital signs } \\
\text { unavailable }\end{array}$ & $\begin{array}{l}\text { Database of physiologic data } \\
\text { collected during transport with } \\
\text { additional data collected } \\
\text { retrospectively via chart review. }\end{array}$ \\
\hline
\end{tabular}




\begin{tabular}{|c|c|c|c|}
\hline $\begin{array}{l}\text { Author, Year } \\
\text { (See Appendix B for } \\
\text { complete reference) }\end{array}$ & Eligibility Criteria & $\begin{array}{l}\text { Age Groups Included (Age Range Used }{ }^{\star} \text { ): \% } \\
\text { of Study Population }\end{array}$ & Type of Population \\
\hline $\begin{array}{l}\text { Chen, } 2009 \\
\text { *Chen } 2007,2008, \\
2009, \text { and } 2010 \text { draw } \\
\text { from the same } 898 \\
\text { patients, but differ in } \\
\text { eligibility criteria, } \\
\text { number analyzed, and } \\
\text { some measures } \\
\text { evaluated. }\end{array}$ & $\begin{array}{l}\text { Included: Patients with at least } 5 \text { seconds of consecutive reliable RR } \\
\text { data. } \\
\text { Excluded: Patients with out of hospital intubation or who did not } \\
\text { have at least } 5 \text { seconds of reliable HR, SBP, and DBP data. } \\
\text { Thoracic injury subgroup: Patients with injuries to the thorax } \\
\text { identified by a search of abbreviated injury-scale codes in the } \\
\text { database. }\end{array}$ & NR & Civilian \\
\hline $\begin{array}{l}\text { Chen, } 2010 \\
\text { *Chen 2007, 2008, } \\
2009 \text {, and } 2010 \text { draw } \\
\text { from the same } 898 \\
\text { patients, but differ in } \\
\text { eligibility criteria, } \\
\text { number analyzed, and } \\
\text { some measures } \\
\text { evaluated. }\end{array}$ & $\begin{array}{l}\text { Included: Patients who had within the first } 25 \text { minutes of transport: } \\
\geq 45 \text { seconds continuous, clean PPG waveform data; } \geq 45 \\
\text { seconds continuous, nonzero HR, RR, and SpO2 data; and at } \\
\text { least one SBP and DBP measurement. } \\
\\
\text { Excluded: Patients without clean PPG } \\
\text { waveform data or missing any one of the basic vital signs. }\end{array}$ & NR & Civilian \\
\hline
\end{tabular}




\begin{tabular}{|c|c|c|c|c|}
\hline $\begin{array}{l}\text { Author, Year } \\
\text { (See Appendix B for } \\
\text { complete reference) } \\
\end{array}$ & Mechanism or Type Injury & Mode of Transport & $\begin{array}{l}\text { Other Population Characteristics } \\
\text { (Sex, Race) }\end{array}$ & $\begin{array}{l}\text { Name of Measure Being } \\
\text { Evaluated }\end{array}$ \\
\hline $\begin{array}{l}\text { Chen, } 2009 \\
\\
{ }^{\star} \text { Chen 2007, 2008, } \\
2009 \text {, and } 2010 \text { draw } \\
\text { from the same } 898 \\
\text { patients, but differ in } \\
\text { eligibility criteria, } \\
\text { number analyzed, and } \\
\text { some measures } \\
\text { evaluated. }\end{array}$ & $\begin{array}{l}\text { Blunt: } 87 \% \\
\text { Penetrating: } 13 \%\end{array}$ & Helicopter & $\begin{array}{l}\text { Male: } 76 \%(247 / 326) \\
\text { Race: NR } \\
\text { Age (mean): } 38 \text { (SD 16) }\end{array}$ & $\begin{array}{l}\text { Breath index (RR/PP) } \\
\text { DBP } \\
\text { Hemorrhage index (HR x } \\
\text { RR)/(MAP x PP) } \\
\text { HR } \\
\text { MAP } \\
\text { PP } \\
\text { RR } \\
\text { SBP } \\
\text { SI } \\
\text { standard measurement vs. } \\
\text { reliable automated }\end{array}$ \\
\hline $\begin{array}{l}\text { Chen, } 2010 \\
\\
\text { *Chen 2007, 2008, } \\
2009, \text { and } 2010 \text { draw } \\
\text { from the same } 898 \\
\text { patients, but differ in } \\
\text { eligibility criteria, } \\
\text { number analyzed, and } \\
\text { some measures } \\
\text { evaluated. }\end{array}$ & Blunt: 90\% & Helicopter & \begin{tabular}{|l} 
Male: $77 \%$ \\
Race: NR \\
Age (mean): 37 (SD 15)
\end{tabular} & $\begin{array}{l}\text { HR } \\
\text { Respiration-induced waveform } \\
\text { variation metrics } \\
\text { SBP }\end{array}$ \\
\hline
\end{tabular}




\begin{tabular}{|c|c|c|c|c|}
\hline $\begin{array}{l}\text { Author, Year } \\
\text { (See Appendix B for } \\
\text { complete reference) }\end{array}$ & $\begin{array}{l}\text { Location and Timing of } \\
\text { Measurement }\end{array}$ & Method of Measurement & $\begin{array}{l}\text { Personnel Administering Test or } \\
\text { Using Measure }\end{array}$ & Equipment Used/Needed \\
\hline $\begin{array}{l}\text { Chen, } 2009 \\
\text { ^Chen 2007, 2008, } \\
2009, \text { and } 2010 \text { draw } \\
\text { from the same } 898 \\
\text { patients, but differ in } \\
\text { eligibility criteria, } \\
\text { number analyzed, and } \\
\text { some measures } \\
\text { evaluated. }\end{array}$ & $\begin{array}{l}\text { Out of Hospital: during } \\
\text { Resuscitation }\end{array}$ & $\begin{array}{l}\text { Automated by monitor: ECG, } \\
\text { respiratory waveform; and } \\
\text { SBP, DBP, and MAP using } \\
\text { standard oscillometric device. } \\
\text { Algorithms: } \\
\text { Standard RR: average of non- } \\
\text { zero RR } \\
\text { Reliable RR: investigational } \\
\text { Reliable vital signs: calculated } \\
\text { average of reliable data during } \\
\text { patient transport }\end{array}$ & NR & $\begin{array}{l}\text { Propaq 206EL vital-sign } \\
\text { monitors (Protocol Systems) }\end{array}$ \\
\hline $\begin{array}{l}\text { Chen, } 2010 \\
\text { *Chen 2007, 2008, } \\
2009, \text { and } 2010 \text { draw } \\
\text { from the same } 898 \\
\text { patients, but differ in } \\
\text { eligibility criteria, } \\
\text { number analyzed, and } \\
\text { some measures } \\
\text { evaluated. }\end{array}$ & $\begin{array}{l}\text { Out of Hospital: during } \\
\text { Resuscitation }\end{array}$ & $\begin{array}{l}\text { Automated measurement by } \\
\text { monitor: } \\
\text { HR (ECG-derived) } \\
\text { Photoplethysmogram } \\
\text { Respiratory waveform } \\
\text { SBP } \\
\\
\text { Automated algorithm- } \\
\text { calculated: } \\
\text { Reliable HR } \\
\text { Reliable SBP }\end{array}$ & NR & $\begin{array}{l}\text { Propaq 206EL transport monitor } \\
\text { (Protocol Systems, Beaverton, } \\
\text { Oregon) }\end{array}$ \\
\hline
\end{tabular}




\begin{tabular}{|c|c|c|c|c|}
\hline $\begin{array}{l}\text { Author, Year } \\
\text { (See Appendix B for } \\
\text { complete reference) }\end{array}$ & $\begin{array}{l}\text { Threshold Value(s) for Physiologic } \\
\text { Measures }\end{array}$ & $\begin{array}{l}\text { Indicator of Serious Injury Used } \\
\text { (including definition and time period) }\end{array}$ & Funding Source & Risk of Bias \\
\hline $\begin{array}{l}\text { Chen, } 2009 \\
\text { *Chen } 2007,2008, \\
2009, \text { and } 2010 \text { draw } \\
\text { from the same } 898 \\
\text { patients, but differ in } \\
\text { eligibility criteria, } \\
\text { number analyzed, and } \\
\text { some measures } \\
\text { evaluated. }\end{array}$ & Reliable RR: independent algorithm rating $\geq 2$ & $\begin{array}{l}\text { Major respiratory interventions: ED intubation } \\
\text { or subsequent tube thoracotomy. } \\
\text { Major hemorrhage: Blood transfusion in the } \\
\text { hospital with documented injuries that were } \\
\text { consistent with hemorrhage, as determined by } \\
\text { chart review (laceration of solid organs, } \\
\text { thoracic or abdominal hematomas, explicit } \\
\text { vascular injury and operative repair, or limb } \\
\text { amputation). }\end{array}$ & NR & Moderate \\
\hline $\begin{array}{l}\text { Chen, } 2010 \\
\text { *Chen 2007, 2008, } \\
2009, \text { and } 2010 \text { draw } \\
\text { from the same } 898 \\
\text { patients, but differ in } \\
\text { eligibility criteria, } \\
\text { number analyzed, and } \\
\text { some measures } \\
\text { evaluated. }\end{array}$ & NR & $\begin{array}{l}\text { Major hemorrhage: } \geq 1 \text { unit of packed red } \\
\text { blood cell (PRBC) transfusion within } 24 \mathrm{~h} \text { after } \\
\text { hospital arrival and had a documented injury } \\
\text { that was explicitly hemorrhagic, which was one } \\
\text { or more of the following: laceration or fracture } \\
\text { of a solid organ; thoracic or abdominal } \\
\text { hematomas; explicit vascular injury that } \\
\text { required operative repair; or limb amputation. }\end{array}$ & $\begin{array}{l}\text { Partially supported by the Combat } \\
\text { Casualty Care Research Area } \\
\text { Directorate of the US Army Medical } \\
\text { Research and Materiel Command, } \\
\text { Fort } \\
\text { Detrick, MD. }\end{array}$ & Moderate \\
\hline
\end{tabular}




\begin{tabular}{|c|c|c|c|c|}
\hline $\begin{array}{l}\text { Author, Year } \\
\text { (See Appendix B for } \\
\text { complete reference) } \\
\end{array}$ & Study Design & Setting and Dates Performed & Number of Study Subjects & Data Source \\
\hline Cherry, 2007 & Retrospective & $\begin{array}{l}\text { USA, Pennsylvania } \\
\text { Urban vs. rural: NR } \\
\text { Level I trauma center } \\
\text { 1/1/2004 to } 12 / 31 / 2004 \\
1 \text { year }\end{array}$ & $\begin{array}{l}494 \text { analyzed } \\
1,969 \text { identified }\end{array}$ & $\begin{array}{l}\text { Trauma registry for a single } \\
\text { trauma center. }\end{array}$ \\
\hline Cooke, 2006a & $\begin{array}{l}\text { Retrospective unmatched } \\
\text { case-control }\end{array}$ & $\begin{array}{l}\text { USA, Texas } \\
\text { Urban } \\
\text { Level I trauma center } \\
\text { Study time period: NR }\end{array}$ & \begin{tabular}{|l}
30 analyzed \\
15 Died \\
15 Lived \\
\\
Died: \\
93 identified \\
66 excluded for incomplete data, no recorded \\
ECG, or head AIS $>2$ \\
11 excluded for poor quality of ECG signal
\end{tabular} & $\begin{array}{l}\text { Trauma Vitals database, } \\
\text { developed by the U.S. Army } \\
\text { Institute of Surgical Research. }\end{array}$ \\
\hline
\end{tabular}




\begin{tabular}{|c|c|c|c|}
\hline $\begin{array}{l}\text { Author, Year } \\
\text { (See Appendix B for } \\
\text { complete reference) } \\
\end{array}$ & Eligibility Criteria & $\begin{array}{l}\text { Age Groups Included (Age Range Used*): \% } \\
\text { of Study Population }\end{array}$ & Type of Population \\
\hline Cherry, 2007 & $\begin{array}{l}\text { Included: Trauma patients who met criteria for trauma team } \\
\text { activation. } \\
\text { Excluded: Patients with penetrating injuries, traumatic arrests, and } \\
\text { interfacility transfers. }\end{array}$ & NR & Civilian \\
\hline Cooke, 2006a & $\begin{array}{l}\text { Died (cases) } \\
\text { Included: Patients who died from their injuries. } \\
\text { Excluded: Patients with incomplete data, no ECG recorded, poor } \\
\text { quality of ECG signal, or who had an AIS head score }>2 \text {. } \\
\text { Lived (controls) } \\
\text { Included: Patients who lived. } \\
\text { Excluded: Similar exclusion criteria. }\end{array}$ & NR & Civilian \\
\hline
\end{tabular}




\begin{tabular}{|c|c|c|c|c|}
\hline $\begin{array}{l}\text { Author, Year } \\
\text { (See Appendix B for } \\
\text { complete reference) } \\
\end{array}$ & Mechanism or Type Injury & Mode of Transport & $\begin{array}{l}\text { Other Population Characteristics } \\
\text { (Sex, Race) }\end{array}$ & $\begin{array}{l}\text { Name of Measure Being } \\
\text { Evaluated }\end{array}$ \\
\hline Cherry, 2007 & Blunt: $100 \%$ & $\mid \mathrm{NR}$ & $\begin{array}{l}\text { Overall: } \\
\text { Male: NR } \\
\text { Race: NR } \\
\text { Age (mean): NR* } \\
\text { Level } 1 \text { activation: } \\
\text { Age (median): } 41 \text { (IQR } 25 \text { to 55) } \\
\text { Level } 2 \text { activation: } \\
\text { Age (median): } 43 \text { (IQR } 28 \text { to 58) } \\
\text { Level } 3 \text { activation: } \\
\text { Age (median): } 42 \text { (IQR } 28 \text { to 57) } \\
\text { * Mean age not reported for overall } \\
\text { population, but medians and IQRs } \\
\text { reported by subgroups. }\end{array}$ & SBP \\
\hline Cooke, 2006a & Blunt: $66.5 \%$ & Helicopter & $\begin{array}{l}\text { Male: } 87 \%(26 / 30) \\
\text { Race: NR } \\
\text { Age (mean): } 39 \text { (SD 3) }\end{array}$ & $\begin{array}{l}\text { Heart rate variability } \\
\text { Intubation status }\end{array}$ \\
\hline
\end{tabular}




\begin{tabular}{|c|c|c|c|c|}
\hline \begin{tabular}{|l|} 
Author, Year \\
(See Appendix B for \\
complete reference)
\end{tabular} & $\begin{array}{l}\text { Location and Timing of } \\
\text { Measurement } \\
\end{array}$ & Method of Measurement & $\begin{array}{l}\text { Personnel Administering Test or } \\
\text { Using Measure } \\
\end{array}$ & Equipment Used/Needed \\
\hline Cherry, 2007 & ED: on arrival & NR & NR & NR \\
\hline
\end{tabular}




\begin{tabular}{|c|c|c|c|c|}
\hline $\begin{array}{l}\text { Author, Year } \\
\text { (See Appendix B for } \\
\text { complete reference) }\end{array}$ & $\begin{array}{l}\text { Threshold Value(s) for Physiologic } \\
\text { Measures }\end{array}$ & $\begin{array}{l}\text { Indicator of Serious Injury Used } \\
\text { (including definition and time period) }\end{array}$ & Funding Source & Risk of Bias \\
\hline Cherry, 2007 & SBP $<90 \mathrm{~mm} \mathrm{Hg}$ & Mortality: NR & NR & Moderate \\
\hline Cooke, 2006a & $\begin{array}{l}\text { Clean ECG signal: first } 2 \text { minutes of continuous } \\
\text { data able to identify individual R waves for each } \\
\text { cardiac cycle with certainty. } \\
\text { 2-minute data sets for analysis determined } \\
\text { based on availability of clean ECG signals. }\end{array}$ & Mortality: NR & $\begin{array}{l}\text { Supported by the United States } \\
\text { Army Medical Research and } \\
\text { Materiel Command Combat } \\
\text { Casualty Care Research Program } \\
\text { (STO III ME 2001 02) and the } \\
\text { United States Special Operations } \\
\text { Command (MIPR 051-80482). }\end{array}$ & High \\
\hline
\end{tabular}




\begin{tabular}{|c|c|c|c|c|}
\hline $\begin{array}{l}\text { Author, Year } \\
\text { (See Appendix B for } \\
\text { complete reference) }\end{array}$ & Study Design & Setting and Dates Performed & Number of Study Subjects & Data Source \\
\hline Courville, 2009 & Retrospective & $\begin{array}{l}\text { USA } \\
\text { Setting: NR (national database) } \\
\text { Trauma level: NR } \\
2001 \text { to } 2005 \\
5 \text { years }\end{array}$ & $\begin{array}{l}224,682 \text { analyzed } \\
245,490 \text { identified }<18 \text { years old } \\
676 \text { excluded for no valid mortality indicator } \\
19,907 \text { excluded for missing time or } \\
\text { admission }>1 \text { day after injury } \\
245 \text { excluded: NR } \\
\text { CHAID model } \\
\text { cohort randomly divided } \\
\text { - training data: } 112,342 \\
\text { - testing data: } 112,286\end{array}$ & NTDB, version 6.2 \\
\hline Cudnik, 2012 & Prospective & $\begin{array}{l}\text { USA, Ohio } \\
\text { Urban and rural } \\
\text { Level I trauma centers } \\
10 / 2009 \text { to } 9 / 010 \\
1 \text { year }\end{array}$ & 557 analyzed & $\begin{array}{l}\text { Primary data collection of out-of- } \\
\text { hospital data from EMS. Hospital } \\
\text { data from each institution's } \\
\text { trauma registry. }\end{array}$ \\
\hline Davis, 1996 & Retrospective & $\begin{array}{l}\text { USA, California } \\
\text { Urban } \\
\text { Trauma system level: NR } \\
\text { 7/1/1990 to 8/31/1995 } \\
5 \text { years, } 2 \text { months }\end{array}$ & $\begin{array}{l}\text { 2,954 analyzed } \\
5,264 \text { in registry }\end{array}$ & $\begin{array}{l}\text { Trauma registry for a single } \\
\text { hospital. (UCSF/Fresno Valley } \\
\text { Medical Center) }\end{array}$ \\
\hline DeMuro, 2013 & Retrospective & $\begin{array}{l}\text { USA, New York } \\
\text { Suburban } \\
\text { Trauma system level: NR (regional trauma } \\
\text { center) } \\
1 / 1 / 2000 \text { to } 12 / 31 / 2010 \\
11 \text { years }\end{array}$ & $\begin{array}{l}\text { 4,277 analyzed } \\
4,292 \text { identified } \\
16 \text { excluded for incomplete data }\end{array}$ & $\begin{array}{l}\text { Trauma One database, an } \\
\text { electronic retrospective } \\
\text { database/chart review for one } \\
\text { hospital. } \\
\text { Data reported to National } \\
\text { Trauma Data Bank as well as } \\
\text { state and local reporting }\end{array}$ \\
\hline
\end{tabular}




\begin{tabular}{|c|c|c|c|}
\hline $\begin{array}{l}\text { Author, Year } \\
\text { (See Appendix B for } \\
\text { complete reference) }\end{array}$ & Eligibility Criteria & $\begin{array}{l}\text { Age Groups Included (Age Range Used*): \% } \\
\text { of Study Population }\end{array}$ & Type of Population \\
\hline Courville, 2009 & $\begin{array}{l}\text { Included: Patients <18 years old. } \\
\text { Excluded: Patients without a valid mortality indicator (hospital } \\
\text { disposition status other than dead or alive), and those admitted >1 } \\
\text { day after injury or with missing data on time between injury and } \\
\text { admission. }\end{array}$ & Children (<18): $100 \%$ & Civilian \\
\hline Cudnik, 2012 & $\begin{array}{l}\text { Included: Patients age } \geq 16 \text { years who were transported by medical } \\
\text { helicopter (by a single air transport agency) directly from the scene } \\
\text { of injury to one of the two trauma centers. } \\
\text { Excluded: NR }\end{array}$ & Adults ( $\geq 16): 100 \%$ & Civilian \\
\hline Davis, 1996 & $\begin{array}{l}\text { Included: Patients with an arterial blood gas obtained within } 1 \text { hour } \\
\text { of admission. } \\
\text { Excluded: Patients }<5 \text { year old, with trauma caused by thermal } \\
\text { injury, or with seizure or diabetic ketoacidosis. }\end{array}$ & Children and adults ( $\geq 5$ ): $100 \%$ & Civilian \\
\hline DeMuro, 2013 & $\begin{array}{l}\text { Included: Patients } 16 \text { years or older who had sustained trauma. } \\
\text { Excluded: Patients who were transferred from another hospital and } \\
\text { those who suffered traumatic brain injury as determined by chart } \\
\text { review of discharge codes. }\end{array}$ & $\begin{array}{l}\text { Adults }(\geq 16): 100 \% \\
\text { Elderly }(\geq 65): 49 \%(2,093 / 4,277)\end{array}$ & Civilian \\
\hline
\end{tabular}




\begin{tabular}{|c|c|c|c|c|}
\hline $\begin{array}{l}\text { Author, Year } \\
\text { (See Appendix B for } \\
\text { complete reference) }\end{array}$ & Mechanism or Type Injury & Mode of Transport & $\begin{array}{l}\text { Other Population Characteristics } \\
\text { (Sex, Race) }\end{array}$ & $\begin{array}{l}\text { Name of Measure Being } \\
\text { Evaluated }\end{array}$ \\
\hline Courville, 2009 & \begin{tabular}{|l|} 
Blunt: $86 \%$ \\
Penetrating: $8 \%$ \\
Burn: $3 \%$
\end{tabular} & NR & $\begin{array}{l}\text { Male: } 65 \% \\
\text { Race (\% of reported, } \mathrm{n}=207,077 \text { ) } \\
\text { - White: } 60 \% \\
\text { - Black: } 17 \% \\
\text { - Hispanic: } 11 \% \\
\text { - Asian/Pacific Islander: } 1 \% \\
\text { - Native American: } 0.6 \% \\
\text { - Other: } 3 \% \\
\text { Age: NR }\end{array}$ & \begin{tabular}{|l} 
Airway status \\
Chi-square-assisted interaction \\
detection (CHAID) model
\end{tabular} \\
\hline Cudnik, 2012 & \begin{tabular}{|l} 
Type of injury \\
Penetrating: $3 \%$ \\
Blunt: $97 \%$
\end{tabular} & Helicopter & $\begin{array}{l}\text { Male: } 67 \% \\
\text { Race } \\
\text { - White: 95\% } \\
\text { Age (median): } 39 \text { (IQR 24-52) }\end{array}$ & $\begin{array}{l}\text { Model (derived by multivariate } \\
\text { analysis) consisting of: age }>44 \text {, } \\
\text { SBP <90, flail chest injury, GCS } \\
<14\end{array}$ \\
\hline Davis, 1996 & Blunt: 71\% & NR & \begin{tabular}{|l} 
Male: $77 \%$ \\
Race: NR \\
Age (mean): 32 (SD 0.3)
\end{tabular} & $\mathrm{BD}$ \\
\hline DeMuro, 2013 & \begin{tabular}{|l} 
Blunt: $93 \%(3,971 / 4,276)$ \\
Penetrating: $7 \%(305 / 4,276)$
\end{tabular} & NR & NR & $\mid \mathrm{SI}$ \\
\hline
\end{tabular}




\begin{tabular}{|c|c|c|c|c|}
\hline $\begin{array}{l}\text { Author, Year } \\
\text { (See Appendix B for } \\
\text { complete reference) }\end{array}$ & $\begin{array}{l}\text { Location and Timing of } \\
\text { Measurement }\end{array}$ & Method of Measurement & $\begin{array}{l}\text { Personnel Administering Test or } \\
\text { Using Measure }\end{array}$ & Equipment Used/Needec \\
\hline Courville, 2009 & $\begin{array}{l}\text { Out of Hospital: NR } \\
\text { ED: on admission }\end{array}$ & NR & NR & NR \\
\hline Cudnik, 2012 & Out of Hospital: on arrival & NR & EMS on arrival & NR \\
\hline Davis, 1996 & ED: on arrival & BD: arterial & $\mathrm{NR}$ & NR \\
\hline DeMuro, 2013 & ED: on arrival & NR & NR & NR \\
\hline
\end{tabular}




\begin{tabular}{|c|c|c|c|c|}
\hline $\begin{array}{l}\text { Author, Year } \\
\text { (See Appendix B for } \\
\text { complete reference) }\end{array}$ & $\begin{array}{l}\text { Threshold Value(s) for Physiologic } \\
\text { Measures }\end{array}$ & $\begin{array}{l}\text { Indicator of Serious Injury Used } \\
\text { (including definition and time period) }\end{array}$ & Funding Source & Risk of Bias \\
\hline Courville, 2009 & $\begin{array}{l}\text { Airway and sedation status: } \\
\text { - breathing spontaneously, not intubated or } \\
\text { chemically sedated } \\
\text { - chemically sedated } \\
\text { - intubated } \\
\text { - intubated and chemically sedated } \\
\text { CHAID model: age, sex, race, days from injury } \\
\text { to admission, ED vital signs (SBP, temp, RR), } \\
\text { ED airway and sedation status, ED and field } \\
\text { GCS, mechanism }\end{array}$ & Mortality: in-hospital & $\begin{array}{l}\text { No outside pharmaceutical or } \\
\text { industry support. None of the } \\
\text { authors received financial support } \\
\text { for the study. }\end{array}$ & Low \\
\hline Cudnik, 2012 & $\begin{array}{l}\text { Predetermined, based on the State of Ohio } \\
\text { Trauma Triage Criteria } \\
- \text { SBP }<90 \mathrm{mmHg} \\
\text { - GCS }<14 \\
\text { Predetermined: NR } \\
\text { - Age }>44 \text { years }\end{array}$ & Mortality: in-hospital death from any cause & $\begin{array}{l}\text { Ohio Department of Public Safety } \\
\text { Trauma Grants Program Award } \\
\text { (\#DPS01-0000017362) }\end{array}$ & Moderate \\
\hline Davis, 1996 & $\begin{array}{l}\text { BD } \\
\text { Mild: }-3 \text { to }-5 \\
\text { Moderate: }-6 \text { to }-9 \\
\text { Severe: } \leq-10\end{array}$ & $\begin{array}{l}\text { Blood transfusion: PRBC transfusion within } 24 \\
\text { hours of admission. } \\
\text { Mortality: NR }\end{array}$ & NR & Moderate \\
\hline DeMuro, 2013 & $\begin{array}{l}\text { SI: evaluated at cutpoints in increments of } 0.1 \\
\text { from } 0.1 \text { to } 2.0 \text {. } \\
\text { - standard cutoff examined: }>0.9 \text { vs. } \leq 0.9\end{array}$ & $\begin{array}{l}\text { Bleeding: transfusion of } \geq 2 \text { PRBC units within } \\
24 \text { hours of admission, or any injury requiring } \\
\text { surgery or interventional radiology for } \\
\text { hemostasis within } 24 \text { hours of admission. }\end{array}$ & NR & Moderate \\
\hline
\end{tabular}




\begin{tabular}{|c|c|c|c|c|}
\hline $\begin{array}{l}\text { Author, Year } \\
\text { (See Appendix B for } \\
\text { complete reference) }\end{array}$ & Study Design & Setting and Dates Performed & Number of Study Subjects & Data Source \\
\hline Dinh, 2014 & Retrospective & $\begin{array}{l}\text { Australia, New South Wales } \\
\text { Urban } \\
\text { Major trauma center } \\
1 / 2007 \text { to } 12 / 2011 \\
5 \text { years }\end{array}$ & $\begin{array}{l}3,027 \text { analyzed } \\
3,393 \text { identified } \\
366 \text { excluded for not directly transferred from } \\
\text { scene }\end{array}$ & $\begin{array}{l}\text { Trauma registry data for a single } \\
\text { trauma center. }\end{array}$ \\
\hline Dunham, 2017 & Retrospective & $\begin{array}{l}\text { South Africa, Pietermaritzburg } \\
\text { Urban vs. rural: NR } \\
\text { Trauma system level: NR } \\
2010 \text { to } 2015 \\
6 \text { years }\end{array}$ & $\begin{array}{l}1,863 \text { analyzed } \\
9,573 \text { trauma admissions } \\
5,132 \text { excluded for non-penetrating trauma } \\
2,465 \text { excluded for no recorded BD } \\
113 \text { excluded for incomplete vital signs } \\
\text { dataset }\end{array}$ & $\begin{array}{l}\text { Trauma database for } 2 \text { trauma } \\
\text { centers }\end{array}$ \\
\hline Dunne, 2005 & Prospective & $\begin{array}{l}\text { USA, Maryland } \\
\text { Urban } \\
\text { Level I trauma center } \\
1998 \text { to } 2000 \\
3 \text { years }\end{array}$ & $\begin{array}{l}13,526 \text { analyzed for lactate } \\
15,179 \text { in study } \\
1,563 \text { without lactate measurement }\end{array}$ & $\begin{array}{l}\text { Trauma database at } \\
\text { Level I trauma center }\end{array}$ \\
\hline Eastridge, 2007 & Retrospective & $\begin{array}{l}\text { USA } \\
\text { Urban vs. rural: NR (national database) } \\
\text { Trauma system level: NR } \\
\text { Study time period: NR }\end{array}$ & $\begin{array}{l}729,736 \text { analyzed } \\
870,634 \text { identified } \\
140,898 \text { excluded for GCS score } \leq 8 \text { and BD } \\
<5\end{array}$ & NTDB version 5.0 \\
\hline
\end{tabular}




\begin{tabular}{|c|c|c|c|}
\hline $\begin{array}{l}\text { Author, Year } \\
\text { (See Appendix B for } \\
\text { complete reference) }\end{array}$ & Eligibility Criteria & $\begin{array}{l}\text { Age Groups Included (Age Range Used*): \% } \\
\text { of Study Population }\end{array}$ & Type of Population \\
\hline Dinh, 2014 & $\begin{array}{l}\text { Included: Patients } \geq 15 \text { years old who had trauma team assessment } \\
\text { and management in the ED, and who were transported directly to } \\
\text { the hospital by air or ground ambulance. } \\
\text { Excluded: Patients who arrived by private vehicle, were transported } \\
\text { from other hospitals, were dead on arrival (absent vital signs and } \\
\text { GCS score of 3), or who were still inpatients on 12/31/2011. }\end{array}$ & $\begin{array}{l}\text { Adults ( }(\geq 15): 100 \% \\
\text { Elderly }(\geq 65): 17 \%(525 / 3,027)\end{array}$ & Civilian \\
\hline Dunham, 2017 & $\begin{array}{l}\text { Included: Patients } \geq 16 \text { years old with penetrating mechanism of } \\
\text { traumatic injury and who had a complete dataset for HR, SBP, GCS } \\
\text { and BD recorded at admission. } \\
\text { Excluded: No exclusion criteria specified. }\end{array}$ & Adults ( $\geq 16): 100 \%$ & Civilian \\
\hline Dunne, 2005 & $\begin{array}{l}\text { Included: Patients admitted to the trauma center. } \\
\text { Excluded: No exclusion criteria specified. }\end{array}$ & NR & Civilian \\
\hline Eastridge, 2007 & $\begin{array}{l}\text { Included: Patients with ED SBP and mortality data. } \\
\text { Excluded: Patients with severe head injury or TBI, based on GCS } \\
\text { score } \leq 8 \text { and } B D<-5 \text {. }\end{array}$ & NR & Civilian \\
\hline
\end{tabular}




\begin{tabular}{|c|c|c|c|c|}
\hline $\begin{array}{l}\text { Author, Year } \\
\text { (See Appendix B for } \\
\text { complete reference) } \\
\end{array}$ & Mechanism or Type Injury & Mode of Transport & $\begin{array}{l}\text { Other Population Characteristics } \\
\text { (Sex, Race) }\end{array}$ & $\begin{array}{l}\text { Name of Measure Being } \\
\text { Evaluated }\end{array}$ \\
\hline Dinh, 2014 & $\begin{array}{l}\text { Type of injury } \\
\text { Penetrating: } 4 \% \\
\text { Mechanism of injury } \\
\text { Falls: } 27 \% \\
\text { Motor vehicle crash: } 24 \% \\
\text { Motorbike crash: } 10 \% \\
\text { Pedestrian: } 14 \% \\
\text { Cyclist: } 10 \% \\
\text { Assault: } 9 \% \\
\text { Other: } 6 \%\end{array}$ & $\begin{array}{l}\text { Helicopter or ground } \\
\text { ambulance }\end{array}$ & $\begin{array}{l}\text { Male: 66\% } \\
\text { Race: NR } \\
\text { Age (mean): } 43 \text { (SD 20) }\end{array}$ & \begin{tabular}{|l}
$\mathrm{HR}$ \\
$\mathrm{RR}$ \\
SBP \\
Vital signs: SBP, HR, and RR
\end{tabular} \\
\hline Dunham, 2017 & Penetrating: 100\% & $\mathrm{NR}$ & $\begin{array}{l}\text { Male: } 90 \%(1,679 / 1,863) \\
\text { Race: NR } \\
\text { Age (mean): } 29 \text { (SD 11) }\end{array}$ & $\begin{array}{l}\text { BD } \\
\text { HR } \\
\text { SBP } \\
\text { SI }\end{array}$ \\
\hline Dunne, 2005 & $\begin{array}{l}\text { Blunt: } 77 \% \\
\text { - Motor vehicle crash: } 48 \% \\
\text { - Falls: } 23 \% \\
\text { - Pedestrian struck: } 5 \% \\
\text { - Other: } 1 \% \\
\text { Penetrating: } 23 \%\end{array}$ & NR & $\begin{array}{l}\text { Overall study population }(\mathrm{n}=15,179) \\
\text { Male: } 71 \% \\
\text { Race } \\
\text { - Caucasian: } 59 \% \\
\text { - Non-Caucasian: } 41 \% \\
\text { Age (mean): } 37 \text { (SD 19) }\end{array}$ & Lactate \\
\hline Eastridge, 2007 & NR & NR & NR & SBP \\
\hline
\end{tabular}




\begin{tabular}{|c|c|c|c|c|}
\hline \begin{tabular}{|l|} 
Author, Year \\
(See Appendix B for \\
complete reference) \\
\end{tabular} & $\begin{array}{l}\text { Location and Timing of } \\
\text { Measurement }\end{array}$ & Method of Measurement & $\begin{array}{l}\text { Personnel Administering Test or } \\
\text { Using Measure }\end{array}$ & Equipment Used/Needed \\
\hline Dinh, 2014 & ED: on arrival & NR & NR & NR \\
\hline Dunham, 2017 & ED: on arrival & NR & NR & $\mathrm{NR}$ \\
\hline Eastridge, 2007 & ED: not specified & NR & NR & NR \\
\hline
\end{tabular}




\begin{tabular}{|c|c|c|c|c|}
\hline \begin{tabular}{|l|} 
Author, Year \\
(See Appendix B for \\
complete reference) \\
\end{tabular} & $\begin{array}{l}\text { Threshold Value(s) for Physiologic } \\
\text { Measures }\end{array}$ & $\begin{array}{l}\text { Indicator of Serious Injury Used } \\
\text { (including definition and time period) }\end{array}$ & Funding Source & Risk of Bias \\
\hline Dinh, 2014 & $\begin{array}{l}\text { Abnormal vital signs: } \\
-\mathrm{HR}<50 \text { or }>110 \\
-\mathrm{RR}<10 \text { or }>24 \\
-\mathrm{SBP}<90 \text { or }>180\end{array}$ & $\begin{array}{l}\text { Major trauma: ICU admission at any point in } \\
\text { hospitalization, ISS }>15 \text {, or in-hospital death. }\end{array}$ & $\begin{array}{l}\text { Funding NR } \\
\text { Conflict of interest declared: None. }\end{array}$ & Moderate \\
\hline Dunham, 2017 & $\begin{array}{l}\text { BD classification of hemorrhagic shock class } \\
\text { group: } \\
\text { 1: }>-2.0 \\
\text { 2: }-2.0 \text { to }-5.9 \\
\text { 3: }-6.0 \text { to }-9.9 \\
4: \leq-10.0\end{array}$ & Mortality: timing not specified & NR & High \\
\hline Dunne, 2005 & Lactate $>6.0 \mathrm{mmol} / \mathrm{L}$ & Mortality & NR & Moderate \\
\hline Eastridge, 2007 & SBP $\leq 90$ vs $\leq 110 \mathrm{mmHg}$ for hypotension & Mortality: overall & NR & Moderate \\
\hline
\end{tabular}




\begin{tabular}{|c|c|c|c|c|}
\hline $\begin{array}{l}\text { Author, Year } \\
\text { (See Appendix B for } \\
\text { complete reference) }\end{array}$ & Study Design & Setting and Dates Performed & Number of Study Subjects & Data Source \\
\hline Edla, 2015b & Retrospective & $\begin{array}{l}\text { USA, Texas and Massachusetts } \\
\text { Urban and rural } \\
\text { Level I trauma centers } \\
\text { Dataset } 1 \text { (Texas): } \\
8 / 2001 \text { to } 4 / 2004 \\
2 \text { years, } 9 \text { months } \\
\text { Dataset } 2 \text { (Massachusetts): } \\
2 / 2010 \text { to } 12 / 2012 \\
2 \text { years, } 11 \text { months }\end{array}$ & $\begin{array}{l}402 \text { analyzed } \\
\text { Dataset 1: } 273 \text { analyzed } \\
\text { Dataset } 2: 129 \text { analyzed } \\
999 \text { identified } \\
597 \text { excluded } \\
\text { - } 43 \text { excluded for death in field } \\
-90 \text { excluded for transfusion without } \\
\text { hemorrhagic injury } \\
\text { - } 464 \text { excluded for incomplete vital signs }\end{array}$ & $\begin{array}{l}\text { Datasets from Memorial } \\
\text { Hermann Life Flight (Houston, } \\
\text { Texas) and Boston Medflight } \\
\text { (Bedford, Massachusetts) air } \\
\text { ambulances. }\end{array}$ \\
\hline Engum, 2000 & Prospective & $\begin{array}{l}\text { USA, Indiana } \\
\text { Urban } \\
\text { Level I Trauma Center } \\
\text { Study dates: NR } \\
3 \text { years }\end{array}$ & 1,285 analyzed & $\begin{array}{l}\text { Pediatric Trauma Service } \\
\text { Trauma Registry }\end{array}$ \\
\hline Folkert, 2015 & Retrospective & $\begin{array}{l}\text { USA, Pennsylvania } \\
\text { Urban } \\
\text { Level I trauma center } \\
1 / 1 / 2006 \text { to } 12 / 31 / 2010 \\
5 \text { years }\end{array}$ & 132 analyzed & $\begin{array}{l}\text { Retrospective analysis of trauma } \\
\text { registry data for a single } \\
\text { institution }\end{array}$ \\
\hline Franklin, 2000 & Retrospective & $\begin{array}{l}\text { USA, Kentucky } \\
\text { Urban and rural } \\
\text { Level I trauma center } \\
\text { 7/1993 to } 10 / 1998 \\
5 \text { years, } 4 \text { months }\end{array}$ & $\begin{array}{l}\text { 4,194 analyzed } \\
6,976 \text { identified } \\
2,539 \text { excluded for no available prehospital } \\
\text { data } \\
193 \text { excluded for immediate death in ED }\end{array}$ & $\begin{array}{l}\text { Trauma registry for a single } \\
\text { trauma center and primary data } \\
\text { collection from medical records. }\end{array}$ \\
\hline
\end{tabular}




\begin{tabular}{|c|c|c|c|}
\hline \begin{tabular}{|l|} 
Author, Year \\
(See Appendix B for \\
complete reference)
\end{tabular} & Eligibility Criteria & $\begin{array}{l}\text { Age Groups Included (Age Range Used*): \% } \\
\text { of Study Population }\end{array}$ & Type of Population \\
\hline Edla, 2015b & $\begin{array}{l}\text { Included: Patients } \geq 18 \text { years old with a complete set of reliable } \\
\text { investigational metrics: HR, SBP, PP, and } 3 \text { heart rate variability } \\
\text { metrics. Automated computer algorithm used to identify reliable vital } \\
\text { signs. } \\
\text { Excluded: Patients who died before hospital admission, those who } \\
\text { received PRBC transfusion without an explicitly hemorrhagic injury } \\
\text { (documented solid organ injury, thoracic or abdominal hematoma, or } \\
\text { vascular injury requiring a procedure for hemostasis), and those with } \\
\text { an incomplete set of reliable vital signs. }\end{array}$ & Adults ( $\geq 18): 100 \%$ & Civilian \\
\hline Engum, 2000 & $\begin{array}{l}\text { Included: Patients age 0-15 years evaluated by the pediatric trauma } \\
\text { service. } \\
\text { Excluded: No exclusion criteria specified. }\end{array}$ & Children ( $\leq 15):$ 100\% & Civilian \\
\hline Folkert, 2015 & $\begin{array}{l}\text { Included: Patients who were hemodynamically stable on } \\
\text { presentation to } \mathrm{ED}(\mathrm{HR}<101 \text { and } \mathrm{SBP}>90) \text { with isolated } \\
\text { penetrating trauma to the extremities and had venous lactate } \\
\text { measured during initial evaluation. } \\
\\
\text { Excluded: Patients }<16 \text { years old, who were pregnant, prisoners, } \\
\text { and those with injuries in body regions other than the extremities. }\end{array}$ & Adults ( $\geq 16): 100 \%$ & Civilian \\
\hline Franklin, 2000 & $\begin{array}{l}\text { Included: Patients who had emergent trauma consultation in the ED } \\
\text { or were admitted to the trauma service for }>24 \text { hours. } \\
\text { Excluded: Patients with burn injuries, those with no available } \\
\text { prehospital data, and patients who died immediately in the ED. }\end{array}$ & NR & Civilian \\
\hline
\end{tabular}




\begin{tabular}{|c|c|c|c|c|}
\hline $\begin{array}{l}\text { Author, Year } \\
\text { (See Appendix B for } \\
\text { complete reference) }\end{array}$ & Mechanism or Type Injury & Mode of Transport & $\begin{array}{l}\text { Other Population Characteristics } \\
\text { (Sex, Race) }\end{array}$ & $\begin{array}{l}\text { Name of Measure Being } \\
\text { Evaluated }\end{array}$ \\
\hline Edla, 2015b & $\begin{array}{l}\text { Blunt: } 89 \% \\
\text { Penetrating: } 10 \% \\
\text { NR: } 1 \%\end{array}$ & Helicopter & $\begin{array}{l}\text { Male: } 76 \% \\
\text { Race: NR } \\
\text { Age (mean): } 39 \text { (SD 16) }\end{array}$ & $\begin{array}{l}\text { HR } \\
\text { HRV metrics } \\
\text { - Rate of sinus arrhythmia (RSA) } \\
\text { - Sample entropy (SampEn) } \\
\text { - Standard deviation of the R-to- } \\
\text { R intervals (SDNN) } \\
\text { Pulse pressure (SBP-DBP) } \\
\text { RR } \\
\text { SBP }\end{array}$ \\
\hline Engum, 2000 & $\begin{array}{l}\text { Injury type or mechanism (injury triage criteria } \\
\text { distribution) } \\
\text { Pedestrian struck >20 mph: } 22 \% \\
\text { Second or third degree burn involving >15\% } \\
\text { total body surface area: } 6 \% \\
\text { Penetrating injury to head, neck, chest, } \\
\text { abdomen, or groin: } 5 \% \\
\text { Rollover of vehicle: } 5 \% \\
\text { Fall from >20 feet: } 3 \% \\
\text { Ejection from vehicle: } 1 \%\end{array}$ & NR & $\begin{array}{l}\text { Male: } 63 \% \\
\text { Race: NR } \\
\text { Age (mean): } 7 \text { (range 1-15) }\end{array}$ & $\begin{array}{l}\text { SBP } \\
\text { RR }\end{array}$ \\
\hline Folkert, 2015 & $\begin{array}{l}\text { Penetrating: } 100 \% \\
\text { Mechanism of injury } \\
\text { Gunshot: } 74 \% \\
\text { Stab: } 23 \% \\
\text { Other: } 3 \%\end{array}$ & NR & $\begin{array}{l}\text { Male: } 91 \% \\
\text { Race: } \\
\text { African American: } 89 \% \\
\text { Caucasian: } 8 \% \\
\text { Other: 3\% } \\
\text { Age (median): } 25 \text { (IQR 20-34) }\end{array}$ & Lactate \\
\hline Franklin, 2000 & $\begin{array}{l}\text { Identified patients (database) } \\
\text { Blunt: } 83 \% \\
\text { Patients with prehospital or ED hypotension } \\
\text { Blunt: } 73 \% \\
\text { Penetrating: } 27 \%\end{array}$ & NR & $\begin{array}{l}\text { Identified patients (database) } \\
\text { Male: } 72 \% \\
\text { Patients with prehospital hypotension } \\
\text { (including patients with immediate ED } \\
\text { death) } \\
\text { Male: } 67 \% \\
\text { Race: NR } \\
\text { Age (mean): } 41\end{array}$ & SBP \\
\hline
\end{tabular}




\begin{tabular}{|c|c|c|c|c|}
\hline $\begin{array}{l}\text { Author, Year } \\
\text { (See Appendix B for } \\
\text { complete reference) } \\
\end{array}$ & $\begin{array}{l}\text { Location and Timing of } \\
\text { Measurement }\end{array}$ & Method of Measurement & $\begin{array}{l}\text { Personnel Administering Test or } \\
\text { Using Measure }\end{array}$ & Equipment Used/Needed \\
\hline Edla, 2015b & $\begin{array}{l}\text { Out of Hospital: during } \\
\text { Resuscitation }\end{array}$ & $\begin{array}{l}\text { Vital signs by patient monitor } \\
\text { with reliable measurements } \\
\text { determined by automated } \\
\text { computer algorithms. } \\
\text { HRV metrics calculated from } \\
\text { ECG from patient monitor }\end{array}$ & NR & $\begin{array}{l}\text { Propaq } 206 \text { vital signs monitors } \\
\text { (Welch-Allyn, Beaverton, } \\
\text { Oregon) } \\
\text { Sample entropy (SampEn) } \\
\text { computed using PhysioTools } \\
\text { software "sampen.m" }\end{array}$ \\
\hline Engum, 2000 & NR & NR & NR & NR \\
\hline Folkert, 2015 & ED: on admission & Lactate: venous & NR & $\begin{array}{l}\text { Lactate: UniCel DxC 600/800 } \\
\text { analyzer }\end{array}$ \\
\hline Franklin, 2000 & $\begin{array}{l}\text { Out of hospital: not specified } \\
\text { ED: on arrival }\end{array}$ & NR & NR & NR \\
\hline
\end{tabular}




\begin{tabular}{|c|c|c|c|c|}
\hline $\begin{array}{l}\text { Author, Year } \\
\text { (See Appendix B for } \\
\text { complete reference) }\end{array}$ & $\begin{array}{l}\text { Threshold Value(s) for Physiologic } \\
\text { Measures }\end{array}$ & $\begin{array}{l}\text { Indicator of Serious Injury Used } \\
\text { (including definition and time period) }\end{array}$ & Funding Source & Risk of Bias \\
\hline Edla, 2015b & $\begin{array}{l}\text { HRV normal ranges - } \\
\text { RSA (cpm) 19-26 } \\
\text { SDEn (ms) 23-53 } \\
\text { SampEn: 0.9-1.4 } \\
\text { Routine vital signs }\end{array}$ & $\begin{array}{l}\text { Blood transfusion with different thresholds: } \\
\text { blood transfusion within } 24 \text { hours with } \\
\text { hemorrhagic injury defined as a documented } \\
\text { solid organ injury, thoracic or abdominal } \\
\text { hematoma, or vascular injury requiring a } \\
\text { procedure for hemostasis. } \\
\text { - thresholds (number PRBC units transfused): } \\
\geq 1, \geq 5, \geq 9\end{array}$ & NR & Moderate \\
\hline Engum, 2000 & $\begin{array}{l}\text { RR }<10 \text { or }>29 \\
\text { SBP } \leq 90 \mathrm{~mm} \mathrm{Hg} \\
\text { Predetermined }\end{array}$ & $\begin{array}{l}\text { Major trauma: death in the ED, pediatric ICU } \\
\text { admission, or requiring a major surgical } \\
\text { procedure (craniotomy, neck exploration, } \\
\text { thoracotomy, median sternotomy, exploratory } \\
\text { laparotomy, and limb-threatening vascular } \\
\text { procedures). } \\
\text { Minor trauma: discharged from ED, admission } \\
\text { to ward, or a requiring minor surgical } \\
\text { procedure. }\end{array}$ & NR & Moderate \\
\hline Folkert, 2015 & $\begin{array}{l}\text { Lactate: elevated }>2.2 \mathrm{mmol} / \mathrm{L} \\
\text { laboratory-defined cut point as upper limit of } \\
\text { reference range by assay manufacturer }\end{array}$ & $\begin{array}{l}\text { Clinically significant bleeding: need for packed } \\
\text { red blood cell transfusion or intervention to } \\
\text { control bleeding (surgery or } \\
\text { angioembolization), presenting hemoglobin of } \\
<7 \mathrm{mg} / \mathrm{dL} \text { or a decrease in hemoglobin } \geq 2 \mathrm{~g} / \mathrm{dL} \\
\text { in } 24 \text { hours. }\end{array}$ & $\begin{array}{l}\text { Supported by the United States } \\
\text { National Heart, Lung, and Blood } \\
\text { Institute, Award Number K12 HL } \\
109009 .\end{array}$ & Moderate \\
\hline Franklin, 2000 & Hypotension: SBP <90 mmHg & $\begin{array}{l}\text { ICU admission: ED disposition to ICU } \\
\text { Urgent operation: abdominal, thoracic, or } \\
\text { vascular/amputation procedure } \\
\text { ED disposition to OR } \\
\text { Mortality: ED } \\
\text { Mortality: late (in-hospital excluding ED) } \\
\text { Mortality: overall in-hospital (ED or late) }\end{array}$ & NR & Moderate \\
\hline
\end{tabular}




\begin{tabular}{|c|c|c|c|c|}
\hline $\begin{array}{l}\text { Author, Year } \\
\text { (See Appendix B for } \\
\text { complete reference) }\end{array}$ & Study Design & Setting and Dates Performed & Number of Study Subjects & Data Source \\
\hline Garner, 2001 & Retrospective & $\begin{array}{l}\text { Australia, New South Wales } \\
\text { Urban and rural } \\
\text { Level I and II trauma centers } \\
1 / 1994 \text { to } 12 / 1994 \\
1 \text { year }\end{array}$ & $\begin{array}{l}1,144 \text { analyzed } \\
1,192 \text { identified } \\
48 \text { excluded for missing or incomplete } \\
\text { ambulance case sheets }\end{array}$ & $\begin{array}{l}\text { Trauma registries for } 2 \text { trauma } \\
\text { centers. }\end{array}$ \\
\hline Gebhart, 2007 & Retrospective & $\begin{array}{l}\text { USA, Ohio } \\
\text { Urban } \\
\text { Level II trauma center }\end{array}$ & $\begin{array}{l}355 \text { analyzed } \\
357 \text { identified }\end{array}$ & $\begin{array}{l}\text { Trauma database for a single } \\
\text { trauma center. }\end{array}$ \\
\hline Gray, 1997 & Retrospective & $\begin{array}{l}\text { UK, England } \\
\text { Urban } \\
\text { Trauma system level: NR } \\
1 / 1 / 1993 \text { to } 6 / 7 / 1995 \\
2 \text { years, } 5 \text { months }\end{array}$ & $\begin{array}{l}213 \text { analyzed } \\
293 \text { direct admissions identified } \\
80 \text { excluded for incomplete data }\end{array}$ & $\begin{array}{l}\text { Resuscitation records and Major } \\
\text { Trauma Outcome Study (MTOS) } \\
\text { database }\end{array}$ \\
\hline Grimme, 2005 & Retrospective & $\begin{array}{l}\text { Germany } \\
\text { Urban and rural } \\
70-80 \text { trauma centers } \\
\text { 1/1/1993 to12/31/2001 } \\
9 \text { years }\end{array}$ & 6,346 analyzed & German Trauma Registry \\
\hline
\end{tabular}




\begin{tabular}{|c|c|c|c|}
\hline \begin{tabular}{|l|} 
Author, Year \\
(See Appendix B for \\
complete reference) \\
\end{tabular} & Eligibility Criteria & $\begin{array}{l}\text { Age Groups Included (Age Range Used*): \% } \\
\text { of Study Population }\end{array}$ & Type of Population \\
\hline Garner, 2001 & $\begin{array}{l}\text { Included: Patients } \geq 14 \text { years old with traumatic injury and an ED } \\
\text { stay longer than } 4 \text { hours or inpatient admission, and who were } \\
\text { transported directly from the incident scene. } \\
\text { Excluded: No exclusion criteria specified. }\end{array}$ & Adults ( $\geq 14): 100 \%$ & Civilian \\
\hline Gebhart, 2007 & $\begin{array}{l}\text { Included: Random selection of trauma patients in database. } \\
\text { Excluded: Patients without recorded GCS score. }\end{array}$ & NR (presumably 100\% adult) & Civilian \\
\hline Gray, 1997 & $\begin{array}{l}\text { Included: Patients admitted to the ED who were entered into the } \\
\text { trauma database and had CRAMS score and physiologic } \\
\text { components of the T-RTS recorded. } \\
\text { Excluded: Patients who were secondary transfers and those with } \\
\text { incomplete data. }\end{array}$ & $\begin{array}{l}\text { Mixed; percentages not provided } \\
\text { range: 2-95 }\end{array}$ & Civilian \\
\hline Grimme, 2005 & $\begin{array}{l}\text { Included: Patients with documentation in the German Trauma } \\
\text { Registry, including patients who died in the ED or who had minor } \\
\text { injuries; and who had clinical documentation by admitting physician. } \\
\text { Excluded: No exclusion criteria specified. }\end{array}$ & Adults ( $\geq 16): 100 \%$ & Civilian \\
\hline
\end{tabular}




\begin{tabular}{|c|c|c|c|c|}
\hline $\begin{array}{l}\text { Author, Year } \\
\text { (See Appendix B for } \\
\text { complete reference) } \\
\end{array}$ & Mechanism or Type Injury & Mode of Transport & $\begin{array}{l}\text { Other Population Characteristics } \\
\text { (Sex, Race) }\end{array}$ & $\begin{array}{l}\text { Name of Measure Being } \\
\text { Evaluated }\end{array}$ \\
\hline Garner, 2001 & $\begin{array}{l}\text { Motor vehicle crash occupant: } 39.1 \% \\
\text { Fall <5 m: } 21.3 \% \\
\text { Pedestrians and pedal cyclists: } 10.1 \% \\
\text { Motorcycle crash: } 6.6 \% \\
\text { Sports related: } 4.3 \% \\
\text { Blunt assault: } 4.3 \% \\
\text { Industrial accident: } 3.6 \% \\
\text { Stabbing: } 2.6 \% \\
\text { Fall >5 m: } 2.4 \% \\
\text { Burns: } 1.8 \% \\
\text { Gunshot wound: } 0.1 \%\end{array}$ & $\begin{array}{l}\text { Ambulance (land vs. } \\
\text { air not specified) }\end{array}$ & $\begin{array}{l}\text { Male: 65\% } \\
\text { Race: NR } \\
\text { Age (median): } 33 \text { (IQR 21-53) }\end{array}$ & \begin{tabular}{|l} 
Capillary refill \\
HR \\
RR \\
SBP \\
START \\
modified START \\
Triage Sieve \\
CareFlight Triage
\end{tabular} \\
\hline Gebhart, 2007 & NR & NR & $\begin{array}{l}\text { Male: } 59 \%(210 / 355) \\
\text { Race: NR } \\
\text { Age (mean): } 41 \text { (SD 21) }\end{array}$ & $\begin{array}{l}\text { START triage protocol (using } \\
\text { tabulated scoring) }\end{array}$ \\
\hline Gray, 1997 & NR & NR & $\begin{array}{l}\text { Male: NR } \\
\text { Race: NR } \\
\text { Age (median): } 33 \text { (range: 2-95) }\end{array}$ & $\begin{array}{l}\text { CRAMS scale } \\
\text { T-RTS }\end{array}$ \\
\hline Grimme, 2005 & $\begin{array}{l}\text { Type of Injury (more than one type of injury } \\
\text { may be reported) Blunt } \\
\text { trauma: } 96.2 \% \\
\text { Penetrating trauma: } 5.6 \% \\
\text { Mechanism of Injury } \\
\text { Motor vehicle accident: } 64.9 \% \\
\text { Fall from a height: } 12.2 \% \\
\text { Suicide: } 4.1 \% \\
\text { Other: } 18.8 \%\end{array}$ & Helicopter or Land & \begin{tabular}{|l|} 
Male: $76 \%$ \\
Race: NR \\
Age (mean): 33 (range 16-81)
\end{tabular} & \begin{tabular}{|l} 
HR \\
RR \\
RTS \\
SBP \\
SI
\end{tabular} \\
\hline
\end{tabular}




\begin{tabular}{|c|c|c|c|c|}
\hline \begin{tabular}{|l|} 
Author, Year \\
(See Appendix B for \\
complete reference)
\end{tabular} & $\begin{array}{l}\text { Location and Timing of } \\
\text { Measurement }\end{array}$ & Method of Measurement & $\begin{array}{l}\text { Personnel Administering Test or } \\
\text { Using Measure }\end{array}$ & Equipment Used/Needed \\
\hline Garner, 2001 & ED: on arrival & NR & NR & NR \\
\hline Gebhart, 2007 & ED: on arrival & NR & NR & NR \\
\hline Gray, 1997 & ED: on admission & NR & NR & NR \\
\hline Grimme, 2005 & Out of Hospital: on EMS arrival & NR & EMS on arrival & NR \\
\hline
\end{tabular}




\begin{tabular}{|c|c|c|c|c|}
\hline $\begin{array}{l}\text { Author, Year } \\
\text { (See Appendix B for } \\
\text { complete reference) }\end{array}$ & $\begin{array}{l}\text { Threshold Value(s) for Physiologic } \\
\text { Measures }\end{array}$ & $\begin{array}{l}\text { Indicator of Serious Injury Used } \\
\text { (including definition and time period) }\end{array}$ & Funding Source & Risk of Bias \\
\hline Garner, 2001 & $\begin{array}{l}\text { All triage algorithms: transport by ambulance } \\
\text { used as stand-in indicator of inability to walk } \\
\text { modified START: SBP }<80 \text { used as stand-in for } \\
\text { no palpable pulse }\end{array}$ & $\begin{array}{l}\text { Critical injury: life-saving intervention } \\
\text { determined as a nonorthopedic operative } \\
\text { procedure within } 6 \text { hours of admission, fluid } \\
\text { resuscitation }>1,000 \mathrm{~mL} \text { with SBP }<90, \\
\text { invasive central nervous system monitoring } \\
\text { and positive head CT scan, airway or } \\
\text { ventilatory assistance (excluding for sedation), } \\
\text { or decompression of a pneumothorax. }\end{array}$ & NR & Moderate \\
\hline Gebhart, 2007 & START tabulated score thresholds: $\leq 1 ; \geq 2$ & Mortality: inpatient & NR & Low \\
\hline Gray, 1997 & $\begin{array}{l}\text { CRAMS score }<9 \\
\text { T-RTS }<12 \text { (optimal cutoff), }<8 \\
\text { Optimal cut-offs where ratio of sensitivity } \\
\text { specificity are closest to } 1 \text {. }\end{array}$ & $\begin{array}{l}\text { Major injury (composite): ISS } \geq 15 \text {, ICU } \\
\text { admission or death. }\end{array}$ & NR & Moderate \\
\hline Grimme, 2005 & $\begin{array}{l}\text { SI: } 0.3-0.79,0.8-1.29, \geq 1.3 \\
\text { SBP: }<100.100-120 \\
\text { HR <60 bpm: bradycardia } \\
\text { RR: } 10-17,18-24\end{array}$ & Mortality: NR & NR & Moderate \\
\hline
\end{tabular}




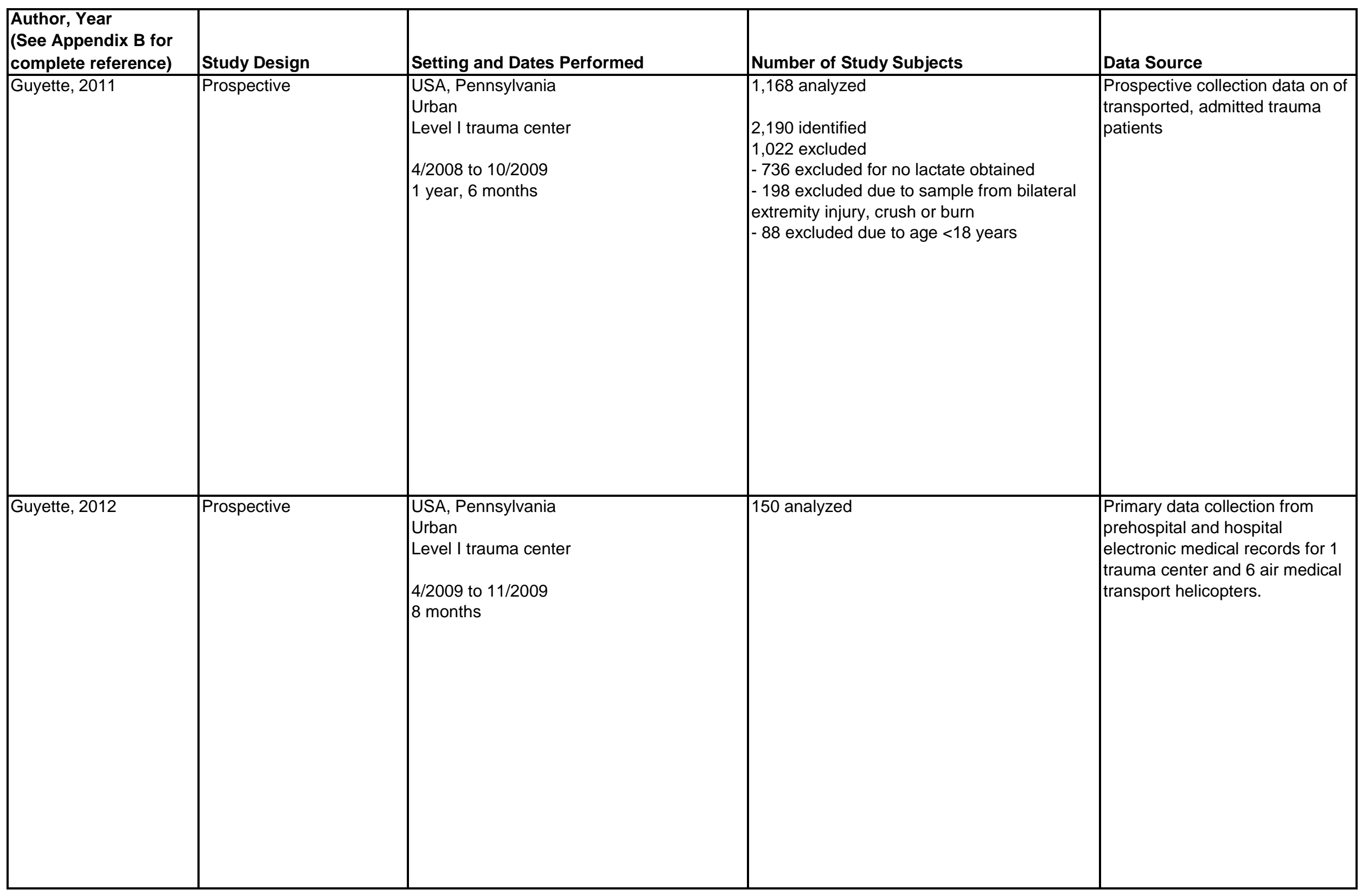




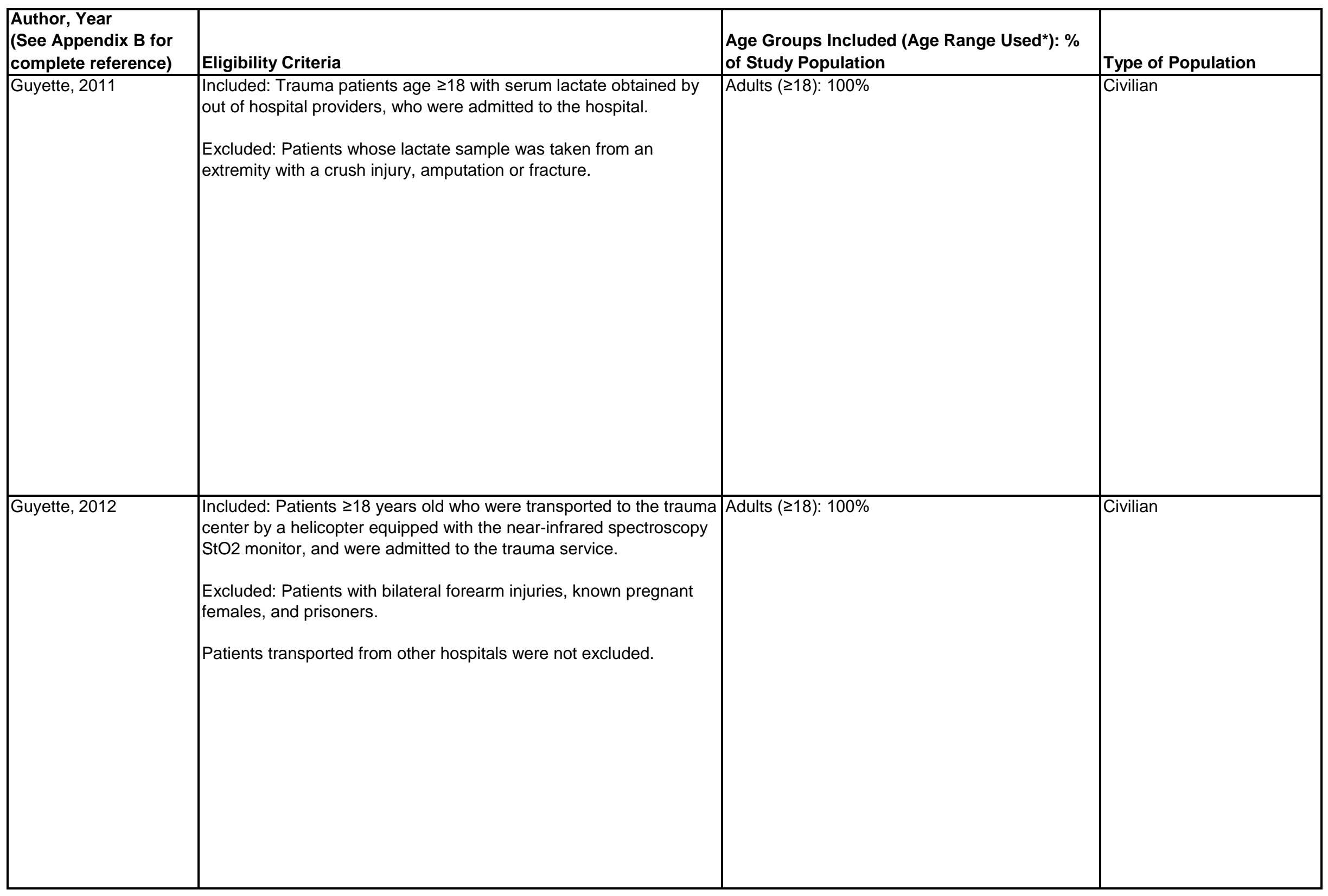




\begin{tabular}{|c|c|c|c|c|}
\hline $\begin{array}{l}\text { Author, Year } \\
\text { (See Appendix B for } \\
\text { complete reference) } \\
\end{array}$ & Mechanism or Type Injury & Mode of Transport & $\begin{array}{l}\text { Other Population Characteristics } \\
\text { (Sex, Race) }\end{array}$ & $\begin{array}{l}\text { Name of Measure Being } \\
\text { Evaluated }\end{array}$ \\
\hline Guyette, 2011 & $\begin{array}{l}\text { Type of injury } \\
\text {-Penetrating: } 4 \% \\
\\
\text { Mechanism of injury } \\
\text {-Fall: } 25 \% \\
\text {-Motor vehicle crash: } 62 \% \\
\text {-Stab/shot: } 4 \% \\
\text {-Other: } 9 \% \\
\\
\text { Site of injury (more than one site of injury may } \\
\text { be reported) } \\
\text {-Head/neck: } 50 \% \\
\text {-Face: } 22 \% \\
\text {-Chest: } 30 \% \\
\text {--Abdomen: } 20 \% \\
\text {-Extremity: } 84 \%\end{array}$ & Helicopter & $\begin{array}{l}\text { Male: } 68 \% \\
\text { Race: NR } \\
\text { Age (median): } 44 \text { (IQR 27-58) }\end{array}$ & $\begin{array}{l}\text { HR } \\
\text { Lactate } \\
\text { SBP } \\
\text { Predictor models using different } \\
\text { combinations of: age, sex, SBP, } \\
\text { HR, RR, GCS and lactate }\end{array}$ \\
\hline Guyette, 2012 & $\begin{array}{l}\text { Type of injury } \\
\text { Penetrating trauma: } 4 \%(6 / 150) \\
\\
\text { Mechanism of injury } \\
\text { Fall: } 25 \% \text { (38/150) } \\
\text { Motor vehicle collision: } 62 \%(93 / 150) \\
\text { Stab/shot: } 4 \%(6 / 150) \\
\text { Other: } 9 \%(13 / 150)\end{array}$ & Helicopter & $\begin{array}{l}\text { Male: } 60 \% \text { (90/150) } \\
\text { Race: NR } \\
\text { Age (mean): } 47 \text { (SD 20) }\end{array}$ & \begin{tabular}{|l}
$\mathrm{DeO} 2$ \\
$\mathrm{ReO} 2$ \\
$\mathrm{SBP}$
\end{tabular} \\
\hline
\end{tabular}




\begin{tabular}{|c|c|c|c|c|}
\hline \begin{tabular}{|l} 
Author, Year \\
(See Appendix B for \\
complete reference) \\
\end{tabular} & $\begin{array}{l}\text { Location and Timing of } \\
\text { Measurement }\end{array}$ & Method of Measurement & $\begin{array}{l}\text { Personnel Administering Test or } \\
\text { Using Measure }\end{array}$ & Equipment Used/Needed \\
\hline Guyette, 2011 & Out of Hospital: not specified & Lactate: venous and capillary & EMS on arrival & $\begin{array}{l}\text { Point of care serum lactate } \\
\text { meter (Lactate Pro, FACT, } \\
\text { Canada) }\end{array}$ \\
\hline Guyette, 2012 & $\begin{array}{l}\text { Out of hospital: during } \\
\text { Resuscitation }\end{array}$ & $\begin{array}{l}\text { DeO2 and ReO2: near-infrared } \\
\text { spectroscopy StO2 monitor } \\
\text { applied to thenar eminence, } \\
\text { vascular occlusion test was } \\
\text { performed and slopes } \\
\text { calculated for deoxygenation } \\
\text { and reoxygenation phases. } \\
\text { DeO2 using Pearson's } \\
\text { coefficients of regression (r2) } \\
\text { for the first } 25 \% \text { of descent and } \\
\text { ReO2 slope using entire } \\
\text { recovery period. } \\
\text { SBP: automated continuous }\end{array}$ & Helicopter flight crew members & $\begin{array}{l}\text { StO2: near-infrared } \\
\text { spectroscopy StO2 (InSpectra } \\
\text { StO2; Hutchinson Industries; } \\
\text { Hutchinson, MN) } \\
\text { SBP: LIFEPAK } 12 \text { monitors } \\
\text { (PhysioControl; Redmond, WA) }\end{array}$ \\
\hline
\end{tabular}




\begin{tabular}{|c|c|c|c|c|}
\hline $\begin{array}{l}\text { Author, Year } \\
\text { (See Appendix B for } \\
\text { complete reference) }\end{array}$ & $\begin{array}{l}\text { Threshold Value(s) for Physiologic } \\
\text { Measures }\end{array}$ & $\begin{array}{l}\text { Indicator of Serious Injury Used } \\
\text { (including definition and time period) }\end{array}$ & Funding Source & Risk of Bias \\
\hline Guyette, 2011 & $\begin{array}{l}\mathrm{HR}>110 \\
\text { Lactate }>2 \\
\mathrm{RR} \geq 30 \\
\mathrm{SBP}<100 \\
\mathrm{SI}>0.8\end{array}$ & $\begin{array}{l}\text { Mortality: inpatient } \\
\text { Emergent surgery: any of the following } \\
\text { procedures for hemorrhage control in the first } \\
24 \text { hours of hospitalization: thoracotomy, } \\
\text { laparotomy, pelvic fixation, and embolization. } \\
\\
\text { Multiple organ dysfunction: MOD score }>6 \text {; } \\
\mathrm{MOD} \text { score is the sum of the following ordinal }^{\text {subscales: (a) the respiratory system }} \\
\left(\mathrm{PaO}_{2} / \mathrm{FIO}_{2} \text { ratio); (b) the renal system (serum }\right. \\
\text { creatinine concentration); (c) the hepatic } \\
\text { system (serum bilirubin concentration); (d) the } \\
\text { hematologic system (platelet count); (e) the } \\
\text { central nervous system (GCS); and (f) the } \\
\text { cardiovascular system (heart rate } X \text { central } \\
\text { venous pressure/mean arterial pressure) }\end{array}$ & $\begin{array}{l}\text { Partially supported by the Fogarty } \\
\text { International Center NIH Grant No. } \\
1 \text { D43 TW007560-01. }\end{array}$ & Moderate \\
\hline Guyette, 2012 & Lowest SBP: lowest recorded value for SBP & $\begin{array}{l}\text { Need for in-hospital life-saving intervention: } \\
\text { emergent operation or emergent transfusion in } \\
\text { the first } 24 \text { hours of hospitalization. Emergent } \\
\text { operation defined as any of these procedures } \\
\text { in the first } 24 \text { hours of hospitalization for } \\
\text { hemorrhage control: thoracotomy, laparotomy, } \\
\text { pelvic fixation or embolization. Emergent } \\
\text { transfusion defined as any blood transfused in } \\
\text { the first } 24 \text { hours of hospitalization. The trigger } \\
\text { for transfusion is hypotension (SBP }<90 \text { ) not } \\
\text { responsive to } 2 \mathrm{~L} \text { of crystalloid, or at the } \\
\text { discretion of the command physician } \\
\text { (prehospital) or trauma surgeon (trauma bay). }\end{array}$ & $\begin{array}{l}\text { Supported in part by USAF FA7014- } \\
07-\mathrm{C}-0053 \text { and NHLBI HL07820. }\end{array}$ & Moderate \\
\hline
\end{tabular}




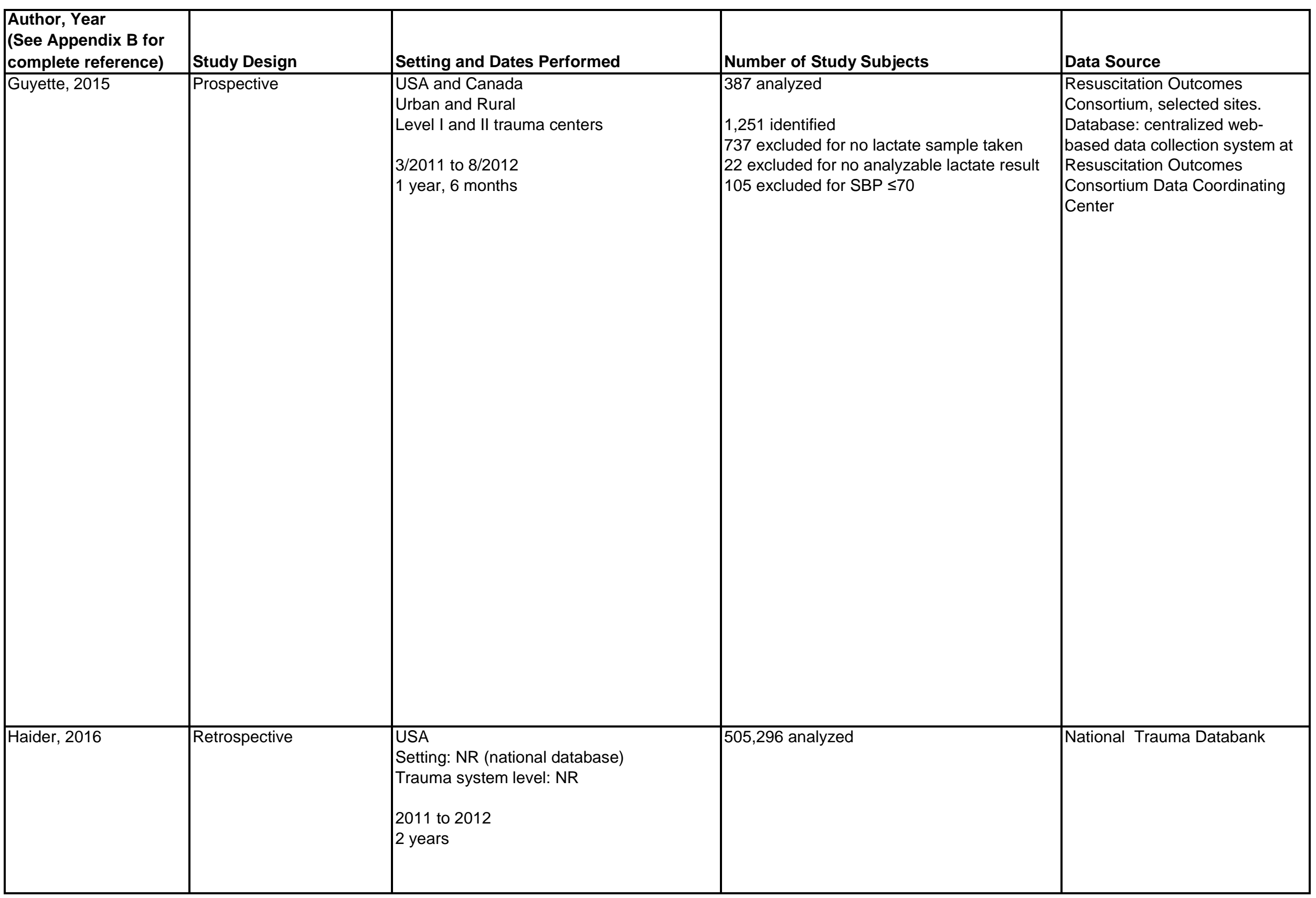




\begin{tabular}{|c|c|c|c|}
\hline $\begin{array}{l}\text { Author, Year } \\
\text { (See Appendix B for } \\
\text { complete reference) }\end{array}$ & Eligibility Criteria & $\begin{array}{l}\text { Age Groups Included (Age Range Used*): \% } \\
\text { of Study Population }\end{array}$ & Type of Population \\
\hline Guyette, 2015 & $\begin{array}{l}\text { Included: Patients with blunt or penetrating trauma transported by } \\
\text { ground EMS with an out of hospital SBP } 71-100 \mathrm{mmHg} \text {. } \\
\text { Excluded: Patients }<15 \text { years old, obvious isolated penetrating head } \\
\text { injury, drowning, asphyxia caused by hanging, burns on }>20 \% \text { of } \\
\text { total body surface area, or those with prisoner status. }\end{array}$ & Adults ( $\geq 15): 100 \%$ & Civilian \\
\hline
\end{tabular}




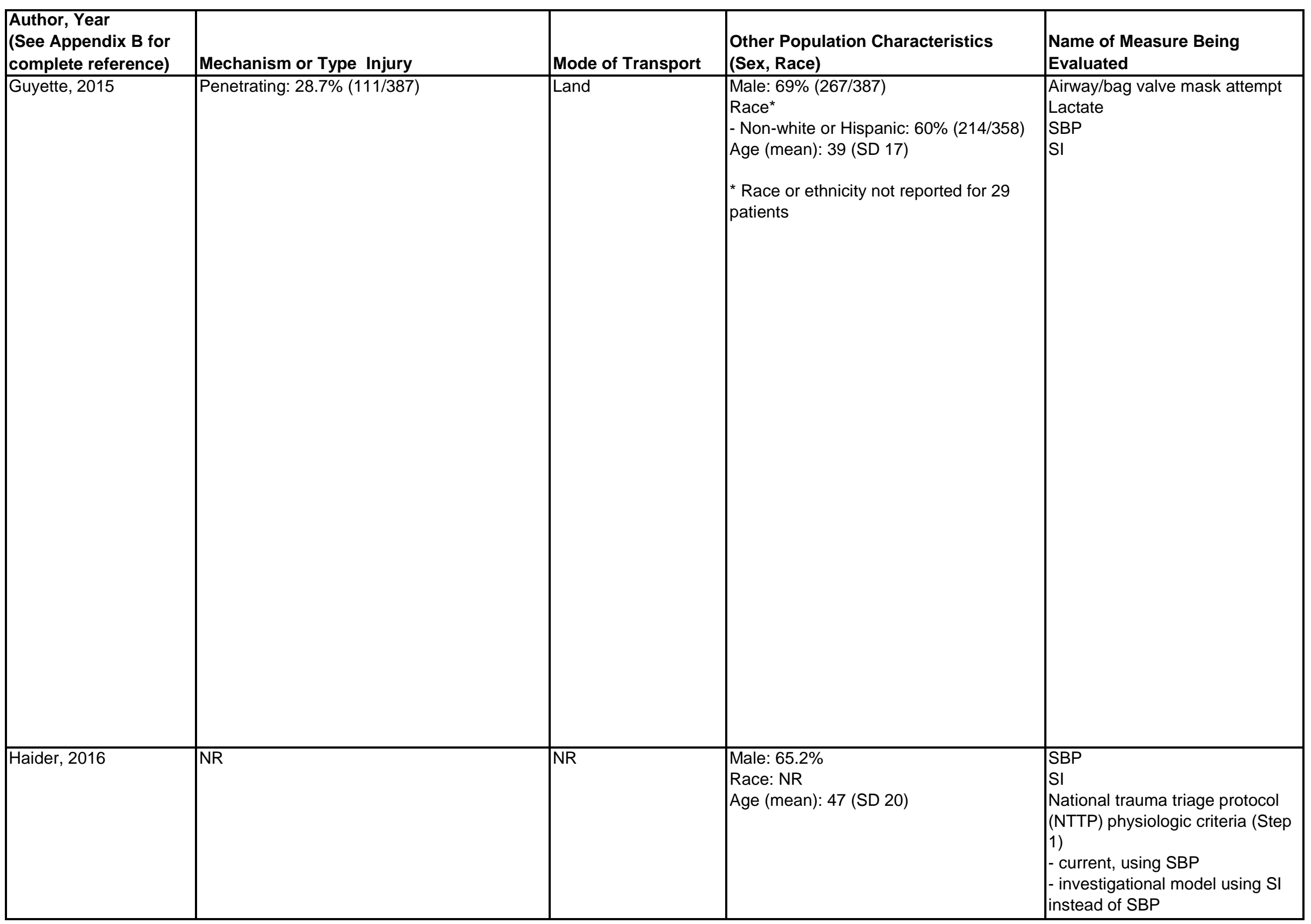




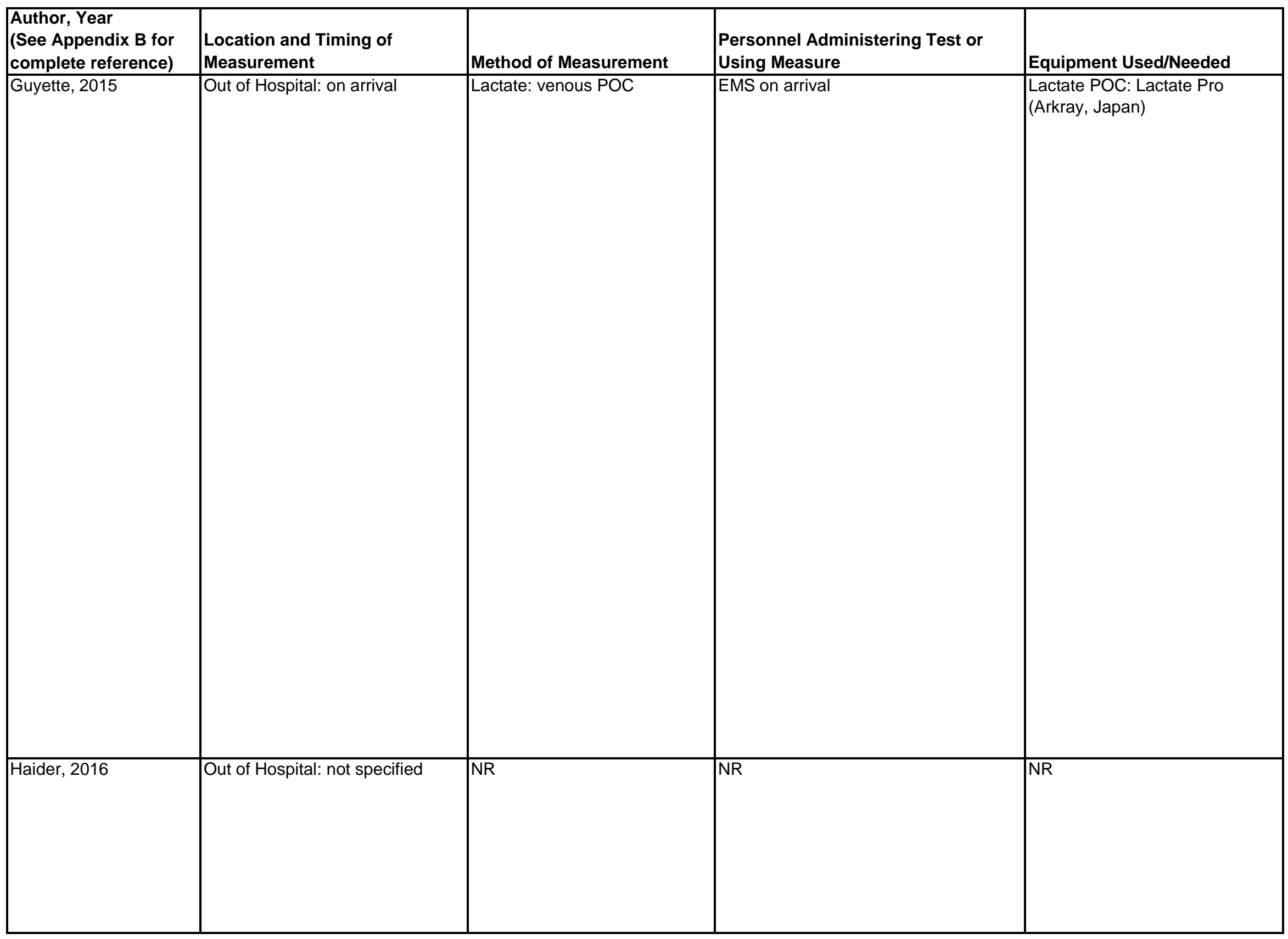

D-84 


\begin{tabular}{|c|c|c|c|c|}
\hline $\begin{array}{l}\text { Author, Year } \\
\text { (See Appendix B for } \\
\text { complete reference) } \\
\end{array}$ & $\begin{array}{l}\text { Threshold Value(s) for Physiologic } \\
\text { Measures }\end{array}$ & $\begin{array}{l}\text { Indicator of Serious Injury Used } \\
\text { (including definition and time period) }\end{array}$ & Funding Source & Risk of Bias \\
\hline Guyette, 2015 & $\begin{array}{l}\text { Lactate cut point: Predetermined to equal the } \\
\text { value yielding the same specificity as EMS SBP } \\
\leq 90 \text {. "P-LAC decision rule" } \\
-\geq 2.5 \text { for overall group } \\
- \text { NR for early vs late lactate subgroups } \\
\text { For multivariate analysis: } 2.5 \text { and } 4.0 \text { "knots" = } \\
\text { cutoff points selected from prior studies } \\
\\
\text { Early lactate: lactate measured }<15 \text { minutes } \\
\text { after } 911 \text { call } \\
\text { Late lactate: measured }>15 \text { minutes after } 911 \\
\text { call }\end{array}$ & $\begin{array}{l}\text { Need for resuscitative care: Any of the } \\
\text { following within } 6 \text { hours of ED arrival: blood } \\
\text { transfusion of } \geq 5 \text { units; intervention for } \\
\text { hemorrhage (including thoracotomy, } \\
\text { laparotomy, pelvic fixation or interventional } \\
\text { radiology embolization); or death (including } \\
\text { death before ED arrival). }\end{array}$ & $\begin{array}{l}\text { The Resuscitation Outcomes } \\
\text { Consortium is supported by a series } \\
\text { of cooperative agreements to nine } \\
\text { regional clinical centers and one } \\
\text { Data Coordinating Center from the } \\
\text { National Heart, Lung and Blood } \\
\text { Institute in partnership with the US } \\
\text { Army Medical Research \& Material } \\
\text { Command, The Canadian Institutes } \\
\text { of Health Research (CIHR) - } \\
\text { Institute of Circulatory and } \\
\text { Respiratory Health, Defense } \\
\text { Research and Development } \\
\text { Canada, the Heart, Stroke } \\
\text { Foundation of Canada and the } \\
\text { American Heart Association. These } \\
\text { are: } 5 \text { OO1 HL077863V - University } \\
\text { of Washington Data Coordinating } \\
\text { Center, HL077866 - Medical } \\
\text { College of Wisconsin, HL077867 - } \\
\text { University of Washington, } \\
\text { HL077871 - University of } \\
\text { Pittsburgh, HL077873 - Oregon } \\
\text { Health and Science University, } \\
\text { HL077881 - University of Alabama } \\
\text { at Birmingham, HL077887 - } \\
\text { University of Texas SW Medical } \\
\text { Ctr/Dallas, HL077908 - University of } \\
\text { California San Diego }\end{array}$ & Moderate \\
\hline Haider, 2016 & $\begin{array}{l}\mathrm{SBP}<90 \\
\mathrm{SI}>1.0\end{array}$ & $\begin{array}{l}\text { Trauma center need: ISS }>15 \text {, ED disposition } \\
\text { to emergency surgery, ICU LOS }>1 \text { day, or } \\
\text { death in ED. }\end{array}$ & $\begin{array}{l}\text { Authors declare no conflicts of } \\
\text { interest. }\end{array}$ & Moderate \\
\hline
\end{tabular}




\begin{tabular}{|c|c|c|c|c|}
\hline $\begin{array}{l}\text { Author, Year } \\
\text { (See Appendix B for } \\
\text { complete reference) }\end{array}$ & Study Design & Setting and Dates Performed & Number of Study Subjects & Data Source \\
\hline Hamada, 2014 & Retrospective & $\begin{array}{l}\text { France, lle de France (Paris) } \\
\text { Urban } \\
\text { Major trauma center } \\
1 / 1 / 2011 \text { to } 9 / 30 / 2012 \\
1 \text { year, } 9 \text { months }\end{array}$ & $\begin{array}{l}825 \text { analyzed } \\
998 \text { identified } \\
173 \text { excluded for no direct admission in first } \\
24 \text { hours }\end{array}$ & Medical records of 2 hospitals. \\
\hline Henry, 1996 & Prospective & $\begin{array}{l}\text { USA, New York } \\
\text { Suburban and rural } \\
\text { Trauma system level: NR } \\
1 / 25 / 1994 \text { to } 6 / 30 / 1994 \\
5 \text { months }\end{array}$ & $\begin{array}{l}1,545 \text { analyzed } \\
1,601 \text { with data collected } \\
56 \text { excluded: } \\
-34 \text { excluded for motorcycle injuries } \\
-22 \text { excluded for unavailable medical records }\end{array}$ & $\begin{array}{l}\text { Primary data collection by EMS } \\
\text { personnel. Hospital data by } \\
\text { review of medical records. }\end{array}$ \\
\hline Holcomb, 2005 & Retrospective & $\begin{array}{l}\text { USA, Texas } \\
\text { Urban } \\
\text { Level I trauma center } \\
5 / 2002 \text { to } 4 / 2004 \\
2 \text { years }\end{array}$ & $\begin{array}{l}381 \text { analyzed } \\
920 \text { identified } \\
137 \text { excluded for head injury } \\
339 \text { excluded for pulse character not } \\
\text { recorded (data collected } 8 / 2001 \text { to } 5 / 2002 \text { ) } \\
63 \text { excluded for SpO2 of } 0 \% \text { or unable to } \\
\text { record value, or were dead at admission }\end{array}$ & $\begin{array}{l}\text { Trauma Vitals Database, for } \\
\text { transport to a single trauma } \\
\text { center (Memorial Hermann } \\
\text { Hospital) }\end{array}$ \\
\hline Holcomb, 2005b & Prospective & $\begin{array}{l}\text { USA, Texas } \\
\text { Urban } \\
\text { Level I trauma center } \\
8 / 1 / 2001 \text { to } 3 / 7 / 2002 \\
7 \text { months }\end{array}$ & 216 analyzed & Primary data collection \\
\hline
\end{tabular}




\begin{tabular}{|c|c|c|c|}
\hline $\begin{array}{l}\text { Author, Year } \\
\text { (See Appendix B for } \\
\text { complete reference) }\end{array}$ & Eligibility Criteria & $\begin{array}{l}\text { Age Groups Included (Age Range Used*): \% } \\
\text { of Study Population }\end{array}$ & Type of Population \\
\hline Hamada, 2014 & $\begin{array}{l}\text { Included: Patients admitted for suspicion of major trauma. } \\
\text { Excluded: Patients who were not directly admitted within } 24 \text { hours } \\
\text { after trauma. }\end{array}$ & $\begin{array}{l}\text { Overall: NR (mean age 37) } \\
\text { Elderly ( } \geq 65): 7 \%(66 / 825)\end{array}$ & Civilian \\
\hline Henry, 1996 & $\begin{array}{l}\text { Included: Patients who were victims of motor vehicle crashes who } \\
\text { received spinal immobilization by EMS and were transported to any } \\
\text { of } 12 \text { ambulance receiving hospitals. } \\
\text { Excluded: Patients not transported by EMS, those with motorcycle } \\
\text { crashes, or with unavailable medical records. }\end{array}$ & NR & Civilian \\
\hline Holcomb, 2005 & $\begin{array}{l}\text { Included: Trauma patients transported from the scene by life flight } \\
\text { helicopter service. } \\
\\
\text { Excluded: Patients with head injuries (head AIS score } \geq 3 \text { ), those } \\
\text { without data for pulse character, or who had an } \mathrm{SpO} 2 \text { of } 0 \% \text { or value } \\
\text { was not able to be recorded by the monitor, and those who were } \\
\text { dead at admission to the hospital. }\end{array}$ & NR & Civilian \\
\hline Holcomb, 2005b & $\begin{array}{l}\text { Included: Patients transported directly from the incident scene who } \\
\text { had an injury necessitating admission to the hospital. } \\
\text { Excluded: Patients discharged home from the emergency } \\
\text { department. }\end{array}$ & \begin{tabular}{|l} 
Adults (>18): 79\% \\
Children (2-18): $21 \%$
\end{tabular} & Civilian \\
\hline
\end{tabular}




\begin{tabular}{|c|c|c|c|c|}
\hline $\begin{array}{l}\text { Author, Year } \\
\text { (See Appendix B for } \\
\text { complete reference) } \\
\end{array}$ & Mechanism or Type Injury & Mode of Transport & $\begin{array}{l}\text { Other Population Characteristics } \\
\text { (Sex, Race) }\end{array}$ & $\begin{array}{l}\text { Name of Measure Being } \\
\text { Evaluated }\end{array}$ \\
\hline Hamada, 2014 & $\begin{array}{l}\text { Type of injury } \\
\text { Blunt: } 93.1 \% \\
\text { Penetrating: } 6.9 \% \\
\\
\text { Mechanism of injury } \\
\text { Firearm: } 2 \% \\
\text { Stabbing: } 5 \% \\
\text { Pedestrian/cyclist: } 11 \% \\
\text { Car crash: } 19 \% \\
\text { Motorbike: } 28 \% \\
\text { Fall: } 28 \% \\
\text { Other: } 7 \%\end{array}$ & NR & $\begin{array}{l}\text { Male: } 79 \% \\
\text { Race: NR } \\
\text { Age (mean): } 37 \text { (SD 17) }\end{array}$ & $\begin{array}{l}\text { Airway support (assisted } \\
\text { ventilation) } \\
\text { SpO2 } \\
\text { SBP }\end{array}$ \\
\hline Henry, 1996 & $\begin{array}{l}\text { Type of injury: NR } \\
\text { Mechanism of injury } \\
\text { Motor vehicle crash: } 100 \%\end{array}$ & Land and Helicopter & $\begin{array}{l}\text { Male: } 47 \% \\
\text { Race: NR } \\
\text { Age (median): } 30 \text { (range } 0 \text { to } 93 \text { ) }\end{array}$ & $\begin{array}{l}\text { RR } \\
\text { SBP }\end{array}$ \\
\hline Holcomb, 2005 & \begin{tabular}{|l|} 
Blunt: $88 \%$ \\
Penetrating: $12 \%$
\end{tabular} & Helicopter & $\begin{array}{l}\text { Male: } 72 \% \\
\text { Race: NR } \\
\text { Age (mean): } 36 \text { (SD 15) }\end{array}$ & $\begin{array}{l}\text { SBP } \\
\text { Models using vital signs and } \\
\text { scores which differed based on } \\
\text { method of measurement } \\
\text { - manual (group 1) } \\
\text { - semi automated (group 2) } \\
\text { - automated (group 3) }\end{array}$ \\
\hline Holcomb, 2005b & \begin{tabular}{|l} 
Blunt: 90\% \\
Penetrating: $10 \%$
\end{tabular} & Helicopter & $\begin{array}{l}\text { Male: } 73 \% \\
\text { Race: NR } \\
\text { Age (mean): } 33 \text { (SD 17) }\end{array}$ & \begin{tabular}{|l} 
Capillary refill \\
HR \\
RR \\
SBP \\
SBP plus GCS motor
\end{tabular} \\
\hline
\end{tabular}




\begin{tabular}{|c|c|c|c|c|}
\hline $\begin{array}{l}\text { Author, Year } \\
\text { (See Appendix B for } \\
\text { complete reference) }\end{array}$ & $\begin{array}{l}\text { Location and Timing of } \\
\text { Measurement }\end{array}$ & Method of Measurement & $\begin{array}{l}\text { Personnel Administering Test or } \\
\text { Using Measure }\end{array}$ & Equipment Used/Needed \\
\hline Hamada, 2014 & $\begin{array}{l}\text { Out of hospital: worst value } \\
\text { Obtained }\end{array}$ & NR & NR & NR \\
\hline Henry, 1996 & Out of Hospital: on EMS arrival & Not specified & EMS on arrival & NR \\
\hline Holcomb, 2005 & $\begin{array}{l}\text { Out of Hospital: during } \\
\text { Resuscitation }\end{array}$ & $\begin{array}{l}\text { Group } 1 \text { (manual): no } \\
\text { equipment } \\
\text { Group } 2 \text { (semi automated): } \\
\text { light source and minimal } \\
\text { instruments } \\
\text { Group } 3 \text { (automated): } \\
\text { automated, vital signs monitor }\end{array}$ & Flight medic and nurse & $\begin{array}{l}\text { Vital signs monitors: Propaq } \\
\text { 206EL (Welch Allyn, } \\
\text { Skaneateles Falls, NY) or PIC } \\
50 \text { defibrillator/vital signs } \\
\text { monitor (Welch Allyn) }\end{array}$ \\
\hline Holcomb, 2005b & $\begin{array}{l}\text { Out of Hospital: during } \\
\text { Resuscitation }\end{array}$ & $\begin{array}{l}\text { Vital signs: automated using } \\
\text { portable patient monitor }\end{array}$ & Flight medical personnel & $\begin{array}{l}\text { Propaq } 206 \text { monitor (Welch } \\
\text { Allyn, Beaverton, Oregon) }\end{array}$ \\
\hline
\end{tabular}




\begin{tabular}{|c|c|c|c|c|}
\hline $\begin{array}{l}\text { Author, Year } \\
\text { (See Appendix B for } \\
\text { complete reference) }\end{array}$ & $\begin{array}{l}\text { Threshold Value(s) for Physiologic } \\
\text { Measures }\end{array}$ & $\begin{array}{l}\text { Indicator of Serious Injury Used } \\
\text { (including definition and time period) }\end{array}$ & Funding Source & Risk of Bias \\
\hline Hamada, 2014 & $\begin{array}{l}\mathrm{SpO} 2<90 \% \\
\mathrm{SBP}<90 \mathrm{mmHg}\end{array}$ & Major trauma: ISS >15 & $\begin{array}{l}\text { Authors declare no conflicts of } \\
\text { interest. }\end{array}$ & Moderate \\
\hline Henry, 1996 & $\begin{array}{l}\text { RR }<10 \text { or }>29 \text { breaths per minute } \\
\text { SBP }<90 \mathrm{mmHg} \\
\text { Predetermined, American College of Surgeons } \\
\text { Trauma Triage Criteria }\end{array}$ & $\begin{array}{l}\text { Major nonorthopedic operative interventions or } \\
\text { death } \\
\text { - Major non-orthopedic operative intervention: } \\
\text { craniotomy. laparotomy, thoracotomy, or } \\
\text { spinal stabilization } \\
\text { - Death: in-hospital } \\
\text { ISS } \geq 16 \\
\text { Hospital LOS }>2 \text { days }\end{array}$ & $\begin{array}{l}\text { Funded by the New York State } \\
\text { Department of Health Regional } \\
\text { Trauma Quality Assurance } \\
\text { Demonstration Project }\end{array}$ & Low \\
\hline Holcomb, 2005 & SBP $<99$ & $\begin{array}{l}\text { LSI defined using a consensus } \\
\text { recommendation of a multidisciplinary panel of } \\
\text { trauma experts }\end{array}$ & $\begin{array}{l}\text { Supported by the United States } \\
\text { Army Medical Research and } \\
\text { Materiel Command Combat } \\
\text { Casualty Care Research Program } \\
\text { (E52-0021-2005-USAISR) and the } \\
\text { United States Special Operations } \\
\text { Command (MIPR 051-80482). }\end{array}$ & High \\
\hline Holcomb, 2005b & $\begin{array}{l}\text { Capillary refill } \\
\text { Delayed: }>2 \text { seconds } \\
\text { SBP } \\
\text { Hypotensive: }<90 \mathrm{mmHg} \\
\text { GCS motor score } \\
\text { Abnormal: }<6\end{array}$ & $\begin{array}{l}\text { LSI: pre-hospital or hospital intubation, chest } \\
\text { tube, needle thoracentesis, cricothyroidotomy, } \\
\text { pericardiocentesis, CPR, defibrillation, blood } \\
\text { transfusion, operative intervention or } \\
\text { arteriogram. }\end{array}$ & $\begin{array}{l}\text { Supported by grants from the U.S. } \\
\text { Army Combat Casualty Care } \\
\text { Program and the Defense } \\
\text { Advanced Research Projects } \\
\text { Agency. }\end{array}$ & Moderate \\
\hline
\end{tabular}




\begin{tabular}{|c|c|c|c|c|}
\hline $\begin{array}{l}\text { Author, Year } \\
\text { (See Appendix B for } \\
\text { complete reference) }\end{array}$ & Study Design & Setting and Dates Performed & Number of Study Subjects & Data Source \\
\hline Horne, 2013 & Retrospective & $\begin{array}{l}\text { Iraq and Afghanistan (UK military) } \\
\text { Setting: Combat } \\
2005 \text { to } 2010 \\
6 \text { years }\end{array}$ & $\begin{array}{l}1,657 \text { analyzed (overall dataset) } \\
1,213 \text { with complete data for comparative } \\
\text { analysis }\end{array}$ & $\begin{array}{l}\text { Joint Theatre Trauma Registry; } \\
\text { Royal Centre for Defence } \\
\text { Medicine, Birmingham UK }\end{array}$ \\
\hline Ichwan, 2015 & Retrospective & $\begin{array}{l}\text { USA, Ohio } \\
\text { Urban and rural (statewide) } \\
\text { Trauma system level: NR (both trauma and } \\
\text { nontrauma centers) } \\
2006 \text { to } 2011 \\
6 \text { years }\end{array}$ & $\begin{array}{l}101,577 \text { analyzed } \\
133,962 \text { identified } \\
30,342 \text { excluded for non-EMS transport } \\
2,043 \text { excluded for missing data to calculate } \\
\text { ISS }\end{array}$ & $\begin{array}{l}\text { Ohio Trauma Registry, includes } \\
\text { EMS run sheet data }\end{array}$ \\
\hline Imhoff, 2014 & Retrospective & $\begin{array}{l}\text { USA, Kansas } \\
\text { Urban } \\
\text { Level I Trauma Center } \\
\text { Study dates: NR } \\
4 \text { years }\end{array}$ & 3,680 analyzed & $\begin{array}{l}\text { Trauma registry for a single } \\
\text { trauma center; chart review. }\end{array}$ \\
\hline Jo, 2014 & Retrospective & $\begin{array}{l}\text { South Korea } \\
\text { Urban } \\
\text { Trauma system level: NR (regional trauma } \\
\text { center) } \\
4 / 1 / 2010 \text { to } 3 / 31 / 2011 \\
1 \text { year }\end{array}$ & $\begin{array}{l}299 \text { analyzed } \\
502 \text { identified } \\
203 \text { excluded for no initial lactate level }\end{array}$ & Internal hospital data \\
\hline
\end{tabular}




\begin{tabular}{|c|c|c|c|}
\hline $\begin{array}{l}\text { Author, Year } \\
\text { (See Appendix B for } \\
\text { complete reference) }\end{array}$ & Eligibility Criteria & $\begin{array}{l}\text { Age Groups Included (Age Range Used*): \% } \\
\text { of Study Population }\end{array}$ & Type of Population \\
\hline Horne, 2013 & $\begin{array}{l}\text { Included: All military or civilian trauma patients with pre-hospital } \\
\text { data. } \\
\text { Excluded: No exclusion criteria specified. } \\
\text { Comparative analysis dataset: Excluded patients with an incomplete } \\
\text { set of physiologic data in which the data present did not } \\
\text { automatically classify the patient as Priority } 1 .\end{array}$ & NR & $\begin{array}{l}\text { Military (may include some } \\
\text { Civilians) }\end{array}$ \\
\hline Ichwan, 2015 & $\begin{array}{l}\text { Included: Patients age } \geq 16 \text { years with EMS transport from the } \\
\text { scene. } \\
\text { Excluded: Patients who were not transported by EMS or had absent } \\
\text { data to calculate ISS. }\end{array}$ & $\begin{array}{l}\text { Adults ( }(\geq 16): 100 \% \\
\text { Elderly ( } \geq 70): 33 \%\end{array}$ & Civilian \\
\hline Imhoff, 2014 & $\begin{array}{l}\text { Included: Patients } \geq 14 \text { years old with trauma. } \\
\text { Excluded: Patients who were transferred from other hospitals, those } \\
\text { with burns or drowning-related injuries, or had insufficient vital sign } \\
\text { documentation to calculate the REMS score. }\end{array}$ & Adults ( $(\geq 14): 100 \%$ & Civilian \\
\hline Jo, 2014 & $\begin{array}{l}\text { Included: Patients } \geq 15 \text { years old with blunt trauma, ISS } \geq 9 \text { and } \\
\text { serum lactate level taken on ED arrival. } \\
\text { Excluded: No exclusion criteria specified. }\end{array}$ & Adults ( $(\geq 15): 100 \%$ & Civilian \\
\hline
\end{tabular}




\begin{tabular}{|c|c|c|c|c|}
\hline $\begin{array}{l}\text { Author, Year } \\
\text { (See Appendix B for } \\
\text { complete reference) }\end{array}$ & Mechanism or Type Injury & Mode of Transport & $\begin{array}{l}\text { Other Population Characteristics } \\
\text { (Sex, Race) }\end{array}$ & $\begin{array}{l}\text { Name of Measure Being } \\
\text { Evaluated }\end{array}$ \\
\hline Horne, 2013 & NR & NR & NR & $\begin{array}{l}\text { Triage Sieve, UK } \\
\text { - Civilian version } \\
\text { - Military version }\end{array}$ \\
\hline Ichwan, 2015 & $\begin{array}{l}\text { Blunt: } 90 \% \\
\text { Penetrating: } 9 \% \\
\text { Burns: } 1 \% \\
\text { Asphyxial: }<1 \%\end{array}$ & \begin{tabular}{|l|} 
Land vs. air: not \\
specified \\
- Interhospital transfer: \\
$14 \%$
\end{tabular} & $\begin{array}{l}\text { Male: } 55 \% \\
\text { Race } \\
\text { - White: } 79 \% \\
\text { - Black :14\% } \\
\text { - Hispanic: } 1.4 \% \\
\text { - Indian/Alaskan/Native: } 0.1 \% \\
\text { - Asian/Pacific Islander: } 0.6 \% \\
\text { - Other: } 0.8 \% \\
\text { - Undocumented: } 4.5 \% \\
\text { Age (mean): } 55 \text { (SD 23) }\end{array}$ & $\begin{array}{l}\text { Adult trauma triage criteria } \\
\text { Geriatric trauma triage criteria: } \\
\text { uses different thresholds for SBP } \\
\text { and GCS, and additional } \\
\text { anatomic and cause of injury } \\
\text { criteria }\end{array}$ \\
\hline Imhoff, 2014 & NR & NR & $\begin{array}{l}\text { Male: } 74 \% \\
\text { Race } \\
\text { - White } 62 \% \\
\text { - Black: } 23 \% \\
\text { - Other: } 15 \% \\
\text { Age (mean): } 37 \text { (SD 17) }\end{array}$ & \begin{tabular}{|l} 
HR \\
MAP \\
Oxygen saturation \\
REMS \\
RR \\
RTS \\
SI
\end{tabular} \\
\hline Jo, 2014 & $\begin{array}{l}\text { Type of injury } \\
\text { - Blunt: } 100 \% \\
\text { Mechanism of injury } \\
\text {-Motor vehicle crash: } 56 \% \\
\text {-Fall: } 11 \% \\
\text {-Other: } 33 \%\end{array}$ & $\begin{array}{l}\text { EMS: } 67 \% \text { (land vS. } \\
\text { air not specified) } \\
\text { Interhospital transfer: } \\
18 \% \\
\text { Other: } 15 \%\end{array}$ & $\begin{array}{l}\text { Male: } 69 \% \text { (207/299) } \\
\text { Race: NR } \\
\text { Age (median): } 62 \text { (IQR 45-73) }\end{array}$ & $\begin{array}{l}\text { ViEWS-L (VitalPAC Early } \\
\text { Warning Score-Lactate) }\end{array}$ \\
\hline
\end{tabular}




\begin{tabular}{|c|c|c|c|c|}
\hline $\begin{array}{l}\text { Author, Year } \\
\text { (See Appendix B for } \\
\text { complete reference) }\end{array}$ & $\begin{array}{l}\text { Location and Timing of } \\
\text { Measurement }\end{array}$ & Method of Measurement & $\begin{array}{l}\text { Personnel Administering Test or } \\
\text { Using Measure }\end{array}$ & Equipment Used/Needed \\
\hline Horne, 2013 & Out of Hospital: not specified & NR & NR & NR \\
\hline Ichwan, 2015 & $\begin{array}{l}\text { Out of hospital: on arrival } \\
\text { - GCS } \\
\text { ED: on admission } \\
\text { - RR, SBP } \\
\text { - GCS (used if missing out of } \\
\text { hospital value) }\end{array}$ & NR & NR & NR \\
\hline Jo, 2014 & ED: on arrival & Lactate: arterial & ED clinician & $\begin{array}{l}\text { Lactate: Stat Profile Critical Care } \\
\text { Xpress Analyzer (Nova } \\
\text { Biomedical, Waltham, } \\
\text { Massachusetts) }\end{array}$ \\
\hline
\end{tabular}




\begin{tabular}{|c|c|c|c|c|}
\hline \begin{tabular}{|l} 
Author, Year \\
(See Appendix B for \\
complete reference)
\end{tabular} & $\begin{array}{l}\text { Threshold Value(s) for Physiologic } \\
\text { Measures }\end{array}$ & $\begin{array}{l}\text { Indicator of Serious Injury Used } \\
\text { (including definition and time period) }\end{array}$ & Funding Source & Risk of Bias \\
\hline Horne, 2013 & \begin{tabular}{|l|} 
Triage Sieve protocol, military version \\
- GCS $<13$ in lieu of unconscious status
\end{tabular} & $\begin{array}{l}\text { Priority } 1 \text { casualty: Resource based definition; } \\
\text { list of LSI including (but not limited to): } \\
\text { intubation, surgical airway, thoracostomy, } \\
\text { operative intervention for bleeding control, }>4 \\
\text { units blood product transfusion, proximal } \\
\text { amputation, laparotomy, thoracotomy, } \\
\text { pericardial window, or CPR/ACLS activation. }\end{array}$ & $\begin{array}{l}\text { Conflict of interest: authors declare } \\
\text { no conflict of interest. }\end{array}$ & High \\
\hline Ichwan, 2015 & $\begin{array}{l}\text { Triage criteria - differences in Adult vs. Geriatric } \\
\text { - SBP }<90 \text { vs. }<100 \\
\text { - GCS } \leq 13 \text { vs. } \leq 14 \text { if known or suspected } \\
\text { traumatic brain injury } \\
\text { - Other differences in anatomic and cause of } \\
\text { injury criteria. }\end{array}$ & $\begin{array}{l}\text { Need for trauma center care: ISS }>15 \text {, OR visit } \\
\text { within } 48 \text { hours, ICU admission or in-hospital } \\
\text { mortality. }\end{array}$ & $\begin{array}{l}\text { Study funded through a } 2013 \\
\text { Trauma Grant from the Ohio } \\
\text { Department of Public Safety. Author } \\
\text { support: Ohio State University } \\
\text { College of Medicine Roessler } \\
\text { Scholarship (Ichwan), and the } \\
\text { National Institute on Aging } \\
\text { 1K23AG038351-01 (Caterino). }\end{array}$ & Moderate \\
\hline Imhoff, 2014 & NR & Mortality: in-hospital & $\begin{array}{l}\text { No specific grant for this research } \\
\text { from any funding agency in the } \\
\text { public, commercial or non-for-profit } \\
\text { sectors. }\end{array}$ & Moderate \\
\hline Jo, 2014 & NR & Mortality: in-hospital & $\begin{array}{l}\text { Conflict of interest: authors declare } \\
\text { no conflict of interest. }\end{array}$ & Moderate \\
\hline
\end{tabular}




\begin{tabular}{|c|c|c|c|c|}
\hline $\begin{array}{l}\text { Author, Year } \\
\text { (See Appendix B for } \\
\text { complete reference) }\end{array}$ & Study Design & Setting and Dates Performed & Number of Study Subjects & Data Source \\
\hline Jones, 2014 & Retrospective & $\begin{array}{l}\text { Norway, Oslo } \\
\text { Urban } \\
\text { Trauma system level: NR (major trauma } \\
\text { hospital) } \\
\text { Overall } \\
8 / 1 / 2000-7 / 31 / 2008 \\
8 \text { years } \\
\text { Derivation data set: } 8 / 1 / 2000 \text { to } 7 / 31 / 2006 \\
\text { Validation data set: } 8 / 1 / 2006 \text { to } 7 / 31 / 2008\end{array}$ & $\begin{array}{l}\text { 5,363 derivation data set } \\
2,517 \text { validation data set } \\
\text { Derivation data set } \\
5,409 \text { identified } \\
\text { - } 46 \text { excluded for missing information on } \\
\text { variables of interest } \\
\text { Validation data set } \\
2,521 \text { identified } \\
-4 \text { excluded for missing information on model } \\
\text { predictors }\end{array}$ & $\begin{array}{l}\text { Hospital trauma registry. Survival } \\
\text { status obtained from patient } \\
\text { records and the Norwegian } \\
\text { Population Registry. }\end{array}$ \\
\hline Joosse, 2014 & Retrospective & $\begin{array}{l}\text { The Netherlands } \\
\text { Urban and rural } \\
2 \text { Level I trauma centers } \\
\text { Center A (urban) } \\
2004 \text { to } 2010 \\
7 \text { years } \\
\text { Center B (rural) } \\
2006 \text { to } 2011 \\
6 \text { years }\end{array}$ & $\begin{array}{l}, 418 \text { analyzed } \\
-3,001 \text { in Center A } \\
-1,417 \text { in Center B }\end{array}$ & $\begin{array}{l}\text { Trauma registries for two trauma } \\
\text { centers. }\end{array}$ \\
\hline Khasawneh, 2014 & Retrospective & $\begin{array}{l}\text { USA } \\
\text { Rural } \\
\text { Trauma system level: NR } \\
1 / 2011 \text { to } 7 / 2012 \\
1 \text { year, } 7 \text { months }\end{array}$ & $\begin{array}{l}325 \text { analyzed } \\
-23 \text { with } \mathrm{StO} 2<65 \% \\
-302 \text { with } \mathrm{StO} 2 \geq 65 \\
\\
632 \text { identified } \\
307 \text { excluded due to no StO2 value }\end{array}$ & $\begin{array}{l}\text { Prospective collection of internal } \\
\text { data }\end{array}$ \\
\hline
\end{tabular}




\begin{tabular}{|c|c|c|c|}
\hline $\begin{array}{l}\text { Author, Year } \\
\text { (See Appendix B for } \\
\text { complete reference) }\end{array}$ & Eligibility Criteria & $\begin{array}{l}\text { Age Groups Included (Age Range Used*): \% } \\
\text { of Study Population }\end{array}$ & Type of Population \\
\hline Jones, 2014 & $\begin{array}{l}\text { Included: Patients who arrived within } 24 \text { hours after injury, including } \\
\text { local hospital transfers, who had trauma team activation; and } \\
\text { patients with ISS } \geq 10 \text {, head AIS } \geq 3 \text { and /or penetrating injuries } \\
\text { towards the head, neck, torso, and/or proximal to elbow or knee. } \\
\text { Excluded: Patients with isolated single extremity fractures in which } \\
\text { the trauma team was not activated. } \\
\text { Patients classified as dead on ED arrival were not excluded. }\end{array}$ & $\begin{array}{l}\text { Children and Adults } \\
\text { Derivation data set } \\
\text { Age } 0-14: 10 \%(535 / 5,363) \\
\text { Age } 15-64: 77 \%(4,141 / 5,363) \\
\text { Age } 65-84: 11 \%(578 / 5,363) \\
\text { Age } \geq 85: 2 \%(109 / 5,363)\end{array}$ & Civilian \\
\hline Joosse, 2014 & $\begin{array}{l}\text { Included*: Trauma patients admitted to the hospital, those who died } \\
\text { in the ED, and those referred immediately after trauma. } \\
\text { Excluded: Patients <16 years old, those who were declared dead on } \\
\text { arrival, or were discharged home directly from the ED. } \\
\text { ^ Center A: All patients treated at the trauma resuscitation room. } \\
\text { * Center B: Patients triaged as "code red" (judged as potentially } \\
\text { severe trauma patients). }\end{array}$ & Adults ( $\geq 16): 100 \%$ & Civilian \\
\hline Khasawneh, 2014 & Included: Highest tier triage trauma patients with $\mathrm{StO}_{2}$ measures. & Adults ( $\geq 18): 100 \%$ & Civilian \\
\hline
\end{tabular}




\begin{tabular}{|c|c|c|c|c|}
\hline $\begin{array}{l}\text { Author, Year } \\
\text { (See Appendix B for } \\
\text { complete reference) }\end{array}$ & Mechanism or Type Injury & Mode of Transport & $\begin{array}{l}\text { Other Population Characteristics } \\
\text { (Sex, Race) }\end{array}$ & $\begin{array}{l}\text { Name of Measure Being } \\
\text { Evaluated }\end{array}$ \\
\hline \begin{tabular}{|l|} 
Jones, 2014 \\
\end{tabular} & \begin{tabular}{|l} 
Derivation data set \\
Blunt: $90.9 \%$ \\
Penetrating: $9.1 \%$ \\
\\
Validation data set: NR
\end{tabular} & Land and Helicopter & $\begin{array}{l}\text { Derivation dataset } \\
\text { Male: } 71.7 \% \\
\text { Race: NR } \\
\text { Age (median): } 33 \text { (IQR 22-51) } \\
\text { Validation dataset } \\
\text { Male: NR } \\
\text { Race: NR } \\
\text { Age (median): } 34 \text { (IQR 21-51) }\end{array}$ & \begin{tabular}{|l} 
Intubation status \\
RR \\
SBP \\
T-RTS
\end{tabular} \\
\hline \begin{tabular}{|l} 
Joosse, 2014 \\
\end{tabular} & $\begin{array}{l}\text { Blunt: 92\% } \\
\text { Penetrating: NR }\end{array}$ & NR & $\begin{array}{l}\text { Male: } 72 \% \\
\text { Race: NR } \\
\text { Age (mean): } 43 \text { (SD 19) }\end{array}$ & $\begin{array}{l}\text { Emergency Trauma Score } \\
\text { (EMTRAS): uses age, GCS, base } \\
\text { excess, and prothrombin time }\end{array}$ \\
\hline Khasawneh, 2014 & Blunt: $87 \%$ & NR & $\begin{array}{l}\text { Male: } 74 \% \\
\text { Race: NR } \\
\text { Age (mean): } 46 \text { (SD NR) }\end{array}$ & $\mathrm{StO}_{2}$ \\
\hline
\end{tabular}




\begin{tabular}{|c|c|c|c|c|}
\hline \begin{tabular}{|l} 
Author, Year \\
(See Appendix B for \\
complete reference) \\
\end{tabular} & $\begin{array}{l}\text { Location and Timing of } \\
\text { Measurement }\end{array}$ & Method of Measurement & $\begin{array}{l}\text { Personnel Administering Test or } \\
\text { Using Measure }\end{array}$ & Equipment Used/Needed \\
\hline Jones, 2014 & $\begin{array}{l}\text { ED: not specified } \\
\text { GCS and RR for patients } \\
\text { intubated and in general } \\
\text { anesthesia on ED arrival: Out of } \\
\text { hospital, immediately before } \\
\text { intubation }\end{array}$ & NR & Hospital staff and trauma registrars & NR \\
\hline Joosse, 2014 & ED: on arrival & $\begin{array}{l}\text { Base excess: arterial blood gas } \\
\text { GCS: most recent value before } \\
\text { intubation, if indicated }\end{array}$ & NR & NR \\
\hline Khasawneh, 2014 & ED: on arrival & \begin{tabular}{|l|}
$\mathrm{StO}_{2}$ oxygenation monitor, \\
measured from patient's thenar \\
eminence
\end{tabular} & NR & \begin{tabular}{|l} 
InSpectra $\mathrm{StO}_{2}$ oxygenation \\
monitor (Hutchinson Technology \\
Inc., Hutchinson, Minnesota)
\end{tabular} \\
\hline
\end{tabular}




\begin{tabular}{|c|c|c|c|c|}
\hline \begin{tabular}{|l|} 
Author, Year \\
(See Appendix B for \\
complete reference) \\
\end{tabular} & $\begin{array}{l}\text { Threshold Value(s) for Physiologic } \\
\text { Measures }\end{array}$ & $\begin{array}{l}\text { Indicator of Serious Injury Used } \\
\text { (including definition and time period) }\end{array}$ & Funding Source & Risk of Bias \\
\hline Jones, 2014 & $\begin{array}{l}\text { RR: }<10 \text { or }>29 \\
\text { SBP: }<90 \\
\text { T-RTS: }<8,<12\end{array}$ & Mortality: 30 days after injury & $\begin{array}{l}\text { Co-author (N. O. Skaga) received } \\
\text { financial support from The } \\
\text { Norwegian Air Ambulance } \\
\text { Foundation and the South-Eastern } \\
\text { Norway Regional Health Authority. }\end{array}$ & Moderate \\
\hline Joosse, 2014 & NR & Mortality: in-hospital & $\begin{array}{l}\text { Conflict of interest: authors declare } \\
\text { no conflict of interest. }\end{array}$ & Low \\
\hline Khasawneh, 2014 & $\mathrm{StO}_{2}:<65$ & $\begin{array}{l}\text { Transfusion: any blood product with } 24 \text { hours } \\
\text { after injury } \\
\text { Massive transfusion } \\
\text { Mortality } \\
\text { Surgical intervention }\end{array}$ & $\begin{array}{l}\text { No external funding. No support of } \\
\text { any kind was received from } \\
\text { Hutchinson Technology, the } \\
\text { manufacturer of the oxygenation } \\
\text { monitor. }\end{array}$ & Moderate \\
\hline
\end{tabular}




\begin{tabular}{|c|c|c|c|c|}
\hline $\begin{array}{l}\text { Author, Year } \\
\text { (See Appendix B for } \\
\text { complete reference) }\end{array}$ & Study Design & Setting and Dates Performed & Number of Study Subjects & Data Source \\
\hline Kim, 2016 & Retrospective & $\begin{array}{l}\text { South Korea } \\
\text { Urban vs. rural: Nationwide } \\
\text { Trauma system level: NR (20 tertiary } \\
\text { academic hospitals) } \\
1 / 2008 \text { to } 12 / 2013 \\
6 \text { years }\end{array}$ & $\begin{array}{l}45,880 \text { analyzed } \\
1,179,157 \text { total injured patients } \\
1,067,726 \text { excluded for age }<65 \text { or unknown } \\
591 \text { excluded for death on arrival } \\
8,297 \text { excluded for traumatic brain injury } \\
14,819 \text { excluded for non-traumatic injury } \\
8,048 \text { excluded for missing vital signs } \\
33,796 \text { excluded for time to ER }>6 \text { hours or } \\
\text { unknown }\end{array}$ & $\begin{array}{l}\text { Emergency Department-based } \\
\text { Injury In-depth Surveillance } \\
\text { (EDIIS) database of Korea }\end{array}$ \\
\hline King, 1996 & Retrospective & $\begin{array}{l}\text { USA, Ohio } \\
\text { Urban } \\
\text { Level I trauma center } \\
8 / 1 / 1992 \text { to } 7 / 31 / 1994 \\
2 \text { years }\end{array}$ & $\begin{array}{l}1,101 \text { analyzed } \\
1,738 \text { identified } \\
289 \text { excluded for GCS } \leq 8 \\
107 \text { excluded for minor injury } \\
158 \text { excluded for age } \leq 14 \\
83 \text { excluded for incomplete documentation }\end{array}$ & $\begin{array}{l}\text { Trauma registry for a single } \\
\text { trauma center. }\end{array}$ \\
\hline King, 2009 & Retrospective & $\begin{array}{l}\text { USA, Florida } \\
\text { Urban } \\
\text { Level I trauma center } \\
12 / 2007 \text { to } 11 / 2008 \\
1 \text { year }\end{array}$ & $\begin{array}{l}75 \text { analyzed } \\
95 \text { enrolled } \\
12 \text { excluded for short recording time (<200 } \\
\text { QRS complexes) } \\
2 \text { excluded for technical problem with the } \\
\text { recording (missing leads, extreme artifact, or } \\
\text { a recording unable to be interpreted } \\
\text { meaningfully due to noise } \\
6 \text { excluded for incomplete data from medical } \\
\text { record or trauma registry }\end{array}$ & $\begin{array}{l}\text { Primary data collection } \\
\text { (prospective collection during } \\
\text { helicopter transport) and medical } \\
\text { records. }\end{array}$ \\
\hline
\end{tabular}




\begin{tabular}{|c|c|c|c|}
\hline $\begin{array}{l}\text { Author, Year } \\
\text { (See Appendix B for } \\
\text { complete reference) }\end{array}$ & Eligibility Criteria & $\begin{array}{l}\text { Age Groups Included (Age Range Used*): \% } \\
\text { of Study Population }\end{array}$ & Type of Population \\
\hline Kim, 2016 & $\begin{array}{l}\text { Included: Injured patients age } \geq 65 \text { years. } \\
\text { Excluded: Patients who were dead on arrival to ED, who had } \\
\text { isolated traumatic brain injury, those who had non-traumatic injuries } \\
\text { (such as burn, drowning, or drug intoxication), lacked data on vital } \\
\text { signs, those with injury occurring }<6 \text { hours prior to ED arrival or with } \\
\text { unknown time parameter. }\end{array}$ & Elderly ( $\geq 65): 100 \%$ & Civilian \\
\hline King, 1996 & $\begin{array}{l}\text { Included: Patients who required evaluation by the trauma service for } \\
\text { trauma alert or trauma consult as indicated based on internal triage } \\
\text { criteria. } \\
\text { Excluded: Patients } \leq 14 \text { years old, those with minor trauma not } \\
\text { requiring consultation or admission (i.e. single system injuries such } \\
\text { as extremity sprains or contusions, with stable vital signs), who had } \\
\text { severe head injury (GCS score } \leq 8 \text { ), and those with incomplete } \\
\text { records or documentation. }\end{array}$ & Adults ( $\geq 15): 100 \%$ & Civilian \\
\hline King, 2009 & $\begin{array}{l}\text { Included: Patients with trauma requiring out of hospital helicopter } \\
\text { transport to the level I trauma center. } \\
\\
\text { Excluded: Patients who had measurement artifact or technical } \\
\text { problems with ECG recordings. }\end{array}$ & NR & Civilian \\
\hline
\end{tabular}




\begin{tabular}{|c|c|c|c|c|}
\hline $\begin{array}{l}\text { Author, Year } \\
\text { (See Appendix B for } \\
\text { complete reference) } \\
\end{array}$ & Mechanism or Type Injury & Mode of Transport & $\begin{array}{l}\text { Other Population Characteristics } \\
\text { (Sex, Race) }\end{array}$ & $\begin{array}{l}\text { Name of Measure Being } \\
\text { Evaluated }\end{array}$ \\
\hline Kim, 2016 & $\begin{array}{l}\text { Mechanism of injury } \\
\text { Traffic accident: } 25.5 \%(11,709 / 45,880) \\
\text { Falling: } 54.6 \%(25,038 / 45,880) \\
\text { Blunt force: } 11.5 \%(5,286 / 45,880) \\
\text { Penetrating: } 7.6 \%(3,503 / 45,880) \\
\text { Other: } 0.7 \%(344 / 45,880)\end{array}$ & $\begin{array}{l}\text { EMS from field: } 40 \% \\
\text { (18.285/45,880) } \\
\text { EMS interhospital: } 5 \% \\
(2,468 / 45,880) \\
\text { Ambulatory: 48\% } \\
(21,899 / 45,880) \\
\text { Unknown: } 7 \% \\
(3,228 / 45,880)\end{array}$ & $\begin{array}{l}\text { Male: } 46 \%(21,223 / 45,880) \\
\text { Race: NR } \\
\text { Age (median): } 72 \text { (IQR: 68-78) }\end{array}$ & $\begin{array}{l}\text { Age shock index (Age SI): Age x } \\
\text { SI } \\
\text { Modified shock index (MSI): } \\
\text { HR/MAP } \\
\text { SI }\end{array}$ \\
\hline King, 1996 & \begin{tabular}{|l} 
Blunt: $84 \%(925 / 1,101)$ \\
Penetrating: $16 \%(176 / 1,101)$
\end{tabular} & $\begin{array}{l}\text { Ambulance or } \\
\text { helicopter }\end{array}$ & $\begin{array}{l}\text { Male: } 71 \% \\
\text { Race: NR } \\
\text { Age (mean): } 37 \text { (SD 18) }\end{array}$ & \begin{tabular}{|l}
$\mathrm{HR}$ \\
$\mathrm{SBP}$ \\
$\mathrm{SI}$
\end{tabular} \\
\hline King, 2009 & NR & Helicopter & $\begin{array}{l}\text { Male: } 63 \%(47 / 75) \\
\text { Race: NR } \\
\text { Age (mean): } 47 \text { (SD 20) }\end{array}$ & $\begin{array}{l}\text { Heart rate variability } \\
\text { HR } \\
\text { SBP }\end{array}$ \\
\hline
\end{tabular}




\begin{tabular}{|c|c|c|c|c|}
\hline $\begin{array}{l}\text { Author, Year } \\
\text { (See Appendix B for } \\
\text { complete reference) }\end{array}$ & $\begin{array}{l}\text { Location and Timing of } \\
\text { Measurement }\end{array}$ & Method of Measurement & $\begin{array}{l}\text { Personnel Administering Test or } \\
\text { Using Measure }\end{array}$ & Equipment Used/Needed \\
\hline Kim, 2016 & ED: on arrival & NR & NR & NR \\
\hline King, 1996 & ED: on arrival & NR & NR & NR \\
\hline King, 2009 & $\begin{array}{l}\text { Out of Hospital: during } \\
\text { Resuscitation }\end{array}$ & $\begin{array}{l}\text { ECG: digital Holter monitor } \\
\text { Heart rate variability: standard } \\
\text { deviation of the normal-to- } \\
\text { normal R-R interval (SDNN) } \\
\text { HR: NR } \\
\text { SBP: NR }\end{array}$ & NR & $\begin{array}{l}\text { ECG recording: 2-Channel } \\
\text { SEER Light recorder (GE } \\
\text { Healthcare, Milwaukee, } \\
\text { Wisconsin) } \\
\text { ECG analysis: Mars Holter } \\
\text { monitor system (GE Healthcare) } \\
\text { and proprietary software }\end{array}$ \\
\hline
\end{tabular}




\begin{tabular}{|c|c|c|c|c|}
\hline $\begin{array}{l}\text { Author, Year } \\
\text { (See Appendix B for } \\
\text { complete reference) }\end{array}$ & $\begin{array}{l}\text { Threshold Value(s) for Physiologic } \\
\text { Measures }\end{array}$ & $\begin{array}{l}\text { Indicator of Serious Injury Used } \\
\text { (including definition and time period) }\end{array}$ & Funding Source & Risk of Bias \\
\hline Kim, 2016 & $\begin{array}{l}\text { Hemodynamic instability: } \\
\text { Age SI } \geq 50 \\
\text { Modified } S \mathrm{SI} \geq 1.3 \\
\mathrm{SI} \geq 1\end{array}$ & $\begin{array}{l}\text { Mortality: in-hospital } \\
\text { Mortality: ED }\end{array}$ & NR & High \\
\hline King, 1996 & $\begin{array}{l}\text { Thresholds chosen as value that maximizes } \\
\text { sensitivity and specificity. }\end{array}$ & $\begin{array}{l}\text { Early mortality: } 24 \text {-hour } \\
\text { ISS } \geq 16 \\
\text { ICU admission: ICU stay } \geq 1 \text { day } \\
\text { Blood transfusion } \geq 2 \text { units }\end{array}$ & NR & Moderate \\
\hline King, 2009 & $\begin{array}{l}\text { Heart rate variability } \\
\text { SDNN cutoffs: } 24 \mathrm{msec}, 39 \mathrm{msec}, 55 \mathrm{msec} \\
-24 \text { msec chosen to attain } \geq 80 \% \text { sensitivity }\end{array}$ & $\begin{array}{l}\text { Serious injury: Two out of three trauma } \\
\text { surgeons classified patient as seriously injured } \\
\text { through blinded review of patient charts and } \\
\text { final diagnoses. Any death was considered } \\
\text { serious injury. } \\
\text { Life-saving intervention in OR: Two out of } \\
\text { three trauma surgeons classified surgery as } \\
\text { "life-saving" through blinded review. }\end{array}$ & $\begin{array}{l}\text { Partially supported by the Office of } \\
\text { Naval Research grant N140610670. }\end{array}$ & Moderate \\
\hline
\end{tabular}




\begin{tabular}{|c|c|c|c|c|}
\hline $\begin{array}{l}\text { Author, Year } \\
\text { (See Appendix B for } \\
\text { complete reference) }\end{array}$ & Study Design & Setting and Dates Performed & Number of Study Subjects & Data Source \\
\hline Kondo, 2011 & Prospective & $\begin{array}{l}\text { Japan } \\
\text { Urban vs. rural: NR (national) } \\
\text { Level I trauma center equivalent (114 } \\
\text { hospitals) } \\
2004 \text { to } 2009 \\
6 \text { years }\end{array}$ & $\begin{array}{l}13,691 \text { analyzed for validation } \\
42,336 \text { in database } \\
3,217 \text { excluded for age }<16 \\
280 \text { excluded for cardiac arrest } \\
1,519 \text { excluded for burn injury } \\
185 \text { excluded for other cause of trauma } \\
1,403 \text { excluded for unknown cause of trauma } \\
8,578 \text { excluded for incomplete important data } \\
13,463 \text { used for score derivation }\end{array}$ & $\begin{array}{l}\text { Japan Trauma Data Bank } \\
\text { (JTDB) }\end{array}$ \\
\hline Kuo, 2016 & Retrospective & $\begin{array}{l}\text { Taiwan } \\
\text { Urban } \\
\text { Level I trauma center } \\
1 / 1 / 2009 \text { to } 12 / 31 / 2014 \\
6 \text { years } \\
\text { *Study population may include patients in } \\
\text { Lai, } 2016\end{array}$ & $\begin{array}{l}17,992 \text { analyzed for reverse shock index } \\
20,106 \text { in study } \\
2,114 \text { with trauma team activation, reverse } \\
\text { shock index value not provided }\end{array}$ & $\begin{array}{l}\text { Trauma registry for a single } \\
\text { trauma center. }\end{array}$ \\
\hline Lai, 2016 & Retrospective & $\begin{array}{l}\text { Taiwan } \\
\text { Urban vs. rural: NR } \\
\text { Level I regional trauma center } \\
1 / 1 / 2009 \text { to } 12 / 31 / 2013 \\
5 \text { years } \\
\text { *Study population may overlap with Kuo, } \\
2016\end{array}$ & $\begin{array}{l}3,715 \text { analyzed } \\
16,548 \text { in registry } \\
3,909 / 16,548 \text { excluded for transfer from } \\
\text { another hospital } \\
8,924 / 16,548 \text { excluded for arrival by private } \\
\text { vehicle }\end{array}$ & $\begin{array}{l}\text { Trauma registry from one Level I } \\
\text { regional trauma center }\end{array}$ \\
\hline Lalezarzadeh, 2009 & Retrospective & $\begin{array}{l}\text { USA, California } \\
\text { Urban } \\
\text { Level II trauma center } \\
1 / 1 / 2003 \text { to } 12 / 31 / 2007 \\
5 \text { years }\end{array}$ & $\begin{array}{l}\text { 6,964 analyzed } \\
9,179 \text { identified } \\
1,881 \text { excluded for inadequate } \\
\text { documentation } \\
7,298 \text { eligible } \\
167 \text { excluded for dead on arrival } \\
77 \text { excluded for transfer to another facility for } \\
\text { higher level of care } \\
90 \text { excluded for insufficient ED data }\end{array}$ & $\begin{array}{l}\text { Trauma registry for a single } \\
\text { trauma center. }\end{array}$ \\
\hline
\end{tabular}




\begin{tabular}{|c|c|c|c|}
\hline $\begin{array}{l}\text { Author, Year } \\
\text { (See Appendix B for } \\
\text { complete reference) }\end{array}$ & Eligibility Criteria & $\begin{array}{l}\text { Age Groups Included (Age Range Used*): \% } \\
\text { of Study Population }\end{array}$ & Type of Population \\
\hline Kondo, 2011 & $\begin{array}{l}\text { Included: Patients with ISS }>3 \text {. } \\
\text { Excluded: Patients }<16 \text { years old, those who died at trauma scene, } \\
\text { had other trauma mechanism such as burn, or with incomplete } \\
\text { important data (age, GCS, SBP, RR, or ISS). } \\
\text { Severe trauma subgroup: ISS }>16\end{array}$ & Adults ( $\geq 16): 100 \%$ & Civilian \\
\hline Kuo, 2016 & $\begin{array}{l}\text { Included: Patients for whom there was not a trauma team activation. } \\
\text { Excluded: Patients who died before hospital arrival or were } \\
\text { discharged against advice from the ED. }\end{array}$ & 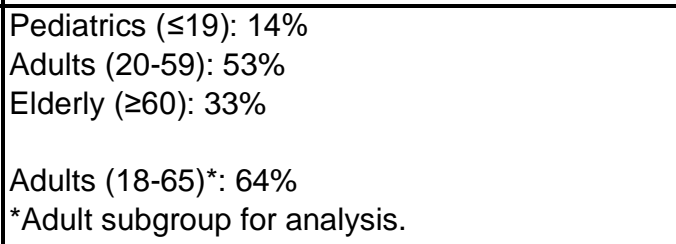 & Civilian \\
\hline Lai, 2016 & $\begin{array}{l}\text { Included: Patients in the trauma registry who were transferred by } \\
\text { EMS and hospitalized. } \\
\text { Excluded: Patients transferred from other hospitals, deceased on } \\
\text { arrival to ED, who arrived by private vehicle, were discharged from } \\
\text { the ED, or who had incomplete data. }\end{array}$ & NR & Civilian \\
\hline Lalezarzadeh, 2009 & $\begin{array}{l}\text { Included: Patients with adequate out of hospital data available. } \\
\text { Excluded: Patients who were dead on arrival, transferred to another } \\
\text { facility for a higher level of care, or who had incomplete data in the } \\
\text { ED. }\end{array}$ & NR & Civilian \\
\hline
\end{tabular}




\begin{tabular}{|c|c|c|c|c|}
\hline $\begin{array}{l}\text { Author, Year } \\
\text { (See Appendix B for } \\
\text { complete reference) } \\
\end{array}$ & Mechanism or Type Injury & Mode of Transport & $\begin{array}{l}\text { Other Population Characteristics } \\
\text { (Sex, Race) }\end{array}$ & $\begin{array}{l}\text { Name of Measure Being } \\
\text { Evaluated }\end{array}$ \\
\hline Kondo, 2011 & $\begin{array}{l}\text { Blunt: } 94.5 \%(12,939 / 13,691) \\
\text { Penetrating: 5.5\% }(752 / 13,691)\end{array}$ & $\begin{array}{l}\text { Ambulance: } 87.2 \% \\
\text { (11,511/13,691) } \\
\text { Helicopter: 6.4\% } \\
(841 / 13,691) \\
\text { Doctor's car: } 3.2 \% \\
\text { (422/13,691) } \\
\text { Own car: } 1.9 \% \\
(250 / 13,691) \\
\text { On foot: } 0.5 \% \\
(62 / 13,691) \\
\text { Other: } 0.8 \% \\
(109 / 13,691)\end{array}$ & $\begin{array}{l}\text { Male: 69\% (9.494/13,691) } \\
\text { Race: NR } \\
\text { Age (mean): } 51 \text { (SD 22) }\end{array}$ & $\begin{array}{l}\text { GAP score (GCS, Age, SBP) } \\
\text { MGAP score (Mechanism, GCS, } \\
\text { Age, SBP) } \\
\text { RTS } \\
\text { SBP } \\
\text { T-RTS }\end{array}$ \\
\hline Kuo, 2016 & $\begin{array}{l}\text { Blunt vs. Penetrating: NR } \\
\text { Mechanism of injury } \\
\text { Motor vehicle: } 2 \% \\
\text { Motorcycle: } 41 \% \\
\text { Bicycle: } 4 \% \\
\text { Pedestrian: } 2 \% \\
\text { Fall: } 31 \% \\
\text { Unspecified: } 20 \%\end{array}$ & NR & $\begin{array}{l}\text { Male: } 57 \% \\
\text { Race: NR } \\
\text { Age (mean): } 47 \text { (SD 22) }\end{array}$ & Reverse shock index (SBP/HR) \\
\hline Lai, 2016 & NR & NR & $\begin{array}{l}\text { Male: } 59 \%(2,177 / 3,715) \\
\text { Race: NR } \\
\text { Age (mean): } 42 \text { (SD 14) }\end{array}$ & Reverse shock index \\
\hline Lalezarzadeh, 2009 & $\begin{array}{l}\text { Blunt: } 84 \%(5,830 / 6,964) \\
\text { Penetrating: } 16 \%(1,134 / 6,964)\end{array}$ & NR & $\begin{array}{l}\text { Male: 75\% } \\
\text { Race: NR } \\
\text { Age (mean): } 35 \text { (SD NR) }\end{array}$ & SBP \\
\hline
\end{tabular}




\begin{tabular}{|c|c|c|c|c|}
\hline \begin{tabular}{|l|} 
Author, Year \\
(See Appendix B for \\
complete reference)
\end{tabular} & $\begin{array}{l}\text { Location and Timing of } \\
\text { Measurement }\end{array}$ & Method of Measurement & $\begin{array}{l}\text { Personnel Administering Test or } \\
\text { Using Measure }\end{array}$ & Equipment Used/Needed \\
\hline Kondo, 2011 & ED: on arrival & NR & NR & NR \\
\hline Kuo, 2016 & ED: on arrival & NR & NR & NR \\
\hline Lai, 2016 & $\begin{array}{l}\text { Out of Hospital: on EMS arrival } \\
\text { ED: on arrival }\end{array}$ & NR & NR & NR \\
\hline Lalezarzadeh, 2009 & $\begin{array}{l}\text { Out of Hospital: on EMS arrival } \\
\text { ED: on arrival }\end{array}$ & NR & NR & NR \\
\hline
\end{tabular}

D-109 


\begin{tabular}{|c|c|c|c|c|}
\hline $\begin{array}{l}\text { Author, Year } \\
\text { (See Appendix B for } \\
\text { complete reference) } \\
\end{array}$ & $\begin{array}{l}\text { Threshold Value(s) for Physiologic } \\
\text { Measures }\end{array}$ & $\begin{array}{l}\text { Indicator of Serious Injury Used } \\
\text { (including definition and time period) }\end{array}$ & Funding Source & Risk of Bias \\
\hline Kondo, 2011 & $\begin{array}{l}\text { SBP: }<60,60-120,>120 \\
\text { Age: }<60 \text { or } \geq 60 \\
\text { Thresholds equal to those in the MGAP scoring } \\
\text { system, which were predetermined based on } \\
\text { clinical knowledge. }\end{array}$ & $\begin{array}{l}\text { Mortality } \\
\text { - Short-term: death in the ED or OR } \\
\text { - Long-term: death at discharge }\end{array}$ & $\mathrm{NR}$ & Moderate \\
\hline Kuo, 2016 & Reverse $\mathrm{SI}<1$ : SBP lower than the HR & $\begin{array}{l}\text { Blood transfusion in ED } \\
\text { ISS } \geq 16 \\
\text { Mortality: in-hospital }\end{array}$ & $\begin{array}{l}\text { Supported by a grant from Chang } \\
\text { Gung Memorial Hospital } \\
\text { (CDRPG8C0032 and } \\
\text { CDRPG8C0033). }\end{array}$ & Moderate \\
\hline Lai, 2016 & Reverse $\mathrm{SI}<1$ : shock & $\begin{array}{l}\text { Mortality: in-hospital } \\
\text { Blood transfusion } \\
\text { ISS } \geq 16\end{array}$ & $\begin{array}{l}\text { Supported by a grant from Chang } \\
\text { Gung Memorial Hospital } \\
\text { (CDRPG8C0031) }\end{array}$ & Moderate \\
\hline Lalezarzadeh, 2009 & $\begin{array}{l}\text { Predefined cutoffs, based on iterative review } \\
\text { SBP, out of hospital } \\
\text { S80: severe hypotension } \\
\text { 81-100: moderate hypotension } \\
\text { 101-120: mild hypotension } \\
\text { >120: normotension } \\
\text { SBP, ED } \\
\text { S90: hypotension }\end{array}$ & $\begin{array}{l}\text { Operative intervention: ED disposition to OR } \\
\text { ICU admission: ED disposition to ICU } \\
\text { Mortality: in-hospital }\end{array}$ & $\mathrm{NR}$ & High \\
\hline
\end{tabular}




\begin{tabular}{|c|c|c|c|c|}
\hline $\begin{array}{l}\text { Author, Year } \\
\text { (See Appendix B for } \\
\text { complete reference) }\end{array}$ & Study Design & Setting and Dates Performed & Number of Study Subjects & Data Source \\
\hline Lee, 2014 & Retrospective & $\begin{array}{l}\text { Singapore } \\
\text { Urban } \\
\text { Trauma level: NR } \\
1 / 2011 \text { to } 12 / 2012 \\
2 \text { years }\end{array}$ & $\begin{array}{l}92 \text { analyzed } \\
51,001 \text { trauma-related ED consultations } \\
4,746 \text { admissions }\end{array}$ & $\begin{array}{l}\text { Trauma registry for a single } \\
\text { hospital. }\end{array}$ \\
\hline Lehmann, 2007 & Retrospective & $\begin{array}{l}\text { USA, Washington } \\
\text { Setting: Military base } \\
\text { Level II trauma center } \\
1 / 2002 \text { to } 12 / 2005 \\
4 \text { years }\end{array}$ & $\begin{array}{l}1,495 \text { analyzed } \\
1,782 \text { in registry }\end{array}$ & $\begin{array}{l}\text { Trauma registry for a single } \\
\text { trauma center. }\end{array}$ \\
\hline Lerner, 2017 & Prospective & $\begin{array}{l}\text { USA, New York, Texas and Wisconsin } \\
\text { Urban } \\
\text { Trauma system level: NR (pediatric trauma } \\
\text { centers) } \\
6 / 2009 \text { to } 8 / 2012 \\
3 \text { years, } 3 \text { months }\end{array}$ & $\begin{array}{l}\text { 5,594 analyzed } \\
\text { 8,307 ED patients } \\
2,697 \text { missed enrollment } \\
16 \text { excluded for incomplete outcome data }\end{array}$ & Primary data collection \\
\hline
\end{tabular}




\begin{tabular}{|c|c|c|c|}
\hline \begin{tabular}{|l|} 
Author, Year \\
(See Appendix B for \\
complete reference) \\
\end{tabular} & Eligibility Criteria & $\begin{array}{l}\text { Age Groups Included (Age Range Used*): \% } \\
\text { of Study Population }\end{array}$ & Type of Population \\
\hline Lee, 2014 & $\begin{array}{l}\text { Included: Patients with ISS } \geq 9 \text { who were admitted. } \\
\text { Excluded: Patients with submersion injury and those transferred } \\
\text { from other hospitals. }\end{array}$ & $\begin{array}{l}\text { Pediatrics }(\leq 16): 100 \% \\
<5 \text { years: } 52 \%(48 / 92) \\
\text { 5-9 years: } 23 \%(21 / 92) \\
\text { 10-14 years: } 18 \%(17 / 92) \\
\geq 15 \text { years: } 2.2 \%(2 / 92)\end{array}$ & Civilian \\
\hline Lehmann, 2007 & $\begin{array}{l}\text { Included: Adult ( }>16 \text { years) trauma patients. } \\
\text { Excluded: Patients with burn as the primary mechanism of injury, } \\
\text { and those transferred from ED to another facility. }\end{array}$ & Adults (>16): $100 \%$ & Military and Civilian \\
\hline Lerner, 2017 & $\begin{array}{l}\text { Included: Patients } \leq 15 \text { years old who were transported to the ED by } \\
\text { EMS with traumatic mechanism of injury. } \\
\text { Excluded: Patients transported by means other than ground or air } \\
\text { ambulance, or if EMS provider had not seen the scene of injury } \\
\text { (e.g., interfacility transfers or transport by multiple agencies in } \\
\text { serial). }\end{array}$ & Pediatrics ( $\leq 15):$ 100\% & Civilian \\
\hline
\end{tabular}




\begin{tabular}{|c|c|c|c|c|}
\hline $\begin{array}{l}\text { Author, Year } \\
\text { (See Appendix B for } \\
\text { complete reference) }\end{array}$ & Mechanism or Type Injury & Mode of Transport & $\begin{array}{l}\text { Other Population Characteristics } \\
\text { (Sex, Race) }\end{array}$ & $\begin{array}{l}\text { Name of Measure Being } \\
\text { Evaluated }\end{array}$ \\
\hline Lee, 2014 & $\begin{array}{l}\text { Falls: } 68 \% \text { (63/92) } \\
\text { Road traffic accident: 19\% (17/92) } \\
\text { Burn: } 13 \% \text { (12/92) }\end{array}$ & NR & $\begin{array}{l}\text { Male: } 63 \%(58 / 92) \\
\text { Race: NR } \\
\text { Age (median): } 4.75 \text { (range } 2 \text { months to } \\
15 \text { years) }\end{array}$ & $\begin{array}{l}\text { PTS (Pediatric Trauma Score) } \\
\text { RR }\end{array}$ \\
\hline Lehmann, 2007 & $\begin{array}{l}\text { Blunt: } 88 \%(1,315 / 1,495) \\
\text { Penetrating: } 12 \%(179 / 1,495)\end{array}$ & $\mathrm{NR}$ & $\begin{array}{l}\text { Male: } 70 \%(1,045 / 1,495) \\
\text { Race: NR } \\
\text { Age (mean): } 41 \text { (SD 22) }\end{array}$ & $\begin{array}{l}\mathrm{HR} \\
\mathrm{SBP}\end{array}$ \\
\hline Lerner, 2017 & $\begin{array}{l}\text { Mechanism of injury } \\
\text { Assault, gun shot, and stabbing: } 3.9 \% \\
\text { (216/5,594) } \\
\text { Bicyclist struck: } 2.3 \%(128 / 5,594) \\
\text { Burn: } 1.9 \%(104 / 5,594) \\
\text { Fall: } 34.2 \%(1,915 / 5,594) \\
\text { Motor vehicle crash: } 21.6 \%(1,206 / 5,594) \\
\text { Motorcycle crash: } 0.4 \%(21 / 5,594) \\
\text { Pedestrian struck: } 6.6 \%(368 / 5,594) \\
\text { Sports injury: } 7.7 \%(429 / 5,594) \\
\text { Other: } 21.6 \%(1,207 / 5,594)\end{array}$ & $\begin{array}{l}\text { EMS ground or air } \\
\text { ambulance }\end{array}$ & $\begin{array}{l}\text { Male: } 60 \%(3,365 / 5,594) \\
\text { Race: NR } \\
\text { Age (mean): } 8 \text { (SD 5) }\end{array}$ & \begin{tabular}{|l} 
RR \\
SBP \\
Physiologic criteria of the Field \\
Triage Guidelines (GCS, RR, \\
SBP)
\end{tabular} \\
\hline
\end{tabular}




\begin{tabular}{|c|c|c|c|c|}
\hline \begin{tabular}{|l|} 
Author, Year \\
(See Appendix B for \\
complete reference) \\
\end{tabular} & $\begin{array}{l}\text { Location and Timing of } \\
\text { Measurement }\end{array}$ & Method of Measurement & $\begin{array}{l}\text { Personnel Administering Test or } \\
\text { Using Measure }\end{array}$ & Equipment Used/Needed \\
\hline Lee, 2014 & ED: not specified & NR & NR & $\mathrm{NR}$ \\
\hline Lehmann, 2007 & $\begin{array}{l}\text { Out of Hospital: NR } \\
\text { ED: NR }\end{array}$ & NR & NR & NR \\
\hline Lerner, 2017 & $\begin{array}{l}\text { Out of hospital: on arrival } \\
\text { ED: on arrival }\end{array}$ & NR & NR & NR \\
\hline
\end{tabular}




\begin{tabular}{|c|c|c|c|c|}
\hline $\begin{array}{l}\text { Author, Year } \\
\text { (See Appendix B for } \\
\text { complete reference) } \\
\end{array}$ & $\begin{array}{l}\text { Threshold Value(s) for Physiologic } \\
\text { Measures }\end{array}$ & $\begin{array}{l}\text { Indicator of Serious Injury Used } \\
\text { (including definition and time period) }\end{array}$ & Funding Source & Risk of Bias \\
\hline Lee, 2014 & $\begin{array}{l}\text { PTS } \geq 8 \\
\text { RR above or below normal range } \\
\text { Predetermined: NR }\end{array}$ & $\begin{array}{l}\text { Major trauma: ISS } \geq 16 \text {, admission to the ICU, } \\
\text { life- or limb-saving procedures, or mortality. } \\
\text { Calculation of ISS retrospectively performed } \\
\text { by an Association for the Advancement of } \\
\text { Automotive Medicine accredited database } \\
\text { coordinator. } \\
\text { Receipt of resuscitation in ED: endotracheal } \\
\text { intubation, tube thoracotomy, intravenous fluid } \\
\text { infusion } \geq 20 \mathrm{~mL} / \mathrm{kg} \text { body weight within the first } \\
30 \text { minutes, or unmatched emergency blood } \\
\text { transfusion. }\end{array}$ & NR & Low \\
\hline Lehmann, 2007 & $\begin{array}{l}\text { HR } \\
\text { <60 bpm: bradycardia } \\
>110 \text { bpm: tachycardia } \\
\text { SBP } \\
\text { EMS SBP <100 mmHg: hypotension } \\
\text { ED SBP }<90 \mathrm{mmHg} \text { : hypotension }\end{array}$ & $\begin{array}{l}\text { Emergent intervention: Urgent surgical } \\
\text { procedure in the OR (laparotomy, } \\
\text { thoracotomy, craniotomy, or neck exploration), } \\
\text { or required any of these procedures in the ED: } \\
\text { intubation or surgical airway, tube or needle } \\
\text { thoracostomy, thoracotomy, } \\
\text { pericardiocentesis, central venous catheter } \\
\text { placement, blood transfusion, or } \\
\text { cardiopulmonary resuscitation. }\end{array}$ & NR & Moderate \\
\hline Lerner, 2017 & $\begin{array}{l}\mathrm{SBP}<90 \\
\mathrm{RR}<10 \text { or }>29\end{array}$ & $\begin{array}{l}\text { Trauma center need: ICU admission, death, or } \\
\text { non-orthopedic surgery within } 24 \text { hours of } \\
\text { hospital arrival. }\end{array}$ & $\begin{array}{l}\text { Supported by grant R01CE001835 } \\
\text { from the Centers for Disease } \\
\text { Control and Prevention (CDC). }\end{array}$ & Low \\
\hline
\end{tabular}




\begin{tabular}{|c|c|c|c|c|}
\hline $\begin{array}{l}\text { Author, Year } \\
\text { (See Appendix B for } \\
\text { complete reference) }\end{array}$ & Study Design & Setting and Dates Performed & Number of Study Subjects & Data Source \\
\hline Lin, 2011 & Prospective & $\begin{array}{l}\text { USA, Florida } \\
\text { Urban } \\
\text { Level I trauma center } \\
\\
7 / 1 / 2007 \text { to } 9 / 30 / 2007 \\
3 \text { months }\end{array}$ & 601 analyzed & $\begin{array}{l}\text { Prospective entry of trauma } \\
\text { patients at a single trauma } \\
\text { center. }\end{array}$ \\
\hline Lipsky, 2006 & Prospective & $\begin{array}{l}\text { USA, California } \\
\text { Urban } \\
\text { Level I trauma center } \\
\text { 9/1/1995 - 8/31/1996 } \\
1 \text { year }\end{array}$ & $\begin{array}{l}1,028 \text { analyzed } \\
1,227 \text { identified } \\
33 \text { excluded for cardiopulmonary arrest in the } \\
\text { field } \\
127 \text { excluded for inadequate documentation } \\
39 \text { excluded for ED hypotension }\end{array}$ & Primary data collection \\
\hline $\begin{array}{l}\text { Liu, 2014a } \\
\text { *Includes the study } \\
\text { population from Liu, } \\
\text { 2014b/Liu, 2015b }\end{array}$ & Prospective & $\begin{array}{l}\text { USA, Texas } \\
\text { Urban } \\
\text { Level I trauma center } \\
6 / 27 / 2011 \text { to } 1 / 6 / 2012 \\
6 \text { months }\end{array}$ & $\begin{array}{l}305 \text { analyzed } \\
\text { - } 104 \text { wireless monitor group* } \\
\text { - } 201 \text { standard monitor group } \\
\text { *Wireless monitor group comprised of the } \\
\text { study population for Liu, 2014b/Liu 2015b } \\
\text { (WVSM database). }\end{array}$ & $\begin{array}{l}\text { Primary data collection/WVSM } \\
\text { database }\end{array}$ \\
\hline
\end{tabular}




\begin{tabular}{|c|c|c|c|}
\hline $\begin{array}{l}\text { Author, Year } \\
\text { (See Appendix B for } \\
\text { complete reference) }\end{array}$ & Eligibility Criteria & $\begin{array}{l}\text { Age Groups Included (Age Range Used*): \% } \\
\text { of Study Population }\end{array}$ & Type of Population \\
\hline Lin, 2011 & $\begin{array}{l}\text { Included: Patients meeting the Miami-Dade county trauma center } \\
\text { triage criteria. } \\
\text { Excluded: Patients }<15 \text { years old, those with thermal, chemical, or } \\
\text { electrical injury, who had a cardiac arrest prior to any surgical } \\
\text { procedure, were transferred from another hospital, or those without } \\
\text { adequate out of hospital data. }\end{array}$ & $\begin{array}{l}\text { Adults ( }(\geq 15): 100 \% \\
\text { Elderly (>55): } 17 \%(103 / 601)\end{array}$ & Civilian \\
\hline Lipsky, 2006 & $\begin{array}{l}\text { Included: Patients transported by EMS who had normal SBP on ED } \\
\text { presentation. } \\
\text { Excluded: Patients who did not meet trauma criteria, were in } \\
\text { cardiopulmonary arrest at any time in the field, those not transported } \\
\text { by EMS or were transferred from another facility. }\end{array}$ & NR & Civilian \\
\hline \begin{tabular}{|l} 
Liu, 2014a \\
*Includes the study \\
population from Liu, \\
2014b/Liu, 2015b
\end{tabular} & $\begin{array}{l}\text { Included: Patients }>18 \text { years old classified as a Code } 2 \text { or } 3 \\
\text { (nonemergency but highly important response or life-threatening } \\
\text { response) who suffered blunt or penetrating trauma and were } \\
\text { transported directly from the scene to the trauma center by } \\
\text { helicopter. } \\
\\
\text { Patients who did not wear the WVSM due to technical issues, time } \\
\text { shortage, arm injuries precluding device use, device unavailable, or } \\
\text { provider's decision, were assigned to the control group. }\end{array}$ & Adults ( $\geq 18$ ): $100 \%$ & Civilian \\
\hline
\end{tabular}




\begin{tabular}{|c|c|c|c|c|}
\hline $\begin{array}{l}\text { Author, Year } \\
\text { (See Appendix B for } \\
\text { complete reference) }\end{array}$ & Mechanism or Type Injury & Mode of Transport & $\begin{array}{l}\text { Other Population Characteristics } \\
\text { (Sex, Race) }\end{array}$ & $\begin{array}{l}\text { Name of Measure Being } \\
\text { Evaluated }\end{array}$ \\
\hline Lin, 2011 & $\begin{array}{l}\text { Blunt: } 69.38 \% \text { (417/601) } \\
\text { - Motor vehicle crash: } 31.9 \%(192 / 601) \\
\text { - Pedestrian hit by car: } 8.7 \%(52 / 601) \\
\text { - Motorcycle crash: } 9.7 \%(58 / 601) \\
\text { - Fall: } 10.8 \%(65 / 601) \\
\text { - Water sports: } 1.2 \%(7 / 601) \\
\text { - Industrial/crush: } 2.3 \%(14 / 601) \\
\text { - Assault: } 4.8 \%(29 / 601) \\
\\
\text { Penetrating: } 30.62 \%(185 / 601) \\
\text { - Gunshot wounds: } 17.3 \%(104 / 601) \\
\text { - Stab wound: } 13.3 \%(80 / 601)\end{array}$ & NR & $\begin{array}{l}\text { Male: } 81 \%(490 / 601) \\
\text { Race: NR } \\
\text { Age (mean): } 38 \text { (SD 18; range } 15 \text { to 100) }\end{array}$ & SBP \\
\hline Lipsky, 2006 & \begin{tabular}{|l|} 
Blunt: $73 \%$ \\
Penetrating: $27 \%$
\end{tabular} & $\begin{array}{l}\text { EMS, land vs. air not } \\
\text { specified }\end{array}$ & $\begin{array}{l}\text { Male: } 76 \% \\
\text { Race: NR } \\
\text { Age (median): } 28 \text { (IQR 18-39) }\end{array}$ & SBP \\
\hline $\begin{array}{l}\text { Liu, 2014a } \\
* \text { Includes the study } \\
\text { population from Liu, } \\
\text { 2014b/Liu, 2015b }\end{array}$ & NR & Helicopter & \begin{tabular}{|l} 
Male: $66 \%$ \\
Race \\
- White: $63 \%$ \\
- Black: $10 \%$ \\
- Hispanic: $21 \%$ \\
- Asian/Pacific 1\% \\
- Not Recorded: $5 \%$ \\
Age (mean): 39 (SD 16)
\end{tabular} & $\begin{array}{l}\text { Combined vital signs: HR, RR, } \\
\text { and SBP } \\
\text { HR } \\
\text { RR } \\
\text { SBP }\end{array}$ \\
\hline
\end{tabular}




\begin{tabular}{|c|c|c|c|c|}
\hline $\begin{array}{l}\text { Author, Year } \\
\text { (See Appendix B for } \\
\text { complete reference) }\end{array}$ & $\begin{array}{l}\text { Location and Timing of } \\
\text { Measurement }\end{array}$ & Method of Measurement & $\begin{array}{l}\text { Personnel Administering Test or } \\
\text { Using Measure }\end{array}$ & Equipment Used/Needed \\
\hline Lin, 2011 & $\begin{array}{l}\text { Out of Hospital: during } \\
\text { resuscitation } \\
\text { ED: on arrival }\end{array}$ & NR & NR & $\mathrm{NR}$ \\
\hline Lipsky, 2006 & $\begin{array}{l}\text { Out of Hospital: not specified } \\
\text { ED: on arrival }\end{array}$ & $\begin{array}{l}\text { SBP } \\
\text { - EMS: auscultation or } \\
\text { palpation } \\
\text { - ED: auscultation or } \\
\text { automated }\end{array}$ & NR & NR \\
\hline \begin{tabular}{|l} 
Liu, 2014a \\
*Includes the study \\
population from Liu, \\
2014b/Liu, 2015b
\end{tabular} & Out of Hospital: continuous & $\begin{array}{l}\text { Vital signs: automated } \\
\text { - standard vital signs monitor } \\
\text { or wireless vital signs monitor }\end{array}$ & NR & $\begin{array}{l}\text { Wireless vital signs monitor: } \\
\text { WVSM (Athena GTX, Inc. Des } \\
\text { Moines, lowa) } \\
\text { Standard vital signs monitor: } \\
\text { LIFEPAK } 12 \text { (Physio- Control, } \\
\text { Inc., Redmond, Washington) }\end{array}$ \\
\hline
\end{tabular}




\begin{tabular}{|c|c|c|c|c|}
\hline $\begin{array}{l}\text { Author, Year } \\
\text { (See Appendix B for } \\
\text { complete reference) }\end{array}$ & $\begin{array}{l}\text { Threshold Value(s) for Physiologic } \\
\text { Measures }\end{array}$ & $\begin{array}{l}\text { Indicator of Serious Injury Used } \\
\text { (including definition and time period) }\end{array}$ & Funding Source & Risk of Bias \\
\hline Lin, 2011 & $\begin{array}{l}\text { SBP } \leq 90 \mathrm{mmHg} \\
\text { Predetermined: based on trauma team } \\
\text { activation criteria }\end{array}$ & $\begin{array}{l}\text { Major trauma: emergency surgery, ISS } \geq 16 \text {, or } \\
\text { need for ICU care. } \\
\text { Very severe trauma: ISS } \geq 25 \\
\text { Emergency surgery: life-saving operation } \\
\text { needed within minutes }\end{array}$ & NR & High \\
\hline Lipsky, 2006 & $\begin{array}{l}\text { Hypotension: } \\
\text { - Adults: SBP }<90 \text { for adults } \\
\text { - Children }<10 \text { years old: SBP }<(2 \times \text { [age in } \\
\text { years] }+70) \\
\text { - nonpalpable pulse in any anatomic location }\end{array}$ & $\begin{array}{l}\text { Need for an emergent therapeutic operation: } 2 \\
\text { out of } 3 \text { surgeons categorized surgery as } \\
\text { therapeutic, considered as organ repair that } \\
\text { could not have been managed nonoperatively, } \\
\text { or intra-thoracic or intra-abdominal injuries } \\
\text { grade III or higher on organ injury scale. }\end{array}$ & $\begin{array}{l}\text { Partial support by grants from the } \\
\text { State of California Emergency } \\
\text { Medical Services Authority (Federal } \\
\text { Block Grant Fund numbers } 4016, \\
\text { 4062). }\end{array}$ & High \\
\hline $\begin{array}{l}\text { Liu, 2014a } \\
\text { *Includes the study } \\
\text { population from Liu, } \\
\text { 2014b/Liu, 2015b }\end{array}$ & NR & $\begin{array}{l}\text { LSI: separated into prehospital or ED } \\
\text { - Prehospital: blood transfusion, CPR, chest } \\
\text { tube, intubation, needle decompression, } \\
\text { pericardiocentesis, surgical cricothyrotomy, } \\
\text { thoracotomy, or tourniquet. } \\
\text { - ED: endotracheal intubation, blood product } \\
\text { transfusion, tube thoracostomy, CPR, needle } \\
\text { decompression, angioembolization, surgical } \\
\text { cricothyrotomy, thoracotomy, cardioversion, or } \\
\text { tourniquet. }\end{array}$ & $\begin{array}{l}\text { Supported by the National Trauma } \\
\text { Institute, the Combat Casualty Care } \\
\text { Research Program, and the State } \\
\text { of Texas Emerging Technology } \\
\text { Fund. Athena GTX thanked for use } \\
\text { of Murphy Factor to support } \\
\text { protocol development. }\end{array}$ & High \\
\hline
\end{tabular}




\begin{tabular}{|c|c|c|c|c|}
\hline $\begin{array}{l}\text { Author, Year } \\
\text { (See Appendix B for } \\
\text { complete reference) }\end{array}$ & Study Design & Setting and Dates Performed & Number of Study Subjects & Data Source \\
\hline $\begin{array}{l}\text { Liu, 2014b } \\
\text { Liu, 2015b } \\
\text { *Study population } \\
\text { included in Liu, 2014a }\end{array}$ & Prospective & $\begin{array}{l}\text { USA, Texas } \\
\text { Urban } \\
\text { Level I trauma center } \\
6 / 27 / 2011 \text { to } 1 / 6 / 2012 \\
6 \text { months }\end{array}$ & $\begin{array}{l}104 \text { analyzed } \\
\star \text { This study population comprises the WVSM } \\
\text { database. }\end{array}$ & $\begin{array}{l}\text { Primary data collection (makes } \\
\text { up WVSM database) }\end{array}$ \\
\hline Liu, 2014c & Retrospective & $\begin{array}{l}\text { USA, Texas } \\
\text { Urban } \\
\text { Level I trauma centers } \\
\text { Training dataset } \\
\text { Time period: NR } \\
\text { Validation dataset } \\
\begin{array}{l}1 / 27 / 20111 \text { to } 1 / 6 / 2012 \\
6 \text { months }\end{array}\end{array}$ & $\begin{array}{l}79 \text { in training dataset } \\
24 \text { in validation dataset } \\
\text { Validation dataset } \\
104 \text { in database* } \\
-72 \text { excluded for no LSI } \\
-8 \text { excluded for no corresponding LSI } \\
\text { prediction } \\
\text { *Validation database, WVSM, is the study } \\
\text { population of Liu, 2014b/Liu, 2015b }\end{array}$ & $\begin{array}{l}\text { Training dataset: Trauma Vitals } \\
\text { database } \\
\text { Validation dataset: Wireless Vital } \\
\text { Signs Monitor trial }\end{array}$ \\
\hline Liu, 2015a & Retrospective & $\begin{array}{l}\text { USA, Texas } \\
\text { Urban } \\
\text { Level I trauma centers } \\
\text { Study dates: NR }\end{array}$ & 108 analyzed & Trauma Vitals (TV) database \\
\hline
\end{tabular}




\begin{tabular}{|c|c|c|c|}
\hline $\begin{array}{l}\text { Author, Year } \\
\text { (See Appendix B for } \\
\text { complete reference) }\end{array}$ & Eligibility Criteria & $\begin{array}{l}\text { Age Groups Included (Age Range Used*): \% } \\
\text { of Study Population }\end{array}$ & Type of Population \\
\hline $\begin{array}{l}\text { Liu, 2014b } \\
\text { Liu, 2015b } \\
\text { ×Study population } \\
\text { included in Liu, 2014a }\end{array}$ & $\begin{array}{l}\text { Included: Patients }>18 \text { years old classified as a Code } 2 \text { or } 3 \text { trauma } \\
\text { patient, who suffered blunt or penetrating trauma and were } \\
\text { transported directly from the scene to the trauma center by } \\
\text { helicopter. } \\
\text { Excluded: Patients discharged home from the ED, pregnant women, } \\
\text { age }<18 \text { years, and those transported from a nursing home. }\end{array}$ & Adults ( $\geq 18): 100 \%$ & Civilian \\
\hline Liu, 2014c & $\begin{array}{l}\text { Overall } \\
\text { Included: Severe trauma patients with blunt or penetrating injury } \\
\text { transported from the scene by helicopter to a study trauma center. } \\
\text { Additional criteria for each dataset: } \\
\text { Training: Data from these patients selected based on } 3 \text { criteria: } 1 \text { ) } \\
\text { availability of vital signs and Murphy Factor score; } 2 \text { ) BP measured } \\
\text { over } \geq 15 \text { min with change from initial measurement; } 3 \text { ) HR } \\
\text { measurements uncorrupted by electromechanical noise. } \\
\text { Validation: Patients with injury requiring hospital admission. } \\
\text { Excluded: no exclusion criteria specified. }\end{array}$ & Adults ( $\geq 18): 100 \%$ & Civilian \\
\hline Liu, 2015a & $\begin{array}{l}\text { Included: Patients with blunt or penetrating injury transported from } \\
\text { the scene to either study trauma center by helicopter, and with the } \\
\text { following available in the database: vital signs data; ECG } \\
\text { waveforms; and manual verification of all R-to-R interval (RRI) } \\
\text { sequences. } \\
\text { Excluded: no exclusion criteria specified. }\end{array}$ & NR (presumably 100\% adult) & Civilian \\
\hline
\end{tabular}




\begin{tabular}{|c|c|c|c|c|}
\hline $\begin{array}{l}\text { Author, Year } \\
\text { (See Appendix B for } \\
\text { complete reference) }\end{array}$ & Mechanism or Type Injury & Mode of Transport & $\begin{array}{l}\text { Other Population Characteristics } \\
\text { (Sex, Race) }\end{array}$ & $\begin{array}{l}\text { Name of Measure Being } \\
\text { Evaluated }\end{array}$ \\
\hline \begin{tabular}{|l} 
Liu, 2014b \\
Liu, 2015b \\
*Study population \\
included in Liu, 2014a
\end{tabular} & $\begin{array}{l}\text { Blunt: 90\% } \\
\text { Penetrating: 10\% }\end{array}$ & Helicopter & $\begin{array}{l}\text { Male: } 79 \% \\
\text { Race } \\
\text { - White/Caucasian: 60\% } \\
\text { - Black: 10\% } \\
\text { - Hispanic: } 22 \% \\
\text { - Asian/Pacific: } 1 \% \\
\text { - Not Recorded: } 7 \% \\
\text { Age (mean): } 40 \text { (SD 16) }\end{array}$ & $\begin{array}{l}\text { HR } \\
\text { RR } \\
\text { HR data quality indices (\% valid; } \\
\text { deviation ratio) } \\
\text { Heart rate variability (HF power } \\
\text { to LF power ratio) } \\
\text { Heart rate complexity (sample } \\
\text { entropy) } \\
\text { Machine learning model using } \\
\text { HR, GCS, and heart rate } \\
\text { complexity } \\
\text { Models from multivariate } \\
\text { analyses (combinations of vital } \\
\text { signs, HRC, and GCS) }\end{array}$ \\
\hline Liu, 2014c & Blunt or penetrating & Helicopter & $\begin{array}{l}\text { Male: } 65 \% \\
\text { Race } \\
\text { - White/Caucasian: 60\% } \\
\text { - Black: 10\% } \\
\text { - Hispanic: } 22 \% \\
\text { - Asian/Pacific: } 1 \% \\
\text { - Not recorded: 7\% } \\
\text { Age (mean): } 39 \text { (SD 16) }\end{array}$ & \begin{tabular}{|l} 
HR \\
RR \\
SBP \\
Multiparameter machine learning \\
algorithms using vital signs and \\
Murphy Factor using 16 features \\
or 24 features \\
- Multilayer perceptron \\
- Single logit
\end{tabular} \\
\hline Liu, 2015a & \begin{tabular}{|l} 
Blunt: $86 \%$ \\
Penetrating: $12 \%$ \\
Not recorded: $2 \%$
\end{tabular} & Helicopter & $\begin{array}{l}\text { Male: } 76 \% \text { (82/108) } \\
\text { Race } \\
\text { - White: } 41 \% \\
\text { - Black: } 6 \% \\
\text { - Hispanic: } 22 \% \\
\text { - Asian/Pacific: } 3 \% \\
\text { - Not recorded: } 28 \% \\
\text { Age (mean): } 37 \text { (SD 14) }\end{array}$ & $\begin{array}{l}\text { HR } \\
\text { HRC: sample entropy } \\
\text { HRV: Poincaré ratio, SD1/SD2 }\end{array}$ \\
\hline
\end{tabular}




\begin{tabular}{|c|c|c|c|c|}
\hline $\begin{array}{l}\text { Author, Year } \\
\text { (See Appendix B for } \\
\text { complete reference) }\end{array}$ & $\begin{array}{l}\text { Location and Timing of } \\
\text { Measurement }\end{array}$ & Method of Measurement & $\begin{array}{l}\text { Personnel Administering Test or } \\
\text { Using Measure }\end{array}$ & Equipment Used/Needed \\
\hline \begin{tabular}{|l} 
Liu, 2014b \\
Liu, 2015b \\
*Study population \\
included in Liu, 2014a
\end{tabular} & $\begin{array}{l}\text { Out of Hospital: continuous } \\
\text { ED: continuous }\end{array}$ & $\begin{array}{l}\text { Vital signs: automated monitor } \\
\text { with single-lead ECG waveform } \\
\text { and thumb-mounted pulse } \\
\text { oximeter }\end{array}$ & NR & $\begin{array}{l}\text { Wireless Vital Signs Monitor } \\
\text { (Athena GTX, Inc. Des Moines, } \\
\text { lowa) }\end{array}$ \\
\hline Liu, 2014c & $\begin{array}{l}\text { Out of hospital: during } \\
\text { resuscitation }\end{array}$ & $\begin{array}{l}\text { Machine learning algorithms: } \\
\text { Vital signs measured } \\
\text { automatically by monitors } \\
\text { using ECG waveforms, } \\
\text { photoplethysmogram, pulse } \\
\text { oximeter and respiratory } \\
\text { waveform; and calculated } \\
\text { measurements of SI, pulse } \\
\text { pressure, and Murphy Factor. }\end{array}$ & NR & $\begin{array}{l}\text { Vital signs monitors } \\
\text { Training dataset: Propaq } 206 \text { or } \\
\text { PIC } 50 \text { (Welch Allyn; } \\
\text { Skaneateles Falls, NY) } \\
\text { Validation dataset: Wireless } \\
\text { Vital Signs Monitor (WVSM, } \\
\text { Athena GTX; Des Moines, IA) } \\
\\
\text { Machine learning modeler } \\
\text { (WEKA; University of Waikato, } \\
\text { New Zealand) }\end{array}$ \\
\hline Liu, 2015a & $\begin{array}{l}\text { Out of Hospital: during } \\
\text { resuscitation }\end{array}$ & Automated vital signs monitor & Emergency Medical Services Medics & $\begin{array}{l}\text { Vital signs monitor: Welch Allyn } \\
\text { PIC } 50 \text { (Welch Allyn, } \\
\text { Skaneateles Falls, NY) }\end{array}$ \\
\hline
\end{tabular}




\begin{tabular}{|c|c|c|c|c|}
\hline $\begin{array}{l}\text { Author, Year } \\
\text { (See Appendix B for } \\
\text { complete reference) }\end{array}$ & $\begin{array}{l}\text { Threshold Value(s) for Physiologic } \\
\text { Measures }\end{array}$ & $\begin{array}{l}\text { Indicator of Serious Injury Used } \\
\text { (including definition and time period) }\end{array}$ & Funding Source & Risk of Bias \\
\hline $\begin{array}{l}\text { Liu, 2014b } \\
\text { Liu, 2015b } \\
\text { ×Study population } \\
\text { included in Liu, 2014a }\end{array}$ & $\begin{array}{l}\mathrm{HR} \geq 110 \\
\mathrm{RR} 20-26 \\
\text { Cutoffs for highest quartile }\end{array}$ & $\begin{array}{l}\text { LSI: blood transfusion, chest tube, } \\
\text { endotracheal intubation, needle } \\
\text { decompression, CPR, cricothyrotomy, } \\
\text { thoracotomy, tourniquet, angioembolization, or } \\
\text { cardioversion. } \\
\text { - reported total and separated by out of } \\
\text { hospital and ED }\end{array}$ & $\begin{array}{l}\text { National Trauma Institute, the } \\
\text { Combat Casualty Care Research } \\
\text { Program and the State of Texas } \\
\text { Emerging Technology Fund }\end{array}$ & High \\
\hline Liu, 2014c & $\begin{array}{l}\text { Hybrid system basic detection rules (applied in } \\
\text { the following order to filter out patients who } \\
\text { required immediate attention) } \\
\text { - SBP }<90 \text { or }>200 \\
\text { - DBP }<40 \text { or }>140 \\
\text { - Pulse pressure }<20 \text { or }>100 \\
\text { - MAP }<60 \text { or }>180 \\
\text { - Oxygen saturation }<85 \% \\
\text { - mean HR }>130 \\
\text { - mean } \mathrm{SI}<0.2 \text { or }>1.6 \\
\text { - max SBP }>120 \text { and max DBP }>80 \text { and max } \\
\text { MAP }>100 \text { and mean } \mathrm{HR}>115 \text { and max oxygen } \\
\text { saturation } \leq 95 \% \\
\text { - MAP }>131 \text { and max RR }>40 \\
\text { - max SBP }>160 \text { and max DBP }>120 \text { and mean } \\
\text { RR }>40\end{array}$ & $\begin{array}{l}\text { LSI: endotracheal intubation, transfusion, tube } \\
\text { thoracostomy, cardiopulmonary resuscitation, } \\
\text { needle decompression, angioembolization, } \\
\text { cricothyrotomy, thoracotomy, or cardioversion. }\end{array}$ & $\begin{array}{l}\text { Supported by the National Trauma } \\
\text { Institute, the US Army Combat } \\
\text { Casualty Care Research Program, } \\
\text { and the State of Texas Emergency } \\
\text { Technology Fund. Athena GTX, Inc. } \\
\text { thanked for use of the Murphy } \\
\text { Factor to support algorithm } \\
\text { development. }\end{array}$ & High \\
\hline Liu, 2015a & NR & $\begin{array}{l}\text { LSI: interventions performed prehospital or in } \\
\text { ED; endotracheal intubation, blood transfusion, } \\
\text { tube thoracostomy, CPR, needle } \\
\text { decompression, angioembolization, } \\
\text { cricothyrotomy, thoracotomy, or cardioversion. } \\
\text { Mortality: not specified }\end{array}$ & $\begin{array}{l}\text { The National Trauma Institute, the } \\
\text { Combat Casualty Care Research } \\
\text { Program and the State of Texas } \\
\text { Emerging Technology Fund. }\end{array}$ & Moderate \\
\hline
\end{tabular}




\begin{tabular}{|c|c|c|c|c|}
\hline $\begin{array}{l}\text { Author, Year } \\
\text { (See Appendix B for } \\
\text { complete reference) }\end{array}$ & Study Design & Setting and Dates Performed & Number of Study Subjects & Data Source \\
\hline $\begin{array}{l}\text { Mackenzie, } 2014 \\
\text { *Mackenzie, } 2014 \text { study } \\
\text { population is included in } \\
\text { Shackelford, } 2015\end{array}$ & Prospective & $\begin{array}{l}\text { USA, Maryland } \\
\text { Urban } \\
\text { Level I trauma center } \\
12 / 2011 \text { to } 6 / 2012 \\
7 \text { months }\end{array}$ & 556 analyzed & $\begin{array}{l}\text { Primary collection of data then } \\
\text { stored in centralized data } \\
\text { repository; in-hospital mortality } \\
\text { and hospital LOS obtained from } \\
\text { the trauma registry; blood use } \\
\text { was cross-validated with blood } \\
\text { bank records. }\end{array}$ \\
\hline $\begin{array}{l}\text { Mackenzie, } 2015 \\
\text { *Mackenzie 2015, } \\
\text { Shackelford 2015, and } \\
\text { Yang } 2016 \text { draw from } \\
\text { the same population, } \\
\text { but differ in eligibility } \\
\text { criteria, number } \\
\text { analyzed, and } \\
\text { measures evaluated. }\end{array}$ & Prospective & $\begin{array}{l}\text { USA, Maryland } \\
\text { Urban } \\
\text { Trauma system level: NR } \\
\text { Study period: NR }\end{array}$ & 135 analyzed & $\begin{array}{l}\text { Primary data collection and } \\
\text { patient chart review }\end{array}$ \\
\hline Matsushima, 2016 & Retrospective & $\begin{array}{l}\text { USA, California } \\
\text { Urban } \\
\text { Trauma system level: NR } \\
1 / 2002-12 / 2012 \\
11 \text { years }\end{array}$ & $\begin{array}{l}3,998 \text { analyzed } \\
10,554 \text { identified } \\
6,556 \text { excluded due to triage criteria in } \\
\text { addition to motor vehicle intrusion }\end{array}$ & County trauma database \\
\hline McManus, 2005 & Retrospective & 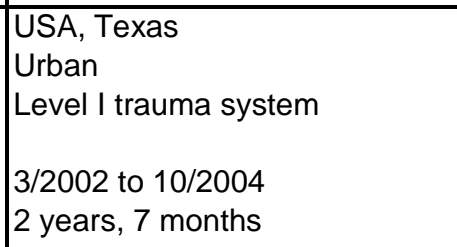 & 342 analyzed ( $n$ varied by outcome) & Trauma Vitals System \\
\hline
\end{tabular}




\begin{tabular}{|c|c|c|c|}
\hline $\begin{array}{l}\text { Author, Year } \\
\text { (See Appendix B for } \\
\text { complete reference) }\end{array}$ & Eligibility Criteria & $\begin{array}{l}\text { Age Groups Included (Age Range Used*): \% } \\
\text { of Study Population }\end{array}$ & Type of Population \\
\hline \begin{tabular}{|l|} 
Mackenzie, 2014 \\
*Mackenzie, 2014 study \\
population is included in \\
Shackelford, 2015
\end{tabular} & $\begin{array}{l}\text { Included: Patients }>17 \text { years old who were admitted directly from the } \\
\text { scene of injury and any of: EMS SI }>0.62 \text {; rated as EMS Priority } 1 \text { as } \\
\text { critically ill or injured requiring immediate attention or unstable with } \\
\text { life-threatening injury or illness without available pre-hospital vital } \\
\text { signs. } \\
\text { Excluded: Patients with cervical spine injury with neurologic deficit, } \\
\text { those surviving }<15 \text { minutes }\end{array}$ & Adults (>17): $100 \%$ & Civilian \\
\hline $\begin{array}{l}\text { Mackenzie, } 2015 \\
\text { *Mackenzie 2015, } \\
\text { Shackelford 2015, and } \\
\text { Yang } 2016 \text { draw from } \\
\text { the same population, } \\
\text { but differ in eligibility } \\
\text { criteria, number } \\
\text { analyzed, and } \\
\text { measures evaluated. }\end{array}$ & $\begin{array}{l}\text { Included: Trauma patients age } \geq 18 \text { years who survived } \geq 15 \text { minutes } \\
\text { after ED admission, and who had an } \mathrm{SI}>0.61 \text { or were categorized } \\
\text { as EMS Priority } 1 \text {. } \\
\text { Excluded: None specified. } \\
\text { No patients were excluded because of an inability to obtain good } \\
\text { quality waveform signals. }\end{array}$ & Adults ( $\geq 18): 100 \%$ & Civilian \\
\hline Matsushima, 2016 & $\begin{array}{l}\text { Included: Patients involved in a motor vehicle crash with motor } \\
\text { vehicle intrusion as the only trauma triage criterion met. } \\
\text { Excluded: Patients with missing out-of-hospital vital signs and those } \\
\text { who met trauma center triage criteria in addition to motor vehicle } \\
\text { intrusion. }\end{array}$ & $\begin{array}{l}\text { Children ( } \leq 18): 12.3 \% \\
\text { Adults (19-64): } 80.5 \% \\
\text { Elderly ( } \geq 65): 7.2 \%\end{array}$ & Civilian \\
\hline McManus, 2005 & $\begin{array}{l}\text { Included: Patients age } 18-50 \text { years with records that contained } \\
\text { radial pulse character. } \\
\text { Excluded: Patients with head injuries (AIS head > 2). }\end{array}$ & Adults (18-50): 100\% & Civilian \\
\hline
\end{tabular}




\begin{tabular}{|c|c|c|c|c|}
\hline $\begin{array}{l}\text { Author, Year } \\
\text { (See Appendix B for } \\
\text { complete reference) }\end{array}$ & Mechanism or Type Injury & Mode of Transport & $\begin{array}{l}\text { Other Population Characteristics } \\
\text { (Sex, Race) }\end{array}$ & $\begin{array}{l}\text { Name of Measure Being } \\
\text { Evaluated }\end{array}$ \\
\hline \begin{tabular}{|l|} 
Mackenzie, 2014 \\
*Mackenzie, 2014 study \\
population is included in \\
Shackelford, 2015
\end{tabular} & $\begin{array}{l}\text { Type of injury } \\
\text { Blunt: } 84.5 \%(470 / 556) \\
\text { Penetrating: } 10.1 \%(56 / 556) \\
\text { Mechanism of injury } \\
\text { Motor vehicle-related: } 46.9 \%(261 / 556) \\
\text { Falls: } 26 \% \text { (145/556) } \\
\text { Interpersonal violence: } 16 \%(89 / 556)\end{array}$ & NR & $\begin{array}{l}\text { Male: 69\% (381/556) } \\
\text { Race: NR } \\
\text { Age (mean): } 40 \text { (SD 17) }\end{array}$ & $\begin{array}{l}\text { HR } \\
\text { SBP } \\
\text { SI } \\
\text { Vital signs features } \\
\text { PPG waveform: } 12 \text { features of } \\
\text { amplitude } \\
\text { HR and SpO2 signals features } \\
\text { (14 each) included dose and } \\
\text { percentage of abnormal for } \\
\text { different thresholds; and mean } \\
\text { value and quartiles }\end{array}$ \\
\hline $\begin{array}{l}\text { Mackenzie, } 2015 \\
\text { *Mackenzie 2015, } \\
\text { Shackelford 2015, and } \\
\text { Yang } 2016 \text { draw from } \\
\text { the same population, } \\
\text { but differ in eligibility } \\
\text { criteria, number } \\
\text { analyzed, and } \\
\text { measures evaluated. }\end{array}$ & $\begin{array}{l}\text { Type of injury } \\
\text { Blunt: } 79.3 \%(107 / 135) \\
\text { Penetrating: } 16.3 \%(22 / 135) \\
\text { Other: } 4.4 \% \\
\\
\text { Mechanism of injury } \\
\text { Motor vehicle-associated: } 48.9 \%(66 / 135) \\
\text { Falls: } 16.3 \%(22 / 135) \\
\text { Interpersonal violence: } 24.4 \%(33 / 135) \\
\text { Other: } 10.4 \%(14 / 135)\end{array}$ & NR & $\begin{array}{l}\text { Male: } 70 \% \text { (95/135) } \\
\text { Race: NR } \\
\text { Age (mean): } 39 \text { (SD 17) }\end{array}$ & $\begin{array}{l}\text { Pulse oximeter (PPG) algorithms } \\
\text { to predict life-saving } \\
\text { interventions } \\
\text { - algorithms were specific to } \\
\text { each life-saving intervention }\end{array}$ \\
\hline Matsushima, 2016 & $\begin{array}{l}\text { Specific injuries (not exhaustive list) } \\
\text { Brain injury: } 4.5 \% \\
\text { Hemo/pneumothorax: } 5.7 \% \\
\text { Lung contusions: } 6.9 \% \\
\text { Cervical fractures: } 6.1 \% \\
\text { Rib fractures: } 12.3 \% \\
\text { Pelvic fractures: } 7.4 \%\end{array}$ & NR & $\begin{array}{l}\text { Male: } 57 \% \\
\text { Race: NR } \\
\text { Age (mean): NR }\end{array}$ & $\begin{array}{l}\text { HR } \\
\text { SBP }\end{array}$ \\
\hline McManus, 2005 & Blunt: $89 \%$ & Helicopter & $\begin{array}{l}\text { Male: } 75 \% \\
\text { Race } \\
\text { - African-American: } 10 \% \\
\text { - Asian: } 3 \% \\
\text { - Hispanic: } 35 \% \\
\text { - White: } 50 \% \\
\text { - Other: } 2 \% \\
\text { Age (mean): } 32 \text { (range 18-50) }\end{array}$ & Radial pulse character \\
\hline
\end{tabular}




\begin{tabular}{|c|c|c|c|c|}
\hline \begin{tabular}{|l} 
Author, Year \\
(See Appendix B for \\
complete reference) \\
\end{tabular} & $\begin{array}{l}\text { Location and Timing of } \\
\text { Measurement }\end{array}$ & Method of Measurement & $\begin{array}{l}\text { Personnel Administering Test or } \\
\text { Using Measure }\end{array}$ & Equipment Used/Needed \\
\hline \begin{tabular}{|l|} 
Mackenzie, 2014 \\
*Mackenzie, 2014 study \\
population is included in \\
Shackelford, 2015
\end{tabular} & $\begin{array}{l}\text { Out of hospital: not specified } \\
\text { - HR, SBP } \\
\text { ED: } 1 \text { hour beginning at time of } \\
\text { arrival } \\
\text { - continuous vital signs signals: } \\
\text { HR, PPG, and SpO2 }\end{array}$ & $\begin{array}{l}\text { HR and SBP (out of hospital): } \\
\text { NR } \\
\text { Vital signs signals in ED: } \\
\text { continuous collection by } \\
\text { automated patient monitors } \\
\text { PPG signals were filtered after } \\
\text { collection to reduce noise } \\
\text { using a PPG-SQI }\end{array}$ & NR & $\begin{array}{l}\text { Vital signs data collection: } \\
\text { BedMaster software (Excel } \\
\text { Medical Electronics, Jupiter, FL) } \\
\text { and networked patient monitors } \\
\text { (GE-Marquette-Solar-7000/8000, } \\
\text { GE Healthcare, Little Chalfont, } \\
\text { United Kingdom) }\end{array}$ \\
\hline $\begin{array}{l}\text { Mackenzie, } 2015 \\
\text { *Mackenzie 2015, } \\
\text { Shackelford 2015, and } \\
\text { Yang } 2016 \text { draw from } \\
\text { the same population, } \\
\text { but differ in eligibility } \\
\text { criteria, number } \\
\text { analyzed, and } \\
\text { measures evaluated. }\end{array}$ & ED: on arrival & $\begin{array}{l}\text { Pulse oximeter: automated, } \\
\text { continuous } \\
\text { PPG waveform from pulse } \\
\text { oximeter } \\
\text { PPG signal features: } \\
\text { automated analysis }\end{array}$ & NR & NR \\
\hline Matsushima, 2016 & Out of Hospital: not specified & NR & NR & NR \\
\hline McManus, 2005 & $\begin{array}{l}\text { Out of hospital: on arrival } \\
\text { Radial pulse character assessed } \\
\text { prior to BP measurement }\end{array}$ & $\begin{array}{l}\text { BP automated } \\
\text { Radial pulse character: manual }\end{array}$ & Paramedic & $\begin{array}{l}\text { Propaq } 206 \text { EL (Welch Allyn, } \\
\text { Skaneateles Falls NY) }\end{array}$ \\
\hline
\end{tabular}




\begin{tabular}{|c|c|c|c|c|}
\hline $\begin{array}{l}\text { Author, Year } \\
\text { (See Appendix B for } \\
\text { complete reference) }\end{array}$ & $\begin{array}{l}\text { Threshold Value(s) for Physiologic } \\
\text { Measures }\end{array}$ & $\begin{array}{l}\text { Indicator of Serious Injury Used } \\
\text { (including definition and time period) }\end{array}$ & Funding Source & Risk of Bias \\
\hline \begin{tabular}{|l|} 
Mackenzie, 2014 \\
*Mackenzie, 2014 study \\
population is included in \\
Shackelford, 2015
\end{tabular} & $\begin{array}{l}\text { Optimal thresholds determined by Youden index } \\
\text { were used to calculate sensitivity and specificity. }\end{array}$ & $\begin{array}{l}\text { All models } \\
\text { Blood transfusion: any transfusion within } 24 \\
\text { hours } \\
\text { Blood transfusion within } 3 \text { hours } \\
\text { Models with all vital signs features (group } 3 \\
\text { and 4) } \\
\text { Massive transfusion: }>4 \text { units pRBCs } \\
\text { transfused in <4 hours } \\
\text { Mortality: in-hospital } \\
\text { Hospital LOS }>3 \text { days }\end{array}$ & $\begin{array}{l}\text { Partially funded by US Air Force } \\
\text { (USAF) FA8650-11-2-6D01 and } \\
\text { USAF FA8650-11-2-6142 and } \\
\text { Office of Naval Research (ONR) } \\
\text { N00014-12-C-0120. }\end{array}$ & Moderate \\
\hline $\begin{array}{l}\text { Mackenzie, } 2015 \\
\text { *Mackenzie 2015, } \\
\text { Shackelford 2015, and } \\
\text { Yang } 2016 \text { draw from } \\
\text { the same population, } \\
\text { but differ in eligibility } \\
\text { criteria, number } \\
\text { analyzed, and } \\
\text { measures evaluated. }\end{array}$ & $\begin{array}{l}\text { Pulse oximeter signal features included: } \\
\text { amplitude of PPG waveform from peak to valley; } \\
\text { total millivolts of the PPG waveform amplitude; } \\
\text { IQR of PPG amplitude; } 25 \text { th percentile and 75th } \\
\text { percentile of PPG amplitude; oxygen saturation } \\
\text { features; and HR signal features. }\end{array}$ & $\begin{array}{l}\text { Blood transfusion within } 6 \text { hours } \\
\text { Surgical intervention within } 6 \text { hours } \\
\text { Endotracheal intubation within } 1 \text { hour }\end{array}$ & $\begin{array}{l}\text { Partially funded by the US Air Force } \\
\text { (USAF) FA8650-11-2-6D01 and } \\
\text { USAF FA8650-11-2-6142 and } \\
\text { Office Naval Research (ONR) } \\
\text { N00014-12-C-0120. }\end{array}$ & Moderate \\
\hline Matsushima, 2016 & $\begin{array}{l}\text { SBP }<110 \\
\mathrm{HR}>100 \\
\text { predetermined }\end{array}$ & $\begin{array}{l}\text { Need for trauma center resources: ED } \\
\text { intubation, non-orthopedic surgical procedure, } \\
\text { ICU admission or in-hospital mortality. }\end{array}$ & $\begin{array}{l}\text { No internal and external financial } \\
\text { support was used for this study. }\end{array}$ & Moderate \\
\hline McManus, 2005 & Radial pulse character: normal, weak, or absent & $\begin{array}{l}\text { ICU admission } \\
\text { Intubation } \\
\text { Mortality }\end{array}$ & $\begin{array}{l}\text { Medical equipment supplied by } \\
\text { Welch Allyn Protocol, Inc. }\end{array}$ & High \\
\hline
\end{tabular}




\begin{tabular}{|c|c|c|c|c|}
\hline $\begin{array}{l}\text { Author, Year } \\
\text { (See Appendix B for } \\
\text { complete reference) }\end{array}$ & Study Design & Setting and Dates Performed & Number of Study Subjects & Data Source \\
\hline McNab, 2013 & Retrospective & $\begin{array}{l}\text { USA, Florida } \\
\text { Urban and rural } \\
\text { Level I trauma center } \\
1 / 1 / 2006 \text { to } 12 / 31 / 2010 \\
5 \text { years }\end{array}$ & $\begin{array}{l}15,394 \text { analyzed } \\
16,269 \text { identified } \\
875 \text { excluded for early mortality }\end{array}$ & $\begin{array}{l}\text { Trauma Registry of American } \\
\text { College of Surgeons from one } \\
\text { trauma center. }\end{array}$ \\
\hline Miller, 2017 & Retrospective & $\begin{array}{l}\text { USA } \\
\text { Urban vs. rural: National registry } \\
758 \text { trauma centers, Level I-IV } \\
1 / 1 / 2012 \text { to } 12 / 31 / 2012 \\
1 \text { year }\end{array}$ & $\begin{array}{l}429,711 \text { analyzed } \\
833,311 \text { in database } \\
300,720 \text { excluded for transferred patient, }<16 \\
\text { years old, or not having blunt or penetrating } \\
\text { trauma } \\
102,880 \text { excluded for missing values for HR, } \\
\text { RR, SBP, GCS or oxygen saturation }\end{array}$ & U.S. NTDB \\
\hline Mizushima, 2011 & Retrospective & $\begin{array}{l}\text { Japan, Osaka } \\
\text { Urban } \\
\text { Level I trauma center equivalent } \\
1 / 1 / 2002 \text { to } 12 / 31 / 2008 \\
7 \text { years }\end{array}$ & 1,742 analyzed & Local trauma registry \\
\hline Montoya, 2015 & Retrospective & $\begin{array}{l}\text { Colombia, Neiva } \\
\text { Urban and rural } \\
\text { Level I trauma center } \\
1 / 2013 \text { to } 12 / 2013 \\
1 \text { year }\end{array}$ & 666 analyzed & $\begin{array}{l}\text { Medical record review using } \\
\text { standardized form. }\end{array}$ \\
\hline
\end{tabular}




\begin{tabular}{|c|c|c|c|}
\hline $\begin{array}{l}\text { Author, Year } \\
\text { (See Appendix B for } \\
\text { complete reference) } \\
\end{array}$ & Eligibility Criteria & $\begin{array}{l}\text { Age Groups Included (Age Range Used }{ }^{*} \text { ): \% } \\
\text { of Study Population }\end{array}$ & Type of Population \\
\hline McNab, 2013 & $\begin{array}{l}\text { Included: Trauma patients presenting during study period. } \\
\text { Excluded: Patients }<16 \text { years old, those with incomplete data and } \\
\text { those not transported directly from the scene by EMS. Patients who } \\
\text { died in the trauma center immediately on arrival or soon after } \\
\text { hospital admission were excluded from analysis. }\end{array}$ & $\begin{array}{l}\text { Adults (>16): } 100 \% \\
\text { Elderly ( } \geq 60): 12 \% \\
\\
\text { Distribution } \\
\text { Age 16-20: } 12 \% \\
\text { Age 20.1-30: } 29 \% \\
\text { Age 30.1-40: } 18 \% \\
\text { Age 40.1-50: } 19 \% \\
\text { Age 50.1-60: } 13 \% \\
\text { Age } \geq 60.112 \%\end{array}$ & Civilian \\
\hline Miller, 2017 & $\begin{array}{l}\text { Included: Patients } \geq 16 \text { years old with blunt and/or penetrating } \\
\text { injuries. } \\
\text { Excluded: Patients transferred from another facility, burn and/or } \\
\text { drowning victims, and those with missing data necessary to a } \\
\text { modified Rapid Emergency Medicine Score (mREMS). }\end{array}$ & $\begin{array}{l}\text { Adults ( } \geq 16): 100 \% \\
\text { Elderly }(\geq 65): 30 \% \\
\text { Distribution } \\
<45: 44 \% \\
45-54: 14 \% \\
55-64: 12 \% \\
65-74: 9 \% \\
>74: 21 \%\end{array}$ & Civilian \\
\hline Mizushima, 2011 & $\begin{array}{l}\text { Included: Patients } \geq 16 \text { years old with trauma. } \\
\text { Excluded: Patients who were dead on arrival. }\end{array}$ & Adults ( $(\geq 16): 100 \%$ & Civilian \\
\hline Montoya, 2015 & $\begin{array}{l}\text { Included: Trauma patients age } 18-50 \text { years with shock index taken } \\
\text { at admission. } \\
\text { Excluded: Patients with a history of hypertension or metabolic } \\
\text { syndrome. }\end{array}$ & Adults (18-50): 100\% & Civilian \\
\hline
\end{tabular}




\begin{tabular}{|c|c|c|c|c|}
\hline $\begin{array}{l}\text { Author, Year } \\
\text { (See Appendix B for } \\
\text { complete reference) } \\
\end{array}$ & Mechanism or Type Injury & Mode of Transport & $\begin{array}{l}\text { Other Population Characteristics } \\
\text { (Sex, Race) }\end{array}$ & $\begin{array}{l}\text { Name of Measure Being } \\
\text { Evaluated }\end{array}$ \\
\hline McNab, 2013 & $\begin{array}{l}\text { Overall } \\
\text { Mechanism: NR } \\
\text { Identified (includes early mortality patients): } \\
\text { Motor vehicle crash: } 44.9 \% \\
\text { Falls: } 11.2 \% \\
\text { Gunshot wounds: } 9.6 \% \text { Motorcycle } \\
\text { crashes: } 8.7 \% \text { Pedestrians struck by } \\
\text { vehicles: } 6.3 \% \text { Stab wounds: } 5.8 \%\end{array}$ & NR & $\begin{array}{l}\text { Male: NR } \\
\text { Race: NR } \\
\text { Age (mean): } 39 \text { (range } 16 \text { to 100) }\end{array}$ & $\begin{array}{l}\text { SI increase from prehospital to } \\
\text { trauma center }\end{array}$ \\
\hline Miller, 2017 & \begin{tabular}{|l|} 
Type of injury: \\
Blunt trauma: $89.3 \%(383,709 / 429.711)$ \\
Penetrating trauma: $10.7 \%(46,002 / 429,711)$
\end{tabular} & NR & $\begin{array}{l}\text { Male: } 61 \%(263,957 / 429,711) \\
\text { Race } \\
\text { - White: } 72 \%(298,213 / 429,711) \\
\text { - Black: } 16 \%(64,311 / 429,711) \\
\text { - Other: } 12 \%(49,856 / 429,711) \\
\text { Age (mean): } 50 \text { (SD 23) }\end{array}$ & $\begin{array}{l}\text { MGAP } \\
\text { mREMS } \\
\text { RTS } \\
\text { SI }\end{array}$ \\
\hline Mizushima, 2011 & $\begin{array}{l}\text { Blunt: 94.5\% } \\
\text { Penetrating: 5.5\% }\end{array}$ & NR & $\begin{array}{l}\text { Male: } 72 \% \\
\text { Race: NR } \\
\text { Age (mean): } 44 \text { (SD 20) }\end{array}$ & $\begin{array}{l}\text { Base Deficit } \\
\text { Lactate }\end{array}$ \\
\hline Montoya, 2015 & \begin{tabular}{|l|} 
Blunt: $78 \%(522 / 666)$ \\
Penetrating: $22 \%(144 / 666)$
\end{tabular} & NR & $\begin{array}{l}\text { Male: } 75 \%(501 / 666) \\
\text { Race: NR } \\
\text { Age (mean): } 33 \text { (SD 15) }\end{array}$ & $\mathrm{SI}$ \\
\hline
\end{tabular}




\begin{tabular}{|c|c|c|c|c|}
\hline $\begin{array}{l}\text { Author, Year } \\
\text { (See Appendix B for } \\
\text { complete reference) }\end{array}$ & $\begin{array}{l}\text { Location and Timing of } \\
\text { Measurement }\end{array}$ & Method of Measurement & $\begin{array}{l}\text { Personnel Administering Test or } \\
\text { Using Measure }\end{array}$ & Equipment Used/Needed \\
\hline McNab, 2013 & $\begin{array}{l}\text { Out of hospital: on EMS arrival } \\
\text { ED: on arrival }\end{array}$ & NR & NR & NR \\
\hline Miller, 2017 & ED: not specified & NR & $\begin{array}{l}\text { NR } \\
\text { Scores calculated in data analysis } \\
\text { phase }\end{array}$ & NR \\
\hline Mizushima, 2011 & ED: not specified & NR & NR & NR \\
\hline Montoya, 2015 & ED: on arrival & NR & NR & NR \\
\hline
\end{tabular}




\begin{tabular}{|c|c|c|c|c|}
\hline \begin{tabular}{|l|} 
Author, Year \\
(See Appendix B for \\
complete reference) \\
\end{tabular} & $\begin{array}{l}\text { Threshold Value(s) for Physiologic } \\
\text { Measures }\end{array}$ & $\begin{array}{l}\text { Indicator of Serious Injury Used } \\
\text { (including definition and time period) }\end{array}$ & Funding Source & Risk of Bias \\
\hline McNab, 2013 & NR & Mortality: NR & NR & Moderate \\
\hline Miller, 2017 & NR & Mortality: in-hospital & No funding sources for this study. & Moderate \\
\hline Mizushima, 2011 & $\begin{array}{l}\text { Base deficit: }<-5 \text { and }<-10 \\
\text { Lactate: }>2.5 \text { and }>5.0\end{array}$ & Mortality: NR & $\mathrm{NR}$ & Moderate \\
\hline Montoya, 2015 & $\mathrm{SI}>0.9$ & Mortality: 24-hour & \begin{tabular}{|l|} 
Funding NR \\
Conflict of interest declared: None.
\end{tabular} & High \\
\hline
\end{tabular}




\begin{tabular}{|c|c|c|c|c|}
\hline \begin{tabular}{|l|} 
Author, Year \\
(See Appendix B for \\
complete reference)
\end{tabular} & Study Design & Setting and Dates Performed & Number of Study Subjects & Data Source \\
\hline Moore, 2006 & Retrospective & $\begin{array}{l}\text { Canada, Quebec } \\
\text { Urban } \\
\text { Level I trauma centers } \\
4 / 1995 \text { to } 3 / 2003 \\
8 \text { years }\end{array}$ & 22,388 analyzed & $\begin{array}{l}\text { Trauma registries of } 3 \text { trauma } \\
\text { centers. }\end{array}$ \\
\hline Moront, 1996 & Retrospective & $\begin{array}{l}\text { USA, Texas } \\
\text { Urban } \\
\text { Level I pediatric trauma center } \\
\text { Study dates: NR } \\
4 \text { years }\end{array}$ & 3,861 analyzed & $\begin{array}{l}\text { Trauma registry for a single } \\
\text { trauma center. }\end{array}$ \\
\hline Mutschler, 2013 & Retrospective & $\begin{array}{l}\text { Germany } \\
\text { Setting: NR (multicenter database) } \\
\text { Trauma system level: NR (approximately } \\
600 \text { hospitals) } \\
2002 \text { to } 2011 \\
10 \text { years }\end{array}$ & 21,853 analyzed & $\begin{array}{l}\text { TraumaRegister DGU of the } \\
\text { German Trauma Society }\end{array}$ \\
\hline
\end{tabular}




\begin{tabular}{|c|c|c|c|}
\hline \begin{tabular}{|l|} 
Author, Year \\
(See Appendix B for \\
complete reference)
\end{tabular} & Eligibility Criteria & $\begin{array}{l}\text { Age Groups Included (Age Range Used*): \% } \\
\text { of Study Population }\end{array}$ & Type of Population \\
\hline Moore, 2006 & $\begin{array}{l}\text { Included: Patients } \geq 16 \text { years old with trauma who had a hospital } \\
\text { length of stay } \geq 3 \text { days, were admitted to the ICU, had been } \\
\text { transferred from another hospital, or died. } \\
\text { Excluded: Patients who died on arrival, had isolated hip fractures, or } \\
\text { were }<16 \text { years old. }\end{array}$ & $\begin{array}{l}\text { Adults }(\geq 16): 100 \% \\
\text { Elderly }(\geq 65): 30 \% \\
\\
\text { Age ranges: } \\
\text { 17-54: } 59.4 \%(13,289 / 22,388) \\
55-64: 10.7 \%(2,393 / 22,388) \\
65-74: 11.5 \%(2,566 / 22,388) \\
75-84: 12.1 \%(2,715 / 22,388) \\
85-106: 6.4 \%(1,425 / 22,388)\end{array}$ & Civilian \\
\hline Moront, 1996 & $\begin{array}{l}\text { Included: Children }<15 \text { years old transported by EMS personnel with } \\
\text { blunt or penetrating trauma. } \\
\text { Excluded: No exclusion criteria specified. }\end{array}$ & Children (<15): 100\% & Civilian \\
\hline Mutschler, 2013 & $\begin{array}{l}\text { Included: Patients } \geq 16 \text { years old, with primary admission, and for } \\
\text { whom there were complete datasets for SBP, HR, GCS, and BD on } \\
\text { ED admission. } \\
\text { Excluded: Not specified. }\end{array}$ & Adults ( $\geq 16): 100 \%$ & Civilian \\
\hline
\end{tabular}




\begin{tabular}{|c|c|c|c|c|}
\hline $\begin{array}{l}\text { Author, Year } \\
\text { (See Appendix B for } \\
\text { complete reference) }\end{array}$ & Mechanism or Type Injury & Mode of Transport & $\begin{array}{l}\text { Other Population Characteristics } \\
\text { (Sex, Race) }\end{array}$ & $\begin{array}{l}\text { Name of Measure Being } \\
\text { Evaluated }\end{array}$ \\
\hline Moore, 2006 & $\begin{array}{l}\text { Mechanism of injury } \\
\text { Motor vehicle collision: } 32.9 \%(7,329 / 22,388) \\
\text { Fall: } 46.4 \%(10.363 / 22,388) \\
\text { Firearm: } 2.0 \%(435 / 22,388) \text { Stab } \\
\text { wound: } 2.5 \%(565 / 22,388) \text { Blunt } \\
\text { object: } 8.4 \%(1,878 / 22,388) \\
\text { Other: } 7.8 \%(1,795 / 22,388)\end{array}$ & NR & $\begin{array}{l}\text { Male: NR } \\
\text { Race: NR } \\
\text { Age }\left(\text { mean*}^{\star}\right): 51(N R) \\
\text { *mean calculated using midpoint of age } \\
\text { intervals }\end{array}$ & $\begin{array}{l}\text { RR } \\
\text { RTS } \\
\text { SBP }\end{array}$ \\
\hline Moront, 1996 & $\begin{array}{l}\text { Mechanism of injury } \\
\text { (approximations from graph) } \\
\text { Children transported by air } \\
\text { Motor vehicle crash: } 35 \% \\
\text { Pedestrian: } 15-20 \% \\
\text { Falls: } 20-25 \% \\
\text { Bike: } 10-15 \% \\
\text { Gunshot or stab wound: }<5 \% \\
\text { Abuse: }<5 \% \\
\text { Children transported by ground } \\
\text { Motor vehicle crash: } 20 \% \\
\text { Pedestrian: } 20-25 \% \\
\text { Falls: } 30-35 \% \\
\text { Bike: } 5-10 \% \\
\text { Gunshot or stab wound: } 5-10 \% \\
\text { Abuse: }<5 \%\end{array}$ & Mixed & $\begin{array}{l}\text { Male: NR } \\
\text { Race: NR } \\
\text { Age (mean): } 7 \text { (SD 4) }\end{array}$ & $\begin{array}{l}\text { Combined triage criteria: GCS } \\
<12 \text { and } \mathrm{HR}>160\end{array}$ \\
\hline Mutschler, 2013 & Blunt: 93\% $(20,215 / 21,853)$ & NR & $\begin{array}{l}\text { Male: } 73 \%(16,005 / 21,853) \\
\text { Race: NR } \\
\text { Age (mean): } 45 \text { (SD 20) }\end{array}$ & $\mathrm{SI}$ \\
\hline
\end{tabular}




\begin{tabular}{|c|c|c|c|c|}
\hline \begin{tabular}{|l|} 
Author, Year \\
(See Appendix B for \\
complete reference) \\
\end{tabular} & $\begin{array}{l}\text { Location and Timing of } \\
\text { Measurement }\end{array}$ & Method of Measurement & $\begin{array}{l}\text { Personnel Administering Test or } \\
\text { Using Measure }\end{array}$ & Equipment Used/Needed \\
\hline Moore, 2006 & NR & NR & NR & NR \\
\hline Moront, 1996 & $\begin{array}{l}\text { Unclear; measures taken out of } \\
\text { hospital and in hospital. }\end{array}$ & NA & NR & NR \\
\hline Mutschler, 2013 & ED: on arrival & $\begin{array}{l}\text { SI: calculated for each } \\
\text { individual by the ratio of HR to } \\
\text { SBP. }\end{array}$ & NR & NR \\
\hline
\end{tabular}




\begin{tabular}{|c|c|c|c|c|}
\hline \begin{tabular}{|l|} 
Author, Year \\
(See Appendix B for \\
complete reference)
\end{tabular} & $\begin{array}{l}\text { Threshold Value(s) for Physiologic } \\
\text { Measures }\end{array}$ & $\begin{array}{l}\text { Indicator of Serious Injury Used } \\
\text { (including definition and time period) }\end{array}$ & Funding Source & Risk of Bias \\
\hline Moore, 2006 & $\begin{array}{l}\text { Coded values for SBP, RR, GCS are those used } \\
\text { in the RTS }\end{array}$ & Mortality: in-hospital & $\begin{array}{l}\text { Supported by the Canadian } \\
\text { Institutes of Health Research } \\
\text { through a doctoral research award, } \\
\text { and Fonds de la recherche en } \\
\text { santé du Québec (grant number } \\
\text { 015102). }\end{array}$ & Low \\
\hline Moront, 1996 & $\begin{array}{l}\mathrm{GCS}<12 \\
\mathrm{HR}>120\end{array}$ & $\begin{array}{l}\text { Need for immediate transport to trauma } \\
\text { center: TRISS probability of survival }<0.95\end{array}$ & NR & Moderate \\
\hline Mutschler, 2013 & $\mathrm{SI}>1.0$ & $\begin{array}{l}\text { Mortality: in-hospital } \\
\text { Blood transfusion: } \geq 1 \text { blood product transfused }\end{array}$ & This is an unfunded study. & Moderate \\
\hline
\end{tabular}




\begin{tabular}{|c|c|c|c|c|}
\hline $\begin{array}{l}\text { Author, Year } \\
\text { (See Appendix B for } \\
\text { complete reference) } \\
\end{array}$ & Study Design & Setting and Dates Performed & Number of Study Subjects & Data Source \\
\hline Nabaweesi, 2014 & Retrospective & $\begin{array}{l}\text { USA } \\
\text { Urban and suburban } \\
\text { Level I pediatric trauma center } \\
1 / 1 / 2008 \text { to } 12 / 31 / 2011 \\
4 \text { years }\end{array}$ & $\begin{array}{l}1,991 \text { analyzed } \\
3,213 \text { identified } \\
21 \text { excluded for age } \geq 15 \\
436 \text { excluded for non-EMS transport to ED } \\
459 \text { excluded for transfer from another facility } \\
62 \text { excluded for burn injury } \\
100 \text { excluded for no trauma team activation } \\
144 \text { not in analysis, reason not specified }\end{array}$ & $\begin{array}{l}\text { Pediatric Trauma Collector } \\
\text { Registry }\end{array}$ \\
\hline Newgard, 2009 & Retrospective & $\begin{array}{l}\text { USA and Canada } \\
\text { Urban and rural } \\
\text { Level I to Level IV trauma centers and non- } \\
\text { trauma centers } \\
12 / 1 / 2005 \text { to } 2 / 28 / 2007 \\
1 \text { year, } 3 \text { months }\end{array}$ & $\begin{array}{l}955 \text { analyzed } \\
382(40 \%) \text { used as validation set } \\
1,096 \text { met inclusion criteria } \\
141 \text { excluded for missing outcome } \\
\text { information }\end{array}$ & $\begin{array}{l}\text { Resuscitation Outcomes } \\
\text { Consortium Epistry Trauma } \\
\text { Registry }\end{array}$ \\
\hline
\end{tabular}




\begin{tabular}{|c|c|c|c|}
\hline $\begin{array}{l}\text { Author, Year } \\
\text { (See Appendix B for } \\
\text { complete reference) } \\
\end{array}$ & Eligibility Criteria & $\begin{array}{l}\text { Age Groups Included (Age Range Used*): \% } \\
\text { of Study Population }\end{array}$ & Type of Population \\
\hline Nabaweesi, 2014 & $\begin{array}{l}\text { Included: Patients age } \leq 14 \text { years who were transported by EMS } \\
\text { from scene of injury to the trauma center and for whom a trauma } \\
\text { team activation was initiated. } \\
\text { Excluded: Patients transferred from other acute care facilities, } \\
\text { arrived at the ED as a walk in or by private vehicle, those older than } \\
14 \text { years, or who presented with simultaneous burn and traumatic } \\
\text { injuries or with penetrating mechanism of injury. }\end{array}$ & Children (s14): $100 \%$ & Civilian \\
\hline Newgard, 2009 & $\begin{array}{l}\text { Included: Children age } \leq 14 \text { years with injury (any blunt, penetrating, } \\
\text { or burn mechanism suspected by EMS to be due to trauma), and } \\
\text { who had EMS provider evaluation and documented physiologic } \\
\text { abnormality (SBP } \leq 90 \mathrm{mmHg} \text {, respiratory rate }<10 \text { or }>29 \\
\text { breaths/min, GCS score } \leq 12 \text {, or attempted field intubation) at any } \\
\text { point during out-of-hospital resuscitation. } \\
\\
\text { Excluded: Children judged to be dead on EMS arrival with no } \\
\text { attempted resuscitation. }\end{array}$ & Children (s14): $100 \%$ & Civilian \\
\hline
\end{tabular}




\begin{tabular}{|c|c|c|c|c|}
\hline $\begin{array}{l}\text { Author, Year } \\
\text { (See Appendix B for } \\
\text { complete reference) }\end{array}$ & Mechanism or Type Injury & Mode of Transport & $\begin{array}{l}\text { Other Population Characteristics } \\
\text { (Sex, Race) }\end{array}$ & $\begin{array}{l}\text { Name of Measure Being } \\
\text { Evaluated }\end{array}$ \\
\hline Nabaweesi, 2014 & $\begin{array}{l}\text { Blunt: } 93.1 \% \\
\text { Penetrating: } 3.6 \%\end{array}$ & Mixed & $\begin{array}{l}\text { Male: NR } \\
\text { Race: NR } \\
\text { Age (median) } \\
\text { - full TTA group: } 6 \\
\text { - without full TTA group: } 8 \\
\text { *Stated: The analysis of gender, race and } \\
\text { age categories did not show any } \\
\text { significant differences between patients } \\
\text { with full TTA vs. partial TTA. }\end{array}$ & \begin{tabular}{|l|}
$\mathrm{HR}$ \\
$\mathrm{RR}$ \\
$\mathrm{SBP}$
\end{tabular} \\
\hline Newgard, 2009 & $\begin{array}{l}\text { Penetrating: } 5.0 \%(48 / 955) \\
\text { Burns: } 5.7 \%(54 / 955) \\
\text { Mechanism of injury } \\
\text { Motor vehicle: } 14.7 \%(140 / 955) \\
\text { Cyclist or pedestrian: } 12.3 \%(117 / 955) \\
\text { Stabbing or firearm: } 3.8 \%(36 / 955) \\
\text { Fall: } 44.8 \%(428 / 955) \\
\text { Other: } 23.1 \%(221 / 955)\end{array}$ & NR & $\begin{array}{l}\text { Male: } 61 \% \text { (582/955) } \\
\text { Race: NR } \\
\text { Age (mean): } 5 \text { (SD 5) }\end{array}$ & $\begin{array}{l}\text { Out of hospital Pediatric Clinical } \\
\text { Decision Tree physiologic } \\
\text { measures } \\
\text { RR } \\
\text { SBP }\end{array}$ \\
\hline
\end{tabular}




\begin{tabular}{|c|c|c|c|c|}
\hline $\begin{array}{l}\text { Author, Year } \\
\text { (See Appendix B for } \\
\text { complete reference) }\end{array}$ & $\begin{array}{l}\text { Location and Timing of } \\
\text { Measurement }\end{array}$ & Method of Measurement & $\begin{array}{l}\text { Personnel Administering Test or } \\
\text { Using Measure }\end{array}$ & Equipment Used/Needed \\
\hline Nabaweesi, 2014 & NR & NR & NR & NR \\
\hline Newgard, 2009 & Out of Hospital: on EMS arrival & NR & EMS on arrival & NR \\
\hline
\end{tabular}




\begin{tabular}{|c|c|c|c|c|}
\hline $\begin{array}{l}\text { Author, Year } \\
\text { (See Appendix B for } \\
\text { complete reference) } \\
\end{array}$ & $\begin{array}{l}\text { Threshold Value(s) for Physiologic } \\
\text { Measures }\end{array}$ & $\begin{array}{l}\text { Indicator of Serious Injury Used } \\
\text { (including definition and time period) }\end{array}$ & Funding Source & Risk of Bias \\
\hline Nabaweesi, 2014 & $\begin{array}{l}\text { Low SBP: } \\
<80 \mathrm{mmHg} \text { if }<5 \text { years } \\
<90 \mathrm{mmHg} \text { if } \geq 5 \text { years } \\
\text { Abnormal HR: } \\
<60 \text { or }>160 \text { if }<5 \text { years } \\
<50 \text { or }>140 \text { if } \geq 5 \text { years } \\
\\
\text { Respiratory distress: } \\
\mathrm{RR}<20 \text { or }>60 \text { if }<1 \text { year } \\
\mathrm{RR}<10 \text { or }>40 \text { if } \geq 1 \text { year }\end{array}$ & $\begin{array}{l}\text { Intense resource use: ED disposition to ICU, } \\
\text { OR or Morgue }\end{array}$ & NR & Moderate \\
\hline Newgard, 2009 & $\begin{array}{l}\text { RR }<10 \text { or }>29 \\
\text { SBP } \leq 90 \\
\text { Out of hospital Pediatric Clinical Decision Tree } \\
\text { physiologic measures: } \\
\text { GCS }<11 \\
\text { SaO }<95 \% \\
\text { SBP }>96 \mathrm{~mm} \mathrm{Hg} \\
\text { assisted ventilation }\end{array}$ & $\begin{array}{l}\text { Mortality: field or in-hospital } \\
\text { Hospital length of stay }>2 \text { days }\end{array}$ & \begin{tabular}{|l} 
The Resuscitation Outcomes \\
Consortium was supported by \\
cooperative agreements (5U01 \\
HL077863, HL077871, HL077872, \\
HL077866, HL077908, HL077867, \\
HL077885, HL077873) from the \\
National Heart, Lung and Blood \\
Institute, National Institute of \\
Neurological Disorders and Stroke, \\
U.S. Army Medical Research\& \\
Materiel Command, The Canadian \\
Institutes of Health Research \\
(CIHR)-Institute of Circulatory and \\
Respiratory Health, Defence \\
Research and Development \\
Canada, the Heart and Stroke \\
Foundation of Canada, and the \\
American Heart Association.
\end{tabular} & Moderate \\
\hline
\end{tabular}




\begin{tabular}{|c|c|c|c|c|}
\hline \begin{tabular}{|l|} 
Author, Year \\
(See Appendix B for \\
complete reference)
\end{tabular} & Study Design & Setting and Dates Performed & Number of Study Subjects & Data Source \\
\hline \begin{tabular}{|l|} 
Newgard, 2014 \\
*Newgard, 2016 study \\
population is included in \\
Newgard, 2014
\end{tabular} & Retrospective & $\begin{array}{l}\text { USA, multiple states } \\
\text { Urban and rural } \\
\text { Level I to Level } V \text { trauma centers and } \\
\text { nontrauma centers (122 sites) } \\
\text { 1/1/2006 to } 12 / 31 / 2008 \\
3 \text { years }\end{array}$ & 44,890 analyzed & Internal hospital data \\
\hline
\end{tabular}




\begin{tabular}{|c|c|c|c|}
\hline $\begin{array}{l}\text { Author, Year } \\
\text { (See Appendix B for } \\
\text { complete reference) }\end{array}$ & Eligibility Criteria & $\begin{array}{l}\text { Age Groups Included (Age Range Used*): \% } \\
\text { of Study Population }\end{array}$ & Type of Population \\
\hline \begin{tabular}{|l|} 
Newgard, 2014 \\
*Newgard, 2016 study \\
population is included in \\
Newgard, 2014
\end{tabular} & $\begin{array}{l}\text { Included: Injured patients } \geq 55 \text { years old for whom the 9-1-1 EMS } \\
\text { system was activated and were transported by EMS to an acute } \\
\text { care hospital. } \\
\text { Excluded: Patients who were interhospital transfers without an initial } \\
\text { EMS presentation, non-transported patients, and those who died in } \\
\text { the field. }\end{array}$ & Elderly ( $\geq 55): 100 \%$ & Civilian \\
\hline
\end{tabular}




\begin{tabular}{|c|c|c|c|c|}
\hline $\begin{array}{l}\text { Author, Year } \\
\text { (See Appendix B for } \\
\text { complete reference) }\end{array}$ & Mechanism or Type Injury & Mode of Transport & $\begin{array}{l}\text { Other Population Characteristics } \\
\text { (Sex, Race) }\end{array}$ & $\begin{array}{l}\text { Name of Measure Being } \\
\text { Evaluated }\end{array}$ \\
\hline $\begin{array}{l}\text { Newgard, } 2014 \\
\text { *Newgard, } 2016 \text { study } \\
\text { population is included in } \\
\text { Newgard, } 2014\end{array}$ & $\begin{array}{l}\text { Mechanism of injury - } \\
\text { Gunshot: } 0.2 \% \\
\text { Stabbing: } 0.4 \% \\
\text { Assault: } 1.3 \% \\
\text { Fall: } 71.4 \% \\
\text { Motor vehicle accident: } 16.5 \% \\
\text { Pedestrian v auto: } 1.9 \% \\
\text { Bicycle: } 0.7 \% \\
\text { Other: } 7.6 \%\end{array}$ & NR & $\begin{array}{l}\text { Male: } 37 \% \\
\text { Race: NR } \\
\text { Age (median): } 77 \text { (IQR 64-85) }\end{array}$ & \begin{tabular}{|l|} 
Assisted ventilation \\
RR \\
SBP \\
Physiologic triage criteria - \\
current protocol \\
Revised physiologic triage \\
criteria and decision tree models
\end{tabular} \\
\hline
\end{tabular}




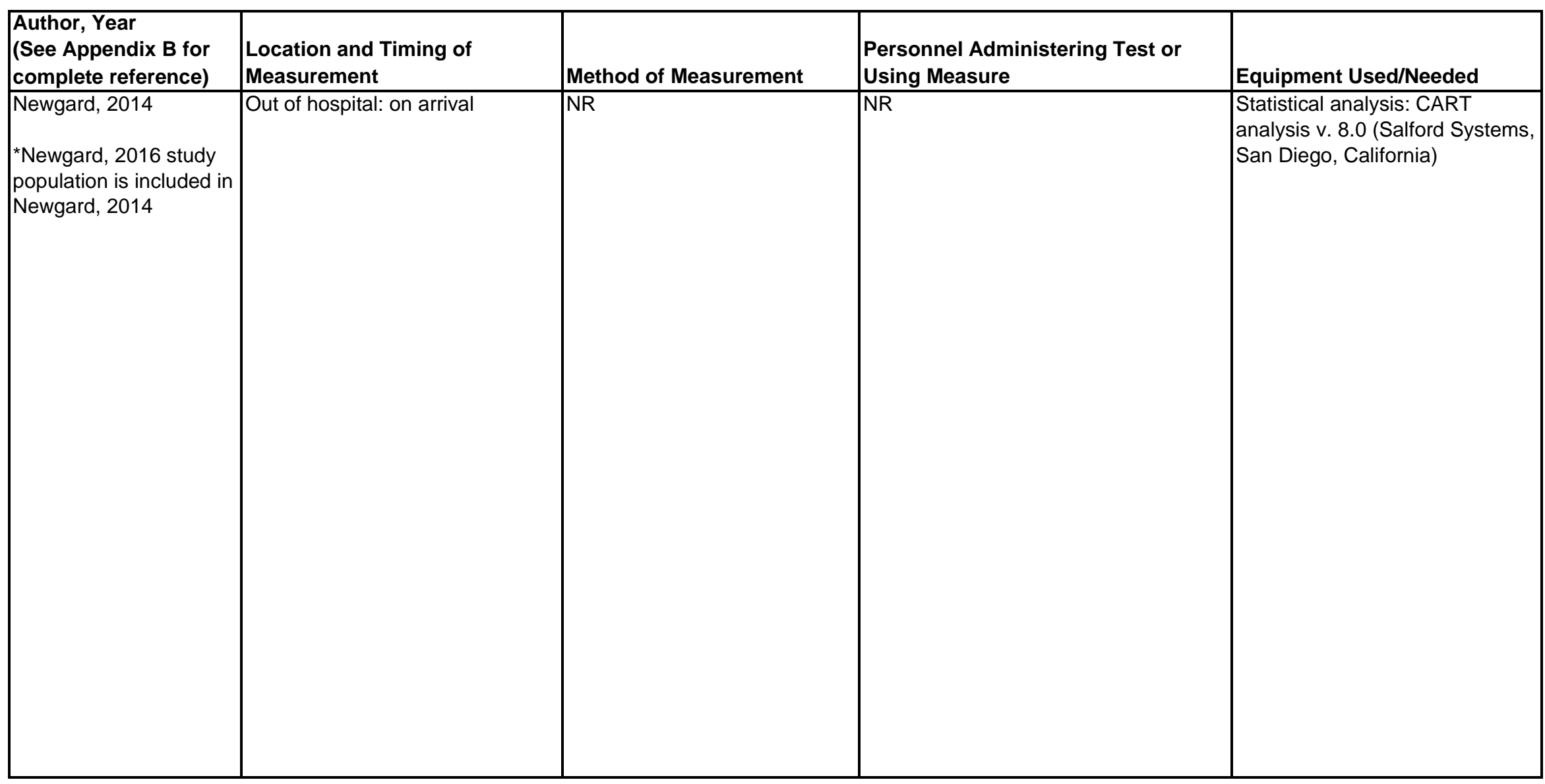




\begin{tabular}{|c|c|c|c|c|}
\hline $\begin{array}{l}\text { Author, Year } \\
\text { (See Appendix B for } \\
\text { complete reference) }\end{array}$ & $\begin{array}{l}\text { Threshold Value(s) for Physiologic } \\
\text { Measures }\end{array}$ & $\begin{array}{l}\text { Indicator of Serious Injury Used } \\
\text { (including definition and time period) }\end{array}$ & Funding Source & Risk of Bias \\
\hline \begin{tabular}{|l|} 
Newgard, 2014 \\
*Newgard, 2016 study \\
population is included in \\
Newgard, 2014
\end{tabular} & $\begin{array}{l}\text { Revised physiologic triage criteria: } \\
\text { - GCS } \leq 14 \\
- \text { RR }<10 \text { or }>24 \text { or assisted ventilation } \\
\text { - } \mathrm{SBP}<110 \text { or }>200\end{array}$ & Serious injury: ISS $\geq 16$ & $\begin{array}{l}\text { Robert Wood Johnson Foundation } \\
\text { Physician Faculty Scholars } \\
\text { Program; the Oregon Clinical and } \\
\text { Translational Research Institute } \\
\text { (grant \#UL1 RR024140); UC Davis } \\
\text { Clinical and Translational Science } \\
\text { Center (grant \#UL1 RR024146); } \\
\text { Stanford Center for Clinical and } \\
\text { Translational Education and } \\
\text { Research (grant \#1UL1 } \\
\text { RR025744); University of Utah } \\
\text { Center for Clinical and Translational } \\
\text { Science (grant \#UL1-RR025764 } \\
\text { and C06-RR11234); and UCSF } \\
\text { Clinical and Translational Science } \\
\text { Institute (grant \#UL1 RR024131). } \\
\text { All Clinical and Translational } \\
\text { Science Awards are from the } \\
\text { National Center for Research } \\
\text { Resources, a component of the } \\
\text { National Institutes of Health (NIH), } \\
\text { and NIH Roadmap for Medical } \\
\text { Research. }\end{array}$ & Moderate \\
\hline
\end{tabular}




\begin{tabular}{|c|c|c|c|c|}
\hline $\begin{array}{l}\text { Author, Year } \\
\text { (See Appendix B for } \\
\text { complete reference) }\end{array}$ & Study Design & Setting and Dates Performed & Number of Study Subjects & Data Source \\
\hline $\begin{array}{l}\text { Newgard, } 2016 \\
\text { *Newgard, } 2016 \text { study } \\
\text { population is included in } \\
\text { Newgard, } 2014\end{array}$ & Retrospective & $\begin{array}{l}\text { USA, multiple states } \\
\text { Urban and rural } \\
\text { Levels I through } \vee \text { trauma centers and } \\
\text { nontrauma hospitals (122 sites) } \\
1 / 1 / 2006 \text { to } 12 / 31 / 2008 \\
3 \text { years }\end{array}$ & $\begin{array}{l}13,401 \text { analyzed (validation sample) } \\
\text { 33,298 in overall study } \\
-19,897 \text { in derivation sample } \\
-13,401 \text { in validation sample }\end{array}$ & \begin{tabular}{|l} 
Trauma registries, ED \\
databases, EMS charts, and \\
matched EMS phone records.
\end{tabular} \\
\hline Ocak, 2009 & Retrospective case-control & $\begin{array}{l}\text { The Netherlands } \\
\text { Setting: NR } \\
3 \text { Level I trauma centers } \\
\text { 7/2004 to 6/2005 } \\
1 \text { year }\end{array}$ & $\begin{array}{l}302 \text { analyzed } \\
151 \text { in major trauma group } \\
151 \text { in minor trauma group } \\
\\
2,548 \text { identified } \\
1,152 \text { excluded for age }<18 \text { years, missing } \\
\text { AIS scores, or not directly transported } \\
\text { Major trauma group } \\
177 \text { identified with ISS }>15 \\
26 \text { excluded for no prehospital data } \\
\text { Minor trauma group } \\
1,219 \text { identified with ISS } 1-15 \\
151 \text { randomly selected for control group }\end{array}$ & $\begin{array}{l}\text { Primary data collection from } \\
\text { ambulance forms. Patients } \\
\text { identified using the regional } \\
\text { trauma registry of the Trauma } \\
\text { Center West-Netherlands. }\end{array}$ \\
\hline
\end{tabular}




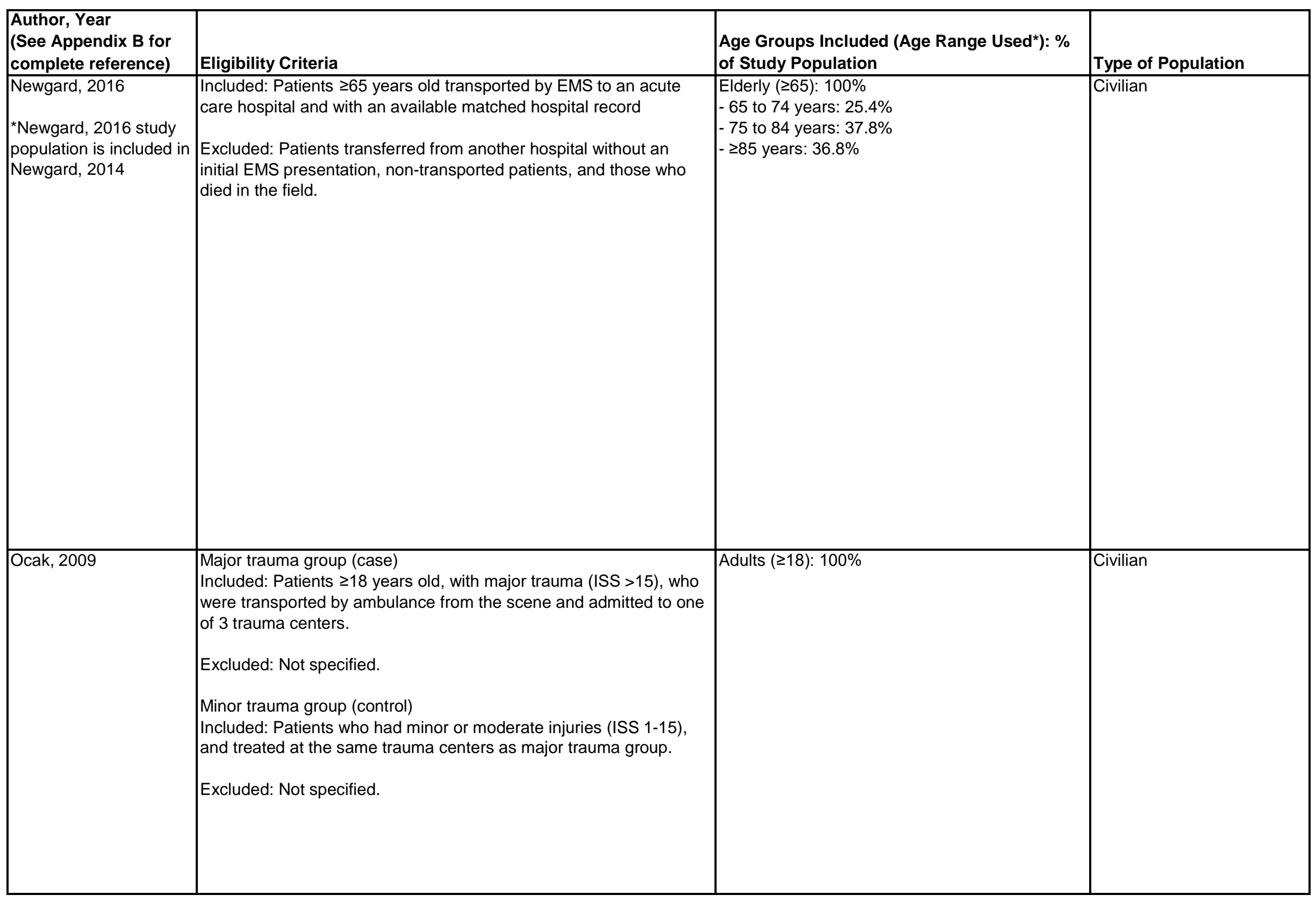




\begin{tabular}{|c|c|c|c|c|}
\hline $\begin{array}{l}\text { Author, Year } \\
\text { (See Appendix B for } \\
\text { complete reference) } \\
\end{array}$ & Mechanism or Type Injury & Mode of Transport & $\begin{array}{l}\text { Other Population Characteristics } \\
\text { (Sex, Race) }\end{array}$ & $\begin{array}{l}\text { Name of Measure Being } \\
\text { Evaluated }\end{array}$ \\
\hline \begin{tabular}{|l|} 
Newgard, 2016 \\
*Newgard, 2016 study \\
population is included in \\
Newgard, 2014
\end{tabular} & $\begin{array}{l}\text { Mechanism of injury } \\
\text { Gunshot wound: } 0.1 \% \\
\text { Stabbing: } 0.2 \% \\
\text { Assault: } 0.6 \% \\
\text { Fall: } 79.6 \% \\
\text { Motor vehicle crash: } 9.9 \% \\
\text { Pedestrian vs. auto: } 1.3 \% \\
\text { Bicycle: } 0.3 \% \\
\text { Other: } 8.0 \%\end{array}$ & NR & $\begin{array}{l}\text { Male: } 32 \% \\
\text { Race: NR } \\
\text { Age (mean): NR }\end{array}$ & $\begin{array}{l}\text { National field triage guidelines } \\
\text { Alternative elderly-specific triage } \\
\text { protocol: uses current triage } \\
\text { criteria, GCS, SBP, RR, and HR }\end{array}$ \\
\hline Ocak, 2009 & $\begin{array}{l}\text { Type of injury } \\
\text { Blunt: } 95 \% \\
\\
\text { Mechanism of injury } \\
\text { Traffic: } 44 \% \\
\text { Home-leisure: } 41 \% \\
\text { Sport: } 2 \% \\
\text { Violence: } 5 \% \\
\text { Self-inflicted: } 2 \% \\
\text { Work: } 5 \% \\
\text { Unknown: } 1 \%\end{array}$ & $\begin{array}{l}\text { Ambulance (air vs. } \\
\text { ground not specified) }\end{array}$ & $\begin{array}{l}\text { Male: } 60 \% \\
\text { Race: NR } \\
\text { Age (mean): } 54 \text { (SD 24) }\end{array}$ & $\begin{array}{l}\text { Physiologic component of the } \\
\text { ACS-COT field triage protocol: } \\
\text { GCS, SBP, RR } \\
\text { RR } \\
\text { SBP }\end{array}$ \\
\hline
\end{tabular}




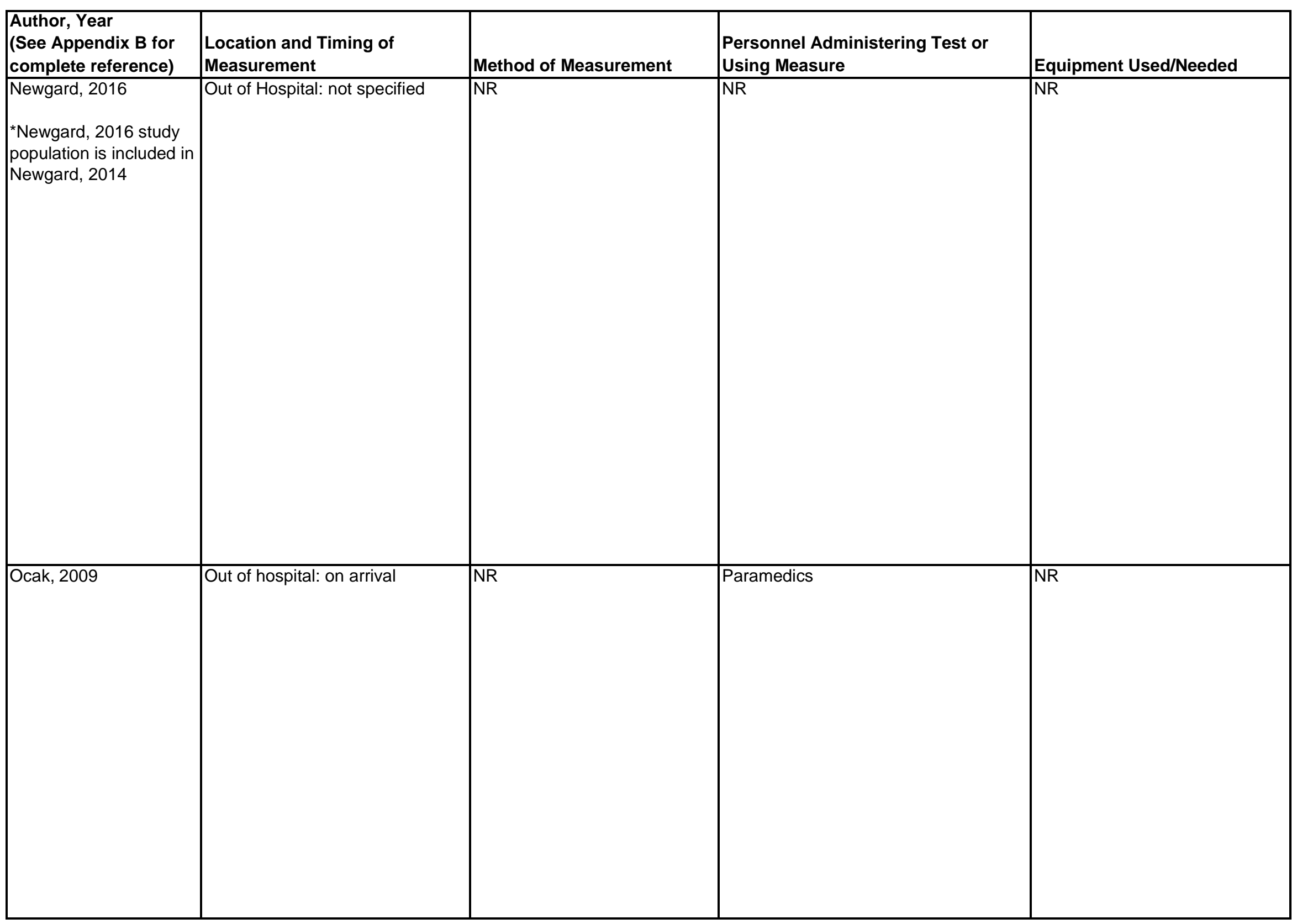




\begin{tabular}{|c|c|c|c|c|}
\hline $\begin{array}{l}\text { Author, Year } \\
\text { (See Appendix B for } \\
\text { complete reference) }\end{array}$ & $\begin{array}{l}\text { Threshold Value(s) for Physiologic } \\
\text { Measures }\end{array}$ & $\begin{array}{l}\text { Indicator of Serious Injury Used } \\
\text { (including definition and time period) }\end{array}$ & Funding Source & Risk of Bias \\
\hline \begin{tabular}{|l|} 
Newgard, 2016 \\
*Newgard, 2016 study \\
population is included in \\
Newgard, 2014
\end{tabular} & $\begin{array}{l}\text { Alternative elderly-specific triage criteria } \\
\text { any of the following: } \\
\text { - A positive triage criterion from the current } \\
\text { guidelines } \\
\text { - } G C S \leq 14 \\
\text { - } \text { SBP } \leq 110 \text { or } \geq 200 \\
\text { - Respiratory rate }<10 \text { or }>29 \\
\text { - Heart rate } \leq 60 \text { or } \geq 110\end{array}$ & Serious injury: ISS $\geq 16$ & $\begin{array}{l}\text { Supported by the Robert Wood } \\
\text { Johnson Foundation Physician } \\
\text { Faculty Scholars Program; Clinical } \\
\text { and Translational Science Awards } \\
\text { from the National Institutes of } \\
\text { Health National Center for } \\
\text { Advancing Translational Sciences: } \\
\text { Oregon Clinical and Translational } \\
\text { Research Institute (grant \# UL1 } \\
\text { RR024140); UC Davis Clinical and } \\
\text { Translational Science Center (grant } \\
\text { \# UL1 RR024146); Stanford Center } \\
\text { for Clinical and Translational } \\
\text { Education and Research (grant \# } \\
\text { 1UL1 RR025744); University of Utah } \\
\text { Center for Clinical and Translational } \\
\text { Science (grant \# UL1- RR025764 } \\
\text { and C06-RR11234); and UCSF } \\
\text { Clinical and Translational Science } \\
\text { Institute (grant \# UL1 } \\
\text { RR024131). }\end{array}$ & Moderate \\
\hline Ocak, 2009 & $\begin{array}{l}\text { RR }<10 \text { or }>29 \\
\text { SBP }<90\end{array}$ & Major trauma: ISS >15 & NR & Moderate \\
\hline
\end{tabular}




\begin{tabular}{|c|c|c|c|c|}
\hline $\begin{array}{l}\text { Author, Year } \\
\text { (See Appendix B for } \\
\text { complete reference) }\end{array}$ & Study Design & Setting and Dates Performed & Number of Study Subjects & Data Source \\
\hline Pal, 2006 & Prospective & $\begin{array}{l}\text { USA, California } \\
\text { Urban } \\
\text { Trauma center level: NR } \\
10 / 1997 \text { to } 9 / 2003 \\
6 \text { years }\end{array}$ & 5,995 analyzed & $\begin{array}{l}\text { Prospective collection of internal } \\
\text { hospital data }\end{array}$ \\
\hline $\begin{array}{l}\text { Paladino, } 2008 \\
\text { Paladino, } 2011\end{array}$ & Retrospective & $\begin{array}{l}\text { USA, New York } \\
\text { Urban } \\
\text { Level I trauma center } \\
1 / 2003 \text { to } 9 / 2005 \\
2 \text { years, } 9 \text { months }\end{array}$ & 1,435 analyzed & $\begin{array}{l}\text { Prospective collection of internal } \\
\text { trauma registry data for a single } \\
\text { hospital }\end{array}$ \\
\hline Paladino, 2010a & Retrospective & $\begin{array}{l}\text { USA, New York } \\
\text { Urban } \\
\text { Level I trauma center } \\
1 / 2005 \text { to } 12 / 2008 \\
4 \text { years }\end{array}$ & 805 analyzed & $\begin{array}{l}\text { Prospective collection of internal } \\
\text { trauma registry data for a single } \\
\text { hospital. }\end{array}$ \\
\hline Paladino, 2010b & Retrospective & $\begin{array}{l}\text { USA, New York } \\
\text { Urban } \\
\text { Level I trauma center } \\
8 / 2005 \text { to } 8 / 2008 \\
3 \text { years }\end{array}$ & 1,649 analyzed & $\begin{array}{l}\text { Prospective collection of patient } \\
\text { information for a single trauma } \\
\text { center. }\end{array}$ \\
\hline
\end{tabular}




\begin{tabular}{|c|c|c|c|}
\hline $\begin{array}{l}\text { Author, Year } \\
\text { (See Appendix B for } \\
\text { complete reference) }\end{array}$ & Eligibility Criteria & $\begin{array}{l}\text { Age Groups Included (Age Range Used*): \% } \\
\text { of Study Population }\end{array}$ & Type of Population \\
\hline Pal, 2006 & $\begin{array}{l}\text { Included: Trauma patients evaluated at a single trauma center. } \\
\text { Excluded: No exclusion criteria were specified. }\end{array}$ & NR (presumably $100 \%$ adult) & Civilian \\
\hline $\begin{array}{l}\text { Paladino, } 2008 \\
\text { Paladino, } 2011\end{array}$ & $\begin{array}{l}\text { Included: Patients age } \geq 13 \text { with blunt or penetrating trauma } \\
\text { suspected of having significant injury by mechanism. } \\
\text { Excluded: Patients with obvious injuries requiring immediate } \\
\text { surgery, isolated head trauma, those who were transferred from } \\
\text { other institutions or were dead on arrival. }\end{array}$ & $\begin{array}{l}\text { Adults and adolescents ( } \geq 13): 100 \% \\
\text { - range: } 13-95\end{array}$ & Civilian \\
\hline Paladino, 2010a & $\begin{array}{l}\text { Included: Patients age } \geq 13 \text { years with significant mechanisms } \\
\text { defined by trauma team activation protocol of blunt or penetrating } \\
\text { trauma who had blood tests performed as part of their diagnostic } \\
\text { evaluation. } \\
\text { Excluded: Patients with obvious injuries requiring immediate } \\
\text { surgery, those transferred from other institutions or who were dead } \\
\text { on arrival, and patients with history of isolated head trauma. }\end{array}$ & Adults and adolescents ( $\geq 13): 100 \%$ & Civilian \\
\hline Paladino, 2010b & $\begin{array}{l}\text { Included: Patient } \geq 13 \text { years old with blunt or penetrating trauma } \\
\text { suspected of } \\
\text { having significant injury by mechanism. } \\
\text { Excluded: Patients with obvious injuries requiring immediate } \\
\text { surgery, isolated head trauma, were transferred from other } \\
\text { institutions or dead on arrival, and those with history of diabetes } \\
\text { mellitus in the EHR. }\end{array}$ & Adults and adolescents ( $\geq 13): 100 \%$ & Civilian \\
\hline
\end{tabular}




\begin{tabular}{|c|c|c|c|c|}
\hline $\begin{array}{l}\text { Author, Year } \\
\text { (See Appendix B for } \\
\text { complete reference) }\end{array}$ & Mechanism or Type Injury & Mode of Transport & $\begin{array}{l}\text { Other Population Characteristics } \\
\text { (Sex, Race) }\end{array}$ & $\begin{array}{l}\text { Name of Measure Being } \\
\text { Evaluated }\end{array}$ \\
\hline Pal, 2006 & $\begin{array}{l}\text { Blunt: } 80 \% \\
\text { Penetrating: } 20 \%\end{array}$ & NR & $\begin{array}{l}\text { Male: } 81 \% \\
\text { Race: NR } \\
\text { Age (mean): } 37 \text { (SD 0.2) }\end{array}$ & Lactate \\
\hline \begin{tabular}{|l} 
Paladino, 2008 \\
Paladino, 2011
\end{tabular} & $\begin{array}{l}\text { Blunt: } 35 \% \\
\text { Penetrating: } 42 \% \\
\text { Fall: } 12 \% \\
\text { Other: } 11 \%\end{array}$ & NR & $\begin{array}{l}\text { Male: } 81 \% \\
\text { Race: NR } \\
\text { Age (mean): } 35 \text { (SD 17) }\end{array}$ & \begin{tabular}{|l}
$\mathrm{BD}$ \\
$\mathrm{HR}$ \\
Lactate \\
SBP \\
Combinations of abnormal \\
measures: \\
- HR or SBP \\
- HR, SBP, lactate, or BD
\end{tabular} \\
\hline Paladino, 2010a & $\begin{array}{l}\text { Blunt: } 45.6 \% \\
\text { Penetrating: } 34.4 \% \\
\text { Fall: } 17.3 \% \\
\text { Other: } 2.7 \%\end{array}$ & NR & $\begin{array}{l}\text { Male: } 75 \% \\
\text { Race: NR } \\
\text { Age (mean): } 39 \text { (range 13-95) }\end{array}$ & \begin{tabular}{|l} 
BD \\
DBP \\
HR \\
Lactate \\
SBP
\end{tabular} \\
\hline Paladino, 2010b & $\begin{array}{l}\text { Blunt: } 38.3 \% \\
\text { Penetrating: } 43.06 \% \\
\text { Fall: } 12.55 \% \\
\text { Other: } 6.06 \%\end{array}$ & NR & $\begin{array}{l}\text { Male: } 80 \% \\
\text { Race: NR } \\
\text { Age (mean): } 36 \text { (range 13-95) }\end{array}$ & \begin{tabular}{|l|} 
BD \\
Lactate \\
RTS
\end{tabular} \\
\hline
\end{tabular}




\begin{tabular}{|c|c|c|c|c|}
\hline $\begin{array}{l}\text { Author, Year } \\
\text { (See Appendix B for } \\
\text { complete reference) } \\
\end{array}$ & $\begin{array}{l}\text { Location and Timing of } \\
\text { Measurement }\end{array}$ & Method of Measurement & $\begin{array}{l}\text { Personnel Administering Test or } \\
\text { Using Measure } \\
\end{array}$ & Equipment Used/Needed \\
\hline Pal, 2006 & ED: initial value & NR & NR & NR \\
\hline Paladino, 2010b & ED: on arrival & Lactate: arterial & NR & $\begin{array}{l}\text { BD and Lactate: arterial blood } \\
\text { gas using Radiometer ABL } 725 \\
\text { (Copenhagen, Denmark) }\end{array}$ \\
\hline
\end{tabular}




\begin{tabular}{|c|c|c|c|c|}
\hline $\begin{array}{l}\text { Author, Year } \\
\text { (See Appendix B for } \\
\text { complete reference) } \\
\end{array}$ & $\begin{array}{l}\text { Threshold Value(s) for Physiologic } \\
\text { Measures }\end{array}$ & $\begin{array}{l}\text { Indicator of Serious Injury Used } \\
\text { (including definition and time period) }\end{array}$ & Funding Source & Risk of Bias \\
\hline Pal, 2006 & Lactate: $>2.0 \mathrm{mmol} / \mathrm{L}$ & Mortality within 48 hours of admission & NR & Moderate \\
\hline $\begin{array}{l}\text { Paladino, } 2008 \\
\text { Paladino, } 2011\end{array}$ & $\begin{array}{l}\text { Abnormal laboratory values, predetermined } \\
\text { based on hospital normal values } \\
\text { BD }<-2.0 \text { : normal } \\
\text { Lactate }<2.2 \text { : normal } \\
\text { Abnormal vital signs, predetermined: not } \\
\text { specified } \\
\text { HR }>100 \mathrm{bpm} \\
\mathrm{SBP}<90 \mathrm{mmHg} \\
\mathrm{SI}>0.9\end{array}$ & $\begin{array}{l}\text { Major injury: blood transfusion in the first } 24 \\
\text { hours, decrease in hematocrit }>10 \text { points in } \\
\text { the first } 24 \text { hours, or ISS } \geq 16 \text {. }\end{array}$ & $\begin{array}{l}\text { No funding was received for this } \\
\text { study. }\end{array}$ & Moderate \\
\hline Paladino, 2010a & $\begin{array}{l}\text { Predetermined based on hospital normal values } \\
\text { BD >-2.0: normal } \\
\text { Lactate <2.2: normal } \\
\\
\text { Predetermined: NR HR } \\
\leq 100 \text { bpm: normal SBP } \\
\geq 90 \text { mmHg: normal SI } \\
>0.9: \text { abnormal }\end{array}$ & $\begin{array}{l}\text { Major injury: blood transfusion in the first } 24 \\
\text { hours, decrease in hematocrit }>10 \text { points in } \\
\text { the first } 24 \text { hours, or ISS } \geq 16 \text {. }\end{array}$ & NR & Moderate \\
\hline Paladino, 2010b & $\begin{array}{l}\text { Predetermined based on hospital normal values } \\
\mathrm{BD}>-2.0 \text { : normal } \\
\text { Lactate <2.2: normal }\end{array}$ & $\begin{array}{l}\text { Major injury: blood transfusion, decrease in } \\
\text { hematocrit }>10 \text { points in the first } 24 \text { hours, or } \\
\text { ISS } \geq 16 \text {. }\end{array}$ & NR & Moderate \\
\hline
\end{tabular}




\begin{tabular}{|c|c|c|c|c|}
\hline $\begin{array}{l}\text { Author, Year } \\
\text { (See Appendix B for } \\
\text { complete reference) }\end{array}$ & Study Design & Setting and Dates Performed & Number of Study Subjects & Data Source \\
\hline Pandit, 2014 & Retrospective & $\begin{array}{l}\text { USA } \\
\text { Urban vs. rural: NR } \\
\text { Trauma system level: NR } \\
2004 \text { to } 2007 \\
4 \text { years }\end{array}$ & $\begin{array}{l}217,190 \text { analyzed } \\
485,595 \text { identified }\end{array}$ & National Trauma Data Bank \\
\hline Parimi, 2016 & Retrospective & $\begin{array}{l}\text { USA, Maryland } \\
\text { Urban } \\
\text { Level I trauma center } \\
1 / 2009 \text { to } 12 / 2012 \\
4 \text { years }\end{array}$ & $\begin{array}{l}\text { 10,636 analyzed } \\
18,285 \text { trauma admissions } \\
7,649 \text { excluded } \\
-551 \text { excluded for age }<18 \text { years } \\
-35 \text { excluded for death within } 15 \text { minutes of } \\
\text { arrival or deceased on arrival } \\
-5,163 \text { excluded for missing EMS and ED } \\
\text { SBP or HR } \\
-1,900 \text { excluded for missing data for } 5,10 \text {, } \\
\text { and } 15 \text { minute SBP or HR }\end{array}$ & $\begin{array}{l}\text { Trauma registry for a single } \\
\text { trauma center, EHR, and blood } \\
\text { bank records }\end{array}$ \\
\hline Parsikia, 2014 & Retrospective & $\begin{array}{l}\text { USA, Pennsylvania } \\
\text { Urban } \\
\text { Level I trauma center } \\
1 / 2007 \text { to } 6 / 2012 \\
5 \text { years, } 6 \text { months }\end{array}$ & $\begin{array}{l}1,941 \text { analyzed } \\
3,775 \text { identified } \\
571 \text { excluded for no lactate measurement } \\
72 \text { excluded for age }<18 \text { years } \\
110 \text { excluded for ED presentation }>24 \text { hours } \\
\text { after injury } \\
1,065 \text { excluded for lactate measured }>35 \\
\text { minutes after admission } \\
16 \text { excluded for incompletely documented } \\
\text { injuries }\end{array}$ & $\begin{array}{l}\text { Internal hospital database of } \\
\text { prospectively collected data for } \\
\text { acutely injured patients }\end{array}$ \\
\hline
\end{tabular}




\begin{tabular}{|c|c|c|c|}
\hline $\begin{array}{l}\text { Author, Year } \\
\text { (See Appendix B for } \\
\text { complete reference) }\end{array}$ & Eligibility Criteria & $\begin{array}{l}\text { Age Groups Included (Age Range Used*): \% } \\
\text { of Study Population }\end{array}$ & Type of Population \\
\hline Pandit, 2014 & $\begin{array}{l}\text { Included: Patients } \geq 65 \text { years old. } \\
\text { Excluded: Patients transferred from another institution, dead on } \\
\text { presentation, or with burn injuries, isolated TBI, or recorded } \\
\text { comorbidity of hypertension, or who had missing HR or SBP data. }\end{array}$ & $\begin{array}{l}\text { Elderly }(\geq 65): 100 \% \\
-65-74 \text { years: } 39.3 \%(85,454 / 217,190) \\
-75-84 \text { years: } 45.3 \%(98,479 / 217,190) \\
->85 \text { years: } 15.3 \%(33,257 / 217,190)\end{array}$ & Civilian \\
\hline Parimi, 2016 & $\begin{array}{l}\text { Included: Trauma patients transported directly to the trauma center } \\
\text { by helicopter or ambulance. } \\
\text { Excluded: Patients }<18 \text { years old, those in active cardiac arrest on } \\
\text { admission, with missing HR or SBP data, or who died within } 15 \\
\text { minutes of ED arrival. }\end{array}$ & Adults ( $(\geq 18): 100 \%$ & Civilian \\
\hline Parsikia, 2014 & $\begin{array}{l}\text { Included: Trauma patients } \geq 18 \text { years old. } \\
\text { Excluded: Patients presenting to ED }>24 \text { hours after initial injury, or } \\
\text { who had incompletely documented injuries, and those with no } \\
\text { lactate measurement, lactate measured }>35 \text { minutes after } \\
\text { admission, or with unknown timing of lactate. }\end{array}$ & Adults ( $(\geq 18): 100 \%$ & Civilian \\
\hline
\end{tabular}




\begin{tabular}{|c|c|c|c|c|}
\hline $\begin{array}{l}\text { Author, Year } \\
\text { (See Appendix B for } \\
\text { complete reference) }\end{array}$ & Mechanism or Type Injury & Mode of Transport & $\begin{array}{l}\text { Other Population Characteristics } \\
\text { (Sex, Race) }\end{array}$ & $\begin{array}{l}\text { Name of Measure Being } \\
\text { Evaluated }\end{array}$ \\
\hline Pandit, 2014 & $\begin{array}{l}\text { Blunt: 59.9\% }(130,025 / 217,190) \\
\text { Penetrating: 33.1\% }(71,852 / 217,190)\end{array}$ & NR & $\begin{array}{l}\text { Male: } 61 \%(133,223 / 217,190) \\
\text { Race }^{\star} \\
\text { - White: } 88 \%(174,785 / 199,827) \\
\text { - Black: } 7 \%(13,828 / 199,827) \\
\text { - Hispanic: } 6 \%(11,214 / 199,817) \\
\text { Age (mean): } 78(\text { SD } 7) \\
\\
\text { *Race not reported by the study for } \\
17,363 \text { patients. Percentages are of the } \\
\text { 199,827 patients with reported race. May } \\
\text { not total 100\% due to rounding. }\end{array}$ & $\begin{array}{l}\text { HR } \\
\text { SBP } \\
\text { SI }\end{array}$ \\
\hline Parimi, 2016 & $\begin{array}{l}\text { Type of injury } \\
\text { Blunt: } 87.9 \% \\
\text { Penetrating: } 10.0 \% \\
\text { Other: } 2.1 \% \\
\text { Mechanism of injury } \\
\text { Motor vehicle associated: } 49.9 \% \\
\text { Falls: } 26.0 \% \\
\text { Interpersonal violence: } 10.9 \% \\
\text { Other: } 13.1 \% \\
\text { Undocumented: } 0.04 \%\end{array}$ & Helicopter and Land & $\begin{array}{l}\text { Male: } 68 \% \\
\text { Race: NR } \\
\text { Age (mean): } 43 \text { (SD 19) }\end{array}$ & $\begin{array}{l}\text { Prediction models using vital } \\
\text { signs (HR, SBP, SI) at } 5 \text { time } \\
\text { frames: single measurement } \\
\text { prehospital or at admission; and } \\
\text { continuous over } 5 \text { minutes, } 10 \\
\text { minutes, or } 15 \text { minutes. }\end{array}$ \\
\hline Parsikia, 2014 & $\begin{array}{l}\text { Type of injury } \\
\text { Blunt: } 77.1 \% \\
\text { Penetrating: } 22.8 \% \\
\text { Unknown: } 0.1 \% \\
\\
\text { Mechanism of injury } \\
\text { Fall: } 39.3 \% \\
\text { Gunshot: } 16.4 \% \\
\text { Motor vehicle accident: } 14.8 \% \\
\text { Motorcycle accident: } 3.5 \% \\
\text { Pedestrian accident: } 8.5 \% \\
\text { Stabbing: } 5.9 \% \\
\text { Other: } 11.6 \%\end{array}$ & NR & $\begin{array}{l}\text { Male: } 33 \%(637 / 1,941) \\
\text { Race: NR } \\
\text { Age (median): } 47 \text { (IQR 28-67) }\end{array}$ & Lactate \\
\hline
\end{tabular}




\begin{tabular}{|c|c|c|c|c|}
\hline \begin{tabular}{|l|} 
Author, Year \\
(See Appendix B for \\
complete reference) \\
\end{tabular} & $\begin{array}{l}\text { Location and Timing of } \\
\text { Measurement }\end{array}$ & Method of Measurement & $\begin{array}{l}\text { Personnel Administering Test or } \\
\text { Using Measure }\end{array}$ & Equipment Used/Needed \\
\hline 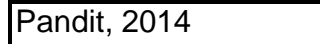 & ED: on arrival & NR & NR & NR \\
\hline Parimi, 2016 & $\begin{array}{l}\text { Out of Hospital: not specified } \\
\text { ED: on arrival and for following } 15 \\
\text { minutes }\end{array}$ & $\begin{array}{l}\text { Prehospital and admission vital } \\
\text { signs: manual Continuous } \\
\text { vital signs: automated } \\
\text { patient monitors } \\
\text { - SBP: noninvasive or arterial }\end{array}$ & NR & $\begin{array}{l}\text { Vital signs measurements: } \\
\text { networked patient monitors (GE- } \\
\text { Morquette-Soar-7000/8000, GE } \\
\text { Healthcare, Little Chalfont, UK) } \\
\text { Vital signs data collection: Bed } \\
\text { Master software (Excel Medical } \\
\text { Electronics, Jupiter, FL) }\end{array}$ \\
\hline Parsikia, 2014 & $\begin{array}{l}\text { ED: on admission } \\
\text { Lactate within } 35 \text { minutes of ED } \\
\text { admission }\end{array}$ & Lactate: venous & NR & NR \\
\hline
\end{tabular}




\begin{tabular}{|c|c|c|c|c|}
\hline $\begin{array}{l}\text { Author, Year } \\
\text { (See Appendix B for } \\
\text { complete reference) }\end{array}$ & $\begin{array}{l}\text { Threshold Value(s) for Physiologic } \\
\text { Measures }\end{array}$ & $\begin{array}{l}\text { Indicator of Serious Injury Used } \\
\text { (including definition and time period) }\end{array}$ & Funding Source & Risk of Bias \\
\hline Pandit, 2014 & SI $\geq 1$ : hemodynamic instability & $\begin{array}{l}\text { Mortality: in-hospital } \\
\text { Blood transfusion requirement: transfusion of } \\
\text { PRBC, whole blood, blood plasma, or human } \\
\text { fibrinogen. } \\
\text { Exploratory laparotomy }\end{array}$ & NR & Moderate \\
\hline Parimi, 2016 & $\begin{array}{l}\text { Extreme values removed during data } \\
\text { preprocessing: } \\
\text { - } \mathrm{HR}<250 \mathrm{bpm} \\
\text { - } \mathrm{SBP}>300 \mathrm{mmHg} \\
\text { Critical thresholds for abnormal vital signs: } \\
\text { - } \mathrm{HR} \geq 120 \mathrm{bpm} \\
\text { - } \mathrm{SBP} \leq 90 \mathrm{mmHg} \\
\text { - } \mathrm{SI} \geq 1.0\end{array}$ & $\begin{array}{l}\text { Massive transfusion, category } 1 \text { (MT1): Blood } \\
\text { transfusion }>4 \text { units in } 4 \text { hours } \\
\text { Massive transfusion, category } 2 \text { (MT2): Blood } \\
\text { transfusion }>10 \text { units in } 24 \text { hours }\end{array}$ & NR & Moderate \\
\hline Parsikia, 2014 & $\mathrm{NR}$ & Mortality: in hospital & NR & Moderate \\
\hline
\end{tabular}




\begin{tabular}{|c|c|c|c|c|}
\hline $\begin{array}{l}\text { Author, Year } \\
\text { (See Appendix B for } \\
\text { complete reference) }\end{array}$ & Study Design & Setting and Dates Performed & Number of Study Subjects & Data Source \\
\hline \begin{tabular}{|l} 
Perel, 2012 \\
Perel, 2013
\end{tabular} & Retrospective & $\begin{array}{l}\text { International } \\
\text { Urban vs. rural: NR (large data sets) } \\
\text { Trauma system level: NR (large number of } \\
\text { hospitals) } \\
\text { Validation data set (TARN): } 2000-2008 \\
9 \text { years }\end{array}$ & \begin{tabular}{|l}
34,347 analyzed \\
Development dataset: 20,127 \\
Validation dataset: 14,220
\end{tabular} & $\begin{array}{l}\text { Development: CRASH-2 trial } \\
\text { Validation: TARN }\end{array}$ \\
\hline Potoka, 2001 & Retrospective & $\begin{array}{l}\text { USA, Pennsylvania } \\
\text { Urban vs. rural: NR (state-wide registry) } \\
\text { Trauma system level: NR (trauma centers) } \\
1993 \text { to } 1997 \\
5 \text { years } \\
\text { Study data set: } 1993 \text { to } 1996 \\
\text { Test data set: } 1997\end{array}$ & $\begin{array}{l}11,978 \text { analyzed } \\
-9730 \text { in study data set } \\
-2248 \text { in test data set } \\
\\
14,284 \text { identified } \\
431 \text { excluded for burn injury } \\
1,875 \text { excluded for incomplete data required } \\
\text { for analysis }\end{array}$ & $\begin{array}{l}\text { Pennsylvania Trauma Outcome } \\
\text { Study registry }\end{array}$ \\
\hline
\end{tabular}




\begin{tabular}{|c|c|c|c|}
\hline \begin{tabular}{|l|} 
Author, Year \\
(See Appendix B for \\
complete reference) \\
\end{tabular} & Eligibility Criteria & $\begin{array}{l}\text { Age Groups Included (Age Range Used*): \% } \\
\text { of Study Population }\end{array}$ & Type of Population \\
\hline \begin{tabular}{|l|} 
Perel, 2012 \\
Perel, 2013
\end{tabular} & $\begin{array}{l}\text { Development dataset } \\
\text { Included: Trauma patients with or at risk of significant bleeding } \\
\text { within } 8 \text { hours of injury. } \\
\text { Excluded: No exclusion criteria were specified. } \\
\text { Validation dataset } \\
\text { Included: Trauma patients age }>15 \text { years with estimated blood loss } \\
\text { of } \geq 20 \% \text {, and who had a hospital length of stay }>3 \text { days, died from } \\
\text { injury at any point during admission, or needed intensive care or } \\
\text { inter-hospital transfer for specialist care. } \\
\text { Excluded: Patients who were dead on hospital arrival, had isolated } \\
\text { losed limb injuries, or were }>65 \text { years old with isolated fractured } \\
\text { neck of femur or pubic ramus. }\end{array}$ & Adults (>15): $100 \%$ & Civilian \\
\hline Potoka, 2001 & $\begin{array}{l}\text { Included: Children ages } 0 \text { to } 16 \text { years who were treated at an } \\
\text { accredited trauma center in the state. } \\
\text { Excluded: Patients without complete data required for analysis, and } \\
\text { burn patients. }\end{array}$ & Children ( $\leq 16): 100 \%$ & Civilian \\
\hline
\end{tabular}




\begin{tabular}{|c|c|c|c|c|}
\hline $\begin{array}{l}\text { Author, Year } \\
\text { (See Appendix B for } \\
\text { complete reference) }\end{array}$ & Mechanism or Type Injury & Mode of Transport & $\begin{array}{l}\text { Other Population Characteristics } \\
\text { (Sex, Race) }\end{array}$ & $\begin{array}{l}\text { Name of Measure Being } \\
\text { Evaluated }\end{array}$ \\
\hline \begin{tabular}{|l|} 
Perel, 2012 \\
Perel, 2013
\end{tabular} & Penetrating: $24.8 \%(8,515 / 34,347)$ & NR & $\begin{array}{l}\text { Male: NR } \\
\text { Race: NR } \\
\text { Age (median) } \\
\text { - Development dataset: } 30 \text { (IQR 24-43) } \\
\text { - Validation dataset: } 39 \text { (IQR 25-57) }\end{array}$ & $\begin{array}{l}\text { Simple prognostic model: uses } \\
\text { age, SBP, GCS score (stratified } \\
\text { by low-, middle-, and high- } \\
\text { income countries) }\end{array}$ \\
\hline Potoka, 2001 & Blunt: $89.1 \%(10,6 / 0 / 11,9 / 8)$ & |NR & $\begin{array}{l}\text { Nale: } 68 \% \text { (8,128/11,9/8) } \\
\text { Race: NR } \\
\text { Age (mean): } 9 \text { (SD 5) }\end{array}$ & $\begin{array}{l}\text { GCS at age-specific cut-offs } \\
\text { RTS: GCS, RR and SBP }\end{array}$ \\
\hline
\end{tabular}




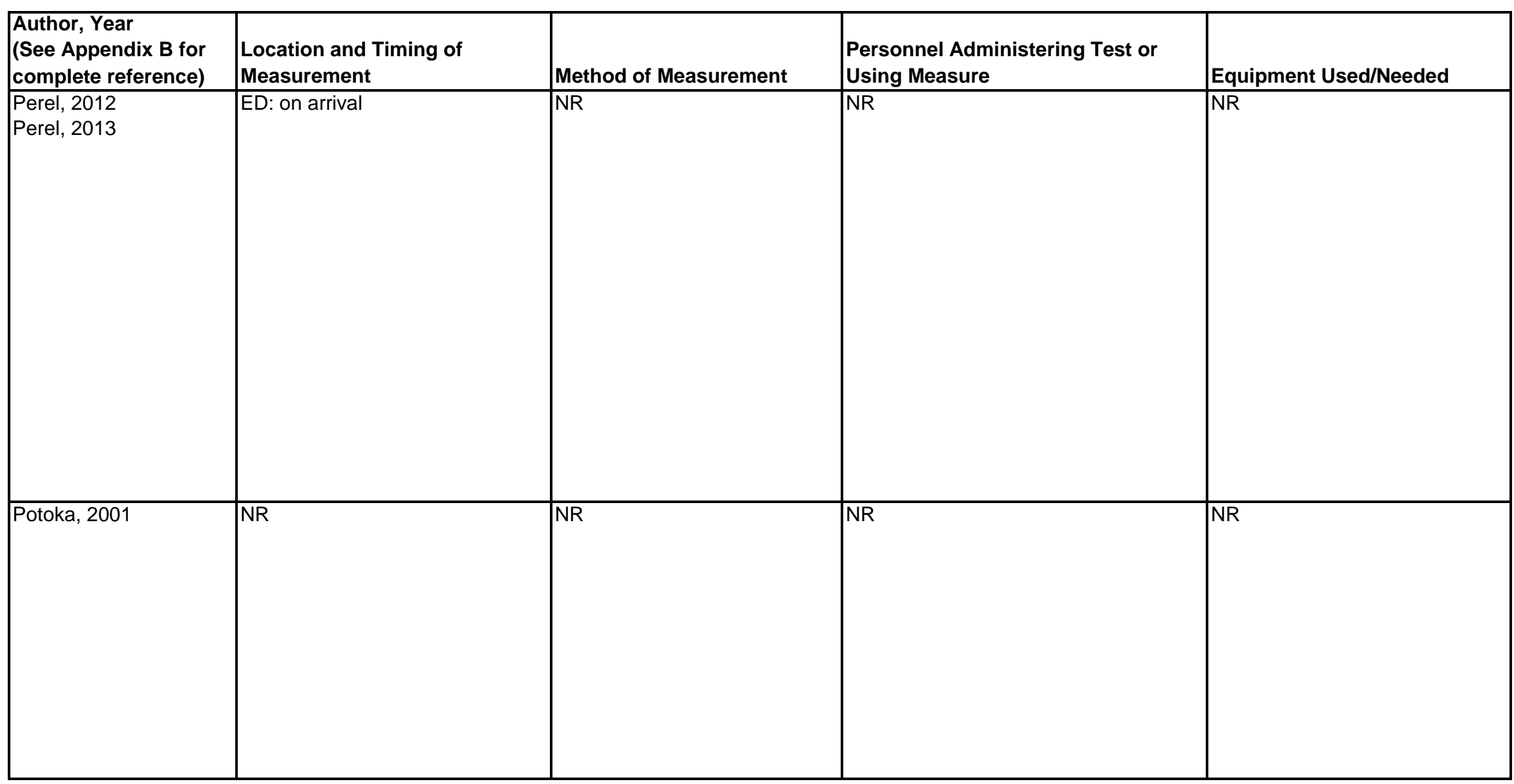




\begin{tabular}{|c|c|c|c|c|}
\hline \begin{tabular}{|l|} 
Author, Year \\
(See Appendix B for \\
complete reference) \\
\end{tabular} & $\begin{array}{l}\text { Threshold Value(s) for Physiologic } \\
\text { Measures }\end{array}$ & $\begin{array}{l}\text { Indicator of Serious Injury Used } \\
\text { (including definition and time period) }\end{array}$ & Funding Source & Risk of Bias \\
\hline \begin{tabular}{|l} 
Perel, 2012 \\
Perel, 2013
\end{tabular} & NR & In-hospital mortality within 4 weeks of injury & $\begin{array}{l}\text { Funded by the UK Health } \\
\text { Technology Assessment } \\
\text { programme (09/22/165). }\end{array}$ & Moderate \\
\hline Potoka, 2001 & $\begin{array}{l}\text { T-ASPTS }<10 \\
\text { RTS }<12\end{array}$ & $\begin{array}{l}\text { ISS >20 } \\
\text { Mortality: time period not specified }\end{array}$ & $\begin{array}{l}\text { Supported in part by the Children's } \\
\text { Hospital Pittsburgh }\end{array}$ & Moderate \\
\hline
\end{tabular}




\begin{tabular}{|l|l|l|l|l|}
\hline $\begin{array}{l}\text { Author, Year } \\
\text { (See Appendix B for } \\
\text { complete reference) }\end{array}$ & Study Design & Setting and Dates Performed & Number of Study Subjects \\
\hline Pottecher, 2016 & Retrospective & $\begin{array}{l}\text { France } \\
\text { Urban vs. rural: NR (regional multicenter } \\
\text { registry) } \\
\text { Levels I-III trauma centers } \\
1 / 1 / 2009 \text { to 12/31/2011 } \\
3 \text { years }\end{array}$ & $\begin{array}{l}2,557 \text { analyzed } \\
3,689 \text { major traumas in registry } \\
594 \text { excluded for non-EMS transport } \\
538 \text { excluded for missing data on HR, BP, or } \\
\text { blood transfusion }\end{array}$ \\
& & & \\
& & \\
\end{tabular}




\begin{tabular}{|l|l|l|l|}
\hline $\begin{array}{l}\text { Author, Year } \\
\text { (See Appendix B for } \\
\text { complete reference) }\end{array}$ & Eligibility Criteria & $\begin{array}{l}\text { Age Groups Included (Age Range Used*): \% } \\
\text { of Study Population }\end{array}$ & Type of Population \\
\hline Pottecher, 2016 & $\begin{array}{l}\text { Included: Major trauma patients in registry. } \\
\text { Excluded: Patients with intractable cardiac arrest prior to EMS } \\
\text { arrival, those who had non-EMS or unknown prehospital transport, } \\
\text { and those with missing data for HR, BP, or blood transfusion. }\end{array}$ & Civilian \\
& & & \\
& & \\
\hline
\end{tabular}




\begin{tabular}{|l|l|l|l|l|}
\hline $\begin{array}{l}\text { Author, Year } \\
\text { (See Appendix B for } \\
\text { complete reference) }\end{array}$ & Mechanism or Type Injury & Mode of Transport & $\begin{array}{l}\text { Other Population Characteristics } \\
\text { (Sex, Race) }\end{array}$ & $\begin{array}{l}\text { Name of Measure Being } \\
\text { Evaluated }\end{array}$ \\
\hline Pottecher, 2016 & $\begin{array}{l}\text { Type of injury } \\
\text { Blunt: 92\% } \\
\text { Penetrating: 8\% } \\
\text { Mechanism of blunt injury } \\
\text { Traffic accident: 47\% } \\
\text { Falls: 19\% } \\
\text { Skiing accidents: 13\% } \\
\text { Other mountain accidents: 10\% } \\
\text { Other: } 3 \% \\
\text { NR: } 8 \%\end{array}$ & $\begin{array}{l}\text { Male: 76\% (1,941/2,557) } \\
\text { Race: NR } \\
\text { Age (mean): 37 (SD 19) }\end{array}$ & $\begin{array}{l}\text { PP/HR ratio } \\
\text { SBP } \\
\text { SI }\end{array}$ \\
& & & \\
& & & \\
& & & \\
\end{tabular}




\begin{tabular}{|l|l|l|l|l|}
\hline $\begin{array}{l}\text { Author, Year } \\
\text { (See Appendix B } \\
\text { for complete }\end{array}$ & $\begin{array}{l}\text { Location and Timing of } \\
\text { Measurement }\end{array}$ & Method of Measurement & $\begin{array}{l}\text { Personnel Administering Test or } \\
\text { Using Measure }\end{array}$ & Equipment Used/Needed \\
\hline Pottecher, 2016 & Out of hospital: on arrival & NR & NR & \\
& & & & \\
& & & & \\
\end{tabular}




\begin{tabular}{|c|c|c|c|c|}
\hline \begin{tabular}{|l|} 
Author, Year \\
(See Appendix B for \\
complete reference)
\end{tabular} & $\begin{array}{l}\text { Threshold Value(s) for Physiologic } \\
\text { Measures }\end{array}$ & $\begin{array}{l}\text { Indicator of Serious Injury Used } \\
\text { (including definition and time period) }\end{array}$ & Funding Source & Risk of Bias \\
\hline Pottecher, 2016 & $\begin{array}{l}\text { Cutoffs maximizing the Youden index: } \\
\text { PP/HR ratio <0.433 for massive transfusion in 1- } \\
\text { and } 24 \text {-hours } \\
\text { SI }>0.967 \text { for massive transfusion in } 24 \text { hours } \\
\text { SI }>0.933 \text { for massive transfusion within } 1 \text { hour } \\
\text { TRENAU triage grading system: A (highest } \\
\text { clinical severity), B, or C (lowest clinical } \\
\text { severity) } \\
\text { - adapted from the French Vittel triage criteria } \\
\text { Gray zone: approach used to determine a range } \\
\text { of values for PP/HR and SI for which no } \\
\text { conclusion can be made concerning } \\
\text { forthcoming massive transfusion. The } \\
\text { boundaries were defined as the values that did } \\
\text { not allow sensitivity and specificity } \geq 90 \% \text {. }\end{array}$ & $\begin{array}{l}\text { Massive transfusion, classic definition: } \\
\text { transfusion of } \geq 10 \text { PRBC units in } 24 \text { hours. } \\
\\
\text { Massive transfusion, critical definition: } \\
\text { transfusion of } \geq 3 \text { PRBC units during the first } \\
\text { hour after admission. }\end{array}$ & $\begin{array}{l}\text { Supported only by institutional } \\
\text { funds. }\end{array}$ & Moderate \\
\hline
\end{tabular}




\begin{tabular}{|c|c|c|c|c|}
\hline $\begin{array}{l}\text { Author, Year } \\
\text { (See Appendix B for } \\
\text { complete reference) }\end{array}$ & Study Design & Setting and Dates Performed & Number of Study Subjects & Data Source \\
\hline Rahmani, 2017 & Prospective & $\begin{array}{l}\text { Iran } \\
\text { Urban } \\
\text { Trauma system level: NR } \\
3 / 2014 \text { to } 10 / 2014 \\
8 \text { months }\end{array}$ & 374 analyzed & Primary data collection \\
\hline Rainer, 2011 & Retrospective & 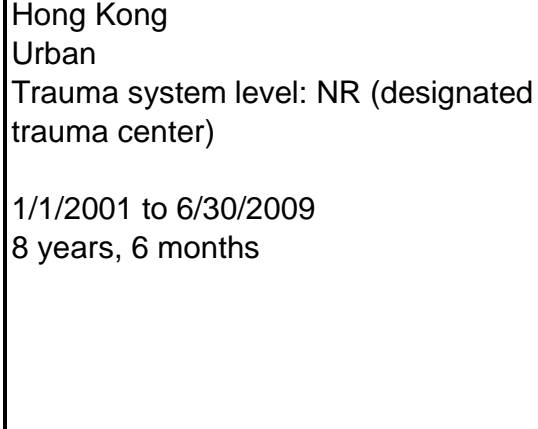 & $\begin{array}{l}\text { 1,891 analyzed } \\
4,336 \text { identified } \\
140 \text { excluded as dead on arrival } \\
293 \text { excluded for age }<12 \text { years } \\
1,829 \text { excluded for ISS }<9 \\
145 \text { excluded for burn injury or drowning } \\
10 \text { excluded for anemia or chronic renal } \\
\text { failure } \\
28 \text { excluded for transfusion }<10 \text { units and } \\
\text { death within } 24 \text { hours }\end{array}$ & $\begin{array}{l}\text { Trauma registry for a single } \\
\text { trauma center }\end{array}$ \\
\hline
\end{tabular}




\begin{tabular}{|c|c|c|c|}
\hline $\begin{array}{l}\text { Author, Year } \\
\text { (See Appendix B for } \\
\text { complete reference) }\end{array}$ & Eligibility Criteria & $\begin{array}{l}\text { Age Groups Included (Age Range Used*): \% } \\
\text { of Study Population }\end{array}$ & Type of Population \\
\hline Rahmani, 2017 & $\begin{array}{l}\text { Included: Patients } \geq 18 \text { years old with multiple trauma ( } \geq 2 \text { severe } \\
\text { injuries in } \geq 2 \text { areas of the body), transported to the ED by EMS or } \\
\text { family members. } \\
\text { Excluded: Patients with isolated trauma, those who had been } \\
\text { transferred from other centers, refused to participate in the study, or } \\
\text { were suffering cardiac arrest on ED arrival. }\end{array}$ & Adults ( $(\geq 18): 100 \%$ & Civilian \\
\hline Rainer, 2011 & $\begin{array}{l}\text { Included: Trauma patients } \geq 12 \text { years old with an ISS } \geq 9 \text {. } \\
\text { Excluded: Patients }<12 \text { years old, those with ISS }<9 \text {, chronic renal } \\
\text { failure or known anemia, any who were transfused }<10 \text { units of } \\
\text { blood and died within } 24 \text { hours, and those who were dead on arrival. }\end{array}$ & Adults and adolescents ( $\geq 12): 100 \%$ & Civilian \\
\hline
\end{tabular}




\begin{tabular}{|c|c|c|c|c|}
\hline $\begin{array}{l}\text { Author, Year } \\
\text { (See Appendix B for } \\
\text { complete reference) } \\
\end{array}$ & Mechanism or Type Injury & Mode of Transport & $\begin{array}{l}\text { Other Population Characteristics } \\
\text { (Sex, Race) }\end{array}$ & $\begin{array}{l}\text { Name of Measure Being } \\
\text { Evaluated }\end{array}$ \\
\hline Rahmani, 2017 & \begin{tabular}{|l|} 
Mechanism of injury: \\
Blunt: $96 \%(359 / 374)$ \\
Penetrating: $4 \%(15 / 374)$
\end{tabular} & NR & $\begin{array}{l}\text { Male: } 82 \% \text { (307/374) } \\
\text { Race: NR } \\
\text { Age (mean): } 40 \text { (SD 18) }\end{array}$ & $\begin{array}{l}\text { GAP } \\
\text { MGAP }\end{array}$ \\
\hline JRamel, ZUAl & $\begin{array}{l}\text { Penetrating: } 4 \% \\
\text { Mechanism of injury } \\
\text { Motor vehicle crash: } 21 \% \\
\text { Pedestrian: } 14 \% \\
\text { Motorcycle crash: } 7 \% \\
\text { Bicycle related: } 8 \% \\
\text { Penetrating causes: } 4 \% \\
\text { Fall: } 35 \% \\
\text { Other: } 11 \%\end{array}$ & jNR & $\begin{array}{l}\text { Race: NR } \\
\text { Age (mean): } 44 \text { (SD 19) }\end{array}$ & $\begin{array}{l}\mathrm{BD} \\
\mathrm{HR} \\
\mathrm{SBP} \\
\mathrm{pH} \\
\text { Predictive model for massive } \\
\text { transfusion (uses SBP, GCS, } \\
\text { HR, BD, hemoglobin, pelvic } \\
\text { fracture and abdominal free fluid) }\end{array}$ \\
\hline
\end{tabular}




\begin{tabular}{|c|c|c|c|c|}
\hline \begin{tabular}{|l|} 
Author, Year \\
(See Appendix B for \\
complete reference)
\end{tabular} & $\begin{array}{l}\text { Location and Timing of } \\
\text { Measurement }\end{array}$ & Method of Measurement & $\begin{array}{l}\text { Personnel Administering Test or } \\
\text { Using Measure }\end{array}$ & Equipment Used/Needed \\
\hline Rahmani, 2017 & ED: not specified & NR & NR & NR \\
\hline
\end{tabular}




\begin{tabular}{|c|c|c|c|c|}
\hline $\begin{array}{l}\text { Author, Year } \\
\text { (See Appendix B for } \\
\text { complete reference) }\end{array}$ & $\begin{array}{l}\text { Threshold Value(s) for Physiologic } \\
\text { Measures }\end{array}$ & $\begin{array}{l}\text { Indicator of Serious Injury Used } \\
\text { (including definition and time period) }\end{array}$ & Funding Source & Risk of Bias \\
\hline Rahmani, 2017 & $\begin{array}{l}\text { Cutoff points; determination method not } \\
\text { described. } \\
\text { GAP } \\
\text { - Need for surgery: } 21 \\
\text { - Mortality, ED: } 18 \\
\text { - Mortality, in-hospital: } 14 \\
\text { MGAP } \\
\text { - Need for surgery: } 25 \\
\text { - Mortality, ED: } 22 \\
\text { - Mortality, in-hospital: } 18 \\
\\
\text { GAP and MGAP scoring systems } \\
\text { Age }<60=5 \text { points } \\
\text { GCS }=3-15 \text { points (direct value) } \\
\text { SBP >120 = } 5 \text { points } \\
\text { SBP } 60-120=3 \text { points } \\
\text { for MGAP, mechanism } \\
\text { Blunt trauma }=4 \text { points }\end{array}$ & $\begin{array}{l}\text { Need for surgery: laparotomy, chest tube } \\
\text { insertion, craniotomy, spinal column and } \\
\text { orthopedic procedures } \\
\text { Mortality: ED } \\
\text { Mortality: in-hospital }\end{array}$ & $\begin{array}{l}\text { Not supported by any funding } \\
\text { organization and there is no } \\
\text { sponsor of the work. }\end{array}$ & Moderate \\
\hline Rainer, 2011 & $\begin{array}{l}\text { BD: }<-5 \mathrm{mmol} / \mathrm{L} \\
\text { HR: } \geq 120 \mathrm{bpm} \\
\text { pH: } \leq 7.33 \\
\text { SBP: }<90 \mathrm{~mm} \text { Hg } \\
\text { Predictive model for massive transfusion: score } \\
\geq 6 \\
\text { scoring system: } \\
1 \text { point each: } \mathrm{GCS} \leq 8, \mathrm{HR} \geq 120 \text {, displaced } \\
\text { pelvic fracture, } \mathrm{BD}<-5, \text { hemoglobin } 7.1-10 \\
2 \text { points: positive } \mathrm{CT} \text { scan or FAST } \\
3 \text { points: } \mathrm{SBP} \leq 90 \\
10 \text { points: hemoglobin } \leq 7\end{array}$ & $\begin{array}{l}\text { Massive transfusion: transfusion of } \geq 10 \text { PRBC } \\
\text { units within } 24 \text { hours }\end{array}$ & No funding sources for this study. & Moderate \\
\hline
\end{tabular}




\begin{tabular}{|c|c|c|c|c|}
\hline $\begin{array}{l}\text { Author, Year } \\
\text { (See Appendix B for } \\
\text { complete reference) }\end{array}$ & Study Design & Setting and Dates Performed & Number of Study Subjects & Data Source \\
\hline Ramanathan, 2015 & Prospective & $\begin{array}{l}\text { USA, Virginia } \\
\text { Urban } \\
\text { Level I trauma center } \\
6 / 2011 \text { to } 7 / 2013 \\
2 \text { years }\end{array}$ & $\begin{array}{l}236 \text { analyzed } \\
288 \text { identified } \\
10 \text { excluded for no lactate measurement } \\
42 \text { excluded as transfer patients }\end{array}$ & $\begin{array}{l}\text { Prospective collection of internal } \\
\text { hospital data }\end{array}$ \\
\hline $\begin{array}{l}\text { Raux, } 2006 \\
\text { *Raux } 2006 \text { (study } \\
\text { population) and Raux } \\
2011 / \text { Sartorius } 2010 \\
\text { (derivation cohort) draw } \\
\text { from the same } \\
\text { population, but number } \\
\text { analyzed differs due to } \\
\text { missing data exclusion } \\
\text { based on different } \\
\text { variables }\end{array}$ & Retrospective & $\begin{array}{l}\text { France } \\
\text { Urban vs. Rural: NR } \\
\text { Trauma system level: NR } \\
2002 \\
1 \text { year }\end{array}$ & $\begin{array}{l}\text { 1,481 analyzed } \\
-675 \text { with both RR and SpO2 measurements } \\
-806 \text { without RR or SpO2 measurements } \\
1,501 \text { identified } \\
20 \text { excluded for missing data }\end{array}$ & $\begin{array}{l}\text { Vittel Trauma Group } \\
\text { epidemiologic study, } \\
\text { prospectively collected }\end{array}$ \\
\hline $\begin{array}{l}\text { Raux, } 2011 \\
\text { Sartorius, } 2010 \\
\text { *Raux } 2006 \text { (study } \\
\text { population) and Raux } \\
\text { 2011/Sartorius } 2010 \\
\text { (derivation cohort) draw } \\
\text { from the same } \\
\text { population, but number } \\
\text { analyzed differs due to } \\
\text { missing data exclusion } \\
\text { based on different } \\
\text { variables }\end{array}$ & Prospective & $\begin{array}{l}\text { France } \\
\text { Urban vs. rural: NR } \\
\text { Trauma system level: NR (multicenter) } \\
\text { Derivation (National) cohort } \\
22 \text { centers } \\
1 / 1 / 2002 \text { to } 12 / 31 / 2002 \\
1 \text { year } \\
\text { Validation (Lyon) cohort } \\
2003 \text { to } 2005 \\
3 \text { years }\end{array}$ & $\begin{array}{l}\text { 2,363 analyzed } \\
-1,360 \text { in National cohort } \\
\text { - 1,003 in Lyon cohort } \\
\text { Derivation/National cohort: } \\
\text { 1,501 identified } \\
141 \text { excluded for missing data } \\
\text { Validation/Lyon cohort: } \\
\text { 1,050 identified } \\
47 \text { excluded for missing data }\end{array}$ & $\begin{array}{l}\text { Prospectively collected; includes } \\
\text { data from the Vittel Trauma } \\
\text { Group epidemiologic study and } \\
\text { 2nd separate cohort. }\end{array}$ \\
\hline
\end{tabular}




\begin{tabular}{|c|c|c|c|}
\hline $\begin{array}{l}\text { Author, Year } \\
\text { (See Appendix B for } \\
\text { complete reference) }\end{array}$ & Eligibility Criteria & $\begin{array}{l}\text { Age Groups Included (Age Range Used*): \% } \\
\text { of Study Population }\end{array}$ & Type of Population \\
\hline Ramanathan, 2015 & $\begin{array}{l}\text { Included: Pediatric patients }<15 \text { years old who met trauma alert } \\
\text { criteria. } \\
\text { Excluded: Patients transferred from other hospitals and those } \\
\text { without lactate measurements. }\end{array}$ & $\begin{array}{l}\text { Children (<15): } 100 \% \\
\text { - Infants (0 to18 months): } 7.6 \% \\
\text { - Toddlers (19 months to } 5 \text { years): } 17.8 \% \\
\text { - School age ( } 6 \text { to } 12 \text { years): } 41.5 \% \\
\text { - Adolescents (13-14 years): } 33.1 \%\end{array}$ & Civilian \\
\hline $\begin{array}{l}\text { Raux, } 2006 \\
\text { *Raux } 2006 \text { (study } \\
\text { population) and Raux } \\
2011 / \text { Sartorius } 2010 \\
\text { (derivation cohort) draw } \\
\text { from the same } \\
\text { population, but number } \\
\text { analyzed differs due to } \\
\text { missing data exclusion } \\
\text { based on different } \\
\text { variables }\end{array}$ & $\begin{array}{l}\text { Included: Trauma patients cared for by a mobile ICU. } \\
\text { Excluded: Patients with important data missing. }\end{array}$ & NR & Civilian \\
\hline $\begin{array}{l}\text { Raux, } 2011 \\
\text { Sartorius, } 2010 \\
\text { *Raux } 2006 \text { (study } \\
\text { population) and Raux } \\
2011 / \text { Sartorius } 2010 \\
\text { (derivation cohort) draw } \\
\text { from the same } \\
\text { population, but number } \\
\text { analyzed differs due to } \\
\text { missing data exclusion } \\
\text { based on different } \\
\text { variables }\end{array}$ & $\begin{array}{l}\text { Included: Patients cared for by a mobile ICU for trauma severity } \\
\text { warranting medical prehospital care. } \\
\text { Excluded: Patients pronounced dead on the scene and those with } \\
\text { important data missing. }\end{array}$ & NR & Civilian \\
\hline
\end{tabular}




\begin{tabular}{|c|c|c|c|c|}
\hline $\begin{array}{l}\text { Author, Year } \\
\text { (See Appendix B for } \\
\text { complete reference) }\end{array}$ & Mechanism or Type Injury & Mode of Transport & $\begin{array}{l}\text { Other Population Characteristics } \\
\text { (Sex, Race) }\end{array}$ & $\begin{array}{l}\text { Name of Measure Being } \\
\text { Evaluated }\end{array}$ \\
\hline Ramanathan, 2015 & $\begin{array}{l}\text { Mechanism of injury } \\
\text { Motor vehicle crash: } 47 \% \\
\text { Fall: } 12.7 \% \\
\text { Pedestrian injury: } 17.4 \% \\
\text { ATV: } 5.5 \% \\
\text { Assault: } 2.5 \% \\
\text { Bicycle: } 2.5 \% \\
\text { Burn: } 3 \% \\
\text { Gunshot: } 3 \% \\
\text { Other: } 6.4 \%\end{array}$ & NR & $\begin{array}{l}\text { Male: NR } \\
\text { Race: NR } \\
\text { Age (mean): } 9 \text { (SD 5) }\end{array}$ & $\begin{array}{l}\text { Base deficit } \\
\text { Lactate } \\
\text { Lactate and } \mathrm{pH} \\
\mathrm{pH}\end{array}$ \\
\hline $\begin{array}{l}\text { Raux, } 2006 \\
\text { *Raux } 2006 \text { (study } \\
\text { population) and Raux } \\
\text { 2011/Sartorius } 2010 \\
\text { (derivation cohort) draw } \\
\text { from the same } \\
\text { population, but number } \\
\text { analyzed differs due to } \\
\text { missing data exclusion } \\
\text { based on different } \\
\text { variables }\end{array}$ & $\begin{array}{l}\text { Blunt: } 91 \%(1,346 / 1,481) \\
\text { Penetrating: } 9 \%(135 / 1,481) \\
\text { Sites of trauma (multiple sites reported when } \\
\text { applicable) } \\
\text { Head: } 60 \%(896 / 1,481) \\
\text { Spinal: } 23 \%(334 / 1,481) \\
\text { Thoracic: } 49 \%(724 / 1,481) \\
\text { Abdominal: } 25 \%(365 / 1,481) \\
\text { Pelvic: } 20 \%(301 / 1,481) \\
\text { Limb: } 55 \%(812 / 1,421)\end{array}$ & Mobile ICU & $\begin{array}{l}\text { Male: } 75 \%(1,112 / 1,481) \\
\text { Race: NR } \\
\text { Age (mean): } 37 \text { (SD 18) }\end{array}$ & $\begin{array}{l}\text { RR } \\
\text { RTS } \\
\text { SpO2 }\end{array}$ \\
\hline $\begin{array}{l}\text { Raux, } 2011 \\
\text { Sartorius, } 2010 \\
\text { *Raux } 2006 \text { (study } \\
\text { population) and Raux } \\
2011 / \text { Sartorius } 2010 \\
\text { (derivation cohort) draw } \\
\text { from the same } \\
\text { population, but number } \\
\text { analyzed differs due to } \\
\text { missing data exclusion } \\
\text { based on different } \\
\text { variables }\end{array}$ & $\begin{array}{l}\text { Blunt: 89\% }(2,096 / 2,363) \\
\text { Penetrating: } 11 \%(267 / 2,363)\end{array}$ & Mobile ICU & $\begin{array}{l}\text { Male: } 76 \%(1,790 / 2,363) \\
\text { Race: NR } \\
\text { Age (mean): } 38 \text { (SD 17) }\end{array}$ & $\begin{array}{l}\text { HR } \\
\text { MGAP } \\
\text { RTS } \\
\text { SBP } \\
\text { T-RTS }\end{array}$ \\
\hline
\end{tabular}




\begin{tabular}{|c|c|c|c|c|}
\hline \begin{tabular}{|l|} 
Author, Year \\
(See Appendix B for \\
complete reference) \\
\end{tabular} & $\begin{array}{l}\text { Location and Timing of } \\
\text { Measurement }\end{array}$ & Method of Measurement & $\begin{array}{l}\text { Personnel Administering Test or } \\
\text { Using Measure }\end{array}$ & Equipment Used/Needed \\
\hline Ramanathan, 2015 & ED: on admission & NR & NR & NR \\
\hline $\begin{array}{l}\text { Raux, } 2006 \\
\text { *Raux } 2006 \text { (study } \\
\text { population) and Raux } \\
\text { 2011/Sartorius } 2010 \\
\text { (derivation cohort) draw } \\
\text { from the same } \\
\text { population, but number } \\
\text { analyzed differs due to } \\
\text { missing data exclusion } \\
\text { based on different } \\
\text { variables }\end{array}$ & $\begin{array}{l}\text { Out of Hospital: during } \\
\text { resuscitation } \\
\text { ED: on arrival }\end{array}$ & NR & NR & NR \\
\hline \begin{tabular}{|l} 
Raux, 2011 \\
Sartorius, 2010 \\
\\
*Raux 2006 (study \\
population) and Raux \\
2011/Sartorius 2010 \\
(derivation cohort) draw \\
from the same \\
population, but number \\
analyzed differs due to \\
missing data exclusion \\
based on different \\
variables
\end{tabular} & $\begin{array}{l}\text { Out of Hospital: during } \\
\text { resuscitation }\end{array}$ & NR & NR & NR \\
\hline
\end{tabular}




\begin{tabular}{|c|c|c|c|c|}
\hline $\begin{array}{l}\text { Author, Year } \\
\text { (See Appendix B for } \\
\text { complete reference) }\end{array}$ & $\begin{array}{l}\text { Threshold Value(s) for Physiologic } \\
\text { Measures }\end{array}$ & $\begin{array}{l}\text { Indicator of Serious Injury Used } \\
\text { (including definition and time period) }\end{array}$ & Funding Source & Risk of Bias \\
\hline Ramanathan, 2015 & $\begin{array}{l}\text { Lactate }>2.0 \text { and }>4.7 \mathrm{mmol} / \mathrm{L} \\
\text { Base deficit }<-5.0 \mathrm{mmol} / \mathrm{L} \\
\text { acidosis: } \mathrm{pH}<7.30\end{array}$ & $\begin{array}{l}\text { ICU admission } \\
\text { ISS }>15 \\
\text { Major procedure: performed in the OR }\end{array}$ & NR & Low \\
\hline $\begin{array}{l}\text { Raux, } 2006 \\
\text { *Raux } 2006 \text { (study } \\
\text { population) and Raux } \\
2011 / \text { Sartorius } 2010 \\
\text { (derivation cohort) draw } \\
\text { from the same } \\
\text { population, but number } \\
\text { analyzed differs due to } \\
\text { missing data exclusion } \\
\text { based on different } \\
\text { variables }\end{array}$ & $\begin{array}{l}\text { RTS neutralized for RR: effect of RR neutralized } \\
\text { by giving a RR of } 20 \mathrm{~min}^{-1} \text { in all patients. }\end{array}$ & Mortality: 30-day & NR & Moderate \\
\hline $\begin{array}{l}\text { Raux, } 2011 \\
\text { Sartorius, } 2010 \\
\text { *Raux } 2006 \text { (study } \\
\text { population) and Raux } \\
\text { 2011/Sartorius } 2010 \\
\text { (derivation cohort) draw } \\
\text { from the same } \\
\text { population, but number } \\
\text { analyzed differs due to } \\
\text { missing data exclusion } \\
\text { based on different } \\
\text { variables }\end{array}$ & $\begin{array}{l}\text { MGAP }<23 \\
\text { T-RTS }<12 \\
\text { RTS }<7.5 \\
\text { Thresholds corresponding to sensitivity at or } \\
\text { near } 95 \% \\
\text { SBP }>120,60-120, \text { and }<60 \\
\text { Categories supported by clinical observation, no } \\
\text { clear statistical cutoffs }\end{array}$ & $\begin{array}{l}\text { Severe trauma: ISS }>15 \\
\text { ICU LOS }>2 \text { days or death } \\
\text { Massive hemorrhage: blood transfusion of }>6 \\
\text { PRBCs or death from hemorrhagic shock. } \\
\text { Emergency procedure: need for emergency } \\
\text { thoracic drainage, emergency laparotomy, } \\
\text { emergency embolization, or emergency } \\
\text { surgery (other than laparotomy) within the first } \\
3 \text { hours after admission. } \\
\text { Mortality: death from any cause within } 30 \text { days }\end{array}$ & $\begin{array}{l}\text { Conflict of interest: authors declare } \\
\text { no conflict of interest. }\end{array}$ & Moderate \\
\hline
\end{tabular}




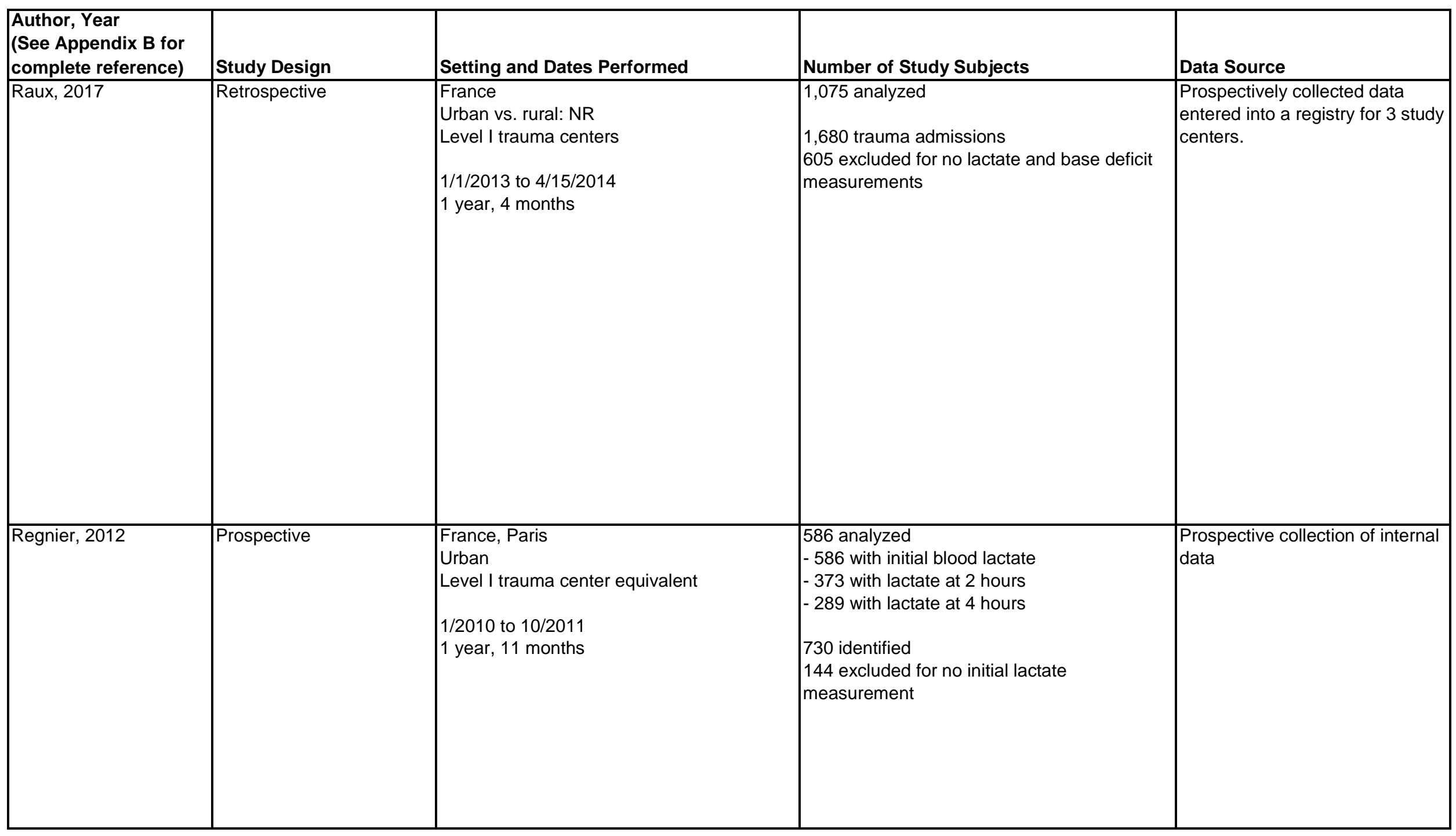




\begin{tabular}{|c|c|c|c|}
\hline \begin{tabular}{|l|} 
Author, Year \\
(See Appendix B for \\
complete reference)
\end{tabular} & Eligibility Criteria & $\begin{array}{l}\text { Age Groups Included (Age Range Used*): \% } \\
\text { of Study Population }\end{array}$ & Type of Population \\
\hline Raux, 2017 & $\begin{array}{l}\text { Included: Trauma patients } \geq 18 \text { years old. } \\
\text { Excluded: Patients without arterial blood lactate and base deficit } \\
\text { measured at admission. }\end{array}$ & Adults ( $\geq 18): 100 \%$ & Civilian \\
\hline Regnier, 2012 & $\begin{array}{l}\text { Included: Trauma patients requiring prehospital care by mobile ICU. } \\
\text { Excluded: Patients without lactate measurement on ED arrival. }\end{array}$ & NR (presumably 100\% adult) & Civilian \\
\hline
\end{tabular}




\begin{tabular}{|c|c|c|c|c|}
\hline $\begin{array}{l}\text { Author, Year } \\
\text { (See Appendix B for } \\
\text { complete reference) }\end{array}$ & Mechanism or Type Injury & Mode of Transport & $\begin{array}{l}\text { Other Population Characteristics } \\
\text { (Sex, Race) }\end{array}$ & $\begin{array}{l}\text { Name of Measure Being } \\
\text { Evaluated }\end{array}$ \\
\hline Raux, 2017 & $\begin{array}{l}\text { Type of injury } \\
\text { Blunt: } 90 \%(965 / 1,075) \\
\text { Penetrating: } 9 \%(100 / 1,075) \\
\text { NR: } 1 \%(10 / 1,075) \\
\\
\text { Mechanism of injury* } \\
\text { Fall: } 29 \%(314 / 1,075) \\
\text { Road crash: } 57 \%(615 / 1,075) \\
\text { Gunshot: } 3 \%(30 / 1,075) \\
\text { Stab wound: } 7 \%(80 / 1,075) \\
\text { Other: } 3 \%(36 / 1,075) \\
\text { ×Percentages may not total } 100 \text { due to } \\
\text { rounding. }\end{array}$ & Medical mobile ICU & $\begin{array}{l}\text { Male: } 78 \%(843 / 1,075) \\
\text { Race: NR } \\
\text { Age (mean): } 39 \text { (SD 18) }\end{array}$ & \begin{tabular}{|l} 
BD \\
Lactate \\
MGAP \\
RTS
\end{tabular} \\
\hline \begin{tabular}{|l} 
Regnier, 2012 \\
\end{tabular} & $\begin{array}{l}\text { Type of injury } \\
\text { Blunt: } 67 \% \\
\text { Penetrating: } 16 \% \\
\text { Not reported: } 17 \% \\
\text { Mechanism of injury* } \\
\text { Fall: } 25 \% \\
\text { Road crash: } 54 \% \\
\text { Gunshot: } 4 \% \\
\text { Stab wound: } 11 \% \\
\text { Other: } 5 \% \\
\star \text { May not total } 100 \% \text { due to rounding }\end{array}$ & Land & $\begin{array}{l}\text { Male: } 75 \% \\
\text { Race: NR } \\
\text { Age (mean): } 38 \text { (SD 15) }\end{array}$ & \begin{tabular}{|l} 
Lactate \\
Lactate Clearance \\
MGAP \\
RTS \\
Combination models: \\
- Model 1: RTS, lactate and \\
lactate clearance \\
- Model 2: MGAP, lactate and \\
lactate clearance
\end{tabular} \\
\hline
\end{tabular}




\begin{tabular}{|c|c|c|c|c|}
\hline \begin{tabular}{|l|} 
Author, Year \\
(See Appendix B for \\
complete reference)
\end{tabular} & $\begin{array}{l}\text { Location and Timing of } \\
\text { Measurement }\end{array}$ & Method of Measurement & $\begin{array}{l}\text { Personnel Administering Test or } \\
\text { Using Measure }\end{array}$ & Equipment Used/Needed \\
\hline Raux, 2017 & $\begin{array}{l}\text { Out of hospital: on arrival } \\
\text { - RTS } \\
\text { - MGAP } \\
\text { ED: on arrival } \\
\text { - Lactate } \\
\text { - BD }\end{array}$ & $\begin{array}{l}\text { Lactate: arterial } \\
\text { BD: arterial blood gas }\end{array}$ & NR & NR \\
\hline
\end{tabular}




\begin{tabular}{|c|c|c|c|c|}
\hline $\begin{array}{l}\text { Author, Year } \\
\text { (See Appendix B for } \\
\text { complete reference) }\end{array}$ & $\begin{array}{l}\text { Threshold Value(s) for Physiologic } \\
\text { Measures }\end{array}$ & $\begin{array}{l}\text { Indicator of Serious Injury Used } \\
\text { (including definition and time period) }\end{array}$ & Funding Source & Risk of Bias \\
\hline Raux, 2017 & $\begin{array}{l}\text { Lactate: } \\
\text { - normal: } \leq 2.2 \mathrm{mmol} / \mathrm{L} \\
\text { - stratification in analyses, based on } \\
\text { associations with mortality rates: } \leq 2.2,2.3-4.9 \text {, } \\
5.0-9.9, \geq 10 \\
\\
\text { Base deficit: } \\
\text { - normal: } \leq 2.0 \mathrm{mmol} / \mathrm{L} \\
\text { - stratification in analyses, based on previous } \\
\text { reporting: } \leq 2.0,2.1-5.9,6.0-9.9, \geq 10\end{array}$ & $\begin{array}{l}\text { Mortality, in-hospital: death occurring within } 30 \\
\text { days after admission or prior to discharge } \\
\text { when discharge occurred within } 30 \text { days; } \\
\text { deaths following hospital discharge were not } \\
\text { considered (patients recorded as alive). } \\
\text { Early death (mortality): death within } 48 \text { hours } \\
\text { Severe trauma: ISS }>15 \\
\text { ICU or mortality: ICU length of stay <2 days } \\
\text { and/or death within } 30 \text { days } \\
\text { Massive hemorrhage: blood transfusion of }>6 \\
\text { PRBCs within } 24 \text { hours and/or death from } \\
\text { hemorrhagic shock } \\
\text { Emergency procedure: need for emergency } \\
\text { thoracic drainage, emergency surgery, } \\
\text { emergency embolization; or emergency } \\
\text { transfusion within the first hour after } \\
\text { admission. }\end{array}$ & $\begin{array}{l}\text { Partial support by TRAUMABASE } \\
\text { group (Clichy, France) and Agence } \\
\text { Régionale de Santé lle de France } \\
\text { (Paris, France). Other support was } \\
\text { provided solely from institutional } \\
\text { and/or departmental sources. }\end{array}$ & Moderate \\
\hline Regnier, 2012 & NR & $\begin{array}{l}\text { Mortality: } 30 \text {-day } \\
\text { Mortality, early within } 48 \text { hours } \\
\text { Severe trauma: ISS }>15 \\
\text { ICU stay } \geq 2 \text { days and/or } 30 \text {-day mortality } \\
\text { Massive hemorrhage: blood transfusion }>6 \\
\text { units within } 24 \text { hours and/or death from } \\
\text { hemorrhagic shock } \\
\text { Need for emergency procedure: thoracic } \\
\text { drainage, surgery, embolization, or emergency } \\
\text { transfusion within } 1 \text { hour of admission. }\end{array}$ & No external funding & Moderate \\
\hline
\end{tabular}




\begin{tabular}{|c|c|c|c|c|}
\hline $\begin{array}{l}\text { Author, Year } \\
\text { (See Appendix B for } \\
\text { complete reference) }\end{array}$ & Study Design & Setting and Dates Performed & Number of Study Subjects & Data Source \\
\hline Reisner, 2016 & Prospective & $\begin{array}{l}\text { USA } \\
\text { Urban vs. rural: NR } \\
\text { Level I trauma center } \\
6 / 2012 \text { to } 10 / 2014 \\
2 \text { years, } 5 \text { months }\end{array}$ & $\begin{array}{l}487 \text { analyzed } \\
942 \text { screened } \\
274 \text { excluded for no IRB-approved NIRS site } \\
95 \text { excluded for no major trauma mechanism } \\
25 \text { excluded for lack of documented HR } \\
\text { and/or BP data within initial evaluation } \\
\text { interval } \\
17 \text { excluded for receiving blood transfusion } \\
\text { without explicit hemorrhagic injuries } \\
44 \text { excluded for data archiving failure }\end{array}$ & $\begin{array}{l}\text { Primary data collection of } \\
\text { convenience sample for one } \\
\text { hospital; combination of } \\
\text { documentation by study staff, ED } \\
\text { nurses, electronic records, and } \\
\text { trauma registry. }\end{array}$ \\
\hline Rickards, 2010 & Retrospective & $\begin{array}{l}\text { USA, Texas } \\
\text { Urban } \\
\text { Level I trauma centers } \\
\text { Study dates: NR }\end{array}$ & $\begin{array}{l}159 \text { analyzed } \\
700 \text { identified } \\
455 \text { excluded for abnormal vital signs or } \\
\text { incomplete records or death within } 24 \text { hours } \\
84 \text { excluded for interference or ectopic beats } \\
\text { or ECG <800 R-to-R intervals } \\
2 \text { excluded as outliers for heart period } \\
\text { variability }\end{array}$ & $\begin{array}{l}\text { Trauma Vitals database from the } \\
\text { U.S. Army Institute of Surgical } \\
\text { Research. }\end{array}$ \\
\hline Ryan, 2011 & Prospective & $\begin{array}{l}\text { USA, Florida } \\
\text { Urban } \\
\text { Level I trauma center } \\
10 / 2008 \text { to } 5 / 2010 \\
1 \text { year, } 8 \text { months }\end{array}$ & 216 analyzed & $\begin{array}{l}\text { Primary data collection, checked } \\
\text { against patient chart and trauma } \\
\text { registry data. }\end{array}$ \\
\hline
\end{tabular}




\begin{tabular}{|c|c|c|c|}
\hline $\begin{array}{l}\text { Author, Year } \\
\text { (See Appendix B for } \\
\text { complete reference) }\end{array}$ & Eligibility Criteria & $\begin{array}{l}\text { Age Groups Included (Age Range Used*): \% } \\
\text { of Study Population }\end{array}$ & Type of Population \\
\hline Reisner, 2016 & $\begin{array}{l}\text { Included: Patients } \geq 18 \text { years old. } \\
\text { Excluded: Patients transferred from another hospital if prior workup } \\
\text { already ruled out hemorrhagic injury, who had no suitable near- } \\
\text { infrared spectrometry (NIRS) sensor placement site overlying the } \\
\text { deltoid or thigh (due to tattoos, visible skin injury, gross blood, } \\
\text { visible rash, clothing, request of treating clinician, or evident } \\
\text { hirsutism), those with an estimated body mass index }<19 \text { or }>40 \\
\mathrm{~kg} / \mathrm{m}^{2}, \text { with minor trauma, who received blood transfusion but lacked } \\
\text { documented hemorrhagic injury, and patients in which there was a } \\
\text { failure to record } \mathrm{SmO}_{2}, \mathrm{HR} \text {, and BP within a matching } 10-\text { minute } \\
\text { interval during initial evaluation. }\end{array}$ & Adults ( $\geq 18): 100 \%$ & Civilian \\
\hline Rickards, 2010 & $\begin{array}{l}\text { Included: Patients with electronic vital sign data collected on a PIC- } \\
50 \text { vital signs monitor, who had normal standard vital signs (SBP } \\
\geq 90 \text {, motor GCS of } 6 \text {, normal radial pulse, and normal capillary } \\
\text { refill), and had a continuous ECG recorded. } \\
\text { Excluded: Patients with <800 continuous R-to-R intervals on ECG } \\
\text { without noise or interference, those with ECG waveform with }>0.5 \% \\
\text { ectopic beats, and outliers on heart rate variability ( }>6 \text { standard } \\
\text { deviations away from the multivariate normal distribution). }\end{array}$ & Adults & Civilian \\
\hline Ryan, 2011 & $\begin{array}{l}\text { Included: Patients who had a trauma team activation and received a } \\
\text { head CT scan. } \\
\text { Excluded: Patients who did not receive a head CT scan. }\end{array}$ & $\begin{array}{l}\text { Adults }(\geq 18): 100 \% \\
\text { range: } 18-91 \text { years }\end{array}$ & Civilian \\
\hline
\end{tabular}




\begin{tabular}{|c|c|c|c|c|}
\hline $\begin{array}{l}\text { Author, Year } \\
\text { (See Appendix B for } \\
\text { complete reference) }\end{array}$ & Mechanism or Type Injury & Mode of Transport & $\begin{array}{l}\text { Other Population Characteristics } \\
\text { (Sex, Race) }\end{array}$ & $\begin{array}{l}\text { Name of Measure Being } \\
\text { Evaluated }\end{array}$ \\
\hline Reisner, 2016 & Blunt: $90 \%$ & NR & $\begin{array}{l}\text { Male: } 68 \% \\
\text { Race: NR } \\
\text { Age (median): } 47 \text { (IQR 31-64) }\end{array}$ & $\begin{array}{l}\mathrm{HR} \\
\text { Muscle oxygen saturation } \\
\left(\mathrm{SmO}_{2}\right) \\
\mathrm{PP} \\
\mathrm{SBP} \\
\mathrm{SI}\end{array}$ \\
\hline Rickards, 2010 & $\begin{array}{l}\text { Blunt: 84.3\% (134/159) } \\
\text { Penetrating: } 11.3 \%(18 / 159) \\
\text { Unknown: } 4.4 \%(7 / 159)\end{array}$ & Helicopter or ground & $\begin{array}{l}\text { Male: 63\% (100/159) } \\
\text { Race: NR } \\
\text { Age (mean): } 38 \text { (SD 1) }\end{array}$ & $\begin{array}{l}\text { Heart rate variability: fractal } \\
\text { dimensions by curve length (FD- } \\
\text { L) }\end{array}$ \\
\hline Ryan, 2011 & Spinal cord injury: 3.7\% (8/216) & NR & $\begin{array}{l}\text { Male: } 75 \%(162 / 216) \\
\text { Race: NR } \\
\text { Age (mean): } 50 \text { (SD 1) }\end{array}$ & $\begin{array}{l}\text { HRV features } \\
\text { - spectral frequency at high } \\
\text { frequency } \\
\text { - spectral power at very low } \\
\text { frequency (VLF) } \\
\text { - low to high frequency index } \\
\text { ratio (LF/HF) } \\
\text { Mechanical ventilation } \\
\text { Mortality score: algorithm using } \\
\text { HRV features and age }\end{array}$ \\
\hline
\end{tabular}




\begin{tabular}{|c|c|c|c|c|}
\hline $\begin{array}{l}\text { Author, Year } \\
\text { (See Appendix B for } \\
\text { complete reference) }\end{array}$ & $\begin{array}{l}\text { Location and Timing of } \\
\text { Measurement }\end{array}$ & Method of Measurement & $\begin{array}{l}\text { Personnel Administering Test or } \\
\text { Using Measure }\end{array}$ & Equipment Used/Needed \\
\hline Reisner, 2016 & ED: on arrival & $\begin{array}{l}\text { SmO2: NIRS } \\
\text { HR: vital signs monitor } \\
\text { BP: vital signs monitor }\end{array}$ & $\begin{array}{l}\text { SmO2: sensor placed on ED arrival by } \\
\text { study staff; measurements recorded by } \\
\text { study staff }\end{array}$ & $\begin{array}{l}\text { SmO2: CareGuide } 1100 \text { tissue } \\
\text { oximeter (Reflectance Medical, } \\
\text { Inc., Westborough, } \\
\text { Massachusetts) } \\
\text { Vital signs monitors: Solar } \\
\text { patient monitors (General } \\
\text { Electric, Milwaukee, Wisconsin) } \\
\\
\text { Data archive } \\
\text { - Vital signs from monitors: } \\
\text { BedMasterEx software (Excel } \\
\text { Medical, Jupiter, Florida) } \\
\text { - Study data: REDCap }\end{array}$ \\
\hline Ryan, 2011 & ED: on admission & $\begin{array}{l}\text { HRV: ECG by digital recorder; } \\
\text { ectopic beats manually verified }\end{array}$ & Research staff & $\begin{array}{l}\text { ECG: two-channel SEER Light } \\
\text { recorder (GE Healthcare, } \\
\text { Milwaukee, WI) } \\
\text { HRV analysis: Mars Holter } \\
\text { monitor system (GE Healthcare) } \\
\text { and proprietary software; MARS } \\
\text { software suite to identify ectopic } \\
\text { beats }\end{array}$ \\
\hline
\end{tabular}




\begin{tabular}{|c|c|c|c|c|}
\hline $\begin{array}{l}\text { Author, Year } \\
\text { (See Appendix B for } \\
\text { complete reference) }\end{array}$ & $\begin{array}{l}\text { Threshold Value(s) for Physiologic } \\
\text { Measures }\end{array}$ & $\begin{array}{l}\text { Indicator of Serious Injury Used } \\
\text { (including definition and time period) }\end{array}$ & Funding Source & Risk of Bias \\
\hline Reisner, 2016 & NR & $\begin{array}{l}\text { Hemorrhagic injury requiring blood transfusion } \\
\text { - Hemorrhagic injury: any of the following: } \\
\text { laceration or fracture of a solid organ; } \\
\text { documented hematoma within the thorax, } \\
\text { peritoneum, retroperitoneum, or pelvis; } \\
\text { vascular injury that required operative repair or } \\
\text { angioembolization; or limb amputation. } \\
\text { - Blood transfusion } \geq 3 \text { units PRBCs } \\
\text { Hemorrhagic injury with receipt of } \geq 9 \text { units } \\
\text { PRBCs }\end{array}$ & $\begin{array}{l}\text { Supported by the Combat Casualty } \\
\text { Care Research Area Directorate of } \\
\text { the U.S. Army Medical Research } \\
\text { and Materiel Command, Fort } \\
\text { Detrick, Maryland. }\end{array}$ & Moderate \\
\hline Rickards, 2010 & NR & $\begin{array}{l}\text { Life-saving intervention: intubation, chest tube, } \\
\text { pRBC transfusion, pericardiocentesis, } \\
\text { cricothyrotomy, thoracotomy, angiography with } \\
\text { or without embolization, needle } \\
\text { decompression, cardioversion, } \\
\text { cardiopulmonary resuscitation or surgical } \\
\text { intervention. }\end{array}$ & $\begin{array}{l}\text { Partially supported by the U.S. } \\
\text { Army Combat Casualty Care } \\
\text { Research Program. }\end{array}$ & Moderate \\
\hline Ryan, 2011 & $\begin{array}{l}\text { Mortality Score cutoff } 51.3 \\
\text { threshold determined using cumulative } \\
\text { distribution frequency of all patients }\end{array}$ & Mortality: overall & $\begin{array}{l}\text { Partial support by Grant } \\
\text { N140610670 from the Office of } \\
\text { Naval Research. }\end{array}$ & Moderate \\
\hline
\end{tabular}




\begin{tabular}{|c|c|c|c|c|}
\hline $\begin{array}{l}\text { Author, Year } \\
\text { (See Appendix B for } \\
\text { complete reference) }\end{array}$ & Study Design & Setting and Dates Performed & Number of Study Subjects & Data Source \\
\hline Sammour, 2009 & Retrospective & $\begin{array}{l}\text { New Zealand, Auckland } \\
\text { Urban } \\
\text { Trauma system level: NR (tertiary hospital) } \\
5 / 2000 \text { to } 9 / 2006 \\
6 \text { years, } 5 \text { months }\end{array}$ & $\begin{array}{l}1,197 \text { analyzed } \\
1,297 \text { identified with trauma team activation } \\
70 \text { excluded for burns } \\
30 \text { excluded with diabetes }\end{array}$ & $\begin{array}{l}\text { Prospective collection of internal } \\
\text { data in trauma database }\end{array}$ \\
\hline Schenarts, 2008 & Retrospective & $\begin{array}{l}\text { USA, North Carolina } \\
\text { Rural } \\
\text { Level I trauma center } \\
1 / 1 / 2000 \text { to } 12 / 31 / 2005 \\
6 \text { years }\end{array}$ & $\begin{array}{l}\text { 2,130 analyzed } \\
-44 / 2,130 \text { EMS SBP }<90 \text { and ED SBP } \geq 90 \\
\text { (hypotensive group) } \\
-2,086 / 2,130 \text { with both EMS and ED SBP } \\
\geq 90 \text { (normotensive group) } \\
\\
7,199 \text { identified } \\
\text { 1,286 excluded for SBP not documented } \\
3,706 \text { excluded for transfer from other } \\
\text { hospitals } \\
77 \text { excluded for hypotension on ED arrival }\end{array}$ & $\begin{array}{l}\text { National Trauma Registry of the } \\
\text { American College of Surgeons } \\
\text { for a single trauma center. }\end{array}$ \\
\hline $\begin{array}{l}\text { Shackelford, } 2015 \\
\text { ×Mackenzie 2015, } \\
\text { Shackelford 2015, and } \\
\text { Yang } 2016 \text { draw from } \\
\text { the same population, } \\
\text { but differ in eligibility } \\
\text { criteria, number } \\
\text { analyzed, and } \\
\text { measures evaluated. } \\
\text { ^Mackenzie, } 2014 \text { study } \\
\text { population included in } \\
\text { Shackelford, } 2015\end{array}$ & Prospective & $\begin{array}{l}\text { USA, Maryland } \\
\text { Urban } \\
\text { Trauma system level: NR } \\
\text { Study period: NR }\end{array}$ & $\begin{array}{l}852 \text { analyzed } \\
-557 \text { subjects = Mackenzie } 2014 \text { study } \\
\text { population } \\
-295 \text { additional subjects } \\
1,191 \text { enrolled } \\
293 \text { excluded for incomplete pulse oximetry } \\
\text { signal data } \\
46 \text { excluded for incomplete laboratory } \\
\text { availability }\end{array}$ & $\begin{array}{l}\text { Primary data collection with } \\
\text { blood use cross-validated } \\
\text { against blood bank records. }\end{array}$ \\
\hline
\end{tabular}




\begin{tabular}{|c|c|c|c|}
\hline $\begin{array}{l}\text { Author, Year } \\
\text { (See Appendix B for } \\
\text { complete reference) }\end{array}$ & Eligibility Criteria & $\begin{array}{l}\text { Age Groups Included (Age Range Used*): \% } \\
\text { of Study Population }\end{array}$ & Type of Population \\
\hline Sammour, 2009 & $\begin{array}{l}\text { Included: Trauma patients } \geq 15 \text { years old with trauma team } \\
\text { activation. } \\
\text { Excluded: Patients with burn injury and diabetics. Note: patients on } \\
\text { steroid treatment were not excluded. }\end{array}$ & Adults ( $\geq 15): 100 \%$ & Civilian \\
\hline Schenarts, 2008 & $\begin{array}{l}\text { Included: Patients age } \geq 16 \text { years, transported directly from the } \\
\text { scene, and who were normotensive (SBP } \geq 90 \mathrm{mmHg} \text { ) on arrival to } \\
\text { the ED. } \\
\text { Excluded: Patients transferred from other hospitals or with } \\
\text { incomplete data. }\end{array}$ & Adults ( $\geq 16): 100 \%$ & Civilian \\
\hline $\begin{array}{l}\text { Shackelford, } 2015 \\
\text { *Mackenzie 2015, } \\
\text { Shackelford 2015, and } \\
\text { Yang } 2016 \text { draw from } \\
\text { the same population, } \\
\text { but differ in eligibility } \\
\text { criteria, number } \\
\text { analyzed, and } \\
\text { measures evaluated. } \\
\text { ^Mackenzie, 2014 study } \\
\text { population included in } \\
\text { Shackelford, } 2015\end{array}$ & $\begin{array}{l}\text { Included: Patients } \geq 18 \text { years old admitted directly from the scene of } \\
\text { injury with } \geq 5 \text { minutes of the first } 15 \text { minutes of pulse oximetry signal } \\
\text { meeting quality index criteria, and who also had any of: EMS SI } \\
\geq 0.62 \text {; "Priority 1" designation by EMS (critically ill or injured person } \\
\text { requiring immediate attention); or, unstable patient with a life- } \\
\text { threatening injury without EMS vital signs. } \\
\text { Excluded: Patients who died within } 15 \text { minutes of ED admission or } \\
\text { had cervical spine injury with neurological impairment. }\end{array}$ & Adults ( $\geq 18): 100 \%$ & Civilian \\
\hline
\end{tabular}




\begin{tabular}{|c|c|c|c|c|}
\hline $\begin{array}{l}\text { Author, Year } \\
\text { (See Appendix B for } \\
\text { complete reference) }\end{array}$ & Mechanism or Type Injury & Mode of Transport & $\begin{array}{l}\text { Other Population Characteristics } \\
\text { (Sex, Race) }\end{array}$ & $\begin{array}{l}\text { Name of Measure Being } \\
\text { Evaluated }\end{array}$ \\
\hline Sammour, 2009 & $\begin{array}{l}\text { Mechanism of injury* } \\
\text { Road traffic accident: } 62 \% \\
\text { Assault: } 13 \% \\
\text { Fall: } 9 \% \\
\text { Self inflicted; } 5 \% \\
\text { Work related: } 3 \% \\
\text { Sport: } 2 \% \\
\text { Animal related: } 1 \% \\
\text { Unknown: } 6 \% \\
\text { *Total may not equal } 100 \% \text { due to rounding }\end{array}$ & NR & $\begin{array}{l}\text { Male: } 75 \% \\
\text { Race: NR } \\
\text { Age (median): } 31 \text { (range 15-90) }\end{array}$ & Lactate \\
\hline Schenarts, 2008 & Blunt: 93\% & NR & $\begin{array}{l}\text { Male: } 56 \% \\
\text { Race: NR } \\
\text { Age (mean): } 50 \text { (SD 24) }\end{array}$ & SBP \\
\hline $\begin{array}{l}\text { Shackelford, } 2015 \\
\text { ×Mackenzie 2015, } \\
\text { Shackelford 2015, and } \\
\text { Yang } 2016 \text { draw from } \\
\text { the same population, } \\
\text { but differ in eligibility } \\
\text { criteria, number } \\
\text { analyzed, and } \\
\text { measures evaluated. } \\
\text { ^Mackenzie, } 2014 \text { study } \\
\text { population included in } \\
\text { Shackelford, } 2015\end{array}$ & $\begin{array}{l}\text { Type of injury } \\
\text { Blunt: } 81.8 \%(796 / 852) \\
\text { Penetrating: } 31.3 \%(113 / 852) \\
\text { Other: } 4.9 \%(42 / 852) \\
\\
\text { Mechanism of injury } \\
\text { Motor vehicle associated: } 47.2 \%(402 / 852) \\
\text { Falls: } 22.5 \% \text { (192/852) } \\
\text { Interpersonal violence: } 17.8 \%(152 / 852) \\
\text { Other: } 12.4 \% \text { (106/852) }\end{array}$ & NR & $\begin{array}{l}\text { Male: } 70 \% \text { (593/852) } \\
\text { Race: NR } \\
\text { Age (mean): } 40 \text { (SD 18) }\end{array}$ & $\begin{array}{l}\text { Lactate } \\
\text { Decision-assist algorithms: use } \\
\text { HR, SBP, pulse oximetry } \\
\text { features, laboratory tests }\end{array}$ \\
\hline
\end{tabular}




\begin{tabular}{|c|c|c|c|c|}
\hline $\begin{array}{l}\text { Author, Year } \\
\text { (See Appendix B for } \\
\text { complete reference) }\end{array}$ & $\begin{array}{l}\text { Location and Timing of } \\
\text { Measurement }\end{array}$ & Method of Measurement & $\begin{array}{l}\text { Personnel Administering Test or } \\
\text { Using Measure }\end{array}$ & Equipment Used/Needed \\
\hline Sammour, 2009 & ED: on arrival & Lactate: arterial & ED clinician & NR \\
\hline Schenarts, 2008 & $\begin{array}{l}\text { Out of Hospital: during } \\
\text { resuscitation } \\
\text { ED: on arrival }\end{array}$ & $\begin{array}{l}\text { SBP: either manual or } \\
\text { automated }\end{array}$ & NR & $\begin{array}{l}\text { SBP: auscultatory method, } \\
\text { automated oscillometric device, } \\
\text { or palpation method }\end{array}$ \\
\hline $\begin{array}{l}\text { Shackelford, } 2015 \\
\text { *Mackenzie 2015, } \\
\text { Shackelford 2015, and } \\
\text { Yang } 2016 \text { draw from } \\
\text { the same population, } \\
\text { but differ in eligibility } \\
\text { criteria, number } \\
\text { analyzed, and } \\
\text { measures evaluated. } \\
\text { *Mackenzie, } 2014 \text { study } \\
\text { population included in } \\
\text { Shackelford, } 2015\end{array}$ & $\begin{array}{l}\text { Out of hospital: on arrival } \\
\text { - HR } \\
\text { - SBP } \\
\text { ED: on arrival } \\
\text { - Pulse oximetry features } \\
\text { - Laboratory tests }\end{array}$ & $\begin{array}{l}\text { Laboratory tests: venous blood } \\
\text { sample } \\
\text { Pulse oximetry features: } \\
\text { waveforms recorded at } 240 \mathrm{~Hz} \text {, } \\
\text { filtered to reduce noise using a } \\
\text { pulse oximetry signal quality } \\
\text { index. }\end{array}$ & NR & $\begin{array}{l}\text { Laboratory tests: standard } \\
\text { hospital-based chemistry and } \\
\text { hematology analyzers } \\
\text { - lab data sets correspond to } \\
\text { iSTAT point-of-care analyzer } \\
\text { cartridges (Abbott Laboratories } \\
\text { Inc., Chicago, IL) } \\
\text { Pulse oximeter: NR }\end{array}$ \\
\hline
\end{tabular}




\begin{tabular}{|c|c|c|c|c|}
\hline $\begin{array}{l}\text { Author, Year } \\
\text { (See Appendix B for } \\
\text { complete reference) }\end{array}$ & $\begin{array}{l}\text { Threshold Value(s) for Physiologic } \\
\text { Measures }\end{array}$ & $\begin{array}{l}\text { Indicator of Serious Injury Used } \\
\text { (including definition and time period) }\end{array}$ & Funding Source & Risk of Bias \\
\hline Sammour, 2009 & Lactate $>2.0 \mathrm{mmol} / \mathrm{L}$ & $\begin{array}{l}\text { Mortality: All-cause death directly related to } \\
\text { the trauma event. }\end{array}$ & No external funding & High \\
\hline Schenarts, 2008 & $\begin{array}{l}\text { SBP }<90 \mathrm{mmHg}=\text { hypotension } \\
\text { Predetermined: NR }\end{array}$ & $\begin{array}{l}\text { ICU, OR or death in ED } \\
\text { ISS >16 } \\
\text { Mortality: in-hospital }\end{array}$ & NR & High \\
\hline \begin{tabular}{|l|} 
Shackelford, 2015 \\
*Mackenzie 2015, \\
Shackelford 2015, and \\
Yang 2016 draw from \\
the same population, \\
but differ in eligibility \\
criteria, number \\
analyzed, and \\
measures evaluated. \\
*Mackenzie, 2014 study \\
population included in \\
Shackelford, 2015
\end{tabular} & NR & $\begin{array}{l}\text { Blood transfusion: any transfusion within the } \\
\text { first } 3 \text { hours. } \\
\text { Rapid blood transfusion: transfusion of } \geq 5 \\
\text { units of RBCs in the first } 4 \text { hours after } \\
\text { admission. } \\
\text { Massive transfusion: } \geq 10 \text { units of pRBCs } \\
\text { transfused within the first } 24 \text { hours after } \\
\text { admission. }\end{array}$ & $\begin{array}{l}\text { Supported by grant FA8650-11-2- } \\
\text { 6D01, US Air Force Medical } \\
\text { Support Agency/Medical } \\
\text { Modernization Directorate. No } \\
\text { funding was received from NIH, } \\
\text { Welcome Trust, or HHMI. }\end{array}$ & Moderate \\
\hline
\end{tabular}




\begin{tabular}{|c|c|c|c|c|}
\hline $\begin{array}{l}\text { Author, Year } \\
\text { (See Appendix B for } \\
\text { complete reference) }\end{array}$ & Study Design & Setting and Dates Performed & Number of Study Subjects & Data Source \\
\hline Shah, 2013 & Prospective & $\begin{array}{l}\text { USA, 4-state region } \\
\text { Urban vs. Rural: NR } \\
\text { Level I pediatric trauma center } \\
4 / 2008 \text { to } 3 / 2010 \\
2 \text { years }\end{array}$ & $\begin{array}{l}217 \text { analyzed } \\
493 \text { identified } \\
269 \text { excluded for no EMS lactate } \\
7 \text { excluded for missing data }\end{array}$ & $\begin{array}{l}\text { Prospective collection to out of } \\
\text { hospital database, and cross- } \\
\text { linked to hospital EHR. }\end{array}$ \\
\hline Shoemaker, 2005 & Prospective & $\begin{array}{l}\text { USA, California } \\
\text { Urban } \\
\text { Level I trauma center } \\
\text { Study time period: NR }\end{array}$ & $\begin{array}{l}185 \text { analyzed } \\
\text { No patients were excluded }\end{array}$ & Primary data collection \\
\hline St John, 2016 & Retrospective case-control & $\begin{array}{l}\text { USA, Washington } \\
\text { Urban } \\
\text { Level I trauma center } \\
1 / 1 / 2011 \text { to } 12 / 31 / 2012 \\
2 \text { years }\end{array}$ & $\begin{array}{l}3,224 \text { analyzed } \\
-721 \text { elderly } \\
-2,503 \text { non-elderly } \\
\text { Elderly } \\
1,151 \text { elderly identified } \\
361 \text { excluded for isolated TBI } \\
47 \text { excluded for isolated burn injury } \\
19 \text { excluded for isolated extremity injury } \\
2 \text { excluded for isolated suffocation } \\
2 \text { excluded for isolated drowning }\end{array}$ & $\begin{array}{l}\text { Harborview Medical Center } \\
\text { trauma registry, trauma registry } \\
\text { for a single hospital. }\end{array}$ \\
\hline
\end{tabular}




\begin{tabular}{|c|c|c|c|}
\hline $\begin{array}{l}\text { Author, Year } \\
\text { (See Appendix B for } \\
\text { complete reference) }\end{array}$ & Eligibility Criteria & $\begin{array}{l}\text { Age Groups Included (Age Range Used*): \% } \\
\text { of Study Population }\end{array}$ & Type of Population \\
\hline Shah, 2013 & $\begin{array}{l}\text { Included pediatric patients ( }<18 \text { years) with an out of hospital lactate } \\
\text { measured and who were admitted to the hospital*. } \\
\text { Excluded: Patients whose lactate sample was taken from an } \\
\text { extremity with a crush injury, amputation, or fracture, and patients } \\
\text { with missing data. } \\
\text { * Note: All trauma patients transported by air during this period were } \\
\text { admitted to the hospital. }\end{array}$ & $\begin{array}{l}\text { Pediatrics }(<18): 100 \% \\
\text { - range: } 0-17 \text { years }\end{array}$ & Civilian \\
\hline Shoemaker, 2005 & $\begin{array}{l}\text { Included: Patients with major blunt or penetrating injuries and } \\
\text { significant risk of mortality or morbidity. } \\
\text { Excluded: not specified }\end{array}$ & Mixed; percentages not provided & Civilian \\
\hline St John, 2016 & $\begin{array}{l}\text { Included: Patients age } \geq 18 \text { years found to have severe multisystem } \\
\text { injury (death in the first } 24 \text { hours, blood transfusion in the first } 24 \\
\text { hours, ED disposition to the OR in the first } 4 \text { hours, or ED } \\
\text { disposition to the ICU. } \\
\text { Excluded: Patients with TTA or hospital admission data that were } \\
\text { incomplete or conflicting across multiple variables, and those with } \\
\text { isolated burn injury, isolated drowning, isolated asphyxiation, or } \\
\text { isolated TBI. }\end{array}$ & $\begin{array}{l}\text { Adults }(\geq 18): 100 \% \\
\text { Elderly }(\geq 65): 22 \%(721 / 3,224)\end{array}$ & Civilian \\
\hline
\end{tabular}




\begin{tabular}{|c|c|c|c|c|}
\hline $\begin{array}{l}\text { Author, Year } \\
\text { (See Appendix B for } \\
\text { complete reference) }\end{array}$ & Mechanism or Type Injury & Mode of Transport & $\begin{array}{l}\text { Other Population Characteristics } \\
\text { (Sex, Race) }\end{array}$ & $\begin{array}{l}\text { Name of Measure Being } \\
\text { Evaluated }\end{array}$ \\
\hline Shah, 2013 & $\begin{array}{l}\text { Injury Type } \\
\text { Head and neck: } 65 \%(142 / 217) \\
\text { Extremity: } 32 \%(70 / 217) \\
\text { Face: } 18 \%(40 / 217) \\
\text { Chest: } 10 \%(22 / 217) \\
\text { Abdomen: } 18 \%(39 / 217)\end{array}$ & $\begin{array}{l}\text { Helicopter } \\
\text { Transported directly } \\
\text { from field: } 46 \% \\
(100 / 217) \\
\text { Interfacility transport: } \\
54 \%(117 / 217)\end{array}$ & $\begin{array}{l}\text { Male: 69\% (149/217) } \\
\text { Race: NR } \\
\text { Age (median): } 11 \text { (IQR 6-14) }\end{array}$ & Lactate \\
\hline Shoemaker, 2005 & $\begin{array}{l}\text { Survivors } \\
\text { Blunt trauma: } 35 \% / 57 \% \\
\text { Fall: } 7 \% / 0 \% \\
\text { Gunshot: } 41 \% / 39 \% \\
\text { Stab wound: } 17 \% / 4 \% \\
\text { Nonsurvivors } \\
\text { Blunt trauma: } 57 \% \\
\text { Fall: } 10 \% \\
\text { Gunshot wound: } 39 \% \\
\text { Stab wound: } 4 \%\end{array}$ & NR & $\begin{array}{l}\text { Overall } \\
\text { Male: } 81 \%(149 / 185) \\
\text { Race: NR } \\
\text { Age (mean): NR } \\
\text { Survivors } \\
\text { Age (mean): } 32 \text { (SD 15) } \\
\text { Nonsurvivors } \\
\text { Age (mean): } 39 \text { (SD 21) }\end{array}$ & $\begin{array}{l}\text { Cardiac Index } \\
\text { HR } \\
\text { MAP } \\
\text { Oxygen delivery }\left(\mathrm{DO}_{2}\right) \text { Survival } \\
\text { Probability prediction model } \\
\text { (using noninvasive } \\
\text { hemodynamic monitoring) } \\
\text { Transcutaneous oxygen tension } \\
\text { indexed to fraction of inspired } \\
\text { oxygen (PtcO2/FIO2) }\end{array}$ \\
\hline St John, 2016 & $\begin{array}{l}\text { Type of injury } \\
\text { Blunt: } 82.1 \%(2,648 / 3,224) \\
\text { Penetrating: } 16.9 \%(545 / 3,224) \\
\text { Unspecified: } 1.0 \%(26 / 3,224) \\
\text { Mechanism of injury } \\
\text { Fall: } 27.5 \%(886 / 3,224) \\
\text { Motor vehicle collision: } 23.5 \%(757 / 3,224) \\
\text { Motorcycle collision: } 1.0 \%(321 / 3,224) \\
\text { Assault: } 6.2 \%(200 / 3,224) \\
\text { Pedestrian struck: } 6.1 \%(197 / 3,224) \\
\text { Bicycle collision: } 4.0 \%(128 / 3,224) \\
\text { Other blunt injury: } 4.9 \%(159 / 3,224) \\
\text { Stab wound: } 7.9 \%(254 / 3,224) \\
\text { Gunshot wound: } 6.5 \%(211 / 3,224) \\
\text { Other penetrating injury: } 2.5 \%(80 / 3,224)\end{array}$ & NR & $\begin{array}{l}\text { Male: } 72 \%(2,325 / 3,224) \\
\text { Race: NR } \\
\text { Age (mean): NR }\end{array}$ & $\begin{array}{l}\text { BD } \\
\text { HR } \\
\text { SBP }\end{array}$ \\
\hline
\end{tabular}




\begin{tabular}{|c|c|c|c|c|}
\hline $\begin{array}{l}\text { Author, Year } \\
\text { (See Appendix B for } \\
\text { complete reference) }\end{array}$ & $\begin{array}{l}\text { Location and Timing of } \\
\text { Measurement }\end{array}$ & Method of Measurement & $\begin{array}{l}\text { Personnel Administering Test or } \\
\text { Using Measure }\end{array}$ & Equipment Used/Needed \\
\hline Shah, 2013 & Out of hospital: on EMS arrival & $\begin{array}{l}\text { Lactate: POC, peripheral } \\
\text { venous or capillary } \\
\text { Vital signs: automated, using } \\
\text { vital signs monitor }\end{array}$ & EMS: on arrival & $\begin{array}{l}\text { POC serum lactate meter } \\
\text { (Lactate Pro; FaCT Canada, } \\
\text { Quesnel, British Columbia, } \\
\text { Canada) } \\
\text { Vital signs monitor: LIFEPAK } 12 \\
\text { monitor (PhysioControl, } \\
\text { Redmond, Washington) }\end{array}$ \\
\hline Shoemaker, 2005 & ED: within 1 hour of admission & $\begin{array}{l}\text { Noninvasive monitoring } \\
\text { - Cardiac output and cardiac } \\
\text { index: thoracic bioelectric } \\
\text { impedance } \\
\text { - SaO2: routine pulse oximetry } \\
\text { - Transcutaneous carbon } \\
\text { dioxide tension (PtcCO2) and } \\
\text { transcutaneous oxygen tension } \\
\text { (PtcO2): continuous } \\
\text { transcutaneous using } \\
\text { electrodes }\end{array}$ & NR & $\begin{array}{l}\text { Cardiac output and cardiac } \\
\text { index: thoracic bio electric } \\
\text { impedance device (IQ 101, } \\
\text { Noninvasive Medical } \\
\text { Technologies LLC, Auburn Hills, } \\
\text { MI) } \\
\text { SaO2: pulse oximeter (Nellcor, } \\
\text { Pleasanton, CA) } \\
\text { PtcO2: Clark polarographic } \\
\text { oxygen electrode } \\
\text { PtcCO2: Severinghaus electrode } \\
\text { Clark polarographic oxygen } \\
\text { electrode } \\
\text { Severinghaus Electrode }\end{array}$ \\
\hline St John, 2016 & \begin{tabular}{|l} 
ED: on arrival \\
- SBP used lowest value recorded
\end{tabular} & NR & NR & NR \\
\hline
\end{tabular}




\begin{tabular}{|c|c|c|c|c|}
\hline $\begin{array}{l}\text { Author, Year } \\
\text { (See Appendix B for } \\
\text { complete reference) }\end{array}$ & $\begin{array}{l}\text { Threshold Value(s) for Physiologic } \\
\text { Measures }\end{array}$ & $\begin{array}{l}\text { Indicator of Serious Injury Used } \\
\text { (including definition and time period) }\end{array}$ & Funding Source & Risk of Bias \\
\hline Shah, 2013 & $\begin{array}{l}\text { Lactate: cut point of } 2 \mathrm{mmol} / \mathrm{L} \\
\text { Vital signs: normal vs. abnormal, per age- } \\
\text { specific Pediatric Advanced Life Support } \\
\text { guidelines }\end{array}$ & $\begin{array}{l}\text { Need for critical care: within } 24 \text { hours } \\
\text { receiving vasopressor support, endotracheal } \\
\text { intubation, or transfusion; emergent surgery; } \\
\text { admission to the pediatric ICU. }\end{array}$ & NR & Moderate \\
\hline Shoemaker, 2005 & $\begin{array}{l}\text { Survival probability prediction model: stochastic } \\
\text { analysis to determine survival probability using } \\
\text { "nearest neighbors" approach with primary } \\
\text { diagnosis, covariates, and hemodynamic } \\
\text { variables. Noninvasive hemodynamic values } \\
\text { included cardiac output, cardiac index, MAP, } \\
\text { HR, arterial oxygen saturation (SaO2), oxygen } \\
\text { delivery (DO2) and transcutaneous oxygen } \\
\text { tension indexed to fraction of inspired oxygen } \\
\text { (PtcO2/FIO2). }\end{array}$ & Mortality: in-hospital & $\begin{array}{l}\text { Supported in part by grants RR- } \\
\text { 11526, GM-65619, and DOD } \\
\text { BAA99-1 from the National } \\
\text { Institutes of Health (Bethesda, MD); } \\
\text { and by DAMD 17-01-2-0070 from } \\
\text { the U.S. Army Medical Research } \\
\text { Acquisition Activity (Fort Detrick, } \\
\text { MD). }\end{array}$ & Low \\
\hline St John, 2016 & NR & $\begin{array}{l}\text { Severe multisystem injury: death in the first } 24 \\
\text { hours, blood transfusion in the first } 24 \text { hours, } \\
\text { ED disposition to the OR in the first } 4 \text { hours or } \\
\text { ED disposition to the ICU. }\end{array}$ & NR & Moderate \\
\hline
\end{tabular}




\begin{tabular}{|c|c|c|c|c|}
\hline $\begin{array}{l}\text { Author, Year } \\
\text { (See Appendix B for } \\
\text { complete reference) }\end{array}$ & Study Design & Setting and Dates Performed & Number of Study Subjects & Data Source \\
\hline Stanworth, 2010 & Retrospective & $\begin{array}{l}\text { International: UK, Norway, USA, The } \\
\text { Netherlands and Germany } \\
\text { Setting: NR } \\
\text { Trauma system level: NR (major trauma } \\
\text { centers) } \\
\\
\text { Datasets from London, San Francisco, } \\
\text { Amsterdam, and Germany } \\
2007 \\
1 \text { year } \\
\text { Dataset from Oslo } \\
2 \text { years }\end{array}$ & $\begin{array}{l}\text { 5,693 analyzed } \\
\text { Internal validation datasets } \\
\text { London }(n=788) \\
\text { Oslo }(n=2,167) \\
\text { San Francisco }(n=384) \\
\text { Amsterdam }(n=649) \\
\\
\text { External validation dataset } \\
\text { Germany }(n=1,705)\end{array}$ & $\begin{array}{l}\text { Trauma registries of } 4 \text { trauma } \\
\text { centers in a research network, } \\
\text { and The Trauma Registry of the } \\
\text { Deutsche Gesellschaft für } \\
\text { Unfallchirurgie in Germany. }\end{array}$ \\
\hline Tamim, 2002 & Retrospective & $\begin{array}{l}\text { Canada, Montreal } \\
\text { Urban } \\
\text { Level I trauma centers } \\
4 / 1993 \text { to } 12 / 1996 \\
3 \text { years, } 9 \text { months }\end{array}$ & $\begin{array}{l}1,291 \text { analyzed } \\
2,847 \text { identified } \\
1,556 \text { excluded for incomplete Prehospital } \\
\text { Index data }\end{array}$ & $\begin{array}{l}\text { Emergency medical service } \\
\text { (Urgences-santé) data files and } \\
\text { trauma registry data files. }\end{array}$ \\
\hline Van Haren, 2014 & Prospective & $\begin{array}{l}\text { USA, Florida } \\
\text { Urban } \\
\text { Level I trauma center } \\
12 / 2011 \text { to } 6 / 2013 \\
1 \text { year, } 7 \text { months }\end{array}$ & $\begin{array}{l}96 \text { analyzed } \\
113 \text { identified } \\
17 \text { excluded as non-trauma }\end{array}$ & Primary Data Collection \\
\hline
\end{tabular}




\begin{tabular}{|c|c|c|c|}
\hline $\begin{array}{l}\text { Author, Year } \\
\text { (See Appendix B for } \\
\text { complete reference) }\end{array}$ & Eligibility Criteria & $\begin{array}{l}\text { Age Groups Included (Age Range Used*): \% } \\
\text { of Study Population }\end{array}$ & Type of Population \\
\hline Stanworth, 2010 & Included: All patients in the datasets were included. & $\begin{array}{l}\text { Adults: } 100 \% \\
\text { range: } 20-58\end{array}$ & Civilian \\
\hline Tamim, 2002 & $\begin{array}{l}\text { Included: Patients }>15 \text { years old transported by Urgences-santé } \\
\text { (EMS) to either of } 2 \text { study trauma centers from the scene of injury, } \\
\text { were alive on ED arrival, and either died in the ED or were admitted } \\
\text { to the hospital. } \\
\text { Excluded: Patients for whom complete data was not available for the } \\
\text { Prehospital Index (PHI) values evaluated at the scene of injury. }\end{array}$ & Adults (>15): 100\% & Civilian \\
\hline Van Haren, 2014 & $\begin{array}{l}\text { Included: Trauma patients transported by EMS participating in } \\
\text { study. } \\
\text { Excluded: Patients }<18 \text { years old and those who were pregnant or } \\
\text { incarcerated. }\end{array}$ & Adults ( $(\geq 18): 100 \%$ & Civilian \\
\hline
\end{tabular}




\begin{tabular}{|c|c|c|c|c|}
\hline $\begin{array}{l}\text { Author, Year } \\
\text { (See Appendix B for } \\
\text { complete reference) } \\
\end{array}$ & Mechanism or Type Injury & Mode of Transport & $\begin{array}{l}\text { Other Population Characteristics } \\
\text { (Sex, Race) }\end{array}$ & $\begin{array}{l}\text { Name of Measure Being } \\
\text { Evaluated }\end{array}$ \\
\hline Stanworth, 2010 & Penetrating: $10 \%(580 / 5,693)$ & NR & $\begin{array}{l}\text { Male: } 73 \%(4,161 / 5,693) \\
\text { Race: NR } \\
\text { Age (mean): } 36 \text { (range: } 20 \text { to } 58 \text { ) }\end{array}$ & $\begin{array}{l}\mathrm{BD} \\
\mathrm{SBP}\end{array}$ \\
\hline Tamim, 2002 & $\begin{array}{l}\text { Type of injury } \\
\text { Penetrating: } 7.5 \%(97 / 1,291) \\
\\
\text { Mechanism of injury* } \\
\text { Driver: } 11 \%(142 / 1,291) \\
\text { Passenger: } 4 \%(54 / 1,291) \\
\text { Motorcycle: } 3 \%(41 / 1,291) \\
\text { Cyclist: } 2 \%(22 / 1,291) \\
\text { Pedestrian: } 9 \%(116 / 1,291) \\
\text { Fall: } 43 \%(550 / 1,291) \\
\text { Firearm, stab, knife: } 14 \%(178 / 1,291) \\
\text { Blunt object: } 14 \%(119 / 1,291) \\
\text { Other: } 6 \%(72 / 1,291) \\
\text { *Percentages may not total } 100 \text { due to } \\
\text { rounding. }\end{array}$ & NR & $\begin{array}{l}\text { Male: 62\% (797/1,291) } \\
\text { Race: NR } \\
\text { Age (mean): } 51 \text { (SD 23) }\end{array}$ & Prehospital Index (PHI) score \\
\hline Van Haren, 2014 & Blunt: 83\% & Land and Helicopter & $\begin{array}{l}\text { Male: } 82 \% \\
\text { Race: NR } \\
\text { Age (mean): } 48 \text { (SD 19) }\end{array}$ & \begin{tabular}{|l}
$\mathrm{HR}$ \\
$\mathrm{SaO} 2$ \\
$\mathrm{SBP}$ \\
Murphy Factor (injury acuity \\
algorithm using vital signs) \\
Vital signs (combined HR, SBP \\
and SaO2)
\end{tabular} \\
\hline
\end{tabular}




\begin{tabular}{|c|c|c|c|c|}
\hline $\begin{array}{l}\text { Author, Year } \\
\text { (See Appendix B for } \\
\text { complete reference) }\end{array}$ & $\begin{array}{l}\text { Location and Timing of } \\
\text { Measurement }\end{array}$ & Method of Measurement & $\begin{array}{l}\text { Personnel Administering Test or } \\
\text { Using Measure }\end{array}$ & Equipment Used/Needed \\
\hline Stanworth, 2010 & ED: on arrival & NR & NR & NR \\
\hline Tamim, 2002 & Out of hospital: at scene & NR & NR & NR \\
\hline Van Haren, 2014 & $\begin{array}{l}\text { Out of Hospital: during } \\
\text { resuscitation } \\
\text { ED: on arrival }\end{array}$ & Automated vital signs monitors & NR & $\begin{array}{l}\text { Miniature wireless vital signs } \\
\text { monitor: MiniMedic (Athena } \\
\text { GTX) } \\
\text { Standard vital signs monitor: } \\
\text { Physio-Control LIFPAK } \\
\text { (Medtronic) or Propaq MD } \\
\text { (Welch Allyn) }\end{array}$ \\
\hline
\end{tabular}




\begin{tabular}{|c|c|c|c|c|}
\hline $\begin{array}{l}\text { Author, Year } \\
\text { (See Appendix B for } \\
\text { complete reference) }\end{array}$ & $\begin{array}{l}\text { Threshold Value(s) for Physiologic } \\
\text { Measures }\end{array}$ & $\begin{array}{l}\text { Indicator of Serious Injury Used } \\
\text { (including definition and time period) }\end{array}$ & Funding Source & Risk of Bias \\
\hline Stanworth, 2010 & NR & $\begin{array}{l}\text { Massive transfusion: } \geq 10 \text { units PRBCs } \\
\text { transfused within the first } 24 \text { hours }\end{array}$ & $\begin{array}{l}\text { There was no external funding for } \\
\text { the study. }\end{array}$ & Moderate \\
\hline Tamim, 2002 & NR & $\begin{array}{l}\text { Major injury requiring treatment at a Level I } \\
\text { trauma center: any of } 3 \text { criteria: } 1 \text { ) death in ED } \\
\text { or within } 7 \text { days after hospital admission; 2) } \\
\text { surgical intervention within } 4 \text { days after } \\
\text { admission (nonorthopedic except hip-fracture } \\
\text { surgery, and nonplastic); 3) ICU admission } \\
\text { within } 7 \text { days after admission. }\end{array}$ & $\begin{array}{l}\text { Supported by the National Health } \\
\text { Research and Development } \\
\text { Program (NHRDP) and the Fonds } \\
\text { pour la formation de chercheurs et } \\
\text { l'aide à la recherche (FCAR). }\end{array}$ & Moderate \\
\hline Van Haren, 2014 & $\begin{array}{l}\mathrm{HR}>100 \text { beats } / \mathrm{min} \\
\mathrm{SaO} 2<95 \% \\
\mathrm{SBP}<90 \mathrm{~mm} \mathrm{Hg} \\
\text { Murphy Factor }>3 \\
\text { Clinically relevant cutoffs }\end{array}$ & $\begin{array}{l}\text { LSI, pre-hospital or in hospital: intubation, } \\
\text { cricothyroidotomy, needle decompression, } \\
\text { tube thoracostomy, central line insertion, blood } \\
\text { product transfusion, or operative intervention. }\end{array}$ & $\begin{array}{l}\text { Supported in part by grant } \\
\text { \#N140610670 from the Office of } \\
\text { Naval Research and } \\
\text { W81XWH1120098 from the US } \\
\text { Army Medical Research and } \\
\text { Material Command. Mark Darrah, } \\
\text { PhD (CEO of Athena GTX, Des } \\
\text { Moines, IA) provided the } \\
\text { MiniMedics. }\end{array}$ & Moderate \\
\hline
\end{tabular}




\begin{tabular}{|c|c|c|c|c|}
\hline $\begin{array}{l}\text { Author, Year } \\
\text { (See Appendix B for } \\
\text { complete reference) }\end{array}$ & Study Design & Setting and Dates Performed & Number of Study Subjects & Data Source \\
\hline Vandromme, 2010 & Retrospective & $\begin{array}{l}\text { USA, Alabama } \\
\text { Urban } \\
\text { Level I trauma center } \\
1 / 2000 \text { to } 1 / 2009 \\
9 \text { years }\end{array}$ & $\begin{array}{l}\text { 2,519 analyzed } \\
-787 / 2,519 \text { with EMS SBP } 90-110 \\
-2,413 / 2,519 \text { with blood lactate } \\
\text { measurement } \\
\text { 31,032 evaluated at trauma center }\end{array}$ & $\begin{array}{l}\text { Trauma registry for a single } \\
\text { trauma center. } \\
\text { Out of hospital SBP collected } \\
\text { from patient care reports } \\
\text { provided by EMS. }\end{array}$ \\
\hline Vandromme, 2011 & Retrospective & $\begin{array}{l}\text { USA, Alabama } \\
\text { Urban } \\
\text { Level I trauma center } \\
1 / 1 / 2000 \text { to } 10 / 12 / 2008 \\
9 \text { years }\end{array}$ & $\begin{array}{l}\text { 8,111 analyzed } \\
20,095 \text { identified } \\
3,382 \text { excluded as patient transfers } \\
774 \text { excluded for out of hospital SBP } \leq 90 \\
7,828 \text { excluded for no recorded out of } \\
\text { hospital vital signs }\end{array}$ & $\begin{array}{l}\text { University of Alabama at } \\
\text { Birmingham University Hospital } \\
\text { trauma registry. }\end{array}$ \\
\hline Vandromme, 2011b & Retrospective & $\begin{array}{l}\text { USA, Alabama } \\
\text { Urban and rural } \\
\text { Level I trauma center } \\
\text { Overall study period } \\
1 / 2005 \text { to } 12 / 2008 \\
4 \text { years } \\
\text { Developmental cohort } \\
1 / 2005 \text { to } 1 / 22 / 2007 \\
2 \text { years } \\
\text { Validation cohort } \\
1 / 23 / 2007 \text { to } 12 / 2008 \\
2 \text { years }\end{array}$ & $\begin{array}{l}514 \text { analyzed } \\
306 \text { in developmental cohort } \\
208 \text { in validation cohort } \\
>12,000 \text { identified } \\
\text { for feasibility, a subset of these were selected } \\
\text { for analysis } \\
\text { - patients categorized by \# of PRBC units } \\
\text { transfused ( } 0,1-3,4-6,7-9, \text { or massive } \\
\text { transfusion of } \geq 10 \text { units) } \\
\text { - equal proportion of patients taken from all } \\
\text { but the massive transfusion category } \\
\text { - all patients were included from the massive } \\
\text { transfusion category }\end{array}$ & $\begin{array}{l}\text { Medical records and blood bank } \\
\text { data. }\end{array}$ \\
\hline Vassallo, 2015 & Prospective & $\begin{array}{l}\text { Afghanistan, Camp Bastion } \\
\text { UK military base } \\
\text { Trauma system level: not applicable } \\
\text { (military base) } \\
3 / 2011 \text { to } 9 / 2011 \\
6 \text { months }\end{array}$ & $\begin{array}{l}345 \text { analyzed } \\
482 \text { identified } \\
33 \text { excluded for indeterminate Priority One } \\
\text { designation } \\
104 \text { excluded for no SI recorded }\end{array}$ & $\begin{array}{l}\text { Prospective collection using } \\
\text { standardized data sheet. }\end{array}$ \\
\hline
\end{tabular}




\begin{tabular}{|c|c|c|c|}
\hline $\begin{array}{l}\text { Author, Year } \\
\text { (See Appendix B for } \\
\text { complete reference) }\end{array}$ & Eligibility Criteria & $\begin{array}{l}\text { Age Groups Included (Age Range Used*): \% } \\
\text { of Study Population }\end{array}$ & Type of Population \\
\hline Vandromme, 2010 & Included: Patients with SBP $90-110 \mathrm{mmHg}$ on arrival to ED. & NR & Civilian \\
\hline Vandromme, 2011 & $\begin{array}{l}\text { Included: Patients with blunt mechanism of injury and out of hospital } \\
\text { SBP }>90 \mathrm{~mm} \mathrm{Hg} \text {. } \\
\text { Excluded: Patients who were transferred from another facility, had } \\
\text { penetrating injury, an out of hospital SBP } \leq 90 \mathrm{~mm} \mathrm{Hg} \text {, or had no out } \\
\text { of hospital vital signs in the UAB trauma registry. }\end{array}$ & NR & Civilian \\
\hline Vandromme, 2011b & $\begin{array}{l}\text { Included: Patients admitted to the trauma service. } \\
\text { Excluded: No exclusion criteria detailed. }\end{array}$ & NR & Civilian \\
\hline Vassallo, 2015 & $\begin{array}{l}\text { Included: Trauma patients }>18 \text { years who met trauma team } \\
\text { activation criteria. } \\
\text { Excluded: Patients with missing data on prehospital or in-hospital } \\
\text { interventions performed, and those for whom the triage sort and SI } \\
\text { couldn't be calculated. }\end{array}$ & Adults (>18): $100 \%$ & Military \\
\hline
\end{tabular}




\begin{tabular}{|c|c|c|c|c|}
\hline $\begin{array}{l}\text { Author, Year } \\
\text { (See Appendix B for } \\
\text { complete reference) }\end{array}$ & Mechanism or Type Injury & Mode of Transport & $\begin{array}{l}\text { Other Population Characteristics } \\
\text { (Sex, Race) }\end{array}$ & $\begin{array}{l}\text { Name of Measure Being } \\
\text { Evaluated }\end{array}$ \\
\hline Vandromme, 2010 & \begin{tabular}{|l} 
Blunt: $75.0 \%$ \\
Penetrating: $17.9 \%$
\end{tabular} & NR & $\begin{array}{l}\text { Male: } 63.9 \% \\
\text { Race } \\
\text { - White } 67.2 \% \\
\text { - African-American 28.0\% } \\
\text { Age (mean): } 38.5\end{array}$ & $\begin{array}{l}\text { Lactate } \\
\text { SBP }\end{array}$ \\
\hline Vandromme, 2011 & Blunt: $100 \%$ & NR & $\begin{array}{l}\text { Male: } 66.8 \% \\
\text { Race: NR } \\
\text { Age (mean): } 38.4\end{array}$ & SI \\
\hline Vandromme, 2011b & $\mathrm{NR}$ & NR & NR & \begin{tabular}{|l|} 
LR \\
Lactate \\
Predictive model for massive \\
transfusion (uses hemoglobin \\
SBP, international normalized \\
ratio, lactate, and HR) \\
SBP
\end{tabular} \\
\hline Vassallo, 2015 & NR & NR & NR & $\begin{array}{l}\text { SI } \\
\text { Triage Sort }\end{array}$ \\
\hline
\end{tabular}




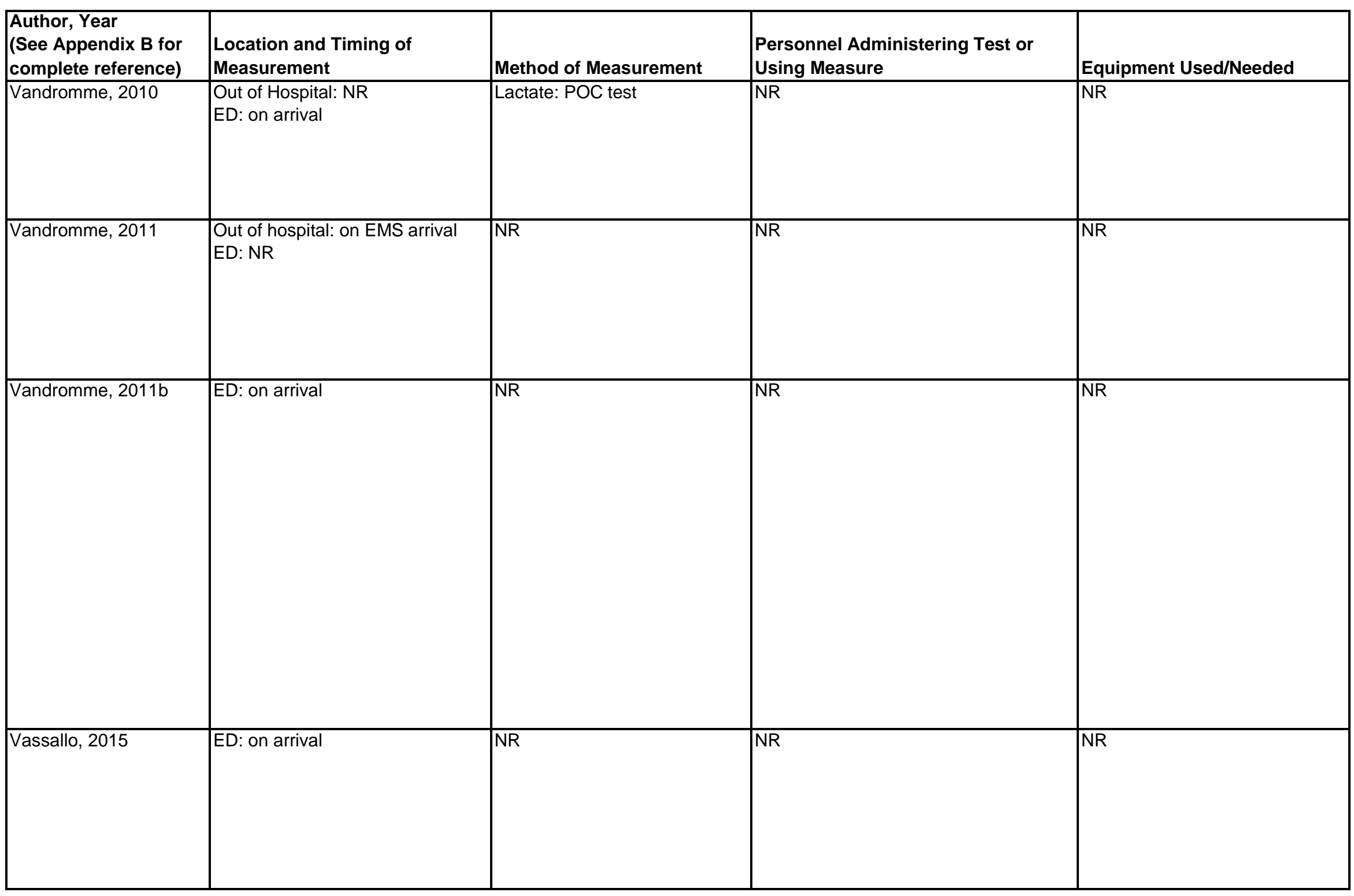




\begin{tabular}{|c|c|c|c|c|}
\hline \begin{tabular}{|l|} 
Author, Year \\
(See Appendix B for \\
complete reference) \\
\end{tabular} & $\begin{array}{l}\text { Threshold Value(s) for Physiologic } \\
\text { Measures }\end{array}$ & $\begin{array}{l}\text { Indicator of Serious Injury Used } \\
\text { (including definition and time period) }\end{array}$ & Funding Source & Risk of Bias \\
\hline Vandromme, 2010 & $\begin{array}{l}\text { SBP 90-100 } \\
\text { Predetermined: patients most likely to be } \\
\text { undertriaged. }\end{array}$ & $\begin{array}{l}\text { Mortality: in-hospital } \\
\text { Significant blood transfusion: } \geq 6 \text { PRBC units } \\
\text { within the first } 24 \text { hours of hospital admission }\end{array}$ & NR & Moderate \\
\hline Vandromme, 2011 & $\mathrm{SI}>0.9$ & $\begin{array}{l}\text { Massive transfusion: } \geq 10 \text { PRBC units within } 24 \\
\text { hours of hospital arrival. } \\
\text { Mortality }\end{array}$ & NR & High \\
\hline Vandromme, 2011b & $\begin{array}{l}\mathrm{HR}>105 \mathrm{bpm} \\
\mathrm{SBP}<110 \mathrm{mmHg} \text { Lactate } \\
>5 \mathrm{mmol} / \mathrm{L} \text { Hemoglobin } \\
(\mathrm{Hb}) \leq 11 \mathrm{~g} / \mathrm{dL} \text { INR }>1.5\end{array}$ & $\begin{array}{l}\text { Massive transfusion: } \geq 10 \text { units PRBCs } \\
\text { transfused within the first } 24 \text { hours of } \\
\text { admission }\end{array}$ & NR & Moderate \\
\hline Vassallo, 2015 & $\begin{array}{l}\text { SI cutpoints: } \geq 0.90, \geq 1.0, \geq 0.75 \\
\text { Triage sort score } \leq 10 \text { : priority one designation }\end{array}$ & $\begin{array}{l}\text { Priority One designation: Patients who } \\
\text { received a life-saving intervention (predefined } \\
\text { list), or who died in the ED. }\end{array}$ & $\begin{array}{l}\text { Study not commissioned. } \\
\text { Conflict of interest declared: } \\
\text { authors JV, SH and JES are serving } \\
\text { members of the HM Armed Forces. }\end{array}$ & Moderate \\
\hline
\end{tabular}




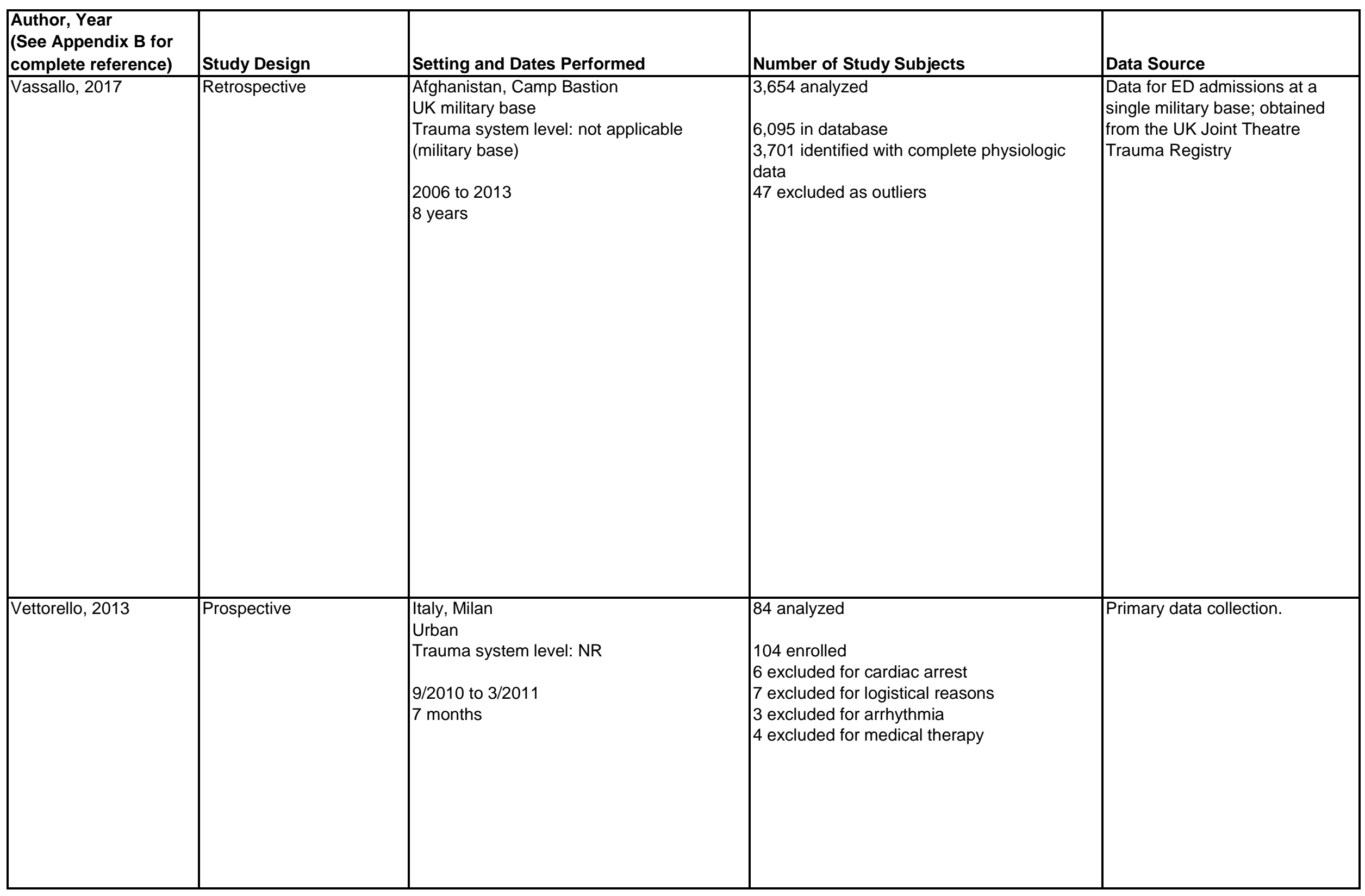




\begin{tabular}{|c|c|c|c|}
\hline $\begin{array}{l}\text { Author, Year } \\
\text { (See Appendix B for } \\
\text { complete reference) }\end{array}$ & Eligibility Criteria & $\begin{array}{l}\text { Age Groups Included (Age Range Used*): \% } \\
\text { of Study Population }\end{array}$ & Type of Population \\
\hline Vassallo, 2017 & $\begin{array}{l}\text { Included: Trauma patients } \geq 18 \text { years old presenting to the ED at the } \\
\text { study site (Camp Bastion military base), and who had complete } \\
\text { recordings of physiologic parameters on ED arrival (SBP, HR, GCS, } \\
\text { and RR). } \\
\text { - The UK Joint Theatre Trauma Registry includes: All seriously } \\
\text { injured patients (including UK military, coalition forces, detainees, } \\
\text { and local civilians) who had trauma team activation in a deployed } \\
\text { field hospital or Primary Casualty Receiving Facility afloat and those } \\
\text { returned to Royal Centre for Defence Medicine for definitive } \\
\text { treatment. } \\
\text { Excluded: Patients with outlying physiologic parameter (SBP }>206 \text {, } \\
\text { HR }>170 \text {, or RR }>45 \text { ). }\end{array}$ & Adults ( $(\geq 18): 100 \%$ & $\begin{array}{l}\text { Military } \\
\text { - includes local civilians and } \\
\text { detainees }\end{array}$ \\
\hline Vettorello, 2013 & $\begin{array}{l}\text { Included: Patients with major trauma criteria and response by } \\
\text { helicopter EMS. } \\
\\
\text { Excluded: Patients }<18 \text { years old, those with need for immediate } \\
\text { resuscitation before iHAT recording, cardiac arrest, chronic illnesses } \\
\text { involving the autonomic nervous system (such as diabetes or } \\
\text { hypertension, any neurologic disease), absent sinus rhythm, } \\
\text { supraventricular ectopic beats }>5 \% \text { of recorded beats, } \\
\text { intraventricular or bundle branch blocks, artificial pacemaker, burns } \\
\text { or amputations prohibiting monitoring, spinal cord trauma, or } \\
\text { medical therapy. }\end{array}$ & Adults ( $(\geq 18): 100 \%$ & Civilian \\
\hline
\end{tabular}




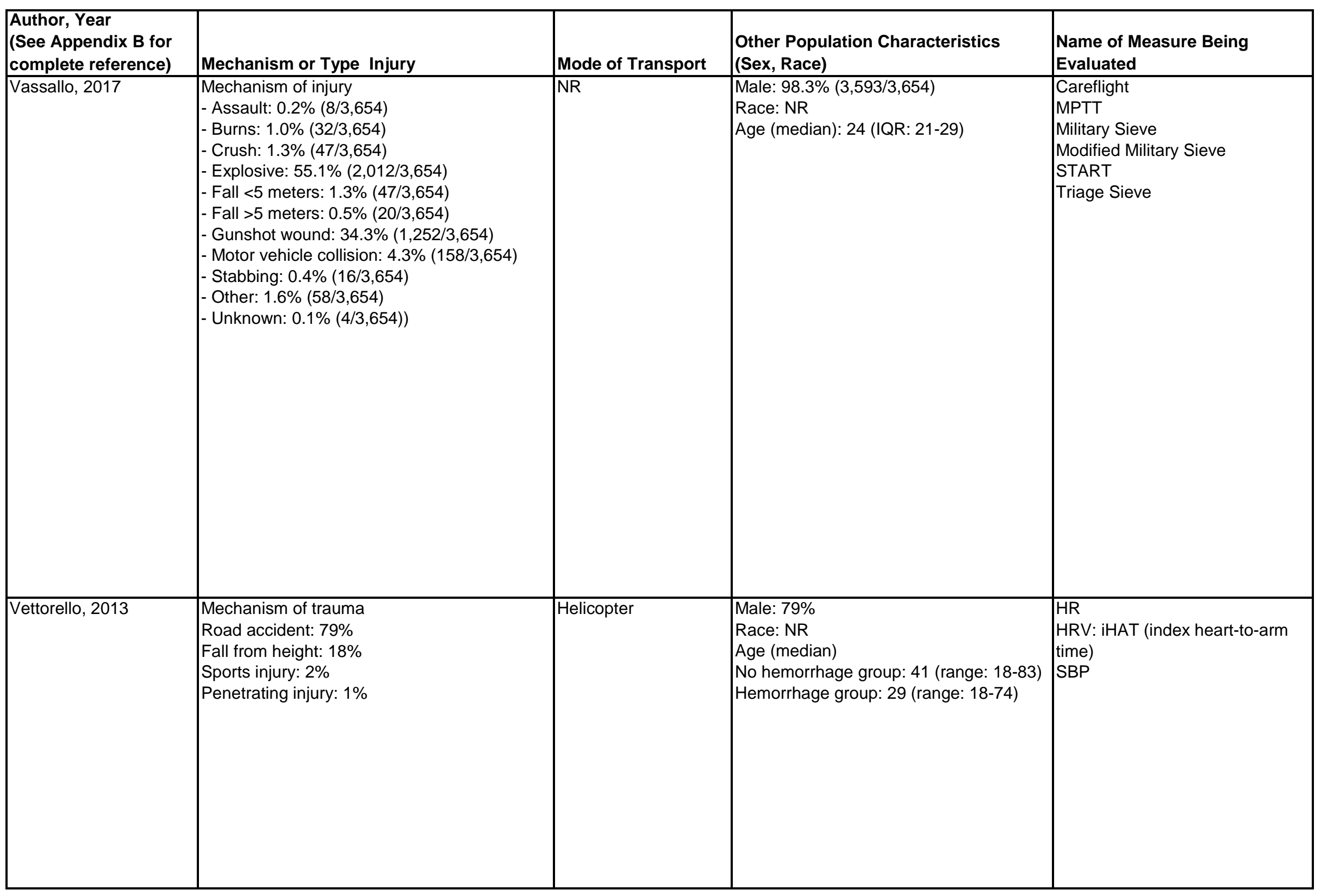




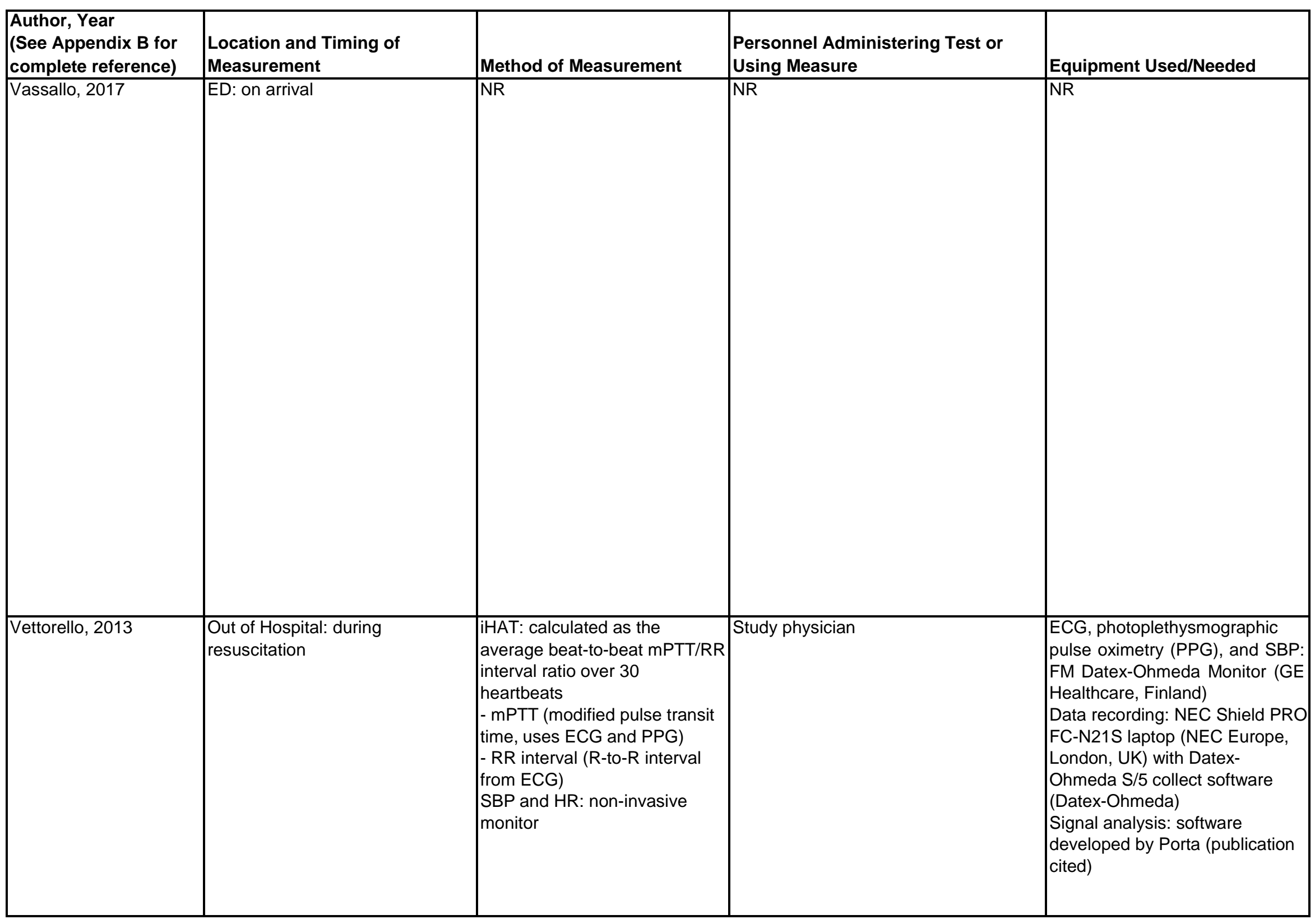




\begin{tabular}{|c|c|c|c|c|}
\hline \begin{tabular}{|l|} 
Author, Year \\
(See Appendix B for \\
complete reference) \\
\end{tabular} & $\begin{array}{l}\text { Threshold Value(s) for Physiologic } \\
\text { Measures }\end{array}$ & $\begin{array}{l}\text { Indicator of Serious Injury Used } \\
\text { (including definition and time period) }\end{array}$ & Funding Source & Risk of Bias \\
\hline Vassallo, 2017 & $\begin{array}{l}\text { All patients were assumed to be non-ambulant } \\
\text { due to limitations of data in registry and } \\
\text { inclusion criteria. } \\
\text { Careflight and START: SBP of } 90 \text { was used as } \\
\text { surrogate for presence of a radial pulse and } \\
\text { absence of hypotension since the JTTR doesn't } \\
\text { record radial pulse as a variable. } \\
\text { MPTT: variables derived as optimum values for } \\
\text { performance in isolation at predicting need for } \\
\text { LSI through logistical regression models. }\end{array}$ & $\begin{array}{l}\text { Life-saving intervention: endotracheal } \\
\text { intubation and rapid sequence induction, } \\
\text { surgical airway, or mechanical ventilation; } \\
\text { thoracostomy; application of a chest seal, } \\
\text { thoracotomy or pericardial window; application } \\
\text { of a tourniquet or use of hemostatic agents or } \\
\text { interventional radiology for hemorrhage } \\
\text { control; arterial ligation, shunt, or cross } \\
\text { clamping; transfusion of uncross-matched } \\
\text { blood, } \geq 4 \text { units of blood, or administration of } \\
\text { tranexamic acid; insertion of an intra-osseous } \\
\text { device for resuscitation; laparotomy; limb } \\
\text { traction and coded pelvic injury; CPR or } \\
\text { administration of epinephrine, atropine, } \\
\text { amiodarone, or other "Resus Drugs"; } \\
\text { neurosurgery for intracranial hemorrhage, or } \\
\text { craniotomy/burr hole insertion; C1-C3 spinal } \\
\text { fracture; administration of a seizure- } \\
\text { terminating medication; rewarming for initial } \\
\text { core temp <32 degrees Celsius; correction of } \\
\text { low blood sugar; or administration of chemical } \\
\text { antidote }\end{array}$ & NR & High \\
\hline Vettorello, 2013 & $\begin{array}{l}\text { Optimal cutpoints calculated by Euclidean } \\
\text { method. } \\
\text { iHAT }>58.78 \% \\
\text { HR }>99 \\
\text { SBP }<125\end{array}$ & $\begin{array}{l}\text { Blood transfusion or bleeding control: } \\
\text { Transfusion of } \geq 4 \text { PRBC units within } 6 \text { hours of } \\
\text { admission and/or urgent laparotomy or } \\
\text { radiological intervention for bleeding control } \\
\text { within } 3 \text { hours. }\end{array}$ & $\begin{array}{l}\text { No financial support from any } \\
\text { company. }\end{array}$ & High \\
\hline
\end{tabular}




\begin{tabular}{|c|c|c|c|c|}
\hline \begin{tabular}{|l} 
Author, Year \\
(See Appendix B for \\
complete reference)
\end{tabular} & Study Design & Setting and Dates Performed & Number of Study Subjects & Data Source \\
\hline Williams, 2016 & Prospective & $\begin{array}{l}\text { USA, Florida } \\
\text { Urban } \\
\text { Level I trauma center } \\
10 / 1 / 2012 \text { to } 6 / 30 / 2014 \\
1 \text { year, } 9 \text { months }\end{array}$ & $\begin{array}{l}170 \text { analyzed } \\
171 \text { enrolled } \\
1 \text { withdrew consent }\end{array}$ & $\begin{array}{l}\text { Data collected at enrollment and } \\
\text { by chart review. }\end{array}$ \\
\hline Woodford, 2012 & Retrospective & $\begin{array}{l}\text { USA, Maryland } \\
\text { Urban } \\
\text { Level I trauma center } \\
5 / 2007 \text { to } 2 / 2008 \\
10 \text { months }\end{array}$ & $\begin{array}{l}120 \text { analyzed } \\
177 \text { identified } \\
57 \text { excluded for missing data }\end{array}$ & $\begin{array}{l}\text { Maryland trauma registry and } \\
\text { primary collection of EMS vital } \\
\text { signs. Patients transported to } \\
\text { Shock Trauma Center. }\end{array}$ \\
\hline $\begin{array}{l}\text { Yang, } 2016 \\
\text { *Mackenzie 2015, } \\
\text { Shackelford 2015, and } \\
\text { Yang } 2016 \text { draw from } \\
\text { the same population, } \\
\text { but differ in eligibility } \\
\text { criteria, number } \\
\text { analyzed, and } \\
\text { measures evaluated. }\end{array}$ & Prospective & $\begin{array}{l}\text { USA, Maryland } \\
\text { Urban } \\
\text { Level I trauma center } \\
12 / 2011 \text { to } 5 / 2013 \\
18 \text { months }\end{array}$ & $\begin{array}{l}677 \text { analyzed } \\
1,191 \text { admitted to trauma resuscitation unit } \\
\text { and met age and EMS SI criteria } \\
480 \text { excluded for no continuous oximetry } \\
\text { monitoring } \\
34 \text { excluded for incomplete laboratory blood } \\
\text { tests }\end{array}$ & $\begin{array}{l}\text { Prospective, consecutive } \\
\text { enrollment of trauma patients at } \\
\text { a single trauma center. Primary } \\
\text { data collection by research } \\
\text { assistant. }\end{array}$ \\
\hline
\end{tabular}




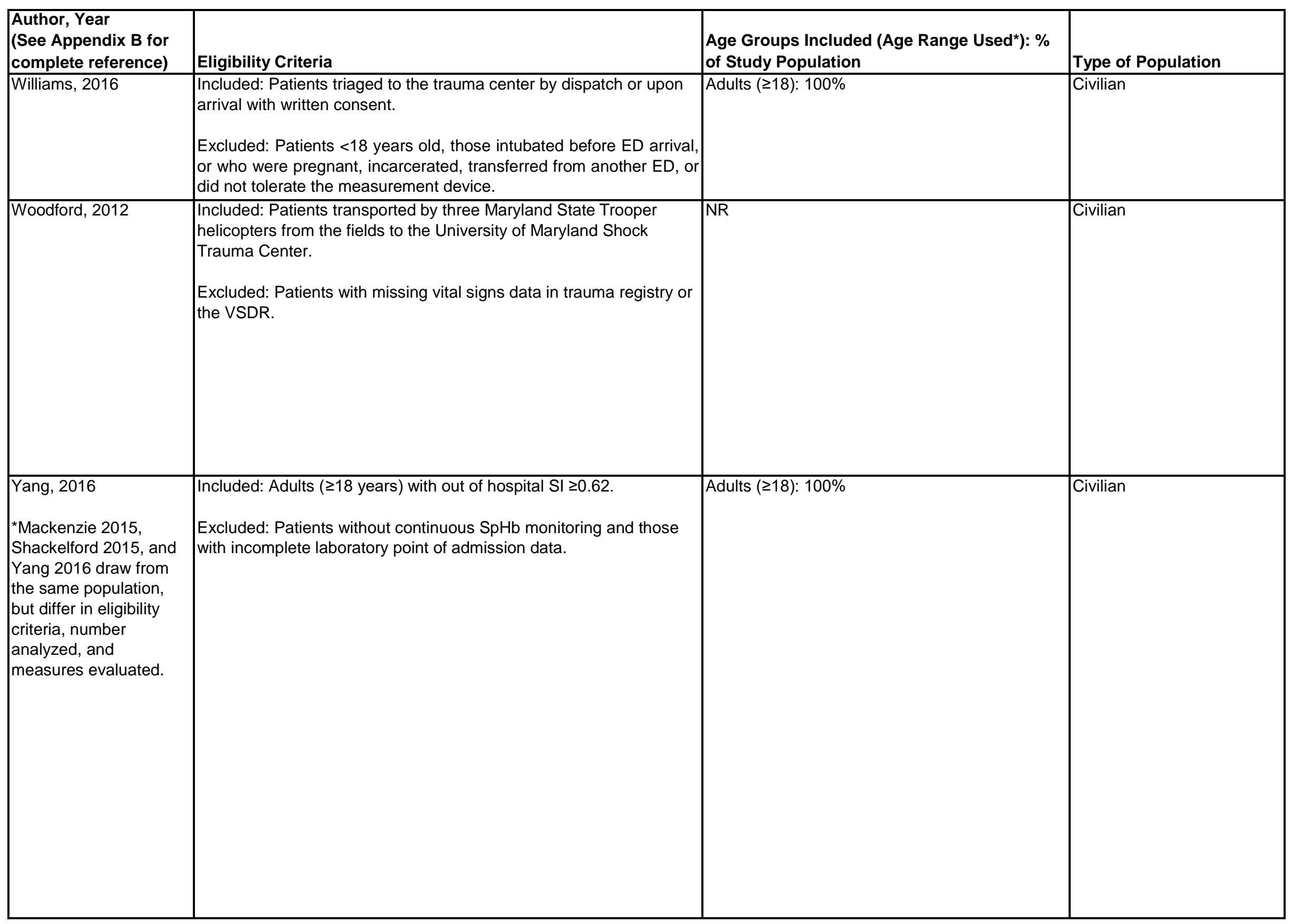




\begin{tabular}{|c|c|c|c|c|}
\hline $\begin{array}{l}\text { Author, Year } \\
\text { (See Appendix B for } \\
\text { complete reference) }\end{array}$ & Mechanism or Type Injury & Mode of Transport & $\begin{array}{l}\text { Other Population Characteristics } \\
\text { (Sex, Race) }\end{array}$ & $\begin{array}{l}\text { Name of Measure Being } \\
\text { Evaluated }\end{array}$ \\
\hline Williams, 2016 & $\begin{array}{l}\text { Blunt: } 89 \% \\
\text { Penetrating: 9\% } \\
\text { Burn: } 2 \%\end{array}$ & NR & $\begin{array}{l}\text { Male: } 67 \% \\
\text { Race } \\
\text { - Black: } 27 \% \\
\text { - White: } 71 \% \\
\text { - All other: } 2 \% \\
\text { Age (mean): } 43 \text { (range: 18-82) }\end{array}$ & ETCO2 \\
\hline Woodford, 2012 & NR & Helicopter & $\begin{array}{l}\text { Male: } 63 \% \text { (75/120) } \\
\text { Race: NR } \\
\text { Age (mean): } 42 \text { (range 18-86) }\end{array}$ & $\begin{array}{l}\text { GCS }+\mathrm{SpO} 2 \\
\mathrm{HR} \\
\mathrm{SpO}_{2} \\
\mathrm{RTS} \\
\mathrm{SBP} \\
\mathrm{SI}\end{array}$ \\
\hline $\begin{array}{l}\text { Yang, } 2016 \\
\text { *Mackenzie 2015, } \\
\text { Shackelford 2015, and } \\
\text { Yang } 2016 \text { draw from } \\
\text { the same population, } \\
\text { but differ in eligibility } \\
\text { criteria, number } \\
\text { analyzed, and } \\
\text { measures evaluated. }\end{array}$ & $\begin{array}{l}\text { Type of injury: } \\
\text { Blunt: } 87.0 \%(589 / 677) \\
\text { Penetrating: } 11.7 \%(79 / 677) \\
\text { Other: } 1.3 \% \text { (9/677) } \\
\text { Mechanism of injury } \\
\text { Motor vehicle associated: } 52.3 \%(354 / 677) \\
\text { Falls: } 20.8 \% \text { (141/677) } \\
\text { Interpersonal violence: } 19.5 \%(132 / 677) \\
\text { Other: } 7.4 \% \text { (50/677) }\end{array}$ & NR & $\begin{array}{l}\text { Male: } 70.8 \% \text { (479/677) } \\
\text { Race: NR } \\
\text { Age (mean): } 38.7 \text { (SD 16.6) }\end{array}$ & $\begin{array}{l}\text { Decision support models using } \\
\text { combinations of } 4 \text { features of } \\
\text { HR, SI, non-invasive } \mathrm{Hb}(\mathrm{SpHb}), \\
\text { and laboratory Hb; and other } \\
\text { laboratory tests (partial } \\
\text { thromboplastin time, INR, } \\
\text { fibrinogen, lactate, and glucose). } \\
\text { Models are adjusted for age and } \\
\text { sex. } \\
\text { - HR model: EMS HR with and } \\
\text { without combinations of features } \\
\text { adjusted for age and sex. } \\
\text { - SI model: EMS SI with and } \\
\text { without combinations of features } \\
\text { adjusted for age and sex }\end{array}$ \\
\hline
\end{tabular}




\begin{tabular}{|c|c|c|c|c|}
\hline $\begin{array}{l}\text { Author, Year } \\
\text { (See Appendix B for } \\
\text { complete reference) }\end{array}$ & $\begin{array}{l}\text { Location and Timing of } \\
\text { Measurement }\end{array}$ & Method of Measurement & $\begin{array}{l}\text { Personnel Administering Test or } \\
\text { Using Measure }\end{array}$ & Equipment Used/Needed \\
\hline Williams, 2016 & ED: within 30 minutes of arrival & $\begin{array}{l}\text { ET CO2: average of } 3 \\
\text { readings, measured by } \\
\text { sidestream sampling nasal } \\
\text { cannula }\end{array}$ & Research assistant & $\begin{array}{l}\text { Nihon Kohden TG-920P } \\
\text { capnography cable attached to } \\
\text { standard ED monitor (Nihon } \\
\text { Kohden Corp., Tokyo, Japan) }\end{array}$ \\
\hline Woodford, 2012 & $\begin{array}{l}\text { Out of hospital: } \\
\text { - VSDR: continuous during } \\
\text { resuscitation } \\
\text { Trauma registry data: on arrival }\end{array}$ & $\begin{array}{l}\text { VSDR: automated patient vital } \\
\text { signs monitor } \\
\text { - HR: pulse oximeter-derived } \\
\text { - } \mathrm{SpO}_{2} \text { : automated } \\
\text { - SBP: non-invasive, } \\
\text { automated } \\
\text { Trauma registry vital signs: } \\
\text { manually collected }\end{array}$ & NR & $\begin{array}{l}\text { Vital signs monitor: Propaq 206E } \\
\text { Vital signs data and event } \\
\text { recorder: interface with vital } \\
\text { signs monitor via miniature } \\
\text { personal computer } \\
\text { Waveform analysis: software } \\
\text { application created in Matlab } \\
\text { V7.7.0.471 (MathWorks, Natick, } \\
\text { Massachusetts) and MedCalc } \\
\text { V11.0 (MedCalc Software, } \\
\text { Mariakerke, Belgium) }\end{array}$ \\
\hline $\begin{array}{l}\text { Yang, } 2016 \\
\star \text { *Mackenzie 2015, } \\
\text { Shackelford 2015, and } \\
\text { Yang } 2016 \text { draw from } \\
\text { the same population, } \\
\text { but differ in eligibility } \\
\text { criteria, number } \\
\text { analyzed, and } \\
\text { measures evaluated. }\end{array}$ & $\begin{array}{l}\text { Out of hospital: NR } \\
\text { ED: } \\
\text { - blood draw on arrival for lab } \\
\text { tests (Hb and other tests) } \\
\text { - SpHb continuous monitoring } \\
\text { and vital sign collection for } 15 \\
\text { minutes after admission; SpHb } \\
\text { also recorded at time of blood } \\
\text { draw }\end{array}$ & $\begin{array}{l}\text { Hemoglobin } \\
\text { - Noninvasive }(\mathrm{SpHb}) \text { : } \\
\text { automated sensor } \\
\text { - Laboratory Hb concentration: } \\
\text { venous } \\
\text { Vital signs: automated }\end{array}$ & $\begin{array}{l}\text { Research assistant recorded } \mathrm{SpHb} \\
\text { reading at time of laboratory blood } \\
\text { draw. }\end{array}$ & $\begin{array}{l}\text { Noninvasive hemoglobin } \\
\text { (SpHb): Masimo Rainbow Pulse } \\
\text { CO-Oximetry (Masimo } \\
\text { Corporation, Irvine, California), } \\
\text { using Masimo Rad-87 (ver. } \\
\text { 1405) software and Rev F } \\
\text { sensor. } \\
\text { Vital signs: BedMaster (GE } \\
\text { Marquette, Milwaukee, } \\
\text { Wisconsin) } \\
\text { Laboratory Hb concentration: } \\
\text { Sysmex XN-2000 Automated } \\
\text { Hematology Analyzer; Sysmex } \\
\text { Corp., Kobe, Japan) } \\
\text { Laboratory glucose: Analyzer } \\
\text { NSN 6630015205212; Abbott } \\
\text { Laboratories Inc., Chicago, } \\
\text { Illinois. }\end{array}$ \\
\hline
\end{tabular}




\begin{tabular}{|c|c|c|c|c|}
\hline $\begin{array}{l}\text { Author, Year } \\
\text { (See Appendix B for } \\
\text { complete reference) }\end{array}$ & $\begin{array}{l}\text { Threshold Value(s) for Physiologic } \\
\text { Measures }\end{array}$ & $\begin{array}{l}\text { Indicator of Serious Injury Used } \\
\text { (including definition and time period) }\end{array}$ & Funding Source & Risk of Bias \\
\hline Williams, 2016 & $\begin{array}{l}\text { ETCO2 } \leq 30 \mathrm{~mm} \mathrm{Hg} \\
\text { based on prior studies }\end{array}$ & $\begin{array}{l}\text { Severe injury: ICU admission, operative } \\
\text { intervention, acute clinically significant finding } \\
\text { on CT, invasive procedure, blood product } \\
\text { transfusion or acute blood loss anemia. }\end{array}$ & $\begin{array}{l}\text { Supported by a University of Florida } \\
\text { Faculty Dean's Fund Grant. }\end{array}$ & Moderate \\
\hline Woodford, 2012 & $\begin{array}{l}\text { Abnormal vital signs: } \\
\mathrm{SpO}_{2}<90 \% \mathrm{HR} \\
>110 \mathrm{bpm} \mathrm{SBP} \\
<90 \mathrm{mmHg} \\
\text { Predetermined: NR; cut-off points determined to } \\
\text { by the research group and others be clinically } \\
\text { relevant }\end{array}$ & Mortality: NR & $\begin{array}{l}\text { Supported by DoD-TATRC grants } \\
\text { W81XWH-05-0374, W81XWH-06-C- } \\
\text { 0034, W81XWH-07-2-0118, AND } \\
\text { FA8650-11-2-6DO1. }\end{array}$ & Moderate \\
\hline \begin{tabular}{|l} 
Yang, 2016 \\
\\
*Mackenzie 2015, \\
Shackelford 2015, and \\
Yang 2016 draw from \\
the same population, \\
but differ in eligibility \\
criteria, number \\
analyzed, and \\
measures evaluated.
\end{tabular} & \begin{tabular}{|l} 
Inclusion criterion of $\mathrm{SI} \geq 0.62$ \\
How value was determined was not reported.
\end{tabular} & $\begin{array}{l}\text { Blood transfusion: use of pRBC 1-3 hours } \\
\text { after admission, validated via blood bank } \\
\text { records } \\
\text { Mortality: NR }\end{array}$ & $\begin{array}{l}\text { Funded by U.S. Air Force (FA8650- } \\
\text { 11-2-6D01) Continuing Noninvasive } \\
\text { Monitoring and the Development of } \\
\text { Predictive Triage Indices for } \\
\text { Outcomes Following Trauma. } \\
\text { Masimo (Masimo Corporation, } \\
\text { Irvine, California) provided the } \\
\text { SpHb monitors but had no role in } \\
\text { the design, execution, or analysis of } \\
\text { this research. }\end{array}$ & Moderate \\
\hline
\end{tabular}




\begin{tabular}{|c|c|c|c|c|}
\hline $\begin{array}{l}\text { Author, Year } \\
\text { (See Appendix B for } \\
\text { complete reference) }\end{array}$ & Study Design & Setting and Dates Performed & Number of Study Subjects & Data Source \\
\hline Yuen, 2016 & Retrospective & $\begin{array}{l}\text { Hong Kong } \\
\text { Urban } \\
\text { Trauma system level: NR } \\
1 / 1 / 2010 \text { to } 12 / 31 / 2011 \text { (validation dataset) } \\
2 \text { years }\end{array}$ & $\begin{array}{l}850 \text { analyzed (validation cases) } \\
1.998 \text { identified } \\
-1,057 \text { used for development } \\
-850 \text { used for validation }\end{array}$ & $\begin{array}{l}\text { Hong Kong East Cluster Trauma } \\
\text { Registry }\end{array}$ \\
\hline Zarzaur, 2008 & Retrospective & $\begin{array}{l}\text { USA, Tennessee } \\
\text { Urban } \\
\text { Level I trauma center } \\
1996 \text { to } 2005 \\
10 \text { years }\end{array}$ & $\begin{array}{l}16,077 \text { analyzed } \\
36,599 \text { identified } \\
4,350 \text { excluded for no palpable pulse } \\
6,513 \text { excluded for significant brain or spinal } \\
\text { cord injury } \\
4,300 \text { excluded for presentation }>24 \text { hours } \\
\text { after injury } \\
5,359 \text { excluded for no blunt injury }\end{array}$ & $\begin{array}{l}\text { Trauma registry for a single } \\
\text { trauma center. }\end{array}$ \\
\hline
\end{tabular}




\begin{tabular}{|c|c|c|c|}
\hline $\begin{array}{l}\text { Author, Year } \\
\text { (See Appendix B for } \\
\text { complete reference) }\end{array}$ & Eligibility Criteria & $\begin{array}{l}\text { Age Groups Included (Age Range Used*): \% } \\
\text { of Study Population }\end{array}$ & Type of Population \\
\hline Yuen, 2016 & $\begin{array}{l}\text { Two hospitals in registry: Pamela Youde Nethersole Eastern } \\
\text { Hospital (PYNEH), and Ruttonjee Hospital (RH) } \\
\text { Included: Patients with trauma team activation for both hospitals; } \\
\text { Hong Kong Hospital Authority triage category } 1 \text { or } 2 \text { trauma cases } \\
\text { in PYNEH; neurological trauma patients transferred from RH to } \\
\text { PYNEH; trauma patients who died and had received medical } \\
\text { intervention in the ED of PYNEH. } \\
\text { Excluded: Non-trauma patients; Hong Kong Hospital Authority triage } \\
\text { categories } 3,4 \text {, or } 5 \text { trauma cases in PYNEH that did not require } \\
\text { trauma team activation; trauma patients who died and did not } \\
\text { receive medical intervention in the ED of PYNEH; patients with } \\
\text { unknown age. }\end{array}$ & $\begin{array}{l}\text { Mixed; percentages not provided } \\
\text { Range: } 2 \text { months - } 102 \text { years }\end{array}$ & Civilian \\
\hline Zarzaur, 2008 & $\begin{array}{l}\text { Included: Patients } 18-81 \text { years old, with blunt trauma, and a } \\
\text { palpable pulse (defined as HR }>10 \text { bpm or SBP }>30 \mathrm{mmHg} \text { ) on } \\
\text { admission. } \\
\text { Excluded: Patients with spinal cord injuries, significant brain injuries } \\
\text { (head AIS score } \geq 3 \text { ), who had missing values for admission HR or } \\
\text { SBP, or who presented }>24 \text { hours after the time of injury. }\end{array}$ & $\begin{array}{l}\text { Adults }(\geq 18): 100 \% \\
\text { - Young (<55 years): } 85 \% \\
\text { - Elderly ( } \geq 55 \text { years): } 15 \%\end{array}$ & Civilian \\
\hline
\end{tabular}




\begin{tabular}{|c|c|c|c|c|}
\hline $\begin{array}{l}\text { Author, Year } \\
\text { (See Appendix B for } \\
\text { complete reference) }\end{array}$ & Mechanism or Type Injury & Mode of Transport & $\begin{array}{l}\text { Other Population Characteristics } \\
\text { (Sex, Race) }\end{array}$ & $\begin{array}{l}\text { Name of Measure Being } \\
\text { Evaluated }\end{array}$ \\
\hline Yuen, 2016 & $\begin{array}{l}\text { All identified (development and validation) } \\
\text { Blunt: } 98 \%\end{array}$ & NR & $\begin{array}{l}\text { All identified (development and } \\
\text { validation) } \\
\text { Male: } 66 \% \\
\text { Race: NR } \\
\text { Age (mean): } 48 \text { (SD 25) }\end{array}$ & $\begin{array}{l}\text { RTS } \\
\text { Simplified emergency trauma } \\
\text { score - uses GCS, RR, } \\
\text { mechanism of injury, and age }\end{array}$ \\
\hline Zarzaur, 2008 & Blunt: $100 \%$ & NR & $\begin{array}{l}\text { Male: } 67 \% \\
\text { Race: NR } \\
\text { Age (mean): } 39 \text { (SD 16) }\end{array}$ & $\begin{array}{l}\text { Age } \times \text { SI } \\
\text { HR } \\
\text { SBP } \\
\text { SI }\end{array}$ \\
\hline
\end{tabular}




\begin{tabular}{|l|l|l|l|l|}
\hline $\begin{array}{l}\text { Author, Year } \\
\text { (See Appendix B for } \\
\text { complete reference) }\end{array}$ & $\begin{array}{l}\text { Location and Timing of } \\
\text { Measurement }\end{array}$ & Method of Measurement & $\begin{array}{l}\text { Personnel Administering Test or } \\
\text { Using Measure }\end{array}$ & Equipment Used/Needed \\
\hline Yuen, 2016 & ED: not specified & NR & NR & \\
& & & & \\
\hline Zarzaur, 2008 & ED: on arrival & NR & & \\
& & & & \\
& & & & \\
\hline
\end{tabular}




\begin{tabular}{|l|l|l|l|}
\hline $\begin{array}{l}\text { Author, Year } \\
\text { (See Appendix B for } \\
\text { complete reference) }\end{array}$ & $\begin{array}{l}\text { Threshold Value(s) for Physiologic } \\
\text { Measures }\end{array}$ & $\begin{array}{l}\text { Indicator of Serious Injury Used } \\
\text { (including definition and time period) }\end{array}$ & \multicolumn{1}{c|}{ Funding Source } \\
\hline Yuen, 2016 & $\begin{array}{l}\text { Simplified emergency trauma score }=60 \text { : cut-off } \\
\text { point }\end{array}$ & Mortality: NR & NR \\
& $\begin{array}{l}\text { Cutpoints based on Youden's index to maximize } \\
\text { sensitivity and specificity for predicting 48-hour } \\
\text { mortality: } \\
\text { Overall } \\
\text { SI } \geq 0.83 \\
\text { Age } x \text { SI } \geq 32.3 \\
\text { Elderly } \\
\text { Age } x \text { SI } \geq 52.1\end{array}$ & $\begin{array}{l}\text { Mortality: 48-hour } \\
\text { Blood transfusion: receipt of } \geq 4 \text { units of blood } \\
\text { within 48 hours of admission }\end{array}$ & NR \\
\hline Zarzaur, 2008 & & \\
\hline
\end{tabular}

See Appendix B. Included Studies for full study references.

ABG = arterial blood gas: ACS-COT = American College of Surgeons Committee on Trauma; AIS = Abbreviated Injury Scale; AOR = adjusted odds ratio; APACHE II = Acute Physiology and Chronic Health Evaluation II; AUROC = area under the receiver operating characteristic curve; $\mathrm{BD}$ = base deficit; $\mathrm{BP}=$ blood pressure; CHAID = chi-square automatic interaction detection; CI = confidence interval; $\mathrm{CNS}$ = central nervous system; $\mathrm{CPR}$ = cardiopulmonary resuscitation; $\mathrm{CRAMS}=$ Circulation, Respiration, Abdomen, Motor, and Speech; $\mathrm{CT}$ = computed tomography; DBP = diastolic blood pressure; ECG = electrocardiogram; ED = emergency department; EHR = electronic health record; EMS = emergency medical services; EMT = emergency medical technician; EMTRAS = Emergency Trauma Score; ETCO2 = end-tidal carbon dioxide; FTS = Field Triage Score; GAP = Glasgow Coma Scale, Age, and Arterial Pressure; GCS = Glasgow Coma Scale; Hb = hemoglobin; $\mathrm{HF}$ = high frequency; $\mathrm{HR}$ = heart rate; HRC = heart rate complexity; HRV = heart rate variability; ICD-9 = International Classification of Diseases 9th Revision; ICU = intensive care unit; INR = international normalized ratio; IQR = interquartile range; ISS = Injury Severity Score; IV = intravenous; LF = low frequency; LOS = length of stay; LSI = life-saving intervention; MAP = mean arterial pressure; MGAP = Mechanism, Glasgow Coma Scale, Age, and Arterial Pressure; MOD = multiple organ dysfunction; MPTT = Modified Physiological Triage Tool; NA = not applicable; NIRS = near-infrared spectrometry; NLR = negative likelihood ratio; NPV = negative predictive value; NR = not reported; NTDB = National Trauma Data Bank; NTTP = National Trauma Triage Protocol: $\mathrm{OH}$ = out-of-hospital; $\mathrm{OR}=$ operating room; $\mathrm{pCO}_{2}=$ partial pressure of carbon dioxide; PHI = Prehospital Index; PLR = positive likelihood ratio; POC = point of care; $\mathrm{PP}=$ pulse pressure; PPG = photoplethysmography, photoplethysmogram; PPV = positive predictive value; $\mathrm{PRBC}$ = packed red blood cell; PTS = Pediatric Trauma Score; RBC = red blood cell; REMS = Rapid Emergency Medicine Score; ROC = receiver operating characteristic; RR = respiratory rate; RTS = Revised Trauma Score; SaO2 = oxygen saturation; SBP = systolic blood pressure; SD = standard deviation; Sen = sensitivity; SETS = Simplified Emergency Trauma Score; SI = shock index; SLCO2 = sublingual partial pressure of carbon dioxide; SmO2 = muscle oxygen saturation; Sp = specificity; $\mathrm{SpHb}=$ noninvasive continuous hemoglobin concentration; $\mathrm{SpO} 2$ = peripheral oxygen saturation; START = Simple Triage and Rapid Treatment; StO2 = tissue oxygen saturation; TARN = Trauma Audit and Research Network; T-ASPTS = Triage Age-Specific Pediatric Trauma Score; TBI = traumatic brain injury; TRISS = Trauma and Injury Severity Score; T-RTS = Revised Trauma Score for Triage; ViEWS-L = VitalPAC Early Warning Score-Lactate; vs. = versus; VSDR = vital signs data and event recorder; WVSM = wireless vital signs monitor 
Table D2. Univariate results

\begin{tabular}{|c|c|c|c|c|c|}
\hline $\begin{array}{l}\text { Author, Year } \\
\text { (See Appendix B for } \\
\text { complete reference) }\end{array}$ & Measure & Indicator of Serious Injury & $\begin{array}{l}\text { Reported Sensitivity } \\
(95 \% \mathrm{Cl})\end{array}$ & $\begin{array}{l}\text { Reported Specificity } \\
(95 \% \mathrm{Cl})\end{array}$ & $\begin{array}{l}\text { Reported PPV } \\
(95 \% \mathrm{Cl})\end{array}$ \\
\hline Ahun, 2014 & GAP $<19$ & 24-hour mortality & $83.33 \%$ (36.1 to 97.2$)$ & $87.50 \%(78.7$ to 93.6$)$ & NR \\
\hline Ahun, 2014 & MGAP $<23$ & 24-hour mortality & $100.00 \%$ (54.1 to 100.0$)$ & $89.77 \%$ (81.5 to 95.2) & NR \\
\hline Ahun, 2014 & RTS $<5.68$ & 24-hour mortality & $50.00 \%$ (12.4 to 87.6$)$ & $100.00 \%$ (95.9 to 100.0) & NR \\
\hline Ahun, 2014 & GAP $<21$ & 4-week mortality & $91.67 \%$ (61.5 to 99.8$)$ & $78.41 \%(68.4$ to 86.5$)$ & NR \\
\hline Ahun, 2014 & MGAP ) $<25$ & 4-week mortality & $100.00 \%(73.5$ to 100.0$)$ & $80.68 \%(70.9$ to 88.3$)$ & NR \\
\hline Ahun, 2014 & RTS $<5.97$ & 4-week mortality & $41.67 \%(15.2$ to 72.3$)$ & $95.45 \%$ (88.8 to 98.7$)$ & NR \\
\hline Al-Salamah, 2004 & T-RTS $<12$ & Mortality, in-hospital & $84 \%(\mathrm{Cl} \mathrm{NR})$ & $64 \%(\mathrm{Cl} \mathrm{NR})$ & NR \\
\hline Al-Salamah, 2004 & RR (using RTS scoring 0-4) & Mortality, in-hospital & NR & NR & NR \\
\hline Al-Salamah, 2004 & T-RTS & Mortality, in-hospital & NR & NR & NR \\
\hline Al-Salamah, 2004 & SBP (using RTS scoring 0-4) & Mortality, in-hospital & NR & NR & NR \\
\hline Allen, 2014 & $\mathrm{BD}<-7$ & Blood transfusion & $29 \%(\mathrm{NR})$ & $95 \%(\mathrm{NR})$ & NR \\
\hline Allen, 2014 & $\mathrm{BD}<-5$ & Blood transfusion & $54 \%(N R)$ & $88 \%(\mathrm{NR})$ & NR \\
\hline Allen, 2014 & $\mathrm{BD}<0$ & Blood transfusion & $94 \%(N R)$ & $30 \%(N R)$ & NR \\
\hline Arbabi, 2004 & $\mathrm{SBP}<90, \mathrm{ED}$ & Mortality & $\begin{array}{l}41.72 \%(39.00 \text { to } 44.48) \\
\text { calculated }\end{array}$ & $\begin{array}{l}97.78 \%(97.50 \text { to } 98.04) \\
\text { calculated }\end{array}$ & $\begin{array}{l}67.17 \%(64.10 \text { to } 70.10) \\
\text { calculated }\end{array}$ \\
\hline Arbabi, 2004 & $\mathrm{SBP}<120, \mathrm{ED}$ & Mortality & $\begin{array}{l}60.94 \%(58.20 \text { to } 63.62) \\
\text { calculated }\end{array}$ & $\begin{array}{l}80.60 \%(79.87 \text { to } 81.31) \\
\text { calculated }\end{array}$ & $\begin{array}{l}25.49 \%(24.42 \text { to } 26.59) \\
\text { calculated }\end{array}$ \\
\hline Arbabi, 2004 & SBP $<90$, EMS & Mortality & $\begin{array}{l}50.86 \%(47.49 \text { to } 54.21) \\
\text { calculated }\end{array}$ & $\begin{array}{l}86.64 \%(85.76 \text { to } 87.50) \\
\text { calculated }\end{array}$ & $\begin{array}{l}35.74 \%(33.66 \text { to } 37.87) \\
\text { calculated }\end{array}$ \\
\hline Arbabi, 2004 & SBP $<120$, EMS & Mortality & $\begin{array}{l}67.54 \% \text { (64.33 to } 70.63) \\
\text { calculated }\end{array}$ & $\begin{array}{l}59.81 \%(58.56 \text { to } 61.05) \\
\text { calculated }\end{array}$ & $\begin{array}{l}19.73 \%(18.87 \text { to } 20.62) \\
\text { calculated }\end{array}$ \\
\hline Aslar, 2004 & APACHE II score $\geq 15$ & Mortality, 30-day in-hospital & $\begin{array}{l}80.00 \%(59.30 \text { to } 93.17) \\
\text { calculated }\end{array}$ & $\begin{array}{l}94.87 \%(82.68 \text { to } 99.37) \\
\text { calculated }\end{array}$ & $\begin{array}{l}90.91 \%(71.88 \text { to } 97.51) \\
\text { calculated }\end{array}$ \\
\hline Aslar, 2004 & $\mathrm{BD} \leq-6$ & Mortality, 30-day in-hospital & $\begin{array}{l}76.00 \%(54.87 \text { to } 90.64) \\
\text { calculated }\end{array}$ & $\begin{array}{l}62.16 \%(44.76 \text { to } 77.54) \\
\text { calculated }\end{array}$ & $\begin{array}{l}57.58 \%(45.94 \text { to } 68.43) \\
\text { calculated }\end{array}$ \\
\hline Aslar, 2004 & Lactate $\geq 4$ & Mortality, 30-day in-hospital & $\begin{array}{l}84.00 \%(63.92 \text { to } 95.46) \\
\text { calculated }\end{array}$ & $\begin{array}{l}86.49 \%(71.23 \text { to } 95.46) \\
\text { calculated }\end{array}$ & $\begin{array}{l}80.77 \%(64.62 \text { to } 90.62) \\
\text { calculated }\end{array}$ \\
\hline Aslar, 2004 & $\mathrm{pH} \leq 7.3$ & Mortality, 30-day in-hospital & $\begin{array}{l}72.00 \%(50.61 \text { to } 87.93) \\
\text { calculated }\end{array}$ & $\begin{array}{l}84.62 \%(69.47 \text { to } 94.14) \\
\text { calculated }\end{array}$ & $\begin{array}{l}75.00 \%(58.01 \text { to } 86.69) \\
\text { calculated }\end{array}$ \\
\hline
\end{tabular}




\begin{tabular}{|c|c|c|c|c|c|}
\hline $\begin{array}{l}\text { Author, Year } \\
\text { (See Appendix B for } \\
\text { complete reference) }\end{array}$ & $\begin{array}{l}\text { Reported NPV } \\
(95 \% \mathrm{CI})\end{array}$ & Reported PLR & Reported NLR & $\begin{array}{l}\text { AUROC Univariate } \\
\text { AUC }(95 \% \mathrm{CI})\end{array}$ & $\begin{array}{l}\text { Other Measures of } \\
\text { Diagnostic Accuracy }\end{array}$ \\
\hline Ahun, 2014 & NR & NR & NR & 0.910 (CI NR), $p<0.001$ & NR \\
\hline Ahun, 2014 & NR & NR & NR & 0.970 (Cl NR), $p<0.001$ & NR \\
\hline Ahun, 2014 & NR & NR & NR & 0.727 (CI NR), $p=0.012$ & NR \\
\hline Ahun, 2014 & NR & NR & NR & 0.904 (CI NR), $p<0.001$ & NR \\
\hline Ahun, 2014 & NR & NR & NR & 0.938 (Cl NR), $p<0.001$ & NR \\
\hline Ahun, 2014 & NR & NR & NR & $0.680(\mathrm{Cl} \mathrm{NR}), \mathrm{p}=0.026$ & NR \\
\hline Al-Salamah, 2004 & $\widehat{N R}$ & NR & $\widehat{N R}$ & NR & NR \\
\hline Al-Salamah, 2004 & NR & NR & NR & $0.68(\mathrm{Cl} N R)$, tau c $=0.21$ & NR \\
\hline Al-Salamah, 2004 & NR & NR & NR & $0.83(\mathrm{Cl} N R)$, tau $\mathrm{c}=0.39$ & $\widehat{N R}$ \\
\hline Al-Salamah, 2004 & NR & NR & NR & $0.63(\mathrm{Cl} N R), \operatorname{tau} \mathrm{c}=0.15$ & NR \\
\hline Allen, 2014 & NR & NR & NR & NR & NR \\
\hline Allen, 2014 & NR & NR & NR & NR & NR \\
\hline Allen, 2014 & NR & NR & NR & NR & NR \\
\hline Arbabi, 2004 & $\begin{array}{l}93.90 \%(93.63 \text { to } 94.16) \\
\text { calculated }\end{array}$ & $\begin{array}{l}18.78(16.39 \text { to } 21.53) \\
\text { calculated }\end{array}$ & $\begin{array}{l}0.60(0.57 \text { to } 0.62) \\
\text { calculated }\end{array}$ & NR & NR \\
\hline Arbabi, 2004 & $\begin{array}{l}94.99 \%(94.65 \text { to } 95.30) \\
\text { calculated }\end{array}$ & $\begin{array}{l}3.14(2.97 \text { to } 3.33) \\
\text { calculated }\end{array}$ & $\begin{array}{l}0.48(0.45 \text { to } 0.52) \\
\text { calculated }\end{array}$ & NR & NR \\
\hline Arbabi, 2004 & $\begin{array}{l}92.35 \% \text { (91.86 to 92.82) } \\
\text { calculated }\end{array}$ & $\begin{array}{l}3.81(3.47 \text { to } 4.17) \\
\text { calculated }\end{array}$ & $\begin{array}{l}0.57(0.53 \text { to } 0.61) \\
\text { calculated }\end{array}$ & NR & NR \\
\hline Arbabi, 2004 & $\begin{array}{l}92.65 \% \text { (91.95 to 93.29) } \\
\text { calculated }\end{array}$ & $\begin{array}{l}1.68(1.59 \text { to } 1.78) \\
\text { calculated }\end{array}$ & $\begin{array}{l}0.54(0.49 \text { to } 0.60) \\
\text { calculated }\end{array}$ & NR & NR \\
\hline Aslar, 2004 & $\begin{array}{l}88.10 \%(77.10 \text { to } 94.21) \\
\text { calculated }\end{array}$ & $\begin{array}{l}15.60(3.99 \text { to } 61.03) \\
\text { calculated }\end{array}$ & $\begin{array}{l}0.21(0.10 \text { to } 0.46) \\
\text { calculated }\end{array}$ & NR & NR \\
\hline Aslar, 2004 & $\begin{array}{l}79.31 \%(64.62 \text { to } 88.95) \\
\text { calculated }\end{array}$ & $\begin{array}{l}2.01(1.26 \text { to } 3.21) \\
\text { calculated }\end{array}$ & $\begin{array}{l}0.39(0.18 \text { to } 0.81) \\
\text { calculated }\end{array}$ & NR & NR \\
\hline Aslar, 2004 & $\begin{array}{l}88.89 \%(76.36 \text { to } 95.20) \\
\text { calculated }\end{array}$ & $\begin{array}{l}6.22(2.70 \text { to } 14.30) \\
\text { calculated }\end{array}$ & $\begin{array}{l}0.19(0.07 \text { to } 0.46) \\
\text { calculated }\end{array}$ & NR & NR \\
\hline Aslar, 2004 & $\begin{array}{l}82.50 \%(71.26 \text { to } 89.96) \\
\text { calculated }\end{array}$ & $\begin{array}{l}4.68(2.15 \text { to } 10.16) \\
\text { calculated }\end{array}$ & $\begin{array}{l}0.33(0.17 \text { to } 0.63) \\
\text { calculated }\end{array}$ & NR & NR \\
\hline
\end{tabular}




\begin{tabular}{|c|c|c|c|c|c|}
\hline $\begin{array}{l}\text { Author, Year } \\
\text { (See Appendix B for } \\
\text { complete reference) }\end{array}$ & Measure & Indicator of Serious Injury & $\begin{array}{l}\text { Reported Sensitivity } \\
(95 \% \mathrm{Cl})\end{array}$ & $\begin{array}{l}\text { Reported Specificity } \\
(95 \% \mathrm{Cl})\end{array}$ & $\begin{array}{l}\text { Reported PPV } \\
(95 \% \mathrm{Cl})\end{array}$ \\
\hline Aslar, 2004 & RTS $\leq 8$ & Mortality, 30-day in-hospital & $\begin{array}{l}68.00 \%(46.50 \text { to } 85.05) \\
\text { calculated }\end{array}$ & $\begin{array}{l}94.87 \%(82.68 \text { to } 99.37) \\
\text { calculated }\end{array}$ & $\begin{array}{l}89.47 \%(68.21 \text { to } 97.12) \\
\text { calculated }\end{array}$ \\
\hline Aslar, 2004 & $\mathrm{SI}>0.9$ & Mortality, 30-day in-hospital & $\begin{array}{l}84.00 \%(63.92 \text { to } 95.46) \\
\text { calculated }\end{array}$ & $\begin{array}{l}23.08 \%(11.13 \text { to } 39.33) \\
\text { calculated }\end{array}$ & $\begin{array}{l}41.18 \%(35.45 \text { to } 47.15) \\
\text { calculated }\end{array}$ \\
\hline Baron, 2004 & Base deficit & $\begin{array}{l}\text { Blood loss (none vs. minimal- } \\
\text { moderate or severe) }\end{array}$ & NR & NR & NR \\
\hline Baron, 2004 & Lactate & $\begin{array}{l}\text { Blood loss (none vs. minimal- } \\
\text { moderate or severe) }\end{array}$ & NR & NR & NR \\
\hline Baron, 2004 & SLCO2 & $\begin{array}{l}\text { Blood loss (none vs. minimal- } \\
\text { moderate or severe) }\end{array}$ & NR & NR & NR \\
\hline Baron, 2004 & $\mathrm{SLCO} 2>45 \mathrm{mmHg}$ & $\begin{array}{l}\text { Blood loss (none vs. minimal- } \\
\text { moderate or severe) }\end{array}$ & $90 \%$ (79 to 96$)$ & $45 \%(31$ to 60$)$ & $65 \%$ (53 to 75$)$ \\
\hline Baron, 2007 & Base deficit & Mortality & NR & NR & NR \\
\hline Baron, 2007 & Lactate & Mortality & NR & NR & NR \\
\hline Baron, 2007 & SLCO2 & Mortality & NR & NR & NR \\
\hline Baron, 2007 & $\mathrm{SLCO} 2>62 \mathrm{mmHg}$ & Mortality & $75 \%(N R)$ & $86 \%(N R)$ & NR \\
\hline Baron, 2007 & SLCO2 & Blood transfusion & NR & NR & NR \\
\hline Baron, 2007 & SLCO2 & ICU stay & NR & $\widehat{N R}$ & NR \\
\hline Beekley, 2010 & StO2 $\leq 75$ & Blood Transfusion & $64 \%(48-78)$ & $59 \%(49-69)$ & $39 \%(27-51)$ \\
\hline Beekley, 2010 & StO2 $\leq 80$ & Blood transfusion & $76 \%(61-88)$ & $41 \%(31-51)$ & $34 \%(25-45)$ \\
\hline Beekley, 2010 & $B D<-4$ & Blood transfusion & $40 \%(24-57)$ & $90 \%(82-95)$ & $63 \%(41-81)$ \\
\hline Beekley, 2010 & $B D<-5$ & Blood transfusion & $32 \%(18-49)$ & $92 \%(85-97)$ & $63 \%(38-84)$ \\
\hline Beekley, 2010 & BD $<-6$ & Blood transfusion & $29 \%(15-46)$ & $95 \%(88-98)$ & $69 \%(41-89)$ \\
\hline Beekley, 2010 & $\mathrm{BD}<-7$ & Blood transfusion & $21 \%(10-37)$ & $96 \%(89-99)$ & $67 \%(35-90)$ \\
\hline Beekley, 2010 & SBP & Blood transfusion & NR & NR & $\mathrm{NR}$ \\
\hline Beekley, 2010 & $\mathrm{HR}$ & Blood transfusion & NR & NR & NR \\
\hline Beekley, 2010 & DBP & Blood transfusion & NR & NR & NR \\
\hline Beekley, 2010 & Radial pulse character & Blood transfusion & NR & NR & NR \\
\hline Beekley, 2010 & Base deficit & Blood transfusion & NR & NR & NR \\
\hline Beekley, 2010 & $\mathrm{pH}$ & Blood transfusion & NR & NR & NR \\
\hline Beekley, 2010 & StO2 average & Blood transfusion & NR & NR & NR \\
\hline Beekley, 2010 & StO2 minimum & Blood transfusion & NR & NR & NR \\
\hline Beekley, 2010 & StO2 $\leq 75$ & LSI & $61 \%(49-72)$ & $65 \%(53-76)$ & $63 \%(50-74)$ \\
\hline Beekley, 2010 & StO2 $\leq 80$ & LSI & $75 \%(63-84)$ & $47 \%(35-59)$ & $57 \%(47-68)$ \\
\hline Beekley, 2010 & $B D<-4$ & LSI & $28 \%(17-40)$ & $91 \%(81-96)$ & $75 \%(53-90)$ \\
\hline Beekley, 2010 & $B D<-5$ & LSI & $23 \%(14-35)$ & $94 \%(85-98)$ & $79 \%(54-94)$ \\
\hline Beekley, 2010 & BD $<-6$ & LSI & $20 \%(11-32)$ & $95 \%(87-99)$ & $81 \%(54-95)$ \\
\hline Beekley, 2010 & BD $<-7$ & LSI & $15 \%(8-26)$ & $97 \%(89-100)$ & $83 \%(52-98)$ \\
\hline
\end{tabular}

D-233 


\begin{tabular}{|c|c|c|c|c|c|}
\hline $\begin{array}{l}\text { Author, Year } \\
\text { (See Appendix B for } \\
\text { complete reference) }\end{array}$ & $\begin{array}{l}\text { Reported NPV } \\
(95 \% \mathrm{Cl})\end{array}$ & Reported PLR & Reported NLR & $\begin{array}{l}\text { AUROC Univariate } \\
\text { AUC }(95 \% \mathrm{CI})\end{array}$ & $\begin{array}{l}\text { Other Measures of } \\
\text { Diagnostic Accuracy }\end{array}$ \\
\hline Aslar, 2004 & $\begin{array}{l}82.22 \%(72.22 \text { to } 89.16) \\
\text { calculated }\end{array}$ & $\begin{array}{l}13.26(3.35 \text { to } 52.52) \\
\text { calculated }\end{array}$ & $\begin{array}{l}0.34(0.19 \text { to } 0.60) \\
\text { calculated }\end{array}$ & NR & NR \\
\hline Aslar, 2004 & $\begin{array}{l}69.23 \%(43.67 \text { to } 86.72) \\
\text { calculated }\end{array}$ & $\begin{array}{l}1.09(0.86 \text { to } 1.39) \\
\text { calculated }\end{array}$ & $\begin{array}{l}0.69(0.24 \text { to } 2.01) \\
\text { calculated }\end{array}$ & NR & NR \\
\hline Baron, 2004 & NR & NR & NR & $0.76(0.68-0.85), p<0.001$ & NR \\
\hline Baron, 2004 & NR & NR & NR & $0.69(0.59-0.80), p<0.001$ & NR \\
\hline Baron, 2004 & NR & NR & NR & $0.74(0.65-0.84), p<0.001$ & NR \\
\hline Baron, 2004 & $79 \%(60$ to 92$)$ & 1.63 (1.25 to 2.12$)$ & $0.23(0.10$ to 0.53$)$ & NR & NR \\
\hline Baron, 2007 & NR & NR & NR & $0.87(0.77$ to 0.98$), p<0.001$ & NR \\
\hline Baron, 2007 & NR & NR & NR & 0.80 (0.69 to 0.91$), p<0.001$ & NR \\
\hline Baron, 2007 & NR & NR & NR & $0.82(0.70$ to 0.96$), p<0.001$ & NR \\
\hline Baron, 2007 & NR & $5.4(\mathrm{NR})$ & $0.29(\mathrm{NR})$ & NR & NR \\
\hline Baron, 2007 & NR & NR & NR & $0.64(0.49$ to 0.79$), p<0.05$ & NR \\
\hline Baron, 2007 & NR & NR & NR & $0.71(0.58$ to 0.84$), p<0.01$ & NR \\
\hline Beekley, 2010 & $81 \%(70-89)$ & NR & NR & NR & NR \\
\hline Beekley, 2010 & $81 \%(68-91)$ & NR & NR & NR & NR \\
\hline Beekley, 2010 & $78 \%(69-86)$ & NR & NR & NR & NR \\
\hline Beekley, 2010 & $76 \%(67-84)$ & NR & NR & NR & NR \\
\hline Beekley, 2010 & $76 \%(67-84)$ & NR & NR & NR & NR \\
\hline Beekley, 2010 & $74 \%(65-82)$ & NR & NR & NR & NR \\
\hline Beekley, 2010 & NR & NR & NR & $0.77(0.69$ to 0.85$)$ & NR \\
\hline Beekley, 2010 & NR & NR & NR & 0.68 (0.59 to 0.77$)$ & NR \\
\hline Beekley, 2010 & NR & NR & NR & $0.64(0.55$ to 0.73$)$ & NR \\
\hline Beekley, 2010 & NR & NR & NR & $0.61(0.52$ to 0.70$)$ & NR \\
\hline Beekley, 2010 & NR & NR & NR & $0.70(0.61$ to 0.79$)$ & NR \\
\hline Beekley, 2010 & NR & NR & NR & $0.70(0.61$ to 0.79$)$ & NR \\
\hline Beekley, 2010 & NR & NR & NR & $0.64(0.55$ to 0.73$)$ & NR \\
\hline Beekley, 2010 & NR & NR & NR & $0.69(0.61$ to 0.77$)$ & NR \\
\hline Beekley, 2010 & $64 \%(52-74)$ & NR & NR & NR & NR \\
\hline Beekley, 2010 & $66 \%(52-78)$ & NR & NR & NR & NR \\
\hline Beekley, 2010 & $55 \%(45-65)$ & NR & NR & NR & NR \\
\hline Beekley, 2010 & $55 \%$ 45-64) & NR & NR & NR & NR \\
\hline Beekley, 2010 & $54 \%(44-63)$ & NR & NR & NR & NR \\
\hline Beekley, 2010 & $53 \%(44-62)$ & NR & NR & NR & NR \\
\hline
\end{tabular}




\begin{tabular}{|c|c|c|c|c|c|}
\hline $\begin{array}{l}\text { Author, Year } \\
\text { (See Appendix B for } \\
\text { complete reference) }\end{array}$ & Measure & Indicator of Serious Injury & $\begin{array}{l}\text { Reported Sensitivity } \\
(95 \% \mathrm{Cl})\end{array}$ & $\begin{array}{l}\text { Reported Specificity } \\
(95 \% \mathrm{Cl})\end{array}$ & $\begin{array}{l}\text { Reported PPV } \\
(95 \% \mathrm{Cl})\end{array}$ \\
\hline Beekley, 2010 & SBP & LSI & NR & NR & NR \\
\hline Beekley, 2010 & HR & LSI & NR & NR & NR \\
\hline Beekley, 2010 & DBP & LSI & NR & NR & NR \\
\hline Beekley, 2010 & Radial pulse character & LSI & NR & NR & NR \\
\hline Beekley, 2010 & Base deficit & LSI & NR & NR & NR \\
\hline Beekley, 2010 & $\mathrm{pH}$ & LSI & NR & NR & NR \\
\hline Beekley, 2010 & StO2 average & LSI & NR & NR & NR \\
\hline Beekley, 2010 & StO2 minimum & LSI & NR & NR & NR \\
\hline Beekley, 2010 & StO2 $\leq 78$ & LSI or blood transfusion & $71 \%(\mathrm{NR})$ & NR & NR \\
\hline Beekley, 2010 & StO2 $\leq 75$ & Massive transfusion & $90 \%(56-100)$ & $55 \%(47-64)$ & $13 \%(6-23)$ \\
\hline Beekley, 2010 & $\mathrm{StO} 2 \leq 78$ & Massive transfusion & $100 \%(\mathrm{NR})$ & NR & NR \\
\hline Beekley, 2010 & StO2 $\leq 80$ & Massive transfusion & $100 \%(69-100)$ & $39 \%(30-47)$ & $11 \%(5-19)$ \\
\hline Beekley, 2010 & $B D<-4$ & Massive transfusion & $38 \%(9-76)$ & $83 \%(75-89)$ & $13 \%(3-32)$ \\
\hline Beekley, 2010 & $B D<-5$ & Massive transfusion & $25 \%(3-65)$ & $86 \%(78-92)$ & $11 \%(1-33)$ \\
\hline Beekley, 2010 & $B D<-6$ & Massive transfusion & $25 \%(3-65)$ & $88 \%(81-94)$ & $13 \%(2-38)$ \\
\hline Beekley, 2010 & BD $<-7$ & Massive transfusion & $25 \%(3-65)$ & $92 \%(85-96)$ & $17 \%(2-48)$ \\
\hline Beekley, 2010 & SBP & Massive transfusion & $\sqrt{N R}$ & $\overline{N R}$ & NR \\
\hline Beekley, 2010 & HR & Massive transfusion & $\widehat{N R}$ & $\overline{N R}$ & NR \\
\hline Beekley, 2010 & DBP & Massive transfusion & NR & NR & NR \\
\hline Beekley, 2010 & Radial pulse character & Massive transfusion & NR & NR & NR \\
\hline Beekley, 2010 & Base deficit & Massive transfusion & NR & NR & NR \\
\hline Beekley, 2010 & $\mathrm{pH}$ & Massive transfusion & NR & NR & NR \\
\hline Bond, 1997 & Prehospital Index $(\mathrm{PHI}) \geq 4$ & ISS $\geq 16$ & $41 \%(N R)$ & $98 \%(\mathrm{NR})$ & $40 \%(N R)$ \\
\hline Bond, 1997 & $\begin{array}{l}\text { Prehospital Index } \geq 4 \text { or } \\
\text { mechanism of injury }\end{array}$ & ISS $\geq 16$ & $78 \%(N R)$ & $89 \%(N R)$ & $17 \%(\mathrm{NR})$ \\
\hline
\end{tabular}




\begin{tabular}{|c|c|c|c|c|c|}
\hline $\begin{array}{l}\text { Author, Year } \\
\text { (See Appendix B for } \\
\text { complete reference) }\end{array}$ & $\begin{array}{l}\text { Reported NPV } \\
(95 \% \mathrm{Cl})\end{array}$ & Reported PLR & Reported NLR & $\begin{array}{l}\text { AUROC Univariate } \\
\text { AUC }(95 \% \mathrm{CI})\end{array}$ & $\begin{array}{l}\text { Other Measures of } \\
\text { Diagnostic Accuracy }\end{array}$ \\
\hline Beekley, 2010 & NRR & NR & NR & $0.65(0.58$ to 0.72$)$ & NR \\
\hline Beekley, 2010 & NR & NR & NR & $0.74(0.67$ to 0.81$)$ & NR \\
\hline Beekley, 2010 & NR & NR & NR & 0.59 (0.51 to 0.67$)$ & NR \\
\hline Beekley, 2010 & NR & NR & NR & $0.58(0.50$ to 0.66$)$ & NR \\
\hline Beekley, 2010 & NR & $\overline{N R}$ & $\widehat{N R}$ & $0.71(0.64$ to 0.78$)$ & $\widehat{N R}$ \\
\hline Beekley, 2010 & NR & NR & NR & $0.68(0.60$ to 0.76$)$ & NR \\
\hline Beekley, 2010 & NR & NR & NR & $0.61(0.53$ to 0.69$)$ & NR \\
\hline Beekley, 2010 & NR & NR & NR & $0.67(0.60$ to 0.74$)$ & NR \\
\hline Beekley, 2010 & NR & NR & NR & NR & NR \\
\hline Beekley, 2010 & NR & NR & NR & NR & NR \\
\hline Beekley, 2010 & NR & NR & NR & NR & NR \\
\hline Beekley, 2010 & NR & NR & NR & NR & NR \\
\hline Beekley, 2010 & NR & NR & NR & NR & NR \\
\hline Beekley, 2010 & NR & NR & NR & NR & NR \\
\hline Beekley, 2010 & NR & NR & NR & NR & NR \\
\hline Beekley, 2010 & NR & NR & NR & NR & NR \\
\hline Beekley, 2010 & NR & NR & NR & $0.70(0.54$ to 0.86$)$ & $\overline{N R}$ \\
\hline Beekley, 2010 & NR & NR & NR & $0.78(0.63$ to 0.93$)$ & NR \\
\hline Beekley, 2010 & NR & NR & NR & $0.70(0.54$ to 0.86$)$ & NR \\
\hline Beekley, 2010 & NR & NR & NR & $0.72(0.57$ to 0.87$)$ & NR \\
\hline Beekley, 2010 & NR & NR & NR & 0.69 (0.51 to 0.87$)$ & NR \\
\hline Beekley, 2010 & NR & NR & NR & 0.75 (0.59 to 0.91$)$ & NR \\
\hline Bond, 1997 & $98 \%(N R)$ & NR & NR & NR & $\begin{array}{l}\text { Accuracy: } 97 \% \\
\text { Undertriage: } 59 \% \\
\text { Overtriage: } 2.0 \% \\
\text { Undertriage = false negative } \\
\text { rate } \\
\text { Overtriage = false positive rate }\end{array}$ \\
\hline Bond, 1997 & $99 \%(N R)$ & NR & NR & NR & $\begin{array}{l}\text { Accuracy: } 89 \% \\
\text { Undertriage: } 22 \% \\
\text { Overtriage: } 11.0 \% \\
\text { Undertriage = false negative } \\
\text { rate } \\
\text { Overtriage = false positive rate }\end{array}$ \\
\hline
\end{tabular}




\begin{tabular}{|c|c|c|c|c|c|}
\hline $\begin{array}{l}\text { Author, Year } \\
\text { (See Appendix B for } \\
\text { complete reference) }\end{array}$ & Measure & Indicator of Serious Injury & $\begin{array}{l}\text { Reported Sensitivity } \\
(95 \% \mathrm{Cl})\end{array}$ & $\begin{array}{l}\text { Reported Specificity } \\
(95 \% \mathrm{Cl})\end{array}$ & $\begin{array}{l}\text { Reported PPV } \\
(95 \% \mathrm{Cl})\end{array}$ \\
\hline Bouzat, 2016 & Lactate $\geq 3.5$, capillary & Blood transfusion $\geq 4$ units & $\begin{array}{l}100 \%(74 \text { to } 100) \text { reported } \\
100.00 \%(73.54 \text { to } 100.00) \\
\text { calculated }\end{array}$ & $\begin{array}{l}53 \%(43 \text { to } 62) \text { reported } \\
53.70 \%(43.85 \text { to } 63.35) \\
\text { calculated }\end{array}$ & $\begin{array}{l}19.35 \%(16.38 \text { to } 22.72) \\
\text { calculated }\end{array}$ \\
\hline Bouzat, 2016 & Lactate $\geq 3.5$, capillary & $\begin{array}{l}\text { Emergency treatment for } \\
\text { hemostasis (surgery or } \\
\text { embolization) }\end{array}$ & $\begin{array}{l}68.75 \%(49.99 \text { to } 83.88) \\
\text { calculated }\end{array}$ & $\begin{array}{l}54.55 \%(43.58 \text { to } 65.20) \\
\text { calculated }\end{array}$ & $\begin{array}{l}35.48 \%(28.40 \text { to } 43.27) \\
\text { calculated }\end{array}$ \\
\hline Bouzat, 2016 & Lactate, capillary & Blood transfusion $\geq 4$ units & NR & NR & NR \\
\hline Bouzat, 2016 & Lactate, capillary & Blood transfusion, any & NR & NR & NR \\
\hline Bouzat, 2016 & Lactate, serum & Blood transfusion, any & NR & NR & $\mathrm{NR}$ \\
\hline Bouzat, 2016 & $\mathrm{SI}$ & Blood transfusion $\geq 4$ units & NR & NR & NR \\
\hline Brown, 2011 & $\begin{array}{l}\text { Physiologic criteria of NTTP } \\
\text { (step 1): GCS } \leq 14, \text { SBP }<90 \text { or } \\
\text { RR }<10 \text { or }>29\end{array}$ & Trauma center need & $32 \%(\mathrm{NR})$ & $91 \%(\mathrm{NR})$ & $72 \%(\mathrm{NR})$ \\
\hline Brown, 2015a & SBP <118: elderly & Mortality & $29 \%(\mathrm{Cl} \mathrm{NR})$ & $86 \%(\mathrm{Cl} N R)$ & $\mathrm{NR}$ \\
\hline Brown, 2015a & SBP <106: adults & Mortality & $49 \%(\mathrm{Cl} N R)$ & $88 \%(\mathrm{CI} N R)$ & NR \\
\hline Brown, 2015a & SBP <90: adults & Trauma center need & $10 \%(\mathrm{Cl} \mathrm{NR})$ & $98 \%(\mathrm{Cl} \mathrm{NR})$ & $79 \%(\mathrm{Cl} N R)$ \\
\hline Brown, 2015a & SBP <110: adults & Trauma center need & $23 \%(\mathrm{Cl} \mathrm{NR})$ & $90 \%(\mathrm{Cl} N R)$ & $63 \%(\mathrm{Cl} N R)$ \\
\hline Brown, 2015a & SBP <90: elderly & Trauma center need & $5 \%(\mathrm{Cl} N R)$ & $99 \%(\mathrm{Cl} N R)$ & $66 \%(\mathrm{Cl} \mathrm{NR})$ \\
\hline Brown, 2015a & SBP <110: elderly & Trauma center need & $13 \%(\mathrm{Cl} \mathrm{NR})$ & $93 \%(\mathrm{Cl} \mathrm{NR})$ & $50 \%(\mathrm{Cl} \mathrm{NR})$ \\
\hline Brown, 2015a & SBP <122: elderly & Trauma center need & $22 \%(\mathrm{Cl} \mathrm{NR})$ & $83 \%(\mathrm{Cl} N R)$ & NR \\
\hline Brown, 2015a & SBP <118: adults & Trauma center need & $32 \%(\mathrm{Cl} N R)$ & $73 \%(\mathrm{Cl} N R)$ & NR \\
\hline Brown, 2016b & Lactate $>4.0$ & Trauma center need & $\begin{array}{l}23.21 \%(21.26 \text { to } 25.25) \\
\text { calculated }\end{array}$ & $\begin{array}{l}92.81 \%(92.02 \text { to } 93.54) \\
\text { calculated }\end{array}$ & $\begin{array}{l}55.54 \%(52.21 \text { to } 58.83) \\
\text { calculated }\end{array}$ \\
\hline Brown, 2016b & Lactate $\geq 2.5$ & Trauma center need & $\begin{array}{l}52.46 \%(50.10 \text { to } 54.80) \\
\text { calculated }\end{array}$ & $\begin{array}{l}71.33 \%(69.99 \text { to } 72.64) \\
\text { calculated }\end{array}$ & $\begin{array}{l}41.45 \%(39.92 \text { to } 43.01) \\
\text { calculated }\end{array}$ \\
\hline Bruijns, 2013 & Blood pressure-age index $\leq 1.5$ & Mortality, 48-hour & $33.2 \%(27.6-39.3)$ & $95.0 \%(94.8-95.1)$ & NR \\
\hline Bruijns, 2013 & Blood pressure-age index $\leq 1.7$ & Mortality, 48-hour & $46.4 \%$ (40.3 to 52.6$)$ & $90 \%$ (89.8 to 90.3$)$ & NR \\
\hline Bruijns, 2013 & $\begin{array}{l}\text { Blood pressure-age index: } \\
\text { moderately injured }\end{array}$ & Mortality, 48-hour & NR & NR & NR \\
\hline Bruijns, 2013 & $\begin{array}{l}\text { Blood pressure-age index: } \\
\text { overall }\end{array}$ & Mortality, 48-hour & NR & NR & NR \\
\hline
\end{tabular}




\begin{tabular}{|c|c|c|c|c|c|}
\hline $\begin{array}{l}\text { Author, Year } \\
\text { (See Appendix B for } \\
\text { complete reference) }\end{array}$ & $\begin{array}{l}\text { Reported NPV } \\
(95 \% \mathrm{CI})\end{array}$ & Reported PLR & Reported NLR & $\begin{array}{l}\text { AUROC Univariate } \\
\text { AUC }(95 \% \mathrm{CI})\end{array}$ & $\begin{array}{l}\text { Other Measures of } \\
\text { Diagnostic Accuracy }\end{array}$ \\
\hline Bouzat, 2016 & $\begin{array}{l}100.00 \% \\
\text { calculated }\end{array}$ & $\begin{array}{l}2.16(1.76 \text { to } 2.65) \\
\text { calculated }\end{array}$ & $\begin{array}{l}0.00 \\
\text { calculated }\end{array}$ & NR & NR \\
\hline Bouzat, 2016 & $\begin{array}{l}82.76 \%(73.51 \text { to } 89.25) \\
\text { calculated }\end{array}$ & $\begin{array}{l}1.51(1.09 \text { to } 2.10) \\
\text { calculated }\end{array}$ & $\begin{array}{l}0.57 \text { (0.33 to 0.99) } \\
\text { calculated }\end{array}$ & NR & NR \\
\hline Bouzat, 2016 & NR & NR & NR & $0.68(0.58$ to 0.78$)$ & NR \\
\hline Bouzat, 2016 & NR & NR & NR & $0.59(0.46$ to 0.72$)$ & NR \\
\hline Bouzat, 2016 & NR & NR & NR & $0.77(0.62$ to 0.91$)$ & NR \\
\hline Bouzat, 2016 & NR & NR & NR & $0.68(0.51$ to 0.85$)$ & NR \\
\hline Brown, 2011 & $65 \%(\mathrm{NR})$ & NR & NR & NR & $\begin{array}{l}\text { Undertriage rate: } 68 \%(\mathrm{NR}) \\
\text { Overtriage rate: } 9 \%(\mathrm{NR}) \\
\text { Undertriage = false negative } \\
\text { rate } \\
\text { Overtriage = false positive rate }\end{array}$ \\
\hline Brown, 2015a & NR & NR & NR & NR & NR \\
\hline Brown, 2015a & NR & NR & NR & NR & NR \\
\hline Brown, 2015a & $59 \%(\mathrm{Cl} \mathrm{NR})$ & NR & NR & $0.539(0.538$ to 0.541$)$ & NR \\
\hline Brown, 2015a & $61 \%(\mathrm{Cl} \mathrm{NR})$ & NR & NR & $0.564(0.563$ to 0.566$)$ & NR \\
\hline Brown, 2015a & $67 \%(\mathrm{Cl} N R)$ & NR & NR & 0.519 (0.517 to 0.522$)$ & NR \\
\hline Brown, 2015a & $68 \%(\mathrm{Cl} N R)$ & NR & NR & $0.532(0.530$ to 0.534$)$ & NR \\
\hline Brown, 2015a & NR & NR & NR & NR & NR \\
\hline Brown, 2015a & NR & NR & NR & NR & NR \\
\hline Brown, 2016b & $\begin{array}{l}75.74 \% \text { (75.25 to } 76.23) \\
\text { calculated }\end{array}$ & $\begin{array}{l}3.23(2.82 \text { to } 3.69) \\
\text { calculated }\end{array}$ & $\begin{array}{l}0.83(0.81 \text { to } 0.85) \\
\text { calculated }\end{array}$ & NR & NR \\
\hline Brown, 2016b & $\begin{array}{l}79.49 \%(78.63 \text { to } 80.33) \\
\text { calculated }\end{array}$ & $\begin{array}{l}1.83(1.72 \text { to } 1.95) \\
\text { calculated }\end{array}$ & $\begin{array}{l}0.67(0.63 \text { to } 0.70) \\
\text { calculated }\end{array}$ & NR & NR \\
\hline Bruijns, 2013 & NR & $6.6(5.6-7.9)$ & NR & NR & NR \\
\hline Bruijns, 2013 & NR & 4.7 (4.1 to 5.3$)$ & NR & NR & NR \\
\hline Bruijns, 2013 & NR & NR & NR & $0.83(0.78$ to 0.88$)$ & NR \\
\hline Bruijns, 2013 & NR & NR & NR & $0.74(0.71$ to 0.78$)$ & NR \\
\hline
\end{tabular}




\begin{tabular}{|c|c|c|c|c|c|}
\hline $\begin{array}{l}\text { Author, Year } \\
\text { (See Appendix B for } \\
\text { complete reference) }\end{array}$ & Measure & Indicator of Serious Injury & $\begin{array}{l}\text { Reported Sensitivity } \\
(95 \% \mathrm{Cl})\end{array}$ & $\begin{array}{l}\text { Reported Specificity } \\
(95 \% \mathrm{Cl})\end{array}$ & $\begin{array}{l}\text { Reported PPV } \\
(95 \% \mathrm{Cl})\end{array}$ \\
\hline Bruijns, 2013 & $\begin{array}{l}\text { Blood pressure-age index: } \\
\text { severely injured }\end{array}$ & Mortality, 48-hour & NR & NR & NR \\
\hline Bruijns, 2013 & $H R \geq 104$ & Mortality, 48-hour & $41.1 \%(35.2-47.3)$ & $89.6 \%(89.4-89.9)$ & NR \\
\hline Bruijns, 2013 & $\mathrm{HR} \geq 112$ & Mortality, 48-hour & $27.2 \%(22.0-33.0)$ & $95.0 \%(94.8-95.1)$ & NR \\
\hline Bruijns, 2013 & HR: moderately injured & Mortality, 48-hour & NR & NR & NR \\
\hline Bruijns, 2013 & HR: overall & Mortality, 48-hour & NR & NR & NR \\
\hline Bruijns, 2013 & HR: severely injured & Mortality, 48-hour & NR & NR & NR \\
\hline Bruijns, 2013 & HR metric, Minpulse $\leq 44$ & Mortality, 48-hour & $30.9 \%(25.5-36.9)$ & $94.9 \%(94.8-95.1)$ & NR \\
\hline Bruijns, 2013 & HR metric, Minpulse $\leq 54$ & Mortality, 48-hour & $43.0 \%$ (37.0 to 49.2) & $90.0 \%$ (89.8 to 90.2$)$ & NR \\
\hline Bruijns, 2013 & $\begin{array}{l}\text { HR metric, Minpulse: moderately } \\
\text { injured }\end{array}$ & Mortality, 48-hour & NR & NR & NR \\
\hline Bruijns, 2013 & HR metric, Minpulse: overall & Mortality, 48-hour & NR & NR & NR \\
\hline Bruijns, 2013 & $\begin{array}{l}\text { HR metric, Minpulse: severely } \\
\text { injured }\end{array}$ & Mortality, 48-hour & NR & NR & NR \\
\hline Bruijns, 2013 & HR metric, Pulse max index $\geq 60$ & Mortality, 48-hour & $46.0 \%$ (40.0 to 52.2) & $90.0 \%(89.7$ to 90.2$)$ & NR \\
\hline Bruijns, 2013 & HR metric, Pulse max index $\geq 70$ & Mortality, 48-hour & $34.0 \%(28.3-40.1)$ & $95.0 \%(94.8-95.1)$ & NR \\
\hline Bruijns, 2013 & $\begin{array}{l}\text { HR metric, Pulse max index: } \\
\text { moderately injured }\end{array}$ & Mortality, 48-hour & NR & NR & NR \\
\hline Bruijns, 2013 & $\begin{array}{l}\text { HR metric, Pulse max index: } \\
\text { overall }\end{array}$ & Mortality, 48-hour & NR & NR & NR \\
\hline Bruijns, 2013 & $\begin{array}{l}\text { HR metric, Pulse max index: } \\
\text { severely injured }\end{array}$ & Mortality, 48-hour & NR & NR & NR \\
\hline Bruijns, 2013 & $R R \geq 24$ & Mortality, 48-hour & $39.6 \%(33.7-45.8)$ & $87.8 \%(87.6-88.1)$ & NR \\
\hline Bruijns, 2013 & $\mathrm{RR} \geq 27$ & Mortality, 48-hour & $25.7 \%(20.6-31.4)$ & $95.3 \%(95.1-95.4)$ & NR \\
\hline Bruijns, 2013 & RR: moderately injured & Mortality, 48-hour & NR & NR & NR \\
\hline Bruijns, 2013 & RR: overall & Mortality, 48-hour & NR & NR & NR \\
\hline Bruijns, 2013 & RR: severely injured & Mortality, 48-hour & NR & NR & NR \\
\hline Bruijns, 2013 & $\mathrm{SBP} \leq 101$ & Mortality, 48-hour & $31.3 \%(25.9-37.3)$ & $94.1 \%(93.9-94.2)$ & NR \\
\hline Bruijns, 2013 & $\mathrm{SBP} \leq 110$ & Mortality, 48-hour & $36.6 \%(30.9-42.7)$ & $89.8 \%(89.6-90.0)$ & NR \\
\hline Bruijns, 2013 & SBP: moderately injured & Mortality, 48-hour & NR & NR & NR \\
\hline Bruijns, 2013 & SBP: overall & Mortality, 48-hour & NR & NR & NR \\
\hline Bruijns, 2013 & SBP: severely injured & Mortality, 48-hour & NR & NR & NR \\
\hline Bruijns, 2013 & $\mathrm{SI} \geq 0.8$ & Mortality, 48-hour & $45.3 \%$ (39.2 to 51.5) & $90.0 \%$ (89.8 to 90.2$)$ & NR \\
\hline Bruijns, 2013 & $\mathrm{SI} \geq 0.9$ & Mortality, 48-hour & $37.4 \%(31.6-43.5)$ & $95.0 \%(94.9-95.2)$ & NR \\
\hline Bruijns, 2013 & SI: moderately injured & Mortality, 48-hour & NR & NR & NR \\
\hline Bruijns, 2013 & SI: overall & Mortality, 48-hour & NR & NR & NR \\
\hline Bruijns, 2013 & SI: severely injured & Mortality, 48-hour & NR & NR & NR \\
\hline Bruijns, 2013 & SIA (SI x Age) $\geq 48$ & Mortality, 48-hour & $55.1 \%(48.9$ to 61.2$)$ & $90.0 \%$ (89.7 to 90.2$)$ & NR \\
\hline
\end{tabular}

D-239 


\begin{tabular}{|c|c|c|c|c|c|}
\hline $\begin{array}{l}\text { Author, Year } \\
\text { (See Appendix B for } \\
\text { complete reference) }\end{array}$ & $\begin{array}{l}\text { Reported NPV } \\
(95 \% \mathrm{Cl})\end{array}$ & Reported PLR & Reported NLR & $\begin{array}{l}\text { AUROC Univariate } \\
\text { AUC }(95 \% \mathrm{Cl})\end{array}$ & \begin{tabular}{|l} 
Other Measures of \\
Diagnostic Accuracy
\end{tabular} \\
\hline Bruijns, 2013 & NR & NR & NR & $0.71(0.66$ to 0.75$)$ & NR \\
\hline Bruijns, 2013 & NR & $4.0(3.4-4.6)$ & NR & NR & NR \\
\hline Bruijns, 2013 & NR & $5.4(4.4-6.6)$ & NR & NR & NR \\
\hline Bruijns, 2013 & NR & NR & NR & $0.61(0.54$ to 0.68$)$ & NR \\
\hline Bruijns, 2013 & NR & NR & NR & $0.69(0.65$ to 0.73$)$ & NR \\
\hline Bruijns, 2013 & NR & NR & NR & $0.64(0.59$ to 0.69$)$ & NR \\
\hline Bruijns, 2013 & NR & $6.1(5.1-7.3)$ & NR & NR & NR \\
\hline Bruijns, 2013 & NR & $4.3(3.7$ to 5.0$)$ & NR & NR & NR \\
\hline Bruijns, 2013 & NR & NR & NR & $0.82(0.77$ to 0.87$)$ & NR \\
\hline Bruijns, 2013 & NR & NR & NR & $0.77(0.74$ to 0.80$)$ & NR \\
\hline Bruijns, 2013 & NR & NR & NR & $0.73(0.68$ to 0.77$)$ & NR \\
\hline Bruijns, 2013 & NR & 4.6 (4.0 to 5.2$)$ & NR & NR & NR \\
\hline Bruijns, 2013 & NR & $6.7(5.7-8.0)$ & NR & NR & NR \\
\hline Bruijns, 2013 & NR & NR & NR & $0.77(0.71$ to 0.83$)$ & NR \\
\hline Bruijns, 2013 & NR & NR & NR & $0.77(0.73$ to 0.80$)$ & NR \\
\hline Bruijns, 2013 & NR & NR & NR & 0.71 (0.66 to 0.75$)$ & NR \\
\hline Bruijns, 2013 & NR & $3.3(2.8-3.8)$ & NR & NR & NR \\
\hline Bruijns, 2013 & NR & $5.4(4.4-6.7)$ & NR & NR & NR \\
\hline Bruijns, 2013 & NR & NR & NR & $0.59(0.52$ to 0.65$)$ & NR \\
\hline Bruijns, 2013 & NR & NR & NR & $0.66(0.62$ to 0.70$)$ & NR \\
\hline Bruijns, 2013 & NR & NR & NR & $0.57(0.52$ to 0.62$)$ & NR \\
\hline Bruijns, 2013 & NR & $5.3(4.4-6.3)$ & NR & NR & NR \\
\hline Bruijns, 2013 & NR & $3.6(3.1-4.2)$ & NR & NR & NR \\
\hline Bruijns, 2013 & NR & NR & NR & $0.59(0.51$ to 0.66$)$ & NR \\
\hline Bruijns, 2013 & NR & NR & NR & $0.66(0.62$ to 0.70$)$ & $\mathrm{NR}$ \\
\hline Bruijns, 2013 & NR & NR & NR & $0.65(0.60$ to 0.70$)$ & NR \\
\hline Bruijns, 2013 & NR & 4.5 (4.0 to 5.2$)$ & NR & NR & NR \\
\hline Bruijns, 2013 & NR & $7.5(6.4-8.8)$ & NR & NR & NR \\
\hline Bruijns, 2013 & NR & NR & NR & 0.65 (0.58 to 0.72$)$ & NR \\
\hline Bruijns, 2013 & NR & NR & NR & $0.73(0.70$ to 0.77$)$ & NR \\
\hline Bruijns, 2013 & NR & NR & NR & $0.69(0.64$ to 0.73$)$ & NR \\
\hline Bruijns, 2013 & NR & $5.5(4.9$ to 6.1$)$ & NR & NR & NR \\
\hline
\end{tabular}




\begin{tabular}{|c|c|c|c|c|c|}
\hline $\begin{array}{l}\text { Author, Year } \\
\text { (See Appendix B for } \\
\text { complete reference) }\end{array}$ & Measure & Indicator of Serious Injury & $\begin{array}{l}\text { Reported Sensitivity } \\
(95 \% \mathrm{Cl})\end{array}$ & $\begin{array}{l}\text { Reported Specificity } \\
(95 \% \mathrm{Cl})\end{array}$ & $\begin{array}{l}\text { Reported PPV } \\
(95 \% \mathrm{Cl})\end{array}$ \\
\hline Bruijns, 2013 & SIA $($ SI $\times$ Age $) \geq 55$ & Mortality, 48-hour & $42.3 \%(36.3-48.5)$ & $95.0 \%(94.8-95.1)$ & NR \\
\hline Bruijns, 2013 & $\begin{array}{l}\text { SIA (SI x age): moderately } \\
\text { injured }\end{array}$ & Mortality, 48-hour & NR & NR & NR \\
\hline Bruijns, 2013 & SIA (SI $x$ age): overall & Mortality, 48-hour & NR & NR & NR \\
\hline Bruijns, 2013 & SIA (SI x age): severely injured & Mortality, 48-hour & NR & NR & NR \\
\hline Bruijns, 2014 & HR difference (ED-EMS) & Mortality: 48-hour & NR & NR & NR \\
\hline Bruijns, 2014 & HR difference $\geq 14$ (ED-EMS) & Mortality: 48-hour & $9 \%(4.5$ to 16.8$)$ & $90 \%$ (89.9 to 90.6$)$ & NR \\
\hline Bruijns, 2014 & HR difference $\geq 21$ (ED-EMS) & Mortality: 48-hour & $7 \%(3.1$ to 14.4$)$ & $95 \%$ (94.6 to 95.1) & NR \\
\hline Bruijns, 2014 & RR difference (ED-EMS) & Mortality: 48-hour & NR & NR & NR \\
\hline Bruijns, 2014 & RR difference $\geq 6$ (ED-EMS) & Mortality: 48-hour & $26 \%$ (18.0 to 35.9$)$ & $89 \%$ (88.9 to 89.7$)$ & NR \\
\hline Bruijns, 2014 & RR difference $\geq 8$ (ED-EMS) & Mortality: 48-hour & $13 \%(7.4$ to 21.6$)$ & $96 \%(96.0$ to 96.4$)$ & NR \\
\hline Bruijns, 2014 & SBP difference (ED-EMS) & Mortality: 48-hour & NR & NR & NR \\
\hline Bruijns, 2014 & SBP difference $\leq-26$ (ED-EMS) & Mortality: 48-hour & $14 \%(8.1$ to 22.7$)$ & $90 \%(89.4$ to 90.1$)$ & NR \\
\hline Bruijns, 2014 & SBP difference $\leq-37$ (ED-EMS) & Mortality: 48-hour & $8 \%(3.8$ to 15.6$)$ & $95 \%$ (94.7 to 95.3$)$ & NR \\
\hline Bruijns, 2014 & SI $\geq 0.2$ difference (ED-EMS) & Mortality: 48-hour & $12 \%(6.6$ to 20.4$)$ & $95 \%$ (94.8 to 95.3$)$ & NR \\
\hline Bruijns, 2014 & SI difference (ED-EMS) & Mortality: 48-hour & NR & NR & NR \\
\hline Bruijns, 2014 & SI difference $\geq 0.1$ (ED-EMS) & Mortality: 48-hour & $20 \%(12.9$ to 29.4$)$ & $90 \%(89.7$ to 90.4$)$ & NR \\
\hline Callaway, 2009 & $\mathrm{BD}$ & Mortality & NR & NR & NR \\
\hline Callaway, 2009 & BD 0 to $-6: \geq 65$ years & Mortality & $\begin{array}{l}36.94 \%(27.97-46.62) \\
\text { calculated }\end{array}$ & $\begin{array}{l}76.60 \%(72.50-80.35) \\
\text { calculated }\end{array}$ & $\begin{array}{l}27.15 \%(21.76-33.32) \\
\text { calculated }\end{array}$ \\
\hline Callaway, 2009 & BD < -6: $\geq 65$ years & Mortality & $\begin{array}{l}\text { 15.32\% (9.18-23.39) } \\
\text { calculated }\end{array}$ & $\begin{array}{l}\text { 94.47\% (92.00-96.35) } \\
\text { calculated }\end{array}$ & $\begin{array}{l}\text { 39.53\% (26.89-53.75) } \\
\text { calculated }\end{array}$ \\
\hline Callaway, 2009 & Lactate & Mortality & NR & NR & NR \\
\hline Callaway, 2009 & Lactate $\geq 2.5: \geq 65$ years & Mortality & $\begin{array}{l}41.07 \%(31.86 \text { to } 50.76) \\
\text { calculated }\end{array}$ & $\begin{array}{l}76.05 \%(71.96 \text { to } 79.82) \\
\text { calculated }\end{array}$ & $\begin{array}{l}28.75 \%(23.48 \text { to } 34.66) \\
\text { calculated }\end{array}$ \\
\hline Callaway, 2009 & Lactate $>4.0: \geq 65$ years & Mortality & $\begin{array}{l}\text { 18.75\% (12.00-27.22) } \\
\text { calculated }\end{array}$ & $\begin{array}{l}\text { 93.28\% (90.64-95.36) } \\
\text { calculated }\end{array}$ & $\begin{array}{l}39.62 \%(28.26-52.23) \\
\text { calculated }\end{array}$ \\
\hline Cannon, 2009 & $\mathrm{SI}>0.9, \mathrm{ED}$ & Mortality & $\begin{array}{l}40.98 \%(34.17 \text { to } 48.04) \\
\text { calculated }\end{array}$ & $\begin{array}{l}80.18 \%(78.47 \text { to } 81.81) \\
\text { calculated }\end{array}$ & $\begin{array}{l}15.91 \%(13.60 \text { to } 18.53) \\
\text { calculated }\end{array}$ \\
\hline Cannon, 2009 & $\mathrm{SI}>0.9$ and $\mathrm{SBP} \geq 90, \mathrm{ED}$ & Mortality & $\begin{array}{l}32.56 \%(25.62 \text { to } 40.11) \\
\text { calculated }\end{array}$ & $\begin{array}{l}82.47 \%(80.81 \text { to } 84.05) \\
\text { calculated }\end{array}$ & $\begin{array}{l}12.84 \% \text { (10.45 to } 15.69) \\
\text { calculated }\end{array}$ \\
\hline
\end{tabular}




\begin{tabular}{|c|c|c|c|c|c|}
\hline $\begin{array}{l}\text { Author, Year } \\
\text { (See Appendix B for } \\
\text { complete reference) }\end{array}$ & $\begin{array}{l}\text { Reported NPV } \\
(95 \% \mathrm{Cl})\end{array}$ & Reported PLR & Reported NLR & $\begin{array}{l}\text { AUROC Univariate } \\
\text { AUC }(95 \% \mathrm{CI})\end{array}$ & $\begin{array}{l}\text { Other Measures of } \\
\text { Diagnostic Accuracy }\end{array}$ \\
\hline Bruijns, 2013 & NR & $8.4(7.2-9.7)$ & NR & NR & NR \\
\hline Bruijns, 2013 & NR & NR & NR & $0.85(0.80$ to 0.90$)$ & NR \\
\hline Bruijns, 2013 & NR & NR & NR & $0.79(0.76$ to 0.82$)$ & NR \\
\hline Bruijns, 2013 & NR & NR & NR & $0.74(0.70$ to 0.78$)$ & NR \\
\hline Bruijns, 2014 & NR & NR & NR & $0.51(0.46$ to 0.6$), p=0.5$ & NR \\
\hline Bruijns, 2014 & NR & $0.9(0.5$ to 1.7$)$ & NR & NR & NR \\
\hline Bruijns, 2014 & NR & $1.4(0.7$ to 2.8$)$ & NR & NR & NR \\
\hline Bruijns, 2014 & NR & NR & NR & 0.56 (0.50 to 0.63$), p=0.02$ & NR \\
\hline Bruijns, 2014 & NR & $2.4(1.7$ to 3.4$)$ & NR & NR & NR \\
\hline Bruijns, 2014 & NR & $3.4(2.1$ to 5.7$)$ & NR & NR & NR \\
\hline Bruijns, 2014 & NR & NR & NR & $0.57(0.52$ to 0.63$), p<0.01$ & NR \\
\hline Bruijns, 2014 & NR & $1.4(0.8$ to 2.2$)$ & NR & NR & NR \\
\hline Bruijns, 2014 & NR & $1.6(0.8$ to 3.1$)$ & NR & NR & NR \\
\hline Bruijns, 2014 & NR & $2.4(1.4$ to 4.1$)$ & NR & NR & NR \\
\hline Bruijns, 2014 & NR & NR & NR & 0.53 (0.47 to 0.59$), p=0.22$ & NR \\
\hline Bruijns, 2014 & NR & $2.0(1.4$ to 3.0$)$ & NR & NR & NR \\
\hline Callaway, 2009 & NR & NR & NR & $0.65(\mathrm{NR})$ & NR \\
\hline Callaway, 2009 & $\begin{array}{l}83.72 \%(81.56-85.67) \\
\text { calculated }\end{array}$ & $\begin{array}{l}1.58(1.18-2.12) \\
\text { calculated }\end{array}$ & $\begin{array}{l}0.82(0.71-0.96) \\
\text { calculated }\end{array}$ & NR & NR \\
\hline Callaway, 2009 & $\begin{array}{l}82.53 \%(81.31-83.68) \\
\text { calculated }\end{array}$ & $\begin{array}{l}2.77(1.56-4.92) \\
\text { calculated }\end{array}$ & $\begin{array}{l}0.90(0.83-0.97) \\
\text { calculated }\end{array}$ & NR & NR \\
\hline Callaway, 2009 & NR & NR & NR & $0.63(\mathrm{NR})$ & NR \\
\hline Callaway, 2009 & $\begin{array}{l}84.58 \%(82.34 \text { to } 86.58) \\
\text { calculated }\end{array}$ & $\begin{array}{l}1.71(1.30 \text { to } 2.25) \\
\text { calculated }\end{array}$ & $\begin{array}{l}0.77(0.66 \text { to } 0.91) \\
\text { calculated }\end{array}$ & NR & NR \\
\hline Callaway, 2009 & $\begin{array}{l}\text { 82.99\% (81.65-84.25) } \\
\text { calculated }\end{array}$ & $\begin{array}{l}2.79(1.67-4.65) \\
\text { calculated }\end{array}$ & $\begin{array}{l}0.87(0.79-0.96) \\
\text { calculated }\end{array}$ & NR & NR \\
\hline Cannon, 2009 & $\begin{array}{l}93.69 \%(92.97 \text { to } 94.34) \\
\text { calculated }\end{array}$ & $\begin{array}{l}2.07(1.72 \text { to } 2.49) \\
\text { calculated }\end{array}$ & $\begin{array}{l}0.74(0.66 \text { to } 0.83) \\
\text { calculated }\end{array}$ & NR & NR \\
\hline Cannon, 2009 & $\begin{array}{l}\text { 93.91\% (93.27 to } 94.48) \\
\text { calculated }\end{array}$ & $\begin{array}{l}1.86(1.47 \text { to } 2.35) \\
\text { calculated }\end{array}$ & $\begin{array}{l}0.82(0.74 \text { to } 0.91) \\
\text { calculated }\end{array}$ & NR & NR \\
\hline
\end{tabular}




\begin{tabular}{|c|c|c|c|c|c|}
\hline $\begin{array}{l}\text { Author, Year } \\
\text { (See Appendix B for } \\
\text { complete reference) }\end{array}$ & Measure & Indicator of Serious Injury & $\begin{array}{l}\text { Reported Sensitivity } \\
(95 \% \mathrm{Cl})\end{array}$ & $\begin{array}{l}\text { Reported Specificity } \\
(95 \% \mathrm{Cl})\end{array}$ & $\begin{array}{l}\text { Reported PPV } \\
(95 \% \mathrm{Cl})\end{array}$ \\
\hline Cannon, 2009 & SI $>0.9$, EMS & Mortality & $\begin{array}{l}43.75 \%(32.68 \text { to } 55.30) \\
\text { calculated }\end{array}$ & $\begin{array}{l}67.13 \%(64.24 \text { to } 69.92) \\
\text { calculated }\end{array}$ & $\begin{array}{l}8.93 \%(7.01 \text { to } 11.31) \\
\text { calculated }\end{array}$ \\
\hline Cannon, 2009 & $\begin{array}{l}\text { SI increase } \geq 0.3 \text { from EMS to } \\
\text { ED }\end{array}$ & Mortality & $\begin{array}{l}20.00 \%(11.89 \text { to } 30.44) \\
\text { calculated }\end{array}$ & $\begin{array}{l}96.13 \%(94.81 \text { to } 97.20) \\
\text { calculated }\end{array}$ & $\begin{array}{l}27.59 \%(18.33 \text { to } 39.27) \\
\text { calculated }\end{array}$ \\
\hline Cannon, 2009 & $\begin{array}{l}\text { SI increase (any) from EMS to } \\
\text { ED }\end{array}$ & Mortality & $\begin{array}{l}45.00 \%(33.85 \text { to } 56.53) \\
\text { calculated }\end{array}$ & $\begin{array}{l}67.50 \%(64.62 \text { to } 70.28) \\
\text { calculated }\end{array}$ & $\begin{array}{l}9.25 \%(7.31 \text { to } 11.65) \\
\text { calculated }\end{array}$ \\
\hline Caputo, 2012 & ET CO2 $<35 \mathrm{mmHg}$ & Massive transfusion & $\begin{array}{l}97.22 \%(85.47 \text { to } 99.93) \\
\text { calculated }\end{array}$ & $\begin{array}{l}66.67 \%(54.29 \text { to } 77.56) \\
\text { calculated }\end{array}$ & $\begin{array}{l}60.34 \%(52.04 \text { to } 68.09) \\
\text { calculated }\end{array}$ \\
\hline Caputo, 2012 & Lactate $>4 \mathrm{mmol} / \mathrm{L}$ & Massive transfusion & $\begin{array}{l}91.67 \%(77.53 \text { to } 98.25) \\
\text { calculated }\end{array}$ & $\begin{array}{l}85.51 \%(74.96 \text { to } 92.83) \\
\text { calculated }\end{array}$ & $\begin{array}{l}76.74 \%(64.85 \text { to } 85.51) \\
\text { calculated }\end{array}$ \\
\hline Caputo, 2012 & ET CO2 $<35 \mathrm{mmHg}$ & Operative intervention & $\begin{array}{l}81.97 \%(70.02 \text { to } 90.64) \\
\text { calculated }\end{array}$ & $\begin{array}{l}81.82 \%(67.29 \text { to } 91.81) \\
\text { calculated }\end{array}$ & $\begin{array}{l}86.21 \%(76.76 \text { to } 92.20) \\
\text { calculated }\end{array}$ \\
\hline Caputo, 2012 & Lactate $>4 \mathrm{mmol} / \mathrm{L}$ & Operative intervention & $\begin{array}{l}54.10 \%(40.85 \text { to } 66.94) \\
\text { calculated }\end{array}$ & $\begin{array}{l}77.27 \%(62.16 \text { to } 88.53) \\
\text { calculated }\end{array}$ & $\begin{array}{l}76.74 \%(64.61 \text { to } 85.64) \\
\text { calculated }\end{array}$ \\
\hline Caputo, 2012 & SBP $<100$ & Operative intervention & $\begin{array}{l}6.56 \%(1.82 \text { to } 15.95) \\
\text { calculated }\end{array}$ & $\begin{array}{l}97.73 \%(87.98 \text { to } 99.94) \\
\text { calculated }\end{array}$ & $\begin{array}{l}80.00 \%(41.04 \text { to } 44.98) \\
\text { calculated }\end{array}$ \\
\hline Caputo, 2015 & $\mathrm{BD}<-2$ & Massive transfusion & $59 \%$ (45 to 72$)$ & $59 \%(45$ to 71$)$ & $58 \%$ (44 to 72$)$ \\
\hline Caputo, 2015 & Lactate $>4$ & Massive transfusion & $54 \%$ (39 to 68$)$ & $75 \%(62$ to 84$)$ & $59 \%(44$ to 75$)$ \\
\hline Caputo, 2015 & $B D<-2$ & Operative intervention & $57 \%$ (42 to 76$)$ & $61 \%(52$ to 77$)$ & $55 \%$ (43 to 70$)$ \\
\hline Caputo, 2015 & Lactate $>4$ & Operative intervention & $55 \%(41$ to 67$)$ & $76 \%(65$ to 87$)$ & $60 \%(46$ to 78$)$ \\
\hline Chan, 1997 & $\begin{array}{l}\mathrm{SBP}<90(\mathrm{EMS}) \\
\text { all patients normotensive at ED } \\
\text { arrival }\end{array}$ & Blood transfusion & $\begin{array}{l}80.00 \%(44.39 \text { to } 97.48) \\
\text { calculated }\end{array}$ & $\begin{array}{l}53.19 \%(42.61 \text { to } 63.56) \\
\text { calculated }\end{array}$ & $\begin{array}{l}15.38 \%(11.08 \text { to } 20.96) \\
\text { calculated }\end{array}$ \\
\hline Chan, 1997 & $\begin{array}{l}\mathrm{SBP}<90(\mathrm{EMS}) \\
\text { all patients normotensive at ED } \\
\text { arrival }\end{array}$ & ICU admission & $\begin{array}{l}70.00 \%(53.47 \text { to } 83.44) \\
\text { calculated }\end{array}$ & $\begin{array}{l}62.50 \%(49.51 \text { to } 74.30) \\
\text { calculated }\end{array}$ & $\begin{array}{l}53.85 \%(44.48 \text { to } 62.95) \\
\text { calculated }\end{array}$ \\
\hline Chan, 1997 & $\begin{array}{l}\mathrm{SBP}<90(\mathrm{EMS}) \\
\text { all patients normotensive at ED } \\
\text { arrival }\end{array}$ & Mortality & $\begin{array}{l}90.91 \%(58.72 \text { to } 99.77) \\
\text { calculated }\end{array}$ & $\begin{array}{l}54.84 \% \text { (44.17 to } 65.91) \\
\text { calculated }\end{array}$ & $\begin{array}{l}19.23 \%(15.10 \text { to } 24.17) \\
\text { calculated }\end{array}$ \\
\hline Chen, 2007 & SBP linear classifier & Major hemorrhage & NR & NR & $\widehat{N R}$ \\
\hline Chen, 2007 & SI linear classifier & Major hemorrhage & NR & NR & NR \\
\hline
\end{tabular}




\begin{tabular}{|c|c|c|c|c|c|}
\hline $\begin{array}{l}\text { Author, Year } \\
\text { (See Appendix B for } \\
\text { complete reference) }\end{array}$ & $\begin{array}{l}\text { Reported NPV } \\
(95 \% \mathrm{Cl})\end{array}$ & Reported PLR & Reported NLR & $\begin{array}{l}\text { AUROC Univariate } \\
\text { AUC }(95 \% \mathrm{CI})\end{array}$ & $\begin{array}{l}\text { Other Measures of } \\
\text { Diagnostic Accuracy }\end{array}$ \\
\hline Cannon, 2009 & $\begin{array}{l}94.19 \%(93.00 \text { to } 95.18) \\
\text { calculated }\end{array}$ & $\begin{array}{l}1.33(1.02 \text { to } 1.73) \\
\text { calculated }\end{array}$ & $\begin{array}{l}0.84(0.69 \text { to } 1.02) \\
\text { calculated }\end{array}$ & NR & NR \\
\hline Cannon, 2009 & $\begin{array}{l}94.22 \%(93.59 \text { to } 94.80) \\
\text { calculated }\end{array}$ & $\begin{array}{l}4.78(2.96 \text { to } 7.72) \\
\text { calculated }\end{array}$ & $\begin{array}{l}0.77 \text { (0.66 to } 0.90) \\
\text { calculated }\end{array}$ & NR & NR \\
\hline Cannon, 2009 & $\begin{array}{l}94.34 \% \text { (93.15 to } 95.33) \\
\text { calculated }\end{array}$ & $\begin{array}{l}1.38(1.07 \text { to } 1.79) \\
\text { calculated }\end{array}$ & $\begin{array}{l}0.81(0.67 \text { to } 1.00) \\
\text { calculated }\end{array}$ & NR & NR \\
\hline Caputo, 2012 & $\begin{array}{l}97.87 \%(86.86 \text { to } 99.69) \\
\text { calculated }\end{array}$ & $\begin{array}{l}2.92(2.08 \text { to } 4.09) \\
\text { calculated }\end{array}$ & $\begin{array}{l}0.04(0.01 \text { to } 0.29) \\
\text { calculated }\end{array}$ & NR & NR \\
\hline Caputo, 2012 & $\begin{array}{l}95.16 \%(86.89 \text { to } 98.32) \\
\text { calculated }\end{array}$ & $\begin{array}{l}6.33(3.54 \text { to } 11.31) \\
\text { calculated }\end{array}$ & $\begin{array}{l}0.10(0.03 \text { to } 0.29) \\
\text { calculated }\end{array}$ & NR & NR \\
\hline Caputo, 2012 & $\begin{array}{l}76.60 \%(65.31 \text { to } 85.05) \\
\text { calculated }\end{array}$ & $\begin{array}{l}4.51(2.38 \text { to } 8.53) \\
\text { calculated }\end{array}$ & $\begin{array}{l}0.22(0.13 \text { to } 0.38) \\
\text { calculated }\end{array}$ & NR & NR \\
\hline Caputo, 2012 & $\begin{array}{l}54.84 \% \text { (46.96 to } 62.49) \\
\text { calculated }\end{array}$ & $\begin{array}{l}2.38(1.32 \text { to } 4.30) \\
\text { calculated }\end{array}$ & $\begin{array}{l}0.59(0.43 \text { to } 0.81) \\
\text { calculated }\end{array}$ & NR & NR \\
\hline Caputo, 2012 & $\begin{array}{l}43.00 \%(41.04 \text { to } 44.98) \\
\text { calculated }\end{array}$ & $\begin{array}{l}2.89(0.33 \text { to } 24.94) \\
\text { calculated }\end{array}$ & $\begin{array}{l}0.96(0.88 \text { to } 1.04) \\
\text { calculated }\end{array}$ & NR & NR \\
\hline Caputo, 2015 & $60 \%$ (46 to 74$)$ & $1.44(0.96$ to 2.15$)$ & 0.69 (0.46 to 1.04$)$ & $0.82(0.75$ to 0.89$)$ & NR \\
\hline Caputo, 2015 & $70 \%$ (59 to 81) & 2.11 (1.25 to 3.56$)$ & $0.62(0.43$ to 0.89$)$ & $0.83(0.7$ to 0.95$)$ & NR \\
\hline Caputo, 2015 & $56 \%$ (36 to 66$)$ & $1.5(0.99$ to 2.3$)$ & $0.75(0.5$ to 1.0$)$ & $0.67(0.58$ to 0.76$)$ & NR \\
\hline Caputo, 2015 & $75 \%$ (64 to 88$)$ & 2.21 (1.25 to 3.7) & $0.66(0.47$ to 0.96$)$ & 0.62 (0.5 to 0.73$)$ & NR \\
\hline Chan, 1997 & $\begin{array}{l}96.15 \%(87.71 \text { to } 98.87) \\
\text { calculated }\end{array}$ & $\begin{array}{l}1.71 \text { (1.17 to } 2.49) \\
\text { calculated }\end{array}$ & $\begin{array}{l}0.38(0.11 \text { to } 1.32) \\
\text { calculated }\end{array}$ & NR & NR \\
\hline Chan, 1997 & $\begin{array}{l}76.92 \%(66.68 \text { to } 84.74) \\
\text { calculated }\end{array}$ & $\begin{array}{l}1.87(1.28 \text { to } 2.72) \\
\text { calculated }\end{array}$ & $\begin{array}{l}0.48(0.29 \text { to } 0.80) \\
\text { calculated }\end{array}$ & NR & NR \\
\hline Chan, 1997 & $\begin{array}{l}98.08 \%(88.63 \text { to } 99.70) \\
\text { calculated }\end{array}$ & $\begin{array}{l}2.01(1.50 \text { to } 2.69) \\
\text { calculated }\end{array}$ & $\begin{array}{l}0.17(0.03 \text { to } 1.08) \\
\text { calculated }\end{array}$ & NR & NR \\
\hline Chen, 2007 & NR & NR & NR & $0.71(0.706$ to 0.714$)$ & NR \\
\hline Chen, 2007 & NR & NR & NR & $0.77(\mathrm{NR})$ & NR \\
\hline
\end{tabular}




\begin{tabular}{|c|c|c|c|c|c|}
\hline $\begin{array}{l}\text { Author, Year } \\
\text { (See Appendix B for } \\
\text { complete reference) }\end{array}$ & Measure & Indicator of Serious Injury & $\begin{array}{l}\text { Reported Sensitivity } \\
(95 \% \mathrm{Cl})\end{array}$ & $\begin{array}{l}\text { Reported Specificity } \\
(95 \% \mathrm{Cl})\end{array}$ & $\begin{array}{l}\text { Reported PPV } \\
(95 \% \mathrm{Cl})\end{array}$ \\
\hline Chen, 2007 & $\begin{array}{l}\text { Pulse pressure (PP) linear } \\
\text { classifier }\end{array}$ & Major hemorrhage & NR & NR & NR \\
\hline $\begin{array}{l}\text { Chen, } 2008 \\
\\
\text { *Chen 2008, Chen } \\
2009 \text {, and Chen } 2010 \\
\text { draw from the same } \\
898 \text { patients, but differ } \\
\text { in eligibility criteria, } \\
\text { number analyzed, and } \\
\text { some measures } \\
\text { evaluated. }\end{array}$ & $\begin{array}{l}\text { Ensemble classifier (non-linear } \\
\text { model of vital signs that allows } \\
\text { missing data; uses HR, RR, } \\
\text { DBP, SBP, and SaO2) }\end{array}$ & Hemorrhage & $\begin{array}{l}90 \% \text { (NR) } \\
\text { Set as clinically relevant } \\
\text { level to determine specificity }\end{array}$ & $40 \%$ (SD 0.10) & NR \\
\hline $\begin{array}{l}\text { Chen, } 2008 \\
\\
{ }^{*} \text { Chen 2008, Chen } \\
2009, \text { and Chen } 2010 \\
\text { draw from the same } \\
898 \text { patients, but differ } \\
\text { in eligibility criteria, } \\
\text { number analyzed, and } \\
\text { some measures } \\
\text { evaluated. }\end{array}$ & $\begin{array}{l}\text { Ensemble classifier (non-linear } \\
\text { model of vital signs that allows } \\
\text { missing data) }\end{array}$ & Hemorrhage & $69 \%$ (SD 0.08) & $68 \%$ (SD 0.09) & NR \\
\hline $\begin{array}{l}\text { Chen, } 2008 \\
\\
{ }^{\star} \text { Chen 2008, Chen } \\
2009, \text { and Chen } 2010 \\
\text { draw from the same } \\
898 \text { patients, but differ } \\
\text { in eligibility criteria, } \\
\text { number analyzed, and } \\
\text { some measures } \\
\text { evaluated. }\end{array}$ & $\begin{array}{l}\text { Hemorrhage index (HR } x \\
\text { RR)/(MAP x pulse pressure) }\end{array}$ & Hemorrhage & NR & NR & $\overline{N R}$ \\
\hline
\end{tabular}




\begin{tabular}{|c|c|c|c|c|c|}
\hline $\begin{array}{l}\text { Author, Year } \\
\text { (See Appendix B for } \\
\text { complete reference) }\end{array}$ & \begin{tabular}{|l} 
Reported NPV \\
$(95 \% \mathrm{Cl})$
\end{tabular} & Reported PLR & Reported NLR & $\begin{array}{l}\text { AUROC Univariate } \\
\text { AUC }(95 \% \mathrm{Cl})\end{array}$ & $\begin{array}{l}\text { Other Measures of } \\
\text { Diagnostic Accuracy }\end{array}$ \\
\hline Chen, 2007 & NRR & NR & NR & 0.73 (NR) & NR \\
\hline $\begin{array}{l}\text { Chen, } 2008 \\
\\
{ }^{\star} \text { Chen 2008, Chen } \\
2009, \text { and Chen } 2010 \\
\text { draw from the same } \\
898 \text { patients, but differ } \\
\text { in eligibility criteria, } \\
\text { number analyzed, and } \\
\text { some measures } \\
\text { evaluated. }\end{array}$ & NR & NR & NR & NR & $\mathrm{NR}$ \\
\hline $\begin{array}{l}\text { Chen, } 2008 \\
\\
{ }^{*} \text { Chen 2008, Chen } \\
2009, \text { and Chen } 2010 \\
\text { draw from the same } \\
898 \text { patients, but differ } \\
\text { in eligibility criteria, } \\
\text { number analyzed, and } \\
\text { some measures } \\
\text { evaluated. }\end{array}$ & NR & NR & NR & 0.76 (SD 0.05) & NR \\
\hline $\begin{array}{l}\text { Chen, } 2008 \\
\\
{ }^{\star} \text { Chen 2008, Chen } \\
2009, \text { and Chen } 2010 \\
\text { draw from the same } \\
898 \text { patients, but differ } \\
\text { in eligibility criteria, } \\
\text { number analyzed, and } \\
\text { some measures } \\
\text { evaluated. }\end{array}$ & NR & NR & NR & 0.73 (SD 0.06) & NR \\
\hline
\end{tabular}




\begin{tabular}{|c|c|c|c|c|c|}
\hline $\begin{array}{l}\text { Author, Year } \\
\text { (See Appendix B for } \\
\text { complete reference) }\end{array}$ & Measure & Indicator of Serious Injury & $\begin{array}{l}\text { Reported Sensitivity } \\
(95 \% \mathrm{Cl})\end{array}$ & $\begin{array}{l}\text { Reported Specificity } \\
(95 \% \mathrm{Cl})\end{array}$ & $\begin{array}{l}\text { Reported PPV } \\
(95 \% \mathrm{Cl})\end{array}$ \\
\hline $\begin{array}{l}\text { Chen, } 2008 \\
\\
{ }^{*} \text { Chen 2008, Chen } \\
2009, \text { and Chen } 2010 \\
\text { draw from the same } \\
898 \text { patients, but differ } \\
\text { in eligibility criteria, } \\
\text { number analyzed, and } \\
\text { some measures } \\
\text { evaluated. }\end{array}$ & $\mathrm{HR} / \mathrm{PP}$ & Hemorrhage & NR & NR & NR \\
\hline $\begin{array}{l}\text { Chen, } 2008 \\
\text { *Chen 2008, Chen } \\
2009 \text {, and Chen } 2010 \\
\text { draw from the same } \\
898 \text { patients, but differ } \\
\text { in eligibility criteria, } \\
\text { number analyzed, and } \\
\text { some measures } \\
\text { evaluated. }\end{array}$ & Pulse pressure & Hemorrhage & NR & NR & NR \\
\hline $\begin{array}{l}\text { Chen, } 2008 \\
\\
{ }^{*} \text { Chen 2008, Chen } \\
2009, \text { and Chen } 2010 \\
\text { draw from the same } \\
898 \text { patients, but differ } \\
\text { in eligibility criteria, } \\
\text { number analyzed, and } \\
\text { some measures } \\
\text { evaluated. }\end{array}$ & RR/pulse pressure & Hemorrhage & NR & NR & NR \\
\hline $\begin{array}{l}\text { Chen, } 2008 \\
\\
{ }^{*} \text { Chen } 2008, \text { Chen } \\
2009, \text { and Chen } 2010 \\
\text { draw from the same } \\
898 \text { patients, but differ } \\
\text { in eligibility criteria, } \\
\text { number analyzed, and } \\
\text { some measures } \\
\text { evaluated. }\end{array}$ & $\mathrm{SI}$ & Hemorrhage & NR & NR & NR \\
\hline
\end{tabular}




\begin{tabular}{|c|c|c|c|c|c|}
\hline $\begin{array}{l}\text { Author, Year } \\
\text { (See Appendix B for } \\
\text { complete reference) }\end{array}$ & $\begin{array}{l}\text { Reported NPV } \\
(95 \% \mathrm{Cl})\end{array}$ & Reported PLR & Reported NLR & $\begin{array}{l}\text { AUROC Univariate } \\
\text { AUC }(95 \% \mathrm{Cl})\end{array}$ & $\begin{array}{l}\text { Other Measures of } \\
\text { Diagnostic Accuracy }\end{array}$ \\
\hline $\begin{array}{l}\text { Chen, } 2008 \\
\\
{ }^{*} \text { Chen 2008, Chen } \\
2009, \text { and Chen } 2010 \\
\text { draw from the same } \\
898 \text { patients, but differ } \\
\text { in eligibility criteria, } \\
\text { number analyzed, and } \\
\text { some measures } \\
\text { evaluated. }\end{array}$ & NR & NR & NR & 0.75 (SD 0.10) & NR \\
\hline $\begin{array}{l}\text { Chen, } 2008 \\
\\
{ }^{*} \text { Chen } 2008, \text { Chen } \\
2009, \text { and Chen } 2010 \\
\text { draw from the same } \\
898 \text { patients, but differ } \\
\text { in eligibility criteria, } \\
\text { number analyzed, and } \\
\text { some measures } \\
\text { evaluated. }\end{array}$ & NR & NR & $\widehat{N R}$ & 0.73 (SD 0.06) & NR \\
\hline $\begin{array}{l}\text { Chen, } 2008 \\
\\
{ }^{*} \text { Chen 2008, Chen } \\
2009, \text { and Chen } 2010 \\
\text { draw from the same } \\
898 \text { patients, but differ } \\
\text { in eligibility criteria, } \\
\text { number analyzed, and } \\
\text { some measures } \\
\text { evaluated. }\end{array}$ & NR & NR & NR & 0.67 (SD 0.08) & NR \\
\hline $\begin{array}{l}\text { Chen, } 2008 \\
\\
{ }^{*} \text { Chen } 2008, \text { Chen } \\
2009, \text { and Chen } 2010 \\
\text { draw from the same } \\
898 \text { patients, but differ } \\
\text { in eligibility criteria, } \\
\text { number analyzed, and } \\
\text { some measures } \\
\text { evaluated. }\end{array}$ & NR & NR & NR & 0.76 (SD 0.06) & NR \\
\hline
\end{tabular}




\begin{tabular}{|c|c|c|c|c|c|}
\hline $\begin{array}{l}\text { Author, Year } \\
\text { (See Appendix B for } \\
\text { complete reference) }\end{array}$ & Measure & Indicator of Serious Injury & $\begin{array}{l}\text { Reported Sensitivity } \\
(95 \% \mathrm{Cl})\end{array}$ & $\begin{array}{l}\text { Reported Specificity } \\
(95 \% \mathrm{Cl})\end{array}$ & $\begin{array}{l}\text { Reported PPV } \\
(95 \% \mathrm{Cl})\end{array}$ \\
\hline $\begin{array}{l}\text { Chen, } 2009 \\
\text { *Chen } 2008 \text {, Chen } \\
2009 \text {, and Chen } 2010 \\
\text { draw from the same } \\
898 \text { patients, but differ } \\
\text { in eligibility criteria, } \\
\text { number analyzed, and } \\
\text { some measures } \\
\text { evaluated. }\end{array}$ & RR, standard: overall & Major hemorrhage & NR & NR & NR \\
\hline $\begin{array}{l}\text { Chen, } 2009 \\
\text { *Chen } 2008 \text {, Chen } \\
2009 \text {, and Chen } 2010 \\
\text { draw from the same } \\
898 \text { patients, but differ } \\
\text { in eligibility criteria, } \\
\text { number analyzed, and } \\
\text { some measures } \\
\text { evaluated. }\end{array}$ & RR, standard: thoracic injury & Major hemorrhage & NR & NR & NR \\
\hline $\begin{array}{l}\text { Chen, } 2009 \\
\text { *Chen } 2008, \text { Chen } \\
2009, \text { and Chen } 2010 \\
\text { draw from the same } \\
898 \text { patients, but differ } \\
\text { in eligibility criteria, } \\
\text { number analyzed, and } \\
\text { some measures } \\
\text { evaluated. }\end{array}$ & SBP, reliable & Major hemorrhage & NR & NR & NR \\
\hline $\begin{array}{l}\text { Chen, } 2009 \\
\text { *Chen } 2008 \text {, Chen } \\
2009 \text {, and Chen } 2010 \\
\text { draw from the same } \\
898 \text { patients, but differ } \\
\text { in eligibility criteria, } \\
\text { number analyzed, and } \\
\text { some measures } \\
\text { evaluated. }\end{array}$ & SI, reliable & Major hemorrhage & NR & NR & NR \\
\hline
\end{tabular}




\begin{tabular}{|c|c|c|c|c|c|}
\hline $\begin{array}{l}\text { Author, Year } \\
\text { (See Appendix B for } \\
\text { complete reference) }\end{array}$ & $\begin{array}{l}\text { Reported NPV } \\
(95 \% \mathrm{Cl})\end{array}$ & Reported PLR & Reported NLR & $\begin{array}{l}\text { AUROC Univariate } \\
\text { AUC }(95 \% \mathrm{Cl})\end{array}$ & $\begin{array}{l}\text { Other Measures of } \\
\text { Diagnostic Accuracy }\end{array}$ \\
\hline $\begin{array}{l}\text { Chen, } 2009 \\
\\
{ }^{*} \text { Chen 2008, Chen } \\
2009, \text { and Chen } 2010 \\
\text { draw from the same } \\
898 \text { patients, but differ } \\
\text { in eligibility criteria, } \\
\text { number analyzed, and } \\
\text { some measures } \\
\text { evaluated. }\end{array}$ & NR & NR & NR & $0.60(0.49$ to 0.70$)$ & NR \\
\hline $\begin{array}{l}\text { Chen, } 2009 \\
\\
{ }^{*} \text { Chen } 2008, \text { Chen } \\
2009, \text { and Chen } 2010 \\
\text { draw from the same } \\
898 \text { patients, but differ } \\
\text { in eligibility criteria, } \\
\text { number analyzed, and } \\
\text { some measures } \\
\text { evaluated. }\end{array}$ & NR & $\mathrm{NR}$ & $\mathrm{NR}$ & $0.56(0.39$ to 0.71$)$ & NR \\
\hline $\begin{array}{l}\text { Chen, } 2009 \\
\\
{ }^{*} \text { Chen } 2008, \text { Chen } \\
2009, \text { and Chen } 2010 \\
\text { draw from the same } \\
898 \text { patients, but differ } \\
\text { in eligibility criteria, } \\
\text { number analyzed, and } \\
\text { some measures } \\
\text { evaluated. } \\
\end{array}$ & NR & NR & NR & $0.71(0.61$ to 0.80$)$ & NR \\
\hline $\begin{array}{l}\text { Chen, } 2009 \\
\text { *Chen 2008, Chen } \\
2009 \text {, and Chen } 2010 \\
\text { draw from the same } \\
898 \text { patients, but differ } \\
\text { in eligibility criteria, } \\
\text { number analyzed, and } \\
\text { some measures } \\
\text { evaluated. }\end{array}$ & NR & NR & NR & $0.78(0.67$ to 0.86$)$ & NR \\
\hline
\end{tabular}




\begin{tabular}{|c|c|c|c|c|c|}
\hline $\begin{array}{l}\text { Author, Year } \\
\text { (See Appendix B for } \\
\text { complete reference) }\end{array}$ & Measure & Indicator of Serious Injury & $\begin{array}{l}\text { Reported Sensitivity } \\
(95 \% \mathrm{Cl})\end{array}$ & $\begin{array}{l}\text { Reported Specificity } \\
(95 \% \mathrm{Cl})\end{array}$ & $\begin{array}{l}\text { Reported PPV } \\
(95 \% \mathrm{Cl})\end{array}$ \\
\hline $\begin{array}{l}\text { Chen, } 2009 \\
\text { *Chen } 2008 \text {, Chen } \\
2009 \text {, and Chen } 2010 \\
\text { draw from the same } \\
898 \text { patients, but differ } \\
\text { in eligibility criteria, } \\
\text { number analyzed, and } \\
\text { some measures } \\
\text { evaluated. }\end{array}$ & RR, reliable: nonthoracic & $\begin{array}{l}\text { Major in-hospital respiratory } \\
\text { intervention }\end{array}$ & NR & NR & NR \\
\hline $\begin{array}{l}\text { Chen, } 2009 \\
\text { *Chen } 2008 \text {, Chen } \\
2009 \text {, and Chen } 2010 \\
\text { draw from the same } \\
898 \text { patients, but differ } \\
\text { in eligibility criteria, } \\
\text { number analyzed, and } \\
\text { some measures } \\
\text { evaluated. }\end{array}$ & RR, reliable: overall & $\begin{array}{l}\text { Major in-hospital respiratory } \\
\text { intervention }\end{array}$ & NR & NR & NR \\
\hline $\begin{array}{l}\text { Chen, } 2009 \\
\text { *Chen } 2008 \text {, Chen } \\
2009 \text {, and Chen } 2010 \\
\text { draw from the same } \\
898 \text { patients, but differ } \\
\text { in eligibility criteria, } \\
\text { number analyzed, and } \\
\text { some measures } \\
\text { evaluated. }\end{array}$ & RR, reliable: thoracic injury & $\begin{array}{l}\text { Major in-hospital respiratory } \\
\text { intervention }\end{array}$ & NR & NR & NR \\
\hline $\begin{array}{l}\text { Chen, } 2009 \\
\text { *Chen } 2008 \text {, Chen } \\
2009 \text {, and Chen } 2010 \\
\text { draw from the same } \\
898 \text { patients, but differ } \\
\text { in eligibility criteria, } \\
\text { number analyzed, and } \\
\text { some measures } \\
\text { evaluated. }\end{array}$ & RR, standard: nonthoracic & $\begin{array}{l}\text { Major in-hospital respiratory } \\
\text { intervention }\end{array}$ & NR & NR & NR \\
\hline
\end{tabular}




\begin{tabular}{|c|c|c|c|c|c|}
\hline $\begin{array}{l}\text { Author, Year } \\
\text { (See Appendix B for } \\
\text { complete reference) }\end{array}$ & $\begin{array}{l}\text { Reported NPV } \\
(95 \% \mathrm{Cl})\end{array}$ & Reported PLR & Reported NLR & $\begin{array}{l}\text { AUROC Univariate } \\
\text { AUC }(95 \% \mathrm{Cl})\end{array}$ & $\begin{array}{l}\text { Other Measures of } \\
\text { Diagnostic Accuracy }\end{array}$ \\
\hline $\begin{array}{l}\text { Chen, } 2009 \\
\\
{ }^{*} \text { Chen 2008, Chen } \\
2009, \text { and Chen } 2010 \\
\text { draw from the same } \\
898 \text { patients, but differ } \\
\text { in eligibility criteria, } \\
\text { number analyzed, and } \\
\text { some measures } \\
\text { evaluated. }\end{array}$ & NR & NR & NR & $0.73(0.49$ to 0.89$)$ & NR \\
\hline $\begin{array}{l}\text { Chen, } 2009 \\
\\
{ }^{*} \text { Chen } 2008, \text { Chen } \\
2009, \text { and Chen } 2010 \\
\text { draw from the same } \\
898 \text { patients, but differ } \\
\text { in eligibility criteria, } \\
\text { number analyzed, and } \\
\text { some measures } \\
\text { evaluated. }\end{array}$ & NR & $\mathrm{NR}$ & $\mathrm{NR}$ & 0.67 (0.57 to 0.77$)$ & NR \\
\hline $\begin{array}{l}\text { Chen, } 2009 \\
\\
{ }^{*} \text { Chen } 2008, \text { Chen } \\
2009, \text { and Chen } 2010 \\
\text { draw from the same } \\
898 \text { patients, but differ } \\
\text { in eligibility criteria, } \\
\text { number analyzed, and } \\
\text { some measures } \\
\text { evaluated. } \\
\end{array}$ & NR & NR & NR & $0.63(0.51$ to 0.75$)$ & NR \\
\hline $\begin{array}{l}\text { Chen, } 2009 \\
\text { *Chen 2008, Chen } \\
2009 \text {, and Chen } 2010 \\
\text { draw from the same } \\
898 \text { patients, but differ } \\
\text { in eligibility criteria, } \\
\text { number analyzed, and } \\
\text { some measures } \\
\text { evaluated. }\end{array}$ & NR & NR & NR & $0.56(0.37$ to 0.74$)$ & NR \\
\hline
\end{tabular}




\begin{tabular}{|c|c|c|c|c|c|}
\hline $\begin{array}{l}\text { Author, Year } \\
\text { (See Appendix B for } \\
\text { complete reference) }\end{array}$ & Measure & Indicator of Serious Injury & $\begin{array}{l}\text { Reported Sensitivity } \\
(95 \% \mathrm{Cl})\end{array}$ & $\begin{array}{l}\text { Reported Specificity } \\
(95 \% \mathrm{Cl})\end{array}$ & $\begin{array}{l}\text { Reported PPV } \\
(95 \% \mathrm{Cl})\end{array}$ \\
\hline $\begin{array}{l}\text { Chen, } 2009 \\
\text { *Chen } 2008 \text {, Chen } \\
2009 \text {, and Chen } 2010 \\
\text { draw from the same } \\
898 \text { patients, but differ } \\
\text { in eligibility criteria, } \\
\text { number analyzed, and } \\
\text { some measures } \\
\text { evaluated. }\end{array}$ & RR, standard: overall & $\begin{array}{l}\text { Major in-hospital respiratory } \\
\text { intervention }\end{array}$ & NR & NR & NR \\
\hline $\begin{array}{l}\text { Chen, } 2009 \\
\text { *Chen } 2008 \text {, Chen } \\
2009 \text {, and Chen } 2010 \\
\text { draw from the same } \\
898 \text { patients, but differ } \\
\text { in eligibility criteria, } \\
\text { number analyzed, and } \\
\text { some measures } \\
\text { evaluated. }\end{array}$ & RR, standard: thoracic injury & $\begin{array}{l}\text { Major in-hospital respiratory } \\
\text { intervention }\end{array}$ & NR & NR & NR \\
\hline $\begin{array}{l}\text { Chen, } 2009 \\
\text { Note: Chen 2008, Chen } \\
2009 \text {, and Chen } 2010 \\
\text { draw from the same } \\
898 \text { patients, but differ } \\
\text { in eligibility criteria, } \\
\text { number analyzed, and } \\
\text { some measures } \\
\text { evaluated. }\end{array}$ & $\begin{array}{l}\text { Breath index (RR/pulse } \\
\text { pressure), reliable }\end{array}$ & Major hemorrhage & NR & NR & NR \\
\hline
\end{tabular}




\begin{tabular}{|c|c|c|c|c|c|}
\hline $\begin{array}{l}\text { Author, Year } \\
\text { (See Appendix B for } \\
\text { complete reference) }\end{array}$ & $\begin{array}{l}\text { Reported NPV } \\
(95 \% \mathrm{Cl})\end{array}$ & Reported PLR & Reported NLR & $\begin{array}{l}\text { AUROC Univariate } \\
\text { AUC }(95 \% \mathrm{Cl})\end{array}$ & $\begin{array}{l}\text { Other Measures of } \\
\text { Diagnostic Accuracy }\end{array}$ \\
\hline $\begin{array}{l}\text { Chen, } 2009 \\
\text { *Chen } 2008 \text {, Chen } \\
2009 \text {, and Chen } 2010 \\
\text { draw from the same } \\
898 \text { patients, but differ } \\
\text { in eligibility criteria, } \\
\text { number analyzed, and } \\
\text { some measures } \\
\text { evaluated. }\end{array}$ & NR & NR & NR & $0.59(0.48$ to 0.69$)$ & NR \\
\hline $\begin{array}{l}\text { Chen, } 2009 \\
\text { *Chen } 2008 \text {, Chen } \\
2009 \text {, and Chen } 2010 \\
\text { draw from the same } \\
898 \text { patients, but differ } \\
\text { in eligibility criteria, } \\
\text { number analyzed, and } \\
\text { some measures } \\
\text { evaluated. }\end{array}$ & NR & NR & NR & $0.52(0.38$ to 0.66$)$ & NR \\
\hline $\begin{array}{l}\text { Chen, } 2009 \\
\text { Note: Chen 2008, Chen } \\
2009 \text {, and Chen } 2010 \\
\text { draw from the same } \\
898 \text { patients, but differ } \\
\text { in eligibility criteria, } \\
\text { number analyzed, and } \\
\text { some measures } \\
\text { evaluated. }\end{array}$ & NR & NR & NR & $0.85(0.77$ to 0.91$)$ & NR \\
\hline
\end{tabular}




\begin{tabular}{|c|c|c|c|c|c|}
\hline $\begin{array}{l}\text { Author, Year } \\
\text { (See Appendix B for } \\
\text { complete reference) }\end{array}$ & Measure & Indicator of Serious Injury & $\begin{array}{l}\text { Reported Sensitivity } \\
(95 \% \mathrm{Cl})\end{array}$ & $\begin{array}{l}\text { Reported Specificity } \\
(95 \% \mathrm{Cl})\end{array}$ & $\begin{array}{l}\text { Reported PPV } \\
(95 \% \mathrm{Cl})\end{array}$ \\
\hline $\begin{array}{l}\text { Chen, } 2009 \\
\text { Note: Chen 2008, Chen } \\
2009 \text {, and Chen } 2010 \\
\text { draw from the same } \\
898 \text { patients, but differ } \\
\text { in eligibility criteria, } \\
\text { number analyzed, and } \\
\text { some measures } \\
\text { evaluated. }\end{array}$ & DBP, reliable & Major hemorrhage & NR & NR & NR \\
\hline $\begin{array}{l}\text { Chen, } 2009 \\
\text { Note: Chen 2008, Chen } \\
2009 \text {, and Chen } 2010 \\
\text { draw from the same } \\
898 \text { patients, but differ } \\
\text { in eligibility criteria, } \\
\text { number analyzed, and } \\
\text { some measures } \\
\text { evaluated. }\end{array}$ & HR, reliable & Major hemorrhage & NR & NR & NR \\
\hline $\begin{array}{l}\text { Chen, } 2009 \\
\text { Note: Chen 2008, Chen } \\
2009 \text {, and Chen } 2010 \\
\text { draw from the same } \\
898 \text { patients, but differ } \\
\text { in eligibility criteria, } \\
\text { number analyzed, and } \\
\text { some measures } \\
\text { evaluated. }\end{array}$ & MAP, reliable & Major hemorrhage & NR & NR & NR \\
\hline
\end{tabular}




\begin{tabular}{|c|c|c|c|c|c|}
\hline $\begin{array}{l}\text { Author, Year } \\
\text { (See Appendix B for } \\
\text { complete reference) }\end{array}$ & $\begin{array}{l}\text { Reported NPV } \\
(95 \% \mathrm{Cl})\end{array}$ & Reported PLR & Reported NLR & $\begin{array}{l}\text { AUROC Univariate } \\
\text { AUC }(95 \% \mathrm{CI})\end{array}$ & $\begin{array}{l}\text { Other Measures of } \\
\text { Diagnostic Accuracy }\end{array}$ \\
\hline $\begin{array}{l}\text { Chen, } 2009 \\
\text { Note: Chen 2008, Chen } \\
\text { 2009, and Chen } 2010 \\
\text { draw from the same } \\
898 \text { patients, but differ } \\
\text { in eligibility criteria, } \\
\text { number analyzed, and } \\
\text { some measures } \\
\text { evaluated. }\end{array}$ & NR & NR & NR & 0.55 (0.43 to 0.67$)$ & NR \\
\hline $\begin{array}{l}\text { Chen, } 2009 \\
\text { Note: Chen 2008, Chen } \\
2009 \text {, and Chen } 2010 \\
\text { draw from the same } \\
898 \text { patients, but differ } \\
\text { in eligibility criteria, } \\
\text { number analyzed, and } \\
\text { some measures } \\
\text { evaluated. }\end{array}$ & NR & NR & NR & $0.74(0.63$ to 0.83$)$ & NR \\
\hline $\begin{array}{l}\text { Chen, } 2009 \\
\text { Note: Chen 2008, Chen } \\
\text { 2009, and Chen } 2010 \\
\text { draw from the same } \\
898 \text { patients, but differ } \\
\text { in eligibility criteria, } \\
\text { number analyzed, and } \\
\text { some measures } \\
\text { evaluated. }\end{array}$ & NR & NR & NR & $0.60(0.49$ to 0.71$)$ & NR \\
\hline
\end{tabular}




\begin{tabular}{|c|c|c|c|c|c|}
\hline $\begin{array}{l}\text { Author, Year } \\
\text { (See Appendix B for } \\
\text { complete reference) }\end{array}$ & Measure & Indicator of Serious Injury & $\begin{array}{l}\text { Reported Sensitivity } \\
(95 \% \mathrm{Cl})\end{array}$ & $\begin{array}{l}\text { Reported Specificity } \\
(95 \% \mathrm{Cl})\end{array}$ & $\begin{array}{l}\text { Reported PPV } \\
(95 \% \mathrm{Cl})\end{array}$ \\
\hline $\begin{array}{l}\text { Chen, } 2009 \\
\text { Note: Chen 2008, Chen } \\
2009 \text {, and Chen } 2010 \\
\text { draw from the same } \\
898 \text { patients, but differ } \\
\text { in eligibility criteria, } \\
\text { number analyzed, and } \\
\text { some measures } \\
\text { evaluated. }\end{array}$ & PP, reliable & Major hemorrhage & NR & NR & NR \\
\hline $\begin{array}{l}\text { Chen, } 2009 \\
\text { Note: Chen 2008, Chen } \\
2009 \text {, and Chen } 2010 \\
\text { draw from the same } \\
898 \text { patients, but differ } \\
\text { in eligibility criteria, } \\
\text { number analyzed, and } \\
\text { some measures } \\
\text { evaluated. }\end{array}$ & RR, reliable: nonthoracic & Major hemorrhage & NR & NR & NR \\
\hline $\begin{array}{l}\text { Chen, } 2009 \\
\text { Note: Chen 2008, Chen } \\
2009 \text {, and Chen } 2010 \\
\text { draw from the same } \\
898 \text { patients, but differ } \\
\text { in eligibility criteria, } \\
\text { number analyzed, and } \\
\text { some measures } \\
\text { evaluated. }\end{array}$ & RR, reliable: overall & Major hemorrhage & NR & NR & NR \\
\hline
\end{tabular}




\begin{tabular}{|c|c|c|c|c|c|}
\hline $\begin{array}{l}\text { Author, Year } \\
\text { (See Appendix B for } \\
\text { complete reference) }\end{array}$ & $\begin{array}{l}\text { Reported NPV } \\
(95 \% \mathrm{Cl})\end{array}$ & Reported PLR & Reported NLR & $\begin{array}{l}\text { AUROC Univariate } \\
\text { AUC }(95 \% \mathrm{Cl})\end{array}$ & $\begin{array}{l}\text { Other Measures of } \\
\text { Diagnostic Accuracy }\end{array}$ \\
\hline $\begin{array}{l}\text { Chen, } 2009 \\
\text { Note: Chen 2008, Chen } \\
\text { 2009, and Chen } 2010 \\
\text { draw from the same } \\
898 \text { patients, but differ } \\
\text { in eligibility criteria, } \\
\text { number analyzed, and } \\
\text { some measures } \\
\text { evaluated. }\end{array}$ & NR & NR & NR & $0.78(0.69$ to 0.86$)$ & NR \\
\hline $\begin{array}{l}\text { Chen, } 2009 \\
\text { Note: Chen 2008, Chen } \\
2009 \text {, and Chen } 2010 \\
\text { draw from the same } \\
898 \text { patients, but differ } \\
\text { in eligibility criteria, } \\
\text { number analyzed, and } \\
\text { some measures } \\
\text { evaluated. }\end{array}$ & NR & NR & NR & 0.79 (0.66 to 0.89$)$ & NR \\
\hline $\begin{array}{l}\text { Chen, } 2009 \\
\text { Note: Chen 2008, Chen } \\
2009, \text { and Chen } 2010 \\
\text { draw from the same } \\
898 \text { patients, but differ } \\
\text { in eligibility criteria, } \\
\text { number analyzed, and } \\
\text { some measures } \\
\text { evaluated. }\end{array}$ & NR & NR & NR & 0.77 (0.67 to 0.85$)$ & NR \\
\hline
\end{tabular}




\begin{tabular}{|c|c|c|c|c|c|}
\hline $\begin{array}{l}\text { Author, Year } \\
\text { (See Appendix B for } \\
\text { complete reference) }\end{array}$ & Measure & Indicator of Serious Injury & $\begin{array}{l}\text { Reported Sensitivity } \\
(95 \% \mathrm{Cl})\end{array}$ & $\begin{array}{l}\text { Reported Specificity } \\
(95 \% \mathrm{Cl})\end{array}$ & $\begin{array}{l}\text { Reported PPV } \\
(95 \% \mathrm{Cl})\end{array}$ \\
\hline $\begin{array}{l}\text { Chen, } 2009 \\
\text { Note: Chen 2008, Chen } \\
2009 \text {, and Chen } 2010 \\
\text { draw from the same } \\
898 \text { patients, but differ } \\
\text { in eligibility criteria, } \\
\text { number analyzed, and } \\
\text { some measures } \\
\text { evaluated. }\end{array}$ & RR, reliable: thoracic injury & Major hemorrhage & NR & NR & NR \\
\hline $\begin{array}{l}\text { Chen, } 2009 \\
\\
\text { Note: Chen 2008, Chen } \\
2009 \text {, and Chen } 2010 \\
\text { draw from the same } \\
898 \text { patients, but differ } \\
\text { in eligibility criteria, } \\
\text { number analyzed, and } \\
\text { some measures } \\
\text { evaluated. }\end{array}$ & RR, standard: nonthoracic & Major hemorrhage & NR & NR & NR \\
\hline $\begin{array}{l}\text { Chen, } 2010 \\
\\
{ }^{*} \text { Chen } 2010, \text { Chen } \\
2009, \text { and Chen } 2008 \\
\text { draw from the same } \\
898 \text { patients, but differ } \\
\text { in eligibility criteria, } \\
\text { number analyzed, and } \\
\text { some measures } \\
\text { evaluated. }\end{array}$ & $\begin{array}{l}\text { Amplitude IQR, } \\
\text { photoplethysmogram (PPG) } \\
\text { metric }\end{array}$ & Major hemorrhage & $\overline{N R}$ & $\overline{N R}$ & NR \\
\hline
\end{tabular}




\begin{tabular}{|c|c|c|c|c|c|}
\hline $\begin{array}{l}\text { Author, Year } \\
\text { (See Appendix B for } \\
\text { complete reference) }\end{array}$ & $\begin{array}{l}\text { Reported NPV } \\
(95 \% \mathrm{Cl})\end{array}$ & Reported PLR & Reported NLR & $\begin{array}{l}\text { AUROC Univariate } \\
\text { AUC }(95 \% \mathrm{Cl})\end{array}$ & $\begin{array}{l}\text { Other Measures of } \\
\text { Diagnostic Accuracy }\end{array}$ \\
\hline $\begin{array}{l}\text { Chen, } 2009 \\
\text { Note: Chen 2008, Chen } \\
2009 \text {, and Chen } 2010 \\
\text { draw from the same } \\
898 \text { patients, but differ } \\
\text { in eligibility criteria, } \\
\text { number analyzed, and } \\
\text { some measures } \\
\text { evaluated. }\end{array}$ & NR & NR & $N R$ & $0.76(0.61$ to 0.87$)$ & NR \\
\hline $\begin{array}{l}\text { Chen, } 2009 \\
\text { Note: Chen 2008, Chen } \\
\text { 2009, and Chen } 2010 \\
\text { draw from the same } \\
898 \text { patients, but differ } \\
\text { in eligibility criteria, } \\
\text { number analyzed, and } \\
\text { some measures } \\
\text { evaluated. }\end{array}$ & NR & NR & NR & $0.60(0.45$ to 0.73$)$ & NR \\
\hline $\begin{array}{l}\text { Chen, } 2010 \\
\\
{ }^{*} \text { Chen 2010, Chen } \\
2009, \text { and Chen } 2008 \\
\text { draw from the same } \\
898 \text { patients, but differ } \\
\text { in eligibility criteria, } \\
\text { number analyzed, and } \\
\text { some measures } \\
\text { evaluated. }\end{array}$ & NR & NR & NR & 0.64 (0.51 to 0.75$)$ & NR \\
\hline
\end{tabular}




\begin{tabular}{|c|c|c|c|c|c|}
\hline $\begin{array}{l}\text { Author, Year } \\
\text { (See Appendix B for } \\
\text { complete reference) }\end{array}$ & Measure & Indicator of Serious Injury & $\begin{array}{l}\text { Reported Sensitivity } \\
(95 \% \mathrm{Cl})\end{array}$ & $\begin{array}{l}\text { Reported Specificity } \\
(95 \% \mathrm{Cl})\end{array}$ & $\begin{array}{l}\text { Reported PPV } \\
(95 \% \mathrm{Cl})\end{array}$ \\
\hline $\begin{array}{l}\text { Chen, } 2010 \\
\\
{ }^{*} \text { Chen } 2010, \text { Chen } \\
2009, \text { and Chen } 2008 \\
\text { draw from the same } \\
898 \text { patients, but differ } \\
\text { in eligibility criteria, } \\
\text { number analyzed, and } \\
\text { some measures } \\
\text { evaluated. }\end{array}$ & $\begin{array}{l}\text { Amplitude max-min, } \\
\text { photoplethysmogram (PPG) } \\
\text { metric }\end{array}$ & Major hemorrhage & NR & NR & NR \\
\hline $\begin{array}{l}\text { Chen, } 2010 \\
\\
\text { *Chen 2010, Chen } \\
2009, \text { and Chen } 2008 \\
\text { draw from the same } \\
898 \text { patients, but differ } \\
\text { in eligibility criteria, } \\
\text { number analyzed, and } \\
\text { some measures } \\
\text { evaluated. }\end{array}$ & $\mathrm{HR}$, reliable & Major hemorrhage & NR & $\mathrm{NR}$ & NR \\
\hline $\begin{array}{l}\text { Chen, } 2010 \\
\text { *Chen 2010, Chen } \\
\text { 2009, and Chen } 2008 \\
\text { draw from the same } \\
898 \text { patients, but differ } \\
\text { in eligibility criteria, } \\
\text { number analyzed, and } \\
\text { some measures } \\
\text { evaluated. }\end{array}$ & $\begin{array}{l}\text { Metric and reliable vital signs } \\
\text { model: peak height IQR metric, } \\
\text { HR, RR, SpO2, SBP, and DBP }\end{array}$ & Major hemorrhage & $73 \%(\mathrm{NR})$ & $82 \%(\mathrm{NR})$ & NR \\
\hline $\begin{array}{l}\text { Chen, } 2010 \\
\\
\text { *Chen 2010, Chen } \\
2009 \text {, and Chen } 2008 \\
\text { draw from the same } \\
898 \text { patients, but differ } \\
\text { in eligibility criteria, } \\
\text { number analyzed, and } \\
\text { some measures } \\
\text { evaluated. }\end{array}$ & $\begin{array}{l}\text { Peak height IQR, } \\
\text { photoplethysmogram (PPG) } \\
\text { metric }\end{array}$ & Major hemorrhage & $54 \%(N R)$ & $73 \%(N R)$ & NR \\
\hline
\end{tabular}




\begin{tabular}{|c|c|c|c|c|c|}
\hline $\begin{array}{l}\text { Author, Year } \\
\text { (See Appendix B for } \\
\text { complete reference) }\end{array}$ & \begin{tabular}{|l} 
Reported NPV \\
$(95 \% \mathrm{Cl})$
\end{tabular} & Reported PLR & Reported NLR & $\begin{array}{l}\text { AUROC Univariate } \\
\text { AUC }(95 \% \mathrm{Cl})\end{array}$ & $\begin{array}{l}\text { Other Measures of } \\
\text { Diagnostic Accuracy }\end{array}$ \\
\hline $\begin{array}{l}\text { Chen, } 2010 \\
\\
* \text { Chen 2010, Chen } \\
2009 \text {, and Chen } 2008 \\
\text { draw from the same } \\
898 \text { patients, but differ } \\
\text { in eligibility criteria, } \\
\text { number analyzed, and } \\
\text { some measures } \\
\text { evaluated. }\end{array}$ & NR & NR & NR & $0.57(0.45$ to 0.68$)$ & $\overline{N R}$ \\
\hline $\begin{array}{l}\text { Chen, } 2010 \\
\\
{ }^{*} \text { Chen } 2010, \text { Chen } \\
2009, \text { and Chen } 2008 \\
\text { draw from the same } \\
898 \text { patients, but differ } \\
\text { in eligibility criteria, } \\
\text { number analyzed, and } \\
\text { some measures } \\
\text { evaluated. }\end{array}$ & $\overline{N R}$ & NR & NR & $0.62(0.50$ to 0.73$)$ & NR \\
\hline $\begin{array}{l}\text { Chen, } 2010 \\
\\
\text { *Chen 2010, Chen } \\
2009 \text {, and Chen } 2008 \\
\text { draw from the same } \\
898 \text { patients, but differ } \\
\text { in eligibility criteria, } \\
\text { number analyzed, and } \\
\text { some measures } \\
\text { evaluated. }\end{array}$ & NR & NR & NR & NR & NR \\
\hline $\begin{array}{l}\text { Chen, } 2010 \\
\\
\text { *Chen 2010, Chen } \\
2009 \text {, and Chen } 2008 \\
\text { draw from the same } \\
898 \text { patients, but differ } \\
\text { in eligibility criteria, } \\
\text { number analyzed, and } \\
\text { some measures } \\
\text { evaluated. }\end{array}$ & NR & NR & NR & 0.65 (0.54 to 0.76$)$ & $\mathrm{NR}$ \\
\hline
\end{tabular}




\begin{tabular}{|c|c|c|c|c|c|}
\hline $\begin{array}{l}\text { Author, Year } \\
\text { (See Appendix B for } \\
\text { complete reference) }\end{array}$ & Measure & Indicator of Serious Injury & $\begin{array}{l}\text { Reported Sensitivity } \\
(95 \% \mathrm{Cl})\end{array}$ & $\begin{array}{l}\text { Reported Specificity } \\
(95 \% \mathrm{Cl})\end{array}$ & $\begin{array}{l}\text { Reported PPV } \\
(95 \% \mathrm{Cl})\end{array}$ \\
\hline $\begin{array}{l}\text { Chen, } 2010 \\
\text { *Chen } 2010, \text { Chen } \\
2009, \text { and Chen } 2008 \\
\text { draw from the same } \\
898 \text { patients, but differ } \\
\text { in eligibility criteria, } \\
\text { number analyzed, and } \\
\text { some measures } \\
\text { evaluated. }\end{array}$ & $\begin{array}{l}\text { Peak height max-min, } \\
\text { photoplethysmogram (PPG) } \\
\text { metric }\end{array}$ & Major hemorrhage & $\widehat{N R}$ & NR & NR \\
\hline $\begin{array}{l}\text { Chen, } 2010 \\
\text { *Chen } 2010, \text { Chen } \\
2009 \text {, and Chen } 2008 \\
\text { draw from the same } \\
898 \text { patients, but differ } \\
\text { in eligibility criteria, } \\
\text { number analyzed, and } \\
\text { some measures } \\
\text { evaluated. }\end{array}$ & $\begin{array}{l}\text { Reliable vital signs model: HR, } \\
\text { RR, SpO2, SBP, and DBP }\end{array}$ & Major hemorrhage & $77 \%(\mathrm{Cl} \mathrm{NR})$ & $76 \%(\mathrm{Cl} N R)$ & NR \\
\hline $\begin{array}{l}\text { Chen, } 2010 \\
\text { *Chen } 2010, \text { Chen } \\
2009 \text {, and Chen } 2008 \\
\text { draw from the same } \\
898 \text { patients, but differ } \\
\text { in eligibility criteria, } \\
\text { number analyzed, and } \\
\text { some measures } \\
\text { evaluated. }\end{array}$ & SBP, reliable & Major hemorrhage & NR & NR & NR \\
\hline Cooke, 2006a & Intubation status & Mortality & $\begin{array}{l}53.33 \%(26.59 \text { to } 78.73) \\
\text { calculated }\end{array}$ & $\begin{array}{l}100.00 \%(78.20 \text { to } 100.00) \\
\text { calculated }\end{array}$ & $\begin{array}{l}100.00 \%(\mathrm{Cl} \text { not able to } \\
\text { be calculated }) \\
\text { calculated }\end{array}$ \\
\hline
\end{tabular}




\begin{tabular}{|c|c|c|c|c|c|}
\hline $\begin{array}{l}\text { Author, Year } \\
\text { (See Appendix B for } \\
\text { complete reference) }\end{array}$ & $\begin{array}{l}\text { Reported NPV } \\
(95 \% \mathrm{Cl})\end{array}$ & Reported PLR & Reported NLR & $\begin{array}{l}\text { AUROC Univariate } \\
\text { AUC }(95 \% \mathrm{CI})\end{array}$ & $\begin{array}{l}\text { Other Measures of } \\
\text { Diagnostic Accuracy }\end{array}$ \\
\hline $\begin{array}{l}\text { Chen, } 2010 \\
{ }^{\star} \text { Chen } 2010, \text { Chen } \\
2009, \text { and Chen } 2008 \\
\text { draw from the same } \\
898 \text { patients, but differ } \\
\text { in eligibility criteria, } \\
\text { number analyzed, and } \\
\text { some measures } \\
\text { evaluated. }\end{array}$ & NR & NR & NR & $0.60(0.48$ to 0.71$)$ & NR \\
\hline $\begin{array}{l}\text { Chen, } 2010 \\
{ }^{\star} \text { Chen } 2010 \text {, Chen } \\
2009 \text {, and Chen } 2008 \\
\text { draw from the same } \\
898 \text { patients, but differ } \\
\text { in eligibility criteria, } \\
\text { number analyzed, and } \\
\text { some measures } \\
\text { evaluated. }\end{array}$ & NR & NR & NR & NR & NR \\
\hline $\begin{array}{l}\text { Chen, } 2010 \\
{ }^{\star} \text { Chen } 2010, \text { Chen } \\
2009, \text { and Chen } 2008 \\
\text { draw from the same } \\
898 \text { patients, but differ } \\
\text { in eligibility criteria, } \\
\text { number analyzed, and } \\
\text { some measures } \\
\text { evaluated. }\end{array}$ & NR & NR & NR & $0.75(0.65$ to 0.84$)$ & NR \\
\hline Cooke, $2006 a$ & $\begin{array}{l}68.18 \%(55.51 \text { to } 78.64) \\
\text { calculated }\end{array}$ & not able to be calculated & $\begin{array}{l}0.47(0.27 \text { to } 0.80) \\
\text { calculated }\end{array}$ & NR & NR \\
\hline
\end{tabular}




\begin{tabular}{|c|c|c|c|c|c|}
\hline $\begin{array}{l}\text { Author, Year } \\
\text { (See Appendix B for } \\
\text { complete reference) }\end{array}$ & Measure & Indicator of Serious Injury & $\begin{array}{l}\text { Reported Sensitivity } \\
(95 \% \mathrm{Cl})\end{array}$ & $\begin{array}{l}\text { Reported Specificity } \\
(95 \% \mathrm{Cl})\end{array}$ & $\begin{array}{l}\text { Reported PPV } \\
(95 \% \mathrm{Cl})\end{array}$ \\
\hline Courville, 2009 & $\begin{array}{l}\text { Chi-square-assisted interaction } \\
\text { detection model (CHAID) for } \\
\text { mortality: testing data } \\
\text { model uses: demographics; ED } \\
\text { SBP, RR, temperature, GCS, } \\
\text { airway status; EMS GCS; } \\
\text { mechanism; days since injury }\end{array}$ & Mortality, in-hospital & $59.9 \%(\mathrm{Cl} \mathrm{NR})$ & $99.0 \%(\mathrm{Cl} \mathrm{NR})$ & $58.2 \%(\mathrm{Cl} \mathrm{NR})$ \\
\hline Courville, 2009 & $\begin{array}{l}\text { Airway: intubated, with or without } \\
\text { chemical sedation }\end{array}$ & Mortality, in-hospital & $\begin{array}{l}55.26 \%(53.52 \text { to } 56.98) \\
\text { calculated }\end{array}$ & $\begin{array}{l}96.71 \%(96.62 \text { to } 96.80) \\
\text { calculated }\end{array}$ & $\begin{array}{l}26.68 \%(25.87 \text { to } 27.49) \\
\text { calculated }\end{array}$ \\
\hline Davis, 1996 & BD -3 to -5 (mild) & Blood transfusion & $\begin{array}{l}23.82 \%(21.01 \text { to } 26.80) \\
\text { calculated }\end{array}$ & $\begin{array}{l}73.38 \%(71.43 \text { to } 75.27) \\
\text { calculated }\end{array}$ & $\begin{array}{l}27.03 \%(24.38 \text { to } 29.86) \\
\text { calculated }\end{array}$ \\
\hline Davis, 1996 & BD -6 to -9 (moderate) & Blood transfusion & $\begin{array}{l}29.60 \%(26.57 \text { to } 32.76) \\
\text { calculated }\end{array}$ & $\begin{array}{l}\text { 92.48\% (91.27 to 93.58) } \\
\text { calculated }\end{array}$ & $\begin{array}{l}61.99 \%(57.61 \text { to } 66.18) \\
\text { calculated }\end{array}$ \\
\hline Davis, 1996 & $\mathrm{BD} \leq-10$ (severe) & Blood transfusion & $\begin{array}{l}27.75 \%(24.78 \text { to } 30.86) \\
\text { calculated }\end{array}$ & $\begin{array}{l}98.13 \%(97.46 \text { to } 98.67) \\
\text { calculated }\end{array}$ & $\begin{array}{l}86.02 \%(81.58 \text { to } 89.53) \\
\text { calculated }\end{array}$ \\
\hline Davis, 1996 & BD -3 to -5 (mild) & Mortality & $\begin{array}{l}19.86 \%(16.16 \text { to } 23.98) \\
\text { calculated }\end{array}$ & $\begin{array}{l}73.21 \%(71.44 \text { to } 74.93) \\
\text { calculated }\end{array}$ & $\begin{array}{l}11.02 \%(9.19 \text { to } 13.17) \\
\text { calculated }\end{array}$ \\
\hline Davis, 1996 & BD -6 to -9 (moderate) & Mortality & $\begin{array}{l}22.46 \% \text { (18.57 to } 26.74) \\
\text { calculated }\end{array}$ & $\begin{array}{l}87.44 \% \text { ( } 86.08 \text { to } 88.70) \\
\text { calculated }\end{array}$ & $\begin{array}{l}23.00 \% \text { (19.58 to } 26.83) \\
\text { calculated }\end{array}$ \\
\hline Davis, 1996 & $\mathrm{BD} \leq-10$ (severe) & Mortality & $\begin{array}{l}33.81 \%(29.31 \text { to } 38.53) \\
\text { calculated }\end{array}$ & $\begin{array}{l}94.63 \%(93.68 \text { to } 95.47) \\
\text { calculated }\end{array}$ & $\begin{array}{l}51.25 \% \text { (45.99 to } 56.49) \\
\text { calculated }\end{array}$ \\
\hline DeMuro, 2013 & SI $\geq 0.8$, elderly $\geq 65$ years & Bleeding & $58.8 \%(\mathrm{NR})$ & $91.9 \%(\mathrm{NR})$ & $5.6 \%(N R)$ \\
\hline DeMuro, 2013 & $\mathrm{SI} \geq 0.8$, overall & Bleeding & $76.1 \%(\mathrm{NR})$ & $87.4 \%(\mathrm{NR})$ & $11.3 \%(\mathrm{NR})$ \\
\hline DeMuro, 2013 & SI $\geq 0.8$, adult $<65$ years & Bleeding & $80.3 \%(\mathrm{NR})$ & $83 \%(\mathrm{NR})$ & $13.7 \%(\mathrm{NR})$ \\
\hline DeMuro, 2013 & SI $\geq 0.9$, elderly $\geq 65$ years & Bleeding & $41.2 \%(\mathrm{NR})$ & $95.7 \%(\mathrm{NR})$ & $7.3 \%(\mathrm{NR})$ \\
\hline DeMuro, 2013 & $\mathrm{SI} \geq 0.9$, overall & Bleeding & $54.5 \%(N R)$ & $93.6 \%(\mathrm{NR})$ & $15.2 \%(\mathrm{NR})$ \\
\hline
\end{tabular}




\begin{tabular}{|c|c|c|c|c|c|}
\hline $\begin{array}{l}\text { Author, Year } \\
\text { (See Appendix B for } \\
\text { complete reference) }\end{array}$ & $\begin{array}{l}\text { Reported NPV } \\
(95 \% \mathrm{Cl}) \\
\end{array}$ & Reported PLR & Reported NLR & $\begin{array}{l}\text { AUROC Univariate } \\
\text { AUC }(95 \% \mathrm{CI})\end{array}$ & $\begin{array}{l}\text { Other Measures of } \\
\text { Diagnostic Accuracy }\end{array}$ \\
\hline Courville, 2009 & $99.1 \%(\mathrm{Cl} N R)$ & NR & NR & NR & NR \\
\hline Courville, 2009 & $\begin{array}{l}99.01 \%(98.97 \text { to } 99.05) \\
\text { calculated }\end{array}$ & $\begin{array}{l}16.80(16.12 \text { to } 17.51) \\
\text { calculated }\end{array}$ & $\begin{array}{l}0.46(0.45 \text { to } 0.48) \\
\text { calculated }\end{array}$ & NR & NR \\
\hline Davis, 1996 & $\begin{array}{l}69.94 \%(68.97 \text { to } 70.88) \\
\text { calculated }\end{array}$ & $\begin{array}{l}0.89(0.78 \text { to } 1.03) \\
\text { calculated }\end{array}$ & $\begin{array}{l}1.04(0.99 \text { to } 1.09) \\
\text { calculated }\end{array}$ & NR & NR \\
\hline Davis, 1996 & $\begin{array}{l}76.03 \%(75.21 \text { to } 76.84) \\
\text { calculated }\end{array}$ & $\begin{array}{l}3.94(3.28 \text { to } 4.72) \\
\text { calculated }\end{array}$ & $\begin{array}{l}0.76(0.73 \text { to } 0.80) \\
\text { calculated }\end{array}$ & NR & NR \\
\hline Davis, 1996 & $\begin{array}{l}76.64 \%(75.88 \text { to } 77.37) \\
\text { calculated }\end{array}$ & $\begin{array}{l}14.86(10.70 \text { to } 20.65) \\
\text { calculated }\end{array}$ & $\begin{array}{l}0.74(0.71 \text { to } 0.77) \\
\text { calculated }\end{array}$ & NR & NR \\
\hline Davis, 1996 & $\begin{array}{l}84.53 \%(83.83 \text { to } 85.21) \\
\text { calculated }\end{array}$ & $\begin{array}{l}0.74(0.61 \text { to } 0.91) \\
\text { calculated }\end{array}$ & $\begin{array}{l}1.09(1.04 \text { to } 1.15) \\
\text { calculated }\end{array}$ & NR & NR \\
\hline Davis, 1996 & $\begin{array}{l}87.09 \%(86.48 \text { to } 87.68) \\
\text { calculated }\end{array}$ & $\begin{array}{l}1.79(1.46 \text { to } 2.19) \\
\text { calculated }\end{array}$ & $\begin{array}{l}0.89(0.84 \text { to } 0.94) \\
\text { calculated }\end{array}$ & NR & NR \\
\hline Davis, 1996 & $\begin{array}{l}89.53 \%(88.87 \text { to } 90.16) \\
\text { calculated }\end{array}$ & $\begin{array}{l}6.29(5.09 \text { to } 7.77) \\
\text { calculated }\end{array}$ & $\begin{array}{l}0.70(0.65 \text { to } 0.75) \\
\text { calculated }\end{array}$ & NR & NR \\
\hline DeMuro, 2013 & $99.6 \%$ (NR) & NR & NR & NR & NR \\
\hline DeMuro, 2013 & 99.4\% (NR) & NR & NR & NR & NR \\
\hline DeMuro, 2013 & $99.2 \%$ (NR) & NR & NR & NR & NR \\
\hline DeMuro, 2013 & $99.5 \%$ (NR) & NR & NR & NR & NR \\
\hline DeMuro, 2013 & $99.0 \%$ (NR) & NR & NR & NR & NR \\
\hline
\end{tabular}




\begin{tabular}{|c|c|c|c|c|c|}
\hline $\begin{array}{l}\text { Author, Year } \\
\text { (See Appendix B for } \\
\text { complete reference) }\end{array}$ & Measure & Indicator of Serious Injury & $\begin{array}{l}\text { Reported Sensitivity } \\
(95 \% \mathrm{Cl})\end{array}$ & $\begin{array}{l}\text { Reported Specificity } \\
(95 \% \mathrm{Cl})\end{array}$ & $\begin{array}{l}\text { Reported PPV } \\
(95 \% \mathrm{Cl})\end{array}$ \\
\hline DeMuro, 2013 & SI $\geq 0.9$, adult $<65$ years & Bleeding & $57.7 \%(\mathrm{NR})$ & $91 \%(\mathrm{NR})$ & $18.7 \%(\mathrm{NR})$ \\
\hline DeMuro, 2013 & $\mathrm{SI} \geq 1.0$, overall & Bleeding & $39.8 \%(\mathrm{NR})$ & $97.2 \%(\mathrm{NR})$ & $22.9 \%(\mathrm{NR})$ \\
\hline DeMuro, 2013 & SI $\geq 1.0$, elderly $>65$ years & Bleeding & $29.4 \%(\mathrm{NR})$ & $98.1 \%(\mathrm{NR})$ & $11.1 \%(\mathrm{NR})$ \\
\hline DeMuro, 2013 & SI $\geq 1.0$, adult $<65$ years & Bleeding & $42.3 \%(\mathrm{NR})$ & $96 \%(\mathrm{NR})$ & $27.8 \%(\mathrm{NR})$ \\
\hline Dinh, 2014 & $\mathrm{SBP}<90$ or $>180, \mathrm{EMS}$ & Major trauma & $\begin{array}{l}14.66 \%(12.04 \text { to } 17.60) \\
\text { calculated }\end{array}$ & $\begin{array}{l}97.39 \%(96.66 \text { to } 97.99) \\
\text { calculated }\end{array}$ & $\begin{array}{l}60.76 \%(53.24 \text { to } 67.80) \\
\text { calculated }\end{array}$ \\
\hline Dinh, 2014 & $\mathrm{HR}<50$ or $>110, \mathrm{EMS}$ & Major trauma & $\begin{array}{l}27.48 \%(24.09 \text { to } 31.07) \\
\text { calculated }\end{array}$ & $\begin{array}{l}\text { 93.93\% (92.89 to } 94.86) \\
\text { calculated }\end{array}$ & $\begin{array}{l}55.56 \%(50.55 \text { to } 60.46) \\
\text { calculated }\end{array}$ \\
\hline Dinh, 2014 & $\mathrm{RR}<10$ or $>24, \mathrm{EMS}$ & Major trauma & $\begin{array}{l}19.85 \%(16.86 \text { to } 23.11) \\
\text { calculated }\end{array}$ & $\begin{array}{l}97.05 \%(96.29 \text { to } 97.69) \\
\text { calculated }\end{array}$ & $\begin{array}{l}65.00 \%(58.46 \text { to } 71.02) \\
\text { calculated }\end{array}$ \\
\hline Dinh, 2014 & $\begin{array}{l}\text { Vital signs, EMS: abnormal HR, } \\
\text { SBP, or RR }\end{array}$ & Major trauma & $\begin{array}{l}42.60 \%(38.77 \text { to } 46.48) \\
\text { calculated }\end{array}$ & $\begin{array}{l}89.25 \%(87.93 \text { to } 90.47) \\
\text { calculated }\end{array}$ & $\begin{array}{l}52.25 \%(48.60 \text { to } 55.87) \\
\text { calculated }\end{array}$ \\
\hline Dunham, 2017 & $\mathrm{BD}$ & Mortality: NR & NR & NR & NR \\
\hline Dunham, 2017 & $\mathrm{HR}$ & Mortality: NR & NR & NR & NR \\
\hline Dunham, 2017 & SBP & Mortality: NR & NR & NR & NR \\
\hline Dunham, 2017 & $\mathrm{SI}$ & Mortality: NR & NR & NR & NR \\
\hline Dunne, 2005 & Lactate $>6$ & Mortality & $\begin{array}{l}55.3 \%(51.3 \text { to } 59.3) \\
\text { calculated }\end{array}$ & $\begin{array}{l}91.7 \%(91.2 \text { to } 92.1) \\
\text { calculated }\end{array}$ & NR \\
\hline Eastridge, 2007 & $\mathrm{SBP}<110, \mathrm{ED}$ & Mortality & $33.7 \%(\mathrm{Cl} \mathrm{NR})$ & $87.5 \%(\mathrm{Cl} \mathrm{NR})$ & $5.2 \%(\mathrm{Cl} N R)$ \\
\hline Eastridge, 2007 & SBP <90, ED & Mortality & $18.7 \%(\mathrm{Cl} \mathrm{NR})$ & $97.6 \%(\mathrm{Cl} \mathrm{NR})$ & $13.7 \%(\mathrm{Cl} \mathrm{NR})$ \\
\hline Eastridge, 2007 & SBP 123 (optimal cutoff), ED & Mortality & $47 \%(\mathrm{Cl} \mathrm{NR})$ & $69.7 \%(\mathrm{Cl} N R)$ & NR \\
\hline Eastridge, 2007 & SBP, ED & Mortality & NR & NR & NR \\
\hline Edla, 2015b & $\mathrm{HR}$ & $\begin{array}{l}\text { Blood transfusion } \geq 1 \mathrm{pRBC} \text { unit in } \\
24 \text { hours }\end{array}$ & NR & NR & NR \\
\hline Edla, 2015b & Pulse pressure (SBP - DBP) & $\begin{array}{l}\text { Blood transfusion } \geq 1 \text { pRBC unit in } \\
24 \text { hours }\end{array}$ & NR & NR & NR \\
\hline Edla, 2015b & RR & $\begin{array}{l}\text { Blood transfusion } \geq 1 \text { pRBC unit in } \\
24 \text { hours }\end{array}$ & NR & NR & NR \\
\hline Edla, 2015b & SBP & $\begin{array}{l}\text { Blood transfusion } \geq 1 \text { pRBC unit in } \\
24 \text { hours }\end{array}$ & NR & NR & NR \\
\hline
\end{tabular}




\begin{tabular}{|c|c|c|c|c|c|}
\hline $\begin{array}{l}\text { Author, Year } \\
\text { (See Appendix B for } \\
\text { complete reference) }\end{array}$ & $\begin{array}{l}\text { Reported NPV } \\
(95 \% \mathrm{Cl})\end{array}$ & Reported PLR & Reported NLR & $\begin{array}{l}\text { AUROC Univariate } \\
\text { AUC }(95 \% \mathrm{CI})\end{array}$ & $\begin{array}{l}\text { Other Measures of } \\
\text { Diagnostic Accuracy }\end{array}$ \\
\hline DeMuro, 2013 & $98.5 \%(\mathrm{NR})$ & NR & NR & NR & NR \\
\hline DeMuro, 2013 & $98.7 \%(\mathrm{NR})$ & NR & NR & NR & NR \\
\hline DeMuro, 2013 & $99.4 \%(N R)$ & NR & NR & NR & NR \\
\hline DeMuro, 2013 & $98.0 \%(\mathrm{NR})$ & NR & NR & NR & NR \\
\hline Dinh, 2014 & $\begin{array}{l}80.52 \%(80.00 \text { to } 81.02) \\
\text { calculated }\end{array}$ & $\begin{array}{l}5.61(4.12 \text { to } 7.63) \\
\text { calculated }\end{array}$ & $\begin{array}{l}0.88(0.85 \text { to } 0.91) \\
\text { calculated }\end{array}$ & NR & NR \\
\hline Dinh, 2014 & $\begin{array}{l}82.43 \%(81.72 \text { to } 83.11) \\
\text { calculated }\end{array}$ & $\begin{array}{l}4.53(3.70 \text { to } 5.54) \\
\text { calculated }\end{array}$ & $\begin{array}{l}0.77(0.74 \text { to } 0.81) \\
\text { calculated }\end{array}$ & NR & NR \\
\hline Dinh, 2014 & $\begin{array}{l}81.43 \% \text { (80.84 to } 82.01) \\
\text { calculated }\end{array}$ & $\begin{array}{l}6.73(5.10 \text { to } 8.88) \\
\text { calculated }\end{array}$ & $\begin{array}{l}0.83(0.79 \text { to } 0.86) \\
\text { calculated }\end{array}$ & NR & NR \\
\hline Dinh, 2014 & $\begin{array}{l}84.92 \%(84.03 \text { to } 85.76) \\
\text { calculated }\end{array}$ & $\begin{array}{l}3.96(3.42 \text { to } 4.59) \\
\text { calculated }\end{array}$ & $\begin{array}{l}0.64(0.60 \text { to } 0.69) \\
\text { calculated }\end{array}$ & NR & NR \\
\hline Dunham, 2017 & NR & NR & NR & $0.900(0.850$ to 0.949$)$ & NR \\
\hline Dunham, 2017 & NR & NR & NR & $0.667(0.562$ to 0.771$)$ & NR \\
\hline Dunham, 2017 & NR & NR & NR & $0.753(0.651$ to 0.854$)$ & NR \\
\hline Dunham, 2017 & NR & NR & NR & $0.773(0.685$ to 0.861$)$ & NR \\
\hline Dunne, 2005 & NR & NR & NR & NR & NR \\
\hline Eastridge, 2007 & NR & NR & NR & NR & NR \\
\hline Eastridge, 2007 & NR & NR & NR & NR & NR \\
\hline Eastridge, 2007 & NR & NR & NR & NR & NR \\
\hline Eastridge, 2007 & NR & NR & NR & 0.582 (0.577 to 0.588$), p<0.001$ & NR \\
\hline Edla, 2015b & NR & NR & NR & $0.68(0.59$ to 0.76$)$ & NR \\
\hline Edla, 2015b & NR & NR & NR & $0.74(0.65$ to 0.81$)$ & NR \\
\hline Edla, 2015b & NR & NR & NR & $0.65(0.56$ to 0.73$)$ & NR \\
\hline Edla, 2015b & NR & NR & NR & $0.70(0.61$ to 0.78$)$ & NR \\
\hline
\end{tabular}




\begin{tabular}{|c|c|c|c|c|c|}
\hline $\begin{array}{l}\text { Author, Year } \\
\text { (See Appendix B for } \\
\text { complete reference) }\end{array}$ & Measure & Indicator of Serious Injury & $\begin{array}{l}\text { Reported Sensitivity } \\
(95 \% \mathrm{Cl})\end{array}$ & $\begin{array}{l}\text { Reported Specificity } \\
(95 \% \mathrm{Cl})\end{array}$ & $\begin{array}{l}\text { Reported PPV } \\
(95 \% \mathrm{CI})\end{array}$ \\
\hline Edla, 2015b & $\begin{array}{l}\text { HRV: Standard deviation of the } \\
\text { R-to-R intervals (SDNN) }\end{array}$ & $\begin{array}{l}\text { Blood transfusion } \geq 1 \text { pRBC units } \\
\text { in } 24 \text { hours }\end{array}$ & NR & NR & NR \\
\hline Edla, 2015b & HRV: Sample entropy (SampEn) & $\begin{array}{l}\text { Blood transfusion } \geq 1 \text { pRBC units } \\
\text { in } 24 \text { hours }\end{array}$ & NR & NR & NR \\
\hline Edla, 2015b & $\begin{array}{l}\text { HRV: Rate of sinus arrhythmia } \\
\text { (RSA) }\end{array}$ & $\begin{array}{l}\text { Blood transfusion } \geq 1 \text { pRBC units } \\
\text { in } 24 \text { hours }\end{array}$ & NR & NR & NR \\
\hline Edla, 2015b & HR & $\begin{array}{l}\text { Blood transfusion } \geq 5 \text { pRBC units } \\
\text { in } 24 \text { hours }\end{array}$ & NR & NR & NR \\
\hline Edla, 2015b & Pulse pressure (SBP - DBP) & $\begin{array}{l}\text { Blood transfusion } \geq 5 \text { pRBC units } \\
\text { in } 24 \text { hours }\end{array}$ & NR & NR & NR \\
\hline Edla, 2015b & $\mathrm{RR}$ & $\begin{array}{l}\text { Blood transfusion } \geq 5 \text { pRBC units } \\
\text { in } 24 \text { hours }\end{array}$ & NR & NR & NR \\
\hline Edla, 2015b & SBP & $\begin{array}{l}\text { Blood transfusion } \geq 5 \text { pRBC units } \\
\text { in } 24 \text { hours }\end{array}$ & NR & NR & NR \\
\hline Edla, 2015b & $\begin{array}{l}\text { HRV: Standard deviation of the } \\
\text { R-to-R intervals (SDNN) }\end{array}$ & $\begin{array}{l}\text { Blood transfusion } \geq 5 \text { pRBC units } \\
\text { in } 24 \text { hours }\end{array}$ & NR & NR & NR \\
\hline Edla, 2015b & HRV: Sample entropy (SampEn) & $\begin{array}{l}\text { Blood transfusion } \geq 5 \text { pRBC units } \\
\text { in } 24 \text { hours }\end{array}$ & NR & NR & NR \\
\hline Edla, 2015b & $\begin{array}{l}\text { HRV: Rate of sinus arrhythmia } \\
\text { (RSA) }\end{array}$ & $\begin{array}{l}\text { Blood transfusion } \geq 5 \text { pRBC units } \\
\text { in } 24 \text { hours }\end{array}$ & NR & NR & NR \\
\hline Edla, 2015b & $\mathrm{HR}$ & $\begin{array}{l}\text { Blood transfusion } \geq 9 \text { pRBC units } \\
\text { in } 24 \text { hours }\end{array}$ & NR & NR & NR \\
\hline Edla, 2015b & Pulse pressure (SBP - DBP) & $\begin{array}{l}\text { Blood transfusion } \geq 9 \text { pRBC units } \\
\text { in } 24 \text { hours }\end{array}$ & NR & NR & NR \\
\hline Edla, 2015b & $\mathrm{RR}$ & $\begin{array}{l}\text { Blood transfusion } \geq 9 p R B C \text { units } \\
\text { in } 24 \text { hours }\end{array}$ & NR & NR & NR \\
\hline Edla, 2015b & SBP & $\begin{array}{l}\text { Blood transfusion } \geq 9 \text { pRBC units } \\
\text { in } 24 \text { hours }\end{array}$ & NR & NR & NR \\
\hline Edla, 2015b & $\begin{array}{l}\text { HRV: Standard deviation of the } \\
\text { R-to-R intervals (SDNN) }\end{array}$ & $\begin{array}{l}\text { Blood transfusion } \geq 9 p R B C \text { units } \\
\text { in } 24 \text { hours }\end{array}$ & NR & NR & NR \\
\hline Edla, 2015b & HRV: Sample entropy (SampEn) & $\begin{array}{l}\text { Blood transfusion } \geq 9 \text { pRBC units } \\
\text { in } 24 \text { hours }\end{array}$ & NR & NR & NR \\
\hline Edla, 2015b & $\begin{array}{l}\text { HRV: Rate of sinus arrhythmia } \\
\text { (RSA) }\end{array}$ & $\begin{array}{l}\text { Blood transfusion } \geq 9 \text { pRBC units } \\
\text { in } 24 \text { hours }\end{array}$ & NR & NR & NR \\
\hline Engum, 2000 & $\mathrm{RR}<10$ or $>29$ & Major trauma & $\begin{array}{l}2.11 \%(0.92 \text { to } 4.12) \\
\text { calculated }\end{array}$ & $\begin{array}{l}99.67 \% \text { (99.04 to } 99.93) \\
\text { calculated }\end{array}$ & $\begin{array}{l}73 \% \text { (NR) } \\
\text { calculated: } 72.73 \% \\
\text { (41.56 to 90.91) }\end{array}$ \\
\hline Engum, 2000 & SBP $\leq 90$ & Major trauma & $\begin{array}{l}14.78 \%(11.36 \text { to } 18.75) \\
\text { calculated }\end{array}$ & $\begin{array}{l}99.01 \%(98.12 \text { to } 99.54) \\
\text { calculated }\end{array}$ & $\begin{array}{l}86 \% \text { (NR) } \\
\text { calculated: } 86.15 \% \\
\text { (75.67 to } 92.57)\end{array}$ \\
\hline
\end{tabular}




\begin{tabular}{|c|c|c|c|c|c|}
\hline $\begin{array}{l}\text { Author, Year } \\
\text { (See Appendix B for } \\
\text { complete reference) }\end{array}$ & $\begin{array}{l}\text { Reported NPV } \\
(95 \% \mathrm{Cl})\end{array}$ & Reported PLR & Reported NLR & $\begin{array}{l}\text { AUROC Univariate } \\
\text { AUC }(95 \% \mathrm{CI})\end{array}$ & $\begin{array}{l}\text { Other Measures of } \\
\text { Diagnostic Accuracy }\end{array}$ \\
\hline Edla, 2015b & NR & NR & NR & $0.67(0.59$ to 0.75$)$ & NR \\
\hline Edla, 2015b & NR & NR & NR & $0.60(0.53$ to 0.68$)$ & NR \\
\hline Edla, 2015b & NR & NR & NR & $0.72(0.64$ to 0.79$)$ & NR \\
\hline Edla, 2015b & NR & NR & NR & $0.74(0.59$ to 0.84$)$ & NR \\
\hline Edla, 2015b & NR & NR & NR & $0.79(0.68$ to 0.88$)$ & NR \\
\hline Edla, 2015b & NR & NR & NR & $0.74(0.63$ to 0.83$)$ & NR \\
\hline Edla, 2015b & NR & NR & NR & 0.72 (0.58 to 0.82$)$ & NR \\
\hline Edla, 2015b & NR & NR & NR & $0.72(0.61$ to 0.82$)$ & NR \\
\hline Edla, 2015b & NR & NR & NR & $0.63(0.52$ to 0.73$)$ & NR \\
\hline Edla, 2015b & NR & NR & NR & $0.76(0.62$ to 0.85$)$ & NR \\
\hline Edla, 2015b & NR & NR & NR & $0.72(0.53$ to 0.85$)$ & NR \\
\hline Edla, 2015b & NR & NR & NR & $0.79(0.61$ to 0.90$)$ & NR \\
\hline Edla, 2015b & NR & NR & NR & $0.73(0.53$ to 0.84$)$ & NR \\
\hline Edla, 2015b & NR & NR & NR & $0.73(0.55$ to 0.86$)$ & NR \\
\hline Edla, 2015b & NR & NR & NR & 0.71 (0.57 to 0.82$)$ & NR \\
\hline Edla, 2015b & NR & NR & NR & $0.62(0.46$ to 0.75$)$ & NR \\
\hline Edla, 2015b & NR & NR & NR & 0.79 (0.64 to 0.89$)$ & NR \\
\hline Engum, 2000 & $\begin{array}{l}70.88 \% \text { (70.56 to } 71.19) \\
\text { calculated }\end{array}$ & $\begin{array}{l}6.37(1.70 \text { to } 23.90) \\
\text { calculated }\end{array}$ & $\begin{array}{l}0.98(0.97 \text { to } 1.00) \\
\text { calculated }\end{array}$ & NR & NR \\
\hline Engum, 2000 & $\begin{array}{l}73.52 \%(72.69 \text { to } 74.34) \\
\text { calculated }\end{array}$ & $\begin{array}{l}14.87(7.43 \text { to } 29.76) \\
\text { calculated }\end{array}$ & $\begin{array}{l}0.86(0.83 \text { to } 0.90) \\
\text { calculated }\end{array}$ & NR & NR \\
\hline
\end{tabular}




\begin{tabular}{|c|c|c|c|c|c|}
\hline $\begin{array}{l}\text { Author, Year } \\
\text { (See Appendix B for } \\
\text { complete reference) }\end{array}$ & Measure & Indicator of Serious Injury & $\begin{array}{l}\text { Reported Sensitivity } \\
(95 \% \mathrm{Cl})\end{array}$ & $\begin{array}{l}\text { Reported Specificity } \\
(95 \% \mathrm{Cl})\end{array}$ & $\begin{array}{l}\text { Reported PPV } \\
(95 \% \mathrm{Cl})\end{array}$ \\
\hline Folkert, 2015 & Lactate $>2.2$ & Blood transfusion & $\begin{array}{l}71.43 \%(41.90 \text { to } 91.61) \\
\text { calculated }\end{array}$ & $\begin{array}{l}33.05 \%(24.67 \text { to } 42.31) \\
\text { calculated }\end{array}$ & $\begin{array}{l}11.24 \%(8.15 \text { to } 15.29) \\
\text { calculated }\end{array}$ \\
\hline Folkert, 2015 & $\begin{array}{l}\text { Lactate } \\
\text { (continuous variable) }\end{array}$ & Clinically significant bleeding & NR & NR & NR \\
\hline Folkert, 2015 & Lactate $>2.2$ & Clinically significant bleeding & $\begin{array}{l}68.63 \%(54.11 \text { to } 80.89) \\
\text { calculated }\end{array}$ & $\begin{array}{l}33.33 \%(23.24 \text { to } 44.68) \\
\text { calculated }\end{array}$ & $\begin{array}{l}39.33 \%(33.74 \text { to } 45.20) \\
\text { calculated }\end{array}$ \\
\hline Folkert, 2015 & Lactate $>2.2$ & $\begin{array}{l}\text { Operative intervention for } \\
\text { bleeding control }\end{array}$ & $\begin{array}{l}63.89 \%(46.22 \text { to } 79.18) \\
\text { calculated }\end{array}$ & $\begin{array}{l}30.53 \%(21.49 \text { to } 40.82) \\
\text { calculated }\end{array}$ & $\begin{array}{l}25.84 \%(20.86 \text { to } 31.55) \\
\text { calculated }\end{array}$ \\
\hline Franklin, 2000 & SBP <90, EMS & ICU admission & $\begin{array}{l}15.61 \%(13.42 \text { to } 18.00) \\
\text { calculated }\end{array}$ & $\begin{array}{l}86.17 \%(84.92 \text { to } 87.35) \\
\text { calculated }\end{array}$ & $\begin{array}{l}26.25 \%(23.14 \text { to } 29.63) \\
\text { calculated }\end{array}$ \\
\hline Franklin, 2000 & $\begin{array}{l}\text { SBP <90, EMS: subgroup with } \\
\text { any SBP <90 (ED or EMS) }\end{array}$ & Urgent operation & $\begin{array}{l}34.45 \% \text { (30.64 to } 38.41) \\
\text { calculated }\end{array}$ & $\begin{array}{l}69.23 \%(60.54 \text { to } 77.02) \\
\text { calculated }\end{array}$ & $\begin{array}{l}83.74 \% \text { (79.55 to } 87.21) \\
\text { calculated }\end{array}$ \\
\hline Franklin, 2000 & SBP <90, EMS & ED disposition to OR & $\begin{array}{l}21.85 \% \text { (19.60 to } 24.24) \\
\text { calculated }\end{array}$ & $\begin{array}{l}89.01 \%(87.83 \text { to } 90.12) \\
\text { calculated }\end{array}$ & $\begin{array}{l}46.15 \%(42.54 \text { to } 49.81) \\
\text { calculated }\end{array}$ \\
\hline Franklin, 2000 & SBP <90, EMS & Mortality: in-hospital & $\begin{array}{l}44.06 \%(38.22 \text { to } 50.02) \\
\text { calculated }\end{array}$ & $\begin{array}{l}87.92 \%(86.86 \text { to } 88.93) \\
\text { calculated }\end{array}$ & $\begin{array}{l}21.07 \%(18.60 \text { to } 23.77) \\
\text { calculated }\end{array}$ \\
\hline Franklin, 2000 & SBP <90, EMS & Mortality: ED & $\begin{array}{l}50.00 \%(34.56 \text { to } 65.44) \\
\text { calculated }\end{array}$ & $\begin{array}{l}86.12 \%(85.03 \text { to } 87.16) \\
\text { calculated }\end{array}$ & $\begin{array}{l}3.68 \%(2.74 \text { to } 4.93) \\
\text { calculated }\end{array}$ \\
\hline Garner, 2001 & Capillary refill >2 seconds & Critical injury & $36.3 \%(\mathrm{NR})$ & $93.2 \%(\mathrm{NR})$ & NR \\
\hline Garner, 2001 & CareFlight Triage algorithm & Critical injury & $82 \%(75$ to 88$)$ & $96 \%$ (94 to 97$)$ & NR \\
\hline Garner, 2001 & $\mathrm{HR}$ & Critical injury & NR & NR & NR \\
\hline Garner, 2001 & $\mathrm{HR}>120$ & Critical injury & $33.3 \%(\mathrm{NR})$ & $91.8 \%(\mathrm{NR})$ & NR \\
\hline Garner, 2001 & $\begin{array}{l}\text { Modified Simple Triage and } \\
\text { Rapid Treatment algorithm } \\
\text { (modified START), using } \\
\text { palpable radial pulse }\end{array}$ & Critical injury & $84 \%(76$ to 89$)$ & $91 \%$ (89 to 93$)$ & NR \\
\hline Garner, 2001 & RR & Critical injury & NR & NR & NR \\
\hline Garner, 2001 & $\mathrm{RR}<10$ or $>29$ & Critical injury & $25.2 \%(\mathrm{NR})$ & $95.3 \%(\mathrm{NR})$ & NR \\
\hline Garner, 2001 & RR >29 & Critical injury & $14.8 \%(\mathrm{NR})$ & 95.3\% (NR) & NR \\
\hline Garner, 2001 & SBP & Critical injury & NR & NR & NR \\
\hline Garner, 2001 & SBP <80 & Critical injury & $30.4 \%$ (NR) & $99.2 \%(N R)$ & NR \\
\hline
\end{tabular}




\begin{tabular}{|c|c|c|c|c|c|}
\hline $\begin{array}{l}\text { Author, Year } \\
\text { (See Appendix B for } \\
\text { complete reference) }\end{array}$ & $\begin{array}{l}\text { Reported NPV } \\
(95 \% \mathrm{Cl})\end{array}$ & Reported PLR & Reported NLR & $\begin{array}{l}\text { AUROC Univariate } \\
\text { AUC }(95 \% \mathrm{CI})\end{array}$ & $\begin{array}{l}\text { Other Measures of } \\
\text { Diagnostic Accuracy }\end{array}$ \\
\hline Folkert, 2015 & $\begin{array}{l}90.70 \%(80.38 \text { to } 95.87) \\
\text { calculated }\end{array}$ & $\begin{array}{l}1.07(0.75 \text { to } 1.52) \\
\text { calculated }\end{array}$ & $\begin{array}{l}0.86(0.36 \text { to } 2.06) \\
\text { calculated }\end{array}$ & NR & NR \\
\hline Folkert, 2015 & NR & NR & NR & $0.57(0.46$ to 0.67$)$ & NR \\
\hline Folkert, 2015 & $\begin{array}{l}62.79 \%(5.34 \text { to } 73.75) \\
\text { calculated }\end{array}$ & $\begin{array}{l}1.03(0.81 \text { to } 1.31) \\
\text { calculated }\end{array}$ & $\begin{array}{l}0.94(0.57 \text { to } 1.57) \\
\text { calculated }\end{array}$ & $0.51(0.42$ to 0.59$)$ & NR \\
\hline Folkert, 2015 & $\begin{array}{l}69.05 \%(56.77 \text { to } 79.12) \\
\text { calculated }\end{array}$ & $\begin{array}{l}0.92(0.70 \text { to } 1.22) \\
\text { calculated }\end{array}$ & $\begin{array}{l}1.18(0.70 \text { to } 2.01) \\
\text { calculated }\end{array}$ & NR & NR \\
\hline Franklin, 2000 & $\begin{array}{l}76.39 \%(75.85 \text { to } 76.93) \\
\text { calculated }\end{array}$ & $\begin{array}{l}1.13(0.95 \text { to } 1.33) \\
\text { calculated }\end{array}$ & $\begin{array}{l}0.98(0.95 \text { to } 1.01) \\
\text { calculated }\end{array}$ & NR & NR \\
\hline Franklin, 2000 & $\begin{array}{l}18.67 \%(16.80 \text { to } 20.70) \\
\text { calculated }\end{array}$ & $\begin{array}{l}1.12(0.85 \text { to } 1.48) \\
\text { calculated }\end{array}$ & $\begin{array}{l}0.95(0.83 \text { to } 1.08) \\
\text { calculated }\end{array}$ & NR & NR \\
\hline Franklin, 2000 & $\begin{array}{l}72.55 \%(71.91 \text { to } 73.18) \\
\text { calculated }\end{array}$ & $\begin{array}{l}1.99(1.72 \text { to } 2.30) \\
\text { calculated }\end{array}$ & $\begin{array}{l}0.88(0.85 \text { to } 0.91) \\
\text { calculated }\end{array}$ & NR & NR \\
\hline Franklin, 2000 & $\begin{array}{l}95.55 \% \text { (95.09 to 95.97) } \\
\text { calculated }\end{array}$ & $\begin{array}{l}3.65(3.12 \text { to } 4.26) \\
\text { calculated }\end{array}$ & $\begin{array}{l}0.64(0.57 \text { to } 0.71) \\
\text { calculated }\end{array}$ & NR & NR \\
\hline Franklin, 2000 & $\begin{array}{l}99.39 \%(99.18 \text { to } 99.54) \\
\text { calculated }\end{array}$ & $\begin{array}{l}3.60(2.66 \text { to } 4.89) \\
\text { calculated }\end{array}$ & $\begin{array}{l}0.58(0.43 \text { to } 0.78) \\
\text { calculated }\end{array}$ & NR & NR \\
\hline Garner, 2001 & NR & NR & NR & NR & NR \\
\hline Garner, 2001 & NR & NR & NR & NR & NR \\
\hline Garner, 2001 & NR & NR & NR & $0.64(0.58$ to 0.70$)$ & NR \\
\hline Garner, 2001 & NR & NR & NR & NR & NR \\
\hline Garner, 2001 & NR & NR & NR & NR & NR \\
\hline Garner, 2001 & NR & NR & NR & $0.50(0.43$ to 0.56$)$ & NR \\
\hline Garner, 2001 & NR & NR & NR & NR & NR \\
\hline Garner, 2001 & NR & NR & NR & NR & NR \\
\hline Garner, 2001 & NR & NR & NR & $0.72(0.67$ to 0.77$)$ & NR \\
\hline Garner, 2001 & NR & NR & NR & NR & NR \\
\hline
\end{tabular}




\begin{tabular}{|c|c|c|c|c|c|}
\hline $\begin{array}{l}\text { Author, Year } \\
\text { (See Appendix B for } \\
\text { complete reference) }\end{array}$ & Measure & Indicator of Serious Injury & $\begin{array}{l}\text { Reported Sensitivity } \\
(95 \% \mathrm{Cl})\end{array}$ & $\begin{array}{l}\text { Reported Specificity } \\
(95 \% \mathrm{Cl})\end{array}$ & $\begin{array}{l}\text { Reported PPV } \\
(95 \% \mathrm{Cl})\end{array}$ \\
\hline Garner, 2001 & $\begin{array}{l}\text { Simple Triage and Rapid } \\
\text { Treatment algorithm (START), } \\
\text { using capillary refill }\end{array}$ & Critical injury & $85 \%(78$ to 90$)$ & $86 \%(84$ to 88$)$ & NR \\
\hline Garner, 2001 & $\begin{array}{l}\text { Triage Sieve algorithm, using } \\
\text { capillary refill }\end{array}$ & Critical injury & $45 \%(37$ to 54$)$ & $89 \%(87$ to 91$)$ & NR \\
\hline Garner, 2001 & Triage Sieve algorithm, using HR & Critical injury & $45 \%(37$ to 54$)$ & $88 \%(86$ to 90$)$ & NR \\
\hline Gebhart, 2007 & $\begin{array}{l}\text { START triage: tabulated score } \\
\leq 1\end{array}$ & Mortality: inpatient & $57 \%(\mathrm{NR})$ & $96 \%(\mathrm{NR})$ & $40 \%(N R)$ \\
\hline Gebhart, 2007 & $\begin{array}{l}\text { START triage: tabulated score } \\
\geq 2\end{array}$ & Mortality: inpatient & $85 \%(\mathrm{NR})$ & $63 \%(\mathrm{NR})$ & $8 \%(\mathrm{NR})$ \\
\hline Gray, 1997 & T-RTS $<12$ & Major injury composite & $60 \%(49.3$ to 69.6$)$ & $90 \%(84.1$ to 95.2$)$ & NR \\
\hline Gray, 1997 & T-RTS $<8$ & Major injury composite & $19 \%(11.4$ to 27.7$)$ & $100 \%(96.9$ to 100$)$ & NR \\
\hline Gray, 1997 & CRAMS score $<9$ & Major injury composite & $69 \%(58.9$ to 78.1$)$ & $75 \%(67.1$ to 82.9$)$ & NR \\
\hline Grimme, 2005 & HR & Organ failure & NR & NR & NR \\
\hline Grimme, 2005 & $\mathrm{RR}$ & Organ failure & NR & NR & NR \\
\hline Grimme, 2005 & RTS & Organ failure & NR & NR & $\overline{N R}$ \\
\hline Grimme, 2005 & SBP & Organ failure & NR & NR & NR \\
\hline Grimme, 2005 & $\mathrm{SI}$ & Organ Failure & NR & NR & NR \\
\hline Guyette, 2012 & Deoxygenation slope (DeO2) & Life-saving intervention & NR & NR & NR \\
\hline Guyette, 2015 & Lactate (POC), EMS & Need for resuscitative care & NR & NR & NR \\
\hline Guyette, 2015 & Lactate $\geq 2.5$ (POC), EMS & Need for resuscitative care & $93 \%$ (84 to 98$)$ & $49 \%(\mathrm{NR})$ & NR \\
\hline Guyette, 2015 & $\begin{array}{l}\text { Lactate (POC), EMS: early } \\
\text { lactate subgroup }\end{array}$ & Need for resuscitative care & $100 \%$ (73 to 100$)$ & NR & NR \\
\hline Guyette, 2015 & $\begin{array}{l}\text { Lactate (POC), EMS: late lactate } \\
\text { subgroup }\end{array}$ & Need for resuscitative care & $89 \%(77$ to 96$)$ & NR & NR \\
\hline Guyette, 2015 & SBP, EMS & Need for resuscitative care & NR & NR & NR \\
\hline Guyette, 2015 & SBP $\leq 90$, EMS & Need for resuscitative care & $67 \%$ (55 to 78$)$ & $48 \%(\mathrm{NR})$ & NR \\
\hline Guyette, 2015 & $\begin{array}{l}\text { SBP } \leq 90, \text { EMS; early lactate } \\
\text { subgroup }\end{array}$ & Need for resuscitative care & $59 \%$ (33 to 82) & NR & NR \\
\hline Guyette, 2015 & $\begin{array}{l}\text { SBP } \leq 90, \text { EMS; late lactate } \\
\text { subgroup }\end{array}$ & Need for resuscitative care & $70 \%$ (56 to 82$)$ & NR & NR \\
\hline Guyette, 2015 & $\mathrm{SI}$ & Need for resuscitative care & NR & NR & NR \\
\hline Haider, 2016 & SBP $<90$ & Trauma center need & NR & NR & NR \\
\hline Haider, 2016 & SI $>1.0$ & Trauma center need & NR & NR & NR \\
\hline
\end{tabular}




\begin{tabular}{|c|c|c|c|c|c|}
\hline $\begin{array}{l}\text { Author, Year } \\
\text { (See Appendix B for } \\
\text { complete reference) }\end{array}$ & $\begin{array}{l}\text { Reported NPV } \\
(95 \% \mathrm{Cl})\end{array}$ & Reported PLR & Reported NLR & $\begin{array}{l}\text { AUROC Univariate } \\
\text { AUC }(95 \% \mathrm{Cl})\end{array}$ & $\begin{array}{l}\text { Other Measures of } \\
\text { Diagnostic Accuracy }\end{array}$ \\
\hline Garner, 2001 & NR & NR & NR & NR & NR \\
\hline Garner, 2001 & NR & NR & NR & NR & NR \\
\hline Garner, 2001 & NR & NR & NR & NR & NR \\
\hline Gebhart, 2007 & $98 \%(\mathrm{NR})$ & NR & NR & $0.57(\mathrm{NR})$ & NR \\
\hline Gebhart, 2007 & $99 \%(\mathrm{NR})$ & NR & NR & $0.86(\mathrm{NR})$ & NR \\
\hline Gray, 1997 & NR & NR & NR & NR & NR \\
\hline Gray, 1997 & NR & NR & NR & NR & NR \\
\hline Gray, 1997 & NR & NR & NR & NR & NR \\
\hline Grimme, 2005 & NR & NR & NR & 0.579 (NR) & NR \\
\hline Grimme, 2005 & NR & NR & NR & 0.377 (NR) & NR \\
\hline Grimme, 2005 & NR & NR & NR & 0.633 (NR) & NR \\
\hline Grimme, 2005 & NR & NR & NR & 0.564 (NR) & NR \\
\hline Grimme, 2005 & NR & NR & NR & 0.684 (NR) & NR \\
\hline Guyette, 2012 & NR & NR & NR & 0.7119 (NR) & $\begin{array}{l}\text { Abnormal DeO2 identified } 56 \% \\
\text { of patients requiring LSI } \\
(29 / 52) \text { and } 88 \% \text { of } \\
\text { hypotensive patients requiring } \\
\text { LSI (7/8). }\end{array}$ \\
\hline Guyette, 2015 & NR & NR & NR & $0.78(0.73$ to 0.83$)$ & NR \\
\hline Guyette, 2015 & $97 \%$ (93 to 99$)$ & NR & NR & NR & NR \\
\hline Guyette, 2015 & NR & NR & NR & NR & NR \\
\hline Guyette, 2015 & NR & NR & NR & NR & NR \\
\hline Guyette, 2015 & NR & NR & NR & $0.59(0.53$ to 0.66$)$ & NR \\
\hline Guyette, 2015 & $87 \%(81$ to 91$)$ & NR & NR & NR & NR \\
\hline Guyette, 2015 & NR & NR & NR & NR & NR \\
\hline Guyette, 2015 & NR & NR & NR & NR & NR \\
\hline Guyette, 2015 & NR & NR & NR & $0.66(0.60$ to 0.74$)$ & NR \\
\hline Haider, 2016 & NR & NR & NR & $0.526(0.524-0.527)$ & NR \\
\hline Haider, 2016 & NR & NR & NR & $0.534(0.532-0.535)$ & NR \\
\hline
\end{tabular}




\begin{tabular}{|c|c|c|c|c|c|}
\hline $\begin{array}{l}\text { Author, Year } \\
\text { (See Appendix B for } \\
\text { complete reference) }\end{array}$ & Measure & Indicator of Serious Injury & $\begin{array}{l}\text { Reported Sensitivity } \\
(95 \% \mathrm{Cl})\end{array}$ & $\begin{array}{l}\text { Reported Specificity } \\
(95 \% \mathrm{Cl})\end{array}$ & $\begin{array}{l}\text { Reported PPV } \\
(95 \% \mathrm{CI})\end{array}$ \\
\hline Haider, 2016 & \begin{tabular}{|l} 
National Trauma Triage \\
Protocol, physiologic step 1 \\
(current, using SBP <90) \\
\end{tabular} & Trauma center need & NR & NR & NR \\
\hline Haider, 2016 & $\begin{array}{l}\text { National Trauma Triage } \\
\text { Protocol, physiologic step } 1 \text { - } \\
\text { investigational model using SI } \\
>1.0 \\
(\mathrm{SI}>1.0 \text { instead of SBP <90) }\end{array}$ & Trauma center need & NR & NR & NR \\
\hline Hamada, 2014 & $\begin{array}{l}\text { Oxygen saturation (SpO2) } \\
<90 \% \text {, EMS }\end{array}$ & Major trauma & $16 \%(\mathrm{NR})$ & $94 \%(N R)$ & $79 \%(N R)$ \\
\hline Hamada, 2014 & SBP $<90$, EMS & Major trauma & $34 \%(\mathrm{NR})$ & $86 \%(\mathrm{NR})$ & $77 \%(\mathrm{NR})$ \\
\hline Hamada, 2014 & $\begin{array}{l}\text { Airway support (assisted } \\
\text { ventilation) }\end{array}$ & Major trauma & $52 \%(N R)$ & $88 \%(N R)$ & $86 \%(\mathrm{NR})$ \\
\hline Henry, 1996 & SBP $<90$ & LOS $>2$ days & $46 \%(\mathrm{NR})$ & $88 \%(\mathrm{NR})$ & $25 \%(\mathrm{NR})$ \\
\hline Henry, 1996 & SBP $<90$ & $\begin{array}{l}\text { Major non-orthopedic } \\
\text { interventions or death }\end{array}$ & $55 \%(N R)$ & $99 \%(N R)$ & $46 \%(N R)$ \\
\hline Holcomb, 2005 & SBP $<99$ & Life-saving intervention & $\begin{array}{l}50.67 \%(38.86 \text { to } 62.42) \\
\text { calculated }\end{array}$ & $\begin{array}{l}82.35 \%(77.61 \text { to } 86.46) \\
\text { calculated }\end{array}$ & $\begin{array}{l}41.30 \%(33.61 \text { to } 49.45) \\
\text { calculated }\end{array}$ \\
\hline Holcomb, 2005b & Capillary refill >2 seconds & Life-saving intervention & $\begin{array}{l}22.08 \%(13.42 \text { to } 32.98) \\
\text { calculated }\end{array}$ & $\begin{array}{l}98.40 \% \text { (94.34 to } 99.81) \\
\text { calculated }\end{array}$ & $\begin{array}{l}89.47 \%(66.88 \text { to } 97.28) \\
\text { calculated }\end{array}$ \\
\hline Holcomb, 2005b & $\mathrm{RR} \geq 19$ & Life-saving intervention & $\begin{array}{l}79.37 \%(67.30 \text { to } 88.53) \\
\text { calculated }\end{array}$ & $\begin{array}{l}11.19 \%(6.40 \text { to } 17.79) \\
\text { calculated }\end{array}$ & $\begin{array}{l}29.59 \%(26.76 \text { to } 32.57) \\
\text { calculated }\end{array}$ \\
\hline Holcomb, 2005b & $\mathrm{RR} \geq 21$ & Life-saving intervention & $\begin{array}{l}66.67 \%(53.66 \text { to } 78.05) \\
\text { calculated }\end{array}$ & $\begin{array}{l}26.12 \%(18.92 \text { to } 34.41) \\
\text { calculated }\end{array}$ & $\begin{array}{l}29.79 \%(25.53 \text { to } 34.17) \\
\text { calculated }\end{array}$ \\
\hline Holcomb, 2005b & $\mathrm{RR} \geq 24$ & Life-saving intervention & $\begin{array}{l}38.10 \%(26.15 \text { to } 51.20) \\
\text { calculated }\end{array}$ & $\begin{array}{l}69.40 \%(60.86 \text { to } 77.07) \\
\text { calculated }\end{array}$ & $\begin{array}{l}36.92 \%(28.08 \text { to } 46.74) \\
\text { calculated }\end{array}$ \\
\hline Holcomb, 2005b & SBP $<90$ & Life-saving intervention & $\begin{array}{l}33.75 \%(23.55 \text { to } 45.19) \\
\text { calculated }\end{array}$ & $\begin{array}{l}97.06 \%(92.64 \text { to } 99.19) \\
\text { calculated }\end{array}$ & $\begin{array}{l}87.10 \%(71.02 \text { to } 94.90) \\
\text { calculated }\end{array}$ \\
\hline Holcomb, 2005b & $H R \geq 100$ & Life-saving intervention & $\begin{array}{l}60.00 \%(48.44 \text { to } 70.80) \\
\text { calculated }\end{array}$ & $\begin{array}{l}51.47 \%(42.75 \text { to } 60.12) \\
\text { calculated }\end{array}$ & $\begin{array}{l}42.11 \%(36.18 \text { to } 48.26) \\
\text { calculated }\end{array}$ \\
\hline Holcomb, 2005b & $H R \geq 116$ & Life-saving intervention & $\begin{array}{l}21.83 \%(15.34 \text { to } 29.53) \\
\text { calculated }\end{array}$ & $\begin{array}{l}66.22 \%(54.28 \text { to } 76.81) \\
\text { calculated }\end{array}$ & $\begin{array}{l}55.36 \%(44.26 \text { to } 65.94) \\
\text { calculated }\end{array}$ \\
\hline
\end{tabular}




\begin{tabular}{|c|c|c|c|c|c|}
\hline $\begin{array}{l}\text { Author, Year } \\
\text { (See Appendix B for } \\
\text { complete reference) }\end{array}$ & $\begin{array}{l}\text { Reported NPV } \\
(95 \% \mathrm{Cl})\end{array}$ & Reported PLR & Reported NLR & $\begin{array}{l}\text { AUROC Univariate } \\
\text { AUC }(95 \% \mathrm{CI})\end{array}$ & $\begin{array}{l}\text { Other Measures of } \\
\text { Diagnostic Accuracy }\end{array}$ \\
\hline Haider, 2016 & NR & NR & NR & $0.599(0.597-0.601)$ & NR \\
\hline Haider, 2016 & NR & NR & NR & $0.604(0.603-0.606)$ & NR \\
\hline Hamada, 2014 & $44 \%$ (NR) & $2.6(\mathrm{NR})$ & 0.9 (NR) & NR & NR \\
\hline Hamada, 2014 & $48 \%(\mathrm{NR})$ & $2.4(\mathrm{NR})$ & 0.8 (NR) & NR & NR \\
\hline Hamada, 2014 & $56 \%(\mathrm{NR})$ & $4.4(\mathrm{NR})$ & 0.6 (NR) & NR & NR \\
\hline Henry, 1996 & $95 \%(N R)$ & NR & NR & NR & NR \\
\hline Henry, 1996 & $99 \%(N R)$ & NR & NR & NR & NR \\
\hline Holcomb, 2005 & $\begin{array}{l}87.20 \%(84.33 \text { to } 89.60) \\
\text { calculated }\end{array}$ & $\begin{array}{l}2.87(2.07 \text { to } 3.99) \\
\text { calculated }\end{array}$ & $\begin{array}{l}0.60(0.47 \text { to } 0.76) \\
\text { calculated }\end{array}$ & NR & NR \\
\hline Holcomb, 2005b & $\begin{array}{l}67.21 \%(64.49 \text { to } 69.82) \\
\text { calculated }\end{array}$ & $\begin{array}{l}13.80(3.28 \text { to } 58.09) \\
\text { calculated }\end{array}$ & $\begin{array}{l}0.79(0.70 \text { to } 0.89) \\
\text { calculated }\end{array}$ & NR & NR \\
\hline Holcomb, 2005b & $\begin{array}{l}53.57 \%(36.90 \text { to } 69.48) \\
\text { calculated }\end{array}$ & $\begin{array}{l}0.89(0.78 \text { to } 1.03) \\
\text { calculated }\end{array}$ & $\begin{array}{l}1.84(0.93 \text { to } 3.64) \\
\text { calculated }\end{array}$ & NR & NR \\
\hline Holcomb, 2005b & $\begin{array}{l}62.50 \% \text { (51.51 to } 72.34) \\
\text { calculated }\end{array}$ & $\begin{array}{l}0.90(0.74 \text { to } 1.10) \\
\text { calculated }\end{array}$ & $\begin{array}{l}1.28(0.81 \text { to } 2.00) \\
\text { calculated }\end{array}$ & NR & NR \\
\hline Holcomb, 2005b & $\begin{array}{l}70.45 \% \text { (65.59 to } 74.89) \\
\text { calculated }\end{array}$ & $\begin{array}{l}1.25(0.83 \text { to } 1.87) \\
\text { calculated }\end{array}$ & $\begin{array}{l}0.89(0.71 \text { to } 1.12) \\
\text { calculated }\end{array}$ & NR & NR \\
\hline Holcomb, 2005b & $\begin{array}{l}71.35 \%(67.99 \text { to } 74.49) \\
\text { calculated }\end{array}$ & $\begin{array}{l}11.47(4.17 \text { to } 31.60) \\
\text { calculated }\end{array}$ & $\begin{array}{l}0.68(0.58 \text { to } 0.80) \\
\text { calculated }\end{array}$ & NR & NR \\
\hline Holcomb, 2005b & $\begin{array}{l}68.63 \%(61.51 \text { to } 74.97) \\
\text { calculated }\end{array}$ & $\begin{array}{l}1.24(0.96 \text { to } 1.59) \\
\text { calculated }\end{array}$ & $\begin{array}{l}0.78(0.57 \text { to } 1.06) \\
\text { calculated }\end{array}$ & NR & NR \\
\hline Holcomb, 2005b & $\begin{array}{l}30.62 \%(26.85 \text { to } 34.68) \\
\text { calculated }\end{array}$ & $\begin{array}{l}0.65(0.41 \text { to } 1.01) \\
\text { calculated }\end{array}$ & $\begin{array}{l}1.18(0.98 \text { to } 1.42) \\
\text { calculated }\end{array}$ & NR & NR \\
\hline
\end{tabular}




\begin{tabular}{|c|c|c|c|c|c|}
\hline $\begin{array}{l}\text { Author, Year } \\
\text { (See Appendix B for } \\
\text { complete reference) }\end{array}$ & Measure & Indicator of Serious Injury & $\begin{array}{l}\text { Reported Sensitivity } \\
(95 \% \mathrm{Cl})\end{array}$ & $\begin{array}{l}\text { Reported Specificity } \\
(95 \% \mathrm{Cl})\end{array}$ & $\begin{array}{l}\text { Reported PPV } \\
(95 \% \mathrm{Cl})\end{array}$ \\
\hline Horne, 2013 & $\begin{array}{l}\text { Triage Sieve military: complete } \\
\text { data subgroup } \\
\mathrm{RR}<10 \text { or }>29, \mathrm{HR}>120 \text {, or } \\
\mathrm{GCS}<13\end{array}$ & $\begin{array}{l}\text { Priority } 1 \text { casualty (life-saving } \\
\text { intervention) }\end{array}$ & $58.5 \%(58.4-62.1)$ & $89.2 \%(84.7-90.4)$ & NR \\
\hline Horne, 2013 & $\begin{array}{l}\text { Triage Sieve military: overall } \\
\text { dataset } \\
\text { alternate thresholds: } R R<12 \text { or } \\
>24, \mathrm{HR}<60 \text { or }>120 \text {, or GCS } \\
<13\end{array}$ & $\begin{array}{l}\text { Priority } 1 \text { casualty (life-saving } \\
\text { intervention) }\end{array}$ & $72.3 \%(\mathrm{NR})$ & $77.1 \%(\mathrm{NR})$ & NR \\
\hline Horne, 2013 & $\begin{array}{l}\text { Triage Sieve military: overall } \\
\text { dataset } \\
\mathrm{RR}<10 \text { or }>29, \mathrm{HR}>120 \text {, or } \\
\mathrm{GCS}<13\end{array}$ & $\begin{array}{l}\text { Priority } 1 \text { casualty (life-saving } \\
\text { intervention) }\end{array}$ & $65.2 \%(\mathrm{NR})$ & $89.2 \%(N R)$ & NR \\
\hline Horne, 2013 & $\begin{array}{l}\text { Triage Sieve civilian: overall } \\
\text { dataset } \\
\mathrm{RR}<10 \text { or }>29 \text {, or } \mathrm{HR}>120\end{array}$ & $\begin{array}{l}\text { Priority } 1 \text { casualty (life-saving } \\
\text { intervention) }\end{array}$ & $41.8 \%(\mathrm{NR})$ & $91.7 \%(\mathrm{NR})$ & NR \\
\hline Horne, 2013 & $\begin{array}{l}\text { Triage Sieve civilian: complete } \\
\text { data subgroup } \\
\mathrm{RR}<10 \text { or }>29 \text {, or } \mathrm{HR}>120\end{array}$ & $\begin{array}{l}\text { Priority } 1 \text { casualty (life-saving } \\
\text { intervention) }\end{array}$ & $53.2 \%(49.4-56.8)$ & $87.8 \%(84.7-90.4)$ & NR \\
\hline Ichwan, 2015 & $\begin{array}{l}\text { Geriatric triage criteria: elderly } \\
>70 \text { years }\end{array}$ & OR visit within 48 hours & $47 \%$ (46 to 49$)$ & $42 \%$ (41 to 42$)$ & NR \\
\hline Ichwan, 2015 & $\begin{array}{l}\text { Geriatric triage criteria: non- } \\
\text { elderly } \leq 70 \text { years }\end{array}$ & OR visit within 48 hours & $73 \%(72$ to 73$)$ & $27 \%$ (26 to 27$)$ & NR \\
\hline Ichwan, 2015 & $\begin{array}{l}\text { Geriatric triage criteria: elderly } \\
>70 \text { years }\end{array}$ & ICU admission & $81 \%(80$ to 82$)$ & $48 \%(47$ to 48$)$ & NR \\
\hline Ichwan, 2015 & $\begin{array}{l}\text { Geriatric triage criteria: } \text { non- } \\
\text { elderly } \leq 70 \text { years }\end{array}$ & ICU admission & $91 \%(90$ to 91$)$ & $34 \%$ (33 to 34) & NR \\
\hline Ichwan, 2015 & $\begin{array}{l}\text { Geriatric triage criteria: elderly } \\
>70 \text { years }\end{array}$ & Mortality & $90 \%$ (89 to 91$)$ & $45 \%$ (45 to 46$)$ & NR \\
\hline Ichwan, 2015 & $\begin{array}{l}\text { Geriatric triage criteria: non- } \\
\text { elderly } \leq 70 \text { years }\end{array}$ & Mortality & $99 \%(99$ to 100$)$ & $30 \%(29$ to 30$)$ & NR \\
\hline Ichwan, 2015 & $\begin{array}{l}\text { Geriatric triage criteria: elderly } \\
>70 \text { years }\end{array}$ & ISS >15 & $93 \%$ (92 to 93$)$ & $49 \%$ (48 to 49$)$ & NR \\
\hline Ichwan, 2015 & $\begin{array}{l}\text { Geriatric triage criteria: non- } \\
\text { elderly } \leq 70 \text { years }\end{array}$ & ISS >15 & $94 \%$ (94 to 95) & $35 \%$ (35 to 35) & NR \\
\hline Ichwan, 2015 & $\begin{array}{l}\text { Adult triage criteria: elderly }>70 \\
\text { years }\end{array}$ & OR visit within 48 hours & $35 \%$ (34 to 37$)$ & $57 \%(56$ to 58$)$ & $\overline{N R}$ \\
\hline Ichwan, 2015 & $\begin{array}{l}\text { Adult triage criteria: non-elderly } \\
\leq 70 \text { years }\end{array}$ & OR visit within 48 hours & $65 \%$ (64 to 65$)$ & $36 \%$ (35 to 36$)$ & NR \\
\hline
\end{tabular}




\begin{tabular}{|c|c|c|c|c|c|}
\hline $\begin{array}{l}\text { Author, Year } \\
\text { (See Appendix B for } \\
\text { complete reference) }\end{array}$ & $\begin{array}{l}\text { Reported NPV } \\
(95 \% \mathrm{Cl})\end{array}$ & Reported PLR & Reported NLR & $\begin{array}{l}\text { AUROC Univariate } \\
\text { AUC }(95 \% \mathrm{Cl})\end{array}$ & $\begin{array}{l}\text { Other Measures of } \\
\text { Diagnostic Accuracy }\end{array}$ \\
\hline Horne, 2013 & NR & NR & NR & NR & $\mathrm{NR}$ \\
\hline Horne, 2013 & NR & NR & NR & NR & NR \\
\hline Horne, 2013 & NR & NR & NR & NR & NR \\
\hline Horne, 2013 & NR & NR & NR & NR & NR \\
\hline Horne, 2013 & NR & NR & NR & NR & NR \\
\hline Ichwan, 2015 & NR & NR & NR & $0.44(\mathrm{NR})$ & NR \\
\hline Ichwan, 2015 & NR & NR & NR & $0.5(\mathrm{NR})$ & NR \\
\hline Ichwan, 2015 & NR & NR & NR & $0.64(\mathrm{NR})$ & $\overline{N R}$ \\
\hline Ichwan, 2015 & NR & NR & NR & 0.62 (NR) & NR \\
\hline Ichwan, 2015 & NR & NR & NR & 0.68 (NR) & NR \\
\hline Ichwan, 2015 & NR & NR & NR & $0.64(\mathrm{NR})$ & NR \\
\hline Ichwan, 2015 & NR & NR & NR & $0.71(\mathrm{NR})$ & NR \\
\hline Ichwan, 2015 & NR & NR & NR & $0.65(\mathrm{NR})$ & NR \\
\hline Ichwan, 2015 & $\sqrt{N R}$ & NR & NR & $0.46(\mathrm{NR})$ & $\overline{N R}$ \\
\hline Ichwan, 2015 & NR & NR & NR & $0.5(\mathrm{NR})$ & NR \\
\hline
\end{tabular}




\begin{tabular}{|c|c|c|c|c|c|}
\hline $\begin{array}{l}\text { Author, Year } \\
\text { (See Appendix B for } \\
\text { complete reference) }\end{array}$ & Measure & Indicator of Serious Injury & $\begin{array}{l}\text { Reported Sensitivity } \\
(95 \% \mathrm{Cl})\end{array}$ & $\begin{array}{l}\text { Reported Specificity } \\
(95 \% \mathrm{Cl})\end{array}$ & $\begin{array}{l}\text { Reported PPV } \\
(95 \% \mathrm{Cl})\end{array}$ \\
\hline Ichwan, 2015 & $\begin{array}{l}\text { Adult triage criteria: elderly }>70 \\
\text { years }\end{array}$ & ICU admission & $56 \%(55$ to 57$)$ & $61 \%(60$ to 62$)$ & NR \\
\hline Ichwan, 2015 & $\begin{array}{l}\text { Adult triage criteria: non-elderly } \\
\leq 70 \text { years }\end{array}$ & ICU admission & $82 \%(82$ to 83$)$ & $42 \%(42$ to 43$)$ & NR \\
\hline Ichwan, 2015 & $\begin{array}{l}\text { Adult triage criteria: elderly }>70 \\
\text { years }\end{array}$ & Mortality & $74 \%(72$ to 76$)$ & $60 \%(60$ to 61$)$ & NR \\
\hline Ichwan, 2015 & $\begin{array}{l}\text { Adult triage criteria: non-elderly } \\
\leq 70 \text { years }\end{array}$ & Mortality & $98 \%$ (97 to 98$)$ & $39 \%$ (39 to 39$)$ & NR \\
\hline Ichwan, 2015 & $\begin{array}{l}\text { Adult triage criteria: elderly }>70 \\
\text { years }\end{array}$ & ISS $>15$ & $61 \%(60$ to 62$)$ & $61 \%(61$ to 62$)$ & NR \\
\hline Ichwan, 2015 & $\begin{array}{l}\text { Adult triage criteria: non-elderly } \\
\leq 70 \text { years }\end{array}$ & ISS $>15$ & $87 \%(86$ to 87$)$ & $44 \%$ (44 to 45$)$ & NR \\
\hline Imhoff, 2014 & $\begin{array}{l}\text { REMS (Rapid Emergency } \\
\text { Medicine Score) }\end{array}$ & Mortality, in-hospital & NR & NR & NR \\
\hline Imhoff, 2014 & RTS & Mortality, in-hospital & $\widehat{N R}$ & NR & $\widehat{N R}$ \\
\hline Imhoff, 2014 & $\mid \mathrm{SI}$ & Mortality, in-hospital & NR & NR & NR \\
\hline Jo, 2014 & $\begin{array}{l}\text { ViEWS-L (VitalPAC early } \\
\text { warning score-lactate): uses BP, } \\
\text { HR, RR, temperature, SpO2, } \\
\text { need for supplemental O2, CNS } \\
\text { grade not "alert", and lactate } \\
\text { level }\end{array}$ & Mortality, in-hospital & NR & NR & NR \\
\hline Jones, 2014 & SBP $<90$ & Mortality, 30-day & $\begin{array}{l}29.25 \%(24.96 \text { to } 33.83) \\
\text { calculated }\end{array}$ & $\begin{array}{l}97.41 \%(96.93 \text { to } 97.83) \\
\text { calculated }\end{array}$ & $\begin{array}{l}49.21 \%(43.59 \text { to } 54.85) \\
\text { calculated }\end{array}$ \\
\hline Jones, 2014 & $\mathrm{RR}<10$ or $>29$ & Mortality, 30-day & $\begin{array}{l}42.45 \% \text { (37.70 to } 47.31) \\
\text { calculated }\end{array}$ & $\begin{array}{l}93.70 \%(92.99 \text { to } 94.36) \\
\text { calculated }\end{array}$ & $\begin{array}{l}36.66 \%(33.15 \text { to } 40.31) \\
\text { calculated }\end{array}$ \\
\hline Jones, 2014 & T-RTS $<12$ & Mortality, 30-day & $\begin{array}{l}84.20 \%(80.37 \text { to } 87.54) \\
\text { calculated }\end{array}$ & $\begin{array}{l}77.22 \%(76.03 \text { to } 78.39) \\
\text { calculated }\end{array}$ & $\begin{array}{l}24.09 \%(22.91 \text { to } 25.31) \\
\text { calculated }\end{array}$ \\
\hline Jones, 2014 & T-RTS $\leq 8$ & Mortality, 30-day & $\begin{array}{l}54.01 \%(49.13 \text { to } 58.83) \\
\text { calculated }\end{array}$ & $\begin{array}{l}96.11 \%(95.54 \text { to } 96.63) \\
\text { calculated }\end{array}$ & $\begin{array}{l}54.39 \%(50.30 \text { to } 58.43) \\
\text { calculated }\end{array}$ \\
\hline Jones, 2014 & $\begin{array}{l}\text { Intubation status: derivation data } \\
\text { set }\end{array}$ & Mortality, 30-day & $\begin{array}{l}56.60 \%(51.74 \text { to } 61.38) \\
\text { calculated }\end{array}$ & $\begin{array}{l}84.92 \%(83.89 \text { to } 85.90) \\
\text { calculated }\end{array}$ & $\begin{array}{l}24.37 \%(22.46 \text { to } 26.38) \\
\text { calculated }\end{array}$ \\
\hline
\end{tabular}




\begin{tabular}{|c|c|c|c|c|c|}
\hline $\begin{array}{l}\text { Author, Year } \\
\text { (See Appendix B for } \\
\text { complete reference) }\end{array}$ & $\begin{array}{l}\text { Reported NPV } \\
(95 \% \mathrm{Cl})\end{array}$ & Reported PLR & Reported NLR & $\begin{array}{l}\text { AUROC Univariate } \\
\text { AUC }(95 \% \mathrm{Cl})\end{array}$ & $\begin{array}{l}\text { Other Measures of } \\
\text { Diagnostic Accuracy }\end{array}$ \\
\hline Ichwan, 2015 & NR & NR & NR & 0.58 (NR) & NR \\
\hline Ichwan, 2015 & NR & NR & NR & $0.62(\mathrm{NR})$ & NR \\
\hline Ichwan, 2015 & NR & NR & NR & $0.67(\mathrm{NR})$ & NR \\
\hline Ichwan, 2015 & NR & NR & NR & $0.68(\mathrm{NR})$ & NR \\
\hline Ichwan, 2015 & NR & NR & NR & $0.61(\mathrm{NR})$ & NR \\
\hline Ichwan, 2015 & NR & NR & NR & 0.65 (NR) & NR \\
\hline Imhoff, 2014 & NR & NR & NR & 0.91 (0.909 to 0.911$)$ & NR \\
\hline Imhoff, 2014 & NR & NR & NR & $0.89(0.889$ to 0.891$)$ & NR \\
\hline Imhoff, 2014 & NR & NR & NR & $0.55(0.54$ to 0.56$)$ & NR \\
\hline Jo, 2014 & NR & NR & NR & $0.838(0.771$ to 0.906$)$ & $\begin{array}{l}\text { Net reclassification } \\
\text { improvement: ViEWS-L vs. } \\
\text { TRISS, } 10 \% \text { cutoff for risk of } \\
\text { death: } 22.4 \%(95 \% \mathrm{CI}: 3.9 \text { to } \\
\text { 41), } p=0.04\end{array}$ \\
\hline Jones, 2014 & $\begin{array}{l}94.13 \%(93.78 \text { to } 94.46) \\
\text { calculated }\end{array}$ & $\begin{array}{l}11.28(9.00 \text { to } 14.15) \\
\text { calculated }\end{array}$ & $\begin{array}{l}0.73(0.68 \text { to } 0.77) \\
\text { calculated }\end{array}$ & NR & NR \\
\hline Jones, 2014 & $\begin{array}{l}94.99 \%(94.59 \text { to } 95.37) \\
\text { calculated }\end{array}$ & $\begin{array}{l}6.74(5.78 \text { to } 7.87) \\
\text { calculated }\end{array}$ & $\begin{array}{l}0.61(0.57 \text { to } 0.67) \\
\text { calculated }\end{array}$ & NR & NR \\
\hline Jones, 2014 & $\begin{array}{l}98.27 \%(97.86 \text { to } 98.61) \\
\text { calculated }\end{array}$ & $\begin{array}{l}3.70(3.46 \text { to } 3.95) \\
\text { calculated }\end{array}$ & $\begin{array}{l}0.20(0.16 \text { to } 0.26) \\
\text { calculated }\end{array}$ & NR & NR \\
\hline Jones, 2014 & $\begin{array}{l}96.05 \%(95.64 \text { to } 96.43) \\
\text { calculated }\end{array}$ & $\begin{array}{l}13.89(11.79 \text { to } 16.37) \\
\text { calculated }\end{array}$ & $\begin{array}{l}0.48(0.43 \text { to } 0.53) \\
\text { calculated }\end{array}$ & NR & NR \\
\hline Jones, 2014 & $\begin{array}{l}95.80 \%(95.33 \text { to } 96.22) \\
\text { calculated }\end{array}$ & $\begin{array}{l}3.75 \text { (3.37 to } 4.17) \\
\text { calculated }\end{array}$ & $\begin{array}{l}0.51(0.46 \text { to } 0.57) \\
\text { calculated }\end{array}$ & NR & NR \\
\hline
\end{tabular}




\begin{tabular}{|c|c|c|c|c|c|}
\hline $\begin{array}{l}\text { Author, Year } \\
\text { (See Appendix B for } \\
\text { complete reference) }\end{array}$ & Measure & Indicator of Serious Injury & $\begin{array}{l}\text { Reported Sensitivity } \\
(95 \% \mathrm{Cl})\end{array}$ & $\begin{array}{l}\text { Reported Specificity } \\
(95 \% \mathrm{Cl})\end{array}$ & $\begin{array}{l}\text { Reported PPV } \\
(95 \% \mathrm{Cl})\end{array}$ \\
\hline Joosse, 2014 & $\begin{array}{l}\text { EMTRAS (age, GCS, base } \\
\text { excess, prothrombin time): } \\
\text { center A }\end{array}$ & Mortality, in-hospital & NR & NR & NR \\
\hline Joosse, 2014 & $\begin{array}{l}\text { EMTRAS (age, GCS, base } \\
\text { excess, prothrombin time): } \\
\text { center B }\end{array}$ & Mortality, in-hospital & NR & NR & NR \\
\hline Joosse, 2014 & $\begin{array}{l}\text { EMTRAS (age, GCS, base } \\
\text { excess, prothrombin time): } \\
\text { patients with ISS } \geq 16 \text {, center A }\end{array}$ & Mortality, in-hospital & NR & NR & NR \\
\hline Joosse, 2014 & $\begin{array}{l}\text { EMTRAS (age, GCS, base } \\
\text { excess, prothrombin time): } \\
\text { patients with ISS } \geq 16 \text {, center B }\end{array}$ & Mortality, in-hospital & NR & NR & NR \\
\hline Joosse, 2014 & $\begin{array}{l}\text { EMTRAS (age, GCS, base } \\
\text { excess, prothrombin time): } \\
\text { patients with ISS }<16 \text {, center A }\end{array}$ & Mortality, in-hospital & NR & NR & NR \\
\hline Joosse, 2014 & $\begin{array}{l}\text { EMTRAS (age, GCS, base } \\
\text { excess, prothrombin time): } \\
\text { patients with ISS }<16 \text {, center B }\end{array}$ & Mortality, in-hospital & NR & NR & NR \\
\hline Khasawneh, 2014 & StO2 <65\% & Massive transfusion & $25 \%(9-49)$ & $94 \%(90-96)$ & $21 \%(8-44)$ \\
\hline Kim, 2016 & Age SI & Mortality: in-hospital & NR & NR & NR \\
\hline Kim, 2016 & Age SI & Mortality: ED & NR & NR & NR \\
\hline Kim, 2016 & Age SI $\geq 49$ & Mortality: in-hospital & $73.0 \%(\mathrm{NR})$ & $74.9 \%(\mathrm{NR})$ & NR \\
\hline Kim, 2016 & Age $\mathrm{SI} \geq 50$ & Mortality: in-hospital & $\begin{array}{l}69.42 \%(65.31 \text { to } 73.31) \\
\text { calculated }\end{array}$ & $\begin{array}{l}78.66 \%(78.28 \text { to } 79.03) \\
\text { calculated }\end{array}$ & $\begin{array}{l}3.68 \%(3.48 \text { to } 3.90) \\
\text { calculated }\end{array}$ \\
\hline Kim, 2016 & Age SI $\geq 50$ & Mortality: ED & NR & NR & NR \\
\hline Kim, 2016 & Age SI $\geq 55$ & Mortality: in-hospital & $62.1 \%(\mathrm{NR})$ & $87.1 \%(\mathrm{NR})$ & NR \\
\hline Kim, 2016 & Age SI: age $\geq 85$ & Mortality: ED & NR & NR & NR \\
\hline
\end{tabular}




\begin{tabular}{|c|c|c|c|c|c|}
\hline $\begin{array}{l}\text { Author, Year } \\
\text { (See Appendix B for } \\
\text { complete reference) }\end{array}$ & $\begin{array}{l}\text { Reported NPV } \\
(95 \% \mathrm{Cl})\end{array}$ & Reported PLR & Reported NLR & $\begin{array}{l}\text { AUROC Univariate } \\
\text { AUC }(95 \% \mathrm{Cl})\end{array}$ & $\begin{array}{l}\text { Other Measures of } \\
\text { Diagnostic Accuracy }\end{array}$ \\
\hline Joosse, 2014 & $\mathrm{NR}$ & NR & NR & $0.94(0.93$ to 0.96$)$ & NR \\
\hline Joosse, 2014 & NR & NR & NR & $0.92(0.90$ to 0.94$)$ & NR \\
\hline Joosse, 2014 & NR & NR & NR & $0.90(\mathrm{NR})$ & NR \\
\hline Joosse, 2014 & NR & NR & NR & 0.89 (NR) & NR \\
\hline Joosse, 2014 & NR & NR & NR & 0.94 (NR) & NR \\
\hline Joosse, 2014 & NR & NR & NR & $0.82(\mathrm{NR})$ & NR \\
\hline Khasawneh, 2014 & $95 \%(91-97)$ & NR & NR & NR & NR \\
\hline Kim, 2016 & NR & NR & NR & $\begin{array}{l}0.808(0.785 \text { to } 0.831) \text {, continuous } \\
\text { model }\end{array}$ & NR \\
\hline Kim, 2016 & NR & NR & NR & $\begin{array}{l}0.890(0.860 \text { to } 0.920) \text {, continuous } \\
\text { model }\end{array}$ & NR \\
\hline Kim, 2016 & NR & NR & NR & NR & NR \\
\hline Kim, 2016 & $\begin{array}{l}99.55 \%(99.48 \text { to } 99.60) \\
\text { calculated }\end{array}$ & $\begin{array}{l}3.25(3.07 \text { to } 3.45) \\
\text { calculated }\end{array}$ & $\begin{array}{l}0.39(0.34 \text { to } 0.44) \\
\text { calculated }\end{array}$ & $\begin{array}{l}0.740(0.721 \text { to } 0.760), \text { binary } \\
\text { model }\end{array}$ & NR \\
\hline Kim, 2016 & NR & NR & NR & $\begin{array}{l}0.807(0.780 \text { to } 0.834), \text { binary } \\
\text { model }\end{array}$ & NR \\
\hline Kim, 2016 & NR & NR & NR & NR & NR \\
\hline Kim, 2016 & NR & NR & NR & $\begin{array}{l}0.744(0.707 \text { to } 0.782), \text { binary } \\
\text { model } \\
0.909(0.857 \text { to } 0.962) \text {, continuous } \\
\text { model }\end{array}$ & NR \\
\hline
\end{tabular}




\begin{tabular}{|c|c|c|c|c|c|}
\hline $\begin{array}{l}\text { Author, Year } \\
\text { (See Appendix B for } \\
\text { complete reference) }\end{array}$ & Measure & Indicator of Serious Injury & $\begin{array}{l}\text { Reported Sensitivity } \\
(95 \% \mathrm{Cl})\end{array}$ & $\begin{array}{l}\text { Reported Specificity } \\
(95 \% \mathrm{Cl})\end{array}$ & $\begin{array}{l}\text { Reported PPV } \\
(95 \% \mathrm{Cl})\end{array}$ \\
\hline Kim, 2016 & Age SI: ages 65-74 & Mortality: ED & NR & NR & NR \\
\hline Kim, 2016 & Age SI: ages 75-84 & Mortality: ED & NR & NR & NR \\
\hline Kim, 2016 & Modified SI (HR/mean BP) & Mortality: in-hospital & NR & NR & NR \\
\hline Kim, 2016 & Modified SI (HR/mean BP) & Mortality: ED & NR & NR & NR \\
\hline Kim, 2016 & Modified SI $\geq 0.9(\mathrm{HR} /$ mean BP) & Mortality: in-hospital & $75.8 \%(\mathrm{NR})$ & $65.4 \%(\mathrm{NR})$ & NR \\
\hline Kim, 2016 & Modified SI $\geq 1.1$ (HR/mean BP) & Mortality: in-hospital & $55.9 \%(\mathrm{NR})$ & $90.9 \%(\mathrm{NR})$ & NR \\
\hline Kim, 2016 & Modified SI $\geq 1.3(\mathrm{HR} /$ mean BP) & Mortality: in-hospital & $\begin{array}{l}38.65 \%(34.49 \text { to } 42.93) \\
\text { calculated }\end{array}$ & $\begin{array}{l}97.77 \%(97.63 \text { to } 97.90) \\
\text { calculated }\end{array}$ & $\begin{array}{l}16.91 \%(15.25 \text { to } 18.71) \\
\text { calculated }\end{array}$ \\
\hline Kim, 2016 & Modified SI $\geq 1.3(\mathrm{HR} /$ mean BP) & Mortality: ED & NR & NR & NR \\
\hline Kim, 2016 & SI & Mortality: in-hospital & NR & NR & NR \\
\hline Kim, 2016 & $\mathrm{SI}$ & Mortality: ED & NR & NR & NR \\
\hline Kim, 2016 & $\mathrm{SI} \geq 0.7$ & Mortality: in-hospital & $70.0 \%(\mathrm{NR})$ & $73.6 \%(\mathrm{NR})$ & NR \\
\hline Kim, 2016 & SI $\geq 0.8$ & Mortality: in-hospital & $58.5 \%(N R)$ & $89.4 \%(\mathrm{NR})$ & NR \\
\hline Kim, 2016 & $\mathrm{SI} \geq 1$ & Mortality: in-hospital & $\begin{array}{l}36.59 \%(32.49 \text { to } 40.83) \\
\text { calculated }\end{array}$ & $\begin{array}{l}98.23 \%(98.11 \text { to } 98.35) \\
\text { calculated }\end{array}$ & $\begin{array}{l}19.58 \%(17.60 \text { to } 21.73) \\
\text { calculated }\end{array}$ \\
\hline Kim, 2016 & $\mathrm{SI} \geq 1$ & Mortality: ED & NR & NR & NR \\
\hline King, 1996 & $S I \geq 0.83$ & $\begin{array}{l}\text { Severe injury: mortality <24 hour, } \\
\text { ISS } \geq 16 \text {, ICU admission or blood } \\
\text { transfusion } \geq 2 \text { units }\end{array}$ & $37 \%$ (33 to 42$)$ & $83 \%(80$ to 87$)$ & $73 \%(67$ to 77$)$ \\
\hline King, 1996 & $\mathrm{SI} \geq 1.10$ & Mortality: 24-hour & $57 \%(20$ to 94$)$ & $94 \%(92$ to 95$)$ & $5 \%(0$ to 10$)$ \\
\hline King, 1996 & $\mathrm{SI} \geq 0.71$ & ISS $\geq 16$ & $65 \%$ (59 to 71$)$ & $57 \%(54$ to 61$)$ & $32 \%(28$ to 36$)$ \\
\hline King, 1996 & SI $\geq 0.77$ & ICU admission & $44 \%$ (40 to 48$)$ & $73 \%(69$ to 76$)$ & $57 \%(52$ to 62$)$ \\
\hline King, 1996 & $\mathrm{SI} \geq 0.85$ & Blood transfusion $\geq 2$ units & $54 \%(46$ to 63$)$ & $80 \%$ (77 to 83$)$ & $29 \%(23$ to 35$)$ \\
\hline King, 1996 & $\mathrm{HR} \geq 112$ & Mortality: 24-hour & $43 \%(6$ to 80$)$ & $82 \%(80$ to 84$)$ & $2 \%(0$ to 3$)$ \\
\hline
\end{tabular}




\begin{tabular}{|c|c|c|c|c|c|}
\hline $\begin{array}{l}\text { Author, Year } \\
\text { (See Appendix B for } \\
\text { complete reference) } \\
\end{array}$ & $\begin{array}{l}\text { Reported NPV } \\
(95 \% \mathrm{Cl})\end{array}$ & Reported PLR & Reported NLR & $\begin{array}{l}\text { AUROC Univariate } \\
\text { AUC }(95 \% \mathrm{CI})\end{array}$ & \begin{tabular}{|l} 
Other Measures of \\
Diagnostic Accuracy
\end{tabular} \\
\hline Kim, 2016 & NR & NR & NR & $\begin{array}{l}0.816(0.773 \text { to } 0.860), \text { binary } \\
\text { model } \\
0.876(0.824 \text { to } 0.927), \text { continuous } \\
\text { model }\end{array}$ & NR \\
\hline Kim, 2016 & NR & NR & NR & $\begin{array}{l}0.779(0.738 \text { to } 0.821), \text { binary } \\
\text { model } \\
0.882(0.828 \text { to } 0.926) \text {, continuous } \\
\text { model }\end{array}$ & NR \\
\hline Kim, 2016 & NR & NR & NR & $\begin{array}{l}0.788 \text { ( } 0.765 \text { to } 0.812) \text {, continuous } \\
\text { model }\end{array}$ & NR \\
\hline Kim, 2016 & NR & NR & NR & $\begin{array}{l}0.884 \text { ( } 0.853 \text { to } 0.915), \text { continuous } \\
\text { model }\end{array}$ & NR \\
\hline Kim, 2016 & NR & NR & NR & NR & NR \\
\hline Kim, 2016 & NR & NR & NR & NR & NR \\
\hline Kim, 2016 & $\begin{array}{l}99.27 \%(99.22 \text { to } 99.32) \\
\text { calculated }\end{array}$ & $\begin{array}{l}17.32(15.31 \text { to } 19.59) \\
\text { calculated }\end{array}$ & $\begin{array}{l}0.63(0.59 \text { to } 0.67) \\
\text { calculated }\end{array}$ & $\begin{array}{l}0.682(0.661 \text { to } 0.703), \text { binary } \\
\text { model }\end{array}$ & NR \\
\hline Kim, 2016 & NR & NR & NR & $\begin{array}{l}0.779(0.744 \text { to } 0.814), \text { binary } \\
\text { model }\end{array}$ & NR \\
\hline Kim, 2016 & NR & NR & NR & $\begin{array}{l}0.786 \text { ( } 0.762 \text { to } 0.810), \text { continuous } \\
\text { model }\end{array}$ & NR \\
\hline Kim, 2016 & NR & NR & NR & $\begin{array}{l}0.880 \text { ( } 0.848 \text { to } 0.911) \text {, continuous } \\
\text { model }\end{array}$ & NR \\
\hline Kim, 2016 & NR & NR & NR & NR & NR \\
\hline Kim, 2016 & NR & NR & NR & NR & NR \\
\hline Kim, 2016 & $\begin{array}{l}99.25 \%(99.20 \text { to } 99.29) \\
\text { calculated }\end{array}$ & $\begin{array}{l}20.71(18.17 \text { to } 23.61) \\
\text { calculated }\end{array}$ & $\begin{array}{l}0.65(0.61 \text { to } 0.69) \\
\text { calculated }\end{array}$ & $\begin{array}{l}0.674(0.654 \text { to } 0.695), \text { binary } \\
\text { model }\end{array}$ & NR \\
\hline Kim, 2016 & NR & NR & NR & $\begin{array}{l}0.771(0.735 \text { to } 0.806), \text { binary } \\
\text { model }\end{array}$ & NR \\
\hline King, 1996 & $53 \%$ (50 to 57 ) & NR & NR & 0.61 (SD 0.02) & NR \\
\hline King, 1996 & $99 \%$ (99 to 100$)$ & NR & NR & 0.75 (SD 0.10) & Accuracy: $93 \%$ (92 to 95) \\
\hline King, 1996 & $84 \%$ (81 to 87$)$ & NR & NR & 0.62 (SD 0.02) & Accuracy: $60 \%$ (56 to 62 ) \\
\hline King, 1996 & $61 \%$ (57 to 64$)$ & NR & NR & 0.58 (SD 0.02) & Accuracy: $60 \%$ (57 to 62 ) \\
\hline King, 1996 & $92 \%$ (90 to 94$)$ & NR & NR & 0.70 (SD 0.03) & Accuracy: $77 \%$ (74 to 79$)$ \\
\hline King, 1996 & $99 \%$ (99 to 100) & NR & NR & NR & Accuracy: $82 \%$ (80 to 84$)$ \\
\hline
\end{tabular}




\begin{tabular}{|c|c|c|c|c|c|}
\hline $\begin{array}{l}\text { Author, Year } \\
\text { (See Appendix B for } \\
\text { complete reference) }\end{array}$ & Measure & Indicator of Serious Injury & $\begin{array}{l}\text { Reported Sensitivity } \\
(95 \% \mathrm{Cl})\end{array}$ & $\begin{array}{l}\text { Reported Specificity } \\
(95 \% \mathrm{Cl})\end{array}$ & $\begin{array}{l}\text { Reported PPV } \\
(95 \% \mathrm{Cl})\end{array}$ \\
\hline King, 1996 & $\mathrm{HR} \geq 102$ & ISS $\geq 16$ & $41 \%$ (35 to 47$)$ & $71 \%(68$ to 75$)$ & $30 \%(26$ to 35$)$ \\
\hline King, 1996 & $\mathrm{HR} \geq 109$ & ICU admission & $27 \%(23$ to 31$)$ & $83 \%(80$ to 86$)$ & $58 \%(52$ to 64$)$ \\
\hline King, 1996 & $\mathrm{HR} \geq 113$ & Blood transfusion $\geq 2$ units & $36 \%(28$ to 44$)$ & $87 \%$ (85 to 89$)$ & $29 \%(22$ to 36$)$ \\
\hline King, 1996 & SBP $\leq 104$ & Mortality: 24-hour & $100 \%(100$ to 100$)$ & $91 \%$ (89 to 92$)$ & $6 \%(2$ to 11$)$ \\
\hline King, 1996 & SBP $\leq 127$ & ISS $\geq 16$ & $56 \%(50$ to 62$)$ & $64 \%$ (61 to 68$)$ & $33 \%(28$ to 37$)$ \\
\hline King, 1996 & $\mathrm{SBP} \leq 119$ & ICU admission & $33 \%(29$ to 37$)$ & $80 \%$ (76 to 83$)$ & $57 \%(52$ to 63$)$ \\
\hline King, 1996 & SBP $\leq 120$ & Blood transfusion $\geq 2$ units & $51 \%(42$ to 59$)$ & $77 \%$ (74 to 80$)$ & $25 \%(20$ to 30$)$ \\
\hline King, 2009 & Heart rate variability: SDNN & Life-saving intervention in OR & NR & NR & NR \\
\hline King, 2009 & $\begin{array}{l}\text { Heart rate variability: SDNN }<24 \\
\text { msec }\end{array}$ & Life-saving intervention in OR & $80 \%(\mathrm{NR})$ & $75 \%(N R)$ & $33 \%(\mathrm{NR})$ \\
\hline King, 2009 & Heart rate variability: SDNN & Serious injury & NR & NR & NR \\
\hline King, 2009 & $\begin{array}{l}\text { Heart rate variability: SDNN }<39 \\
\text { msec }\end{array}$ & Serious injury & $80 \%(\mathrm{NR})$ & NR & $63 \%(\mathrm{NR})$ \\
\hline King, 2009 & $\begin{array}{l}\text { Heart rate variability: SDNN }<55 \\
\text { msec }\end{array}$ & Serious injury & $94 \%(N R)$ & NR & $59 \%(N R)$ \\
\hline Kondo, 2011 & $\begin{array}{l}\text { GAP score (Glasgow coma } \\
\text { scale, Age, Systolic blood } \\
\text { pressure) }\end{array}$ & Mortality, in ED or OR & NR & NR & NR \\
\hline Kondo, 2011 & $\begin{array}{l}\text { GAP score (Glasgow coma } \\
\text { scale, Age, Systolic blood } \\
\text { pressure); severe trauma } \\
\text { subgroup }(\text { ISS }>16)\end{array}$ & Mortality, in ED or OR & NR & NR & NR \\
\hline Kondo, 2011 & $\begin{array}{l}\text { MGAP score (Mechanism, } \\
\text { Glasgow coma scale, Age, } \\
\text { Systolic blood pressure) }\end{array}$ & Mortality, in ED or OR & NR & NR & NR \\
\hline Kondo, 2011 & RTS & Mortality, in ED or OR & NR & NR & NR \\
\hline Kondo, 2011 & T-RTS & Mortality, in ED or OR & NR & NR & NR \\
\hline Kondo, 2011 & GAP score & Mortality, in-hospital & NR & NR & NR \\
\hline Kondo, 2011 & $\begin{array}{l}\text { GAP score ); severe trauma } \\
\text { subgroup (ISS >16) }\end{array}$ & Mortality, in-hospital & NR & NR & NR \\
\hline Kondo, 2011 & MGAP score & Mortality, in-hospital & NR & NR & NR \\
\hline Kondo, 2011 & RTS & Mortality, in-hospital & NR & NR & NR \\
\hline Kondo, 2011 & T-RTS & Mortality, in-hospital & NR & NR & NR \\
\hline Kuo, 2016 & Reverse SI <1: overall & Mortality, in-hospital & $\begin{array}{l}11.32 \%(5.99 \text { to } 18.94) \\
\text { calculated }\end{array}$ & $\begin{array}{l}96.80 \%(96.53 \text { to } 97.05) \\
\text { calculated }\end{array}$ & $\begin{array}{l}2.05 \%(1.21 \text { to } 3.47) \\
\text { calculated }\end{array}$ \\
\hline Kuo, 2016 & Reverse SI <1: overall & ISS $\geq 16$ & $\begin{array}{l}4.66 \%(3.70 \text { to } 5.77) \\
\text { calculated }\end{array}$ & $\begin{array}{l}96.89 \%(96.62 \text { to } 97.16) \\
\text { calculated }\end{array}$ & $\begin{array}{l}13.50 \%(11.02 \text { to } 16.45) \\
\text { calculated }\end{array}$ \\
\hline
\end{tabular}




\begin{tabular}{|c|c|c|c|c|c|}
\hline $\begin{array}{l}\text { Author, Year } \\
\text { (See Appendix B for } \\
\text { complete reference) }\end{array}$ & $\begin{array}{l}\text { Reported NPV } \\
(95 \% \mathrm{Cl})\end{array}$ & Reported PLR & Reported NLR & $\begin{array}{l}\text { AUROC Univariate } \\
\text { AUC }(95 \% \mathrm{CI})\end{array}$ & $\begin{array}{l}\text { Other Measures of } \\
\text { Diagnostic Accuracy }\end{array}$ \\
\hline King, 1996 & $80 \%$ (77 to 83$)$ & $\mathrm{NR}$ & NR & NR & Accuracy: $64 \%$ (61 to 67 ) \\
\hline King, 1996 & $58 \%(55$ to 61$)$ & NR & NR & NR & Accuracy: $58 \%$ (55 to 61 ) \\
\hline King, 1996 & $90 \%$ (88 to 92$)$ & NR & NR & NR & Accuracy: $80 \%$ (78 to 83) \\
\hline King, 1996 & $100 \%(100$ to 100$)$ & NR & NR & NR & Accuracy: $91 \%$ (89 to 92) \\
\hline King, 1996 & $83 \%(80$ to 86$)$ & NR & NR & NR & Accuracy: $62 \%$ (60 to 75$)$ \\
\hline King, 1996 & $59 \%$ (55 to 62$)$ & NR & NR & NR & Accuracy: $58 \%$ (55 to 61 ) \\
\hline King, 1996 & $91 \%$ (89 to 93) & NR & NR & NR & Accuracy: $73 \%$ (71 to 76) \\
\hline King, 2009 & NR & NR & NR & $0.74(\mathrm{NR})$ & NR \\
\hline King, 2009 & $96 \%(N R)$ & NR & NR & NR & Overall accuracy: $76 \%$ \\
\hline King, 2009 & NR & NR & NR & $0.80(\mathrm{NR})$ & NR \\
\hline King, 2009 & NR & NR & NR & NR & Over-triage rate: $37 \%$ \\
\hline King, 2009 & NR & NR & NR & NR & Over-triage rate: $41 \%$ \\
\hline Kondo, 2011 & NR & NR & NR & 0.965 (NR) & NR \\
\hline Kondo, 2011 & NR & NR & NR & $0.943(\mathrm{NR})$ & NR \\
\hline Kondo, 2011 & NR & NR & NR & 0.954 (NR) & NR \\
\hline Kondo, 2011 & NR & NR & NR & 0.966 (NR) & NR \\
\hline Kondo, 2011 & NR & NR & NR & 0.968 (NR) & NR \\
\hline Kondo, 2011 & NR & NR & NR & 0.933 (NR) & NR \\
\hline Kondo, 2011 & NR & NR & NR & 0.905 (NR) & NR \\
\hline Kondo, 2011 & NR & NR & NR & $0.924(\mathrm{NR})$ & NR \\
\hline Kondo, 2011 & NR & NR & NR & 0.919 (NR) & NR \\
\hline Kondo, 2011 & NR & NR & NR & $0.917(\mathrm{NR})$ & NR \\
\hline Kuo, 2016 & $\begin{array}{l}99.46 \%(99.42 \text { to } 99.50) \\
\text { calculated }\end{array}$ & $\begin{array}{l}3.53(2.06 \text { to } 6.06) \\
\text { calculated }\end{array}$ & $\begin{array}{l}0.92(0.86 \text { to } 0.98) \\
\text { calculated }\end{array}$ & NR & NR \\
\hline Kuo, 2016 & $\begin{array}{l}90.71 \%(90.62 \text { to } 90.80) \\
\text { calculated }\end{array}$ & $\begin{array}{l}1.50(1.19 \text { to } 1.89) \\
\text { calculated }\end{array}$ & $\begin{array}{l}0.98(0.97 \text { to } 0.99) \\
\text { calculated }\end{array}$ & NR & NR \\
\hline
\end{tabular}




\begin{tabular}{|c|c|c|c|c|c|}
\hline $\begin{array}{l}\text { Author, Year } \\
\text { (See Appendix B for } \\
\text { complete reference) }\end{array}$ & Measure & Indicator of Serious Injury & $\begin{array}{l}\text { Reported Sensitivity } \\
(95 \% \mathrm{Cl})\end{array}$ & $\begin{array}{l}\text { Reported Specificity } \\
(95 \% \mathrm{Cl})\end{array}$ & $\begin{array}{l}\text { Reported PPV } \\
(95 \% \mathrm{Cl})\end{array}$ \\
\hline Kuo, 2016 & Reverse $\mathrm{SI}<1$ : adults 18-65 & Mortality, in-hospital & $\begin{array}{l}7.89 \%(1.66 \text { to } 21.38) \\
\text { calculated }\end{array}$ & $\begin{array}{l}98.66 \%(98.43 \text { to } 98.86) \\
\text { calculated }\end{array}$ & $\begin{array}{l}1.90 \%(0.64 \text { to } 5.48) \\
\text { calculated }\end{array}$ \\
\hline Kuo, 2016 & Reverse $\mathrm{SI}<1$ : adults 18-65 & ISS $\geq 16$ & $\begin{array}{l}4.11 \%(2.99 \text { to } 5.50) \\
\text { calculated }\end{array}$ & $\begin{array}{l}98.91 \%(98.69 \text { to } 99.10) \\
\text { calculated }\end{array}$ & $\begin{array}{l}27.22 \%(20.24 \text { to } 34.54) \\
\text { calculated }\end{array}$ \\
\hline Kuo, 2016 & Reverse $\mathrm{SI}<1$ : adults 18-65 & Blood transfusion in ED & $\begin{array}{l}9.19 \%(6.09 \text { to } 13.17) \\
\text { calculated }\end{array}$ & $\begin{array}{l}96.84 \% \text { (96.58 to } 97.10) \\
\text { calculated }\end{array}$ & $\begin{array}{l}4.44 \%(3.10 \text { to } 6.34) \\
\text { calculated }\end{array}$ \\
\hline Lai, 2016 & Reverse $\mathrm{SI}<1$, EMS & Blood transfusion & $\begin{array}{l}14.39 \%(8.89 \text { to } 21.56) \\
\text { calculated }\end{array}$ & $\begin{array}{l}96.48 \%(95.83 \text { to } 97.06) \\
\text { calculated }\end{array}$ & $\begin{array}{l}13.10 \%(8.77 \text { to } 19.13) \\
\text { calculated }\end{array}$ \\
\hline Lai, 2016 & Reverse $\mathrm{SI}<1$, ED & Blood transfusion & $\begin{array}{l}27.27 \%(19.89 \text { to } 35.71) \\
\text { calculated }\end{array}$ & $\begin{array}{l}97.32 \%(96.74 \text { to } 97.82) \\
\text { calculated }\end{array}$ & $\begin{array}{l}27.27 \%(21.04 \text { to } 34.54) \\
\text { calculated }\end{array}$ \\
\hline Lai, 2016 & Reverse $\mathrm{SI}<1$, EMS & ISS $\geq 16$ & $\begin{array}{l}5.94 \%(4.38 \text { to } 7.85) \\
\text { calculated }\end{array}$ & $\begin{array}{l}96.63 \%(95.92 \text { to } 97.26) \\
\text { calculated }\end{array}$ & $\begin{array}{l}31.72 \%(24.84 \text { to } 39.51) \\
\text { calculated }\end{array}$ \\
\hline Lai, 2016 & Reverse $\mathrm{SI}<1$, EMS & Mortality & $\begin{array}{l}6.52 \%(1.37 \text { to } 17.90) \\
\text { calculated }\end{array}$ & $\begin{array}{l}96.13 \%(95.45 \text { to } 96.73) \\
\text { calculated }\end{array}$ & $\begin{array}{l}2.07 \%(0.69 \text { to } 6.00) \\
\text { calculated }\end{array}$ \\
\hline Lai, 2016 & Reverse $\mathrm{SI}<1$, ED & ISS $\geq 16$ & $\begin{array}{l}7.88 \%(6.08 \text { to } 10.01) \\
\text { calculated }\end{array}$ & $\begin{array}{l}97.59 \%(96.96 \text { to } 98.11) \\
\text { calculated }\end{array}$ & $\begin{array}{l}46.21 \%(38.11 \text { to } 54.51) \\
\text { calculated }\end{array}$ \\
\hline Lai, 2016 & Reverse $\mathrm{SI}<1$, ED & Mortality & $\begin{array}{l}28.26 \% \text { (15.99 to } 43.46) \\
\text { calculated }\end{array}$ & $\begin{array}{l}96.76 \%(96.13 \text { to } 97.31) \\
\text { calculated }\end{array}$ & $\begin{array}{l}9.85 \%(6.25 \text { to } 15.17) \\
\text { calculated }\end{array}$ \\
\hline Lalezarzadeh, 2009 & SBP $\leq 80$, EMS & ICU admission & $\begin{array}{l}5.33 \%(4.33 \text { to } 6.49) \\
\text { calculated }\end{array}$ & $\begin{array}{l}96.48 \% \text { (95.95 to } 96.97) \\
\text { calculated }\end{array}$ & $\begin{array}{l}33.94 \%(28.72 \text { to } 39.57) \\
\text { calculated }\end{array}$ \\
\hline Lalezarzadeh, 2009 & SBP $\leq 100$, EMS & ICU admission & $\begin{array}{l}16.74 \%(15.03 \text { to } 18.57) \\
\text { calculated }\end{array}$ & $\begin{array}{l}86.74 \%(85.78 \text { to } 87.65) \\
\text { calculated }\end{array}$ & $\begin{array}{l}29.95 \%(27.39 \text { to } 32.64) \\
\text { calculated }\end{array}$ \\
\hline Lalezarzadeh, 2009 & $\mathrm{SBP} \leq 90, \mathrm{ED}$ & ICU admission & $\begin{array}{l}3.92 \%(3.06 \text { to } 4.93) \\
\text { calculated }\end{array}$ & $\begin{array}{l}97.96 \%(97.54 \text { to } 98.33) \\
\text { calculated }\end{array}$ & $\begin{array}{l}39.43 \% \text { (32.57 to } 46.73) \\
\text { calculated }\end{array}$ \\
\hline Lalezarzadeh, 2009 & $\mathrm{SBP} \leq 80, \mathrm{EMS}$ & Mortality & $\begin{array}{l}24.04 \% \text { (18.40 to } 30.43) \\
\text { calculated }\end{array}$ & $\begin{array}{l}96.64 \% \text { (96.18 to } 97.06) \\
\text { calculated }\end{array}$ & $\begin{array}{l}18.05 \%(14.35 \text { to } 22.45) \\
\text { calculated }\end{array}$ \\
\hline
\end{tabular}




\begin{tabular}{|c|c|c|c|c|c|}
\hline $\begin{array}{l}\text { Author, Year } \\
\text { (See Appendix B for } \\
\text { complete reference) }\end{array}$ & $\begin{array}{l}\text { Reported NPV } \\
(95 \% \mathrm{Cl})\end{array}$ & Reported PLR & Reported NLR & $\begin{array}{l}\text { AUROC Univariate } \\
\text { AUC }(95 \% \mathrm{CI})\end{array}$ & $\begin{array}{l}\text { Other Measures of } \\
\text { Diagnostic Accuracy }\end{array}$ \\
\hline Kuo, 2016 & $\begin{array}{l}99.69 \%(99.66 \text { to } 99.72) \\
\text { calculated }\end{array}$ & $\begin{array}{l}5.88(1.96 \text { to } 17.62) \\
\text { calculated }\end{array}$ & $\begin{array}{l}0.93(0.85 \text { to } 1.02) \\
\text { Calculated }\end{array}$ & NR & NR \\
\hline Kuo, 2016 & $\begin{array}{l}\text { 91.23\% (91.13 to } 91.33) \\
\text { calculated }\end{array}$ & $\begin{array}{l}3.77 \text { (2.67 to 5.32) } \\
\text { calculated }\end{array}$ & $\begin{array}{l}0.97 \text { (0.96 to 0.98) } \\
\text { Calculated }\end{array}$ & NR & NR \\
\hline Kuo, 2016 & $\begin{array}{l}98.52 \%(98.47 \text { to } 98.58) \\
\text { calculated }\end{array}$ & $\begin{array}{l}2.91(2.00 \text { to } 4.24) \\
\text { calculated }\end{array}$ & $\begin{array}{l}0.94(0.90 \text { to } 0.97) \\
\text { Calculated }\end{array}$ & NR & NR \\
\hline Lai, 2016 & $\begin{array}{l}96.83 \%(96.61 \text { to } 97.04) \\
\text { calculated }\end{array}$ & $\begin{array}{l}4.09(2.61 \text { to } 6.42) \\
\text { calculated }\end{array}$ & $\begin{array}{l}0.89(0.83 \text { to } 0.95) \\
\text { Calculated }\end{array}$ & NR & NR \\
\hline Lai, 2016 & $\begin{array}{l}\text { 97.32\% (97.03 to } 97.58) \\
\text { calculated }\end{array}$ & $\begin{array}{l}10.18 \text { (7.23 to } 14.32) \\
\text { calculated }\end{array}$ & $\begin{array}{l}0.75(0.67 \text { to } 0.83) \\
\text { Calculated }\end{array}$ & NR & NR \\
\hline Lai, 2016 & $\begin{array}{l}79.61 \%(79.30 \text { to } 79.91) \\
\text { calculated }\end{array}$ & $\begin{array}{l}1.77(1.26 \text { to } 2.48) \\
\text { calculated }\end{array}$ & $\begin{array}{l}0.97(0.96 \text { to } 0.99) \\
\text { Calculated }\end{array}$ & NR & NR \\
\hline Lai, 2016 & $\begin{array}{l}98.80 \%(98.70 \text { to } 98.88) \\
\text { calculated }\end{array}$ & $\begin{array}{l}1.69(0.56 \text { to } 5.09) \\
\text { calculated }\end{array}$ & $\begin{array}{l}0.97(0.90 \text { to } 1.05) \\
\text { Calculated }\end{array}$ & NR & NR \\
\hline Lai, 2016 & $\begin{array}{l}80.10 \%(79.76 \text { to } 80.44) \\
\text { calculated }\end{array}$ & $\begin{array}{l}3.26(2.34 \text { to } 4.55) \\
\text { calculated }\end{array}$ & $\begin{array}{l}0.94(0.92 \text { to } 0.96) \\
\text { Calculated }\end{array}$ & NR & NR \\
\hline Lai, 2016 & $\begin{array}{l}99.08 \% \text { (98.90 to } 99.23) \\
\text { calculated }\end{array}$ & $\begin{array}{l}8.71(5.32 \text { to } 14.27) \\
\text { calculated }\end{array}$ & $\begin{array}{l}0.74(0.62 \text { to } 0.89) \\
\text { Calculated }\end{array}$ & NR & NR \\
\hline Lalezarzadeh, 2009 & $\begin{array}{l}75.06 \% \text { ( } 74.83 \text { to } 75.28) \\
\text { calculated }\end{array}$ & $\begin{array}{l}1.52(1.19 \text { to } 1.93) \\
\text { calculated }\end{array}$ & $\begin{array}{l}0.98(0.97 \text { to } 0.99) \\
\text { Calculated }\end{array}$ & NR & NR \\
\hline Lalezarzadeh, 2009 & $\begin{array}{l}75.46 \% \text { (75.03 to } 75.90) \\
\text { calculated }\end{array}$ & $\begin{array}{l}1.26(1.11 \text { to } 1.43) \\
\text { calculated }\end{array}$ & $\begin{array}{l}0.96(0.94 \text { to } 0.98) \\
\text { Calculated }\end{array}$ & NR & NR \\
\hline Lalezarzadeh, 2009 & $\begin{array}{l}75.06 \% \text { ( } 74.87 \text { to } 75.25) \\
\text { calculated }\end{array}$ & $\begin{array}{l}1.92(1.43 \text { to } 2.59) \\
\text { calculated }\end{array}$ & $\begin{array}{l}0.98 \text { (0.97 to } 0.99) \\
\text { Calculated }\end{array}$ & NR & NR \\
\hline Lalezarzadeh, 2009 & $\begin{array}{l}97.64 \% \text { (97.45 to } 97.81) \\
\text { calculated }\end{array}$ & $\begin{array}{l}7.15(5.44 \text { to } 9.40) \\
\text { calculated }\end{array}$ & $\begin{array}{l}0.79(0.73 \text { to } 0.85) \\
\text { Calculated }\end{array}$ & NR & NR \\
\hline
\end{tabular}




\begin{tabular}{|c|c|c|c|c|c|}
\hline $\begin{array}{l}\text { Author, Year } \\
\text { (See Appendix B for } \\
\text { complete reference) }\end{array}$ & Measure & Indicator of Serious Injury & $\begin{array}{l}\text { Reported Sensitivity } \\
(95 \% \mathrm{Cl})\end{array}$ & $\begin{array}{l}\text { Reported Specificity } \\
(95 \% \mathrm{Cl})\end{array}$ & $\begin{array}{l}\text { Reported PPV } \\
(95 \% \mathrm{Cl})\end{array}$ \\
\hline Lalezarzadeh, 2009 & SBP $\leq 100$, EMS & Mortality & $\begin{array}{l}38.46 \%(31.82 \text { to } 45.44) \\
\text { calculated }\end{array}$ & $\begin{array}{l}86.6 \%(85.77 \text { to } 87.41) \\
\text { calculated }\end{array}$ & $\begin{array}{l}8.12 \%(6.86 \text { to } 9.59) \\
\text { calculated }\end{array}$ \\
\hline Lalezarzadeh, 2009 & $\mathrm{SBP} \leq 90, \mathrm{ED}$ & Mortality & $\begin{array}{l}23.56 \% \text { (17.97 to } 29.92) \\
\text { calculated }\end{array}$ & $\begin{array}{l}98.13 \%(97.78 \text { to } 98.44) \\
\text { Calculated }\end{array}$ & $\begin{array}{l}28 \%(22.37 \text { to } 34.42) \\
\text { calculated }\end{array}$ \\
\hline Lalezarzadeh, 2009 & $\mathrm{SBP} \leq 80, \mathrm{EMS}$ & Operative intervention & $\begin{array}{l}9.6 \% \text { ( } 7.96 \text { to } 11.45) \\
\text { calculated }\end{array}$ & $\begin{array}{l}97.14 \% \text { (96.68 to } 97.56) \\
\text { Calculated }\end{array}$ & $\begin{array}{l}40.07 \%(34.65 \text { to } 45.75) \\
\text { calculated }\end{array}$ \\
\hline Lalezarzadeh, 2009 & SBP $\leq 100$, EMS & Operative intervention & $\begin{array}{l}23.1 \%(20.70 \text { to } 25.64) \\
\text { calculated }\end{array}$ & $\begin{array}{l}87.64 \% \text { (86.76 to } 88.47 \text { ) } \\
\text { Calculated }\end{array}$ & $\begin{array}{l}27.11 \%(24.70 \text { to } 29.66) \\
\text { calculated }\end{array}$ \\
\hline Lalezarzadeh, 2009 & $\mathrm{SBP} \leq 90, \mathrm{ED}$ & Operative intervention & $\begin{array}{l}6.23 \%(4.90 \text { to } 7.78) \\
\text { calculated }\end{array}$ & $\begin{array}{l}98.23 \%(97.85 \text { to } 98.55) \\
\text { Calculated }\end{array}$ & $\begin{array}{l}41.14 \%(34.24 \text { to } 48.41) \\
\text { calculated }\end{array}$ \\
\hline Lee, 2014 & Abnormal RR (age-specific) & Major trauma & $53.8 \%(\mathrm{NR})$ & $60.6 \%(\mathrm{NR})$ & $35 \%(N R)$ \\
\hline Lee, 2014 & $\begin{array}{l}\text { Combined criteria (PTS } \leq 8, \text { GCS } \\
\leq 10, \text { Abnormal RR) }\end{array}$ & Major trauma & $69.2 \%(\mathrm{NR})$ & $53 \%(\mathrm{NR})$ & $36.7 \%(\mathrm{NR})$ \\
\hline Lee, 2014 & GCS $\leq 10$ & Major trauma & $26.9 \%(\mathrm{NR})$ & $100 \%(\mathrm{NR})$ & $100 \%(\mathrm{NR})$ \\
\hline Lee, 2014 & PTS $\leq 8$ & Major trauma & $61.5 \%(\mathrm{NR})$ & $77.3 \%(\mathrm{NR})$ & $51.6 \%(\mathrm{NR})$ \\
\hline Lee, 2014 & Abnormal RR (age-specific) & Receipt of resuscitation in the ED & $76.2 \%(\mathrm{NR})$ & $66.2 \%(\mathrm{NR})$ & $40 \%(N R)$ \\
\hline Lee, 2014 & $\begin{array}{l}\text { Combined criteria (PTS } \leq 8, \text { GCS } \\
\leq 10, \text { Abnormal RR) }\end{array}$ & Receipt of resuscitation in the ED & $90.5 \%(\mathrm{NR})$ & $57.7 \%(\mathrm{NR})$ & $38.8 \%(\mathrm{NR})$ \\
\hline Lee, 2014 & GCS $\leq 10$ & Receipt of resuscitation in the ED & $28.6 \%(\mathrm{NR})$ & $98.6 \%(\mathrm{NR})$ & $85.7 \%(\mathrm{NR})$ \\
\hline Lee, 2014 & PTS $\leq 8$ & Receipt of resuscitation in the ED & $90.5 \%(\mathrm{NR})$ & $83.1 \%(\mathrm{NR})$ & $61.3 \%(\mathrm{NR})$ \\
\hline Lehmann, 2007 & SBP $<90$, ED & Emergent intervention & $\begin{array}{l}20.74 \% \text { (15.19 to } 27.25) \\
\text { calculated }\end{array}$ & $\begin{array}{l}95.96 \% \text { (94.66 to } 97.02) \\
\text { Calculated }\end{array}$ & $\begin{array}{l}45.35 \%(35.84 \text { to } 55.21) \\
\text { calculated }\end{array}$ \\
\hline Lehmann, 2007 & EMS HR $<60$ or $>110$ bpm & Emergent intervention & $\begin{array}{l}23.94 \% \text { (18.03 to 30.69) } \\
\text { calculated }\end{array}$ & $\begin{array}{l}82.98 \%(80.69 \text { to } 85.09) \\
\text { Calculated }\end{array}$ & $\begin{array}{l}18.52 \%(14.60 \text { to } 23.20) \\
\text { calculated }\end{array}$ \\
\hline Lehmann, 2007 & SBP $<100$, EMS & Emergent intervention & $\begin{array}{l}10.11 \%(6.20 \text { to } 15.33) \\
\text { calculated }\end{array}$ & $\begin{array}{l}98.97 \% \text { (98.20 to 99.47) } \\
\text { Calculated }\end{array}$ & $\begin{array}{l}61.29 \%(43.87 \text { to } 76.24) \\
\text { calculated }\end{array}$ \\
\hline Lerner, 2017 & $\begin{array}{l}\text { Physiologic criteria of Field } \\
\text { Triage Guidelines }(\mathrm{GCS} \leq 13 \text {, } \\
\text { SBP }<90 \text {, and RR }<10 \text { or }>29 \text { ) }\end{array}$ & Trauma center need & $\begin{array}{l}49.10 \%(43.10 \text { to } 55.13) \\
\text { calculated }\end{array}$ & $\begin{array}{l}82.41 \%(81.36 \text { to } 83.42) \\
\text { Calculated }\end{array}$ & $\begin{array}{l}12.78 \%(11.37 \text { to } 14.34) \\
\text { calculated }\end{array}$ \\
\hline
\end{tabular}




\begin{tabular}{|c|c|c|c|c|c|}
\hline $\begin{array}{l}\text { Author, Year } \\
\text { (See Appendix B for } \\
\text { complete reference) }\end{array}$ & $\begin{array}{l}\text { Reported NPV } \\
(95 \% \mathrm{CI})\end{array}$ & Reported PLR & Reported NLR & $\begin{array}{l}\text { AUROC Univariate } \\
\text { AUC }(95 \% \mathrm{CI})\end{array}$ & $\begin{array}{l}\text { Other Measures of } \\
\text { Diagnostic Accuracy }\end{array}$ \\
\hline Lalezarzadeh, 2009 & $\begin{array}{l}97.86 \%(97.62 \text { to } 98.07) \\
\text { calculated }\end{array}$ & $\begin{array}{l}2.87(2.39 \text { to } 3.45) \\
\text { calculated }\end{array}$ & $\begin{array}{l}0.71(0.64 \text { to } 0.79) \\
\text { calculated }\end{array}$ & NR & NR \\
\hline Lalezarzadeh, 2009 & $\begin{array}{l}97.66 \% \text { (97.48 to } 97.82) \\
\text { calculated }\end{array}$ & $\begin{array}{l}12.63(9.36 \text { to } 17.05) \\
\text { calculated }\end{array}$ & $\begin{array}{l}0.78(0.72 \text { to } 0.84) \\
\text { calculated }\end{array}$ & NR & NR \\
\hline Lalezarzadeh, 2009 & $\begin{array}{l}84.37 \%(84.12 \text { to } 84.63) \\
\text { calculated }\end{array}$ & $\begin{array}{l}3.36(2.66 \text { to } 4.24) \\
\text { calculated }\end{array}$ & $\begin{array}{l}0.93(0.91 \text { to } 0.95) \\
\text { calculated }\end{array}$ & NR & NR \\
\hline Lalezarzadeh, 2009 & $\begin{array}{l}85.13 \% \text { (84.71 to } 85.54) \\
\text { calculated }\end{array}$ & $\begin{array}{l}1.87 \text { (1.65 to } 2.12) \\
\text { calculated }\end{array}$ & $\begin{array}{l}0.88(0.85 \text { to } 0.91) \\
\text { calculated }\end{array}$ & NR & NR \\
\hline Lalezarzadeh, 2009 & $\begin{array}{l}84.03 \% \text { (83.83 to } 84.24) \\
\text { calculated }\end{array}$ & $\begin{array}{l}3.51(2.62 \text { to } 4.71) \\
\text { Calculated }\end{array}$ & $\begin{array}{l}0.95(0.94 \text { to } 0.97) \\
\text { calculated }\end{array}$ & NR & NR \\
\hline Lee, 2014 & $76.9 \%(\mathrm{NR})$ & NR & NR & NR & NR \\
\hline Lee, 2014 & $81.4 \%(\mathrm{NR})$ & NR & NR & NR & NR \\
\hline Lee, 2014 & $77.6 \%(\mathrm{NR})$ & NR & NR & NR & NR \\
\hline Lee, 2014 & $83.6 \%(\mathrm{NR})$ & NR & NR & NR & NR \\
\hline Lee, 2014 & $90.4 \%(\mathrm{NR})$ & NR & NR & NR & NR \\
\hline Lee, 2014 & $95.3 \%(\mathrm{NR})$ & NR & NR & NR & NR \\
\hline Lee, 2014 & $82.4 \%(\mathrm{NR})$ & NR & NR & NR & NR \\
\hline Lee, 2014 & $96.7 \%(\mathrm{NR})$ & NR & NR & NR & NR \\
\hline Lehmann, 2007 & $\begin{array}{l}88.22 \%(87.43 \text { to } 88.97) \\
\text { calculated }\end{array}$ & $\begin{array}{l}5.13(3.46 \text { to } 7.62) \\
\text { Calculated }\end{array}$ & $\begin{array}{l}0.83(0.77 \text { to } 0.89) \\
\text { calculated }\end{array}$ & NR & NR \\
\hline Lehmann, 2007 & $\begin{array}{l}87.09 \%(86.12 \text { to } 88.01) \\
\text { calculated }\end{array}$ & $\begin{array}{l}1.41 \text { (1.06 to } 1.87) \\
\text { Calculated }\end{array}$ & $\begin{array}{l}0.92(0.84 \text { to } 1.00) \\
\text { calculated }\end{array}$ & NR & NR \\
\hline Lehmann, 2007 & $\begin{array}{l}87.20 \%(86.65 \text { to } 87.73) \\
\text { calculated }\end{array}$ & $\begin{array}{l}9.79(4.83 \text { to } 19.85) \\
\text { Calculated }\end{array}$ & $\begin{array}{l}0.91(0.87 \text { to } 0.95) \\
\text { calculated }\end{array}$ & NR & NR \\
\hline Lerner, 2017 & $\begin{array}{l}96.86 \%(96.49 \text { to } 97.19) \\
\text { calculated }\end{array}$ & $\begin{array}{l}2.8(2.4 \text { to } 3.2) \text { reported } \\
2.79(2.44 \text { to } 3.19) \\
\text { Calculated }\end{array}$ & $\begin{array}{l}0.62(0.55 \text { to } 0.69) \\
\text { calculated }\end{array}$ & NR & $\begin{array}{l}51 \% \text { under-triage rate } \\
18 \% \text { over-triage rate }\end{array}$ \\
\hline
\end{tabular}




\begin{tabular}{|c|c|c|c|c|c|}
\hline $\begin{array}{l}\text { Author, Year } \\
\text { (See Appendix B for } \\
\text { complete reference) }\end{array}$ & Measure & Indicator of Serious Injury & $\begin{array}{l}\text { Reported Sensitivity } \\
(95 \% \mathrm{Cl})\end{array}$ & $\begin{array}{l}\text { Reported Specificity } \\
(95 \% \mathrm{Cl})\end{array}$ & $\begin{array}{l}\text { Reported PPV } \\
(95 \% \mathrm{Cl})\end{array}$ \\
\hline Lerner, 2017 & $\mathrm{RR}<10$ or $>29$ & Trauma center need & NR & NR & NR \\
\hline Lerner, 2017 & SBP $<90$ & Trauma center need & NR & NR & NR \\
\hline Lin, 2011 & $\mathrm{SBP} \leq 90, \mathrm{EMS}$ & Emergency surgery & $\begin{array}{l}53.85 \%(37.18 \text { to } 69.91) \\
\text { calculated }\end{array}$ & $\begin{array}{l}91.64 \%(89.03 \text { to } 93.79) \\
\text { calculated }\end{array}$ & $\begin{array}{l}30.88 \%(23.06 \text { to } 39.98) \\
\text { calculated }\end{array}$ \\
\hline Lin, 2011 & $\mathrm{SBP} \leq 90, \mathrm{EMS}$ & ISS $\geq 25$ & $\begin{array}{l}29.37 \%(21.59 \text { to } 38.14) \\
\text { calculated }\end{array}$ & $\begin{array}{l}93.47 \% \text { (90.86 to } 95.52) \\
\text { calculated }\end{array}$ & $\begin{array}{l}54.41 \%(43.59 \text { to } 64.84) \\
\text { calculated }\end{array}$ \\
\hline Lin, 2011 & $\mathrm{SBP} \leq 90, \mathrm{EMS}$ & Major trauma & $\begin{array}{l}22.63 \%(17.53 \text { to } 28.42) \\
\text { calculated }\end{array}$ & $\begin{array}{l}96.37 \%(93.87 \text { to } 98.05) \\
\text { calculated }\end{array}$ & $\begin{array}{l}80.88 \%(71.27 \text { to } 88.33) \\
\text { calculated }\end{array}$ \\
\hline Lin, 2011 & $\mathrm{SBP} \leq 90, \mathrm{ED}$ & Major trauma & $\begin{array}{l}18.11 \%(13.48 \text { to } 23.54) \\
\text { calculated }\end{array}$ & $\begin{array}{l}95.81 \%(93.18 \text { to } 97.64) \\
\text { calculated }\end{array}$ & $\begin{array}{l}74.58 \%(62.56 \text { to } 83.74) \\
\text { calculated }\end{array}$ \\
\hline Lipsky, 2006 & $\begin{array}{l}\text { SBP: hypotensive in field; } \\
\text { normotensive in ED }\end{array}$ & Emergent therapeutic operation & $\begin{array}{l}19.26 \%(12.98 \text { to } 26.93) \\
\text { calculated }\end{array}$ & $\begin{array}{l}94.96 \%(93.31 \text { to } 96.30) \\
\text { calculated }\end{array}$ & $\begin{array}{l}36.62 \%(26.97 \text { to } 47.48) \\
\text { calculated }\end{array}$ \\
\hline Lipsky, 2006 & $\begin{array}{l}\text { SBP: hypotensive in field; } \\
\text { normotensive in ED }\end{array}$ & Mortality & $\begin{array}{l}14.29 \%(4.03 \text { to } 32.67) \\
\text { calculated }\end{array}$ & $\begin{array}{l}93.29 \%(91.56 \text { to } 94.76) \\
\text { calculated }\end{array}$ & $\begin{array}{l}5.63 \%(2.29 \text { to } 13.22) \\
\text { calculated }\end{array}$ \\
\hline Lipsky, 2006 & $\begin{array}{l}\text { SBP: hypotensive in field; } \\
\text { normotensive in ED }\end{array}$ & Emergent surgery within 6 hours & $\begin{array}{l}16.07 \%(10.87 \text { to } 22.51) \\
\text { calculated }\end{array}$ & $\begin{array}{l}94.88 \%(93.19 \text { to } 96.26) \\
\text { calculated }\end{array}$ & $\begin{array}{l}38.03 \%(28.13 \text { to } 49.03) \\
\text { calculated }\end{array}$ \\
\hline Liu, 2014a & $\mathrm{RR} \geq 20$ & $\begin{array}{l}\text { Life-saving intervention in field or } \\
\text { ED }\end{array}$ & $\begin{array}{l}37.88 \%(26.22 \text { to } 50.66) \\
\text { calculated }\end{array}$ & $\begin{array}{l}67.60 \%(60.21 \text { to } 74.39) \\
\text { calculated }\end{array}$ & $\begin{array}{l}30.12 \%(22.86 \text { to } 38.53) \\
\text { calculated }\end{array}$ \\
\hline Liu, 2014a & $\mathrm{HR}>105$ & $\begin{array}{l}\text { Life-saving intervention in field or } \\
\text { ED }\end{array}$ & $\begin{array}{l}41.67 \%(32.25 \text { to } 51.55) \\
\text { calculated }\end{array}$ & $\begin{array}{l}84.07 \%(77.92 \text { to } 89.06) \\
\text { calculated }\end{array}$ & $\begin{array}{l}60.81 \%(50.95 \text { to } 69.86) \\
\text { calculated }\end{array}$ \\
\hline Liu, 2014b & $\mathrm{HR} \geq 110$ & $\begin{array}{l}\text { Life-saving intervention in field or } \\
\text { ED }\end{array}$ & $\begin{array}{l}41.94 \%(24.55 \text { to } 60.92) \\
\text { calculated }\end{array}$ & $\begin{array}{l}88.57 \%(78.72 \text { to } 94.93) \\
\text { calculated }\end{array}$ & $\begin{array}{l}61.90 \%(42.87 \text { to } 77.87) \\
\text { calculated }\end{array}$ \\
\hline Liu, 2014b & $\mathrm{RR} \geq 20$ & $\begin{array}{l}\text { Life-saving intervention in field or } \\
\text { ED }\end{array}$ & $\begin{array}{l}26.67 \%(7.79 \text { to } 55.10) \\
\text { calculated }\end{array}$ & $\begin{array}{l}74.65 \%(62.92 \text { to } 84.23) \\
\text { calculated }\end{array}$ & $\begin{array}{l}18.18 \%(8.07 \text { to } 36.01) \\
\text { calculated }\end{array}$ \\
\hline
\end{tabular}




\begin{tabular}{|c|c|c|c|c|c|}
\hline $\begin{array}{l}\text { Author, Year } \\
\text { (See Appendix B for } \\
\text { complete reference) }\end{array}$ & $\begin{array}{l}\text { Reported NPV } \\
(95 \% \mathrm{Cl})\end{array}$ & Reported PLR & Reported NLR & $\begin{array}{l}\text { AUROC Univariate } \\
\text { AUC }(95 \% \mathrm{CI})\end{array}$ & $\begin{array}{l}\text { Other Measures of } \\
\text { Diagnostic Accuracy }\end{array}$ \\
\hline Lerner, 2017 & NR & $2.2(1.8$ to 2.6$)$ & NR & NR & $\begin{array}{l}69 \% \text { under-triage rate } \\
14 \% \text { over-triage rate }\end{array}$ \\
\hline Lerner, 2017 & NR & $3.5(2.5$ to 5.1$)$ & NR & NR & $\begin{array}{l}87 \% \text { under-triage rate } \\
4 \% \text { over-triage rate }\end{array}$ \\
\hline Lin, 2011 & $\begin{array}{l}\text { 96.62\% (95.32 to } 97.57) \\
\text { calculated }\end{array}$ & $\begin{array}{l}6.44(4.32 \text { to } 9.60) \\
\text { calculated }\end{array}$ & $\begin{array}{l}0.50(0.36 \text { to } 0.71) \\
\text { calculated }\end{array}$ & NR & NR \\
\hline Lin, 2011 & $\begin{array}{l}\text { 83.30\% (81.64 to 84.84) } \\
\text { calculated }\end{array}$ & $\begin{array}{l}4.50(2.91 \text { to } 6.95) \\
\text { calculated }\end{array}$ & $\begin{array}{l}0.76(0.67 \text { to } 0.85) \\
\text { calculated }\end{array}$ & NR & NR \\
\hline Lin, 2011 & $\begin{array}{l}64.73 \%(63.09 \text { to } 66.33) \\
\text { calculated }\end{array}$ & $\begin{array}{l}6.23(3.48 \text { to } 11.16) \\
\text { calculated }\end{array}$ & $\begin{array}{l}0.80(0.75 \text { to } 0.86) \\
\text { calculated }\end{array}$ & NR & NR \\
\hline Lin, 2011 & $\begin{array}{l}63.28 \% \text { (61.81 to } 64.73) \\
\text { calculated }\end{array}$ & $\begin{array}{l}4.32(2.46 \text { to } 7.59) \\
\text { calculated }\end{array}$ & $\begin{array}{l}0.85(0.80 \text { to } 0.91) \\
\text { calculated }\end{array}$ & NR & NR \\
\hline Lipsky, 2006 & $\begin{array}{l}88.61 \%(97.74 \text { to } 89.43) \\
\text { calculated }\end{array}$ & $\begin{array}{l}3.82(2.44 \text { to } 5.98) \\
\text { calculated }\end{array}$ & $\begin{array}{l}0.85 \text { (0.78 to 0.92) } \\
\text { calculated }\end{array}$ & NR & NR \\
\hline Lipsky, 2006 & $97.49 \%$ (97.09 to 97.84$)$ & $\begin{array}{l}2.13(0.84 \text { to } 5.43) \\
\text { calculated }\end{array}$ & $\begin{array}{l}0.92(0.79 \text { to } 1.07) \\
\text { calculated }\end{array}$ & NR & NR \\
\hline Lipsky, 2006 & $\begin{array}{l}85.27 \%(84.39 \text { to } 86.10) \\
\text { calculated }\end{array}$ & $\begin{array}{l}3.14(2.00 \text { to } 4.93) \\
\text { calculated }\end{array}$ & $\begin{array}{l}0.88(0.83 \text { to } 0.95) \\
\text { calculated }\end{array}$ & NR & NR \\
\hline Liu, 2014a & $\begin{array}{l}74.69 \%(70.44 \text { to } 78.52) \\
\text { calculated }\end{array}$ & $\begin{array}{l}1.17(0.80 \text { to } 1.70) \\
\text { calculated }\end{array}$ & $\begin{array}{l}0.92(0.74 \text { to } 1.14) \\
\text { calculated }\end{array}$ & NR & NR \\
\hline Liu, 2014a & $\begin{array}{l}70.83 \%(67.17 \text { to } 74.25) \\
\text { calculated }\end{array}$ & $\begin{array}{l}2.61(1.75 \text { to } 3.91) \\
\text { calculated }\end{array}$ & $\begin{array}{l}0.69(0.58 \text { to } 0.82) \\
\text { calculated }\end{array}$ & NR & NR \\
\hline Liu, 2014b & $\begin{array}{l}77.50 \%(71.63 \text { to } 82.46) \\
\text { calculated }\end{array}$ & $\begin{array}{l}3.67 \text { (1.69 to } 7.95) \\
\text { calculated }\end{array}$ & $\begin{array}{l}0.66(0.48 \text { to } 0.89) \\
\text { calculated }\end{array}$ & NR & NR \\
\hline Liu, 2014b & $\begin{array}{l}82.81 \%(77.53 \text { to } 87.06) \\
\text { calculated }\end{array}$ & $\begin{array}{l}1.05(0.42 \text { to } 2.66) \\
\text { calculated }\end{array}$ & $\begin{array}{l}0.98(0.70 \text { to } 1.37) \\
\text { calculated }\end{array}$ & NR & NR \\
\hline
\end{tabular}




\begin{tabular}{|c|c|c|c|c|c|}
\hline $\begin{array}{l}\text { Author, Year } \\
\text { (See Appendix B for } \\
\text { complete reference) }\end{array}$ & Measure & Indicator of Serious Injury & $\begin{array}{l}\text { Reported Sensitivity } \\
(95 \% \mathrm{Cl})\end{array}$ & $\begin{array}{l}\text { Reported Specificity } \\
(95 \% \mathrm{Cl})\end{array}$ & $\begin{array}{l}\text { Reported PPV } \\
(95 \% \mathrm{Cl})\end{array}$ \\
\hline Liu, 2014c & $\begin{array}{l}\text { Machine learning model using } \\
\text { vital signs: Multilayer perceptron } \\
\text { with } 24 \text { features } \\
\text { - within } 5 \text { minutes; true positive } \\
\geq 30 \% \text { probability }\end{array}$ & Life-saving intervention & $\begin{array}{l}89.8 \%(\mathrm{NR}) \text { reported } \\
89.83 \%(79.17 \text { to } 96.18) \\
\text { calculated }\end{array}$ & $\begin{array}{l}98.31 \%(94.01 \text { to } 99.79) \\
\text { calculated }\end{array}$ & $\begin{array}{l}96.4 \%(\mathrm{NR}) \text { reported } \\
96.36 \%(86.99 \text { to } 99.06) \\
\text { calculated }\end{array}$ \\
\hline Liu, 2014c & $\begin{array}{l}\text { Machine learning model using } \\
\text { vital signs: Multilayer perceptron } \\
\text { with } 24 \text { features } \\
\text { - within } 60 \text { seconds; true positive } \\
\geq 30 \% \text { probability }\end{array}$ & Life-saving intervention & $\begin{array}{l}76.27 \%(63.41 \text { to } 86.38) \\
\text { calculated }\end{array}$ & $\begin{array}{l}95.76 \%(90.39 \text { to } 98.61) \\
\text { calculated }\end{array}$ & $\begin{array}{l}90.00 \%(79.05 \text { to } 95.55) \\
\text { calculated }\end{array}$ \\
\hline Liu, 2014c & $\begin{array}{l}\text { Machine learning model using } \\
\text { vital signs: Multilayer perceptron } \\
\text { with } 24 \text { features } \\
\text { - within } 3 \text { minutes; true positive } \\
\geq 30 \% \text { probability }\end{array}$ & Life-saving intervention & $\begin{array}{l}88.14 \%(77.07 \text { to } 95.09) \\
\text { calculated }\end{array}$ & $\begin{array}{l}97.46 \%(92.75 \text { to } 99.47) \\
\text { calculated }\end{array}$ & $\begin{array}{l}94.55 \%(84.96 \text { to } 98.15) \\
\text { calculated }\end{array}$ \\
\hline Liu, 2014c & $\begin{array}{l}\text { Machine learning model using } \\
\text { vital signs: Multilayer perceptron } \\
\text { with } 24 \text { features } \\
\text { - at recorded time; true positive } \\
\geq 30 \% \text { probability }\end{array}$ & Life-saving intervention & $\begin{array}{l}69.49 \% \text { (56.13 to } 80.81) \\
\text { calculated }\end{array}$ & $\begin{array}{l}91.53 \%(84.97 \text { to } 95.86) \\
\text { calculated }\end{array}$ & $\begin{array}{l}80.39 \% \text { (68.88 to } 88.37) \\
\text { calculated }\end{array}$ \\
\hline Liu, 2014c & SBP <80: Training database & Life-saving intervention & $\begin{array}{l}58.18 \%(44.11 \text { to } 71.35) \\
\text { calculated }\end{array}$ & $\begin{array}{l}66.67 \%(44.68 \text { to } 84.37) \\
\text { calculated }\end{array}$ & $\begin{array}{l}80.00 \%(68.52 \text { to } 88.03) \\
\text { calculated }\end{array}$ \\
\hline Liu, 2014c & $\begin{array}{l}R R^{\star} \leq 10 \text { : Training database } \\
\star \text { Using patients with known } \\
\text { values only }(n=59 / 79)\end{array}$ & Life-saving intervention & $\begin{array}{l}22.86 \%(10.42 \text { to } 40.14) \\
\text { calculated }\end{array}$ & $\begin{array}{l}100.00 \%(76.84 \text { to } 100.00) \\
\text { calculated }\end{array}$ & $\begin{array}{l}100.00 \% \\
\text { calculated }\end{array}$ \\
\hline Liu, 2014c & $\begin{array}{l}\mathrm{HR}^{*}>105: \text { Both databases } \\
\star \text { Using patients with known } \\
\text { values only }(\mathrm{n}=322 / 384)\end{array}$ & Life-saving intervention & $\begin{array}{l}47.33 \%(38.55 \text { to } 56.23) \\
\text { calculated }\end{array}$ & $\begin{array}{l}83.77 \%(77.76 \text { to } 88.70) \\
\text { calculated }\end{array}$ & $\begin{array}{l}66.67 \%(58.02 \text { to } 74.32) \\
\text { calculated }\end{array}$ \\
\hline $\begin{array}{l}\text { Mackenzie, } 2015 \\
\text { *Mackenzie 2015, } \\
\text { Shackelford 2015, and } \\
\text { Yang } 2016 \text { draw from } \\
\text { the same population, } \\
\text { but differ in eligibility } \\
\text { criteria, number } \\
\text { analyzed, and } \\
\text { measures evaluated. }\end{array}$ & $\begin{array}{l}\text { Pulse oximeter (PPG) algorithm } \\
\text { to predict blood transfusion }\end{array}$ & Blood transfusion within 6 hours & $100 \%(\mathrm{NR})$ & $70 \%(\mathrm{NR})$ & NR \\
\hline
\end{tabular}




\begin{tabular}{|c|c|c|c|c|c|}
\hline $\begin{array}{l}\text { Author, Year } \\
\text { (See Appendix B for } \\
\text { complete reference) }\end{array}$ & $\begin{array}{l}\text { Reported NPV } \\
(95 \% \mathrm{Cl})\end{array}$ & Reported PLR & Reported NLR & $\begin{array}{l}\text { AUROC Univariate } \\
\text { AUC }(95 \% \mathrm{CI})\end{array}$ & $\begin{array}{l}\text { Other Measures of } \\
\text { Diagnostic Accuracy }\end{array}$ \\
\hline Liu, 2014c & $\begin{array}{l}95.08 \%(90.05 \text { to } 97.64) \\
\text { calculated }\end{array}$ & $\begin{array}{l}53.00(13.38 \text { to } 210.00) \\
\text { calculated }\end{array}$ & $\begin{array}{l}0.10(0.05 \text { to } 0.22) \\
\text { calculated }\end{array}$ & NR & NR \\
\hline Liu, 2014c & $\begin{array}{l}88.98 \%(83.61 \text { to } 92.74) \\
\text { calculated }\end{array}$ & $\begin{array}{l}18.00(7.54 \text { to } 42.94) \\
\text { calculated }\end{array}$ & $\begin{array}{l}0.25(0.16 \text { to } 0.39) \\
\text { calculated }\end{array}$ & NR & NR \\
\hline Liu, 2014c & $\begin{array}{l}94.26 \%(89.12 \text { to } 97.05) \\
\text { calculated }\end{array}$ & $\begin{array}{l}34.67(11.30 \text { to } 106.36) \\
\text { calculated }\end{array}$ & $\begin{array}{l}0.12(0.06 \text { to } 0.24) \\
\text { calculated }\end{array}$ & NR & NR \\
\hline Liu, 2014c & $\begin{array}{l}85.71 \%(80.26 \text { to } 89.85) \\
\text { calculated }\end{array}$ & $\begin{array}{l}8.20(4.43 \text { to } 15.19) \\
\text { calculated }\end{array}$ & $\begin{array}{l}0.33(0.23 \text { to } 0.49) \\
\text { calculated }\end{array}$ & NR & NR \\
\hline Liu, 2014c & $\begin{array}{l}41.03 \%(31.35 \text { to } 51.45) \\
\text { calculated }\end{array}$ & $\begin{array}{l}1.75(0.95 \text { to } 3.21) \\
\text { calculated }\end{array}$ & $\begin{array}{l}0.63(0.41 \text { to } 0.96) \\
\text { calculated }\end{array}$ & NR & NR \\
\hline Liu, 2014c & $\begin{array}{l}34.15 \%(30.21 \text { to } 38.31) \\
\text { calculated }\end{array}$ & $\begin{array}{l}\text { Undefined } \\
\text { (specificity = 100\%) }\end{array}$ & $\begin{array}{l}0.77(0.64 \text { to } 0.92) \\
\text { calculated }\end{array}$ & NR & NR \\
\hline Liu, 2014c & $\begin{array}{l}69.87 \%(66.09 \text { to } 73.40) \\
\text { calculated }\end{array}$ & $\begin{array}{l}2.92(2.02 \text { to } 4.22) \\
\text { calculated }\end{array}$ & $\begin{array}{l}0.63(0.53 \text { to } 0.75) \\
\text { calculated }\end{array}$ & NR & NR \\
\hline $\begin{array}{l}\text { Mackenzie, } 2015 \\
\star \text { *Mackenzie 2015, } \\
\text { Shackelford 2015, and } \\
\text { Yang } 2016 \text { draw from } \\
\text { the same population, } \\
\text { but differ in eligibility } \\
\text { criteria, number } \\
\text { analyzed, and } \\
\text { measures evaluated. }\end{array}$ & NR & NR & NR & $0.92(\mathrm{NR})$ & NR \\
\hline
\end{tabular}




\begin{tabular}{|c|c|c|c|c|c|}
\hline $\begin{array}{l}\text { Author, Year } \\
\text { (See Appendix B for } \\
\text { complete reference) }\end{array}$ & Measure & Indicator of Serious Injury & $\begin{array}{l}\text { Reported Sensitivity } \\
(95 \% \mathrm{Cl})\end{array}$ & $\begin{array}{l}\text { Reported Specificity } \\
(95 \% \mathrm{Cl})\end{array}$ & $\begin{array}{l}\text { Reported PPV } \\
(95 \% \mathrm{Cl})\end{array}$ \\
\hline $\begin{array}{l}\text { Mackenzie, } 2015 \\
\star \text { ×Mackenzie 2015, } \\
\text { Shackelford 2015, and } \\
\text { Yang } 2016 \text { draw from } \\
\text { the same population, } \\
\text { but differ in eligibility } \\
\text { criteria, number } \\
\text { analyzed, and } \\
\text { measures evaluated. }\end{array}$ & $\begin{array}{l}\text { Pulse oximeter (PPG) algorithm } \\
\text { to predict surgical intervention }\end{array}$ & $\begin{array}{l}\text { Surgical intervention within } 6 \\
\text { hours }\end{array}$ & NR & NR & NR \\
\hline $\begin{array}{l}\text { Mackenzie, } 2015 \\
\star \text { ×Mackenzie 2015, } \\
\text { Shackelford 2015, and } \\
\text { Yang } 2016 \text { draw from } \\
\text { the same population, } \\
\text { but differ in eligibility } \\
\text { criteria, number } \\
\text { analyzed, and } \\
\text { measures evaluated. }\end{array}$ & $\begin{array}{l}\text { Pulse oximeter (PPG) algorithm } \\
\text { to predict endotracheal } \\
\text { intubation }\end{array}$ & $\begin{array}{l}\text { Endotracheal intubation within } 1 \\
\text { hour }\end{array}$ & NR & NR & NR \\
\hline McManus, 2005 & Radial pulse character, weak & ICU admission & $\begin{array}{l}14.04 \%(8.24 \text { to } 21.79) \\
\text { Calculated }\end{array}$ & $\begin{array}{l}97.00 \%(93.58 \text { to } 98.89) \\
\text { calculated }\end{array}$ & $\begin{array}{l}72.73 \%(51.78 \text { to } 86.88) \\
\text { calculated }\end{array}$ \\
\hline McManus, 2005 & Radial pulse character, weak & Intubation & $\begin{array}{l}26.67 \%(16.07 \text { to } 39.66) \\
\text { Calculated }\end{array}$ & $\begin{array}{l}95.37 \%(92.22 \text { to } 97.51) \\
\text { calculated }\end{array}$ & $\begin{array}{l}55.17 \%(38.48 \text { to } 70.77) \\
\text { calculated }\end{array}$ \\
\hline McManus, 2005 & Radial pulse character: weak & Mortality & $\begin{array}{l}50.00 \%(24.65 \text { to } 75.35) \\
\text { Calculated }\end{array}$ & $\begin{array}{l}93.83 \%(90.63 \text { to } 96.19) \\
\text { calculated }\end{array}$ & $\begin{array}{l}28.57 \%(17.30 \text { to } 43.34) \\
\text { calculated }\end{array}$ \\
\hline Miller, 2017 & modified REMS (mREMS) & Mortality: in-hospital & NR & NR & NR \\
\hline Miller, 2017 & MGAP & Mortality: in-hospital & NR & NR & NR \\
\hline Miller, 2017 & RTS & Mortality: in-hospital & NR & NR & NR \\
\hline Miller, 2017 & $\mathrm{SI}$ & Mortality: in-hospital & NR & NR & NR \\
\hline Mizushima, 2011 & $\mathrm{BD}<-10$ & Mortality & $\begin{array}{l}32.67 \%(25.24 \text { to } 40.79( \\
\text { Calculated }\end{array}$ & $\begin{array}{l}96.80 \%(95.81 \text { to } 97.61) \\
\text { calculated }\end{array}$ & $\begin{array}{l}49.00 \% \text { (40.26 to } 57.80) \\
\text { calculated }\end{array}$ \\
\hline
\end{tabular}




\begin{tabular}{|c|c|c|c|c|c|}
\hline $\begin{array}{l}\text { Author, Year } \\
\text { (See Appendix B for } \\
\text { complete reference) }\end{array}$ & $\begin{array}{l}\text { Reported NPV } \\
(95 \% \mathrm{Cl})\end{array}$ & Reported PLR & Reported NLR & $\begin{array}{l}\text { AUROC Univariate } \\
\text { AUC }(95 \% \mathrm{CI})\end{array}$ & $\begin{array}{l}\text { Other Measures of } \\
\text { Diagnostic Accuracy }\end{array}$ \\
\hline $\begin{array}{l}\text { Mackenzie, } 2015 \\
\text { *Mackenzie 2015, } \\
\text { Shackelford 2015, and } \\
\text { Yang } 2016 \text { draw from } \\
\text { the same population, } \\
\text { but differ in eligibility } \\
\text { criteria, number } \\
\text { analyzed, and } \\
\text { measures evaluated. }\end{array}$ & NR & NR & NR & $0.74(\mathrm{NR})$ & NR \\
\hline $\begin{array}{l}\text { Mackenzie, } 2015 \\
\text { *Mackenzie 2015, } \\
\text { Shackelford 2015, and } \\
\text { Yang } 2016 \text { draw from } \\
\text { the same population, } \\
\text { but differ in eligibility } \\
\text { criteria, number } \\
\text { analyzed, and } \\
\text { measures evaluated. }\end{array}$ & NR & NR & NR & $0.92(\mathrm{NR})$ & NR \\
\hline McManus, 2005 & $\begin{array}{l}66.44 \%(64.68 \text { to } 68.16) \\
\text { calculated }\end{array}$ & $\begin{array}{l}4.68(1.88 \text { to } 11.62) \\
\text { calculated }\end{array}$ & $\begin{array}{l}0.89(0.82 \text { to } 0.96) \\
\text { calculated }\end{array}$ & NR & NR \\
\hline McManus, 2005 & $\begin{array}{l}85.90 \%(83.92 \text { to } 87.67) \\
\text { calculated }\end{array}$ & $\begin{array}{l}5.76(2.93 \text { to } 11.34) \\
\text { calculated }\end{array}$ & $\begin{array}{l}0.77(0.66 \text { to } 0.90) \\
\text { calculated }\end{array}$ & NR & NR \\
\hline McManus, 2005 & $\begin{array}{l}97.44 \%(95.88 \text { to } 98.41) \\
\text { calculated }\end{array}$ & $\begin{array}{l}8.10(4.24 \text { to } 15.49) \\
\text { calculated }\end{array}$ & $\begin{array}{l}0.53(0.33 \text { to } 0.87) \\
\text { calculated }\end{array}$ & NR & NR \\
\hline Miller, 2017 & NR & NR & NR & $0.967(0.963$ to 0.971$)$ & NR \\
\hline Miller, 2017 & NR & NR & NR & 0.964 (0.959 to 0.968$)$ & NR \\
\hline Miller, 2017 & $\overline{N R}$ & $\overline{N R}$ & $\overline{N R}$ & $0.959(0.955$ to 0.964$)$ & $\overline{N R}$ \\
\hline Miller, 2017 & NR & NR & NR & $0.670(0.650$ to 0.690$)$ & NR \\
\hline Mizushima, 2011 & $\begin{array}{l}93.85 \%(93.17 \text { to } 94.46) \\
\text { calculated }\end{array}$ & $\begin{array}{l}10.20(7.15 \text { to } 14.54) \\
\text { calculated }\end{array}$ & $\begin{array}{l}0.70(0.62 \text { to } 0.78) \\
\text { calculated }\end{array}$ & NR & NR \\
\hline
\end{tabular}




\begin{tabular}{|c|c|c|c|c|c|}
\hline $\begin{array}{l}\text { Author, Year } \\
\text { (See Appendix B for } \\
\text { complete reference) }\end{array}$ & Measure & Indicator of Serious Injury & $\begin{array}{l}\text { Reported Sensitivity } \\
(95 \% \mathrm{Cl})\end{array}$ & $\begin{array}{l}\text { Reported Specificity } \\
(95 \% \mathrm{Cl})\end{array}$ & $\begin{array}{l}\text { Reported PPV } \\
(95 \% \mathrm{Cl})\end{array}$ \\
\hline Mizushima, 2011 & $B D<-5$ & Mortality & $\begin{array}{l}56.00 \%(47.67 \text { to } 64.09) \\
\text { Calculated }\end{array}$ & $\begin{array}{l}87.75 \%(86.04 \text { to } 89.32) \\
\text { calculated }\end{array}$ & $\begin{array}{l}30.11 \%(26.20 \text { to } 34.33) \\
\text { calculated }\end{array}$ \\
\hline Mizushima, 2011 & Lactate $>2.5$ & Mortality & $\begin{array}{l}82.00 \%(74.90 \text { to } 87.79) \\
\text { Calculated }\end{array}$ & $\begin{array}{l}56.78 \% \text { (54.31 to } 59.23) \\
\text { calculated }\end{array}$ & $\begin{array}{l}15.17 \%(14.00 \text { to } 16.41) \\
\text { calculated }\end{array}$ \\
\hline Mizushima, 2011 & Lactate $>5$ & Mortality & $\begin{array}{l}52.67 \%(44.36 \text { to } 60.87) \\
\text { Calculated }\end{array}$ & $\begin{array}{l}88.38 \%(86.70 \text { to } 89.91) \\
\text { calculated }\end{array}$ & $\begin{array}{l}29.92 \%(25.84 \text { to } 34.36) \\
\text { calculated }\end{array}$ \\
\hline Montoya, 2015 & SI $>0.9$ & Mortality: 24-hour & $\begin{array}{l}\text { 79.52\% (69.24 to } 87.59) \\
\text { Calculated }\end{array}$ & $\begin{array}{l}92.28 \%(89.81 \text { to } 94.31) \\
\text { calculated }\end{array}$ & $\begin{array}{l}59.46 \%(52.04 \text { to } 66.47) \\
\text { calculated }\end{array}$ \\
\hline Moront, 1996 & GCS $<12$ and $H R>160$ & $\begin{array}{l}\text { Need for immediate transport to } \\
\text { trauma center }\end{array}$ & $98.9 \%(\mathrm{Cl} \mathrm{NR})$ & $90.1 \%(\mathrm{Cl} \mathrm{NR})$ & NR \\
\hline Mutschler, 2013 & $\mathrm{SI}>1.0$ & Mortality: in-hospital & $\begin{array}{l}32.90 \% \text { (31.16 to } 34.67) \\
\text { Calculated }\end{array}$ & $\begin{array}{l}87.67 \%(87.19 \text { to } 88.13) \\
\text { calculated }\end{array}$ & $\begin{array}{l}28.31 \%(27.01 \text { to } 29.65) \\
\text { calculated }\end{array}$ \\
\hline Mutschler, 2013 & $\mathrm{SI}$ & Blood transfusion & NR & NR & NR \\
\hline Mutschler, 2013 & $\mathrm{BD}$ & Blood transfusion & NR & NR & NR \\
\hline Newgard, 2009 & RR $<10$ or $>29$ & Death or LOS $>2$ days & $\begin{array}{l}44.13 \%(36.73 \text { to } 51.73) \\
\text { Calculated }\end{array}$ & $\begin{array}{l}53.09 \%(49.51 \text { to } 56.65) \\
\text { calculated }\end{array}$ & $\begin{array}{l}17.83 \%(15.33 \text { to } 20.64) \\
\text { calculated }\end{array}$ \\
\hline Newgard, 2009 & SBP $\leq 90$ & Death or LOS $>2$ days & $\begin{array}{l}24.02 \%(17.96 \text { to } 30.96) \\
\text { Calculated }\end{array}$ & $\begin{array}{l}53.99 \%(50.41 \text { to } 57.55) \\
\text { calculated }\end{array}$ & $\begin{array}{l}10.75 \%(8.41 \text { to } 13.65) \\
\text { calculated }\end{array}$ \\
\hline Newgard, 2009 & $\begin{array}{l}\text { Out-of-hospital Pediatric Clinical } \\
\text { Decision Tree, physiologic } \\
\text { measures only (ventilatory } \\
\text { assistance, GCS <11, SaO2 } \\
<95 \%, \text { SBP >96): validation } \\
\text { group }\end{array}$ & Death or LOS $>2$ days & $76.5 \%$ (66.4 to 86.6$)$ & $71.7 \%(66.7$ to 76.6$)$ & $36.9 \%$ (28.9 to 44.8$)$ \\
\hline $\begin{array}{l}\text { Newgard, } 2014 \\
\text { *Newgard, } 2016 \text { study } \\
\text { population is included in } \\
\text { Newgard, } 2014\end{array}$ & $\mathrm{SBP}<90, \mathrm{EMS}$ & Serious injury & $\begin{array}{l}4.08 \%(3.31 \text { to } 4.97) \\
\text { Calculated }\end{array}$ & $\begin{array}{l}\text { 98.52\% (98.40 to } 98.63) \\
\text { calculated }\end{array}$ & $\begin{array}{l}13.10 \%(10.88 \text { to } 15.71) \\
\text { calculated }\end{array}$ \\
\hline
\end{tabular}




\begin{tabular}{|c|c|c|c|c|c|}
\hline $\begin{array}{l}\text { Author, Year } \\
\text { (See Appendix B for } \\
\text { complete reference) }\end{array}$ & $\begin{array}{l}\text { Reported NPV } \\
(95 \% \mathrm{Cl})\end{array}$ & Reported PLR & Reported NLR & $\begin{array}{l}\text { AUROC Univariate } \\
\text { AUC }(95 \% \mathrm{CI})\end{array}$ & $\begin{array}{l}\text { Other Measures of } \\
\text { Diagnostic Accuracy }\end{array}$ \\
\hline Mizushima, 2011 & $\begin{array}{l}95.49 \%(94.64 \text { to } 96.21) \\
\text { calculated }\end{array}$ & $\begin{array}{l}4.57(3.77 \text { to } 5.55) \\
\text { calculated }\end{array}$ & $\begin{array}{l}0.50(0.42 \text { to } 0.60) \\
\text { calculated }\end{array}$ & NR & NR \\
\hline Mizushima, 2011 & $\begin{array}{l}\text { 97.10\% (95.96 to } 97.93) \\
\text { calculated }\end{array}$ & $\begin{array}{l}1.90(1.73 \text { to } 2.08) \\
\text { calculated }\end{array}$ & $\begin{array}{l}0.32(0.22 \text { to } 0.45) \\
\text { calculated }\end{array}$ & NR & NR \\
\hline Mizushima, 2011 & $\begin{array}{l}95.20 \%(94.36 \text { to } 95.92) \\
\text { calculated }\end{array}$ & $\begin{array}{l}4.53(3.70 \text { to } 5.55) \\
\text { calculated }\end{array}$ & $\begin{array}{l}0.54(0.45 \text { to } 0.63) \\
\text { calculated }\end{array}$ & NR & NR \\
\hline Montoya, 2015 & $\begin{array}{l}96.94 \%(95.39 \text { to } 97.98) \\
\text { calculated }\end{array}$ & $\begin{array}{l}10.30(7.62 \text { to } 13.92) \\
\text { calculated }\end{array}$ & $\begin{array}{l}0.22(0.15 \text { to } 0.34) \\
\text { calculated }\end{array}$ & NR & NR \\
\hline Moront, 1996 & NR & NR & NR & NR & NR \\
\hline Mutschler, 2013 & $\begin{array}{l}89.82 \%(89.58 \text { to } 90.06) \\
\text { calculated }\end{array}$ & $\begin{array}{l}2.67(2.50 \text { to } 2.85) \\
\text { calculated }\end{array}$ & $\begin{array}{l}0.77(0.75 \text { to } 0.79) \\
\text { calculated }\end{array}$ & NR & NR \\
\hline Mutschler, 2013 & NR & NR & NR & $0.719(0.710$ to 0.728$)$ & NR \\
\hline Mutschler, 2013 & NR & NR & NR & $0.711(0.703$ to 0.720$)$ & NR \\
\hline Newgard, 2009 & $\begin{array}{l}80.47 \%(78.07 \text { to } 82.66) \\
\text { calculated }\end{array}$ & $\begin{array}{l}0.94(0.79 \text { to } 1.13) \\
\text { calculated }\end{array}$ & $\begin{array}{l}1.05(0.91 \text { to } 1.22) \\
\text { calculated }\end{array}$ & NR & NR \\
\hline Newgard, 2009 & $\begin{array}{l}75.50 \% \text { (73.50 to } 77.38) \\
\text { calculated }\end{array}$ & $\begin{array}{l}0.52(0.40 \text { to } 0.69) \\
\text { calculated }\end{array}$ & $\begin{array}{l}1.41(1.27 \text { to } 1.56) \\
\text { calculated }\end{array}$ & NR & NR \\
\hline Newgard, 2009 & $93.4 \%(90.2$ to 96.5$)$ & $2.70(2.11$ to 3.29$)$ & 0.33 (0.19 to 0.47$)$ & NR & NR \\
\hline $\begin{array}{l}\text { Newgard, } 2014 \\
\text { *Newgard, } 2016 \text { study } \\
\text { population is included in } \\
\text { Newgard, } 2014\end{array}$ & $\begin{array}{l}\text { 94.94\% (94.90 to } 94.98) \\
\text { calculated }\end{array}$ & $\begin{array}{l}2.76(2.23 \text { to } 3.41) \\
\text { calculated }\end{array}$ & $\begin{array}{l}0.97 \text { (0.97 to 0.98) } \\
\text { calculated }\end{array}$ & NR & NR \\
\hline
\end{tabular}




\begin{tabular}{|c|c|c|c|c|c|}
\hline $\begin{array}{l}\text { Author, Year } \\
\text { (See Appendix B for } \\
\text { complete reference) }\end{array}$ & Measure & Indicator of Serious Injury & $\begin{array}{l}\text { Reported Sensitivity } \\
(95 \% \mathrm{Cl})\end{array}$ & $\begin{array}{l}\text { Reported Specificity } \\
(95 \% \mathrm{Cl})\end{array}$ & $\begin{array}{l}\text { Reported PPV } \\
(95 \% \mathrm{Cl})\end{array}$ \\
\hline $\begin{array}{l}\text { Newgard, } 2014 \\
\star N e w g a r d, 2016 \text { study } \\
\text { population is included in } \\
\text { Newgard, } 2014\end{array}$ & RR $<10$ or $>29$, EMS & Serious injury & $\begin{array}{l}6.31 \%(5.36 \text { to } 7.38) \\
\text { Calculated }\end{array}$ & $\begin{array}{l}98.63 \%(98.51 \text { to } 98.73) \\
\text { calculated }\end{array}$ & $\begin{array}{l}20.08 \%(17.41 \text { to } 23.05) \\
\text { calculated }\end{array}$ \\
\hline $\begin{array}{l}\text { Newgard, } 2014 \\
\text { *Newgard, } 2016 \text { study } \\
\text { population is included in } \\
\text { Newgard, } 2014\end{array}$ & Assisted ventilation, EMS & Serious injury & $\begin{array}{l}\text { 7.90\% (6.84 to 9.08) } \\
\text { Calculated }\end{array}$ & $\begin{array}{l}99.60 \%(99.53 \text { to } 99.66) \\
\text { calculated }\end{array}$ & $\begin{array}{l}51.83 \%(46.74 \text { to } 56.89) \\
\text { calculated }\end{array}$ \\
\hline $\begin{array}{l}\text { Newgard, } 2016 \\
\text { *Newgard, } 2016 \text { study } \\
\text { population is included in } \\
\text { Newgard, } 2014\end{array}$ & $\begin{array}{l}\text { Alternative elderly-specific triage } \\
\text { guidelines }\end{array}$ & Serious injury & $92.1 \%(89.8$ to 94.5$)$ & $41.5 \%$ (40.6 to 42.4) & NR \\
\hline $\begin{array}{l}\text { Newgard, } 2016 \\
\text { *Newgard, } 2016 \text { study } \\
\text { population is included in } \\
\text { Newgard, } 2014\end{array}$ & Current triage guidelines & Serious injury & $75.9 \%(72.5$ to 79.3$)$ & $77.8 \%(77.1$ to 78.5$)$ & NR \\
\hline Ocak, 2009 & $\begin{array}{l}\text { ACS-COT field triage protocol - } \\
\text { physiologic component (EMS) } \\
\text { - any of: GCS }<14 \text {, SBP }<90, \text { RR } \\
<10 \text { or }>29\end{array}$ & Major trauma & $\begin{array}{l}62.91 \%(54.69 \text { to } 70.63) \\
\text { Calculated }\end{array}$ & $\begin{array}{l}93.38 \%(88.16 \text { to } 96.78) \\
\text { calculated }\end{array}$ & $\begin{array}{l}90.48 \%(83.75 \text { to } 94.60) \\
\text { calculated }\end{array}$ \\
\hline Ocak, 2009 & SBP $<90$, EMS & Major trauma & $\begin{array}{l}9.27 \%(5.16 \text { to } 15.07) \\
\text { Calculated }\end{array}$ & $\begin{array}{l}99.34 \%(96.37 \text { to } 99.98) \\
\text { calculated }\end{array}$ & $\begin{array}{l}93.33 \%(65.09 \text { to } 99.06) \\
\text { calculated }\end{array}$ \\
\hline Ocak, 2009 & RR $<10$ or $>29$, EMS & Major trauma & $\begin{array}{l}15.23 \%(9.91 \text { to } 21.97) \\
\text { Calculated }\end{array}$ & $\begin{array}{l}99.34 \%(96.37 \text { to } 99.98) \\
\text { calculated }\end{array}$ & $\begin{array}{l}95.83 \%(75.88 \text { to } 99.41) \\
\text { calculated }\end{array}$ \\
\hline Pal, 2006 & Lactate $>2.0$ & Mortality: 48-hour & $85 \%(\mathrm{Cl} N R)$ & $38 \%(\mathrm{Cl} N R)$ & $4 \%(\mathrm{Cl} \mathrm{NR})$ \\
\hline Pal, 2006 & Lactate: patients with GCS $\geq 7$ & Mortality: 48-hour & NR & NR & $20 \%(\mathrm{Cl} \mathrm{NR})$ \\
\hline Pal, 2006 & Lactate & Mortality: 48-hour & NR & NR & NR \\
\hline Pal, 2006 & Lactate: age $>50$ years & Mortality: 48-hour & NR & NR & NR \\
\hline
\end{tabular}




\begin{tabular}{|c|c|c|c|c|c|}
\hline $\begin{array}{l}\text { Author, Year } \\
\text { (See Appendix B for } \\
\text { complete reference) }\end{array}$ & $\begin{array}{l}\text { Reported NPV } \\
(95 \% \mathrm{Cl})\end{array}$ & Reported PLR & Reported NLR & $\begin{array}{l}\text { AUROC Univariate } \\
\text { AUC }(95 \% \mathrm{CI})\end{array}$ & $\begin{array}{l}\text { Other Measures of } \\
\text { Diagnostic Accuracy }\end{array}$ \\
\hline $\begin{array}{l}\text { Newgard, } 2014 \\
\star N e w g a r d, 2016 \text { study } \\
\text { population is included in } \\
\text { Newgard, } 2014\end{array}$ & $\begin{array}{l}95.06 \%(95.01 \text { to } 95.11) \\
\text { calculated }\end{array}$ & $\begin{array}{l}4.59(3.85 \text { to } 5.48) \\
\text { calculated }\end{array}$ & $\begin{array}{l}0.95(0.94 \text { to } 0.96) \\
\text { calculated }\end{array}$ & NR & NR \\
\hline $\begin{array}{l}\text { Newgard, } 2014 \\
\text { *Newgard, } 2016 \text { study } \\
\text { population is included in } \\
\text { Newgard, } 2014\end{array}$ & $\begin{array}{l}95.19 \%(95.13 \text { to } 95.24) \\
\text { calculated }\end{array}$ & $\begin{array}{l}19.67(16.04 \text { to } 24.12) \\
\text { calculated }\end{array}$ & $\begin{array}{l}0.92(0.91 \text { to } 0.94) \\
\text { calculated }\end{array}$ & NR & NR \\
\hline $\begin{array}{l}\text { Newgard, } 2016 \\
\text { *Newgard, } 2016 \text { study } \\
\text { population is included in } \\
\text { Newgard, } 2014\end{array}$ & NR & NR & NR & $0.67(0.66$ to 0.68$)$ & NR \\
\hline $\begin{array}{l}\text { Newgard, } 2016 \\
\text { *Newgard, } 2016 \text { study } \\
\text { population is included in } \\
\text { Newgard, } 2014\end{array}$ & NR & NR & NR & $0.77(0.75$ to 0.79$)$ & NR \\
\hline Ocak, 2009 & $\begin{array}{l}71.57 \% \text { (67.07 to } 75.68) \\
\text { calculated }\end{array}$ & $\begin{array}{l}9.50(5.16 \text { to } 17.51) \\
\text { calculated }\end{array}$ & $\begin{array}{l}0.40(0.32 \text { to } 0.49) \\
\text { Calculated }\end{array}$ & NR & NR \\
\hline Ocak, 2009 & $\begin{array}{l}52.26 \%(50.95 \text { to } 53.58) \\
\text { calculated }\end{array}$ & $\begin{array}{l}14.00(1.86 \text { to } 105.14) \\
\text { calculated }\end{array}$ & $\begin{array}{l}0.91(0.87 \text { to } 0.96) \\
\text { Calculated }\end{array}$ & NR & NR \\
\hline Ocak, 2009 & $\begin{array}{l}53.96 \%(52.24 \text { to } 55.66) \\
\text { calculated }\end{array}$ & $\begin{array}{l}23.00(3.15 \text { to } 168.16) \\
\text { calculated }\end{array}$ & $\begin{array}{l}0.85(0.80 \text { to } 0.91) \\
\text { Calculated }\end{array}$ & NR & NR \\
\hline Pal, 2006 & NR & NR & NR & NR & NR \\
\hline Pal, 2006 & NR & NR & NR & $0.71(\mathrm{Cl} \mathrm{NR})$ & NR \\
\hline Pal, 2006 & NR & NR & NR & $0.72(\mathrm{Cl} \mathrm{NR})$ & NR \\
\hline Pal, 2006 & NR & NR & NR & 0.65 (Cl NR) & NR \\
\hline
\end{tabular}




\begin{tabular}{|c|c|c|c|c|c|}
\hline $\begin{array}{l}\text { Author, Year } \\
\text { (See Appendix B for } \\
\text { complete reference) }\end{array}$ & Measure & Indicator of Serious Injury & $\begin{array}{l}\text { Reported Sensitivity } \\
(95 \% \mathrm{Cl})\end{array}$ & $\begin{array}{l}\text { Reported Specificity } \\
(95 \% \mathrm{Cl})\end{array}$ & $\begin{array}{l}\text { Reported PPV } \\
(95 \% \mathrm{Cl})\end{array}$ \\
\hline Pal, 2006 & Lactate: age $>60$ years & Mortality: 48-hour & NR & NR & NR \\
\hline Pal, 2006 & Lactate: age $>70$ years & Mortality: 48-hour & NR & NR & NR \\
\hline Paladino, 2008 & $\begin{array}{l}\text { Combination, any of: lactate } \\
>2.2, \mathrm{BD}<-2.0, \mathrm{HR}>100 \text { or } \\
\mathrm{SBP}<90\end{array}$ & Major injury & $76.4 \%(71.1-81.8)$ & $48 \%(45-51)$ & NR \\
\hline Paladino, 2008 & $\begin{array}{l}\text { Combination: } \mathrm{HR}>100 \text { or SBP } \\
<90\end{array}$ & Major injury & $40.9 \%(34.7-47.1)$ & $75 \%(72-77)$ & NR \\
\hline Paladino, 2008 & $\begin{array}{l}\text { BD < -1.3: subgroup with normal } \\
\text { vital signs }\end{array}$ & Major injury & $56 \%(\mathrm{NR})$ & $71 \%(\mathrm{NR})$ & NR \\
\hline Paladino, 2008 & $\begin{array}{l}\text { BD: subgroup with normal vital } \\
\text { signs }\end{array}$ & Major injury & NR & NR & NR \\
\hline Paladino, 2008 & $\mathrm{HR}>100$ & Major injury & $37.6 \%$ (31.5 to 43.7) & NR & NR \\
\hline Paladino, 2008 & $\begin{array}{l}\text { Lactate }>2.5 \text { : subgroup with } \\
\text { normal vital signs }\end{array}$ & Major injury & $76 \%(\mathrm{Cl} \mathrm{NR})$ & $49 \%(\mathrm{Cl} \mathrm{NR})$ & NR \\
\hline Paladino, 2008 & $\begin{array}{l}\text { Lactate: subgroup with normal } \\
\text { vital signs }\end{array}$ & Major injury & NR & NR & NR \\
\hline Paladino, 2008 & SBP $<90$ & Major injury & NR & $99.4 \%$ (99 to 99.8$)$ & NR \\
\hline Paladino, 2010a & $B D$ & Major injury & NR & NR & NR \\
\hline Paladino, 2010a & DBP & Major injury & NR & NR & NR \\
\hline Paladino, 2010a & HR & Major injury & NR & NR & NR \\
\hline Paladino, 2010a & Lactate & Major injury & NR & NR & NR \\
\hline Paladino, 2010a & SBP & Major injury & NR & NR & NR \\
\hline Paladino, 2010b & $B D$ & Major injury & NR & NR & NR \\
\hline Paladino, 2010b & Lactate & Major injury & NR & $\overline{N R}$ & NR \\
\hline Paladino, 2010b & RTS & Major injury & NR & NR & NR \\
\hline Paladino, 2011 & $\mathrm{BD}, \mathrm{ED}$ & Major injury & NR & NR & NR \\
\hline Paladino, 2011 & HR, ED & Major injury & NR & NR & NR \\
\hline Paladino, 2011 & Lactate, ED & Major injury & NR & NR & NR \\
\hline \begin{tabular}{|l|} 
Paladino, 2011 \\
\end{tabular} & SBP, ED & Major injury & NR & NR & NR \\
\hline Paladino, 2011 & $\mathrm{SI} \geq 0.70, \mathrm{ED}$ & Major injury & $56 \%$ (50 to 63) & $61 \%$ (59 to 65$)$ & NR \\
\hline Paladino, 2011 & $\mathrm{SI} \geq 0.80, \mathrm{ED}$ & Major injury & $36 \%$ (30 to 43) & $81 \%$ (79 to 83$)$ & NR \\
\hline Paladino, 2011 & $\mathrm{SI} \geq 0.90, \mathrm{ED}$ & Major injury & $24 \%$ (19 to 30$)$ & $92 \%$ (90 to 93$)$ & NR \\
\hline Paladino, 2011 & $\mathrm{SI} \geq 1.0, \mathrm{ED}$ & Major injury & $18 \%$ (13 to 23$)$ & $96 \%$ (95 to 97 ) & NR \\
\hline Paladino, 2011 & SI, ED & Major injury & NR & NR & NR \\
\hline Paladino, 2011 & $\begin{array}{l}\text { SI, ED: subgroup with normal } \\
\text { vital signs ( } \mathrm{SBP} \geq 90, \mathrm{HR} \leq 100 \text { ) }\end{array}$ & Major injury & NR & NR & NR \\
\hline Pandit, 2014 & $\begin{array}{l}\mathrm{SI} \geq 1, \mathrm{ED} \\
\text { (study limited to elderly) }\end{array}$ & Blood transfusion & $\begin{array}{l}5.80 \%(5.44 \text { to } 6.17) \\
\text { calculated }\end{array}$ & $\begin{array}{l}\text { 97.19\% (97.11 to } 97.26) \\
\text { calculated }\end{array}$ & $\begin{array}{l}14.08 \%(13.28 \text { to } 14.91) \\
\text { calculated }\end{array}$ \\
\hline
\end{tabular}




\begin{tabular}{|c|c|c|c|c|c|}
\hline $\begin{array}{l}\text { Author, Year } \\
\text { (See Appendix B for } \\
\text { complete reference) }\end{array}$ & $\begin{array}{l}\text { Reported NPV } \\
(95 \% \mathrm{Cl})\end{array}$ & Reported PLR & Reported NLR & $\begin{array}{l}\text { AUROC Univariate } \\
\text { AUC }(95 \% \mathrm{CI})\end{array}$ & $\begin{array}{l}\text { Other Measures of } \\
\text { Diagnostic Accuracy }\end{array}$ \\
\hline Pal, 2006 & NR & NR & NR & $0.63(\mathrm{Cl} \mathrm{NR})$ & NR \\
\hline Pal, 2006 & NR & $\overline{N R}$ & $\widehat{N R}$ & $0.62(\mathrm{Cl} \mathrm{NR})$ & $\widehat{N R}$ \\
\hline Paladino, 2008 & $90.9 \%(\mathrm{NR})$ & $1.47(1.34$ to 1.6$)$ & $0.49(0.39$ to 0.62$)$ & NR & NR \\
\hline Paladino, 2008 & $86.2 \%(\mathrm{NR})$ & 1.62 (1.35 to 1.93$)$ & $0.79(0.71$ to 0.88$)$ & NR & NR \\
\hline Paladino, 2008 & NR & NR & NR & NR & NR \\
\hline Paladino, 2008 & NR & NR & NR & 0.68 (0.63 to 0.73$), p<0.0001$ & NR \\
\hline Paladino, 2008 & NR & NR & NR & NR & NR \\
\hline Paladino, 2008 & NR & NR & NR & NR & NR \\
\hline Paladino, 2008 & NR & NR & NR & 0.64 (0.58 to 0.69$), p<0.0001$ & NR \\
\hline Paladino, 2008 & NR & $11.3(\mathrm{Cl} \mathrm{NR})$ & NR & NR & NR \\
\hline Paladino, 2010a & NR & NR & NR & $0.69(0.63$ to 0.74$)$ & SE 0.028 \\
\hline Paladino, 2010a & NR & NR & NR & 0.49 (CI NR) & NR \\
\hline Paladino, 2010a & NR & NR & NR & $0.61(\mathrm{Cl} \mathrm{NR})$ & NR \\
\hline Paladino, 2010a & NR & NR & NR & $0.66(0.60$ to 0.71$)$ & SE 0.028 \\
\hline Paladino, 2010a & NR & NR & NR & 0.51 (CI NR) & NR \\
\hline Paladino, 2010b & NR & NR & NR & $0.72(0.68$ to 0.76$)$ & SE 0.018 \\
\hline Paladino, 2010b & NR & NR & NR & 0.71 (0.67 to 0.75$)$ & SE 0.018 \\
\hline Paladino, 2010b & NR & NR & NR & $0.63(0.60$ to 0.67$)$ & NR \\
\hline Paladino, 2011 & NR & NR & NR & $0.72(0.69$ to 0.76$)$ & NR \\
\hline Paladino, 2011 & NR & NR & NR & 0.58 (0.54 to 0.62$)$ & NR \\
\hline Paladino, 2011 & NR & NR & NR & $0.69(0.65$ to 0.73$)$ & NR \\
\hline Paladino, 2011 & NR & NR & NR & $0.61(0.56$ to 0.65$)$ & NR \\
\hline Paladino, 2011 & NR & 1.48 (1.29 to 1.68$)$ & 0.7 (0.61 to 0.82$)$ & NR & NR \\
\hline Paladino, 2011 & NR & 1.90 (1.55 to 2.33$)$ & $0.79(0.71$ to 0.86$)$ & NR & NR \\
\hline Paladino, 2011 & NR & $2.91(2.17$ to 3.89$)$ & $0.83(0.77$ to 0.89$)$ & NR & NR \\
\hline Paladino, 2011 & NR & 4.71 (3.17 to 6.98$)$ & $0.85(0.81$ to 0.91$)$ & NR & NR \\
\hline Paladino, 2011 & NR & NR & NR & 0.63 (0.59 to 0.67$)$ & NR \\
\hline Paladino, 2011 & NR & NR & NR & $0.56(0.51$ to 0.61$)$ & NR \\
\hline Pandit, 2014 & $\begin{array}{l}92.85 \%(92.83 \text { to } 92.88) \\
\text { calculated }\end{array}$ & $\begin{array}{l}2.06(1.93 \text { to } 2.21) \\
\text { calculated }\end{array}$ & $\begin{array}{l}0.97 \text { (0.97 to 0.97) } \\
\text { calculated }\end{array}$ & NR & NR \\
\hline
\end{tabular}




\begin{tabular}{|c|c|c|c|c|c|}
\hline $\begin{array}{l}\text { Author, Year } \\
\text { (See Appendix B for } \\
\text { complete reference) }\end{array}$ & Measure & Indicator of Serious Injury & $\begin{array}{l}\text { Reported Sensitivity } \\
(95 \% \mathrm{Cl})\end{array}$ & $\begin{array}{l}\text { Reported Specificity } \\
(95 \% \mathrm{Cl})\end{array}$ & $\begin{array}{l}\text { Reported PPV } \\
(95 \% \mathrm{Cl})\end{array}$ \\
\hline Pandit, 2014 & $\begin{array}{l}\mathrm{SI} \geq 1, \mathrm{ED} \\
\text { (study limited to elderly) }\end{array}$ & Exploratory laparotomy & $\begin{array}{l}7.54 \%(6.84 \text { to } 8.29) \\
\text { calculated }\end{array}$ & $\begin{array}{l}97.08 \%(97.01 \text { to } 97.15) \\
\text { calculated }\end{array}$ & $\begin{array}{l}6.00 \%(5.47 \text { to } 6.58) \\
\text { calculated }\end{array}$ \\
\hline Pandit, 2014 & $\begin{array}{l}\text { SI } \geq 1, \text { ED } \\
\text { (study limited to elderly) }\end{array}$ & Mortality & $\begin{array}{l}45 \%(\mathrm{Cl} N \mathrm{NR}) \text { reported } \\
12.7 \%(12.0 \text { to } 13.4) \\
\text { calculated }\end{array}$ & $\begin{array}{l}97 \%(\mathrm{Cl} N R) \text { reported } \\
97.4 \%(97.3 \text { to } 97.5) \\
\text { calculated }\end{array}$ & $\begin{array}{l}82 \%(\mathrm{Cl} N R) \text { reported } \\
17.2 \%(16.4 \text { to } 18.1) \\
\text { calculated }\end{array}$ \\
\hline Parimi, 2016 & $\begin{array}{l}\text { Continuous vital signs, } 10- \\
\text { minute model }\end{array}$ & $\begin{array}{l}\text { Massive transfusion (MT1): } 4 \\
\text { units in } 4 \text { hours }\end{array}$ & $80 \%(N R)$ & $87 \%(N R)$ & $14 \%(N R)$ \\
\hline Parimi, 2016 & $\begin{array}{l}\text { Continuous vital signs, 15- } \\
\text { minute model }\end{array}$ & $\begin{array}{l}\text { Massive transfusion (MT1): } 4 \\
\text { units in } 4 \text { hours }\end{array}$ & $82 \%(N R)$ & $87 \%(N R)$ & $15 \%(\mathrm{NR})$ \\
\hline Parimi, 2016 & $\begin{array}{l}\text { Continuous vital signs, 5-minute } \\
\text { model }\end{array}$ & $\begin{array}{l}\text { Massive transfusion (MT1): } 4 \\
\text { units in } 4 \text { hours }\end{array}$ & $78 \%(\mathrm{NR})$ & $85 \%(N R)$ & $12 \%(\mathrm{NR})$ \\
\hline Parimi, 2016 & $\begin{array}{l}\text { Admission vital signs model: HR, } \\
\text { SBP, and SI }\end{array}$ & $\begin{array}{l}\text { Massive transfusion (MT1): } 4 \\
\text { units in } 4 \text { hours }\end{array}$ & $71 \%(\mathrm{NR})$ & $87 \%(\mathrm{NR})$ & $13 \%(\mathrm{NR})$ \\
\hline Parimi, 2016 & $\begin{array}{l}\text { Preadmission vital signs model: } \\
\text { HR, SBP and SI }\end{array}$ & $\begin{array}{l}\text { Massive transfusion (MT1): } 4 \\
\text { units in } 4 \text { hours }\end{array}$ & $72 \%(N R)$ & $84 \%(N R)$ & $10 \%(\mathrm{NR})$ \\
\hline Parimi, 2016 & $\begin{array}{l}\text { Continuous vital signs, } 10- \\
\text { minute model }\end{array}$ & $\begin{array}{l}\text { Massive transfusion (MT2): } 10 \\
\text { units in } 24 \text { hours }\end{array}$ & $83 \%(N R)$ & $88 \%(N R)$ & $10 \%(\mathrm{NR})$ \\
\hline Parimi, 2016 & $\begin{array}{l}\text { Continuous vital signs, 15- } \\
\text { minute model }\end{array}$ & $\begin{array}{l}\text { Massive transfusion (MT2): } 10 \\
\text { units in } 24 \text { hours }\end{array}$ & $87 \%(\mathrm{NR})$ & $89 \%(N R)$ & $11 \%(\mathrm{NR})$ \\
\hline Parimi, 2016 & $\begin{array}{l}\text { Continuous vital signs, 5-minute } \\
\text { model }\end{array}$ & $\begin{array}{l}\text { Massive transfusion (MT2): } 10 \\
\text { units in } 24 \text { hours }\end{array}$ & $83 \%(N R)$ & $85 \%(N R)$ & $8 \%(\mathrm{NR})$ \\
\hline Parimi, 2016 & $\begin{array}{l}\text { Admission vital signs model: HR, } \\
\text { SBP, and SI }\end{array}$ & $\begin{array}{l}\text { Massive transfusion (MT2): } 10 \\
\text { units in } 24 \text { hours }\end{array}$ & $77 \%(\mathrm{NR})$ & $87 \%(N R)$ & $10 \%(\mathrm{NR})$ \\
\hline Parimi, 2016 & $\begin{array}{l}\text { Preadmission vital signs model: } \\
\text { HR, SBP and SI }\end{array}$ & $\begin{array}{l}\text { Massive transfusion (MT2): } 10 \\
\text { units in } 24 \text { hours }\end{array}$ & $77 \%(\mathrm{NR})$ & $83 \%(N R)$ & $7 \%(\mathrm{NR})$ \\
\hline Parsikia, 2014 & Lactate & Mortality & NR & NR & NR \\
\hline Perel, 2012 & $\begin{array}{l}\text { Simple prognostic model (age, } \\
\text { SBP, GCS score): Development } \\
\text { data set } \\
\text { Chart stratified by low-, middle-, } \\
\text { or high-income country }\end{array}$ & Mortality: in-hospital & $\widehat{N R}$ & NR & NR \\
\hline Perel, 2012 & $\begin{array}{l}\text { Simple prognostic model (age, } \\
\text { SBP, GCS score): Development } \\
\text { data set } \\
\text { Chart stratified by low-, middle-, } \\
\text { or high-income country }\end{array}$ & Mortality: in-hospital & NR & NR & NR \\
\hline
\end{tabular}




\begin{tabular}{|c|c|c|c|c|c|}
\hline $\begin{array}{l}\text { Author, Year } \\
\text { (See Appendix B for } \\
\text { complete reference) }\end{array}$ & $\begin{array}{l}\text { Reported NPV } \\
(95 \% \mathrm{Cl})\end{array}$ & Reported PLR & Reported NLR & $\begin{array}{l}\text { AUROC Univariate } \\
\text { AUC }(95 \% \mathrm{Cl})\end{array}$ & $\begin{array}{l}\text { Other Measures of } \\
\text { Diagnostic Accuracy }\end{array}$ \\
\hline Pandit, 2014 & $\begin{array}{l}97.70 \%(97.68 \text { to } 97.72) \\
\text { calculated }\end{array}$ & $\begin{array}{l}2.58(2.34 \text { to } 2.85) \\
\text { calculated }\end{array}$ & $\begin{array}{l}0.95(0.95 \text { to } 0.96) \\
\text { calculated }\end{array}$ & NR & NR \\
\hline Pandit, 2014 & $\begin{array}{l}67 \%(\mathrm{Cl} \mathrm{NR}) \text { reported } \\
96.3 \%(96.3 \text { to } 96.3) \\
\text { calculated }\end{array}$ & $\begin{array}{l}\text { NR } \\
4.83 \text { (4.55 to } 5.14) \\
\text { calculated }\end{array}$ & $\begin{array}{l}\text { NR } \\
0.90(0.89 \text { to } 0.90) \\
\text { calculated }\end{array}$ & NR & Accuracy = 85\% \\
\hline Parimi, 2016 & $99 \%(\mathrm{NR})$ & NR & NR & $0.87(0.86-0.88)$ & NR \\
\hline Parimi, 2016 & $99 \%(\mathrm{NR})$ & NR & NR & $0.89(0.88-0.90)$ & NR \\
\hline Parimi, 2016 & $99 \%(\mathrm{NR})$ & NR & NR & $0.85(0.84-0.86)$ & NR \\
\hline Parimi, 2016 & $99 \%(\mathrm{NR})$ & NR & NR & $0.82(0.81-0.83)$ & NR \\
\hline Parimi, 2016 & $99 \%(\mathrm{NR})$ & NR & NR & $0.81(0.80-0.81)$ & NR \\
\hline Parimi, 2016 & $99 \%(\mathrm{NR})$ & NR & NR & $0.88(0.87-0.90)$ & NR \\
\hline Parimi, 2016 & $99 \%(\mathrm{NR})$ & NR & NR & $0.91(0.91-0.92)$ & NR \\
\hline Parimi, 2016 & $99 \%(N R)$ & NR & NR & $0.86(0.85-0.88)$ & NR \\
\hline Parimi, 2016 & $99 \%(\mathrm{NR})$ & NR & NR & $0.85(0.83-0.86)$ & NR \\
\hline Parimi, 2016 & $99 \%(N R)$ & NR & NR & $0.82(0.81-0.84)$ & NR \\
\hline Parsikia, 2014 & NR & NR & NR & 0.634 (NR) & NR \\
\hline Perel, 2012 & NR & NR & NR & $0.82(\mathrm{NR})$ & NR \\
\hline Perel, 2012 & NR & NR & NR & 0.86 (NR) & NR \\
\hline
\end{tabular}




\begin{tabular}{|c|c|c|c|c|c|}
\hline $\begin{array}{l}\text { Author, Year } \\
\text { (See Appendix B for } \\
\text { complete reference) }\end{array}$ & Measure & Indicator of Serious Injury & $\begin{array}{l}\text { Reported Sensitivity } \\
(95 \% \mathrm{Cl})\end{array}$ & $\begin{array}{l}\text { Reported Specificity } \\
(95 \% \mathrm{Cl})\end{array}$ & $\begin{array}{l}\text { Reported PPV (95\% } \\
\mathrm{Cl})\end{array}$ \\
\hline Potoka, 2001 & RTS <12: test data set & ISS $>20$ & $64.86 \%(\mathrm{NR})$ & $77.71 \%(\mathrm{NR})$ & NR \\
\hline Potoka, 2001 & T-ASPTS <10: test data set & ISS $>20$ & $49.43 \%(\mathrm{NR})$ & $91.83 \%(\mathrm{NR})$ & NR \\
\hline Potoka, 2001 & RTS <12: test data set & Mortality & $100.00 \%(\mathrm{NR})$ & $74.05 \%(\mathrm{NR})$ & NR \\
\hline Potoka, 2001 & T-ASPTS <10: test data set & Mortality & $96.97 \%(\mathrm{NR})$ & $88.83 \%(\mathrm{NR})$ & NR \\
\hline Potoka, 2001 & T-ASPTS <10: study data set & ISS $>20$ & $68.06 \%(\mathrm{NR})$ & $75.18 \%(\mathrm{NR})$ & NR \\
\hline Potoka, 2001 & T-ASPTS <10: study data set & Mortality & $98.84 \%(\mathrm{NR})$ & $89.02 \%(N R)$ & NR \\
\hline Pottecher, 2016 & PP/HR ratio & Massive transfusion ( $\geq 10$ units in 24 hours) & NR & NR & NR \\
\hline Pottecher, 2016 & PP/HR ratio & Massive transfusion ( $\geq 3$ units in 1 hour) & NR & NR & NR \\
\hline Pottecher, 2016 & PP/HR ratio $<0.443$ & Massive transfusion ( $\geq 10$ units in 24 hours) & $75 \%(\mathrm{NR})$ & $74 \%(\mathrm{NR})$ & NR \\
\hline Pottecher, 2016 & $\mathrm{PP} / \mathrm{HR}$ ratio $<0.443$ & Massive transfusion ( $\geq 3$ units in 1 hour) & $75 \%(N R)$ & $62 \%(\mathrm{NR})$ & NR \\
\hline Pottecher, 2016 & $\begin{array}{l}\text { PP/HR ratio: Grade A or B } \\
\text { patients (higher severity) }\end{array}$ & Massive transfusion ( $\geq 10$ units in 24 hours) & NR & NR & NR \\
\hline Pottecher, 2016 & $\begin{array}{l}\text { PP/HR ratio: Grade A or B } \\
\text { patients (higher severity) }\end{array}$ & Massive transfusion ( $\geq 3$ units in 1 hour) & NR & NR & NR \\
\hline Pottecher, 2016 & $\begin{array}{l}\text { PP/HR ratio: Grade C patients } \\
\text { (lower severity) }\end{array}$ & Massive transfusion ( $\geq 10$ units in 24 hours) & NR & NR & NR \\
\hline Pottecher, 2016 & $\begin{array}{l}\text { PP/HR ratio: Grade C patients } \\
\text { (lower severity) }\end{array}$ & Massive transfusion ( $\geq 3$ units in 1 hour) & NR & NR & NR \\
\hline Pottecher, 2016 & SBP & Massive transfusion ( $\geq 10$ units in 24 hours) & NR & NR & NR \\
\hline Pottecher, 2016 & SBP & Massive transfusion ( $\geq 3$ units in 1 hour) & NR & NR & NR \\
\hline Pottecher, 2016 & $\mathrm{SI}$ & Massive transfusion ( $\geq 10$ units in 24 hours) & NR & NR & NR \\
\hline Pottecher, 2016 & $\mathrm{SI}$ & Massive transfusion ( $\geq 3$ units in 1 hour) & NR & NR & NR \\
\hline Pottecher, 2016 & $\mathrm{SI}>0.933$ & Massive transfusion ( $\geq 3$ units in 1 hour) & $53 \%(N R)$ & $85 \%(N R)$ & NR \\
\hline Pottecher, 2016 & $\mathrm{SI}>0.967$ & Massive transfusion ( $\geq 10$ units in 24 hours) & $68 \%(\mathrm{NR})$ & $86 \%(\mathrm{NR})$ & NR \\
\hline Pottecher, 2016 & $\begin{array}{l}\text { SI: Grade A or B patients (higher } \\
\text { severity) }\end{array}$ & Massive transfusion ( $\geq 10$ units in 24 hours) & NR & NR & NR \\
\hline Pottecher, 2016 & $\begin{array}{l}\text { SI: Grade A or B patients (higher } \\
\text { severity) }\end{array}$ & Massive transfusion ( $\geq 3$ units in 1 hour) & NR & NR & NR \\
\hline Pottecher, 2016 & $\begin{array}{l}\text { SI: Grade C patients (lower } \\
\text { severity) }\end{array}$ & Massive transfusion ( $\geq 10$ units in 24 hours) & NR & NR & NR \\
\hline
\end{tabular}




\begin{tabular}{|c|c|c|c|c|c|}
\hline $\begin{array}{l}\text { Author, Year } \\
\text { (See Appendix B for } \\
\text { complete reference) }\end{array}$ & $\begin{array}{l}\text { Reported NPV } \\
(95 \% \mathrm{Cl})\end{array}$ & Reported PLR & Reported NLR & $\begin{array}{l}\text { AUROC Univariate } \\
\text { AUC }(95 \% \mathrm{Cl})\end{array}$ & $\begin{array}{l}\text { Other Measures of } \\
\text { Diagnostic Accuracy }\end{array}$ \\
\hline Potoka, 2001 & NR & NR & NR & NR & NR \\
\hline Potoka, 2001 & NR & NR & NR & NR & NR \\
\hline Potoka, 2001 & NR & NR & NR & NR & NR \\
\hline Potoka, 2001 & NR & NR & NR & NR & NR \\
\hline Potoka, 2001 & NR & NR & NR & NR & NR \\
\hline Potoka, 2001 & NR & NR & NR & NR & NR \\
\hline Pottecher, 2016 & NR & NR & NR & $0.767(0.70$ to 0.84$)$ & NR \\
\hline Pottecher, 2016 & NR & NR & NR & $0.713(0.67$ to 0.76$)$ & NR \\
\hline Pottecher, 2016 & NR & $2.94(\mathrm{NR})$ & $0.35(\mathrm{NR})$ & NR & $\begin{array}{l}\text { Gray zone: } 0.330 \text { to } 0.681 \\
61 \% \text { of patients }\end{array}$ \\
\hline Pottecher, 2016 & NR & $1.95(\mathrm{NR})$ & $0.41(\mathrm{NR})$ & NR & $\begin{array}{l}\text { Gray zone: } 0.336 \text { to } 0.701 \\
62 \% \text { of patients }\end{array}$ \\
\hline Pottecher, 2016 & NR & NR & NR & $0.72(0.65$ to 0.73$)$ & NR \\
\hline Pottecher, 2016 & NR & NR & NR & $0.69(0.64$ to 0.73$)$ & NR \\
\hline Pottecher, 2016 & NR & NR & NR & $0.91(0.82$ to 1.00$)$ & NR \\
\hline Pottecher, 2016 & NR & NR & NR & $0.72(0.59$ to 0.84$)$ & NR \\
\hline Pottecher, 2016 & NR & NR & NR & $0.61(0.57$ to 0.64$)$ & NR \\
\hline Pottecher, 2016 & NR & NR & NR & $0.62(0.56$ to 0.67$)$ & NR \\
\hline Pottecher, 2016 & NR & NR & NR & $0.802(0.74$ to 0.87$)$ & NR \\
\hline Pottecher, 2016 & NR & NR & NR & $0.722(0.68$ to 0.77$)$ & NR \\
\hline Pottecher, 2016 & NR & $3.54(\mathrm{NR})$ & $0.56(\mathrm{NR})$ & NR & $\begin{array}{l}\text { Gray zone: } 0.547 \text { to } 1.000) \\
71 \% \text { of patients }\end{array}$ \\
\hline Pottecher, 2016 & NR & 4.74 (NR) & 0.39 (NR) & NR & $\begin{array}{l}\text { Gray zone: } 0.694 \text { to } 1.029) \\
40 \% \text { of patients }\end{array}$ \\
\hline Pottecher, 2016 & NR & NR & NR & $0.76(0.65$ to 0.79$)$ & NR \\
\hline Pottecher, 2016 & NR & NR & NR & $0.70(0.66$ to 0.73$)$ & NR \\
\hline Pottecher, 2016 & NR & NR & NR & $0.87(0.79$ to 1.00$)$ & NR \\
\hline
\end{tabular}




\begin{tabular}{|c|c|c|c|c|c|}
\hline $\begin{array}{l}\text { Author, Year } \\
\text { (See Appendix B for } \\
\text { complete reference) }\end{array}$ & Measure & Indicator of Serious Injury & $\begin{array}{l}\text { Reported Sensitivity } \\
(95 \% \mathrm{Cl})\end{array}$ & $\begin{array}{l}\text { Reported Specificity } \\
(95 \% \mathrm{Cl})\end{array}$ & $\begin{array}{l}\text { Reported PPV } \\
(95 \% \mathrm{Cl})\end{array}$ \\
\hline Pottecher, 2016 & $\begin{array}{l}\text { SI: Grade C patients (lower } \\
\text { severity) }\end{array}$ & $\begin{array}{l}\text { Massive transfusion ( } \geq 3 \text { units in } 1 \\
\text { hour) }\end{array}$ & NR & NR & NR \\
\hline Rahmani, 2017 & GAP & Need for surgery & NR & NR & NR \\
\hline Rahmani, 2017 & GAP $\leq 21$ & Need for surgery & $75 \%(\mathrm{NR})$ & $57 \%(\mathrm{NR})$ & $64 \%(N R)$ \\
\hline Rahmani, 2017 & GAP & Mortality: ED & NR & NR & NR \\
\hline Rahmani, 2017 & GAP $\leq 18$ & Mortality: ED & $88 \%(\mathrm{NR})$ & $85 \%(N R)$ & $85 \%(N R)$ \\
\hline Rahmani, 2017 & GAP & Mortality: in-hospital & NR & NR & NR \\
\hline Rahmani, 2017 & GAP $\leq 14$ & Mortality: in-hospital & $98 \%(\mathrm{NR})$ & $91 \%(\mathrm{NR})$ & $91 \%(\mathrm{NR})$ \\
\hline Rahmani, 2017 & MGAP & Need for surgery & NR & NR & NR \\
\hline Rahmani, 2017 & MGAP $\leq 25$ & Need for surgery & $74 \%(\mathrm{NR})$ & $60 \%(\mathrm{NR})$ & $65 \%(N R)$ \\
\hline Rahmani, 2017 & MGAP & Mortality: ED & NR & NR & NR \\
\hline Rahmani, 2017 & MGAP $\leq 22$ & Mortality: ED & $87 \%(\mathrm{NR})$ & $85 \%(\mathrm{NR})$ & $85 \%(\mathrm{NR})$ \\
\hline Rahmani, 2017 & MGAP & Mortality: in-hospital & NR & NR & NR \\
\hline Rahmani, 2017 & MGAP $\leq 18$ & Mortality: in-hospital & $98 \%(\mathrm{NR})$ & $91 \%(\mathrm{NR})$ & $91 \%(\mathrm{NR})$ \\
\hline Rainer, 2011 & SBP $\leq 90$ & Massive transfusion & $\begin{array}{l}38.04 \%(28.12 \text { to } 48.76) \\
\text { calculated }\end{array}$ & $\begin{array}{l}\text { 97.05\% (96.16 to } 97.79) \\
\text { calculated }\end{array}$ & $\begin{array}{l}39.77 \%(31.28 \text { to } 48.93) \\
\text { calculated }\end{array}$ \\
\hline Rainer, 2011 & $H R \geq 120$ & Massive transfusion & $\begin{array}{l}26.09 \% \text { (17.48 to } 36.29) \\
\text { calculated }\end{array}$ & $\begin{array}{l}95.50 \%(94.43 \text { to } 96.41) \\
\text { calculated }\end{array}$ & $\begin{array}{l}22.86 \%(16.51 \text { to } 30.75) \\
\text { calculated }\end{array}$ \\
\hline Rainer, 2011 & $B D<-5$ & Massive transfusion & $\begin{array}{l}41.30 \%(31.13 \text { to } 52.05) \\
\text { calculated }\end{array}$ & $\begin{array}{l}94.16 \%(92.98 \text { to } 95.20) \\
\text { calculated }\end{array}$ & $\begin{array}{l}26.57 \%(21.04 \text { to } 32.96) \\
\text { calculated }\end{array}$ \\
\hline Rainer, 2011 & $\mathrm{pH}<7.33$ & Massive transfusion & $\begin{array}{l}35.87 \%(26.13 \text { to } 46.54) \\
\text { calculated }\end{array}$ & $\begin{array}{l}95.16 \%(94.07 \text { to } 96.11) \\
\text { calculated }\end{array}$ & $\begin{array}{l}27.50 \%(21.23 \text { to } 34.80) \\
\text { calculated }\end{array}$ \\
\hline Rainer, 2011 & $\begin{array}{l}\text { Predictive model for massive } \\
\text { transfusion, score } \geq 6 \text { : uses SBP, } \\
\text { GCS, HR, BD, hemoglobin, } \\
\text { pelvic fracture and abdominal } \\
\text { free fluid }\end{array}$ & Massive transfusion & $31.5 \%(22.2$ to 42.0$)$ & $99.7 \%$ (99.3 to 99.9$)$ & $82.9 \%(66.4$ to 93.4$)$ \\
\hline Rainer, 2011 & $\begin{array}{l}\text { Predictive model for massive } \\
\text { transfusion: uses SBP, GCS, } \\
\text { HR, BD, hemoglobin, pelvic } \\
\text { fracture and abdominal free fluid }\end{array}$ & Massive transfusion & NR & NR & NR \\
\hline Ramanathan, 2015 & Lactate $>2.0$ & ICU admission & $77.9 \%(67.0-86.6)$ & $58.5 \%(50.4-66.2)$ & $47.6 \%(38.6-56.7)$ \\
\hline Ramanathan, 2015 & $B D<-5$ & ISS >15 & $25.0 \%(13.2-40.3)$ & $98.3 \%(95.1-99.6)$ & $78.6 \%(49.2-95.1)$ \\
\hline Ramanathan, 2015 & Lactate $>2.0$ and $\mathrm{pH}<7.30$ & ISS >15 & $55.6 \%(40.0-70.3)$ & $95.1 \%(91.0-97.7)$ & $73.5 \%(55.6-87.1)$ \\
\hline Ramanathan, 2015 & Lactate $>4.7$ & ISS $>15$ & $26.7 \%(14.6-41.9)$ & $95.8 \%(91.9-98.2)$ & $60.0 \%(36.1-80.8)$ \\
\hline
\end{tabular}




\begin{tabular}{|c|c|c|c|c|c|}
\hline $\begin{array}{l}\text { Author, Year } \\
\text { (See Appendix B for } \\
\text { complete reference) }\end{array}$ & $\begin{array}{l}\text { Reported NPV } \\
(95 \% \mathrm{CI})\end{array}$ & Reported PLR & Reported NLR & $\begin{array}{l}\text { AUROC Univariate } \\
\text { AUC }(95 \% \mathrm{CI})\end{array}$ & $\begin{array}{l}\text { Other Measures of } \\
\text { Diagnostic Accuracy }\end{array}$ \\
\hline Pottecher, 2016 & NR & NR & NR & $0.54(0.33$ to 0.74$)$ & NR \\
\hline Rahmani, 2017 & NR & NR & NR & $0.74(\mathrm{NR})$ & NR \\
\hline Rahmani, 2017 & $70 \%(\mathrm{NR})$ & NR & NR & NR & Youden Index: 0.32 \\
\hline Rahmani, 2017 & NR & NR & NR & $0.93(\mathrm{NR})$ & NR \\
\hline Rahmani, 2017 & $87 \%(\mathrm{NR})$ & NR & NR & NR & Youden Index: 0.73 \\
\hline Rahmani, 2017 & NR & NR & NR & $0.99(\mathrm{NR})$ & NR \\
\hline Rahmani, 2017 & $98 \%(\mathrm{NR})$ & NR & NR & NR & Youden Index: 0.89 \\
\hline Rahmani, 2017 & NR & NR & NR & 0.75 (NR) & NR \\
\hline Rahmani, 2017 & $70 \%(\mathrm{NR})$ & NR & NR & NR & Youden Index: 0.34 \\
\hline Rahmani, 2017 & NR & NR & NR & $0.93(\mathrm{NR})$ & NR \\
\hline Rahmani, 2017 & $88 \%(\mathrm{NR})$ & NR & NR & NR & Youden Index: 0.72 \\
\hline Rahmani, 2017 & NR & NR & NR & $0.99(\mathrm{NR})$ & NR \\
\hline Rahmani, 2017 & $98 \%(\mathrm{NR})$ & NR & NR & NR & Youden Index: 0.89 \\
\hline Rainer, 2011 & $\begin{array}{l}\text { 96.84\% (96.31 to } 97.29) \\
\text { calculated }\end{array}$ & $\begin{array}{l}12.91(8.90 \text { to } 18.73) \\
\text { calculated }\end{array}$ & $\begin{array}{l}0.64(0.54 \text { to } 0.75) \\
\text { calculated }\end{array}$ & NR & NR \\
\hline Rainer, 2011 & $\begin{array}{l}96.19 \%(95.72 \text { to } 96.61) \\
\text { calculated }\end{array}$ & $\begin{array}{l}5.79(3.87 \text { to } 8.68) \\
\text { calculated }\end{array}$ & $\begin{array}{l}0.77(0.69 \text { to } 0.87) \\
\text { calculated }\end{array}$ & NR & NR \\
\hline Rainer, 2011 & $\begin{array}{l}96.91 \%(96.35 \text { to } 97.39) \\
\text { calculated }\end{array}$ & $\begin{array}{l}7.08(5.21 \text { to } 9.61) \\
\text { calculated }\end{array}$ & $\begin{array}{l}0.62(0.52 \text { to } 0.74) \\
\text { calculated }\end{array}$ & NR & NR \\
\hline Rainer, 2011 & $\begin{array}{l}96.67 \%(96.14 \text { to } 97.13) \\
\text { calculated }\end{array}$ & $\begin{array}{l}7.42(5.27 \text { to } 10.44) \\
\text { calculated }\end{array}$ & $\begin{array}{l}0.67(0.58 \text { to } 0.79) \\
\text { calculated }\end{array}$ & NR & NR \\
\hline Rainer, 2011 & $96.6 \%(95.7$ to 97.4$)$ & 94.5 (69.9 to 127.7$)$ & NR & NR & $\begin{array}{l}\text { Overall correct classification: } \\
96.9 \%\end{array}$ \\
\hline Rainer, 2011 & NR & NR & NR & 0.889 (NR) & NR \\
\hline Ramanathan, 2015 & $84.5 \%(76.4-90.7)$ & NR & NR & NR & NR \\
\hline Ramanathan, 2015 & $84.0 \%(78.2-88.7)$ & NR & NR & NR & NR \\
\hline Ramanathan, 2015 & $89.8 \%(84.7-93.6)$ & NR & NR & NR & NR \\
\hline Ramanathan, 2015 & $84.7 \%(79.2-89.2)$ & NR & NR & 0.7056 (NR) & NR \\
\hline
\end{tabular}




\begin{tabular}{|c|c|c|c|c|c|}
\hline $\begin{array}{l}\text { Author, Year } \\
\text { (See Appendix B for } \\
\text { complete reference) }\end{array}$ & Measure & Indicator of Serious Injury & $\begin{array}{l}\text { Reported Sensitivity } \\
(95 \% \mathrm{Cl})\end{array}$ & $\begin{array}{l}\text { Reported Specificity } \\
(95 \% \mathrm{Cl})\end{array}$ & $\begin{array}{l}\text { Reported PPV } \\
(95 \% \mathrm{Cl})\end{array}$ \\
\hline Ramanathan, 2015 & Lactate $\geq 2.0:$ age $0-18$ months & ISS >15 & $6.7 \%(1.5-18.3)$ & $92.1 \%(87.4-95.5)$ & $16.7 \%(3.8-41.4)$ \\
\hline Ramanathan, 2015 & Lactate $\geq 2.0:$ age $13-14$ years & ISS >15 & $35.6 \%(21.9-51.2)$ & $67.5 \%(60.4-74.1)$ & $20.5 \%(12.2-31.2)$ \\
\hline Ramanathan, 2015 & $\begin{array}{l}\text { Lactate } \geq 2.0 \text { : age } 19 \text { months to } 5 \\
\text { years }\end{array}$ & ISS $>15$ & $17.8 \%(8.0-32.1)$ & $82.2 \%(76.0-87.3)$ & $19.1 \%(8.6-34.1)$ \\
\hline Ramanathan, 2015 & Lactate $\geq 2.0$ : age $6-12$ years & ISS >15 & $40.0 \%(25.7-55.7)$ & $58.1 \%(50.8-65.2)$ & $18.4 \%(11.3-27.5)$ \\
\hline Ramanathan, 2015 & Lactate $\geq 2.0:$ overall & ISS $>15$ & $86.7 \%(73.2-94.9)$ & $54.4 \%(47.1-61.6)$ & $30.9 \%(23.0-39.8)$ \\
\hline Ramanathan, 2015 & $\mathrm{pH}<7.30$ & ISS >15 & $56.8 \%(41.0-71.6)$ & $94.3 \%(89.9-97.2)$ & $71.4 \%(53.7-85.3)$ \\
\hline Ramanathan, 2015 & Lactate $>2.0$ & Major procedure & $70.6 \%(56.2-82.5)$ & $51.3 \%(43.9-58.7)$ & $28.6 \%(20.9-37.3)$ \\
\hline Raux, 2006 & RR, EMS & Mortality & NR & NR & NR \\
\hline Raux, 2006 & SpO2 & Mortality & NR & NR & NR \\
\hline Raux, 2011 & MGAP: National cohort & Emergency procedure & NR & NR & NR \\
\hline Raux, 2011 & RTS: National cohort & Emergency procedure & NR & NR & NR \\
\hline Raux, 2011 & $\begin{array}{l}\text { Triage Revised Trauma Score (T- } \\
\text { RTS): National cohort }\end{array}$ & Emergency procedure & NR & NR & NR \\
\hline Raux, 2011 & MGAP: Lyon cohort & ICU LOS >2 days & NR & NR & NR \\
\hline Raux, 2011 & RTS: Lyon cohort & ICU LOS >2 days & NR & NR & NR \\
\hline Raux, 2011 & $\begin{array}{l}\text { Triage Revised Trauma Score (T- } \\
\text { RTS): Lyon cohort }\end{array}$ & ICU LOS >2 days & NR & NR & NR \\
\hline Raux, 2011 & MGAP: National cohort & Massive hemorrhage & NR & NR & NR \\
\hline Raux, 2011 & RTS: National cohort & Massive hemorrhage & NR & NR & NR \\
\hline Raux, 2011 & $\begin{array}{l}\text { Triage Revised Trauma Score (T- } \\
\text { RTS): National cohort }\end{array}$ & Massive hemorrhage & NR & NR & NR \\
\hline Raux, 2011 & MGAP: National cohort & Mortality & NR & NR & NR \\
\hline Raux, 2011 & RTS: National cohort & Mortality & NR & NR & NR \\
\hline Raux, 2011 & $\begin{array}{l}\text { Triage Revised Trauma Score (T- } \\
\text { RTS): National cohort }\end{array}$ & Mortality & NR & NR & NR \\
\hline Raux, 2011 & MGAP: National cohort & Severe trauma & NR & NR & NR \\
\hline Raux, 2011 & RTS: National cohort & Severe trauma & NR & NR & $\mathrm{NR}$ \\
\hline Raux, 2011 & $\begin{array}{l}\text { Triage Revised Trauma Score (T- } \\
\text { RTS): National cohort }\end{array}$ & Severe trauma & NR & NR & NR \\
\hline Raux, 2011 & $\begin{array}{l}\text { Mechanical ventilation: National } \\
\text { cohort }\end{array}$ & Emergency procedure & $\begin{array}{l}44.74 \%(40.97 \text { to } 48.55) \\
\text { calculated }\end{array}$ & $\begin{array}{l}61.09 \%(57.30 \text { to } 64.79) \\
\text { calculated }\end{array}$ & $\begin{array}{l}53.78 \%(50.64 \text { to } 56.89) \\
\text { calculated }\end{array}$ \\
\hline Raux, 2017 & $\mathrm{BD}$ & Mortality, 30-day in-hospital & NR & NR & NR \\
\hline
\end{tabular}




\begin{tabular}{|c|c|c|c|c|c|}
\hline $\begin{array}{l}\text { Author, Year } \\
\text { (See Appendix B for } \\
\text { complete reference) }\end{array}$ & $\begin{array}{l}\text { Reported NPV } \\
(95 \% \mathrm{Cl})\end{array}$ & Reported PLR & Reported NLR & $\begin{array}{l}\text { AUROC Univariate } \\
\text { AUC }(95 \% \mathrm{CI})\end{array}$ & $\begin{array}{l}\text { Other Measures of } \\
\text { Diagnostic Accuracy }\end{array}$ \\
\hline Ramanathan, 2015 & $80.7 \%(74.9-85.7)$ & NR & NR & NR & NR \\
\hline Ramanathan, 2015 & $81.6 \%(74.7-87.3)$ & NR & NR & NR & NR \\
\hline Ramanathan, 2015 & $80.9 \%(74.7-86.2)$ & NR & NR & NR & NR \\
\hline Ramanathan, 2015 & $80.4 \%(72.8-86.7)$ & NR & NR & NR & NR \\
\hline Ramanathan, 2015 & $94.5 \%(88.5-97.9)$ & NR & NR & 0.6515 (NR) & NR \\
\hline Ramanathan, 2015 & $89.7 \%$ (84.4-93.7) & NR & NR & NR & NR \\
\hline \begin{tabular}{|l|} 
Ramanathan, 2015 \\
\end{tabular} & $86.4 \%(78.5-92.2)$ & NR & NR & NR & NR \\
\hline Raux, 2006 & NR & NR & NR & 0.691 (SD 0.024) & NR \\
\hline Raux, 2006 & NR & NR & NR & 0.747 (SD 0.022) & NR \\
\hline Raux, 2011 & NR & NR & NR & $0.53(0.44$ to 0.50$)$ & NR \\
\hline Raux, 2011 & NR & NR & NR & $0.51(0.48$ to 0.54$)$ & NR \\
\hline Raux, 2011 & NR & NR & NR & $0.52(0.49$ to 0.54$)$ & NR \\
\hline \begin{tabular}{|l|} 
Raux, 2011 \\
\end{tabular} & NR & NR & NR & $0.85(0.79$ to 0.88$)$ & NR \\
\hline Raux, 2011 & NR & NR & NR & $0.83(0.81$ to 0.86$)$ & NR \\
\hline Raux, 2011 & NR & NR & NR & $0.83(0.81$ to 0.86$)$ & NR \\
\hline Raux, 2011 & NR & NR & NR & 0.70 (0.66 to 0.73$)$ & NR \\
\hline Raux, 2011 & NR & NR & NR & 0.72 (0.69 to 0.73$)$ & NR \\
\hline Raux, 2011 & NR & NR & NR & $0.73(0.70$ to 0.77$)$ & NR \\
\hline Raux, 2011 & NR & NR & NR & 0.90 (0.88 to 0.92$)$ & NR \\
\hline \begin{tabular}{|l|} 
Raux, 2011 \\
\end{tabular} & NR & NR & NR & $0.90(0.88$ to 0.92$)$ & NR \\
\hline Raux, 2011 & NR & NR & NR & $0.88(0.86$ to 0.92$)$ & NR \\
\hline Raux, 2011 & NR & NR & NR & $0.75(0.73$ to 0.78$)$ & NR \\
\hline \begin{tabular}{|l|} 
Raux, 2011 \\
\end{tabular} & NR & NR & NR & $0.75(0.73$ to 0.78$)$ & NR \\
\hline Raux, 2011 & NR & NR & NR & $0.74(0.71$ to 0.76$)$ & NR \\
\hline Raux, 2011 & $\begin{array}{l}52.21 \%(49.95 \text { to } 54.46) \\
\text { calculated }\end{array}$ & $\begin{array}{l}1.15(1.01 \text { to } 1.30) \\
\text { calculated }\end{array}$ & $\begin{array}{l}0.90(0.83 \text { to } 0.99) \\
\text { calculated }\end{array}$ & NR & NR \\
\hline Raux, 2017 & NR & NR & NR & $0.75(0.70$ to 0.80$)$ & NR \\
\hline
\end{tabular}




\begin{tabular}{|c|c|c|c|c|c|}
\hline $\begin{array}{l}\text { Author, Year } \\
\text { (See Appendix B for } \\
\text { complete reference) }\end{array}$ & Measure & Indicator of Serious Injury & $\begin{array}{l}\text { Reported Sensitivity } \\
(95 \% \mathrm{Cl})\end{array}$ & $\begin{array}{l}\text { Reported Specificity } \\
(95 \% \mathrm{Cl})\end{array}$ & $\begin{array}{l}\text { Reported PPV } \\
(95 \% \mathrm{Cl})\end{array}$ \\
\hline Raux, 2017 & $\mathrm{BD}$ & Mortality: 48-hour & NR & NR & NR \\
\hline Raux, 2017 & $\mathrm{BD}$ & Severe trauma: ISS >15 & NR & NR & NR \\
\hline Raux, 2017 & $\mathrm{BD}$ & Massive hemorrhage & NR & NR & NR \\
\hline Raux, 2017 & $\mathrm{BD}$ & Emergency procedure & NR & NR & NR \\
\hline Raux, 2017 & $\mathrm{BD}$ & $\begin{array}{l}\text { ICU LOS }>2 \text { days or in-hospital } \\
\text { mortality }\end{array}$ & NR & NR & NR \\
\hline Raux, 2017 & BD; normotensive subgroup & Mortality, 30-day in-hospital & NR & NR & NR \\
\hline Raux, 2017 & BD; TRISS $>0.9$ subgroup & Mortality, 30-day in-hospital & NR & $\overline{N R}$ & NR \\
\hline Raux, 2017 & Lactate & Mortality, 30-day in-hospital & NR & NR & NR \\
\hline Raux, 2017 & Lactate & Mortality: 48-hour & NR & NR & NR \\
\hline Raux, 2017 & Lactate & Severe trauma: ISS >15 & NR & NR & NR \\
\hline Raux, 2017 & Lactate & Massive hemorrhage & NR & NR & NR \\
\hline Raux, 2017 & Lactate & Emergency procedure & NR & NR & NR \\
\hline Raux, 2017 & Lactate & $\begin{array}{l}\text { ICU LOS }>2 \text { days or in-hospital } \\
\text { mortality }\end{array}$ & NR & NR & NR \\
\hline Raux, 2017 & Lactate; normotensive subgroup & Mortality: 30-day in-hospital & NR & NR & NR \\
\hline Raux, 2017 & Lactate; TRISS >0.9 subgroup & Mortality: 30-day in-hospital & NR & NR & NR \\
\hline Raux, 2017 & MGAP & Mortality: 30-day in-hospital & NR & NR & NR \\
\hline Raux, 2017 & RTS & Mortality: 30-day in-hospital & NR & NR & NR \\
\hline Regnier, 2012 & Lactate $\geq 2.2$ & Mortality: 30-day & $\begin{array}{l}78.21 \%(67.41 \text { to } 86.76) \\
\text { calculated }\end{array}$ & $\begin{array}{l}47.64 \%(43.22 \text { to } 52.08) \\
\text { calculated }\end{array}$ & $\begin{array}{l}\text { 18.65\% (16.57 to 20.93) } \\
\text { calculated }\end{array}$ \\
\hline Regnier, 2012 & Lactate & ICU stay $>2$ days or death & NR & NR & NR \\
\hline Regnier, 2012 & Lactate clearance (corrected) & ICU stay $>2$ days or death & NR & NR & NR \\
\hline Regnier, 2012 & Lactate & ISS >15 & NR & NR & NR \\
\hline Regnier, 2012 & Lactate clearance (corrected) & ISS >15 & NR & NR & NR \\
\hline Regnier, 2012 & Lactate & Massive hemorrhage & NR & NR & NR \\
\hline Regnier, 2012 & Lactate clearance (corrected) & Massive hemorrhage & NR & NR & NR \\
\hline Regnier, 2012 & Lactate & Mortality: 30-day & NR & NR & NR \\
\hline Regnier, 2012 & Lactate clearance (corrected) & Mortality: 30-day & NR & NR & NR \\
\hline Regnier, 2012 & Lactate clearance: 0-4 hours & Mortality: 30-day & NR & NR & NR \\
\hline Regnier, 2012 & Lactate clearance: $2-4$ hours & Mortality: 30-day & NR & NR & NR \\
\hline Regnier, 2012 & Lactate & Mortality within 48 hours & NR & NR & NR \\
\hline Regnier, 2012 & Lactate clearance (corrected) & Mortality within 48 hours & NR & NR & NR \\
\hline Regnier, 2012 & Lactate: normotensive subgroup & Mortality: 30-day & NR & NR & NR \\
\hline
\end{tabular}




\begin{tabular}{|c|c|c|c|c|c|}
\hline $\begin{array}{l}\text { Author, Year } \\
\text { (See Appendix B for } \\
\text { complete reference) }\end{array}$ & $\begin{array}{l}\text { Reported NPV } \\
(95 \% \mathrm{Cl})\end{array}$ & Reported PLR & Reported NLR & $\begin{array}{l}\text { AUROC Univariate } \\
\text { AUC }(95 \% \mathrm{CI})\end{array}$ & $\begin{array}{l}\text { Other Measures of } \\
\text { Diagnostic Accuracy }\end{array}$ \\
\hline Raux, 2017 & NR & $\mathrm{NR}$ & NR & $0.82(0.75$ to 0.87$)$ & NR \\
\hline Raux, 2017 & NR & NR & NR & $0.67(0.63$ to 0.70$)$ & NR \\
\hline Raux, 2017 & NR & NR & NR & $0.85(0.81$ to 0.89$)$ & NR \\
\hline Raux, 2017 & NR & NR & NR & $0.74(0.68$ to 0.80$)$ & NR \\
\hline Raux, 2017 & NR & NR & NR & $0.70(0.67$ to 0.73$)$ & NR \\
\hline Raux, 2017 & NR & NR & NR & $0.58(0.45$ to 0.69$)$ & NR \\
\hline Raux, 2017 & NR & NR & NR & $0.64(0.56$ to 0.79$)$ & NR \\
\hline Raux, 2017 & NR & NR & NR & $0.77(0.72$ to 0.81$)$ & NR \\
\hline Raux, 2017 & NR & NR & NR & $0.83(0.77$ to 0.88$)$ & NR \\
\hline Raux, 2017 & NR & NR & NR & $0.66(0.63$ to 0.70$)$ & NR \\
\hline Raux, 2017 & NR & NR & NR & $0.83(0.78$ to 0.86$)$ & NR \\
\hline Raux, 2017 & NR & NR & NR & $0.72(0.65$ to 0.77$)$ & NR \\
\hline Raux, 2017 & NR & NR & NR & $0.65(0.62$ to 0.69$)$ & NR \\
\hline Raux, 2017 & NR & NR & NR & $0.68(0.59$ to 0.76$)$ & NR \\
\hline Raux, 2017 & NR & NR & NR & $0.74(0.62$ to 0.82$)$ & NR \\
\hline Raux, 2017 & NR & NR & NR & 0.90 (0.87 to 0.92$)$ & NR \\
\hline Raux, 2017 & NR & NR & NR & $0.89(0.85$ to 0.92$)$ & NR \\
\hline Regnier, 2012 & $\begin{array}{l}93.44 \%(90.25 \text { to } 95.63) \\
\text { calculated }\end{array}$ & $\begin{array}{l}1.49(1.29 \text { to } 1.72) \\
\text { calculated }\end{array}$ & $\begin{array}{l}0.46(0.30 \text { to } 0.70) \\
\text { calculated }\end{array}$ & NR & NR \\
\hline Regnier, 2012 & NR & NR & NR & $0.70(0.65$ to 0.74$)$ & NR \\
\hline Regnier, 2012 & NR & NR & NR & $0.63(0.58$ to 0.68$)$ & NR \\
\hline Regnier, 2012 & NR & NR & NR & $0.61(0.55$ to 0.65$)$ & NR \\
\hline Regnier, 2012 & NR & NR & NR & $0.59(0.54$ to 0.64$)$ & NR \\
\hline Regnier, 2012 & NR & NR & NR & $0.86(0.80$ to 0.90$)$ & NR \\
\hline Regnier, 2012 & NR & NR & NR & $0.69(0.62$ to 0.74$)$ & NR \\
\hline Regnier, 2012 & NR & NR & NR & $0.78(0.73$ to 0.83$)$ & NR \\
\hline Regnier, 2012 & NR & NR & NR & $0.70(0.66$ to 0.74$)$ & NR \\
\hline Regnier, 2012 & NR & NR & NR & $0.52(0.41$ to 0.62$)$ & NR \\
\hline Regnier, 2012 & NR & NR & NR & $0.52(0.39$ to 0.61$)$ & NR \\
\hline Regnier, 2012 & NR & NR & NR & $0.84(0.77$ to 0.90$)$ & NR \\
\hline Regnier, 2012 & NR & NR & NR & 0.75 (0.66 to 0.82$)$ & NR \\
\hline Regnier, 2012 & NR & NR & NR & $0.63(0.51$ to 0.87$)$ & NR \\
\hline
\end{tabular}




\begin{tabular}{|c|c|c|c|c|c|}
\hline $\begin{array}{l}\text { Author, Year } \\
\text { (See Appendix B for } \\
\text { complete reference) }\end{array}$ & Measure & Indicator of Serious Injury & $\begin{array}{l}\text { Reported Sensitivity } \\
(95 \% \mathrm{Cl})\end{array}$ & $\begin{array}{l}\text { Reported Specificity } \\
(95 \% \mathrm{Cl})\end{array}$ & $\begin{array}{l}\text { Reported PPV } \\
(95 \% \mathrm{Cl})\end{array}$ \\
\hline Regnier, 2012 & $\begin{array}{l}\text { Lactate clearance (corrected): } \\
\text { normotensive subgroup }\end{array}$ & Mortality: 30-day & NR & NR & NR \\
\hline Regnier, 2012 & Lactate: subgroup with lactate $\geq 5$ & Mortality: 30-day & NR & NR & NR \\
\hline Regnier, 2012 & $\begin{array}{l}\text { Lactate clearance (corrected): } \\
\text { subgroup with lactate } \geq 5\end{array}$ & Mortality: 30-day & NR & NR & NR \\
\hline Regnier, 2012 & Lactate & Need for emergency procedure & NR & NR & NR \\
\hline Regnier, 2012 & Lactate clearance (corrected) & Need for emergency procedure & NR & NR & NR \\
\hline Reisner, 2016 & HR, ED & $\begin{array}{l}\text { Hemorrhagic injury requiring } \\
\text { blood transfusion } \geq 3 \text { units PRBCs }\end{array}$ & NR & NR & NR \\
\hline Reisner, 2016 & $\begin{array}{l}\text { Muscle oxygen saturation } \\
\left(\mathrm{SmO}_{2}\right)\end{array}$ & $\begin{array}{l}\text { Hemorrhagic injury requiring } \\
\text { blood transfusion } \geq 3 \text { units } P R B C s\end{array}$ & NR & NR & NR \\
\hline Reisner, 2016 & Pulse pressure (SBP - DBP), ED & $\begin{array}{l}\text { Hemorrhagic injury requiring } \\
\text { blood transfusion } \geq 3 \text { units } \mathrm{PRBC}\end{array}$ & NR & NR & NR \\
\hline Reisner, 2016 & SBP, ED & $\begin{array}{l}\text { Hemorrhagic injury requiring } \\
\text { blood transfusion } \geq 3 \text { units PRBCs }\end{array}$ & NR & NR & NR \\
\hline Reisner, 2016 & SI, ED & $\begin{array}{l}\text { Hemorrhagic injury requiring } \\
\text { blood transfusion } \geq 3 \text { units } P R B C s\end{array}$ & NR & NR & NR \\
\hline Ryan, 2011b & $\begin{array}{l}\text { Heart rate variability: VLF (using } \\
\text { mean-rank score) }\end{array}$ & Mortality & NR & NR & NR \\
\hline Ryan, 2011b & $\begin{array}{l}\text { Heart rate variability: LF/HF } \\
\text { (using mean-rank score) }\end{array}$ & Mortality & NR & NR & NR \\
\hline Ryan, 2011b & Mechanical ventilation & Mortality & $\begin{array}{l}32.14 \%(15.88 \text { to } 52.35) \\
\text { calculated }\end{array}$ & $\begin{array}{l}\text { 95.21\% (91.11 to } 97.79) \\
\text { calculated }\end{array}$ & $\begin{array}{l}50.00 \%(30.27 \text { to } 69.73) \\
\text { calculated }\end{array}$ \\
\hline Sammour, 2009 & Lactate & Mortality & NR & NR & NR \\
\hline Sammour, 2009 & Lactate $>2.0$ & Mortality & $81.0 \%(\mathrm{Cl} \mathrm{NR})$ & $56.8 \%(\mathrm{Cl} N R)$ & $13.0 \%(\mathrm{Cl} \mathrm{NR})$ \\
\hline Sammour, 2009 & $\begin{array}{l}\text { Lactate: subgroup of patients } \\
\text { with ICU admission }\end{array}$ & Mortality & NR & NR & NR \\
\hline Sartorius, 2010 & $\begin{array}{l}\text { Revised trauma score (RTS) } \\
<7.5 \text { : derivation cohort }\end{array}$ & Mortality: 30-day all cause & $95 \%(92-97)$ & $38 \%(35-41)$ & $26 \%(23-29)$ \\
\hline
\end{tabular}

D-313 


\begin{tabular}{|c|c|c|c|c|c|}
\hline $\begin{array}{l}\text { Author, Year } \\
\text { (See Appendix B for } \\
\text { complete reference) }\end{array}$ & $\begin{array}{l}\text { Reported NPV } \\
(95 \% \mathrm{Cl})\end{array}$ & Reported PLR & Reported NLR & $\begin{array}{l}\text { AUROC Univariate } \\
\text { AUC }(95 \% \mathrm{Cl})\end{array}$ & $\begin{array}{l}\text { Other Measures of } \\
\text { Diagnostic Accuracy }\end{array}$ \\
\hline Regnier, 2012 & NR & NR & NR & $0.65(0.53$ to 0.75$)$ & NR \\
\hline Regnier, 2012 & NR & NR & NR & $0.77(0.60$ to 0.87$)$ & NR \\
\hline Regnier, 2012 & NR & NR & NR & $0.67(0.51$ to 0.78$)$ & NR \\
\hline Regnier, 2012 & NR & NR & NR & 0.65 (0.59 to 0.70$)$ & NR \\
\hline Regnier, 2012 & NR & NR & NR & 0.64 (0.58 to 0.69$)$ & NR \\
\hline Reisner, 2016 & NR & NR & NR & $0.70(0.56$ to 0.81$)$ & NR \\
\hline Reisner, 2016 & NR & NR & NR & $0.76(0.65$ to 0.84$)$ & NR \\
\hline Reisner, 2016 & NR & NR & NR & $0.68(0.54$ to 0.80$)$ & NR \\
\hline Reisner, 2016 & NR & NR & NR & 0.62 (0.47 to 0.75$)$ & NR \\
\hline Reisner, 2016 & NR & NR & NR & 0.75 (0.61 to 0.85$)$ & NR \\
\hline Ryan, 2011b & NR & NR & NR & $\begin{array}{l}0.67(\mathrm{NR}) \\
\text { univariate regression analysis }\end{array}$ & NR \\
\hline Ryan, 2011b & NR & NR & NR & $\begin{array}{l}0.68(\mathrm{NR}) \\
\text { univariate regression analysis }\end{array}$ & NR \\
\hline Ryan, 2011b & $\begin{array}{l}90.40 \%(87.93 \text { to } 92.41) \\
\text { calculated }\end{array}$ & $\begin{array}{l}6.71(2.92 \text { to } 15.46) \\
\text { calculated }\end{array}$ & $\begin{array}{l}0.71(0.55 \text { to } 0.92) \\
\text { calculated }\end{array}$ & NR & NR \\
\hline Sammour, 2009 & NR & NR & NR & $0.716(\mathrm{NR})$ & NR \\
\hline Sammour, 2009 & 97.4\% (CI NR) & $\mathrm{NR}$ & NR & NR & NR \\
\hline Sammour, 2009 & NR & NR & NR & 0.637 (NR) & NR \\
\hline Sartorius, 2010 & $97 \%(95-98)$ & 1.54 (1.46-1.63) & $0.12(0.07-0.22)$ & NR & Accuracy: 32\% (30-35) \\
\hline
\end{tabular}




\begin{tabular}{|c|c|c|c|c|c|}
\hline $\begin{array}{l}\text { Author, Year } \\
\text { (See Appendix B for } \\
\text { complete reference) }\end{array}$ & Measure & Indicator of Serious Injury & $\begin{array}{l}\text { Reported Sensitivity } \\
(95 \% \mathrm{Cl})\end{array}$ & $\begin{array}{l}\text { Reported Specificity } \\
(95 \% \mathrm{Cl})\end{array}$ & $\begin{array}{l}\text { Reported PPV } \\
(95 \% \mathrm{Cl})\end{array}$ \\
\hline Sartorius, 2010 & Revised trauma score (RTS) & Mortality: 30-day all cause & NR & NR & NR \\
\hline Sartorius, 2010 & $\begin{array}{l}\text { Triage-Revised trauma score (T- } \\
\text { RTS) <12: derivation cohort }\end{array}$ & Mortality: 30-day all cause & $96 \%(93-98)$ & $42 \%(39-45)$ & $27 \%(24-30)$ \\
\hline Sartorius, 2010 & $\begin{array}{l}\text { Triage-Revised trauma score (T- } \\
\text { RTS) }\end{array}$ & Mortality: 30-day all cause & NR & NR & NR \\
\hline Sartorius, 2010 & $\begin{array}{l}\text { Mechanism, GCS, Age and } \\
\text { Arterial Pressure (MGAP) <23: } \\
\text { derivation cohort }\end{array}$ & Mortality: 30-day all cause & $95 \%(91-97)$ & $70 \%(67-73)$ & $47 \%(43-52)$ \\
\hline Sartorius, 2010 & $\begin{array}{l}\text { Mechanism, GCS, Age and } \\
\text { Arterial Pressure (MGAP) }\end{array}$ & Mortality: 30-day all cause & NR & NR & NR \\
\hline Sartorius, 2010 & $\begin{array}{l}\text { Mechanical ventilation, } \\
\text { prehospital: derivation cohort }\end{array}$ & Mortality: 30-day all cause & $\begin{array}{l}39.02 \% \text { (34.99 to 43.16) } \\
\text { calculated }\end{array}$ & $\begin{array}{l}96.46 \%(94.92 \text { to } 97.64) \\
\text { calculated }\end{array}$ & $\begin{array}{l}88.80 \%(84.45 \text { to } 92.05) \\
\text { calculated }\end{array}$ \\
\hline Schenarts, 2008 & SBP $<90$, EMS & In-hospital mortality & $\begin{array}{l}7.78 \%(3.18 \text { to } 15.37) \\
\text { calculated }\end{array}$ & $\begin{array}{l}98.19 \%(97.51 \text { to } 98.72) \\
\text { calculated }\end{array}$ & $\begin{array}{l}15.91 \%(7.98 \text { to } 29.21) \\
\text { calculated }\end{array}$ \\
\hline Schenarts, 2008 & SBP $<90$, EMS & ISS $>16$ & $\begin{array}{l}4.95 \%(3.23 \text { to } 7.22) \\
\text { calculated }\end{array}$ & $\begin{array}{l}98.83 \%(98.18 \text { to } 99.29) \\
\text { calculated }\end{array}$ & $\begin{array}{l}56.82 \%(42.22 \text { to } 70.32) \\
\text { calculated }\end{array}$ \\
\hline Schenarts, 2008 & SBP $<90$, EMS & ICU, OR, or death in $\mathrm{E}$ & $\begin{array}{l}4.43 \%(3.01 \text { to } 6.27) \\
\text { calculated }\end{array}$ & $\begin{array}{l}99.04 \% \text { (98.39 to } 99.47) \\
\text { calculated }\end{array}$ & $\begin{array}{l}68.18 \%(53.35 \text { to } 80.06) \\
\text { calculated }\end{array}$ \\
\hline Shah, 2013 & $\begin{array}{l}\text { EMS lactate, POC = } 2 \mathrm{mmol} / \mathrm{L} ; \\
\text { normal EMS vital signs and GCS }\end{array}$ & Need for critical care & $64 \%(N R)$ & $66 \%(N R)$ & NR \\
\hline Shoemaker, 2005 & $\begin{array}{l}\text { Cardiac Index, data over first } 4 \\
\text { hours }\end{array}$ & Mortality & NR & NR & NR \\
\hline Shoemaker, 2005 & Cardiac Index, initial value & Mortality & NR & NR & NR \\
\hline
\end{tabular}




\begin{tabular}{|c|c|c|c|c|c|}
\hline $\begin{array}{l}\text { Author, Year } \\
\text { (See Appendix B for } \\
\text { complete reference) }\end{array}$ & $\begin{array}{l}\text { Reported NPV } \\
(95 \% \mathrm{Cl})\end{array}$ & Reported PLR & Reported NLR & $\begin{array}{l}\text { AUROC Univariate } \\
\text { AUC }(95 \% \mathrm{CI})\end{array}$ & $\begin{array}{l}\text { Other Measures of } \\
\text { Diagnostic Accuracy }\end{array}$ \\
\hline Sartorius, 2010 & NR & NR & NR & $\begin{array}{l}\text { AUC }(95 \% \mathrm{Cl}) \\
\text { Derivation cohort: } 0.90(0.88-0.92) \\
\text { Validation cohort: } 0.88(0.85-0.91)\end{array}$ & NR \\
\hline Sartorius, 2010 & $98 \%(96-99)$ & $1.65(1.56-1.75)$ & $0.09(0.05-0.18)$ & NR & Accuracy: 35\% (32-38) \\
\hline Sartorius, 2010 & NR & NR & NR & $\begin{array}{l}\text { AUC }(95 \% \mathrm{Cl}) \\
\text { Derivation cohort: } 0.88(0.86-0.92) \\
\text { Validation cohort: } 0.88(0.85-0.91)\end{array}$ & NR \\
\hline Sartorius, 2010 & $98 \%(96-99)$ & $3.13(2.82-3.48)$ & $0.07(0.04-0.13)$ & NR & Accuracy: 45\% (43-48) \\
\hline Sartorius, 2010 & NR & NR & NR & $\begin{array}{l}\text { AUC }(95 \% \mathrm{Cl}) \\
\text { Derivation cohort: } 0.90(0.88-0.92) \\
\text { Validation cohort:0.91 }(0.88-0.93)\end{array}$ & NR \\
\hline Sartorius, 2010 & $\begin{array}{l}68.74 \% \text { (67.28 to } 70.16) \\
\text { calculated }\end{array}$ & $\begin{array}{l}11.02(7.55 \text { to } 16.09) \\
\text { calculated }\end{array}$ & $\begin{array}{l}0.63(0.59 \text { to } 0.68) \\
\text { calculated }\end{array}$ & NR & NR \\
\hline Schenarts, 2008 & $\begin{array}{l}96.02 \%(95.78 \text { to } 96.25) \\
\text { calculated }\end{array}$ & $\begin{array}{l}4.29(1.97 \text { to } 9.35) \\
\text { calculated }\end{array}$ & $\begin{array}{l}0.94(0.88 \text { to } 1.00) \\
\text { calculated }\end{array}$ & NR & NR \\
\hline Schenarts, 2008 & $\begin{array}{l}76.99 \%(76.62 \text { to } 77.35) \\
\text { calculated }\end{array}$ & $\begin{array}{l}4.23(2.35 \text { to } 7.62) \\
\text { calculated }\end{array}$ & $\begin{array}{l}0.96(0.94 \text { to } 0.98) \\
\text { calculated }\end{array}$ & NR & NR \\
\hline Schenarts, 2008 & $\begin{array}{l}68.98 \%(68.62 \text { to } 69.35) \\
\text { calculated }\end{array}$ & $\begin{array}{l}4.60(2.45 \text { to } 8.62) \\
\text { calculated }\end{array}$ & $\begin{array}{l}0.96(0.95 \text { to } 0.98) \\
\text { calculated }\end{array}$ & NR & NR \\
\hline Shah, 2013 & NR & NR & NR & NR & NR \\
\hline Shoemaker, 2005 & NR & NR & NR & $0.68(\mathrm{NR})$ & NR \\
\hline Shoemaker, 2005 & NR & NR & NR & $0.61(\mathrm{NR})$ & NR \\
\hline
\end{tabular}




\begin{tabular}{|c|c|c|c|c|c|}
\hline $\begin{array}{l}\text { Author, Year } \\
\text { (See Appendix B for } \\
\text { complete reference) }\end{array}$ & Measure & Indicator of Serious Injury & $\begin{array}{l}\text { Reported Sensitivity } \\
(95 \% \mathrm{Cl})\end{array}$ & $\begin{array}{l}\text { Reported Specificity } \\
(95 \% \mathrm{Cl})\end{array}$ & $\begin{array}{l}\text { Reported PPV } \\
(95 \% \mathrm{Cl})\end{array}$ \\
\hline Shoemaker, 2005 & $\begin{array}{l}\text { Oxygen delivery (DO2), initial } \\
\text { value }\end{array}$ & Mortality & NR & NR & NR \\
\hline Shoemaker, 2005 & HR, initial value & Mortality & NR & NR & NR \\
\hline Shoemaker, 2005 & MAP, data over first 4 hours & Mortality & NR & NR & NR \\
\hline Shoemaker, 2005 & MAP, initial value & Mortality & NR & NR & NR \\
\hline Shoemaker, 2005 & $\begin{array}{l}\text { Survival prediction model, data } \\
\text { over first } 4 \text { hours } \\
\text { - uses noninvasive } \\
\text { hemodynamic monitoring and } \\
\text { diagnosis variables }\end{array}$ & Mortality & NR & NR & NR \\
\hline Shoemaker, 2005 & $\begin{array}{l}\text { Survival prediction model, initial } \\
\text { values } \\
\text { - uses noninvasive } \\
\text { hemodynamic monitoring and } \\
\text { diagnosis variables }\end{array}$ & Mortality & NR & NR & NR \\
\hline Shoemaker, 2005 & $\begin{array}{l}\text { Transcutaneous oxygen } \\
\text { tension/FIO2 ratio (PtcO2/FIO2), } \\
\text { data over first } 4 \text { hours }\end{array}$ & Mortality & NR & NR & NR \\
\hline Shoemaker, 2005 & $\begin{array}{l}\text { Transcutaneous oxygen } \\
\text { tension/FIO2 ratio (PtcO2/FIO2), } \\
\text { initial value }\end{array}$ & Mortality & NR & NR & NR \\
\hline Tamim, 2002 & Prehospital Index $(\mathrm{PHI}) \geq 4$ & $\begin{array}{l}\text { Major injury (mortality, surgical } \\
\text { intervention, ICU care) }\end{array}$ & $35 \%$ (32 to 38$)$ & $91 \%$ (90 to 93$)$ & $77 \%$ (74 to 79$)$ \\
\hline Tamim, 2002 & Prehospital Index $(\mathrm{PHI}) \geq 7$ & $\begin{array}{l}\text { Major injury (mortality, surgical } \\
\text { intervention, ICU care) }\end{array}$ & $17 \%$ (15 to 19$)$ & $97 \%$ (96 to 98$)$ & $83 \%(81$ to 85$)$ \\
\hline Tamim, 2002 & Prehospital Index $(\mathrm{PHI}) \geq 1$ & $\begin{array}{l}\text { Major injury (mortality, surgical } \\
\text { intervention, ICU care) }\end{array}$ & $55 \%$ (52 to 57 ) & $71 \%(69$ to 74$)$ & $60 \%$ (58 to 63$)$ \\
\hline Tamim, 2002 & Prehospital Index (PHI) & $\begin{array}{l}\text { Major injury (mortality, surgical } \\
\text { intervention, ICU care) }\end{array}$ & NR & NR & NR \\
\hline Van Haren, 2014 & $\begin{array}{l}\text { Vital signs, combined: HR }>100, \\
\text { SBP }<90, \text { SaO2 <95\% }\end{array}$ & LSI & $44 \%(N R)$ & $75 \%(N R)$ & $64 \%(N R)$ \\
\hline Van Haren, 2014 & HR $>100$ & LSI & $30 \%(N R)$ & $79 \%(N R)$ & $58 \%(N R)$ \\
\hline Van Haren, 2014 & $\begin{array}{l}\text { Murphy Factor }>3 \text { (over entire } \\
\text { transport time) }\end{array}$ & LSI & $39 \%(N R)$ & $81 \%(\mathrm{NR})$ & $68 \%(\mathrm{NR})$ \\
\hline Van Haren, 2014 & Murphy Factor (continuous) & LSI & NR & NR & NR \\
\hline
\end{tabular}




\begin{tabular}{|c|c|c|c|c|c|}
\hline $\begin{array}{l}\text { Author, Year } \\
\text { (See Appendix B for } \\
\text { complete reference) }\end{array}$ & $\begin{array}{l}\text { Reported NPV } \\
(95 \% \mathrm{CI})\end{array}$ & Reported PLR & Reported NLR & $\begin{array}{l}\text { AUROC Univariate } \\
\text { AUC }(95 \% \mathrm{CI})\end{array}$ & $\begin{array}{l}\text { Other Measures of } \\
\text { Diagnostic Accuracy }\end{array}$ \\
\hline Shoemaker, 2005 & NR & NR & NR & $0.41(\mathrm{NR})$ & NR \\
\hline Shoemaker, 2005 & NR & NR & NR & $0.63(\mathrm{NR})$ & NR \\
\hline Shoemaker, 2005 & NR & NR & NR & $0.73(\mathrm{NR})$ & NR \\
\hline Shoemaker, 2005 & NR & NR & NR & $0.67(\mathrm{NR})$ & NR \\
\hline Shoemaker, 2005 & NR & NR & NR & $0.88(\mathrm{NR})$ & NR \\
\hline Shoemaker, 2005 & NR & NR & NR & $0.81(\mathrm{NR})$ & NR \\
\hline Shoemaker, 2005 & NR & NR & NR & $0.74(\mathrm{NR})$ & NR \\
\hline Shoemaker, 2005 & NR & NR & NR & 0.77 (NR) & NR \\
\hline Tamim, 2002 & $64 \%$ (61 to 66$)$ & NR & NR & NR & NR \\
\hline Tamim, 2002 & $59 \%$ (57 to 62 ) & NR & NR & NR & NR \\
\hline Tamim, 2002 & $66 \%$ (63 to 69) & NR & NR & NR & NR \\
\hline Tamim, 2002 & NR & NR & NR & 0.66 (SE 0.02) & NR \\
\hline Van Haren, 2014 & $57 \%(\mathrm{NR})$ & NR & NR & 0.607 (NR), $p=0.119$ & NR \\
\hline Van Haren, 2014 & $54 \%(N R)$ & NR & NR & $0.535(\mathrm{NR}), p=0.612$ & NR \\
\hline Van Haren, 2014 & $57 \%(N R)$ & NR & NR & $0.620(\mathrm{NR}), p=0.081$ & NR \\
\hline Van Haren, 2014 & NR & NR & NR & $0.619(\mathrm{NR}), \mathrm{p}=0.075$ & NR \\
\hline
\end{tabular}




\begin{tabular}{|c|c|c|c|c|c|}
\hline $\begin{array}{l}\text { Author, Year } \\
\text { (See Appendix B for } \\
\text { complete reference) }\end{array}$ & Measure & Indicator of Serious Injury & $\begin{array}{l}\text { Reported Sensitivity } \\
(95 \% \mathrm{Cl})\end{array}$ & $\begin{array}{l}\text { Reported Specificity } \\
(95 \% \mathrm{Cl})\end{array}$ & $\begin{array}{l}\text { Reported PPV } \\
(95 \% \mathrm{Cl})\end{array}$ \\
\hline Van Haren, 2014 & SaO2 <95\% & LSI & $13 \%(\mathrm{NR})$ & $94 \%(\mathrm{NR})$ & $67 \%(\mathrm{NR})$ \\
\hline Van Haren, 2014 & SBP $<90$ & LSI & $8 \%(\mathrm{NR})$ & $96 \%(\mathrm{NR})$ & $67 \%(\mathrm{NR})$ \\
\hline Vandromme, 2010 & $\begin{array}{l}\text { Lactate (ED POC test): group } \\
\text { with ED SBP 90-110 }\end{array}$ & Mortality & NR & NR & NR \\
\hline Vandromme, 2010 & $\begin{array}{l}\text { Lactate (ED POC test): Group } \\
\text { with EMS and ED SBP 90-110 }\end{array}$ & Mortality & NR & NR & NR \\
\hline Vandromme, 2010 & $\begin{array}{l}\text { SBP (ED): Group with ED SBP } \\
90-110\end{array}$ & Mortality & NR & NR & NR \\
\hline Vandromme, 2010 & $\begin{array}{l}\text { SBP (ED): Group with EMS and } \\
\text { ED SBP 90-110 }\end{array}$ & Mortality & NR & NR & NR \\
\hline Vandromme, 2010 & Lactate $>2.5$ (ED) & Mortality, in-hospital & $\begin{array}{l}81.98 \%(75.40 \text { to } 87.41) \\
\text { calculated }\end{array}$ & $\begin{array}{l}56.78 \%(54.69 \text { to } 58.85) \\
\text { calculated }\end{array}$ & $\begin{array}{l}12.81 \%(11.89 \text { to } 13.78) \\
\text { calculated }\end{array}$ \\
\hline Vandromme, 2010 & Lactate >5 (ED) & Mortality, in-hospital & $\begin{array}{l}42.80 \%(36.76 \text { to } 90.06) \\
\text { calculated }\end{array}$ & $\begin{array}{l}88.73 \%(87.30 \text { to } 90.06) \\
\text { calculated }\end{array}$ & $\begin{array}{l}32.47 \%(28.57 \text { to } 36.63) \\
\text { calculated }\end{array}$ \\
\hline Vandromme, 2010 & $\begin{array}{l}\text { Lactate (ED POC test): group } \\
\text { with ED SBP 90-110 }\end{array}$ & Significant transfusion & NR & NR & NR \\
\hline Vandromme, 2010 & $\begin{array}{l}\text { Lactate (ED POC test): Group } \\
\text { with EMS and ED SBP 90-110 }\end{array}$ & Significant transfusion & NR & NR & NR \\
\hline Vandromme, 2010 & Lactate $>2.5$ (ED) & Significant transfusion & $\begin{array}{l}77.27 \%(71.74 \text { to } 82.19) \\
\text { calculated }\end{array}$ & $\begin{array}{l}57.05 \% \text { (54.89 to 59.18) } \\
\text { calculated }\end{array}$ & $\begin{array}{l}18.55 \%(17.34 \text { to } 19.82) \\
\text { calculated }\end{array}$ \\
\hline Vandromme, 2010 & Lactate $>5$ (ED) & Significant transfusion & $\begin{array}{l}43.02 \%(35.51 \text { to } 50.78) \\
\text { calculated }\end{array}$ & $\begin{array}{l}87.66 \%(86.22 \text { to } 89.00) \\
\text { calculated }\end{array}$ & $\begin{array}{l}21.26 \% \text { (18.04 to } 24.89) \\
\text { calculated }\end{array}$ \\
\hline Vandromme, 2010 & $\begin{array}{l}\text { SBP (ED): Group with ED SBP } \\
90-110\end{array}$ & Significant transfusion & NR & NR & NR \\
\hline Vandromme, 2010 & $\begin{array}{l}\text { SBP (ED): Group with EMS and } \\
\text { ED SBP } 90-110\end{array}$ & Significant transfusion & NR & NR & NR \\
\hline Vandromme, 2011 & SI $>0.9$, EMS & Mortality & $\begin{array}{l}25.00 \% \text { (18.98 to 31.82) } \\
\text { calculated }\end{array}$ & $\begin{array}{l}81.77 \%(80.91 \text { to } 82.62) \\
\text { calculated }\end{array}$ & $\begin{array}{l}3.15 \%(2.47 \text { to } 4.02) \\
\text { calculated }\end{array}$ \\
\hline Vandromme, 2011 & SI $>0.9$, EMS & Massive transfusion & $\begin{array}{l}34.89 \%(29.30 \text { to } 40.81) \\
\text { calculated }\end{array}$ & $\begin{array}{l}82.20 \%(81.34 \text { to } 83.04) \\
\text { calculated }\end{array}$ & $\begin{array}{l}6.51 \%(5.56 \text { to } 7.60) \\
\text { calculated }\end{array}$ \\
\hline Vandromme, 2011b & $\begin{array}{l}\text { Lactate } \geq 5 \text { : developmental } \\
\text { cohort }\end{array}$ & Massive transfusion & NR & NR & NR \\
\hline
\end{tabular}




\begin{tabular}{|c|c|c|c|c|c|}
\hline $\begin{array}{l}\text { Author, Year } \\
\text { (See Appendix B for } \\
\text { complete reference) }\end{array}$ & $\begin{array}{l}\text { Reported NPV } \\
(95 \% \mathrm{Cl})\end{array}$ & Reported PLR & Reported NLR & $\begin{array}{l}\text { AUROC Univariate } \\
\text { AUC }(95 \% \mathrm{Cl})\end{array}$ & $\begin{array}{l}\text { Other Measures of } \\
\text { Diagnostic Accuracy }\end{array}$ \\
\hline Van Haren, 2014 & $53 \%(\mathrm{NR})$ & $\mathrm{NR}$ & NR & $0.530(\mathrm{NR}), p=0.660$ & NR \\
\hline Van Haren, 2014 & $52 \%(N R)$ & NR & NR & $0.544(\mathrm{NR}), \mathrm{p}=0.524$ & NR \\
\hline Vandromme, 2010 & NR & NR & NR & 0.76 (Cl NR) & NR \\
\hline Vandromme, 2010 & NR & NR & NR & $0.74(\mathrm{Cl} \mathrm{NR})$ & NR \\
\hline Vandromme, 2010 & NR & NR & NR & $0.61(\mathrm{Cl} \mathrm{NR})$ & NR \\
\hline Vandromme, 2010 & NR & NR & NR & $0.60(\mathrm{Cl} \mathrm{NR})$ & NR \\
\hline Vandromme, 2010 & $\begin{array}{l}97.60 \%(96.72 \text { to } 98.25) \\
\text { calculated }\end{array}$ & $\begin{array}{l}1.90(1.74 \text { to } 2.06) \\
\text { calculated }\end{array}$ & $\begin{array}{l}0.32(0.23 \text { to } 0.44) \\
\text { calculated }\end{array}$ & NR & NR \\
\hline Vandromme, 2010 & $\begin{array}{l}92.46 \%(91.69 \text { to } 93.16) \\
\text { calculated }\end{array}$ & $\begin{array}{l}3.80(3.16 \text { to } 4.57) \\
\text { calculated }\end{array}$ & $\begin{array}{l}0.64(0.58 \text { to } 0.72) \\
\text { calculated }\end{array}$ & NR & NR \\
\hline Vandromme, 2010 & NR & NR & NR & $0.76(\mathrm{Cl} \mathrm{NR})$ & NR \\
\hline Vandromme, 2010 & NR & NR & NR & $0.72(\mathrm{Cl} \mathrm{NR})$ & NR \\
\hline Vandromme, 2010 & $\begin{array}{l}95.20 \%(94.06 \text { to } 96.13) \\
\text { calculated }\end{array}$ & $\begin{array}{l}1.80(1.66 \text { to } 1.95) \\
\text { calculated }\end{array}$ & $\begin{array}{l}0.40(0.32 \text { to } 0.50) \\
\text { calculated }\end{array}$ & NR & NR \\
\hline Vandromme, 2010 & $\begin{array}{l}95.21 \%(94.57 \text { to } 95.77) \\
\text { calculated }\end{array}$ & $\begin{array}{l}3.49(2.84 \text { to } 4.28) \\
\text { calculated }\end{array}$ & $\begin{array}{l}0.65(0.57 \text { to } 0.74) \\
\text { calculated }\end{array}$ & NR & NR \\
\hline Vandromme, 2010 & NR & NR & NR & $0.60(\mathrm{Cl} \mathrm{NR})$ & NR \\
\hline Vandromme, 2010 & NR & NR & NR & $0.61(\mathrm{Cl} \mathrm{NR})$ & NR \\
\hline Vandromme, 2011 & $\begin{array}{l}97.87 \%(97.69 \text { to } 98.04) \\
\text { calculated }\end{array}$ & $\begin{array}{l}1.37(1.07 \text { to } 1.76) \\
\text { calculated }\end{array}$ & $\begin{array}{l}0.92(0.84 \text { to } 1.00) \\
\text { calculated }\end{array}$ & NR & NR \\
\hline Vandromme, 2011 & $\begin{array}{l}97.27 \%(97.03 \text { to } 97.49) \\
\text { calculated }\end{array}$ & $\begin{array}{l}1.96(1.66 \text { to } 2.32) \\
\text { calculated }\end{array}$ & $\begin{array}{l}0.79(0.73 \text { to } 0.86) \\
\text { calculated }\end{array}$ & NR & NR \\
\hline Vandromme, 2011b & NR & NR & NR & 0.71 (NR) & NR \\
\hline
\end{tabular}




\begin{tabular}{|c|c|c|c|c|c|}
\hline $\begin{array}{l}\text { Author, Year } \\
\text { (See Appendix B for } \\
\text { complete reference) }\end{array}$ & Measure & Indicator of Serious Injury & $\begin{array}{l}\text { Reported Sensitivity } \\
(95 \% \mathrm{Cl})\end{array}$ & $\begin{array}{l}\text { Reported Specificity } \\
(95 \% \mathrm{Cl})\end{array}$ & $\begin{array}{l}\text { Reported PPV } \\
(95 \% \mathrm{Cl})\end{array}$ \\
\hline Vandromme, 2011b & $\begin{array}{l}\text { SBP < 110: developmental } \\
\text { cohort }\end{array}$ & Massive transfusion & NR & NR & NR \\
\hline Vandromme, 2011b & HR > 105: developmental cohort & Massive transfusion & NR & NR & NR \\
\hline Vassallo, 2015 & $\mathrm{SI} \geq 0.90$ & $\begin{array}{l}\text { Life-saving intervention or death } \\
\text { in ED }\end{array}$ & $52.7 \%(45.8$ to 59.6$)$ & $93.0 \%(88.7$ to 97.2$)$ & NR \\
\hline Vassallo, 2015 & $\mathrm{SI} \geq 1.0$ & $\begin{array}{l}\text { Life-saving intervention or death } \\
\text { in ED }\end{array}$ & $41.9 \%(35.1$ to 48.7$)$ & $94.4 \%(90.6$ to 98.2$)$ & NR \\
\hline Vassallo, 2015 & $\mathrm{SI} \geq 0.75$ & $\begin{array}{l}\text { Life-saving intervention or death } \\
\text { in ED }\end{array}$ & $70.0 \%(63.6$ to 76.3$)$ & $74.6 \%(67.5$ to 81.8$)$ & NR \\
\hline Vassallo, 2015 & $\begin{array}{l}\text { Triage Sort (TSO) } \leq 10: \text { uses } \\
\text { GCS, RR, SBP }\end{array}$ & $\begin{array}{l}\text { Life-saving intervention or death } \\
\text { in ED }\end{array}$ & $58.6 \%(51.8$ to 65.4$)$ & $88.7 \%(83.5$ to 93.9$)$ & NR \\
\hline Vassallo, 2017 & Careflight (uses SBP, GCS) & Life-saving intervention & $33.5 \%$ (31.3 to 35.8$)$ & $98.4 \%$ (97.7 to 98.9$)$ & $95.0 \%(\mathrm{NR})$ \\
\hline Vassallo, 2017 & $\begin{array}{l}\text { Modified Physiological Triage } \\
\text { Tool (MPTT) (uses HR, GCS, } \\
\text { RR) }\end{array}$ & Life-saving intervention & $69.9 \%(67.7$ to 72.0$)$ & $65.3 \%(63.2$ to 67.5$)$ & $64.8 \%(\mathrm{NR})$ \\
\hline Vassallo, 2017 & $\begin{array}{l}\text { Military Sieve (uses HR, RR, } \\
\text { GCS) }\end{array}$ & Life-saving intervention & $43.8 \%(41.5$ to 46.2$)$ & $93.6 \%(92.4$ to 94.6$)$ & $86.2 \%(\mathrm{NR})$ \\
\hline Vassallo, 2017 & $\begin{array}{l}\text { Modified Military Sieve (uses HR, } \\
\text { RR, GCS) }\end{array}$ & Life-saving intervention & $50.9 \%(48.6$ to 53.3$)$ & $87.5 \%$ (85.9 to 88.9) & $78.8 \%(\mathrm{NR})$ \\
\hline Vassallo, 2017 & $\begin{array}{l}\text { START (Simple triage and rapid } \\
\text { treatment): } R R \geq 30, S B P<90 \text {, } \\
\text { GCS }<13\end{array}$ & Life-saving intervention & $38.7 \%(36.5$ to 41.1$)$ & $96.9 \%$ (96.0 to 97.6$)$ & 91.9\% (NR) \\
\hline Vassallo, 2017 & Triage Sieve (uses HR, RR) & Life-saving intervention & $24.8 \%(22.8$ to 26.9$)$ & $94.7 \%$ (93.6 to 95.7$)$ & $81.2 \%(\mathrm{NR})$ \\
\hline Vettorello, 2013 & HR $>99$ & $\begin{array}{l}\text { Blood transfusion or bleeding } \\
\text { Control }\end{array}$ & $100 \%(\mathrm{NR})$ & $64.4 \%(\mathrm{NR})$ & NR \\
\hline Vettorello, 2013 & $\mathrm{HR}$ & $\begin{array}{l}\text { Blood transfusion or bleeding } \\
\text { Control }\end{array}$ & NR & NR & NR \\
\hline Vettorello, 2013 & SBP $<125$ & $\begin{array}{l}\text { Blood transfusion or bleeding } \\
\text { Control }\end{array}$ & $100 \%(\mathrm{NR})$ & $66.7 \%(\mathrm{NR})$ & NR \\
\hline Vettorello, 2013 & SBP & $\begin{array}{l}\text { Blood transfusion or bleeding } \\
\text { Control }\end{array}$ & NR & NR & NR \\
\hline Vettorello, 2013 & $\begin{array}{l}\text { Heart rate variability: heart-to- } \\
\text { arm time index (iHAT) }>58.78 \%\end{array}$ & $\begin{array}{l}\text { Blood transfusion or bleeding } \\
\text { Control }\end{array}$ & $90.9 \%(58.7$ to 99.8$)$ & $100 \%(94.9$ to 100$)$ & NR \\
\hline Vettorello, 2013 & $\begin{array}{l}\text { Heart rate variability: heart-to- } \\
\text { arm time index (iHAT) }\end{array}$ & $\begin{array}{l}\text { Blood transfusion or bleeding } \\
\text { Control }\end{array}$ & NR & NR & NR \\
\hline
\end{tabular}




\begin{tabular}{|c|c|c|c|c|c|}
\hline $\begin{array}{l}\text { Author, Year } \\
\text { (See Appendix B for } \\
\text { complete reference) }\end{array}$ & $\begin{array}{l}\text { Reported NPV } \\
(95 \% \mathrm{Cl})\end{array}$ & Reported PLR & Reported NLR & $\begin{array}{l}\text { AUROC Univariate } \\
\text { AUC }(95 \% \mathrm{CI})\end{array}$ & $\begin{array}{l}\text { Other Measures of } \\
\text { Diagnostic Accuracy }\end{array}$ \\
\hline Vandromme, 2011b & NR & NR & NR & $0.72(\mathrm{NR})$ & NR \\
\hline Vandromme, 2011b & NR & NR & NR & $0.65(\mathrm{NR})$ & NR \\
\hline Vassallo, 2015 & NR & NR & NR & NR & NR \\
\hline Vassallo, 2015 & NR & NR & NR & NR & NR \\
\hline Vassallo, 2015 & NR & NR & NR & NR & NR \\
\hline Vassallo, 2015 & NR & NR & NR & NR & NR \\
\hline Vassallo, 2017 & NR & NR & NR & NR & $\begin{array}{l}\text { Under triage: } 66.5 \% \\
\text { Over triage: } 5.0 \%\end{array}$ \\
\hline Vassallo, 2017 & NR & NR & NR & NR & $\begin{array}{l}\text { Under triage: } 30.1 \% \\
\text { Over triage: } 35.2 \%\end{array}$ \\
\hline Vassallo, 2017 & NR & NR & NR & NR & $\begin{array}{l}\text { Under triage: } 56.2 \% \\
\text { Over triage: } 13.8 \%\end{array}$ \\
\hline Vassallo, 2017 & NR & NR & NR & NR & $\begin{array}{l}\text { Under triage: } 49.1 \% \\
\text { Over triage: } 21.2 \%\end{array}$ \\
\hline Vassallo, 2017 & NR & NR & NR & NR & $\begin{array}{l}\text { Under triage: } 61.3 \% \\
\text { Over triage: } 8.1 \%\end{array}$ \\
\hline Vassallo, 2017 & NR & NR & NR & NR & $\begin{array}{l}\text { Under triage: } 75.2 \% \\
\text { Over triage: } 18.8 \%\end{array}$ \\
\hline Vettorello, 2013 & NR & 2.81 (2.40 to 3.30$)$ & NR & NR & NR \\
\hline Vettorello, 2013 & NR & NR & NR & 0.835 (0.734 to 0.909$)$ & NR \\
\hline Vettorello, 2013 & NR & $3.00(2.50-3.50)$ & NR & NR & NR \\
\hline Vettorello, 2013 & NR & NR & NR & 0.911 (0.824 to 0.963$)$ & NR \\
\hline Vettorello, 2013 & NR & Infinite & NR & NR & NR \\
\hline Vettorello, 2013 & NR & NR & NR & $0.952(0.880$ to 0.987$)$ & NR \\
\hline
\end{tabular}




\begin{tabular}{|c|c|c|c|c|c|}
\hline $\begin{array}{l}\text { Author, Year } \\
\text { (See Appendix B for } \\
\text { complete reference) }\end{array}$ & Measure & Indicator of Serious Injury & $\begin{array}{l}\text { Reported Sensitivity } \\
(95 \% \mathrm{Cl})\end{array}$ & $\begin{array}{l}\text { Reported Specificity } \\
(95 \% \mathrm{Cl})\end{array}$ & $\begin{array}{l}\text { Reported PPV } \\
(95 \% \mathrm{Cl})\end{array}$ \\
\hline Williams, 2016 & End-tidal CO2 $\left(\mathrm{ETCO}_{2}\right) \leq 30$ & Blood transfusion & $\begin{array}{l}62.50 \%(24.49 \text { to } 91.48) \\
\text { calculated }\end{array}$ & $\begin{array}{l}67.28 \%(59.48 \text { to } 74.44) \\
\text { calculated }\end{array}$ & $\begin{array}{l}8.62 \%(5.02 \text { to } 14.42) \\
\text { calculated }\end{array}$ \\
\hline Williams, 2016 & End-tidal $\mathrm{CO} 2\left(\mathrm{ETCO}_{2}\right) \leq 30$ & ICU or OR admission & $\begin{array}{l}63.64 \%(40.66 \text { to } 82.80) \\
\text { calculated }\end{array}$ & $\begin{array}{l}70.27 \%(62.21 \text { to } 77.50) \\
\text { calculated }\end{array}$ & $\begin{array}{l}24.14 \%(17.56 \text { to } 32.22) \\
\text { calculated }\end{array}$ \\
\hline Williams, 2016 & End-tidal CO2 $\left(\mathrm{ETCO}_{2}\right) \leq 30$ & Invasive procedure & $\begin{array}{l}47.22 \%(30.41 \text { to } 64.51) \\
\text { calculated }\end{array}$ & $\begin{array}{l}69.40 \%(60.86 \text { to } 77.07) \\
\text { calculated }\end{array}$ & $\begin{array}{l}29.31 \%(21.25 \text { to } 38.91) \\
\text { calculated }\end{array}$ \\
\hline Williams, 2016 & End-tidal CO2 $\left(\mathrm{ETCO}_{2}\right) \leq 30$ & Severe injury composite & $\begin{array}{l}52.73 \%(38.80 \text { to } 66.35) \\
\text { calculated }\end{array}$ & $\begin{array}{l}74.78 \%(65.83 \text { to } 82.42) \\
\text { calculated }\end{array}$ & $\begin{array}{l}50.00 \%(40.08 \text { to } 59.92) \\
\text { calculated }\end{array}$ \\
\hline Woodford, 2012 & $\begin{array}{l}\text { HR (automated), EMS (mean, all } \\
\text { values) }\end{array}$ & Mortality & $63 \%(\mathrm{Cl} \mathrm{NR})$ & $85 \%(\mathrm{Cl} N R)$ & NR \\
\hline Woodford, 2012 & $\begin{array}{l}\text { HR }>110 \text { (automated), EMS } \\
\text { (mean, abnormal values only) }\end{array}$ & Mortality & $38 \%(\mathrm{Cl} \mathrm{NR})$ & $93 \%(\mathrm{Cl} N R)$ & NR \\
\hline Woodford, 2012 & $\begin{array}{l}\text { HR >110 (standard, all values), } \\
\text { EMS }\end{array}$ & Mortality & $50 \%(\mathrm{Cl} \mathrm{NR})$ & $88 \%(\mathrm{Cl} N R)$ & NR \\
\hline Woodford, 2012 & $\begin{array}{l}\text { HR }>110, \text { EMS (standard, } \\
\text { abnormal values only) }\end{array}$ & Mortality & $63 \%(\mathrm{Cl} \mathrm{NR})$ & $79 \%(\mathrm{Cl} N R)$ & NR \\
\hline Woodford, 2012 & $\begin{array}{l}\text { Oxygen saturation }\left(\mathrm{SpO}_{2}\right) \\
\text { (mean), EMS (continuous ) }\end{array}$ & Mortality & $63 \%(\mathrm{Cl} \mathrm{NR})$ & $85 \%(\mathrm{Cl} \mathrm{NR})$ & NR \\
\hline Woodford, 2012 & $\begin{array}{l}\text { Oxygen saturation }\left(\mathrm{SpO}_{2}\right)<90, \\
\text { EMS (standard, all values) }\end{array}$ & Mortality & $38 \%(\mathrm{Cl} \mathrm{NR})$ & $99 \%(\mathrm{Cl} N R)$ & NR \\
\hline Woodford, 2012 & $\begin{array}{l}\text { Oxygen saturation }\left(\mathrm{SpO}_{2}\right)<90 \% \\
(\text { mean), EMS (continuous) }\end{array}$ & Mortality & $50 \%(\mathrm{Cl} \mathrm{NR})$ & $96 \%(\mathrm{Cl} N R)$ & NR \\
\hline Woodford, 2012 & $\begin{array}{l}\text { Oxygen saturation }\left(\mathrm{SpO}_{2}\right), \text { EMS } \\
\text { (abnormal values only) }\end{array}$ & Mortality & $38 \%(\mathrm{Cl} N R)$ & $99 \%(\mathrm{Cl} \mathrm{NR})$ & NR \\
\hline Woodford, 2012 & RTS, threshold not specified & Mortality & $63 \%(N R)$ & $83 \%(\mathrm{NR})$ & NR \\
\hline Woodford, 2012 & $\begin{array}{l}\text { SBP }<90 \text { (mean), EMS } \\
\text { (continuous) }\end{array}$ & Mortality & $25 \%(\mathrm{Cl} N R)$ & $99 \%(\mathrm{Cl} \mathrm{NR})$ & NR \\
\hline Woodford, 2012 & $\begin{array}{l}\text { SBP <90, EMS (standard, all } \\
\text { values) }\end{array}$ & Mortality & $13 \%(\mathrm{Cl} N R)$ & $98 \%(\mathrm{Cl} \mathrm{NR})$ & NR \\
\hline Woodford, 2012 & $\begin{array}{l}\text { SBP, EMS (standard, abnormal } \\
\text { values only) }\end{array}$ & Mortality & $63 \%(\mathrm{Cl} N R)$ & $76 \%$ (CI NR) & NR \\
\hline Woodford, 2012 & SI, ED & Mortality & $63 \%(\mathrm{Cl} N R)$ & $96 \%(\mathrm{Cl} N R)$ & NR \\
\hline
\end{tabular}




\begin{tabular}{|c|c|c|c|c|c|}
\hline $\begin{array}{l}\text { Author, Year } \\
\text { (See Appendix B for } \\
\text { complete reference) }\end{array}$ & $\begin{array}{l}\text { Reported NPV } \\
(95 \% \mathrm{Cl})\end{array}$ & Reported PLR & Reported NLR & $\begin{array}{l}\text { AUROC Univariate } \\
\text { AUC }(95 \% \mathrm{Cl})\end{array}$ & $\begin{array}{l}\text { Other Measures of } \\
\text { Diagnostic Accuracy }\end{array}$ \\
\hline Williams, 2016 & $\begin{array}{l}97.32 \%(93.65 \text { to } 98.89) \\
\text { calculated }\end{array}$ & $\begin{array}{l}1.91(1.07 \text { to } 3.41) \\
\text { calculated }\end{array}$ & $\begin{array}{l}0.56(0.23 \text { to } 1.37) \\
\text { calculated }\end{array}$ & NR & NR \\
\hline Williams, 2016 & $\begin{array}{l}92.86 \%(88.10 \text { to } 95.80) \\
\text { calculated }\end{array}$ & $\begin{array}{l}2.14(1.43 \text { to } 3.20) \\
\text { calculated }\end{array}$ & $\begin{array}{l}0.52(0.29 \text { to } 0.91) \\
\text { calculated }\end{array}$ & NR & NR \\
\hline Williams, 2016 & $\begin{array}{l}83.04 \% \text { (77.89 to } 87.18) \\
\text { calculated }\end{array}$ & $\begin{array}{l}1.54(1.00 \text { to } 2.37) \\
\text { calculated }\end{array}$ & $\begin{array}{l}0.76(0.55 \text { to } 1.06) \\
\text { calculated }\end{array}$ & NR & NR \\
\hline Williams, 2016 & $\begin{array}{l}76.79 \%(71.05 \text { to } 81.68) \\
\text { calculated }\end{array}$ & $\begin{array}{l}2.09(1.40 \text { to } 3.13) \\
\text { calculated }\end{array}$ & $\begin{array}{l}0.63(0.47 \text { to } 0.85) \\
\text { calculated }\end{array}$ & NR & NR \\
\hline Woodford, 2012 & NR & NR & NR & $0.70(0.50$ to 0.91$), p=0.03$ & NR \\
\hline Woodford, 2012 & NR & NR & NR & 0.65 (0.44 to 0.86$), p=0.08$ & NR \\
\hline Woodford, 2012 & NR & NR & NR & $0.69(0.48$ to 0.90$), p=0.04$ & NR \\
\hline Woodford, 2012 & NR & NR & NR & $0.60(0.38$ to 0.81$), p=0.19$ & NR \\
\hline Woodford, 2012 & NR & NR & NR & $0.76(0.56$ to 0.96$), p=0.005$ & NR \\
\hline Woodford, 2012 & NR & NR & NR & 0.68 (0.47 to 0.89$), p=0.04$ & NR \\
\hline Woodford, 2012 & NR & NR & NR & 0.73 (0.53 to 0.94$), p=0.01$ & NR \\
\hline Woodford, 2012 & NR & NR & NR & 0.59 (0.38 to 0.81$), p=0.20$ & NR \\
\hline Woodford, 2012 & NR & NR & NR & $0.73(0.53$ to 0.94$)$ & NR \\
\hline Woodford, 2012 & NR & NR & NR & 0.62 (0.41 to 0.83$), p=0.14$ & NR \\
\hline Woodford, 2012 & NR & NR & NR & 0.55 (0.34 to 0.77$), p=0.31$ & NR \\
\hline Woodford, 2012 & NR & NR & NR & 0.71 (0.50 to 0.92$), p=0.02$ & NR \\
\hline Woodford, 2012 & NR & NR & NR & $0.63(0.42$ to 0.85$), p=0.11$ & NR \\
\hline
\end{tabular}




\begin{tabular}{|c|c|c|c|c|c|}
\hline $\begin{array}{l}\text { Author, Year } \\
\text { (See Appendix B for } \\
\text { complete reference) }\end{array}$ & Measure & Indicator of Serious Injury & $\begin{array}{l}\text { Reported Sensitivity } \\
(95 \% \mathrm{Cl})\end{array}$ & $\begin{array}{l}\text { Reported Specificity } \\
(95 \% \mathrm{Cl})\end{array}$ & $\begin{array}{l}\text { Reported PPV } \\
(95 \% \mathrm{Cl})\end{array}$ \\
\hline Yuen, 2016 & RTS & Mortality & NR & NR & NR \\
\hline Yuen, 2016 & $\begin{array}{l}\text { Simplified emergency trauma } \\
\text { score (SETS) = } 60 \\
\text { SETS uses GCS, RR, } \\
\text { mechanism of injury, and age }\end{array}$ & Mortality & $64 \%(\mathrm{Cl} \mathrm{NR})$ & $98.1 \%(\mathrm{Cl} \mathrm{NR})$ & $64 \%(\mathrm{Cl} \mathrm{NR})$ \\
\hline Yuen, 2016 & $\begin{array}{l}\text { Simplified emergency trauma } \\
\text { score (SETS): uses GCS, RR, } \\
\text { mechanism of injury, and age }\end{array}$ & Mortality & NR & NR & NR \\
\hline Zarzaur, 2008 & SI $\geq 0.83$ : overall & Mortality: 48-hour & $73 \%(\mathrm{NR})$ & $79 \%(\mathrm{NR})$ & NR \\
\hline Zarzaur, 2008 & Age $\times$ SI $\geq 32.3$ : overall & Mortality: 48-hour & $78 \%(\mathrm{NR})$ & $74 \%(\mathrm{NR})$ & NR \\
\hline Zarzaur, 2008 & Age $\times$ SI $\geq 52.1$ : elderly $(\geq 55)$ & Mortality: 48-hour & $72 \%(\mathrm{NR})$ & $81 \%(\mathrm{NR})$ & NR \\
\hline Zarzaur, 2008 & HR: overall & Mortality: 48-hour & NR & NR & NR \\
\hline Zarzaur, 2008 & SBP: overall & Mortality: 48-hour & NR & $\widehat{N R}$ & NR \\
\hline Zarzaur, 2008 & SI: overall & Mortality: 48-hour & NR & NR & NR \\
\hline Zarzaur, 2008 & Age x SI: overall & Mortality: 48-hour & $\overline{N R}$ & $\widehat{N R}$ & NR \\
\hline Zarzaur, 2008 & HR: young $(<55)$ & Mortality: 48-hour & NR & NR & NR \\
\hline Zarzaur, 2008 & SBP: young $(<55)$ & Mortality: 48-hour & NR & NR & NR \\
\hline Zarzaur, 2008 & SI: young $(<55)$ & Mortality: 48-hour & NR & NR & NR \\
\hline Zarzaur, 2008 & Age $x$ SI: young $(<55)$ & Mortality: 48-hour & NR & NR & NR \\
\hline Zarzaur, 2008 & HR: elderly $(\geq 55)$ & Mortality: 48-hour & NR & NR & NR \\
\hline Zarzaur, 2008 & SBP: elderly ( $\geq 55)$ & Mortality: 48-hour & NR & NR & NR \\
\hline Zarzaur, 2008 & SI: elderly $(\geq 55)$ & Mortality: 48-hour & NR & $\overline{N R}$ & NR \\
\hline Zarzaur, 2008 & Age $\times$ SI: elderly $(\geq 55)$ & Mortality: 48-hour & NR & NR & NR \\
\hline Zarzaur, 2008 & HR: overall & Blood transfusion & NR & NR & NR \\
\hline Zarzaur, 2008 & SBP: overall & Blood transfusion & NR & NR & NR \\
\hline Zarzaur, 2008 & SI: overall & Blood transfusion & NR & NR & NR \\
\hline Zarzaur, 2008 & Age x SI: overall & Blood transfusion & NR & NR & NR \\
\hline Zarzaur, 2008 & HR: young $(<55)$ & Blood transfusion & NR & NR & NR \\
\hline Zarzaur, 2008 & SBP: young $(<55)$ & Blood transfusion & NR & NR & NR \\
\hline Zarzaur, 2008 & SI: young $(<55)$ & Blood transfusion & NR & NR & NR \\
\hline Zarzaur, 2008 & Age $x$ SI: young $(<55)$ & Blood transfusion & NR & NR & NR \\
\hline Zarzaur, 2008 & HR: elderly $(\geq 55)$ & Blood transfusion & NR & NR & NR \\
\hline Zarzaur, 2008 & SBP: elderly $(\geq 55)$ & Blood transfusion & NR & NR & NR \\
\hline Zarzaur, 2008 & SI: elderly $(\geq 55)$ & Blood transfusion & NR & NR & NR \\
\hline Zarzaur, 2008 & Age $\times$ SI: elderly $(\geq 55)$ & Blood transfusion & NR & NR & NR \\
\hline
\end{tabular}




\begin{tabular}{|c|c|c|c|c|c|}
\hline $\begin{array}{l}\text { Author, Year } \\
\text { (See Appendix B for } \\
\text { complete reference) }\end{array}$ & $\begin{array}{l}\text { Reported NPV } \\
(95 \% \mathrm{Cl})\end{array}$ & Reported PLR & Reported NLR & $\begin{array}{l}\text { AUROC Univariate } \\
\text { AUC }(95 \% \mathrm{Cl})\end{array}$ & $\begin{array}{l}\text { Other Measures of } \\
\text { Diagnostic Accuracy }\end{array}$ \\
\hline Yuen, 2016 & NR & NR & NR & $0.85(\mathrm{Cl} \mathrm{NR})$ & NR \\
\hline Yuen, 2016 & NR & NR & NR & NR & NR \\
\hline Yuen, 2016 & NR & NR & NR & $0.94(\mathrm{Cl} \mathrm{NR})$ & NR \\
\hline Zarzaur, 2008 & NR & NR & NR & NR & NR \\
\hline Zarzaur, 2008 & NR & NR & NR & NR & NR \\
\hline Zarzaur, 2008 & NR & NR & NR & NR & NR \\
\hline Zarzaur, 2008 & NR & NR & NR & $0.717(0.675$ to 0.760$)$ & NR \\
\hline Zarzaur, 2008 & NR & NR & NR & $0.753(0.711$ to 0.795$)$ & NR \\
\hline Zarzaur, 2008 & NR & NR & NR & 0.813 (0.776 to 0.849$)$ & NR \\
\hline Zarzaur, 2008 & NR & NR & NR & 0.831 (0.800 to 0.862$)$ & NR \\
\hline Zarzaur, 2008 & NR & NR & NR & $0.767(0.716$ to 0.817$)$ & NR \\
\hline Zarzaur, 2008 & NR & NR & NR & $0.770(0.719$ to 0.821$)$ & NR \\
\hline Zarzaur, 2008 & NR & NR & NR & $0.856(0.818$ to 0.900$)$ & NR \\
\hline Zarzaur, 2008 & NR & NR & NR & 0.808 (0.765 to 0.851$)$ & NR \\
\hline Zarzaur, 2008 & NR & NR & NR & 0.660 (0.589 to 0.731$)$ & NR \\
\hline Zarzaur, 2008 & NR & NR & NR & $0.761(0.695$ to 0.827$)$ & NR \\
\hline Zarzaur, 2008 & NR & NR & NR & 0.789 (0.730 to 0.848$)$ & NR \\
\hline Zarzaur, 2008 & NR & NR & NR & $0.830(0.780$ to 0.880$)$ & NR \\
\hline Zarzaur, 2008 & NR & NR & NR & $0.713(0.696$ to 0.731$)$ & NR \\
\hline Zarzaur, 2008 & NR & NR & NR & 0.711 (0.693 to 0.719$)$ & NR \\
\hline Zarzaur, 2008 & NR & NR & NR & 0.783 (0.767 to 0.799$)$ & NR \\
\hline Zarzaur, 2008 & NR & NR & NR & $0.759(0.743$ to 0.775$)$ & NR \\
\hline Zarzaur, 2008 & NR & NR & NR & $0.743(0.724$ to 0.762$)$ & NR \\
\hline Zarzaur, 2008 & NR & NR & NR & $0.708(0.687$ to 0.729$)$ & NR \\
\hline Zarzaur, 2008 & NR & NR & NR & $0.797(0.779$ to 0.815$)$ & NR \\
\hline Zarzaur, 2008 & NR & NR & NR & 0.749 (0.731 to 0.768$)$ & NR \\
\hline Zarzaur, 2008 & NR & NR & NR & $0.642(0.604$ to 0.681$)$ & NR \\
\hline Zarzaur, 2008 & NR & NR & NR & $0.762(0.730$ to 0.793$)$ & NR \\
\hline Zarzaur, 2008 & NR & NR & NR & $0.789(0.758$ to 0.819$)$ & NR \\
\hline Zarzaur, 2008 & NR & NR & NR & 0.805 (0.776 to 0.834$)$ & NR \\
\hline
\end{tabular}

\section{See Appendix B. Included Studies for full study references.}

ABG = arterial blood gas: ACS-COT = American College of Surgeons Committee on Trauma; AIS = Abbreviated Injury Scale; AOR = adjusted odds ratio; APACHE II = Acute Physiology and Chronic Health Evaluation II; AUROC = area under the receiver operating characteristic curve; BD = base deficit; BP = blood pressure; CHAID = chi-square automatic interaction detection; CI = confidence interval; $\mathrm{CNS}$ = central nervous system; $\mathrm{CPR}$ = cardiopulmonary resuscitation; CRAMS = Circulation, Respiration, Abdomen, Motor, and Speech; CT = computed tomography; DBP = diastolic blood pressure; ECG = electrocardiogram; ED = emergency department; EHR = electronic health record; EMS = emergency medical services; EMT = emergency medical technician; EMTRAS = Emergency Trauma Score; ETCO2 = end-tidal carbon dioxide; FTS = Field Triage Score; GAP = Glasgow Coma Scale, Age, and Arterial Pressure; GCS = Glasgow Coma Scale; HR = heart rate; HRC = heart rate complexity; HRV = heart rate variability; ICD-9 = International Classification of Diseases 9th Revision; ICU = intensive care unit; INR = international normalized ratio; IQR = interquartile range; ISS = Injury Severity Score; IV = intravenous; LOS = length of stay; LSI = life-saving intervention; MAP = mean arterial pressure; MGAP = Mechanism, Glasgow Coma Scale, Age, and Arterial Pressure; MOD = multiple organ dysfunction; MPTT = Modified Physiological Triage Tool; NA = not applicable; NIRS = near-infrared spectrometry; NLR = negative likelihood ratio; NPV = negative predictive value; NR = not reported; NTDB = National Trauma Data Bank; NTTP = National Trauma Triage Protocol: OH = out-of-hospital; OR = operating room; $\mathrm{pCO}_{2}$ = partial pressure of carbon dioxide; PHI = Prehospital Index; PLR = positive likelihood ratio; POC = point of care; PP = pulse pressure; PPG = photoplethysmography, photoplethysmogram; 


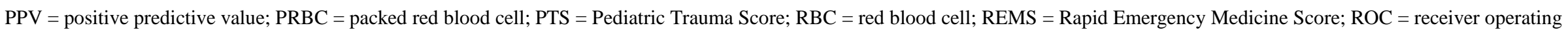

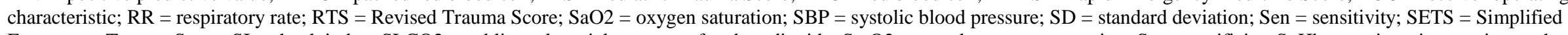

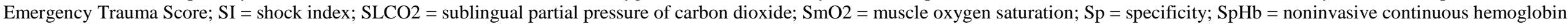

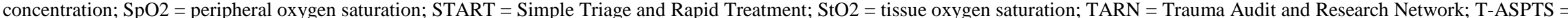

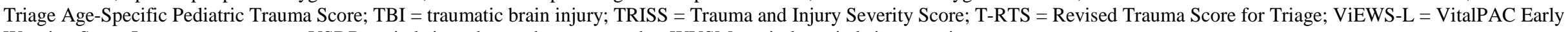
Warning Score-Lactate; vs. = versus; VSDR = vital signs data and event recorder; WVSM = wireless vital signs monitor 
Table D3. Multivariate results

\begin{tabular}{|c|c|c|c|c|c|}
\hline $\begin{array}{l}\text { Author, Year } \\
\text { (See Appendix B } \\
\text { for complete } \\
\text { reference) }\end{array}$ & Measure & $\begin{array}{l}\text { Indicator of } \\
\text { Serious Injury }\end{array}$ & Method for Constructing Multivariate Model & $\begin{array}{l}\text { Risk Estimates } \\
\text { Multivariate }\end{array}$ & $\begin{array}{l}\text { AUROC Multivariate } \\
\text { AUC }(95 \% \mathrm{Cl})\end{array}$ \\
\hline Allen, 2014 & $B D<0$ & $\begin{array}{l}\text { Blood } \\
\text { transfusion }\end{array}$ & $\begin{array}{l}\text { Multivariate logistic regression. Results of univariate analyses were used to identify } \\
\text { variables for inclusion in the regression. Variables included age-specific } \\
\text { hypotension, base deficit, age-specific tachycardia, altered mental status and } \\
\text { hematocrit. }\end{array}$ & $\begin{array}{l}\text { AOR }(95 \% \mathrm{Cl}): 4.14 \\
(1.38 \text { to } 12.39)\end{array}$ & NR \\
\hline Aslar, 2004 & APACHE II score & $\begin{array}{l}\text { Mortality, 30- } \\
\text { day in-hospital }\end{array}$ & $\begin{array}{l}\text { Multivariate logistic regression. Candidate variables were those with } p<0.15 \text { on } \\
\text { univariate test. Analysis was confirmed by using LogXact test. Pearson's and } \\
\text { Spearman's correlation coefficients were used for degree of association between } \\
\text { variables (parametric and non-parametric, respectively). Final model included } \\
\text { APACHE II and lactate. }\end{array}$ & $\begin{array}{l}\text { AOR }(95 \% \mathrm{Cl}): 26.17 \\
(3.99 \text { to } 171.59) \\
\text { Beta regression } \\
\text { coefficient: } 3.26 \text { (SE } \\
0.96), p=0.0007\end{array}$ & NR \\
\hline Aslar, 2004 & Lactate & $\begin{array}{l}\text { Mortality, 30- } \\
\text { day in-hospital }\end{array}$ & $\begin{array}{l}\text { Multivariate logistic regression. Candidate variables were those with } p<0.15 \text { on } \\
\text { univariate test. Analysis was confirmed by using LogXact test. Pearson's and } \\
\text { Spearman's correlation coefficients were used for degree of association between } \\
\text { variables (parametric and non-parametric, respectively). Final model included } \\
\text { APACHE II and lactate. }\end{array}$ & $\begin{array}{l}\text { AOR }(95 \% \mathrm{Cl}): 10.58 \\
(1.88 \text { to } 59.24) \\
\text { Beta regression } \\
\text { coefficient: } 2.36 \text { (SE } \\
0.88), p=0.0073\end{array}$ & NR \\
\hline Aslar, 2004 & $\begin{array}{l}\text { Multivariate } \\
\text { model: APACHE } \\
\text { Il score and } \\
\text { lactate }\end{array}$ & $\begin{array}{l}\text { Mortality, 30- } \\
\text { day in-hospital }\end{array}$ & $\begin{array}{l}\text { Multivariate logistic regression. Candidate variables were those with } \mathrm{p}<0.15 \text { on } \\
\text { univariate test. Analysis was confirmed by using LogXact test. Pearson's and } \\
\text { Spearman's correlation coefficients were used for degree of association between } \\
\text { variables (parametric and non-parametric, respectively). Final model included } \\
\text { APACHE II and lactate. }\end{array}$ & NR & $\begin{array}{l}\text { AUC: NR } \\
\text { Sensitivity: } 79.2 \% \\
\text { Specificity: } 94.6 \%\end{array}$ \\
\hline $\begin{array}{l}\text { Batchinsky, } 2007 \\
\text { * Batchinsky } 2007 \\
\text { and Batchinsky } \\
2009 \text { analyze the } \\
\text { same ECGs, but } \\
\text { differ in measures } \\
\text { evaluated. }\end{array}$ & $\begin{array}{l}\text { Prehospital } \\
\text { model 1: } \\
\text { approximate } \\
\text { entropy, } \\
\text { distribution of } \\
\text { symbol } 2 \text { and } \\
\text { GCS motor } \\
\text { component }\end{array}$ & Mortality & $\begin{array}{l}\text { Multiple logistic regressions to identify independent predictors of mortality, using } \\
\text { stepwise selection and likelihood ratio tests. Candidate variables were ECG-derived } \\
\text { metrics, GCS motor component, and ISS. Models were constructed with three } \\
\text { overlapping phases to represent a diagnostic problem: 1) "remote triage" using only } \\
\text { R-to-R interval metrics; 2) "prehospital care" using R-to-R interval metrics plus field } \\
\text { data including motor component of GCS; 3) "definitive care" using data available } \\
\text { during hospitalization, including the ISS. Variables with p value of } 0.2 \text { by univariate } \\
\text { analysis were chosen as candidates for the logistic regression. Model fit estimated } \\
\text { using the Hosmer- Lemeshow goodness-of-fit test, and ROC curves constructed to } \\
\text { assess diagnostic performance, with repeat analysis excluding outliers. } \\
\text { Final predictive models } \\
\text { - in the prehospital predictive model, distribution of symbol } 2 \text { was no longer retained } \\
\text { after excluding outliers ("model 2") } \\
\text { Remote triage model: approximate entropy and distribution of symbol } 2 \\
\text { Prehospital model 1: approximate entropy, distribution of symbol } 2 \text { and GCS motor } \\
\text { component } \\
\text { Prehospital model 2: approximate entropy and GCS motor component }\end{array}$ & NR & $0.886(0.75$ to 1.0$)$ \\
\hline
\end{tabular}




\begin{tabular}{|c|c|c|c|c|c|}
\hline $\begin{array}{l}\text { Author, Year } \\
\text { (See Appendix B } \\
\text { for complete } \\
\text { reference) }\end{array}$ & Measure & $\begin{array}{l}\text { Indicator of } \\
\text { Serious Injury }\end{array}$ & Method for Constructing Multivariate Model & $\begin{array}{l}\text { Risk Estimates } \\
\text { Multivariate }\end{array}$ & $\begin{array}{l}\text { AUROC Multivariate } \\
\text { AUC }(95 \% \mathrm{Cl})\end{array}$ \\
\hline $\begin{array}{l}\text { Batchinsky, } 2007 \\
\text { * Batchinsky } 2007 \\
\text { and Batchinsky } \\
2009 \text { analyze the } \\
\text { same ECGs, but } \\
\text { differ in measures } \\
\text { evaluated. }\end{array}$ & \begin{tabular}{|l|} 
Prehospital \\
model 2: \\
approximate \\
entropy and GCS \\
motor component \\
excluding outliers
\end{tabular} & Mortality & $\begin{array}{l}\text { Multiple logistic regressions to identify independent predictors of mortality, using } \\
\text { stepwise selection and likelihood ratio tests. Candidate variables were ECG-derived } \\
\text { metrics, GCS motor component, and ISS. Models were constructed with three } \\
\text { overlapping phases to represent a diagnostic problem: 1) "remote triage" using only } \\
\text { R-to-R interval metrics; 2) "prehospital care" using R-to-R interval metrics plus field } \\
\text { data including motor component of GCS; } 3 \text { ) "definitive care" using data available } \\
\text { during hospitalization, including the ISS. Variables with p value of } 0.2 \text { by univariate } \\
\text { analysis were chosen as candidates for the logistic regression. Model fit estimated } \\
\text { using the Hosmer- Lemeshow goodness-of-fit test, and ROC curves constructed to } \\
\text { assess diagnostic performance, with repeat analysis excluding outliers. } \\
\text { Final predictive models } \\
\text { - in the prehospital predictive model, distribution of symbol } 2 \text { was no longer retained } \\
\text { after excluding outliers ("model 2") } \\
\text { Remote triage model: approximate entropy and distribution of symbol } 2 \\
\text { Prehospital model 1: approximate entropy, distribution of symbol } 2 \text { and GCS motor } \\
\text { component } \\
\text { Prehospital model 2: approximate entropy and GCS motor component }\end{array}$ & NR & $0.92(0.80$ to 1.0$)$ \\
\hline $\begin{array}{l}\text { Batchinsky, } 2007 \\
\text { * Batchinsky } 2007 \\
\text { and Batchinsky } \\
2009 \text { analyze the } \\
\text { same ECGs, but } \\
\text { differ in measures } \\
\text { evaluated. }\end{array}$ & $\begin{array}{l}\text { Remote triage } \\
\text { model: } \\
\text { approximate } \\
\text { entropy and } \\
\text { distribution of } \\
\text { symbol } 2\end{array}$ & Mortality & $\begin{array}{l}\text { Multiple logistic regressions to identify independent predictors of mortality, using } \\
\text { stepwise selection and likelihood ratio tests. Candidate variables were ECG-derived } \\
\text { metrics, GCS motor component, and ISS. Models were constructed with three } \\
\text { overlapping phases to represent a diagnostic problem: 1) "remote triage" using only } \\
\text { R-to-R interval metrics; 2) "prehospital care" using R-to-R interval metrics plus field } \\
\text { data including motor component of GCS; } 3 \text { ) "definitive care" using data available } \\
\text { during hospitalization, including the ISS. Variables with p value of } 0.2 \text { by univariate } \\
\text { analysis were chosen as candidates for the logistic regression. Model fit estimated } \\
\text { using the Hosmer- Lemeshow goodness-of-fit test, and ROC curves constructed to } \\
\text { assess diagnostic performance, with repeat analysis excluding outliers. } \\
\text { Final predictive models } \\
\text { - in the prehospital predictive model, distribution of symbol } 2 \text { was no longer retained } \\
\text { after excluding outliers ("model 2") } \\
\text { Remote triage model: approximate entropy and distribution of symbol } 2 \\
\text { Prehospital model 1: approximate entropy, distribution of symbol } 2 \text { and GCS motor } \\
\text { component } \\
\text { Prehospital model 2: approximate entropy and GCS motor component }\end{array}$ & NR & $0.86(0.71$ to 1.0$)$ \\
\hline
\end{tabular}




\begin{tabular}{|c|c|c|c|c|c|}
\hline $\begin{array}{l}\text { Author, Year } \\
\text { (See Appendix B } \\
\text { for complete } \\
\text { reference) }\end{array}$ & Measure & $\begin{array}{l}\text { Indicator of } \\
\text { Serious Injury }\end{array}$ & Method for Constructing Multivariate Model & $\begin{array}{l}\text { Risk Estimates } \\
\text { Multivariate }\end{array}$ & $\begin{array}{l}\text { AUROC Multivariate } \\
\text { AUC }(95 \% \mathrm{Cl})\end{array}$ \\
\hline $\begin{array}{l}\text { Batchinsky, } 2007 \\
\text { * Batchinsky } 2007 \\
\text { and Batchinsky } \\
2009 \text { analyze the } \\
\text { same ECGs, but } \\
\text { differ in measures } \\
\text { evaluated. }\end{array}$ & \begin{tabular}{|l|} 
Remote triage \\
model: \\
approximate \\
entropy and \\
distribution of \\
symbol 2 \\
excluding outliers
\end{tabular} & Mortality & $\begin{array}{l}\text { Multiple logistic regressions to identify independent predictors of mortality, using } \\
\text { stepwise selection and likelihood ratio tests. Candidate variables were ECG-derived } \\
\text { metrics, GCS motor component, and ISS. Models were constructed with three } \\
\text { overlapping phases to represent a diagnostic problem: 1) "remote triage" using only } \\
\text { R-to-R interval metrics; 2) "prehospital care" using R-to-R interval metrics plus field } \\
\text { data including motor component of GCS; } 3 \text { ) "definitive care" using data available } \\
\text { during hospitalization, including the ISS. Variables with p value of } 0.2 \text { by univariate } \\
\text { analysis were chosen as candidates for the logistic regression. Model fit estimated } \\
\text { using the Hosmer- Lemeshow goodness-of-fit test, and ROC curves constructed to } \\
\text { assess diagnostic performance, with repeat analysis excluding outliers. } \\
\text { Final predictive models } \\
\text { - in the prehospital predictive model, distribution of symbol } 2 \text { was no longer retained } \\
\text { after excluding outliers ("model 2") } \\
\text { Remote triage model: approximate entropy and distribution of symbol } 2 \\
\text { Prehospital model 1: approximate entropy, distribution of symbol } 2 \text { and GCS motor } \\
\text { component } \\
\text { Prehospital model 2: approximate entropy and GCS motor component }\end{array}$ & NR & $0.956(0.86$ to 1.0$)$ \\
\hline $\begin{array}{l}\text { Batchinsky, } 2009 \\
\text { * Batchinsky } 2009 \\
\text { and Batchinsky } \\
2007 \text { analyze the } \\
\text { same ECGs, but } \\
\text { differ in measures } \\
\text { evaluated. }\end{array}$ & $\begin{array}{l}\text { ECG complexity, } \\
\text { sample entropy } \\
\text { (SampEn): } 800 \\
\text { beat data set }\end{array}$ & Mortality & $\begin{array}{l}\text { Multiple logistic regressions with stepwise selection and likelihood ratio tests with } \\
\text { candidate variables of all available ECG-derived metrics with a p value }<0.2 \text { by } \\
\text { univariate analysis (SampEn used instead of ApEn in analysis). Estimation of model } \\
\text { fit was by the Hosmer-Lemeshow goodness-of-fit test and estimated odds ratios by } \\
\text { the maximum likelihood method. } \\
\text { Final models: in all data sets, SampEn was retained as the only independent } \\
\text { predictor of death. }\end{array}$ & $\begin{array}{l}\text { AOR }(95 \% \text { Cl): } 0.00007 \\
(0 \text { to } 0.124)\end{array}$ & $0.895(0.780$ to 1.010$)$ \\
\hline $\begin{array}{l}\text { Batchinsky, } 2009 \\
\text { * Batchinsky } 2009 \\
\text { and Batchinsky } \\
2007 \text { analyze the } \\
\text { same ECGs, but } \\
\text { differ in measures } \\
\text { evaluated. }\end{array}$ & $\begin{array}{l}\text { ECG complexity, } \\
\text { sample entropy } \\
\text { (SampEn): } 200 \\
\text { beat data set }\end{array}$ & Mortality & $\begin{array}{l}\text { Multiple logistic regressions with stepwise selection and likelihood ratio tests with } \\
\text { candidate variables of all available ECG-derived metrics with a p value }<0.2 \text { by } \\
\text { univariate analysis (SampEn used instead of ApEn in analysis). Estimation of model } \\
\text { fit was by the Hosmer-Lemeshow goodness-of-fit test and estimated odds ratios by } \\
\text { the maximum likelihood method. } \\
\text { Final models: in all data sets, SampEn was retained as the only independent } \\
\text { predictor of death. }\end{array}$ & $\begin{array}{l}\text { AOR }(95 \% \mathrm{Cl}): 0.00045 \\
(0 \text { to } 0.159)\end{array}$ & $0.895(0.781$ to 1.000$)$ \\
\hline
\end{tabular}




\begin{tabular}{|c|c|c|c|c|c|}
\hline $\begin{array}{l}\text { Author, Year } \\
\text { (See Appendix B } \\
\text { for complete } \\
\text { reference) }\end{array}$ & Measure & $\begin{array}{l}\text { Indicator of } \\
\text { Serious Injury }\end{array}$ & Method for Constructing Multivariate Model & $\begin{array}{l}\text { Risk Estimates } \\
\text { Multivariate }\end{array}$ & $\begin{array}{l}\text { AUROC Multivariate } \\
\text { AUC }(95 \% \mathrm{Cl})\end{array}$ \\
\hline $\begin{array}{l}\text { Batchinsky, } 2009 \\
\text { * Batchinsky } 2009 \\
\text { and Batchinsky } \\
2007 \text { analyze the } \\
\text { same ECGs, but } \\
\text { differ in measures } \\
\text { evaluated. }\end{array}$ & $\begin{array}{l}\text { ECG complexity, } \\
\text { sample entropy } \\
\text { (SampEn): } 100 \\
\text { beat data set }\end{array}$ & Mortality & $\begin{array}{l}\text { Multiple logistic regressions with stepwise selection and likelihood ratio tests with } \\
\text { candidate variables of all available ECG-derived metrics with a p value }<0.2 \text { by } \\
\text { univariate analysis (SampEn used instead of ApEn in analysis). Estimation of model } \\
\text { fit was by the Hosmer-Lemeshow goodness-of-fit test and estimated odds ratios by } \\
\text { the maximum likelihood method. } \\
\text { Final models: in all data sets, SampEn was retained as the only independent } \\
\text { predictor of death. }\end{array}$ & $\begin{array}{l}\text { AOR }(95 \% \mathrm{Cl}): 0.024 \\
(0.001 \text { to } 0.494)\end{array}$ & $0.821(0.662$ to 0.980$)$ \\
\hline Batchinsky, 2009b & $\begin{array}{l}\text { HRC: Artificial } \\
\text { neural network } \\
\text { using ECG- } \\
\text { derived new vital } \\
\text { signs }\end{array}$ & $\begin{array}{l}\text { Life-saving } \\
\text { intervention }\end{array}$ & $\begin{array}{l}\text { Artificial neural network model to identify patients who received a life-saving } \\
\text { intervention using } 16 \text { ECG-derived new vital signs. ROC curves for models after 3- } \\
\text { fold, } 5 \text {-fold, and } 10 \text {-fold cross validation; the set of variables differed by a few } \\
\text { between the cross validation models. }\end{array}$ & NR & $\begin{array}{l}\text { AUC }(95 \% \mathrm{Cl}) \\
\text { 3-fold cross validation: } \\
0.864 \text { (NR) } \\
\text { 5-fold cross validation: } \\
0.861 \text { (NR) } \\
\text { 10-fold cross } \\
\text { validation: } 0.868 \\
(0.812 \text { to } 0.924)\end{array}$ \\
\hline Beekley, 2010 & $\mathrm{BD}$ & LSI & $\begin{array}{l}\text { Multivariate logistic regression using stepwise backward elimination technique } \\
\text { retaining INR, hematocrit, BD, and DBP. }\end{array}$ & $\begin{array}{l}\text { AOR }(95 \% \mathrm{Cl}): 1.54(1.1 \\
\text { to } 2.2), \text { for change of }-2 \\
\mathrm{mEq} / \mathrm{L}\end{array}$ & NR \\
\hline Beekley, 2010 & DBP & LSI & $\begin{array}{l}\text { Multivariate logistic regression using stepwise backward elimination technique } \\
\text { retaining INR, hematocrit, BD, and DBP. }\end{array}$ & $\begin{array}{l}\text { AOR }(95 \% \mathrm{Cl}): 1.54(1.1 \\
\text { to } 2.2) \text {, for change of }-2\end{array}$ & NR \\
\hline Beekley, 2010 & \begin{tabular}{|l} 
Multivariate \\
model to predict \\
blood \\
transfusion: SBP, \\
INR, tissue \\
hemoglobin \\
index, and \\
hematocrit \\
\end{tabular} & LSI & $\begin{array}{l}\text { Multivariate logistic regression using stepwise backward elimination technique to } \\
\text { predict any blood transfusion; variables retained were SBP, INR, tissue hemoglobin } \\
\text { index, and hematocrit. }\end{array}$ & NR & $0.90(0.84$ to 0.96$)$ \\
\hline Beekley, 2010 & $\begin{array}{l}\text { Multivariate } \\
\text { model to predict } \\
\text { LSI: INR, } \\
\text { Hematocrit, BD, } \\
\text { DBP }\end{array}$ & LSI & $\begin{array}{l}\text { Multivariate logistic regression using stepwise backward elimination technique to } \\
\text { predict LSI; variables retained were INR, hematocrit, BD, and DBP. }\end{array}$ & NR & $0.85(0.79$ to 0.91$)$ \\
\hline Beekley, 2010 & SBP & \begin{tabular}{|l|} 
Blood \\
Transfusion
\end{tabular} & $\begin{array}{l}\text { Multivariate logistic regression using stepwise backward elimination technique } \\
\text { retaining SBP, INR, tissue hemoglobin index, and hematocrit. }\end{array}$ & $\begin{array}{l}\text { AOR }(95 \% \mathrm{Cl}): 1.40(1.1 \\
\text { to } 1.8) \\
\text { for change of }-10 \mathrm{mmHg}\end{array}$ & NR \\
\hline
\end{tabular}




\begin{tabular}{|c|c|c|c|c|c|}
\hline $\begin{array}{l}\text { Author, Year } \\
\text { (See Appendix B } \\
\text { for complete } \\
\text { reference) }\end{array}$ & Measure & $\begin{array}{l}\text { Indicator of } \\
\text { Serious Injury }\end{array}$ & Method for Constructing Multivariate Model & $\begin{array}{l}\text { Risk Estimates } \\
\text { Multivariate }\end{array}$ & $\begin{array}{l}\text { AUROC Multivariate } \\
\text { AUC }(95 \% \mathrm{Cl})\end{array}$ \\
\hline Brown, 2011 & SBP $<90$ & ICU admission & $\begin{array}{l}\text { Stepwise logistical regression analysis using all physiologic and anatomic criteria } \\
\text { (NTTP steps } 1 \text { and } 2 \text { ). Entry of an individual triage criterion into the model was set at } \\
\text { p }<0.1 \text {; confidence intervals calculated as } 99 \% \text {, with } p<0.01 \text { considered significant. }\end{array}$ & $\begin{array}{l}\text { AOR (99\% Cl): } 0.80 \\
(0.79-0.82), p<0.01\end{array}$ & NR \\
\hline Brown, 2011 & RR $<10$ or $>29$ & ICU admission & $\begin{array}{l}\text { Stepwise logistical regression analysis using all physiologic and anatomic criteria } \\
\text { (NTTP steps } 1 \text { and } 2 \text { ). Entry of an individual triage criterion into the model was set at } \\
\text { p<0.1; confidence intervals calculated as } 99 \% \text {, with } p<0.01 \text { considered significant. }\end{array}$ & $\begin{array}{l}\text { AOR (99\% Cl): } 1.45 \\
(1.43-1.46), p<0.01\end{array}$ & NR \\
\hline Brown, 2011 & SBP $<90$ & $\begin{array}{l}\text { Trauma center } \\
\text { need }\end{array}$ & $\begin{array}{l}\text { Stepwise logistical regression analysis using all physiologic and anatomic criteria } \\
\text { (NTTP steps } 1 \text { and } 2 \text { ). Entry of an individual triage criterion into the model was set at } \\
\text { p<0.1; confidence intervals calculated as } 99 \% \text {, with } p<0.01 \text { considered significant. }\end{array}$ & $\begin{array}{l}\text { AOR (99\% Cl): } 1.32 \\
(1.29-1.34), p<0.01\end{array}$ & NR \\
\hline Brown, 2011 & RR $<10$ or $>29$ & $\begin{array}{l}\text { Trauma center } \\
\text { need }\end{array}$ & $\begin{array}{l}\text { Stepwise logistical regression analysis using all physiologic and anatomic criteria } \\
\text { (NTTP steps } 1 \text { and } 2 \text { ). Entry of an individual triage criterion into the model was set at } \\
\text { p }<0.1 \text {; confidence intervals calculated as } 99 \% \text {, with } p<0.01 \text { considered significant. }\end{array}$ & $\begin{array}{l}\text { AOR (99\% Cl): } 1.59 \\
(1.56-1.61), p<0.01\end{array}$ & NR \\
\hline Brown, 2011 & SBP $<90$ & ISS $>15$ & $\begin{array}{l}\text { Stepwise logistical regression analysis using all physiologic and anatomic criteria } \\
\text { (NTTP steps } 1 \text { and } 2 \text { ). Entry of an individual triage criterion into the model was set at } \\
\text { p<0.1; confidence intervals calculated as } 99 \% \text {, with } p<0.01 \text { considered significant. }\end{array}$ & $\begin{array}{l}\text { AOR (99\% Cl): } 1.50 \\
(1.48-1.53), p<0.01\end{array}$ & NR \\
\hline Brown, 2011 & SBP $<90$ & Urgent surgery & $\begin{array}{l}\text { Stepwise logistical regression analysis using all physiologic and anatomic criteria } \\
\text { (NTTP steps } 1 \text { and } 2 \text { ). Entry of an individual triage criterion into the model was set at } \\
\text { p }<0.1 \text {; confidence intervals calculated as } 99 \% \text {, with } p<0.01 \text { considered significant. }\end{array}$ & $\begin{array}{l}\text { AOR (99\% Cl): } 1.17 \\
(1.15-1.19), p<0.01\end{array}$ & NR \\
\hline Brown, 2011 & RR $<10$ or $>29$ & Urgent surgery & $\begin{array}{l}\text { Stepwise logistical regression analysis using all physiologic and anatomic criteria } \\
\text { (NTTP steps } 1 \text { and } 2 \text { ). Entry of an individual triage criterion into the model was set at } \\
\text { p<0.1; confidence intervals calculated as } 99 \% \text {, with } p<0.01 \text { considered significant. }\end{array}$ & $\begin{array}{l}\text { AOR (99\% Cl): } 1.05 \\
(1.04-1.07), p<0.01\end{array}$ & NR \\
\hline Cancio, 2008 & $\begin{array}{l}\text { HRC and motor } \\
\text { GCS model: } \\
\text { Sample Entropy } \\
\text { (SampEn) and } \\
\text { Detrended } \\
\text { Fluctuations }\end{array}$ & LSI & $\begin{array}{l}\text { Multiple logistic regressions with stepwise selection and likelihood ratio tests using R } \\
\text { to-R interval time series variables, GCS motor component, and BP. Maximum } \\
\text { likelihood method was used to estimate the odds ratios and confidence intervals. }\end{array}$ & NR & $0.897(0.839$ to 0.956$)$ \\
\hline Cancio, 2008 & $\begin{array}{l}\text { HRC model: } \\
\text { Sample Entropy } \\
\text { (SampEn) and } \\
\text { Detrended } \\
\text { Fluctuations } \\
\text { Analysis (DFA) }\end{array}$ & LSI & $\begin{array}{l}\text { Multiple logistic regressions with stepwise selection and likelihood ratio tests using R- } \\
\text { to-R interval time series variables, GCS motor component, and BP. Maximum } \\
\text { likelihood method was used to estimate the odds ratios and confidence intervals. }\end{array}$ & NR & $0.760(0.682$ to 0.838$)$ \\
\hline
\end{tabular}




\begin{tabular}{|c|c|c|c|c|c|}
\hline $\begin{array}{l}\text { Author, Year } \\
\text { (See Appendix B } \\
\text { for complete } \\
\text { reference) }\end{array}$ & Measure & $\begin{array}{l}\text { Indicator of } \\
\text { Serious Injury }\end{array}$ & Method for Constructing Multivariate Model & $\begin{array}{l}\text { Risk Estimates } \\
\text { Multivariate }\end{array}$ & $\begin{array}{l}\text { AUROC Multivariate } \\
\text { AUC }(95 \% \mathrm{CI})\end{array}$ \\
\hline Cancio, 2008 & $\begin{array}{l}\text { HRC: Detrended } \\
\text { Fluctuations } \\
\text { Analysis (DFA) }\end{array}$ & LSI & $\begin{array}{l}\text { Multiple logistic regressions with stepwise selection and likelihood ratio tests using R } \\
\text { to-R interval time series variables, GCS motor component, and BP. Maximum } \\
\text { likelihood method was used to estimate the odds ratios and confidence intervals. }\end{array}$ & $\begin{array}{l}\text { AOR }(95 \% \mathrm{Cl}) \\
\text { SampEn and DFA model: } \\
0.186(0.081 \text { to } 0.428) \\
\text { SampEn, DFA and GCS } \\
\text { motor model: } 0.142 \\
(0.045 \text { to } 0.445)\end{array}$ & NR \\
\hline Cancio, 2008 & $\begin{array}{l}\text { HRC: Sample } \\
\text { Entropy } \\
\text { (SampEn) }\end{array}$ & LSI & $\begin{array}{l}\text { Multiple logistic regressions with stepwise selection and likelihood ratio tests using R- } \\
\text { to-R interval time series variables, GCS motor component, and BP. Maximum } \\
\text { likelihood method was used to estimate the odds ratios and confidence intervals. }\end{array}$ & $\begin{array}{l}\text { AOR }(95 \% \mathrm{Cl}) \\
\text { SampEn and DFA model: } \\
0.081(0.026 \text { to } 0.251) \\
\text { SampEn, DFA and GCS } \\
\text { motor model: } 0.077 \\
(0.016 \text { to } 0.362)\end{array}$ & NR \\
\hline Cancio, 2008a & DBP & $\begin{array}{l}\text { Massive } \\
\text { transfusion }\end{array}$ & $\begin{array}{l}\text { Logistic regression analysis using backwards likelihood ratio method with candidate } \\
\text { variables different on univariate analysis by } p<0.10 \text {. The probability of an outcome is } \\
\text { given by logistic regression analysis, where } p=e^{k} /\left(1+e^{k}\right) \text {. } \\
\text { DBP as variable in multivariate model with } F T S_{07} \text { for massive transfusion: } k=-0.740 \\
-0.376 \times \mathrm{FTS}_{07}-0.011 \times \text { DBP }\end{array}$ & $\begin{array}{l}\text { AOR }(95 \% \mathrm{Cl}): 0.989 \\
(0.979 \text { to } 1.000)\end{array}$ & NR \\
\hline Cancio, 2008a & DBP & $\begin{array}{l}\text { Massive } \\
\text { transfusion }\end{array}$ & $\begin{array}{l}\text { Logistic regression analysis using backwards likelihood ratio method with candidate } \\
\text { variables different on univariate analysis by } p<0.10 \text {. The probability of an outcome is } \\
\text { given by logistic regression analysis, where } p=e^{k} /\left(1+e^{k}\right) \text {. } \\
\text { DBP as variable in RTS-based model for massive transfusion: } k=0.638-0.115 x \\
\text { RTS - } 0.011 \times \text { DBP }+0.358 \times \text { SI }\end{array}$ & $\begin{array}{l}\text { AOR }(95 \% \mathrm{Cl}): 0.989 \\
(0.978 \text { to } 0.999)\end{array}$ & NR \\
\hline Cancio, 2008a & \begin{tabular}{|l|} 
FTS \\
Triage $($ new Field \\
uses GCS $<8$ \\
and SBP $<100$
\end{tabular} & $\begin{array}{l}\text { Mortality, in- } \\
\text { hospital }\end{array}$ & $\begin{array}{l}\text { Logistic regression analysis using backwards likelihood ratio method with candidate } \\
\text { variables different on univariate analysis by } p<0.10 \text {. The probability of an outcome is } \\
\text { given by logistic regression analysis, where } p=e^{k} /\left(1+e^{k}\right) \text {. } \\
\text { Model with } \mathrm{FTS}_{07} \text { for mortality: } \mathrm{k}=-0.716-1.009 \times \mathrm{FTS}_{07}\end{array}$ & $\begin{array}{l}\text { AOR }(95 \% \mathrm{Cl}): 0.365 \\
(0.255 \text { to } 0.521)\end{array}$ & NR \\
\hline Cancio, 2008a & \begin{tabular}{|l|} 
FTS $_{07}($ new Field \\
Triage Score): \\
uses GCS $<8$ \\
and SBP $<100$
\end{tabular} & $\begin{array}{l}\text { Massive } \\
\text { transfusion }\end{array}$ & $\begin{array}{l}\text { Logistic regression analysis using backwards likelihood ratio method with candidate } \\
\text { variables different on univariate analysis by } p<0.10 \text {. The probability of an outcome is } \\
\text { given by logistic regression analysis, where } p=e^{k} /\left(1+e^{k}\right) \text {. } \\
\text { Model with } \mathrm{FTS}_{07} \text { for massive transfusion: } k=-0.740-0.376 \times \mathrm{FTS}_{07}-0.011 \times \text { DBP }\end{array}$ & $\begin{array}{l}\text { AOR }(95 \% \mathrm{Cl}): 0.687 \\
(0.524 \text { to } 0.900)\end{array}$ & NR \\
\hline
\end{tabular}




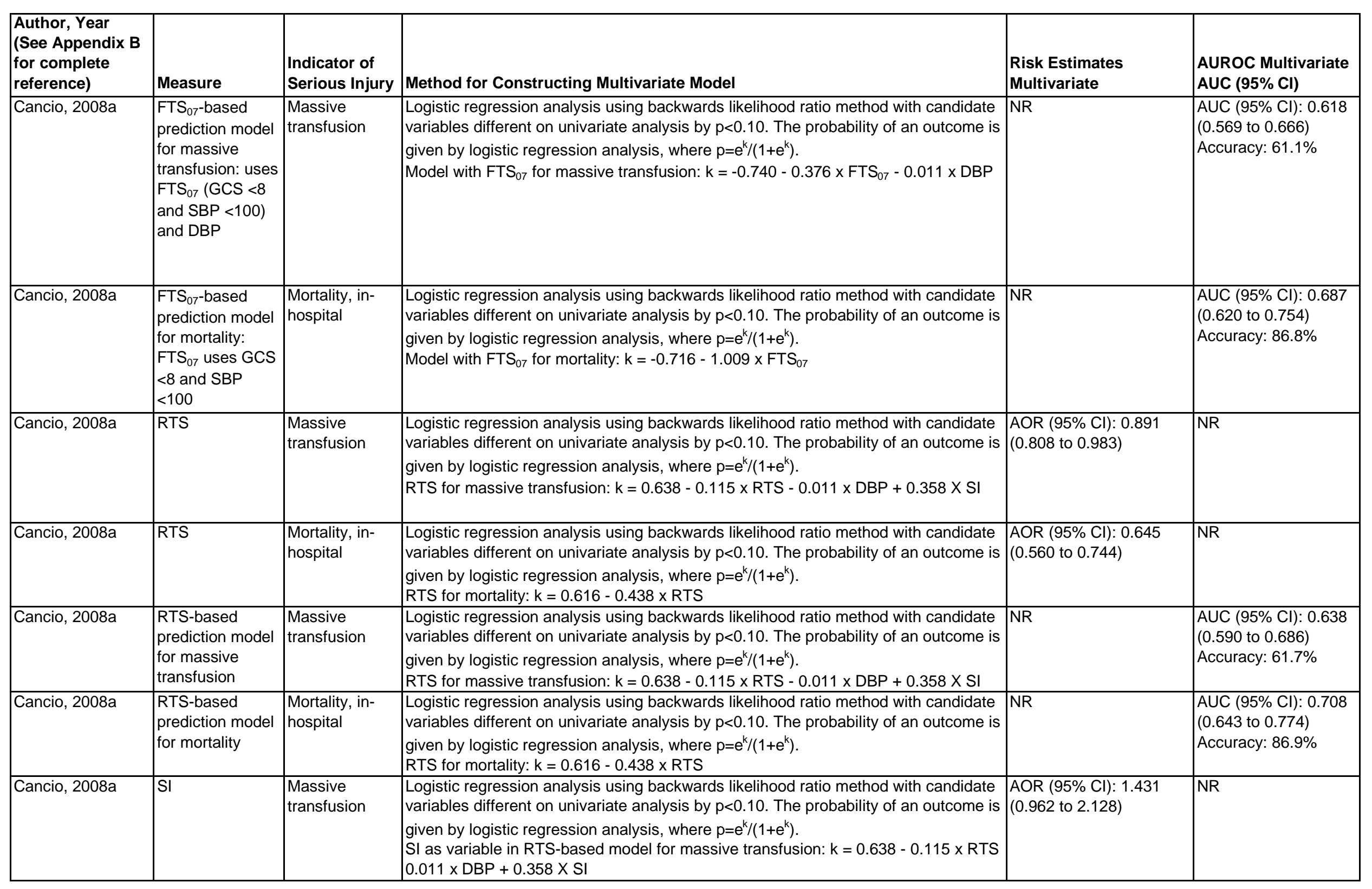




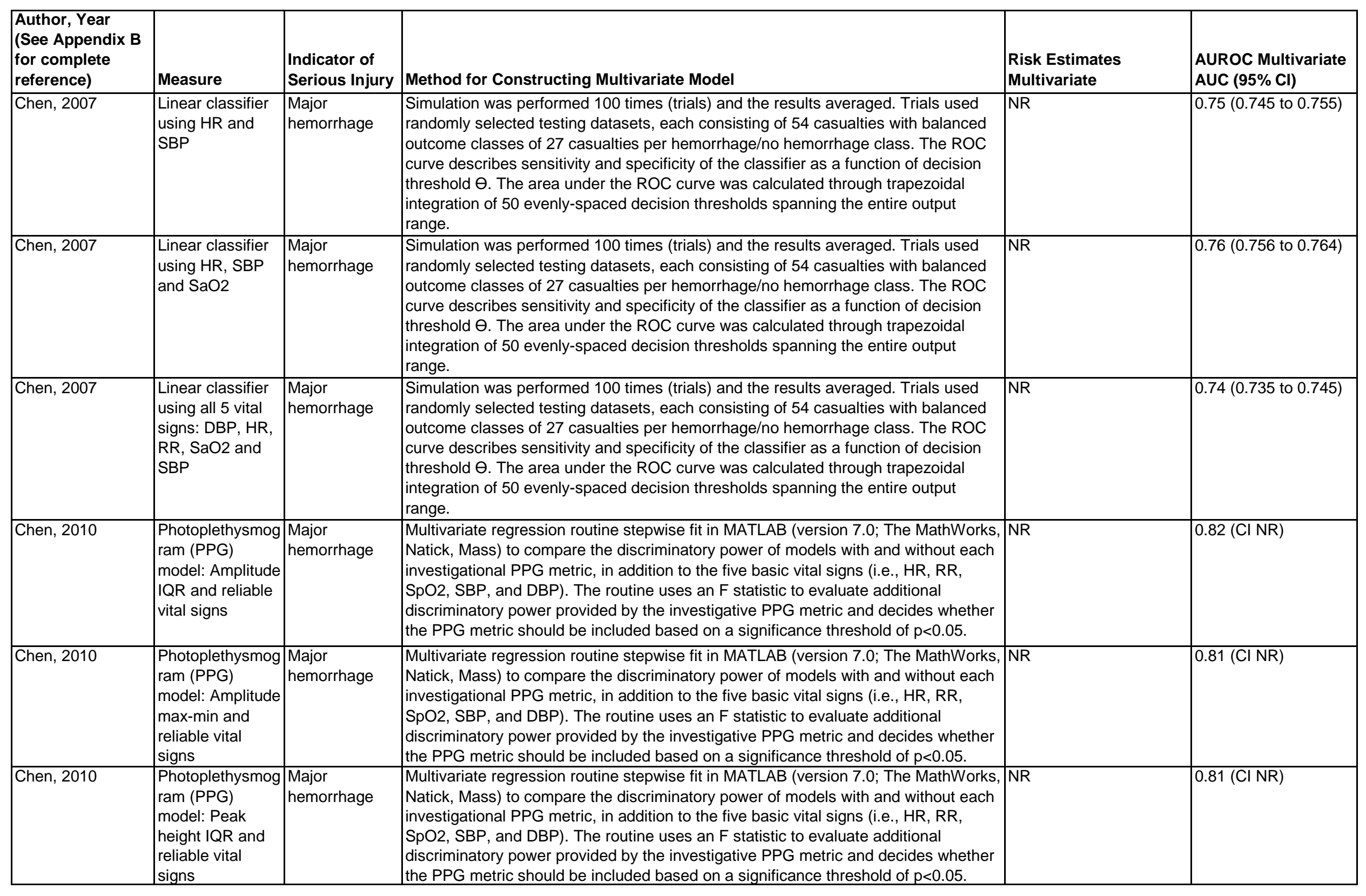




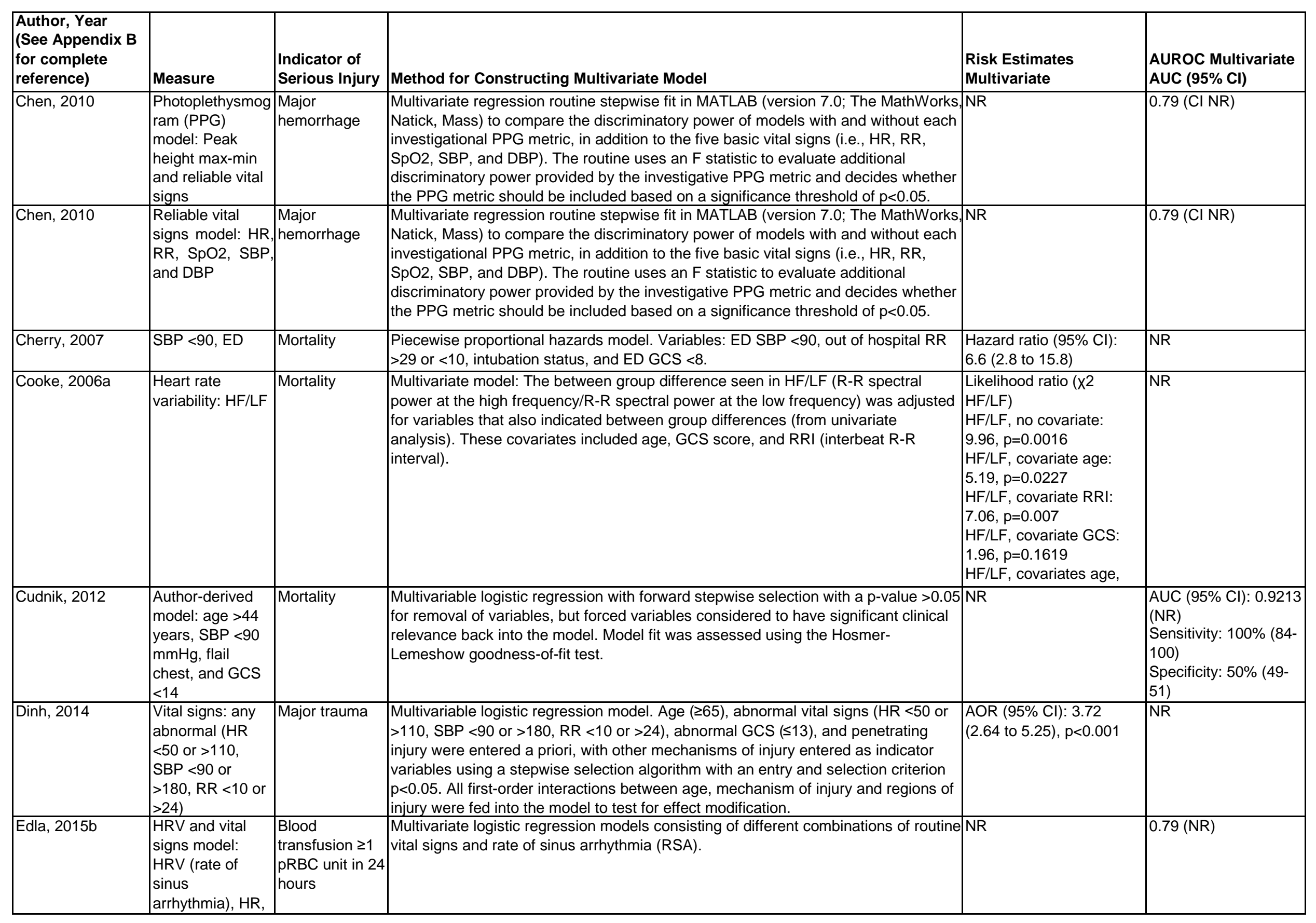




\begin{tabular}{|c|c|c|c|c|c|}
\hline $\begin{array}{l}\text { Author, Year } \\
\text { (See Appendix B } \\
\text { for complete } \\
\text { reference) }\end{array}$ & Measure & \begin{tabular}{|l|} 
Indicator of \\
Serious Injury
\end{tabular} & Method for Constructing Multivariate Model & $\begin{array}{l}\text { Risk Estimates } \\
\text { Multivariate }\end{array}$ & $\begin{array}{l}\text { AUROC Multivariate } \\
\text { AUC }(95 \% \mathrm{Cl})\end{array}$ \\
\hline Edla, 2015b & \begin{tabular}{|l|} 
HRV and vital \\
signs model: \\
HRV (rate of \\
sinus \\
arrhythmia), HR, \\
\end{tabular} & $\begin{array}{l}\text { Blood } \\
\text { transfusion } \geq 5 \\
\text { pRBC units in } \\
24 \text { hours }\end{array}$ & $\begin{array}{l}\text { Multivariate logistic regression models consisting of different combinations of routine } \\
\text { vital signs and rate of sinus arrhythmia (RSA). }\end{array}$ & NR & $0.86(\mathrm{NR})$ \\
\hline Edla, 2015b & $\begin{array}{l}\text { Vital signs } \\
\text { model: HR, RR, } \\
\text { SBP, pulse } \\
\text { pressure }\end{array}$ & \begin{tabular}{|l|} 
Blood \\
transfusion $\geq 1$ \\
pRBC unit in 24 \\
hours
\end{tabular} & $\begin{array}{l}\text { Multivariate logistic regression models consisting of different combinations of routine } \\
\text { vital signs and rate of sinus arrhythmia (RSA). }\end{array}$ & NR & $0.79(0.70$ to 0.85$)$ \\
\hline Edla, 2015b & $\begin{array}{l}\text { Vital signs } \\
\text { model: HR, RR, } \\
\text { SBP, pulse } \\
\text { pressure }\end{array}$ & $\begin{array}{l}\text { Blood } \\
\text { transfusion } \geq 5 \\
\text { pRBC units in } \\
24 \text { hours }\end{array}$ & $\begin{array}{l}\text { Multivariate logistic regression models consisting of different combinations of routine } \\
\text { vital signs and rate of sinus arrhythmia (RSA). }\end{array}$ & NR & $0.85(0.73$ to 0.92$)$ \\
\hline Edla, 2015b & $\begin{array}{l}\text { Vital signs } \\
\text { model: HR, RR, } \\
\text { SBP, pulse } \\
\text { pressure }\end{array}$ & $\begin{array}{l}\text { Blood } \\
\text { transfusion } \geq 9 \\
\text { pRBC units in } \\
24 \text { hours } \\
\end{array}$ & $\begin{array}{l}\text { Multivariate logistic regression models consisting of different combinations of routine } \\
\text { vital signs and rate of sinus arrhythmia (RSA). }\end{array}$ & NR & $0.86(0.73$ to 0.94$)$ \\
\hline Garner, 2001 & \begin{tabular}{|l|}
$\begin{array}{l}\text { Capillary refill }>2 \\
\text { seconds }\end{array}$ \\
\end{tabular} & Critical injury & $\begin{array}{l}\text { Logistic regression model using physiologic variables predicting critical injury. The } \\
\text { Hosmer-Lemeshow test was used to determine goodness of fit, and means of } \\
\text { correlation among independent factors and the variance inflate factor were used to } \\
\text { assess colinearity. A jackknife technique was used to validate the model. } \\
\text { Model } 1 \text { variables: RR } \geq 30 \text { vs. }<30 \text { breaths/min, GCS-motor component } \leq 5 \text { vs. } 6 \text {, } \\
\text { SBP }<80 \text { vs. } \geq 80 \mathrm{~mm} \mathrm{Hg} \text {, capillary refill }>2 \text { vs. } \leq 2 \text { seconds, and HR }>120 \text { vs. } \leq 120 \\
\text { bpm. } \\
\text { Model } 2 \text { variables: RR }<10 \text { or }>29 \text { vs. } 10-29 \text { breaths/min, GCS-motor component } \leq 5 \\
\text { vs. } 6, \mathrm{SBP}<80 \text { vs. } \geq 80 \mathrm{~mm} \mathrm{Hg} \text {, capillary refill }>2 \text { vs. } \leq 2 \text { seconds, and HR }>120 \text { vs. } \\
\leq 120 \text { bpm. } \\
\text { *Models } 1 \& 2 \text { use different respiratory rate variables, but the other variables are the } \\
\text { same. }\end{array}$ & $\begin{array}{l}\text { AOR }(95 \% \mathrm{Cl}) \\
\text { Model 1: } 3.56 \text { (1.31 to } \\
9.67) \\
\text { Model 2: } 3.39 \text { (1.22 to } \\
9.44)\end{array}$ & NR \\
\hline
\end{tabular}




\begin{tabular}{|c|c|c|c|c|c|}
\hline $\begin{array}{l}\text { Author, Year } \\
\text { (See Appendix B } \\
\text { for complete } \\
\text { reference) }\end{array}$ & Measure & \begin{tabular}{|l} 
Indicator of \\
Serious Injury
\end{tabular} & Method for Constructing Multivariate Model & $\begin{array}{l}\text { Risk Estimates } \\
\text { Multivariate }\end{array}$ & $\begin{array}{l}\text { AUROC Multivariate } \\
\text { AUC }(95 \% \mathrm{Cl})\end{array}$ \\
\hline Garner, 2001 & $\mathrm{HR}>120$ & Critical injury & $\begin{array}{l}\text { Logistic regression model using physiologic variables predicting critical injury. The } \\
\text { Hosmer-Lemeshow test was used to determine goodness of fit, and means of } \\
\text { correlation among independent factors and the variance inflate factor were used to } \\
\text { assess colinearity. A jackknife technique was used to validate the model. } \\
\text { Model } 1 \text { variables: RR } \geq 30 \text { vs. }<30 \text { breaths/min, GCS-motor component } \leq 5 \text { vs. } 6 \text {, } \\
\text { SBP }<80 \text { vs. } \geq 80 \mathrm{~mm} \mathrm{Hg} \text {, capillary refill }>2 \text { vs. } \leq 2 \text { seconds, and HR }>120 \text { vs. } \leq 120 \\
\text { bpm. } \\
\text { Model } 2 \text { variables: RR }<10 \text { or }>29 \text { vs. } 10-29 \text { breaths/min, GCS-motor component } \leq 5 \\
\text { vs. } 6, \mathrm{SBP}<80 \text { vs. } \geq 80 \mathrm{~mm} \mathrm{Hg} \text {, capillary refill }>2 \text { vs. } \leq 2 \text { seconds, and HR }>120 \text { vs. } \\
\leq 120 \text { bpm. } \\
\text { *Models } 1 \& 2 \text { use different respiratory rate variables, but the other variables are the } \\
\text { same. }\end{array}$ & $\begin{array}{l}\text { AOR }(95 \% \mathrm{Cl}) \\
\text { Model 1: } 2.53 \\
(1.15-5.60) \\
\text { Model 2: } 2.45 \\
(1.10-5.48)\end{array}$ & NR \\
\hline Garner, 2001 & RR $<10$ or $>29$ & Critical injury & $\begin{array}{l}\text { Logistic regression model using physiologic variables predicting critical injury. The } \\
\text { Hosmer-Lemeshow test was used to determine goodness of fit, and means of } \\
\text { correlation among independent factors and the variance inflate factor were used to } \\
\text { assess colinearity. A jackknife technique was used to validate the model. } \\
\text { Model } 1 \text { variables: RR } \geq 30 \text { vs. }<30 \text { breaths/min, GCS-motor component } \leq 5 \text { vs. } 6 \text {, } \\
\text { SBP }<80 \text { vs. } \geq 80 \mathrm{~mm} \mathrm{Hg} \text {, capillary refill }>2 \text { vs. } \leq 2 \text { seconds, and HR }>120 \text { vs. } \leq 120 \\
\text { bpm. } \\
\text { Model } 2 \text { variables: } R R<10 \text { or }>29 \text { vs. } 10-29 \text { breaths/min, GCS-motor component } \leq 5 \\
\text { vs. } 6, \mathrm{SBP}<80 \text { vs. } \geq 80 \mathrm{~mm} \mathrm{Hg} \text {, capillary refill }>2 \text { vs. } \leq 2 \text { seconds, and HR }>120 \text { vs. } \\
\leq 120 \text { bpm. } \\
\text { *Models } 1 \& 2 \text { use different respiratory rate variables, but the other variables are the } \\
\text { same. }\end{array}$ & $\begin{array}{l}\text { AOR }(95 \% \mathrm{Cl}): 2.64 \\
(1.21 \text { to } 5.76)\end{array}$ & NR \\
\hline Garner, 2001 & $\mathrm{RR} \geq 30$ & Critical injury & $\begin{array}{l}\text { Logistic regression model using physiologic variables predicting critical injury. The } \\
\text { Hosmer-Lemeshow test was used to determine goodness of fit, and means of } \\
\text { correlation among independent factors and the variance inflate factor were used to } \\
\text { assess colinearity. A jackknife technique was used to validate the model. } \\
\text { Model } 1 \text { variables: RR } \geq 30 \text { vs. }<30 \text { breaths/min, GCS-motor component } \leq 5 \text { vs. } 6 \text {, } \\
\text { SBP }<80 \text { vs. } \geq 80 \mathrm{~mm} \mathrm{Hg} \text {, capillary refill }>2 \text { vs. } \leq 2 \text { seconds, and HR }>120 \text { vs. } \leq 120 \\
\text { bpm. } \\
\text { Model } 2 \text { variables: } R R<10 \text { or }>29 \text { vs. } 10-29 \text { breaths/min, GCS-motor component } \leq 5 \\
\text { vs. } 6, \mathrm{SBP}<80 \text { vs. } \geq 80 \mathrm{~mm} \mathrm{Hg} \text {, capillary refill }>2 \text { vs. } \leq 2 \text { seconds, and HR }>120 \text { vs. } \\
\leq 120 \text { bpm. } \\
\text { *Models } 1 \& 2 \text { use different respiratory rate variables, but the other variables are the } \\
\text { same. }\end{array}$ & $\begin{array}{l}\text { AOR }(95 \% \mathrm{Cl}): 2.35 \\
(0.99 \text { to } 5.61)\end{array}$ & NR \\
\hline
\end{tabular}




\begin{tabular}{|c|c|c|c|c|c|}
\hline \begin{tabular}{|l} 
Author, Year \\
(See Appendix B \\
for complete \\
reference)
\end{tabular} & Measure & $\begin{array}{l}\text { Indicator of } \\
\text { Serious Injury }\end{array}$ & Method for Constructing Multivariate Model & $\begin{array}{l}\text { Risk Estimates } \\
\text { Multivariate }\end{array}$ & $\begin{array}{l}\text { AUROC Multivariate } \\
\text { AUC }(95 \% \mathrm{Cl})\end{array}$ \\
\hline Garner, 2001 & SBP $<80$ & Critical injury & $\begin{array}{l}\text { Logistic regression model using physiologic variables predicting critical injury. The } \\
\text { Hosmer-Lemeshow test was used to determine goodness of fit, and means of } \\
\text { correlation among independent factors and the variance inflate factor were used to } \\
\text { assess colinearity. A jackknife technique was used to validate the model. } \\
\text { Model } 1 \text { variables: RR } \geq 30 \text { vs. }<30 \text { breaths/min, GCS-motor component } \leq 5 \text { vs. } 6 \text {, SBP } \\
<80 \text { vs. } \geq 80 \mathrm{~mm} \mathrm{Hg} \text {, capillary refill }>2 \text { vs. } \leq 2 \text { seconds, and HR }>120 \text { vs. } \leq 120 \mathrm{bpm} \text {. } \\
\text { Model } 2 \text { variables: RR }<10 \text { or }>29 \text { vs. } 10-29 \text { breaths/min, GCS-motor component } \leq 5 \text { vs. } \\
6 \text {, SBP }<80 \text { vs. } \geq 80 \mathrm{~mm} \mathrm{Hg} \text {, capillary refill }>2 \text { vs. } \leq 2 \text { seconds, and HR }>120 \text { vs. } \\
\leq 120 \text { bpm. } \\
\star \text { Models } 1 \& 2 \text { use different respiratory rate variables, but the other variables are the } \\
\text { same. }\end{array}$ & $\begin{array}{l}\text { AOR }(95 \% \text { Cl): } \\
\text { Model 1: } 31.73 \text { (9.18 } \\
\text { to } \\
\text { 109.71) } \\
\text { Model 2: } 31.00(8.74 \\
\text { to } \\
110.01)\end{array}$ & NR \\
\hline Guyette, 2011 & $\mathrm{HR}>110$ & Mortality & $\begin{array}{l}\text { Multivariable logistic regression with candidate variables of age, sex, initial SBP } \\
<100, \mathrm{HR}>110, \mathrm{RR} \geq 30 \text { and } \mathrm{GCS}<15 \text {. Interactions between the variables were } \\
\text { systematically searched, and colinearity was considered when } \mathrm{r}>0.8 \text { (Spearman } \\
\text { coefficient matrix correlation). Discrimination of the final models with and without } \\
\text { serum lactate }(>2.0 \mathrm{mmol} / \mathrm{L} \text { ) was assessed by the likelihood ratio } \mathrm{x} 2 \text { statistics and the } \\
\text { difference in the area under the ROC curves. }\end{array}$ & $\begin{array}{l}\text { AOR }(95 \% \mathrm{Cl}): 0.97 \\
(0.96 \text { to } 0.98)\end{array}$ & NR \\
\hline Guyette, 2011 & Lactate $>2.0$ & $\begin{array}{l}\text { Emergent } \\
\text { surgery }\end{array}$ & $\begin{array}{l}\text { Multivariable logistic regression with candidate variables of age, sex, initial SBP } \\
<100, \mathrm{HR}>110, \mathrm{RR} \geq 30 \text { and GCS }<15 \text {. Interactions between the variables were } \\
\text { systematically searched, and colinearity was considered when } r>0.8 \text { (Spearman } \\
\text { coefficient matrix correlation). Discrimination of the final models with and without } \\
\text { serum lactate }(>2.0 \mathrm{mmol} / \mathrm{L} \text { ) was assessed by the likelihood ratio } x 2 \text { statistics and the } \\
\text { difference in the area under the ROC curves. }\end{array}$ & $\begin{array}{l}\text { AOR }(95 \% \text { Cl): } 1.13 \\
(1.05 \text { to } 1.21)\end{array}$ & NR \\
\hline Guyette, 2011 & Lactate $>2.0$ & Mortality & $\begin{array}{l}\text { Multivariable logistic regression with candidate variables of age, sex, initial SBP } \\
<100, \mathrm{HR}>110, \mathrm{RR} \geq 30 \text { and GCS }<15 \text {. Interactions between the variables were } \\
\text { systematically searched, and colinearity was considered when } r>0.8 \text { (Spearman } \\
\text { coefficient matrix correlation). Discrimination of the final models with and without } \\
\text { serum lactate }(>2.0 \mathrm{mmol} / \mathrm{L} \text { ) was assessed by the likelihood ratio } \mathrm{x} 2 \text { statistics and the } \\
\text { difference in the area under the ROC curves. }\end{array}$ & $\begin{array}{l}\text { AOR }(95 \% \text { Cl): } 1.23 \\
\text { (1.14 to } 1.34)\end{array}$ & NR \\
\hline Guyette, 2011 & Lactate $>2.0$ & $\begin{array}{l}\text { Multiple organ } \\
\text { dysfunction }\end{array}$ & $\begin{array}{l}\text { Multivariable logistic regression with candidate variables of age, sex, initial SBP } \\
<100, \mathrm{HR}>110, \mathrm{RR} \geq 30 \text { and GCS }<15 \text {. Interactions between the variables were } \\
\text { systematically searched, and colinearity was considered when } r>0.8 \text { (Spearman } \\
\text { coefficient matrix correlation). Discrimination of the final models with and without } \\
\text { serum lactate }(>2.0 \mathrm{mmol} / \mathrm{L} \text { ) was assessed by the likelihood ratio } \mathrm{x} 2 \text { statistics and the } \\
\text { difference in the area under the ROC curves. }\end{array}$ & $\begin{array}{l}\text { AOR }(95 \% \mathrm{Cl}): 1.14 \\
(1.03 \text { to } 1.23)\end{array}$ & NR \\
\hline
\end{tabular}




\begin{tabular}{|c|c|c|c|c|c|}
\hline $\begin{array}{l}\text { Author, Year } \\
\text { (See Appendix B } \\
\text { for complete } \\
\text { reference) }\end{array}$ & Measure & \begin{tabular}{|l|} 
Indicator of \\
Serious Injury
\end{tabular} & Method for Constructing Multivariate Model & \begin{tabular}{|l} 
Risk Estimates \\
Multivariate
\end{tabular} & $\begin{array}{l}\text { AUROC Multivariate } \\
\text { AUC }(95 \% \mathrm{Cl})\end{array}$ \\
\hline Guyette, 2011 & \begin{tabular}{l|} 
Author-created \\
model: Lactate \\
$>2$, SI $>0.8, \mathrm{HR}$ \\
$>110$, SBP $<100$ \\
RR $\geq 30$, and \\
GCS $<15$
\end{tabular} & $\begin{array}{l}\text { Emergent } \\
\text { operation }\end{array}$ & $\begin{array}{l}\text { Multivariable logistic regression with candidate variables of age, sex, initial SBP } \\
<100, \mathrm{HR}>110, \mathrm{RR} \geq 30 \text { and GCS }<15 \text {. Interactions between the variables were } \\
\text { systematically searched, and colinearity was considered when } r>0.8 \text { (Spearman coefficient } \\
\text { matrix correlation). Discrimination of the final models with and without serum lactate }(>2.0 \\
\text { mmol/L) was assessed by the likelihood ratio } x 2 \text { statistics and the difference in the area } \\
\text { under the ROC curves. }\end{array}$ & NR & $\begin{array}{l}\text { AUC: NR } \\
\text { Sensitivity: } 86 \%(77- \\
93) \\
\text { Specificity: } 25 \%(22- \\
\text { 18) }\end{array}$ \\
\hline Guyette, 2011 & $\begin{array}{l}\text { Author-created } \\
\text { model: Lactate } \\
>2, \text { GCS }<15 \\
\text { HR }>110 \text {, and } \\
\text { SBP }<100\end{array}$ & $\begin{array}{l}\text { Emergent } \\
\text { surgery }\end{array}$ & $\begin{array}{l}\text { Multivariable logistic regression with candidate variables of age, sex, initial SBP } \\
<100, \mathrm{HR}>110, \mathrm{RR} \geq 30 \text { and } \mathrm{GCS}<15 \text {. Interactions between the variables were } \\
\text { systematically searched, and colinearity was considered when } r>0.8 \text { (Spearman coefficient } \\
\text { matrix correlation). Discrimination of the final models with and without serum lactate }(>2.0 \\
\text { mmol/L) was assessed by the likelihood ratio } x 2 \text { statistics and the difference in the area } \\
\text { under the ROC curves. }\end{array}$ & NR & $0.71(\mathrm{Cl} \mathrm{NR})$ \\
\hline Guyette, 2011 & $\begin{array}{l}\text { Author-created } \\
\text { model: } \mathrm{SI}>0.8 \\
\mathrm{HR}>110, \text { SBP } \\
<100, \mathrm{RR} \geq 30 \\
\text { and GCS }<15\end{array}$ & $\begin{array}{l}\text { Emergent } \\
\text { surgery }\end{array}$ & $\begin{array}{l}\text { Multivariable logistic regression with candidate variables of age, sex, initial SBP } \\
<100, \mathrm{HR}>110, \mathrm{RR} \geq 30 \text { and } \mathrm{GCS}<15 \text {. Interactions between the variables were } \\
\text { systematically searched, and colinearity was considered when } r>0.8 \text { (Spearman coefficient } \\
\text { matrix correlation). Discrimination of the final models with and without serum lactate }(>2.0 \\
\text { mmol/L) was assessed by the likelihood ratio } x 2 \text { statistics and the difference in the area } \\
\text { under the ROC curves. }\end{array}$ & NR & $\begin{array}{l}\text { AUC: NR } \\
\text { Sensitivity: } 64 \%(53- \\
74) \\
\text { Specificity: } 51 \%(48- \\
54)\end{array}$ \\
\hline Guyette, 2011 & $\begin{array}{l}\text { Author-created } \\
\text { model: Lactate } \\
>2, \text { GCS }<15 \\
\text { HR }>110 \text {, and } \\
\text { SBP }<100\end{array}$ & Mortality & $\begin{array}{l}\text { Multivariable logistic regression with candidate variables of age, sex, initial SBP } \\
<100, \mathrm{HR}>110, \mathrm{RR} \geq 30 \text { and } \mathrm{GCS}<15 \text {. Interactions between the variables were } \\
\text { systematically searched, and colinearity was considered when } r>0.8 \text { (Spearman coefficient } \\
\text { matrix correlation). Discrimination of the final models with and without serum lactate }(>2.0 \\
\text { mmol/L) was assessed by the likelihood ratio } x 2 \text { statistics and the difference in the area } \\
\text { under the ROC curves. }\end{array}$ & NR & $0.89(\mathrm{Cl} \mathrm{NR})$ \\
\hline Guyette, 2011 & \begin{tabular}{l|} 
Author-created \\
model: Lactate \\
$>2$, SI $>0.8, \mathrm{HR}$ \\
$>110$, SBP $<100$ \\
RR $\geq 30$, and \\
GCS $<15$
\end{tabular} & Mortality & $\begin{array}{l}\text { Multivariable logistic regression with candidate variables of age, sex, initial SBP } \\
<100, \mathrm{HR}>110, \mathrm{RR} \geq 30 \text { and GCS }<15 \text {. Interactions between the variables were } \\
\text { systematically searched, and colinearity was considered when } r>0.8 \text { (Spearman coefficient } \\
\text { matrix correlation). Discrimination of the final models with and without serum lactate }(>2.0 \\
\text { mmol/L) was assessed by the likelihood ratio } x 2 \text { statistics and the difference in the area } \\
\text { under the ROC curves. }\end{array}$ & NR & $\begin{array}{l}\text { AUC: NR } \\
\text { Sensitivity: } 97 \%(89- \\
100) \\
\text { Specificity: } 25 \%(23- \\
28)\end{array}$ \\
\hline Guyette, 2011 & $\begin{array}{l}\text { Author-created } \\
\text { model: } \mathrm{SI}>0.8 \\
\mathrm{HR}>110, \mathrm{SBP} \\
<100, \mathrm{RR} \geq 30 \\
\text { and GCS }<15\end{array}$ & Mortality & $\begin{array}{l}\text { Multivariable logistic regression with candidate variables of age, sex, initial SBP } \\
<100, \mathrm{HR}>110, \mathrm{RR} \geq 30 \text { and GCS }<15 \text {. Interactions between the variables were } \\
\text { systematically searched, and colinearity was considered when } r>0.8 \text { (Spearman coefficient } \\
\text { matrix correlation). Discrimination of the final models with and without serum lactate }(>2.0 \\
\text { mmol/L) was assessed by the likelihood ratio } x 2 \text { statistics and the difference in the area } \\
\text { under the ROC curves. }\end{array}$ & NR & $\begin{array}{l}\text { AUC: NR } \\
\text { Sensitivity: } 88 \%(77- \\
95) \\
\text { Specificity: } 52 \%(49- \\
55)\end{array}$ \\
\hline Guyette, 2011 & $\begin{array}{l}\text { Author-created } \\
\text { model: Lactate } \\
>2, \text { GCS }<15 \\
\text { HR }>110 \text {, and } \\
\text { SBP }<100\end{array}$ & $\begin{array}{l}\text { Multiple organ } \\
\text { dysfunction }\end{array}$ & $\begin{array}{l}\text { Multivariable logistic regression with candidate variables of age, sex, initial SBP } \\
<100, \mathrm{HR}>110, \mathrm{RR} \geq 30 \text { and GCS }<15 \text {. Interactions between the variables were } \\
\text { systematically searched, and colinearity was considered when } r>0.8 \text { (Spearman coefficient } \\
\text { matrix correlation). Discrimination of the final models with and without serum lactate }(>2.0 \\
\text { mmol/L) was assessed by the likelihood ratio } x 2 \text { statistics and the difference in the area } \\
\text { under the ROC curves. }\end{array}$ & NR & $0.81(\mathrm{Cl} N R)$ \\
\hline
\end{tabular}




\begin{tabular}{|c|c|c|c|c|c|}
\hline $\begin{array}{l}\text { Author, Year } \\
\text { (See Appendix B } \\
\text { for complete } \\
\text { reference) }\end{array}$ & Measure & $\begin{array}{l}\text { Indicator of } \\
\text { Serious Injury }\end{array}$ & Method for Constructing Multivariate Model & $\begin{array}{l}\text { Risk Estimates } \\
\text { Multivariate }\end{array}$ & $\begin{array}{l}\text { AUROC Multivariate } \\
\text { AUC }(95 \% \mathrm{Cl})\end{array}$ \\
\hline Guyette, 2011 & $\begin{array}{l}\text { Author-created } \\
\text { model: Lactate } \\
>2, \text { SI }>0.8, \mathrm{HR} \\
>110, \mathrm{SBP}<100 \\
\mathrm{RR} \geq 30, \text { and } \\
\mathrm{GCS}<15\end{array}$ & $\begin{array}{l}\text { Multiple organ } \\
\text { dysfunction }\end{array}$ & $\begin{array}{l}\text { Multivariable logistic regression with candidate variables of age, sex, initial SBP } \\
<100, \mathrm{HR}>110, \mathrm{RR} \geq 30 \text { and } \mathrm{GCS}<15 \text {. Interactions between the variables were } \\
\text { systematically searched, and colinearity was considered when } r>0.8 \text { (Spearman } \\
\text { coefficient matrix correlation). Discrimination of the final models with and without } \\
\text { serum lactate }(>2.0 \mathrm{mmol} / \mathrm{L} \text { ) was assessed by the likelihood ratio } x 2 \text { statistics and } \\
\text { the difference in the area under the ROC curves. }\end{array}$ & NR & $\begin{array}{l}\text { AUC: NR } \\
\text { Sensitivity: 99\% (92- } \\
\text { 100) } \\
\text { Specificity: 25\% (23- } \\
28)\end{array}$ \\
\hline Guyette, 2011 & $\begin{array}{l}\text { Author-created } \\
\text { model: } \mathrm{SI}>0.8 \\
\mathrm{HR}>110, \mathrm{SBP} \\
<100, \mathrm{RR} \geq 30 \\
\text { and GCS }<15\end{array}$ & $\begin{array}{l}\text { Multiple organ } \\
\text { dysfunction }\end{array}$ & $\begin{array}{l}\text { Multivariable logistic regression with candidate variables of age, sex, initial SBP } \\
<100, \mathrm{HR}>110, \mathrm{RR} \geq 30 \text { and GCS }<15 \text {. Interactions between the variables were } \\
\text { systematically searched, and colinearity was considered when } r>0.8 \text { (Spearman } \\
\text { coefficient matrix correlation). Discrimination of the final models with and without } \\
\text { serum lactate }(>2.0 \mathrm{mmol} / \mathrm{L}) \text { was assessed by the likelihood ratio } \times 2 \text { statistics and } \\
\text { the difference in the area under the ROC curves. }\end{array}$ & NR & $\begin{array}{l}\text { AUC: NR } \\
\text { Sensitivity: 94\% (85-98) } \\
\text { Specificity: 53\% (50-56) }\end{array}$ \\
\hline Guyette, 2012 & \begin{tabular}{|l|} 
Deoxygenation \\
slope (DeO2)
\end{tabular} & \begin{tabular}{|l|} 
Life-saving \\
intervention \\
\end{tabular} & $\begin{array}{l}\text { Multivariable logistic regression models using covariates of age, sex, vital signs, } \\
\text { lactate, and mental status (GCS). }\end{array}$ & $\begin{array}{l}\text { AOR }(95 \% \mathrm{Cl}): 2.5 \\
(1.3\end{array}$ & NR \\
\hline Guyette, 2012 & $\begin{array}{l}\text { Reoxygenation } \\
\text { slope (ReO2) } \\
\end{array}$ & \begin{tabular}{|l|} 
Life-saving \\
intervention \\
\end{tabular} & $\begin{array}{l}\text { Multivariable logistic regression models using covariates of age, sex, vital signs, } \\
\text { lactate, and mental status (GCS). }\end{array}$ & $\begin{array}{l}\text { AOR }(95 \% \mathrm{Cl}): 0.8 \\
(0.6\end{array}$ & NR \\
\hline Guyette, 2012 & $\begin{array}{l}\text { SBP, lowest } \\
\text { EMS }\end{array}$ & \begin{tabular}{|l|} 
Life-saving \\
intervention \\
\end{tabular} & $\begin{array}{l}\text { Multivariable logistic regression models using covariates of age, sex, vital signs, } \\
\text { lactate, and mental status (GCS). }\end{array}$ & $\begin{array}{l}\text { AOR }(95 \% \mathrm{Cl}): 0.97 \\
(0.93 \text { to } 0.99), p=0.002\end{array}$ & NR \\
\hline Guyette, 2015 & $\begin{array}{l}\text { Airway or bag } \\
\text { valve mask } \\
\text { attempted }\end{array}$ & $\begin{array}{l}\text { Need for } \\
\text { resuscitative } \\
\text { care }\end{array}$ & $\begin{array}{l}\text { Multivariable logistic regression using: lactate (modeled as a linear spline with knots } \\
\text { at } 2.5 \mathrm{mmol} / \mathrm{L} \text { and } 4.0 \mathrm{mmol} / \mathrm{L} \text { ), age (modeled as spline with one knot at } 45 \text { years), } \\
\text { male sex, penetrating injury, prehospital vital signs (SBP per } 5 \mathrm{mmHg} \text {, SI per } \\
\text { increment of } 0.1 \text {, initial GCS score per increment of } 1 \text { ), airway status (any } \\
\text { airway/bag valve mask attempted), and regional site (as a fixed effect). Two patients } \\
\text { were missing SI and were excluded from the model. }\end{array}$ & $\begin{array}{l}\text { AOR }(95 \% \mathrm{Cl}): 4.55 \\
\text { (1.40 to } 15.43)\end{array}$ & NR \\
\hline Guyette, 2015 & $\begin{array}{l}\text { Lactate (POC), } \\
\text { EMS }\end{array}$ & $\begin{array}{l}\text { Need for } \\
\text { resuscitative } \\
\text { care }\end{array}$ & $\begin{array}{l}\text { Multivariable logistic regression using: lactate (modeled as a linear spline with knots } \\
\text { at } 2.5 \mathrm{mmol} / \mathrm{L} \text { and } 4.0 \mathrm{mmol} / \mathrm{L} \text { ), age (modeled as spline with one knot at } 45 \text { years), } \\
\text { male sex, penetrating injury, prehospital vital signs (SBP per } 5 \mathrm{mmHg} \text {, SI per } \\
\text { increment of } 0.1 \text {, initial GCS score per increment of } 1 \text { ), airway status (any } \\
\text { airway/bag valve mask attempted), and regional site (as a fixed effect). Two patients } \\
\text { were missing SI and were excluded from the model. }\end{array}$ & $\begin{array}{l}\text { AOR }(95 \% \mathrm{Cl}) \\
\text { Lactate: } \\
<2.5: 1.76(0.41 \text { to } \\
12.93) \\
\text { 2.5-3.9: } 3.61(1.67 \text { to } \\
\text { 8.35) }\end{array}$ & NR \\
\hline Guyette, 2015 & SBP, EMS & $\begin{array}{l}\text { Need for } \\
\text { resuscitative } \\
\text { care }\end{array}$ & $\begin{array}{l}\text { Multivariable logistic regression using: lactate (modeled as a linear spline with knots } \\
\text { at } 2.5 \mathrm{mmol} / \mathrm{L} \text { and } 4.0 \mathrm{mmol} / \mathrm{L} \text { ), age (modeled as spline with one knot at } 45 \text { years), } \\
\text { male sex, penetrating injury, prehospital vital signs (SBP per } 5 \mathrm{mmHg} \text {, SI per } \\
\text { increment of } 0.1 \text {, initial GCS score per increment of } 1 \text { ), airway status (any } \\
\text { airway/bag valve mask attempted), and regional site (as a fixed effect). Two patients } \\
\text { were missing SI and were excluded from the model. }\end{array}$ & $\begin{array}{l}\text { AOR }(95 \% \mathrm{Cl}): 0.92 \\
(0.73 \text { to } 1.15)\end{array}$ & NR \\
\hline Guyette, 2015 & SI, EMS & $\begin{array}{l}\text { Need for } \\
\text { resuscitative } \\
\text { care }\end{array}$ & $\begin{array}{l}\text { Multivariable logistic regression using: lactate (modeled as a linear spline with knots } \\
\text { at } 2.5 \mathrm{mmol} / \mathrm{L} \text { and } 4.0 \mathrm{mmol} / \mathrm{L} \text { ), age (modeled as spline with one knot at } 45 \text { years), } \\
\text { male sex, penetrating injury, prehospital vital signs (SBP per } 5 \mathrm{mmHg}, \mathrm{SI} \text { per } \\
\text { increment of } 0.1 \text {, initial GCS score per increment of } 1 \text { ), airway status (any } \\
\text { airway/bag valve mask attempted), and regional site (as a fixed effect). Two patients } \\
\text { were missing SI and were excluded from the model. }\end{array}$ & $\begin{array}{l}\text { AOR }(95 \% \mathrm{Cl}): 1.21 \\
(1.06 \text { to } 1.38)\end{array}$ & NR \\
\hline
\end{tabular}




\begin{tabular}{|c|c|c|c|c|c|}
\hline $\begin{array}{l}\text { Author, Year } \\
\text { (See Appendix B } \\
\text { for complete } \\
\text { reference) }\end{array}$ & Measure & $\begin{array}{l}\text { Indicator of } \\
\text { Serious Injury }\end{array}$ & Method for Constructing Multivariate Model & $\begin{array}{l}\text { Risk Estimates } \\
\text { Multivariate }\end{array}$ & $\begin{array}{l}\text { AUROC Multivariate } \\
\text { AUC }(95 \% \mathrm{Cl})\end{array}$ \\
\hline Henry, 1996 & RR $<10$ or $>29$ & ISS $\geq 16$ & $\begin{array}{l}\text { Logistic regression model containing all ACS trauma triage criteria without regard to } \\
\text { statistical significance. Includes SBP, GCS, RR, } 3 \text { anatomic criteria, age, known } \\
\text { cardiac or respiratory disease and } 8 \text { mechanism criteria. }\end{array}$ & $\begin{array}{l}\text { AOR }(95 \% \mathrm{Cl}): 2.5(0.6- \\
9.8), \text { not significant }\end{array}$ & NR \\
\hline Henry, 1996 & RR $<10$ or $>29$ & $\begin{array}{l}\text { Major non- } \\
\text { orthopedic } \\
\text { interventions or } \\
\text { death }\end{array}$ & $\begin{array}{l}\text { Logistic regression model containing all ACS trauma triage criteria without regard to } \\
\text { statistical significance. Includes SBP, GCS, RR, } 3 \text { anatomic criteria, age, known } \\
\text { cardiac or respiratory disease and } 8 \text { mechanism criteria. }\end{array}$ & $\begin{array}{l}\text { AOR }(95 \% \mathrm{Cl}): 5.0(0.8- \\
29.9), \text { not significant }\end{array}$ & NR \\
\hline Henry, 1996 & SBP $<90$ & ISS $\geq 16$ & $\begin{array}{l}\text { Logistic regression model containing all ACS trauma triage criteria without regard to } \\
\text { statistical significance. Includes SBP, GCS, RR, } 3 \text { anatomic criteria, age, known } \\
\text { cardiac or respiratory disease and } 8 \text { mechanism criteria. }\end{array}$ & $\begin{array}{l}\text { AOR }(95 \% \mathrm{Cl}): 4.6(1.0- \\
19.9), \text { not significant }\end{array}$ & NR \\
\hline Henry, 1996 & SBP $<90$ & \begin{tabular}{l|} 
Major non- \\
orthopedic \\
interventions or \\
death
\end{tabular} & $\begin{array}{l}\text { Logistic regression model containing all ACS trauma triage criteria without regard to } \\
\text { statistical significance. Includes SBP, GCS, RR, } 3 \text { anatomic criteria, age, known } \\
\text { cardiac or respiratory disease and } 8 \text { mechanism criteria. }\end{array}$ & $\begin{array}{l}\text { AOR }(95 \% \mathrm{Cl}): 14.0(2.3- \\
84.0), \text { significant } p \text {-value } \\
\text { not reported }\end{array}$ & NR \\
\hline Holcomb, 2005 & $\begin{array}{l}\text { Automated/Grou } \\
\text { p 3: radial pulse } \\
\text { character, eye } \\
\text { and motor GCS, } \\
\text { and SBP }\end{array}$ & $\begin{array}{l}\text { Life-saving } \\
\text { intervention }\end{array}$ & $\begin{array}{l}\text { Multivariable analysis using a logistic regression model to determine the subset of } \\
\text { variable that best predicted need for LSI. Variables included in analysis varied } \\
\text { according to group. } \\
\text { - Group } 1 \text { (manual): pulse character (radial, femoral, and carotid), capillary refill, } \\
\text { GCS motor and verbal components, and demographics readily available in the field } \\
\text { (sex, age, race, mechanism of injury) } \\
\text { - Group } 2 \text { (semi automated): variables used in Group 1, plus pulse oximetry (SpO2) } \\
\text { and GCS eye component } \\
\text { - Group } 3 \text { (fully automated): variables used in Groups } 1 \text { \& 2, plus all fully automated } \\
\text { (monitor) vital signs (SBP, DBP, MAP, HR), RR, and end-tidal CO2 (EtCO2) }\end{array}$ & NR & $\begin{array}{l}\text { AUC (95\% CI) } \\
\text { Prehospital LSI: } 0.975 \\
\text { (NR) } \\
\text { Hospital LSI: } 0.717 \\
\text { (NR), p <0.05 } \\
\text { Any LSI: } 0.846 \text { (NR) }\end{array}$ \\
\hline Holcomb, 2005 & $\begin{array}{l}\text { Manual/Group 1: } \\
\text { Radial pulse } \\
\text { character, verbal } \\
\text { and motor GCS }\end{array}$ & $\begin{array}{l}\text { Life-saving } \\
\text { intervention }\end{array}$ & $\begin{array}{l}\text { Multivariable analysis using a logistic regression model to determine the subset of } \\
\text { variable that best predicted need for LSI. Variables included in analysis varied } \\
\text { according to group. } \\
\text { - Group } 1 \text { (manual): pulse character (radial, femoral, and carotid), capillary refill, } \\
\text { GCS motor and verbal components, and demographics readily available in the field } \\
\text { (sex, age, race, mechanism of injury) }\end{array}$ & NR & $\begin{array}{l}\text { AUC (95\% CI) } \\
\text { Prehospital LSI: } 0.969 \\
\text { (NR) } \\
\text { Hospital LSI: } 0.619 \\
\text { (NR) } \\
\text { Any LSI: } 0.804 \text { (NR) } \\
\end{array}$ \\
\hline Holcomb, 2005 & \begin{tabular}{|l|} 
Semi- \\
automated/Group \\
2: Radial pulse \\
character, eye \\
and motor GCS
\end{tabular} & $\begin{array}{l}\text { Life-saving } \\
\text { intervention }\end{array}$ & $\begin{array}{l}\text { Multivariable analysis using a logistic regression model to determine the subset of } \\
\text { variable that best predicted need for LSI. Variables included in analysis varied } \\
\text { according to group. } \\
\text { - Group } 1 \text { (manual): pulse character (radial, femoral, and carotid), capillary refill, } \\
\text { GCS motor and verbal components, and demographics readily available in the field } \\
\text { (sex, age, race, mechanism of injury) } \\
\text { - Group } 2 \text { (semi automated): variables used in Group 1, plus pulse oximetry (SpO2) } \\
\text { and GCS eye component }\end{array}$ & NR & $\begin{array}{l}\text { AUC (95\% Cl) } \\
\text { Prehospital LSI: } 0.970 \\
\text { (NR) } \\
\text { Hospital LSI: } 0.616 \\
\text { (NR), p <0.05 } \\
\text { Any LSI: } 0.807 \text { (NR) }\end{array}$ \\
\hline Holcomb, 2005b & \begin{tabular}{l|} 
SBP $<90$ and \\
GCS motor score
\end{tabular} & Need for LSI & $\begin{array}{l}\text { ROC curve derived from two-variable multivariate logistic regression model with } \\
\text { indicator values for abnormal GCS motor score }<6 \text { and abnormal SBP }<90 \text {. }\end{array}$ & NR & $0.744(\mathrm{Cl} \mathrm{NR})$ \\
\hline
\end{tabular}




\begin{tabular}{|c|c|c|c|c|c|}
\hline $\begin{array}{l}\text { Author, Year } \\
\text { (See Appendix B } \\
\text { for complete } \\
\text { reference) }\end{array}$ & Measure & $\begin{array}{l}\text { Indicator of } \\
\text { Serious Injury }\end{array}$ & Method for Constructing Multivariate Model & $\begin{array}{l}\text { Risk Estimates } \\
\text { Multivariate }\end{array}$ & $\begin{array}{l}\text { AUROC Multivariate } \\
\text { AUC }(95 \% \mathrm{Cl})\end{array}$ \\
\hline Holcomb, 2005b & $\begin{array}{l}\mathrm{SBP}<90 \text { and } \\
\text { motor GCS }<6\end{array}$ & Need for LSI & $\begin{array}{l}\text { Multivariate logistic regression models. Initial model evaluation using stepwise } \\
\text { selection with subsequent best-subset regression. Only variables that were statistically } \\
\text { significant and contributed to the stability of the regression estimates were retained in } \\
\text { the final model. Multivariate probabilities were computed by standard transformation of } \\
\text { the logistic regression odds. Used continuous variable cutoff points that are commonly } \\
\text { used in the clinical arena. }\end{array}$ & $\begin{array}{l}\text { Probability of LSI: } \\
95 \%\end{array}$ & NR \\
\hline Holcomb, 2005b & $\begin{array}{l}\mathrm{SBP}<90 \text { and } \\
\text { motor GCS }=6\end{array}$ & Need for LSI & $\begin{array}{l}\text { Multivariate logistic regression models. Initial model evaluation using stepwise } \\
\text { selection with subsequent best-subset regression. Only variables that were statistically } \\
\text { significant and contributed to the stability of the regression estimates were retained in } \\
\text { the final model. Multivariate probabilities were computed by standard transformation of } \\
\text { the logistic regression odds. Used continuous variable cutoff points that are commonly } \\
\text { used in the clinical arena. }\end{array}$ & $\begin{array}{l}\text { Probability of LSI: } \\
77 \%\end{array}$ & NR \\
\hline Holcomb, 2005b & $\begin{array}{l}\mathrm{SBP} \geq 90 \text { and } \\
\text { motor } \mathrm{GCS}<6\end{array}$ & Need for LSI & $\begin{array}{l}\text { Multivariate logistic regression models. Initial model evaluation using stepwise } \\
\text { selection with subsequent best-subset regression. Only variables that were statistically } \\
\text { significant and contributed to the stability of the regression estimates were retained in } \\
\text { the final model. Multivariate probabilities were computed by standard transformation of } \\
\text { the logistic regression odds. Used continuous variable cutoff points that are commonly } \\
\text { used in the clinical arena. }\end{array}$ & $\begin{array}{l}\text { Probability of LSI: } \\
61 \%\end{array}$ & NR \\
\hline Holcomb, 2005b & $\begin{array}{l}\mathrm{SBP} \geq 90 \text { and } \\
\text { motor } \mathrm{GCS}=6\end{array}$ & Need for LSI & $\begin{array}{l}\text { Multivariate logistic regression models. Initial model evaluation using stepwise } \\
\text { selection with subsequent best-subset regression. Only variables that were statistically } \\
\text { significant and contributed to the stability of the regression estimates were retained in } \\
\text { the final model. Multivariate probabilities were computed by standard transformation of } \\
\text { the logistic regression odds. Used continuous variable cutoff points that are commonly } \\
\text { used in the clinical arena. }\end{array}$ & $\begin{array}{l}\text { Probability of LSI: } \\
21 \%\end{array}$ & NR \\
\hline Imhoff, 2014 & $\mathrm{HR}$ & $\begin{array}{l}\text { Mortality, in- } \\
\text { hospital }\end{array}$ & $\begin{array}{l}\text { Multiple logistic regression including all parameters in REMS (age, MAP, HR, RR, } \\
\text { oxygen saturation and GCS). Odds Ratios used to estimate relative strength of } \\
\text { parameters in score. }\end{array}$ & $\begin{array}{l}\text { AOR }(95 \% \mathrm{Cl}): \\
0.996 \\
(0.990-1.002) \\
\end{array}$ & NR \\
\hline Imhoff, 2014 & MAP & $\begin{array}{l}\text { Mortality, in- } \\
\text { hospital }\end{array}$ & $\begin{array}{l}\text { Multiple logistic regression including all parameters in REMS (age, MAP, HR, RR, } \\
\text { oxygen saturation and GCS). Odds Ratios used to estimate relative strength of } \\
\text { parameters in score. }\end{array}$ & $\begin{array}{l}\text { AOR }(95 \% \mathrm{Cl}): \\
0.979 \\
(0.973-0.986)\end{array}$ & NR \\
\hline Imhoff, 2014 & $\begin{array}{l}\text { Oxygen } \\
\text { saturation } \\
(\mathrm{SaO} 2) \\
\end{array}$ & $\begin{array}{l}\text { Mortality, in- } \\
\text { hospital }\end{array}$ & $\begin{array}{l}\text { Multiple logistic regression including all parameters in REMS (age, MAP, HR, RR, } \\
\text { oxygen saturation and GCS). Odds Ratios used to estimate relative strength of } \\
\text { parameters in score. }\end{array}$ & $\begin{array}{l}\text { AOR }(95 \% \mathrm{Cl}): \\
0.961 \\
(0.940-0.982)\end{array}$ & NR \\
\hline King, 2009 & $\begin{array}{l}\text { Heart rate } \\
\text { variability } \\
(\text { SDNN }) \leq 24 \mathrm{msec} \\
\end{array}$ & $\begin{array}{l}\text { Life-saving } \\
\text { intervention in } \\
\text { the OR }\end{array}$ & $\begin{array}{l}\text { Multiple logistic regression model examining the marginal effect of heart rate } \\
\text { variability (SDNN) and controlling for HR, SBP, GCS and subjective high suspicion of } \\
\text { injury. }\end{array}$ & $\begin{array}{l}\text { AOR }(95 \% \mathrm{Cl}): 11.7 \\
(2.1 \\
\text { to } 65.4)\end{array}$ & NR \\
\hline King, 2009 & $\begin{array}{l}\text { Heart rate } \\
\text { variability } \\
(\text { SDNN }) \leq 39 \mathrm{msec}\end{array}$ & Serious injury & $\begin{array}{l}\text { Multiple logistic regression model examining the marginal effect of heart rate } \\
\text { variability (SDNN) and controlling for HR, SBP, GCS and subjective high suspicion of } \\
\text { injury. }\end{array}$ & $\begin{array}{l}\text { AOR }(95 \% \mathrm{Cl}): 5.8 \\
(1.9 \\
\text { to } 17.1)\end{array}$ & NR \\
\hline
\end{tabular}




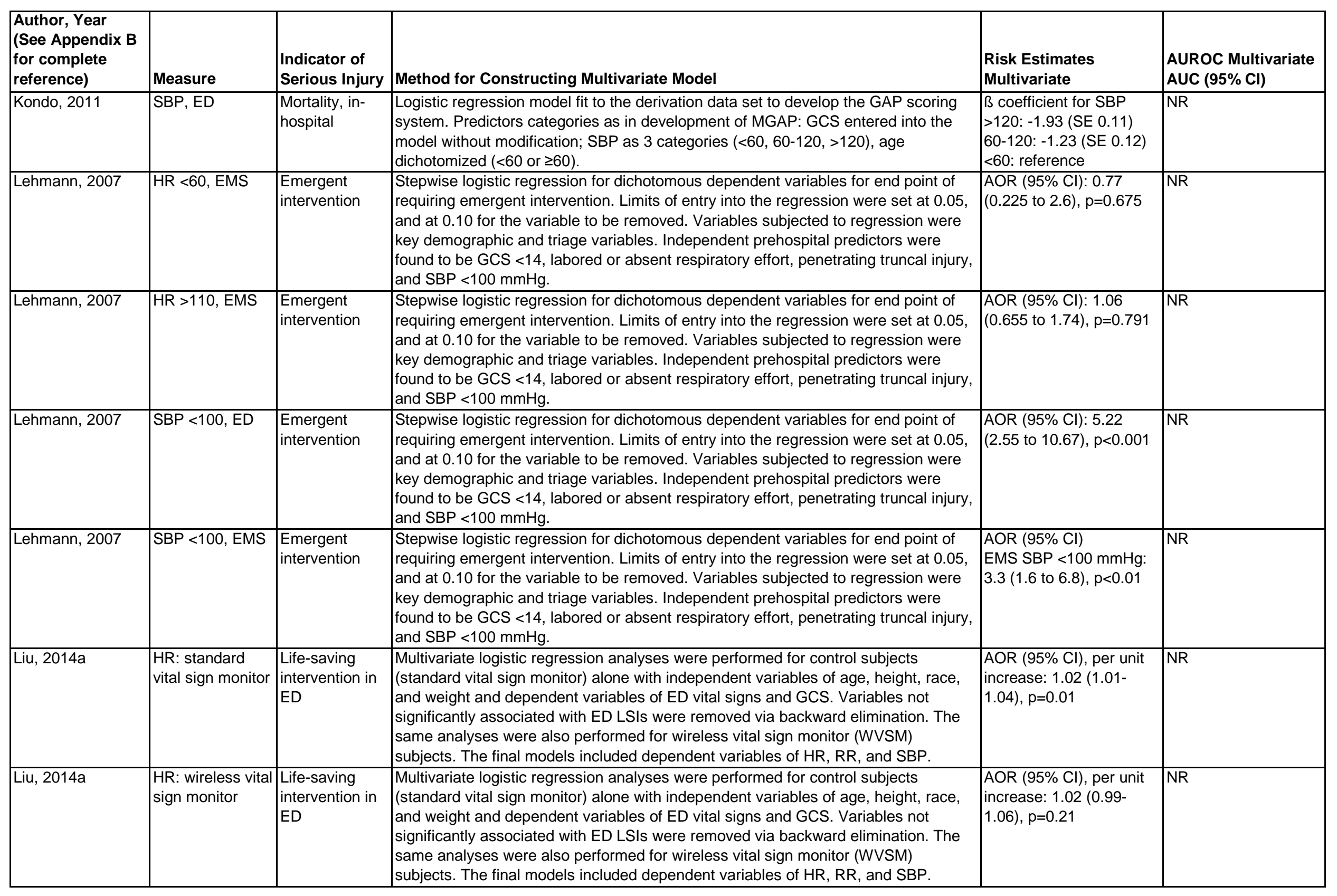




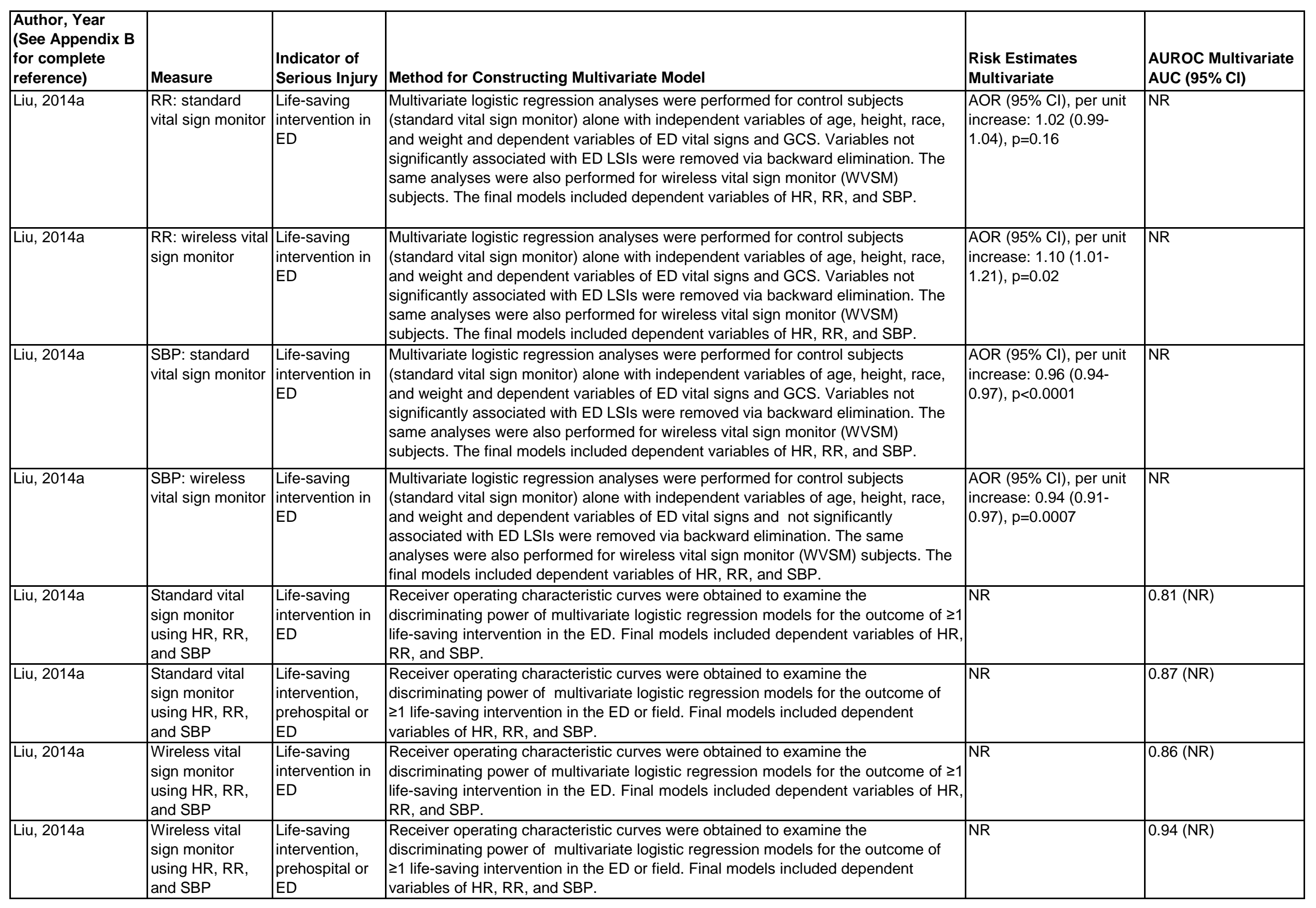




\begin{tabular}{|c|c|c|c|c|c|}
\hline $\begin{array}{l}\text { Author, Year } \\
\text { (See Appendix B } \\
\text { for complete } \\
\text { reference) }\end{array}$ & Measure & $\begin{array}{l}\text { Indicator of } \\
\text { Serious Injury }\end{array}$ & Method for Constructing Multivariate Model & $\begin{array}{l}\text { Risk Estimates } \\
\text { Multivariate }\end{array}$ & $\begin{array}{l}\text { AUROC Multivariate } \\
\text { AUC }(95 \% \mathrm{Cl})\end{array}$ \\
\hline Liu, 2014b & \begin{tabular}{|l} 
Heart rate \\
complexity \\
(HRC)
\end{tabular} & $\begin{array}{l}\text { Life-saving } \\
\text { intervention }\end{array}$ & \begin{tabular}{|l|} 
Initial multivariate logistic regression analysis was done using independent \\
demographic variables of age, height, race and weight, and dependent vital sign \\
variables of HR, SBP, DBP, MAP, RR, and SI. Non-significant factors ( $p>0.05)$ were \\
removed using backward elimination; these were age, height, race and weight. \\
Further analyses were done for the dependent vital sign variables, with and without \\
heart rate complexity (HRC), and with and without total GCS score.
\end{tabular} & $\begin{array}{l}\text { Multivariate model: Vital } \\
\text { signs + minimum HRC } \\
\text { vs. Vital signs + } \\
\text { minimum HRC }+ \text { total } \\
\text { GCS score } \\
\text { AOR }(95 \% \text { CI), per unit } \\
\text { increase: } 0.00001(0.00 \\
\text { to } 0.05) \text { vs. } 0.002(0.00 \\
\text { to } 11.29)\end{array}$ & NR \\
\hline Liu, 2014b & $\mathrm{HR}$ & $\begin{array}{l}\text { Life-saving } \\
\text { intervention }\end{array}$ & $\begin{array}{l}\text { Multivariate model with vital signs alone. } \\
\text { Initial multivariate logistic regression analysis was done using independent } \\
\text { demographic variables of age, height, race and weight, and dependent vital sign } \\
\text { variables of HR, SBP, DBP, MAP, RR, and SI. Non-significant factors ( } p>0.05 \text { ) were } \\
\text { removed using backward elimination. Further analyses were done for the dependent } \\
\text { vital sign variables, with and without heart rate complexity (HRC), and with and } \\
\text { without total GCS score. }\end{array}$ & $\begin{array}{l}\text { Multivariate model: Vital } \\
\text { signs alone vs. Vital } \\
\text { signs + minimum HRC } \\
\text { vs. Vital signs + total } \\
\text { GCS score } \\
\text { AOR }(95 \% \text { Cl), per } \\
\text { beats/min increase: } 1.05 \\
(1.03 \text { to } 1.09) \text { vs. } 1.05 \\
(1.02 \text { to } 1.08) \text { vs. } 1.05 \\
(1.01 \text { to } 1.11)\end{array}$ & NR \\
\hline Liu, 2014b & $\begin{array}{l}\text { Machine learning } \\
\text { model using HR, } \\
\text { GCS, and HRC }\end{array}$ & \begin{tabular}{|l|} 
Life-saving \\
intervention
\end{tabular} & \begin{tabular}{|l|} 
Receiver operator characteristic curves were obtained to examine the discriminating \\
power of the machine learning model, a three-layer perceptron model using inputs of \\
mean HR, GCS score, and heart rate complexity, and 3 hidden nodes. This ML \\
model yielded the best results out of multiple machine learning models including \\
artificial neural networks. Outcome was at least one LSI.
\end{tabular} & NR & 0.99 (NR) \\
\hline Liu, 2014b & $\begin{array}{l}\text { Vital signs + } \\
\text { GCS + HRC } \\
\text { model }\end{array}$ & \begin{tabular}{|l|} 
Life-saving \\
intervention
\end{tabular} & $\begin{array}{l}\text { Multivariate model with vital signs, total GCS score and minimum HRC. } \\
\text { Receiver operator characteristic curves were obtained to examine the discriminating } \\
\text { power of the multivariate models. Models through multivariate logistic regression } \\
\text { analyses with different combinations of vital signs (HR, SBP, DBP, MAP, RR, and } \\
\text { SI), minimum heart rate complexity (HRC), and total GCS score. }\end{array}$ & NR & 0.94 (NR) \\
\hline Liu, 2014b & $\begin{array}{l}\text { Vital signs + } \\
\text { GCS model }\end{array}$ & $\begin{array}{l}\text { Life-saving } \\
\text { intervention }\end{array}$ & $\begin{array}{l}\text { Multivariate model with vital signs and total GCS score. } \\
\text { Receiver operator characteristic curves were obtained to examine the discriminating } \\
\text { power of the multivariate models. Models through multivariate logistic regression } \\
\text { analyses with different combinations of vital signs (HR, SBP, DBP, MAP, RR, and } \\
\text { SI), minimum heart rate complexity (HRC), and total GCS score. }\end{array}$ & NR & $0.92(\mathrm{NR})$ \\
\hline Liu, 2014b & $\begin{array}{l}\text { Vital signs + } \\
\text { HRC model }\end{array}$ & $\begin{array}{l}\text { Life-saving } \\
\text { intervention }\end{array}$ & \begin{tabular}{|l|} 
Multivariate model with vital signs and minimum HRC. \\
Receiver operator characteristic curves were obtained to examine the discriminating \\
power of the multivariate models. Models through multivariate logistic regression \\
analyses with different combinations of vital signs (HR, SBP, DBP, MAP, RR, and \\
SI), minimum heart rate complexity (HRC), and total GCS score.
\end{tabular} & NR & $0.81(\mathrm{NR})$ \\
\hline
\end{tabular}




\begin{tabular}{|c|c|c|c|c|c|}
\hline $\begin{array}{l}\text { Author, Year } \\
\text { (See Appendix B } \\
\text { for complete } \\
\text { reference) }\end{array}$ & Measure & \begin{tabular}{|l} 
Indicator of \\
Serious Injury
\end{tabular} & Method for Constructing Multivariate Model & $\begin{array}{l}\text { Risk Estimates } \\
\text { Multivariate }\end{array}$ & $\begin{array}{l}\text { AUROC Multivariate } \\
\text { AUC }(95 \% \mathrm{CI})\end{array}$ \\
\hline Liu, 2014b & Vital signs model & $\begin{array}{l}\text { Life-saving } \\
\text { intervention }\end{array}$ & $\begin{array}{l}\text { Multivariate model with vital signs only. } \\
\text { Receiver operator characteristic curves were obtained to examine the discriminating } \\
\text { power of the multivariate models. Models through multivariate logistic regression } \\
\text { analyses with different combinations of vital signs (HR, SBP, DBP, MAP, RR, and } \\
\text { SI), minimum heart rate complexity (HRC), and total GCS score. }\end{array}$ & NR & $0.73(\mathrm{NR})$ \\
\hline Liu, 2015a & $\mathrm{HR}$ & LSI & $\begin{array}{l}\text { Multivariate logistic regression modeling was performed to estimate the power of } \\
\text { demographics, vital signs, HRV, HRC, and GCS scores to identify nonsurvivors and } \\
\text { receipt of life-saving interventions. Initial analyses used independent variables of } \\
\text { age, height, race and weight and dependent variables of HR, SBP, DBP, MAP, RR } \\
\text { and SI; factors that were not significant ( } p>0.05 \text { ) were removed via backward } \\
\text { elimination. Further analyses were done for vital signs with and without HRC and } \\
\text { HRV and with and without GCS scores. }\end{array}$ & $\begin{array}{l}\text { Multivariate model: Vital } \\
\text { signs alone vs. Vital } \\
\text { signs + minimum HRC } \\
\text { AOR ( } 95 \% \mathrm{Cl}): 1.01 \\
\text { (0.99 to } 1.04) \text { vs. } 1.00 \\
(0.98 \text { to } 1.03)\end{array}$ & NR \\
\hline Liu, 2015a & HR & Mortality & $\begin{array}{l}\text { Multivariate logistic regression modeling was performed to estimate the power of } \\
\text { demographics, vital signs, HRV, HRC, and GCS scores to identify nonsurvivors and } \\
\text { receipt of life-saving interventions. Initial analyses used independent variables of } \\
\text { age, height, race and weight and dependent variables of HR, SBP, DBP, MAP, RR } \\
\text { and SI; factors that were not significant ( } p>0.05 \text { ) were removed via backward } \\
\text { elimination. Further analyses were done for vital signs with and without HRC and } \\
\text { HRV and with and without GCS scores. }\end{array}$ & $\begin{array}{l}\text { Multivariate model: Vital } \\
\text { signs alone vs. Vital } \\
\text { signs + minimum HRC } \\
\text { vs. Vital signs + } \\
\text { maximum HRV } \\
\text { AOR }(95 \% \mathrm{Cl}): 1.04 \\
(1.01 \text { to } 1.09) \text { vs. } 1.05 \\
(1.01 \text { to } 1.09) \text { vs. } 1.06 \\
(1.02 \text { to } 1.12)\end{array}$ & NR \\
\hline Liu, 2015a & $\begin{array}{l}\text { Maximum HRV } \\
\text { ratio }\end{array}$ & Mortality & $\begin{array}{l}\text { Multivariate logistic regression modeling was performed to estimate the power of } \\
\text { demographics, vital signs, HRV, HRC, and GCS scores to identify nonsurvivors and } \\
\text { receipt of life-saving interventions. Initial analyses used independent variables of } \\
\text { age, height, race and weight and dependent variables of HR, SBP, DBP, MAP, RR } \\
\text { and SI; factors that were not significant ( } p>0.05 \text { ) were removed via backward } \\
\text { elimination. Further analyses were done for vital signs with and without HRC and } \\
\text { HRV and with and without GCS scores. }\end{array}$ & $\begin{array}{l}\text { Multivariate model: Vital } \\
\text { signs + maximum HRV } \\
\text { AOR (95\% Cl): } 9.43 \\
(1.68 \text { to } 76.7), p=0.011\end{array}$ & NR \\
\hline Liu, 2015a & Minimum HRC & LSI & $\begin{array}{l}\text { Multivariate logistic regression modeling was performed to estimate the power of } \\
\text { demographics, vital signs, HRV, HRC, and GCS scores to identify nonsurvivors and } \\
\text { receipt of life-saving interventions. Initial analyses used independent variables of } \\
\text { age, height, race and weight and dependent variables of HR, SBP, DBP, MAP, RR } \\
\text { and SI; factors that were not significant ( } p>0.05 \text { ) were removed via backward } \\
\text { elimination. Further analyses were done for vital signs with and without HRC and } \\
\text { HRV and with and without GCS scores. }\end{array}$ & $\begin{array}{l}\text { Multivariate model: Vital } \\
\text { signs + minimum HRC } \\
\text { vs. Vital signs + } \\
\text { minimum HRC + GCS } \\
\text { score } \\
\text { AOR }(95 \% \mathrm{Cl}): 0.02 \\
(0.00 \text { to } 0.14), \mathrm{p}<0.0001 \\
\text { vs. } 0.01(0.00 \text { to } 0.10)\end{array}$ & NR \\
\hline
\end{tabular}




\begin{tabular}{|c|c|c|c|c|c|}
\hline $\begin{array}{l}\text { Author, Year } \\
\text { (See Appendix B } \\
\text { for complete } \\
\text { reference) }\end{array}$ & Measure & $\begin{array}{l}\text { Indicator of } \\
\text { Serious Injury }\end{array}$ & Method for Constructing Multivariate Model & $\begin{array}{l}\text { Risk Estimates } \\
\text { Multivariate }\end{array}$ & $\begin{array}{l}\text { AUROC } \\
\text { Multivariate } \\
\text { AUC }(95 \% \mathrm{Cl})\end{array}$ \\
\hline Liu, 2015a & $\begin{array}{l}\text { Minimum } \\
\text { HRC }\end{array}$ & Mortality & $\begin{array}{l}\text { Multivariate logistic regression modeling was performed to estimate the power of } \\
\text { demographics, vital signs, HRV, HRC, and GCS scores to identify nonsurvivors and } \\
\text { receipt of life-saving interventions. Initial analyses used independent variables of age, } \\
\text { height, race and weight and dependent variables of HR, SBP, DBP, MAP, RR and SI; } \\
\text { factors that were not significant ( } p>0.05 \text { ) were removed via backward elimination. } \\
\text { Further analyses were done for vital signs with and without HRC and HRV and with and } \\
\text { without GCS scores. }\end{array}$ & $\begin{array}{l}\text { Multivariate model: Vital } \\
\text { signs }+ \text { minimum HRC } \\
\text { vs. Vital signs }+ \text { minimum } \\
\text { HRC }+ \text { GCS score } \\
\text { AOR }(95 \% \text { Cl): } 0.01 \\
(0.00 \text { to } 0.58) \text { vs. } 0.20 \\
(0.01 \text { to } 1.98)\end{array}$ & NR \\
\hline Liu, 2015a & $\begin{array}{l}\text { Vital signs }+ \\
\text { maximum } \\
\text { HRV } \\
\text { model }\end{array}$ & LSI & $\begin{array}{l}\text { Multivariate logistic regression modeling was performed to estimate the power of } \\
\text { demographics, vital signs, HRV, HRC, and GCS scores to identify nonsurvivors and } \\
\text { receipt of life-saving interventions. Initial analyses used independent variables of age, } \\
\text { height, race and weight and dependent variables of HR, SBP, DBP, MAP, RR and SI; } \\
\text { factors that were not significant ( } \mathrm{p}>0.05 \text { ) were removed via backward elimination. } \\
\text { Further analyses were done for vital signs with and without HRC and HRV and with and } \\
\text { without GCS scores. }\end{array}$ & NR & $0.73(\mathrm{NR})$ \\
\hline Liu, 2015a & $\begin{array}{l}\text { Vital signs }+ \\
\text { maximum } \\
\text { HRV } \\
\text { model }\end{array}$ & Mortality & $\begin{array}{l}\text { Multivariate logistic regression modeling was performed to estimate the power of } \\
\text { demographics, vital signs, HRV, HRC, and GCS scores to identify nonsurvivors and } \\
\text { receipt of life-saving interventions. Initial analyses used independent variables of age, } \\
\text { height, race and weight and dependent variables of HR, SBP, DBP, MAP, RR and SI; } \\
\text { factors that were not significant ( } p>0.05 \text { ) were removed via backward elimination. } \\
\text { Further analyses were done for vital signs with and without HRC and HRV and with and } \\
\text { without GCS scores. }\end{array}$ & NR & $0.86(\mathrm{NR})$ \\
\hline Liu, 2015a & $\begin{array}{l}\text { Vital signs + } \\
\text { minimum } \\
\text { HRC + GCS } \\
\text { model }\end{array}$ & LSI & $\begin{array}{l}\text { Multivariate logistic regression modeling was performed to estimate the power of } \\
\text { demographics, vital signs, HRV, HRC, and GCS scores to identify nonsurvivors and } \\
\text { receipt of life-saving interventions. Initial analyses used independent variables of age, } \\
\text { height, race and weight and dependent variables of HR, SBP, DBP, MAP, RR and SI; } \\
\text { factors that were not significant ( } p>0.05 \text { ) were removed via backward elimination. } \\
\text { Further analyses were done for vital signs with and without HRC and HRV and with and } \\
\text { without GCS scores. }\end{array}$ & NR & $0.97(\mathrm{NR})$ \\
\hline Liu, 2015a & $\begin{array}{l}\text { Vital signs + } \\
\text { minimum } \\
\text { HRC + GCS } \\
\text { model }\end{array}$ & Mortality & $\begin{array}{l}\text { Multivariate logistic regression modeling was performed to estimate the power of } \\
\text { demographics, vital signs, HRV, HRC, and GCS scores to identify nonsurvivors and } \\
\text { receipt of life-saving interventions. Initial analyses used independent variables of age, } \\
\text { height, race and weight and dependent variables of HR, SBP, DBP, MAP, RR and SI; } \\
\text { factors that were not significant (p>0.05) were removed via backward elimination. } \\
\text { Further analyses were done for vital signs with and without HRC and HRV and with and } \\
\text { without GCS scores. }\end{array}$ & NR & $0.82(\mathrm{NR})$ \\
\hline
\end{tabular}




\begin{tabular}{|c|c|c|c|c|c|}
\hline $\begin{array}{l}\text { Author, Year } \\
\text { (See Appendix B } \\
\text { for complete } \\
\text { reference) }\end{array}$ & Measure & \begin{tabular}{|l} 
Indicator of \\
Serious Injury
\end{tabular} & Method for Constructing Multivariate Model & $\begin{array}{l}\text { Risk Estimates } \\
\text { Multivariate }\end{array}$ & $\begin{array}{l}\text { AUROC Multivariate } \\
\text { AUC }(95 \% \mathrm{Cl})\end{array}$ \\
\hline Liu, 2015a & $\begin{array}{l}\text { Vital signs }+ \\
\text { minimum HRC } \\
\text { model }\end{array}$ & Mortality & $\begin{array}{l}\text { Multivariate logistic regression modeling was performed to estimate the power of } \\
\text { demographics, vital signs, HRV, HRC, and GCS scores to identify nonsurvivors and } \\
\text { receipt of life-saving interventions. Initial analyses used independent variables of } \\
\text { age, height, race and weight and dependent variables of HR, SBP, DBP, MAP, RR } \\
\text { and SI; factors that were not significant ( } p>0.05 \text { ) were removed via backward } \\
\text { elimination. Further analyses were done for vital signs with and without HRC and } \\
\text { HRV and with and without GCS scores. }\end{array}$ & NR & 0.86 (NR) \\
\hline Liu, 2015a & $\begin{array}{l}\text { Vital signs alone } \\
\text { model }\end{array}$ & LSI & $\begin{array}{l}\text { Multivariate logistic regression modeling was performed to estimate the power of } \\
\text { demographics, vital signs, HRV, HRC, and GCS scores to identify nonsurvivors and } \\
\text { receipt of life-saving interventions. Initial analyses used independent variables of } \\
\text { age, height, race and weight and dependent variables of HR, SBP, DBP, MAP, RR } \\
\text { and SI; factors that were not significant ( } p>0.05 \text { ) were removed via backward } \\
\text { elimination. Further analyses were done for vital signs with and without HRC and } \\
\text { HRV and with and without GCS scores. }\end{array}$ & NR & 0.57 (NR) \\
\hline Liu, 2015a & $\begin{array}{l}\text { Vital signs alone } \\
\text { model }\end{array}$ & Mortality & $\begin{array}{l}\text { Multivariate logistic regression modeling was performed to estimate the power of } \\
\text { demographics, vital signs, HRV, HRC, and GCS scores to identify nonsurvivors and } \\
\text { receipt of life-saving interventions. Initial analyses used independent variables of } \\
\text { age, height, race and weight and dependent variables of HR, SBP, DBP, MAP, RR } \\
\text { and SI; factors that were not significant ( } p>0.05 \text { ) were removed via backward } \\
\text { elimination. Further analyses were done for vital signs with and without HRC and } \\
\text { HRV and with and without GCS scores. }\end{array}$ & NR & $0.79(\mathrm{NR})$ \\
\hline Liu, 2015b & $\mathrm{HR}$ & LSI & $\begin{array}{l}\text { Initial multivariate logistic regression analysis was done using independent } \\
\text { demographic variables of age, height, race and weight, and dependent vital sign } \\
\text { variables of HR, SBP, DBP, MAP, RR, and SI. Non-significant factors ( } p>0.05 \text { ) were } \\
\text { removed using backward elimination. Analyses were done for the dependent vital } \\
\text { sign variables, with and without data quality indices (percent valid values, deviation } \\
\text { ratio). }\end{array}$ & \begin{tabular}{|l|} 
Multivariate models: Vital \\
signs alone vs. Vital \\
signs + data quality \\
indices vs. Vital signs + \\
total GCS score vs. Vital \\
signs + data quality \\
indices + total GCS \\
score \\
AOR (95\% Cl), per unit \\
increase: $1.05(1.03$ to \\
$1.09)$ vs. $1.05(1.02$ to \\
$1.08)$ vs. $1.05(1.01$ to \\
$1.11)$ vs. $1.07(1.02$ to \\
$1.15)$
\end{tabular} & NR \\
\hline
\end{tabular}




\begin{tabular}{|c|c|c|c|c|c|}
\hline $\begin{array}{l}\text { Author, Year } \\
\text { (See Appendix B } \\
\text { for complete } \\
\text { reference) }\end{array}$ & Measure & $\begin{array}{l}\text { Indicator of } \\
\text { Serious Injury }\end{array}$ & Method for Constructing Multivariate Model & $\begin{array}{l}\text { Risk Estimates } \\
\text { Multivariate }\end{array}$ & $\begin{array}{l}\text { AUROC Multivariate } \\
\text { AUC }(95 \% \mathrm{Cl})\end{array}$ \\
\hline Liu, 2015b & $\begin{array}{l}\text { HR data quality: } \\
\% \text { valid values }\end{array}$ & LSI & $\begin{array}{l}\text { Initial multivariate logistic regression analysis was done using independent } \\
\text { demographic variables of age, height, race and weight, and dependent vital sign } \\
\text { variables of HR, SBP, DBP, MAP, RR, and SI. Non-significant factors ( } p>0.05 \text { ) were } \\
\text { removed using backward elimination. Analyses were done for the dependent vital } \\
\text { sign variables, with and without data quality indices (percent valid values, deviation } \\
\text { ratio). }\end{array}$ & $\begin{array}{l}\text { Multivariate models: Vital } \\
\text { signs + data quality } \\
\text { indices vs. Vital signs + } \\
\text { data quality indices + } \\
\text { total GCS score } \\
\text { AOR (95\% Cl), per unit } \\
\text { increase: } 0.97 \text { (0.95 to } \\
0.99) \text { vs. } 0.99 \text { (0.95 to } \\
1.03)\end{array}$ & NR \\
\hline Liu, 2015b & $\begin{array}{l}\text { HR data quality: } \\
\text { deviation ratio }\end{array}$ & LSI & $\begin{array}{l}\text { Initial multivariate logistic regression analysis was done using independent } \\
\text { demographic variables of age, height, race and weight, and dependent vital sign } \\
\text { variables of HR, SBP, DBP, MAP, RR, and SI. Non-significant factors ( } p>0.05 \text { ) were } \\
\text { removed using backward elimination. Analyses were done for the dependent vital } \\
\text { sign variables, with and without data quality indices (percent valid values, deviation } \\
\text { ratio). }\end{array}$ & \begin{tabular}{|l|} 
Multivariate models: Vital \\
signs + data quality \\
indices vs. Vital signs + \\
data quality indices + \\
total GCS score \\
AOR ( $95 \%$ Cl), per unit \\
increase: $0.92(0.86$ to \\
$0.97)$ vs. 0.91 (0.81 to \\
$1.00)$
\end{tabular} & NR \\
\hline Liu, 2015b & $\begin{array}{l}\text { Vital signs + data } \\
\text { quality indices } \\
\text { model }\end{array}$ & LSI & $\begin{array}{l}\text { Multivariate model with vital signs and data quality indices. Receiver operating } \\
\text { characteristic curves were obtained to examine the discriminating power of the } \\
\text { multivariate logistic regression models. } \\
\text { Initial multivariate logistic regression analysis was done using independent } \\
\text { demographic variables of age, height, race and weight, and dependent vital sign } \\
\text { variables of HR, SBP, DBP, MAP, RR, and SI. Non-significant factors ( } \mathrm{p}>0.05 \text { ) were } \\
\text { removed using backward elimination. Analyses were done for the dependent vital } \\
\text { sign variables, with and without data quality indices (percent valid values, deviation } \\
\text { ratio). }\end{array}$ & NR & $0.86(\mathrm{NR})$ \\
\hline Liu, 2015b & $\begin{array}{l}\text { Vital signs + } \\
\text { GCS + data } \\
\text { quality indices } \\
\text { model }\end{array}$ & LSI & $\begin{array}{l}\text { Multivariate model with vital signs + total GCS score + data quality indices. Receiver } \\
\text { operating characteristic curves were obtained to examine the discriminating power } \\
\text { of the multivariate logistic regression models. } \\
\text { Initial multivariate logistic regression analysis was done using independent } \\
\text { demographic variables of age, height, race and weight, and dependent vital sign } \\
\text { variables of HR, SBP, DBP, MAP, RR, and SI. Non-significant factors ( }>0.05 \text { ) were } \\
\text { removed using backward elimination. Analyses were done for the dependent vital } \\
\text { sign variables, with and without data quality indices (percent valid values, deviation } \\
\text { ratio). }\end{array}$ & NR & 0.99 (NR) \\
\hline
\end{tabular}




\begin{tabular}{|c|c|c|c|c|c|}
\hline $\begin{array}{l}\text { Author, Year } \\
\text { (See Appendix B } \\
\text { for complete } \\
\text { reference) }\end{array}$ & Measure & \begin{tabular}{|l} 
Indicator of \\
Serious Injury
\end{tabular} & Method for Constructing Multivariate Model & $\begin{array}{l}\text { Risk Estimates } \\
\text { Multivariate }\end{array}$ & $\begin{array}{l}\text { AUROC Multivariate } \\
\text { AUC }(95 \% \mathrm{Cl})\end{array}$ \\
\hline Liu, 2015b & $\begin{array}{l}\text { Vital signs + } \\
\text { GCS model }\end{array}$ & LSI & $\begin{array}{l}\text { Multivariate model with vital signs + total GCS score. Receiver operating } \\
\text { characteristic curves were obtained to examine the discriminating power of the } \\
\text { multivariate logistic regression models. } \\
\text { Initial multivariate logistic regression analysis was done using independent } \\
\text { demographic variables of age, height, race and weight, and dependent vital sign } \\
\text { variables of HR, SBP, DBP, MAP, RR, and SI. Non-significant factors ( } p>0.05 \text { ) were } \\
\text { removed using backward elimination. Analyses were done for the dependent vital } \\
\text { sign variables, with and without data quality indices (percent valid values, deviation } \\
\text { ratio). }\end{array}$ & NR & $0.92(\mathrm{NR})$ \\
\hline Liu, 2015b & \begin{tabular}{|l|} 
Vital signs model \\
\end{tabular} & LSI & $\begin{array}{l}\text { Multivariate model with vital signs alone. Receiver operating characteristic curves } \\
\text { were obtained to examine the discriminating power of the multivariate logistic } \\
\text { regression models. } \\
\text { Initial multivariate logistic regression analysis was done using independent } \\
\text { demographic variables of age, height, race and weight, and dependent vital sign } \\
\text { variables of HR, SBP, DBP, MAP, RR, and SI. Non-significant factors }(p>0.05) \text { were } \\
\text { removed using backward elimination. Analyses were done for the dependent vital } \\
\text { sign variables, with and without data quality indices (percent valid values, deviation } \\
\text { ratio). }\end{array}$ & NR & $0.73(\mathrm{NR})$ \\
\hline $\begin{array}{l}\text { Mackenzie, } 2014 \\
\text { ×Mackenzie, } 2014 \\
\text { study population } \\
\text { included in } \\
\text { Shackelford, } 2015\end{array}$ & \begin{tabular}{l|} 
Automated \\
prediction, Group \\
1: HR (EMS), \\
age and sex
\end{tabular} & \begin{tabular}{|l|} 
Blood \\
transfusion (3 \\
hours, 24 \\
hours)
\end{tabular} & $\begin{array}{l}\text { Multiple logistic regression models, always adjusted for age and sex, selecting best } \\
\text { combination of vital signs features based on a stepwise procedure. Prediction } \\
\text { models were cross-validated using leave-one-out method for training and testing. } \\
\text { Sensitivity and specificity calculated for optimal thresholds determined by the } \\
\text { Youden index. }\end{array}$ & NR & $\begin{array}{l}\text { Transfusion in } 3 \text { hours } \\
\text { AUC ( } 95 \% \text { CI): } 0.62 \\
(0.51 \text { to } 0.74) \\
\text { Sensitivity } 94 \%, \\
\text { specificity } 29 \% \\
\text { Transfusion in } 24 \\
\text { hours } \\
\text { AUC (95\% Cl): } 0.57 \\
\text { (0.53 to } 0.67 \text { ) } \\
\text { Sensitivity } 38 \%,\end{array}$ \\
\hline $\begin{array}{l}\text { Mackenzie, } 2014 \\
\text { ×Mackenzie, } 2014 \\
\text { study population } \\
\text { included in } \\
\text { Shackelford, } 2015\end{array}$ & \begin{tabular}{l|} 
Automated \\
prediction, Group \\
2: PPG \\
waveform \\
features, HR \\
(EMS), age and \\
sex \\
15 minutes PPG \\
duration
\end{tabular} & \begin{tabular}{|l|} 
Blood \\
transfusion (3 \\
hours, 24 \\
hours)
\end{tabular} & $\begin{array}{l}\text { Multiple logistic regression models, always adjusted for age and sex, selecting best } \\
\text { combination of vital signs features based on a stepwise procedure. Prediction } \\
\text { models were cross-validated using leave-one-out method for training and testing. } \\
\text { Sensitivity and specificity calculated for optimal thresholds determined by the } \\
\text { Youden index. }\end{array}$ & NR & $\begin{array}{l}\text { Transfusion in } 3 \text { hours } \\
\text { AUC ( } 95 \% \mathrm{Cl}): 0.78 \\
(0.65 \text { to } 0.92) \\
\text { Sensitivity } 76 \%, \\
\text { specificity } 78 \% \\
\\
\text { Transfusion in } 24 \\
\text { hours } \\
\text { AUC ( } 95 \% \mathrm{Cl}): 0.74 \\
(0.65 \text { to } 0.84) \\
\text { Sensitivity } 68 \%,\end{array}$ \\
\hline
\end{tabular}




\begin{tabular}{|c|c|c|c|c|c|}
\hline $\begin{array}{l}\text { Author, Year } \\
\text { (See Appendix B } \\
\text { for complete } \\
\text { reference) }\end{array}$ & Measure & $\begin{array}{l}\text { Indicator of } \\
\text { Serious Injury }\end{array}$ & Method for Constructing Multivariate Model & $\begin{array}{l}\text { Risk Estimates } \\
\text { Multivariate }\end{array}$ & $\begin{array}{l}\text { AUROC Multivariate } \\
\text { AUC }(95 \% \mathrm{Cl})\end{array}$ \\
\hline $\begin{array}{l}\text { Mackenzie, } 2014 \\
\star \text { Mackenzie, } 2014 \\
\text { study population } \\
\text { included in } \\
\text { Shackelford, } 2015\end{array}$ & $\begin{array}{l}\text { Automated } \\
\text { prediction, Group } \\
\text { 3: vital signs } \\
\text { features (PPG, HR, } \\
\text { SpO2), HR (EMS), } \\
\text { age and sex } \\
15 \text { minutes PPG } \\
\text { duration }\end{array}$ & $\begin{array}{l}\text { Blood } \\
\text { transfusion (3 } \\
\text { hours, } 24 \\
\text { hours) }\end{array}$ & $\begin{array}{l}\text { Multiple logistic regression models, always adjusted for age and sex, selecting } \\
\text { best combination of vital signs features based on a stepwise procedure. } \\
\text { Prediction models were cross-validated using leave-one-out method for training } \\
\text { and testing. Sensitivity and specificity calculated for optimal thresholds } \\
\text { determined by the Youden index. }\end{array}$ & NR & $\begin{array}{l}\text { Transfusion in } 3 \text { hours } \\
\text { AUC }(95 \% \mathrm{Cl}): 0.83 \\
(0.72 \text { to } 0.95) \\
\text { Sensitivity } 76 \%, \\
\text { specificity } 83 \% \\
\\
\text { Transfusion in } 24 \\
\text { hours } \\
\text { AUC (95\% Cl): } 0.81 \\
(0.72 \text { to } 0.90) \\
\text { Sensitivity } 78 \%,\end{array}$ \\
\hline $\begin{array}{l}\text { Mackenzie, } 2014 \\
\star \text { Mackenzie, } 2014 \\
\text { study population } \\
\text { included in } \\
\text { Shackelford, } 2015\end{array}$ & $\begin{array}{l}\text { Automated } \\
\text { prediction, Group } \\
\text { 3: vital signs } \\
\text { features (PPG, HR, } \\
\text { SpO2), HR (EMS), } \\
\text { age and sex }\end{array}$ & $\begin{array}{l}\text { Massive } \\
\text { transfusion }\end{array}$ & $\begin{array}{l}\text { Multiple logistic regression models, always adjusted for age and sex, selecting } \\
\text { best combination of vital signs features based on a stepwise procedure. } \\
\text { Prediction models were cross-validated using leave-one-out method for training } \\
\text { and testing. Sensitivity and specificity calculated for optimal thresholds } \\
\text { determined by the Youden index. }\end{array}$ & NR & 0.92 (NR) \\
\hline $\begin{array}{l}\text { Mackenzie, } 2014 \\
\star \text { Mackenzie, } 2014 \\
\text { study population } \\
\text { included in } \\
\text { Shackelford, } 2015\end{array}$ & $\begin{array}{l}\text { Automated } \\
\text { prediction, Group } \\
\text { 3: vital signs } \\
\text { features (PPG, HR, } \\
\text { SpO2), HR (EMS), } \\
\text { age and sex }\end{array}$ & $\begin{array}{l}\text { Mortality: in- } \\
\text { hospital }\end{array}$ & $\begin{array}{l}\text { Multiple logistic regression models, always adjusted for age and sex, selecting } \\
\text { best combination of vital signs features based on a stepwise procedure. } \\
\text { Prediction models were cross-validated using leave-one-out method for training } \\
\text { and testing. Sensitivity and specificity calculated for optimal thresholds } \\
\text { determined by the Youden index. }\end{array}$ & NR & 0.94 (NR) \\
\hline $\begin{array}{l}\text { Mackenzie, } 2014 \\
\text { ^Mackenzie, } 2014 \\
\text { study population } \\
\text { included in } \\
\text { Shackelford, } 2015\end{array}$ & $\begin{array}{l}\text { Automated } \\
\text { prediction, Group } \\
\text { 3: vital signs } \\
\text { features (PPG, HR, } \\
\text { SpO2), HR (EMS), } \\
\text { age and sex }\end{array}$ & $\begin{array}{l}\text { Hospital LOS } \\
>3 \text { days }\end{array}$ & $\begin{array}{l}\text { Multiple logistic regression models, always adjusted for age and sex, selecting } \\
\text { best combination of vital signs features based on a stepwise procedure. } \\
\text { Prediction models were cross-validated using leave-one-out method for training } \\
\text { and testing. Sensitivity and specificity calculated for optimal thresholds } \\
\text { determined by the Youden index. }\end{array}$ & NR & $0.72(\mathrm{NR})$ \\
\hline $\begin{array}{l}\text { Mackenzie, } 2014 \\
\text { ^Mackenzie, } 2014 \\
\text { study population } \\
\text { included in } \\
\text { Shackelford, } 2015\end{array}$ & $\begin{array}{l}\text { Automated } \\
\text { prediction, Group } \\
\text { 4: PPG waveform } \\
\text { features, HR } \\
\text { features, SpO2 } \\
\text { features, SI (EMS), } \\
\text { age and sex } \\
15 \text { minutes PPG } \\
\text { duration }\end{array}$ & \begin{tabular}{|l} 
Blood \\
transfusion (3 \\
hours, 24 \\
hours)
\end{tabular} & $\begin{array}{l}\text { Multiple logistic regression models, always adjusted for age and sex, selecting } \\
\text { best } \\
\text { combination of vital signs features based on a stepwise procedure. Prediction } \\
\text { models were cross-validated using leave-one-out method for training and } \\
\text { testing. Sensitivity and specificity calculated for optimal thresholds determined } \\
\text { by the Youden index. }\end{array}$ & NR & $\begin{array}{l}\text { Transfusion in } 3 \text { hours } \\
\text { AUC }(95 \% \mathrm{Cl}): 0.80 \\
(0.68 \text { to } 0.93) \\
\text { Sensitivity } 76 \%, \\
\text { specificity } 80 \% \\
\\
\text { Transfusion in } 24 \\
\text { hours } \\
\text { AUC (95\% Cl): } 0.81 \\
(0.73 \text { to } 0.89) \\
\text { Sensitivity } 81 \% \text {, }\end{array}$ \\
\hline
\end{tabular}




\begin{tabular}{|c|c|c|c|c|c|}
\hline $\begin{array}{l}\text { Author, Year } \\
\text { (See Appendix B } \\
\text { for complete } \\
\text { reference) }\end{array}$ & Measure & \begin{tabular}{|l} 
Indicator of \\
Serious Injury
\end{tabular} & Method for Constructing Multivariate Model & $\begin{array}{l}\text { Risk Estimates } \\
\text { Multivariate }\end{array}$ & $\begin{array}{l}\text { AUROC Multivariate } \\
\text { AUC }(95 \% \mathrm{CI})\end{array}$ \\
\hline $\begin{array}{l}\text { Mackenzie, } 2014 \\
\text { *Mackenzie, } 2014 \\
\text { study population } \\
\text { included in } \\
\text { Shackelford, } 2015\end{array}$ & \begin{tabular}{|l|} 
Automated \\
prediction, Group \\
4: PPG \\
waveform \\
features, HR \\
features, SpO2 \\
features, SI
\end{tabular} & $\begin{array}{l}\text { Mortality: in- } \\
\text { hospital }\end{array}$ & $\begin{array}{l}\text { Multiple logistic regression models, always adjusted for age and sex, selecting best } \\
\text { combination of vital signs features based on a stepwise procedure. Prediction } \\
\text { models were cross-validated using leave-one-out method for training and testing. } \\
\text { Sensitivity and specificity calculated for optimal thresholds determined by the } \\
\text { Youden index. }\end{array}$ & NR & 0.94 (NR) \\
\hline $\begin{array}{l}\text { Mackenzie, } 2014 \\
\text { ×Mackenzie, } 2014 \\
\text { study population } \\
\text { included in } \\
\text { Shackelford, } 2015\end{array}$ & \begin{tabular}{|l|} 
Automated \\
prediction, Group \\
4: PPG \\
waveform \\
features, HR \\
features, SpO2 \\
features, SI \\
\end{tabular} & $\begin{array}{l}\text { Hospital LOS } \\
>3 \text { days }\end{array}$ & $\begin{array}{l}\text { Multiple logistic regression models, always adjusted for age and sex, selecting best } \\
\text { combination of vital signs features based on a stepwise procedure. Prediction } \\
\text { models were cross-validated using leave-one-out method for training and testing. } \\
\text { Sensitivity and specificity calculated for optimal thresholds determined by the } \\
\text { Youden index. }\end{array}$ & NR & $0.71(\mathrm{NR})$ \\
\hline $\begin{array}{l}\text { Mackenzie, } 2014 \\
\text { *Mackenzie, } 2014 \\
\text { study population } \\
\text { included in } \\
\text { Shackelford, } 2015\end{array}$ & \begin{tabular}{|l|} 
Automated \\
prediction, Group \\
4: PPG \\
waveform \\
features, HR \\
features, SpO2 \\
features, SI
\end{tabular} & \begin{tabular}{|l} 
Massive \\
transfusion
\end{tabular} & $\begin{array}{l}\text { Multiple logistic regression models, always adjusted for age and sex, selecting best } \\
\text { combination of vital signs features based on a stepwise procedure. Prediction } \\
\text { models were cross-validated using leave-one-out method for training and testing. } \\
\text { Sensitivity and specificity calculated for optimal thresholds determined by the } \\
\text { Youden index. }\end{array}$ & NR & 0.88 (NR) \\
\hline $\begin{array}{l}\text { Mackenzie, } 2015 \\
\text { ×Mackenzie 2015, } \\
\text { Shackelford 2015, } \\
\text { and Yang } 2016 \\
\text { draw from the } \\
\text { same population, } \\
\text { but differ in } \\
\text { eligibility criteria, } \\
\text { number analyzed, } \\
\text { and measures } \\
\text { evaluated. }\end{array}$ & $\begin{array}{l}\text { Pulse oximeter } \\
\text { (PPG) algorithm } \\
\text { to predict blood } \\
\text { transfusion }\end{array}$ & $\begin{array}{l}\text { Blood } \\
\text { transfusion } \\
\text { within } 6 \text { hours }\end{array}$ & $\begin{array}{l}\text { Algorithms to predict each outcome using } 30 \text { features of the pulse oximeter signal: } \\
12 \text { features of the photoplethysmograph waveform, } 9 \text { features from the SpO2 signal, } \\
\text { and } 9 \text { features from the HR signal. Cross-validation of the model using a leave-one- } \\
\text { out methodology was used to assess the robustness of the algorithm versus clinical } \\
\text { judgment. }\end{array}$ & NR & $\begin{array}{l}\text { AUC (95\% Cl): } 0.92 \\
\text { (NR) } \\
\text { Sensitivity 100\% (NR) } \\
\text { Specificity 70\% (NR) }\end{array}$ \\
\hline
\end{tabular}




\begin{tabular}{|c|c|c|c|c|c|}
\hline \begin{tabular}{l|} 
Author, Year \\
(See Appendix B \\
for complete \\
reference)
\end{tabular} & Measure & $\begin{array}{l}\text { Indicator of } \\
\text { Serious Injury }\end{array}$ & Method for Constructing Multivariate Model & $\begin{array}{l}\text { Risk Estimates } \\
\text { Multivariate }\end{array}$ & $\begin{array}{l}\text { AUROC Multivariate } \\
\text { AUC }(95 \% \mathrm{Cl})\end{array}$ \\
\hline $\begin{array}{l}\text { Mackenzie, } 2015 \\
\text { *Mackenzie 2015, } \\
\text { Shackelford 2015, } \\
\text { and Yang } 2016 \\
\text { draw from the } \\
\text { same population, } \\
\text { but differ in } \\
\text { eligibility criteria, } \\
\text { number analyzed, } \\
\text { and measures } \\
\text { evaluated. }\end{array}$ & \begin{tabular}{|l|} 
Pulse oximeter \\
(PPG) algorithm \\
to predict \\
surgical \\
intervention
\end{tabular} & $\begin{array}{l}\text { Surgical } \\
\text { intervention } \\
\text { within } 6 \text { hours }\end{array}$ & $\begin{array}{l}\text { Algorithms to predict each outcome using } 30 \text { features of the pulse oximeter signal: } \\
12 \text { features of the photoplethysmograph waveform, } 9 \text { features from the SpO2 signal, } \\
\text { and } 9 \text { features from the HR signal. Cross-validation of the model using a leave-one- } \\
\text { out methodology was used to assess the robustness of the algorithm versus clinical } \\
\text { judgment. }\end{array}$ & NR & $0.74(\mathrm{NR})$ \\
\hline Matsushima, 2016 & $H R>100, E M S$ & $\begin{array}{l}\text { Need for } \\
\text { trauma center } \\
\text { care }\end{array}$ & $\begin{array}{l}\text { Multivariable analysis using a logistic regression model. Variables selected as } \\
\text { clinically significant by authors, including age } \geq 65 \text { years, male gender, EMS HR } \\
>100 \text {, EMS SBP }<110 \text {, failure of airbag deployment, and use of seatbelt. }\end{array}$ & $\begin{array}{l}\text { AOR (95\% Cl): } 1.37 \\
\text { (1.13-1.66), } p=0.001\end{array}$ & NR \\
\hline Matsushima, 2016 & SBP $<110$, EMS & $\begin{array}{l}\text { Need for } \\
\text { trauma center } \\
\text { care }\end{array}$ & $\begin{array}{l}\text { Multivariable analysis using a logistic regression model. Variables selected as } \\
\text { clinically significant by authors, including age } \geq 65 \text { years, male gender, EMS HR } \\
>100 \text {, EMS SBP }<110 \text {, failure of airbag deployment, and use of seatbelt. }\end{array}$ & \begin{tabular}{|l|} 
AOR (95\% Cl): 2.41 \\
$(1.78-3.27), p<0.0001$
\end{tabular} & NR \\
\hline McNab, 2013 & $\begin{array}{l}\text { Sl: increase from } \\
\text { prehospital to } \\
\text { trauma center }\end{array}$ & Mortality & $\begin{array}{l}\text { Logistic regression analysis performed on } 2 \text { age groups to investigate increase in } \\
\text { shock index (from out of hospital to ED) and relationship with mortality. Odds Ration } \\
\text { are adjusted for age and sex }\end{array}$ & $\begin{array}{l}\text { AOR }(95 \% \mathrm{Cl}) \\
\text { Age } 16-60: 0.941(\mathrm{NR}) \\
\text { Age } \geq 60.1: 1.826(\mathrm{NR})\end{array}$ & NR \\
\hline Moore, 2006 & SBP & Mortality & $\begin{array}{l}\text { Logistic regression models using GCS, SBP, and RR as coded categories } \\
\text { corresponding to the Revised Trauma Score (RTS) values. Missing values for GCS, } \\
\text { SBP and RR were imputed using Multiple Imputation, with a set of indicator } \\
\text { variables representing trauma center. There were } 4 \text { models evaluated: GCS } \\
\text { (coded), SBP (coded), RR (coded), and RTS (GCS + SBP + RR, all coded). The } \\
\text { models were repeated with fractional polynomial transformations (FP). }\end{array}$ & NR & $\begin{array}{l}\text { AUC }(95 \% \mathrm{Cl}) \\
\text { Coded for RTS model: } \\
0.594 \text { (NR) } \\
\text { Fractional polynomial } \\
\text { model: } 0.666 \text { (NR) }\end{array}$ \\
\hline Moore, 2006 & $\mathrm{RR}$ & Mortality & $\begin{array}{l}\text { Logistic regression models using GCS, SBP, and RR as coded categories } \\
\text { corresponding to the Revised Trauma Score (RTS) values. Missing values for GCS, } \\
\text { SBP and RR were imputed using Multiple Imputation, with a set of indicator } \\
\text { variables representing trauma center. There were } 4 \text { models evaluated: GCS } \\
\text { (coded), SBP (coded), RR (coded), and RTS (GCS + SBP + RR, all coded). The } \\
\text { models were repeated with fractional polynomial transformations (FP). }\end{array}$ & NR & $\begin{array}{l}\text { AUC }(95 \% \mathrm{Cl}) \\
\text { Coded for RTS model: } \\
\text { 0.563 (NR) } \\
\text { Fractional polynomial } \\
\text { model: } 0.655 \text { (NR) }\end{array}$ \\
\hline Moore, 2006 & RTS & Mortality & $\begin{array}{l}\text { Logistic regression models using GCS, SBP, and RR as coded categories } \\
\text { corresponding to the Revised Trauma Score (RTS) values. Missing values for GCS, } \\
\text { SBP and RR were imputed using Multiple Imputation, with a set of indicator } \\
\text { variables representing trauma center. There were } 4 \text { models evaluated: GCS } \\
\text { (coded), SBP (coded), RR (coded), and RTS (GCS + SBP + RR, all coded). The } \\
\text { models were repeated with fractional polynomial transformations (FP). } \\
\text { Fractional polynomial model used transformation of RTS components separately, } \\
\text { and not a transformation of the RTS. }\end{array}$ & NR & $\begin{array}{l}\text { AUC }(95 \% \mathrm{Cl}) \\
\text { RTS coded: } 0.841 \\
\text { (NR) } \\
\text { Fractional polynomial } \\
\text { of components: } 0.874 \\
\text { (NR) }\end{array}$ \\
\hline
\end{tabular}




\begin{tabular}{|c|c|c|c|c|c|}
\hline $\begin{array}{l}\text { Author, Year } \\
\text { (See Appendix B } \\
\text { for complete } \\
\text { reference) }\end{array}$ & Measure & $\begin{array}{l}\text { Indicator of } \\
\text { Serious Injury }\end{array}$ & Method for Constructing Multivariate Model & $\begin{array}{l}\text { Risk Estimates } \\
\text { Multivariate }\end{array}$ & $\begin{array}{l}\text { AUROC Multivariate } \\
\text { AUC }(95 \% \mathrm{Cl})\end{array}$ \\
\hline Nabaweesi, 2014 & $\begin{array}{l}\mathrm{HR} \\
<60 \text { or }>160 \text { if }< \\
5 \text { years } \\
<50 \text { or }>140 \text { if } \geq \\
5 \text { years }\end{array}$ & $\begin{array}{l}\text { Intense } \\
\text { resource use }\end{array}$ & $\begin{array}{l}\text { Multivariate logistic regression to identify potential associations between the } \\
\text { prehospital trauma team activation criteria and ICU use, OR use, and death. } \\
\text { Dependent variable was intense use of resources (ED disposition to the ICU, OR or } \\
\text { morgue) and the following indicator variables: low SBP, respiratory distress, } \\
\text { abnormal heart rate, GCS }<9 \text {, chest injury, abdominal injury, spine injury, air vs. } \\
\text { ground, health insurance, non-white vs. white, ages 5-9 vs. } 0-4 \text {, and ages } 10-14 \text { vs. } \\
0-4 \text {. }\end{array}$ & $\begin{array}{l}\text { AOR }(95 \% \mathrm{Cl}): 2.6(1.04 \\
\text { to } 6.27), p=0.039\end{array}$ & NR \\
\hline Nabaweesi, 2014 & $\begin{array}{l}\text { SBP } \\
<80 \text { if }<5 \text { years } \\
<90 \text { if } \geq 5 \text { years }\end{array}$ & $\begin{array}{l}\text { Intense } \\
\text { resource use }\end{array}$ & $\begin{array}{l}\text { Multivariate logistic regression to identify potential associations between the } \\
\text { prehospital trauma team activation criteria and ICU use, OR use, and death. } \\
\text { Dependent variable was intense use of resources (ED disposition to the ICU, OR or } \\
\text { morgue) and the following indicator variables: low SBP, respiratory distress, } \\
\text { abnormal heart rate, GCS }<9 \text {, chest injury, abdominal injury, spine injury, air vs. } \\
\text { ground, health insurance, non-white vs. white, ages 5-9 vs. 0-4, and ages } 10-14 \text { vs. } \\
0-4 \text {. }\end{array}$ & $\begin{array}{l}\text { AOR }(95 \% \mathrm{Cl}): 0.3 \\
(0.298 \text { to } 3.425), p=0.334\end{array}$ & NR \\
\hline Nabaweesi, 2014 & \begin{tabular}{|l|} 
Respiratory \\
distress \\
$\mathrm{RR}<20$ or $>60$ if \\
$<1$ year \\
$\mathrm{RR}<10$ or $>40$ if \\
$\geq 1$ year
\end{tabular} & $\begin{array}{l}\text { Intense } \\
\text { resource use }\end{array}$ & $\begin{array}{l}\text { Multivariate logistic regression to identify potential associations between the } \\
\text { prehospital trauma team activation criteria and ICU use, OR use, and death. } \\
\text { Dependent variable was intense use of resources (ED disposition to the ICU, OR or } \\
\text { morgue) and the following indicator variables: low SBP, respiratory distress, } \\
\text { abnormal heart rate, GCS }<9 \text {, chest injury, abdominal injury, spine injury, air vs. } \\
\text { ground, health insurance, non-white vs. white, ages 5-9 vs. } 0-4 \text {, and ages } 10-14 \text { vs. } \\
0-4 \text {. }\end{array}$ & $\begin{array}{l}\text { AOR }(95 \% \mathrm{Cl}): 2.9(0.72 \\
\text { to } 11.8), p=0.133\end{array}$ & NR \\
\hline \begin{tabular}{|l|} 
Newgard, 2014 \\
*Newgard, 2016 \\
study population is \\
included in \\
Newgard, 2014
\end{tabular} & $\begin{array}{l}\text { Current } \\
\text { physiologic triage } \\
\text { criteria: validatior } \\
\text { sample }\end{array}$ & Serious injury & $\begin{array}{l}\text { Multivariable regression models, fractional polynomials and binary recursive } \\
\text { partitioning (CART analysis) to evaluate appropriate physiologic cut-points and the } \\
\text { value of different physiologic triage criteria. Three CART analyses using different } \\
\text { combinations of variables and high-sensitivity (95\%) for decision tree generation } \\
\text { were run on a derivation sample (60\% of patients), with cross-validation methods } \\
\text { employed to reduce over-fitting the dataset. Information from the fractional } \\
\text { polynomial models and CART analyses were coupled to generate new physiologic } \\
\text { triage criteria for older adults. }\end{array}$ & NR & $\begin{array}{l}\text { AUC (95\% Cl): } 0.77 \\
\text { (NR) } \\
\text { Sensitivity: } 78.6 \%(\mathrm{Cl} \\
\text { NR) } \\
\text { Specificity: } 75.5 \%(\mathrm{Cl} \\
\text { NR) }\end{array}$ \\
\hline $\begin{array}{l}\text { Newgard, } 2014 \\
\text { *Newgard, } 2016 \\
\text { study population is } \\
\text { included in } \\
\text { Newgard, } 2014\end{array}$ & \begin{tabular}{l|} 
Revised \\
physiologic triage \\
criteria: validation \\
sample \\
(current \\
physiologic triage \\
criteria, GCS \\
$\leq 14$, assisted
\end{tabular} & Serious injury & $\begin{array}{l}\text { Multivariable regression models, fractional polynomials and binary recursive } \\
\text { partitioning (CART analysis) to evaluate appropriate physiologic cut-points and the } \\
\text { value of different physiologic triage criteria. Three CART analyses using different } \\
\text { combinations of variables and high-sensitivity (95\%) for decision tree generation } \\
\text { were run on a derivation sample (60\% of patients), with cross-validation methods } \\
\text { employed to reduce over-fitting the dataset. Information from the fractional } \\
\text { polynomial models and CART analyses were coupled to generate new physiologic } \\
\text { triage criteria for older adults. }\end{array}$ & NR & $\begin{array}{l}\text { AUC (95\% Cl): } 0.73 \\
\text { (NR) } \\
\text { Sensitivity: } 86.3 \%(\mathrm{Cl} \\
\text { NR) } \\
\text { Specificity: } 60.7 \%(\mathrm{Cl} \\
\text { NR) }\end{array}$ \\
\hline
\end{tabular}




\begin{tabular}{|c|c|c|c|c|c|}
\hline $\begin{array}{l}\text { Author, Year } \\
\text { (See Appendix B } \\
\text { for complete } \\
\text { reference) }\end{array}$ & Measure & \begin{tabular}{|l|} 
Indicator of \\
Serious Injury
\end{tabular} & Method for Constructing Multivariate Model & $\begin{array}{l}\text { Risk Estimates } \\
\text { Multivariate }\end{array}$ & $\begin{array}{l}\text { AUROC Multivariate } \\
\text { AUC }(95 \% \mathrm{Cl})\end{array}$ \\
\hline \begin{tabular}{l|} 
Newgard, 2014 \\
*Newgard, 2016 \\
study population is \\
included in \\
Newgard, 2014
\end{tabular} & \begin{tabular}{|l|} 
Decision tree 1 \\
(CART analysis): \\
derivation \\
sample \\
(7 physiologic \\
measures)
\end{tabular} & Serious injury & $\begin{array}{l}\text { Multivariable regression models, fractional polynomials and binary recursive } \\
\text { partitioning (CART analysis) to evaluate appropriate physiologic cut-points and the value } \\
\text { of different physiologic triage criteria. Three CART analyses using different combinations } \\
\text { of variables and high-sensitivity (95\%) for decision tree generation were run on a } \\
\text { derivation sample (60\% of patients), with cross-validation methods employed to reduce } \\
\text { over-fitting the dataset. Information from the fractional polynomial models and CART } \\
\text { analyses were coupled to generate new physiologic triage criteria for older adults. } \\
\text { - Decision Tree 1: physiologic measures; GCS, RR, SBP, SI, assisted ventilation, } \\
\text { intubation and HR }\end{array}$ & NR & $0.68(\mathrm{NR})$ \\
\hline \begin{tabular}{l|} 
Newgard, 2014 \\
*Newgard, 2016 \\
study population is \\
included in \\
Newgard, 2014
\end{tabular} & \begin{tabular}{|l|} 
Decision tree 2 \\
(CART analysis): \\
derivation sample \\
(physiologic \\
measures and \\
current \\
physiologic triage \\
criteria; 11 \\
variables)
\end{tabular} & Serious injury & $\begin{array}{l}\text { Multivariable regression models, fractional polynomials and binary recursive } \\
\text { partitioning (CART analysis) to evaluate appropriate physiologic cut-points and the value } \\
\text { of different physiologic triage criteria. Three CART analyses using different combinations } \\
\text { of variables and high-sensitivity (95\%) for decision tree generation were run on a } \\
\text { derivation sample ( } 60 \% \text { of patients), with cross-validation methods employed to reduce } \\
\text { over-fitting the dataset. Information from the fractional polynomial models and CART } \\
\text { analyses were coupled to generate new physiologic triage criteria for older adults. } \\
\text { - Decision Tree 2: physiologic measures (GCS, RR, SBP, SI, HR, intubation and } \\
\text { assisted ventilation) and current physiologic triage criteria (GCS } \leq 13, \mathrm{SBP}<90 \text {, airway, } \\
\mathrm{RR}<10 \text { or }>29 \text { ) }\end{array}$ & NR & $0.70(\mathrm{NR})$ \\
\hline Rainer, 2011 & $\mathrm{SBP} \leq 90$ & $\begin{array}{l}\text { Massive } \\
\text { transfusion }\end{array}$ & $\begin{array}{l}\text { Multivariate logistic regression with variables significant on univariate analysis } \\
(p<0.05) \text { as candidate variables. Non-significant variables were removed stepwise until } \\
\text { only significant variables remained. Final model variables were used as the predictive } \\
\text { model for massive transfusion, composed of SBP, GCS, HR, displaced pelvic fracture, } \\
\text { positive CT or FAST scan, BD, and hemoglobin. }\end{array}$ & $\begin{array}{l}\text { AOR }(95 \% \mathrm{Cl}): 9.0 \\
(\mathrm{NR})\end{array}$ & NR \\
\hline Rainer, 2011 & $H R \geq 120$ & $\begin{array}{l}\text { Massive } \\
\text { transfusion }\end{array}$ & $\begin{array}{l}\text { Multivariate logistic regression with variables significant on univariate analysis } \\
(p<0.05) \text { as candidate variables. Non-significant variables were removed stepwise until } \\
\text { only significant variables remained. Final model variables were used as the predictive } \\
\text { model for massive transfusion, composed of SBP, GCS, HR, displaced pelvic fracture, } \\
\text { positive CT or FAST scan, BD, and hemoglobin. }\end{array}$ & $\begin{array}{l}\text { AOR }(95 \% \mathrm{Cl}): 3.2 \\
(\mathrm{NR})\end{array}$ & NR \\
\hline Rainer, 2011 & $\mathrm{BD}<-5$ & $\begin{array}{l}\text { Massive } \\
\text { transfusion }\end{array}$ & $\begin{array}{l}\text { Multivariate logistic regression with variables significant on univariate analysis } \\
(p<0.05) \text { as candidate variables. Non-significant variables were removed stepwise until } \\
\text { only significant variables remained. Final model variables were used as the predictive } \\
\text { model for massive transfusion, composed of SBP, GCS, HR, displaced pelvic fracture, } \\
\text { positive CT or FAST scan, BD, and hemoglobin. }\end{array}$ & $\begin{array}{l}\text { AOR }(95 \% \mathrm{Cl}): 4.8 \\
(\mathrm{NR})\end{array}$ & NR \\
\hline Ramanathan, 2015 & Lactate $>2.0$ & ISS $>15$ & $\begin{array}{l}\text { Logistic regression using lactate, base deficit and } \mathrm{pH} \text { as dichotomous variables and } \\
\text { dichotomous outcome of ISS }(\leq 15 \mathrm{vs} \text {. ISS }>15) \text {. }\end{array}$ & $\begin{array}{l}\text { AOR }(95 \% \mathrm{Cl}): \\
3.89\end{array}$ & NR \\
\hline Ramanathan, 2015 & $B D<-5$ & ISS $>15$ & $\begin{array}{l}\text { Logistic regression using lactate, base deficit and } \mathrm{pH} \text { as dichotomous variables and } \\
\text { dichotomous outcome of ISS }(\leq 15 \mathrm{vs} \text {. ISS }>15) \text {. }\end{array}$ & $\begin{array}{l}\text { AOR }(95 \% \mathrm{Cl}): \\
3.09\end{array}$ & NR \\
\hline Ramanathan, 2015 & $\mathrm{pH}<7.30$ & ISS >15 & $\begin{array}{l}\text { Logistic regression using lactate, base deficit and } \mathrm{pH} \text { as dichotomous variables and } \\
\text { dichotomous outcome of ISS ( } \leq 15 \mathrm{vs} \text {. ISS }>15) \text {. }\end{array}$ & $\begin{array}{l}\text { AOR }(95 \% \mathrm{Cl}): \\
9.86\end{array}$ & NR \\
\hline
\end{tabular}




\begin{tabular}{|c|c|c|c|c|c|}
\hline $\begin{array}{l}\text { Author, Year } \\
\text { (See Appendix B } \\
\text { for complete } \\
\text { reference) }\end{array}$ & Measure & $\begin{array}{l}\text { Indicator of } \\
\text { Serious Injury }\end{array}$ & Method for Constructing Multivariate Model & $\begin{array}{l}\text { Risk Estimates } \\
\text { Multivariate }\end{array}$ & $\begin{array}{l}\text { AUROC Multivariate } \\
\text { AUC }(95 \% \mathrm{Cl})\end{array}$ \\
\hline Raux, 2006 & $\begin{array}{l}\text { RTS neutralized } \\
\text { for RR (RTSn) }\end{array}$ & Mortality & $\begin{array}{l}\text { Forced logistic models to predict death by adding RR and SpO2 to RTSn. RR and/or } \\
\text { SpO2 were entered into the models in } 3 \text { different ways: dichotomous variables, } 5 \\
\text { severity classes, and continuous variables. }\end{array}$ & $\begin{array}{l}\text { AOR }(95 \% \mathrm{Cl}): 0.424 \\
(0.360 \text { to } 0.499), p<0.001\end{array}$ & $0.911(\mathrm{Cl} \mathrm{NR})$ \\
\hline $\begin{array}{l}\text { Raux, } 2011 \\
\text { *Raux } 2011 \text { and } \\
\text { Sartorius } 2010 \\
\text { analyze the same } \\
\text { study population }\end{array}$ & $\begin{array}{l}\mathrm{HR} \geq 100: \\
\text { National cohort }\end{array}$ & $\begin{array}{l}\text { Emergency } \\
\text { procedure }\end{array}$ & $\begin{array}{l}\text { Multiple forward stepwise logistic regression using a semiparimonious approach and } \\
\text { only unbiased variables available on the injury scene. Interactions between the } \\
\text { variables were systematically searched, and colinearity between variables was } \\
\text { considered when } r>0.8 \text { (Spearman coefficient matrix correlation). Final model } \\
\text { discrimination was assessed by c-statistics, and calibration by the Hosmer- } \\
\text { Lemeshow statistic, with internal validation performed using } 10 \text {-fold cross validation. }\end{array}$ & $\begin{array}{l}\text { AOR }(95 \% \mathrm{Cl}): 1.42 \\
(1.12 \text { to } 1.79), p=0.004\end{array}$ & NR \\
\hline $\begin{array}{l}\text { Raux, } 2011 \\
\text { *Raux } 2011 \text { and } \\
\text { Sartorius } 2010 \\
\text { analyze the same } \\
\text { study population }\end{array}$ & $\begin{array}{l}\text { SBP }<100: \\
\text { National cohort }\end{array}$ & $\begin{array}{l}\text { Emergency } \\
\text { procedure }\end{array}$ & $\begin{array}{l}\text { Multiple forward stepwise logistic regression using a semiparimonious approach and } \\
\text { only unbiased variables available on the injury scene. Interactions between the } \\
\text { variables were systematically searched, and colinearity between variables was } \\
\text { considered when } r>0.8 \text { (Spearman coefficient matrix correlation). Final model } \\
\text { discrimination was assessed by c-statistics, and calibration by the Hosmer- } \\
\text { Lemeshow statistic, with internal validation performed using } 10 \text {-fold cross validation. }\end{array}$ & $\begin{array}{l}\text { AOR }(95 \% \mathrm{Cl}): 1.42 \\
(1.10 \text { to } 1.84), p=0.006\end{array}$ & NR \\
\hline \begin{tabular}{|l} 
Raux, 2011 \\
${ }^{\star}$ Raux 2011 and \\
Sartorius 2010 \\
analyze the same \\
study population
\end{tabular} & \begin{tabular}{|l|} 
Model using \\
prehospital \\
predictors: \\
penetrating \\
trauma, IV colloid \\
administration \\
$>750 \mathrm{~mL}$, SBP \\
\end{tabular} & $\begin{array}{l}\text { Emergency } \\
\text { procedure }\end{array}$ & $\begin{array}{l}\text { Multiple forward stepwise logistic regression using a semiparimonious approach and } \\
\text { only unbiased variables available on the injury scene. Interactions between the } \\
\text { variables were systematically searched, and colinearity between variables was } \\
\text { considered when } r>0.8 \text { (Spearman coefficient matrix correlation). Final model } \\
\text { discrimination was assessed by c-statistics, and calibration by the Hosmer- } \\
\text { Lemeshow statistic, with internal validation performed using 10-fold cross validation. }\end{array}$ & NR & $\begin{array}{l}\text { AUC }(95 \% \mathrm{Cl}) \\
\text { Derivation cohort } \\
\text { overall: } 0.65 \text { (SD } \\
0.03) \\
\text { After cross validation: } \\
0.65 \text { (SD 0.03) } \\
\text { observed difference } \\
\end{array}$ \\
\hline Raux, 2017 & $\begin{array}{l}\text { Model 1: RTS, } \\
\text { lactate, BD }\end{array}$ & $\begin{array}{l}\text { Mortality, 30- } \\
\text { day in-hospital }\end{array}$ & $\begin{array}{l}\text { Multiple logistic regressions to assess the predictive performances of blood lactate } \\
\text { and base deficit knowing RTS or MGAP score. Discrimination was quantified by } \\
\text { calculating the concordance statistic completed with optimism, the difference of AUC } \\
\text { between the entire population and the cross validated population. Reclassification } \\
\text { was conducted by calculating the net reclassification index. } \\
\text { Blood lactate and base deficit were forced into the models and should be considered } \\
\text { as competitors. }\end{array}$ & NR & $\begin{array}{l}0.88 \text { (NR), optimism } \\
<0.01\end{array}$ \\
\hline Raux, 2017 & $\begin{array}{l}\text { RTS: model } 1 \\
\text { (RTS) }\end{array}$ & $\begin{array}{l}\text { Mortality, 30- } \\
\text { day in-hospital }\end{array}$ & $\begin{array}{l}\text { Multiple logistic regressions to assess the predictive performances of blood lactate } \\
\text { and base deficit knowing RTS or MGAP score. Discrimination was quantified by } \\
\text { calculating the concordance statistic completed with optimism, the difference of AUC } \\
\text { between the entire population and the cross validated population. Reclassification } \\
\text { was conducted by calculating the net reclassification index. } \\
\text { Blood lactate and base deficit were forced into the models and should be considered } \\
\text { as competitors. }\end{array}$ & $\begin{array}{l}\text { AOR }(95 \% \mathrm{Cl}): 2.55 \\
(2.18 \text { to } 2.99), p<0.001 \\
\text { per 1-point decrease }\end{array}$ & NR \\
\hline Raux, 2017 & $\begin{array}{l}\text { Lactate: model } 1 \\
\text { (RTS) }\end{array}$ & $\begin{array}{l}\text { Mortality, 30- } \\
\text { day in-hospital }\end{array}$ & $\begin{array}{l}\text { Multiple logistic regressions to assess the predictive performances of blood lactate } \\
\text { and base deficit knowing RTS or MGAP score. Discrimination was quantified by } \\
\text { calculating the concordance statistic completed with optimism, the difference of AUC } \\
\text { between the entire population and the cross validated population. Reclassification } \\
\text { was conducted by calculating the net reclassification index. Blood lactate and base } \\
\text { deficit were forced into the models and should be considered as competitors. }\end{array}$ & $\begin{array}{l}\text { AOR }(95 \% \mathrm{Cl}): 1.21 \\
(1.05 \text { to } 1.39), p=0.007 \\
\text { per 1-mmol/L increase }\end{array}$ & $\begin{array}{l}\text { AUC }(95 \% \mathrm{Cl}) \text {, with } \\
\text { Lactate vs. baseline } \\
\text { RTS model: } 0.913 \\
(\mathrm{NR}) \text { vs. } 0.890(\mathrm{NR}) \\
\mathrm{p}=0.01 \\
\text { Net reclassification }\end{array}$ \\
\hline
\end{tabular}




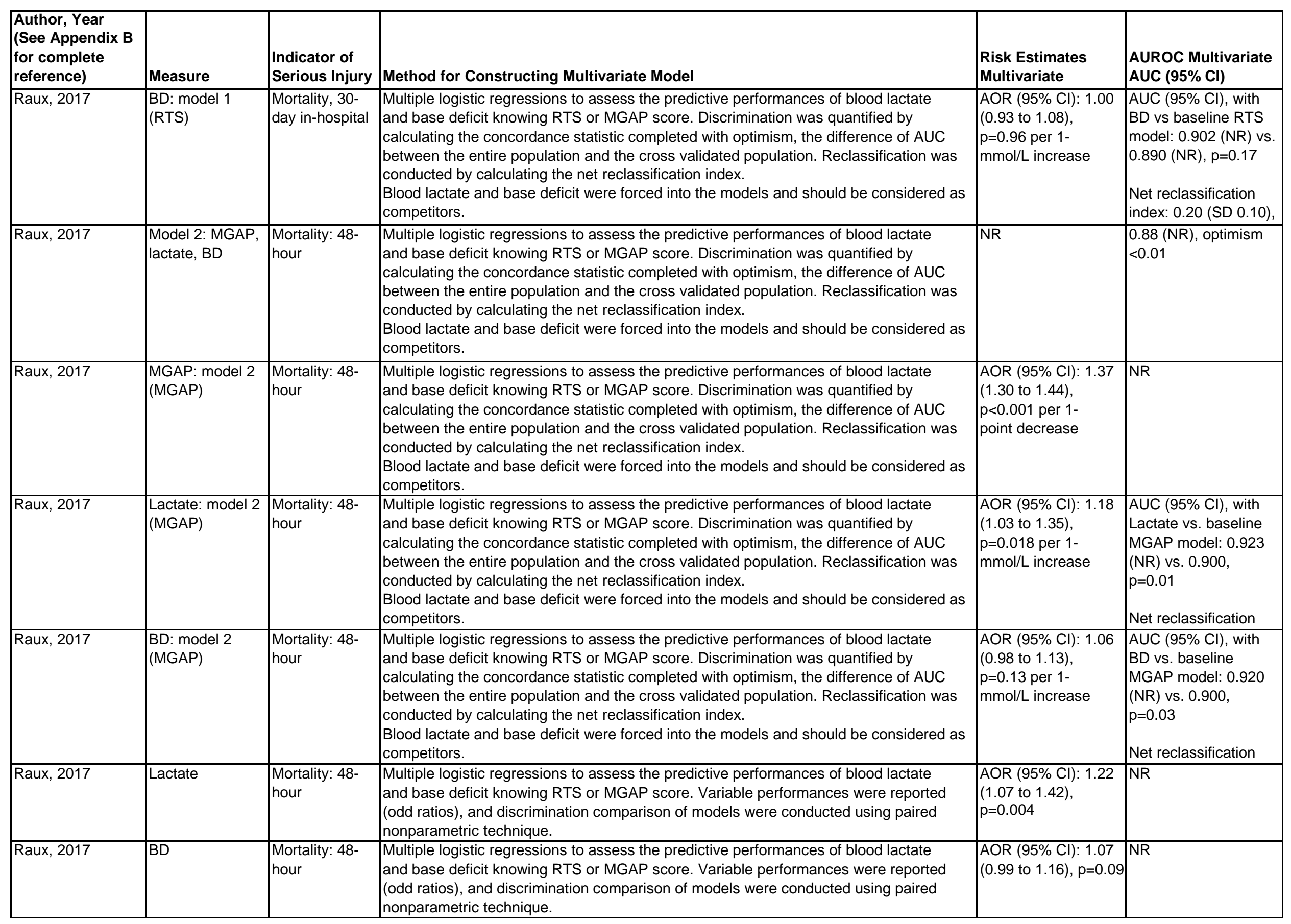




\begin{tabular}{|c|c|c|c|c|c|}
\hline $\begin{array}{l}\text { Author, Year } \\
\text { (See Appendix B } \\
\text { for complete } \\
\text { reference) }\end{array}$ & Measure & \begin{tabular}{|l|} 
Indicator of \\
Serious Injury
\end{tabular} & Method for Constructing Multivariate Model & $\begin{array}{l}\text { Risk Estimates } \\
\text { Multivariate }\end{array}$ & $\begin{array}{l}\text { AUROC Multivariate } \\
\text { AUC }(95 \% \mathrm{Cl})\end{array}$ \\
\hline Raux, 2017 & Lactate & $\begin{array}{l}\text { Severe trauma: } \\
\text { ISS }>15\end{array}$ & $\begin{array}{l}\text { Multiple logistic regressions to assess the predictive performances of blood lactate } \\
\text { and base deficit knowing RTS or MGAP score. Variable performances were reported } \\
\text { (odd ratios), and discrimination comparison of models were conducted using paired } \\
\text { nonparametric technique. }\end{array}$ & $\begin{array}{l}\text { AOR }(95 \% \mathrm{Cl}): 1.14 \\
(1.02 \text { to } 1.27), p=0.02\end{array}$ & NR \\
\hline Raux, 2017 & BD & $\begin{array}{l}\text { Severe trauma: } \\
\text { ISS }>15\end{array}$ & $\begin{array}{l}\text { Multiple logistic regressions to assess the predictive performances of blood lactate } \\
\text { and base deficit knowing RTS or MGAP score. Variable performances were reported } \\
\text { (odd ratios), and discrimination comparison of models were conducted using paired } \\
\text { nonparametric technique. }\end{array}$ & $\begin{array}{l}\text { AOR }(95 \% \mathrm{Cl}): 1.05 \\
(0.99 \text { to } 1.11), p=0.06\end{array}$ & NR \\
\hline Raux, 2017 & Lactate & $\begin{array}{l}\text { Massive } \\
\text { hemorrhage }\end{array}$ & $\begin{array}{l}\text { Multiple logistic regressions to assess the predictive performances of blood lactate } \\
\text { and base deficit knowing RTS or MGAP score. Variable performances were reported } \\
\text { (odd ratios), and discrimination comparison of models were conducted using paired } \\
\text { nonparametric technique. }\end{array}$ & $\begin{array}{l}\text { AOR }(95 \% \mathrm{Cl}): 1.25 \\
(1.10 \text { to } 1.42), p<0.001\end{array}$ & NR \\
\hline Raux, 2017 & $\mathrm{BD}$ & $\begin{array}{l}\text { Massive } \\
\text { hemorrhage }\end{array}$ & $\begin{array}{l}\text { Multiple logistic regressions to assess the predictive performances of blood lactate } \\
\text { and base deficit knowing RTS or MGAP score. Variable performances were reported } \\
\text { (odd ratios), and discrimination comparison of models were conducted using paired } \\
\text { nonparametric technique. }\end{array}$ & $\begin{array}{l}\text { AOR }(95 \% \mathrm{Cl}): 1.21 \\
(1.13 \text { to } 1.29), p<0.001\end{array}$ & NR \\
\hline Raux, 2017 & Lactate & $\begin{array}{l}\text { Emergency } \\
\text { procedure }\end{array}$ & $\begin{array}{l}\text { Multiple logistic regressions to assess the predictive performances of blood lactate } \\
\text { and base deficit knowing RTS or MGAP score. Variable performances were reported } \\
\text { (odd ratios), and discrimination comparison of models were conducted using paired } \\
\text { nonparametric technique. }\end{array}$ & $\begin{array}{l}\text { AOR }(95 \% \mathrm{Cl}): 1.14 \\
(1.00 \text { to } 1.30), p=0.05\end{array}$ & NR \\
\hline Raux, 2017 & $\mathrm{BD}$ & $\begin{array}{l}\text { Emergency } \\
\text { procedure }\end{array}$ & $\begin{array}{l}\text { Multiple logistic regressions to assess the predictive performances of blood lactate } \\
\text { and base deficit knowing RTS or MGAP score. Variable performances were reported } \\
\text { (odd ratios), and discrimination comparison of models were conducted using paired } \\
\text { nonparametric technique. }\end{array}$ & $\begin{array}{l}\text { AOR }(95 \% \mathrm{Cl}): 1.12 \\
(1.04 \text { to } 1.20), p=0.003\end{array}$ & NR \\
\hline Raux, 2017 & Lactate & $\begin{array}{l}\text { ICU LOS }>2 \\
\text { days or in- } \\
\text { hospital } \\
\text { mortality }\end{array}$ & $\begin{array}{l}\text { Multiple logistic regressions to assess the predictive performances of blood lactate } \\
\text { and base deficit knowing RTS or MGAP score. Variable performances were reported } \\
\text { (odd ratios), and discrimination comparison of models were conducted using paired } \\
\text { nonparametric technique. }\end{array}$ & $\begin{array}{l}\text { AOR }(95 \% \mathrm{Cl}): 1.06 \\
(0.93 \text { to } 1.20), p=0.39\end{array}$ & NR \\
\hline Raux, 2017 & $B$ & $\begin{array}{l}\text { ICU LOS }>2 \\
\text { days or in- } \\
\text { hospital } \\
\text { mortality }\end{array}$ & $\begin{array}{l}\text { Multiple logistic regressions to assess the predictive performances of blood lactate } \\
\text { and base deficit knowing RTS or MGAP score. Variable performances were reported } \\
\text { (odd ratios), and discrimination comparison of models were conducted using paired } \\
\text { nonparametric technique. }\end{array}$ & $\begin{array}{l}\text { AOR }(95 \% \mathrm{Cl}): 1.20 \\
(1.12 \text { to } 1.27), p<0.001\end{array}$ & NR \\
\hline Raux, 2017 & $\begin{array}{l}\text { Model } 3 \text { (RTS, } \\
\text { lactate, BD): } \\
\text { normotensive } \\
\text { subgroup }\end{array}$ & $\begin{array}{l}\text { Mortality, 30- } \\
\text { day in-hospital }\end{array}$ & $\begin{array}{l}\text { Subgroup analysis of normotensive patients - EMS and ED SBP }>90 \text { without } \\
\text { administration of vasopressors. Multiple logistic regressions to assess the predictive } \\
\text { performances of blood lactate and base deficit knowing RTS or MGAP score. } \\
\text { Discrimination was quantified by calculating the concordance statistic completed } \\
\text { with optimism, the difference of AUC between the entire population and the cross } \\
\text { validated population. Reclassification was conducted by calculating the net } \\
\text { reclassification index. } \\
\text { Blood lactate and base deficit were forced into the models and should be considered } \\
\text { as competitors. }\end{array}$ & NR & $\begin{array}{l}0.79(\mathrm{NR}) \text {, optimism } \\
<0.01\end{array}$ \\
\hline
\end{tabular}




\begin{tabular}{|c|c|c|c|c|c|}
\hline $\begin{array}{l}\text { Author, Year } \\
\text { (See Appendix B } \\
\text { for complete } \\
\text { reference) }\end{array}$ & Measure & \begin{tabular}{|l} 
Indicator of \\
Serious Injury
\end{tabular} & Method for Constructing Multivariate Model & $\begin{array}{l}\text { Risk Estimates } \\
\text { Multivariate }\end{array}$ & $\begin{array}{l}\text { AUROC Multivariate } \\
\text { AUC }(95 \% \mathrm{Cl})\end{array}$ \\
\hline Raux, 2017 & $\begin{array}{l}\text { Lactate: model } 3 \\
\text { (RTS); } \\
\text { normotensive } \\
\text { subgroup }\end{array}$ & $\begin{array}{l}\text { Mortality, 30- } \\
\text { day in-hospital }\end{array}$ & $\begin{array}{l}\text { Subgroup analysis of normotensive patients - EMS and ED SBP }>90 \text { without } \\
\text { administration of vasopressors. Multiple logistic regressions to assess the predictive } \\
\text { performances of blood lactate and base deficit knowing RTS or MGAP score. } \\
\text { Discrimination was quantified by calculating the concordance statistic completed } \\
\text { with optimism, the difference of AUC between the entire population and the cross } \\
\text { validated population. Reclassification was conducted by calculating the net } \\
\text { reclassification index. } \\
\text { Blood lactate and base deficit were forced into the models and should be considered } \\
\text { as competitors. }\end{array}$ & $\begin{array}{l}\text { AOR }(95 \% \mathrm{Cl}): 1.36 \\
(1.09 \text { to } 1.68), p=0.005 \\
\text { per } 1 \mathrm{mmol} / \mathrm{L} \text { increase }\end{array}$ & $\begin{array}{l}\text { AUC: NR } \\
\text { Net reclassification } \\
\text { index: } 0.425 \text { (SD } \\
0.160), p=0.007\end{array}$ \\
\hline Raux, 2017 & $\begin{array}{l}\text { BD: model } 3 \\
\text { (RTS); } \\
\text { normotensive } \\
\text { subgroup }\end{array}$ & $\begin{array}{l}\text { Mortality, 30- } \\
\text { day in-hospital }\end{array}$ & $\begin{array}{l}\text { Subgroup analysis of normotensive patients - EMS and ED SBP }>90 \text { without } \\
\text { administration of vasopressors. Multiple logistic regressions to assess the predictive } \\
\text { performances of blood lactate and base deficit knowing RTS or MGAP score. } \\
\text { Discrimination was quantified by calculating the concordance statistic completed } \\
\text { with optimism, the difference of AUC between the entire population and the cross } \\
\text { validated population. Reclassification was conducted by calculating the net } \\
\text { reclassification index. } \\
\text { Blood lactate and base deficit were forced into the models and should be considered } \\
\text { as competitors. }\end{array}$ & $\begin{array}{l}\text { AOR }(95 \% \mathrm{Cl}): 1.05 \\
(0.93 \text { to } 1.17), p=0.45 \\
\text { per } 1 \mathrm{mmol} / \mathrm{L} \text { increase }\end{array}$ & $\begin{array}{l}\text { AUC: NR } \\
\text { Net reclassification } \\
\text { index: } 0.231 \text { (SD } \\
0.160), p=0.15\end{array}$ \\
\hline Raux, 2017 & $\begin{array}{l}\text { RTS: model } 3 \\
\text { (RTS); } \\
\text { normotensive } \\
\text { subgroup }\end{array}$ & $\begin{array}{l}\text { Mortality, 30- } \\
\text { day in-hospital }\end{array}$ & $\begin{array}{l}\text { Subgroup analysis of normotensive patients - EMS and ED SBP }>90 \text { without } \\
\text { administration of vasopressors. Multiple logistic regressions to assess the predictive } \\
\text { performances of blood lactate and base deficit knowing RTS or MGAP score. } \\
\text { Discrimination was quantified by calculating the concordance statistic completed } \\
\text { with optimism, the difference of AUC between the entire population and the cross } \\
\text { validated population. Reclassification was conducted by calculating the net } \\
\text { reclassification index. } \\
\text { Blood lactate and base deficit were forced into the models and should be considered } \\
\text { as competitors. }\end{array}$ & $\begin{array}{l}\text { AOR }(95 \% \mathrm{Cl}): 3.06 \\
(2.36 \text { to } 3.96), p<0.001 ; \\
\text { per 1-point decrease }\end{array}$ & NR \\
\hline Raux, 2017 & $\begin{array}{l}\text { Model } 4 \text { (MGAP, } \\
\text { lactate, BD): } \\
\text { normotensive } \\
\text { subgroup }\end{array}$ & $\begin{array}{l}\text { Mortality, 30- } \\
\text { day in-hospital }\end{array}$ & $\begin{array}{l}\text { Subgroup analysis of normotensive patients - EMS and ED SBP }>90 \text { without } \\
\text { administration of vasopressors. Multiple logistic regressions to assess the predictive } \\
\text { performances of blood lactate and base deficit knowing RTS or MGAP score. } \\
\text { Discrimination was quantified by calculating the concordance statistic completed } \\
\text { with optimism, the difference of AUC between the entire population and the cross } \\
\text { validated population. Reclassification was conducted by calculating the net } \\
\text { reclassification index. } \\
\text { Blood lactate and base deficit were forced into the models and should be considered } \\
\text { as competitors. }\end{array}$ & NR & $\begin{array}{l}0.81 \text { (NR), optimism } \\
<0.01\end{array}$ \\
\hline
\end{tabular}




\begin{tabular}{|c|c|c|c|c|c|}
\hline $\begin{array}{l}\text { Author, Year } \\
\text { (See Appendix B } \\
\text { for complete } \\
\text { reference) }\end{array}$ & Measure & $\begin{array}{l}\text { Indicator of } \\
\text { Serious Injury }\end{array}$ & Method for Constructing Multivariate Model & $\begin{array}{l}\text { Risk Estimates } \\
\text { Multivariate }\end{array}$ & $\begin{array}{l}\text { AUROC Multivariate } \\
\text { AUC }(95 \% \mathrm{Cl})\end{array}$ \\
\hline Raux, 2017 & \begin{tabular}{|l|} 
Lactate: model 4 \\
(MGAP); \\
normotensive \\
subgroup
\end{tabular} & \begin{tabular}{|l|} 
Mortality, 30- \\
day in-hospital
\end{tabular} & $\begin{array}{l}\text { Subgroup analysis of normotensive patients - EMS and ED SBP }>90 \text { without } \\
\text { administration of vasopressors. Multiple logistic regressions to assess the predictive } \\
\text { performances of blood lactate and base deficit knowing RTS or MGAP score. } \\
\text { Discrimination was quantified by calculating the concordance statistic completed } \\
\text { with optimism, the difference of AUC between the entire population and the cross } \\
\text { validated population. Reclassification was conducted by calculating the net } \\
\text { reclassification index. } \\
\text { Blood lactate and base deficit were forced into the models and should be considered } \\
\text { as competitors. }\end{array}$ & $\begin{array}{l}\text { AOR }(95 \% \mathrm{Cl}): 1.31 \\
(1.08 \text { to } 1.61), p=0.01 ; \\
\text { per } 1 \mathrm{mmol} / \mathrm{L} \text { increase }\end{array}$ & $\begin{array}{l}\text { AUC: NR } \\
\text { Net reclassification } \\
\text { index: } 0.468(0.160) \text {, } \\
p=0.003\end{array}$ \\
\hline Raux, 2017 & $\begin{array}{l}\text { BD model } 4 \\
(\text { MGAP); } \\
\text { normotensive } \\
\text { subgroup }\end{array}$ & \begin{tabular}{|l|} 
Mortality, 30- \\
day in-hospital
\end{tabular} & $\begin{array}{l}\text { Subgroup analysis of normotensive patients - EMS and ED SBP }>90 \text { without } \\
\text { administration of vasopressors. Multiple logistic regressions to assess the predictive } \\
\text { performances of blood lactate and base deficit knowing RTS or MGAP score. } \\
\text { Discrimination was quantified by calculating the concordance statistic completed } \\
\text { with optimism, the difference of AUC between the entire population and the cross } \\
\text { validated population. Reclassification was conducted by calculating the net } \\
\text { reclassification index. } \\
\text { Blood lactate and base deficit were forced into the models and should be considered } \\
\text { as competitors. }\end{array}$ & $\begin{array}{l}\text { AOR }(95 \% \mathrm{Cl}): 1.07 \\
(0.96 \text { to } 1.20), p=0.21 \\
\text { per } 1 \mathrm{mmol} / \mathrm{L} \text { increase }\end{array}$ & $\begin{array}{l}\text { AUC: NR } \\
\text { Net reclassification } \\
\text { index: } 0.299 \text { (SD } \\
0.160), p=0.06\end{array}$ \\
\hline Raux, 2017 & $\begin{array}{l}\text { MGAP: model } 4 \\
\text { (MGAP); } \\
\text { normotensive } \\
\text { subgroup }\end{array}$ & \begin{tabular}{|l|} 
Mortality, 30- \\
day in-hospital
\end{tabular} & $\begin{array}{l}\text { Subgroup analysis of normotensive patients - EMS and ED SBP }>90 \text { without } \\
\text { administration of vasopressors. Multiple logistic regressions to assess the predictive } \\
\text { performances of blood lactate and base deficit knowing RTS or MGAP score. } \\
\text { Discrimination was quantified by calculating the concordance statistic completed } \\
\text { with optimism, the difference of AUC between the entire population and the cross } \\
\text { validated population. Reclassification was conducted by calculating the net } \\
\text { reclassification index. } \\
\text { Blood lactate and base deficit were forced into the models and should be considered } \\
\text { as competitors. }\end{array}$ & $\begin{array}{l}\text { AOR }(95 \% \mathrm{Cl}): 1.39 \\
(1.29 \text { to } 1.51), p<0.001 ; \\
\text { per 1-point decrease }\end{array}$ & NR \\
\hline Raux, 2017 & $\begin{array}{l}\text { Model } 5 \text { (RTS, } \\
\text { lactate, BD): } \\
\text { TRISS >0.9 } \\
\text { subgroup }\end{array}$ & \begin{tabular}{|l|} 
Mortality, $30-$ \\
day in-hospital
\end{tabular} & $\begin{array}{l}\text { Subgroup analysis of patients with a high probability of survival - TRISS score }>0.9 \text {. } \\
\text { Multiple logistic regressions to assess the predictive performances of blood lactate } \\
\text { and base deficit knowing RTS or MGAP score. Discrimination was quantified by } \\
\text { calculating the concordance statistic completed with optimism, the difference of AUC } \\
\text { between the entire population and the cross validated population. Reclassification } \\
\text { was conducted by calculating the net reclassification index. } \\
\text { Blood lactate and base deficit were forced into the models and should be considered } \\
\text { as competitors. }\end{array}$ & NR & $\begin{array}{l}0.73(\mathrm{NR}) \text {, optimism } \\
<0.01\end{array}$ \\
\hline
\end{tabular}




\begin{tabular}{|c|c|c|c|c|c|}
\hline $\begin{array}{l}\text { Author, Year } \\
\text { (See Appendix B } \\
\text { for complete } \\
\text { reference) }\end{array}$ & Measure & \begin{tabular}{|l} 
Indicator of \\
Serious Injury
\end{tabular} & Method for Constructing Multivariate Model & $\begin{array}{l}\text { Risk Estimates } \\
\text { Multivariate }\end{array}$ & $\begin{array}{l}\text { AUROC Multivariate } \\
\text { AUC }(95 \% \mathrm{Cl})\end{array}$ \\
\hline Raux, 2017 & $\begin{array}{l}\text { Lactate: model } 5 \\
\text { (RTS); TRISS } \\
>0.9 \text { subgroup }\end{array}$ & $\begin{array}{l}\text { Mortality, 30- } \\
\text { day in-hospital }\end{array}$ & $\begin{array}{l}\text { Subgroup analysis of patients with a high probability of survival - TRISS score }>0.9 \text {. } \\
\text { Multiple logistic regressions to assess the predictive performances of blood lactate } \\
\text { and base deficit knowing RTS or MGAP score. Discrimination was quantified by } \\
\text { calculating the concordance statistic completed with optimism, the difference of AUC } \\
\text { between the entire population and the cross validated population. Reclassification } \\
\text { was conducted by calculating the net reclassification index. } \\
\text { Blood lactate and base deficit were forced into the models and should be considered } \\
\text { as competitors. }\end{array}$ & $\begin{array}{l}\text { AOR }(95 \% \mathrm{Cl}): 1.64 \\
(0.99 \text { to } 1.64), p=0.06 \\
\text { per } 1 \mathrm{mmol} / \mathrm{L} \text { increase }\end{array}$ & $\begin{array}{l}\text { AUC: NR } \\
\text { Net reclassification } \\
\text { index: } 0.425 \text { (SD } \\
0.160), p=0.007\end{array}$ \\
\hline Raux, 2017 & $\begin{array}{l}\text { RTS: model } 5 \\
\text { (RTS); TRISS } \\
>0.9 \text { subgroup }\end{array}$ & \begin{tabular}{|l|} 
Mortality, 30- \\
day in-hospital
\end{tabular} & $\begin{array}{l}\text { Subgroup analysis of patients with a high probability of survival - TRISS score }>0.9 \text {. } \\
\text { Multiple logistic regressions to assess the predictive performances of blood lactate } \\
\text { and base deficit knowing RTS or MGAP score. Discrimination was quantified by } \\
\text { calculating the concordance statistic completed with optimism, the difference of AUC } \\
\text { between the entire population and the cross validated population. Reclassification } \\
\text { was conducted by calculating the net reclassification index. } \\
\text { Blood lactate and base deficit were forced into the models and should be considered } \\
\text { as competitors. }\end{array}$ & $\begin{array}{l}\text { AOR }(95 \% \mathrm{Cl}): 3.37 \\
(2.30 \text { to } 4.93), p<0.001 ; \\
\text { per 1-point decrease }\end{array}$ & NR \\
\hline Raux, 2017 & $\begin{array}{l}\text { BD: } \text { model } 5 \\
\text { (RTS); TRISS } \\
>0.9 \text { subgroup }\end{array}$ & \begin{tabular}{|l|} 
Mortality, 30- \\
day in-hospital
\end{tabular} & $\begin{array}{l}\text { Subgroup analysis of patients with a high probability of survival - TRISS score }>0.9 \text {. } \\
\text { Multiple logistic regressions to assess the predictive performances of blood lactate } \\
\text { and base deficit knowing RTS or MGAP score. Discrimination was quantified by } \\
\text { calculating the concordance statistic completed with optimism, the difference of AUC } \\
\text { between the entire population and the cross validated population. Reclassification } \\
\text { was conducted by calculating the net reclassification index. } \\
\text { Blood lactate and base deficit were forced into the models and should be considered } \\
\text { as competitors. }\end{array}$ & $\begin{array}{l}\text { AOR }(95 \% \mathrm{Cl}): 1.01 \\
(0.87 \text { to } 1.17), p=0.88 \\
\text { per } 1 \mathrm{mmol} / \mathrm{L} \text { increase }\end{array}$ & $\begin{array}{l}\text { AUC: NR } \\
\text { Net reclassification } \\
\text { index: } 0.231 \text { (SD } \\
0.160), p=0.15\end{array}$ \\
\hline Raux, 2017 & $\begin{array}{l}\text { Model } 6 \text { (MGAP, } \\
\text { lactate, BD): } \\
\text { TRISS >0.9 } \\
\text { subgroup }\end{array}$ & \begin{tabular}{|l|} 
Mortality, 30- \\
day in-hospital
\end{tabular} & $\begin{array}{l}\text { Subgroup analysis of patients with a high probability of survival - TRISS score }>0.9 \text {. } \\
\text { Multiple logistic regressions to assess the predictive performances of blood lactate } \\
\text { and base deficit knowing RTS or MGAP score. Discrimination was quantified by } \\
\text { calculating the concordance statistic completed with optimism, the difference of AUC } \\
\text { between the entire population and the cross validated population. Reclassification } \\
\text { was conducted by calculating the net reclassification index. } \\
\text { Blood lactate and base deficit were forced into the models and should be considered } \\
\text { as competitors. }\end{array}$ & NR & $\begin{array}{l}0.80 \text { (NR), optimism } \\
<0.01\end{array}$ \\
\hline
\end{tabular}




\begin{tabular}{|c|c|c|c|c|c|}
\hline $\begin{array}{l}\text { Author, Year } \\
\text { (See Appendix B } \\
\text { for complete } \\
\text { reference) }\end{array}$ & Measure & \begin{tabular}{|l} 
Indicator of \\
Serious Injury
\end{tabular} & Method for Constructing Multivariate Model & $\begin{array}{l}\text { Risk Estimates } \\
\text { Multivariate }\end{array}$ & $\begin{array}{l}\text { AUROC Multivariate } \\
\text { AUC }(95 \% \mathrm{Cl})\end{array}$ \\
\hline Raux, 2017 & $\begin{array}{l}\text { MGAP: model } 6 \\
\text { (MGAP); TRISS } \\
>0.9 \text { subgroup }\end{array}$ & $\begin{array}{l}\text { Mortality, 30- } \\
\text { day in-hospital }\end{array}$ & $\begin{array}{l}\text { Subgroup analysis of patients with a high probability of survival - TRISS score }>0.9 \text {. } \\
\text { Multiple logistic regressions to assess the predictive performances of blood lactate } \\
\text { and base deficit knowing RTS or MGAP score. Discrimination was quantified by } \\
\text { calculating the concordance statistic completed with optimism, the difference of AUC } \\
\text { between the entire population and the cross validated population. Reclassification } \\
\text { was conducted by calculating the net reclassification index. } \\
\text { Blood lactate and base deficit were forced into the models and should be considered } \\
\text { as competitors. }\end{array}$ & $\begin{array}{l}\text { AOR }(95 \% \mathrm{Cl}): 1.39 \\
(1.26 \text { to } 1.54), p=0.002 \\
\text { per 1-point decrease }\end{array}$ & NR \\
\hline Raux, 2017 & $\begin{array}{l}\text { Lactate: model } 6 \\
\text { (MGAP); TRISS } \\
>0.9 \text { subgroup }\end{array}$ & $\begin{array}{l}\text { Mortality, } 30- \\
\text { day in-hospital }\end{array}$ & $\begin{array}{l}\text { Subgroup analysis of patients with a high probability of survival - TRISS score }>0.9 \text {. } \\
\text { Multiple logistic regressions to assess the predictive performances of blood lactate } \\
\text { and base deficit knowing RTS or MGAP score. Discrimination was quantified by } \\
\text { calculating the concordance statistic completed with optimism, the difference of AUC } \\
\text { between the entire population and the cross validated population. Reclassification } \\
\text { was conducted by calculating the net reclassification index. } \\
\text { Blood lactate and base deficit were forced into the models and should be considered } \\
\text { as competitors. }\end{array}$ & $\begin{array}{l}\text { AOR }(95 \% \mathrm{Cl}): 1.23 \\
(0.92 \text { to } 1.55), p=0.09 \\
\text { per } 1 \mathrm{mmol} / \mathrm{L} \text { increase }\end{array}$ & $\begin{array}{l}\text { AUC: NR } \\
\text { Net reclassification } \\
\text { index: } 0.468(S D \\
0.160), p=0.003\end{array}$ \\
\hline Raux, 2017 & $\begin{array}{l}\text { BD: model } 6 \\
\text { (MGAP); TRISS } \\
>0.9 \text { subgroup }\end{array}$ & $\begin{array}{l}\text { Mortality, 30- } \\
\text { day in-hospital }\end{array}$ & $\begin{array}{l}\text { Subgroup analysis of patients with a high probability of survival - TRISS score }>0.9 \text {. } \\
\text { Multiple logistic regressions to assess the predictive performances of blood lactate } \\
\text { and base deficit knowing RTS or MGAP score. Discrimination was quantified by } \\
\text { calculating the concordance statistic completed with optimism, the difference of AUC } \\
\text { between the entire population and the cross validated population. Reclassification } \\
\text { was conducted by calculating the net reclassification index. } \\
\text { Blood lactate and base deficit were forced into the models and should be considered } \\
\text { as competitors. }\end{array}$ & $\begin{array}{l}\text { AOR }(95 \% \mathrm{Cl}): 1.06 \\
(0.97 \text { to } 1.21), p=0.43 ; \\
\text { per } 1 \mathrm{mmol} / \mathrm{L} \text { increase }\end{array}$ & $\begin{array}{l}\text { AUC: NR } \\
\text { Net reclassification } \\
\text { index: } 0.299(S D \\
0.160), p=0.06\end{array}$ \\
\hline Regnier, 2012 & $\begin{array}{l}\text { Lactate: Model } 1 \\
\text { (RTS, lactate and } \\
\text { lactate } \\
\text { clearance) }\end{array}$ & $\begin{array}{l}\text { Mortality, 30- } \\
\text { day }\end{array}$ & $\begin{array}{l}\text { Multiple logistic regressions using initial blood lactate, lactate clearance, and either } \\
\text { RTS (Model 1) or MGAP (Model 2). Internal validation was performed using 10-fold } \\
\text { cross validation. ROC curves averaged 1,000 populations boot-strapped from } \\
\text { original study population. Discrimination assessed by AUC and calibration by the } \\
\text { Hosmer-Lemeshow statistic. Subgroup analysis of normotensive patients (SBP >90 } \\
\text { in field and on ED arrival) }\end{array}$ & $\begin{array}{l}\text { AOR }(95 \% \mathrm{Cl}) \\
\text { Overall: } 1.21(1.08 \text { to } \\
1.38), p<0.001 \\
\text { Normotensive subgroup: } \\
0.99(0.77 \text { to } 1.26) \\
p=0.93\end{array}$ & NR \\
\hline
\end{tabular}




\begin{tabular}{|c|c|c|c|c|c|}
\hline $\begin{array}{l}\text { Author, Year } \\
\text { (See Appendix B } \\
\text { for complete } \\
\text { reference) }\end{array}$ & Measure & \begin{tabular}{|l|} 
Indicator of \\
Serious Injury
\end{tabular} & Method for Constructing Multivariate Model & $\begin{array}{l}\text { Risk Estimates } \\
\text { Multivariate }\end{array}$ & $\begin{array}{l}\text { AUROC Multivariate } \\
\text { AUC }(95 \% \mathrm{Cl})\end{array}$ \\
\hline Regnier, 2012 & \begin{tabular}{l|} 
Lactate \\
clearance: Model \\
1 (RTS, lactate \\
and lactate \\
clearance)
\end{tabular} & $\begin{array}{l}\text { Mortality, 30- } \\
\text { day }\end{array}$ & $\begin{array}{l}\text { Multiple logistic regressions using initial blood lactate, lactate clearance, and either } \\
\text { RTS (Model 1) or MGAP (Model 2). Internal validation was performed using 10-fold } \\
\text { cross validation. ROC curves averaged 1,000 populations boot-strapped from } \\
\text { original study population. Discrimination assessed by AUC and calibration by the } \\
\text { Hosmer-Lemeshow statistic. Subgroup analysis of normotensive patients (SBP >90 } \\
\text { in field and on ED arrival) }\end{array}$ & \begin{tabular}{|l|} 
AOR $(95 \% \mathrm{Cl})$ \\
Overall: $1.16(1.01$ to \\
$1.31), p=0.02$ \\
Normotensive subgroup: \\
$1.13(0.93$ to 1.33$)$ \\
$\mathrm{p}=0.14$
\end{tabular} & NR \\
\hline Regnier, 2012 & \begin{tabular}{l|} 
Lactate \\
clearance: Model \\
2 (MGAP, lactate \\
and lactate \\
clearance)
\end{tabular} & $\begin{array}{l}\text { Mortality, 30- } \\
\text { day }\end{array}$ & $\begin{array}{l}\text { Multiple logistic regressions using initial blood lactate, lactate clearance, and either } \\
\text { RTS (Model 1) or MGAP (Model 2). Internal validation was performed using } 10 \text {-fold } \\
\text { cross validation. ROC curves averaged 1,000 populations boot-strapped from } \\
\text { original study population. Discrimination assessed by AUC and calibration by the } \\
\text { Hosmer-Lemeshow statistic. Subgroup analysis of normotensive patients (SBP >90 } \\
\text { in field and on ED arrival) }\end{array}$ & \begin{tabular}{|l|} 
AOR $(95 \% \mathrm{Cl})$ \\
Overall: $1.15(1.00$ to \\
$1.30), p=0.03$ \\
Normotensive subgroup: \\
$1.11(0.93$ to 1.29$)$ \\
$\mathrm{p}=0.17$
\end{tabular} & NR \\
\hline Regnier, 2012 & \begin{tabular}{|l|} 
RTS: Model 1 \\
(RTS, lactate and \\
lactate \\
clearance)
\end{tabular} & $\begin{array}{l}\text { Mortality, 30- } \\
\text { day }\end{array}$ & $\begin{array}{l}\text { Multiple logistic regressions using initial blood lactate, lactate clearance, and either } \\
\text { RTS (Model 1) or MGAP (Model 2). Internal validation was performed using } 10 \text {-fold } \\
\text { cross validation. ROC curves averaged 1,000 populations boot-strapped from } \\
\text { original study population. Discrimination assessed by AUC and calibration by the } \\
\text { Hosmer-Lemeshow statistic. Subgroup analysis of normotensive patients (SBP >90 } \\
\text { in field and on ED arrival) }\end{array}$ & \begin{tabular}{|l|} 
AOR $(95 \% \mathrm{Cl}):$ \\
Overall: $2.06(1.64$ to \\
$2.55), \mathrm{p}<0.001$ \\
Normotensive subgroup: \\
$2.50(1.85$ to 3.49$)$ \\
$\mathrm{p}<0.001$
\end{tabular} & NR \\
\hline Regnier, 2012 & $\begin{array}{l}\text { MGAP: Model } 2 \\
\text { (MGAP, lactate } \\
\text { and lactate } \\
\text { clearance) }\end{array}$ & $\begin{array}{l}\text { Mortality, 30- } \\
\text { day }\end{array}$ & $\begin{array}{l}\text { Multiple logistic regressions using initial blood lactate, lactate clearance, and either } \\
\text { RTS (Model 1) or MGAP (Model 2). Internal validation was performed using 10-fold } \\
\text { cross validation. ROC curves averaged 1,000 populations boot-strapped from } \\
\text { original study population. Discrimination assessed by AUC and calibration by the } \\
\text { Hosmer-Lemeshow statistic. Subgroup analysis of normotensive patients (SBP >90 } \\
\text { in field and on ED arrival) }\end{array}$ & $\begin{array}{l}\text { AOR }(95 \% \mathrm{Cl}) \\
\text { Overall: } 1.21 \text { (1.13 to } \\
\text { 1.29), } \mathrm{p}<0.001 \\
\text { Normotensive subgroup: } \\
1.21(1.10 \text { to } 1.32) \\
\mathrm{p}<0.001\end{array}$ & NR \\
\hline Regnier, 2012 & $\begin{array}{l}\text { Model 1: RTS, } \\
\text { lactate and } \\
\text { lactate clearance }\end{array}$ & $\begin{array}{l}\text { Mortality, 30- } \\
\text { day }\end{array}$ & $\begin{array}{l}\text { Multiple logistic regressions using initial blood lactate, lactate clearance, and either } \\
\text { RTS (Model 1) or MGAP (Model 2). Internal validation was performed using 10-fold } \\
\text { cross validation. ROC curves averaged 1,000 populations boot-strapped from } \\
\text { original study population. Discrimination assessed by AUC and calibration by the } \\
\text { Hosmer-Lemeshow statistic. Subgroup analysis of normotensive patients (SBP >90 } \\
\text { in field and on ED arrival) }\end{array}$ & NR & $\begin{array}{l}\text { AUC (95\% Cl) } \\
\text { Overall: } 0.91(\mathrm{NR}) \\
\text { Normotensive } \\
\text { subgroup: } 0.90 \text { (NR) } \\
\\
\text { Net reclassification } \\
\text { improvement: Model } 1 \\
\text { vs. RTS alone } \\
\text { Overall: } 0.64 \text { (SD } \\
\text { 0.15), p<0.001 } \\
\text { Normotensive } \\
\text { subgroup: } 0.389 \text { (SD }\end{array}$ \\
\hline
\end{tabular}




\begin{tabular}{|c|c|c|c|c|c|}
\hline $\begin{array}{l}\text { Author, Year } \\
\text { (See Appendix B } \\
\text { for complete } \\
\text { reference) }\end{array}$ & Measure & $\begin{array}{l}\text { Indicator of } \\
\text { Serious Injury }\end{array}$ & Method for Constructing Multivariate Model & $\begin{array}{l}\text { Risk Estimates } \\
\text { Multivariate }\end{array}$ & $\begin{array}{l}\text { AUROC Multivariate } \\
\text { AUC }(95 \% \mathrm{Cl})\end{array}$ \\
\hline Regnier, 2012 & $\begin{array}{l}\text { Model 2: MGAP, } \\
\text { lactate and } \\
\text { lactate clearance }\end{array}$ & $\begin{array}{l}\text { Mortality, 30- } \\
\text { day }\end{array}$ & $\begin{array}{l}\text { Multiple logistic regressions using initial blood lactate, lactate clearance, and either } \\
\text { RTS (Model 1) or MGAP (Model 2). Internal validation was performed using 10-fold } \\
\text { cross validation. ROC curves averaged 1,000 populations boot-strapped from } \\
\text { original study population. Discrimination assessed by AUC and calibration by the } \\
\text { Hosmer-Lemeshow statistic. Subgroup analysis of normotensive patients (SBP >90 } \\
\text { in field and on ED arrival) }\end{array}$ & NR & $\begin{array}{l}\text { AUC (95\% Cl) } \\
\text { Overall: } 0.85 \text { (NR) } \\
\text { Normotensive } \\
\text { subgroup: } 0.83 \text { (NR) } \\
\\
\text { Net reclassification } \\
\text { improvement: Model } 2 \\
\text { vs. MGAP alone } \\
\text { Overall: } 0.52 \text { (SD } \\
\text { 0.15), p<0.001 } \\
\text { Normotensive } \\
\text { subgroup: } 0.304 \text { (SD }\end{array}$ \\
\hline Reisner, 2016 & $\begin{array}{l}\text { Muscle oxygen } \\
\text { saturation } \\
\left(\mathrm{SmO}_{2}\right) \text { plus ED } \\
\text { vital signs }(\mathrm{HR} \text {, } \\
\mathrm{SBP}, \text { and } \mathrm{PP})\end{array}$ & $\begin{array}{l}\text { Hemorrhagic } \\
\text { injury requiring } \\
\text { blood } \\
\text { transfusion } \geq 3 \\
\text { units PRBC }\end{array}$ & $\begin{array}{l}\text { Two multivariate logistic regression models: } \\
\text { - using only routine vital signs (variables: } \mathrm{HR}, \mathrm{SBP}, \mathrm{PP} \text { ) } \\
\text { - adding muscle oxygen saturation (variables: } \mathrm{HR}, \mathrm{SBP}, \mathrm{PP} \text {, and } \mathrm{SmO}_{2} \text { ) } \\
\text { Applied DeLong's test to the ROC AUCs from these models with null hypothesis that } \\
\mathrm{SmO}_{2} \text { did not provide additional diagnostic information compare with using routine } \\
\text { vital signs alone. }\end{array}$ & NR & $\begin{array}{l}0.85(0.75 \text { to } 0.91) \\
p<0.05 \text { vs. vital signs } \\
\text { only }\end{array}$ \\
\hline Reisner, 2016 & $\begin{array}{l}\text { Muscle oxygen } \\
\text { saturation } \\
\left(\mathrm{SmO}_{2}\right) \text { plus ED } \\
\text { vital signs }(\mathrm{HR} \text {, } \\
\mathrm{SBP} \text {, and } \mathrm{PP})\end{array}$ & $\begin{array}{l}\text { Hemorrhagic } \\
\text { injury requiring } \\
\text { blood } \\
\text { transfusion } \geq 9 \\
\text { units PRBC }\end{array}$ & $\begin{array}{l}\text { Two multivariate logistic regression models: } \\
\text { - using only routine vital signs (variables: } \mathrm{HR}, \mathrm{SBP}, \mathrm{PP} \text { ) } \\
\text { - adding muscle oxygen saturation (variables: } \mathrm{HR}, \mathrm{SBP}, \mathrm{PP} \text {, and } \mathrm{SmO}_{2} \text { ) } \\
\text { Applied DeLong's test to the ROC AUCs from these models with null hypothesis that } \\
\mathrm{SmO}_{2} \text { did not provide additional diagnostic information compare with using routine } \\
\text { vital signs alone. }\end{array}$ & NR & $\begin{array}{l}0.89(0.76 \text { to } 0.95) \\
p<0.05 \text { vs. vital signs } \\
\text { only }\end{array}$ \\
\hline Reisner, 2016 & $\begin{array}{l}\text { Vital signs (ED } \\
\text { HR, SBP, PP) }\end{array}$ & $\begin{array}{l}\text { Hemorrhagic } \\
\text { injury requiring } \\
\text { blood } \\
\text { transfusion } \geq 3 \\
\text { units PRBC }\end{array}$ & $\begin{array}{l}\text { Two multivariate logistic regression models: } \\
\text { - using only routine vital signs (variables: } \mathrm{HR}, \mathrm{SBP}, \mathrm{PP} \text { ) } \\
\text { - adding muscle oxygen saturation (variables: } \mathrm{HR}, \mathrm{SBP}, \mathrm{PP} \text {, and } \mathrm{SmO}_{2} \text { ) } \\
\text { Applied DeLong's test to the ROC AUCs from these models with null hypothesis that } \\
\mathrm{SmO}_{2} \text { did not provide additional diagnostic information compare with using routine } \\
\text { vital signs alone. }\end{array}$ & NR & $0.77(0.66$ to 0.86$)$ \\
\hline Reisner, 2016 & $\begin{array}{l}\text { Vital signs (ED } \\
\text { HR, SBP, PP) }\end{array}$ & $\begin{array}{l}\text { Hemorrhagic } \\
\text { injury requiring } \\
\text { blood } \\
\text { transfusion } \geq 9 \\
\text { units PRBC }\end{array}$ & $\begin{array}{l}\text { Two multivariate logistic regression models: } \\
\text { - using only routine vital signs (variables: } \mathrm{HR}, \mathrm{SBP}, \mathrm{PP} \text { ) } \\
\text { - adding muscle oxygen saturation (variables: } \mathrm{HR}, \mathrm{SBP}, \mathrm{PP} \text {, and } \mathrm{SmO}_{2} \text { ) } \\
\text { Applied DeLong's test to the ROC AUCs from these models with null hypothesis that } \\
\mathrm{SmO}_{2} \text { did not provide additional diagnostic information compare with using routine } \\
\text { vital signs alone. }\end{array}$ & NR & $0.77(0.61$ to 0.87$)$ \\
\hline
\end{tabular}




\begin{tabular}{|c|c|c|c|c|c|}
\hline $\begin{array}{l}\text { Author, Year } \\
\text { (See Appendix B } \\
\text { for complete } \\
\text { reference) }\end{array}$ & Measure & \begin{tabular}{|l|} 
Indicator of \\
Serious Injury
\end{tabular} & Method for Constructing Multivariate Model & $\begin{array}{l}\text { Risk Estimates } \\
\text { Multivariate }\end{array}$ & $\begin{array}{l}\text { AUROC Multivariate } \\
\text { AUC }(95 \% \mathrm{Cl})\end{array}$ \\
\hline Rickards, 2010 & \begin{tabular}{|l|} 
Heart rate \\
variability: fractal \\
dimensions by \\
curve length (FD- \\
L): patients with \\
normal vital signs
\end{tabular} & $\begin{array}{l}\text { Life-saving } \\
\text { intervention }\end{array}$ & $\begin{array}{l}\text { Multivariate logistic regression to predict LSI vs. No-LSI from heart period variability } \\
\text { metrics. Data were subjected to multivariate outlier analysis (Mahalanobis distances) } \\
\text { prior to analysis, and data transformations were used to normalize skewed } \\
\text { distributions where appropriate. ROC curves were derived from the logistic } \\
\text { prediction equations, as well as other measures of prediction accuracy. }\end{array}$ & NR & $\begin{array}{l}\text { AUC (95\% Cl): } 0.70 \\
\text { (NR) } \\
\text { Sensitivity } 16 \% \\
\text { Specificity } 99 \% \\
\text { Overall correct } \\
\text { classification rate: }\end{array}$ \\
\hline Ryan, 2011b & $\begin{array}{l}\text { Mortality Score } \\
\text { algorithm: age, } \\
\text { VLF, HF (using } \\
\text { mean-rank } \\
\text { scores for VLF } \\
\text { and HF) }\end{array}$ & Mortality & $\begin{array}{l}\text { Multivariate stepwise logistic regression using HRV data (raw and log-transformed) } \\
\text { and patient characteristics to predict mortality with maximum sensitivity, specificity } \\
\text { and efficiency. The maximum likelihood technique was used to generate the } \\
\text { coefficients for each variable. Covariates considered included any variable possibly } \\
\text { influencing mortality. Significance was set at the } 95 \% \text { confidence interval. } \\
\text { Mortality Score }=49.8505-2.0202 \times \ln (\mathrm{VLF})+1.5509 \times \ln (\mathrm{HF})+0.0516 \times \text { age }\end{array}$ & NR & $\begin{array}{l}\text { AUC: } 0.845 \text { (SD } \\
0.059) \\
\text { Sensitivity } 88.2 \% \\
\text { Specificity } 64.9 \% \\
\text { Efficiency* } 65.6 \% \\
\text { *Efficiency defined as }\end{array}$ \\
\hline Ryan, 2011b & \begin{tabular}{|l|} 
Heart rate \\
variability: HF \\
(using mean-rank \\
score)
\end{tabular} & Mortality & $\begin{array}{l}\text { Multivariate stepwise logistic regression using HRV data (raw and log-transformed) } \\
\text { and patient characteristics to predict mortality with maximum sensitivity, specificity } \\
\text { and efficiency. The maximum likelihood technique was used to generate the } \\
\text { coefficients for each variable. Covariates considered included any variable possibly } \\
\text { influencing mortality. Significance was set at the } 95 \% \text { confidence interval. } \\
\text { Mortality Score }=49.8505-2.0202 \times \ln (\mathrm{VLF})+1.5509 \times \ln (\mathrm{HF})+0.0516 \times \text { age }\end{array}$ & $\begin{array}{l}\text { AOR }(95 \% \mathrm{Cl}): 4.716 \\
(1.706 \text { to } 13.301) \\
p=0.002\end{array}$ & NR \\
\hline $\begin{array}{l}\text { Sartorius, } 2010 \\
\text { * Sartorius } 2010 \\
\text { and Raux } 2011 \\
\text { analyze the same } \\
\text { study population }\end{array}$ & $\begin{array}{l}\text { SBP: derivation } \\
\text { cohort }\end{array}$ & $\begin{array}{l}\text { Mortality: } 30- \\
\text { day all cause }\end{array}$ & $\begin{array}{l}\text { Score constructed using multiple forward stepwise logistic regression using } \\
\text { prehospital variables and a semiparsimonious approach with the derivation cohort. } \\
\text { Colinearity was considered when } r>0.8 \text { (Spearman coefficient matrix correlation). } \\
\text { Internal validation was performed using } 10 \text {-fold cross validation. Continuous } \\
\text { variables selected in the model were transformed followed by simplification of the } \\
\text { weight allocated to each variable (to degree possible), which was derived from } \\
\text { logistic regression coefficients. External validation was performed using the } \\
\text { validation cohort. }\end{array}$ & $\begin{array}{l}\text { AOR }(95 \% \mathrm{Cl}) \\
\text { Continuous: } 0.98(0.98- \\
0.99), \text { per } 1 \mathrm{~mm} \mathrm{Hg} \\
\text { increase } \\
\text { Stratified }(>120 \\
\text { reference) } \\
-60-120: 2.7(2.0-3.6) \\
-<60: 5.4(4.1-7.3)\end{array}$ & NR \\
\hline
\end{tabular}




\begin{tabular}{|c|c|c|c|c|c|}
\hline $\begin{array}{l}\text { Author, Year } \\
\text { (See Appendix B } \\
\text { for complete } \\
\text { reference) }\end{array}$ & Measure & \begin{tabular}{|l|} 
Indicator of \\
Serious Injury
\end{tabular} & Method for Constructing Multivariate Model & $\begin{array}{l}\text { Risk Estimates } \\
\text { Multivariate }\end{array}$ & $\begin{array}{l}\text { AUROC Multivariate } \\
\text { AUC }(95 \% \mathrm{Cl})\end{array}$ \\
\hline $\begin{array}{l}\text { Sartorius, } 2010 \\
\text { * Sartorius } 2010 \\
\text { and Raux } 2011 \\
\text { analyze the same } \\
\text { study population }\end{array}$ & \begin{tabular}{|l|} 
MGAP: \\
derivation cohort \\
using continuous \\
variables
\end{tabular} & $\begin{array}{l}\text { Mortality: } 30- \\
\text { day all cause }\end{array}$ & $\begin{array}{l}\text { Score constructed using multiple forward stepwise logistic regression using } \\
\text { prehospital variables and a semiparsimonious approach with the derivation cohort. } \\
\text { Colinearity was considered when } r>0.8 \text { (Spearman coefficient matrix correlation). } \\
\text { Internal validation was performed using } 10 \text {-fold cross validation. Continuous } \\
\text { variables selected in the model were transformed followed by simplification of the } \\
\text { weight allocated to each variable (to degree possible), which was derived from } \\
\text { logistic regression coefficients. External validation was performed using the } \\
\text { validation cohort. }\end{array}$ & NR & 0.907 (SD 0.011) \\
\hline $\begin{array}{l}\text { Shackelford, } 2015 \\
\text { *Mackenzie 2015, } \\
\text { Shackelford 2015, } \\
\text { and Yang } 2016 \\
\text { draw from the } \\
\text { same population, } \\
\text { but differ in } \\
\text { eligibility criteria, } \\
\text { number analyzed, } \\
\text { and measures } \\
\text { evaluated. } \\
\text { ×Mackenzie, } 2014 \\
\text { study population } \\
\text { included in } \\
\text { Shackelford, } 2015\end{array}$ & \begin{tabular}{|l|} 
Lactate; Decision \\
assist algorithm \\
(Model 05, \\
cartridge 3)
\end{tabular} & $\begin{array}{l}\text { Blood } \\
\text { transfusion (3 } \\
\text { hours, rapid, } \\
\text { massive) }\end{array}$ & $\begin{array}{l}\text { Stepwise logistic regression models using selected variables/combinations for each } \\
\text { decision assist algorithm, among: HR, SBP, pulse oximetry features, } 3 \text { sets of } \\
\text { laboratory tests (hematocrit, glucose, potassium, chloride, and bicarbonate; } \\
\text { prothrombin time and INR; or, Lactate). Forward selection using } \mathrm{p}=0.05 \text { and } \\
\text { backward selection using } \mathrm{p}=0.1 \text {. } 10 \text {-fold cross-validation repeated } 10 \text { times was } \\
\text { used to validate the prediction, with models considered not overfitting if they had } \\
<10 \% \text { difference in training and testing AUROC curves. }\end{array}$ & NR & $\begin{array}{l}\text { AUC }(95 \% \mathrm{Cl}) \\
\text { Transfusion in } 3 \\
\text { hours: } 0.77 \text { (NR) } \\
\text { Rapid transfusion: } \\
0.80 \text { (NR) } \\
\text { Massive transfusion: } \\
0.80 \text { (NR) }\end{array}$ \\
\hline
\end{tabular}




\begin{tabular}{|c|c|c|c|c|c|}
\hline $\begin{array}{l}\text { Author, Year } \\
\text { (See Appendix B } \\
\text { for complete } \\
\text { reference) }\end{array}$ & Measure & \begin{tabular}{|l|} 
Indicator of \\
Serious Injury
\end{tabular} & Method for Constructing Multivariate Model & $\begin{array}{l}\text { Risk Estimates } \\
\text { Multivariate }\end{array}$ & $\begin{array}{l}\text { AUROC Multivariate } \\
\text { AUC }(95 \% \mathrm{Cl})\end{array}$ \\
\hline $\begin{array}{l}\text { Shackelford, } 2015 \\
\\
\star \text { *Mackenzie 2015, } \\
\text { Shackelford 2015, } \\
\text { and Yang } 2016 \\
\text { draw from the } \\
\text { same population, } \\
\text { but differ in } \\
\text { eligibility criteria, } \\
\text { number analyzed, } \\
\text { and measures } \\
\text { evaluated. } \\
\text { *Mackenzie, } 2014 \\
\text { study population } \\
\text { included in } \\
\text { Shackelford, } 2015\end{array}$ & \begin{tabular}{|l|} 
Decision-assist \\
algorithm (Model \\
01): HR and \\
SBP, EMS
\end{tabular} & \begin{tabular}{|l} 
Blood \\
transfusion (3 \\
hours, rapid, \\
massive)
\end{tabular} & $\begin{array}{l}\text { Stepwise logistic regression models using selected variables/combinations for each } \\
\text { decision assist algorithm, among: HR, SBP, pulse oximetry features, } 3 \text { sets of } \\
\text { laboratory tests (hematocrit, glucose, potassium, chloride, and bicarbonate; } \\
\text { prothrombin time and INR; or, Lactate). Forward selection using } p=0.05 \text { and } \\
\text { backward selection using } p=0.1 \text {. } 10 \text {-fold cross-validation repeated } 10 \text { times was } \\
\text { used to validate the prediction, with models considered not overfitting if they had } \\
<10 \% \text { difference in training and testing AUROC curves. }\end{array}$ & NR & $\begin{array}{l}\text { AUC }(95 \% \mathrm{Cl}) \\
\text { Transfusion in } 3 \\
\text { hours: } 0.59 \text { (NR) } \\
\text { Rapid transfusion: } \\
0.71 \text { (NR) } \\
\text { Massive transfusion: } \\
0.70 \text { (NR) }\end{array}$ \\
\hline $\begin{array}{l}\text { Shackelford, } 2015 \\
\\
\star \text { Mackenzie 2015, } \\
\text { Shackelford 2015, } \\
\text { and Yang } 2016 \\
\text { draw from the } \\
\text { same population, } \\
\text { but differ in } \\
\text { eligibility criteria, } \\
\text { number analyzed, } \\
\text { and measures } \\
\text { evaluated. } \\
\text { *Mackenzie, } 2014 \\
\text { study population } \\
\text { included in } \\
\text { Shackelford, } 2015\end{array}$ & \begin{tabular}{|l|} 
Decision-assist \\
algorithm (Model \\
03, cartridge 1): \\
Laboratory tests: \\
hematocrit, \\
glucose, \\
potassium, \\
chloride, and \\
bicarbonate
\end{tabular} & \begin{tabular}{|l|} 
Blood \\
transfusion (3 \\
hours, rapid, \\
massive)
\end{tabular} & $\begin{array}{l}\text { Stepwise logistic regression models using selected variables/combinations for each } \\
\text { decision assist algorithm, among: HR, SBP, pulse oximetry features, } 3 \text { sets of } \\
\text { laboratory tests (hematocrit, glucose, potassium, chloride, and bicarbonate; } \\
\text { prothrombin time and INR; or, Lactate). Forward selection using } p=0.05 \text { and } \\
\text { backward selection using } p=0.1 \text {. } 10 \text {-fold cross-validation repeated } 10 \text { times was } \\
\text { used to validate the prediction, with models considered not overfitting if they had } \\
<10 \% \text { difference in training and testing AUROC curves. }\end{array}$ & NR & $\begin{array}{l}\text { AUC }(95 \% \mathrm{Cl}) \\
\text { Transfusion in } 3 \\
\text { hours: } 0.83 \text { (NR) } \\
\text { Rapid transfusion: } \\
0.85 \text { (NR) } \\
\text { Massive transfusion: } \\
0.87 \text { (NR) }\end{array}$ \\
\hline
\end{tabular}




\begin{tabular}{|c|c|c|c|c|c|}
\hline $\begin{array}{l}\text { Author, Year } \\
\text { (See Appendix B } \\
\text { for complete } \\
\text { reference) }\end{array}$ & Measure & \begin{tabular}{|l|} 
Indicator of \\
Serious Injury
\end{tabular} & Method for Constructing Multivariate Model & $\begin{array}{l}\text { Risk Estimates } \\
\text { Multivariate }\end{array}$ & $\begin{array}{l}\text { AUROC Multivariate } \\
\text { AUC }(95 \% \mathrm{Cl})\end{array}$ \\
\hline $\begin{array}{l}\text { Shackelford, } 2015 \\
\text { *Mackenzie } 2015, \\
\text { Shackelford } 2015, \\
\text { and Yang } 2016 \\
\text { draw from the } \\
\text { same population, } \\
\text { but differ in } \\
\text { eligibility criteria, } \\
\text { number analyzed, } \\
\text { and measures } \\
\text { evaluated. } \\
\text { *Mackenzie, } 2014 \\
\text { study population } \\
\text { included in } \\
\text { Shackelford, } 2015\end{array}$ & \begin{tabular}{|l|} 
Decision-assist \\
algorithm (Model \\
04, cartridge 2): \\
Laboratory tests: \\
INR and \\
prothrombin time
\end{tabular} & $\begin{array}{l}\text { Blood } \\
\text { transfusion (3 } \\
\text { hours, rapid, } \\
\text { massive) }\end{array}$ & $\begin{array}{l}\text { Stepwise logistic regression models using selected variables/combinations for each } \\
\text { decision assist algorithm, among: HR, SBP, pulse oximetry features, } 3 \text { sets of } \\
\text { laboratory tests (hematocrit, glucose, potassium, chloride, and bicarbonate; } \\
\text { prothrombin time and INR; or, Lactate). Forward selection using } p=0.05 \text { and } \\
\text { backward selection using } p=0.1 \text {. } 10 \text {-fold cross-validation repeated } 10 \text { times was } \\
\text { used to validate the prediction, with models considered not overfitting if they had } \\
<10 \% \text { difference in training and testing AUROC curves. }\end{array}$ & NR & $\begin{array}{l}\text { AUC }(95 \% \mathrm{Cl}) \\
\text { Transfusion in } 3 \\
\text { hours: } 0.75(\mathrm{NR}) \\
\text { Rapid transfusion: } \\
0.81 \text { (NR) } \\
\text { Massive transfusion: } \\
0.88 \text { (NR) }\end{array}$ \\
\hline $\begin{array}{l}\text { Shackelford, } 2015 \\
\text { ×Mackenzie } 2015, \\
\text { Shackelford } 2015, \\
\text { and Yang } 2016 \\
\text { draw from the } \\
\text { same population, } \\
\text { but differ in } \\
\text { eligibility criteria, } \\
\text { number analyzed, } \\
\text { and measures } \\
\text { evaluated. } \\
\text { ×Mackenzie, } 2014 \\
\text { study population } \\
\text { included in } \\
\text { Shackelford, } 2015\end{array}$ & $\begin{array}{l}\text { Decision-assist } \\
\text { algorithm (Model } \\
\text { 10): HR, SBP, } \\
\text { pulse oximetry } \\
\text { features, and all } \\
\text { laboratory tests }\end{array}$ & \begin{tabular}{|l} 
Blood \\
transfusion (3 \\
hours, rapid, \\
massive)
\end{tabular} & $\begin{array}{l}\text { Stepwise logistic regression models using selected variables/combinations for each } \\
\text { decision assist algorithm, among: HR, SBP, pulse oximetry features, } 3 \text { sets of } \\
\text { laboratory tests (hematocrit, glucose, potassium, chloride, and bicarbonate; } \\
\text { prothrombin time and INR; or, Lactate). Forward selection using } \mathrm{p}=0.05 \text { and } \\
\text { backward selection using } \mathrm{p}=0.1 \text {. } 10 \text {-fold cross-validation repeated } 10 \text { times was } \\
\text { used to validate the prediction, with models considered not overfitting if they had } \\
<10 \% \text { difference in training and testing AUROC curves. }\end{array}$ & NR & $\begin{array}{l}\text { AUC }(95 \% \mathrm{Cl}) \\
\text { Transfusion in } 3 \\
\text { hours: } 0.84 \text { (NR) } \\
\text { Rapid transfusion: } \\
0.89 \text { (NR) } \\
\text { Massive transfusion: } \\
0.91 \text { (NR) }\end{array}$ \\
\hline
\end{tabular}




\begin{tabular}{|c|c|c|c|c|c|}
\hline $\begin{array}{l}\text { Author, Year } \\
\text { (See Appendix B } \\
\text { for complete } \\
\text { reference) }\end{array}$ & Measure & \begin{tabular}{|l} 
Indicator of \\
Serious Injury
\end{tabular} & Method for Constructing Multivariate Model & $\begin{array}{l}\text { Risk Estimates } \\
\text { Multivariate }\end{array}$ & $\begin{array}{l}\text { AUROC Multivariate } \\
\text { AUC }(95 \% \mathrm{Cl})\end{array}$ \\
\hline Shah, 2013 & $\begin{array}{l}\text { Lactate, EMS } \\
(\mathrm{POC})\end{array}$ & $\begin{array}{l}\text { Need for critical } \\
\text { care }\end{array}$ & $\begin{array}{l}\text { Multivariate logistic regression models using determinants having significant } \\
\text { univariate association }(p<0.20) \text { with the need for critical care. Interactions between } \\
\text { the variables were systematically searched and colinearity was considered when } \\
r>0.8 \text { (Spearman coefficient matrix correlation). Calibration of the model was tested } \\
\text { using the Hosmer-Lemeshow statistic. Out of hospital lactate was tested for normal } \\
\text { distribution by visual inspection of histograms and the Kolmogorov-Smirnov test and } \\
\text { was log-transformed for use in logistic regression models. }\end{array}$ & $\begin{array}{l}\text { AOR }(95 \% \mathrm{Cl}) \text {, per } 1 \text {-unit } \\
\text { increase in log- } \\
\text { transformed EMS lactate } \\
\text { Overall: } 1.56(0.97 \text { to } \\
2.50), p=0.06 \\
\text { Subset with normal EMS } \\
\text { vital signs and GCS: } 3.4 \\
(1.3 \text { to } 8.7), p=0.01\end{array}$ & NR \\
\hline St John, 2016 & $\begin{array}{l}\text { BD, ED: elderly } \\
\text { without TTA }\end{array}$ & $\begin{array}{l}\text { Severe } \\
\text { multisystem } \\
\text { injury }\end{array}$ & $\begin{array}{l}\text { Poisson regression with robust standard errors. Analysis looked at the strength of } \\
\text { association between severe multisystem injury and the variables: gender, ISS, GCS } \\
\text { on arrival, and mechanism of injury. ISS was included as a surrogate for overall } \\
\text { clinical assessment of severity of injury. }\end{array}$ & $\begin{array}{l}\text { Relative risk }(95 \% \mathrm{Cl}) \text { : } \\
1.07(0.91 \text { to } 1.25) \\
p=0.437\end{array}$ & NR \\
\hline St John, 2016 & $\begin{array}{l}\text { HR, ED: elderly } \\
\text { without TTA }\end{array}$ & $\begin{array}{l}\text { Severe } \\
\text { multisystem } \\
\text { injury }\end{array}$ & $\begin{array}{l}\text { Poisson regression with robust standard errors. Analysis looked at the strength of } \\
\text { association between severe multisystem injury and the variables: gender, ISS, GCS } \\
\text { on arrival, and mechanism of injury. ISS was included as a surrogate for overall } \\
\text { clinical assessment of severity of injury. }\end{array}$ & $\begin{array}{l}\text { Relative risk }(95 \% \mathrm{Cl}) \text { : } \\
0.83(0.72 \text { to } 0.97) \\
p=0.016 ; \text { per increase of } \\
10 \mathrm{bpm}\end{array}$ & NR \\
\hline St John, 2016 & $\begin{array}{l}\text { SBP, lowest } \\
\text { recorded ED: } \\
\text { elderly without } \\
\text { TTA }\end{array}$ & $\begin{array}{l}\text { Severe } \\
\text { multisystem } \\
\text { injury }\end{array}$ & $\begin{array}{l}\text { Poisson regression with robust standard errors. Analysis looked at the strength of } \\
\text { association between severe multisystem injury and the variables: gender, ISS, GCS } \\
\text { on arrival, and mechanism of injury. ISS was included as a surrogate for overall } \\
\text { clinical assessment of severity of injury. }\end{array}$ & $\begin{array}{l}\text { Relative risk }(95 \% \mathrm{Cl}) \\
0.76(0.64 \text { to } 0.91) \\
p=0.003 ; \text { per increase of } \\
10 \mathrm{~mm} \mathrm{Hg}\end{array}$ & NR \\
\hline Stanworth, 2010 & SBP, ED & $\begin{array}{l}\text { Massive } \\
\text { transfusion }\end{array}$ & $\begin{array}{l}\text { Logistic regression to predict massive transfusion with consideration of all } \\
\text { candidate predictors potentially available on admission and thought to be associated } \\
\text { with transfusion, but excluding center-specific effects. A fractional polynomial was } \\
\text { used to relate the odds of death to PRBCs received by logistic regression. Missing } \\
\text { data addressed through multiple imputation. Continuous variables underwent } \\
\text { normalizing transformations. Backward elimination with p>0.1 was used to select } \\
\text { variables. The same model was also fitted using complete data without imputation } \\
\text { (excluding Amsterdam dataset), with results consistent with the multiple-imputation } \\
\text { analysis. }\end{array}$ & $\begin{array}{l}\text { AOR }(95 \% \text { Cl): } 0.98 \\
(0.97 \text { to } 0.98) \\
\text { Log-odds ratio (SEM): - } \\
0.02(0.003)\end{array}$ & NR \\
\hline Stanworth, 2010 & $\mathrm{BD}, \mathrm{ED}$ & $\begin{array}{l}\text { Massive } \\
\text { Transfusion }\end{array}$ & $\begin{array}{l}\text { Logistic regression to predict massive transfusion with consideration of all } \\
\text { candidate predictors potentially available on admission and thought to be associated } \\
\text { with transfusion, but excluding center-specific effects. A fractional polynomial was } \\
\text { used to relate the odds of death to PRBCs received by logistic regression. Missing } \\
\text { data addressed through multiple imputation. Continuous variables underwent } \\
\text { normalizing transformations. Backward elimination with p>0.1 was used to select } \\
\text { variables. The same model was also fitted using complete data without imputation } \\
\text { (excluding Amsterdam dataset), with results consistent with the multiple-imputation } \\
\text { analysis. }\end{array}$ & $\begin{array}{l}\text { AOR }(95 \% \mathrm{Cl}): 240(91 \\
\text { to } 639) \\
\text { Log-odds ratio }(\mathrm{SEM}): \\
5.48(0.5)\end{array}$ & NR \\
\hline
\end{tabular}




\begin{tabular}{|c|c|c|c|c|c|}
\hline $\begin{array}{l}\text { Author, Year } \\
\text { (See Appendix B } \\
\text { for complete } \\
\text { reference) }\end{array}$ & Measure & $\begin{array}{l}\text { Indicator of } \\
\text { Serious Injury }\end{array}$ & Method for Constructing Multivariate Model & $\begin{array}{l}\text { Risk Estimates } \\
\text { Multivariate }\end{array}$ & $\begin{array}{l}\text { AUROC Multivariate } \\
\text { AUC }(95 \% \mathrm{Cl})\end{array}$ \\
\hline Stanworth, 2010 & $\begin{array}{l}\text { Prediction model } \\
\text { for massive } \\
\text { transfusion: uses } \\
\text { age, time to ED, } \\
\text { penetrating } \\
\text { injury, SBP, BD } \\
\text { and prothrombin } \\
\text { time } \\
\text { External } \\
\text { validation dataset }\end{array}$ & $\begin{array}{l}\text { Massive } \\
\text { transfusion }\end{array}$ & $\begin{array}{l}\text { Model components: Vage; In(time to ED); penetrating injury; SBP; In(25 + BD); } \\
1 /[\text { In(prothrombin time2)]; intercept. } \\
\text { Logistic regression to predict massive transfusion with consideration of all } \\
\text { candidate predictors potentially available on admission and thought to be associated } \\
\text { with transfusion, but excluding center-specific effects. A fractional polynomial was used } \\
\text { to relate the odds of death to PRBCs received by logistic regression. Missing data } \\
\text { addressed through multiple imputation. Continuous variables underwent normalizing } \\
\text { transformations. Backward elimination with p>0.1 was used to select variables. The } \\
\text { same model was also fitted using complete data without imputation (excluding } \\
\text { Amsterdam dataset), with results consistent with the multiple-imputation analysis. }\end{array}$ & NR & $\begin{array}{l}\text { AUC (95\% Cl): } 0.81 \\
\text { (NR) } \\
\text { Sensitivity } 90 \% \\
\text { Specificity: } 50 \% \\
\text { Correct classification } \\
\text { rate: } 58 \%\end{array}$ \\
\hline Stanworth, 2010 & $\begin{array}{l}\text { Prediction model } \\
\text { for massive } \\
\text { transfusion: uses } \\
\text { age, time to ED, } \\
\text { penetrating } \\
\text { injury, SBP, BD } \\
\text { and prothrombin } \\
\text { time. Internal } \\
\text { validation } \\
\text { datasets }\end{array}$ & $\begin{array}{l}\text { Massive } \\
\text { transfusion }\end{array}$ & $\begin{array}{l}\text { Model components: Vage; In(time to ED); penetrating injury; SBP; In( } 25+\mathrm{BD}) ; \\
1 /[\text { In(prothrombin time2)]; intercept. } \\
\text { Logistic regression to predict massive transfusion with consideration of all } \\
\text { candidate predictors potentially available on admission and thought to be associated } \\
\text { with transfusion, but excluding center-specific effects. A fractional polynomial was used } \\
\text { to relate the odds of death to PRBCs received by logistic regression. Missing data } \\
\text { addressed through multiple imputation. Continuous variables underwent normalizing } \\
\text { transformations. Backward elimination with p>0.1 was used to select variables. The } \\
\text { same model was also fitted using complete data without imputation (excluding } \\
\text { Amsterdam dataset), with results consistent with the multiple-imputation analysis. }\end{array}$ & NR & $\begin{array}{l}\text { AUC (95\% Cl): } 0.89 \\
\text { (0.87 to 0.92) } \\
\text { Sensitivity } 90 \% \\
\text { Specificity: } 70 \%\end{array}$ \\
\hline Vandromme, 2011 & SI, ED & $\begin{array}{l}\text { Massive } \\
\text { Transfusion }\end{array}$ & $\begin{array}{l}\text { Proportional hazards regression assuming an equal time at risk for each patient was } \\
\text { used to estimate risk ratios and } 95 \% \text { Cls for the association between } \mathrm{SI} \text { and } \\
\text { massive transfusion using } \mathrm{SI}>0.5 \text { to } 0.7 \text { as the referent category. }\end{array}$ & $\begin{array}{l}\text { Adjusted Risk Ratio } \\
(95 \% \\
\mathrm{Cl}) \\
\mathrm{SI}>0.9 \text { to } 1.1: 3.49 \\
(2.34 \text { to } 5.20) \\
\mathrm{SI}>1.1 \text { to } 1.3: 9.67\end{array}$ & NR \\
\hline Vandromme, 2011 & SI, EMS & $\begin{array}{l}\text { Massive } \\
\text { Transfusion }\end{array}$ & $\begin{array}{l}\text { Proportional hazards regression assuming an equal time at risk for each patient was } \\
\text { used to estimate risk ratios and } 95 \% \text { Cls for the association between } \mathrm{SI} \text { and } \\
\text { massive transfusion using } \mathrm{SI}>0.5 \text { to } 0.7 \text { as the referent category. }\end{array}$ & $\begin{array}{l}\text { Adjusted Risk Ratio } \\
(95 \% \\
\mathrm{Cl}) \\
\mathrm{SI}>0.9 \text { to } 1.1: 1.61 \\
(1.13 \text { to } 2.31) \\
\mathrm{SI}>1.1 \text { to } 1.3: 5.57 \\
\end{array}$ & NR \\
\hline $\begin{array}{l}\text { Vandromme, } \\
2011 b\end{array}$ & $\begin{array}{l}\text { Lactate } \geq 5: \\
\text { developmental } \\
\text { cohort }\end{array}$ & $\begin{array}{l}\text { Massive } \\
\text { transfusion }\end{array}$ & $\begin{array}{l}\text { Logistic regression using the developmental cohort. Variables entered into the model } \\
\text { based on magnitude of predictive ability identified on univariate analysis (most } \\
\text { predictive entered first). The Hosmer-Lemeshow goodness-of-fit test was used to } \\
\text { determine the best-fit model. Statistical weighting were applied to account for } \\
\text { oversampling of the massive transfusion population. The statistical weight for each } \\
\text { patient was the inverse of the probability of selection based on the time period } \\
\text { (developmental or validation cohorts) and number of PRBC units. } \\
\text { The best-fit model is comprised of these dichotomized variables: lactate } \geq 5 \text {, HR } \\
>105, \mathrm{Hb} \leq 11 \text {, INR }>1.5 \text {, SBP }<110 \text {. }\end{array}$ & $\begin{array}{l}\text { AOR }(95 \% \mathrm{Cl}): \\
\text { developmental cohort: } \\
3.13(1.96 \text { to } 5.00) \\
\text { validation cohort: } \\
3.57 \text { (1.89 to } 6.67)\end{array}$ & NR \\
\hline
\end{tabular}




\begin{tabular}{|c|c|c|c|c|c|}
\hline $\begin{array}{l}\text { Author, Year } \\
\text { (See Appendix B } \\
\text { for complete } \\
\text { reference) }\end{array}$ & Measure & $\begin{array}{l}\text { Indicator of } \\
\text { Serious Injury }\end{array}$ & Method for Constructing Multivariate Model & $\begin{array}{l}\text { Risk Estimates } \\
\text { Multivariate }\end{array}$ & $\begin{array}{l}\text { AUROC Multivariate } \\
\text { AUC }(95 \% \mathrm{Cl})\end{array}$ \\
\hline $\begin{array}{l}\text { Vandromme, } \\
2011 b\end{array}$ & $\begin{array}{l}\text { SBP < 110: } \\
\text { developmental } \\
\text { cohort }\end{array}$ & $\begin{array}{l}\text { Massive } \\
\text { Transfusion }\end{array}$ & $\begin{array}{l}\text { Logistic regression using the developmental cohort. Variables entered into the model } \\
\text { based on magnitude of predictive ability identified on univariate analysis (most } \\
\text { predictive entered first). The Hosmer-Lemeshow goodness-of-fit test was used to } \\
\text { determine the best-fit model. Statistical weighting were applied to account for } \\
\text { oversampling of the massive transfusion population. The statistical weight for each } \\
\text { patient was the inverse of the probability of selection based on the time period } \\
\text { (developmental or validation cohorts) and number of PRBC units. } \\
\text { The best-fit model is comprised of these dichotomized variables: lactate } \geq 5 \text {, HR } \\
>105, \mathrm{Hb} \leq 11 \text {, INR }>1.5 \text {, SBP }<110 \text {. }\end{array}$ & $\begin{array}{l}\text { AOR }(95 \% \mathrm{Cl}): \\
\text { Developmental cohort: } \\
2.08(1.27 \text { to } 3.43) \\
\text { Validation cohort: } 35.06 \\
\text { (19.06 to } 64.47)\end{array}$ & NR \\
\hline $\begin{array}{l}\text { Vandromme, } \\
2011 b\end{array}$ & $\begin{array}{l}\text { HR > 105: } \\
\text { developmental } \\
\text { cohort }\end{array}$ & \begin{tabular}{|l} 
Massive \\
Transfusion
\end{tabular} & $\begin{array}{l}\text { Logistic regression using the developmental cohort. Variables entered into the model } \\
\text { based on magnitude of predictive ability identified on univariate analysis (most } \\
\text { predictive entered first). The Hosmer-Lemeshow goodness-of-fit test was used to } \\
\text { determine the best-fit model. Statistical weighting were applied to account for } \\
\text { oversampling of the massive transfusion population. The statistical weight for each } \\
\text { patient was the inverse of the probability of selection based on the time period } \\
\text { (developmental or validation cohorts) and number of PRBC units. } \\
\text { The best-fit model is comprised of these dichotomized variables: lactate } \geq 5 \text {, HR } \\
>105, \mathrm{Hb} \leq 11 \text {, INR }>1.5 \text {, SBP }<110 \text {. }\end{array}$ & $\begin{array}{l}\text { AOR }(95 \% \mathrm{Cl}): \\
\text { Developmental cohort: } \\
3.55(2.22 \text { to } 5.66) \\
\text { Validation cohort: } 3.51 \\
(1.81 \text { to } 6.80)\end{array}$ & NR \\
\hline $\begin{array}{l}\text { Vandromme, } \\
2011 b\end{array}$ & \begin{tabular}{|l|} 
Prediction model \\
(best-fit): Lactate \\
$\geq 5, \mathrm{HR}>105, \mathrm{Hb}$ \\
$\leq 11, \mathrm{INR}>1.5$ \\
$\mathrm{SBP}<110$ \\
developmental \\
cohort
\end{tabular} & \begin{tabular}{|l} 
Massive \\
Transfusion
\end{tabular} & $\begin{array}{l}\text { Logistic regression using the developmental cohort. Variables entered into the model } \\
\text { based on magnitude of predictive ability identified on univariate analysis (most } \\
\text { predictive entered first). The Hosmer-Lemeshow goodness-of-fit test was used to } \\
\text { determine the best-fit model. Statistical weighting were applied to account for } \\
\text { oversampling of the massive transfusion population. The statistical weight for each } \\
\text { patient was the inverse of the probability of selection based on the time period } \\
\text { (developmental or validation cohorts) and number of PRBC units. } \\
\text { The best-fit model is comprised of these dichotomized variables: lactate } \geq 5 \text {, HR } \\
>105, \mathrm{Hb} \leq 11 \text {, INR }>1.5 \text {, SBP }<110 \text {. }\end{array}$ & NR & $0.91(\mathrm{NR})$ \\
\hline $\begin{array}{l}\text { Vandromme, } \\
2011 b\end{array}$ & \begin{tabular}{|l|} 
Prediction model \\
any 4 of 5 \\
positive \\
predictors \\
(highest $A \cup C$ ) \\
- Lactate $\geq 5, \mathrm{HR}$ \\
$>105, \mathrm{Hb} \leq 11$ \\
$\mathrm{INR}>1.5$, or SBP \\
$<110$
\end{tabular} & \begin{tabular}{|l} 
Massive \\
Transfusion
\end{tabular} & $\begin{array}{l}\text { Logistic regression using the developmental cohort. Variables entered into the model } \\
\text { based on magnitude of predictive ability identified on univariate analysis (most } \\
\text { predictive entered first). The Hosmer-Lemeshow goodness-of-fit test was used to } \\
\text { determine the best-fit model. Statistical weighting were applied to account for } \\
\text { oversampling of the massive transfusion population. The statistical weight for each } \\
\text { patient was the inverse of the probability of selection based on the time period } \\
\text { (developmental or validation cohorts) and number of PRBC units. } \\
\text { The best-fit model is comprised of these dichotomized variables: lactate } \geq 5 \text {, HR } \\
>105, \mathrm{Hb} \leq 11 \text {, INR }>1.5 \text {, SBP }<110 \text {. }\end{array}$ & NR & $\begin{array}{l}\text { AUC }(95 \% \mathrm{Cl}): 0.90 \\
\text { (NR) } \\
\text { Developmental cohort } \\
\text { Sensitivity } 27.8 \%, \\
\text { specificity } 99.2 \%, \\
\text { PPV } 43.9 \%, \mathrm{NPV} \\
98.4 \% \\
\text { Validation cohort } \\
\text { Sensitivity } 26.9 \%,\end{array}$ \\
\hline
\end{tabular}




\begin{tabular}{|c|c|c|c|c|c|}
\hline $\begin{array}{l}\text { Author, Year } \\
\text { (See Appendix B } \\
\text { for complete } \\
\text { reference) }\end{array}$ & Measure & $\begin{array}{l}\text { Indicator of } \\
\text { Serious Injury }\end{array}$ & Method for Constructing Multivariate Model & $\begin{array}{l}\text { Risk Estimates } \\
\text { Multivariate }\end{array}$ & $\begin{array}{l}\text { AUROC Multivariate } \\
\text { AUC }(95 \% \mathrm{Cl})\end{array}$ \\
\hline $\begin{array}{l}\text { Vandromme, } \\
2011 b\end{array}$ & \begin{tabular}{|l|} 
Prediction model \\
any 3 of 5 \\
positive \\
predictors (best \\
predictive model) \\
- Lactate $\geq 5, \mathrm{HR}$ \\
$>105, \mathrm{Hb} \leq 11$ \\
$\mathrm{INR}>1.5$, or SBP \\
$<110$
\end{tabular} & $\begin{array}{l}\text { Massive } \\
\text { Transfusion }\end{array}$ & $\begin{array}{l}\text { Logistic regression using the developmental cohort. Variables entered into the model } \\
\text { based on magnitude of predictive ability identified on univariate analysis (most } \\
\text { predictive entered first). The Hosmer-Lemeshow goodness-of-fit test was used to } \\
\text { determine the best-fit model. Statistical weighting were applied to account for } \\
\text { oversampling of the massive transfusion population. The statistical weight for each } \\
\text { patient was the inverse of the probability of selection based on the time period } \\
\text { (developmental or validation cohorts) and number of PRBC units. } \\
\text { The best-fit model is comprised of these dichotomized variables: lactate } \geq 5 \text {, HR } \\
>105, \mathrm{Hb} \leq 11 \text {, INR }>1.5 \text {, SBP }<110 \text {. }\end{array}$ & NR & $\begin{array}{l}\text { AUC: NR } \\
\text { Developmental cohort: } \\
\text { Sensitivity } 53.4 \% \text {, } \\
\text { specificity } 97.6 \% \text {, } \\
\text { PPV 33.4\%, NPV } \\
\text { 98.9\% } \\
\text { Validation cohort: } \\
\text { Sensitivity } 61.3 \%, \\
\text { specificity } 96.0 \%,\end{array}$ \\
\hline Williams, 2016 & $\begin{array}{l}\text { End-tidal CO2 } \\
(\text { ETCO2) }\end{array}$ & $\begin{array}{l}\text { Severe injury } \\
\text { Composite }\end{array}$ & $\begin{array}{l}\text { Multivariable logistic regression analysis to determine if ETCO2 added predictive } \\
\text { ability for primary outcome when combined with age, GCS, SBP or SI. ROC curves } \\
\text { were generated and assessed by paired comparison of resulting AUCs. }\end{array}$ & $\begin{array}{l}\text { AOR (95\% Cl): } 1.06 \\
(1.01-1.13)\end{array}$ & NR \\
\hline Williams, 2016 & $\begin{array}{l}\text { Predictive model } \\
\text { using end-tidal } \\
\text { CO2 (ETCO2) } \\
\text { plus EMS vital }\end{array}$ & $\begin{array}{l}\text { Severe injury } \\
\text { Composite }\end{array}$ & $\begin{array}{l}\text { Multivariable logistic regression analysis to determine if ETCO2 added predictive } \\
\text { ability for primary outcome when combined with age, GCS, SBP or SI. ROC curves } \\
\text { were generated and assessed by paired comparison of resulting AUCs. }\end{array}$ & NR & $0.70(\mathrm{NR})$ \\
\hline Williams, 2016 & $\begin{array}{l}\text { Predictive model } \\
\text { using EMS vital } \\
\text { signs only (age, }\end{array}$ & $\begin{array}{l}\text { Severe injury } \\
\text { Composite }\end{array}$ & $\begin{array}{l}\text { Multivariable logistic regression analysis to determine if ETCO2 added predictive } \\
\text { ability for primary outcome when combined with age, GCS, SBP or SI. ROC curves } \\
\text { were generated and assessed by paired comparison of resulting AUCs. }\end{array}$ & NR & $0.68(\mathrm{NR})$ \\
\hline Woodford, 2012 & $\begin{array}{l}\text { GCS + Oxygen } \\
\text { saturation }\end{array}$ & Mortality & $\begin{array}{l}\text { Multivariable logistic regression using relevant indices of injury from the VSDR data } \\
\text { and trauma registry to determine possible predictive factors for mortality. }\end{array}$ & NR & $0.88(\mathrm{NR})$ \\
\hline $\begin{array}{l}\text { Yang, } 2016 \\
\text { *Mackenzie 2015, } \\
\text { Shackelford 2015, } \\
\text { and Yang } 2016 \\
\text { draw from the } \\
\text { same population, } \\
\text { but differ in } \\
\text { eligibility criteria, } \\
\text { number analyzed, } \\
\text { and measures } \\
\text { evaluated. }\end{array}$ & $\begin{array}{l}\text { HR model and } \\
\text { lab } \mathrm{Hb}\end{array}$ & \begin{tabular}{|l|} 
Blood \\
transfusion, 1-3 \\
hours after \\
admission
\end{tabular} & \begin{tabular}{|l|} 
Multivariate logistic regression models using step-wise feature selection. Forward \\
selection included features with Wald $x 2$ test $\leq 0.2$, and those with significance level \\
$>0.3$ removed by backward selection. 10 -fold cross-validation was repeated 10 times \\
with stratified sampling to examine prediction using previously unseen data.
\end{tabular} & NR & $\begin{array}{l}\text { AUC }(95 \% \mathrm{Cl}): 0.72 \\
(0.60 \text { to } 0.84) \\
\text { sensitivity: } 70 \% \\
\text { specificity: } 73 \%\end{array}$ \\
\hline
\end{tabular}




\begin{tabular}{|c|c|c|c|c|c|}
\hline $\begin{array}{l}\text { Author, Year } \\
\text { (See Appendix B } \\
\text { for complete } \\
\text { reference) }\end{array}$ & Measure & \begin{tabular}{|l|} 
Indicator of \\
Serious Injury
\end{tabular} & Method for Constructing Multivariate Model & $\begin{array}{l}\text { Risk Estimates } \\
\text { Multivariate }\end{array}$ & $\begin{array}{l}\text { AUROC Multivariate } \\
\text { AUC }(95 \% \mathrm{CI})\end{array}$ \\
\hline $\begin{array}{l}\text { Yang, } 2016 \\
\text { *Mackenzie 2015, } \\
\text { Shackelford } 2015, \\
\text { and Yang } 2016 \\
\text { draw from the } \\
\text { same population, } \\
\text { but differ in } \\
\text { eligibility criteria, } \\
\text { number analyzed, } \\
\text { and measures } \\
\text { evaluated. }\end{array}$ & $\begin{array}{l}\text { HR model and } \\
\text { lab Hb } \\
\text { (HR model: age, } \\
\text { sex, EMS HR) }\end{array}$ & Mortality & \begin{tabular}{|l|} 
Multivariate logistic regression models using step-wise feature selection. Forward \\
selection included features with Wald $x 2$ test $\leq 0.2$, and those with significance level \\
$>0.3$ removed by backward selection. 10 -fold cross-validation was repeated 10 times \\
with stratified sampling to examine prediction using previously unseen data.
\end{tabular} & NR & $\begin{array}{l}\text { AUC }(95 \% \mathrm{Cl}): 0.83 \\
\text { ( } 0.73 \text { to } 0.93) \\
\text { sensitivity: } 83 \% \\
\text { specificity: } 71 \%\end{array}$ \\
\hline $\begin{array}{l}\text { Yang, } 2016 \\
\text { *Mackenzie 2015, } \\
\text { Shackelford 2015, } \\
\text { and Yang } 2016 \\
\text { draw from the } \\
\text { same population, } \\
\text { but differ in } \\
\text { eligibility criteria, } \\
\text { number analyzed, } \\
\text { and measures } \\
\text { evaluated. }\end{array}$ & $\begin{array}{l}\text { HR model and } \\
\text { non-invasive Hb } \\
(\mathrm{SpHb}) \\
\text { (HR model: age, } \\
\text { sex, EMS HR) }\end{array}$ & \begin{tabular}{|l|} 
Blood \\
transfusion, 1-3 \\
hours after \\
admission
\end{tabular} & $\begin{array}{l}\text { Multivariate logistic regression models using step-wise feature selection. Forward } \\
\text { selection included features with Wald } x 2 \text { test } \leq 0.2 \text {, and those with significance level } \\
>0.3 \text { removed by backward selection. } 10 \text {-fold cross-validation was repeated } 10 \text { times } \\
\text { with stratified sampling to examine prediction using previously unseen data. }\end{array}$ & NR & $\begin{array}{l}\text { AUC (95\% Cl): } 0.65 \\
\text { ( } 0.53 \text { to } 0.77) \\
\text { sensitivity: } 40 \% \\
\text { specificity: } 86 \%\end{array}$ \\
\hline $\begin{array}{l}\text { Yang, } 2016 \\
\text { *Mackenzie 2015, } \\
\text { Shackelford 2015, } \\
\text { and Yang } 2016 \\
\text { draw from the } \\
\text { same population, } \\
\text { but differ in } \\
\text { eligibility criteria, } \\
\text { number analyzed, } \\
\text { and measures } \\
\text { evaluated. }\end{array}$ & $\begin{array}{l}\text { HR model and } \\
\text { non-invasive Hb } \\
(\mathrm{SpHb}) \\
\text { (HR model: age, } \\
\text { sex, EMS HR) }\end{array}$ & Mortality & $\begin{array}{l}\text { Multivariate logistic regression models using step-wise feature selection. Forward } \\
\text { selection included features with Wald } x 2 \text { test } \leq 0.2 \text {, and those with significance level } \\
>0.3 \text { removed by backward selection. } 10 \text {-fold cross-validation was repeated } 10 \text { times } \\
\text { with stratified sampling to examine prediction using previously unseen data. }\end{array}$ & NR & $\begin{array}{l}\text { AUC }(95 \% \mathrm{Cl}): 0.85 \\
\text { ( } 0.74 \text { to } 0.96) \\
\text { sensitivity: } 83 \% \\
\text { specificity: } 74 \%\end{array}$ \\
\hline
\end{tabular}




\begin{tabular}{|c|c|c|c|c|c|}
\hline $\begin{array}{l}\text { Author, Year } \\
\text { (See Appendix B } \\
\text { for complete } \\
\text { reference) }\end{array}$ & Measure & \begin{tabular}{|l|} 
Indicator of \\
Serious Injury
\end{tabular} & Method for Constructing Multivariate Model & $\begin{array}{l}\text { Risk Estimates } \\
\text { Multivariate }\end{array}$ & $\begin{array}{l}\text { AUROC Multivariate } \\
\text { AUC }(95 \% \mathrm{Cl})\end{array}$ \\
\hline $\begin{array}{l}\text { Yang, } 2016 \\
\text { *Mackenzie 2015, } \\
\text { Shackelford 2015, } \\
\text { and Yang } 2016 \\
\text { draw from the } \\
\text { same population, } \\
\text { but differ in } \\
\text { eligibility criteria, } \\
\text { number analyzed, } \\
\text { and measures } \\
\text { evaluated. }\end{array}$ & \begin{tabular}{|l|} 
HR model and \\
other lab tests \\
(HR model: age, \\
sex, EMS HR)
\end{tabular} & \begin{tabular}{|l|} 
Blood \\
transfusion, 1-3 \\
hours after \\
admission
\end{tabular} & $\begin{array}{l}\text { Multivariate logistic regression models using step-wise feature selection. Forward } \\
\text { selection included features with Wald } x 2 \text { test } \leq 0.2 \text {, and those with significance level } \\
>0.3 \text { removed by backward selection. } 10 \text {-fold cross-validation was repeated } 10 \text { times } \\
\text { with stratified sampling to examine prediction using previously unseen data. }\end{array}$ & NR & $\begin{array}{l}\text { AUC }(95 \% \mathrm{Cl}): 0.88 \\
\text { ( } 0.81 \text { to } 0.96) \\
\text { sensitivity: } 85 \% \\
\text { specificity: } 84 \%\end{array}$ \\
\hline $\begin{array}{l}\text { Yang, } 2016 \\
\text { *Mackenzie 2015, } \\
\text { Shackelford 2015, } \\
\text { and Yang } 2016 \\
\text { draw from the } \\
\text { same population, } \\
\text { but differ in } \\
\text { eligibility criteria, } \\
\text { number analyzed, } \\
\text { and measures } \\
\text { evaluated. }\end{array}$ & \begin{tabular}{l|} 
HR model and \\
other lab tests \\
(HR model: age, \\
sex, EMS HR)
\end{tabular} & Mortality & $\begin{array}{l}\text { Multivariate logistic regression models using step-wise feature selection. Forward } \\
\text { selection included features with Wald } x 2 \text { test } \leq 0.2 \text {, and those with significance level } \\
>0.3 \text { removed by backward selection. } 10 \text {-fold cross-validation was repeated } 10 \text { times } \\
\text { with stratified sampling to examine prediction using previously unseen data. }\end{array}$ & NR & $\begin{array}{l}\text { AUC }(95 \% \mathrm{Cl}): 0.86 \\
\text { ( } 0.76 \text { to } 0.96) \\
\text { sensitivity: } 83 \% \\
\text { specificity: } 75 \%\end{array}$ \\
\hline $\begin{array}{l}\text { Yang, } 2016 \\
\text { *Mackenzie 2015, } \\
\text { Shackelford 2015, } \\
\text { and Yang } 2016 \\
\text { draw from the } \\
\text { same population, } \\
\text { but differ in } \\
\text { eligibility criteria, } \\
\text { number analyzed, } \\
\text { and measures } \\
\text { evaluated. }\end{array}$ & \begin{tabular}{|l|} 
HR model with \\
non-invasive $\mathrm{Hb}$ \\
$(\mathrm{SpHb})$ and other \\
lab tests \\
(HR model: age, \\
sex, EMS HR)
\end{tabular} & \begin{tabular}{|l|} 
Blood \\
transfusion, 1-3 \\
hours after \\
admission
\end{tabular} & $\begin{array}{l}\text { Multivariate logistic regression models using step-wise feature selection. Forward } \\
\text { selection included features with Wald } x 2 \text { test } \leq 0.2 \text {, and those with significance level } \\
>0.3 \text { removed by backward selection. } 10 \text {-fold cross-validation was repeated } 10 \text { times } \\
\text { with stratified sampling to examine prediction using previously unseen data. }\end{array}$ & NR & $\begin{array}{l}\text { AUC }(95 \% \mathrm{Cl}): 0.89 \\
\text { ( } 0.81 \text { to } 0.96) \\
\text { sensitivity: } 75 \% \\
\text { specificity: } 91 \%\end{array}$ \\
\hline
\end{tabular}




\begin{tabular}{|c|c|c|c|c|c|}
\hline $\begin{array}{l}\text { Author, Year } \\
\text { (See Appendix B } \\
\text { for complete } \\
\text { reference) }\end{array}$ & Measure & \begin{tabular}{|l|} 
Indicator of \\
Serious Injury
\end{tabular} & Method for Constructing Multivariate Model & $\begin{array}{l}\text { Risk Estimates } \\
\text { Multivariate }\end{array}$ & $\begin{array}{l}\text { AUROC Multivariate } \\
\text { AUC }(95 \% \mathrm{CI})\end{array}$ \\
\hline $\begin{array}{l}\text { Yang, } 2016 \\
\text { *Mackenzie 2015, } \\
\text { Shackelford 2015, } \\
\text { and Yang } 2016 \\
\text { draw from the } \\
\text { same population, } \\
\text { but differ in } \\
\text { eligibility criteria, } \\
\text { number analyzed, } \\
\text { and measures } \\
\text { evaluated. }\end{array}$ & $\begin{array}{l}\text { HR model with } \\
\text { non-invasive Hb } \\
(\mathrm{SpHb}) \text { and other } \\
\text { lab tests } \\
(\mathrm{HR} \text { model: age, } \\
\text { sex, EMS HR) }\end{array}$ & Mortality & $\begin{array}{l}\text { Multivariate logistic regression models using step-wise feature selection. Forward } \\
\text { selection included features with Wald } x 2 \text { test } \leq 0.2 \text {, and those with significance level } \\
>0.3 \text { removed by backward selection. } 10 \text {-fold cross-validation was repeated } 10 \text { times } \\
\text { with stratified sampling to examine prediction using previously unseen data. }\end{array}$ & NR & $\begin{array}{l}\text { AUC }(95 \% \mathrm{Cl}): 0.92 \\
(0.85 \text { to } 0.98) \\
\text { sensitivity: } 100 \% \\
\text { specificity: } 67 \%\end{array}$ \\
\hline $\begin{array}{l}\text { Yang, } 2016 \\
\\
\star \text { Mackenzie 2015, } \\
\text { Shackelford 2015, } \\
\text { and Yang } 2016 \\
\text { draw from the } \\
\text { same population, } \\
\text { but differ in } \\
\text { eligibility criteria, } \\
\text { number analyzed, } \\
\text { and measures } \\
\text { evaluated. }\end{array}$ & $\begin{array}{l}\text { HR model: age, } \\
\text { sex, EMS HR }\end{array}$ & \begin{tabular}{|l|} 
Blood \\
transfusion, 1-3 \\
hours after \\
admission
\end{tabular} & $\begin{array}{l}\text { Multivariate logistic regression models using step-wise feature selection. Forward } \\
\text { selection included features with Wald } x 2 \text { test } \leq 0.2 \text {, and those with significance level } \\
>0.3 \text { removed by backward selection. } 10 \text {-fold cross-validation was repeated } 10 \text { times } \\
\text { with stratified sampling to examine prediction using previously unseen data. }\end{array}$ & NR & $\begin{array}{l}\text { AUC }(95 \% \mathrm{Cl}): 0.64 \\
(0.52 \text { to } 0.76) \\
\text { sensitivity: } 95 \% \\
\text { specificity: } 29 \%\end{array}$ \\
\hline $\begin{array}{l}\text { Yang, } 2016 \\
\text { *Mackenzie 2015, } \\
\text { Shackelford 2015, } \\
\text { and Yang } 2016 \\
\text { draw from the } \\
\text { same population, } \\
\text { but differ in } \\
\text { eligibility criteria, } \\
\text { number analyzed, } \\
\text { and measures } \\
\text { evaluated. }\end{array}$ & $\begin{array}{l}\text { HR model: age, } \\
\text { sex, EMS HR }\end{array}$ & Mortality & $\begin{array}{l}\text { Multivariate logistic regression models using step-wise feature selection. Forward } \\
\text { selection included features with Wald } x 2 \text { test } \leq 0.2 \text {, and those with significance level } \\
>0.3 \text { removed by backward selection. } 10 \text {-fold cross-validation was repeated } 10 \text { times } \\
\text { with stratified sampling to examine prediction using previously unseen data. }\end{array}$ & NR & $\begin{array}{l}\text { AUC }(95 \% \mathrm{Cl}): 0.79 \\
(0.67 \text { to } 0.91) \\
\text { sensitivity: } 67 \% \\
\text { specificity: } 83 \%\end{array}$ \\
\hline
\end{tabular}




\begin{tabular}{|c|c|c|c|c|c|}
\hline $\begin{array}{l}\text { Author, Year } \\
\text { (See Appendix B } \\
\text { for complete } \\
\text { reference) }\end{array}$ & Measure & \begin{tabular}{|l|} 
Indicator of \\
Serious Injury
\end{tabular} & Method for Constructing Multivariate Model & $\begin{array}{l}\text { Risk Estimates } \\
\text { Multivariate }\end{array}$ & $\begin{array}{l}\text { AUROC Multivariate } \\
\text { AUC }(95 \% \mathrm{CI})\end{array}$ \\
\hline $\begin{array}{l}\text { Yang, } 2016 \\
\text { *Mackenzie 2015, } \\
\text { Shackelford 2015, } \\
\text { and Yang } 2016 \\
\text { draw from the } \\
\text { same population, } \\
\text { but differ in } \\
\text { eligibility criteria, } \\
\text { number analyzed, } \\
\text { and measures } \\
\text { evaluated. }\end{array}$ & $\begin{array}{l}\text { SI model and lab } \\
\mathrm{Hb} \\
\text { (SI model: age, } \\
\text { sex, EMS SI) }\end{array}$ & \begin{tabular}{|l|} 
Blood \\
transfusion, 1-3 \\
hours after \\
admission
\end{tabular} & $\begin{array}{l}\text { Multivariate logistic regression models using step-wise feature selection. Forward } \\
\text { selection included features with Wald } x 2 \text { test } \leq 0.2 \text {, and those with significance level } \\
>0.3 \text { removed by backward selection. } 10 \text {-fold cross-validation was repeated } 10 \text { times } \\
\text { with stratified sampling to examine prediction using previously unseen data. }\end{array}$ & NR & $\begin{array}{l}\text { AUC }(95 \% \mathrm{Cl}): 0.78 \\
(0.65 \text { to } 0.92) \\
\text { sensitivity: } 75 \% \\
\text { specificity: } 85 \%\end{array}$ \\
\hline $\begin{array}{l}\text { Yang, } 2016 \\
\star \text { *Mackenzie 2015, } \\
\text { Shackelford 2015, } \\
\text { and Yang } 2016 \\
\text { draw from the } \\
\text { same population, } \\
\text { but differ in } \\
\text { eligibility criteria, } \\
\text { number analyzed, } \\
\text { and measures } \\
\text { evaluated. }\end{array}$ & $\begin{array}{l}\text { SI model and lab } \\
\mathrm{Hb} \\
\text { (SI model: age, } \\
\text { sex, EMS SI) }\end{array}$ & Mortality & $\begin{array}{l}\text { Multivariate logistic regression models using step-wise feature selection. Forward } \\
\text { selection included features with Wald } x 2 \text { test } \leq 0.2 \text {, and those with significance level } \\
>0.3 \text { removed by backward selection. } 10 \text {-fold cross-validation was repeated } 10 \text { times } \\
\text { with stratified sampling to examine prediction using previously unseen data. }\end{array}$ & NR & $\begin{array}{l}\text { AUC }(95 \% \mathrm{Cl}): 0.78 \\
(0.63 \text { to } 0.93) \\
\text { sensitivity: } 75 \% \\
\text { specificity: } 78 \%\end{array}$ \\
\hline $\begin{array}{l}\text { Yang, } 2016 \\
\text { ×Mackenzie 2015, } \\
\text { Shackelford 2015, } \\
\text { and Yang } 2016 \\
\text { draw from the } \\
\text { same population, } \\
\text { but differ in } \\
\text { eligibility criteria, } \\
\text { number analyzed, } \\
\text { and measures } \\
\text { evaluated. }\end{array}$ & $\begin{array}{l}\text { SI model and } \\
\text { non-invasive Hb } \\
(\mathrm{SpHb}) \\
\text { (SI model: age, } \\
\text { sex, EMS SI) }\end{array}$ & \begin{tabular}{|l|} 
Blood \\
transfusion, 1-3 \\
hours after \\
admission
\end{tabular} & $\begin{array}{l}\text { Multivariate logistic regression models using step-wise feature selection. Forward } \\
\text { selection included features with Wald } x 2 \text { test } \leq 0.2 \text {, and those with significance level } \\
>0.3 \text { removed by backward selection. } 10 \text {-fold cross-validation was repeated } 10 \text { times } \\
\text { with stratified sampling to examine prediction using previously unseen data. }\end{array}$ & NR & $\begin{array}{l}\text { AUC }(95 \% \mathrm{Cl}): 0.80 \\
(0.66 \text { to } 0.93) \\
\text { sensitivity: } 70 \% \\
\text { specificity: } 91 \%\end{array}$ \\
\hline
\end{tabular}




\begin{tabular}{|c|c|c|c|c|c|}
\hline $\begin{array}{l}\text { Author, Year } \\
\text { (See Appendix B } \\
\text { for complete } \\
\text { reference) }\end{array}$ & Measure & $\begin{array}{l}\text { Indicator of } \\
\text { Serious Injury }\end{array}$ & Method for Constructing Multivariate Model & $\begin{array}{l}\text { Risk Estimates } \\
\text { Multivariate }\end{array}$ & $\begin{array}{l}\text { AUROC Multivariate } \\
\text { AUC }(95 \% \mathrm{CI})\end{array}$ \\
\hline $\begin{array}{l}\text { Yang, } 2016 \\
\text { *Mackenzie 2015, } \\
\text { Shackelford 2015, } \\
\text { and Yang } 2016 \\
\text { draw from the } \\
\text { same population, } \\
\text { but differ in } \\
\text { eligibility criteria, } \\
\text { number analyzed, } \\
\text { and measures } \\
\text { evaluated. }\end{array}$ & $\begin{array}{l}\text { SI model and } \\
\text { non-invasive Hb } \\
(\mathrm{SpHb}) \\
\text { (SI model: age, } \\
\text { sex, EMS SI) }\end{array}$ & Mortality & $\begin{array}{l}\text { Multivariate logistic regression models using step-wise feature selection. Forward } \\
\text { selection included features with Wald } x 2 \text { test } \leq 0.2 \text {, and those with significance level } \\
>0.3 \text { removed by backward selection. } 10 \text {-fold cross-validation was repeated } 10 \text { times } \\
\text { with stratified sampling to examine prediction using previously unseen data. }\end{array}$ & NR & $\begin{array}{l}\text { AUC }(95 \% \mathrm{Cl}): 0.90 \\
\text { ( } 0.82 \text { to } 0.98) \\
\text { sensitivity: } 92 \% \\
\text { specificity: } 76 \%\end{array}$ \\
\hline $\begin{array}{l}\text { Yang, } 2016 \\
\text { *Mackenzie 2015, } \\
\text { Shackelford 2015, } \\
\text { and Yang } 2016 \\
\text { draw from the } \\
\text { same population, } \\
\text { but differ in } \\
\text { eligibility criteria, } \\
\text { number analyzed, } \\
\text { and measures } \\
\text { evaluated. }\end{array}$ & $\begin{array}{l}\text { SI model and } \\
\text { other lab tests } \\
\text { (SI model: age, } \\
\text { sex, EMS SI) }\end{array}$ & \begin{tabular}{|l|} 
Blood \\
transfusion, 1-3 \\
hours after \\
admission
\end{tabular} & $\begin{array}{l}\text { Multivariate logistic regression models using step-wise feature selection. Forward } \\
\text { selection included features with Wald } x 2 \text { test } \leq 0.2 \text {, and those with significance level } \\
>0.3 \text { removed by backward selection. } 10 \text {-fold cross-validation was repeated } 10 \text { times } \\
\text { with stratified sampling to examine prediction using previously unseen data. }\end{array}$ & NR & $\begin{array}{l}\text { AUC }(95 \% \mathrm{Cl}): 0.91 \\
(0.85 \text { to } 0.96) \\
\text { sensitivity: } 90 \% \\
\text { specificity: } 77 \%\end{array}$ \\
\hline $\begin{array}{l}\text { Yang, } 2016 \\
\text { *Mackenzie 2015, } \\
\text { Shackelford 2015, } \\
\text { and Yang } 2016 \\
\text { draw from the } \\
\text { same population, } \\
\text { but differ in } \\
\text { eligibility criteria, } \\
\text { number analyzed, } \\
\text { and measures } \\
\text { evaluated. }\end{array}$ & $\begin{array}{l}\text { SI model and } \\
\text { other lab tests } \\
\text { (SI model: age, } \\
\text { sex, EMS SI) }\end{array}$ & Mortality & $\begin{array}{l}\text { Multivariate logistic regression models using step-wise feature selection. Forward } \\
\text { selection included features with Wald } x 2 \text { test } \leq 0.2 \text {, and those with significance level } \\
>0.3 \text { removed by backward selection. } 10 \text {-fold cross-validation was repeated } 10 \text { times } \\
\text { with stratified sampling to examine prediction using previously unseen data. }\end{array}$ & NR & $\begin{array}{l}\text { AUC (95\% } \mathrm{Cl}): 0.81 \\
\text { ( } 0.66 \text { to } 0.96) \\
\text { sensitivity: } 75 \% \\
\text { specificity: } 82 \%\end{array}$ \\
\hline
\end{tabular}




\begin{tabular}{|c|c|c|c|c|c|}
\hline $\begin{array}{l}\text { Author, Year } \\
\text { (See Appendix B } \\
\text { for complete } \\
\text { reference) }\end{array}$ & Measure & \begin{tabular}{|l|} 
Indicator of \\
Serious Injury
\end{tabular} & Method for Constructing Multivariate Model & $\begin{array}{l}\text { Risk Estimates } \\
\text { Multivariate }\end{array}$ & $\begin{array}{l}\text { AUROC Multivariate } \\
\text { AUC }(95 \% \mathrm{CI})\end{array}$ \\
\hline $\begin{array}{l}\text { Yang, } 2016 \\
\text { *Mackenzie 2015, } \\
\text { Shackelford 2015, } \\
\text { and Yang } 2016 \\
\text { draw from the } \\
\text { same population, } \\
\text { but differ in } \\
\text { eligibility criteria, } \\
\text { number analyzed, } \\
\text { and measures } \\
\text { evaluated. }\end{array}$ & $\begin{array}{l}\text { SI model with } \\
\text { non-invasive } \mathrm{Hb} \\
(\mathrm{SpHb}) \text { and other } \\
\text { lab tests } \\
\text { (SI model: age, } \\
\text { sex, EMS SI) }\end{array}$ & \begin{tabular}{|l|} 
Blood \\
transfusion, 1-3 \\
hours after \\
admission
\end{tabular} & $\begin{array}{l}\text { Multivariate logistic regression models using step-wise feature selection. Forward } \\
\text { selection included features with Wald } x 2 \text { test } \leq 0.2 \text {, and those with significance level } \\
>0.3 \text { removed by backward selection. } 10 \text {-fold cross-validation was repeated } 10 \text { times } \\
\text { with stratified sampling to examine prediction using previously unseen data. }\end{array}$ & NR & $\begin{array}{l}\text { AUC }(95 \% \mathrm{Cl}): 0.91 \\
(0.86 \text { to } 0.96) \\
\text { sensitivity: } 95 \% \\
\text { specificity: } 73 \%\end{array}$ \\
\hline $\begin{array}{l}\text { Yang, } 2016 \\
\text { *Mackenzie 2015, } \\
\text { Shackelford 2015, } \\
\text { and Yang } 2016 \\
\text { draw from the } \\
\text { same population, } \\
\text { but differ in } \\
\text { eligibility criteria, } \\
\text { number analyzed, } \\
\text { and measures } \\
\text { evaluated. }\end{array}$ & \begin{tabular}{|l|} 
SI model with \\
non-invasive $\mathrm{Hb}$ \\
(SpHb) and other \\
lab tests \\
(SI model: age, \\
sex, EMS SI)
\end{tabular} & Mortality & $\begin{array}{l}\text { Multivariate logistic regression models using step-wise feature selection. Forward } \\
\text { selection included features with Wald } x 2 \text { test } \leq 0.2 \text {, and those with significance level } \\
>0.3 \text { removed by backward selection. } 10 \text {-fold cross-validation was repeated } 10 \text { times } \\
\text { with stratified sampling to examine prediction using previously unseen data. }\end{array}$ & NR & $\begin{array}{l}\text { AUC }(95 \% \mathrm{Cl}): 0.91 \\
(0.84 \text { to } 0.98) \\
\text { sensitivity: } 92 \% \\
\text { specificity: } 79 \%\end{array}$ \\
\hline $\begin{array}{l}\text { Yang, } 2016 \\
\text { ×Mackenzie 2015, } \\
\text { Shackelford 2015, } \\
\text { and Yang } 2016 \\
\text { draw from the } \\
\text { same population, } \\
\text { but differ in } \\
\text { eligibility criteria, } \\
\text { number analyzed, } \\
\text { and measures } \\
\text { evaluated. }\end{array}$ & $\begin{array}{l}\text { SI model: age, } \\
\text { sex, EMS SI }\end{array}$ & \begin{tabular}{|l|} 
Blood \\
transfusion, 1-3 \\
hours after \\
admission
\end{tabular} & $\begin{array}{l}\text { Multivariate logistic regression models using step-wise feature selection. Forward } \\
\text { selection included features with Wald } x 2 \text { test } \leq 0.2 \text {, and those with significance level } \\
>0.3 \text { removed by backward selection. } 10 \text {-fold cross-validation was repeated } 10 \text { times } \\
\text { with stratified sampling to examine prediction using previously unseen data. }\end{array}$ & NR & $\begin{array}{l}\text { AUC }(95 \% \mathrm{Cl}): 0.78 \\
(0.63 \text { to } 0.92) \\
\text { sensitivity: } 70 \% \\
\text { specificity: } 89 \%\end{array}$ \\
\hline
\end{tabular}




\begin{tabular}{|c|c|c|c|c|c|}
\hline $\begin{array}{l}\text { Author, Year } \\
\text { (See Appendix B } \\
\text { for complete } \\
\text { reference) }\end{array}$ & Measure & $\begin{array}{l}\text { Indicator of } \\
\text { Serious Injury }\end{array}$ & Method for Constructing Multivariate Model & $\begin{array}{l}\text { Risk Estimates } \\
\text { Multivariate }\end{array}$ & $\begin{array}{l}\text { AUROC Multivariate } \\
\text { AUC }(95 \% \mathrm{Cl})\end{array}$ \\
\hline $\begin{array}{l}\text { Yang, } 2016 \\
\text { *Mackenzie 2015, } \\
\text { Shackelford 2015, } \\
\text { and Yang } 2016 \\
\text { draw from the } \\
\text { same population, } \\
\text { but differ in } \\
\text { eligibility criteria, } \\
\text { number analyzed, } \\
\text { and measures } \\
\text { evaluated. }\end{array}$ & $\begin{array}{l}\text { SI model: age, } \\
\text { sex, EMS SI }\end{array}$ & Mortality & $\begin{array}{l}\text { Multivariate logistic regression models using step-wise feature selection. Forward } \\
\text { selection included features with Wald } x 2 \text { test } \leq 0.2 \text {, and those with significance level } \\
>0.3 \text { removed by backward selection. } 10 \text {-fold cross-validation was repeated } 10 \text { times } \\
\text { with stratified sampling to examine prediction using previously unseen data. }\end{array}$ & NR & $\begin{array}{l}\text { AUC }(95 \% \mathrm{Cl}): 0.74 \\
(0.59 \text { to } 0.90) \\
\text { sensitivity: } 83 \% \\
\text { specificity: } 59 \%\end{array}$ \\
\hline
\end{tabular}

\section{See Appendix B. Included Studies for full study references.}

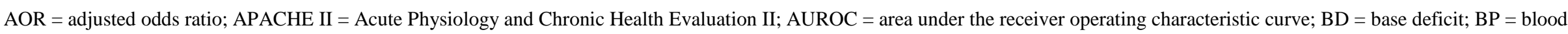

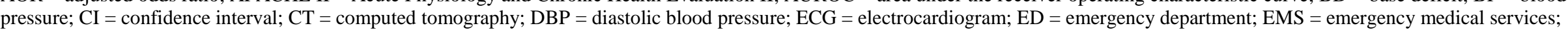

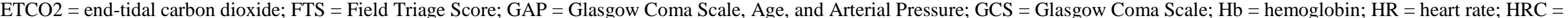

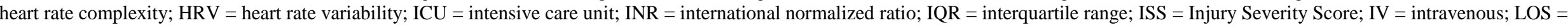

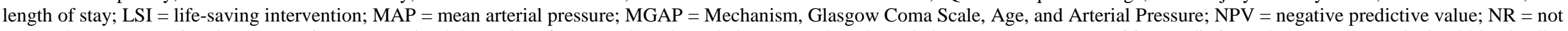

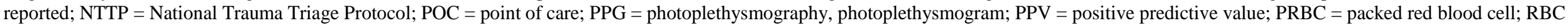

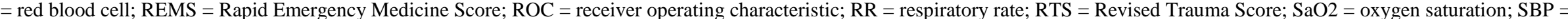

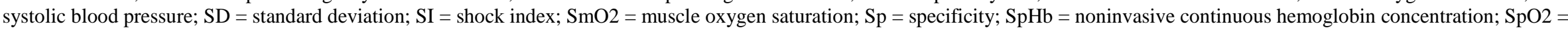
peripheral oxygen saturation; TRISS = Trauma and Injury Severity Score; vs. = versus; VSDR = vital signs data and event recorder; WVSM = wireless vital signs monitor 


\section{Appendix E. Risk of Bias Criteria}

Table E1. Quality in Prognostic Studies (QUIPS) tool, modified

\begin{tabular}{|c|c|c|c|}
\hline Domains & $\begin{array}{l}\text { Prompting Items for } \\
\text { Consideration }\end{array}$ & $\begin{array}{l}\text { QUIPS Tool Ratings } \\
\text { (Overall Risk of Bias) }\end{array}$ & EPC Modifications \\
\hline $\begin{array}{l}\text { Study } \\
\text { Participation }\end{array}$ & $\begin{array}{l}\text { a. Adequate participation in } \\
\text { the study by eligible } \\
\text { persons } \\
\text { b. Description of the } \\
\text { source population or } \\
\text { population of interest } \\
\text { c. Description of the } \\
\text { baseline study sample } \\
\text { d. Adequate description of } \\
\text { the sampling frame and } \\
\text { recruitment } \\
\text { e. Adequate description of } \\
\text { the period and place of } \\
\text { recruitment } \\
\text { f. Adequate description of } \\
\text { inclusion and exclusion } \\
\text { criteria }\end{array}$ & $\begin{array}{l}\text { High bias: The relationship } \\
\text { between the PF and } \\
\text { outcome is very likely to be } \\
\text { different for participants and } \\
\text { eligible nonparticipants } \\
\text { Moderate bias: } \\
\text { The relationship between } \\
\text { the PF and outcome may be } \\
\text { different for participants } \\
\text { and eligible nonparticipants } \\
\text { Low bias: The relationship } \\
\text { between the PF and } \\
\text { outcome is unlikely to be } \\
\text { different for participants and } \\
\text { eligible nonparticipants }\end{array}$ & $\begin{array}{l}\text { * Not Reported can be used for } \\
\text { any domain }\end{array}$ \\
\hline $\begin{array}{l}\text { Study } \\
\text { Attrition }\end{array}$ & $\begin{array}{l}\text { a. Adequate response rate } \\
\text { for study participants } \\
\text { b. Description of attempts } \\
\text { to collect information on } \\
\text { participants who dropped } \\
\text { out } \\
\text { c. Reasons for loss to } \\
\text { followup are provided } \\
\text { d. Adequate description of } \\
\text { participants lost to followup } \\
\text { e. There are no important } \\
\text { differences between } \\
\text { participants who completed } \\
\text { the study and those who } \\
\text { did not }\end{array}$ & $\begin{array}{l}\text { High bias: The relationship } \\
\text { between the PF and } \\
\text { outcome is very likely to be } \\
\text { different for completing and } \\
\text { noncompleting participants } \\
\text { Moderate bias: The } \\
\text { relationship between the PF } \\
\text { and outcome may be } \\
\text { different for completing and } \\
\text { noncompleting participants } \\
\text { Low bias: The relationship } \\
\text { between the PF and } \\
\text { outcome is unlikely to be } \\
\text { different for completing and } \\
\text { noncompleting participants }\end{array}$ & $\begin{array}{l}\text { Include assessment of the impact } \\
\text { of missing data in this domain, not } \\
\text { in others } \\
\text { Consider the percent of missing } \\
\text { data as well as how the study } \\
\text { addressed it (i.e., if there was } \\
\text { imputation done) }\end{array}$ \\
\hline $\begin{array}{l}\text { Prognostic } \\
\text { Factor } \\
\text { Measurement }\end{array}$ & $\begin{array}{l}\text { a. A clear definition or } \\
\text { description of the PF is } \\
\text { provided } \\
\text { b. Method of PF } \\
\text { measurement is } \\
\text { adequately valid and } \\
\text { reliable } \\
\text { c. Continuous variables are } \\
\text { reported or } \\
\text { appropriate cut points are } \\
\text { used } \\
\text { d. The method and setting } \\
\text { of measurement of PF is } \\
\text { the same for all study } \\
\text { participants } \\
\text { e. Adequate proportion of } \\
\text { the study sample has } \\
\text { complete data for the PF } \\
\text { f. Appropriate methods of } \\
\text { imputation are used for } \\
\text { missing PF data. }\end{array}$ & $\begin{array}{l}\text { High bias: The } \\
\text { measurement of the PF is } \\
\text { very likely to be different for } \\
\text { different levels of the } \\
\text { outcome of interest } \\
\text { Moderate bias: The } \\
\text { measurement of } \\
\text { the PF may be different for } \\
\text { different levels of the } \\
\text { outcome of interest } \\
\text { Low bias: The } \\
\text { measurement of the PF is } \\
\text { unlikely to be different for } \\
\text { different levels of the } \\
\text { outcome of interest }\end{array}$ & $\begin{array}{l}\text { Is the measurement of the } \\
\text { physiologic measures of } \\
\text { circulation/respiration/combinations } \\
\text { done well? This included issues } \\
\text { with definitions or instrumentation. } \\
\text { Is the measurement valid, reliable, } \\
\text { reasonable etc. }\end{array}$ \\
\hline
\end{tabular}




\begin{tabular}{|c|c|c|c|}
\hline Domains & $\begin{array}{l}\text { Prompting Items for } \\
\text { Consideration }\end{array}$ & $\begin{array}{l}\text { QUIPS Tool Ratings } \\
\text { (Overall Risk of Bias) }\end{array}$ & EPC Modifications \\
\hline $\begin{array}{l}\text { Outcome } \\
\text { Measurement }\end{array}$ & $\begin{array}{l}\text { a. A clear definition of the } \\
\text { outcome is provided } \\
\text { b. Method of outcome } \\
\text { measurement used is } \\
\text { adequately valid and } \\
\text { reliable } \\
\text { c. The method and setting } \\
\text { of outcome } \\
\text { measurement is the same } \\
\text { for all study } \\
\text { participants }\end{array}$ & $\begin{array}{l}\text { High bias: The } \\
\text { measurement of the } \\
\text { outcome is very likely to be } \\
\text { different related to the } \\
\text { baseline level of the PF } \\
\text { Moderate bias: The } \\
\text { measurement of the } \\
\text { outcome may be different } \\
\text { related to the baseline level } \\
\text { of the PF } \\
\text { Low bias: The } \\
\text { measurement of the } \\
\text { outcome is unlikely to be } \\
\text { different related to the } \\
\text { baseline level of the PF }\end{array}$ & $\begin{array}{l}\text { Similar to PF measurement, but } \\
\text { for us this is about how the } \\
\text { indicator of serious injury is } \\
\text { measured (the ISS, mortality, } \\
\text { major surgery etc.) }\end{array}$ \\
\hline $\begin{array}{l}\text { Study } \\
\text { Confounding }\end{array}$ & $\begin{array}{l}\text { a. All important } \\
\text { confounders are measured } \\
\text { b. Clear definitions of the } \\
\text { important confounders } \\
\text { measured are provided } \\
\text { c. Measurement of all } \\
\text { important confounders is } \\
\text { adequately valid and } \\
\text { reliable } \\
\text { d. The method and setting } \\
\text { of confounding } \\
\text { measurement are the } \\
\text { same for all study } \\
\text { participants } \\
\text { e. Appropriate methods are } \\
\text { used if imputation is used } \\
\text { for missing confounder } \\
\text { data } \\
\text { f. Important potential } \\
\text { confounders are } \\
\text { accounted for in the study } \\
\text { design } \\
\text { g. Important potential } \\
\text { confounders are } \\
\text { accounted for in the } \\
\text { analysis }\end{array}$ & $\begin{array}{l}\text { High bias: The observed } \\
\text { effect of the PF on the } \\
\text { outcome is very likely to be } \\
\text { distorted by another factor } \\
\text { related to PF and outcome } \\
\text { Moderate bias: The } \\
\text { observed effect of the PF on } \\
\text { outcome may be distorted } \\
\text { by another factor related to } \\
\text { PF and outcome } \\
\text { Low bias: The observed } \\
\text { effect of the PF on outcome } \\
\text { is unlikely to be distorted by } \\
\text { another factor related to PF } \\
\text { and outcome }\end{array}$ & $\begin{array}{l}\text { Code as Not Applicable for } \\
\text { Sensitivity/ Specificity -- can't } \\
\text { adjust. }\end{array}$ \\
\hline $\begin{array}{l}\text { Statistical } \\
\text { Analysis and } \\
\text { Reporting }\end{array}$ & $\begin{array}{l}\text { a. Sufficient presentation of } \\
\text { data to assess the } \\
\text { adequacy of the analytic } \\
\text { strategy } \\
\text { b. Strategy for model } \\
\text { building is appropriate and } \\
\text { is based on a conceptual } \\
\text { framework or model } \\
\text { c. The selected statistical } \\
\text { model is adequate for the } \\
\text { design of the study } \\
\text { d. There is no selective } \\
\text { reporting of results }\end{array}$ & $\begin{array}{l}\text { High bias: The reported } \\
\text { results are very likely to be } \\
\text { spurious or biased related } \\
\text { to analysis or reporting } \\
\text { Moderate bias: The } \\
\text { reported results may be } \\
\text { spurious or biased related } \\
\text { to analysis or reporting } \\
\text { Low bias: The reported } \\
\text { results are unlikely to be } \\
\text { spurious or biased related } \\
\text { to analysis or reporting }\end{array}$ & $\begin{array}{l}\text { May be Not Applicable in cases of } \\
\text { sensitivity/specificity and no other } \\
\text { types of analysis. }\end{array}$ \\
\hline
\end{tabular}

\section{Risk Prediction Studies ${ }^{1}$}

\section{Criteria:}

- The study sample adequately represents the population of interest

- The study data available (i.e., participants not lost to followup) adequately represent the study sample 
- The prognostic factor is measured in a similar way for all participants

- The outcome of interest is measured in a similar way for all participants

- Important potential confounding factors are appropriately accounted for

- The observed effect of the prognostic factor on the outcome is very likely to be distorted by another factor related to prognostic factor and outcome.

\section{Definitions of risk of bias based on above criteria:}

Low: $\quad$ The least risk of bias, and results are generally considered more valid than studies with the same study design but more flaws. Low risk of bias studies include clear descriptions of the population, setting, interventions, and comparison groups clear reporting of missing data; apply appropriate means to prevent; and appropriately measure outcomes.

Moderate: Susceptible to some bias, though not enough to necessarily invalidate the results. These studies may not meet all the criteria for "low" risk of bias rating, but do not have flaws likely to cause major bias. The study may also be missing information, making it difficult to assess limitations and potential problems.

High: Have significant flaws that may invalidate the results. They may have a serious or "fatal" flaw or set of flaws in design, analysis, or reporting; large amounts of missing information; or discrepancies in reporting. The results of these studies will be least as likely to reflect flaws in the study design as the true difference between the compared interventions.

\section{Definition of risk of bias based on above criteria:}

Low: $\quad$ Evaluates relevant available screening test; uses a credible reference standard; interprets reference standard independently of screening test; reliability of test assessed; has few or handles missing data in a reasonable manner; includes a large number (>100), broad-spectrum of patients with and without disease; study attempts to enroll a random or consecutive sample of patients who meet inclusion criteria screening cutoffs pre-stated.

Moderate: Evaluates relevant available screening test; uses reasonable although not best standard; interprets reference standard independent of screening test; moderate sample size (50 to 100 subjects) and a "medium" spectrum of patients (i.e. applicable to most screening settings).

High: Has important limitation such as: uses inappropriate reference standard; screening test improperly administered; biased ascertainment of reference standard; very small sample size of very narrow selected spectrum of patients.

\section{Reference}

1. Hayden JA, van der Windt DA, Cartwright JL, et al. Assessing bias in studies of prognostic factors. Ann Intern Med. 2013 Feb 19;158(4):280-6. doi: 10.7326/0003-4819158-4-201302190-00009. PMID: 23420236. 


\section{Appendix F. Risk of Bias Assessment}

Table F1. Risk of bias assessment

\begin{tabular}{|c|c|c|c|c|c|c|c|}
\hline $\begin{array}{l}\text { Author, year } \\
\text { (see Appendix B for full } \\
\text { reference) }\end{array}$ & $\begin{array}{c}\text { Study } \\
\text { Participation }\end{array}$ & Study Attrition & $\begin{array}{l}\text { Prognostic } \\
\text { Factor } \\
\text { Measurement } \\
\end{array}$ & $\begin{array}{c}\text { Outcome } \\
\text { Measurement }\end{array}$ & $\begin{array}{c}\text { Study } \\
\text { Confounding }\end{array}$ & $\begin{array}{l}\text { Statistical } \\
\text { Analysis and } \\
\text { Reporting }\end{array}$ & Risk of Bias \\
\hline Ahun, 2014 & Moderate & Unknown & Low & Low & NA & Low & Moderate \\
\hline Allen, 2014 & Moderate & Low & Low & Low & Moderate & Low & Moderate \\
\hline Al-Salamah, 2004 & Moderate & Low & Low & Low & Moderate & Moderate & Moderate \\
\hline Arbabi, 2004 & Moderate & Unknown & Low & Low & Moderate & Moderate & Moderate \\
\hline Aslar, 2004 & Low & Low & Low & Low & Moderate & Moderate & Moderate \\
\hline Baron, 2004 & Unclear & Low & Low & Moderate & NA & NA & Moderate \\
\hline Baron, 2007 & Moderate & Moderate & Low & Low & Low & Low & Moderate \\
\hline Batchinsky, 2007 & High & High & Low & Low & Moderate & Low & Moderate \\
\hline Batchinsky, 2009 & Moderate & High & Low & Low & Unclear & Moderate & Moderate \\
\hline Batchinsky, 2009b & Moderate & Moderate & Low & Low & High & Low & High \\
\hline Beekley, 2010 & Low & Moderate & Moderate & Low & NA & NA & Moderate \\
\hline Bond, 1997 & Low & Low & Low & Low & Moderate & Low & Moderate \\
\hline Bouzat, 2016 & High & Low & Low & Low & High & Low & High \\
\hline Brown, 2011 & Moderate & Low & Low & Low & Low & Low & Moderate \\
\hline Brown, 2015 & Moderate & Moderate & Low & Low & Moderate & Low & Moderate \\
\hline Brown, 2016 & High & Low & Low & Low & Moderate & Low & Moderate \\
\hline Bruijns, 2013 & Low & Moderate & Moderate & Low & NA & Moderate & Moderate \\
\hline Bruijns, 2014 & Moderate & Low & Low & Low & Moderate & Low & Moderate \\
\hline Callaway, 2009 & Low & Low & Low & Low & Moderate & Low & Moderate \\
\hline Cancio, 2008 & High & High & Moderate & Moderate & High & Moderate & High \\
\hline Cancio, 2008a & Moderate & High & High & Moderate & Moderate & Moderate & High \\
\hline Cannon, 2009 & Low & High & Low & Low & High & Low & Moderate \\
\hline Caputo, 2012 & Low & Low & Low & Low & Moderate & Moderate & Moderate \\
\hline Caputo, 2015 & Low & Low & Low & Low & NA & NA & Low \\
\hline Chan, 1997 & High & High & Low & Low & High & High & High \\
\hline Chen, 2007 & Moderate & Moderate & Low & Low & High & Low & High \\
\hline Chen, 2008 & Low & Unknown & Moderate & Low & Low & Low & Moderate \\
\hline Chen, 2009 & Low & Moderate & Moderate & Low & Moderate & Low & Moderate \\
\hline Chen, 2010 & Low & Moderate & Moderate & Low & Moderate & Low & Moderate \\
\hline Cherry, 2007 & Moderate & Unclear & Low & Low & Low & Low & Moderate \\
\hline Cooke, 2006a & High & High & Moderate & Moderate & High & Moderate & High \\
\hline Courville, 2009 & Low & Moderate & Low & Low & Low & Low & Low \\
\hline Cudnik, 2012 & Low & Moderate & Low & Low & Low & Low & Moderate \\
\hline Davis, 1996 & High & Low & Low & Low & Moderate and NA & Moderate and NA & Moderate \\
\hline
\end{tabular}




\begin{tabular}{|c|c|c|c|c|c|c|c|}
\hline $\begin{array}{l}\text { Author, year } \\
\text { (see Appendix B for full } \\
\text { reference) }\end{array}$ & $\begin{array}{c}\text { Study } \\
\text { Participation }\end{array}$ & Study Attrition & $\begin{array}{l}\text { Prognostic } \\
\text { Factor } \\
\text { Measurement } \\
\end{array}$ & $\begin{array}{c}\text { Outcome } \\
\text { Measurement }\end{array}$ & $\begin{array}{c}\text { Study } \\
\text { Confounding }\end{array}$ & $\begin{array}{l}\text { Statistical } \\
\text { Analysis and } \\
\text { Reporting }\end{array}$ & Risk of Bias \\
\hline DeMuro, 2013 & Moderate & Low & Moderate & Moderate & NA & Moderate & Moderate \\
\hline Dinh, 2014 & Low & Low & Low & Low & Moderate & Low & Moderate \\
\hline Dunham, 2017 & High & High & Low & Low & High & Low & High \\
\hline Dunne, 2005 & Moderate & Moderate & Low & Low & Low & Low & Moderate \\
\hline Eastridge, 2007 & Moderate & Unknown & Low & Low & NA & Low & Moderate \\
\hline Edla, 2015b & High & Moderate & Low & Low & NA & Low & Moderate \\
\hline Engum, 2000 & Low & Moderate & Low & Low & Low & Low & Moderate \\
\hline Franklin, 2000 & Moderate & Low & Low & Low & Moderate & Low & Moderate \\
\hline Folkert, 2015 & Moderate & Moderate & Low & Low & High & Low & Moderate \\
\hline Garner, 2001 & Low & Low & Low & Low & Low & Low & Moderate \\
\hline Gebhart, 2007 & Low & Low & Low & Low & NA & NA & Low \\
\hline Gray, 1997 & Moderate & Low & Low & Low & Moderate & Low & Moderate \\
\hline Grimme, 2005 & Moderate & Unclear & Low & Low & Moderate & Moderate & Moderate \\
\hline Guyette, 2011 & Low & Moderate & Low & Low & Low and NA & Low and NA & Moderate \\
\hline Guyette, 2012 & Moderate & Low & Low & Low & High & Low & Moderate \\
\hline Guyette, 2015 & Moderate & Moderate & Low & Low & Low & Low & Moderate \\
\hline Haider, 2016 & Moderate & Unclear & Low & Low & Low & Moderate & Moderate \\
\hline Hamada, 2014 & Moderate & Low & Low & Low & Low & Low & Moderate \\
\hline Henry, 1996 & Low & Low & Low & Low & Low & Low & Low \\
\hline Holcomb, 2005 & High & High & Moderate & Low & High & Moderate & High \\
\hline Holcomb, 2005b & Moderate & Moderate & Low & Low & Low & Moderate & Moderate \\
\hline Horne, 2013 & High & High & Moderate & Low & High & High & High \\
\hline Ichwan, 2015 & Moderate & Low & Moderate & Low & Low & Low & Moderate \\
\hline Imhoff, 2014 & Moderate & Moderate & Moderate & Low & Low & Moderate & Moderate \\
\hline Jo, 2014 & Moderate & Low & Moderate & Low & NA & NA & Moderate \\
\hline Jones, 2014 & Moderate & Low & Moderate & Low & Moderate & Moderate & Moderate \\
\hline Joosse, 2014 & Moderate & Low & Low & Low & Low & Low & Low \\
\hline Khasawneh, 2014 & Moderate & Low & Low & Low & NA & NA & Moderate \\
\hline Kim, 2016 & High & High & Low & Low & High & Low & High \\
\hline King, 1996 & High & Low & Low & Low & Low & Low & Moderate \\
\hline King, 2009 & High & Moderate & Low & Low & Low & Low & Moderate \\
\hline Kondo, 2011 & Low & Moderate & Low & Low & Low & Low & Moderate \\
\hline Kuo, 2016 & Low & Low & Low & Low & Moderate & Moderate & Moderate \\
\hline Lai, 2016 & Low & Low & Low & Low & Moderate & Low & Moderate \\
\hline Lalezarzadeh, 2009 & Moderate & Moderate & Low & Low & High & Low & High \\
\hline Lee, 2014 & Low & Low & Low & Low & NA & NA & Low \\
\hline Lehmann, 2007 & Moderate & Moderate & Moderate & Low & Moderate & Moderate & Moderate \\
\hline Lerner, 2017 & Moderate & Low & Low & Low & Low & Low & Low \\
\hline
\end{tabular}




\begin{tabular}{|c|c|c|c|c|c|c|c|}
\hline $\begin{array}{l}\text { Author, year } \\
\text { (see Appendix B for full } \\
\text { reference) }\end{array}$ & $\begin{array}{c}\text { Study } \\
\text { Participation }\end{array}$ & Study Attrition & $\begin{array}{l}\text { Prognostic } \\
\text { Factor } \\
\text { Measurement }\end{array}$ & $\begin{array}{c}\text { Outcome } \\
\text { Measurement }\end{array}$ & $\begin{array}{c}\text { Study } \\
\text { Confounding }\end{array}$ & $\begin{array}{l}\text { Statistical } \\
\text { Analysis and } \\
\text { Reporting }\end{array}$ & Risk of Bias \\
\hline Lin, 2011 & Low & Low & Low & Low & High and NA & High and NA & High \\
\hline Lipsky, 2006 & Moderate & Low & Low & Low & High & Low & High \\
\hline Liu, 2014 & High & High & Moderate & Low & Moderate & Moderate & High \\
\hline Liu, 2014b & High & Unclear & Moderate & Low & NA and Moderate & NA and Moderate & High \\
\hline Liu, 2014c & Moderate & Moderate & Low & Low & High & Moderate & High \\
\hline Liu, 2015a & High & Unknown & Low & Low & Low & Moderate & Moderate \\
\hline Liu, 2015b & High & Unclear & Moderate & Low & NA and Moderate & NA and Moderate & High \\
\hline Mackenzie, 2014 & Moderate & Low & Low & Low & Moderate & Low & Moderate \\
\hline Mackenzie, 2015 & Moderate & High & Low & Low & Low & Low & Moderate \\
\hline Matsushima, 2016 & Moderate & Unknown & Low & Low & Low & Low & Moderate \\
\hline McManus, 2005 & Moderate & Unknown & Low & Low & High & Low & High \\
\hline McNab, 2013 & Low & Unknown & Low & Low & Moderate & Low & Moderate \\
\hline Miller, 2017 & Moderate & Low & Low & Low & Moderate & Low & Moderate \\
\hline Mizushima, 2011 & Moderate & Unclear & Moderate & Moderate & Moderate & Moderate & Moderate \\
\hline Montoya, 2015 & High & Low & Moderate & Low & Moderate & Low & High \\
\hline Moore, 2006 & Moderate & Low & Low & Low & Low & Low & Low \\
\hline Moront, 1996 & Moderate & Unknown & Low & Low & High & Moderate & Moderate \\
\hline Mutschler, 2013 & Low & Low & Low & Low & Low & Moderate & Moderate \\
\hline Nabaweesi, 2014 & Low & Low & Low & Low & Moderate & Moderate & Moderate \\
\hline Newgard, 2009 & Low & Moderate & Low & Low & Low & Low & Moderate \\
\hline Newgard, 2014 & Low & Unclear & Low & Low & Moderate & Low & Moderate \\
\hline Newgard, 2016 & Low & Unclear & Low & Low & NA & Low & Moderate \\
\hline Ocak, 2009 & Moderate & Low & Low & Low & Low & Low & Moderate \\
\hline Pal, 2006 & Low & Moderate & Moderate & Low & Low & Low & Moderate \\
\hline Paladino, 2008 & Moderate & Low & Low & Low & NA & NA & Moderate \\
\hline Paladino, 2010a & Moderate & Low & Low & Low & NA & NA & Moderate \\
\hline Paladino, 2010b & Moderate & Low & Low & Low & NA & NA & Moderate \\
\hline Paladino, 2011 & Moderate & Unknown & Low & Low & NA & Low & Moderate \\
\hline Pandit, 2014 & Moderate & Unknown & Low & Low & Low & Low & Moderate \\
\hline Parimi, 2016 & Moderate & High & Low & Low & NA & Low & Moderate \\
\hline Parsikia, 2014 & High & Moderate & Low & Low & Moderate & Moderate & Moderate \\
\hline Perel, 2012 and Perel, 2013* & Low & Unclear & Low & Low & Low & Low & Moderate \\
\hline Potoka, 2001 & Low & Unclear & Low & Low & Low & Low & Moderate \\
\hline Pottecher, 2016 & Moderate & Low & Low & Low & Moderate & Low & Moderate \\
\hline Rahmani, 2017 & Moderate & Low & Low & Low & Moderate & Low & Moderate \\
\hline Rainer, 2011 & High & Low & Low & Low & Low & Moderate & Moderate \\
\hline Ramanathan, 2015 & Low & Low & Low & Low & NA & NA & Low \\
\hline Raux, 2006 & Moderate & Moderate & Low & Low & Moderate & Moderate & Moderate \\
\hline
\end{tabular}




\begin{tabular}{|c|c|c|c|c|c|c|c|}
\hline $\begin{array}{l}\text { Author, year } \\
\text { (see Appendix B for full } \\
\text { reference) }\end{array}$ & $\begin{array}{c}\text { Study } \\
\text { Participation }\end{array}$ & Study Attrition & $\begin{array}{l}\text { Prognostic } \\
\text { Factor } \\
\text { Measurement }\end{array}$ & $\begin{array}{c}\text { Outcome } \\
\text { Measurement }\end{array}$ & $\begin{array}{c}\text { Study } \\
\text { Confounding }\end{array}$ & $\begin{array}{l}\text { Statistical } \\
\text { Analysis and } \\
\text { Reporting }\end{array}$ & Risk of Bias \\
\hline Raux, 2011 & Low & Unclear & Low & Low & NA & Low & Moderate \\
\hline Raux, 2017 & Moderate & High & Low & Low & Moderate & Low & Moderate \\
\hline Regnier, 2012 & Moderate & Low & Low & Low & NA & NA & Moderate \\
\hline Reisner, 2016 & Moderate & Low & Low & Low & Moderate & Moderate & Moderate \\
\hline Rickards, 2010 & Low & Moderate & Low & Low & Moderate & Low & Moderate \\
\hline Ryan, 2011 & Low & Moderate & Low & Low & Moderate & Low & Moderate \\
\hline Sammour, 2009 & High & High & Low & Low & Moderate & Moderate & High \\
\hline Sartorius, 2010 & Low & Unclear & Low & Low & Low & Low & Moderate \\
\hline Schenarts, 2008 & Moderate & Moderate & Low & Low & High & Low & High \\
\hline Shackelford, 2015 & Low & Moderate & Low & Low & Low & Moderate & Moderate \\
\hline Shah, 2013 & Moderate & Low & Low & Low & Low & Low & Moderate \\
\hline Shoemaker, 2005 & Low & Low & Low & Low & NA & Low & Low \\
\hline St. John, 2016 & Moderate & Low & Low & Low & Low & Low & Moderate \\
\hline Stanworth, 2010 & Low & Moderate & Moderate & Low & Moderate & Moderate & Moderate \\
\hline Tamim, 2002 & Moderate & Moderate & Low & Low & Low & Low & Moderate \\
\hline Van Haren, 2014 & Unclear & Unclear & Low & Low & NA & Low & Moderate \\
\hline Vandromme, 2010 & High & Moderate & Low & Low & Low & Low & Moderate \\
\hline Vandromme, 2011 & Low & High & Low & Low & High & Low & High \\
\hline Vandromme, 2011b & Moderate & Moderate & Low & Low & Low & Low & Moderate \\
\hline Vassallo, 2015 & Low & Moderate & Low & Low & NA & Moderate & Moderate \\
\hline Vassallo, 2017 & High & High & Low & Low & High & Low & High \\
\hline Vettorello, 2013 & High & Low & Low & Low & NA & Low & High \\
\hline Williams, 2016 & Moderate & Unclear & Low & Moderate & NA & NA & Moderate \\
\hline Woodford, 2012 & Unclear & Moderate & Low & Low & NA & Low & Moderate \\
\hline Yang, 2016 & Moderate & Moderate & Low & Low & Low & Low & Moderate \\
\hline Yuen, 2016 & Unclear & Unclear & Low & Low & Low & Low & Moderate \\
\hline Zarzaur, 2008 & Low & High & Low & Low & NA & Moderate & Moderate \\
\hline
\end{tabular}

See Appendix B. Included Studies for full study references.

$\mathrm{NA}=$ not applicable, as sensitivity and specificity are not adjusted for confounders 


\section{Appendix G. Multivariate Results Summaries}

Table G1. Measures of circulatory compromise

\begin{tabular}{|c|c|c|c|c|c|c|}
\hline & $\begin{array}{l}\text { Author, } \\
\text { Year } \\
\text { (see } \\
\text { Appendix B } \\
\text { for full } \\
\text { reference) } \\
\end{array}$ & \begin{tabular}{|l|} 
Number \\
Analyzed \\
Age \\
Mean (SD) \\
\end{tabular} & $\begin{array}{l}\text { Measure } \\
\text { (cutpoint) } \\
\text { Subgroup } \\
\end{array}$ & $\begin{array}{l}\text { Serious } \\
\text { Injury } \\
\text { Indicator } \\
\text { Type: } \\
\text { Indicator } \\
\end{array}$ & $\begin{array}{l}\text { Multivariate } \\
\text { Results } \\
\text { Adjusted Odds } \\
\text { Ratio }(95 \% \mathrm{Cl}) \\
\end{array}$ & $\begin{array}{l}\text { Variables Included in } \\
\text { Model }\end{array}$ \\
\hline $\begin{array}{l}\text { Heart Rate: } \\
\text { OH }\end{array}$ & $\begin{array}{l}\text { Barmparas, } \\
2014\end{array}$ & $\begin{array}{l}135,694 \\
\text { NR } \\
\end{array}$ & $\begin{array}{l}\text { HR }(<70) \\
\text { ED GCS } \\
\text { score } \leq 8\end{array}$ & $\begin{array}{l}\text { I: Severe } \\
\text { head injury }\end{array}$ & $1.83(1.58$ to 2.12$)$ & Age, gender, HR and SBP \\
\hline $\begin{array}{l}\text { Heart Rate: } \\
\text { OH }\end{array}$ & $\begin{array}{l}\text { Barmparas, } \\
2014\end{array}$ & $\begin{array}{l}135,694 \\
\text { NR } \\
\end{array}$ & $\begin{array}{l}\mathrm{HR}(<70) \\
\text { ED GCS } \\
\text { score } 9-13\end{array}$ & $\begin{array}{l}\text { I: Severe } \\
\text { head injury }\end{array}$ & 1.68 (1.39 to 2.04$)$ & Age, gender, HR and SBP \\
\hline $\begin{array}{l}\text { Heart Rate: } \\
\text { OH }\end{array}$ & $\begin{array}{l}\text { Barmparas, } \\
2014\end{array}$ & $\begin{array}{l}135,694 \\
\text { NR }\end{array}$ & $\begin{array}{l}\mathrm{HR}(<70) \\
\text { ED GCS } \\
\text { score 14- } \\
15 \\
\end{array}$ & $\begin{array}{l}\text { I: Severe } \\
\text { head injury }\end{array}$ & 1.18 (1.12 to 1.25 & Age, gender, HR and SBP \\
\hline $\begin{array}{l}\text { Heart rate } \\
\text { variability } \\
\text { or } \\
\text { complexity: } \\
\text { OH }\end{array}$ & $\begin{array}{l}\text { Batchinsky, } \\
2009\end{array}$ & 31 & $\begin{array}{l}\text { Heart rate } \\
\text { variability } \\
(800 \\
\text { beats })\end{array}$ & $\begin{array}{l}\text { M: Mortality: } \\
\text { not } \\
\text { specified }\end{array}$ & $\begin{array}{l}0.00007 \text { (0 to } \\
0.124)\end{array}$ & $\begin{array}{l}\text { Data set lengths of } 100, \\
\text { and } 200 \text { beats. }\end{array}$ \\
\hline $\begin{array}{l}\text { Heart rate } \\
\text { variability } \\
\text { or } \\
\text { complexity: } \\
\text { OH }\end{array}$ & $\begin{array}{l}\text { Batchinsky, } \\
2009\end{array}$ & 31 & $\begin{array}{l}\text { Heart rate } \\
\text { variability } \\
(200 \\
\text { beats })\end{array}$ & $\begin{array}{l}\text { M: Mortality: } \\
\text { not } \\
\text { specified }\end{array}$ & $\begin{array}{l}0.00045 \text { (0 to } \\
0.159)\end{array}$ & $\begin{array}{l}\text { Data set lengths of } 100, \\
\text { and } 800 \text { beats. }\end{array}$ \\
\hline $\begin{array}{l}\text { Heart rate } \\
\text { variability } \\
\text { or } \\
\text { complexity: } \\
\text { OH }\end{array}$ & $\begin{array}{l}\text { Batchinsky, } \\
2009\end{array}$ & 31 & $\begin{array}{l}\text { Heart rate } \\
\text { variability } \\
(100 \\
\text { beats })\end{array}$ & $\begin{array}{l}\text { M: Mortality: } \\
\text { not } \\
\text { specified }\end{array}$ & $\begin{array}{l}0.024(0.001 \text { to } \\
0.494)\end{array}$ & $\begin{array}{l}\text { Data set lengths of } 200, \\
\text { and } 800 \text { beats. }\end{array}$ \\
\hline
\end{tabular}




\begin{tabular}{|c|c|c|c|c|c|c|}
\hline & $\begin{array}{l}\text { Author, } \\
\text { Year } \\
\text { (see } \\
\text { Appendix B } \\
\text { for full } \\
\text { reference) }\end{array}$ & $\begin{array}{l}\text { Number } \\
\text { Analyzed } \\
\text { Age } \\
\text { Mean (SD) }\end{array}$ & $\begin{array}{l}\text { Measure } \\
\text { (cutpoint) } \\
\text { Subgroup }\end{array}$ & $\begin{array}{l}\text { Serious } \\
\text { Injury } \\
\text { Indicator } \\
\text { Type: } \\
\text { Indicator }\end{array}$ & $\begin{array}{l}\text { Multivariate } \\
\text { Results } \\
\text { Adjusted Odds } \\
\text { Ratio }(95 \% \mathrm{Cl})\end{array}$ & $\begin{array}{l}\text { Variables Included in } \\
\text { Model }\end{array}$ \\
\hline \begin{tabular}{|l|} 
Heart rate \\
variability \\
or \\
complexity: \\
OH
\end{tabular} & $\begin{array}{l}\text { Cooke, } \\
2006 a\end{array}$ & $\begin{array}{l}30 \\
43(2) \text { died } \\
35(3) \\
\text { survives }\end{array}$ & $\begin{array}{l}\text { Heart rate } \\
\text { variability }\end{array}$ & $\begin{array}{l}\text { M: Mortality: } \\
\text { not } \\
\text { specified }\end{array}$ & $\begin{array}{l}\text { Likelihood ratio } \\
\text { (X2HF/LF) } \\
\text { HF/LF, no } \\
\text { covariate: } 9.96, \\
\text { p=0.0016 } \\
\text { HF/LF, covariate } \\
\text { age: } 5.19, \\
p=0.0227 \\
\text { HF/LF, covariate } \\
\text { RRI: } 7.06, p=0.007 \\
\text { HF/LF, covariate } \\
\text { GCS: } 1.96, \\
p=0.1619 \\
\text { HF/LF, covariates } \\
\text { age, RRI, and } \\
\text { GCS: } 0.43, \\
p=0.487 \\
\text { *HF = R-R interval } \\
\text { spectral power at } \\
\text { the high frequency } \\
(0.15-0.4 \mathrm{~Hz}) \\
\text { *LF = R-R interval } \\
\text { spectral power at } \\
\text { the low frequency } \\
(0.05-0.15 \mathrm{~Hz}) \\
\text { *RRI = interbeat R- } \\
\mathrm{R} \text { interval }\end{array}$ & $\begin{array}{l}\text { Age, GCS score, and RRI } \\
\text { (interbeat R-R interval) }\end{array}$ \\
\hline \begin{tabular}{l|} 
Heart Rate: \\
OH
\end{tabular} & Garner, 2001 & \begin{tabular}{|l}
1,144 \\
(median) \\
33 (IQR \\
$21-53)$ \\
\end{tabular} & $\mathrm{HR}(>120)$ & \begin{tabular}{|l} 
I: Critical \\
Injury
\end{tabular} & $\begin{array}{l}2.53(1.15-5.60) \\
\text { Model } 1 \\
2.45(1.10-5.48) \\
\text { Model } 2\end{array}$ & $\begin{array}{l}\text { RR, GCS-motor, SBP, } \\
\text { capillary refill, and HR. } \\
\text { Models: differ in RR cut } \\
\text { offs: Model1: between } 10 \\
\text { and 29. (normal) } \\
\text { Model 2: } \mathrm{s}<10 \text { or }>29\end{array}$ \\
\hline \begin{tabular}{l|} 
Heart Rate: \\
OH
\end{tabular} & \begin{tabular}{|l} 
Guyette, \\
2011
\end{tabular} & $\begin{array}{l}1,168 \\
\text { Median } 44 \\
\text { IQR } 27 \text { to } \\
58)\end{array}$ & $\mathrm{HR}$ & M: Mortality & $0.97(0.96-0.98)$ & $\begin{array}{l}\text { Age, sex, initial SBP, HR, } \\
\text { RR, and GCS }\end{array}$ \\
\hline $\begin{array}{l}\text { Heart rate } \\
\text { variability } \\
\text { or } \\
\text { complexity: } \\
\text { OH }\end{array}$ & King, 2009 & $\begin{array}{l}75 \\
47(20)\end{array}$ & $\begin{array}{l}\text { Heart rate } \\
\text { variability } \\
\text { (SDNN } \\
\leq 24 \text { msec) }\end{array}$ & \begin{tabular}{|l|} 
R: Life- \\
saving \\
intervention
\end{tabular} & 11.7 (2.1 to 65.4$)$ & $\begin{array}{l}\text { HR, SBP, GCS, and high } \\
\text { suspicion of injury }\end{array}$ \\
\hline $\begin{array}{l}\text { Heart rate } \\
\text { variability } \\
\text { or } \\
\text { complexity: } \\
\text { OH }\end{array}$ & King, 2009 & $\begin{array}{l}75 \\
47(20)\end{array}$ & $\begin{array}{l}\text { Heart rate } \\
\text { variability } \\
\text { (SDNN } \\
\leq 39 \text { msec) }\end{array}$ & $\begin{array}{l}\text { I: Serious } \\
\text { Injury }\end{array}$ & 5.8 (1.9 to 17.1$)$ & $\begin{array}{l}\text { HR, SBP, GCS, and high } \\
\text { suspicion of injury }\end{array}$ \\
\hline
\end{tabular}




\begin{tabular}{|c|c|c|c|c|c|c|}
\hline & $\begin{array}{l}\text { Author, } \\
\text { Year } \\
\text { (see } \\
\text { Appendix B } \\
\text { for full } \\
\text { reference) }\end{array}$ & $\begin{array}{l}\text { Number } \\
\text { Analyzed } \\
\text { Age } \\
\text { Mean (SD) }\end{array}$ & $\begin{array}{l}\text { Measure } \\
\text { (cutpoint) } \\
\text { Subgroup }\end{array}$ & $\begin{array}{l}\text { Serious } \\
\text { Injury } \\
\text { Indicator } \\
\text { Type: } \\
\text { Indicator }\end{array}$ & $\begin{array}{l}\text { Multivariate } \\
\text { Results } \\
\text { Adjusted Odds } \\
\text { Ratio }(95 \% \mathrm{Cl})\end{array}$ & $\begin{array}{l}\text { Variables Included in } \\
\text { Model }\end{array}$ \\
\hline $\begin{array}{l}\text { Heart Rate: } \\
\mathrm{OH}\end{array}$ & Liu, 2014a & $\begin{array}{l}305 \\
39(16)\end{array}$ & $\begin{array}{l}\text { HR using } \\
\text { standard } \\
\text { monitor }\end{array}$ & \begin{tabular}{|l} 
R: Life- \\
saving \\
intervention
\end{tabular} & $\begin{array}{l}1.02(1.01-1.04) \\
p=0.01 \\
\text { per } 1 \text { unit increase }\end{array}$ & $\begin{array}{l}\text { Independent variables of } \\
\text { age, height, race, and } \\
\text { weight and with dependent } \\
\text { variables of in-hospital } \\
\text { initial vital sign } \\
\text { measurements and GCS } \\
\text { scores }\end{array}$ \\
\hline $\begin{array}{l}\text { Heart Rate: } \\
\mathrm{OH}\end{array}$ & Liu, 2014a & $\begin{array}{l}305 \\
39(16)\end{array}$ & $\begin{array}{l}\text { HR using } \\
\text { wireless } \\
\text { monitor }\end{array}$ & \begin{tabular}{|l|} 
R: Life- \\
saving \\
intervention
\end{tabular} & $\begin{array}{l}1.02(0.99-1.06) \\
p=0.21 \\
\text { per } 1 \text { unit increase }\end{array}$ & $\begin{array}{l}\text { Independent variables of } \\
\text { age, height, race, and } \\
\text { weight and with dependent } \\
\text { variables of in-hospital } \\
\text { initial vital sign } \\
\text { measurements and GCS } \\
\text { scores }\end{array}$ \\
\hline $\begin{array}{l}\text { Heart Rate: } \\
\text { OH }\end{array}$ & $\begin{array}{l}\text { Matsushima, } \\
2016\end{array}$ & 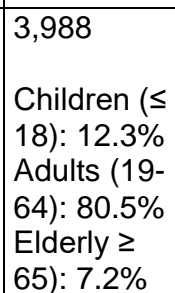 & $\mathrm{HR}(>100)$ & $\begin{array}{l}\text { R: Need for } \\
\text { trauma } \\
\text { center care }\end{array}$ & $1.37(1.13-1.66)$ & $\begin{array}{l}\text { "Clinically significant } \\
\text { variables" } \\
\text { logistic regression }\end{array}$ \\
\hline $\begin{array}{l}\text { Heart Rate: } \\
\text { OH } \\
\text { Children }\end{array}$ & $\begin{array}{l}\text { Nabaweesi, } \\
2014\end{array}$ & $\begin{array}{l}1,991 \\
\text { Median } \\
\text { Age: } 6\end{array}$ & \begin{tabular}{|l}
$\mathrm{HR}$ \\
(abnormal)
\end{tabular} & $\begin{array}{l}\text { R: ED } \\
\text { disposition } \\
\text { to ICU, OR } \\
\text { morgue }\end{array}$ & $\begin{array}{l}2.6(1.04-6.27) \\
p=0.039\end{array}$ & $\begin{array}{l}\text { SBP, respiratory distress, } \\
\text { HR, GCS, chest injury, } \\
\text { abdominal injury, spine } \\
\text { injury, air vs. ground, } \\
\text { health insurance, race, } \\
\text { age }\end{array}$ \\
\hline $\begin{array}{l}\text { Heart Rate: } \\
\text { ED } \\
\text { Elderly } \\
\end{array}$ & Pandit, 2014 & $\begin{array}{l}217,190 \\
77.7(7.1)\end{array}$ & $\mathrm{HR}$ & M: Mortality & $\begin{array}{l}1.1(0.9 \text { to } 1.3) \\
p=0.2\end{array}$ & $\begin{array}{l}\text { Age, male sex, ED SBP, } \\
\text { ED HR, SI, GCS score, } \\
\text { blunt mechanism of } \\
\text { trauma, and ISS }\end{array}$ \\
\hline $\begin{array}{l}\text { Heart Rate: } \\
\text { ED } \\
\text { Elderly }\end{array}$ & Pandit, 2014 & $\begin{array}{l}217,190 \\
77.7(7.1)\end{array}$ & $\begin{array}{l}\mathrm{HR} \\
\text { Age 65-74 }\end{array}$ & M: Mortality & $\begin{array}{l}1.1(0.9 \text { to } 1.9), \\
p=0.6\end{array}$ & $\begin{array}{l}\text { Age, male sex, ED SBP, } \\
\text { ED HR, SI, GCS score, } \\
\text { blunt mechanism of } \\
\text { trauma, and ISS }\end{array}$ \\
\hline $\begin{array}{l}\text { Heart Rate: } \\
\text { ED } \\
\text { Elderly }\end{array}$ & Pandit, 2014 & $\begin{array}{l}217,190 \\
77.7(7.1)\end{array}$ & \begin{tabular}{|l}
$\mathrm{HR}$ \\
Age 75-84
\end{tabular} & M: Mortality & $\begin{array}{l}1.1(0.8 \text { to } 2.1), p- \\
0.5\end{array}$ & $\begin{array}{l}\text { Age, male sex, ED SBP, } \\
\text { ED HR, SI, GCS score, } \\
\text { blunt mechanism of } \\
\text { trauma, and ISS }\end{array}$ \\
\hline $\begin{array}{l}\text { Heart Rate: } \\
\text { ED } \\
\text { Elderly }\end{array}$ & Pandit, 2014 & $\begin{array}{l}217,190 \\
77.7(7.1)\end{array}$ & $\begin{array}{l}\mathrm{HR} \\
\text { Age }>85\end{array}$ & M: Mortality & $\begin{array}{l}1.4(0.8 \text { to } 3.2), \\
p=0.2\end{array}$ & $\begin{array}{l}\text { Age, male sex, ED SBP, } \\
\text { ED HR, SI, GCS score, } \\
\text { blunt mechanism of } \\
\text { trauma, and ISS }\end{array}$ \\
\hline $\begin{array}{l}\text { Heart Rate: } \\
\text { OH }\end{array}$ & Raux, 2011 & $\begin{array}{l}\begin{array}{l}1,360 \\
\text { (national } \\
\text { cohort) }\end{array} \\
38(17)\end{array}$ & $\mathrm{HR}(\geq 100)$ & \begin{tabular}{|l} 
R: \\
Emergency \\
Procedure
\end{tabular} & $\begin{array}{l}1.42(1.12 \text { to } 1.79) \\
p=0.004\end{array}$ & $\begin{array}{l}\text { Penetrating trauma, } \\
\text { intravenous colloid } \\
\text { administration } 750 \mathrm{~mL} \text {, } \\
\text { systolic arterial blood } \\
\text { pressure } 100 \mathrm{mmHg} \text {, and } \\
\text { HR } 100 \mathrm{bpm}\end{array}$ \\
\hline
\end{tabular}

See Appendix B. Included Studies for full study references.

$\mathrm{ED}=$ emergency department; GCS = Glasgow Coma Scale; HF = high frequency; HR = heart rate; IQR = interquartile range; LF = low frequency; $\mathrm{NR}=$ not reported; $\mathrm{OH}$ = out of hospital; $\mathrm{OR}=$ operating room; $\mathrm{RR}$ = respiratory rate; $\mathrm{SBP}=$ systolic blood pressure; SI = shock index 
Table G2. Measures of respiratory compromise

\begin{tabular}{|c|c|c|c|c|c|c|}
\hline & $\begin{array}{l}\text { Author, Year } \\
\text { (see Appendix } \\
\text { B for full } \\
\text { reference) }\end{array}$ & Measure & $\begin{array}{l}\text { Serious } \\
\text { Injury } \\
\text { Indicator } \\
\text { Type: } \\
\text { Specific } \\
\text { Indicator }\end{array}$ & $\begin{array}{l}\text { Number } \\
\text { Analyzed } \\
\text { Age } \\
\text { Mean (SD) }\end{array}$ & $\begin{array}{l}\text { Adjusted } \\
\text { Odds Ratio }\end{array}$ & $\begin{array}{l}\text { Variables } \\
\text { Included in } \\
\text { Model }\end{array}$ \\
\hline $\begin{array}{l}\text { Base } \\
\text { Deficit: ED }\end{array}$ & Aslar, 2004 & Lactate & Mortality & $\begin{array}{l}64 \\
35.7(18.6)\end{array}$ & $\begin{array}{l}\text { Adjusted odds } \\
\text { ratio }(95 \% \mathrm{Cl}) \text { : } \\
10.58(1.88 \text { to } \\
59.24)\end{array}$ & Apache II \\
\hline $\begin{array}{l}\text { Base } \\
\text { Deficit: ED }\end{array}$ & Beekley, 2010 & $\mathrm{BD}$ & LSI & $\begin{array}{l}147 \\
27(11)\end{array}$ & $\begin{array}{l}\text { AOR } \\
\text { BD change of } \\
(-2 \text { mEq/L) } \\
1.54(1.1-2.2)\end{array}$ & $\begin{array}{l}\text { Retained: DBP, } \\
\text { INR, HCT, BD } \\
\text { Not Retained: } \\
\text { SBP, Hgb, THI } \\
\text { Not retained in } \\
\text { any model: } \\
\text { StO2, radial } \\
\text { pulse character, } \\
\text { HR, platelets, } \\
\text { and pH }\end{array}$ \\
\hline $\begin{array}{l}\text { Base } \\
\text { Deficit: ED }\end{array}$ & Dunne, 2005 & $\begin{array}{l}\mathrm{BD}>-6 \\
\mathrm{mmol} / \mathrm{L}\end{array}$ & M: Mortality & $\begin{array}{l}15,179 \\
37(19)\end{array}$ & $\begin{array}{l}\text { Not controlling } \\
\text { for alcohol and } \\
\text { drugs } \\
2.12(1.50- \\
3.010, p=0.0001\end{array}$ & NA \\
\hline $\begin{array}{l}\text { Base } \\
\text { Deficit: ED }\end{array}$ & Dunne, 2005 & $\begin{array}{l}\mathrm{BD}>-6 \\
\mathrm{mmol} / \mathrm{L}\end{array}$ & M: Mortality & $\begin{array}{l}15,179 \\
37(19)\end{array}$ & $\begin{array}{l}\text { Controlling for } \\
\text { alcohol and } \\
\text { drugs } \\
2.51(1.75- \\
3.60) \\
p=0.0001\end{array}$ & $\begin{array}{l}\text { Alcohol and } \\
\text { drug use }\end{array}$ \\
\hline $\begin{array}{l}\text { Base } \\
\text { Deficit: ED }\end{array}$ & Dunne, 2005 & $\begin{array}{l}\text { Decreasing } \\
\text { BD }\end{array}$ & $\begin{array}{l}\text { R: ICU } \\
\text { Admission }\end{array}$ & $\begin{array}{l}15,179 \\
37(19)\end{array}$ & $\begin{array}{l}\text { Not controlling } \\
\text { for alcohol and } \\
\text { drugs } \\
1.00(0.98- \\
1.02), p=0.64\end{array}$ & NA \\
\hline $\begin{array}{l}\text { Base } \\
\text { Deficit: ED }\end{array}$ & Dunne, 2005 & $\begin{array}{l}\mathrm{BD}>-6 \\
\mathrm{mmol} / \mathrm{L}\end{array}$ & $\begin{array}{l}\text { R: ICU } \\
\text { Admission }\end{array}$ & $\begin{array}{l}15,179 \\
37(19)\end{array}$ & $\begin{array}{l}\text { Controlling for } \\
\text { alcohol and } \\
\text { drugs } \\
1.00(0.98- \\
1.05), \text { p0.85 }\end{array}$ & $\begin{array}{l}\text { Alcohol and } \\
\text { drug use }\end{array}$ \\
\hline $\begin{array}{l}\text { Base } \\
\text { Deficit: ED }\end{array}$ & Herbert, 2011 & $\mathrm{BD}$ & $\begin{array}{l}\text { I: Serious } \\
\text { Injury }\end{array}$ & $\begin{array}{l}5934 \\
34.5(14.0)\end{array}$ & $\begin{array}{l}\text { BD: odds ratio } \\
0.76995 \% \mathrm{Cl} \\
0.6800 .858 \\
p=0.0002\end{array}$ & $\begin{array}{l}\text { Lactate, age, } \\
\text { ISS }\end{array}$ \\
\hline $\begin{array}{l}\text { Base } \\
\text { Deficit: ED }\end{array}$ & $\begin{array}{l}\text { St John, } 2016 \\
\text { Elderly }\end{array}$ & $\mathrm{BD}$ & $\begin{array}{l}\text { I: severe } \\
\text { multisystem } \\
\text { injury }\end{array}$ & $\begin{array}{l}3224 \\
\\
\text { Elderly } \\
(\geq 65): \\
22.4 \% \\
(721 / 3,224)\end{array}$ & $\begin{array}{l}\text { RR }(95 \% \mathrm{Cl}) \\
\text { BD: } 1.07(0.91 \\
\text { to } 1.25) \\
\mathrm{p}=0.43\end{array}$ & $\begin{array}{l}\text { Gender, ISS, } \\
\text { GCS on arrival, } \\
\text { and mechanism } \\
\text { of injury. ISS } \\
\text { was included as } \\
\text { a surrogate for } \\
\text { overall clinical } \\
\text { assessment of } \\
\text { severity of } \\
\text { injury. }\end{array}$ \\
\hline
\end{tabular}




\begin{tabular}{|c|c|c|c|c|c|c|}
\hline & $\begin{array}{l}\text { Author, Year } \\
\text { (see Appendix } \\
\text { B for full } \\
\text { reference) }\end{array}$ & Measure & $\begin{array}{l}\text { Serious } \\
\text { Injury } \\
\text { Indicator } \\
\text { Type: } \\
\text { Specific } \\
\text { Indicator }\end{array}$ & $\begin{array}{l}\text { Number } \\
\text { Analyzed } \\
\text { Age } \\
\text { Mean (SD) }\end{array}$ & $\begin{array}{l}\text { Adjusted } \\
\text { Odds Ratio }\end{array}$ & $\begin{array}{l}\text { Variables } \\
\text { Included in } \\
\text { Model }\end{array}$ \\
\hline $\begin{array}{l}\text { ETCO2: } \\
\text { ED }\end{array}$ & Williams, 2016 & $\begin{array}{l}\text { End-tidal } \\
\text { CO2 } \\
\left(\mathrm{ETCO}_{2}\right) \\
\leq 30\end{array}$ & $\begin{array}{l}\text { Severe injury } \\
\text { composite }\end{array}$ & $\begin{array}{l}170 \\
43(N R)\end{array}$ & $\begin{array}{l}\text { Odds ratio } 1.06 \\
(95 \% \text { Cl } 1.01- \\
1.13), \\
p=0.0423\end{array}$ & $\begin{array}{l}\text { Triage vital } \\
\text { signs }\end{array}$ \\
\hline $\begin{array}{l}\text { Oxygen } \\
\text { saturation } \\
\text { ED }\end{array}$ & Imjoff, 2014 & $\begin{array}{l}\mathrm{O} 2 \\
\text { saturation }\end{array}$ & $\begin{array}{l}\text { Mortality, in- } \\
\text { hospital }\end{array}$ & $\begin{array}{l}3680 \\
36.5(17.0) \\
\text { Alive } \\
43.7(21.0) \\
\text { Dead }\end{array}$ & $\begin{array}{l}\text { Adjusted odds } \\
\text { ratio }(95 \% \mathrm{Cl}) \text {, } \\
\text { per } 1 \text { unit } \\
\text { increase: } 0.961 \\
(0.940-0.982) \\
p=0.0004\end{array}$ & $\begin{array}{l}\text { All parameters } \\
\text { in REMS. Odds } \\
\text { ratios used to } \\
\text { estimate } \\
\text { relative strength } \\
\text { of parameters } \\
\text { in score. }\end{array}$ \\
\hline $\begin{array}{l}\text { Oxygen } \\
\text { saturation } \\
\text { ED }\end{array}$ & Khasawneh,2014 & $\begin{array}{l}\text { StO2 } \\
<65 \%\end{array}$ & $\begin{array}{l}\text { R: Massive } \\
\text { Transfusion }\end{array}$ & $\begin{array}{l}325 \\
46(N R)\end{array}$ & $\begin{array}{l}\text { Adjusted odds } \\
\text { ratio }(95 \% \mathrm{Cl}) \text { : } \\
-2.65(-10.2 \text { to }- \\
1.4), p=0.01\end{array}$ & $\begin{array}{l}\text { Age, sex, } \\
\text { relative } \\
\text { probability of } \\
\text { survival, injury } \\
\text { severity score, } \\
\text { mechanism of } \\
\text { trauma, } \\
\text { traumatic brain } \\
\text { injury, use of } \\
\text { anticoagulants } \\
\text { and beta } \\
\text { blockers, } \\
\text { transfer time, } \\
\text { out-of-hospital } \\
\text { blood } \\
\text { transfusion, } \\
\text { SBP, HR, RR, } \\
\text { oxygen } \\
\text { saturation, } \\
\text { GCS, } \\
\text { hemoglobin, } \\
\text { pH, base } \\
\text { deficit, lactate } \\
\text { level, and the } \\
\text { Focused } \\
\text { Assessment } \\
\text { with } \\
\text { Sonography for } \\
\text { Trauma } \\
\text { (FAST). }\end{array}$ \\
\hline $\begin{array}{l}\text { Oxygen } \\
\text { saturation } \\
\mathrm{OH}\end{array}$ & Sagraves, 2009 & $\begin{array}{l}\text { Minimum } \\
\text { STo2 }\end{array}$ & Mortality & $\begin{array}{l}41 \\
N R\end{array}$ & $\begin{array}{l}\text { Odds ratio } 2.28 \\
\text { (95\% Cl NR), } \\
p=0.0423\end{array}$ & $\begin{array}{l}\text { Routine vital } \\
\text { signs } \\
\text { (variables: HR, } \\
\text { SBP, PP) and } \\
\text { STO2 }\end{array}$ \\
\hline $\begin{array}{l}\text { Respiratory } \\
\text { effort: } \mathrm{OH}\end{array}$ & Lehmann, 2007 & $\begin{array}{l}\text { Respiratory } \\
\text { effort }\end{array}$ & $\begin{array}{l}\text { R: Emergent } \\
\text { Intervention }\end{array}$ & $\begin{array}{l}1495 \\
41(22)\end{array}$ & $\begin{array}{l}\text { Adjusted odds } \\
\text { ratio }(95 \% \mathrm{Cl}) \text { : } \\
4.6(1.9 \text { to } 11) \\
p<0.01\end{array}$ & $\begin{array}{l}\text { Age, sex, } \\
\text { mechanism of } \\
\text { injury, HR, GCS, } \\
\text { SBP }\end{array}$ \\
\hline
\end{tabular}




\begin{tabular}{|c|c|c|c|c|c|c|}
\hline & $\begin{array}{l}\text { Author, Year } \\
\text { (see Appendix } \\
\text { B for full } \\
\text { reference) }\end{array}$ & Measure & $\begin{array}{l}\text { Serious } \\
\text { Injury } \\
\text { Indicator } \\
\text { Type: } \\
\text { Specific } \\
\text { Indicator }\end{array}$ & $\begin{array}{l}\text { Number } \\
\text { Analyzed } \\
\text { Age } \\
\text { Mean (SD) }\end{array}$ & $\begin{array}{l}\text { Adjusted } \\
\text { Odds Ratio }\end{array}$ & $\begin{array}{l}\text { Variables } \\
\text { Included in } \\
\text { Model }\end{array}$ \\
\hline RR: ED & Imhoff, 2014 & RR & $\begin{array}{l}\text { Mortality in- } \\
\text { hospital }\end{array}$ & $\begin{array}{l}3680 \\
36.5(17.0) \\
\text { survived } \\
43.7(21.0) \\
\text { died }\end{array}$ & $\begin{array}{l}\text { Adjusted odds } \\
\text { ratio }(95 \% \mathrm{Cl}) \text {, } \\
\text { per } 1 \text { unit } \\
\text { increase: } 1.001 \\
(0.978-1.025) \\
\mathrm{p}=0.9023\end{array}$ & $\begin{array}{l}\text { All parameters } \\
\text { in REMS. Odds } \\
\text { ratios used to } \\
\text { estimate } \\
\text { relative strength } \\
\text { of parameters } \\
\text { in score. }\end{array}$ \\
\hline RR: ED & Parsikia, 2014 & $\mathrm{RR}$ & Mortality & $\begin{array}{l}1941 \\
\text { Median 47 } \\
\text { (IQR 28- } \\
67 \text { ) }\end{array}$ & $\begin{array}{l}\text { Odds ratop } \\
1.05 \text { (1.04 to } \\
1.07)\end{array}$ & $\begin{array}{l}\text { Age, gender, } \\
\text { initial SBP, HR, } \\
\text { respiratory rate, } \\
\text { GCS, packed } \\
\text { red blood cells, } \\
\text { and serum } \\
\text { lactate }\end{array}$ \\
\hline RR: OH & Garner, 2001 & $\mathrm{RR}>29$ & Critical Injury & $\begin{array}{l}1144 \\
\text { Median } 33 \\
\text { IQR } 21 \text { to } \\
\text { 53) }\end{array}$ & $\begin{array}{l}\text { Jackknife } \\
\text { adjusted odds } \\
\text { ratio }(95 \% \mathrm{Cl}) \text { : } \\
2.35(0.99- \\
5.61)\end{array}$ & $\begin{array}{l}\text { RR, GCS- } \\
\text { motor, SBP, } \\
\text { capillary refill, } \\
\text { and HR. } \\
\text { Models: differ in } \\
\text { RR cut offs: } \\
\text { Model1: } \\
\text { between } 10 \text { and } \\
\text { 29. (normal) } \\
\text { Model } 2: \mathrm{s}<10 \\
\text { or }>29\end{array}$ \\
\hline RR: OH & Garner, 2001 & $\begin{array}{l}\mathrm{RR}<10 \text { or } \\
>29\end{array}$ & Critical Injury & $\begin{array}{l}1144 \\
\text { Median } 33 \\
\text { IQR } 21 \text { to } \\
\text { 53) }\end{array}$ & $\begin{array}{l}\text { Jackknife } \\
\text { adjusted odds } \\
\text { ratio }(95 \% \mathrm{Cl}): \\
2.64(1.21- \\
5.76)\end{array}$ & $\begin{array}{l}\text { RR, GCS- } \\
\text { motor, SBP, } \\
\text { capillary refill, } \\
\text { and HR. } \\
\text { Models: differ in } \\
\text { RR cut offs: } \\
\text { Model1: } \\
\text { between } 10 \text { and } \\
\text { 29. (normal) } \\
\text { Model 2: } \mathrm{s}<10 \\
\text { or }>29\end{array}$ \\
\hline RR: OH & Henry, 1996 & $\begin{array}{l}\mathrm{RR}<10 \text { or } \\
>29\end{array}$ & $\begin{array}{l}\text { Major } \\
\text { nonorthopedic } \\
\text { interventions } \\
\text { or death }\end{array}$ & $\begin{array}{l}1545 \\
\text { Median } 30 \\
\text { (range } 0 \text { to } \\
93 \text { ) }\end{array}$ & $\begin{array}{l}\text { Adjusted odds } \\
\text { ratio }(95 \% \mathrm{Cl}) \text { : } \\
5.0(0.8-29.9) \text {, } \\
\text { not significant }\end{array}$ & $\begin{array}{l}\text { II ACS trauma } \\
\text { triage criteria } \\
\text { without regard } \\
\text { to statistical } \\
\text { significance. } \\
\text { Includes SBP, } \\
\text { GCS, RR, } 3 \\
\text { anatomic } \\
\text { criteria, age, } \\
\text { known cardiac } \\
\text { or respiratory } \\
\text { disease and } 8 \\
\text { mechanism } \\
\text { criteria. }\end{array}$ \\
\hline RR: OH & Henry, 1996 & $\begin{array}{l}\mathrm{RR}<10 \text { or } \\
>29\end{array}$ & ISS $\geq 16$ & $\begin{array}{l}1545 \\
\text { Median } 30 \\
\text { (range } 0 \text { to } \\
93 \text { ) } \\
\end{array}$ & $\begin{array}{l}\text { Adjusted odds } \\
\text { ratio }(95 \% \mathrm{Cl}) \text { : } \\
2.5(0.6-9.8), \\
\text { not significant }\end{array}$ & $\begin{array}{l}\text { II ACS trauma } \\
\text { triage criteria }\end{array}$ \\
\hline
\end{tabular}




\begin{tabular}{|c|c|c|c|c|c|c|}
\hline & $\begin{array}{l}\text { Author, Year } \\
\text { (see Appendix } \\
\text { B for full } \\
\text { reference) }\end{array}$ & Measure & $\begin{array}{l}\text { Serious } \\
\text { Injury } \\
\text { Indicator } \\
\text { Type: } \\
\text { Specific } \\
\text { Indicator }\end{array}$ & $\begin{array}{l}\text { Number } \\
\text { Analyzed } \\
\text { Age } \\
\text { Mean (SD) }\end{array}$ & $\begin{array}{l}\text { Adjusted } \\
\text { Odds Ratio }\end{array}$ & $\begin{array}{l}\text { Variables } \\
\text { Included in } \\
\text { Model }\end{array}$ \\
\hline RR: OH & Liu, 2014a & $\begin{array}{l}\text { RR: } \\
\text { standard } \\
\text { monitor }\end{array}$ & LSI in ED & $\begin{array}{l}305 \\
39(16)\end{array}$ & $\begin{array}{l}\text { Adjusted odds } \\
\text { ratio }(95 \% \mathrm{Cl}) \text {, } \\
\text { per unit } \\
\text { increase: } 1.02 \\
(0.99-1.04) \\
\mathrm{p}=0.16\end{array}$ & $\begin{array}{l}\text { Independent } \\
\text { variables of } \\
\text { age, height, } \\
\text { race, and } \\
\text { weight and with } \\
\text { dependent } \\
\text { variables of in- } \\
\text { hospital initial } \\
\text { vital sign } \\
\text { measurements } \\
\text { and GCS } \\
\text { scores }\end{array}$ \\
\hline RR: OH & Liu, 2014a & $\begin{array}{l}\text { RR: } \\
\text { wireless } \\
\text { monitor }\end{array}$ & LSI in ED & $\begin{array}{l}305 \\
39(16)\end{array}$ & $\begin{array}{l}\text { Adjusted odds } \\
\text { ratio }(95 \% \mathrm{Cl}) \text {, } \\
\text { per unit } \\
\text { increase: } 1.10 \\
(1.01-1.21) \\
\mathrm{p}=0.02\end{array}$ & $\begin{array}{l}\text { Independent } \\
\text { variables of } \\
\text { age, height, } \\
\text { race, and } \\
\text { weight and with } \\
\text { dependent } \\
\text { variables of in- } \\
\text { hospital initial } \\
\text { vital sign } \\
\text { measurements } \\
\text { and GCS } \\
\text { scores }\end{array}$ \\
\hline $\begin{array}{l}\text { RR: OH } \\
\text { may be } \\
\text { both }\end{array}$ & Nabaweesi, 2014 & $\begin{array}{l}\text { Respiratory } \\
\text { distress }\end{array}$ & $\begin{array}{l}\text { ICU, OR use, } \\
\text { or mortality }\end{array}$ & $\begin{array}{l}1991 \\
\text { Median } \\
\text { Age: } 6\end{array}$ & $\begin{array}{l}\text { Odds ratio: } 2.9 \\
\text { (95\% } \mathrm{Cl} 0.72- \\
11.8), p=0.133\end{array}$ & $\begin{array}{l}\text { SBP, } \\
\text { respiratory } \\
\text { distress, HR, } \\
\text { GCS, chest } \\
\text { injury, } \\
\text { abdominal } \\
\text { injury, spine } \\
\text { injury, air vs. } \\
\text { ground, health } \\
\text { insurance, race, } \\
\text { age }\end{array}$ \\
\hline
\end{tabular}

See Appendix B. Included Studies for full study references.

$\mathrm{AOR}=$ adjusted odds ratio $\mathrm{BD}$ = base deficit; $\mathrm{CI}=$ confidence interval; $\mathrm{DBP}=$ diastolic blood pressure; $\mathrm{ED}=$ emergency department; GCS = Glasgow Coma Scale; HR = heart rate; ICU = intensive care unit; INR = international normalized ratio; ISS = Injury Severity Score; LSI = life-saving intervention; NA = not applicable; $\mathrm{OH}=$ out of hospital; $\mathrm{PP}=$ pulse pressure; REMS = Rapid Emergency Medicine Score; RR = respiratory rate; SBP = systolic blood pressure; SD = standard deviation; StO2 = tissue oxygen saturation 


\section{Appendix H. Strength of Evidence}

Table H1. Strength of evidence: out-of-hospital

\begin{tabular}{|c|c|c|c|c|c|c|c|c|c|}
\hline Key Question & Measure & $\begin{array}{l}\text { Number } \\
\text { of } \\
\text { Studies } \\
\text { (N) }\end{array}$ & $\begin{array}{c}\text { Study } \\
\text { Limitations } \\
\text { (Low, } \\
\text { Medium, } \\
\text { High) }\end{array}$ & $\begin{array}{l}\text { Directness } \\
\text { (Direct, } \\
\text { Indirect) }\end{array}$ & $\begin{array}{c}\text { Consistenc } \\
\text { y } \\
\text { Consistent, } \\
\text { Inconsistent, } \\
\text { Unknown }\end{array}$ & $\begin{array}{l}\text { Precision } \\
\text { (Precise, } \\
\text { Imprecise) }\end{array}$ & $\begin{array}{c}\text { Reporting } \\
\text { Bias } \\
\text { (Not detected, } \\
\text { Suspected) }\end{array}$ & Main Findings & \begin{tabular}{|} 
Strength of \\
Evidence \\
Grade \\
(Insufficient, \\
Low, \\
Moderate, \\
High)
\end{tabular} \\
\hline \multirow{20}{*}{$\begin{array}{l}\text { KQ } 1 . \\
\text { Predictive } \\
\text { utility of } \\
\text { measures of } \\
\text { circulatory } \\
\text { compromise }\end{array}$} & $\star$ SBP & 9 & Medium & Direct & Consistent & Precise & Not detected & $\begin{array}{l}\text { AUROC: } 0.67(95 \% \mathrm{Cl}, 0.58-0.75 \text {, } \\
\left.\left.\right|^{2}=90.1 \%\right)\end{array}$ & Moderate \\
\hline & $\begin{array}{l}* \text { SBP } \\
<90\end{array}$ & 17 & High & Direct & Inconsistent & Imprecise & Not detected & Sen: $19 \%(12-29 \%, 98.8)$ & Low \\
\hline & $\begin{array}{l}* \text { SBP } \\
<90\end{array}$ & 17 & High & Direct & Consistent & Precise & Not detected & Sp: 95\% (91-97\%, 99.2) & Moderate \\
\hline & $\begin{array}{l}* \text { SBP } \\
<100+\end{array}$ & 6 & Medium & Direct & Inconsistent & Imprecise & Not detected & Sen: 35\% (19-54\%, 99.7) & Low \\
\hline & $\begin{array}{l}* \text { SBP } \\
<100+\end{array}$ & 6 & Medium & Direct & Inconsistent & Imprecise & Not detected & Sp: 88\% (73-95\%, 99.8) & Low \\
\hline & $\star \mathrm{HR}$ & 5 & Medium & Direct & Inconsistent & Imprecise & Not detected & $\begin{array}{l}\text { AUROCs: } 0.67(95 \% \mathrm{Cl} 0.56 \text { to } \\
\left.\text { o.79, } \mathrm{I}^{2}=84.5 \%\right)\end{array}$ & Low \\
\hline & $\begin{array}{l}{ }^{\star} \mathrm{HR}>110 \text { or } \\
120\end{array}$ & 4 & Medium & Direct & Inconsistent & Imprecise & Not detected & Sen: 28\% (20-37\% 41.3) & Low \\
\hline & $\begin{array}{l}{ }^{*} \mathrm{HR}>110 \text { or } \\
120\end{array}$ & 4 & Medium & Direct & Inconsistent & Imprecise & Not detected & Sp: 85\% (74-91\%, 88.0) & Low \\
\hline & $\star \mathrm{SI}$ & 7 & Medium & Direct & Inconsistent & Imprecise & Not detected & $\begin{array}{l}\text { AUROC: } 0.72(95 \% \mathrm{CI} 0.66 \text { to } \\
\left.\text { O. } 77, \mathrm{I}^{2}=54.6 \%\right)\end{array}$ & Low \\
\hline & $* \mathrm{SI}>1$ & 5 & Medium & Direct & Inconsistent & Imprecise & Not detected & Sen: 37\% (22-56\% 94.5) & Low \\
\hline & $\star S I>1$ & 5 & Medium & Direct & Inconsistent & Precise & Not detected & Sp: 85\% (72-92\%, 99.6) & Low \\
\hline & $\mathrm{BD}$ & 0 & - & - & - & - & - & & Insufficient \\
\hline & $\star$ Lactate & 2 & Low & Direct & Inconsistent & Precise & Not detected & $\begin{array}{l}\text { AUROC: } 0.77(95 \% \mathrm{Cl} 0.67 \text { to } \\
\left.\text { O82, } I^{2}=10.2\right)\end{array}$ & Low \\
\hline & $\star$ Lactate $>2$ & 3 & Medium & Direct & Inconsistent & Imprecise & Not detected & Sen: $74 \%(48-90 \%, 98.5)$ & Low \\
\hline & $\star$ Lactate $>2$ & 3 & Medium & Direct & Consistent & Precise & Not detected & Sp: $\quad 62 \%(51-72 \%, 98.6)$ & Moderate \\
\hline & $\star$ Lactate $>4$ & 1 & - & - & - & - & - & Sen:23\% (21-25\%, NA) & Insufficient \\
\hline & $\star{ }^{\circ}$ Lactate $>4$ & 1 & - & - & - & - & - & Sp: 93\% (92-94\%, NA) & Insufficient \\
\hline & HRV/HRC & 7 & High & Direct & Consistent & Imprecise & Not detected & AUROCs: 0.60 to 0.95 & Low \\
\hline & HRV/HRC & 2 & High & Direct & Consistent & Precise & Not detected & Sen: 80 to $90 \%$ & Low \\
\hline & HRV/HRC & 2 & High & Direct & Consistent & Imprecise & Not detected & Sp: 67 to $100 \%$ & Low \\
\hline
\end{tabular}




\begin{tabular}{|c|c|c|c|c|c|c|c|c|c|}
\hline Key Question & Measure & $\begin{array}{c}\text { Number } \\
\text { of } \\
\text { Studies } \\
\text { (N) }\end{array}$ & \begin{tabular}{|c} 
Study \\
Limitations \\
(Low, \\
Medium, \\
High) \\
\end{tabular} & $\begin{array}{c}\text { Directness } \\
\text { (Direct, } \\
\text { Indirect) }\end{array}$ & $\begin{array}{c}\text { Consistenc } \\
\text { y } \\
\text { Consistent, } \\
\text { Inconsistent, } \\
\text { Unknown } \\
\end{array}$ & $\begin{array}{l}\text { Precision } \\
\text { (Precise, } \\
\text { Imprecise) } \\
\end{array}$ & $\begin{array}{c}\text { Reporting } \\
\text { Bias } \\
\text { (Not detected, } \\
\text { Suspected) }\end{array}$ & Main Findings & \begin{tabular}{|c} 
Strength of \\
Evidence \\
Grade \\
(Insufficient, \\
Low, \\
Moderate, \\
High) \\
\end{tabular} \\
\hline \multirow{8}{*}{$\begin{array}{l}\text { KQ } 2 . \\
\text { Predictive } \\
\text { utility of } \\
\text { measures of } \\
\text { respiratory } \\
\text { compromise }\end{array}$} & ${ }^{\star} \mathrm{RR}$ & 3 & Low & Direct & Consistent & Imprecise & Not detected & $\begin{array}{l}0.70(95 \% \mathrm{Cl} 0.66 \text { to } 0.79, \\
\left.I^{2}=16.6 \%\right)\end{array}$ & Low \\
\hline & ${ }^{\star} \mathrm{RR}$ & 6 & Low & Direct & Inconsistent & Imprecise & Not detected & Sen: 13\% (5-29\% 97.8) & Low \\
\hline & ${ }^{\star} \mathrm{RR}$ & 6 & Low & Direct & Inconsistent & Imprecise & Not detected & Sp: 96\% (83-99\%, 99.6) & Low \\
\hline & O2 Sat & 3 & Medium & Direct & Inconsistent & Imprecise & Not detected & AUROCs: 0.530 to 0.747 & Low \\
\hline & O2 Sat & 3 & Medium & Direct & Inconsistent & Imprecise & Not detected & Sen: $13 \%$ to $63 \%$ & Low \\
\hline & O2 Sat & 3 & Medium & Direct & Consistent & Imprecise & Not detected & Sp:85\% to $99 \%$ & Low \\
\hline & \begin{tabular}{|l} 
Airway \\
Support
\end{tabular} & 4 & High & Direct & Inconsistent & Imprecise & Not detected & Sen: $8 \%$ to $53 \%$ & Low \\
\hline & \begin{tabular}{|l|} 
Airway \\
Support
\end{tabular} & 4 & High & Direct & Inconsistent & Imprecise & Not detected & Sp: $61 \%$ to $100 \%$ & Low \\
\hline \multirow{4}{*}{$\begin{array}{l}\text { KQ } 3 . \\
\text { Predictive } \\
\text { utility for } \\
\text { combinations } \\
\text { of measures }\end{array}$} & RTS & 3 & Medium & Direct & Inconsistent & Precise & - & $\begin{array}{l}\text { AUROC: } 0.570(95 \% \mathrm{Cl} 0.423 \text { to } \\
\left.0.720, I^{2}=16.6 \%\right)\end{array}$ & Low \\
\hline & RTS & 1 & - & - & - & - & - & Sen $95 \%$ & Insufficient \\
\hline & RTS & 1 & - & - & - & - & - & Sp: $38 \%$ & Insufficient \\
\hline & GAP & 0 & - & - & - & - & - & & Insufficient \\
\hline
\end{tabular}

AUROC = area under the receiver operating characteristic curve; $\mathrm{HR}=$ heart rate; $\mathrm{HRC}=$ heart rate complexity; $\mathrm{HRV}=$ heart rate variability; $\mathrm{KQ}=\mathrm{Key}$ Question; O2 sat =

oxygen saturation; RR = respiratory rate; GAP=GSC, airway, pressure; RTS = Revised Trauma Scale; SBP = systolic blood pressure; Sen = sensitivity; SI = shock index; Sp = specificity

*Assessment is of pooled studies for the measures analyzed using meta-analysis. 
Table H2. Strength of evidence: emergency department

\begin{tabular}{|c|c|c|c|c|c|c|c|c|c|}
\hline Key Question & Measure & $\begin{array}{l}\text { Number of } \\
\text { Studies } \\
\text { (N) }\end{array}$ & $\begin{array}{c}\text { Study } \\
\text { Limitations } \\
\text { (Low, Medium, } \\
\text { High) }\end{array}$ & $\begin{array}{l}\text { Directness } \\
\text { (Direct, } \\
\text { Indirect) }\end{array}$ & $\begin{array}{c}\text { Consistency } \\
\text { Consistent, } \\
\text { Inconsistent, } \\
\text { Unknown }\end{array}$ & $\begin{array}{l}\text { Precision } \\
\text { (Precise, } \\
\text { Imprecise) }\end{array}$ & $\begin{array}{c}\text { Reporting } \\
\text { Bias } \\
\text { (Not detected, } \\
\text { Suspected) }\end{array}$ & $\begin{array}{c}\text { Main } \\
\text { Findings }\end{array}$ & $\begin{array}{c}\text { Strength of } \\
\text { Evidence } \\
\text { Grade } \\
\text { (Insufficient, } \\
\text { Low, } \\
\text { Moderate, } \\
\text { High) }\end{array}$ \\
\hline \multirow{9}{*}{$\begin{array}{l}\text { KQ 1. Predictive } \\
\text { utility of } \\
\text { measures of } \\
\text { circulatory } \\
\text { compromise }\end{array}$} & $*$ SBP & 12 & Medium & Direct & Consistent & Precise & Not detected & 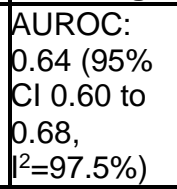 & Moderate \\
\hline & $\begin{array}{l}* \text { SBP } \\
<90\end{array}$ & 9 & Medium & Direct & Inconsistent & Imprecise & Not detected & $\begin{array}{l}\text { Sen: } 18 \% \\
(11-28 \%, \\
99.1) \\
\end{array}$ & Low \\
\hline & $\begin{array}{l}\star \text { SBP } \\
<90\end{array}$ & 9 & Medium & Direct & Consistent & Precise & Not detected & $\begin{array}{l}\text { Sp: } 97 \% \\
(97-98 \%, \\
93.5)\end{array}$ & Moderate \\
\hline & $\begin{array}{l}{ }^{*} \text { SBP } \\
<100+\end{array}$ & 4 & Medium & Direct & Inconsistent & Imprecise & Not detected & $\begin{array}{l}\text { Sen: 35\% } \\
(14-63 \%, \\
98.7) \\
\end{array}$ & Low \\
\hline & $\begin{array}{l}{ }^{*} \text { SBP } \\
<100+\end{array}$ & 4 & Medium & Direct & Consistent & Imprecise & Not detected & $\begin{array}{l}\text { Sp: } 89 \% \\
(75-95 \%, \\
99.5)\end{array}$ & Moderate \\
\hline & $\star \mathrm{HR}$ & 9 & Medium & Direct & Consistent & Precise & Not detected & $\begin{array}{l}\text { AUROC: } \\
\text { 0.66 (95\% } \\
\text { CI } 0.62 \text { to } \\
0.70 \\
\left.1^{2}=83.9 \%\right) \\
\end{array}$ & Moderate \\
\hline & $\star \mathrm{HR}$ & 5 & Medium & Direct & Consistent & Precise & Not detected & $\begin{array}{l}\text { Sen: } 29 \% \\
(26-32 \%, \\
26.7) \\
\end{array}$ & Moderate \\
\hline & $\star \mathrm{HR}$ & 5 & Medium & Direct & Consistent & Precise & Not detected & $\begin{array}{l}\text { Sp: } 93 \% \\
(90-95 \%, \\
94.5)\end{array}$ & Moderate \\
\hline & $\star \mathrm{SI}$ & 11 & Medium & Direct & Consistent & Precise & Not detected & $\begin{array}{l}\text { AUROC: } \\
\text { 0.71 (95\% } \\
\text { CI } 0.66 \text { to } \\
0.76 \\
\left.1^{2}=94.7 \%\right)\end{array}$ & Moderate \\
\hline
\end{tabular}




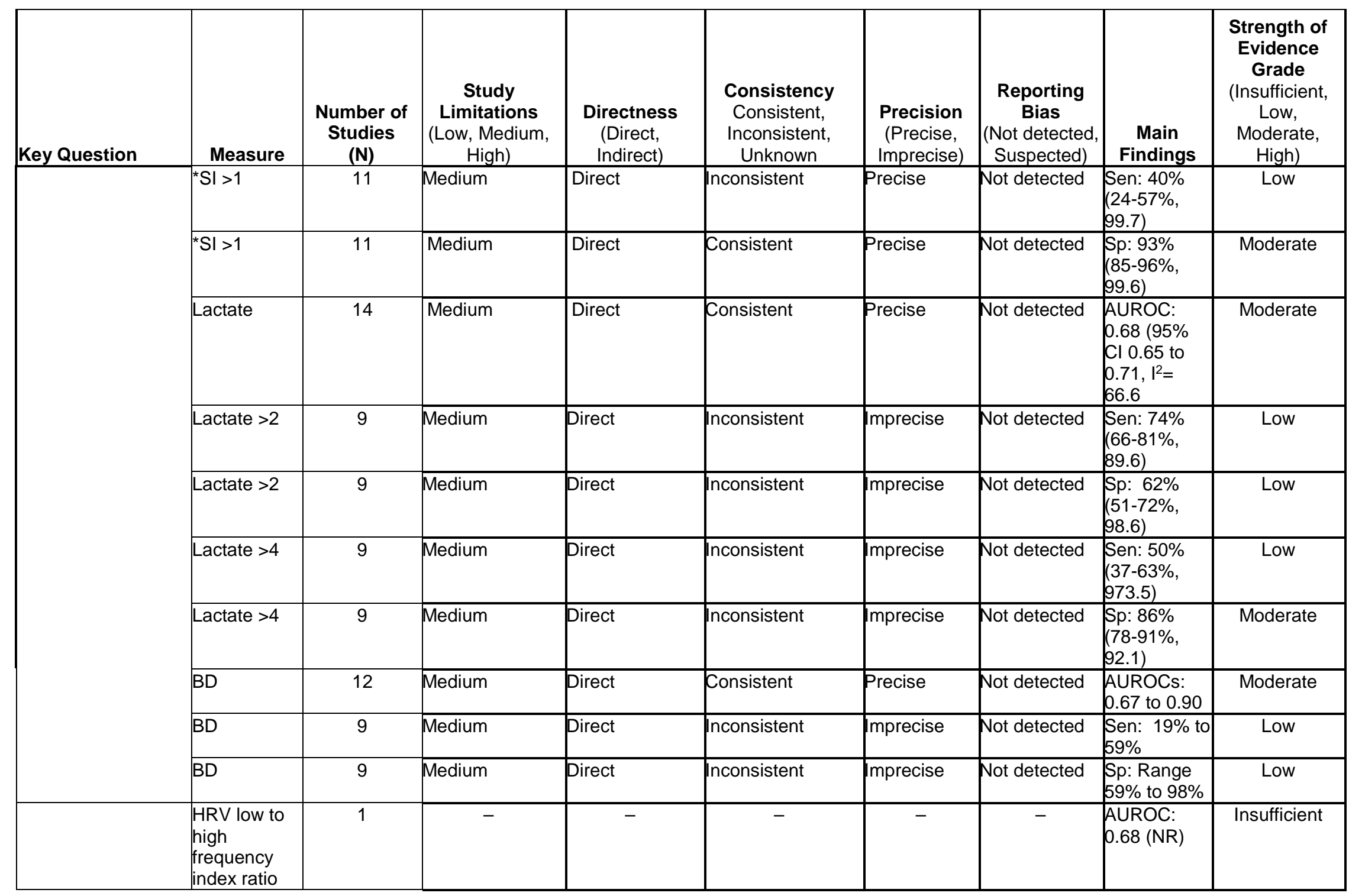




\begin{tabular}{|c|c|c|c|c|c|c|c|c|c|}
\hline Key Question & Measure & $\begin{array}{c}\text { Number of } \\
\text { Studies } \\
\text { (N) }\end{array}$ & $\begin{array}{c}\text { Study } \\
\text { Limitations } \\
\text { (Low, Medium, } \\
\text { High) }\end{array}$ & $\begin{array}{l}\text { Directness } \\
\text { (Direct, } \\
\text { Indirect) }\end{array}$ & $\begin{array}{l}\text { Consistency } \\
\text { Consistent, } \\
\text { Inconsistent, } \\
\text { Unknown }\end{array}$ & $\begin{array}{l}\text { Precision } \\
\text { (Precise, } \\
\text { Imprecise) }\end{array}$ & $\begin{array}{c}\text { Reporting } \\
\text { Bias } \\
\text { (Not detected, } \\
\text { Suspected) }\end{array}$ & $\begin{array}{l}\text { Main } \\
\text { Findings }\end{array}$ & $\begin{array}{c}\text { Strength of } \\
\text { Evidence } \\
\text { Grade } \\
\text { (Insufficient, } \\
\text { Low, } \\
\text { Moderate, } \\
\text { High) }\end{array}$ \\
\hline & $\begin{array}{l}\text { HRV/HRC } \\
\text { spectral } \\
\text { power at } \\
\text { very low } \\
\text { frequency }\end{array}$ & 1 & - & - & - & - & - & $\begin{array}{l}\text { AUROC: } \\
\text { p.67 (NR) }\end{array}$ & Insufficient \\
\hline \multirow{8}{*}{$\begin{array}{l}\text { KQ 2. Predictive } \\
\text { utility of measures } \\
\text { of respiratory } \\
\text { compromise }\end{array}$} & $\mathrm{RR}$ & 3 & Medium & Direct & Consistent & Precise & Not detected & $\begin{array}{l}\text { AUROC: } \\
\text { 0.61 (95\% } \\
\text { CI } 0.48 \text { to } \\
0.74, \\
\left.1^{2}=90.5 \%\right) \\
\end{array}$ & Moderate \\
\hline & RR & 4 & Medium & Direct & Inconsistent & Precise & Not detected & $\begin{array}{l}\text { Sen: } 27 \% \\
(21-35 \%, \\
95.2)\end{array}$ & Moderate \\
\hline & RR & 4 & Medium & Direct & Consistent & Precise & Not detected & $\begin{array}{l}\text { Sp: } 95 \% \\
(94-96 \%, \\
93.5)\end{array}$ & Moderate \\
\hline & O2 Sat & 2 & Medium & Direct & Consistent & Precise & Not detected & $\begin{array}{l}\text { AUROCs: } \\
\text { 0.61 to } 0.76\end{array}$ & Low \\
\hline & O2 Sat & 2 & Medium & Direct & Inconsistent & Imprecise & Not detected & $\begin{array}{l}\text { Sen: } 25 \% \text { to } \\
100 \%\end{array}$ & Low \\
\hline & O2 Sat & 2 & Medium & Direct & Inconsistent & Imprecise & Not detected & $\begin{array}{l}\text { Sp: } 39 \% \text { to } \\
99 \%\end{array}$ & Low \\
\hline & \begin{tabular}{|l|} 
Airway \\
Support
\end{tabular} & 3 & Medium & Direct & Inconsistent & Imprecise & Not detected & $\begin{array}{l}\text { Sen: } 32 \% \text { to } \\
57 \%\end{array}$ & Low \\
\hline & \begin{tabular}{|l} 
Airway \\
Support
\end{tabular} & 3 & Medium & Direct & Inconsistent & Imprecise & Not detected & $\begin{array}{l}\text { Sp: } 85 \% \text { to } \\
96 \%\end{array}$ & Low \\
\hline
\end{tabular}




\begin{tabular}{|c|c|c|c|c|c|c|c|c|c|}
\hline Key Question & Measure & $\begin{array}{c}\text { Number of } \\
\text { Studies } \\
\text { (N) }\end{array}$ & $\begin{array}{c}\text { Study } \\
\text { Limitations } \\
\text { (Low, Medium, } \\
\text { High) } \\
\end{array}$ & $\begin{array}{c}\text { Directness } \\
\text { (Direct, } \\
\text { Indirect) } \\
\end{array}$ & $\begin{array}{c}\text { Consistency } \\
\text { Consistent, } \\
\text { Inconsistent, } \\
\text { Unknown } \\
\end{array}$ & $\begin{array}{l}\text { Precision } \\
\text { (Precise, } \\
\text { Imprecise) } \\
\end{array}$ & \begin{tabular}{|c} 
Reporting \\
Bias \\
(Not detected, \\
Suspected)
\end{tabular} & $\begin{array}{c}\text { Main } \\
\text { Findings } \\
\end{array}$ & $\begin{array}{c}\text { Strength of } \\
\text { Evidence } \\
\text { Grade } \\
\text { (Insufficient, } \\
\text { Low, } \\
\text { Moderate, } \\
\text { High) } \\
\end{array}$ \\
\hline \multirow[t]{6}{*}{$\begin{array}{l}\text { KQ 3. Predictive } \\
\text { utility for } \\
\text { combinations of } \\
\text { measures }\end{array}$} & RTS & 7 & Medium & Direct & Inconsistent & Precise & Not detected & $\begin{array}{l}\text { AUROC } \\
0.88(95 \% \\
\text { CI } 0.82 \text { to } \\
0.92, \\
\left.I^{2}=94.9 \%\right) \\
\end{array}$ & Low \\
\hline & RTS & 6 & Medium & Direct & Inconsistent & Imprecise & Not detected & $\begin{array}{l}\text { Sen:19\% to } \\
84 \%\end{array}$ & Low \\
\hline & RTS & 6 & Medium & Direct & Inconsistent & Imprecise & Not detected & $\begin{array}{l}\text { Sp: } 64 \% \text { to } \\
100 \%\end{array}$ & Low \\
\hline & GAP & 3 & Medium & Direct & Consistent & Precise & Not detected & $\begin{array}{l}\text { AUROC: } \\
0.96 \text { (95\% } \\
\text { CI } 0.90 \text { to } \\
1.00, \\
I^{2}=94.2 \% \text { for } \\
\text { Mortality) }\end{array}$ & Moderate \\
\hline & GAP & 2 & Medium & Direct & Inconsistent & Imprecise & Not detected & $\begin{array}{l}\text { Sen: } 75 \% \text { to } \\
98 \%\end{array}$ & Low \\
\hline & GAP & 2 & Medium & Direct & Inconsistent & Imprecise & Not detected & $\begin{array}{l}\text { Sp: } 57 \% \text { to } \\
91 \%\end{array}$ & Low \\
\hline
\end{tabular}

AUROC = area under the receiver operating characteristic curve; BD = base deficit; ETCO2 = end-tidal carbon dioxide; GAP = Glasgow Coma Scale, age, and arterial pressure; $\mathrm{HR}=$ heart rate; HRC = heart rate complexity; HRV = heart rate variability; KQ = Key Question; O2 sat = oxygen saturation; RR = respiratory rate; RTS = Revised Trauma Scale; SBP = systolic blood pressure; Sen = sensitivity; SI = shock index; SLCO2 = sublingual capnometry; Sp = specificity

*Assessment is of pooled studies for the measures analyzed using meta-analysis. 


\section{Appendix I. Meta-Analysis Results for Studies of Predictive Utility in the Emergency Department Setting}

Figure I1. Pooled sensitivity of emergency department SBP $<90 \mathrm{mmHg}$

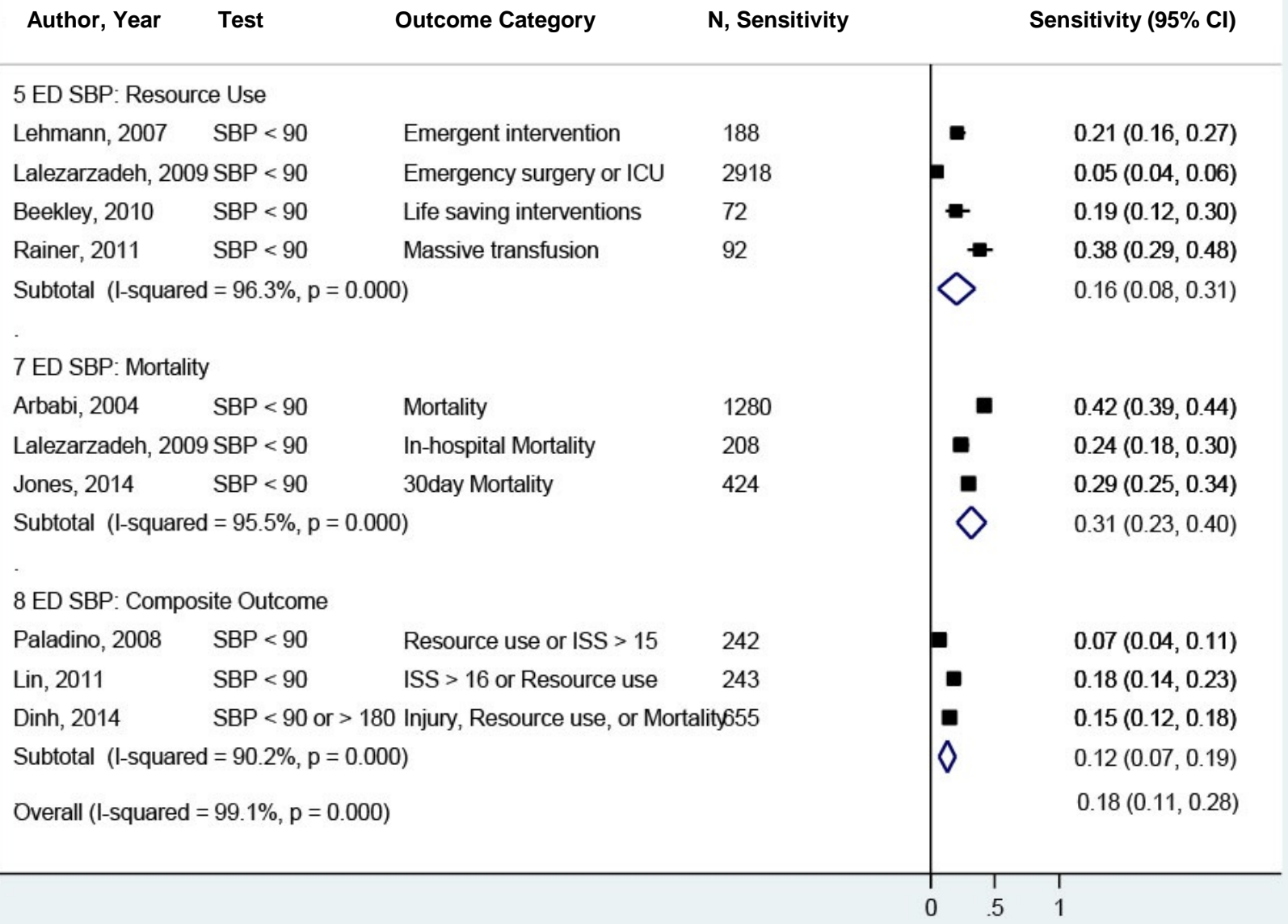

Overall results are from the bivariate logistic mixed effects model analysis. 
Figure 12. Pooled specificity of emergency department SBP $<90 \mathrm{mmHg}$

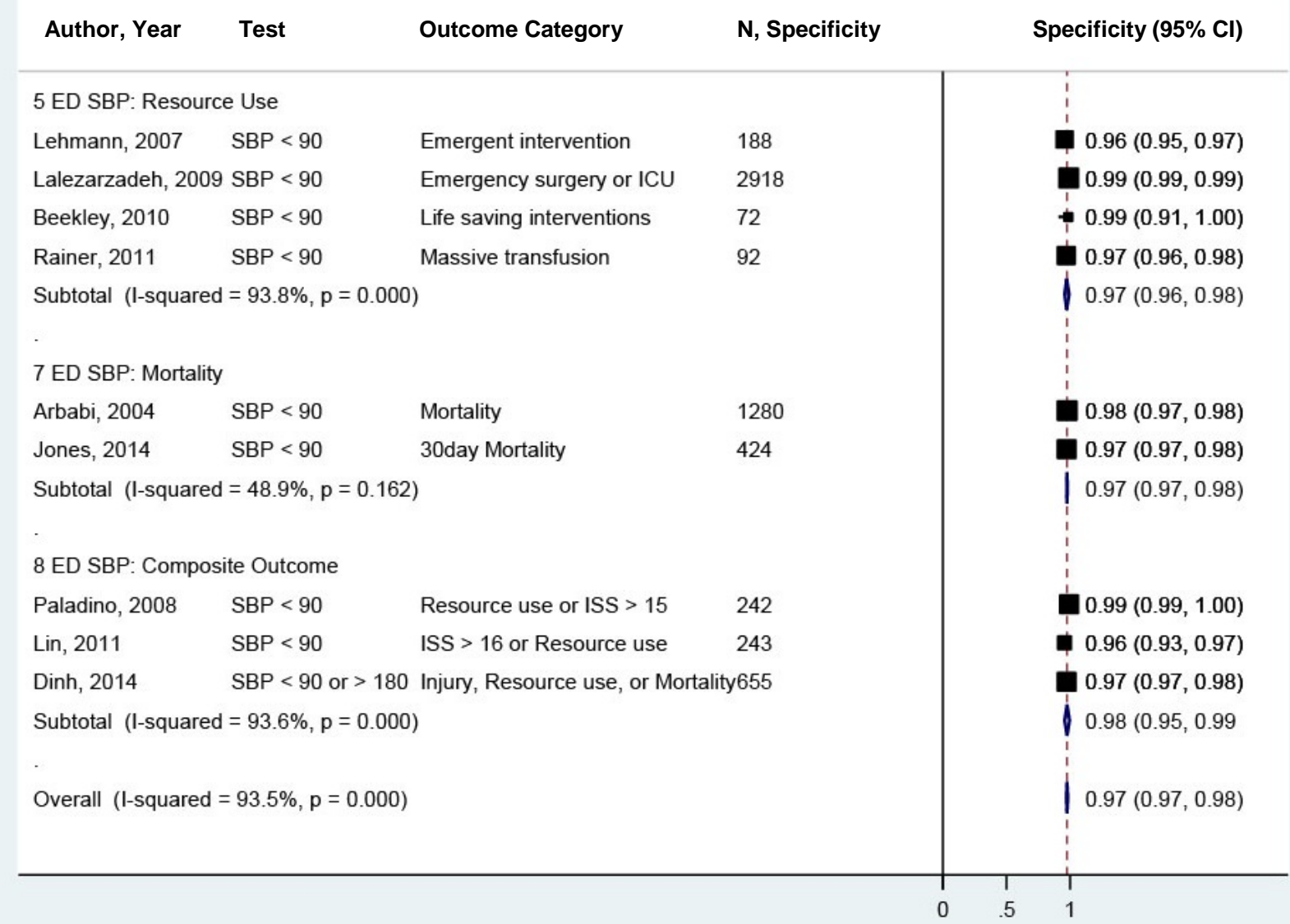

Overall results are from the bivariate logistic mixed effects model analysis. 
Figure 13. Pooled sensitivity of emergency department SBP $<100 \mathrm{mmHg}$

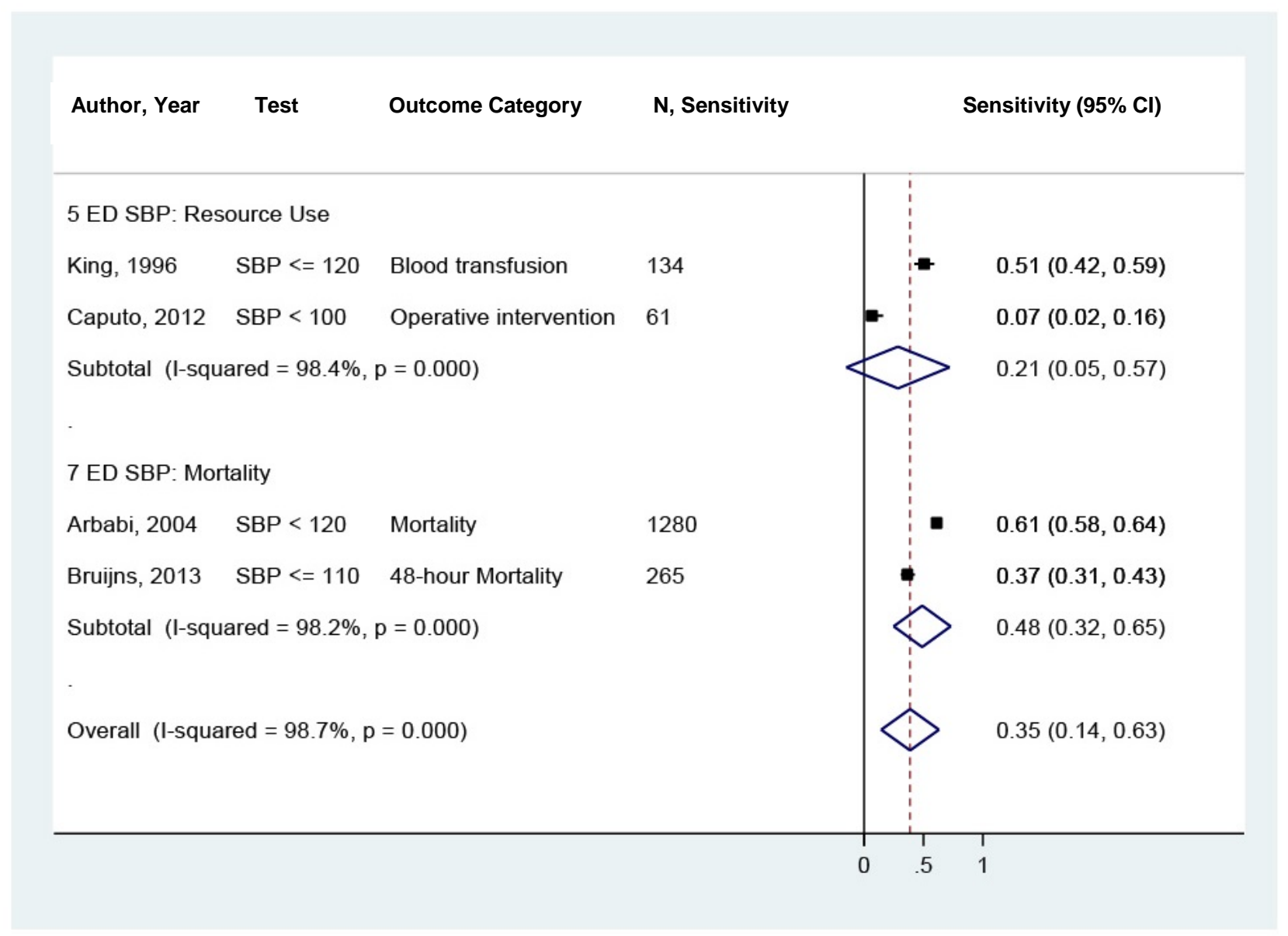

Overall results are from the bivariate logistic mixed effects model analysis. 
Figure 14. Pooled specificity of emergency department SBP $<100 \mathrm{mmHg}$

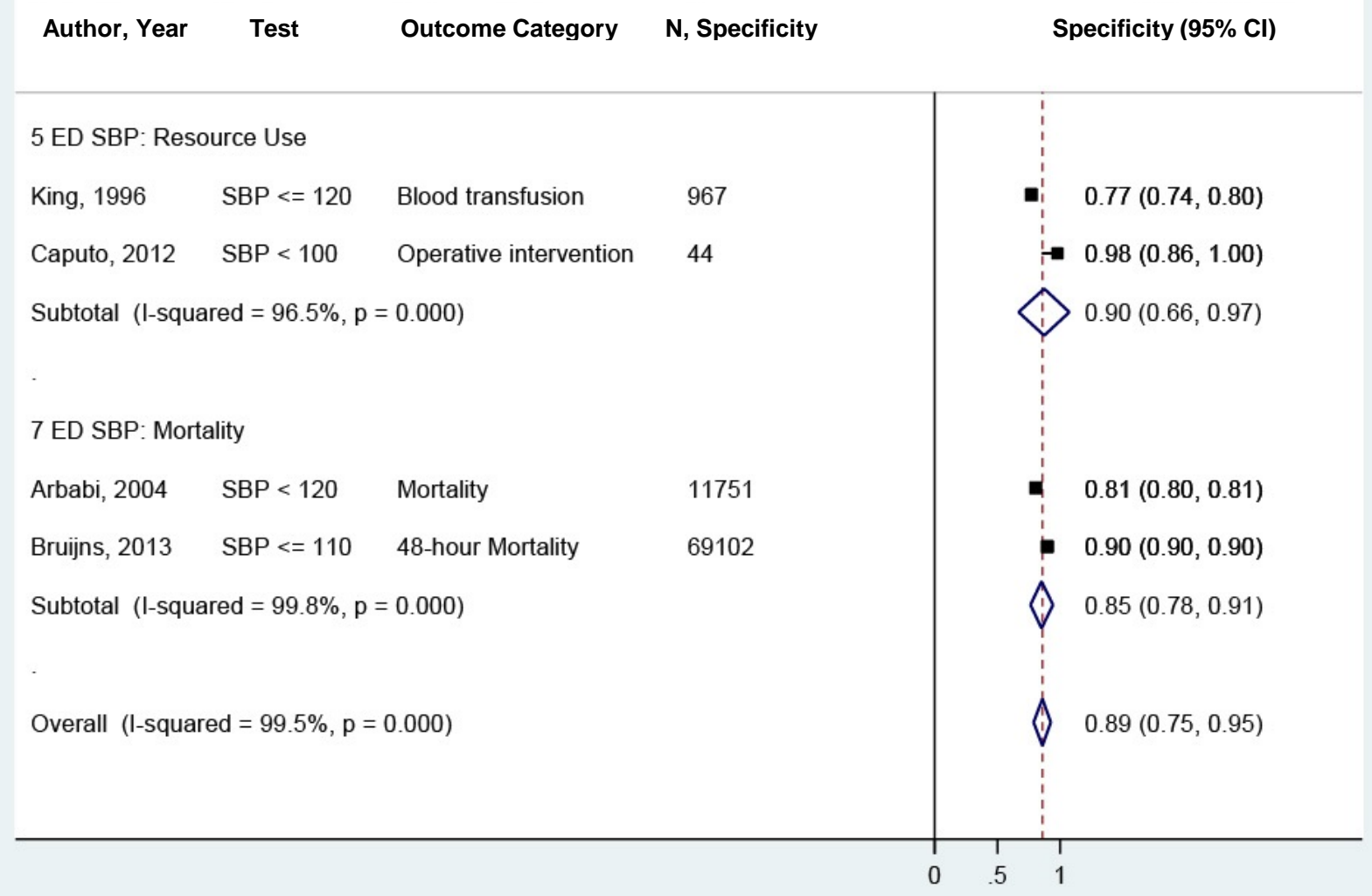

Overall results are from the bivariate logistic mixed effects model analysis. 
Figure I5. Pooled AUROC of emergency department systolic blood pressure

\begin{tabular}{|c|c|c|c|}
\hline Author, Year & Outcome Category & Total $\mathbf{N}$ & AUROC $(95 \% \mathrm{Cl})$ \\
\hline \multicolumn{4}{|c|}{5 ED SBP: Resource Use } \\
\hline Garner, 2001 & Life saving intervention & 1144 & $0.72(0.67,0.77)$ \\
\hline Zarzaur, 2008 & Blood transfusion & 16077 & $0.71(0.69,0.73)$ \\
\hline Beekley, 2010 & Life saving interventions & 147 & $0.65(0.58,0.72)$ \\
\hline Vandromme, 2010 & Blood transfusion & 2413 & $0.60(0.56,0.64)$ \\
\hline Vandromme, 2011b & Massive transfusion & 306 & $0.72(0.66,0.78)$ \\
\hline Reisner, 2016 & 24-hour RBC Transfusion & 487 & $0.62(0.48,0.76)$ \\
\hline $\begin{array}{l}\text { Subtotal (I-squared } \\
7 \text { ED SBP: Mortality }\end{array}$ & $=84.1 \%, p=0.000)$ & & $0.67(0.62,0.72)$ \\
\hline Al-Salamah, 2004 & Mortality, in-hospital & 795 & $0.63(0.58,0.68)$ \\
\hline Eastridge, 2007 & Mortality & 729736 & $0.58(0.58,0.59)$ \\
\hline Zarzaur, 2008 & Mortality: 48-hour & 16077 & $0.75(0.71,0.79)$ \\
\hline Vandromme, 2010 & In-hospital death & 2413 & $0.61(0.57,0.65)$ \\
\hline Bruijns, 2013 & 48-hour Mortality & 69367 & $0.66(0.62,0.70)$ \\
\hline Dunham, 2017 & Mortality & 1863 & $0.75(0.65,0.85)$ \\
\hline $\begin{array}{l}\text { Subtotal (I-squared } \\
8 \text { ED SBP: Composit }\end{array}$ & $\begin{array}{l}=94.4 \%, p=0.000) \\
\text { e Outcome }\end{array}$ & & 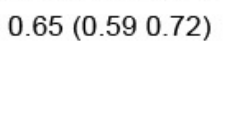 \\
\hline Paladino, 2010a & Resource use or ISS $>15$ & 805 & $0.51(0.46,0.56)$ \\
\hline Paladino, 2011 & Resource use or ISS $>15$ & 1028 & $0.61(0.57,0.65)$ \\
\hline \multicolumn{3}{|c|}{ Subtotal (I-squared $=87.2 \%, p=0.005)$} & $0.56(0.46,0.66)$ \\
\hline \multicolumn{3}{|c|}{ Overall $(\mathrm{I}$-squared $=95.7 \%, p=0.000)$} & $0.64(0.60,0.68)$ \\
\hline
\end{tabular}

Paladino, 2010a = Reference no. 98; Vandromme, 2011b = Reference no. 129.

Overall results are from the bivariate logistic mixed effects model analysis. 
Figure 16. Pooled sensitivity of emergency department heart rate $\geq 110$

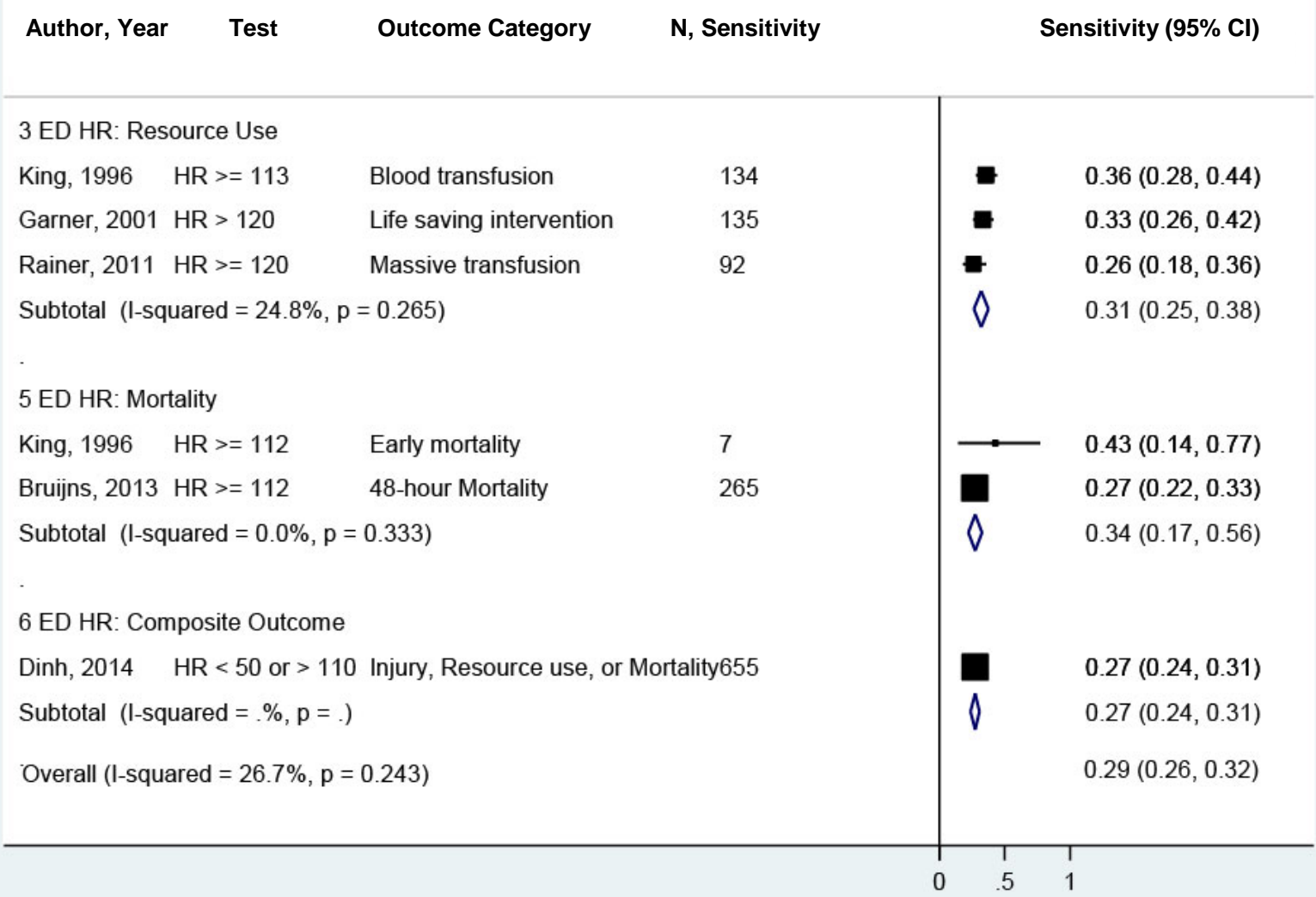

Overall results are from the bivariate logistic mixed effects model analysis. 
Figure 17. Pooled specificity of emergency department heart rate $\geq 110$

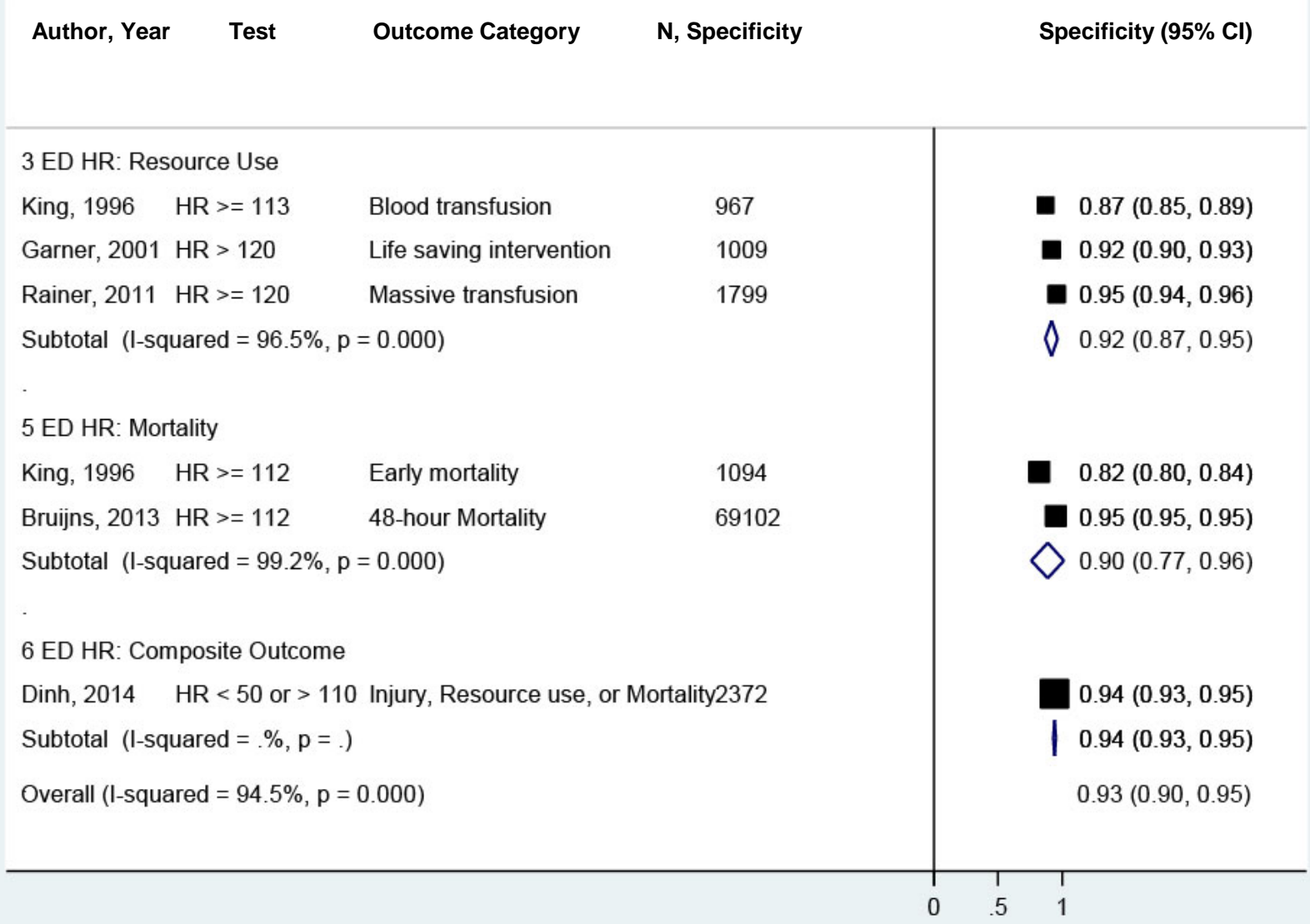

Overall results are from the bivariate logistic mixed effects model analysis. 
Figure 18. Pooled AUROC of emergency department heart rate $\geq 110$

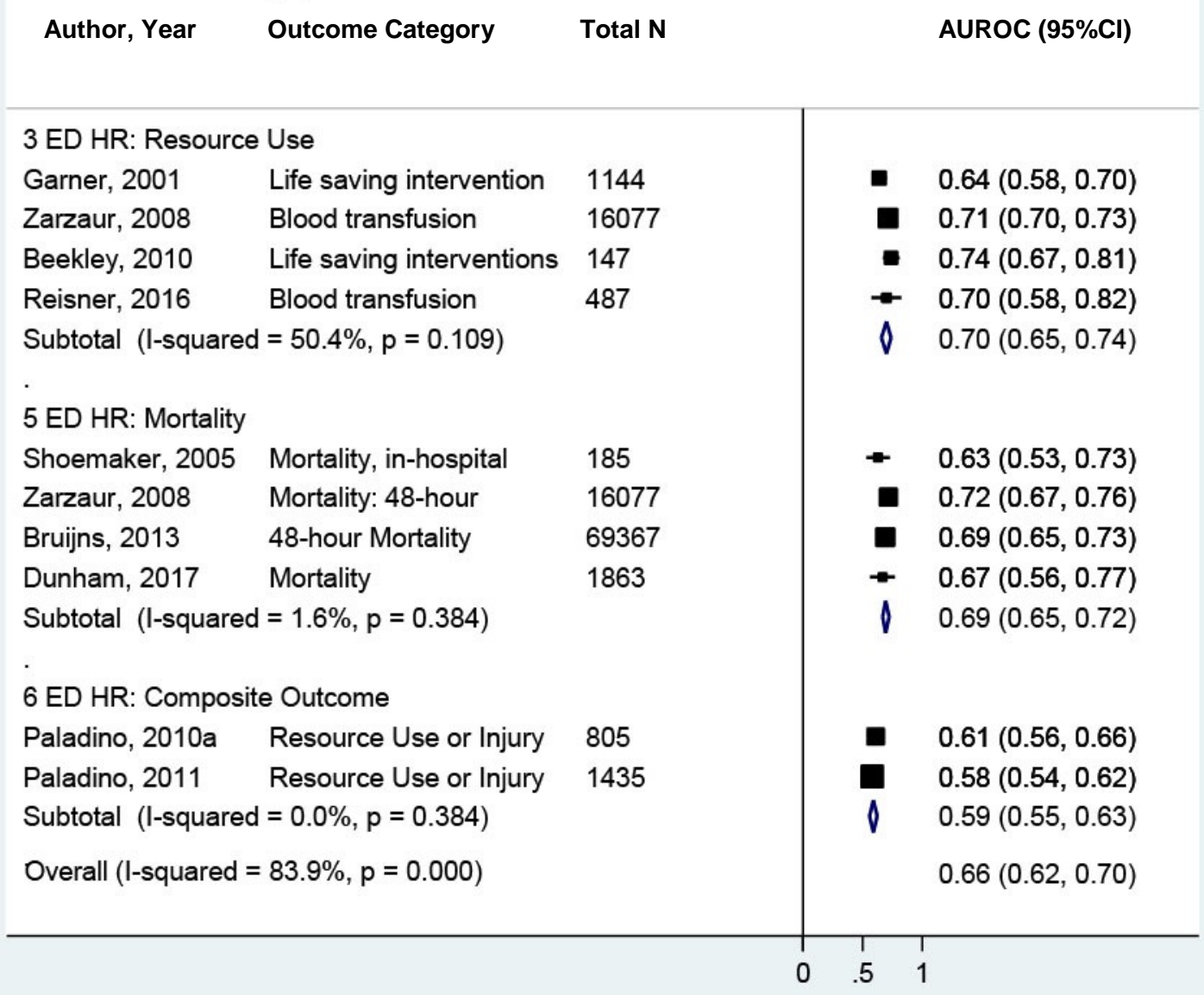

Paladino, 2010a = Reference no. 98.

Overall results are from the bivariate logistic mixed effects model analysis. 
Figure 19. Pooled sensitivity of emergency department shock index

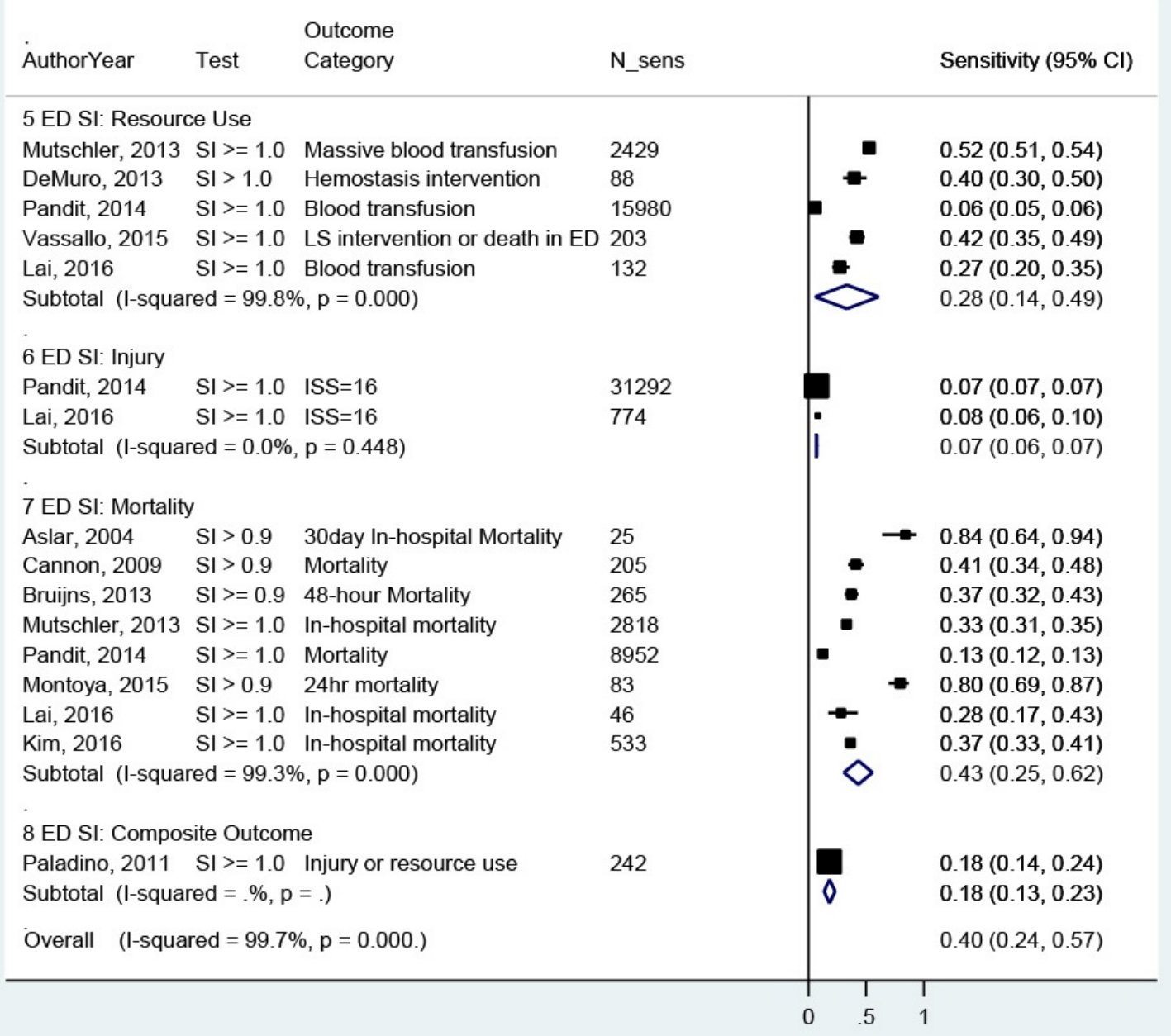

Overall results are from the bivariate logistic mixed effects model analysis. 
Figure I10. Pooled specificity of emergency department shock index, stratified by outcome

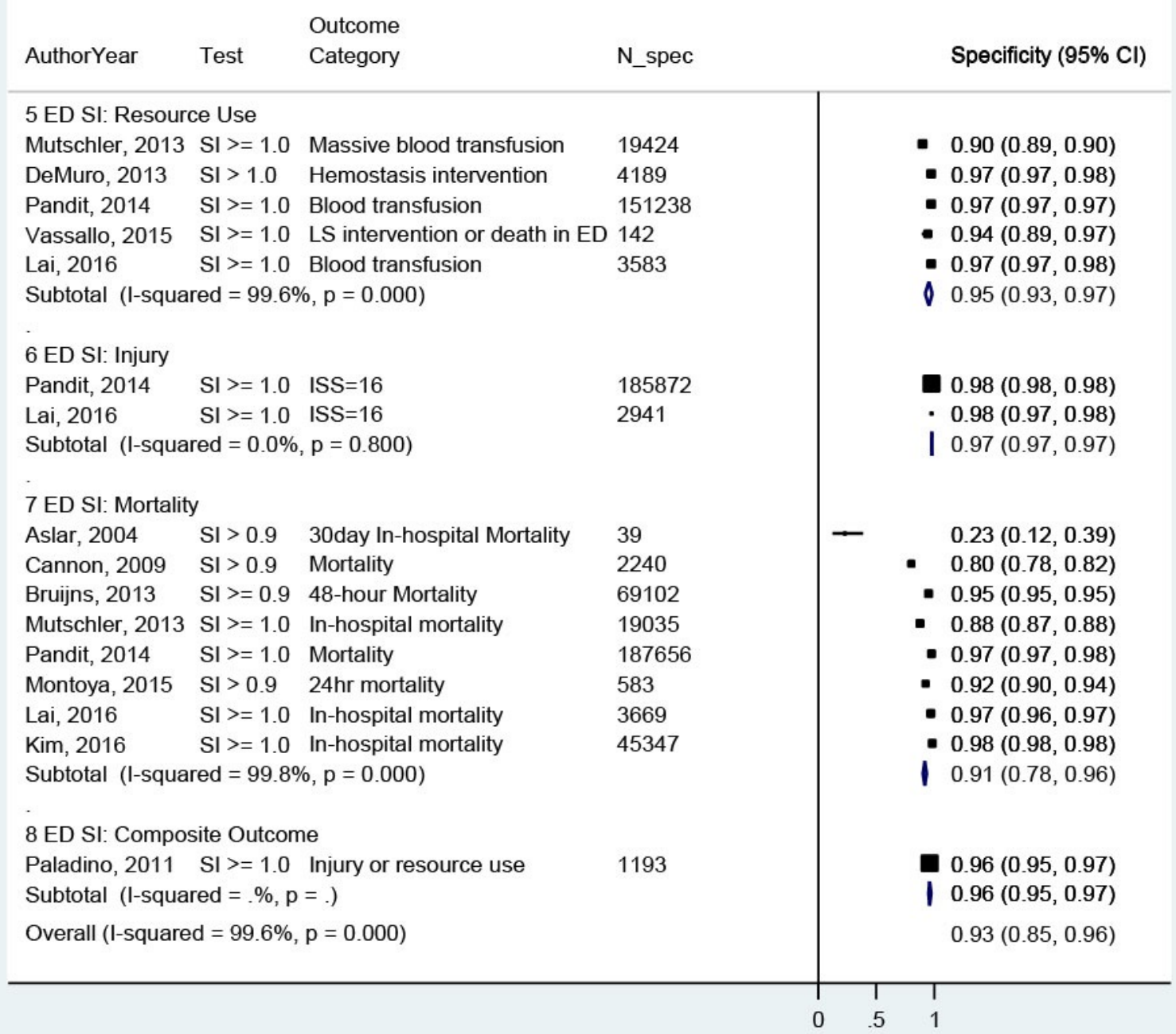

Overall results are from the bivariate logistic mixed effects model analysis. 
Figure I11. Pooled AUROC of emergency department shock index

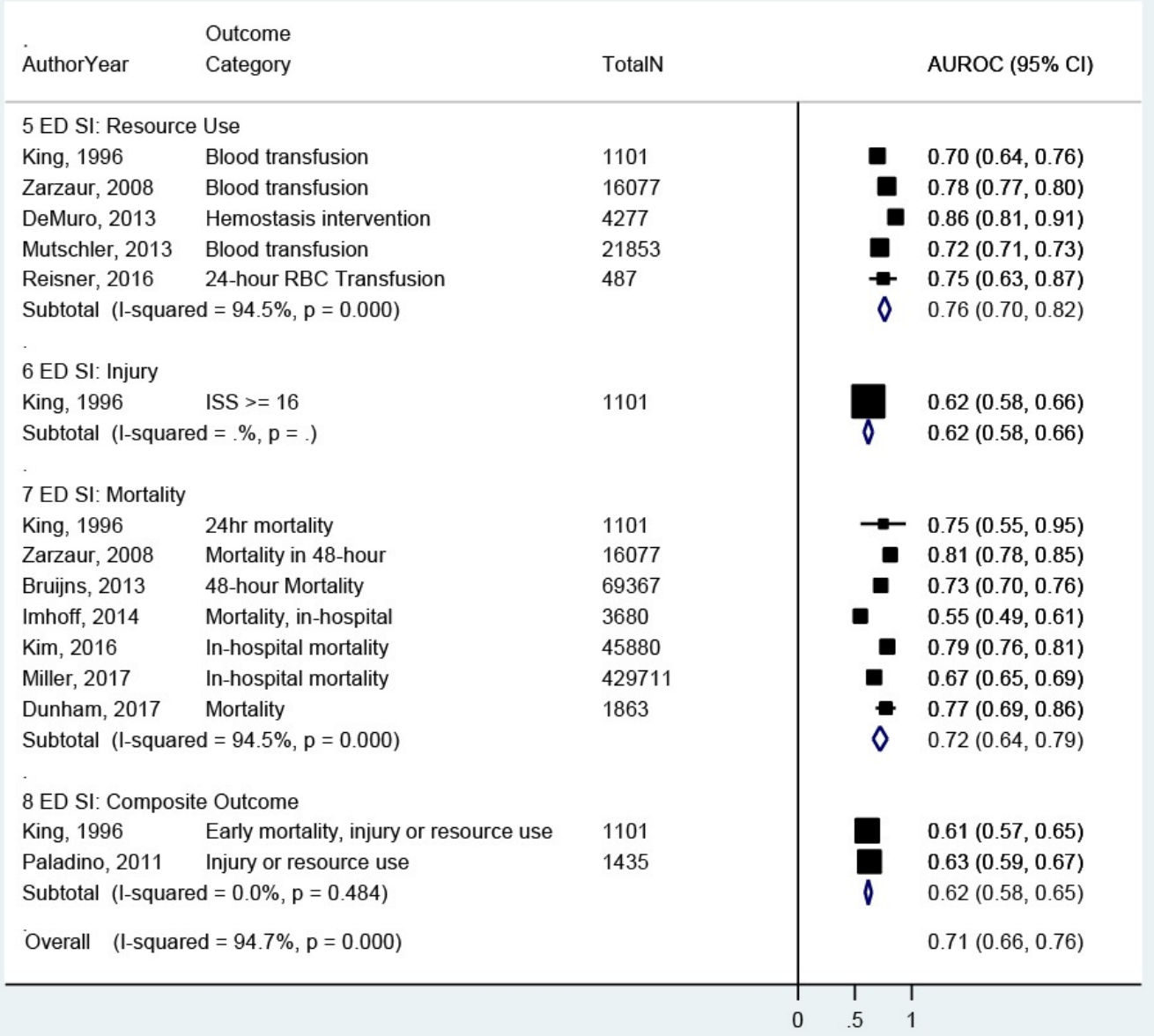

Overall results are from the bivariate logistic mixed effects model analysis. 
Figure 112. Pooled sensitivity of emergency department lactate $>2$

\begin{tabular}{|c|c|c|c|c|c|}
\hline AuthorYear & Test & $\begin{array}{l}\text { Outcome } \\
\text { Category }\end{array}$ & \multicolumn{2}{|l|}{ N_sens } & Sensitivity (95\% Cl) \\
\hline \multicolumn{6}{|c|}{4 ED Lactate: Resource Use } \\
\hline Vandromme, 2010 & Lactate $>2.5$ & Blood transfusion & 264 & - & $0.77(0.72,0.82)$ \\
\hline Folkert, 2015 & Lactate $>2.2$ & Operative intervention & 36 & $\rightarrow$ & $0.64(0.47,0.78)$ \\
\hline Ramanathan, 2015 & Lactate $>2.0$ & Major procedure & 51 & $\rightarrow$ & $0.71(0.57,0.81)$ \\
\hline $\begin{array}{l}\text { Subtotal (I-squared } \\
5 \text { ED Lactate: Injury }\end{array}$ & $=39.4 \%, p=0.1$ & & & $\diamond$ & $0.71(0.62,0.79)$ \\
\hline Ramanathan, 2015 & Lactate $>2.0$ & ISS > 15 & 45 & & $0.87(0.73,0.94)$ \\
\hline \multicolumn{6}{|c|}{6 ED Lactate: Mortality } \\
\hline Pal, 2006 & Lactate $>2.0$ & 48hr Mortality & 180 & - & $0.85(0.79,0.90)$ \\
\hline Callaway, 2009 & Lactate $>=2.5$ & In-hospital Mortality & 112 & - & $0.41(0.32,0.50)$ \\
\hline Sammour, 2009 & Lactate $>2.0$ & Mortality from the index trauma & 13 & $\rightarrow$ & $0.85(0.55,0.96)$ \\
\hline Vandromme, 2010 & Lactate $>2.5$ & In-hospital death & 172 & $\bullet$ & $0.82(0.76,0.87)$ \\
\hline Mizushima, 2011 & Lactate $>2.5$ & Mortality & 150 & - & $0.82(0.75,0.87)$ \\
\hline Regnier, 2012 & Lactate $>2.2$ & 30 day mortality after trauma & 78 & $\rightarrow$ & $0.78(0.68,0.86)$ \\
\hline \multicolumn{6}{|c|}{7 ED Lactate: Composite outcome } \\
\hline Paladino, 2008 & Lactate $>2.5$ & Resource use or ISS $>15$ & 143 & 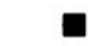 & $0.76(0.69,0.82)$ \\
\hline \multicolumn{4}{|c|}{ Subtotal $(\mathrm{I}$-squared $=\%, \mathrm{p}=)}$. & $\diamond$ & $0.76(0.69,0.83)$ \\
\hline \multicolumn{4}{|c|}{ Overall (I-squared $=89.6 \%, p=0.000)$} & & $0.74(0.66,0.81)$ \\
\hline
\end{tabular}

Overall results are from the bivariate logistic mixed effects model analysis. 
Figure 113. Pooled specificity of emergency department lactate $>2$

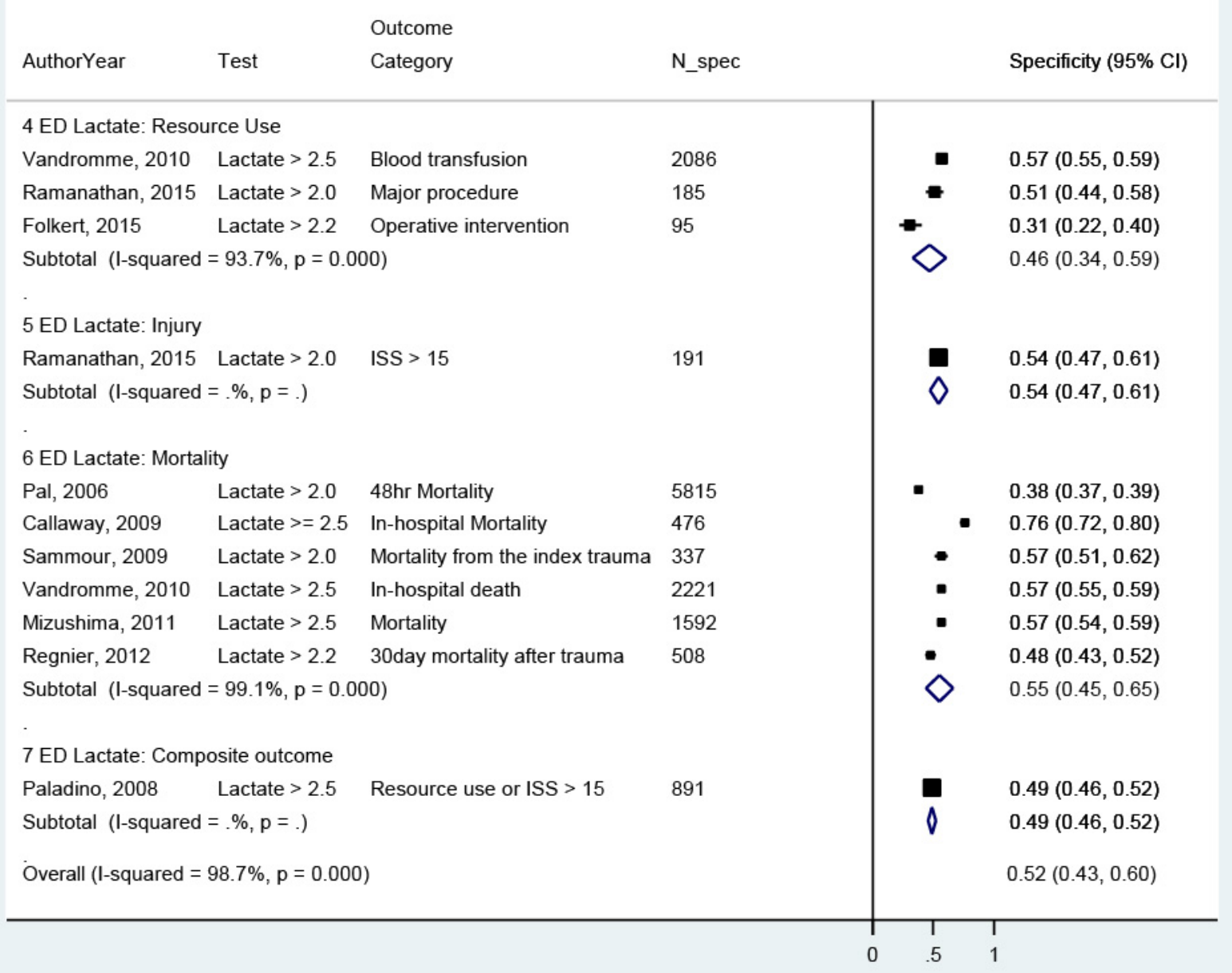

Overall results are from the bivariate logistic mixed effects model analysis. 
Figure I14. Pooled sensitivity of emergency department lactate $>4$

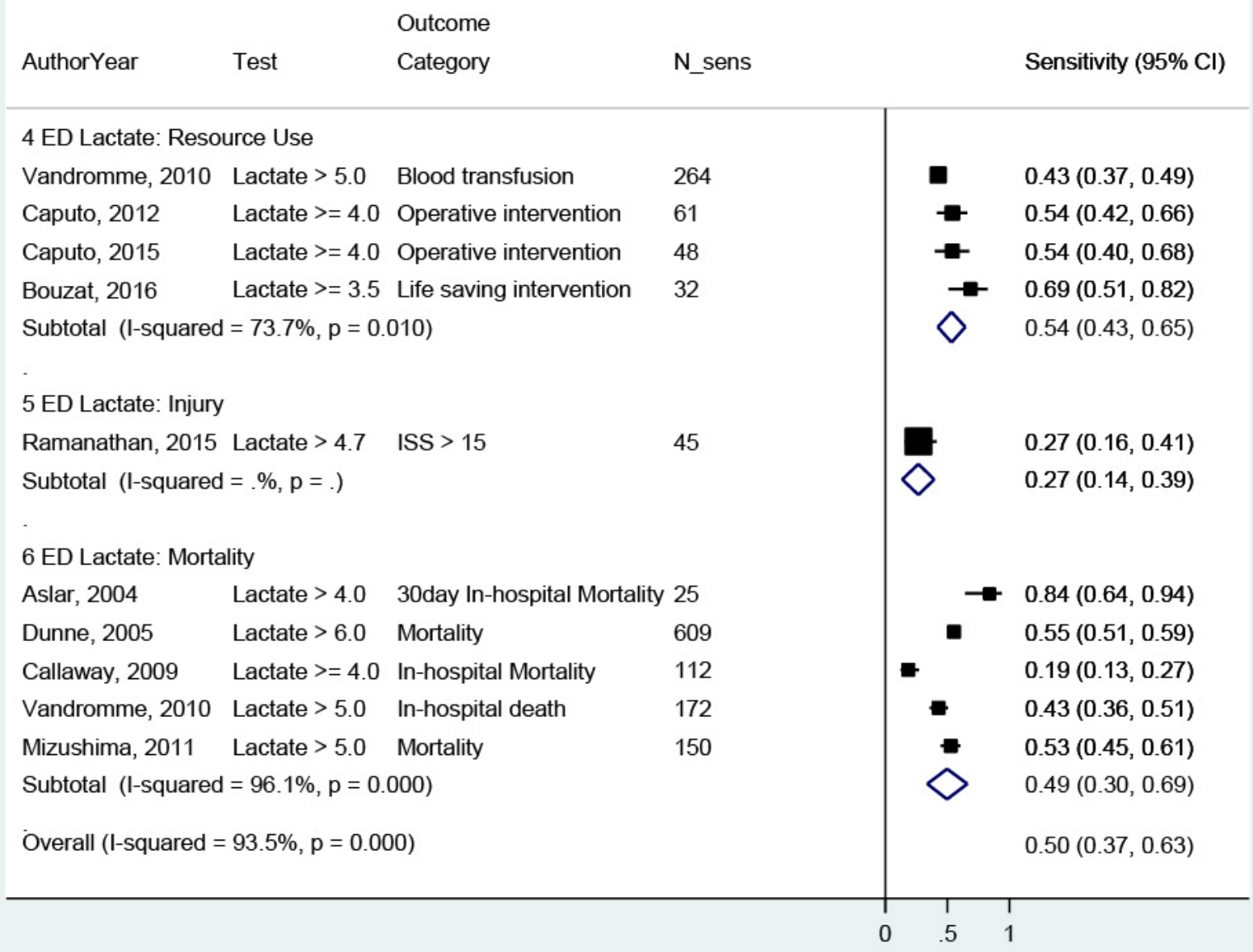

Overall results are from the bivariate logistic mixed effects model analysis. 
Figure 115. Pooled specificity of emergency department lactate $>4$

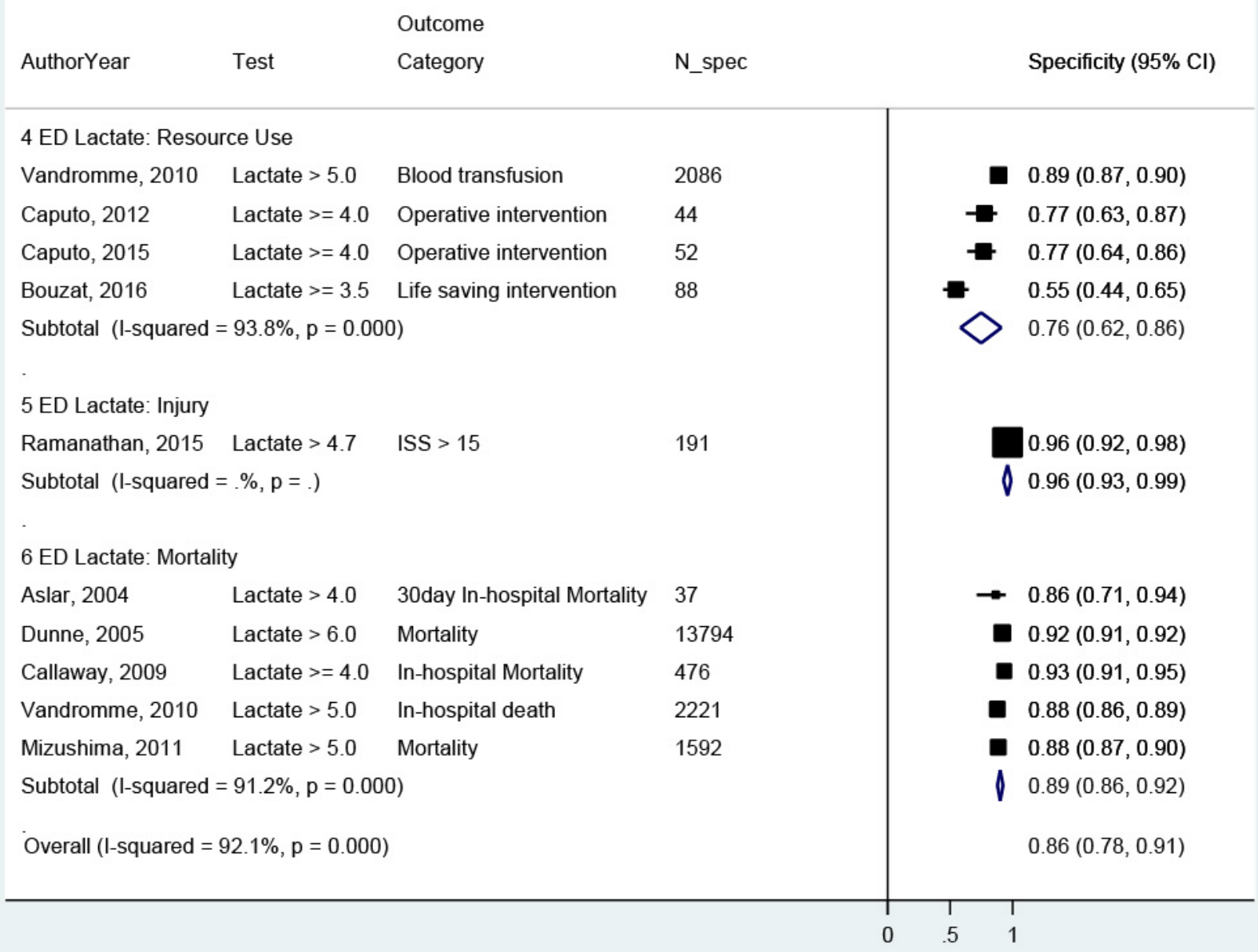

Overall results are from the bivariate logistic mixed effects model analysis. 
Figure I16. Emergency department lactate, stratified by outcome

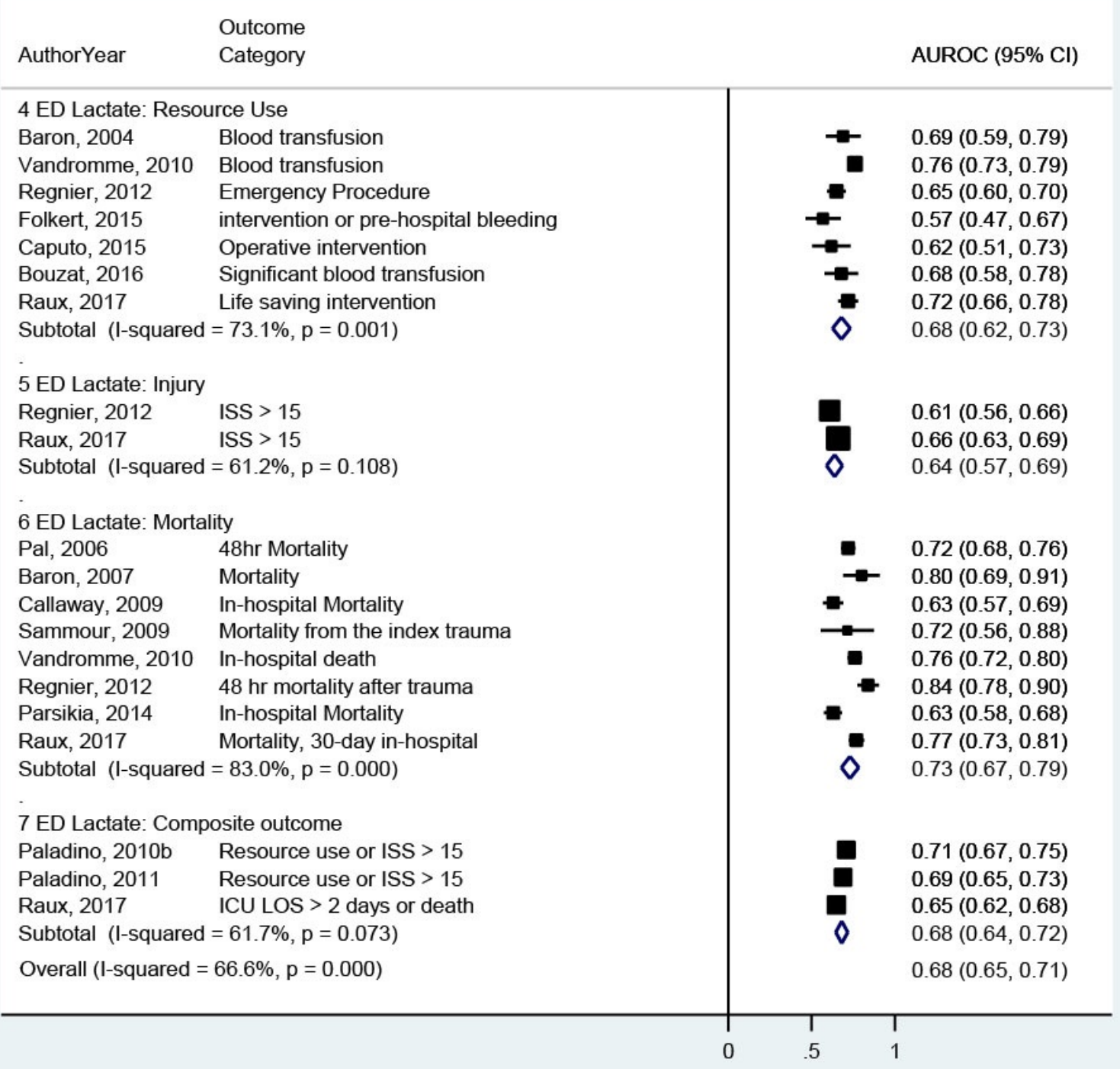

Paladino, 2010b = Reference no. 99.

Overall results are from the bivariate logistic mixed effects model analysis. 


\section{Figure I17. Pooled sensitivity of emergency department respiratory rate}

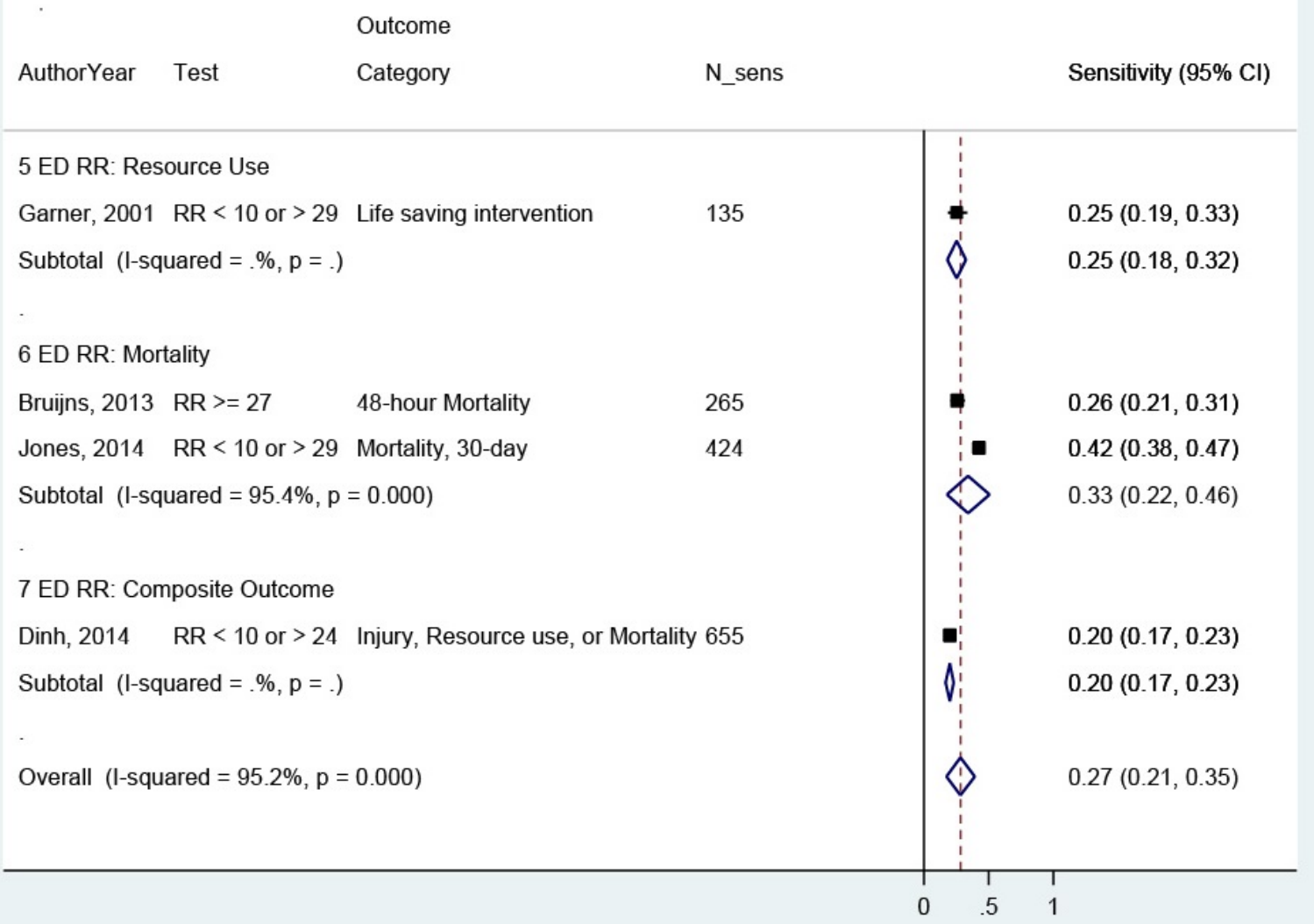

Overall results are from the bivariate logistic mixed effects model analysis. 


\section{Figure I18. Pooled specificity of emergency department respiratory rate}

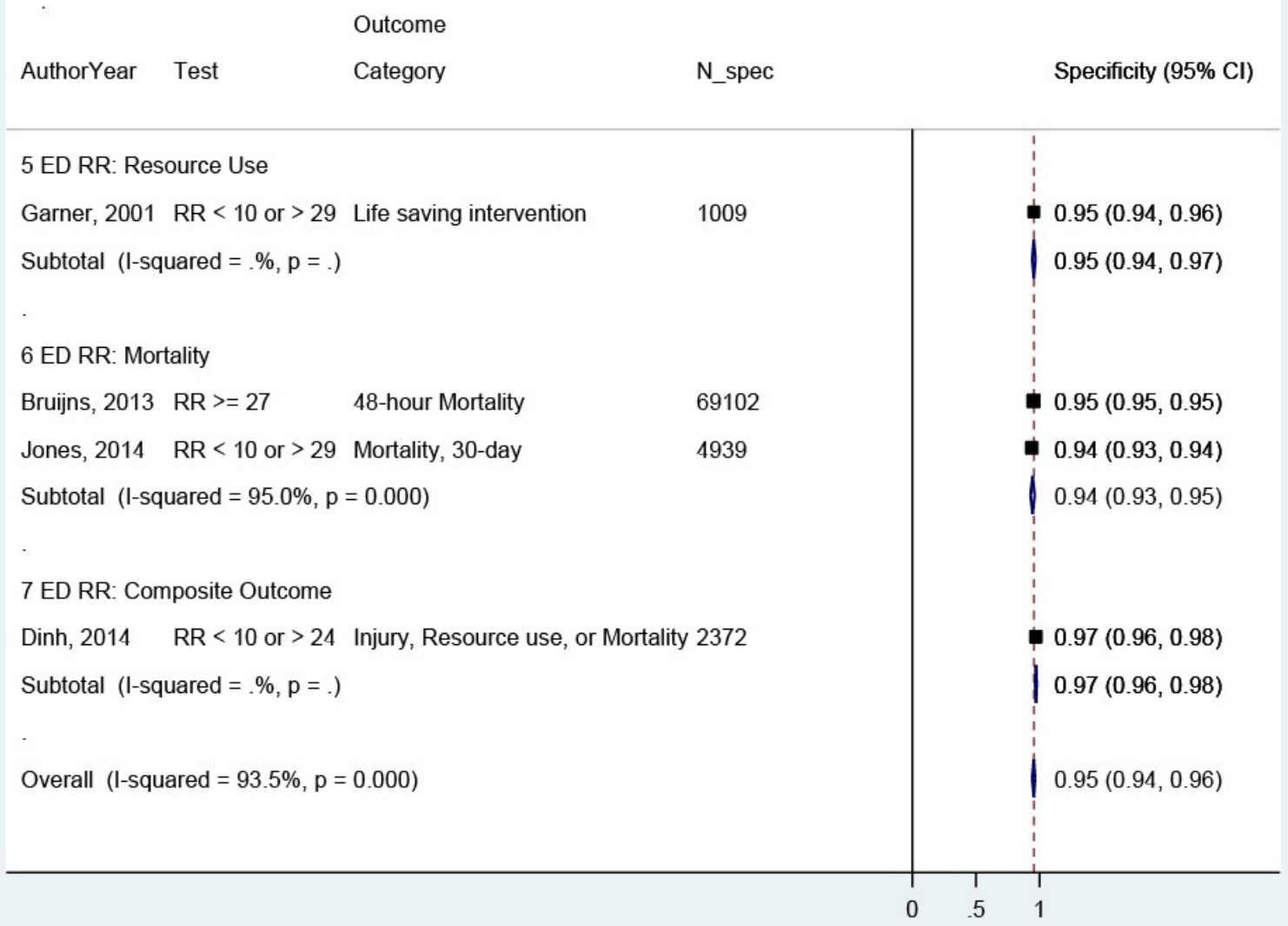

Overall results are from the bivariate logistic mixed effects model analysis. 
Figure I19. Pooled AUROC of emergency department respiratory rate

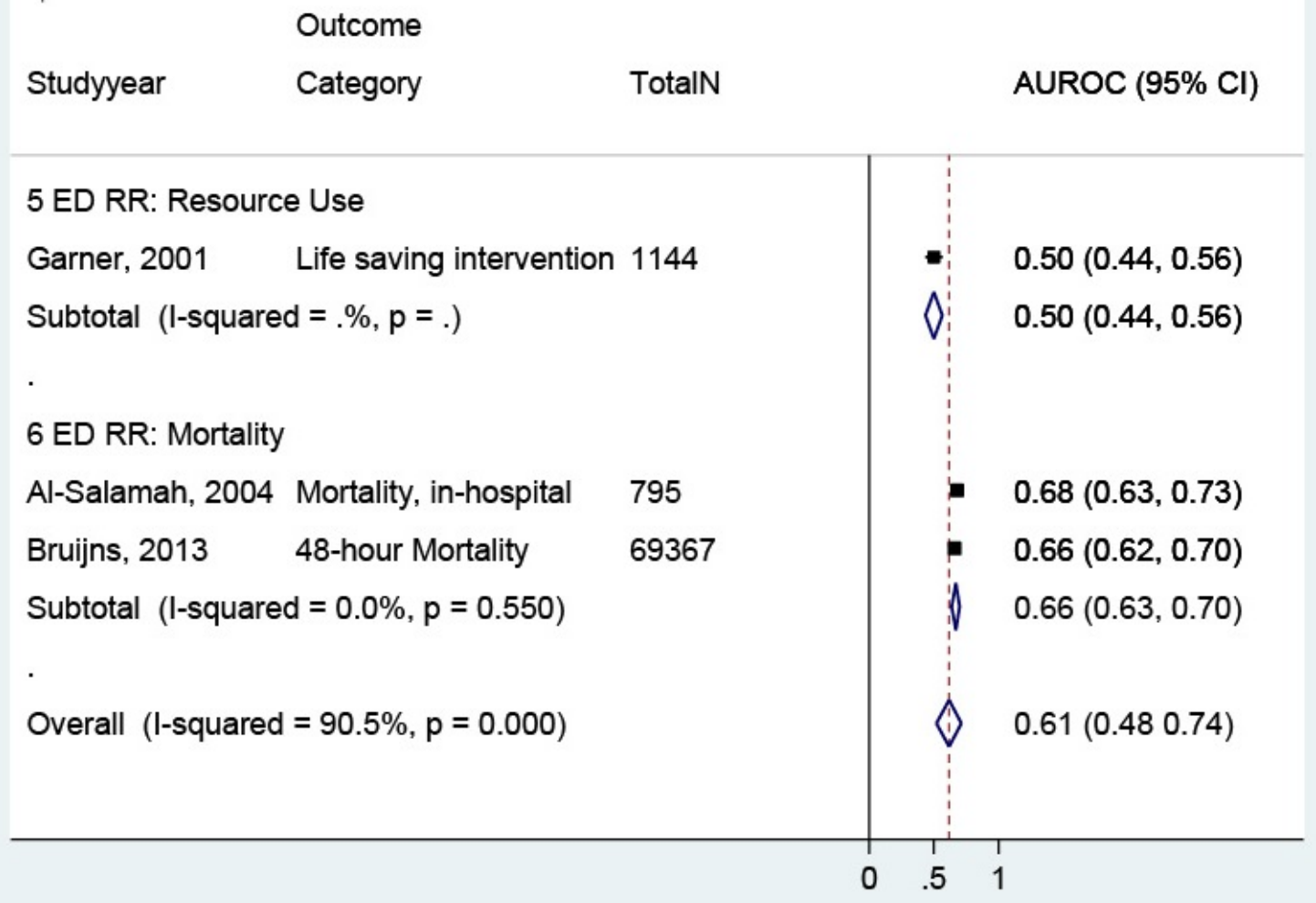

Overall results are from the bivariate logistic mixed effects model analysis. 
Figure 120. AUROC of the Revised Trauma Score

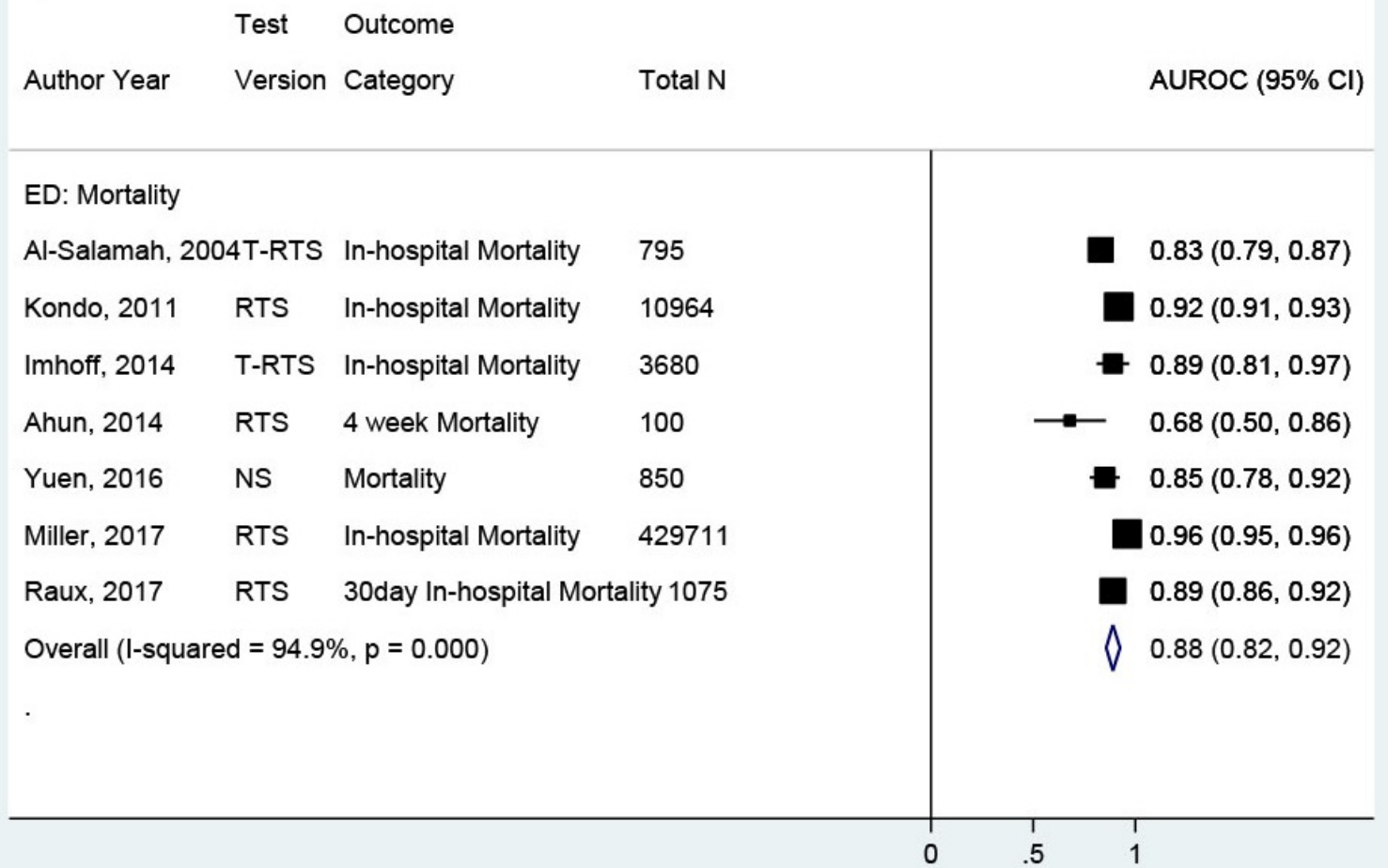

Overall results are from the bivariate logistic mixed effects model analysis. 